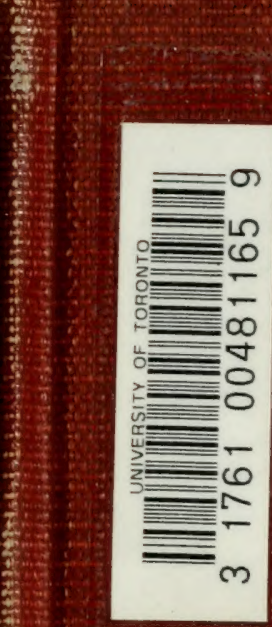

vit.

zin 

RTMENT OF

reromio of cano 





\title{
Allgemeine
}

\section{Anatomie und Physiologie}

des

\section{Nervensystems.}

\author{
Von
}

\section{Albrecht Bethe}

\author{
Dr. phil, et med. \\ Privatdozent der Physiologie an der Universität Straßburg i. Els.
}

Mit 95 Abbildungen im Text und 2 Tafeln.

\author{
Leipzig \\ Verlag: von Georg: Thieme




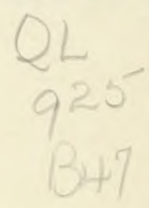

Alle Rechte, besonders das der Übersetzung vorbehalten.

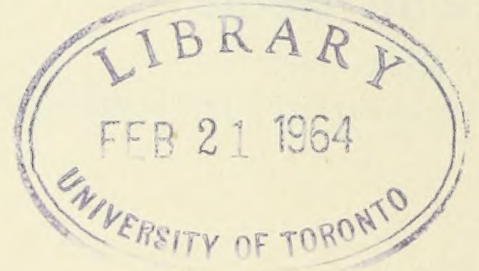

\section{3}




\section{Vorwort.}

Vor beinahe fünf Jahren, als die ausführliche Mitteilung Apáthys „über das leitende Element des Nervensystems" eine lebhafte Bewegung unter den Neurologen anzuregen begonnen hatte, erhielt ich von Herrn Thieme die Aufforderung, eine zusammenfassende Darstellung über die neuen Errungenschaften der Nervenanatomie für seinen Verlag zu schreiben. Damals war noch alles im Fluß. Hätte ich die Arbeit schon zu jener Zeit übernommen, so wäre sie wahrscheinlich schon am Tage des Erscheinens veraltet gewesen. So entschloß ich mich, mit der Ausführung des Auftrages noch einige Zeit zu warten und in der Zwischenzeit meine eignen Erfahrungen auf dem Gebiet der Nervenanatomie zu erweitern. Außerdem lag es mir aber am Herzen, die neuen Ideen auf die allgemeine Physiologie des Nervensystems zu übertragen.

Die Apáthysche Lehre, daß das leitende Element des Nervensystems kontinuierlich verlaufende und von den plasmatischen Teilen des Nervensystems durchaus verschiedene Fibrillen seien, regte naturgemäß zu einer großen Zahl neuer Fragestellungen auf dem Gebiet der Physiologie an. Einen Teil derselben hoffte ich in kurzer Zeit bis zu einem gewissen Grade erledigen und die Resultate dem geplanten Buche einverleiben zu können. In Bezug auf mehrere Fragen gab das Experiment bald befriedigende Antworten; bei anderen mußten zur Lösung zeitraubende Umwege eingeschlagen werden, welche die Ausführung meines Vorhabens verzögerten. Wie es aber in solchen Dingen zu gehen pflegt: Jede in Angriff genommene Frage zeitigte im Verlaufe der Untersuchung neue und wichtige Probleme, die zu einem Lösungsversuch reizten. Schließlich mußten aber die Untersuchungen wenigstens zu einem äußeren Abschluß gebracht werden, wenn das Erscheinen des Buches nicht noch auf lange Zeit hinausgeschoben werden sollte. Dieser Abschluß ist jetzt erfolgt, und ich übergebe die bisherigen Resultate der Öffentlichkeit, bin mir dabei aber wohl bewußt, daß in denselben vieles unvollständig und lückenhaft ist und daß häufig Fragen offen gelassen sind, die vielleicht 
durch einige wenige Versuche zur Entscheidung hätten gebracht werden können.

Die Beschreibung neuer Versuche und Resultate nimmt in der Mehrzahl der Kapitel einen sehr breiten Raum gegenüber der Besprechung des bereits Bekannten ein. Infolgedessen kann das Buch nicht als ein Lehrbuch der allgemeinen Anatomie und Physiologie des Nervensystems angesehen werden. Der referierende Teil ist zwar in manchen Kapiteln annähernd vollständig; in andern Kapiteln hat aber nur der Inhalt der allerwesentlichsten Arbeiten Erwähnung gefunden. Das vorliegende Buch kann daher auch nicht den Titel eines Handbuches der behandelten Materie für sich in Anspruch nehmen. Trotzdem hoffe ich, daß das Buch manchem, der sich über die einschlägigen Fragen unterrichten will, von Nutzen sein wird. Außer für die physiologischen und anatomischen Fachgenossen ist es für alle die geschrieben, welche sich für den Aufbau und die Funktion des Nervensystems interessieren und sich mit einschlägigen Fragen beschäftigen, also für Neurologen, Psychiater und andre. Infolgedessen konnte die Kenntnis der groben anatomischen Verhältnisse und der Grundzüge der Physiologie des Nervensystems als bekannt vorausgesetzt werden.

Spezialuntersuchungen pflegt man heutzutage in Zeitschriften niederzulegen oder, wenn sie ein größeres Gebiet umfassen, monographisch zu behandeln. Hier und dort in ein allgemeineres Buch eingestreute Originaluntersuchungen gehen, wie die Erfahrung lehrt, leicht für das wissenschaftliche BewuBtsein verloren, weil sie niemand unter dem allgemeinen Titel des Werkes vermutet. Wenn ich hier doch eine recht beträchtliche Anzahl von Spezialuntersuchungen auf scheinbar weit voneinander entfernten Gebieten der Öffentlichkeit in Buchform übergebe, so geschieht es deshalb, weil sie alle von einem einheitlichen Gesichtspunkt aus unternommen wurden und dieser nur dann zum Ausdruck gelangen kann, wenn ein gemeinsamer Rahmen die neuen Erfahrungen umfaßt. Fast in jedem Kapitel ist die eine oder andre neue Beobachtung mitgeteilt; im besonderen aber sind es die Kapitel über Nervendegeneration und Nervenregeneration, über die Nervenleitung und über die rhythmischen Bewegungen, welchen ausgedehnte Spezialuntersuchungen zugrunde liegen.

Die Literatur ${ }^{1}$ ) habe ich, so gut es bei der beschränkten Zeit möglich war, durchgesehen. Unter der großen Anzahl einschlägiger Arbeiten mußte aus äußeren Gründen eine Auswahl getroffen werden. Infolgedessen ist auch manche mir selber sehr erwähnenswert er-

1) Arbeiten, welche Ende 1902 und bis zum April 1903 erschienen sind, konnten nur noch in Anmerkungen Berücksichtigung finden. 
scheinende Cntersuchung weder im 'Text noch im Literaturer\%eichnis genannt. Bei jeder wesentlichen Frage sind aber Arbeiten aufgeführt, welehe als Answangsunkt für die Aufsuchung der wanzen Literatur dienen können. Es ist anch leicht möglich, daß mir einige Arbeiten entgangen sind, welche unbedingt hiitten erwähnt werden miissen und daß ich ciedanken äußere, die schom ein andrer einnal niedergeschrieben.

Ich hätte denen, welche sich der Mïhe unterziehen wollen, dies Buch zu lesen, noch mancherlei zur Entschuldigms seiner Mängel und Fehler zu sagen. Da es aber wohl auch mancherlei Gutes enthält, so gebe ich mich der Hoffnung hin, daß man geegen die sichwächen nachsichtig sein wird.

Lnd nun sage ich noch Iferrn 'Thieme, dem Verleger dieses Buches, für das liebenswiirdige Entgegenkommen, das er mir in allen Fragen der äußeren Ausstattung erwiesen hat, meinen besten Dank. 


\section{Inhaltsverzeichnis.}

Vorwort

Abgrenzung des Gebietes.

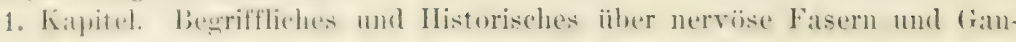
glienzellen

2. Kapitel. Allgemeines ïber die Kontinuitaitsfrage :

3. Kapitel. Historisches iiber die Neurofibrillen

4. Kippitel. Dats Nervensystem wirbelloser Tiere (mit Ausschluf der Nervennetze).

$\therefore$ Kapitel. Die Neurofibrillen im Nervensystem der Wirbeltiere

15. Kapitel. Die Nervennetze und ihre Neurofibrillen

7. Kilpitel. Vergleichmy des Zusammenhatnges der nervïsen Elemente bei verschiedenen Tieren und die Übereinstimmung der Ergebnisse mit den Resultaten des physiologisehen Experimentes

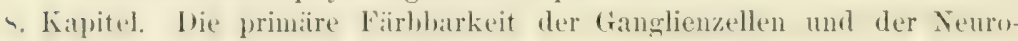
fibrillen

9. Kapitel. Ïher einige andre Zellstrukturen und Zellbestandteile und die Veränderungen der Ganglienzellen nach intra vitam erfolgenden Eingriffen

10. Kapitel. Die Nervendegeneration

11. Kilpitel. Die retrograden Veränderungen der Gamglienzellen nach Verletzung der zugehörigen Nervenfasern und die ehronische Degeneration der Nervenstiimpfe

12. Kappited. Die Zusammenheihng durchschnittener Nerven und die Nervenregeneration . . . . . . . . . . . . . 152

1:. Kapitel. Über die Entwicklung der Nervenelemente . . . . . . . 233

1.. Kapitel. Das Wesen der Nervenleitung . . . . . . . . . . 24s

1.i. Kilpitel. Die Eigenschaften des Zentrahervensystems im allgemeinen 321

16. Kapitel. Die Reflexumkehr . . . . . . . . . . . . . . 335

17. Kitpitel. Die Irreziprozitït der Zentralteile und die Leitungsverzügermug in denselben . . . . . . . . . . . . . . . 342

18. Kapitel. Reizsummation und Bahnung . . . . . . . . . . 350

19. Kapitel. Die Wirkungen von Giften auf das Nervensystem . . . . 35.

20. Kapitel. Der Tonus . . . . . . . . . . . . . . . . . . . 3163

21. Kapitel. Die Hemmung . . . . . . . . . . . . . . . . . 373

22. Kapitel. Die rhythmischen Bewegungen. . . . . . . . . . . . 3y

Literaturverzeichnis . . . . . . . . . . . . . . . 457

Sachregister . . . . . . . . . . . . . . . . 1 . . 3

T'afelerklärung . . . . . . . . . . . . . . . . . . . . 4ל 


\section{Abgrenzung des Gebietes.}

Im Tier- und Pflanzemreich tritt uns eine große Menge von Auslïsmgserscheinmen entgegen, deren Teranlassung in Zustandsänderungen imnerhalb der äußeren Lumgebung der betreffenden Organismen - den auslösenden Reizen — besteht, deren Endresultat lewegung des Organismus oder seiner Teile ist. Die Energie, welche dem Oranismus dabei durch den Reiz zugeführt wird, ist in der Regel freringer als die, welehe sich im Effekt änßert. Das Plus an Enerwie fiihren wir zuriek auf das Freiwerden kinetischer Eneroie immerhall, des Oreanismus selher. Die Quelle der Enerwie sehen wir in chenischen Verbindungen ron hohem Wärmeärquivalent, welche unter dem Einfluß des Reizes zur Verbremmung gebracht werden und so zur Entfaltung ron potentieller Energie füluren. In dieser Weise wirkt mach unserer Vorstellung die äußere Zustandsänderun», der Rei\%, auslösend.

Es ist theoretisch möglich und tatsächlich wohl anch in vielen rein protoplasmatischen Gebilden \%. B. den Amöhen verwirklicht, dats

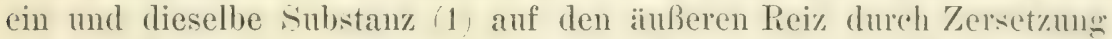
an der Reizstelle reagiert, '2, diese Zersetzung ron Teilchen z.n Teilchen fortpflanzt und 3 , die Bewegun hervorlongt. Ilier wäre also reizanfnehmende oder rezeptorische, reizleitende oder lionduktile und auf den Reiz durch Beweonng reagierende oder effektorischer sulstanz ein und dasselbe. - - bei andem Oranismen ist, wie das Experiment seit langem geereigt hat, eine vollkommene Tremmun ein-

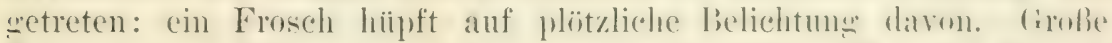
Massen seines Körpers sind dabei manz unbeteilignt. Was sich bewewt sind seine Muskeln; der lieiz wird ihnen in retinderter form durch die Nerven zugeleitet, werden \%. Is. die Hüfnerven durelsishitten, sn tritt der Fiffekt nicht mehr ein. Die Xerven selber sind unfahing liewegunen zu äuliom; sie sind aher auch nicht fähig and den Reiz das Licht - in Funktion zu treten. Die Lichtrezeption wird durch

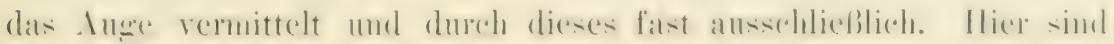
Bet he, Nerrensystem. 


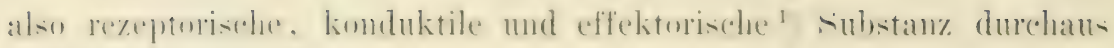
voneinander getrennt.

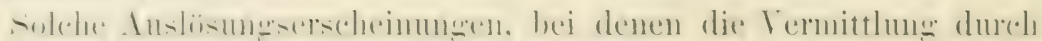
rime hu wir Reflexe - oder Antikinesen, wemn man das Wort Reflex mur aut

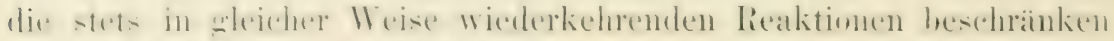

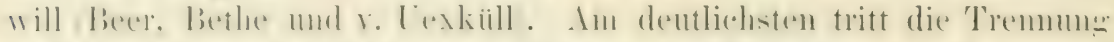

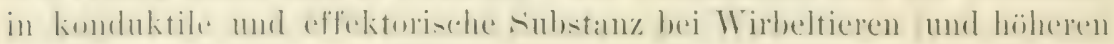
Artikulaten) hervor, weil hier die konduktile Substanz in grobanatomischen Massen - Nerven und Zentralorgane - vorhanden ist.

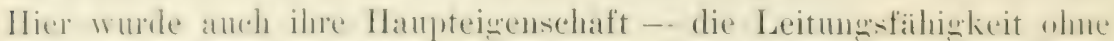
äußere Bewegungsoroange - zuerst auf dem Wege der Nerven-

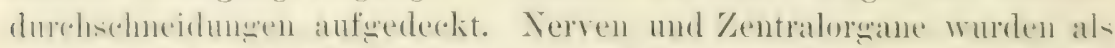

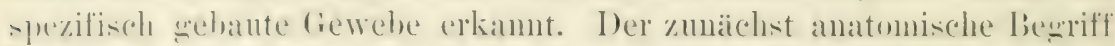

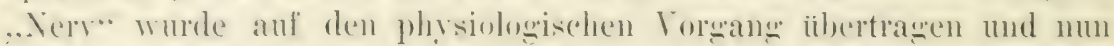

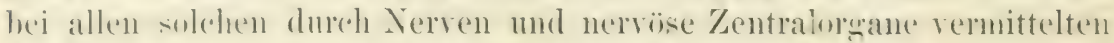

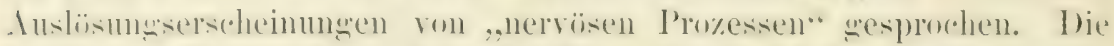
historische Entwicklung des Bespriffes ... Jerväs.' läbt es daher nicht zu, daß man dort von nervösen Prozessen spricht, wo Nerren anatomisch nicht nachweisbar sind, ja dak man den amatemischen Nachlweis der Nerren als erimzlich belanglos bezeichnet. Man kamn atu der Irt wie eine Auslïsmgsersoheinmon ablïuft, wie sie sich bei

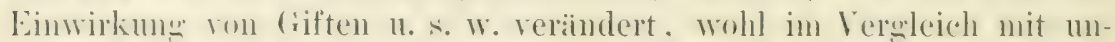

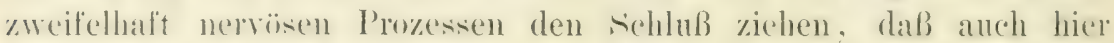

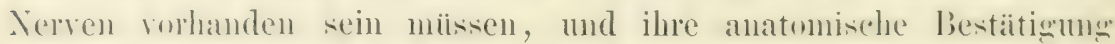
ahwaten, aber nan darf nicht, wemn ihre Bestätigme anshleibt, sagen. hier sind physulogisch Verven vorhanden, anatomisch fehlen sie. l'hisiologisch volhandene, anatomisch fehlende Nerven wibt es nicht. Das, was sich da äuBert, wird daun eben nicht durch Nerven ver-

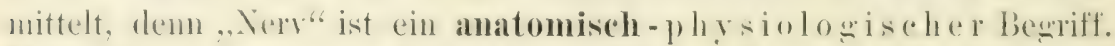

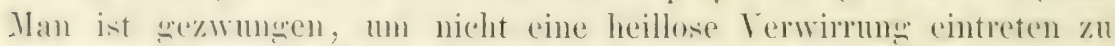
lasson, nene Worte zu bihlen und den Begeriff, ,Nervös" und alles was

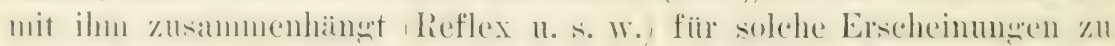
reservieren, die wirklich durch Nerven vermittelt werden.

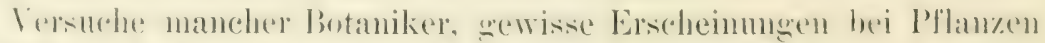

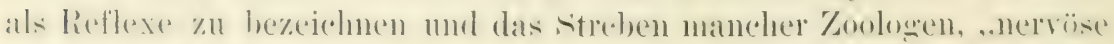

1) In einem gewissen Grade kommt natiirlich auch der effektorischen Sulstanz Rezeptionsfähigkeit (Irritabilitiit) und Konduktibilitiit zu und die konduktile Substanz ist ebenfalls für gewisse Reize rezeptionsfähig. Bei den natiirlichen Vorgängen spielt aber diese Rezeptibilität meist nur insofern eine Rolle, als sie bei der Weiterbeförderung des Erregungsvorganges notwendig ist. Der ainfere (natiirliche) Reiz trifft wohl nur selten konduktile und noch seltener effektorische sulstanz direkt. 


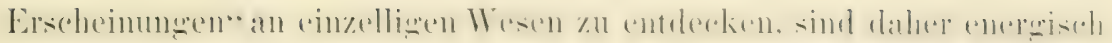

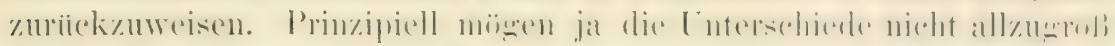

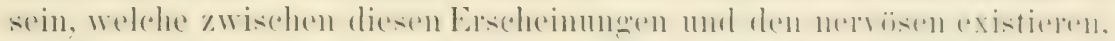
aber es ist höchst mzweekmäßig alle Begriffe in der Wissenschaft zul rerwäissern. ${ }^{1}$ )

Danach würde, so lange wir die Vorgänge bei den nervösen

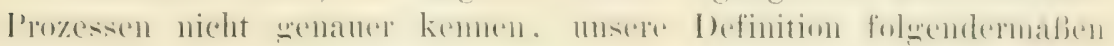
lanten: Nervöse Prozesse sind dureh äukere Reize hervorgerufene Auslösungserscheinungen, bei denen die Leitung des Reizes dureh ein anatomisch wohleharakterisiertes Gewebe geschieht, das nur der Leitung dient. Der Beweis für Torhandensein eines solehen Gewebes muß immer ein doppelter sein: der anatomische Nathweis charakteristischer Nervensubstanz und der physiologische Nachweis, dab nath Kontimuitaitsunterhrechung dieser substanz die hetreffende duslismuserscheinung unterbleibt.

Da sich der Begriff der Nerven und des "Nerrösen" historisch ron den Wirbeltieren ans entwickelt hat, so haben inmer diese als Ausgangspunkt der Lntersuchung zu dienen. Bei ihnen haben wir festzustellen, was an Xerven und an den Zentralorganen anatonisch und phrsiologisch charakteristisch ist. Wenn das geschehen ist, sn wird es - wenigstens oft - nicht schwer sein zu entscheiden, welche Erscheinungen bei niederen Tieren und in strittigen oreanen der Wirbeltiere selbst (Herz, Darm, Ureter 11. s. w.) als nerrös zu bezeichnen sind.

1) Beer, $r$. Uexkiull und ieh haben deshalb rorgeschlagen, Auslösungserscheinungen, welche auf rein protoplasmatischem Wege ror sich gehen oder wenigstens nicht durch eine konduktile Substanz vernittelt werden, die den Namen "Nerv" verdient, im Gegensatz zu den Antikinesen (Reflexe und Antiklisen) als Antitypien (Ruickwirkungen) zu bezeichnen. Eventuell wird man in diesem Begriff noch Unterabteilungen zu machen haben. 


\section{ERSTES KAPITEL.}

\section{Begriffliches und Historisches über nervöse Fasern und Ganglienzellen.}

Die histologische Untersuchung ron Geweben, deren nervöse Fonktion experinentell durchaus sesichert ist, läßt immerhall, des dervensistems vershiedener Tiere und ein und derselhen Tierart selı versehiedene Formelemente unterscheiden, überall aber finden wir zwei Haupttrpen: kernhaltige Protoplasmaklumpen und faserige, zolindrische lichlible, die sich friiher oder spïter in viele oder wenige /weige teilen kimnen. I)ic Zellen ${ }^{1}$ ) werden jetzt fast allgenein (ianglienzellen fूenannt Yervenkïper Valentins, Vervenzellen Källickers und andrer; fuir die fascrigen Elemente in ihrer (iesamtheit soweit sie nerviser mol nicht sliöser oder hindegewehiger Natur sind existiert kein einheitlicher Xame; man wird aher kamm zu Irrtïmern Veranlasimng celoen, wemn man sie einfach als nervise Fasern bezeichnet. obgheich dies Wort sebon einigenal für spezialfälle in . Inwendung sebracht ist. Ibis jetzt ist kein Xervensystem hekamnt geworden, das nur ans dimglienzellen oder nur ans nervïsen Fasern besteht, mol man wird

1) Die Ganglienzellen wurden lingere Zeit vor Aufstellung der Zelltheorie (durch Sehleiden und Schwamm) von Ehrenberg in Jahre 1533 richtig gesehen und beschrieben, aber nur bei Wirbellosen, wo sie anch in der 'Tat mit den damaligen Uethoden (Zerzupfung) am leichtesten darzustellen sind. (Nach der [beschreibung von Leeuwenhoek scheint es mir ïbrigens nicht ausgeschlossen, dafs er bereits im Jahr 16st Andentungen von Ganglienzellen bei Wirbeltieren geselien hat.) Valentin hat hald daranf (1536) die Ganglienzellen als Bestandteil des Wirheltiernervensystems gefunden und bereits ilhre weite Verbreitung (Rüickenmark, Gehirn, Spinalganglien und sympathische Ganglien) erkannt. Über ihre Formen war er noch sehr im mklaren, ebenso ïber ihre liedentung, wie sehon aus seiner l’ezcichmung, Belegkörper oder Belegungsformationen, hervorgeht. Das Jahr 1837 loringt durch Joh. Müller, P'urkinje und Renak die ersten mit unsem hentigen Kenntnissen einigermaten iibereinstimmenden Formbeschreibungen. 


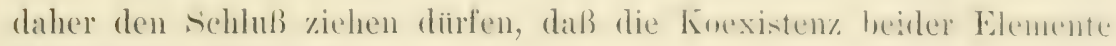
prinzipieller Natur ist.

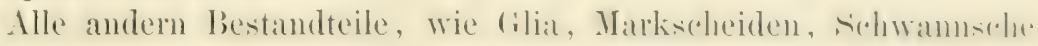
Scheiden tt. S. W., welche in manchen Nervensystemen einen sehr meiten Ramm eimmehmen, kïmmen nul aceidentellex Natur sein, da sie in andern Nervensystemen sanz fehlen. Ihnen mas dort. Wo sie vorhanden sind, eine nicht unbedentende, funktionelle Jedentun:- \% kommen, für den nervösen Jorgang an sich kömnen sie nicht notwendig sein.

Die nerrösen Fasern treten bei höher differenzierten Nervensrstemen nicht selten in zwei äuBerlich ziemlich rerschiedenen Formen auf, welehe bei den Wirbeltieren dureh die Nervenfasern sensu strictiore resp. die Achsenzyliuder mit oder olne Markscheide, ${ }^{1}$, und dureh die L'rotoplasmafortsätze Deiters, 1865 , repräsentiert werden. Max sichultze hat bereits in dem Vorwort zu Deiters nacholassenem IVerke, in dem dieser Ausdruck zum erstemmal gehraucht wurle, seine Hu-

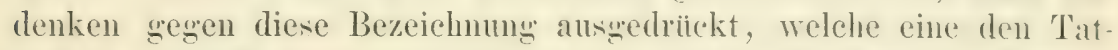
sichen vielleicht nicht entsprechende Gegensitzlichkeit zu den Nervenfasern res]. Achsenzylindern zum Ausdruck bringt und an seiner sitelle

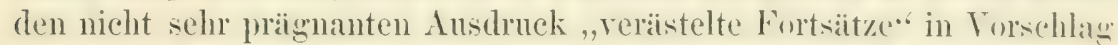
webracht, der sich aber nicht allonem eingebingert hat. wröBere Ver-

Miiller sah bei Myxine (Petromyzon marinus) kernhaltige Klïmpchen mit drei bis fünf Fortsätzen. Purkinje beschrieb und - was für uns wichtiger ist zeichnete multipolare "gangliöse Körperchen" in der Substantia nigra und in der Kleinhirnrinde und Remak erkannte, daß die Körperchen im Rückenmark nicht rund seien, wie sie Valentin beschrieben hatte, sondern oft viele, den Primitivbändern (Achsenzylindern) ähnliche, aber ron ilmen doch verschiedene Fortsïtze hïtten. Ziemlich bald nach Begrïndung der Zellenleher fing man an die Elemente.

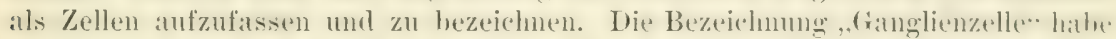
ich zuerst bei R. Wagner gefunden, weif aber nicht, ob er sie zuerst angewandt lat.

1) Von einem Achsenzylinder kann man eigentlich nur dort reden, wo eine Nervenfaser in der Achse einer Scheide, vor allem einer Markscheide, lïuft. Nackte Nervenfasern so zu bezeichnen, wie es häufig geschieht, ist begrifflich ein Unding. Gut beobachtet hat den Achsenzylinder zuerst Remak im Jahre 1537. Er namnte ihn Primitivband. Der Name Achsenzylinder stammt ron Purkinje. Vor Remak ist er nach Ansicht mancher Autoren sehon von Fontana (1787) beobachtet, doch halte ich mit R. nach der Beschreibung, die $\mathbf{F}$. gilst, dies nicht für gesichert. Die Nervenfasern an sich wurden zuerst von dem Begründer der wissensehaftlichen Mikroskopie, Leeuwenhoek, beobachtet und sehon recht gut im Quersehnitt abgebildet (1654). Er erkannte auch schon die Zusammensetzung des Zentrahervensystems aus solchen Fasern, die er allerdings mit vielen späteren Forsehern für Röhren ansah, und fand sie anch sehon bei Wirbellosen. Den Hauptanstof zur mikroskopischen Untersuchung des Nervensystems gab aber erst Ehrenberg (1533) durch die Nenentdeckumg der Gehirnfasern und die Auffindung der Ganglienzellen bei Wirbellosen. 


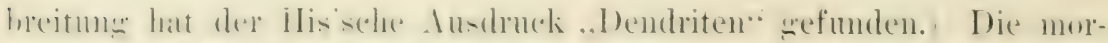

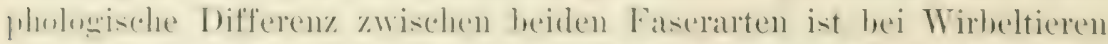

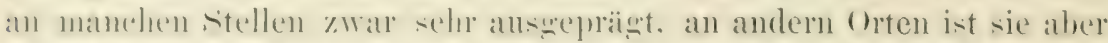

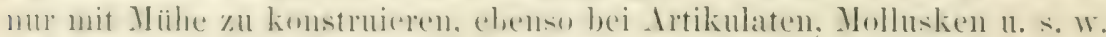
mond hei den niedrigsten formen des Xervensystems existiert sie iiberhatupt nicht. Man wird sich daher schom aus rein vergheidend num-

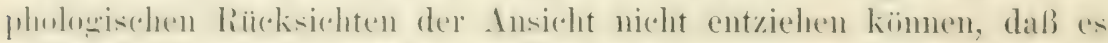

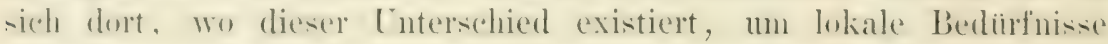
handelt und daß der Untersehied nicht prinzipieller Natur ist.

Seit den Anfängen der histologischen Forschung auf dem Gebiet

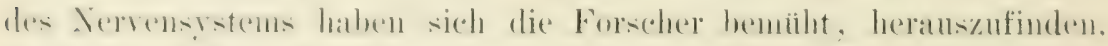

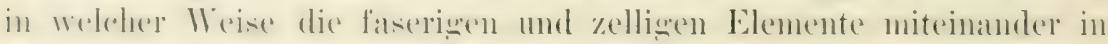

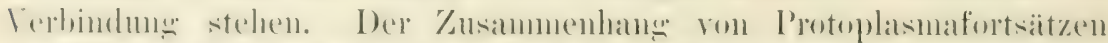

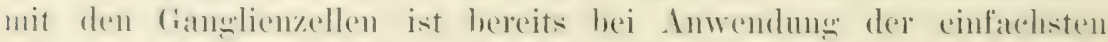

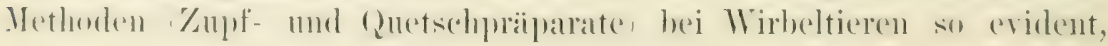
daß hieriber ein Zweifel nie bestanden hat. Sehon den ersten Forschern auf diesem Gebiet (Purkinje, Müller, Remak) war diese

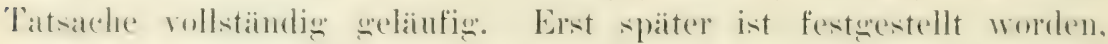

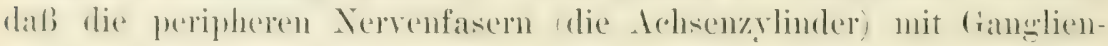
zellen in Zusammenhang ständen und zwar so, daß sich bei den mankhaltigen Fiacem die anfangs nackte Faser erst in riniger Ent-

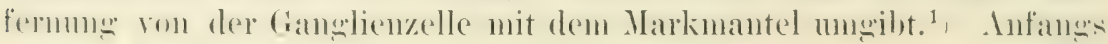

1) Ueber die Entdeckung des Ursprungs der Nervenfasern aus den Ganglienzellen trifft man häufig in der Literatur falsche oder unvollstindige Angaben. Wenn Remaks Beschreibung vom Bau der sympathischen Ganglien ans dem Jahre $153 \mathrm{~s}$ richtig ist - und es liegt kein Grund vor, daran zu zweifeln - , so ist er der erste gewesen, der Nervenfasern (und zwar die nach ilm benannten marklosen Fasern des Sympathicus) ron Ganglienzellen hat entspringen sehen, demn er beschreibt, was durchaus den tatsïchlichen Verhïltnissen entspricht, daß die Zellen der Ganglien mehrere Fortsätze aussenden, die allmählich in Nervenfasern iibergehen. Köllicker hat später (1844) dasselbe beohachtet. Anfangs der vierziger Jahre ist dam mehrfach auch für andre Ganglienzellen behauptet worden, daß sie Nervenfasern den Ursprung geben, so von Hammover (1544) fiur Zellen des Gehirns und Riickenmarks, von Will im selben Jahr für Ganglienzellen wirbelloser Tiere und von Harless (15 46 ) für die Zellen des Lobus electricus von Torpedo. Aus den Abbildungen dieser Autoren laißt sich aber mit Sicherheit erkennen, wie dies auch Wagner ausgesprochen lat, dafs sie keine wirklichen Nervenfasern vor sich gehabt haben oder dab sie Verbindungen sahen, die in Wirklichkeit nicht existieren (Harless). Dar\} markhaltige Nervenfasern von Ganglienzellen entspringen kömen, wurde Ende 1546 gleichzeitig von R. Wagner und Robin gefunden. In der Literatur gilt aher fast allgemein R. Wagner als der alleinige Entdecker dieser 'Tatsache, trotzdem er selber das Verdienst Robins vollkommen anerkamnt hat. Die erste P'ublikation beider Forscher fällt nicht nur beinahe zusammen (IV. 15. Februar Ist7 und R. 3. MIirz desselben Jahres), sondern die Lintdeckung wurde auch von heiden am selben Objekt, den Spinalganglienzellen von Torpedo gemacht. Sie 


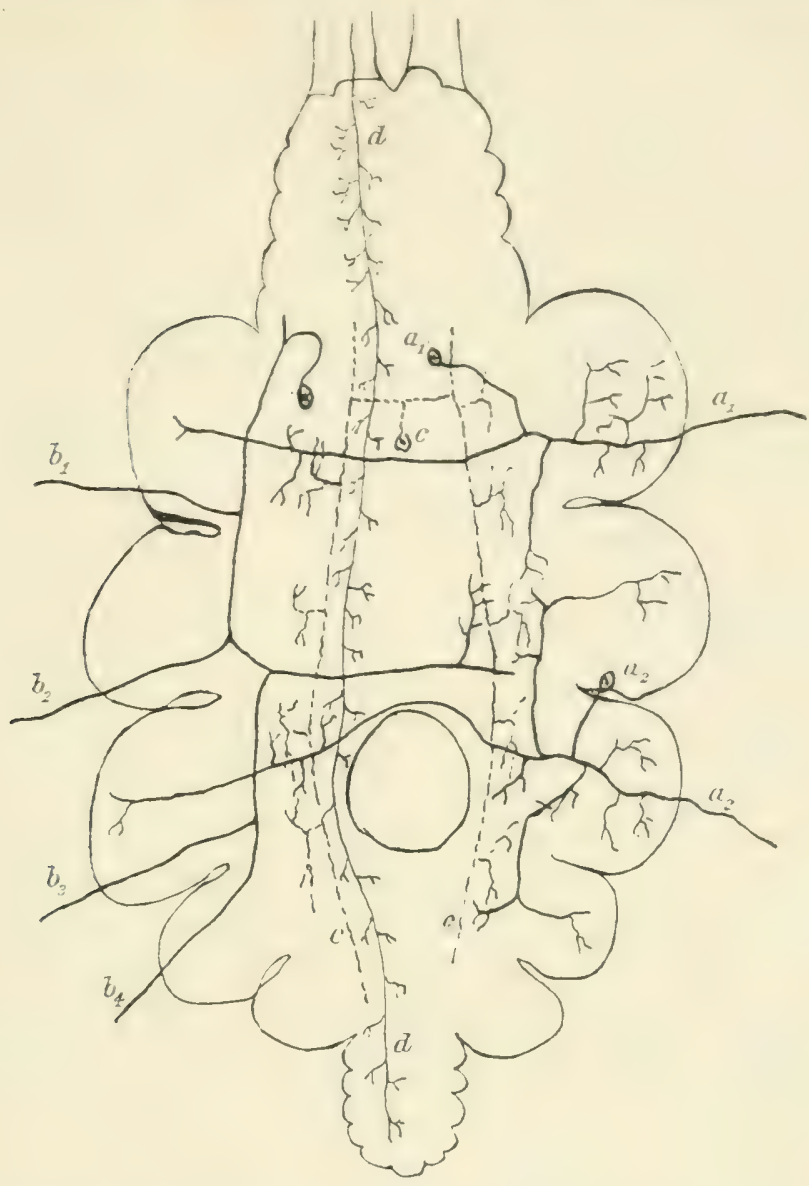

Fig. 1. Bauchmark ron Carcinus Maedas, schematisch. Dasselbe besteht aus einer Anzahl dicht aneinander gedrängter Ganglienpaare, welche durch kurze Längskommissuren miteinander verbunden sind. Torne die kurz abgeschnittenen Schlundkommissuren, Telche die Verbindung mit dens Gehirn herstellen. In die Umrisse des Bauchmarks ist der Verlauf einiger Nervenelemente nach Methylenblaupräparateu eingetragen. Nïheres im Text.

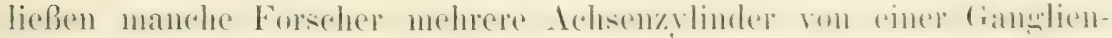
zelle entspringen, man formulierte aber später das Gesetz (Remak

sahen, dafs diese spindelförmigen Zellen nach beiden Seiten hin in markhaltige Nervenfasern ïbergehen und dass die eine zum Rïckenmark zieht, wïhrend die andre in den peripheren Nerv läuft. Wagner sah gleichzeitig, dał die Zellen des Lobus elektricus verschiedene Fortsïitze hïtten, daf der eine homogener sei und dem aus den Markscheiden hervorragenden Achsenzylinder grleiche. Gesehen hat er bei diesen Zellen den Zusammenhang mit markhaltigen Fasern nicht somdern nur erschlossen! Den wirklichen Nachweis hat er nur dort geführt, wo er auch Robin selungen war. An zentralen Gaunglienzellen ist wohl die direkte Beobachtung des Zusammenhanges mit markhaltigen Nervenfasern zuerst Stilling und kurz darauf Remak (1854) an Vorderhornzellen gelumgen. 
[1554-1855] und besonders Deiters [1865]), daß immer nur eine Nervenfaser ron einer Ganglienzelle ausgehe. In der Folgezeit ist hesonders ron Gerlach [1872] die Ansicht vertreten worden, dass

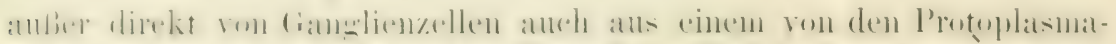

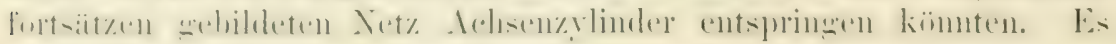
wurde dem aber sehr bald allgemein widersprochen und jetzt gilt es bei den meisten als gesicherter Lehrsatz, daß Achsenzylinder nur ron Zellen direkt auswehen. Trotzdem wenigstens eine Zellart der

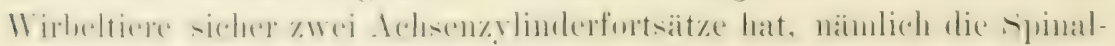
ganglienzellen, so hat man doch aus dem Torhandensein nur eines

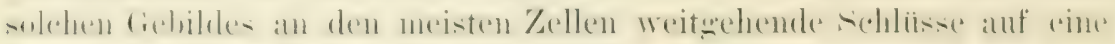
hesondere l'unktion derselben gezogen.

Lïnger als bei den Wirbeltieren hat sich bei den Wirbellosen

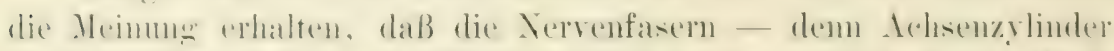

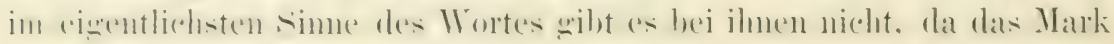
— wenn vorhanden - keinen äußeren Mantel 1 m die Fasern bildet -

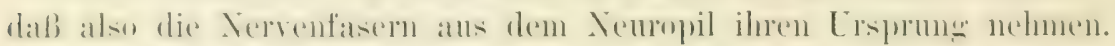

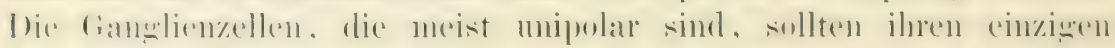

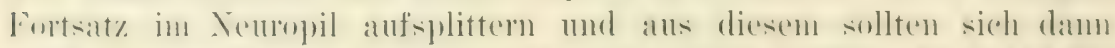

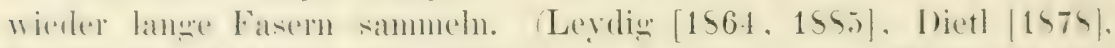

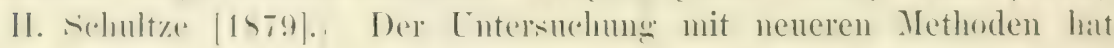
aber anch hier diese bereits früher von vielen \%. B. von Claus an-

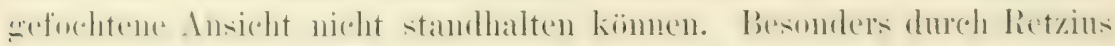
(1890, 1891), Biedermam (1891), und viele spätere Bearbeiter ist

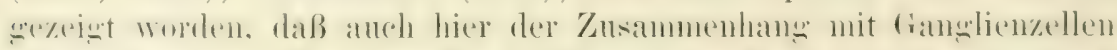

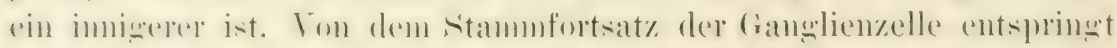

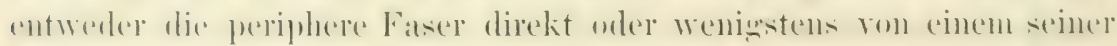
IIauptäste (Fig. 1a). Oh) das $\mathrm{immer}$ so ist, bleibe zunächst dahin-

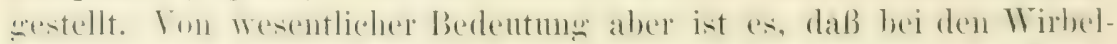

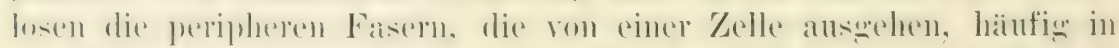

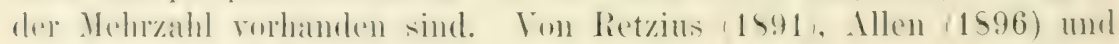
mir (1897) shind Fälle beschrieben worden, in denen zwei, drei ja vier Fasern ron eimer Zelle der Peripherie zustreben (Fig. $\left.1 b_{1}-b_{4}\right)$. 


\section{ZWEITES KAPITEL.}

\section{Allgemeines über die Kontinuitätsfrage.}

Sehr viel schwerer war die Entscheidung zu treffen, ob die Ans-

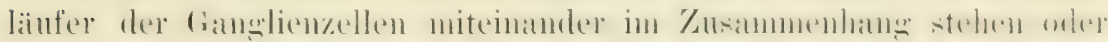
nieht. Für die Wirbeltiere wurle zwar von vielen Autoren ein netz-

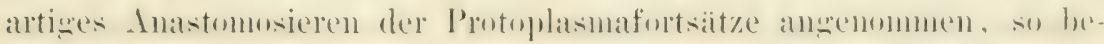
sonders ron Gerlach, aber andre Autoren, wie Deiters, Kölliker und

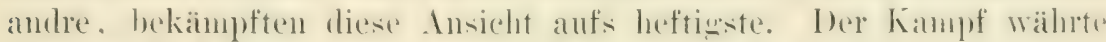

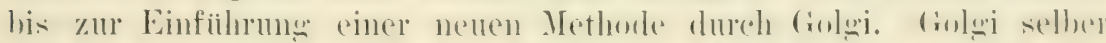

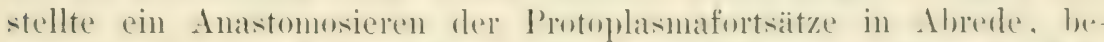

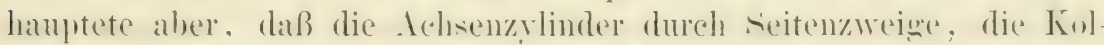

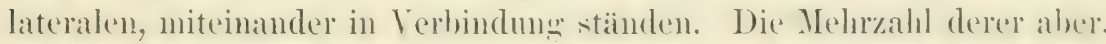
die nach seiner Methode arbeiteten - und das waren seln viele -

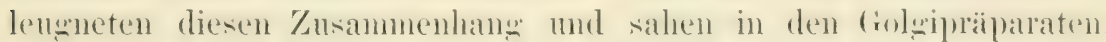
die mit einer bis dahin moneahnten Deutlichkeit die Tervenclemente bis zu den anscheinend letzten Enden darstellten, einen IBeweis dafiur. dak der Achsenzylinder wie die Protoplasmafortsitze diner Ganchenzelle durehaus von denen aller andern franglienzellen wetremut seden.

Wie so hänfig worde hier mit den Wirbellosen war nicht serechnet und so gretan, als ob das Nerrensystem anf die Wirbeltiere beschräkt sei. Bei niedrigen Metazoen, Nednsen und ('tenophoren, war nämlich

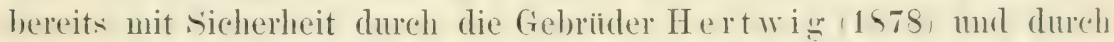
Eimer (1878) gezeigt worden, dab hier dis Nervensystem in Form eines in sich eschlosienen Nerrennetzes vorhanden sti. Auch üher andre Tiere lagen bereits ähnliche Angaben ror. Es war damit erwiesen, daß die wohl abgegrenzten Ansianferebiete, welche dir (iolgipraparate bei Wirbeltieren aufzeigten - Wenn iberhanpt den tatsächlichen Verhältnissen durchans entsprechend - zum mindesten nur

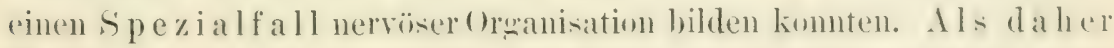
Waldeyer im Jahre 1891 die Lehre von den getrennten Nerveneinheiten in der Neuronentheorie präzisierte, konnte es sich nur um ein Spezialtheorem liandeln und nicht um eine Lehre, die alles, was Nerrenelement ist, in sich zus ammenfaßte.

Die Zahl der Fälle, in denen normalerweise die einzelnen Gan-

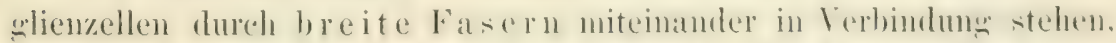
haben sich inzwischen wesentlich verneht. Wir kementrere, hei denen diese Art der Verbindung ïberall zu finden ist, wir kennen andre, bei denen sie wenigstens an gewissen Stellen des Nerven-

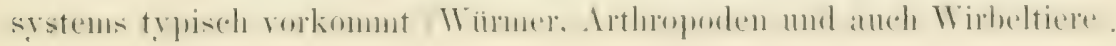


Andrerseits kann kein Kenner der Terhältnisse leugnen, daß im zentralen Nervensysten der Wirbeltiere, Arthropoden u. s. w. derartige

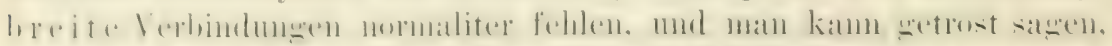

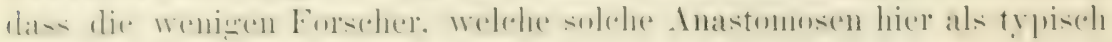
ansehen, dies nul anf Grund schlechter (aber nicht schwer zu el-

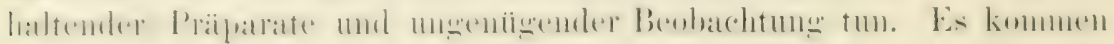
zwal bisweilen in der Retina (Dogiel, 1891, Embden, 1901, ich)

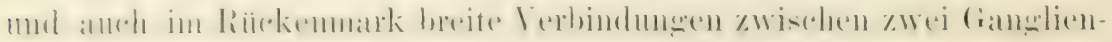
zellen vor, sie gehören aber zu den größten Seltenheiten und sind

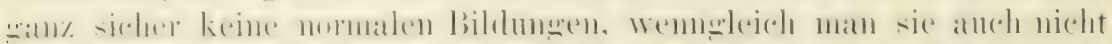

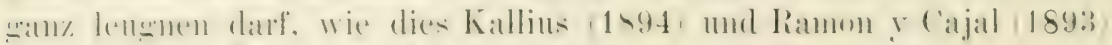

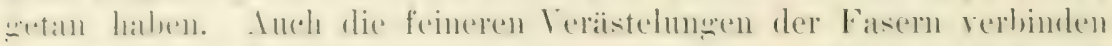

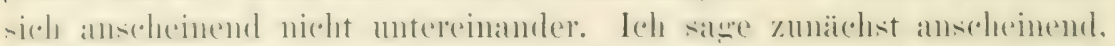
denn so leicht ist die Frage nicht zu entscheiden und ich möchte mich durehaus nicht anf den sicheren standpunkt stellen, den Rammon y Cajal, Kölliker, Lenhossék und andre hier eimnehmen.

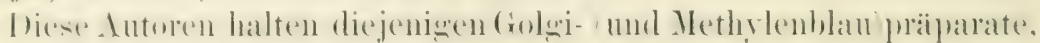
in denen viel gefälot oder inkrustiert ist, für ungeeignet, mu die Frage zu entscheiden, ob die feineren Zweige der Dendriten und Nervenfasern untereinander in Verbindmg stehen oder nicht, und

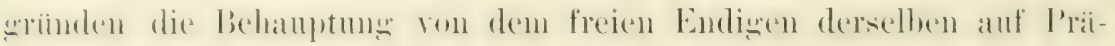
parate, in denen nur einige vereinzelte Elemente zur Darstellung

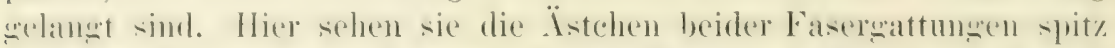

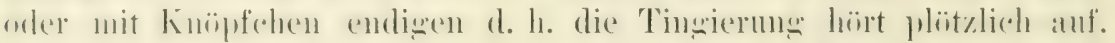
Oh da das natiuliche Ende ist oder ob nu die Reaktion hier auf-

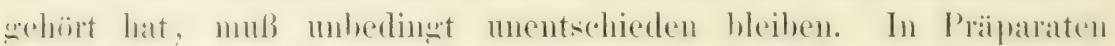
aber, in denen viele Elemente zul Darstellung gekommen sind, ist das Gewirl so groß, daß man wohl schembare Anastomosen sehen

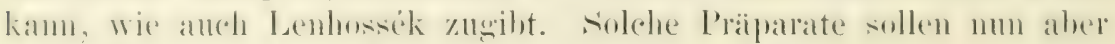

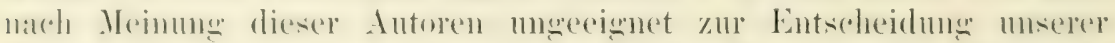

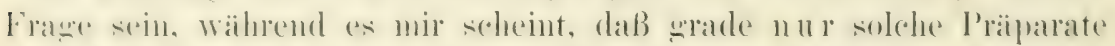

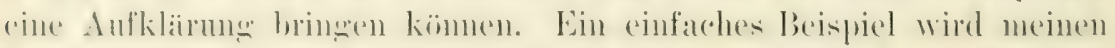

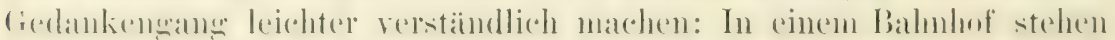
die einzelnen Geleise der verschiedenen Strecken miteinander dureh die Weichen in Verbindung. Wenn wir num so hoch mit einem Luft-

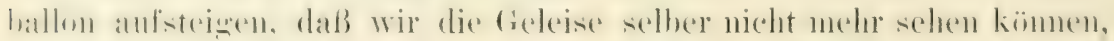
sie aber wahmehmen, wenn sie auf irgend eine Weise markiert sind, so werden wir von ihrem Zusammenhang nichts bemerken, falls nur

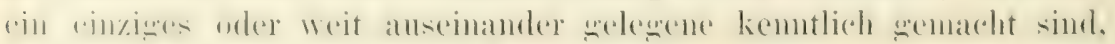
da nur die benachbarten in Zusammenhang stehen. Es wird immer einer zienlich vollstindigen Markierung bedüren, um den wahren

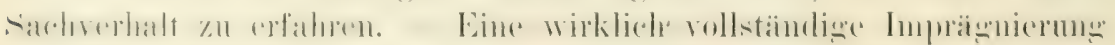
kommt nun bei Golgipräiparaten wohl nie ror und schon eine einiger- 
maßen vollstandige läßt hier und dort im Zweifel, ob nicht doch Anastomosen da sind. Von solehen Stellen wird man aber immer sagen können, daß es sich vielleicht mu kïnstliche Verklebungen handelt, wie sie ja sicherlich ziemlich oft bei dieser Methorle volkommen; andrerseits wird nan aber bei solehen Präparaten, die

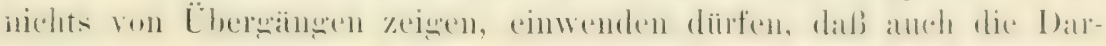
stellmm der einzelnen Elemente eine moollkmmmente ist, dat man jat

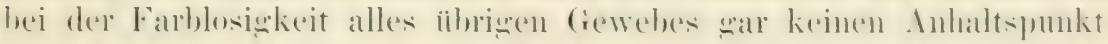

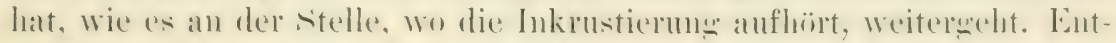

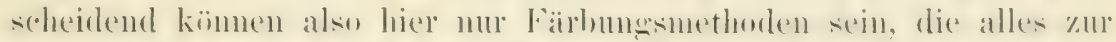

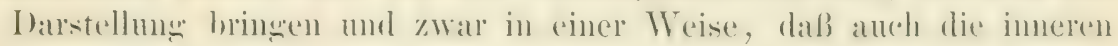

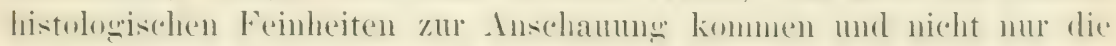

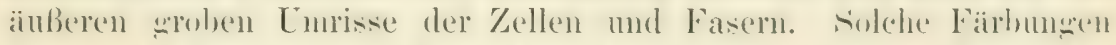
kamm nan zoweilen mit Eisenhämatoxylin und mit meiner Molyhän-

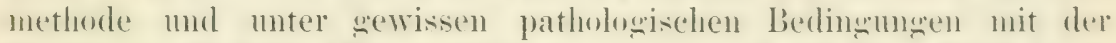
Nisslichen Methode Nissl, 1903, erreichen, und mit ihrer Hilfe kam man wenigstens fül die Protoplasmafortsäte zu einer wewiscen Entscheidung selangen: soweit sie protoplasmatisch sind. endigen sie hlind mit einer Spitze; aber niemals mit einem Knöplehen, wie es nicht selten in Golwipraparaten scheint. Nach meiner Meimmen landelt es sich lei den knopfartigen Endigungen nur um das Ibbrechen der Inkrustierung [die iiberall erfolgen kamn] an einer von den häufin luei dieser Methode zu Tage tretenden Varikositaten). Wie es mit den Vervenfasern steht, werde ich erst weiter unten belenchten, demu hixe liegen die Verhälnisse sehr viel komplizierter und wir wollen vorlänfï mit den Neuronisten annehmen, daß auch sie frei enden.

Wir hätten also a f der einen Seite Nervensysteme odel Teile von Nervensystemen, die nach einem netzartigen Typus (nit großen, breiten Anastomosen zwischen den Ganglienzellen) gebaut sind, auf der andern Seite Nervensysteme, deren Ganglienzellen ingar keiner protoplasmatischen Verbindung miteinander stehen. Weg-

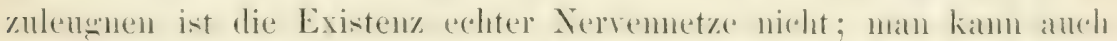

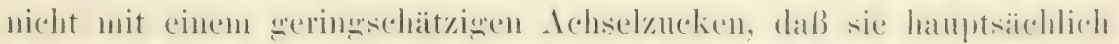

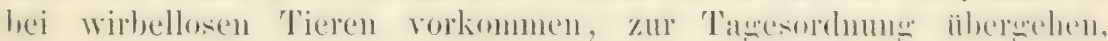
sondern man mub versuchen sich in irgend einer Weise mit ihr abzufinden. Mir selıeinen hier nu zwei Möglichkeiten zu existieren: entweder wirnehmen an, daß es zwei ganz velseliedene Formen neröser Organisation gibt, oder wir gebenes a uf, in dem protoplasmatischen 'leil des Nervengewebes, den uns die meisten Methoden allein zeigen, das Wesentliche zu sehen und suchen nach Elementen, welchedie anscheinend vorliandene Kluft iiberblicken! 
Ich selber habe mich, als ich anfing, mich für die Nerremnetze

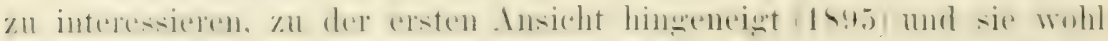
zuerst vertreten. Spater ist sie mabhaingig ron mir anch ron Holmwren (1896) ausgesprochen worden. Ls sind Tiere resp. Orte mit zranz hesonderen physiologischen Verrichtungen, an denen sich die

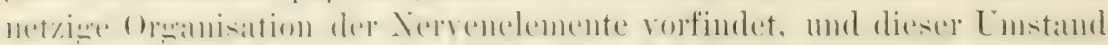

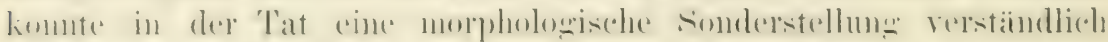

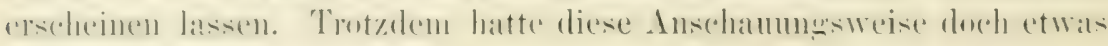
recht Gekiunsteltes an sich.

Die andre Möglichkeit, wenn auch für alle die undiskutierbar, weldefe in dem katum definierbaren l'rotoplasma den Trätere alles

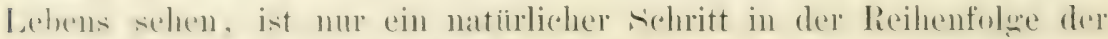

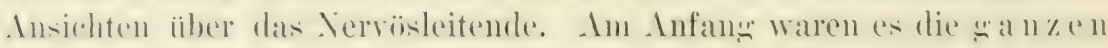
Nerven, die leiteten: nach der Entdeckung der Nervenfasem waren es diese in ihrer Totalitiat und, ats ihre Zusammensetzung ans dem

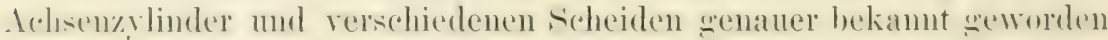
war, entschied man sich nach langem Streit dahin, daß nur die Achsenzylinder das Leitende seien, die Scheiden aber eben nur

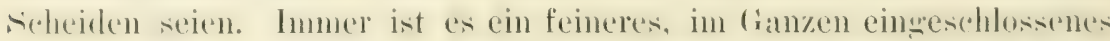
Element, dem die Funktion des Ganzen zugesehoben warde. Als einen Hanptormel für den Wechsel der Ansicht sehen wir hier ïberall din und dieselbe prinzipielle Forderung: die Forderung nach Kontinn it ät! Diese Forderung, auf der man innerhall, einer Leitumgbalun bestand, sable die Neuronentheorie auf, wo es sich fatng bon einer bahn auf die andre handelte, weil man sich nicht vom einem Znsammenhang der protoplasmatischen Teile bei dem Wirbeltierzentralorgan iiberzeugen komnte. Wenn es sich nun zeigen ließe, daB innerhalb der nervösen Fasern und Zellen ein Strukturelement existierte, das dem Kontinuititsbediufnis besser genügte als die umschließenden, protoplasmatischen. Gebilde selbst, so ware damit der Widersprueh in der nervösen Organisation aufgehoben, indem nun, eben eine protoplasmatische Kontinuitat grade so wenig zu existieren brauchte wie etwa ein kontinuierlicher Verlanf der Markscheiden. Wenn nur die Kontinuitat dieses supponierten Elements sich iiberall erweisen ließe, wo nervöse Organisation ist, dann wäle ein einheitliches morphologisches Prinzip gefunden und der Untersehied zwischen Nervennetzen und "Nenronen" im Grunde ebenso sekundärer Natur wie der zwischen markhaltigen und marklosen Fasern! Lin soleh einheitliches, nerröses Strukturelement ist nun schon seiteiner Reihe von Jahren niehts Hypo- 
tetisches mehr. Es existiert in den Primitivibrillen oder Neurofibrillen. Sie sollen die Grundlage aller weiteren Besprechungen sein.

\section{DRIT'IES KAPITEL.}

\section{Historisches über die Neurofibrillen.}

Remak, der Entdecker des Achsemzylinders in den markhaltimen Nervenfosern und der marklosen, hassen Fasem des srmpathischen Servensystems, bezeichmete bei der Publikation dieser wnken Entdeckungen hereits den Achsenzylinder oder, wie er ihn namnte, das I'rinitivband als ein feingestreiftes Gebilde (1535). Wem $11 m$ anch diese vitreifchen sicher nicht die Fihrillen selber waren, so hat er doch wohl den Ausdruck des fibrillären Aufhaus des Achsenzylinders zuerst greschen. In den folgenden Jahren liesen keine nenen anf diesen Punkt gerichteten Angaben vor. Die meisten Autoren, soweit sie ïherhant den Achsenzylinder als selbständiges Elenent anerkannten. sahen ihn als ein homogenes frebille an, oder sie lotten weniustens der Remakschen Beobachtung nichts Jeues hinzuzufümen. I)en nächsten dentlichen Fortschritt weisen zwei Arbeiten von Frommann aus dem Jahre $186 t$ auf. Er behandelte frische Nervenfasern und kileine

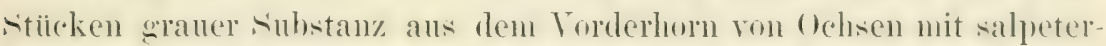
saurem Silher unl erkannte an solchen Präparaten sowohl in Nerrenfascru wie in Vorderhormzellen eine feine fibrilläre streifung. Besmders in den Protoplasmafortsätzen trat diese streifume deutlich hervor: er komute sie aher anch his in die Zelle selber verfolenen. Die Richitig-

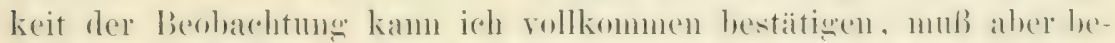

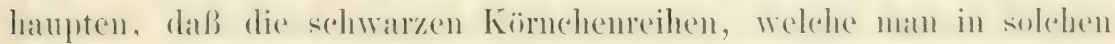

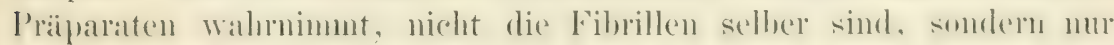

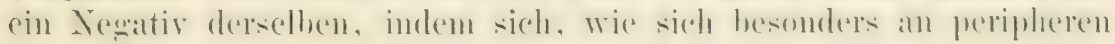

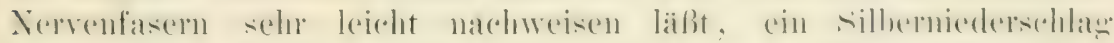
zwischen den Fibrillen bildet. Immerhin bedentet diese Arbeit einen

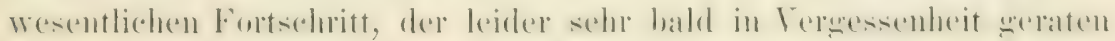

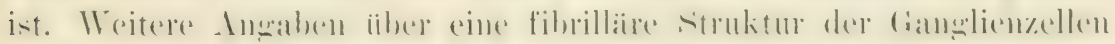
finden sich in dem großen Werke des leider so friilı verstorbenen Deiters (1865). Auch el vermochte an Isolationspraitparaten eine melr 


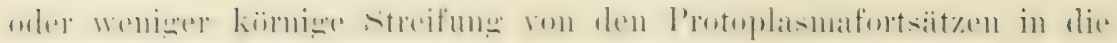
zellen linein $\%$ verfolgen.

Aktuell sollte die Frage aber erst durch die Lntersuchungen von Max schultze werlen. In mehreren Arbeiten (1568 mul 1571) suchte el die Primitivfibrillen, wie er sie benannte, als ein allgemeines

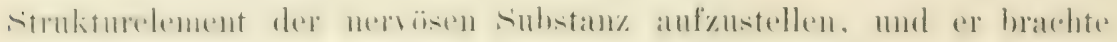
die Anerelewenheit wenigstens theoretisch bis zu einem P'unkt, über

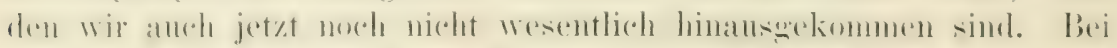

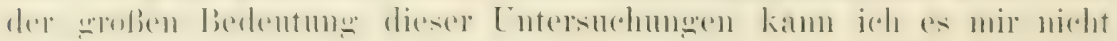
versagen, etwas näher auf dieselben einzugehen.

Anßer der Härtung' mit den damals noch allgemein iiblichen

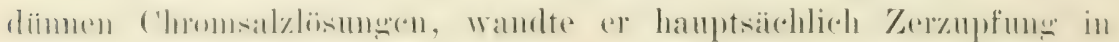
Jodsermm und in Osmiumsaime an. Es gelang ihm, in den Achsen-

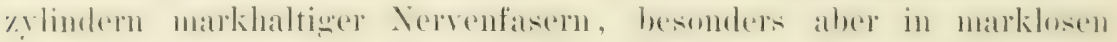

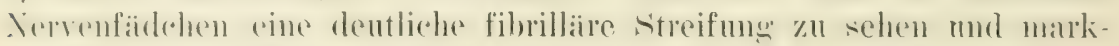
luse Fasern am Ende so aufzusplittern, dak ein canzes liöschel feinster Fibrillen aus ihmen hervorragte. Nit diesem letaten Versuch bewies er klar, daß es sich bei der Streifung nicht um ein optisches 'Trushild handelte, somdern dak die Fibrillen wirkliche kiorperliche

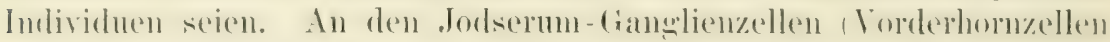
rom Ochsen, Zellen des Lobus eleetrieus von 'lorpedo) sah er mit gröBerer Schärfe und in reiterer Ausdehnung, als es frommann mud Deiters gehungen war, feine Streifen ron den veraistelten Fortsätzen und rom Achsenzylinderfortsatz in die Zellen ziehen. Ja er

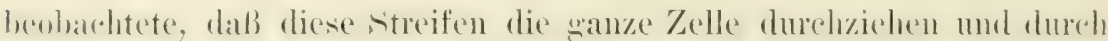
einen andern Fortsatz die Zelle wieder verlassen. Diese Befunde hracliten ihn zu der Torstellunen, dab die Fibrillen das Wosentliohe. das Leitende im Nervensystem seien und daß die Ganglienzellen

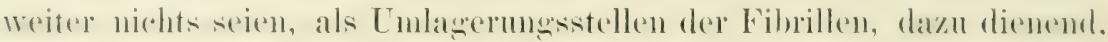
den Fibrillen, welche in einem verästelten Fortsatz verlanfen, es zu

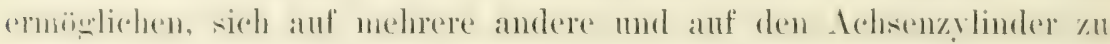
rerteilen. Auch die Tervenfasern sind ihn nur noch Fibrillenbiundel

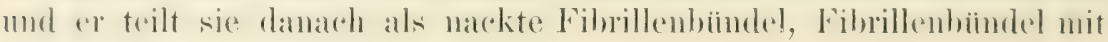
Markscheide 11. S. w, ein.

Lis ist nenerlich ron Apathy (1902) die Frage diskutient worden,

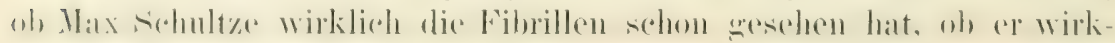

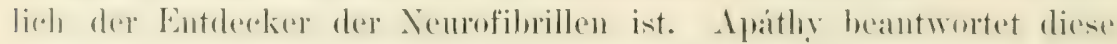
Trage, die ich nnir selber anch schon oft rorgelegt habe, mit ,Nein!" Mit den Methoden, die Schultze angewandt habe, sagt el, kömme er nicht die Fibrillen selber gresehen haben, bezeichnete er doch die

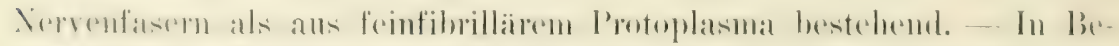

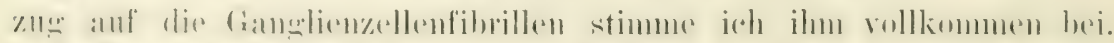

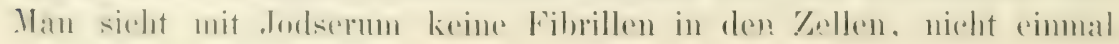


ihn Negatir (das Frommann hier entschieden gesehen hat), somdern

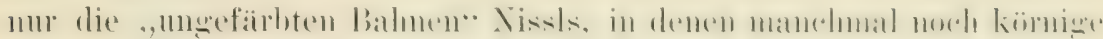
Einlagerungen eine feinere Streifung erkemen lassen. Da diese Bahnen aber den Terlanf der Fibrillen im sroßen Ganzen wiedergeben, so hat er doch auch hiel wenigstens geahnt, was wir erst seit kurzem sicher wissen. ${ }^{1}$ ) Anders aber steht es mit den peripheren

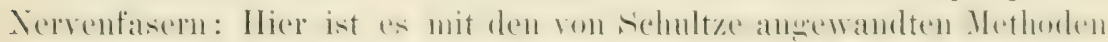

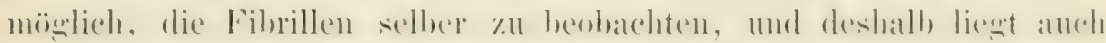
kein Grund vor, daran zu zweifeln, daß er sie gesehen hat. Vor

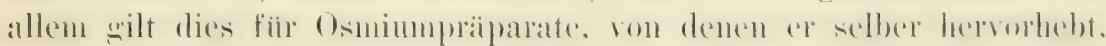
daß sie die Fibrillen besonders gnt erkennen lassen. Es berlarf gar keiner besonders guten Hilfsmittel, mm im nackten, d. h. von der

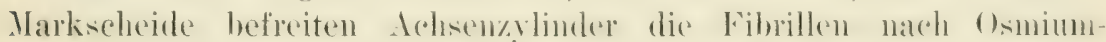

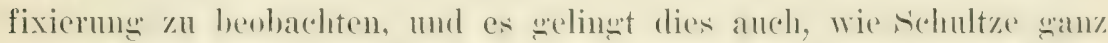
richtien herrorhebt, an solchen Achsenzylindem, die noch mit der Markscheide umgehen sind. Anch spricht er sich schon sanz nuzweidentien dahin aus, daß die Fibrillen in eine Perifibrillärsustanz eingebettet sind, die zwar bei manchen Präparationsmethoden kiomien erscheint. bei der Anwendung von Osmimnsiine aber ganz homogen ist. Ëher die Natur der Fibrillen spricht er sich nicht bestimmt gूenum ans, um den schluß ziehen zu diurfen, dab er sie für eine protoplasmatische streifune wehalten hat und nato seiner sanzen Auffassme des Protoplasmabegriffs kamm man eher ammehmen, daß er sie nicht für protoplasmatisch gehalten hat. I)ie Individualitait der Fibrillen kumte S'chultze bei dem damaligen stand der 'Technik nicht feststellen. dass el aber ihren individuellen Verlauf a 11 a hom, steht wohl anber allem Zweifel. Aber selbst dann, wemn Schultze niemals eine rirkliche Fibrille gesehen hätte, was ich hezweifle, so bleiht es doch sem danerudes Verdienst, die Insicht von einem allen nervösen Elementen semeinsamen und nirgends in den Zentraloroanen endenden, leitenden Fibrillensystem aufgestellt zu haben!

Die erste färberische Darstellnng von Neurofibrillen ist Kupffer

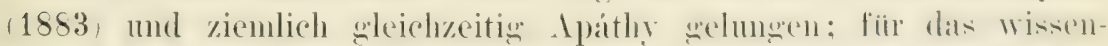

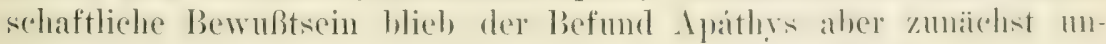

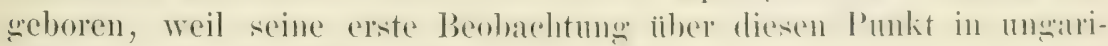
scher Sprache veröffentlicht wurde.

Kupffer fixierte markhaltige Nerven in Osmimmsäure und färbte sie in Säurefuchsin, worauf er sie in feine Schnitte zerlegrte. An

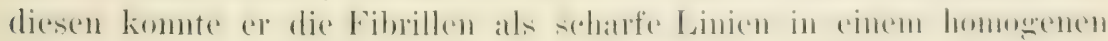
Plasma erkennen, in dem $\mathrm{el}^{\circ}$ sie frei flottieren ließ. Damit war zwar

1) Ganz die gleiche Ansicht hat ror kurzem Nissl (1903) ibber die Schultzeschen Zellbilder geïußert. 
fïr viele Zweifler die fibrilläre struktur der - Idesenzylindere erwiesen.

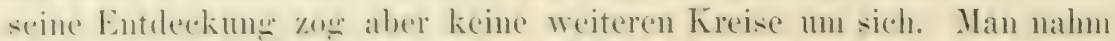

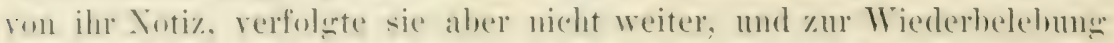
des sohultzschen fiedankens ron einem allgemeinen Formbestandteil des Nerrensystems kam es nicht.

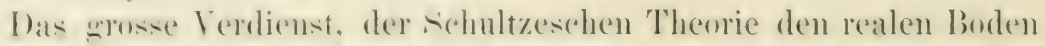

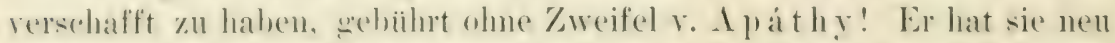
heleht und weiterefofiht und durch seine nureroleichlichen Praiparate in langjahriger Arbeit der. Neurologie eine neue fruchtbare Grundlage gegeben. Sie ist enthalten in dem bisher allein erwhenenen ersten Teil seiner zusammenfassenden Arbeit (1597)

Einigre kleinere fribere Vitteilungen (1857, 1859, 1592 und 159. hrabliten hereits die fundamentalen frumdziige seiner Benhachtumgen

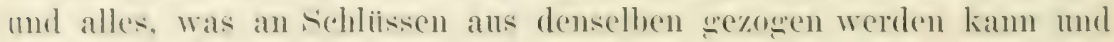
muls. Liei der aprioristischen Form, in der sie ahgefalkt waren, mol del Merkwiirdigkeit der befunde, welche entweder sarnicht oder nur duroh ganz sohematisch erscheinende Abbildungen belegt waren, fanden diese Irheiten wenign Inklange mol ich muls selher sestehen, dab ich sie mit Kopteschiitteh selesen habe. Meine Zweifel schwanden seln schmell, als Ilerr V. Apathy welegentlich eines Zusammentreffens anf del zonlowischen station zu Neapel im Merbst 1596 die Liehenswirdiskeit hatte, mir seine l'räjarate zu zeigen. An thend vor diesem für mich stets denkwibligen Tage hatte ich ihm noch erkbät, dak ich das.

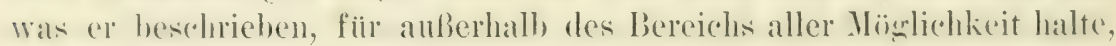
und es könme mur auf Selbsttianschung beruhen, weun er meine, Fibrillen rom soleher Feinheit auf Millimeter als Individuen repfolet m haben. Was mir damals aber gezeigt wurde, war von so überzengendro Klarheit, dab ich meine Opposition nach einigen wokinstelten Einwänden gänzlich anfungeben gezwungen war. Wie es mir gegrangen ist, ging es vielen anderen, und kein Normalsichtiger wird sich den ibserzensenden Eindruck der Mrathrschen Praparate ent-

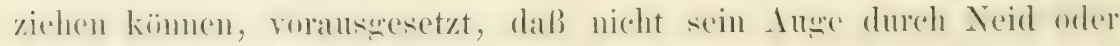
grekrinkte Eitelkeit getriibt ist.

Die umfangreiche, im Jahre 1897 erschienene Arbeit enthält die

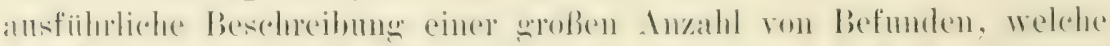

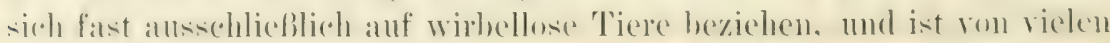

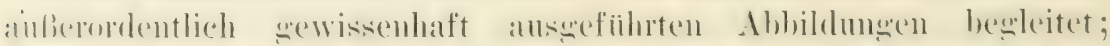

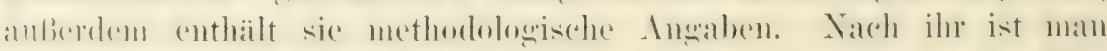

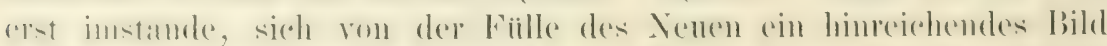

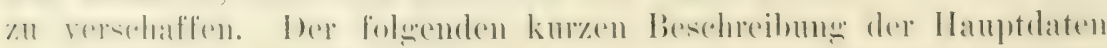

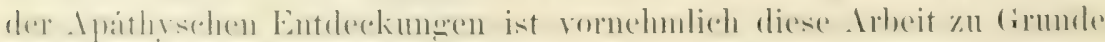
relegt. Viele Einzelheiten sind in den späteren Kapiteln wiedergereben. 
Apátlys Befunde im allgemeinen: Mit Hilfe seiner nenen Ne-

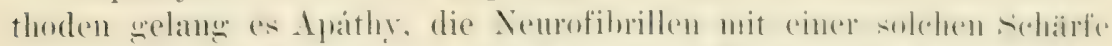

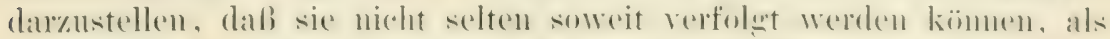

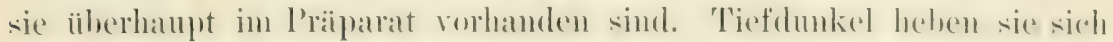
ron dem ungefarbten oder nur schwach gefarbten Grunde wie die

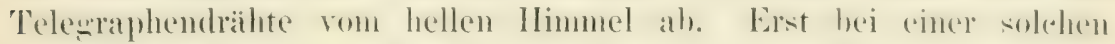

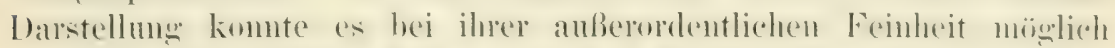
sein, ïber ihren Verlanf finaneres zu finden: Überall kommen sic ror, wo wir von nervöser Funktion wissen, in den Nervenfasern wie in den Ganglienzellen, in den Mnskelfasern wie in den simesepithelzellen und den Drïsenzellen. Von allem mmobenden Gewobe sind

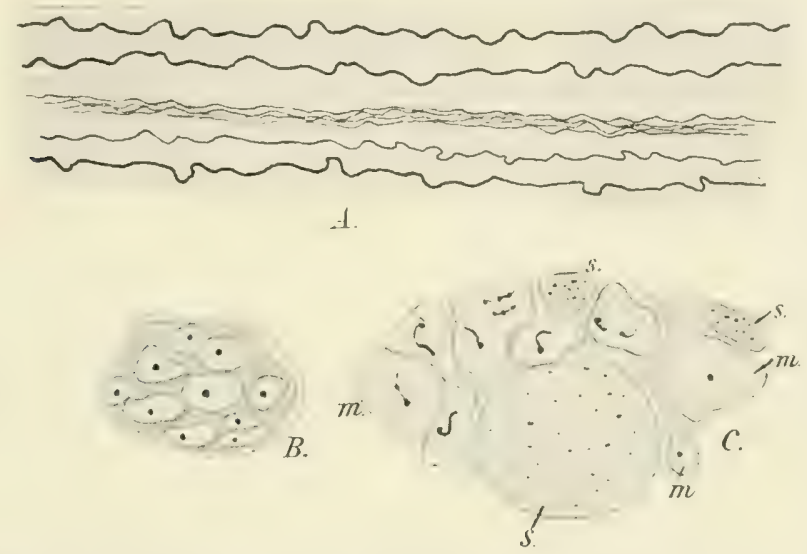

Fig. 2. A Längsschnitt durch einen Teil einer Lïngskommissur von Hirudo nach einem Fibrillenpräparat. Bei der Fixation war die Kommissur nicht gestreckt; daher sind nur die Begrenzungslinien der Nervenfasern glatt, die rerschieden dicken Neurofibrillen aber gewellt. $B$ Querschnitt durch einen dïnnen rein motorischen Nerven von Hirudo. In der ungefärbten Perifibrillärsubstanz jeder Nervenfaser liegt eine dicke Neurofibrille. $C$ Teil eines gemischten Nerven ron Hirndo im Querschnitt. $S$ sensorischer Schlauch. s sensorisches Biindel. $m$ motorische Faser. $(I)$ und $C$ nach Apáthy, 1897, Taf. 23, Fig. 7 und 10.)

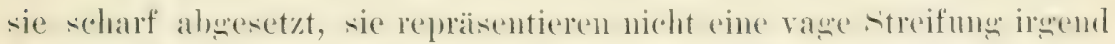
welchen fiewehspotophlasmas, sind nicht streifigne Verdichtumęen der

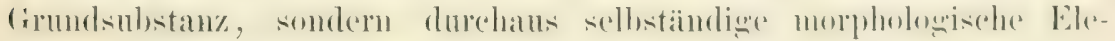

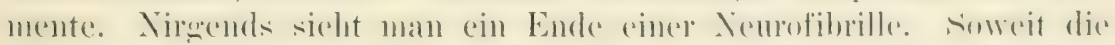
Grenzen des Priparats reichen, kann man die eimmal ins Ange gefaßte Fibrille verfolgen, falls nicht aus irgend einem Grunde die Farbung an einer Stelle ausgeblieben ist. Innerhalb der Nerven-

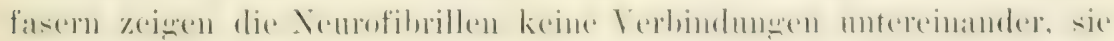
bewahren also vollkommen ihre Individualitait (Fig. 2). Es gibt aber drei Orte, an denen sie ihren isolierten Verlauf aufgeben: in den innervierten Organen, in den Ganghlienzellen und im Nenopil, d. h. dem

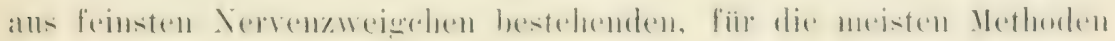
bethe, Nervensystem. 
mauflösbaren Fasergewirr, das bei den Wirbellosen die Mitte der Ganglien ausfiullt.

In den Endorganen (Muskelfasern, Simnesepithelzellen, Driisen\% ander zu verbinden. Tritt nu eine Fibrille ein, so splittert auch sie

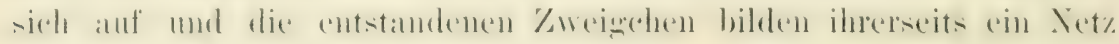
oder einen Korb. In den Ganglienzellen zeigen sich ganz ähnliche

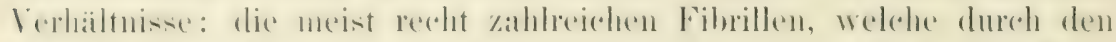

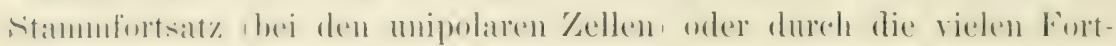

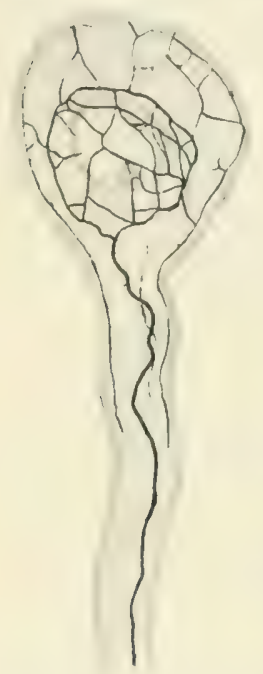

Fig. 3. Motorische (ianglienzelle von Hirudo nach A páthy (Taf. 28, Fig. 7). Die Fibrillen sind im lnteresse der Keproduktion etwas dicker wiedergegeben als in Original. sütze (bei den multipolaren Zellen) in die Zellen eintreten, verzweigen sich, um sich in ihren Zweigen zu einem Netz zu vereinigen (Fig. 3). Eine analoge Netzbildung findet im Neuropil statt, nur daß sich in diesem Netz, dem Elementargitter, wie es Apáthy nemnt, sehr viel mehr Fibrillen zusammenfinden. Ein genaner Vergleich der Fibrillen in den motorischen und den rezeptorischen (sensiblen) Fasern ergab, daß die der ersteren sehr viel dicker sind, als die der letzteren, und dieser Unterschied ist (bei Hirudineen) so charakteristisch, daß die Unterscheidung der einzelnen Fibrillengattungen auch im Zentralnervensystem und sogar in den Gangolienzellen noch möglich ist (motorische und sensorische Fibrillen Apáthys). Es ergab sich num, daß sich die Fibrillen der rezeptorischen Fasern im Neuropil aufsplittern und im Elementargitter ihre Indiridualität rerlieren. Ats dem Elementargitter sammeh sich wieder gleichfalls sehr düme Fasern, die in Ganglienzellen hineinziehen und hier ein äußeres Gitter bilden (Fig. 3). Von diesen ziehen radiäre Fibrillen dem Kern zu und vereinigen sich in seiner Niihe zu einem zweiten, aus dickeren Fibrillen bestehemen Korb, aus dem eine starke Fibrille hervorweht, um sich durch eine motorische Faser direkt zur Muskulatur zu be-

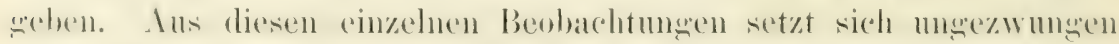

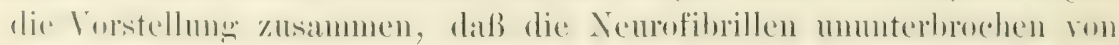
den rezpotorischen Vervenendigungen dureh die rezeptoriseden Xerven

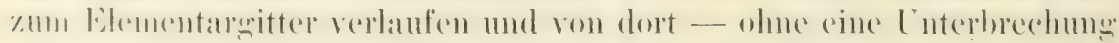
zu erleiden - in die motorisehen Ganglienzellen treten, um hier die motorisetur fribrillen zu formieren, die dam kontinuierlich den Mnskelfistron oder anderen innervierten Gebilden \%ngehen. Mit anderen Worten:

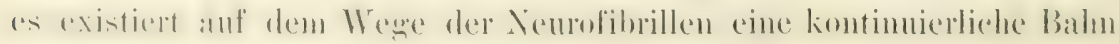
awisehen den rezeptorischen und motorisehen Elementen! 
Über Neurofibrillen bei Wirbeltieren hat Apaithy bis jetzt nur wenige Angaben gemacht. Sie beschrinken sich darauf, daß er sie

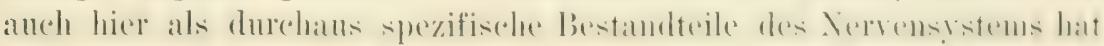
nachweisen kïmlen und dak sie in den peripheren Xervenfascon wi bei den untersuehten wirbellusen Tieren rinen durelans individuellen Verlauf haben.

Auf Grund aller dieser Befunde hailt Apáthy die Neurofibrillen fitr das leitende Element im Nerrensystem, und es ist wohl zweek-

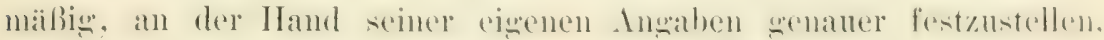
was alles für ihre leitende Natur spricht: Überall, wo sich nervöse Einfluisse geltend machen, hasien sich auch Xemofibrillen nathweisen. sie sind spezifische, ron anderen fibrillären fiehilden wohl unterscheidlare fewehshestandteile, die sich im swöbten Teil ihres lerlaufs durehans als Individuen erweisen. Vom der Peripherie bis zun Zentralorean und vom diesem his an die l'eripherie zurï̀ zeisen sir sine rollkommene Kontinuitait. Üherall dort, wo man ein besonderes fieschehen im Bereich des Nerrensystems anzunchmen firund hat. zeigen die Xeurofibrillen anch ein spezifisches Verhalten. sio wehen sie zu den Ganglienzellen, den Rezptionszellen s'imneszellen, den Driisen- und Inskelzellen charakteristische topographische laeziehungen ein. Schließlich bilden sie dort kontinuierliche Zusammenhänge, wo die plasmatischen Teile wanz unterlurehen oder substantiell diskontinuerlich sind. So ist fast überall im höher organisierten Nervensewehe kein kontinuerlicher Zusammenhang zwischen den plasmatischen Ansläufern verschiedener fanglienzellen vorhanden; die in ilnn enthaltenen Fibrillen kïmnen ihn herstellen, indem sie eine strecke weit als nackte Fibrillen verlaufen. Ganglienzelle und Nervenfaser. ehenso Nervenfaser und Muskelzelle n. $s$. W. sind plasmatisch schart roneinander abgesetzt, die Fibrillen wehen alser kontinuierlich von der einen in die andere iiber.

„Der wesentlichste spezifische Bestandteil der Nerven und das

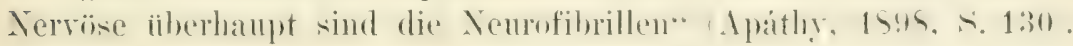

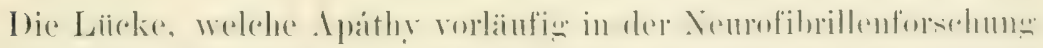
bei den Wirbeltieren gelassen hatte, habe ich zum T'eil wenigstens

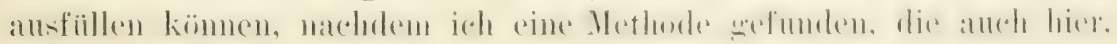
wo die Apáthysehen Methoden nur schwer branchbare Resultate er-

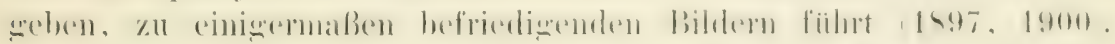
Auch bei den Wirbellosen habe ich einiges Nene zu dem von Apaithy

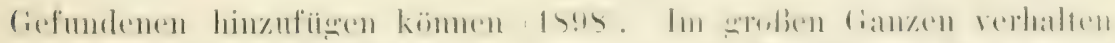

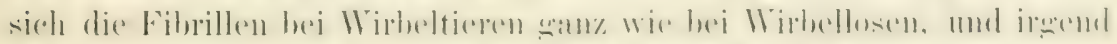

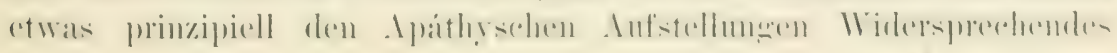


habe ich nicht gefunden. Einige neue Details werde ich in der

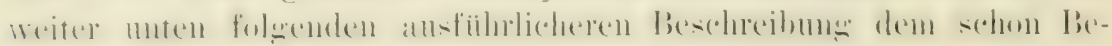
kamnten himzufiigen.

\section{VIERTES KAPITEL.}

\section{Das Nervensystem wirbelloser Tiere (mit Ausschluß der Nervennetze).}

Kinre Beschreibung des Nervensystems der verschiedenen Klassen der Wirbel-

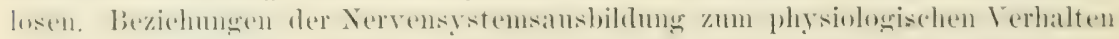
S. 20-25. - Die Form der Ganglienzellen und der mit ihnen verbundenen nervïsen Fasern S. 26-33. - Verlauf der Neurofibrillen in den Nervenfasem S. 33-38. - Verlauf der Neurofibrillen in den zentralen Ganglienzellen S. 35-41. Verbindungen \%wishen rezentorischen mol motorischen Fibrillenbahnens. $41-46$.

Wenn ich den Anfang in der Beschreibung mit den wirbellosen Tieren matelee, so hat dies darin seinen Grund, daß unsere Kemntnisse. hesonder's iiber den Verlauf der Neurofibrillen, hier vollkommener sind. damn aber anch darin, daß die Verhältnisse hei diesen Tierformen entedheden cinfacher liegen. An einfachsten liexen sie zwa bei den Nervennetzen, die sombohl bei Wirbellosen wie bei Wirbeltieren rorkommen, aber ich habe meine Grinde, diese in einem besonderen Kapitel arst später zu besprechen. Zaniächst will ich für diejenigen, denen die Verhältnisse nicht sanz geläufig sind, eine kur\% Übersicht iiber die Formen geben, in denen uns das Nerrensystem bei Wirbellosen entgegentritt.

Bei den Cölenteraten, die von den Zoologen als die niedrigsten Iretayen mach den spongien, die keine nachweisharen Vervenclenente? enthalten) angesehen werden, tritt uns das Nervengewebe diffus im wanzen körper verteilt enteregen. Üherall zerstrent findet man unter dem Epithel, bei manchen Formen anch in Epithel, Gamglienzellen

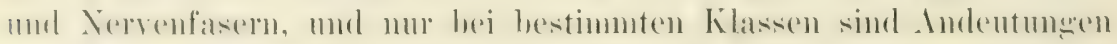
yon Konzentration oder, wenn man will, Zentralisation zu bemerken. Am deutlichsten ist dies bei den craspedoten Medusen der Fall, wo sich eine stärkere Inhäufung ron Ganglienzellen und Nervenfasern am Schimmande im sogenamnten Randring bemerkbar macht. Nit

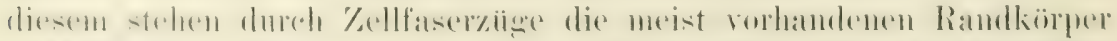

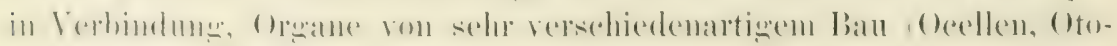
lithensäickchen 11 . s. w.), deren Bedentung als rezeptorische Organe 
schon ans anatomischen Grinden ziemlich zweifellos ist (Fig: 4). Anch radiäe Zellfaserziige kommen ror. Bei weitem der grißte 'Teil aller als Ganglienzellen und Nervenfasern gedenteten Elemente ist aber diffus, plexusartig, über das ganze 'T'ier' (nit Ausmahme der oberen

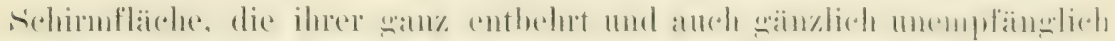
fïr Reize ist) verbreitet. Wahrseheinlich sind bei allen Cölenteraten die Nervenelemente unteremander zu echten Nervennetzen verbunden (0. und R. Hertwig, Eimer, Bethe) und die von Havet (1901) nenerdings fiur Aktinien gemachte entgegengesetzte Behauptung möchte ich vorlüufig noch anzweifeln. (Obwohl seine Schnittrichtung zur Auffindung der Anastomosen so mginstig wie mur möglich ist, so scheint el doch seinen Abbildumgen mach mehrere gefunden zu haben).

Bei den Echinorlermen ist an bestimmten Stellen des Körpers eine stärkere Anhäufung von Nervenelementen volhanden; die Hauptmenge bildet aber anch hier noch einen diffusen, zwischen dem äußeren Körperepithel und der Schale l'esp. der Lederhant gelegrenen Plexus, der sich an der Basis der stachehn bei den seeigedn, verdichtet. In der Körperhöhle, die bei den Echiniden Seeigeln) und Asteriden (Seester-

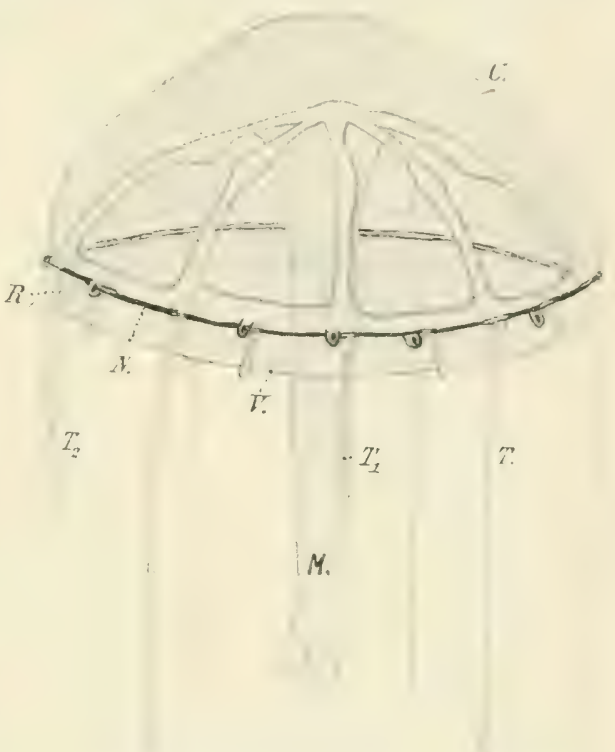

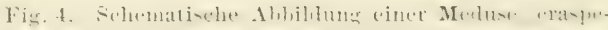

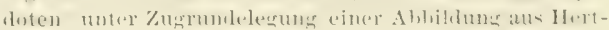
wigs Lehrbuch der Zoologie; $U$ Umbrella, M Magenstie] $T$ Tentakeln ( $T_{1}$ und $T_{2}$ in halber Kontraktion), $N$ der

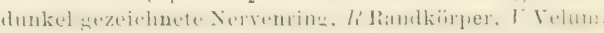
nen) von der Schale, bei den Holothurien von dem mit der Hant ver-

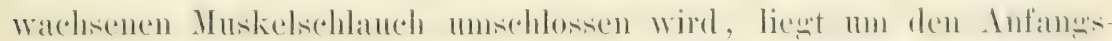

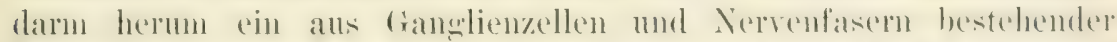

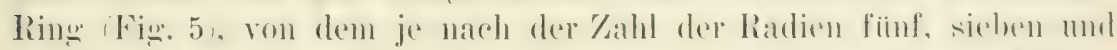

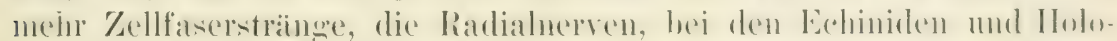
thurien zum analen Pol, bei den Asteroiden in die Mrme verlaufen. Diese Radialnerven stehen mit dem äuBeren Plexus durch feine Nervchen in Verbindung, welche bei den Eehiniden und Asteroiden \%usammen mit den Saugfüen durch die Schale treten. Besondere An-

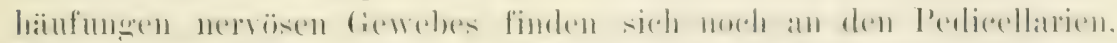

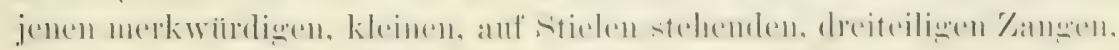
welche in großer Zahl die Hant der Seeigel und seesterne bedecken. 


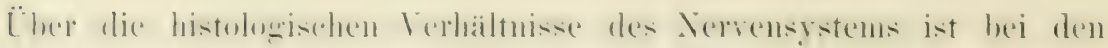
Echinodermen so snt wie nichts bekannt. Es ist auch bei der außer-

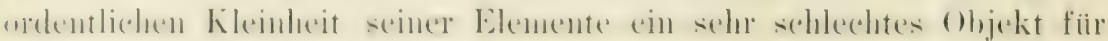
histologrische Untersuchungen.

Im 'Tierkreis der Wïmer tritt eine wesentlich stäkere Zentralisation im Nervensystem zu 'Tage, die sich besonders bei der

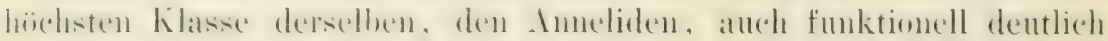
hemerkbar matcht. Lied den heiden moteren Klassen ich hleibe der

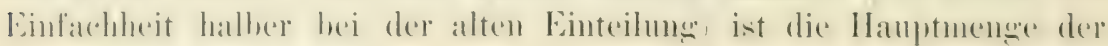

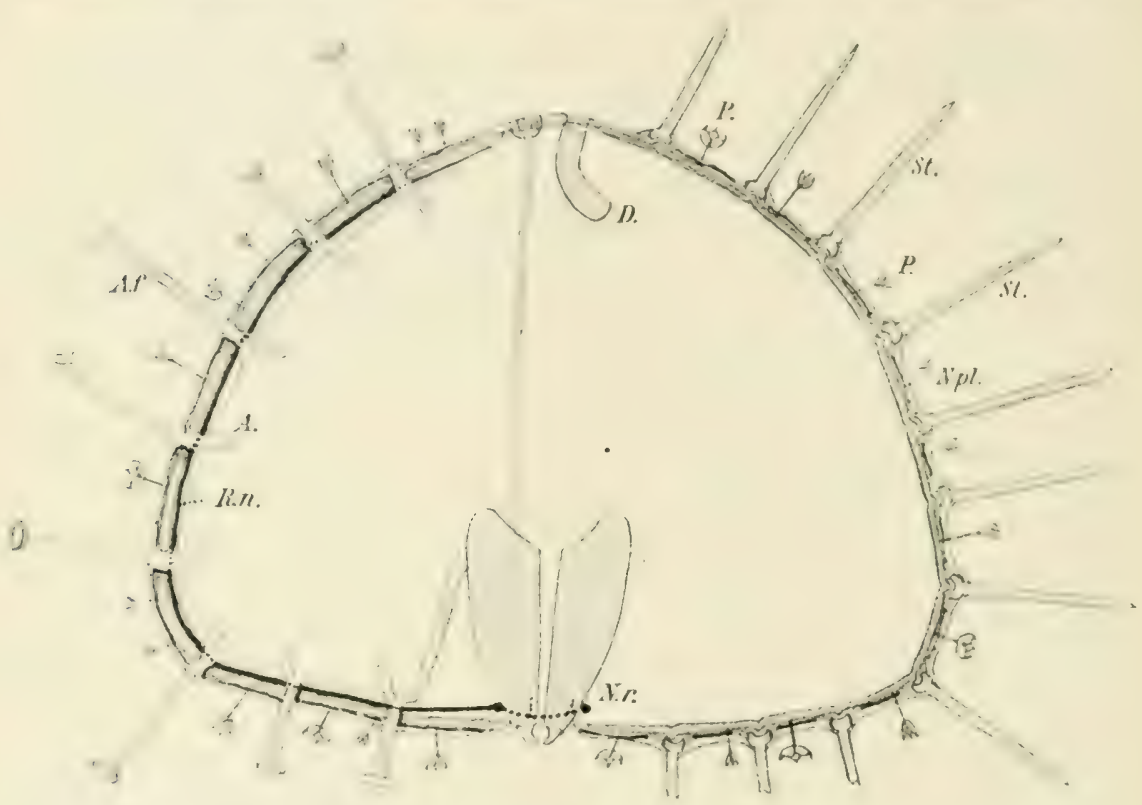

Fig. 5. Schematischer Durchschnitt durch einen Seeigel, zum Teil nach einer Figur ron Huxley. st Stacheln, I'Pedicellarien, A.f Ambulacralfïße, 1 Ampullen, $D$ Darm. Das Nervensystem ist ilunkler gehalten. N.r. Nervenring, R.n. kadialnerv, der mit dem iußeren Plexus, N.pl. am Durchtritt der Füße in Verbindug steht. Die Schale ist schraftiert gezeichnet.

fanglienzellen mul Nervenfasem zu einer Masse vereinint, die ent-

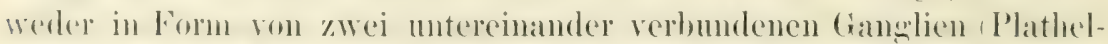

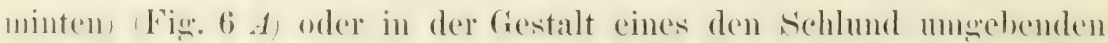

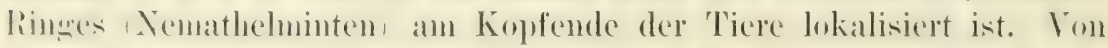
dirser Masse ziehen Faseroinere, die vielfach nit Gamelienzellen durehsetzt sind, und viele dnastomosen miteinander bilden, durch den ganzen Körper. Auch an der äBersten Peripherie wurden — soweit

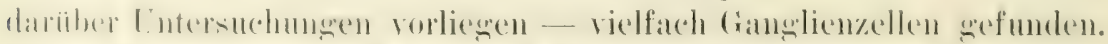

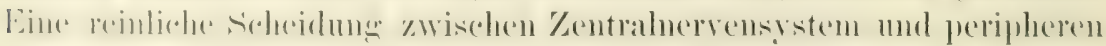
Nerven, wie sie bei höheren Tieren oft recht scharf hervortritt,

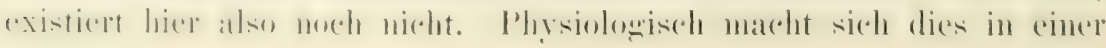




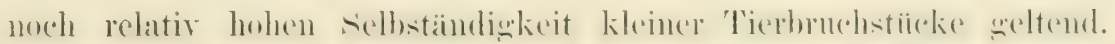

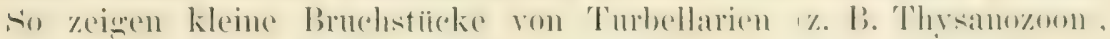
wie wohl zuerst Loeb gezeigt hat und ich bestaitigen kam, noch Reflexe, ror allem den Imdeheflex, der darin hesteht. dalf das auf

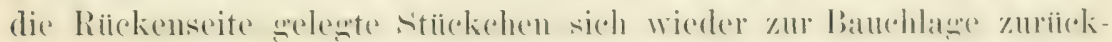

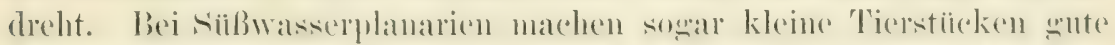

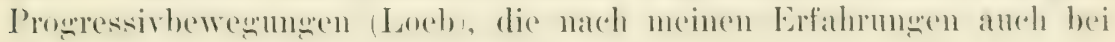
Thysanozoon nicht vollkommen fehlen.

Ein wirkliches Zentrahervensystem in anatomisehen mol physionlogiselen simne findet sich erst bei den höheren Wïrnerm, den Amme-

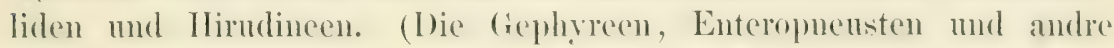
lasse ich mberieksichtignt, weil sie anatomisch nur mangechloft, physior-
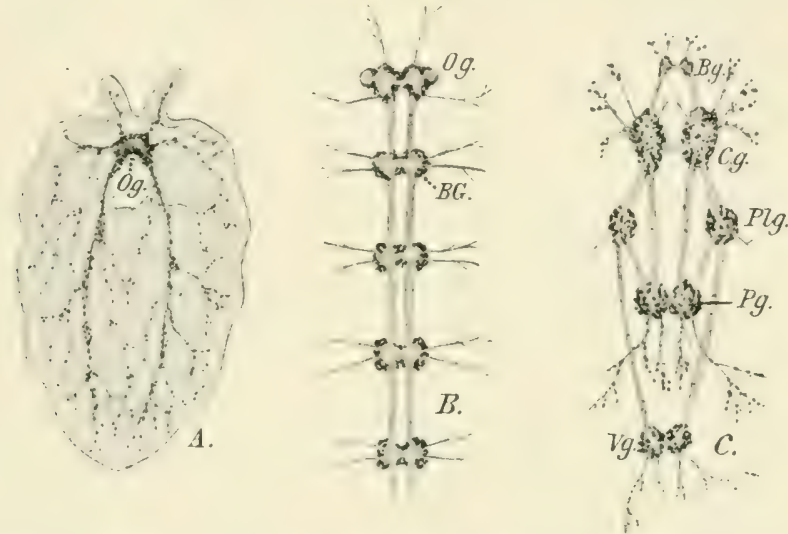

Fig. 6. Schematische Darstellung des Nervensystems: A Von einer Planarie, $L$ Von einem Articulaten (höhere Würmer, Arthropoden), $C$ Von einem Mollusk. Nervenstämme, Kommissuren und Neuropile sind grau gezeichnet; die Lage der Ganglienzellen ist durch schwarze Punkte angedeutet. Og. Oberschlundganglion, $B G$. Bauchganglion, $B g$. Bucealganglion, $C g$. Cerebralganglion, Plg. Pleuralganglion, $\mathrm{Pg}$. Pedalganglion, $\mathrm{Ig}$. Visceralganglion.

logisch gar nicht auf ihr Nervensystem untersucht sind.) Es wird repräsentient durch das Banchmark, das sich auf der ventralen sicite durch das ganze 'Tier hinzicht und nach vorne hin durch zwei den Fichlund unfassende Fascrbiundel, die sichlundkommissmen, mit dem

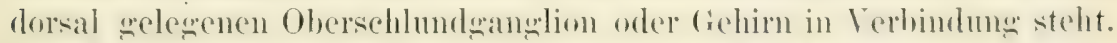
Das banchmark selher ist nicht wie das litiokemmark win wleichmäiger Strang, sondern es setzt sich aus cinzelnen Knoten, den banchganglien, zusammen, die untereinander dureh patrige Kom-

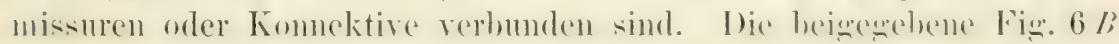
zeigt ein solches Nervensystem in typischer Ausbildumg. Ton den Ganglien gehen nach beiden Seiten Faserstränge ab, welche sich

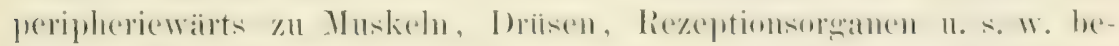
greben. Diese Faserzige, die Nerven, bestehen ebenso wie die Kon- 
missuren nur aus Nervenfasem (und Bindegewebe); Ganglienzellen fehlen in ihnen in del Regel san\%. Bei den Polychäten finden sich besondere kleine Ganglien an den Verven der Parapodien, im übrigen

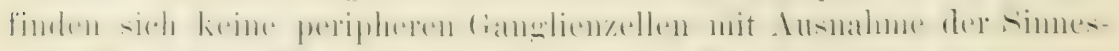

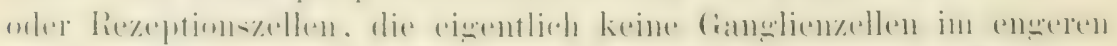
Sinne sind. Am Darm finden sich wieder Nervennetze, anf dic ich erst spaiter eingehen will. Wir treffen also hier zum erstemmal Verhailtnisse, die denen der Wirloeltiere ähnlich sind.

Auch im physiologischen Terhalten kommit dies zum Ausdruck: wähend wir bei den Cölenteraten und Echmodermen eine fast voll-

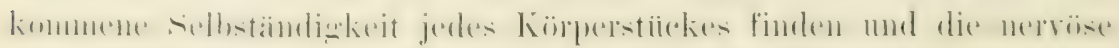

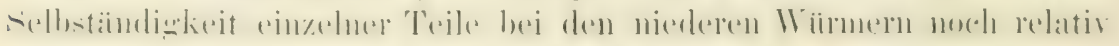
groß ist, fällt hei diesen 'Tieren nach Verletzung des Bauchstranges die nervöse Funktion in den entsprechenden 'Teilen vollkommen aus.

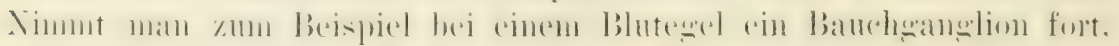

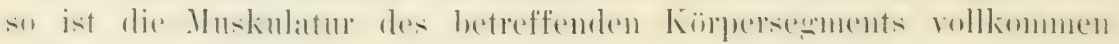

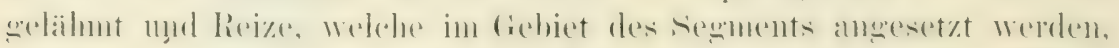
bleiben von den nicht nelähmten 'Teilen unbeantwortet. Der Effelit ist der gleiche, wie bei einem Wirbeltier nach Fortuahme eines Teils

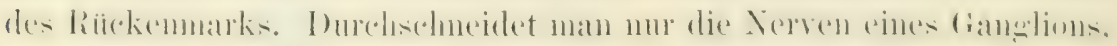

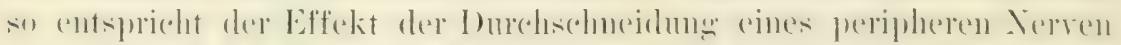

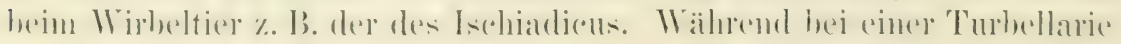

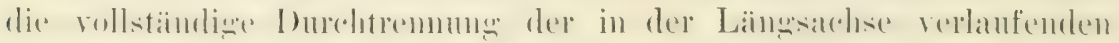
großen Nervenstämme es nicht verhindert, daß Reize, welehe man an

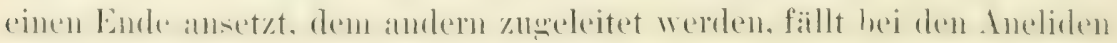

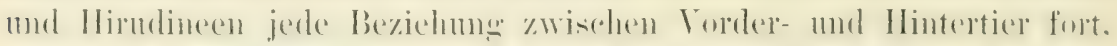

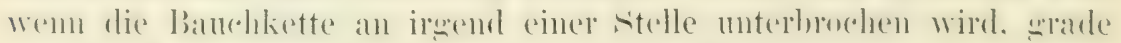
wie hei Wirbeltieren nach Durchschneidung des Rïckemmarks.

Die den soeben betrachteten segmentierten Wïmern in vielen Be-

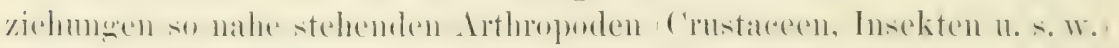
zeigen auch in Bezug auf den Aufbau des Nerrensystems und die

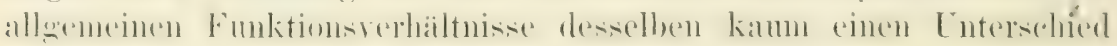
(Fig. $6 \mathrm{~B}$ ). Wie bei den höheren Wïrmern am Darm, so findet man auch hier an gewissen Körperstellen \%. B. unter der Haut nervöse

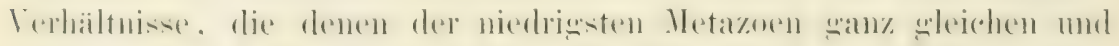

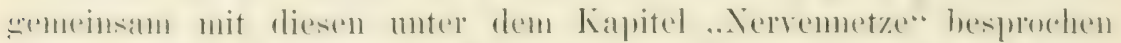

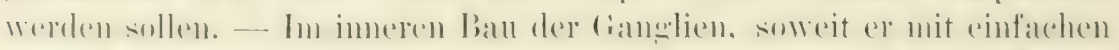

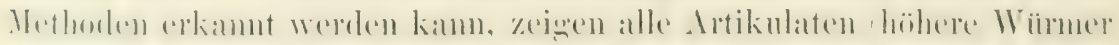

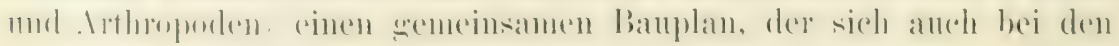
Mollusken und hei manchen niederen Wirmern erkemmen lïßt. Gan-

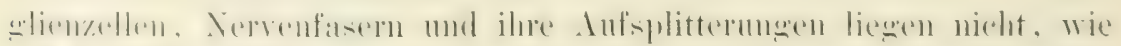

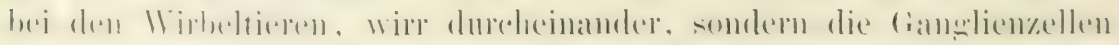
bilden cinen Zellmantel, der die langen Faserziige und die Nerven- 
anfsplitterungen, das Nemopil, muschließt (Fig. 45, S. 103). Diese Anordnung ist ron praktischer Bedentung, weil sie es ermöglieht, an den Ganglienzellen fiu sich zu operieren.

Die Mollnsken, die anch in andern Beziehungen den niederen

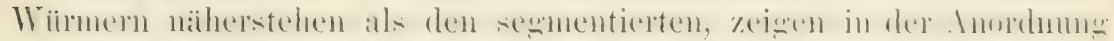
der Nervenelemente Verhältnisse, die an die del 'Turbellarien u. s.w. erimmern, aber von einer höheren Differenzierung zengen. - Das zentrale Nervensystem besteht ans mehreren großen Ganglien oder

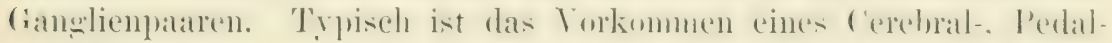

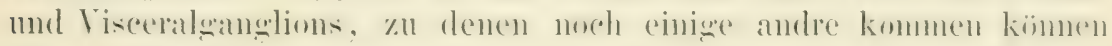
(Fig. $6 \mathrm{C}$ ). Untereinander sind die Ganglien durch lange, meist

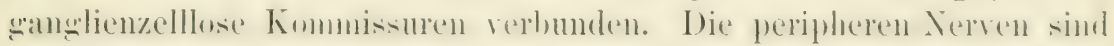

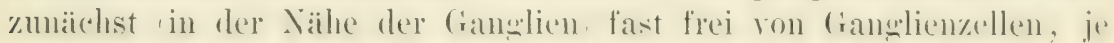
nehr sie sich aber der I'eripherie näherm, desto hä̈figer findet natu

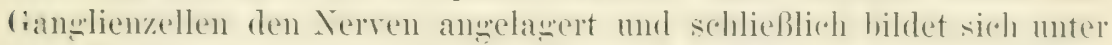

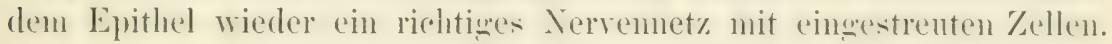
Angaben ïber periphere (ianglienzellen bei Mollusken sind schon ron

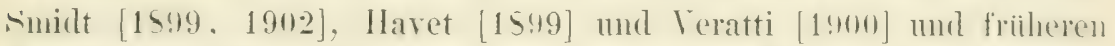
Antrien wemacht, Smidt hat auch schon das Nerremety richitien wesehen. Figene Cntersuchumgen wurden an Aplysia muternummen. Bei diesen Tieren erlischt das licflexlehen nach fortuahne des gesamten Zentralnervensystems ebensowenig wie bei den niederen Wïnern nach Exstirpation deremen Ganglienmascen, wie man leicht an Aplysia und Limax feststellen kann. In I amellibrunchiaten u. s. w. habe ich keine Versuche angestellt.) Die sehr eigenartigen Erscheinmyen werden weiter unten wenaner hesporden werden. - Fiir

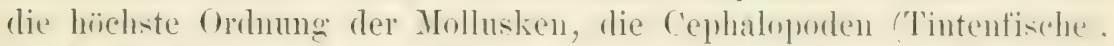
ist das Vorkmmen wrober Mengen peripherer Ganglienzellen besmolers

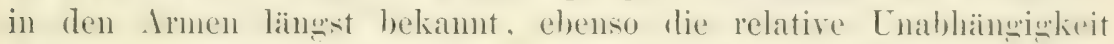
derselhen rom Zentrahervensystem siehe Lexkiill 15!15, wo anch die älteren Angaben zitiert sind).

Auch bei den 'tunikaten (Ascidien und Salpen) erlöschen die

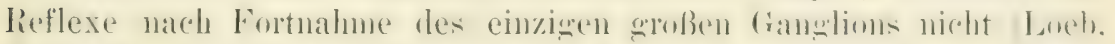

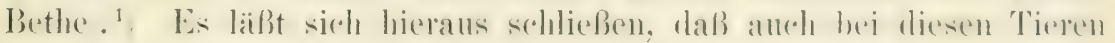
reichliche periphere P'lexus vorhandent sind. Inatomiscels simel sie aluer. soweit mil bekannt, noch nicht mit Sicherheit festgestellt.

Eine anatomische 'T'rennumg' sensibler und motoriseher Nerren-

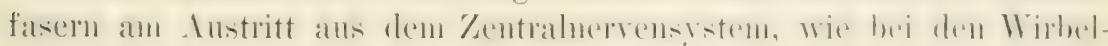
tieren, existiert bei den Evertelnaten nirgends.

Über die Gestalt der Ganglienzellen und die Form und Aus-

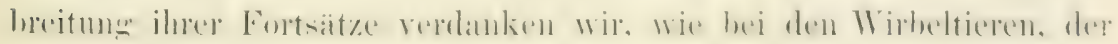




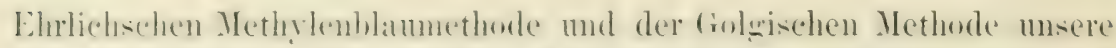
Hanptkenutnisse. Die meisten Lutersuchungen beziehen sich auf Irthropoden und Wiirner: anch die Mollusken haben einige Bearbeiter wefunden. Retzius 14:90, 1591, 1495, Biedermam 1491. Bürser 1591, Allen 1894, 1896, Apáthy 1892, 1897, Lenhossék 1892, Smimow 1894, Bethe 1895, 1897, Haret 1899 und andre). Bei allen unter-

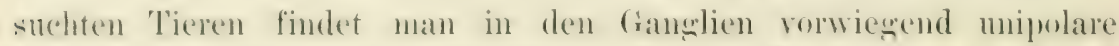
Ganglienzellen rom sehr versehiedened Größe. Ihr kern ist grob und hasig und zoigt immer einen wroben, kugedigen Nucleolus selten mehrere). Von diesen Zellen, die fast immer wie ein Mantel das remopil mugehen, zieht der einzige Fortsaty, der stammfortsat\% oder

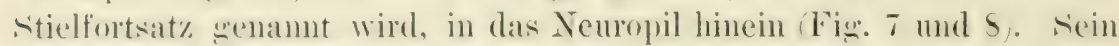

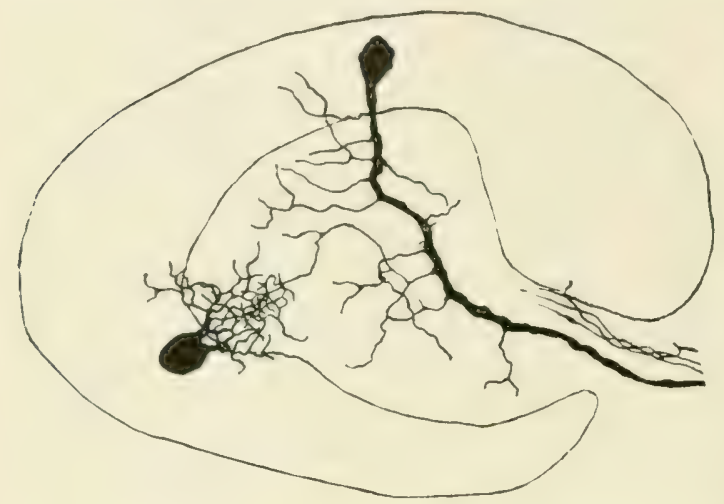

Fig. 7. Durchschnitt eines Ganglions von Limax (Nacktschnecke) nach Veratti (1900) (Golgipriiparat). Rechts ein Element mit peripherer Fiter (uotorisches Nouron:?. Ionks unten cin Element mit rein zentraler Verzweigung. weiteres Schicksal ist sehr verschieden, man kann aber leicht drei Haupttypen herausfinden.

1. Der Stammfortsatz löst sich sehnell in immer feiner werdende Zweige auf (Fig. 7 links inten).

2. Er verläßt unter Abgabe von Seitenzweigen durch einen peripheren Nerven das Ganglion Fig. 7 ohen .

3. Der Stammfortsatz zieht sich durch

mehrere camglien hin, ibherall seitenzweige abgebend, whe aber in einen Nerven eine periphere Faser zu senden (Fig. 1c). Man hat diese Elenente häufiøn mit dem Xamen Issoziationselenente belegot; ich ziche es aber vor, sie Kommissurelemente zu nemmen. weil diesel Name ïber ihre Funktion nichts prïsmmiert.

Die erste Form kommt nicht allzuhäufig vor. Ich habe sie im

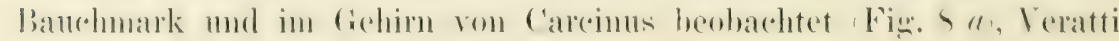
in den Ganglien yon Limax (Fig. 7).

Die zweite Form ist in allen Ganglien der bisher untersuchten Everteblaten in erober Zahl wefmelen worden. Von lietzins 1590

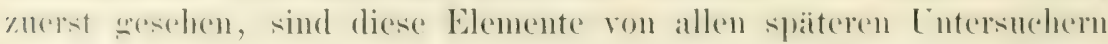
bestaitigt worden. Nur selten ist die periphere Faser die direkte

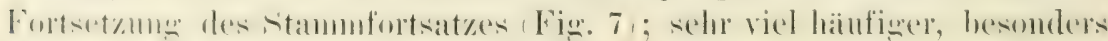
bei Crustaceen, tritt der dümne Stammfortsatz seitlich an eine sehr 
viel dickere, verzweigte Faser heran, die an ihrem einen Ende zur

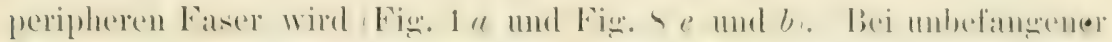

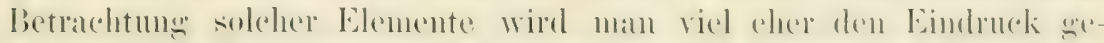

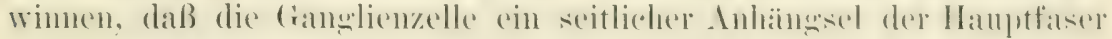
als ihr Ausgangspunkt ist. Zwischen der Dicke der Faser und der

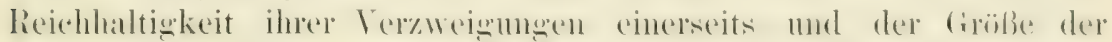

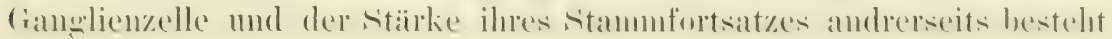

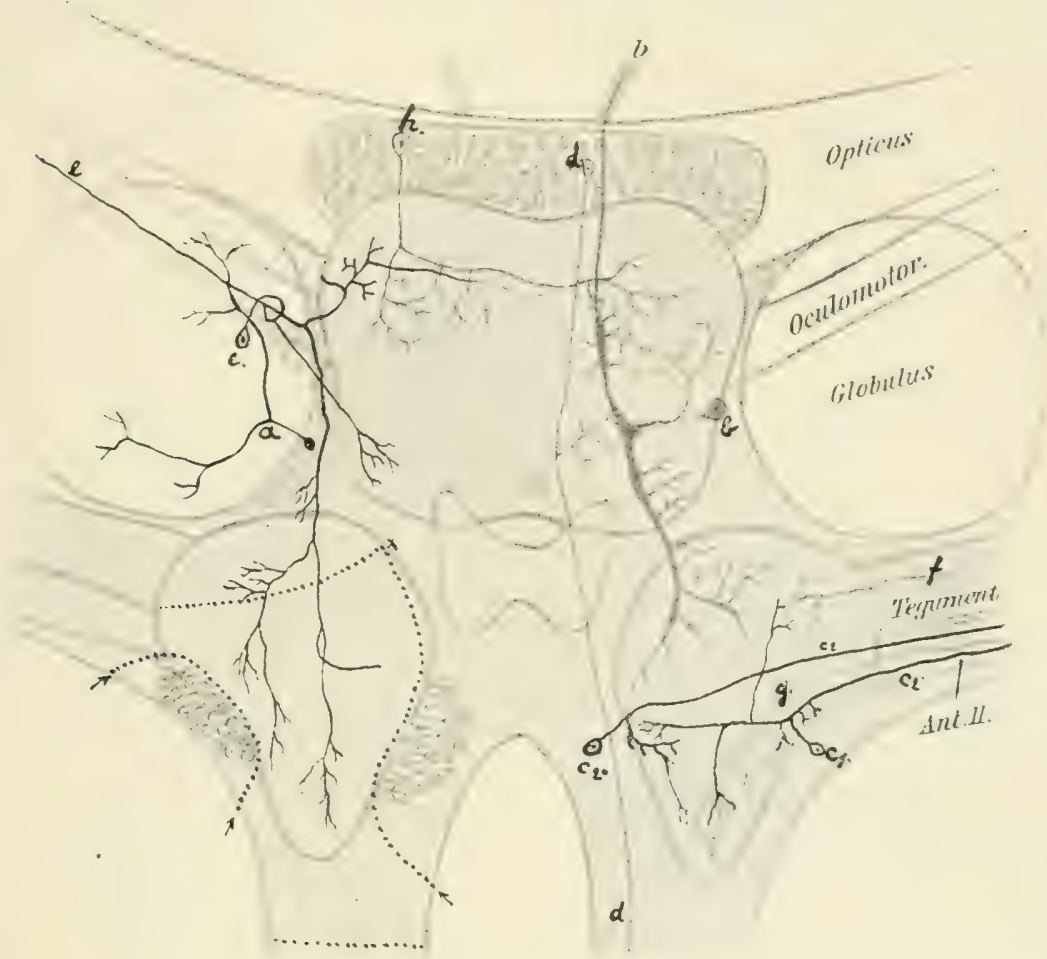

Fig. 8. Schematische Abbildung des Gehims von Carcinus mit dem Verlauf einiger Nervenelemente nach Methylenblaupräparaten. Die Lage der Ganglienzellpolster auf einer Seite angedeutet. Die punktierte Linie (links) deutet die Schnitte an, welche bei der Isolierung des Neuropils der $z$ weiten Atenne gefïhrt werden. (Natiirlicher Durchmesser des ganzen Gehirns $2-3 \mathrm{~mm}$ ). Weiteres siehe in Text.

gar keine Proportionalität; so gibt es Fasern, die immerhalb ilnes Verlanfs im \%entralnervensistem anf lange strecken dicker sind als die zugehorigen Gamplienzellen; hesonders anffallend ist hei diesen aber das Mißrerhältnis zwisehen dem stammenfortsat\% und der mit ihm

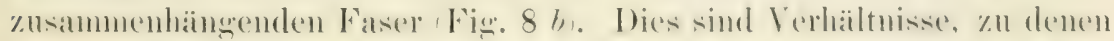

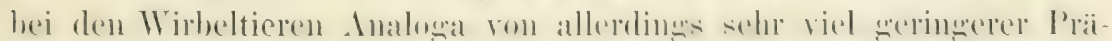

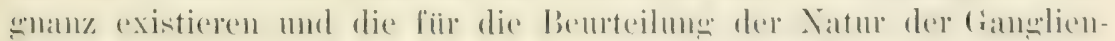
zellen von entschiedenem, aber nicht anerkanntem Wert sind. 
Besnnders bei den Cinstaceen aber anch bei andern Evertebraten

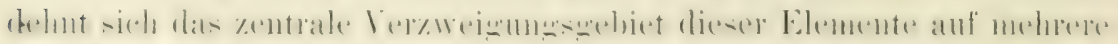
(ianglien aus (Allen 1894, 1595, Bethe 1895). So unfaßt es \%. B. bei Carcints meist noch die beiden Ganglien, welche dem Lrsprungs-

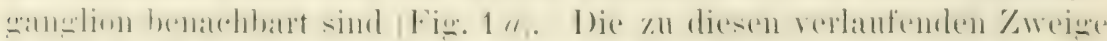

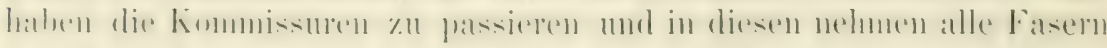
den Charakter peripherer Nervenfasern an d. h. sie umgeben sich mit

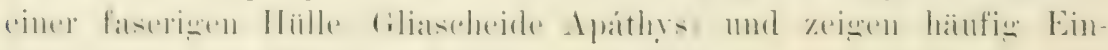
lagerungen von Myelin. Beides fehlt den Stammfortsatz und der Faser, soweit sie im Ganglion verliuft. Wenn man num überhaupt

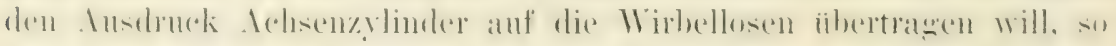
kann man nu die Fasern so nemnen, die ron eben diesen Hüllen ungeben sind. Wir hätten also hier Ganglienzellen vor uns, welche mit drei Achsenzylindern in Verbindung stehen,

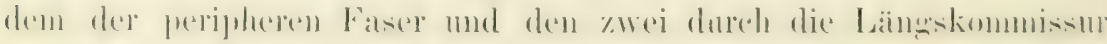
verlaufenden. Noch auffallender sind Ganglienzellen, von denen

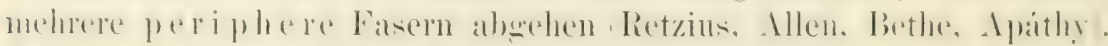
İei den von Apáthy bei Hirudo beobachteten Zellen dieser Art rerlassen alle drei peripheren Fasern das Zentralnervensystem durch

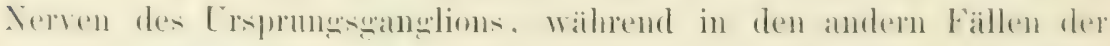
Austritt durch Nerven ron drei oder vier rerschiedenen Ganglien erfolgt. Es wiurde mir höchst gezwung'en erscheinen, wollte man zur

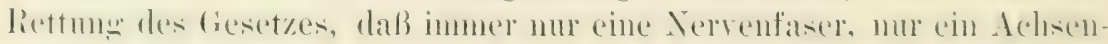
\%linder mit einer fiandienzelle in Verbindung stehen kïme. diese

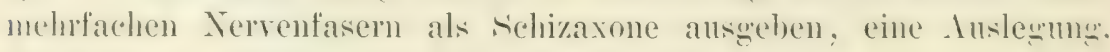
für die mir außerdem jede Grundlage zu fehlen scheint.

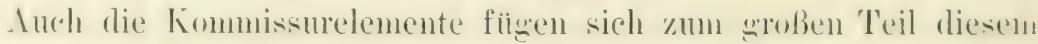

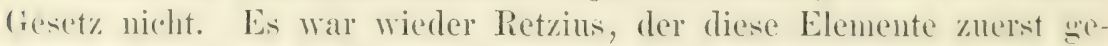
sehen hat (bei Astacus), wenn er sie wohl anch in ihrer Natur nicht klar erkannte. Seitdem sind sie bei fast allen untersuchten Evertebraten gefunden und in besonderer Vollständigkeit von Allen und mir

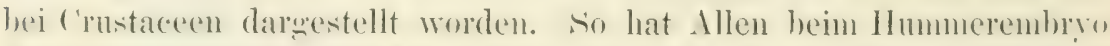

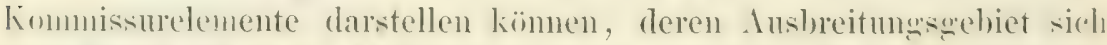

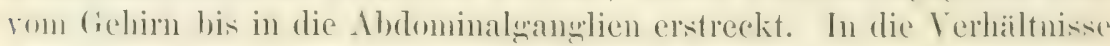
der Iribeltiere ibbarsetzt wïrde das die Verfolgume des Iusläufers eince l'yranidenzelle mehst lerastelungent bis ins ('andalmark be denten! solche Erfolge sind mur hei Anwendung der Vethylenhlan-

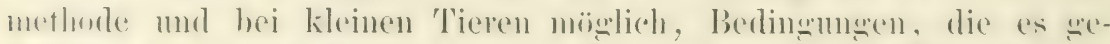
statten. das wamze Vervensystem anf eimmal unter das Mikrosking zu

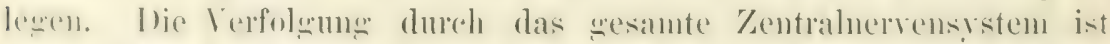

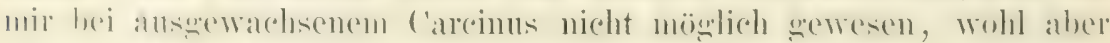

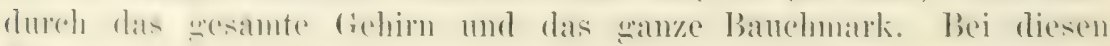

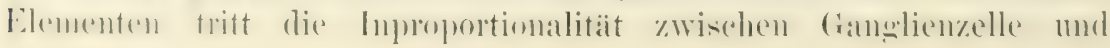




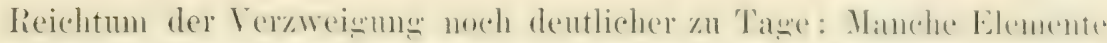

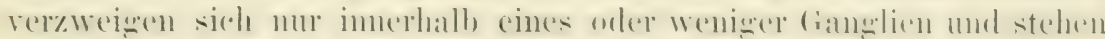

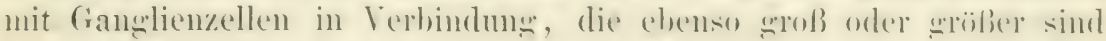

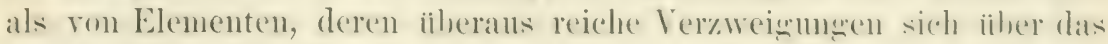

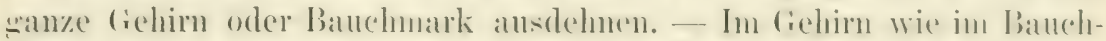
mark existieren Zellen, von denen zwei manchntal anch noch medr)

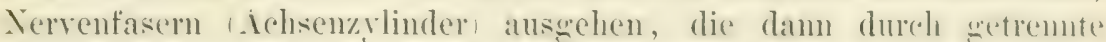

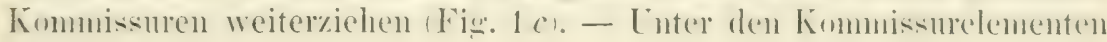

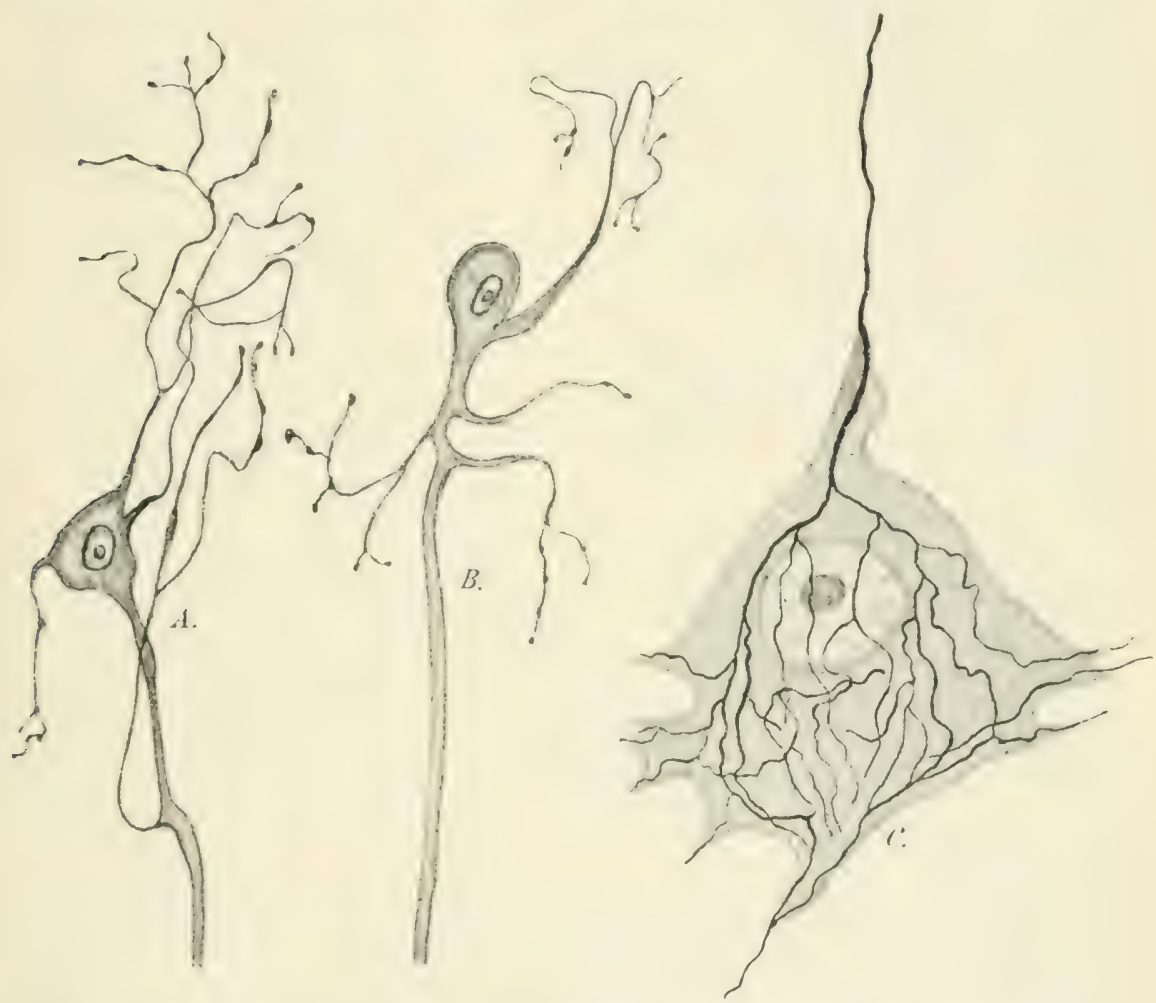

Fig. 9. A und It zwei multipolare Ganglienzellen aus Abdominalganglien des Flubkrebses nach Fetzius (1890) (Methylenb]au). C multipolare Ganglienzelle ron Lumbricus nach Apàthy (1897, Taf. 26, Fig. 6) mit Differenzierung der Neurotibrillen (Goldpriparat; das Original ist farbig).

finden sich hei careinus an versehiedenen stellen lieispiele von vianmmfortsätzen, die erst in großer Entfernung von der Zelle die ersten Seitenzweige abgeben. So kam bei großen Exemplaren die unverzweigte Strecke des Elenentes d (Fig. S) 1 mm lang sein.

AuBer den mipolaren Zellen, die ich bisher besprochen habe,

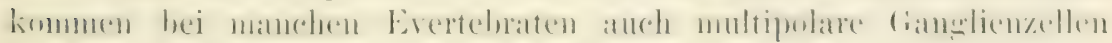
vor. An häufigsten sind sie wohl in den Gangrien der Mollusken 


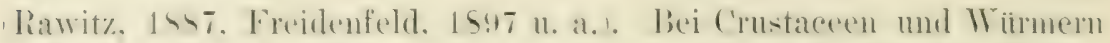
sind sie seltener und kimmmen meist nur an san\% bestinmuten stellen vor. Stets scheint von ihnen eine lange Faser (Nervenfaser) zu ent-pringen. die entweder zur peripheren Faser wird oder dureh cine

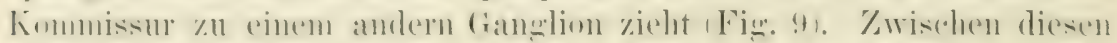
Zellen und den birnförmigen Zellen bilden gewisse Zellen der db-

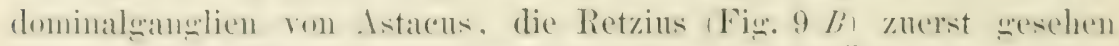
hatt und deren Existen\% ich bestitigen kamm, einen C̈berwang. indem auber dinem stammfortsat\%, der schr frïh seitenzweige abgibt, nur

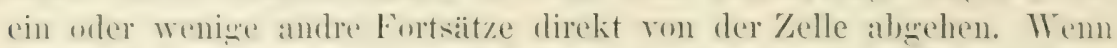
man überhanyt morphologische Verwleiche zwischen den (ianglienzellen der Wirheltiere und der Wirhellosen ziehen will, so kann es wohl keinem Zweifel unterliegen, daß der zur peripheren Faser werdende Fortsatz der multipolaren Zellen dem Achsenfortsatz der Wirbeltiersmanlienzellen vom Deitersehen Typus zu veroleichen ist, wähent die übripen Fortsiitze den Protoplasmafortsät\%en analow zu setzen wären. Jene Ïbergangroformen haben nun Retzius Veranlassung wesehen, die in den Ganglien sich rewweigenden Vebenfortsitze des: stammufortsatzes der birnfömignen Zellen für I'rotoplasmafortsütze zu erklären, die wewissermaken nur an stammfortsat\% heruntergerutscht sind. Andre haben semeint, daß sich die Seitenfortsiitze eher nit den Kollateralen der Wirbeltierachsenzylinder vergleichen ließen und daß die birnförmigen Zellen in Wirklichkeit der P'rotoplasmafortsätze sanz enthehrten. Lenhossék neigt sich der Ansicht von Retzius zu und ich selher stimme ihm vollkommen bei, wemn ich ïberhaupt einen Verogleich ziehen soll. Anch Apathy veroleicht die im Ganglion sich verweigenden Seitenzweige nit den Protoplasmafortsiitzen der Wirheltiere., Ich muß aber gestehen, daß mir die Frage ziemlich intelevanter Natur zu sein scheint.

Außer den bisher besprochenen Elementen, die mit zentralen (ianwlienzellen in leicht sichtharer Verbindung stehen, finden sich in den (ianglien aller Evertebraten andre, bei denen ein Zusammenhang: mit zentral gelegenen Zellen nicht sichthar ist. Es sind Fasem, die durch die peripheren Xerven in die Gamplien eintreten und sich dort in feine Zweige antlosen. Häufig erfahren sie heim Fintrift ins (iangron zucrst eine 'T-fömigne Teilung, und die beiden so entstandenen

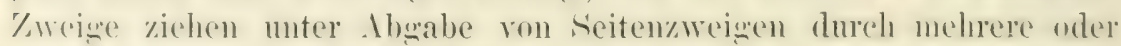
viele Canshlien hindureh Retzius. Biedermam, Lenhussik, Allen, Bethe; Iprithy u. a.). Die Lage dere zugehörigen zellen ist zuerst rom

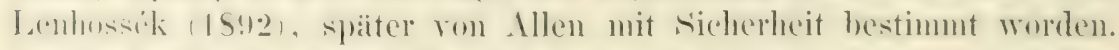
Beiden Forschern gelang es dem einen heim liegenwurm, dem andern

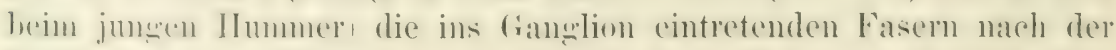
l'eripherie zu verfolten, wo sie sie mit den seit langem dureh Leidiw. 
('lans und vom Rath bekamten bipolaren, ,'imnesnervenzellen" in Vir-

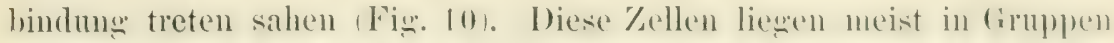
zusammen unter dem Epithel. Ihr peripherer Fortsat\% andet i? lex Iriirmem (Lenhossik, Apáthy, Retziusi mol Mollusken dinilohrist. smidt) frei zwischen den Ejithelzellen, bei Arthopoden im Inneren ron besonderen Simnes- oder Rezeptionshaaren ('lans, vom Rath, Bethe. Retzius) odel an deren Basis (bei manchen Haren ron Astaeus: Retzius, 1895, Bethe, 1896). Durch diese Befunde ist die Natu jener Elemente sicher als sensibel (rezeptorisch) festgestellt.

Neben den Rezeptionszellen finden sich aber bei Wüimern (Smirnow, 1894) und Mollusken (Smidt, Verratti) atch freie Nerrenendig'ungen im Epithel. Die zugehörigen Zellen liegen bei Wiurmern vielleicht im Bauchmark, bei Mollusken, den Untersuchungen von Smidt nach, jedenfalls aber auch ziemlich nahe an der Peripherie.

Diejenigen Elemente des Zentralnervensystems, welche mit zentralen Zellen in Zusammenhang stehen und eine periphere Faser

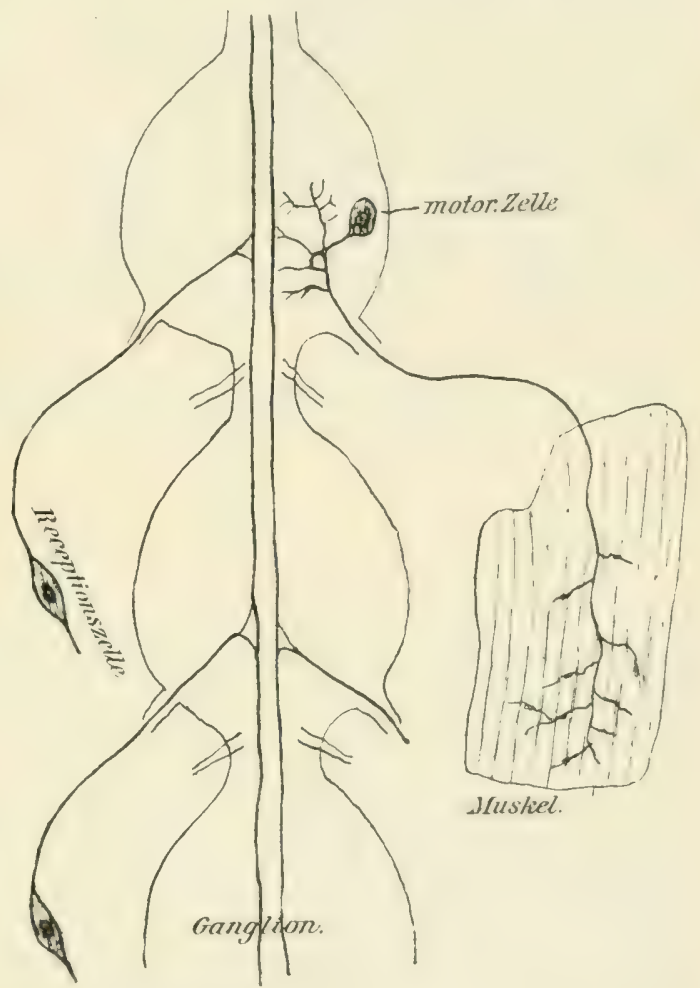

Fig. 10. Zwei Ganglien vom embryonalen II ummer nach Allen (1891, kombiniert aus Fig. 9. und 11). Die zu Grunde liegenden Präparate zeigten den ganzen Verlauf ter angegebenen Nerrenelemente. entsenden, sind jeden-

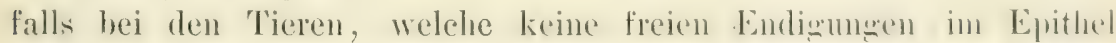
haben, zum wrößten Teil als motorisch und sekreturisch anzusehen. und nur bei Wïrmern und Mollusken könnte hier manehmal eine Kontroverse möglich sein, weil es eben hier freie Endigrngen im

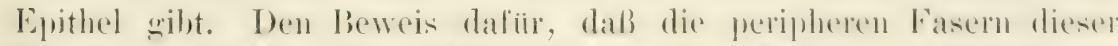

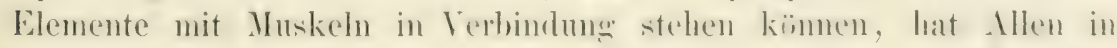
einer seiner vortrefflichen Arbeiten erbracht, indem el auf einem

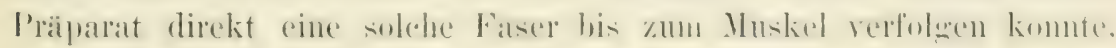


wo sie sich teilte und in motorisole Nervenendignten iiberging Fin.. 101. foweit mil hekamnt, ist dies uberhampt der einzige Fall, wn hisher der direlite Zusimmenhang rom zentralen Gamelienzellen mit der Muskulatur heohatohtet ist. Bei allen andern Tieren ist diesere Zusammenhang nur exschlossen, nicht direkt beobachtet.

Wie wir oben gesehen haben, fallen bei den höheren Würmern und bei den Irthropoden die lieflexe „anz fort, wem die peripheren Verven durchschnitten sind, Während sie hei Mollusken umb niederen Mimmen lis zu dinen wewissen frade bestehen bleiben. Es wird also zunächst zwerkmäBi@ sein fiur die weiteren Betrachtungen die ersteren im Auge zu behalten, dem bei ihnen sind wir zu der An-

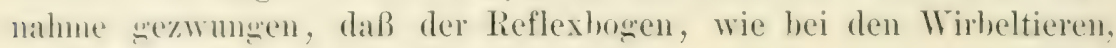
im Zentralnervensystem selber gelegen ist:

sensible, mit peripheren Rezeptionszellen in Verbindung stehende Fasern treten in die Ganglien ein und splittern sich hier auf. In den

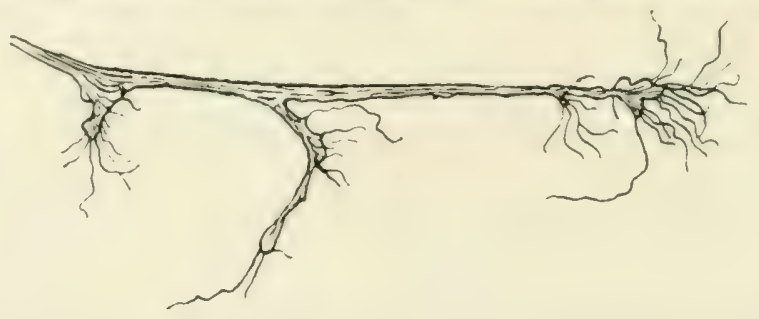

Fig. 11. Ein Teil der zentralen Verzweigung eines sensorischen Schlauchs ron IIirudo nach Apáthy (1897, Taf. 25, Fig. 1. Es ist nur ein Teil der Figur wiedergegeben). (Methylenblauprïparat). Innerhalb der Nervenfaser sind die Neurofibrillen nur angedeutet. An den kolbigen Verdickungen treten die Neurofibrillen aus der Nervenfaser frei ron Perifibrillïrsubstanz aus.

Ganmlien selber liegen motorische tianglienzellen ganz anBerhalh dieses Vermeigmesgehietes, von denen die motorischen Fasem durch die freripheren Nerven direkt bis zur Muskulatur laufen. Iuf ilıem Wrege durchs Xemopil achen sie Verzweigungen ab, die sich mit denen der rezeptorischen Fasern und der Kommissurelemente vermischen. Mehr läßjt sich an den meisten l'räiparaten besonders mit den bei diesen

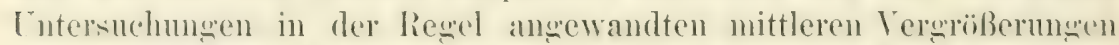

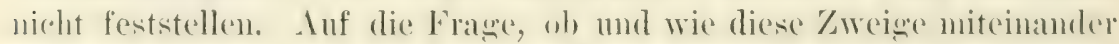
in Verbindmg stehen, erhalten wir keine Antwort. Sie hätte nach dem bisher besprochenen offen bleiben miissen und nicht nach bestimmter Lichtume entschieden werden diufen, dem derartione l'rï-

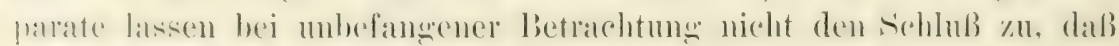
die Fasern da ihr Ende erreichen, wo die Färbung anthört.

Sehr häfig sind nur einzelne Ganglienzellen mit dem Stammfortsaty gefarbot. Ist es da zu Ende? Nein! denn in andern Fällen

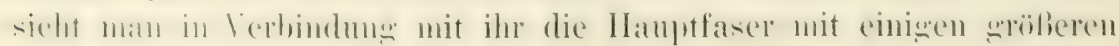
Seitenzweigen. Aher auch da ist nicht das Ende, dem in wieder 


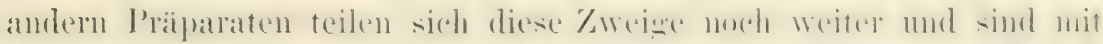

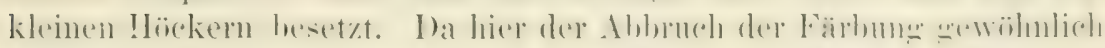
sehr scharf ist, so haben die meisten Beobachtel hier das Ende an-

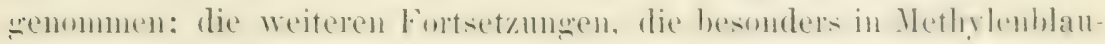
praiparaten häufig noch rorhanden sind, sind den meisten entgangen, weil sie, wenn auch gleich dunkel gefarlot, bei ihrer viel größeren

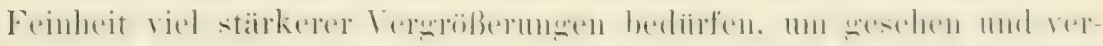
folgt zu werden. Der einzige, der vor der großen Publikation

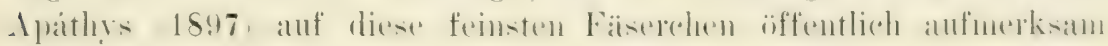
gemacht und sie abgebildet hat, war Biedermann (1891). Er hat auch bereits beobachtet, daß das Immere mancher dickeren Fasern von solchen Fäserchen erfüllt ist, und entwickelt andentungsweise Vor-

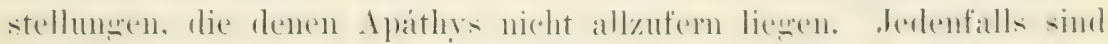
also die zentralen Verzweigungen dort noch nicht zu Eude, wo ihn

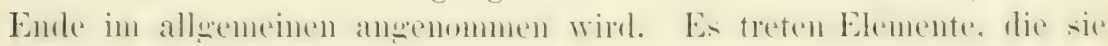
bis dahin in sich eingeschlossen hatten, ans ihmen heraus (Fig. 11

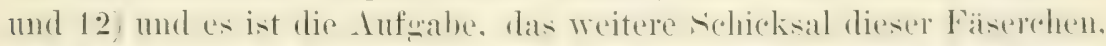
der Veurofibrillen, festzustellen und ihr Verhalten inmerhall, der Fasem und Zellen zu untersuchen.

Der Verlauf der Neurofibrillen in den Nervenfasern.

Am schärfsten und dentlichsten treten die Neurofibrillen in den Fasern (wie in den Zellen) bei der Apáthyschen Goldmethode, der Fäbung mit Hämatein I a und meiner Molyblämmethode hervor. Hier sieht man auf Längs- und Querschnitten, wie die nach auBen von der

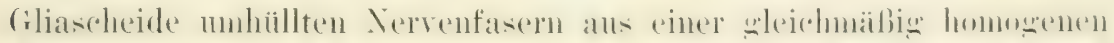
Masse hestehen, der P'erifibrillärsubstan\%, in die die Fibrillen als scharf

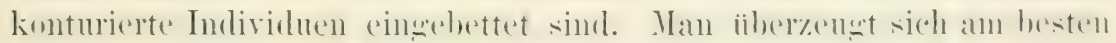
an diesen Prïparaten, daß sie von den Gliafasern ganz verschieden sind, daß sie nie aus den Nerrenfasern austreten, solange sie in Nerren oder Kommissuren rerlaufen, daß sie ihre Individualität bewahren und nur dort ein Ende haben. Wo sie durch das Messer abgeschnitten sind (Fig. 2, S. 17); um sich aber über den Verlauf der

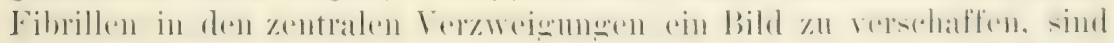

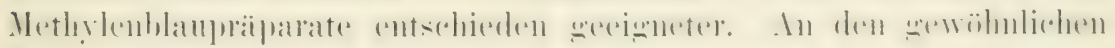

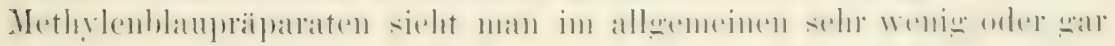
nichts ron den Fibrillen. Wenn man aber die gofäroten Objekte in der

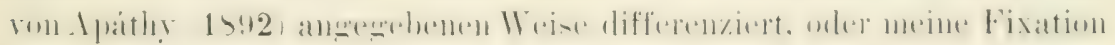
benutzt, so treten die Fibrillen oft recht sehön zu T'age. Nie sind sie so dentlich, wie in den nach den anderen Methoden herwestellten Präiparaten, dafiir luat man aber den Vorteil, ganze Ganglien unter das Mikroskop bringen zu kömnen, während dort tichnitte nötign sind, 
so daß immer nur kume Abschnitte einer Bahn zur Darstellung gre-

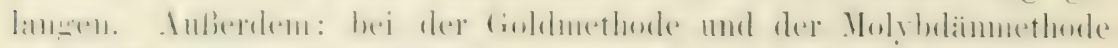
ist die Darstellung der Fibrillen, wemn sie iberhaupt gelingt, meist

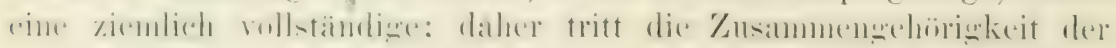
zu ciner Faser gehörignen Fibrillen nur selten deutlich hervor. Da-

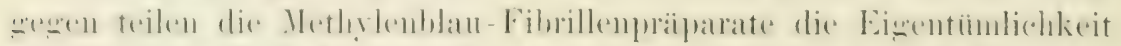

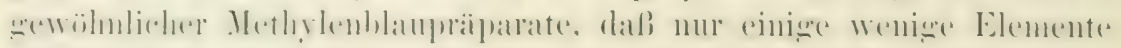

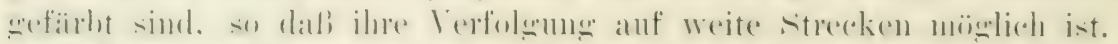

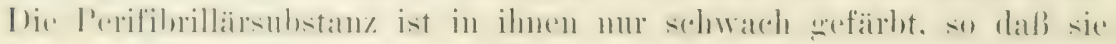
zwar noch dentlich sichtbar ist, aber die in ihr enthaltenen Fibrillen

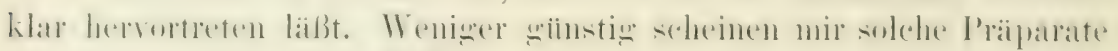
zu sein, bei denen die Differenziermo soweit gegangen ist, daß die Fibrillen allein zu sehen sind, weil hier ihre Beziehungen zur Perifibrilläsubstany, nicht zu erkennen sind.

Fig. 12 stellt einen Teil eines motorischen Elements aus dem

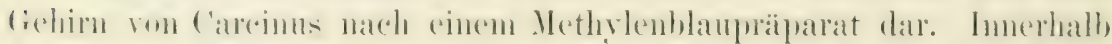

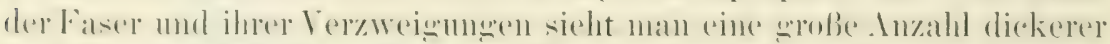

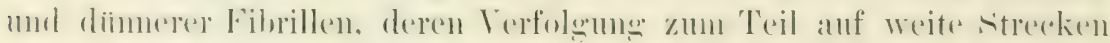
möglich ist. Dort, wo sich Fibrillen in die Tiefe senken, sind sie als

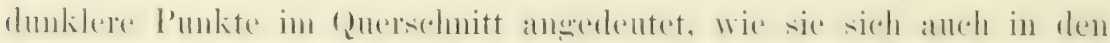

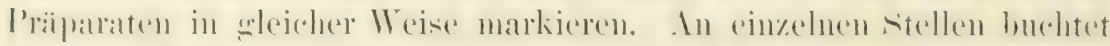

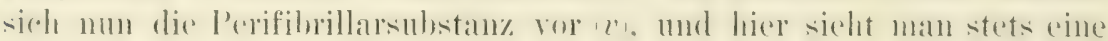
Fibrille austreten, nm nackt, d. h. olme Perifibrillibsubstanz, weiter zu laufen und sich eventuell zu verzweigen. Ein Austreten von Fibrillen aus der eimentlichen Faser, soweit sie bisher vun den meisten Intoren heobahotet sind, ist auch aufs deutlichste an Fig. 11 . Hirudo,

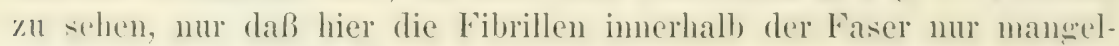
liaft differenziert sind.

Die zentralen Verweiwnuen eines wleichartigen Elentents ebenfalls rom Blutegel) sind in Fig. 13 abgebildet. In dem zu Grunde

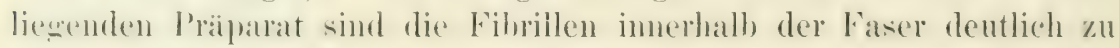
selen, während die ans ilıen plasmatischen Grenzen austretenden

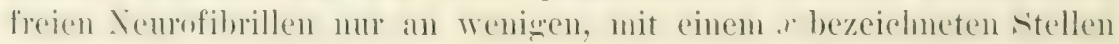
sichtbar sind. Die Mehrzahl scheint am Ende der kolbigen Ver-

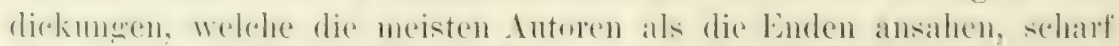

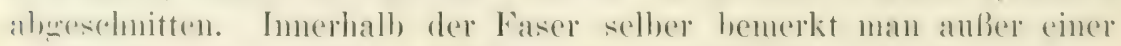

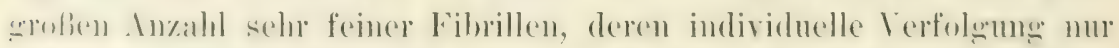
anf kuxe Strecken möglich ist, zwei dickere, die sich in die beiden

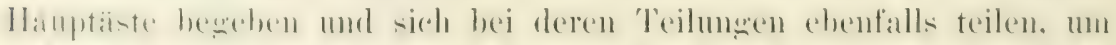

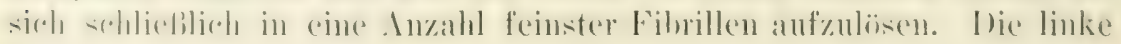
Fibrille ist in der Faser, soweit sie gezeichnet ist, anf die Länge von 200 " der Faser konnte sie noch 1 m weitere 300 " verfolgt werden, im 
ganzen also auf eine Strecke von $500, u$ ! Wemn man die Abbildung (bei normaler Sehschärfe) aus der Entfernung von 2-3 m betrachtet, a) versehwinden die Fibrillen und man erhailt den lindruek, welehere

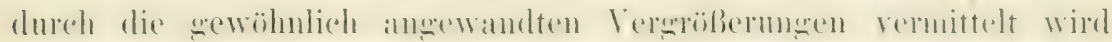
und bei dem einem dort ein Ende zu sein scheint, wo keins ist.

Die Untersuchung der peripheren Nerrenstämme bei Hirudineen,

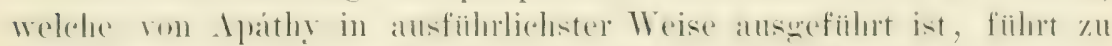
dem liesultat, daß das Fibrillembild nicht in allen Fasern dats weiche ist. In manchen Faserquersehitten (Fig. 2 C, S. 17) bemerkt man eine wrobe Zahl feinster Fibrillen, während in andern nne eine cinzige

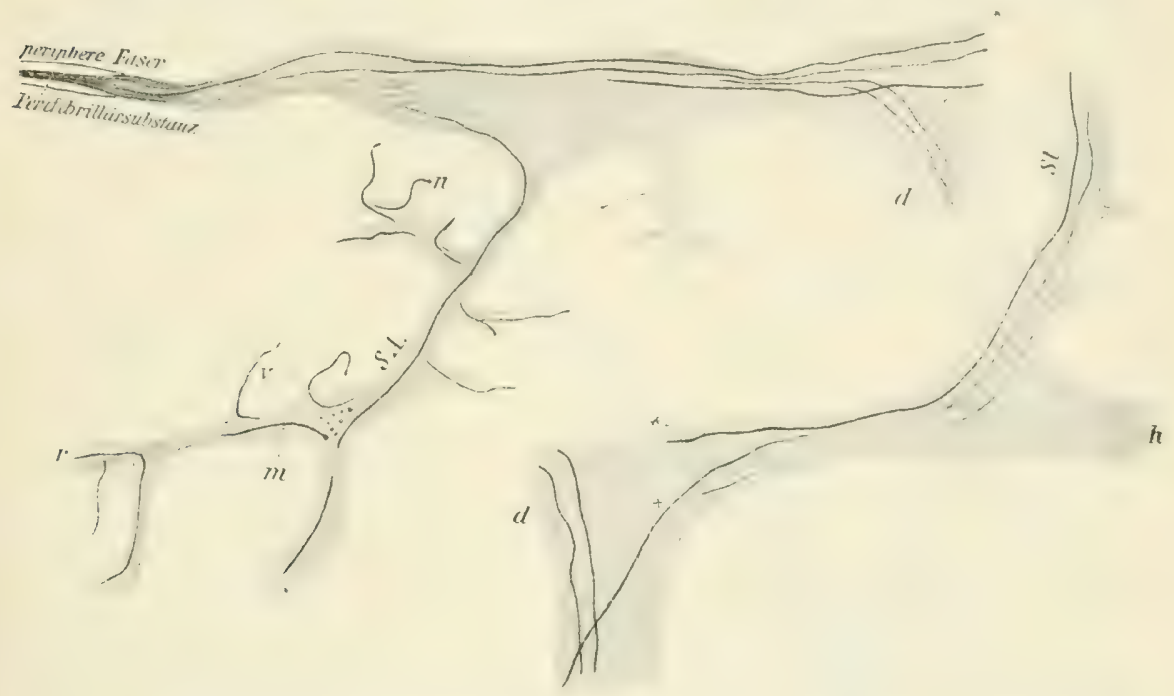

Fig. 12. Teil der zentralen Verzweigung eines motorischen Elements von Carcinus. Differenzierung der Neurofibrillen in einem Methylenblaupräparat. Eine große Anzahl von Fibrillen biegt direkt aus den Seitenästen in die peripher verlaufende Nerrenfaser ein, ohne in den Stammfortsatz der Ganglienzelle (St) einzutreten. (Man hat sich die beiden Schnitte so aufeinander gelegt zu denken, das die + und * sich decken.) (Bethe, 1898.)

viel dickere vorhanden ist. Die Verfolgung der Nerrenfasern in die kleineren Nervenstämme hinein (auf Schnittserien) zeigt nun, daß3 sich die dünneren Fasem $(s)$ mit den feinen Fibrillen bis zur P'eripherie begeben, um sich hier zu teilen und mit den unter der Haut

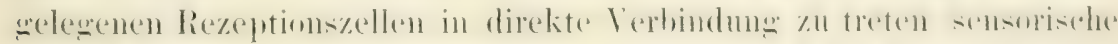

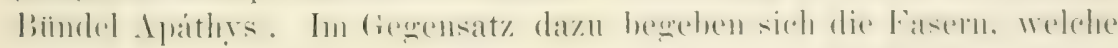
nur eine starke Fibrille enthalten, zur Muskulatur. Es lassen sich

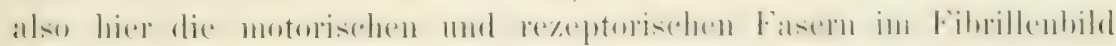
unterscheiden. Die dicken Nervenfasern $(S$ in Fig. 2, $C$ ) mit den vielen

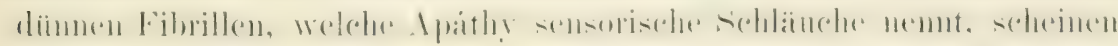
anch rezeptoriseher Natur zu sein. Sie scheinen aber an der I'eripherie nicht mit Rezeptionszellen in Verbindung zu stehen, sondern 


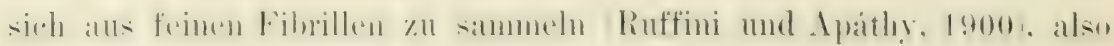
iiherhaupt keine Verbindung mit Ganglienzellen zu haben.

Nach meinen eignen Untersuchungen an Hirudo kann ich diese Befunde durehaus bestitigen, wem ich auch einige wenige Mal in

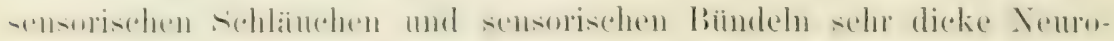

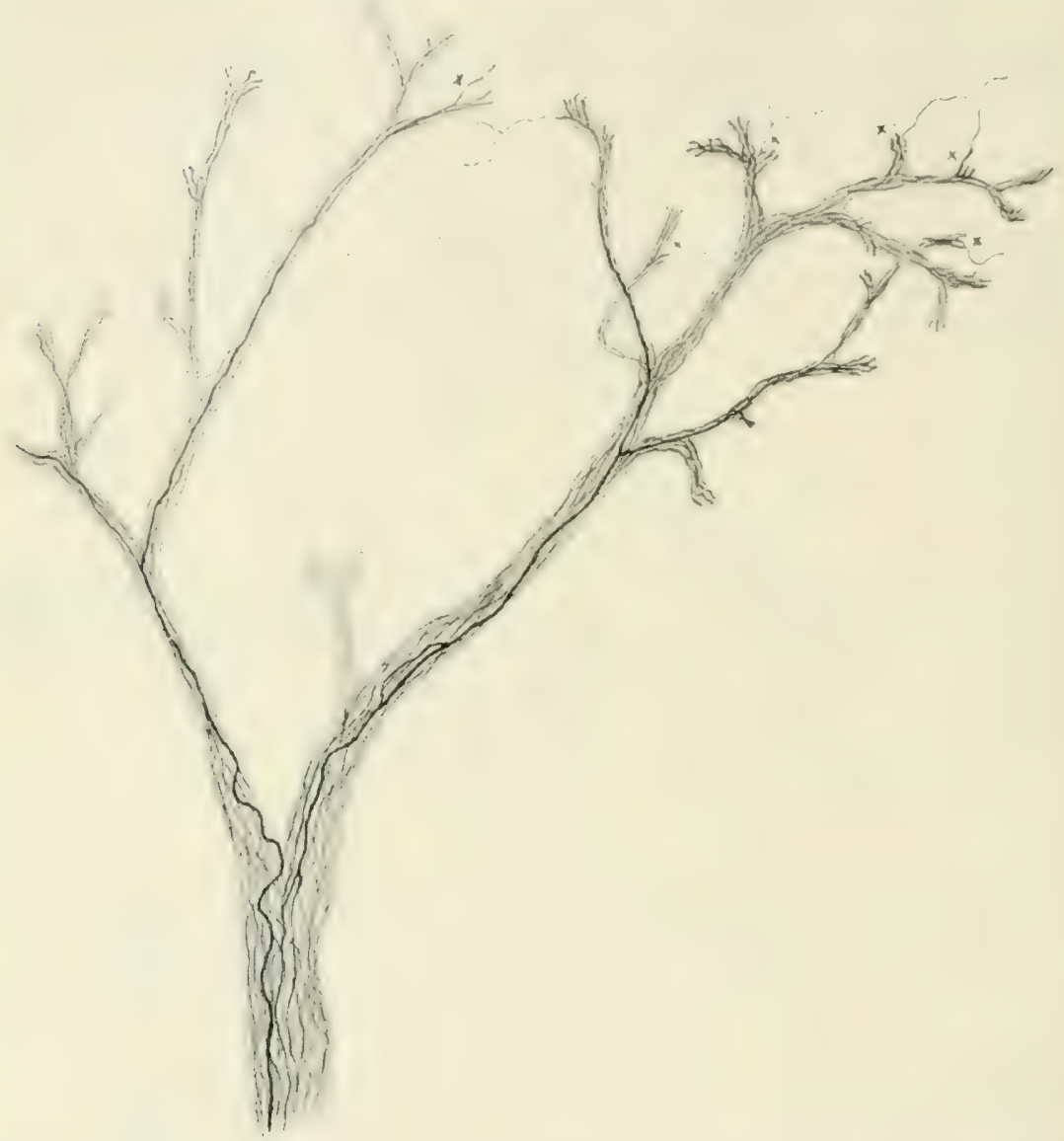

Fig. 13. Zentrale Verzweigung cines sensorischen Schlauchs von Hirulo nach cinem Methylenblaupräparat. Die Fibrillen treten innerhalb der nur schwach gefïrbten Perifibrillarsubstanz deutlich hervor; die zwei dicken Fibrillen teilen sich wiederholt und sind sehr weit $z u$ rerfolgen. Bei + treten Filorillen aus der Faser ins Neuropil aus.

fibrillen gefunden habe (Fig. 13). - In den Kommissuren findet man

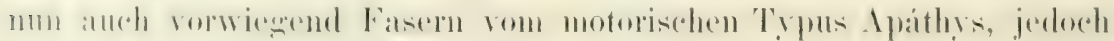

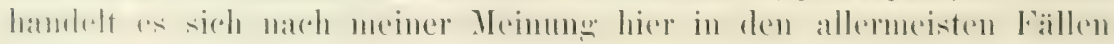
nicht um motorische fasern, die etwa von einem Ganglion zum andern gingen, um sich erst von hier aus zu Muskehn zu begeben, sondem um Fasem yon Kommissurelementen, welehe zunaiehst mit motoriseher 
Funktion nicht mehr zu tum haben, als etwa sensible Fasern. Immerhin ist die Unterscheidung ron motorischen und rezeptorischen (sensorischen) Neurofibrillen bei Hirudo von großem Wert fü die Be-

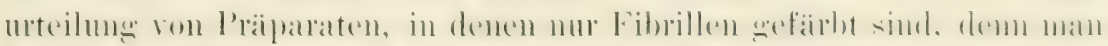
kamn eine Fibrille, die man ron einem peripheren Nerven herkommen sieht, mit ziemlicher sicherheit als wirklich motorisch, d. h. prepipher z!!

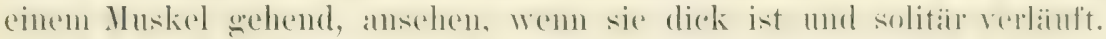

Bei andern Klassen der Evertebraten scheint ein scharfer Unter-

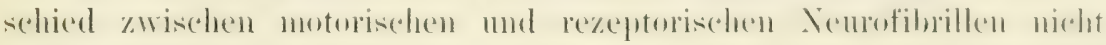
zull existieren. So habe ich ihn wenigstens bei Crustaceen nicht auffinden kömmen (1898). Ich fand dort in rezeptorischen Nerven neben Fasern mit vielen dünnen Fibrillen andre mit nu einer einzigen starken, ebenso in motorischen Fasem häufig ein Bundel feiner

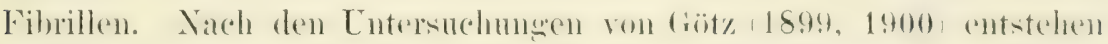

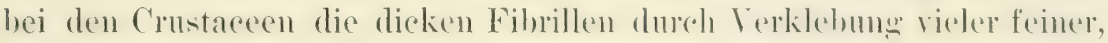
eine Ansicht, die ich selbst von vornherein fiir sehr wahrscheinlich gehalten habe. Wir hätten also bei diesen 'Tieren nur eine dit von Fibrillen: Motorische wie sensible Fasern enthalten nul di n $n \mathrm{l}$ Fibrillen, grade wie bei den höheren Wirbeltieren.

Wie wir oben gesehen haben, stehen die motorisehen Nervenfasern in den Ganglien in der Regel mit je einer Ganglienzelle in Verbindung. Au Methyenhlaupräparaten von Hirudo, in denen die Fibrillen differenziert sind, kann man num manchmal mit Dentlichkeit erkennen, daß sich zu der einen dicken Neurofibrille, welche wir in den peripheren

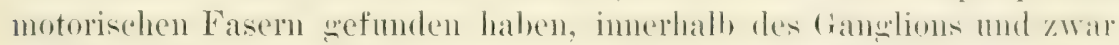
auf den Wege der seitenfortsäte andre diumere Filnillen wexellon, welehe die dicke Fibrille in die Nitte nehmen und so der Ganglienzelle durch deren stammfortsatz zuzichen. Wie hei den rezeptoriselenen Fasern brechen die seitenzweige der motorischen Fasern naroh riniwen

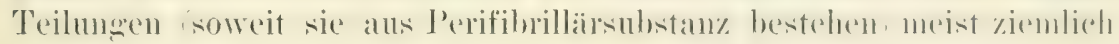
unvermittelt ab und nur die Fibrillen treten ins Xemopil iiber. C̈hnlich wie es oben für ein motorisches Element von Careinus beschriehen ist [Fig. 12].) Anch an spezifischen Fibrillenpräiparaten (Gold- oder

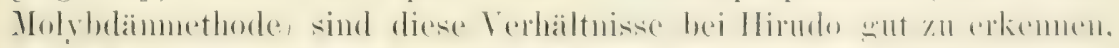

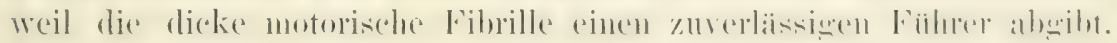
Bei Crustaceen (Careinus, Astacus) sind zur klaren Erkenutuis Methylenblaupräparate nötig, weil, wie erwähnt, die motorischen Nervenfasern ans viclen diimnen Fibrillen bestehen, die anf Schnittserien eine

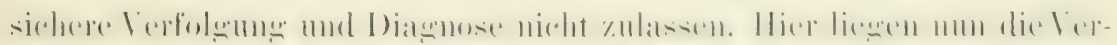

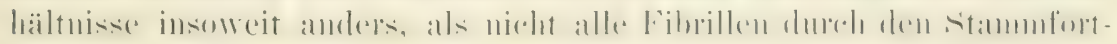
satz der Ganglienzelle zuriehen, sondern nur ein kleiner 'I'eil (rig., 12).

Wir haben also die Nenofibrillen in den motorisehen und rezep-

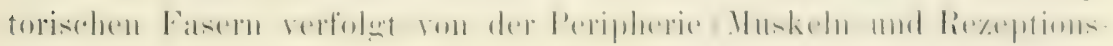


zellen) bis ins (ranglion und wir haben wesehen: 1. daß bei der Verzweignng der rezeptorischen Fasern Neurofibrillen ans den Faseru anstreten, 2. daß in Ganglion in die motorischen Elemente auf dem Wege der Seitenfortsätze Fibrillen eintreten (resp) ans ihnen anstreten), welehe alle (Hirudo) oder zum 'Teil (Carcinus) mit der forler cinem 'T'eil (ler) in der peripheren motorischen Faser verlaufenden Fibrille sich zur Ganglienzelle begeben. Es bleibt also noch zu elïrtern, wie sich die Fibrillen in den Ganglienzellen und bei iluem freien Verlauf im Nemopil verhalten.

\section{Die Neurofibrillen in den zentralen Ganclienzellen.}

Es muterliegt gar keinem Zweifel, daß in allen bisher von Apathy

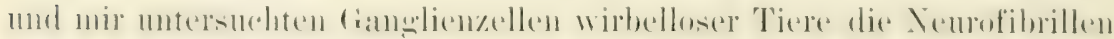

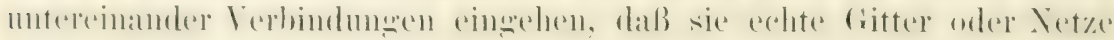
bilden. Gitter oder Netz soll bedeuten, daß die Fäden wirkliche

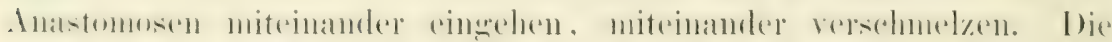

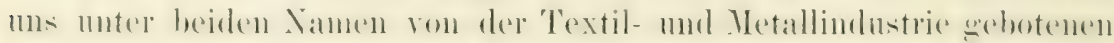
Produkte weisen ein solches Verhalten in der Regel nicht auf. Bei

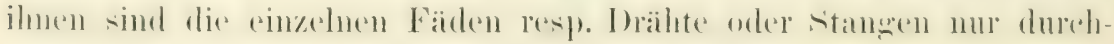
einander geflochten; sie bewahren, wenn es sich nicht grade um geschwoilite Gitter hamdelt, vollkommen ihre Individualitat. Es fohlt eben in der 'Technik das, was wir in tierischen und pflanzliehen (ieweben häufie vor uns haben: Netze mit substantieller Versolunelzung der Fialen. somit fehlt anch in der siprache ein Ausdruck fuir derartige Ciebilde, und wir miissen als Votbehelf uns des Wortes Vet\%

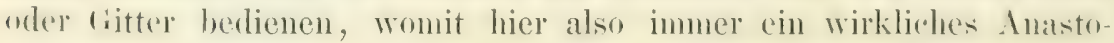
mosenwerk gemeint sein soll. Schon auf den ersten Blick unters.heiden sich die Gitter und Vetze der 'Technik, die aus einzolnen stangen oder faden herowestellt sind, von unseren. Lei jenen überkrowzen sich die Fïden an den Maschenecken, 1. h. es treffen immer vior Fäden in emen Punkt zusammen, während hier keme Krenzuneren vorliegen, sondern immer drei Fäden in einem Punkt konfluieren. Sur die r-firmogen Kinotenpunkte berechtigen \%ur Innahme anastomosierender Netze; die x-fömingen sind dubiös.

Dic Inordnum dieser Gitter in den dianglienzellen ist rersehieden:

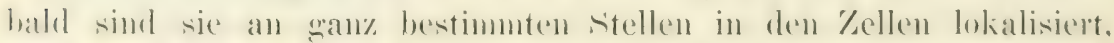

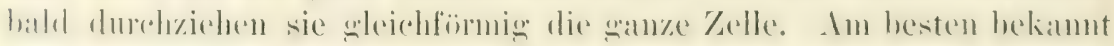
sind durch die Untersuchumgen Apáthys, die ich in allen Punkten

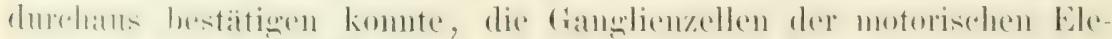
mente von Hirudo. Wir haben die Fibrillen in diesen Elementen bis

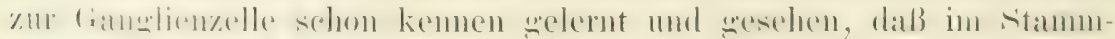
fortsat\% eine dicke (periphere) und viele dimne (dem Neuropil ent-

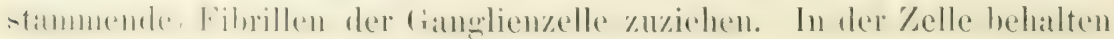


die diumen Fibrillen ihre periphere Lage bei, sie legen sich ziemlich dicht der inneren Grenze der Zelle an. Die dicke Fibrille, welche

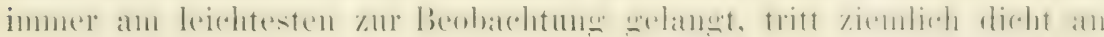
den Kem heran, teilt sich hier in mehrere Äste, welehe den Kern

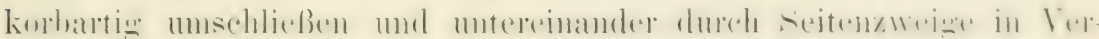
bindung treten, so daß wir ein in sich geschlossenes Net\% ror uns seben (Fig. 3, S. 18, Fig. 14, $a$ und b). Die dümen Fibrillen teilen

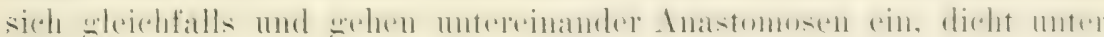
der Zelloberflache ein änßeres Gitter bildend. Zwischen beiden Gittern liegt ein breiter Ramm, weleher von feinen radiären Fibrillen duchzosen wird, die peripher mit dem Außengitter, zentral mit dem

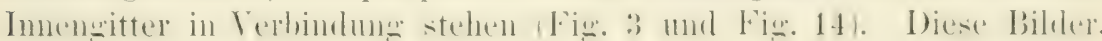
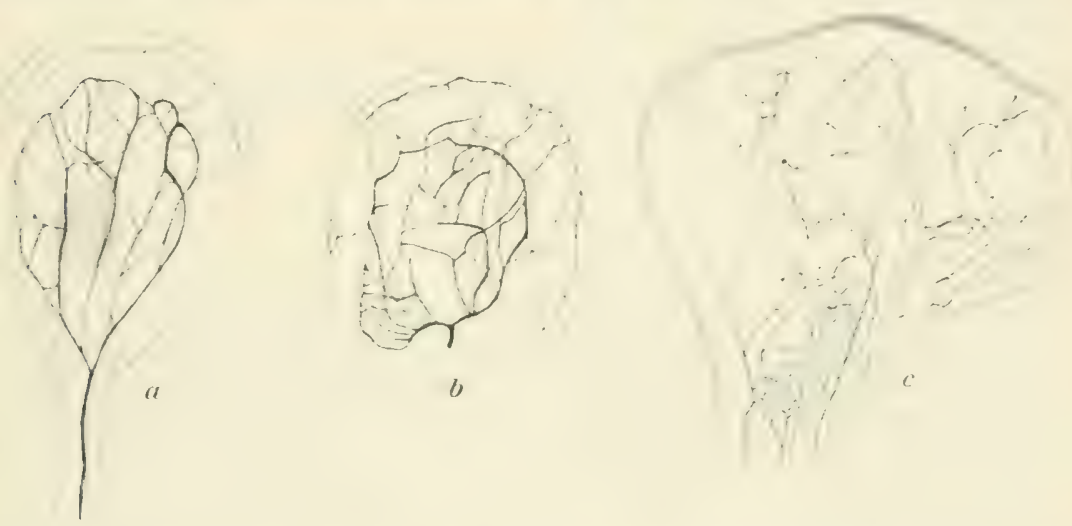

Fig. 14. Drei Ganglienzellen von Hirudo, Die Fibrillen sind nach der Betheschen Molybdänmethode gefïbt. Links zwei Zellen vom motorischen Typus Apáthys mit feinem Außengitter und dickeren Innengitter, ron welchem eine dicke Fibrille in den Stammfortsatz hineinzieht. Rechts eine Zelle rom sensorischen Typus Apáthys. Die beiden ersten Zellen sind fast ohne Benutzung der Mikrometerschraube gezeichnet. Die rechte Zelle wurde bei drei verschiedenen Einstellungen gezeichner und das definitive Bild aus diesen kombiniert.

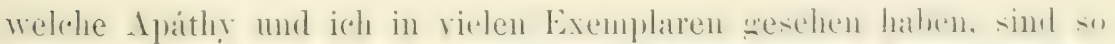

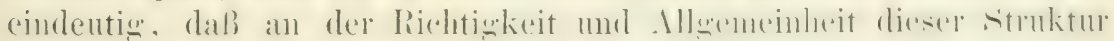
nicht im mindesten gezweifelt werden kann. (Anch Simon [1896] hat

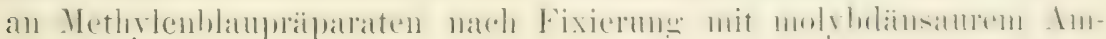
monium T'eile des zentralen Gitters gesehen.)

Eine andre Anordnung der Neurofibrillen findet sich in den großen Ganglienzellen von Hirudo, welche wohl zu. Kommissurclementen gehören. In ilırem imneren und ilnem Stammfortsaty findet man nur diune Fibrillen, welche die Zellen selber in hauptsaichlich

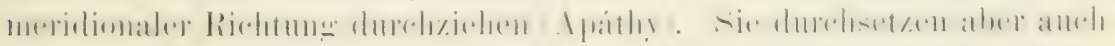
das ganze Plasma und treten durch viele Seitenfibrillen miteinander in netzige Verbindung (Fig. 14c). Auch bei den multipolaren Ganglienzellen, wie sie \%. B. beim Regenwum vorkommen, wird der ganze 
Zellleil, von Fibrillen durehsetzt, ohne daß sich eine bestimmte Anordnung erkennen ließe (Apathy, siehe Fig. 9 c, S. 29). Anch die Gangnlienzellen der Crustaceen, bei denen die Darstellung der Fibrillen

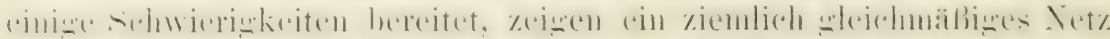

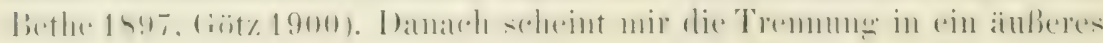
und immeres Gitter, wie es in den motorischen Zellen von Hirudo oft so schön zum Ausdruck kommt, nu' von lokaler Bedeutung zu sein. (Bei einigen Exemplaren von Hirudo, die ich untersuchte, war die Tremung wenig dentlich und fehlte in manchen Zellen ganz. Anch

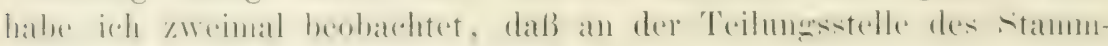
fortsatzes - also canz außerhalb der Zelle - ein zweites deutliches
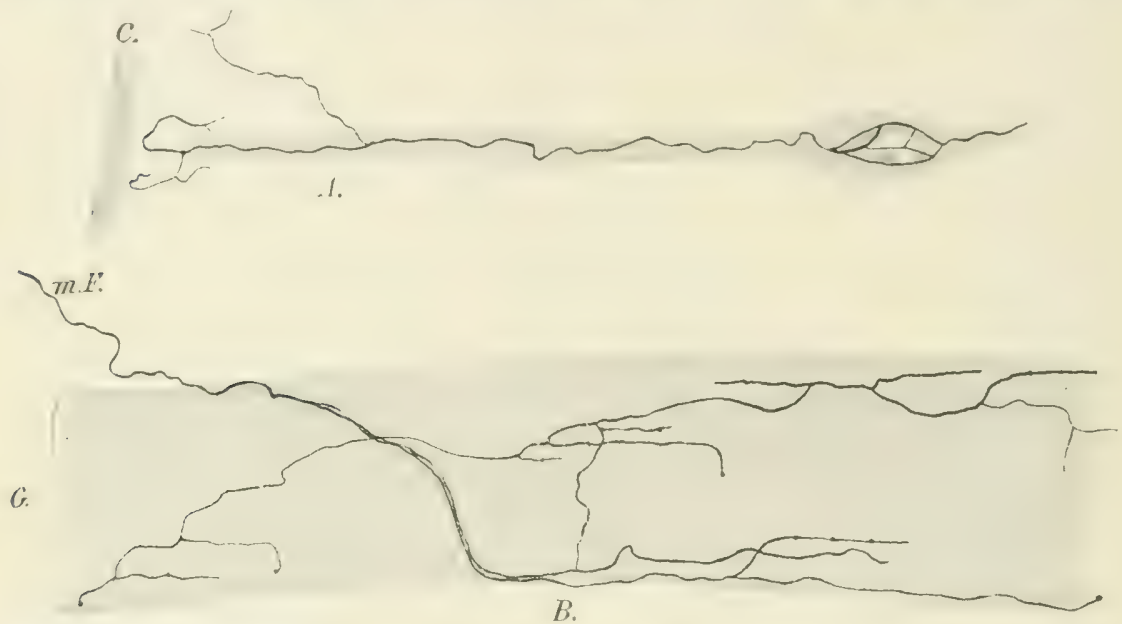

Fig. 15. A Rezeptionszelle von Hirudo nach Apáthy (1897, Taf, 29, Fig. 6). C Cuticularsaum. In ler Zelle ein kleines Gitter um den Kern herum. Von da aus geht cine Fibrille zum Zentrum, eine andre zieht ins Epithel und verzweigt sich dort. - $B$ Verzweigung der Neurotibrillen in einer Iruskelfaser der Darmwand von Pontobdella nach Ipithy (1897, Taf. 32, Fig. 3). m. $F^{7}$ motorische Fibrille auBerhall, der Muskelfaser, $(\dot{r}$ Grenzen der Muskeliaser.

Gitter vorhanden war. Über andre Vertreter wirbelloser Tiere liegen die ausführlichen Nitteilungen Apáthys noeh nicht vor. Über die

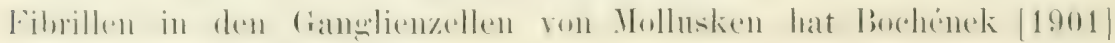
einige Angaben gemacht.)

Ich schließe hier einige Worte über das Verhalten der Neuro-

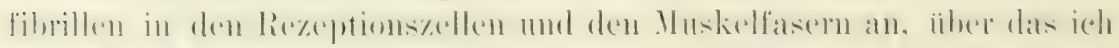
".

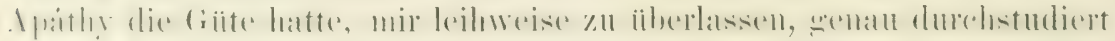
und nit seinen Abbildungen verghliehen habe. - Wie schon erwähnt,

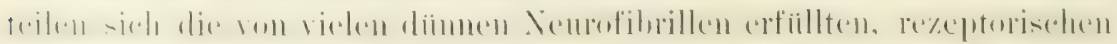
Fasern (sensorischen Bündel) an der Körperperipherie, wo damn die einzehen Ästchen, die nur noch je eine Fibrille enthalten, mit einer

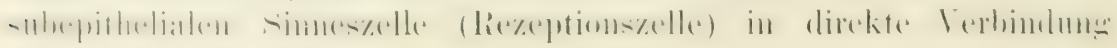


treten. In diesen bipolaren Zellen teilt sich die Fibrille in mehrere İste, die untereinander Anastomosen eingehen (Fig. 15A) und sich

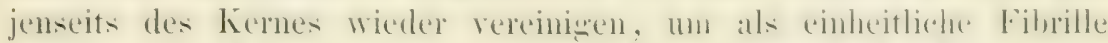
zwischen die Epithel\%ellen zu ziehen. Hier teilt sich die Fihrille ron

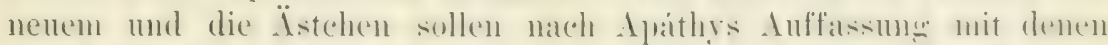
der Fibrillen benachharter lezeptionsollen zu einem subkutikularen

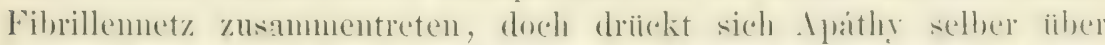

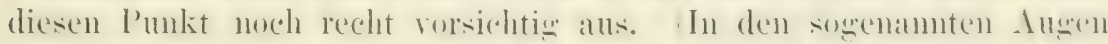
der Hirudineen liegen sehr arrobe liezeptionszollen. Diese enthalten ziem-

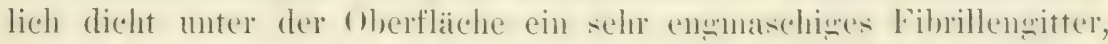
das sich zu ciner dicken zentralwaits ziehenden Fibrille reremint.

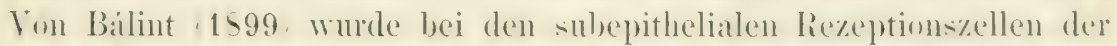
biene cin ganz identisches Verhalten der Veurofibrille nachocewiesen, mur dab hier die peripheriewärts austretende Fibrille sich ungeteilt in das zugehörige Rezeptionshaar hineinbegibt.

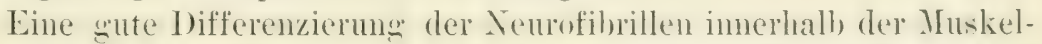
fasern ist Apathy hauptsächlich hei Ascaris und in der Darmwand von Pontobdella gelungen. Von der motorischen Nervenfaser endet an der Muskelfaser 10 ur die P'erifibrillärsubstanz. Die in ihr enthaltene dicke Fibrille aber dringt in die Muskelfaser ein, teilt sich hier in viele Ïste, welche zwischen den Mruskelfibrillen die Faser in der Lïngsichtung durchziehen und manchmal anch wieder anstreten. Die Veurofibrillen treten also bei diesen Tielen sicher mit der kontraktilen Substanz in direkte Beriilırung! (Fig. $15 \mathrm{~B}$ ).

Verbindungen zwischen rezeptorischen und motorischen Fibrillenbahnen.

Nachdem wir den Verlanf der Neurofibrillen innerhalb der Ganylienzellen und der mit ihnen in direktem nnd leicht sichthatrem Zusammenhang stehenden plasmatischen Fasem kemen welernt haben, wenden wir uns der Frage zu, wie die Fibrillen der motorischen und

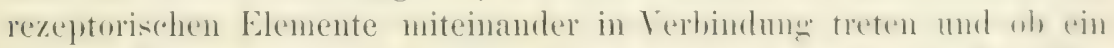

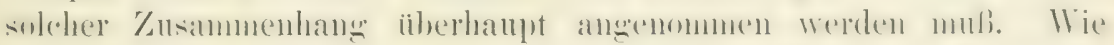
oben gezeigt wurde, treten aus den rezeptorisehen wie aus den moto-

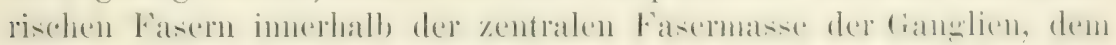

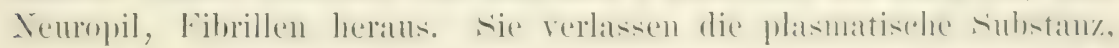
die sie bis dahin mit andem Fibrillen rereint hat und riehen frei weiter. Apátlyy ist es hauptsiichlich an Methylenblaupräparaten goelungen, diese ausgetretenen Fibrillen, die meist selı diunn sind, auf weite Strecken zu verfolgen. Dabei konnte er feststellen, daß sie sich teilen und sich mit andern shelortigen ribrillen in drei-

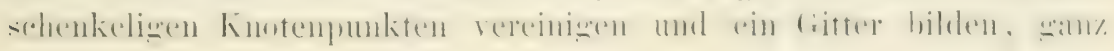




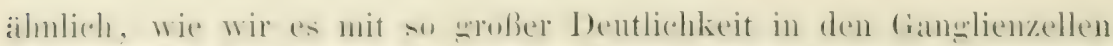

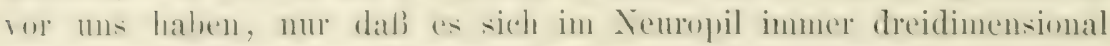
ausdehnt. Auf seinen Abbildungen hat er dies Gitter, das er als

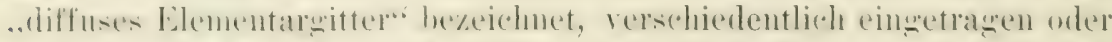

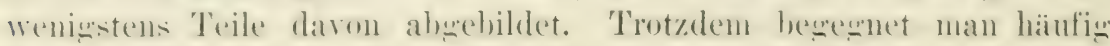

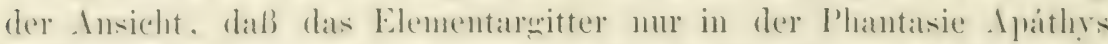

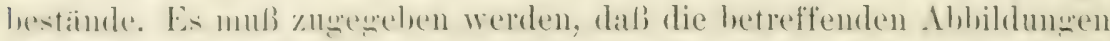
Apathes fior jemanden, der die Verhältnisse nicht kemut, nichts ahsolut Therrengendes an sich haben; die sichuld daran träget aher nicht eine

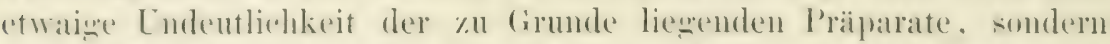
sanz offenbalr die zeichmerische schwierigkeit mehrere Ebenen des Praiparats auf der Ebene des Papiers zu vereinigen und dam ror allem die drt der Reprodulition, bei der die versediedenen I'latten nie so vollkommen zul Deckung kommen, wie es bei so subtilen Linien nötion ist. - A páthy wollte auf den betreffenden Abhildungen nicht nur die Existenz des Elenentarwitters zeizen, sondern zumleich mul vornehnulich darstellen, wie man durch dasselbe hindurch Fibrillen ans re\%ptorischen fasem his in motorische hinein verfolgen könne. Es ist dies vielleicht eine Aufughe, die sich technisch kalmu lïsen laibt, weil die Zeichnum bei dem fortwährenden Wechsel der Ehene nie das Bild, das man im Mikrosknp sieht, wiedereben kamn. Dal3 eine solche Verfolgung im Präbarat bisweilen möglich ist, davon habe ich mich an Methylenblanpräparaten und auch an Molyblänprijaraten einizemal selher üher\%engen kömmen. Ich lege aber anf diese Verfolwung war keinen so wroßen Wert, weil hei der Feinheit der Fibrillen Irrtïmer nur selten $\because 2$ a n\% ausweschlossen sind und es immer nur sehr

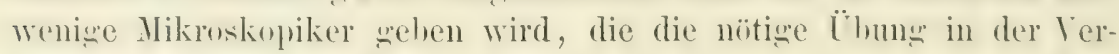
folgung so feiner Fädchen besitzen.

Um die Frage zu entscheiden, ob im Neuropil Fibrillen verschiedener bahmen miteinander anastomosieren, scheint es mir zu geniizen, den Xachweis zu führen, dab ïberhaupt Netzbildungen von deurofibrillen in der Zentralfasermasse der Gamelien existieren. Ich fiige desweren hier die Beschreilune einiger Prajparatenstellen an, wo ohne Veranderung der Einstellung ein Anastomosieren ron fribrillen direkt zu sehen war. Alle diese P'räparate waren nach meiner MolybdinTohnidin-Methode hergestellt. Irh mub aber himzufïgen, dalk derartige

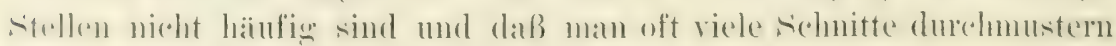
kann, olne auch nur eine einzige zu finden. $)^{1}$ )

1) Inzwischen hat Herr Dr. Prentiss im hiesigen Institut l'räiparate hergestellt, welehe Netze im Neuropil mit auferordentlicher Klarheit und häufig an vielen Stellen zeigen. Nanche seiner Netze sind weit ansgedehnter als die hier beschrichenen, aber nie diffus. Die Arbeit wird im Arch. f. mikrosk. Anat. in allemïchster \%eit erseheinen. 
In Fig. $16 C$ sieht man einen 'T'eil eines, sensorischen Schlanches". Aus diesem löst sich eine Fibrille bei $x$ heraus, die sich zu einem

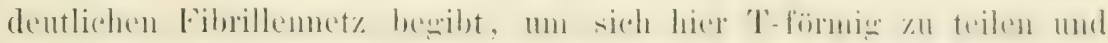
mit feinen Fibrillen, die von andern Seiten kommen, in ihm zu konfluieren. In der Mitte ist das Netz, wohl infolge der Behandlung, zu einem dickeren Strang verklebt. Nach links (m) lost sich eine etwas starkere Fibrille aus dem letz los, welehe ihrem Verlanf nach als exine

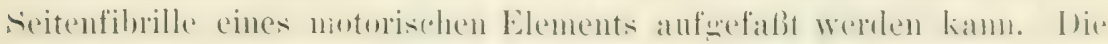

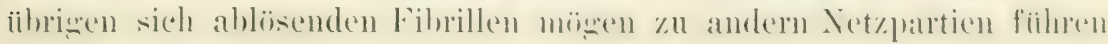
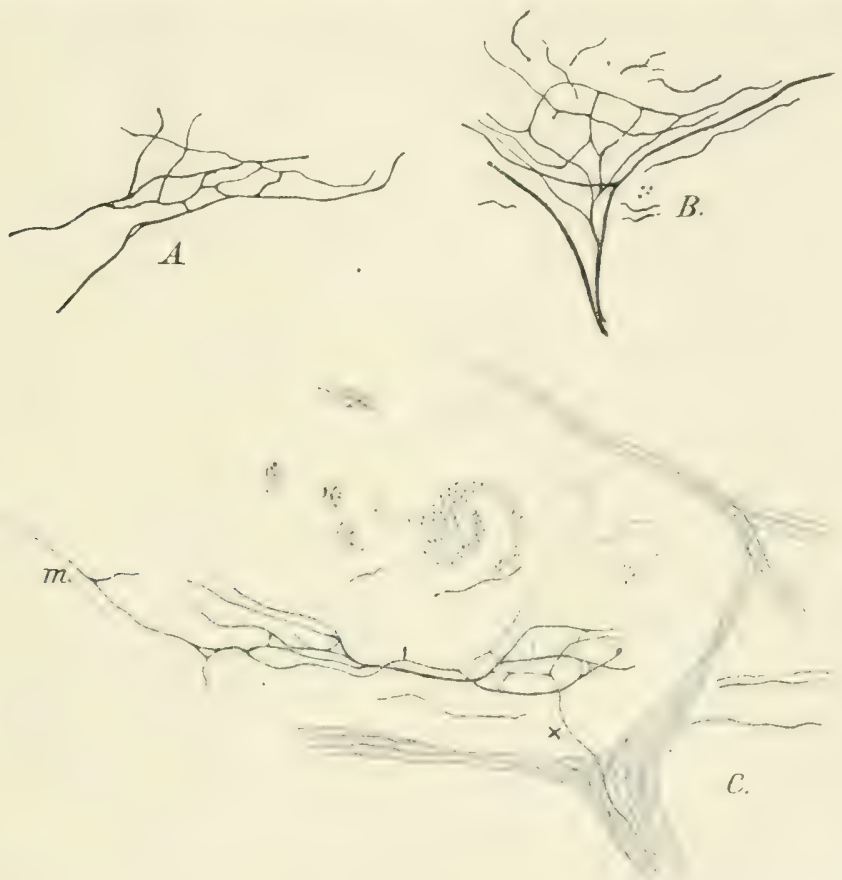

Fin. 16. Drei Fibrillennetze aus dem Neuropil ron Hirudo (Färbung mittels der Betheschen IIolybdinmethode). $A$ und $B$ zwei kleinere Netze, $C$ ein ausgedehnteres Netz, $m$ weithin zu verfolgende Fibrille. Die Fibrille $x$ kommt aus einem sensorischen schlanch.

ondere anch direkt aus rezeptorischen Fasern stammen. C̈hnliche lokiale

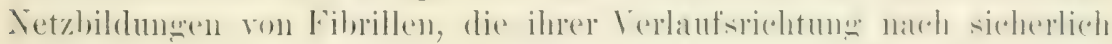
zи ganz verschiedenen Nervenfasern gehören, sind in Nig. $16 A, B$ ab-

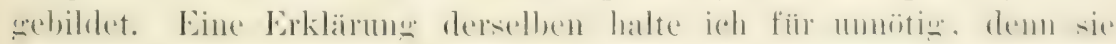
sprechen für sich selber und führen ron nenem den schon von Apaithy gelieferten Beweis, daß Fibrillennetze in der zentralen Fasemasse rorkommen. Ich. habe meluere Stellen abgebildet, um der Meinumg entgegenzutreten, daß es sich um ein seltenes und eventuell pathologisches Vorkommnis wie etwa die breiten Inastomosen zwischen

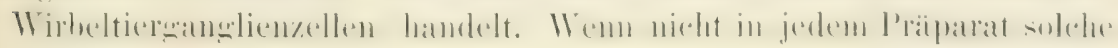


Stellen zu finden sind, so liegt das zum 'Teil an dem Mangel, der

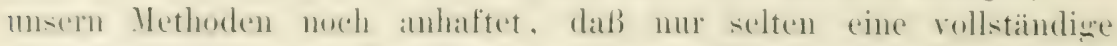
Färbung der feinsten Fibrillen erreicht wird.

Ein diffuses Gitter onder letz in der herkiommlichen bedentumedes Wortes diffus lient nateh meiner Meinume nicht vor. Die Fibrillen, welche alls den rezeptorischen Fasern austreten, mehen nicht sofort an der . Instrittsstedle in Vetzwerk ïber, wemn auch an del Austrittsstelle solches rorlanden ist, somdern winden sich lö̈ufig anf lange strecken zwischen Fasern, Fibrillen mol Set\%werken hindurch, um sich arst damn zu teilen und mit andern Fibrillen netzine Verbindumenen (inzuneden. Ehenso verhält es sich mit den seitenfibrillen der moto. rischen Elemente. Inf diese Veise tritt immer nur eine beschrankte Inzahl von Fihrillen in nähere Beziehmugen, und es scheint nir nicht

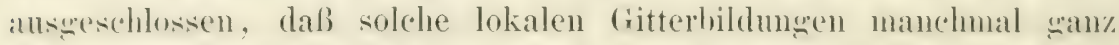
isolielt sind oder nur sanz wenige Verbindungen nit henachbarten (iittern eingehen. ${ }^{1}$, Iuf irgend einem nïheren oder weiteren Trewe werden aber wohl sehlieBlich alle Fibrillen eines franolions und des wesamten Xerrensystens miteinander in Verhindung stehen, wenn nicht allein durch die Gitter der zentralen Fasernasse damn doch duroh diese in Verbindung mit den Gittern der Ganglienzellen. - Wenn alles in Zentralorean diffus mitemander remischt werden sollte, so wäre es ja auch nuverstandlich, daß die Nervenfasern, die Fihrillenkaluel, innerhall, der Ganglien oft so weite und komplizierte True

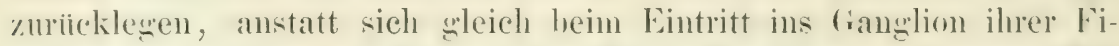
brillen zu entledigen und sie in das Gitter ibherselsen zu lassen. Wie

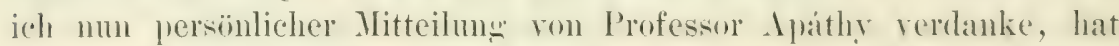
"r unter den Lusdluck, diffus" etwas sanz andres verstanden wisien wollen, als was die meisten Leser der gowiohnlichen Bedentumg nath darmiter restanden haben. Ich lasse deshalb im weiteren diesen nur zu Mißverstandnissen führenden dusdruck wanz fallen und spreche nur von dem Fibrillengitter der zentralen Fasermasse oder des Jenuropils), im Gegensatz zu dem der Ganglienzellen.

Ianche Fibrillen, welche aus sensorischen Bündeln stammen, selen immerhalb des Vemopils, wie es seheint, ïberhanpt keine Verhindungen mit andern Fibrillen ein. Ich habe wenigstens mehrfach eine ('inzelne fribrille direkt ans einem sensorischen biundel in eine Faser treten sehen, die motorischen charakter hatte. In andern Fällen -ill ich Fihrillen, die ans rezeptorischen Fasern kanen, sich in Xeur-

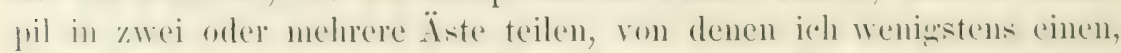
cimmal anch zwei in mzweifelhafte motorische Faseln oder Fasem

1) Durch die Befunde Prentiss ist diese Ansicht noch wesentlich befestigt worlen. 
von Kommissurelementen hinein verfolumen komnte. Dir andern iste (oder der andre) mögren sich mit andern Fibrillen zu Netzen der

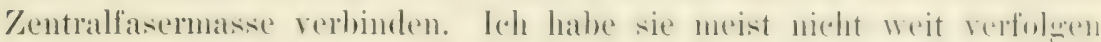
kömnen, weil die obere oder untere Grenze des Schnittes erreicht wurde. Derartige direkt aus einer Faser in die andre verlaufende Fibrillen hat auch dpathy mehrfach gesehen mod absebildet. Iods

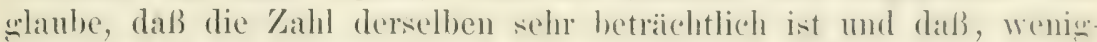
stens bei Hirudo, mehr Fibrillen nur in den fianglienzellens sich nit andern Fihrillen verbinden, ils im Gitter der zentralen Fasemanse. Bei Carcinus whube ich, zwar mehl ans theoretischen firiunden, als

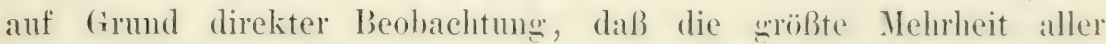
Fibrillen im Neuropil miteinander in Verbindung steht.

Ein Hauptgrund für mich, eine rollkommene Kontinuitait der Fibrillen von der Peripherie durch die Ganglien und wieder bis zur P'eripherie anzunehmen, hesteht darin, daß man auf den vollkommenst gefärbten Fibrillenpräparaten nie ein Ende einer ribrille innerhalh der Schnitte der Ganglien zu resicht bekommt. Jede Fibrille, die man ins Auge faßt, kann bis zu den trenzen des schnittes verfolgt werden, sei es, daß sie ungeteilt bleibt, sich in ihrem Verlauf teilt oder in ein Gitter einer tranglienzelle oder der Fasermasse ïberweht. Nur dort sicht man innerhalb der Fichnitterenzen Fibrillen enden, wo die Färbung nicht ganz geglickt ist; in diesem Fall sicht man sic allnählich blasser werden, bis man sie schließlich wegen vollkommenen Nangels der Färbung nicht mehr verfolgen kann; ein plötzliches Abbrechen etwa mit einem Kö̈pfehen oder dereleichen kummt nicht zn Gesicht, man mïßte dem die dunklen l'unkte, welche sich dort zeišn. wo eine Fibrille nach oben oder unten abbiewt, fälschlich dafuil halten, was einem Ungeübten vielleicht passieren könnte.

Nach alldem wird man nicht umhinkönnen, sich der Ansicht $A$ pathys anzuschließen, da $\beta$ die Neurofibrillen als kontinuierliches Element das ganze periphere und zentrale Nerrensystem durehziehen und daB sie innerhalb der Ganglien die 'Litcken iiberbricken, welche zwischen den plasmatischen Teilen der nerö́sen Elemente bestehen und zur Aufstellung der Kontiguitätslehre Veranlassung gaben.

Des genaueren wird sich dieser kontimuierliche Verlauf etwa

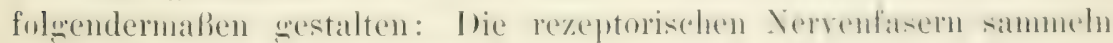

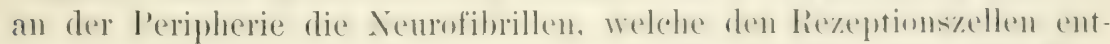
stammen (Fig. 15 A). In den Fasern lanfen die Fibrillen ohne Ver-

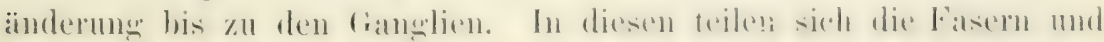
die Fibrillen strömen aus ihmen aus. (Worte wie, strömen", ggehen", ,laufen", „eindringen" $11 . \mathrm{s}$. w. sind natiulich bildlich zu rerstehen.) 
Ein Teil son ihnen welht direkt oder nach vorhergegangener Teilung in die seitenfortsitze andrer Elenente äber. Andre Fihrillen teilen sich melufach in Jemropil und anastomosieren miteinander. Ins dem su enthildeten ditterwerk, dats bald lokal oder mehr wder weniger diffus ist, gehen wieder was stäkere librillen hervor, die wiederum in plasmatische Fasem Kabel son motorischen Elementen order Komnilswrelenenten eintreten. In beiden Faserarten lanfen diese Fibrillen der Ganglienzelle zn. In den motorischen (ianglienzellen bilden die vielen anf dem Itege der seitenfortsiitze in die Faser und den stammfontsat\% gelangten diunnen Veurofibrillen ein (iitter, aus dem direkt oder anf dem Wege eines aweiten Gitters Innengitter die motorische Filnille hervoreht. IDiese verlißit innerhalh der motorischen Verven-

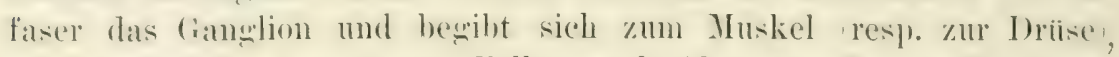
mu hier in die imnervierten Zellen nach Abwerfen des perifibrillïren Mantels einzudringen. Die Fibrillen, welehe in die Ganglienzellen der Kommissurelemente eindringen, bilden hier scleichfalls ein (iitter, aber ans ihm gehen nur andre feine Fibrillen hervor, die in stammfortsitz zurieklanfen, in andern Zweigen desselhen weiterziehen und im selhen oder in einem andern (ianglion wieder ins Veuropil austreten. Dureh diese Elemente werden Teile des Vemropils and seiner Gitter, die weit roneinander entfernt sind, in nühere Beziehungen gesetz.t. so ungefähr wird sich der Fibrillenverlauf heim Regenwum und Blutegel gestalten.

Bei C'rustaceen Careinus, Astacus, liegren die Verhältnisse sicher etwas anders. Bei diesen Tieren geht nur ein kleiner Teil aller Xeurofilmillen dureh die Ganglienzellen, denn, da man bei allen ihren Canglienzellen nur einen kleinen Teil der in den Zweigen des zanzen ... Nenron" vorhandenen Fibrillen in den stammfortsatz ziehen sieht Fig. 12, su kann gegen diese Aufstellung nicht eingewandt werden. daß die Fibrillen, welche die eine \%elle meiden, vielleicht eine andre passieren. Da ich nun anch hier, wie heschrieben, seseben habe, dab die Xenrofibrillen in die Vervenfasem eintreten resp. ans ilmen anstreten. so miissen die Fibrillenüberwinge von Faser zu Faser und ihre Vermischung zum gröbten Teil in der zentralen Fasemanse mud ihren (iittern, die ich allerdings his jetzt nur andentungsweise zu (iesicht bekommen habe, gelegen sein ${ }^{1}$ ). Die l'ig. 42, S. 99, gibt ein Bild, wie ich mir nach dem vorliegenden Material den Fibrillenverlanf bei den Crustaceen vorstellen zu müssen glaube.

1) Prentiss beschreibt in der in Publikation begriffenen Arbeit einige sehr dentliche Gitter im Neuropil von Astacus. 


\section{Die Neurofibrillen im Nervensystem der Wirbeltiere.}

Die Neurofibrillen der Nervenfasern S. $47-55$ (nener Beweis für die Unterbrechmng der Perifibrillïrsubstanz an den Ranvierschen Einschüumgen S. 52-54). - Die Fibrillen in den Ganglienzellen S. 56-60. - Die Bezichumgen zwischen Nervenfasern und Ganglienzellen und die pericellulären Gitter Golginetze) S. 61-7S.

Die Formverhältnisse des Nervensystems der Wirbeltiere werden

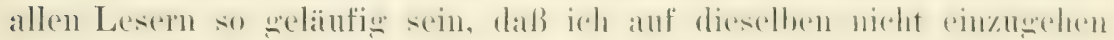
brauche. Es wird anch nicht nötig sein, die rerschiedenartige Gestalt

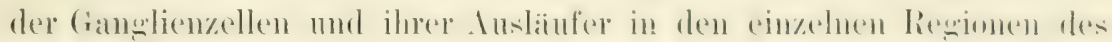

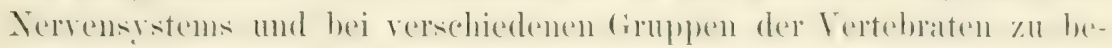
schreiben. (Wer sich hieriber noch näher informieren will, wird das Hauptsäichliche und Wissenswerte in den gesammelten Werken ron

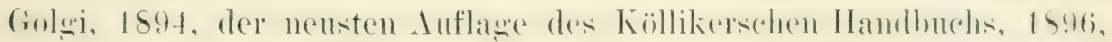
und dem Buch ron Lenhossék, 1895, finden.) Auf einzelne Verhältnisse, die noch kontrovers oder neneren Datums sind, wird am geeigneten Ort eingegangen werden.

Die Nenrofibrillen der Nervenfasern (Achsenzylinder).

Der erste, der in markhaltigen Nervenfasern die Neurofibrillen gesehen hat, war, wie schon erwähnt, Max Schultze. Färberisch darwestellt wurden sie hier zuerst wn kiphfer. lieiden diente abgenelen ron andern, weniger einwandsfreien Methoden, die Max Schultze anwandte) die Osmiumsäure als Fixationsmittel. Auch hente noch ist die Torbehandlung nit (Jomiumsäure das beste und beinathe das einzige Yittel, un die Teurofibrillen der Wirbeltiernervenfasern zur Darstellung zu bringen. Es berult dies, wie tpáthy zunerst herorgehohen hat, nicht darauf, daß die Osmimmsäure die Fibrillen grut färbhar macht, sondern nur darauf, daß de (Ismimnsämre die sichrmmp-

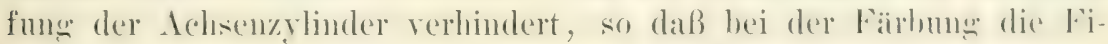
brillen. weldhe ihr dichtester Bestandteil sind, an hesten hervortreten.

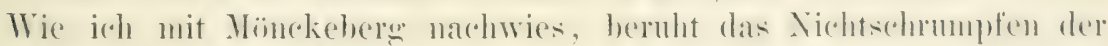

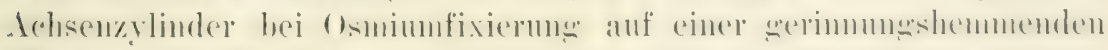

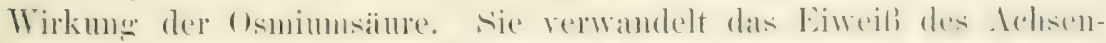
zylinders (wie anch andre Eiweißlösungen) in der Weise, daß atch

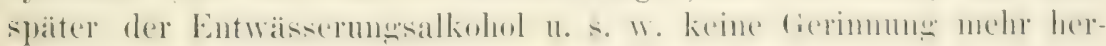
vorruft. Bei allen andren Fixierungen (mit Ausnahme ron stark ab-

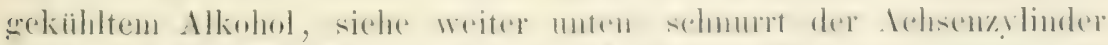

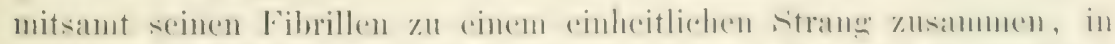

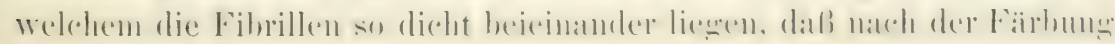




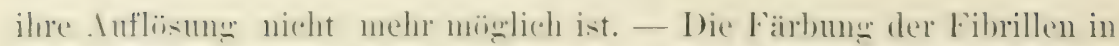

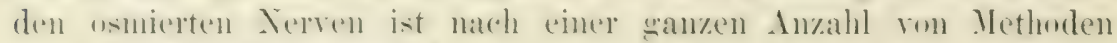
mönlich. die alle an mod fïr sich nichts spezifisches haben und eine wanze Уenger andrer fiewehshestandteile ehenso intensir oder intensirer färben kimmen. In aber die Masse, in die die Fibrillen eingehettet sind. die l'erifihrilläsulstanz, nicht orler fast nicht grefailht wird, so treten die Fibrillen doch sehr deutlich hervor.

Den Ramm immerhalh der Markscheiden, welche durch das redu-

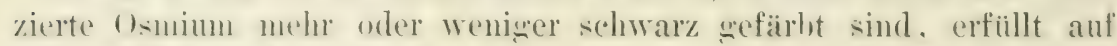
solchen l'rïparaten eine homogen erschemende, hlab oder sall nicht

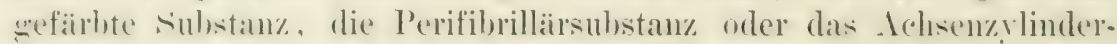
plasma. In dieser erscheinen anf dem Längssolnitt eine wrobe Anzahl feiner, aher durchaus scharf sezeichneter Fibrillen Fis. 17 a. Wrar der Nerr nicht gespannt, so sind die Fibrillen sehr wellig, oh-

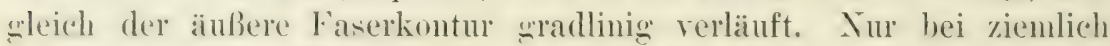
stark wespanten Nerven laufen anch die Filnillen gradlinis und sind nur in diesem Zustand gut zu rerfolgen. Man nimmt an solchen Praiparaten wahr, daß die Fibrillen durohaus individuell nebeneinander herlanfen, nie Terhindungen immerhalh des Ichsenzylinders solange er ungeteilt ist mtereinander eingehen und nie enden, außer an den stellen, wo sie, rom Messer durchtrennt, ein kimstliches Ende zeigen. Es handelt sich also, wie hei den Evertehraten, un wirkliche Fibrillenindividuen. someit es die Grenzen des s'dnittes erlauben, kann man die einzelnen Fibrillen auf weite strecken rerfolgen $100-150$ "1. falls die Nerrenfasern nicht allzu dicht mit Fibrillen amerefullt sind, wie dies hei säugetieren recht häufig der Fall ist Frosch und Fischnerven, Torpedo, scheinen mir die simstigsten (),jekte zn sein, weil hier die Fibrillen relativ dick und nicht allzu zahlleich sind. Eine Verfolwum der einzelnen Fibrille anf noch srößere strecken ist deswren nicht mö̈lich, weil die Markrohre anforeschnitten sein mïssen, wenn nan die Fibrillen dentich sehen will, und wohl kaum ein Infschneiden der Markscheiden anf swöBere strecken mönlich sein diirfte.

Auf den Quersohnitt der Nervenfasem erscheinen die Neurufibrillen als dunkle l'unkte innerhall, des s(hwar\%en Markringes Fig. 17 b.

Von versehiedenen Seiten ist die Existenz von Fibrillen in den Wirheltierachsenzylindern in Ibrede sestellt worden, und das Bild, das Kinffer 11. a. salien, als Trumbild hezeichnet worden, so hesomders von

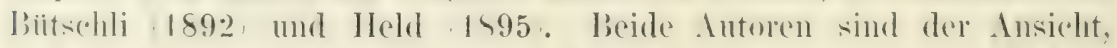
dalf die Fibrillen weiter nichts sind, als die Läingswände von Waben.

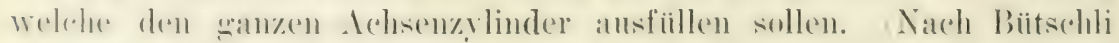

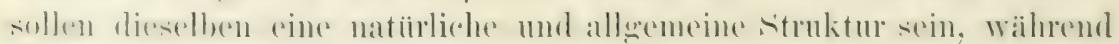
sie Ileld fiur ein Kunstprodukt hielt.) Als Beweis dafuil wurde an-

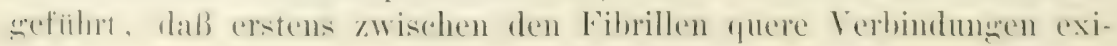




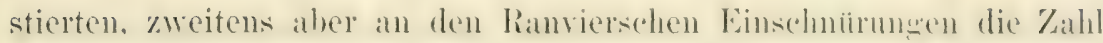
der ,Fibrillen" geringer wiirde, indem die Größe der Waben sich

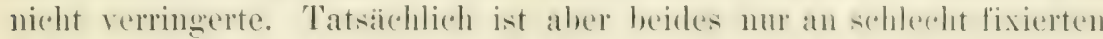
Priparaten zu sehen. Quere Verbindungen existieren im Osmiummaiparat nicht. und die Fibrillen durohziehen in der weichen Inzahl die Ramvierschen Einschniurmonen, in der sie in andern T'eilen des

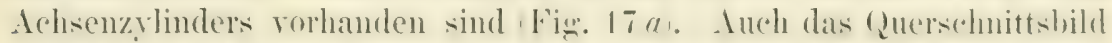

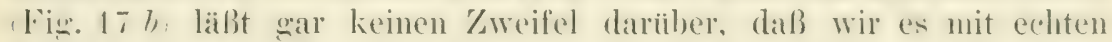
Fibrillen von drehrunder (iestalt und nicht nit Läneswänden ron

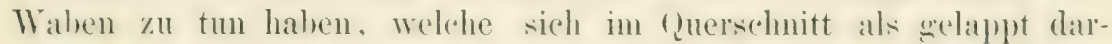
stellen müßten. Schließlich sei als Beweis für ihre Existenz ihre Isolierbarkeit angefuihrt.

Ein Unterschied zwischen den Neurofibrillen der motorischen und sensiblen Vervenfasern besteht wenigstens hei den höheren Wirbeltieren nicht. Hintere wie vordere Wurzeln enthalten hei liana, Lepus. C'anis und Homo nur Nervenfasern, die sich in Fibrillenbild sar nicht romeinander merscheiden mo in diesen wie in jenen mit denselhen diunnen Fibrillen erfült sind. Auch dort, wo ich in peripheren Verlauf sensible und motorische Fasern untersuchte, komnte ich keine Lnterschiede bemerken. Bei Fischen dagegen scheinen Luterschiede vormkommen, wenigstens beschreibt Apathy, daß bei Lophins nur die hinteren Wurelfasern nach dem beschriebenen 'Typus welout sind, während die Faseru der vorderen Wrurzeln nur eine sehr dicke Fibrille enthalten sollen.

Über die Neurofibrillen der marklosen Fasern destrympaticus u. s. w. liegen außer den Angaben von Max schultze fast keine Beobachtungen vor. Thre färberische Darstellume selingt weit schwerer, als hei den markhaltigen. Am besten habe ich sie einigemal in Methrlenhlaupräiparaten zu sehen bekommen.

Ein hesonderes Interesse beansprucht das Vorhalten der sicheiden und der Perifibrilläsubstan\% an den Ranvierschen Einschniirungen. weil es als Beweis für die leitende Natur der Neurofibrillen dienen

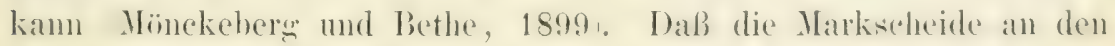
Ranvierschen Einschniurmugen eine Enterbrechung arleidet, ist ohne weiteres an frischen und osmierten Präparaten zu sehen (Ranvier).

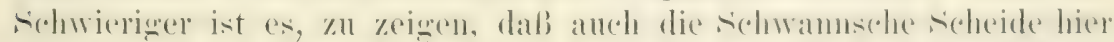

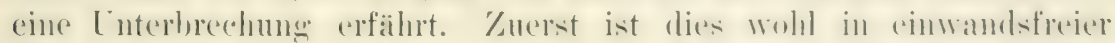
Weise durch boveri (1885) geschehen. Er zeigte - und ich habe

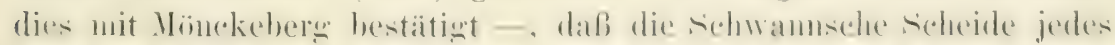

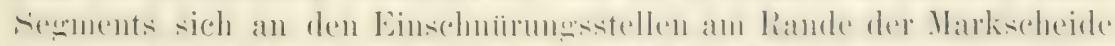

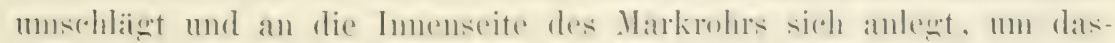

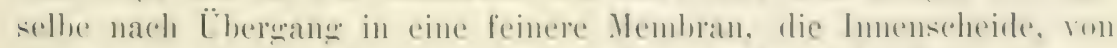

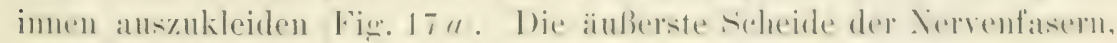




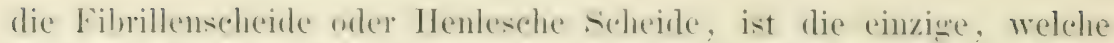
Wher die Einschnörmugen fortzieht: sie hat aher mit der Nervenfaser

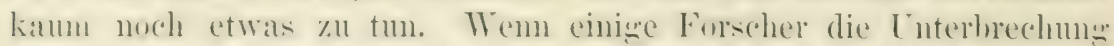
der schwamschen sicheide lengnen, so kam dies nur darauf beruhen. daß sie sie mit der Fibrillenscheide verwechseln.

An in Osmiumsänre zerzupften Nervenfasern bemerkt man nun, wenn man sie in Wasser beobachtet, daß sich auch zwisehen den

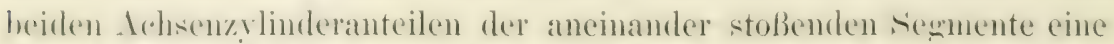
scharfe Grenzlinie befindet. Wendet man Fasern ron seefischen Torpedw an, so bemerkt man heim C̈hertragen in destilliertes Wasser, wie die feine Linie sich verbreitert und zu einem breiten Bande anfyuillt Fig. 17 c. Die Fibrillen durehziehen jetzt das Band wie vorher die Linice. I ch habe mich nicht dem Eindruck verschließen kïmen, daß sich hier entweder eine quellungsähige P'latte befindet oder ein siraltram, der sich mit Wasser imbibiert und der die Perifibrillir'substanz dats Achsenziglinderplasma, der beiden aneinander stoßenden segmente roncinander tremnt. Weitere Aufschlïsse iiler dies Gehilde gehen Präparate, welche mit silhernitrat behandelt sind. An diesen sieht man bekanntlich an der stelle der Ranviersehen s'chüuringe ein schwarzes Kreu\%, das dadureh entsteht, dak sich ein silberniederschlag zwischen den Lmschlags:ändern der sichwannschen scheide einerseits und zwischen den Anfangsteilen des Achsenzylinder's und der Innensoleide andrerseits bildet. In andern Fällen sieht man aber nur eine schwarze Linie, die nichts mit der sichwannsehen sicheide zu tun hat, sondern eine Grenze zwisohen den Hohlräumen der aneinander stofenden Markinhere bildet. Diese Grenzlinien imnerhalb des Achsenzylinders hat 7nerst Engehmann (1850), gesehen und als richtige Zellorenzen snedentet siehe auch redoelst, 1589\%. Iuf Querschnitten bildet sich die (irenzlinie als dümne scheibe ab, welche wie ein sieb durchlöchert ist (Fig. $17 d$ ). Durch diese Löcher treten die Fibrillen von einem rexment in das andre ither. solche siehplatten hat auch Mam färberisch dargestellt, und ich selher habe sie an webeizten l'riparaten nach Alkoholfixierung einigemal gesehen.

Daß hier etwats besonderes vorliegt, weht anch ans solehen l'räparaten hervor, die nit schrumpfend wirkenden Fixierungsmitteln behandelt sind. Ist die Sichrumpfung nicht \%ul stark, \%. B. bei Inwendung von kaltem Alkohol oder von Silbernitrat, so sieht man die Fihrillen häufig nur innerhall, des freien Raums der Markrohre zu einem dïnnen bïndel zusammengesehrumpft, während sie an den Ramrier-

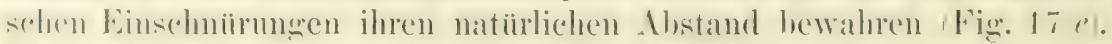
Manchunal sielut man sogar diesen Teil des Ichsenzylinders aus dem

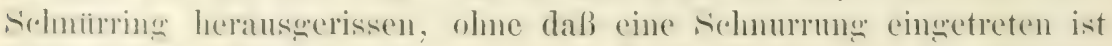
Hig. 17 /. Hieraus gecht hervor, daß die Fihrillen an den sichniir- 
ringen in ihrer Lage festgehalten werden, daß ein mechanisches

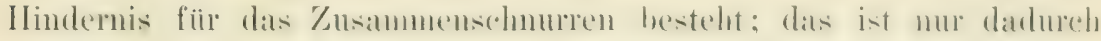
möglich, daß hier entweder eine durchlöcherte P'latte ron festerer Konsisten\% vorhanden ist, als sie das delsenzylinderplasma besitzt,

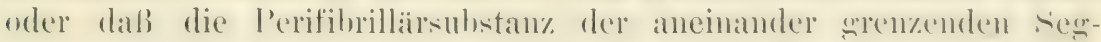
mente muterbochen ist und so ein syaltram mit starker (Hedflärden-

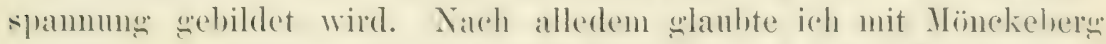
amehmen \% sollen, dal die l'erifibrilläsubstanz an den Ranvierschen

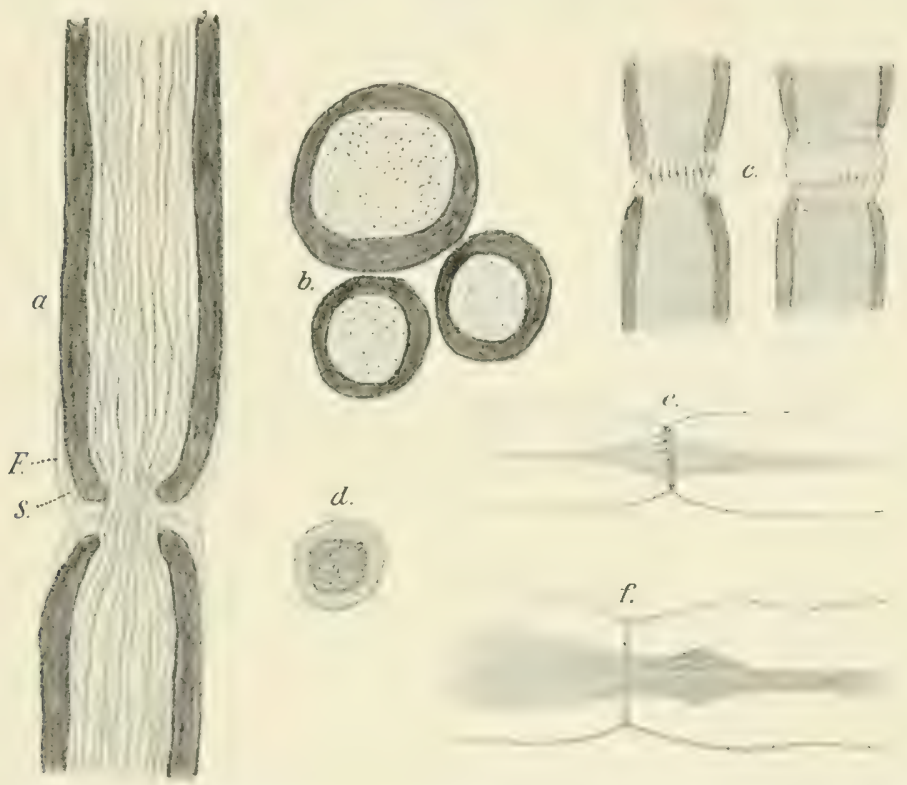

Fig. 17. a Lüngsschnitt einer markhaltigen Nervenfaser mit gefürbten Fibrillen ( $F^{\prime}$ Fibrillenscheide, $S$ Schwannsche Scheide). $b$ Querschnitt durch markhaltige Nervenfasern. $d$ Platte einer Ranvierschen Einschnürung, mit Silber geschwärzt. Man sieht die kleinen Poren, durch welche die Fibrillen hindurchtreten $(a, b$ und $d$ rom Frosch). cosmierte Nervenfasern von Torpedo. Links in Seewasser, rechts nach dem Übertragen in destilliertes Wasser. Bei der rechten Faser ist die Zwischenplatte gequollen, $e$ gesilberte Faser vom Frosch. Der Fibrillenstrang ist außer an der Ranvierschen Einschürung zusammengeschrunpft. $f$ geschrumpfte Faser aus einem Alkoholpräparat (Frosch). Die Zwischenplatte ist beim Zupfen aus der Ranvierschen Einschniirung herausgerissen.

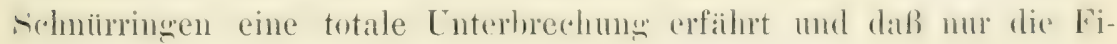
brillen von einem Segrment in das andre iiberg'ehen.

War dieser Schluß richtig, so war damit ein nener Beweis fiur

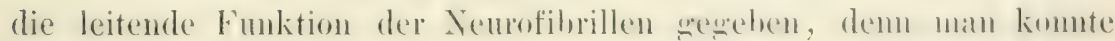

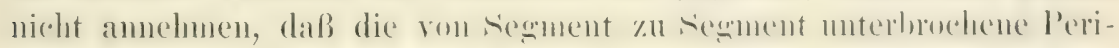
fibrilläisulstanz der Leitung diene. Aber auch nach einer andern

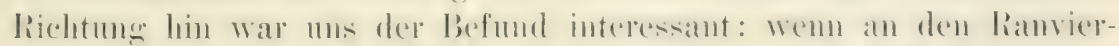

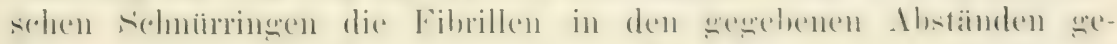
halten werden, so kamn man dieser Eimrichtung eine isolatorisehe Funktion zuschreiben; sie rerhindert, dals dit cinzelnen fribrillen mit 


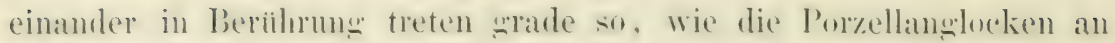
den Telestaphenleitungen eine Berïhrum der Drähte verhindern.

Inzwischen liat nun Verworn (1900) in seinem fiil alle konservativen Elemente sn hocherfreulichen lieferat iiber die Semonentheorie

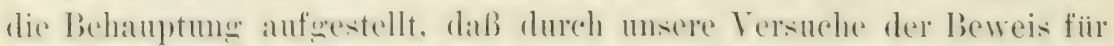

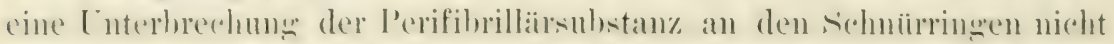

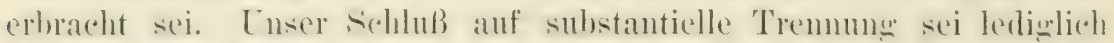
eine suljektive Dentung. entsprungeren ans dem Vorurteil, dals die Fibrillen das Leitende seien. Merkwiirdiperweise führt Terworn von musern Beweisen nur den Quollungsversuch an, anf den allein wir

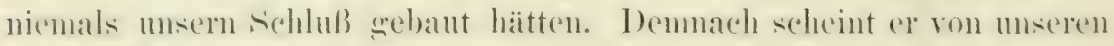
andern lieweisen noch weniger zu halten. Ich hin noch hente andrer

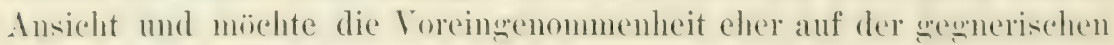
Seite sehen. - Verworns Skeptizismus hat mich aber dazu veranlabt, nach nenen Beweisen für die substantielle Lnterlorechung zu suchen, und dabei bin ich zu einem Versuch selangt, der vielleicht auch Verworn ïberzengen wird. Er entsprang der einfachen C̈berlegung, dab bei wirklichem Abschlub an der lianvierschen Einschuirumo keine Perifibrillärsubstanz dureh dieselbe hindurehtreten kïnne, dab also bei Druck auf das Markmhr der meredriickte Teil desselben nur bis zum nächsten Schnilring anschwellen diufe.

Man kamn diesen Versuch direkt muter dem Mikrosknp anstellen, doch wird a in dieser Form nur für weschicktere Menschen ansfiihrbar sein: ein Stilck aus dem Ischiadicus vom Frosch wird in Blutserum zermpft und eine Faser mit schönem Ranvierschen sichuimring. anfwesucht. Ich lere nun ein l'fertehar etwa einen halhen Villimeter vom Ring entfernt quer über die Faser und decke iiber das Ganze vorsichtig ein Deckglas. Die Faser zeigt unter dem Mikroskop) (Leitz: Objektir 5, Okular I) ihr altes Aussehen. Drickt man num, während man beobachtet, vorsichtig auf das Deckglas, so sieht man die Faser nach dem sichnïring zu anschwellen; am ling macht aber die Schwellung halt. Liegt das Haar nicht weit rom Ring und ist es relativ dick, so daß es viel Masse rerschieben kann, dann kann der diesseitione Fascrabselnitt bereits auf den doppelten oder dreifarden Durchmesser ansohwellen, während der jenseits des limeres enelewene Teil, anch bei minntenlang anhaltendem I)ruck, keine Volumszunahme zeigt. Eine Verringerung der Anschwellung ist anch bei

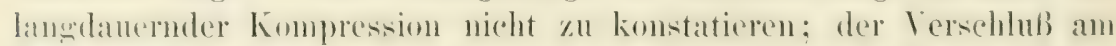

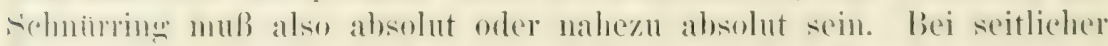

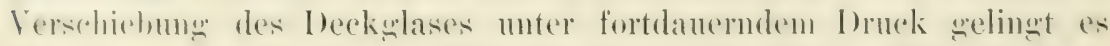

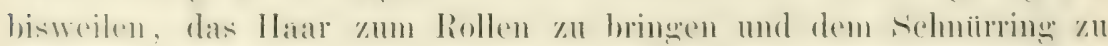
nähern. Dabei kann dann die Anschwellung zur Blase rom vier- bis

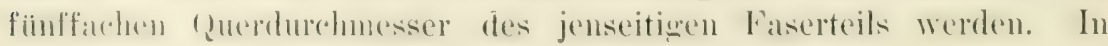


diesem Zustamde platzt die Faser leicht und entleert sich. An welelene Stelle das Platzen eintritt, kamn ich nicht sicher angeben.

Sehr viel leichter ist der Versuch in folgender Weise anzustellen: Ein stanzer Ischiadions rom Frosch wird mit zwei Iselstacheln auf

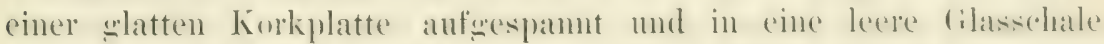
gelegt. Auf den Nerven hängt man dann einen Reiter aus Glas, welcher eine älnnliche Form hat, wie der in Fig. 64 abgebildete Irahtrahnen, nur dab sich an sitelle des Fadens ein querstehendes Kapillarrohr ron ein his anderthalb Millimeter Dicke befindet. Iuf die unten an Reiter angelunchte sichale werden nun so lange kleine Gewichte gelegt, bis der Jerr minter dem Röhrchen sam\% plattgedriokt ist. So bleibt er eine viertel Stunde, damit sich der Druck auswleichen kann wenn dies iberhaupt geschieht!, und dam wird die

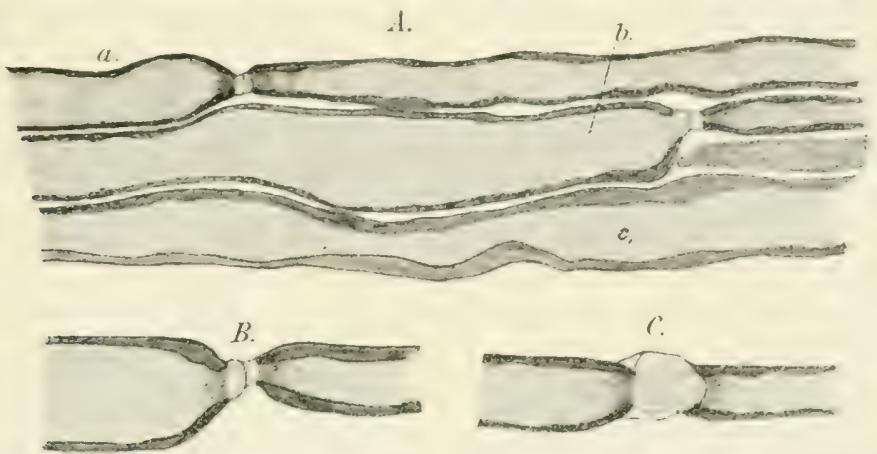

Fig. 18. Nervenfasern rom Frosch, welche durch Kompression (auf der limken Seite außerhalb der Zeichnung) deformiert sind. Beschreibung in Text.

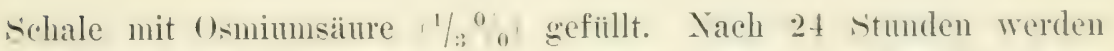
die Crewichte abgenommen, der Nerv entwässert, in I'araffin eingebettet und längs geschnitten.

Die Druckverhälnisse liegen naturgenäß im zanzen Verven wesentlich anders, als in einel cinzehen Faser. Die Fasern hindem sich gegenseitig an der Ausdehnumg, inden das Perinemrium einer Ausdehmug aller Fasern einen erheblichen Widerstand entenesensetzt.

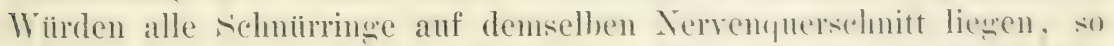

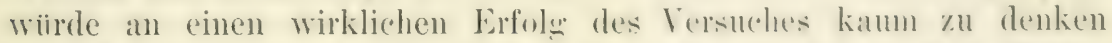
sein, da sie aber sanz rerottelt sind, so bekomm man doch bilder, die den an einzelnen Fasern gewonnenen sehr ähnlich sind. In

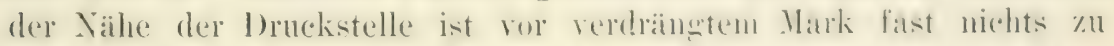

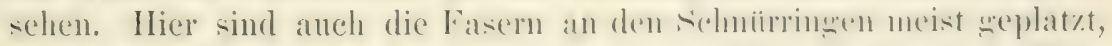

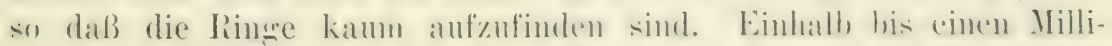

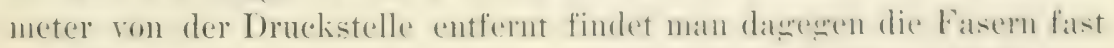

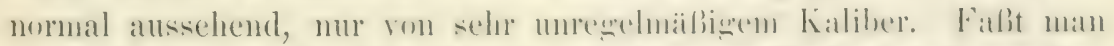
in dieser (iegend einen sichnibring ins Inere, so findet man hesonders 
bei den dickeren fast whe Ansmahme, dabl der Achsemzylinderhuhlramm nach der loruckistelle zn wesentlich weiter ist, als nach der anderm

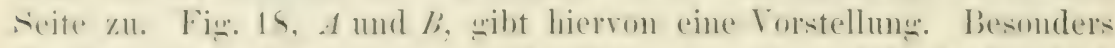

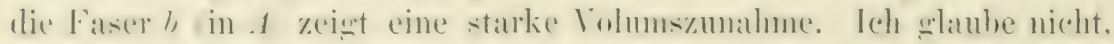
daß der diinnere, anf der andern Seite jedes Schnïrringes ge-

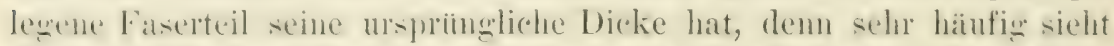
man bei weiterer berfolwung dessellsen das Volumen wanz allmählich zhmehnen. Ith hin viehnehr der Ansicht, dab die muliegenden. noch muter höherem Inruck stehenden Fasem hier jenseits des sidnnimringes die Perifihrillïrsubstanz weiter fortweschoben hahen, was natiulich zu riner Dickenahnalme führen muk. Für den wechselseitigen Druck, den die Fasern anfeinander ausiiben, wibt anch die Faser a in ihrem Verhältnis zur Faser $b$ eine gute Illustration.

In andern Fallen sieht man die Grenzlinie im Schuiirring (die vermutliche I'latte sanz nach der seite des geringeren Drtickes repschoben und die Perifibrillärubstanz aus dem Markiam heraus-

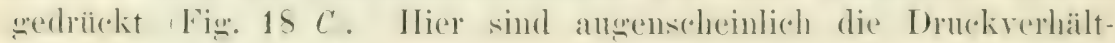

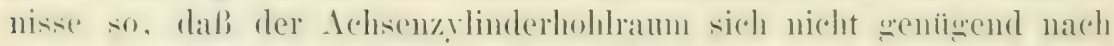

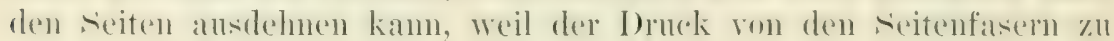
stark ist. Da gibt eher die Schwannsche Scheide und die Imnen-

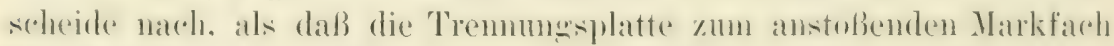
lin durchlorochen wird.

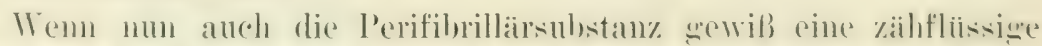

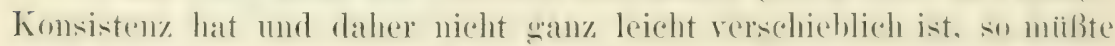
doch, wemn kein alsolutes Hindernis an dieser stelle vorlanden waire. ein Durelatritt derselben dureds den sichnioring stattfinden, da ja die Verschiehnum immerhalh, des Markwohrs sehr sehnell ror sich gedit mol zum eventuellen Answleich des Druckes durch die sichniorringe hindurch gentigend Zeit gelassen wurde. Ich glatube diher nach diesen Versuchen nochmals und mit noch erïberem Natehdruck folgendes behaupten zu diurfen: An den Ranrierschen Einschnürungen ist die Perifibrillärsubstanz vollkommen unterbrochen. Nur die Nenrofibrillen gehenkontinuierlich ron einem Markfach aufs andre ïber. Da dies so ist, können nur die Fibrillen das leitende Element im Nerren sein. (Übrigens scheinen mir diese nenen Versuche doch mehr für eine

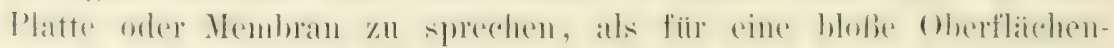
spammung.)

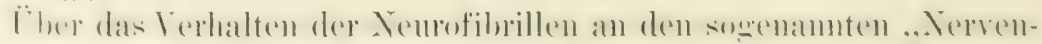
endigungen" ist bei den Wirbeltieren erst seh" wenig bekannt. Es

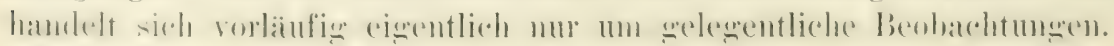

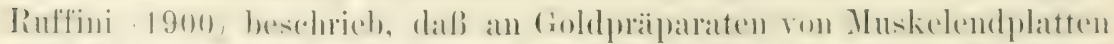

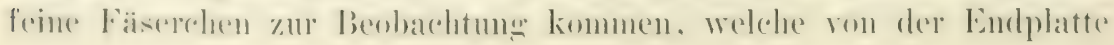


weiterzichen und meist an benachbarte Muskelfasern treten. Den An-

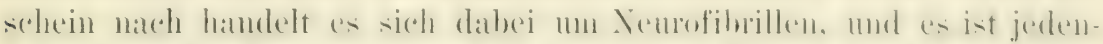

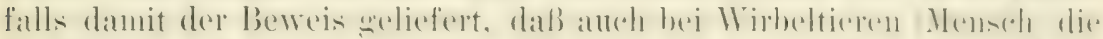

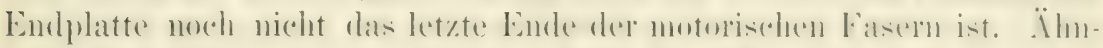

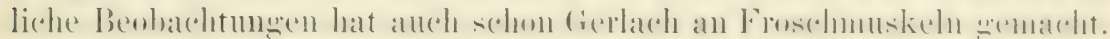

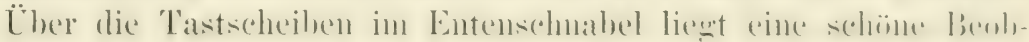
achtumg von Szymonovicz (1896) vor. Er fand an Methylenblan-

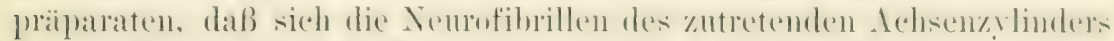
in del Patte flächenhaft anshreiten. sich teilen mul zu einem Noty zusammentreten. Es ist dies, soweit ich sehe, der einzige Beweis, dab anch bei den Wirbeltieren die Nemofibrillen \%u den Endorwanten in spezifische Beziehumen treten. I)ie Lntersuchume bereitet hien noch größere Schrierigkeiten, als bei den Wirbellosen, weil es ror-

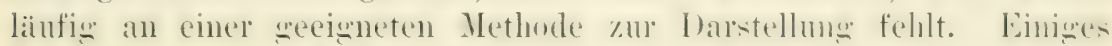
läbt sich zwar an Methrlenblaupraiparaten erkemen, aber nur selten. weil die Fibrillen bei den Wirbeltieren in weit häherem Malse als hei

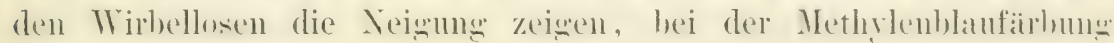
schon ror dem Fixieren zu einem einheitlichen Strang zusammenzuschmuren.

Die narkhaltigen Nervenfasern des zentralen Verrensystems muterscheiden sich ron denen der peripheren Xerven nur dadurch, dah sie der schwamschen scheide entbehen. Das Fibrillenhild weist keine Enterschiede anf. Auch hier ist die Fixiermug mit osmimusäme das einzige Nittel, um mit sicherheit eine Darstellung der Fihrillen in den Fasem zu erziclen. Da die Osmiumsïme su sehr schlecht in wrïhere

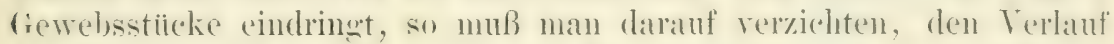
der Fibrillen in den strängen des Rüickemmarks nud andorn Faser-

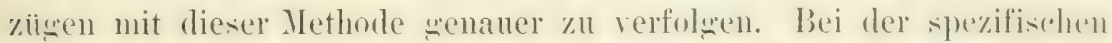

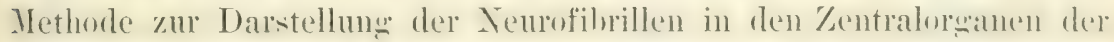
IVirbeltiere meiner Molyblïmmethode. schnuren die Fibrillen in den Achsenzylindern unter dem Einflub der zum frixieren henutzten sil-

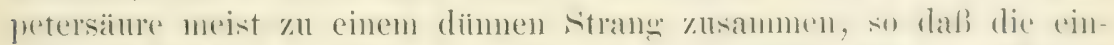
жlnen Individuen nicht nehr wahroenommen werden kïnnen. Finige-

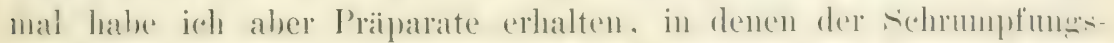

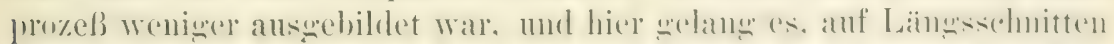

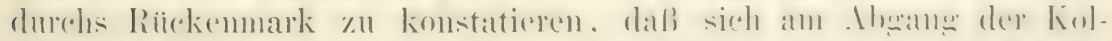

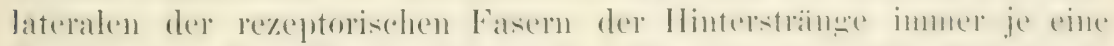

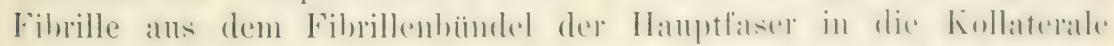
hineinlsegibt.

Die Fibrillen in den Ganglienzellen.

Außer Max Schultze, der wahrscheinlicherweise gar nicht die Fibrillen selber, sondern nur ihr Negativ in den Zellen gesehen hat, 
hathen ror mir mur wenime Forscher Andentuneren der Fibrillen in den Ganglienzellen von Wirbeltieren wahrgenommen. Es sind da zu nennen: Flemming, Lugaro, Lery, Cox und Becker. ${ }^{1}$ ) Keinem dieser

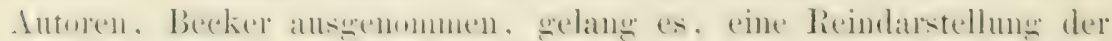
Nenrofibrillen zn erreichen. Üherall waren andre Elemente mit-

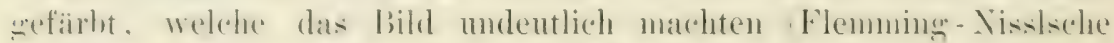

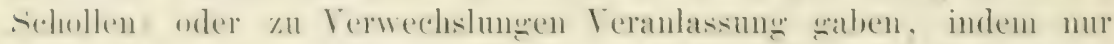
ein Teil von den sichthatren Fibrillen wirkliche seurofibrillen waren. Die l'olere war, dals diesen wenim deutlichen bildern nicht allzuviel dianben ereschenkt wude mud eine Anzahl ron Forschern, so Lenhossék und Cajal, die Existenz von Fibrillen in den Zellen zu lengnen fortfuhen. Die I'räparate ron Mamn, die owelohzeitip mit meinen auf dem Inatomenkomerep in Kiel zum erstemmal öffentlich gereigt wurlen, krankten an allerhand Übelständen. sie reigten zwar die Existenz ron Fibrillen in den Protoplasmafortsiitzen und am Rande der Zellen recht dentlich, vemochten aber kein libl vom allogmeinen Terlanf der Fibrillen in den Zellen zu weluen, weil die sichollen mitgefärbt waren. Ich halte mich infolgerlessen im weiteren nur an meine eimen Befunde, die in nenerer Zeit dureh eine nach meiner Methode ansgeführte Arbeit von Embden bestatisnt und ergainzt sind. ")

Das wichtigste Resultat, das die L'utersuchung des Fibrillenverlanfs in den Ganglienzellen der Wirbeltiere ergeben hat, ist wohl das, daß die Filnillen bei den meisten Zellarten enlatt durch den Zellkïrper hindurchlanfen, ohme im Inneren miteinander Terhindungen

1) Über Apathys Befunde bei Wirbeltieren lagen und liegen keine Veröffentlichungen vor.

2) Von den vielen und berühmten Mikroskopikern, denen ich meine Präparate habe zeigen kömnen, haben alle außer einem, den ich nicht nemnen will, nicht nur die Existenz der Neurofibrillen in den Ganglienzellen der Wirbeltiere anerkannt, sondern auch mit Leichtigkeit das meiste von dem erkennen künnen, was ich iiber den Verlauf derselben in den Zellen und Fortsiitzen beschrieben habe. Yor kurzem hat nun Semi Meyer (1902) eine neve Methode zur Darstellung der Neurofibrillen bei Wirbeltieren veröffentlicht und mitgeteilt, daß er an den mit ilar gewomnenen Präparaten nicht hat bestïtigen kömṇen, daß es Fibrillen

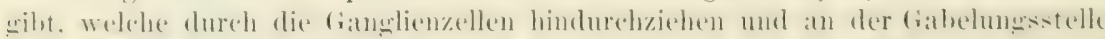
von Protoplasmafortsätzen von einem Ast direkt in den andern ibergehen. Grade der letztere Befund ist an meinen Präparaten fast ïberall so deutlich, daß ilm niemand in Zweifel gezogen hat. Ich muß daraus den Sehluß ziehen, daß die Meyerschen Prïparate nicht amnïhernd die Deutlichkeit besitzen, welehe die meinen zeigen und daß auch die Vergleichspraiparate, die er nach meiner Itethode hergestellt hat, nicht auf der IÏ̈he der möglichen Vollkommenlıeit standen. Wenn er also schreibt: Beide Methoden tangen jede für sich nicht viel, - so seheint er mir da eine Gleichstellung vorzunehmen, die nicht ganz den Tatsachen entsprechen diurfte. 
einzugehen, wie dies hei Wirbellosen in so anfallemler Weise aneschieht (Fig. 19A, $B$ und $D$ ). Die Anzahl von Fibrillen, welche

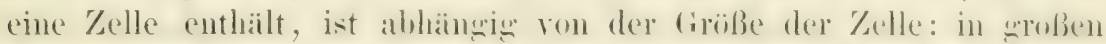
Zellen findet man sehr viele, in kleinen wenige. I)ie Kompliziertheit des Fibrillenverlaufs in der Zelle ist auch \%m Teil ron der Größe del Zellen, damm aber auch yon der Anzahl ihrer Fortsätze abhängign. besonders an Vorderhormzellen tritt dies sehr deutlich zu Tage. Die Vorderhormzellen des Frosehes z. B. besitzen in der Hauptsache eine spindelförnige (iestalt. Die beiden Enden spalten sich in wenige dicke Fortsätze, die sich dann weitel teilen; vom Zellkürper selber gehen aber nur wenige düme Fortsïtze und in der Reurel der Achsenfortsat\% ah. In diesen \%ellen ist der Verlauf der sehr zahlreichen Fibrillen recht cinfach: sie durehziehen in mehreren Bündehn, die sich sehwach verflechten, die Zelle von einem Pol zum andern. Andre Bündel ziehen von den kleinen seieitenfortsïtzen des Zellkörpers und rom Achsenfortsatz in die Pole hinein.

solche in der Hauptsache bipolare Vorderhornzellen kommen anch noch bei säingetieren vor, sind hier aber verhältnismäßiщ selten. Wenm man sie aber zu Gesicht bekommt, so findet man anch hier den Fibrillenverlauf einfach geartet. Die Verflechtungen der einzelnen, durch die Protoplasmafortsätze eintretenden Fibrillenhündel sind zwar stärker answeprägt, aber es gelingrt doch an solchen Zellen noch relativ leicht, nicht nur die Fibrillenbindel, sondern sogar häufig die einzelnen in ilnen enthaltenen Fibrillenindividuen ron einem Fortsatz zum andern zul rerfolgen. So wie die Zellen aber sehr viele Fortsitze haben, die direkt ron Zellkürper entspringen, so bereitet die Verfolgung of «moße Schwieriwkeiten, weil die vielen Bündel stark verflochten sind und häufig. jede Fibrille in den inneren Partien der Zelle ihren einnen Weg einschlïgt. Dicht an der Zelloberfäche verlaufen anch in diesen Zellen die Fibrillen zu Bündeln angeordnet Peripheriefibrillen in fegensatz zu den isolierter verlaufenden Zentralfibrillen, und sind deshalb hier viel leichter zu rerfolgen.

Die Fig. 19 A zeigt eine Vorderhornzelle des Menschen ron mittlerer Komplikation. Man erkent an dieser Figur, wie die in den Fortsätzen parallel verlanfenden Fibrillen sich in der Nähe des zellkïrpers meln und mehr zu einzelnen kleineren bündeh zusanmentum,

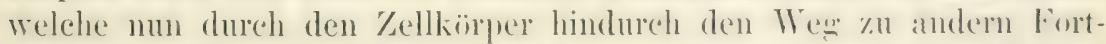

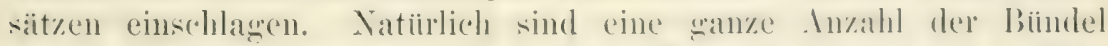

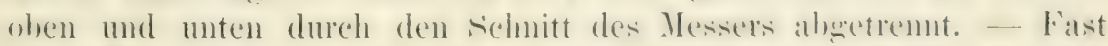
jeder Fortsatz steht mit jedem andern dureh din meln oder weniger

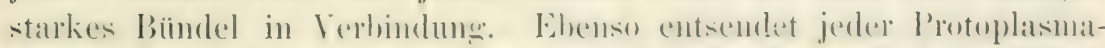

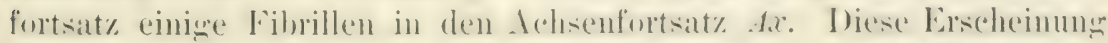
labit sich fast an allen hisher untersuchten \%elltypen anffinden und 


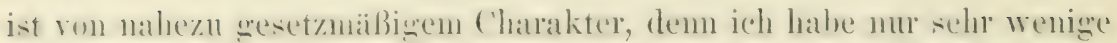
Ansmahnen geselnen, die zum Teil wohl lieine wirklichen . Ausnahnen

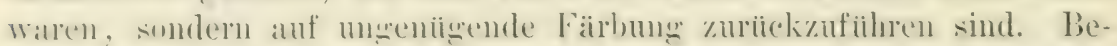
sunders anch bei den P'rannidenzellen der (irobhimrinde, welche mit

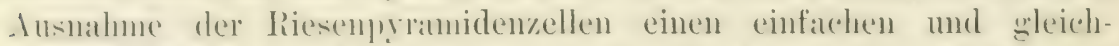
fömigen Findilenterlanf zeigen, ist der Anstansch der Fibrillen oft sehr deutlich zu sehen (Fig. $19 \mathrm{D}$ ).

Su wie die Ilamptprotoplasmafortsitze Fibrillen unteremander ans-

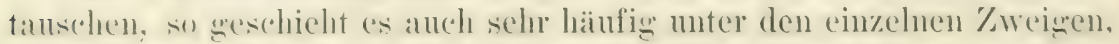
in die sich ein Profoplasmafortsatt\% teilt. Bald wird die Verhondmon durch sanze biundel, bahl nur durch eine cinzige Fibrille heresestellt (Fig. 19 C).

In dieser oder ähnlicher Woise gestaltet sich der Filnillenverlanf bei fast allen fianglienzellen des Zentralnervenststems, wroben und kleinen. Eine vollständige Insuahme hilden nur die spinalganglienzellen. Die Fibrillen des Stammfortsatzes begreben sich in vielen dïnnen IBindehn in den Zellkörper, durchflecthten sich hier in reichster Weise und gehen, wenigstens stellenweise, mzweifelhafte Anastomosen miteinander ein, so dab in Inneren der Zellen ein Filnillengitter zustande kommt, wie wir es hei Wirbellosen kemen selernt haben; wh alle filnillen sich an der (ritterbildumg heteiligen, kam ich allerdings nicht entscheiden. In der stelle, wo sich der stammfortsatz in die periphere Faser und die Faser der hinteren Wurel teilt, verteilen sich die Fibrillen des stammfortsatzes auf beide $\ddot{A}$ ste, wie dies zuerst Lugaro gesehen hat. Direkt von Ast zu Ast verlaufende Fibrillen habe ich hier nie wahrenommen; allerdings war mein benbachtung.smaterial nicht groß.

AnBer in spinalganglienzellen hate ich echte Filnillengitter noch in den \%ellen des Lobus electricus von Torpedo Fin. 20 mit Dentlichkeit wahrgenommen, auch im Basalteil der Ponkinjeschen Zellen und der Zallen des Ammonshorns habe ich Andeutungen von fittern bemerkt. In diesen fällen zieht aber sicherlich der allergrö̈bte 'Teil

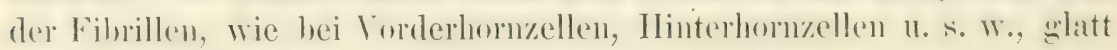
dureh die Zellen hindureh.

Wie ans den Mbildungen ersiedtlich, beeiben imerhall, der Zellkïrper? nud ebenso in den dickeren l'rotoplasmafontsätzen zwischen

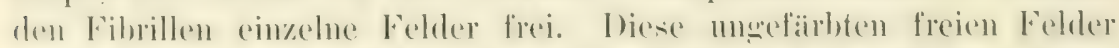

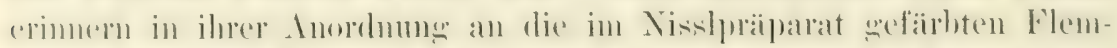

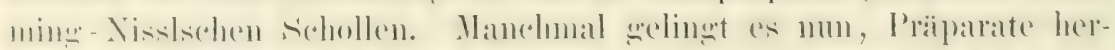

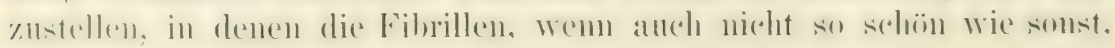

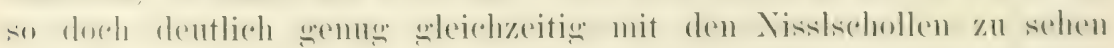
sind (Fig. $19 \mathrm{~B}$ ), und an diesen bestaitigt es sich, daß die Fibrillen

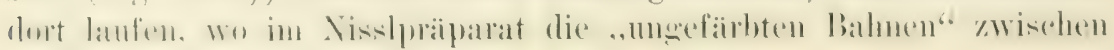




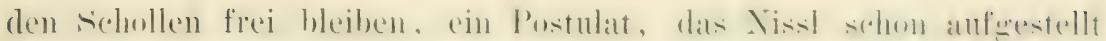

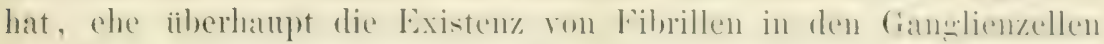
der Wirbeltiere sichergestellt war.

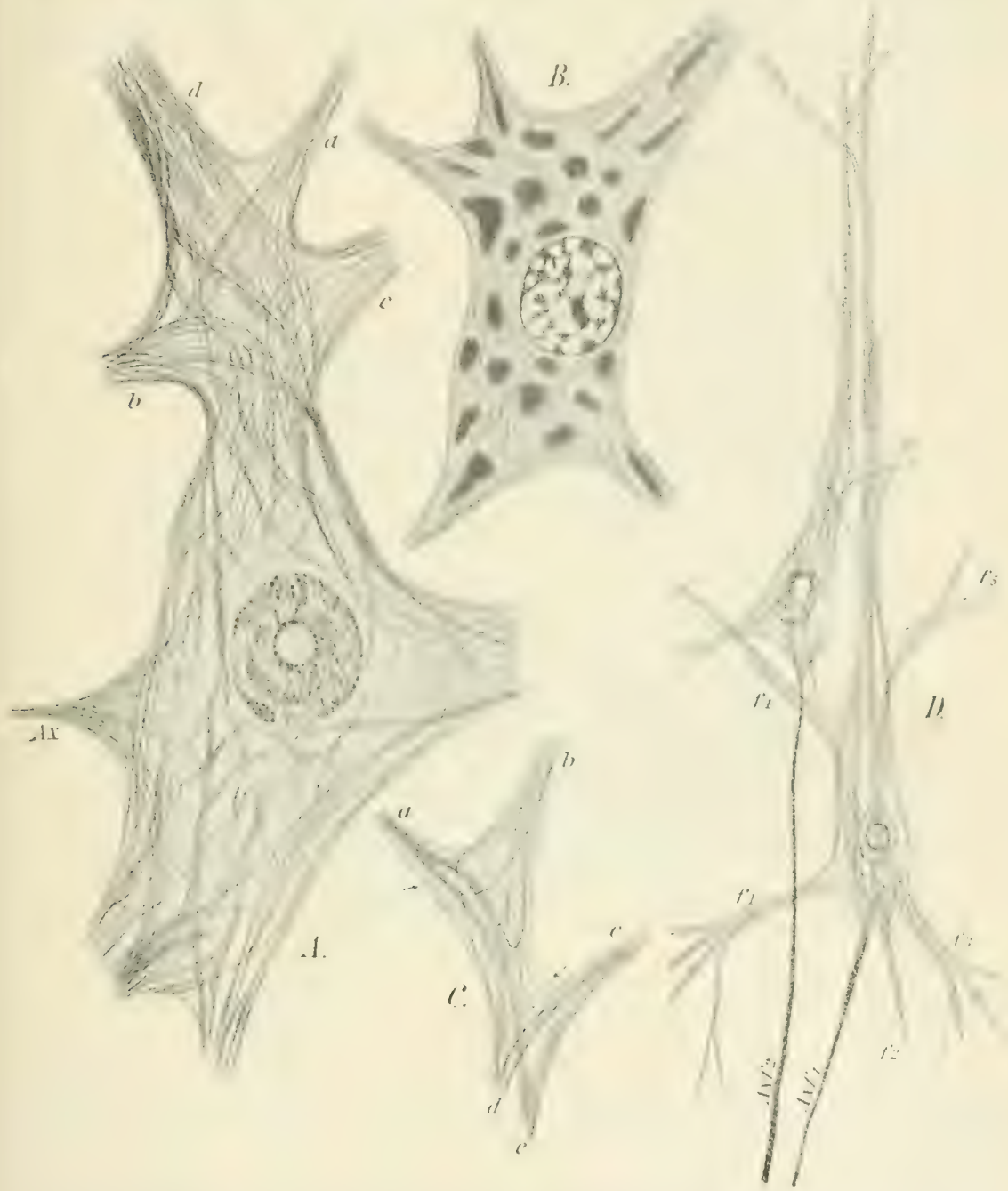

Fig. 19. Ganglienzellen, welche mit der Betheschen Mrolyblänmethode auf Fibrillen gefirbt sind. A Vorderhornzelle vom Menschen, $B$ Zelle aus dem Facialiskern vom Kaninchen mit gleichzeitiger Darstellung der Nisslschollen, $C$ Protoplasmafortsatz einer Vorderhornzelle rom Jenschen, $D$ zwei Pyramidenzellen rom Menschen. (Bethe, 1900.)

Im Anfangsteil des Achsenzylinders - soweit die Zellen iiber-

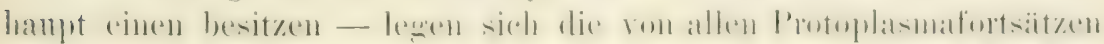

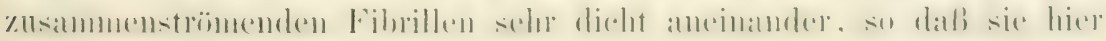
nie gesondert gesehen werden kümnen (Fig. $19 A, D)$. Weiterhin wird 
der Acherenzylinder wieder dicker, und zwat an der stelle, wo er sich

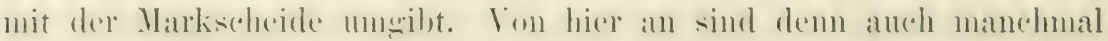
die einzelnen Fibrillen wieder sichtbar: Ob dies Diimerwerden des

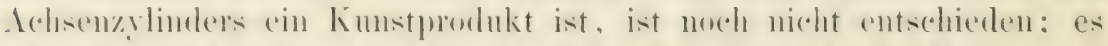

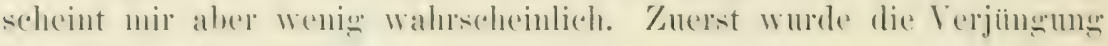
ron Deiters heobachtet.

Wo die Fibrillen des Aehsenzylinders, wenigstens soweit er zur peripheren Faser wird, bleiben, haben wir sehon besprochen. W a s

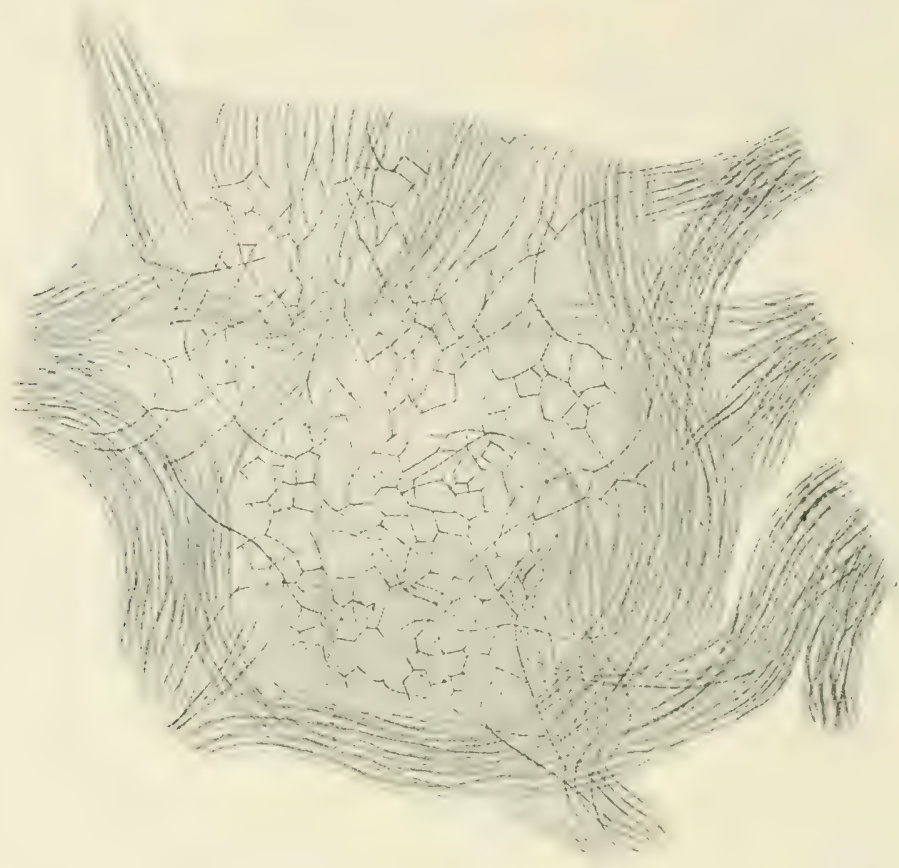

Fig. 20. Zelle aus dem Lobus electricus ron Torpeclo. Molybdänmethode. (Bethe, 1900.)

wird nun aus den Fibrillen der Protoplasmafortsätze und der zentral verlanfenden Achsenzylinder? Woher kommen sie oder wohin gehen sie? Eine direkte Antwort, wie bei den Wirbellosen, geben die Fibrillempräparate rorliaffig anf diese Frage nicht. Die Protoplasmafortsütze teilen sich in feinere Zweige und die Zahla der in ihnen verlanfenden fibrillen nimme immer mehr ab. Schließlich enden die Zweige ziemlich unrermittelt mit einer Spitze, bis zu der man die letzten Fibrillen verfolgen kam,

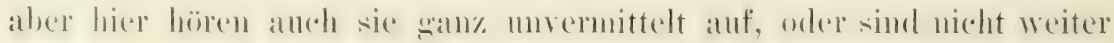
gefärlot. 
Die Beziehungen zwischen Nerrenfasern und Ganglienzellen und die pericellulären Gitter (Golginetze).

Die anfängliche Idee Golgis, daß die Protoplasmafortsätze mu

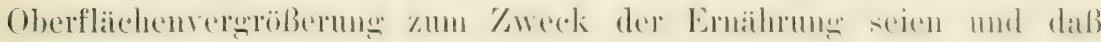

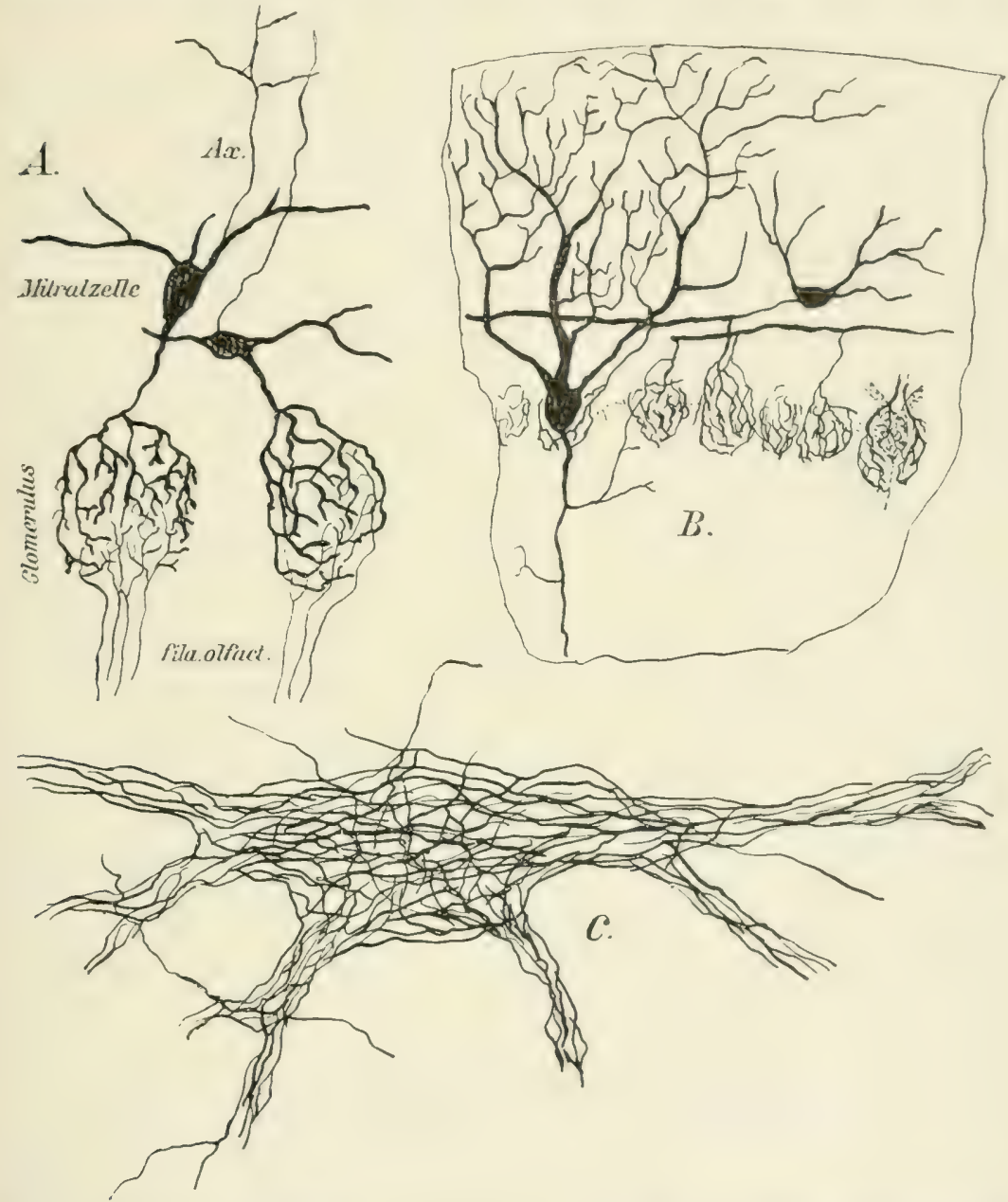

Fig. 21. A Sehematische Darstellung der Verbindung zwischen den P'rotoplasmafortsaitzen der Mitralzellen und der Achsenzylinder der Riechepithelzellen in den Glomertli olfactorii (zum Teil nach r. Kölliker). $B$ Schematischer Schnitt durch die Kleinhirnrinde (\%um Teil nach Edinger), $C$ Achsenzylinderhose um eine Ganglienzelle (unter zu Grundelegung einer Figur von Veratti).

nur den Achsenfortsätyen nervïse Natur zukïme, hat von vornherein wenige Anhänger gefunden und scheint ron ihm selber im Lanfe der Jahre aufgegeben $z u$ sein. Sie hat gegenuiber den sehwerwiegenden

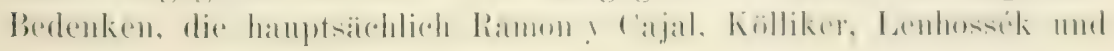




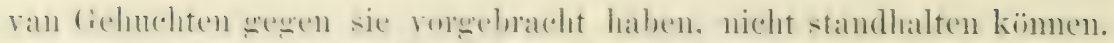

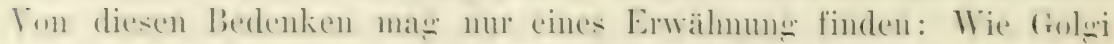

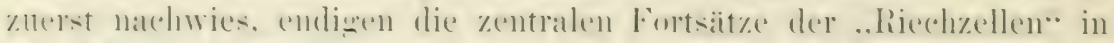

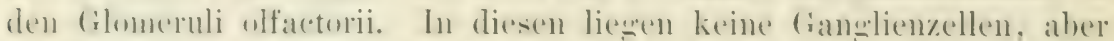
die I'rotoplasmafortsit\%e der Mitral\%ellen rer\%wejenen sich in reichlicher

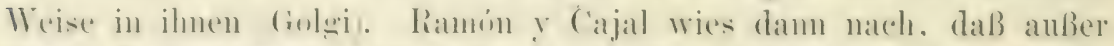
diesen Protoplasmafortsätzen keine nexvësen fiehilde nit den ..Riechnerenfasern” in Verbindump treten, so dab also die Weiterleitumen des Reves motwendigerweise durch die I'rotoplasmatortsätze greschehen

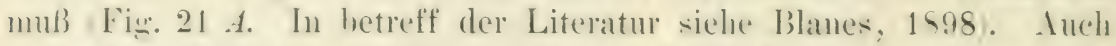
in andern orten. \%. Is, im molekularen Teil des Ammonshorms und

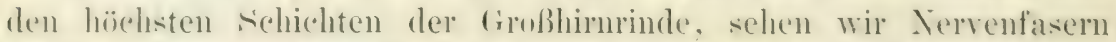
Aemriten sich in Gehieten aufsplittern, wo sall keine (ianghienzellen liegen. so dals sie also nicht in der von Golgi anfangs angenommenen

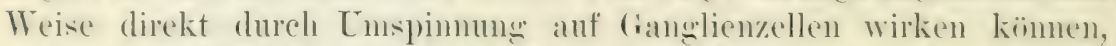
sumdern nur auf dem Trege der Protoplasmafortsätze fhöchstens noch durch Vermittlum andrer Temiten. Die nervöse, reizleitende Natur der Protoplasmafortsätze wird also kaum zu bezreifeln sein.

Daß die Endarborisatiomen der Verrenfasern spezielle Bezichmengen zu den K ̈̈rpern der Ganglienzellen eingelsen, ist nur von wenigen Orten des \%entralorgans hekannt. In allgemeinen lesen sie sich den Protoplasmafortsïzen in gleichem Maße an, wie den Zellkïpern sellst, inden die Faserzweige entweder senkrecht der Oherfliiche zustreben uder dine strecke weit der (Dherfläiche des Zellkürpers uder der I'otoplasinafortsäte, parallel laufen, sich dabei noch weiter teilend. Da die Zahl solcher begleitender fremder Id lsenzylinderäste in der Firsel recht hetrichtich ist, so erscheinen die Zellkiirper und die Fortsitze meichsam in einer ... lchsen\%linderhose" drinsteckend. ${ }^{1}$ Diese Hosen sind nit vielen Methoden inamatoxylinlacke. Molyboünmethode 11. .. w., leicht zu sehen, mit Hilfe der Golwischen Methode sind sie

1) Ob diese Nervenfasern noch den Namen Achsenzylinder verdienen, d. h. ob sie noch eine Markscheide besitzen, ist zweifelhaft. Manchmal wird es der Fall sein, manchmal nicht. Man sollte also einen indifferenten Ausdruck wählen, im Grunde ist die Frage aber ohne Belang. Ich erwihne dies, weil Nissl in seinem Buch (1903) sagt, wir kennten das Schicksal der freien Fasern nach dem Virdust der Markishede nicht, weil mit den spezifischen Achsenzylindermethoden

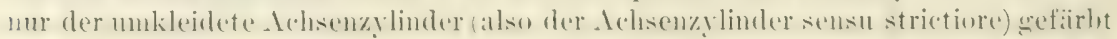
wiirde. - Ich erkenne rollkommen an, daß die Kaplanschen und Beckerschen Achsenzylinderfïrbungen sehr interessant und praktisch wertvoll sind, es ist aber klar, daß eine wirkliche Achsenzylinderfïrbung an Bedentung kaum ïber eine Markscheidenfärbung hinausgehen kamn. Daß die nakte Nervenfaser irgend welche besonderen Stoffe enthalten sollte, welche den Ganglienzellen und

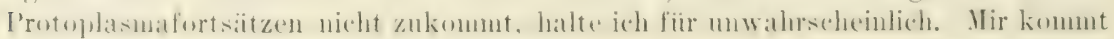
es daher zunïchst verfehlt vor, iberhaupt nach einer spezifischen Methode zur 


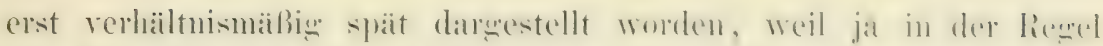

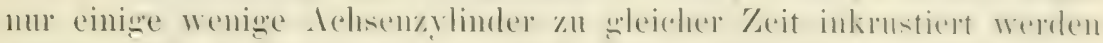

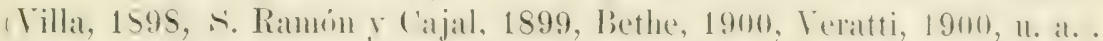
(Fig. $21 C$ ). Am deutlichsten, weil am dichtesten, sind die Achsenzylinderhosen an den lorderhomzellen des Ritckemmalis, in l'atcialiskem, in Deitersschen Kem, in den (biven mod in Nuclens dentatus.

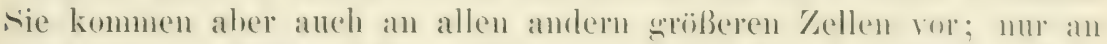
şanz kleinen Zellen (kleine Hinterhornzellen, kleinere Rindenzellen, habe ich sie bis jetzt vermißt.

Eine Bevorzugung des Zellkörpers derart, daß er allein oder in der Ilamptsache ron Tervenfasern eingeschlossen wird, tritt nur an weniwen stellen hervor. Im hekanntesten und auffallendsten ist hier jedenfalls die Alt und Wreise, mit der die dicken Nervenfasem des 'Trapezkïpers allein den Zellkärper becherförmig nit ilıen Ästen ungreifen Held, Källiker, Semi Meyer, Cajal, Vincenzi). Es ist viel ïber dieses ganz vereinzelt dastehende Vorkommmis gestritten worden mud noch in letzter Zeit hat Veratti 1900 , versucht, die Faser als den eignen dehsenfortsatz der Trapezzellen mol den Endkelch als eine Hiille derselben himzustellen. Trotz des sohönen bewoismaterials, das Teratti rorbringt, kam ich mich doch nach meinen eignen Entersuchungen, die ihm bei der Abfassmng seiner Irbeit noch nicht bekannt waren (Bethe, 1900), seiner Ansicht nicht anschließen. Es handelt sich wohl doch 1 wirkliche fremde Nervenfasern, die hier sanz besondere und noch nicht sentigend anfweklärte Bezichmugn eingehen. Teben diesem einen dicken Ichsenzylinder, der sich mit seinen Verzweigungen fast nur auf den Zellkärper beschräinkt, existieren aber anch bei den Trapezzellen richtige Lchsenzylinderhosen, welche Zellkärper und Protoplasmafortsätze in whicher Weise moneben Bethe, Veratti: Nach Nissl, 1903, handelt es sich in den dicken

Färbung der Neuriten zu suchen. Das, was der Neurit überall enthält, sind die Neurofibrillen und die kommen in gleicher Weise auch in den Zellen und Protoplasmafortsïtzen vor. Eine wirkliche Neuritenmethode (Nervenfaserfürbung) wird also voraussichtlich immer auch die Fibrillen in den Ganglienzellen und Dendriten mitfärben, wie dies bei der schönen Methode Bielschowskys der Fall ist, sie wird also keine spezifisehe Achsenzylindermethode sein. - Daß wir num aber doch ïber das Schicksal der marklos gewordenen Neuriten einiges wissen, scheint mir kaum bezweifelt werden zu können; weil sieher viele von den feinen Fasern, die wir mit der Methylenblau- und Golgischen Methode und noch vielen andern Verfahren sehen, Nervenfasern (Neuriten) ohne Markscheide sind; daß dabei manche Verwechslung mit dïnnen Protoplasmafortsätzen rorkommen kann, ist störend, macht aber doch die Erkenntnis der Verhältnisse nicht unmögrich. Im Grunde scheint es mir ganz gleichgiltig zu sein, ob eine Nervenfaser eine Markscheide hat oder nicht, wenn ich sie nur verfolgen kamn; da\} aber bei weitem die meisten fiir Neuriten gehaltenen lasern atuch solche sind, haite ich trotz aller Skepsis fiir gesichert. 
Ardsenzylindern vielledeht nicht welche hier enden, sondern $u m$ das eine Ende intrazentraler Achsen-

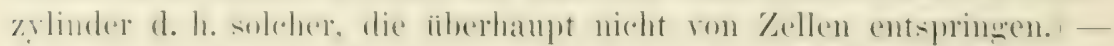

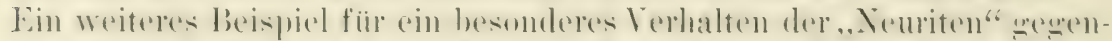

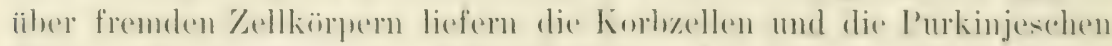

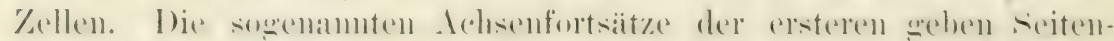

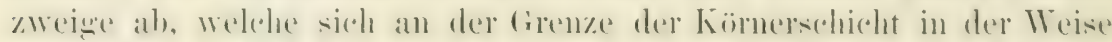

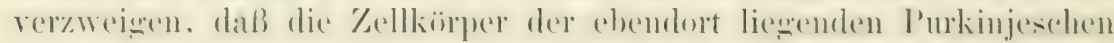

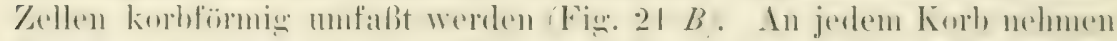

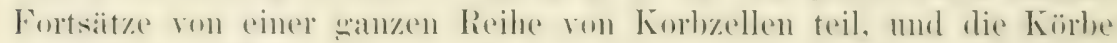
benachbarter Zellen gehen oft ineinander iiber (Cajal u. a.). Nach Käbliker sollen die korbhildenden Fisiserehen frei enden. Wir werden weiter unten sehen, daß dies wohl sicher nicht der Fall ist. Hier soll nur noch bemerkt werden, daß die Anhäufung ron Nervenfaserzweigen in diesen Körben wohl schwerlich nur den \%ellen zuliebe geschieht, demn nur die innerste Lage des aus vielen Faserschichten bestehenden korbes liegt der Zelle an: die andern kömnen sich mehr als eine Zellbreite von der Zelloberfläche entfermen. - Itermit ist die Zahl der Fälle, in denen in den Zentrabromen besondere bokale beziehungen zwischen Zellkärpern und Achsenzylindern resp. Xeuriten hestehen, ersehöplt. Jedenfalls gentïgen sie nicht, Im dem Zellkïrper

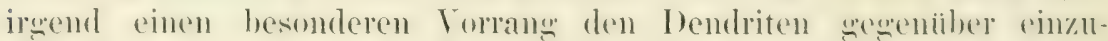
rä̈menen, dem der Fall des Trapezkerns liegt noch nicht wanz klar und in den F'aserkörben steht die P'urkinjesche Zelle nicht mit mehr Nenritenzweigen in Berïhrung, als irgend eine andre Zelle in ihrer Hose.

Bevor die Nervenfaserhosen als allgemein vertheitete Einrichtum crkannt waren, sollten die ,Endbäunchen" der Nenriten hauptsä̈chlich die Zellkïrper ungehen, ohne daß dies eigentlich in answiebigere Weise beobachtet worden wäre. Die einzehen Zweigehen sollten balal mit sipitzchen, bald mit kinöpfohen endigen. sieitdem num in den letzten Jahren meeigt int, wie nicht nur die Zelleiber, sondern anch die Dendriten his an die spitzen san\% in Xervenfasem ${ }^{1}$, die sich noch weiter an ihnen verweigen, eingehiillt simb, ist die Frage, in welcher Weise verschiedene Ganglienzellwebiete miteinander in Verbindung treten, in eine wene Phase setreten, und die Behauptung der achtziger mol nemziger Jahre des rorigen Jahrhunderts, es existiere überall nur Kontisuitait, mulite zum mindesten einer nemen l'rüfung unterworfen werden. Es mußte von neuem untersucht werden, ob diese Fasern nur die

1) d. h. nervöse Fasern, die sicher keine Dendriten sind und zum größeren T'eil als Neuriten und Nemritenzweige fremder Ganglienzellen angesehen werden diurfen. Lin mehr oder weniger großer T'eil dieser Fasem mag ïberhaupt mit keiner Ganglienzelle in direktem Zusammenhang stehen. Daf3 es solehe Fisem greben muß, hat Nissl (1903) indirekt bewiesen! 


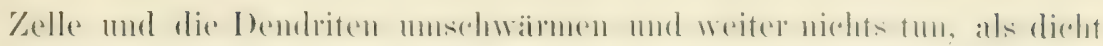
an ihrer Oberfläiche dahinziehen, oder ob sie vielleicht doch mit dem, was sie einschließen, irgend welche näheren Beziehungen eingehen. Andrerseits wurde von nenem die Frage aktuell, ob nicht hier, wo Neuritenzweigchen sich so nahetreten, Anastomosen zwischen versehiedenen Fasern vorhanden sind, wie sie Golgi von Anfang an angenommen hat. An einigen Stellen, besonders in den Faserkörben am Grunde der Purkinjeschen Zellen, ist ein solehes Anastomosieren vel-

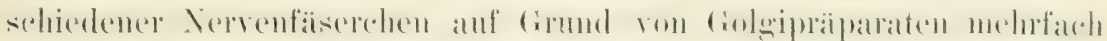

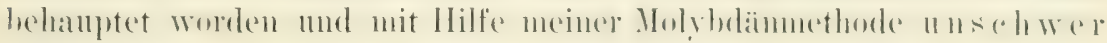
sichel\%ustellen. An den meisten andern Orten ist nach meiner Anf-

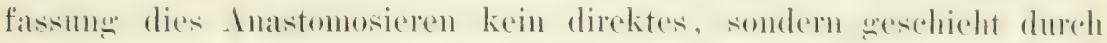

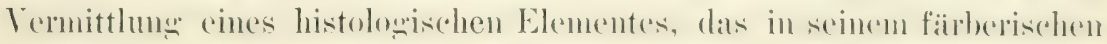
Verhalten ron dem der Nervenfasern abweicht. Es wird repräsentiert

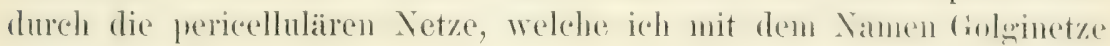
belegt habe.

Zuerst wurden diese Netze von Golgi gesehen, aber nur beiläufig erwähnt. Spaiter (1898) hat er sie an der Hand ron Pråparaten, die

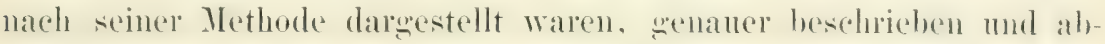
gebildet. Es sind Netze mit polygonalen Maschen, welche sich über

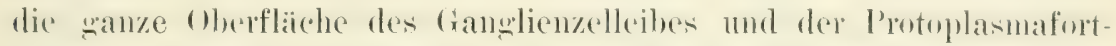
sätze ansbreiten. Sie legen sich der Oberfläche ganz dicht an und hitllen so die ganze Zelle in einen enganliegenden Mantel. Wegen einel gewissen, wenn anch ziemlich entfernten Ïhnlichkeit mit den Netzen, die das Keratingeriist der Markscheiden ansmachen, hicht

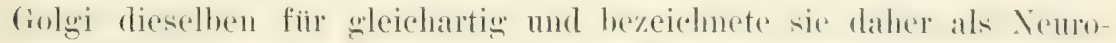

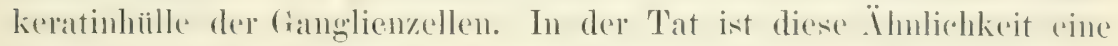

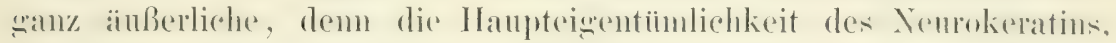
die Unverdanlichkeit, besitzen diese Netze nicht, wie man sich leicht an Verdaumgspräparaten iiberzengen kam.

Der erste, der einen Zusammenhang dieser Netze mit Nervenfasern (Newiten, nackten Achsenzylindern) annahm, war Semi Neyer (1897). Er beobachtete mit Hilfe der Methylenblaumethode an rerschiedenen Stellen des Zentralorgans, daß diime ,Achsenzyliuder" seitlich, häufiger aber an der Spitze der I'rotoplasmafortsaitze an das mmgebende Netz herantraten und anseheinend mit demselben verschmolzen. Er zog hieraus den SchluB, daß die pericellulären Netze Endausbreitungen von Achsenzylindern seien und daß dureh sie ein sehr imniger Kontakt zwischen Achsenzylindern und /ellkörpern hergestellt wiurde; es handle sich aber nur um Kontakt, dem die Grenze zwischen Netz und r/cllsubstanz sei durchans scharf.

Ku\% darauf erschien eine inhaltsreiche Arbeit von Held (1897). in weleher gleichfalls die Netze als Achsenzylinderanshreitumgen anBethe, Norvensystem. 


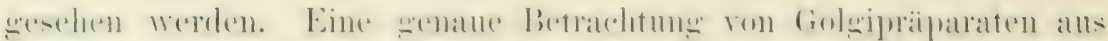

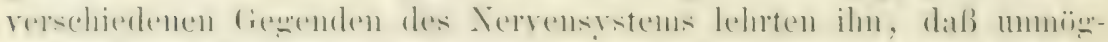

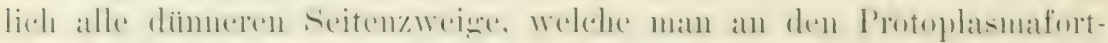

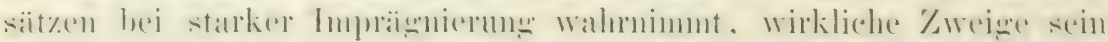

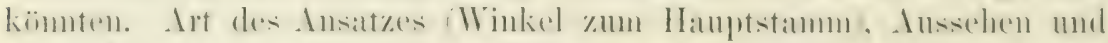

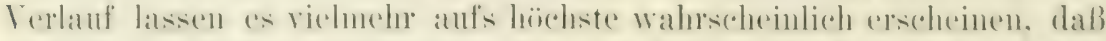

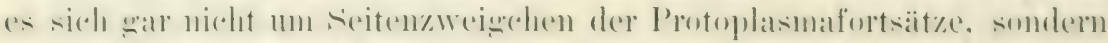

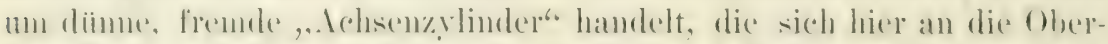

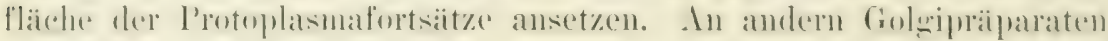
gelang es ihm nun, die Golginetze darzustellen und zu sehen, daß

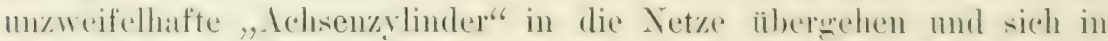

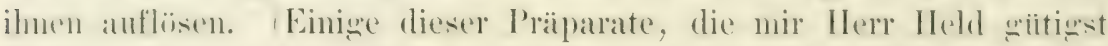

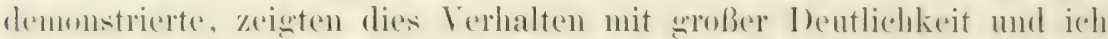

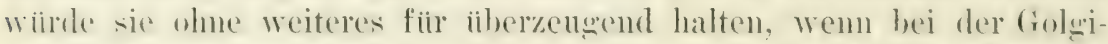
schen Methode nicht immer die Gefahr vorhanden wäre, daßs Dingere. dir benarbhart sind, miteinander rerklehen, ohne in Wirklichkeit in Zns:mmnenhang zu stehen.) Bei Anwendume einer besonderen Methode

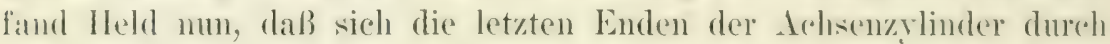
eine besondere Art von Granulationen auszeichnen, welche er als

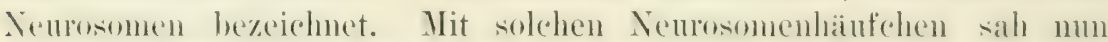

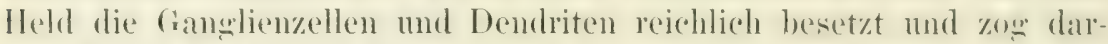

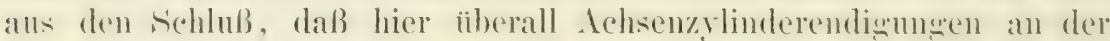
Oherfläche des Zellkörpers vorlägen. Da aber eine scharfe Grenze zwischen Nemosomenhäuf(ehen und Zellplasma sich nicht zeiste, so folgerte er, dak es sich nicht $10 \mathrm{~m}$ eine bloke Beriihrung durch die Achsemzylinder handle, sondern mm eine Konkreszenz, mm Kontinnitït.

In ähulicher Weise sprach sich auch Nissl is st, nach Besichtigman von mir angefertigter Praparate) fiir einen Zusammenhang von Golunet\% mol fremden Nervenfasern aus. Noch ehe ich selher mich zu der Frage geäuBert und meine Befunde beschrieben latte, gab ('ajal 1595) eine Kritik der Golginetze, in der er, sich speziell gegen Nissl und mich wendend und gestiitzt auf Methyelenblaupräparate, die Netze für einc periphere Verdichtung eines allgeneinen, die ganze Zelle durehsetzenden protoplasmatischen Netzes erklärte und vor der nenen Lehre als reaktionail warnte. Eine ähnliche duffassung der folswinetze wurle anf Grund eigner Untersuchungen von Donaggio geäußert.

Es ist wohl kaum zu bestreiten, daß bei dem Golgischen Imprïgnationserfahen Verklebungen zwischen Elementen rorkommen, die direkt nichts mitemander zu tum haben. Wie oft sic vorkmmmen mul bei welohen (xelegenheiten sie zur beobachtnng von nichtexistie renden Yusammenhängen Veranlassmeg geben, dariber kimn die Ne-

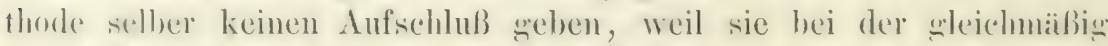

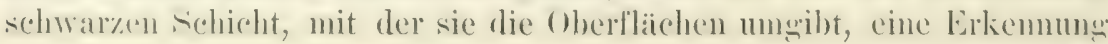




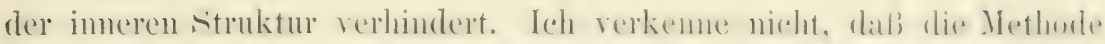

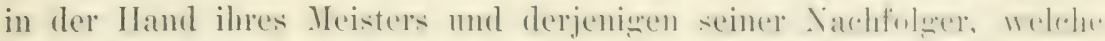
sie nicht kritiklos und nur zu dem Zweek, mit leichter Mïlıe eine erobe Anzahl rom l'ublikationen in die Wrelt zu setzen, anwandten. die Kemutnis vom han des Nervemsystems wesentlich wefordert hat. aber es darf nicht rerlanget werelen, dalf man alles das, was sie might. als Eamelimm himminnt und \%weifel unterdrickt, die herechtint sind.

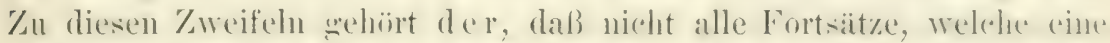

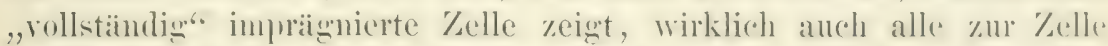
selber rehoren. AuBer der Methylenblaumethede, die in der lland von Dosiel und Ramón y Cajal auch in Zentrahnervensystem so schoinu Resultate gezeitigt hat, besitzen wir moch andre Methoden, welolse hei starker Vereroberung anch die feinsten Fäserehen erkemnen lasion, die alte Kamminmethode, dam die Heidenlainsche Färbmen, meine MoIybdämmethode mud andre. Alle diese Methoden lassen auch von der immeren struktur der Fasern erkemnen. Die letztgenannten heben nicht einzelne wenige Elenente in der Färbmğ hervor, sumbern stellen alles dar, was rorhanden ist. Infolgedessen verlangen sie dumnere solnitte mud es springt nicht das, was an ihnen wesehen werden kam. sufult in die Angen, sondern es bedarf des cingehenden studiuns, aber \% sehen ist in ihnen mehr oler weniger alles, was uberhanpt vorhanden ist. Was nun in solchen Präparaten vor allem gegenüber , roll-

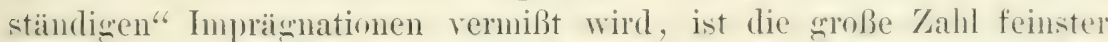
reitenzweige an den I'rotoplasmafortsitzen. Die Inendriten del l'urkinjeschen Zellen nehme ich hierrom ans. Gewil, sie sind anch hier reichlirh greteilt, aber die Teiläste sind stark und die einzelnen Tuilungen liegen weit auseinander, so wie dies sehr häufig auch an

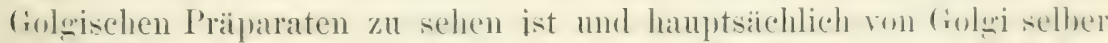

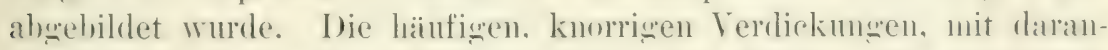
sitzenden viel diuneren Geitenzweigen, die fehlen. Bei mzweifel-

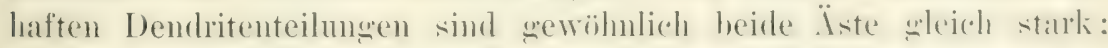
ist der eine dümner, so erleidet der Hauptast doch immer eine $\mathrm{Ab}$ -

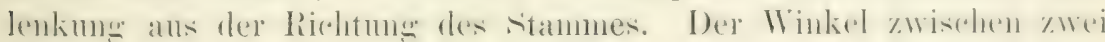

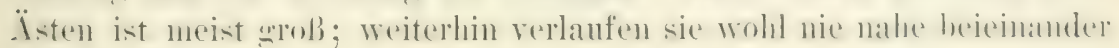
und parallel.

Wenn man nun darauf hin Golgipräparate und die vielen in der

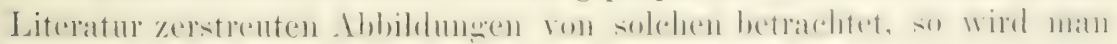
sehr häufig Fälle finden, in denen eine Anzahl von dendritischen Seitenästen sich dem nicht fügen. (Als Beispiele ans der leicht zu. Fig. 539 1. 737 von Kölliker, 1896, an.) Nienals geht ein wirklicher Seitemast eines Protoplasmafortsatzes in del Wreise vom Mauptsamm

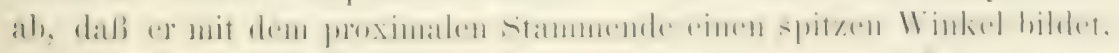


anstatt einen stumpfen. Hber anch solche, "Seitenäste" sieht man nicht selten in Golgipriparaten an den Dendriten und sie sind auch

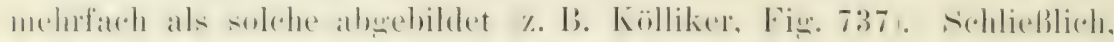

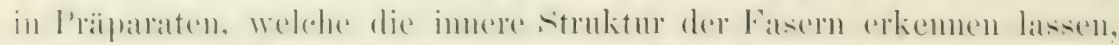

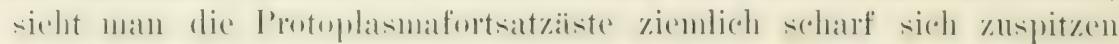
und enden. In Golgipriparaten setzt sich aber dem Anschein nach

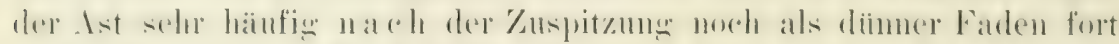
(ะ. B. Golgi, 1894, 'Tafel 6, Fig. 3).

Nach diesen Beobachtungen bin ich wie Held (1897) zu der Ansicht wolangt. dab an solchen stellen Elemente, die direkt nicht zum

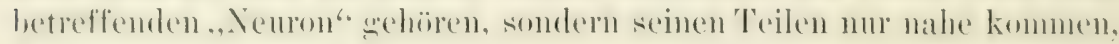
durch den schwarzen Überzug mit ihm verklebt sind. Es ist mun zu (mitscheiden, welcher Irt diese fremelen Elenente sind, die mit den P'ofoplasmafortsitzon resp. dem Zellköryer verklebt zur l)arstellum

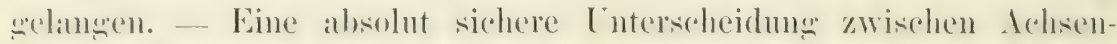
mblindern und Dendriten läßt die Golgische Methode nieht zu auch hei anderm Methoden ist sie oft schmel und manchmal ummömlichi. Ansgehend ron solchen Zellarten, bei denen ein Zweifel dariber, was Achsenfortsatz und was Dendrit ist, nicht existiert (Vorderhomzellen, Pyramidenzellen, l'urkinjesche Zellen), hat man wefunden, daß die Dendriten in der Regel dicker, höckeriger und weniger zylindriseh sind als die Achsenfortsitze. Auch der Modus der Ver-

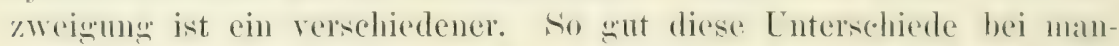
rhen rollarten answebildet sind, so läßt sich doch in andem Fällen (ine sichere Entscheidung nicht treffen. Infolgedessen herscht hei rinigen Zellarten inmer noch Lnklarheit, weleher Fortsat\% als Achsenfortsatz anzusprechen ist. Ja bei manchen \%ellen, \%. I). bei den liorts-

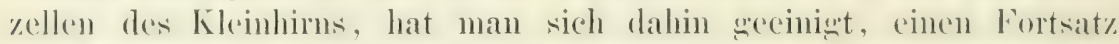

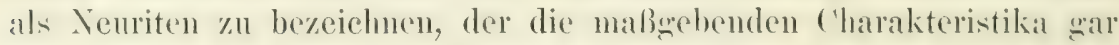
nicht besityt. (Er ist hier dicht an der Kelle diinn, schwillt damn aber zur einer Dicke an, die kein Dendrit dieser \%ellen arreicht und zeigt anch nicht selten im Verlauf knorrige Verdickungen.) So wie es sich $11 \mathrm{~m}$ kur\% abgeschnittene Fäden handelt, die also nicht auf weitere Strecken geprift werden können, ist eine Unterscheidung

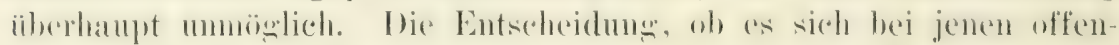
bar fremden, den l'notoplasmafortsaitzen anhaftenden Elementen 1 m

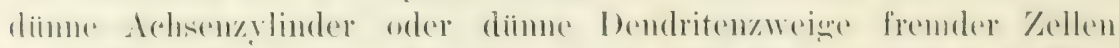

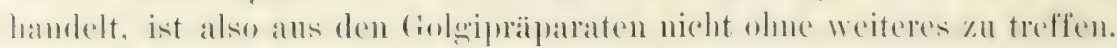
Sich meiner Ansicht kommt beides vor, so daß ich die schon erwähnte Ansicht Helds, es handle sich $u$ fremde Achsenzylinder, nicht in ihrer ganzen Iusdehmung unterschreiben kamn.

Ein seitliches Ansitzen von diunen Achsenzylindern an Proto-

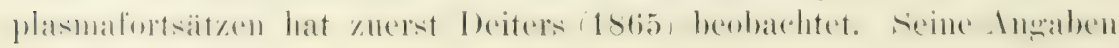




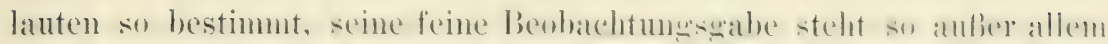

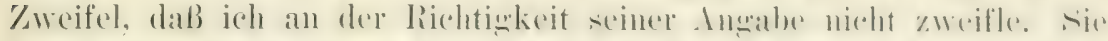

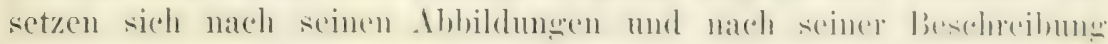
stets mit einem Fißßehen an den Dendriten, der keine Ïnderung in

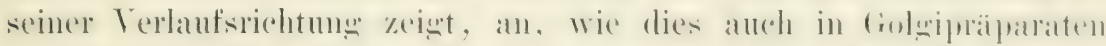
zor sehen ist. Von dïmen Iendritenzweigen waren diese Fäblelen in

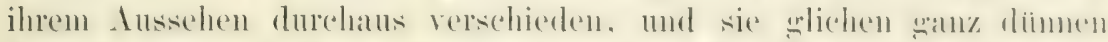

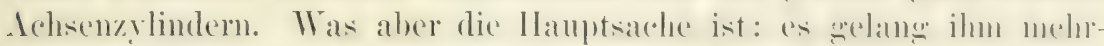

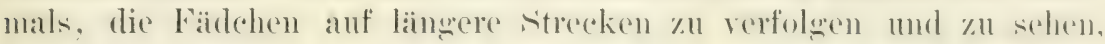
daß sie sich nach einer gewissen Strecke mit einem diumen Markmantel nmgaben.

In weleher Wreise Nervenfaserveriastelungen an Zellen mud I)endriten seitlich herantreten, ist mehrfach mit Hilfe der folenischen Methode,

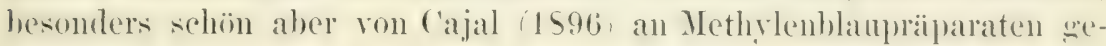

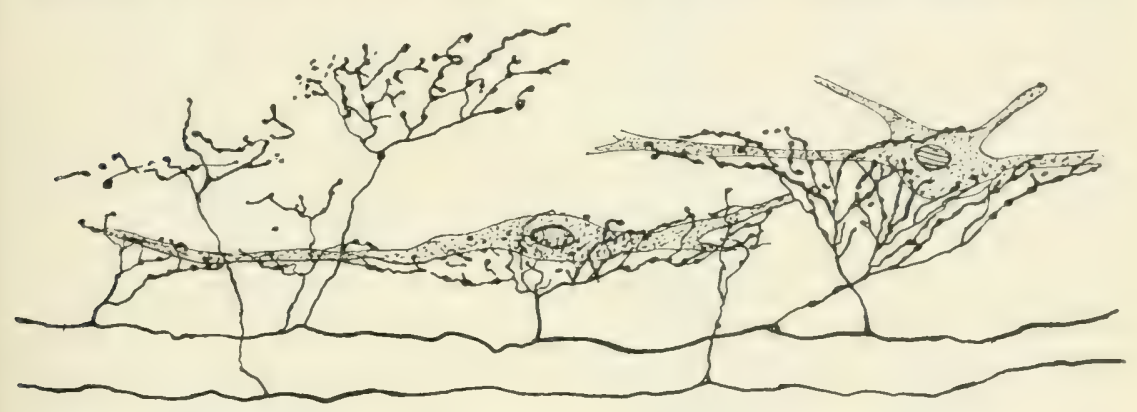

Fig. 22. Hinterstrangsfasern, welche Kollateralen zu Zellen der Substancia gelatinosa senden nach Ramón y Cajal (1896, S. 166, Methylenblaupräparat).

zeigt worden (Fig. 22). Denkt man sich die Zellen und den einen oder den anden Fasemweig auf kurze strecken zusammen inkmsticlt. so erhält man das Bild, das so häufien in folwipräparaten zu selsen ist. I)aß hier die Nervenfaserenden zu den Zellk̈̈rpern und Iendriten in imnige Bezielumeren treten, lient anf der Hand. Es bleibt zu untersuchen, wie weit diese Beziehmugen gehen.

Ich komme auf die Golginetze zuritek: An meinen Molybdän-

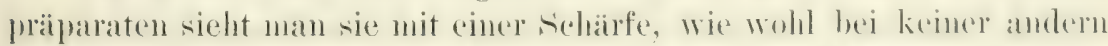

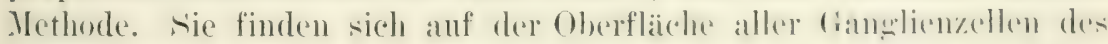

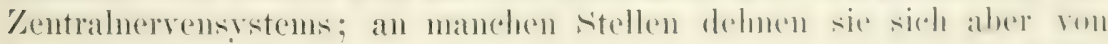
hier aus dureh die ganze grane Substan\% meln oder weniger diffus aus, so in der Großhimrinde, im Kleinhirn, im Ammonshorn und in der Substantia gelatinosa. An den ïbrigen Orten, also besonders in den motorischen Kemen, im Nuclens dentatus, den Oliven u.s. W. bleiben sie zwar anf die Zelloberfliche beschränkt, wo sich aber zwei

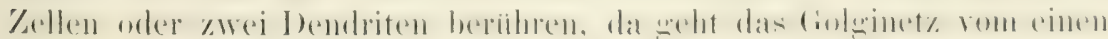


anfs andre uber (Fig. 23 A). Diese Netzhose umkleidet die ganze

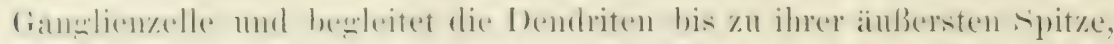

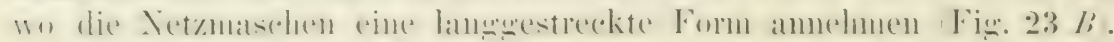

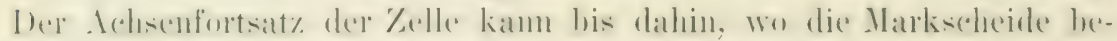

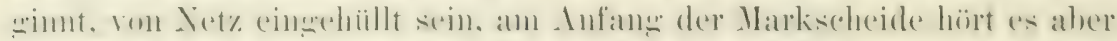

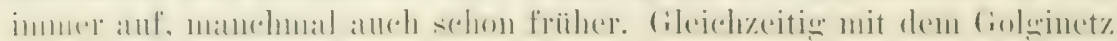

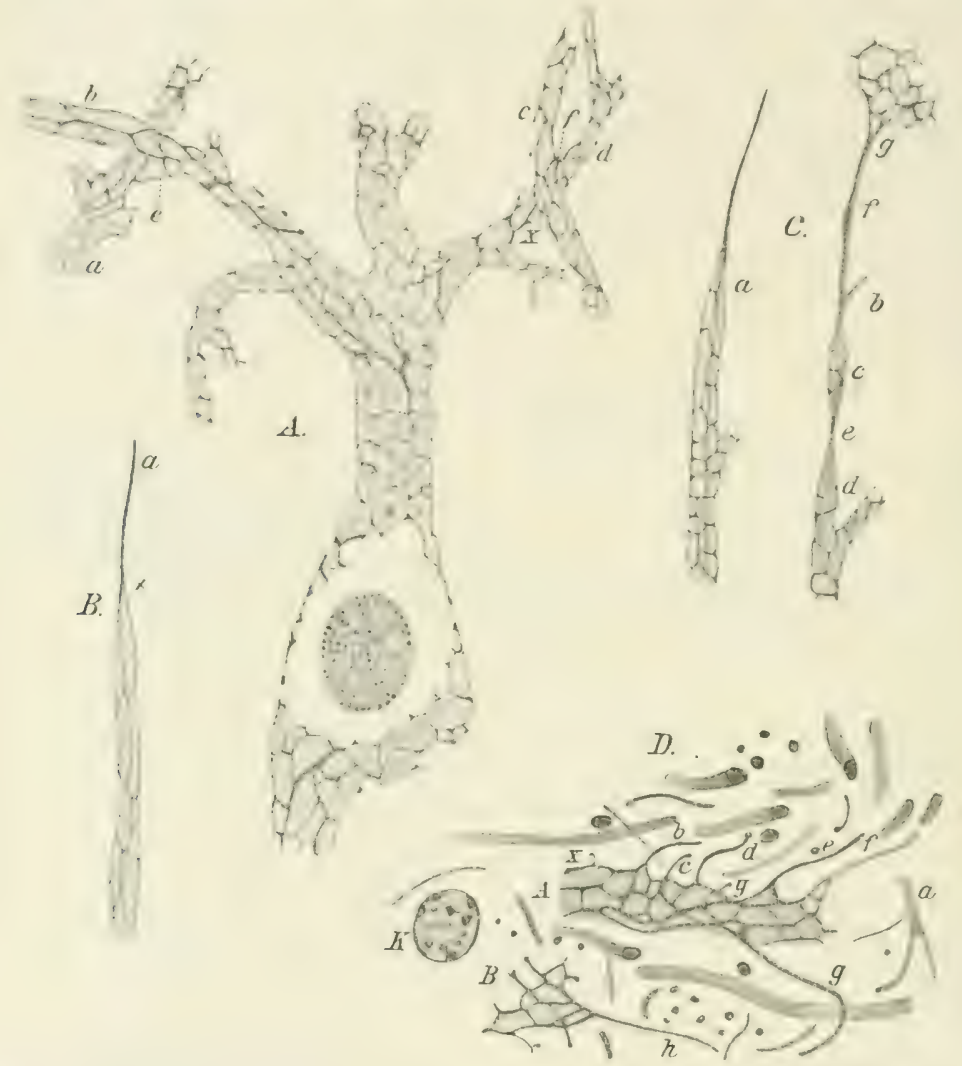

Fig. 23. Golginetze gefïrbt nach der Molybdainmethode. 1 un eine Zelle des Nucleus dentatus rom Ifund, $B$ um das Fnde eines Protoplasmafortsatzes im Olivenkern, $C$ bei $a$ scheinbarer Überfang einer Nervenfaser in das Golginetz eines dinnen Protoplasmafortsatzes. Bei $b$ witirde das gleiche Verhalten vorgetïuseht, wemn nicht der gefürbte Faden $f$ in das Golginetz einer andern $Z$ elle iiberrninge. Der dünne Protoplasmafortsatz ist stellenweise so geschrumpft, daß das Golginetz nicht erkennhar ist. $D$ Übergang von diinnen Nervenfasern in das Golginetz eines Protoplasmafortsatzes. Nach Bethe (1900).

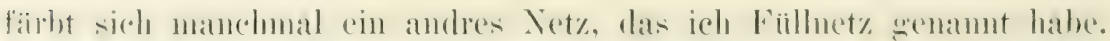
lis kanm meist leicht vom Golginety untersehieden werden und zeight ein

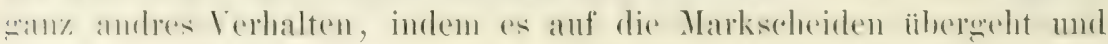
nicht, wie das Golginet\%, auf die grane Substanz beschrinkt ist.

Daß es sich in den Golginetzen um eine spezifische Bildung

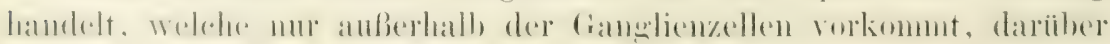


kann nach meiner Meinung gar kein Zweifel bestehen. Der Ansicht Cajals, daß sie immerhalb des Zellplasmas lïgen und nur eine Ver-

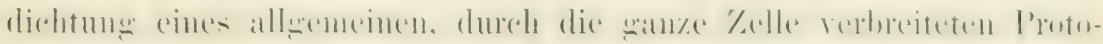

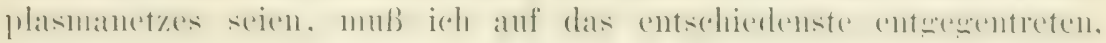
dem auf meinen Präparaten habe ich auch nie die geringste Spur

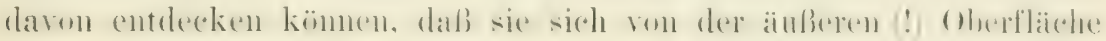
in das Innere der Zellen hinein erstreckten. Mit wleicher Bestimmt-

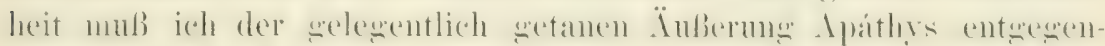

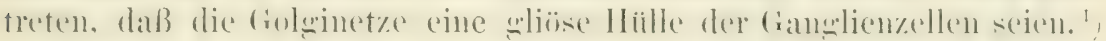
Vorläufig sehe ich auch nicht den mindesten Beweis dafür. Weder zu den Giliakernen node zu den diliafisern oder dem Protoplasma der Gliazellen \%eigen sie irgend welehe Bezichnngen. Ihr wanzes Verhalten

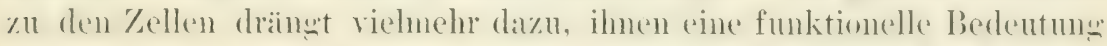

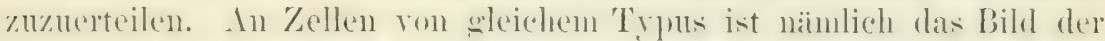
(inlginetze cin durchans gleidhartiges: datgenen ergehen sich zwischen den versohiedenen Zelltypen wesentliche Lnterschiede, die zum Teil so groß sind, daß man aus einem kleinen Stiick Golginetz sehen kann, was für einer Zelle es angehört. So ist das Netz der Zellen des Nucleus dentatus viel großmaschiger, als das ron Vorderhornzellen; an den Zellen des Ammonshorns sind die Maschen eckiger, als an andem Orten: die Olivenzellen sind mit einem denprelten Net\%

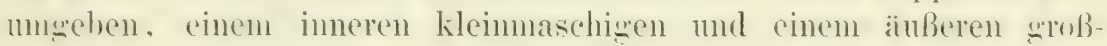
maschigen. welche dureh radiäre stähehen miteinander kommunizieren 11. s. w. Ich kann mir diese Erscheinungen weder im Simne Cajals, noch in dem Apátlyys deuten.

In der Regel ist die Färbung des Golginetzes am schönsten, wenn die Fibrillen und die Nervenfasern gar keine Farbe mehr an-

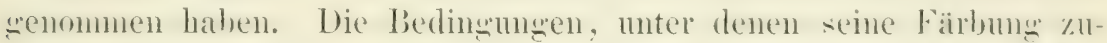
stande kommt, sind eben andre, woraus ich den Schluß ziehe, daß die Substanz des Netzes von der der Fibrillen und Nervenfasern rerschieden ist. So angenehn diese Eigensehaft ist, mu die Jetze selher genau zu studieren, so unangenehm ist sie, um ihre Beziehungen zu

1) In einer kürzlich ersehienenen Arbeit (1902) hat Held seine Meinung dahin verïindert, dafs das Golginetz mit den Neurosomenhaufen nichts zu tum häitte und ein gliöses Gitter sei. Er wirft es mit meinem Fiillgitter zusammen, besonders auf Grund gewisser linge an den marklaltigen lisern, die mir iibrigens lïngst bekamnt waren, deren Ähnlichkeit mit dem Golginetz aber doch nur sehr :iußerlich ist. Direkte Übergiinge vom Fiillnetz oder den Ringen ins Golginetz bestreite ich in ihrer wirklichen Existenz. Stellen, wie sie lleld zeichnet, kenne ich sehr wohl und habe sie seinerzeit grïndlichst studiert; ich kann sie aber nicht einmal in den Zeichnungen Helds als beweiskrïftig ansehen. Demnach muf ich daran festhalten, dafs die Golginetze eine spezifische Oljerflïchenstruktur der Ganglienzellen und Protoplasmafortsiitze sind. 


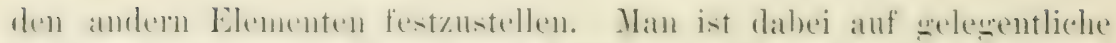

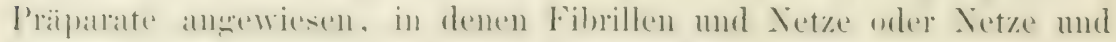
Nervenfasern gleichzeitig dargestellt gefunden werden.

In solehen Präparaten findet man nicht so sehr selten Stellen,

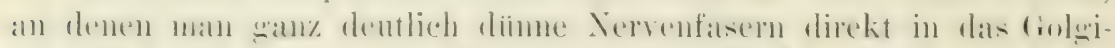

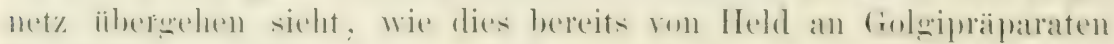
beobachtet ist. Die Gefahr, daß es sich in meinen P'räparaten um

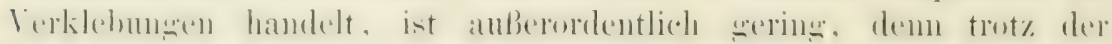
Dunkelheit und Schärfe, mit der die Netze und Nervenfasem in

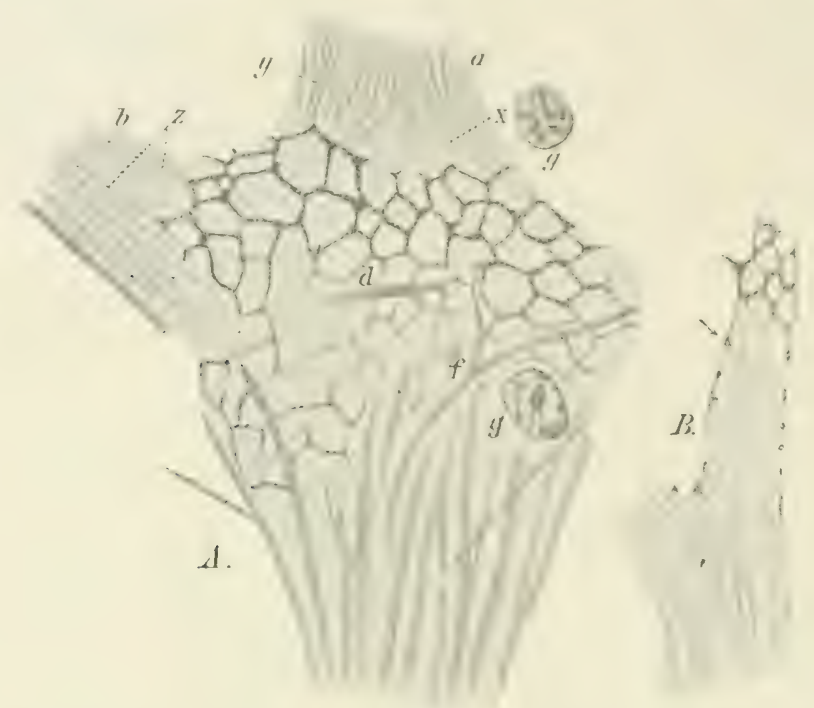

Fig. 21. A Forderhornzelle vom Kalb. Dureh Zufall ist der Schnitt so gefilhrt, alaß bei gleicher Einstellung Nervenfaserhose, Golginetz und in der Zelle rerlaufende Fibrillen zu sehen sind. Dem Anschein nach gehen Nervenfasern und Fibrilen ins Golginetz ïber. 3 Protoplasmafortsatz aus der Medulla des Kaninchens. Gleichzeitige Färbung der Fibrillen und des umgebenden Golginetzes. An der Stelle des I'feils geht eine Fibrille in einen Knotenpunkt des Golginetzes ïber. (Bethe, 1900.)

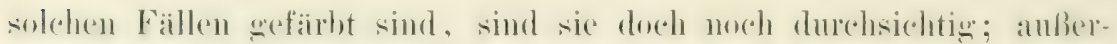
dem ist die Firboung meist so vollstandige, daß man es unbedingt merken nuibte, wemn die Fastern sich nur anlagerten und damn weiterzögen.

Manchmal sieht man anf einer verhailtnismäbign klemen strecke dines Dendriten eine ganze Anzahl solcher diumer Vervenfasern in dats periphere bitter ibergehen ling. 23 $D, b-y$, an andern stellen treten sie in geringerer Anzahl heran. In dieser Figiur $(23 \mathrm{D})$ treten die Fasern seitwärts an den Protoplasmafortsat\%. Wie wir sahen, sind aber die Zellen und Dendriten rom Xervenfaserhesen eintehiillt.

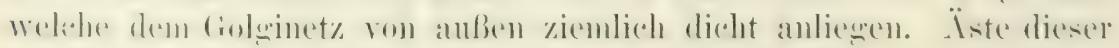

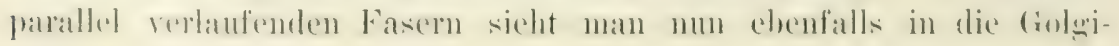


netze iibergehen, wie dies in Fig. $24 d$ zu sehen ist. Die Zelle ist

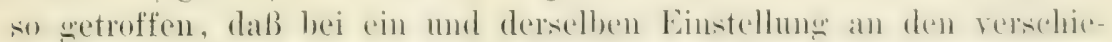
denen stellen die ressehiedenen sichichten zu seden sind. In muteren

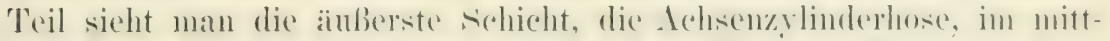

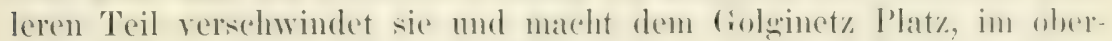
sten Teil sieht man die Nemrofibrillen. In mittleren Teil sieht man nun die Achsenzylinder $d$, $e$ und $f$ sich rerzweigen und ins Netz iibergehen.

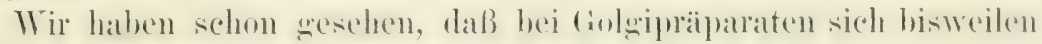
die spritze eines Dendritenzweiges in einen diumen Faden fortsetzt, der einem Achsenzylinder meln ähnlich sicht, als einem l'rotophlasmafortsatz. An solchen Stellen hat nun Semi Meyer in erster Linie Übersainge von Nervenfasem in das den Dendriten mugebende Not\%

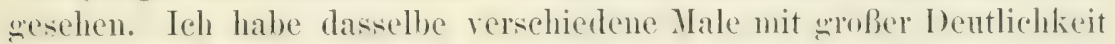
beobachten kïmen (Fim. $23 B$ und $c$, $a$ ), halte diese Fälle aber für nicht so beweisend, weil die diumen Dendriten manchnal so zusammenschnuren, daß auf kuze strecken ein einheitlicher strang entsteht, der einer Nervenfaser sehr ähneln kann (Fig. 23 C, b). Ist solch zusammengeschmurtes Dendritenende kur abgeschnitten, so kann es sehr wohl den L̈beroang eines Achsenzylinders in das Netz eines Dendriten vortiuschen. In dieser Finur geht der zusammengeschmurte Dendritenzwein, d. h. wie ans analogen, nicht gneschnurten stellen hervorgeht, nur sein Golginetz, bei g in das folgmetz eines znoßen I'rotoplasmafortsatzes über, eine Erscheimung, die recht häufign zul'

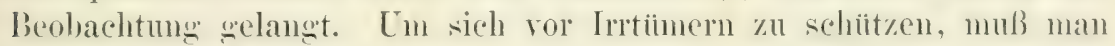
nur Fälle in Betracht ziehen, wo man den für eine Nervenfaser gehaltenen Faden auf längere strecken verfolgen kann, denn das Zusammenschmuren diimmer Dendritenzweige findet immer nu anf ku\% Streeken statt.

Tenn ich mein ganzes Material sichte, so bleiben doch immer noch eine ganze Anzahl ron Fällen ïbrig (unter diesen die hier ab-

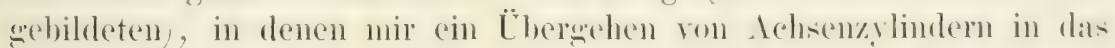
Golginetz iiber allem Zweifel erhaben zu sein soheint. I ch hahe mich trotzlem in meiner diesen Gegenstand wewidneten l'ublikation (1900)

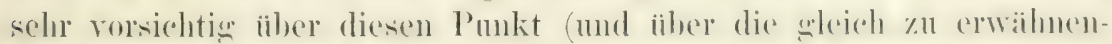

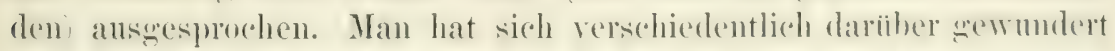

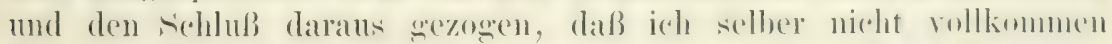

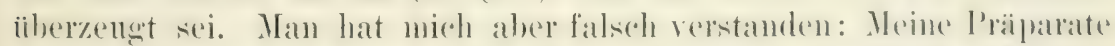

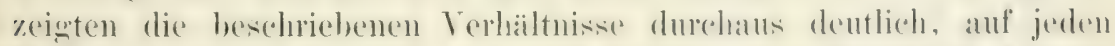

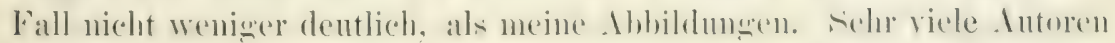

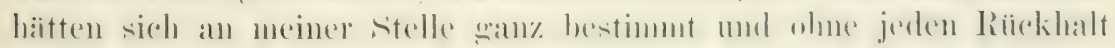
geäußert, und, wenn ich mein Urteil reserviert abgab, so geschah es

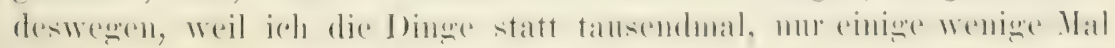




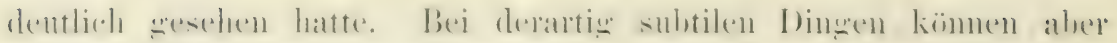
Einzelfälle nicht unhedingt entscheidend sein. ${ }^{1}$ )

In den diumnen Nervenfaser\%weigen habe ich Neurofibrillen höch-

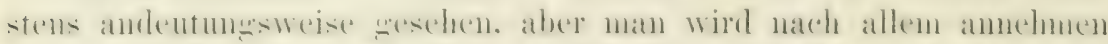

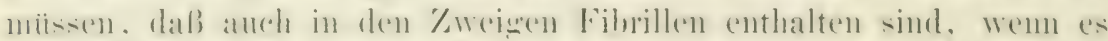
so in den Stämmen ist. Die diunnen Fasern schnuren eben mit noch

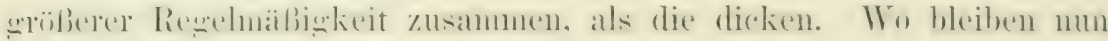

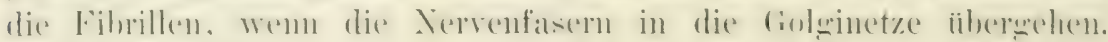

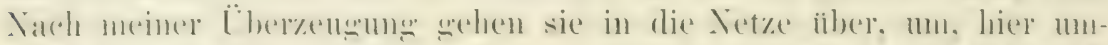

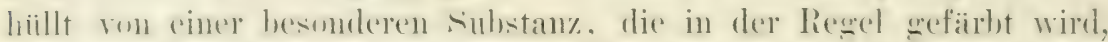

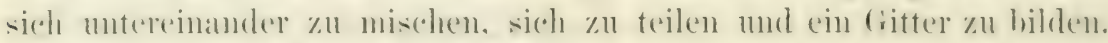

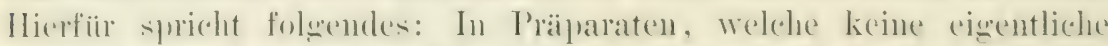

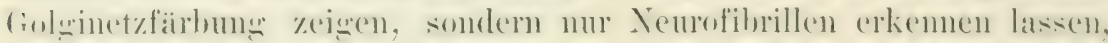

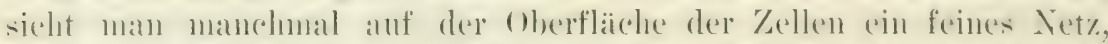

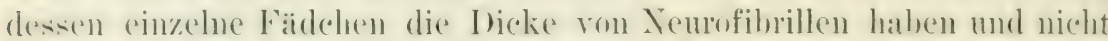
wie dio Netzhalken der somst sichtbaren folswinetze mu vieles dicker sind. In einem andern Fall gelang es mir, innerhalb des hier nur

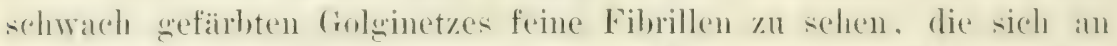

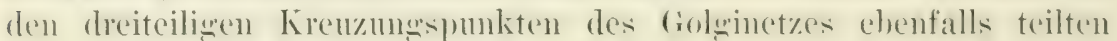
und so ein Netz im Netz bildeten. Wo aber bleiben die Fibrillen weiter:? Anch hierauf hrauche ich nicht mit ciner Ilypothese zut antworten, denn ich habe einige positive Beobachtumenen nach diesere Richtune hin machen können. Wie schon erwahnt, wird die Zahl der Nemofihrillen, welche in einem Protoplasmafortsaty enthalten sind,

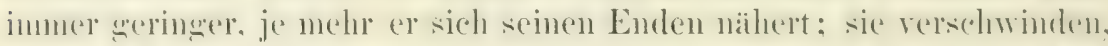

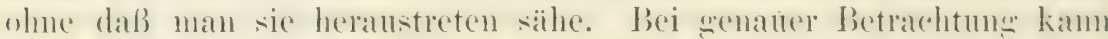
man nun nicht selten beobachten. Wie Fibrillen ans den Ilanptrerland der Fiblillen austreten und senkrecht der Oberfläche des Dendriten zu-

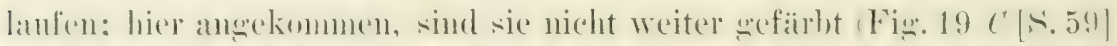
die Fibrillen, auf welche die l'feile dentenj. In andern I'rïbaraten, in

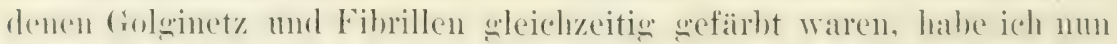

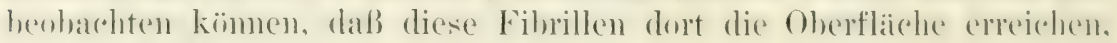
wo ein Knotenpunkt des Golginetzes vorhanden ist (Fig. 24 A, x, y, z

1) In seiner kürzlich erschienenen Arbeit (1902) lïft Held die dïnnen Nervenfasern nicht mehr wie früher in das Golginetz ïbergehen (das er für gliös hält, siehe S. 71) sondern in Häufchen von Plasma, welehe in ten Maschen des Golginetzes liegen, Neurosomen enthalten und untereinander netzig verbunden sind. Sehr hiibsche Übergainge von Nervenfasern ins Golginetz, die er abbildet, hält er fuir „scheinbare "Ủbergänge. Merkwürdigerweise sind die „scheinbaren" Übergänge in seinen Figuren viel überzengender als die „echten“ Zusammenhïnge von Nervenfasern mit Neurosomenhaufen! Ich gebe, wie von jeher, zu, dâ die Frage noch lange nicht abgeschlossen ist; dafs aber die Neurosomenhaufen die eigentlichen Nervenfaserenden sind, scheint mir nach der Heldschen Arbeit viel unwahrscheinlicher, als daß es die Golginetze sind. 


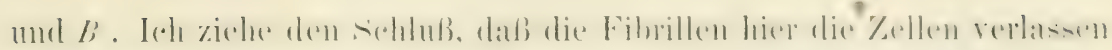
und in das Golginet\% eintreten, $u m$ in ilm weiterzuriehen, oder dab um-

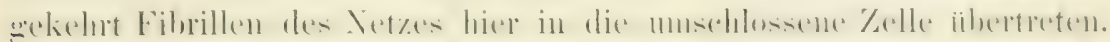

Nach dem angenblicklichen Stand unserer Kenntnisse werden wir

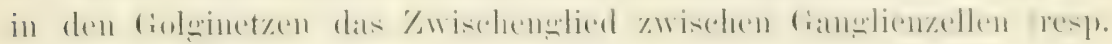
Protoplasmafortsaitzen) und fremden Nervenfasern erblicken und sie dem Fibrillengitter der zentralen Fasermasse bei den Wirbellosen gleichsetzen dürfen, las sich rom ihnen nul datdureh unterschededet, dals dic Fibrillen narckt sind, wälnend sie hier mit einer Substanz iiberzogen sind, welche in ihren Reaktionem voul der P'erifibrillärsulstan\% der Nervenfasern verschieden ist. Immerhin bleibt dicser ganze Iufbau noch sehr hypothetisch und man kamm den zugrumde liegenden (zum Teil noch weiterer Bestaitig'ung bediurfenden) Beobachtungen wohl auch andre Deutungen geben.

Bei Tergleichung der Menge von Ganglienzellen, Dendriten, Achsenzylindern, Gliafasern, Gliazellen und Blutgefaßen, welche in del Hirminde, besonders in der zweiten und dritten Meynertschen Schicht, vorhan-

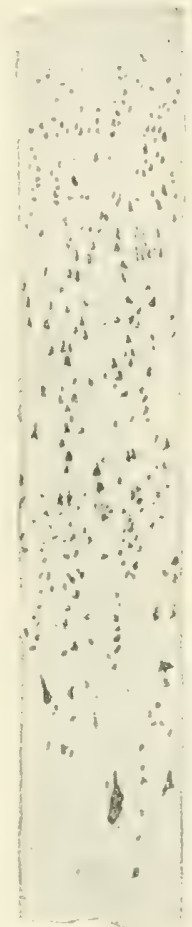

A.

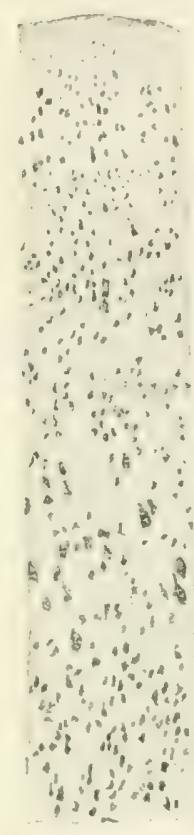

$B$.

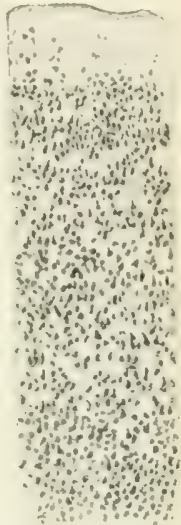

$C^{\prime}$

Fig. 25. Schnitte durch entsprechende Particn der Groshirnrinde $A$ rom Menschen, $B$ rom Hund, $C$ vom Maulwurf bei gleicher Vergrüticrung nach lisst 189s). (1en etwa viermal breiteren - photographischen - Original-

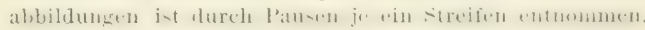
Hierbei mögen kleine Abweichungen rom Original zustande gekommen sein, welche aber bei der Größe der Unterschiede keine diolle spielen künnen. den sind, fand Nissl (1898),

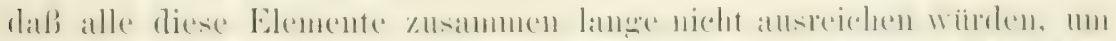

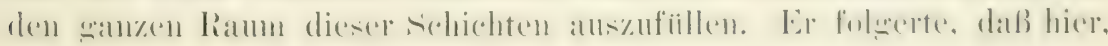
wie anch an andern Orten, eine Zwischensubstanz vorhanden sei, welche weder zu den Zellen noch zu den Nerventasern direkt gehört und die er als "Grau" bezeiehnete. Ton den Zellen selber muB das „Grau" meh" ader weniger unabhängig sein, dem el fand Fälle von Paralyse, in denen die Zellen zwal verindert, aber an Zahl nicht ver- 
lingert waren, wo aber trotzdem dieses Zwischengewebe in hohem

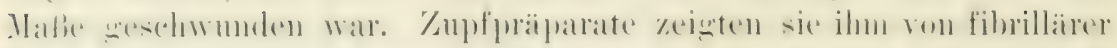
Struktur, mehr komnte er nicht aussagen. Im höchsten Grade auf-

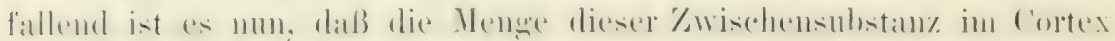

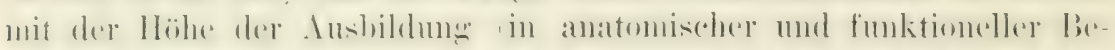

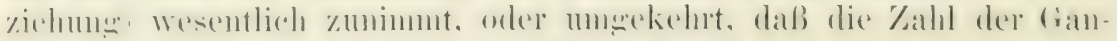

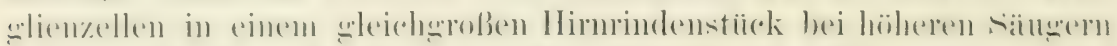
kleiner ist, als bei niederen (Fig. 25). Da die Veristelungen der

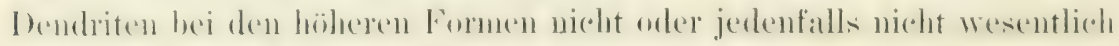

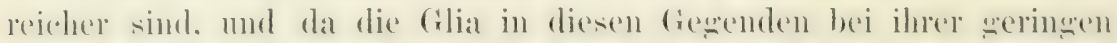

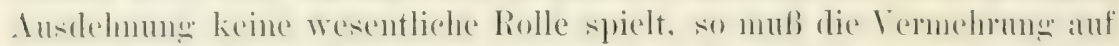

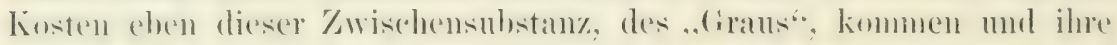
Gegenwart als ein sehr wesentlicher Faktor angesehen werden. ${ }^{1}$ ) -

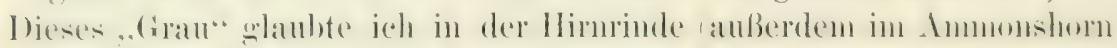

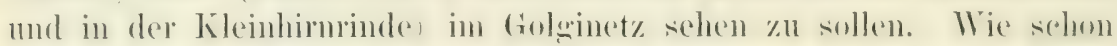

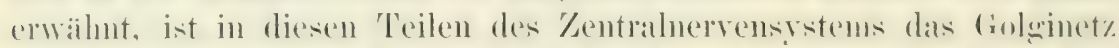

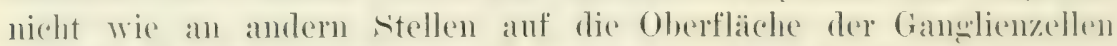
und der Dendriten beschrankt, sondern es dehnt sich ron da aus

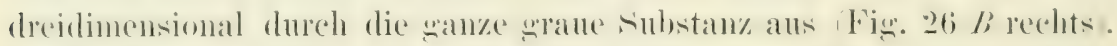
So füllt es also die Lïcken, welche Nissl zwischen Zellen, Fortsaitzen 11. S. W. erkannt hat, aus. $\stackrel{2}{)}$ Ob danit schon das wirkliche „Grau" gefunden ist, bleibt dahingestellt.

Nach meiner Meinung ist die Mitinkrustierung des Golginetzes

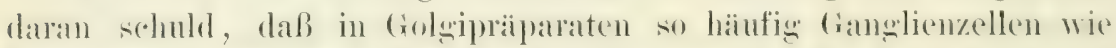
I'rofoplasmafortsit\%e cin rauhes Iussehen zeigen. sind sie watt, wie in Priparaten, die nach andern Methoden gefärbt sind, so lıat nur

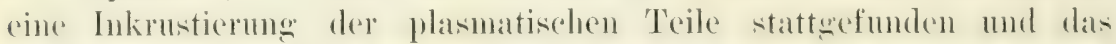

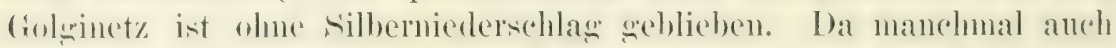
an meinen l'rij)araten anf kurze strecken eine vollstandiwe Fimhiillumen mit Farbstoff zur Beobachtung kommt, so bin ich imstande, den lemeis fur diese Insicht zut geben. Ich will mich dabei anf das frappanteste beispiel beschräken: Bekamntich findet man in Golenipraipat raten die Protoplasmafortsitze dere Pramidenzellen und dere P'urkinje-

1) Zu meinem Erstamen hat die absolut klare Beweisfülrung Nissls, da13 cine Zwischensubstanz vorhanden sei, vielfach Kopfschiitteh hervorgerufen. Es scheint demnach schon soweit gekommen zu sein, daß in der llistologie nur das existiert, was direkt gesehen werden kamn und dafs derjenige, der einen logisehen Schluß zieht, fiir einen Fabulanten gehalten wird.

2) Nissl hat neuerdings (1903) seine Bedenken gegen diese Dentung ausgesprochen. Vor allem hält er es iiberhaupt fiir unsicher, daf mein ,diffuses Golginetz" mit dem pericellulären Golginetz etwas zu tun hat. Ich will gern zngeben, daß diese Bedenken gerechtfertigt sind, obgleich ich es nicht für ausgeschlossen halte, daß meine Deutung richtig ist. 
schen \%ellen oft mit feinen Spitzen besetzt (Fig. 26 A), die meistens an Ende einen kleinen Knopt tragen. Es ist lange dariber gestritten worden, ob dies ein Kunstprodukt oder eine natioliche Struktur sei, und man glaubte, diese Frage sei entschieden, als Cajal (1896) und

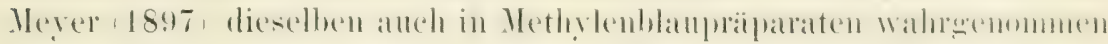
hatten. Nach meiner Ansicht liegt die Wahrheit in der Mitte: so, wie

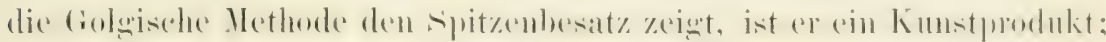
er berulht aber auf einer tatsïchlich volhandenen Struktur, die dureh die Methode falsch dargestellt wird. Die ligur $26 \mathrm{~B}$ gibt hierfiir die Erklärung. Auf der rechten Seite ist das Golginet\% normal ge-

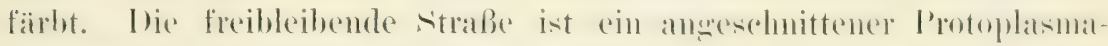
fortsatz, bei $x$ sieht man einen andern ruergeschnitten. Auf der linken Seite befindet sich ein andrer Dendrit, welcher wnten noch nomal gefarbt ist, oben aber eine so starke Anlagerung des Farbstoffes zeigt, daß das Netz nicht mehr erkembar ist. Gleichzeitig ist hier auch, wie dies manchmal geschieht, die Fairbung des diffusen Netzes bei der ersten 'T'eilung' unterbrochen, so daß nu' noch der Knotempunkt zu sehen ist. Auch Cajal hat bereits an Methylenblaupräparaten gesehen, daß bei Mitfärbung des Spitzenbesatzes die Oberfläche des Dendriten retikulär ist; er hat dalaus aber nicht den richtigen Schluß g'ezogen, dals die syitzen ein 'Teil des Yetzes sind und mit dem Dendriten direkt nichts $7 u$

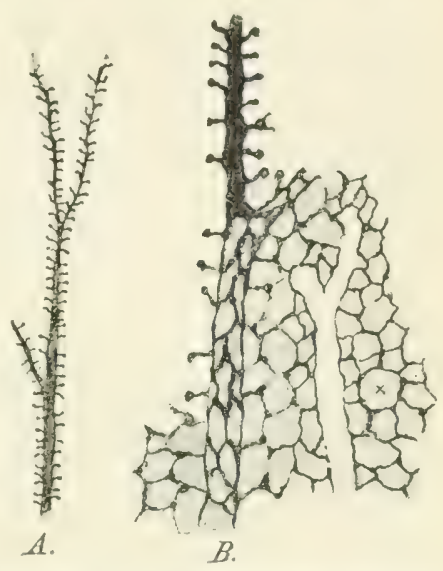

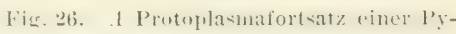
ramidenzelle mit Spitzenbesatz, $B$ zwci Protoplasmafortsätze ron Py ramidenzellen vom denen dex ein ungufirm in umil diffuses Golginetz. (Molybdinmethole.) Beide Abbildungen etwas schemativiert. tum haben, wnd er komnte es auch nicht tun, weil er der irrigen Meinumg war, daß das Net eine Differen-

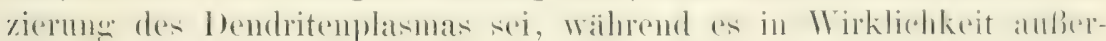
lialb desselben liegt.

Die Golgische Methode hat getzeigt, daß an gewissen Orten des

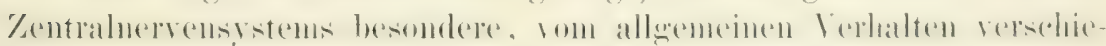
dene Bezichungen zwischen Neurten und P'rotoplasmafortsaitzen olwalten. Dies ist vor allem in den Glomeruli olfactorii, in den Plannes der Körnerschicht des Kleinhirns und, in etwas andrer Weise, in den Körben an Grunde der Purkinjeschen Zellen der t'all. Nlle diese Grte fand bereits Held dureh einen besonderen Reichtum an Veurosomen ausgezeichnet. Ich konnte mun zeigen, daß an diesen Orten das Golginetz in einer Dichte auftritt, wie an kemem andem Ort des Jervensystems. Nach meiner Meimug ist dieser liefund wohl rou 


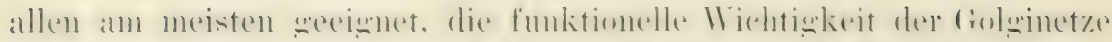

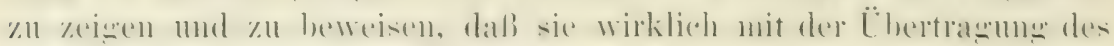
Reizes ron Nervenfasern anf Dendriten zu tum haben.

\section{SECHSTES KAPITEL.}

\section{Die Nervennetze und ihre Neurofibrillen.}

Wesen der Nervennetze. Ihr Vorkommen bei Wirbeltieren, Arthropoden und Mollusken. Bei Coelenteraten bilden sie das ganze Nervensystem S. 75-53. Die Fibrillen in den Nervennetzen bei Pontobdella und beim Frosch S. S4. -

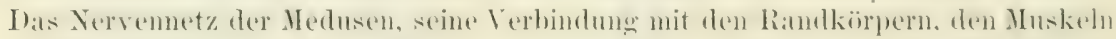
und dem Epithel und die Fibrillen in demselben S. S5-90. - Das Nervennet\% des Frosehherzens S. 90-96.

Unter dem Namen Nervemetz verstehe ich eine Form des Nervensystems, das sich ron der bisher allein betrachteten dureh breite Anastomosen zwischen den Zellen unterseheidet. Fasern und Zellen matchen hier wie dort die Bestandteile aus, aber die Zetlen stehen in direkter Verbindung miteinander und die Fasern weisen keine Cnterschiede moteremander auf: lange Fasem fehlen sanz. Auffallend ist anch vor allem, daß die Netze sich diffus ausbreiten und die Zellen - hier und dort eingestrent - nie zu Ganglien vereinigt sind. Die Ganglienzellen haben meist drei fortsitze, es kommen aber anclo solche mit nur zwei Fortsätzen vor mud manche haben mehr als drei — vier, höchstens fünf (Fï. 27). Eine Cuterscheidung der Furtsitte in Protoplasmafortsätze und Achsemylinderfortsaitze ist mumiglich. Natch meist kurzem Verlauf, während dessen spärlehe Seitenzweige absegeben werden, vereiniwen sich die Fortsitze wiender mit andern Zellen, meist schon mit der zunächst gelegenen.

Bei manchen Tieren (Medusen, Aetinien, Ctenophoren) machen die Neremetze das sanze Nerrensistem ans; bei andern T'ieren treten sie neben dem zentralisierten Nervensystem auf, hier und dort mit ihn Verbindungen eingehend, abor doch anf grobe strecken ziemlich

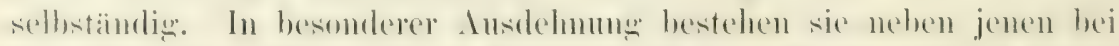

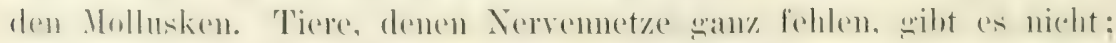

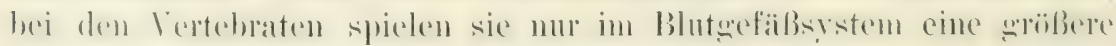
Rolle. Grade hier ist aber das Nervemetz am leichtesten darustellen

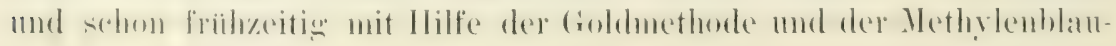


methode beobachtet worden (Golgi, 1594, Dogiel, 1893 mud 1898, Bethe, 1895).

Man findet solche Net\%e an allen Gefïßen von Kaltbliitern und Warmbliitern; an den Arterien sind die Netze an dichtesten, ron

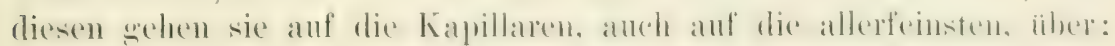
anch an Venen sind sie zu finden, aber hier sind die Maschen sehn groß. Die Figur 28 stellt ein solehes perivasenlares Netz (Arterie)

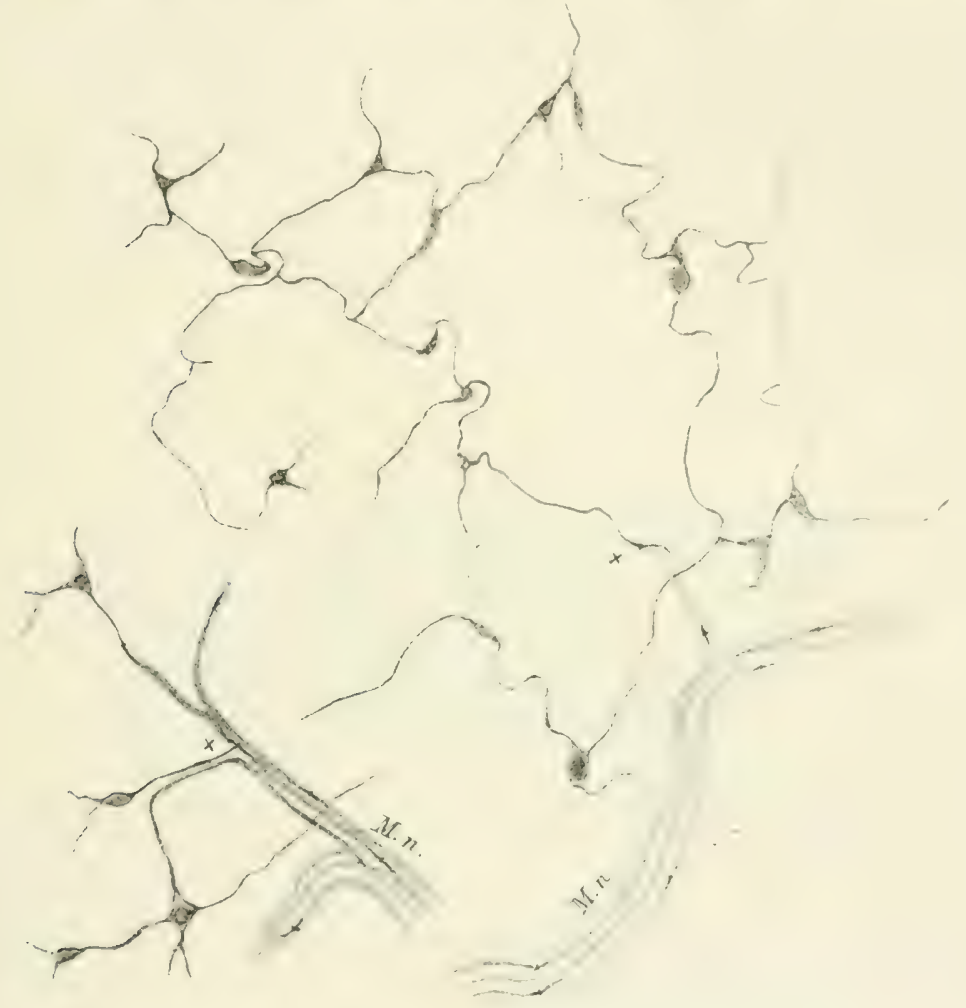

Fig. 27. Nervennetz aus dem Gaumen vom Frosch nach cinem MethylenbIaupräparat. M.n. markhaltiger Nerv. Bei $x$ gehen markhaltige Fasern in das Netz uiber. (Lcitz I, 5).

ans dem Gaumen rom Frosch dar. Hier (im Gammen) sicht man nun,

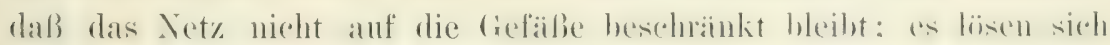
viehmehr stellenweise Fasern ab, welehe mit einem weitmaschigeren

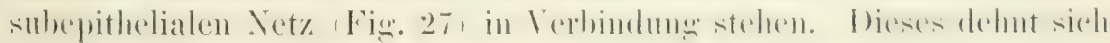
dureh die Haut des ganzen Gammens aus, iiberall wo es mit Gefäßen in Berïhmog kommt, Fasern an ihr Netz abgebend. - Dasselbe

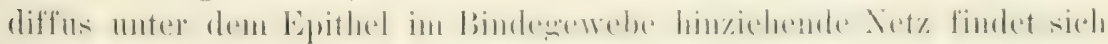
anch an andern Stellen der Frosehhant, doeh ist es im Gaumen wegen des Mangels an Pigment am besten zu sehen. Auch in der Haut des 
Menschen ist ein solches Netz ron diffuser Ausbreitung von Dogiel ma Leontowitsch nachgewiesen worlen. - Von dem perivasculären Jet\% senken sich einige dünnere Fädehen in die Inscularis der Geläße hinein (Dogiel, Bethe); wie sie hier an den Muskelfasern enden, dariber liegt noch nichts sicheres vor, daß sie aber mit der Gefäß-

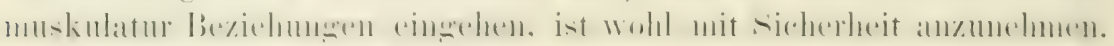

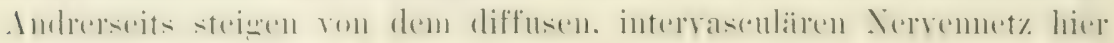
und dort Fiaden zum Epithel empor (Bethe, 1895), welche zwischen

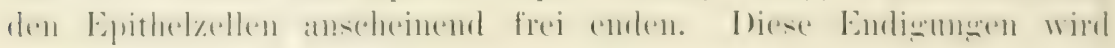
man jedentalls als rezeptorische ansehen miissen.

Daß es sich in diesen Netzen wirklich um nervöse Tetze handelt,

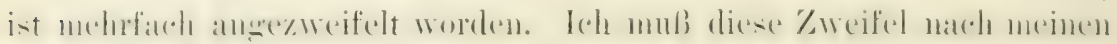
neneren Befunden als ungerechtfertigt bezeichnen. Schon vor acht

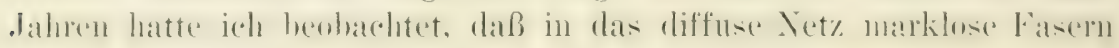

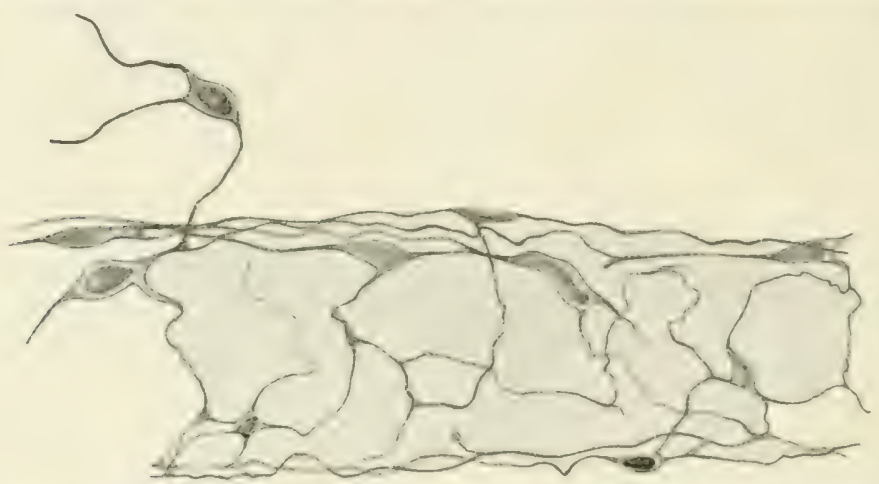

Fig. 28. Xervennetz um eine kleine Arterie rom Frosch (Methylenblaumethode). Links oben eine Zelle des subepithelialen Netzes, welche mit dem perivaskulïren in Verbindung steht. (Nach Bethe. 1895.)

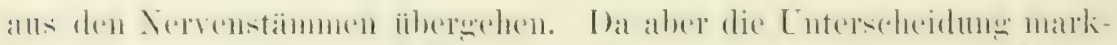

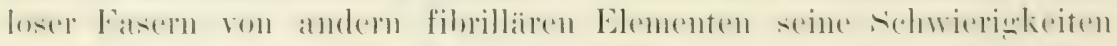

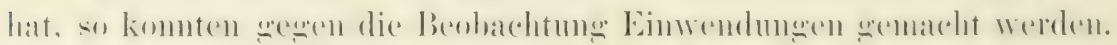
Schon vorher hatte Dogiel (1893) beim Menschen einen Kusammenhang von Netzfasern mit markhat igen Fasern behauptet mol newerding's ist dasselbe ron seiten Leontowitsch's (1900) geschehen; doch

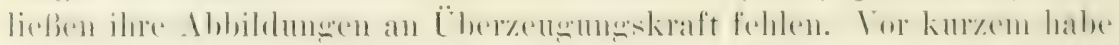
ich mich nun aber von der Richtigkeit dieser Behamptung an einigen

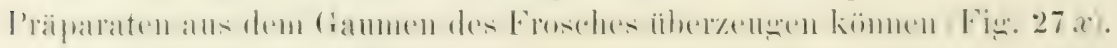
In der Regel treten allerdings die Fasem bereits marklos ans den Nervenstämmen ans, aber bisweilen, wie in den abgebildeten Fallen, begleitet die Markscheide die Faser bis in die Yähe der ersten Ganglienzelle. Einen weiteren Beweis für die nervöse Natur der Netze swibt der Befund von Neurofibrillen in denselben, anf den ich spaiter zuriekkommen werde. 
Subepitheliale Nervennetze, welche mit dem zentralisierten Nerrensystem in Verbindmg stehen, finden sich anch bei Arthopoden und

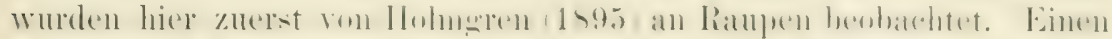

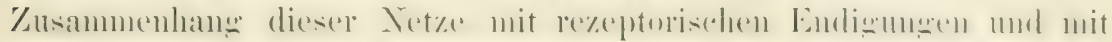

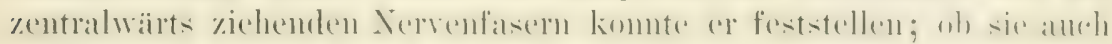

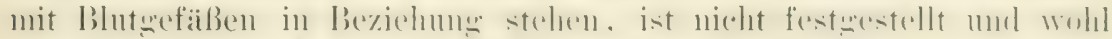

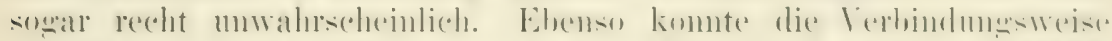

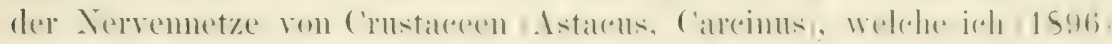

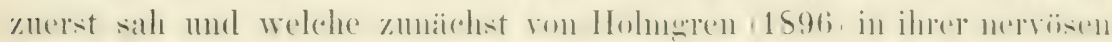

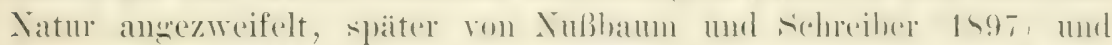

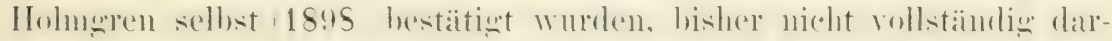
gestellt werden. ${ }^{1}$ ) Immerhin ist es ron Interesse, daß ancd bei diesen Tieren solche subepithelialen Netze existieren und - wenigstens bei Astacus und Caremus - gradeso wie bei Wirbeltieren zwar mit dem \%entahnervensystem zusanmenhängen, aber direkt nichts mit der

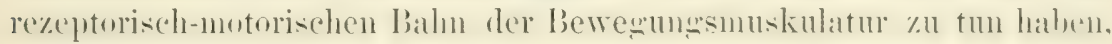
sondern jedenfalls ein in sich geschlossenes Reflexsystem ron besonderen Funktionen darstellen.

Ganz anders liegen die Verhältnisse bei den Mollusken; hier nimmt das Nervennetz noroh einen sehr hreiten Ram in Nerremsistem ein: Es ist eingeschaltet in den Verlauf der peripheren motorischen und rezeptorischen Nerven, so daß das Zentralnervensystem nur die langen Bahnen innerhalb des Nervennetzes repräsentiert.

Bei allen bisher untersuchten Mollusken hat man iiberall an der Peripherie, hesonders aber unter dem Epithel suribere mol klomere Ganglienzellen gefunden. Man findet sie aber auch weiter zentral-

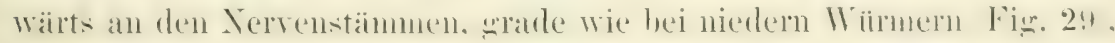
und ich glaube, daß man die Zahl der peripher gelegenen Zellen größer schätzen muß, als die der zentralen, in den Ganglien konzentrierten. Je mehr man sich, ron den zentralen Ganglien kommend, im Verlauf der peripheren Nerven der Peripherie nähert, desto zahlreicher und kleiner werden die den Nerven angelagerten Ganglienzollen. Unter dem Epithel gehen schließlich viele Nervenfasem in ein richtiges Nervennetz über (Aplysia), während andre in bipolaren

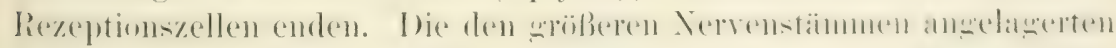
Zellen erweisen sich auf Methylenblaupriparaten als bipolar oder

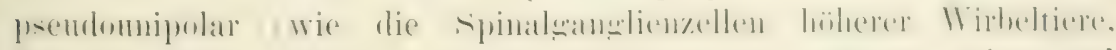
Fig. 29 rechts). Beide Fortsätze zichen im Ilauptstamm weiter und seben dabei Seitenzweige ab, die sich in Nerven selher in feine

1) Ich bleibe dabei, daf die von mir gesehenen Zellen nervös sind; was Holmgren gegen diese Natur und gegren ilıre Identitit mit den Nufbatumselien Zellen vorbringt, laalte ich fiir nicht stichhaltig. 
Zweigchen auflösen oder den Nervenstamm verlassen,

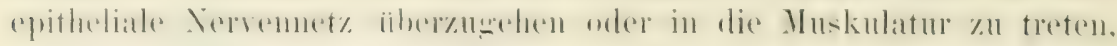
welche ebenfalls von einem Nervennetz durchzogen zu sein scheint:

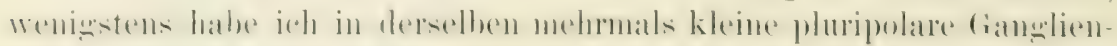

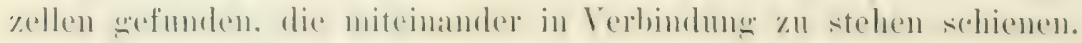

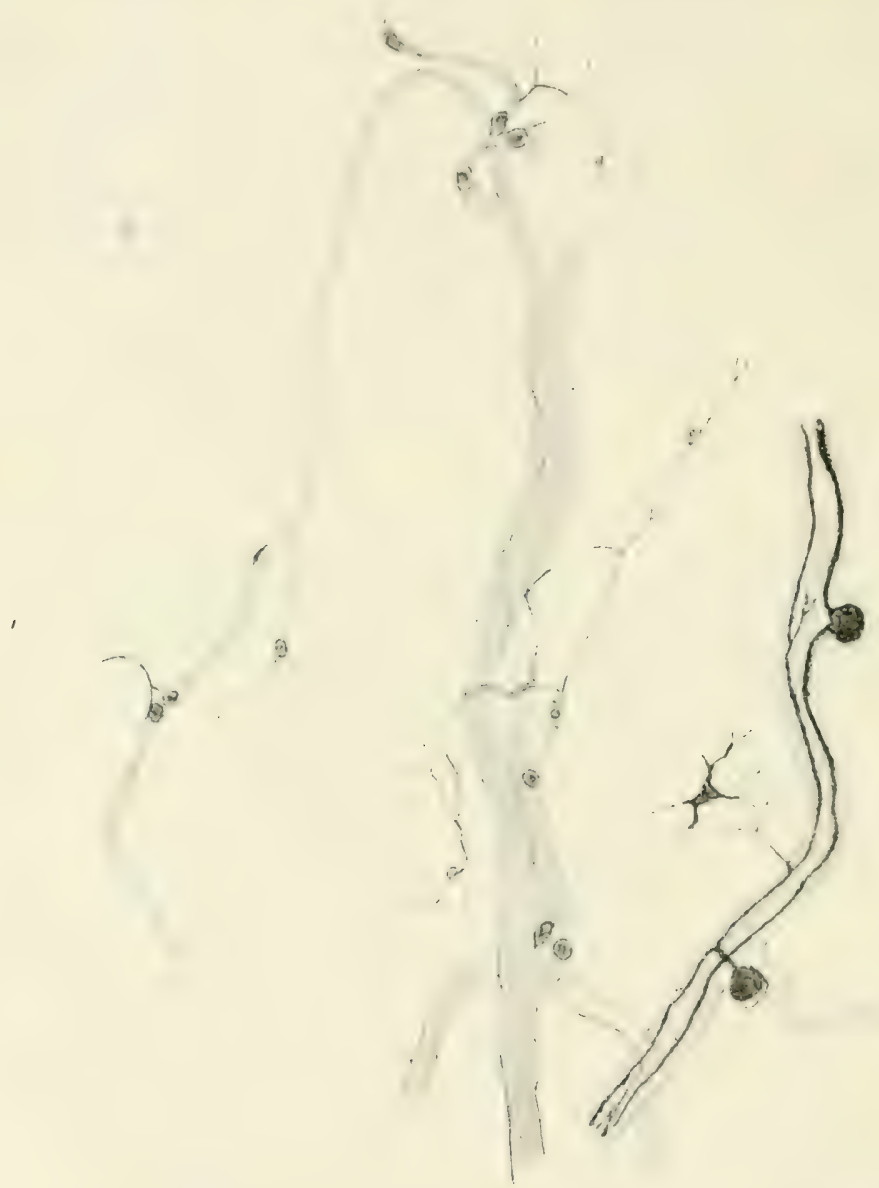

Fig. 29. Nervenst:̈mme aus dem Flügel von Aplysia. (links nach einem Macerationspräparat, Vergrößserung etwa $60 \mathrm{mal}$, rechts nach einem Methylenblaupräparat, Vergrïßerung etwa 200mal.) Man sicht die den Nerven ansitzenden Ganglienzellen. An der rechten Abbildung kann man die Fortsütze ler Ganglienzellen verfolgen. Ls ist hier auch eine von den kleinen multipolaren \%ellen deg subepithelialen Netzes zu sehen.

C̈her die Beziehmen der peripheren Nervenendigmengen zu den subepithelialen Vervennetzen liegen wichtige Lutersuchumen von

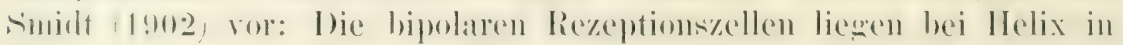
Hanfen zusammen. Ihr einer Fortsatz ondet, wie hei den Arthopoden 
mul IVümern, frei im Epithel, der andre zieht zu einem zentralen

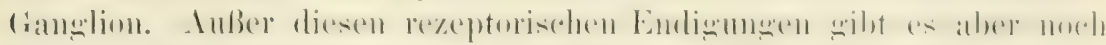
andre, welche von tiefer liegrenden Zellen ausgehen (Fig. $30 \mathrm{~A}$ ). Dicht

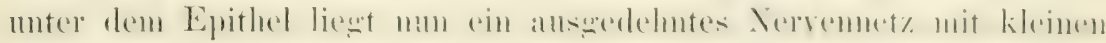
eingestrenten Zellen, welehes in Fig. $30 \mathrm{~B}$ von der Fläche darostellt ist. In dieses gehen Seitenzweige der erwähnten großen Zellen iiber,

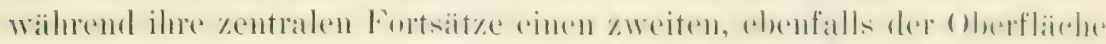

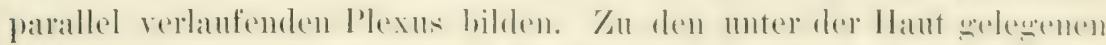

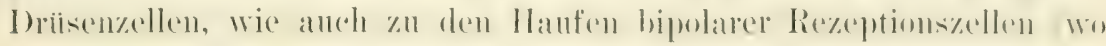
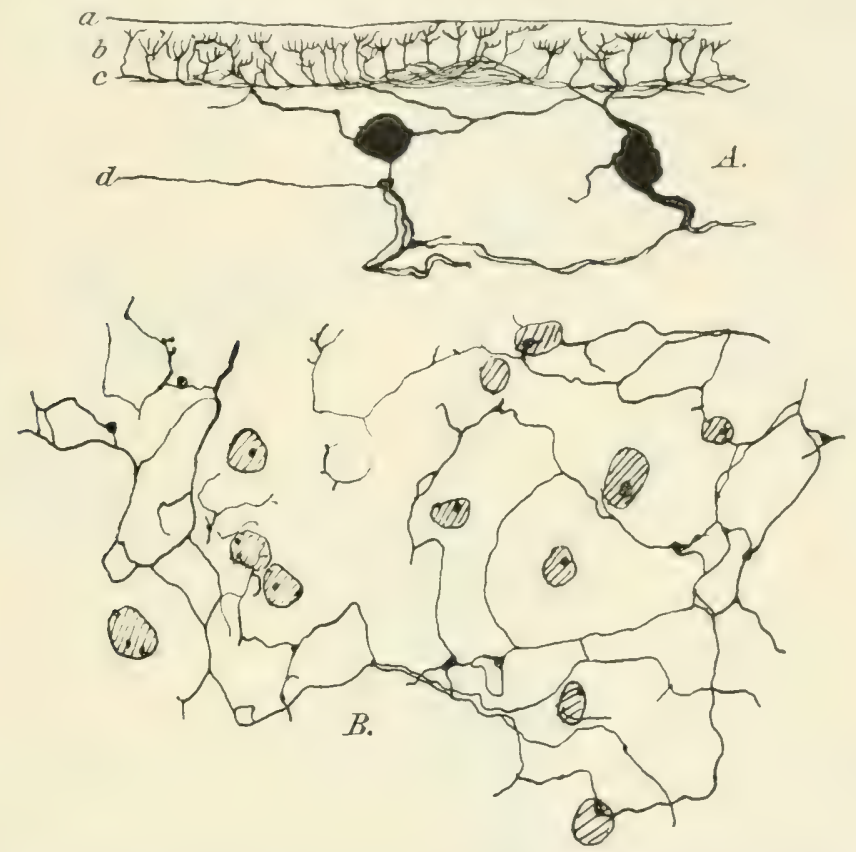

Fig. 30. A Querschnitt durch die Haut von Limax, welcher den oberflïchlichen und den tiefen Fervenplexus zeigt. $B$ Fliichenschnitt durch den oberflichlichen Plexus in seinen Beziehungen zu den Drïsengängen. Man beachte die eingestreuten kleinen Zellen. (Beide Figuren nach Smidt, 190: (rolgische Methode.)

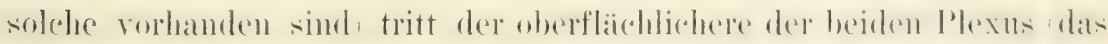

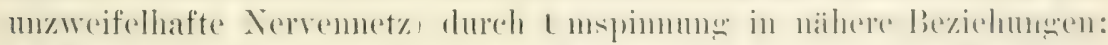

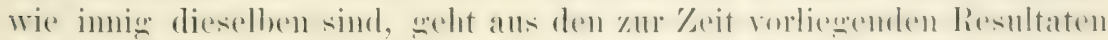
noch nicht hervor, jedenfalls werden wir aber nach allem bisher Be-

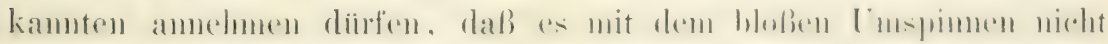
abgetan ist. Der tiefere Plexus lieg't wohl sehon in der Muskulatur,

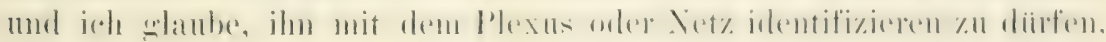
das ich bei Aplysia an dieser Stelle andentungsweise gesehen habe.

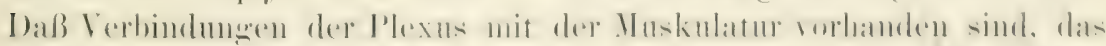

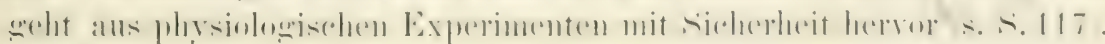


Fibrillen wurden in Nervennetzen zuerst von Apáthy, und zwar

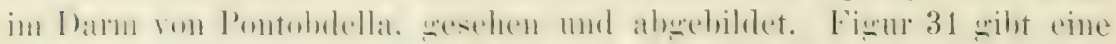

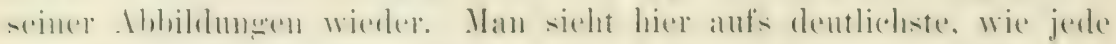
der beiden miteinander durch eine dicke Protoplasmabrücke rer-

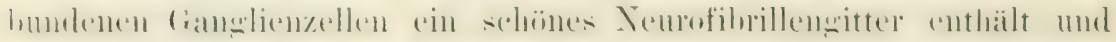
wie diese Gitter durch Fibrillen miteinander in Verbindung stehen.

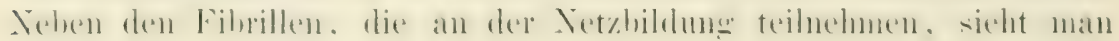

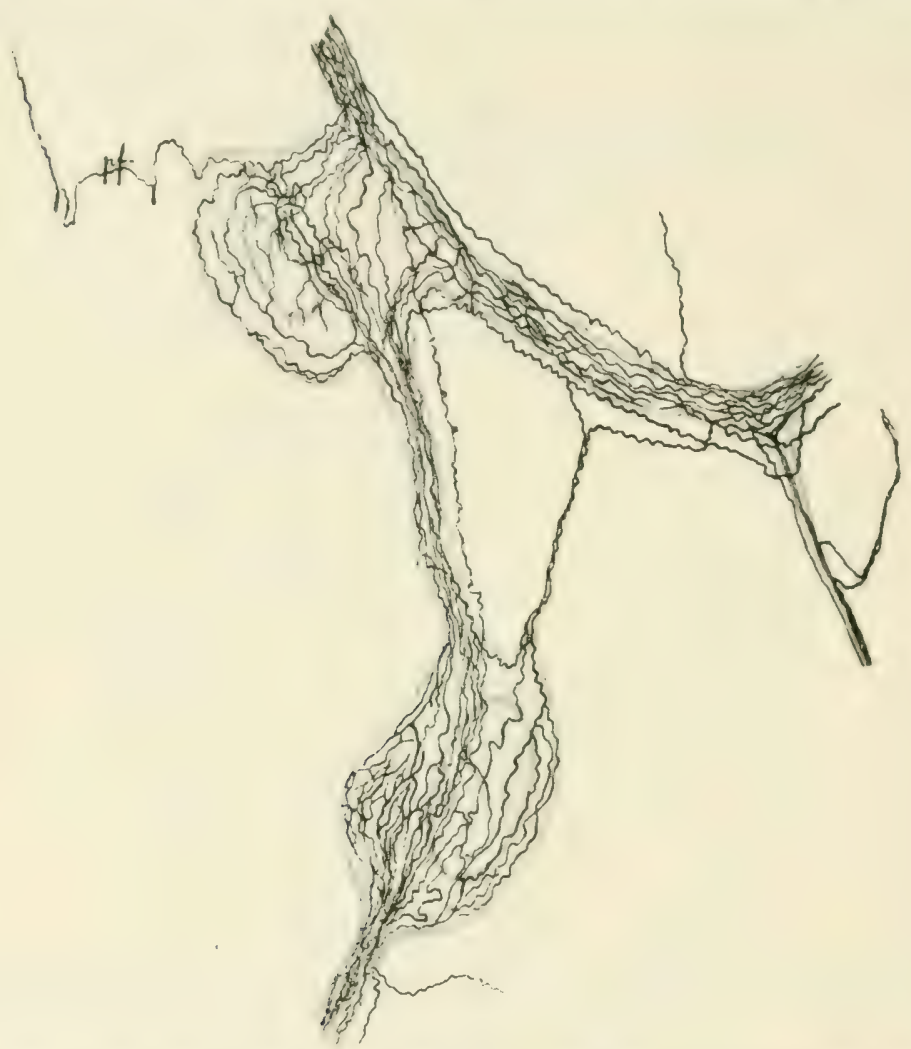

Fig. 31. Zwei Gianglienzellen des Nervennetzes in der Darmwand von Pontobclella nach Apithy (1897, Taf. 28, Fig. 10). (Die Ibbildumg bildet nur cinen Teil des Originals und ist iberhaupt nicht imstande das Original genau wiederzugeben.)

aber auch andre, welche die Ganglienzellen glatt durchzichen, um

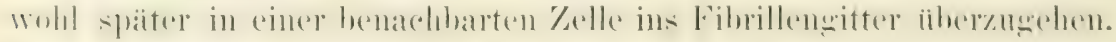
Bei of sieht man dam eine Fibrille aus der oberen Zelle anstreten, wetehe als moterische Fibrille an eine Muskelfaser des barms herantritt.

Ganz ähnliche Resultate habe ich mit Methylenblan in den Jervenuetzen yom Froseh erzielen kömen (Fig. 32). Auch hier sieht man in jeder Zelle ein Fibrillengitter, und bemerkt, wie beide Gitter durch Fibrillen miteinander in Verbindung treten. Von 


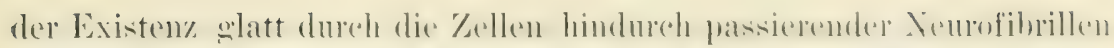

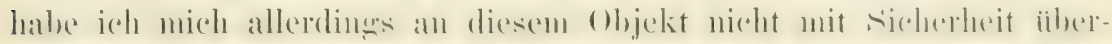
zengen kömnen. Es ist aber doch sehr wohl möglich, daß auch hiè

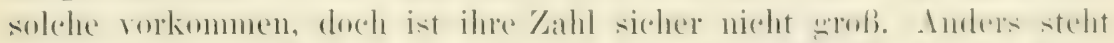

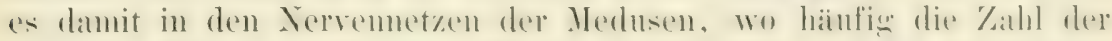

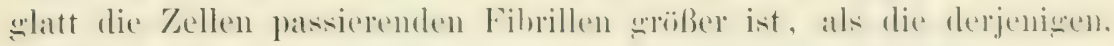
welche an der Gitterbildung imnerhalb der Zellen teilnehmen.

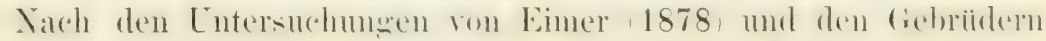
Hertwig (1878) hat das Nervensystem bei den Medusen einen

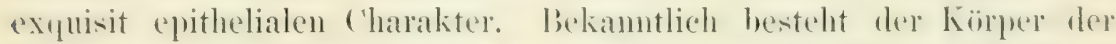
Medusen in der Hauptmasise atus einele ciallerte. In Imeren befindet

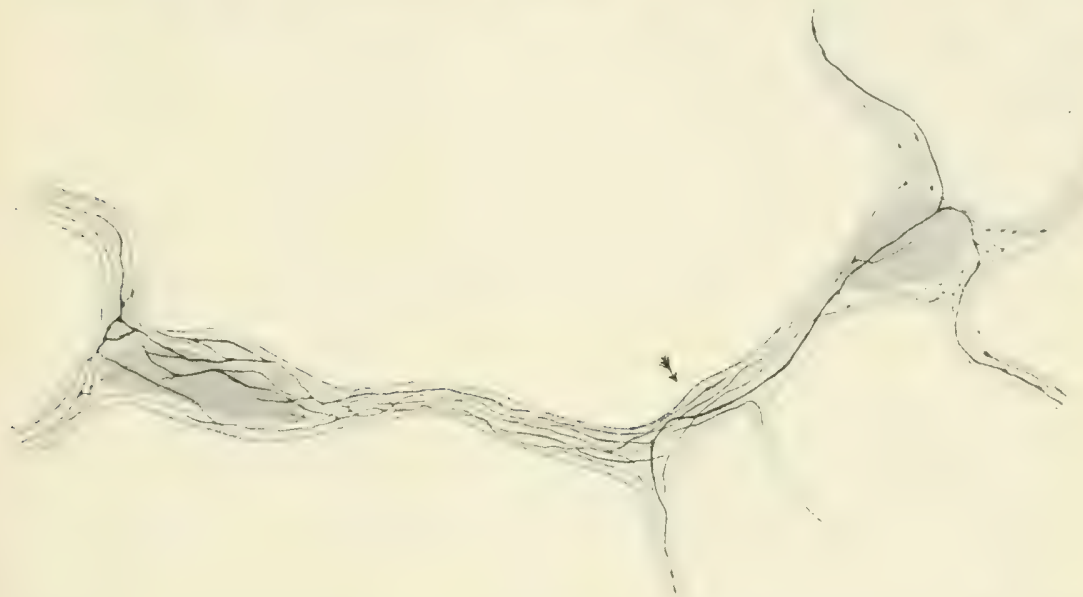

Fig. 32. Zwei Zellen des subepithelialen Nerrennetzes aus dem Gaumen rom Frosch. (Methylenblaupräparat mit Differenzierung der Neurofibrillen. Kerne nur blaß, Plasma fast nicht gefiirbt.) Die Zeichnung ist mit Benutzung der Mikrometerschraube mit Hilfe des Zeicheupparats hergestellt. Da die Ausdehnung über ein Gesichtsfeld hinausging, ist die Figur durch Kombination zweier Zeichnungen entstanden, wobei eine Verbindung der Fibrillen nur dann eingezeichnet wurde, wenn die betreffenden Fibrillen in beiden Bildern genau ideutifiziert werden konnten. Die Stelle, wo beide Zeichnungen zusammentreffen, ist durch einen Pfeil augegeben. Apochromat 1,3, Kompensationsocular 6. (Auf $\%$ verkleinert.)

sich ein velzweigter Hohlraum, der Magen nebst „Gefïßen“". Er iiffuet sich nit einer einzigen öffnumg, dem Munde, nateh anken. Dor innere IJohlraum, wie die äuBere (1)erfläche dere (iallerte ist mit einemt

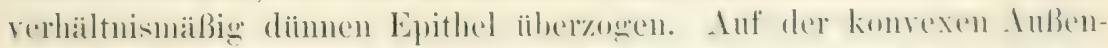

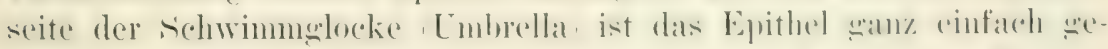
baut; es enthält vor allem nieht die geringsten Spuren von Nervenfasern und Muskeln (außer in einer Partic nahe am Schimmande).

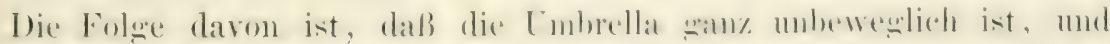
anch die stärsten an dieser angebrachten Reize von seiten der

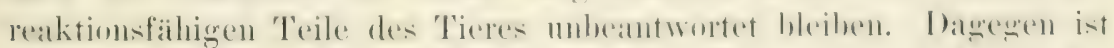

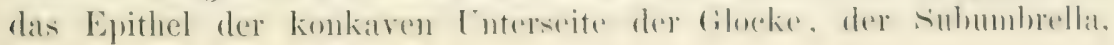




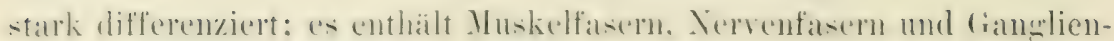
zellen. Besonders bei den craspedoten Medusen haben die Muskel-

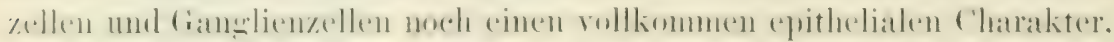

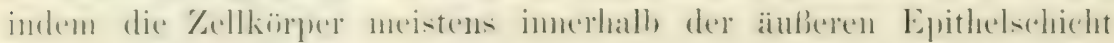

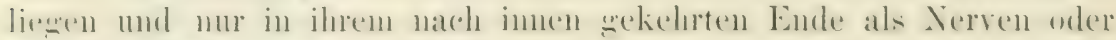

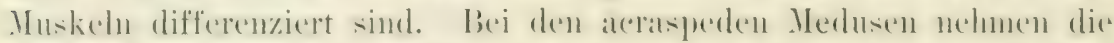

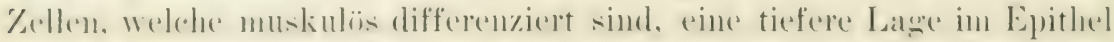

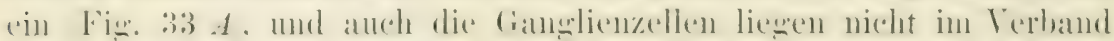
der obersten Epithelschicht, sondern zwischen dieser und der der

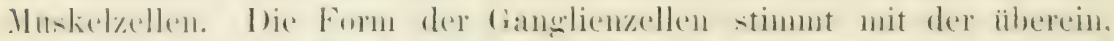

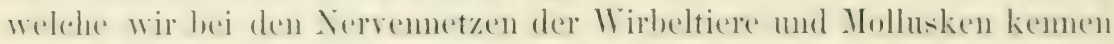
grelernt haben, und es gelang bereits den Gebridern Hertwigr, sich

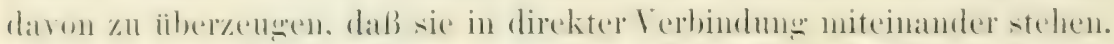

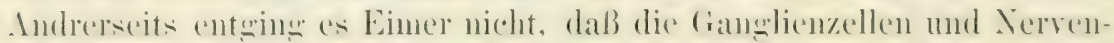

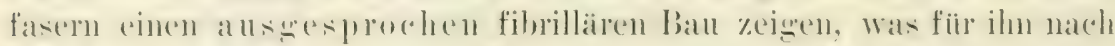

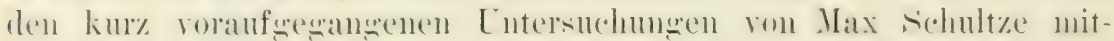
bestimmend war, diesen Elementen nervöse Natur zuzuschreiben.

Spaiter ist das Nervensystem acraspeder Medusen (Rhizostoma,

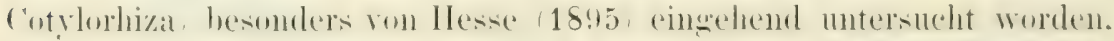
loh habe neine Lntersuchungen anf dieselben beiden Irten beschä̈nkt. weil ich auch an ihmen die meisten meiner physiologischen Untersuchungen gemacht habe. Meine Resultate stimmen mit denen ron Hesse fast durchweg ïberein; nur iber die ribrillen habe ich mancherlei lenes hinzuzufügen, weil mir meine Methode Fixation mit

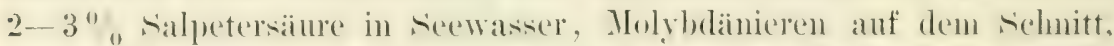

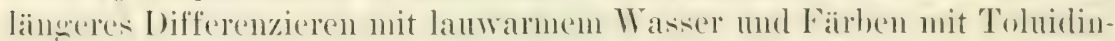
blau bei $56^{\circ} \mathrm{C}$.) eine bessere Darstellung derselben erlaubte.

Lntersucht man einen (guerschnitt der subumbrella von Rhizostoma wele Cotrlorhiza aus einem Teil, der Muskulatur besitzt, so fallen einem sofort zwischen Muskularis und außerer Epithelschicht horizontallaufende Fasern anf, welche im Innern feine Fibrillen zeigen. Ib und zu liegt in einer Anschwellung der Fasern ein Kern, an dem nu' (ain 'Teil der Fibrillen vorbeizieht, während die übrigen sich dent-

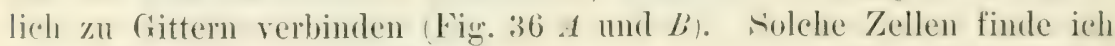
iiberall, wo ïberhaupt Fasern vorhanden sind, auch auborhalb der Ladien, hier allerding's — das mul ich Hesse zugeben - in weringerel Anzalıl. I)ie Zellen haben meist nur zwei dickere Fortsätze, welche auf weite Strecken zu rerfolgen sind. (Hesse gibt an, sie bis zu (j) nun rerfolent zu haben. Gewöhnlich gehen aber von den Zellen selher

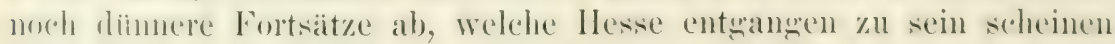

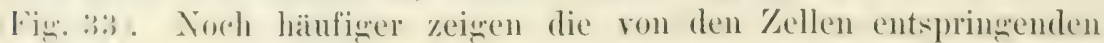
dirken lasern zeitenzweige, welche bald ans einem Bündel von vielen Fibrillen bestelen, hald nur von ciner einzigen Fibrille sehildet werden. 
Diese seitenzweige und Vebenfortsäze zeigen drei verschiedenc Verlanfsrichtungen: 1. Sie wenden sich nach oben und ver\%weisen sich

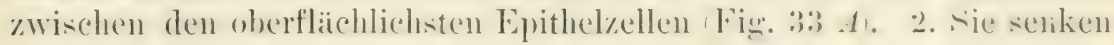

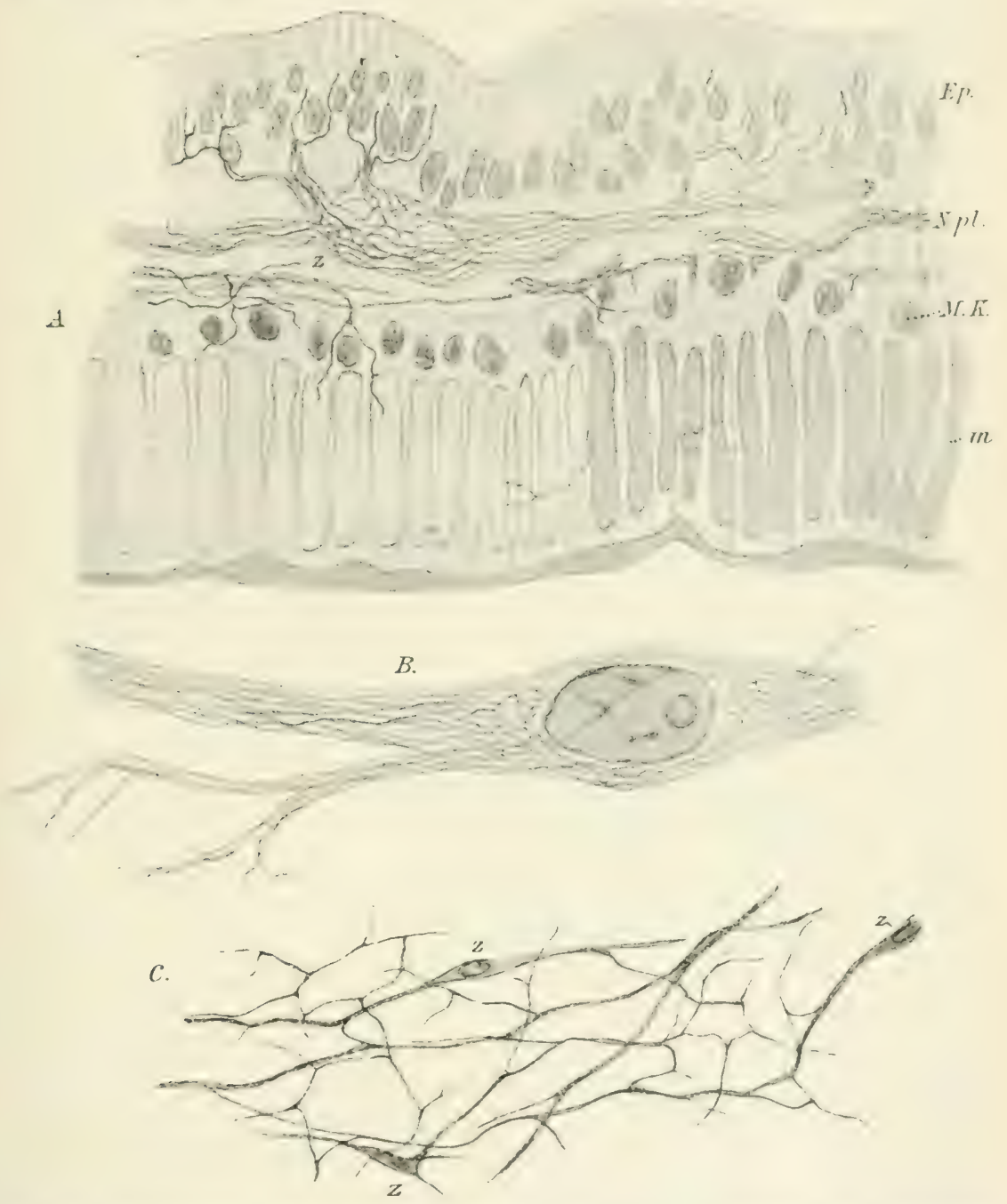

Fig. 33. Nervenelemente von Rhizostoma. A radiürer Schnitt durch ein Muskelfeld der Subumbrella, Ep. Epithel, $m$ quergeschnittene Iuskelfasern, II.K. ilıre Kerne, $\mathrm{N} p$. Nervenplexus. In demselben liegt bei $\approx$ eine große Ganglienzelle mit Fibrillennetz. Von hier gehen fibrillenlaltige Ausliufer ins Epithel und zu den Musheln. I Ebensolche Zelle. $C$ Nervenplexus mit eingestreuten Zellen aus einem Horizontalschnitt. $A$ und $B 1200 \mathrm{mal}, C: 200$ mal vergrübert.

sich in die Tiefe, laufen eine Strecke weit oberhalb der Keme

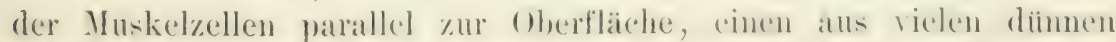
Fasem bestehenden Plexus hildend, mol treten dam \%wischen die 
Mnskelfasem, $11 n$ sich hier in die einzelnen Fibrillen anfzulösen, die sich damn noch weiter teilen, vielleicht sogar in die Muskelfasern eindringen. 3. Ole seitenäste verlaufen parallel zur Oberfläche - dies sind fast immer dickere Zweige - und rerbinden sich nit seitenfortsätzen andrer Zellen zu einem Netz lïin. 33 D. Das letztere kann man natiorlich nur an Horizontalschnitten wnt beobachten. - Wir hahen also hier ein diffuses Nerrennet\% ror uns, das einerseits mit der änberen Epithelschicht, also der rezeptionsfähigen Fläche, andrerseits mit der Muskulatur in Verbindung steht, so daß, da das Netz sich ununterbrochen durch die ganze funktionsfähige subumbrella ansdehnt, jeder Reiz, wo er auch in diesem Gebiet angesetzt werden mag, zu allen Muskelfasem hingelangen kamn, auch dam, wemn der Körper durch heliehig gewählte schnitte zu einem langen Bande anfgerollt ist.

In sehr schöner Weise hat Ilesse gezeignt, wie dieser epitheliale I'lexus, dessen netzine Natur ihm allerdings entgangen war, mit den Randkörpern in Verbindung steht, Organen, deren hohe Bedeutung für die Bewegung der Mledusen zuerst Eimer und nach ihm Romanes aufsedeckt hat. Ihre Physiologie wird uns weiter unten zn beschaftigen haben; hier nur einiges Anatomische: In Finur 34 ist ein schnitt dureh einen Randkörper mit seiner Umgebunğ dargestellt. Der Randkörper ragt, when und seitlich dureh Lappen Wsch.l gedeckt, ins Wasser hinaus. Am Ende befindet sich ein Sark, welcher durch das Epithel einer Gefäßausstülpung gebildet wird und der mit Kalkkristallen ansgefült ist diese liegen in \%ellen. Lmgehen wird der Sack rom äußeren Körperepithel, das besonders an stiel zu einem lohen Zylinderepithel mmgebildet ist. Die einzehen Zellen dieses Epithels gehen nach unten zu in feine Nerrenfasern uiber Ilertwig, welche einen dichten unentwirrharen Filz bilden. Ans diesem Nerrenfilz sehen radial verlanfende Nervenfasern hervor, welche kontinuierlich bis zum Nervennetz der Subumbrella ziehen. Es ist dies nur eine Faserstraße, wenn man will ein Radialnerv, der zum Netz hinfiilırt, denn die angrenzenden Partien sind nervenfrei (siehe das schematische Flächenbild Fï. 35\%. In Radiahnerven liegen viele Gamelienzellen, hesomders dicht hinter den Randkiorperstiel, wo er ("ine ebenfalls mit bohem Epithel besetzte (irule, die innere simnesgrube, durehzieht. Nachdem der Radiahnerv bereits das Netz erreicht hat, findet man immer noch in der radiären Straße, welehe durch den Verlanf der Gefïße leicht erkembar ist, die meisten (ianglienzellen.

Wie die Figur 35 zeigt, breitet sich die Muskulatur auf der Sub-

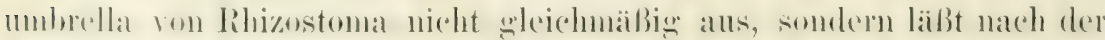

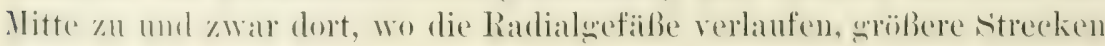




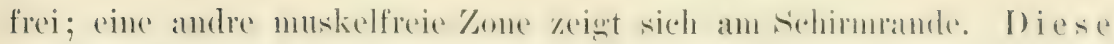
muskelfreien Felder Werden aber rom Nerrentrot ebenso durehzogen, wie die Muskelfeldel selbst. ${ }^{1}$ ) Nur der allerauBerste Schimund bleibt anch frei von Nerrenfasern und

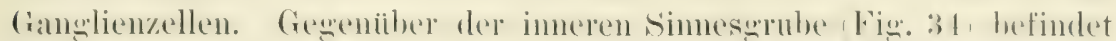

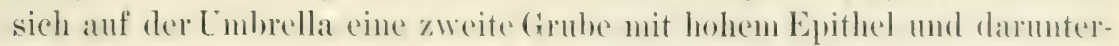
liegenden Vervenplexus, die äuBere simnesgrube. Sie soll mit dem Randkïrperstiul nach Hesse dureh Fasern in Verbindume stehen, Wolche durch die Gallerte hindurehgehen. Ich habe mich nicht ron einer

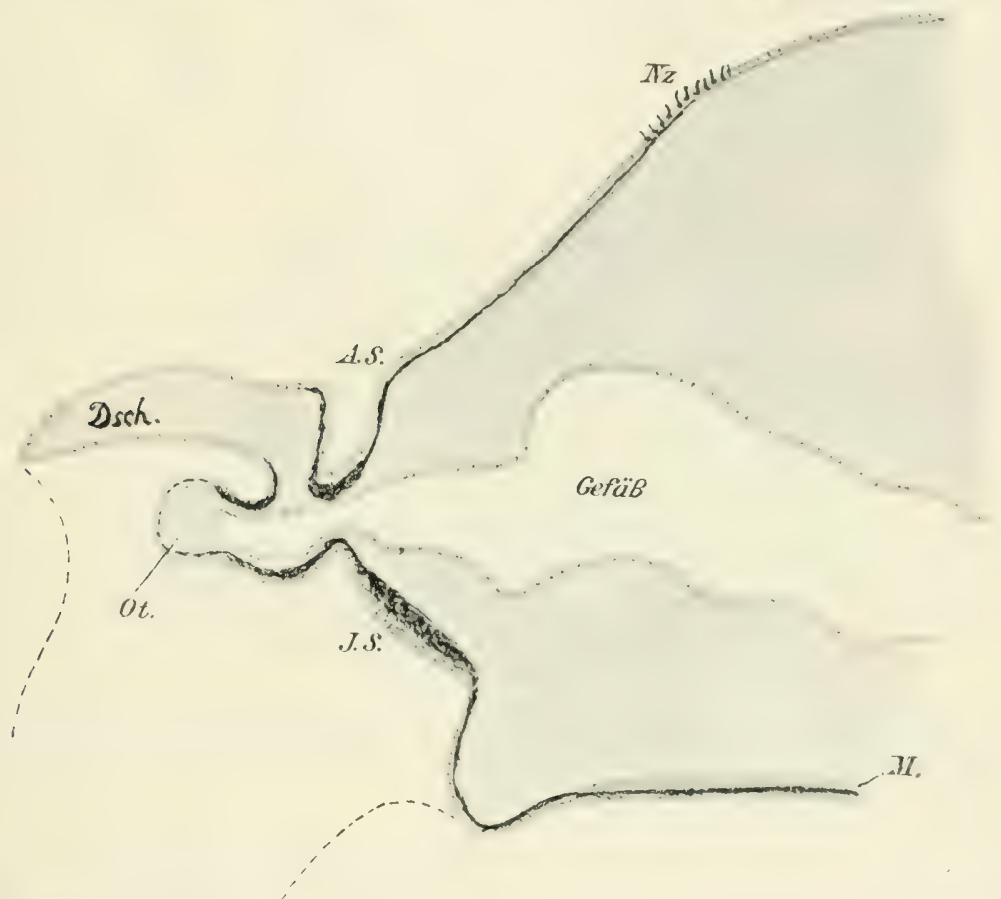

Fig. 34. Radiärer Sehnitt durch einen Randkörper von Rhizostoma. Dseh. Deckschuppe, A.S. iußere, I.S. innere Sinnesgrube, Ot. Otolithenhaufen des Randkörpers, M. Muskulatur, $N_{i}$. Nesselzellen. Schwarz ist der Nervenplexus gezeichnet.

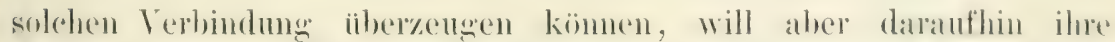
Existenz nicht leuonen, denn sonst wäre diese Grube wanz anber ler-

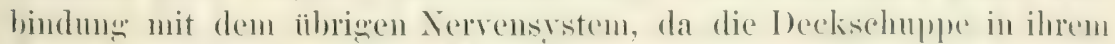
Epithel sanz sicher keine Nervenelenente enthiilt. Vom der änberen

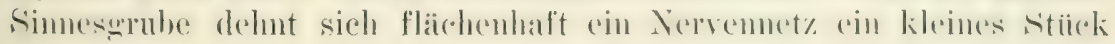

1) Wenn Hesse angibt, daf die Mnskelfasern unter den Radialstrafien fortziehen, so bezieht sich das offenbar nur auf den peripheren Teil derselben. In den zentralen Partien, die ich als muskelfreie Felder bezeichne, findet sich niemals atuch nur eine einzige Muskelfaser, ebenso am Rande. 


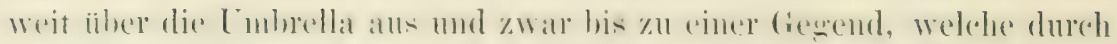

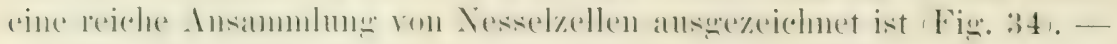

Eine ron den bisher besprochenen etwas differente Form der Nervennetze findet sich in Vorhof und Ventrikel des Frosehherzens. Ich komme damit auf die viel besprochene Frage der Hermerven. besmeders der Verven in der Kammermuskulatur, welche ron den Anatonnen fatst durehgehend dihin beantwortet wird, dak es

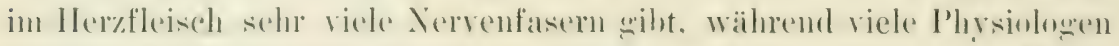

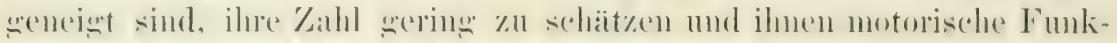

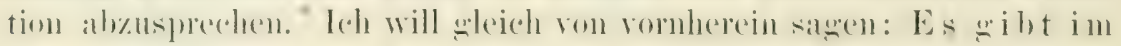
gan a n Körper des Frosehes - und auf den kommt es allein an, dat sich fast alle phesiologineden Lutersuchungen des Herzens auf ihn beziehen - keinen einzigen Muskel, der a ueh nur ann ül herud

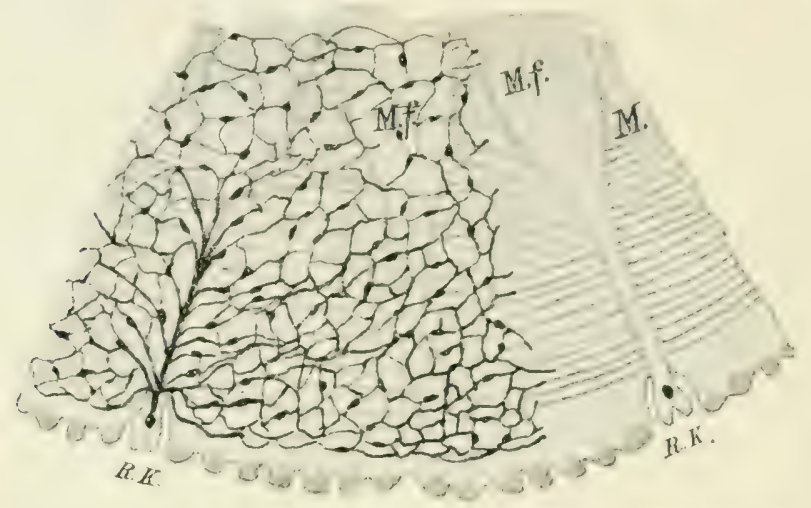

Fig. 35. Etwas schenatisiertes Flächenbild von einem Teil der Subumbrella von Rhizostoma. Rk. Randkörper,, . Muskelfeld, M.f. muskelfreie Felder. Schwarz und im Verhïltnis viel zu groß und nicht genitgend dicht ist das Nervennetz auf der linken Seite eingezeichnet.

soviel Nervenfasern enthielte, wie die Herzmuskulatur. Diese Fasern sind zum größten Treil autochthem und fast durchüingign makklos, so daß sie trotz ihrer Menge leicht äbersehen werden kömen.

Nur bei Inwendung sperifischer Nervenfäbmesmethoden ist man imstande, Anfschliisse iiber den Verlauf und die Zahl der im Herzfleisch enthaltenen Nervenfasern und iiber die Existenz und Verbreitmog von Ganglienzellen in demselben zu crhalten. Daher bahen alle die Untersuchungen, welche, mit alten Methoden unternommen, zu negativen Resultaten führten, nur noch cine sehr geringe Bedentumg Engedmann, 1875, Lüvit, 1880, 11. a.. I Ie crsten, die die Muskulatur

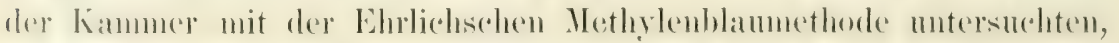

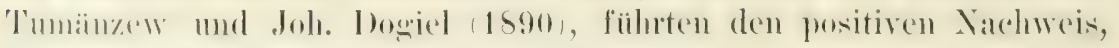

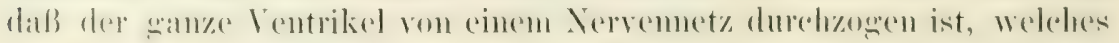
viele kleine Ganglienzellen an den Knotenpunkten enthält. Schon 
friiher haben aber L. Gerlach (1876) und Ranvier (1850), wenn auch nicht so iiberzengend, die reichen Nervenplexus des Her"zleisehes

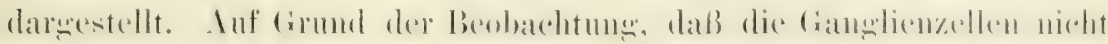

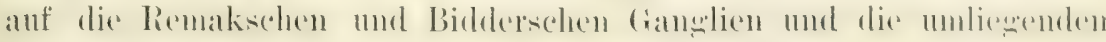
Partien beschränkt seien, wie dies yon Engelmann und andern be-

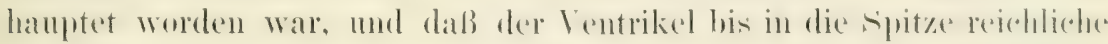

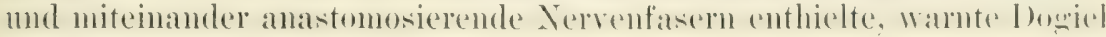
vor der Anmahme der Engelmannsehen Lehre von der muskuläen Erregumgleitung im Herzen — aber vergebens! -

Nervenfasern mit reichlichen Verzweigungen wurden damn späiter

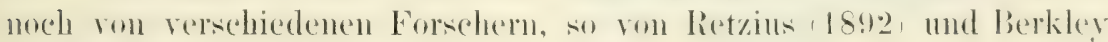

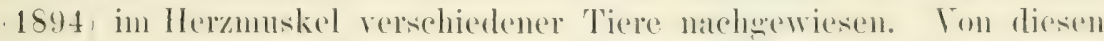
ist aber jedenfalls Berkley am weitesten gekommen, dem er sah (bei der Maus), daß die Fasern hier und dort mit Ganglienzellen in Verhindung stehen und daß die Fasern selher mutereinander roichliche Anastomosen eingehen Golgische Mrethoder. Mit dersalben Methode stellten anch Heimans und Demoor 1894, reichliche Not\% in Iterzen rom Frosch und von Siugetieren dar.

Ich selber labe meine Versuche auf Frösche beschränkt und mich dex Methylenblaninjektion von der Tena abdominalis aus bedient. I L m anch in Inneren eine Fäbung zu ewielen, ohme die topmeraphische Ühersicht zu zerstioren, wurden die anseneschnittenen Ine\%en in vichen Fällen vom sinus ans mit einem Blasebale durchlouftet. Vorfixierune mit Ammonimmpikrat, Nachbehandlung mit Ammonimmmolybdat [Lethe. 1896]. Einbetten in Paraffin, Schnittdicke 20-30 $\mu_{0}$ ) Auf diese IVeise habe ich mehrmak eine recht vollstandige Färome des Nervennetzes erzielen kïnnen. I)as auffallendste dieser Vetze gexentiber den

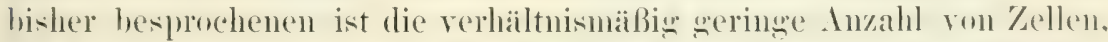
die in ihm enthalten sind. Die Zahl dee Fasern, welehe dureh 'Teilume eines Fortsatzes entstehen, ist eben sehr groß, so daß die Zahl der Zellen gegen die der Fasern mehr zuriektritt. Trotzdem muB ich nach meinen Präparaten die Zahl der Zellen im Ventrikel auf viele

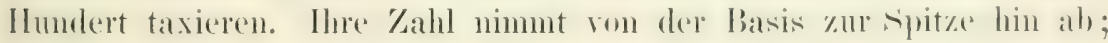
aber anch an der äuBersten sipitze kommen noch fianglienzellen \%ur lieobachtung. Die Herzspitze ist also zwar arm an Ganglienzellen, aber nicht ganglienzellfrei. Die Zellen sind

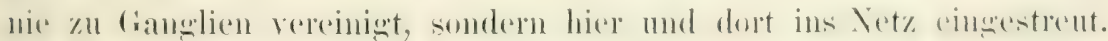
Da sie außerdem ziemlich klein sind - in der Regel kleiner als rote

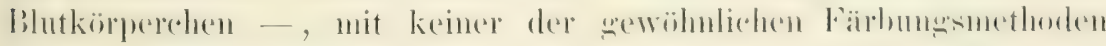
etwas Charakteristisches zeigen und ebenso wie die Zellen des perivaseuläen Netzes kene Nisslschollen enthalten, so sind sie an andern

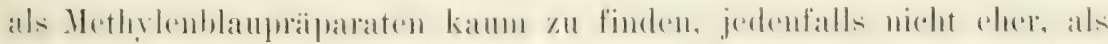
man ihre Lage aus Methylenblaupriparaten kemnen gelernt lat. 
Bekanntlich besteht die Ifuskulatur des Froschherzens ans einzohen Muskeltrabekehn. Welde sich besonders in der Kanmer netzig untereinander verbinden. Auf Schnitten sicht man die Trabekeln wieder ans einzelnen Fatsern zusanmengesetzt. Yaresationsurajparate lassen zwar wie bei den sailuetieren einzehe verzweigte Muskelzellen erkemenen, derch hialt man in nenerer Zeit ron diesen Zellen nicht mehr viel. weil die. Inskielfibrillen sich an die Zellgrenzen nicht kehren und kintimuirlich wanze Reihen rom Zeellen durchziehen ron Ehner. 19001. II. Heddenhain. 19011: heim Frosch soll allerdings nach Ehoner 1900 die Vereinizung der Zellen nur eine geringe Anshildung besitzen. - I le Mnskulatur ron Konhof und Kammer zeigt sidh an der Atrio-Ventrikular-
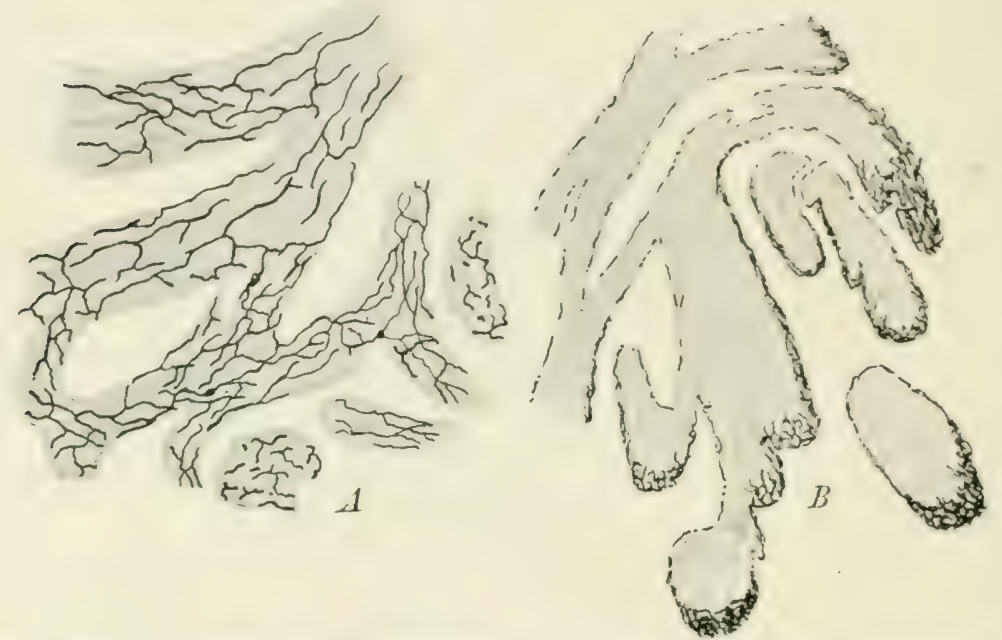

Fig. 36. A Einige Trabekeln des Kammermuskels vom Frosch. Färbung des Nervennetzes mit Methylenblau. Nur die dickeren Fasern sind gezeichnet. B Trabekeln, an denen die elastischen Fasern nach der Weigertschen Methode gefürbt sind. Vergrößerung: Leitz Objek. 3, Ocular I.

snerenze durchaus voneinander getrennt: breite Binderewehsmassen und Bhutgefäße liegen dazwischen. Nur dort, wo die Vorhöfe in die Kammer ühergehen, an den Her\%klaplen, ziehen Muskelhündel von den Vorhöfen an den Klappen entlang der Kammer zu. Xach einigen . Jutoren sollen num diese Bündel kontinuerelich in die Muskulatur der Kamner über-

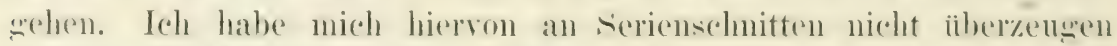

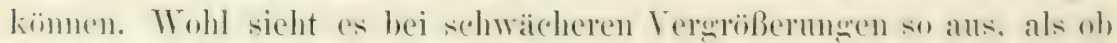

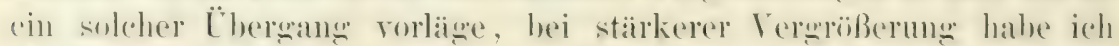
aber den Eindruck gewomnen - besonders an Praiparaten. die mit dere

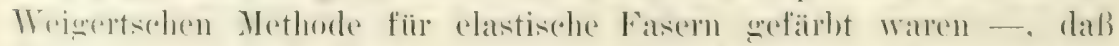

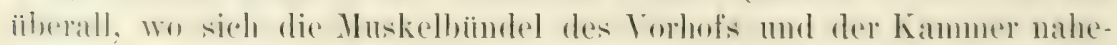

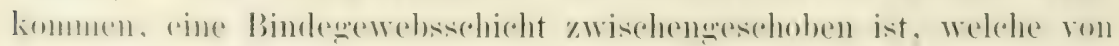
sehr vielen elastisehen Fasem durehsetzt ist. Mir seheint demnach 
die alte Anschaumg vollkommen zu Recht zu bestehen, nach der die II uskulatur der Vorhöfe von der der Kammer überall und rollkommen getrennt ist. Daß andrerseits die Muskulatur der Kammer von der des Bulbus aortae vollkommen gretrennt ist, darïber kamn wohl kanm gestritten werden, und diese Trennung ist ron grade so großer Wichtigkeit für die Dentung der physsiologisehen Vorgainge, wie die zwischen Vorhof- und Kammermuskulatur.

Die Ganglienzellen des Nervennetzes liegen num meist an der Oberfliache der Muskeltrabekeln, und zwar gewöhnlich dort, wo zwei Trabekel sich beriihren, oder im Winkel, wo solche \%usammenstoßen (Fig. $36 A$ und $37 z$ ). Sie haben zwei bis rier fortsuitze, welche sich in die Iruskeltrabekel hineinbegeben und sich dort in eine große Anzahl meist stark varicös gewordener Fasern auf́splittern. Die stärkeren dieser Fasern verbinden sich sehr häufig mit Fasern, welche ron andern Ganglienzellen ausgehen, so daß ein dichtes Fasemetz entstelit, das in und auf den Trabekeln liegt. Diinnere zweige, die vielfach nicht dicker als einzelne Nemrofibrillen sind, dringen augenscheinlich in die ein-

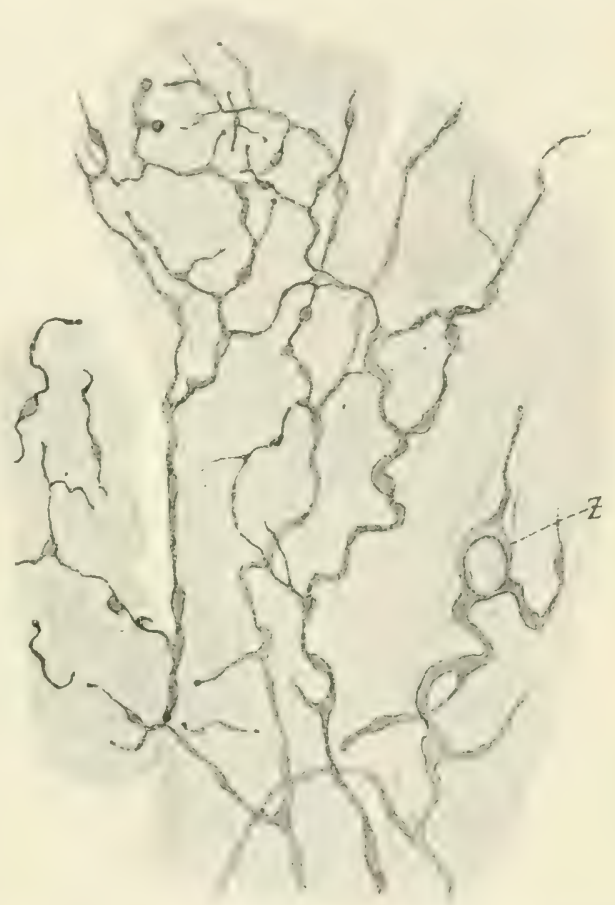

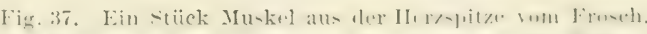

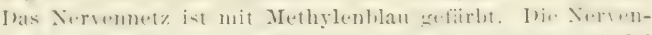
fasern gehen ron einem Muskelbïndel auf die Nachbarbiindel

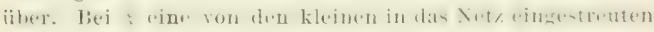
Ganglienzellen. Apochromat 1,3, Compensationsocular 6 . Auf $2 / 3$ rerkleinert. zelnen Muskelfasem selber ein, um sich hier noch weiter zu verzweigen. Wirkliche Nerren-

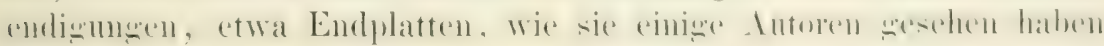
wollen, habe ich nicht entdecken kömnen. Überall da, wo zwei

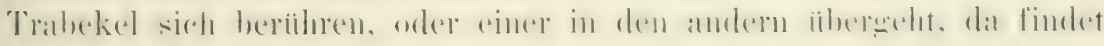
auch eine Verbindung der Nervennetze statt, wie dies in Figur 37 bei starker Vergrößerung dargestellt ist.

Während sich im allgemeinen elastische Fasem mit Methylenblau nicht färben, habe ich eine solehe Färbung im Herzen zweimal ge- 
selene Dannit mir nicht der Einwand gemacht werden kïnnte, meine Netze beständen aus elastischen Fasern, habe ich einen Vergleich

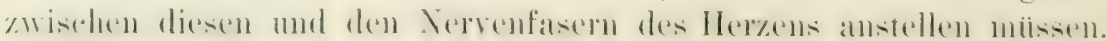

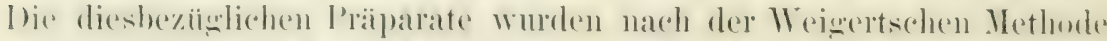

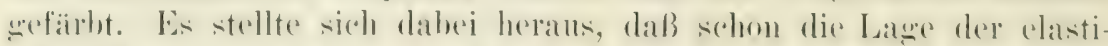

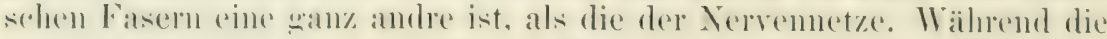

Nervemetze sich hauptsächlich im

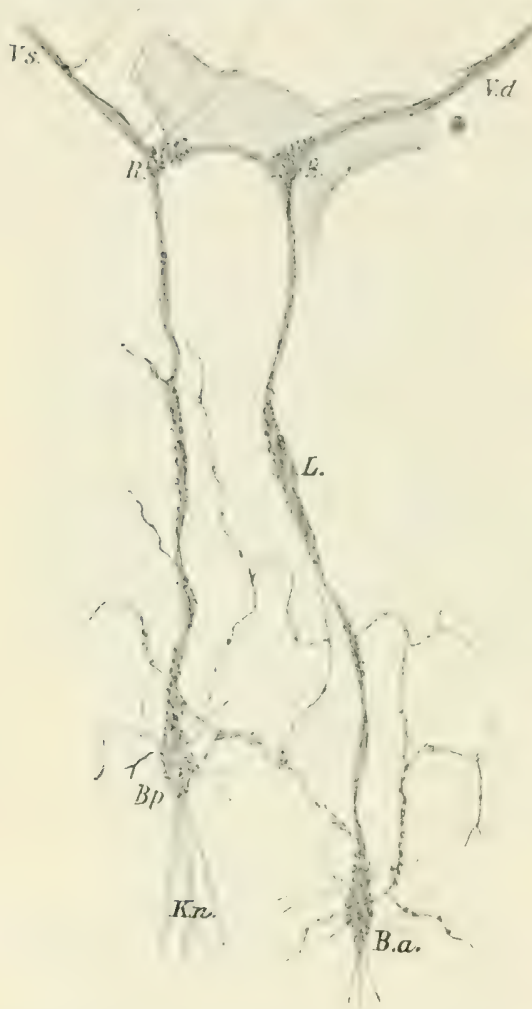

Fig. 38. Ganglien des Herzens nach Dogiel (nach einem eignen Isolationspriparat in einigen Punkten rervollstindigt). IV Vagus, $R$ Remaksche Ganglien, L Ludwigsche Ganglien, B Biddersche Ganglien.

Inneren der 'Trabekeln finden, sind die elastischen Fasem ganz auf ihre Oberfläche beschränkt, hier ein dichtes Netz bildend. Dieses Netz ist immer an den 'Trabekeh am stiirksten, welche dem Druck am meisten ansgesetzt sind, d. h. welehe am Haupthohhraum der Kammer liegen. Reichlich vorhanden ist es anch uiberall dort, wo iiberhaupt Blut hingelangt, also an den Blutlagunen, welche in der Kammer des Froschherzens die CoronargefäBe ersetzen. Dagegen fehlt es fast ganz an den Trabekelfläehen, welche aneinanderstoßen oder blutfreie Spalten umschließen (Fig. 36 B). Im iibrigen ist auch der ganze Charakter der elastischen Fasem ein ganz verschiedener.

Überall an der Oberfläche der Kammer und des Vorhofs ist das Nervemetz in sich geschlossen, anch an der Atrio-Ventrikulargrenze; selbst da, wo sich hier Kammer und Vorhof sebr nahe kommen, sicht man anch nicht eine einzige Briicke, welehe beide Netze miteinander rer-

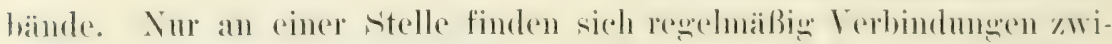
schen den Vorhöfen und dem Netz der Kammer, das ist an den Her\%klaplen. Diese Verbindung ist aber wohl kein direktes Ineinanderflieben beider Netze, d. h. es geht das Nervennetz des Vorhofs nicht an den Klappen entlang in das der Kammer ïber. Die Verbindumg scheint

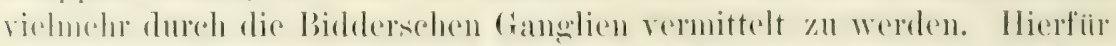

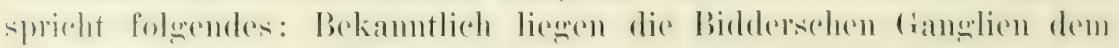
Irsprunge der Atrio-Ventrikularklappen angelagert. Sie bestehen ans 


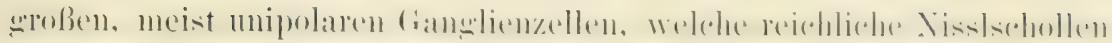

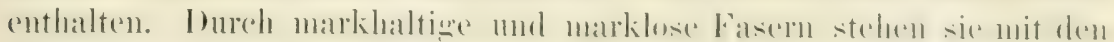
Remakschen Ganglien und weiterhin mit dem Vagus in Terbindung

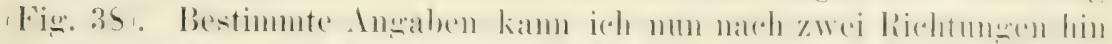

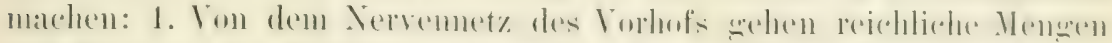

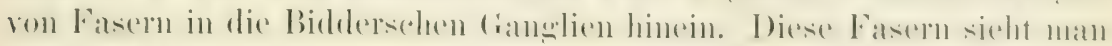

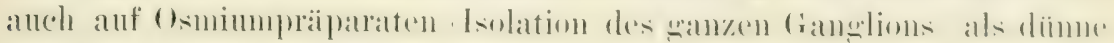
marklose Fasern, welche besonders am proximalen Pol, aber auch an den Längsseiten in jedes der beiden Ganglien eindringen. 2. Die fast durehweg marklosen Fasern, welehe jedes Biddersclue Gangion am distalen Pol rerlassen nnd den Klappen entlang ziehend zu Biindeln vereinigt in die Kammer treten, gehen hier direkt in das Netz der K ammer iiber (F i g. 39). Die zuerst parallel rerlaufenden Faseru teilen sich bein Eintritt in die Kammer (manchmal schon an der Klappenwand) und gehen gewöhnlich bald in eine von den kleinen, dem Netz eigrentïmlichen Ganglienzellen iilere, deren Fortsütze dam zum Teil in die Muskulatur werene, zum 'Teil mit den

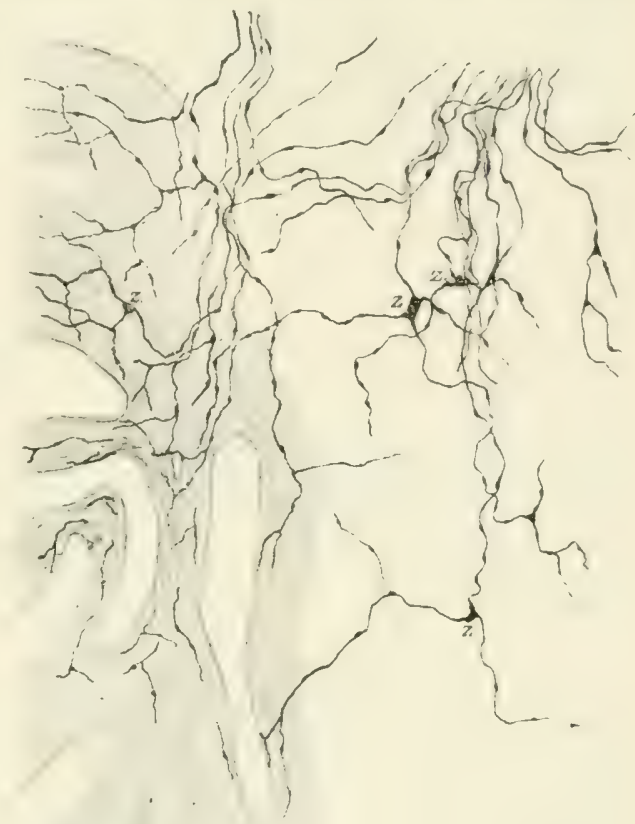
Fortsaitzen andrer solcher

Fig. 39. Einstrahlung der vom Forhof kommenden mark-

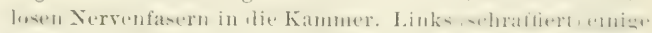
Muskeltrabekeln, die Fasern rechts davon liegen auf einer Klappe. Der Vorhof schlieft sich nach oben hin an die

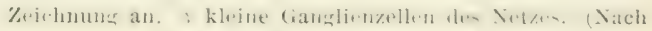

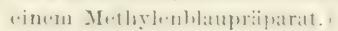

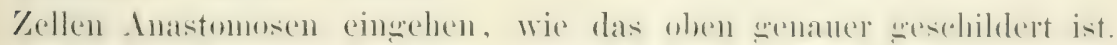

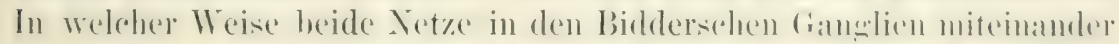

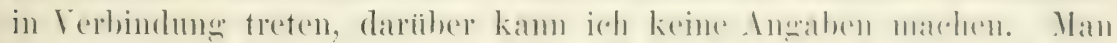

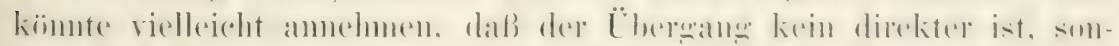

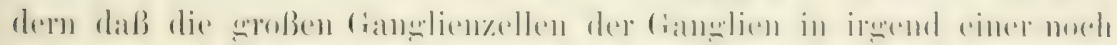
aufzudeckenden Weise zwischen das Nervennetz der Vorkammer mud

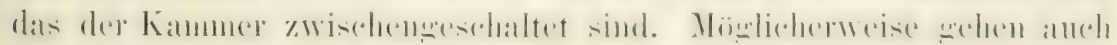
manche der langen Nervenfasern, wetehe an den Klappen entlang 


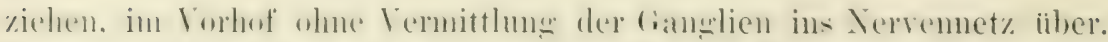

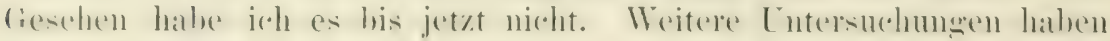
hier zu entscheiden. - Von dieser Verbindungsweise, welehe an drei gnt gefirbten Herzen die einzig sichtbare war, habe ich einmal eine Ansmahme gesehen: auch an diesen vierten Her\% war die Faser-

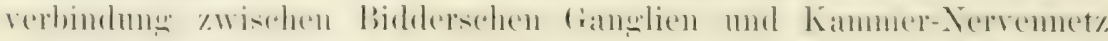

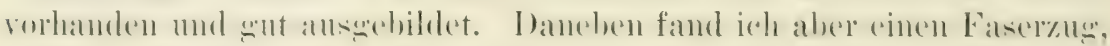
welcher, weit von den Klappen entfernt, auf der linken Seite des

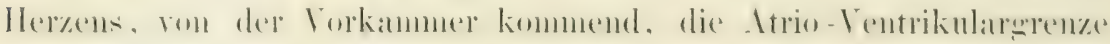
durehsetzte mol sich dam im Netz der Kammer auflöste. Von wo dieser

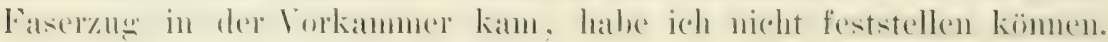

SIEBENTES KAPITEL.

\section{Vergleichung des Zusammenhanges der nervösen Ele- mente bei verschiedenen Tieren und die Übereinstimmung der Ergebnisse mit den Resultaten des physiologischen Experimentes.}

Die Unterschiede zwischen den verschiedenen Formen des Nervensystems sind bedingt durch die Lage der Fibrillengitter und die An- oder Abwesenheit langer Bahnen S. 96-100. - Die beiden Formen des zentralisierten Nervensystems S. 100. - Je höher die Ausbildung desto mehr nimmt die relative Masse der Ganglienzellen ab S. 102-104. - Ursprüngliche Gleichwertigkeit aller Ganglienzellen und ihre topographische Differenzierung bei höherer Entwicklung S. 104. - Ubiquitait der Reflexe bei den Nervennetzen. Ausbreitung des Reizes nach allen Richtungen S. 105 n. f. - Beweise, daß die Reizleitung bei den Medusen nervös ist S. 107. - Irreziprozitiat der Leitung von Nerv anf Muskel bei den Medusen S. 105. - Das Verhältnis zwischen Nervennetz und zentralem Nervensystem S. 111-123. - Die Reflexe bei Planarien ohme Zentrahervensystem S. 111. Aplysia S. 113-118. - Zunahme der peristaltischen Körperbewegungen nach Herausnahme des Zentralnervensystems. Bestehenbleiben der einfacheren Reflexe. Zunahme des Tonus. Ausbreitung des Reizes je nach Stärke desselben S. 115, 116. Bei Reizung der Nervenstïmme tritt keine streng lokalisierte periphere Wirkung ein, sondern eine je nach Stïke des Reizes mehr oder weniger ausgebreitete S. 117, 118. - Versuche an Limax und Arion mit ïhnlichem Erfolge S. 11s-121. Vergleich zwischen den Erscheinungen bei den Mollusken mit den Erfahrungen am Ösophagus und Magen des Frosehes S. 121. - Das vollstindige Erlöschen der Reflexe nach Zerstörung des Zentralnervensystems bei den Tieren, welehe kein peripheres Nervennetz besitzen S. 123, 124.

In Figuren 40-44 habe ich zwar schematisch, aber doch unter

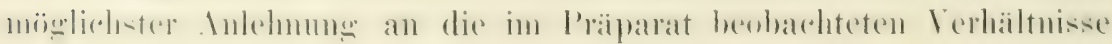


die Verkniipfung der Nervenelemente bei den verschiedenen 'T'yen des Nervensystems dargestellt. - Die alleinige Existenz ron Nerrennetzen bei allen niedrigen Metazoen Medusen, Polypen, Aetinien,

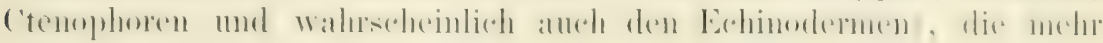
oder weniger epitheliale Lage derselben bei diesen Tieren und allen

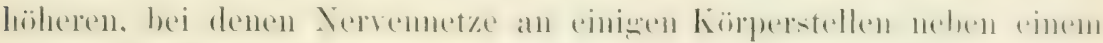

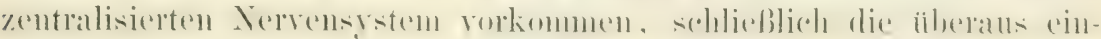

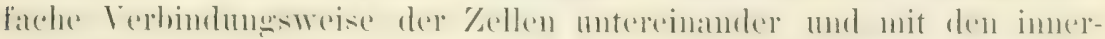
vierten Geweben denten daranf hin, daß wir in den Nerrennetzen die phylogenetisch ailteste Form des Nervensystems rol uns haben. Tou

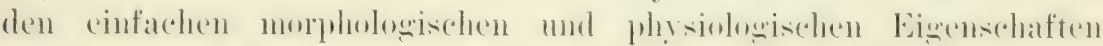

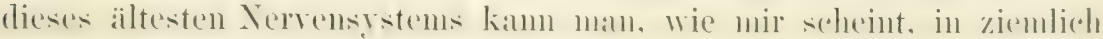

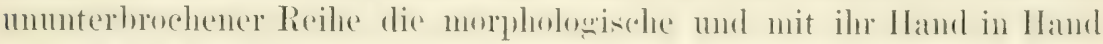

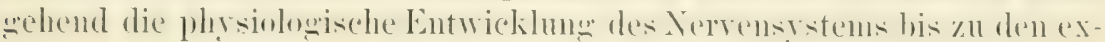

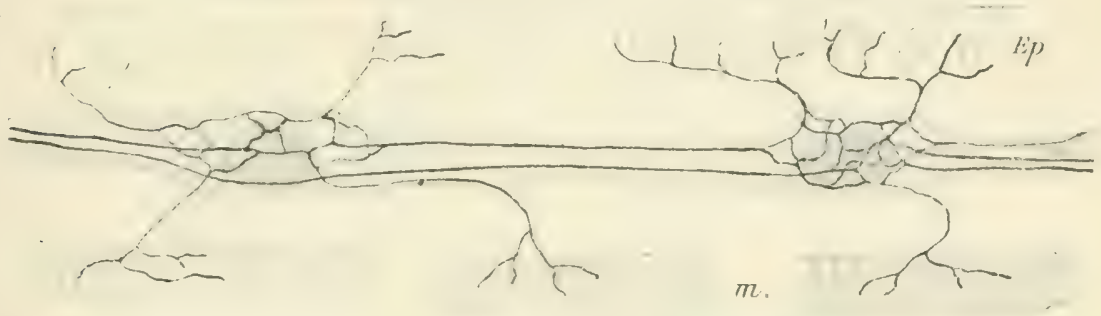

Fig. 40. Schematische Abbildung des Fibrillenverlaufs in einem Nerrennetz (Medusen, subepithelialer Nerrenplexus rom Froschgaumen u. s. w.). Ep. Epithel, m. Muskelfasern.

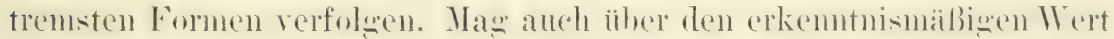

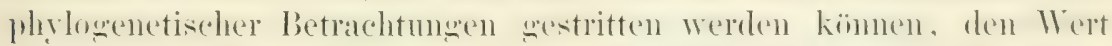
haben sie und werden sie auch immer behalten, daß sie uns die Grup)-

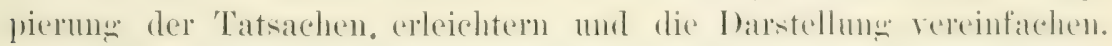

Allen Formen des Nerrensystems gemeinsam ist die Kusammen-

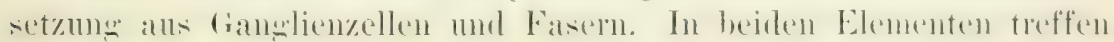

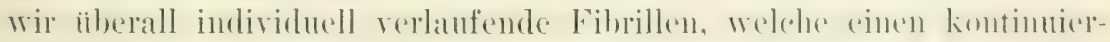

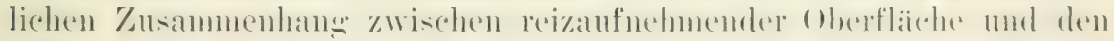
effektorischen Organen - Muskeln, Driisen n. s. W. - rernitteln.

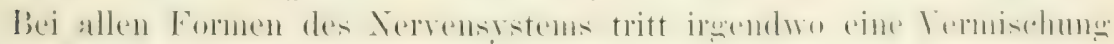

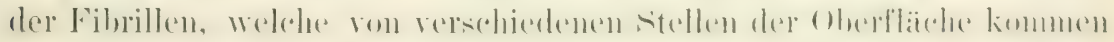
und zu versehiedenen effektorischen Organen hinzichen, vernittels cines Fibrillengitters ein, und es ist ror allem die Lago dieses Gitters, welche die Unterschiede bei den verschiedenen Formen ansmacht. Eimen zweiten, für die grobanatomischen Verhälnisse viel cinschneidenderen Unterschied gibt die Ausbildung lanser bahnen ab, welehe bei allen höheren Formen des Nervensystems in Erscheimmon tritt und eine Zentralisation des Nervensystems mit sich bringt. 


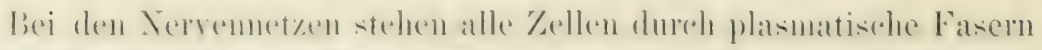

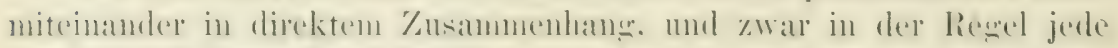
Zelle mit den närohsthemathbarten, mud diese wieder mit ihren Saleh-

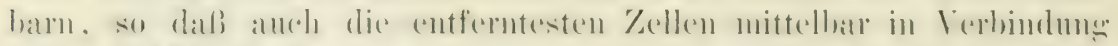

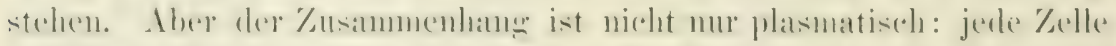

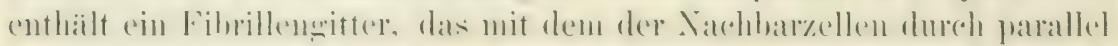

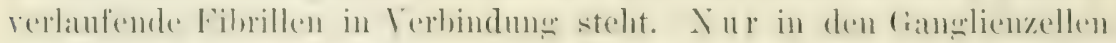
sind hier Gitter vorhanden, zwischen zwei Zellen ist nie ein solehes eingeschaltet (Fig. 40).

Aurh in Xervensystem der Hirudineen spielt das Fibrillengitter der

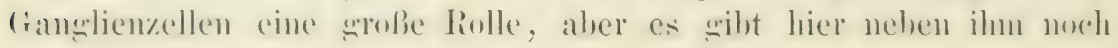

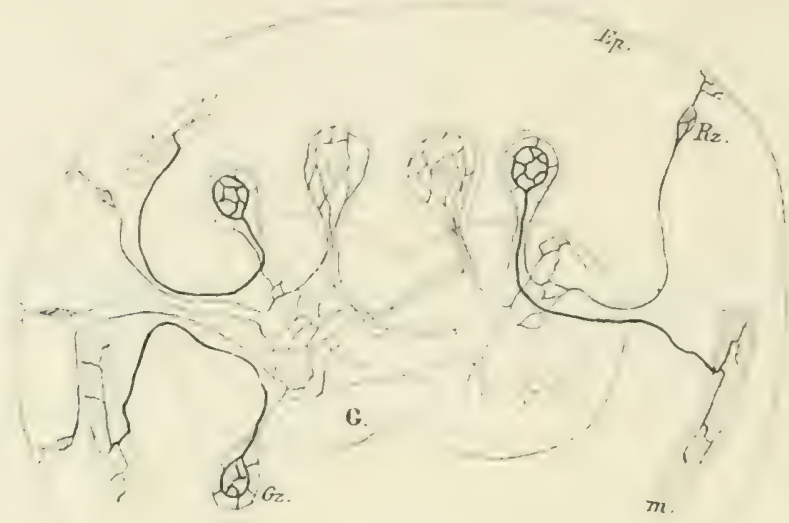

Fig. 41. Schema des Fibrillenverlaufs im Nervensystem ron Würnern (Hirudo). G. Ganglion, $G \approx$ Ganglienzellen, $R \approx$. Rezeptionszellen.

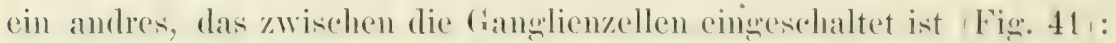
die (Bamplienzellen des zentralen Vervensystems stehen nicht mehr in einem direkten plasmatischen Zusammenhang, somdern die Kontimutät wird nur norh von Filnillen heresestellt, welehe in der Regel dieses zwischengeschaltete Netz passieren. Anf diese Wreise treten die Zellen

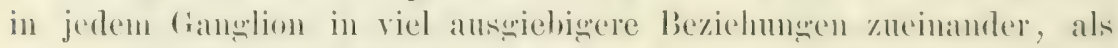
es bei den Nervennetzen möglich ist. Dort ist zwar die Beziehumg

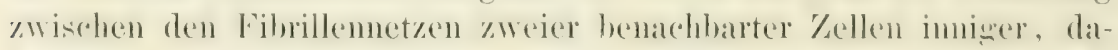
fiir sind aber hier anch relativ weit voneinander entfernte kellen re-

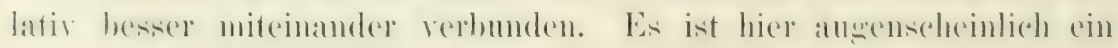
'Teil des Fibrillengitters, das wir bei den Nervennetzen allein in den Ganglienzellen antrafen, aus den Zellen heraus verlagert und zwischen die Zellen cingeschaltet, welche, um diesen Zusammen-

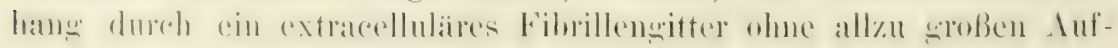


wand von Material zu elmöglichen, auf einen kleinen Raum zusampluengezogen sind.

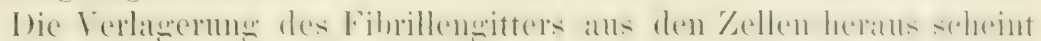
bei den Crustaceen noch ausgesprochener zu sein. In allgemeinen

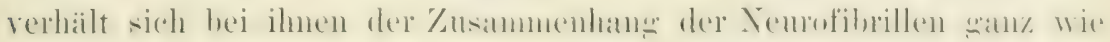
bei den Hirudineen; nur in einem Punkt besteht ein großer Unterschied, weleher zu den Verhältnissen, wie wir sie bei Wirbeltieren

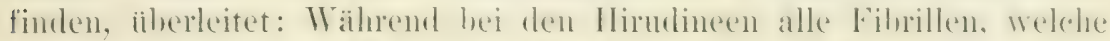
einem plasmatischen komplex (ianglienzelle mol daman hämsenden Fasern und Aufsplitterumenen, also das, was man geemeinhin als Xemom

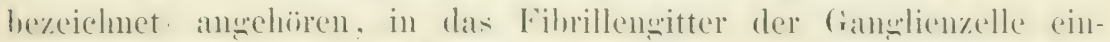

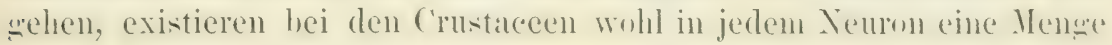

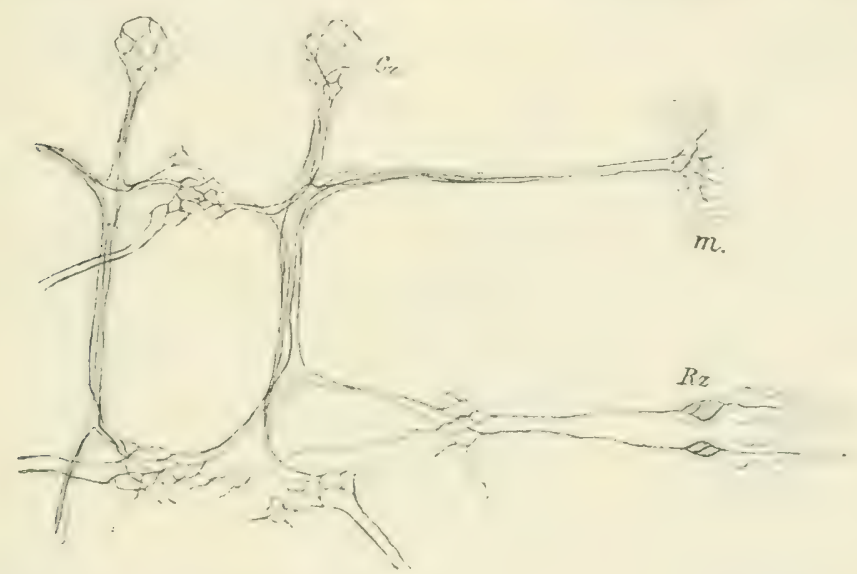

Fig. 42. Sehema des Fibrillenverlaufs im Nervensystem ron Crustaceen (Carcinus).

Fihrillen, welche nicht in das fitter der zugehörigren Gamelienzelle eintreten, ja die Zelle iiberhaupt nicht passieren (Fig. 42).

Lei den Wirbeltieren ist die Verlagerumg des Fibrillengitters ans den fanglienzellen leraus nahezu vollständig gूeworden. Zwar finden sich in einigen \%ellarten anch hier noch Fibrillenwiter s. si, aber in den meisten ist nichts davon zu bemerken. Das ganze Fibrillen-

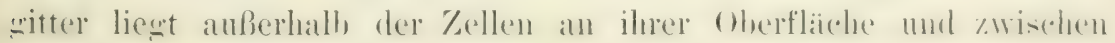
ihnen [pericelluläres diffuses Golginetz (?) (Fig. 43).

Wo wir in der Tierreihe Nerrennetze finden, da sind sie immer

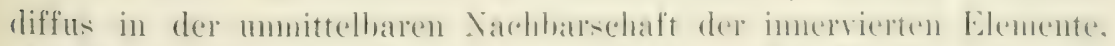

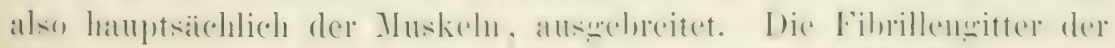
Zellen treten immer nur mit der dicht benachbarten Muskulatur und

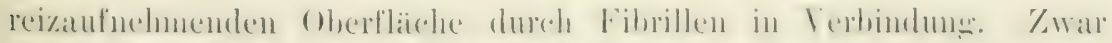

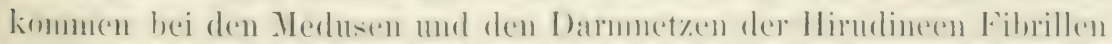

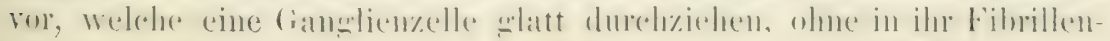


gitter iiberzugehen, aber man wird annehmen diufen, daß sie doch

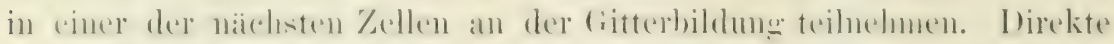
Verbindungen weit entfornter I'artien des Xervemetzes werden jeden-

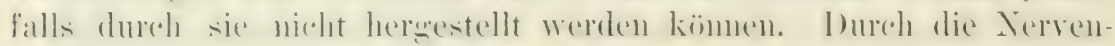
netze - das liegt auf der Hand - können immer nur ganz diffuse lieflexe vermittelt werden: entweder wird ein heis, der an einer stelle

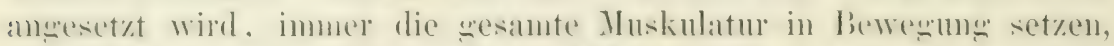

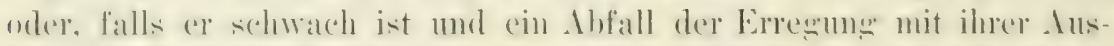

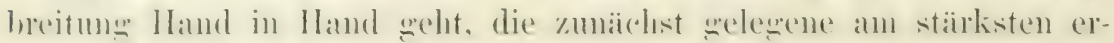

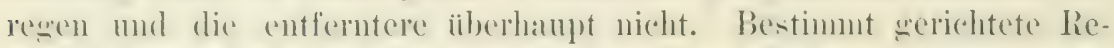
flexe, stirkere Wirkungen an entfernteren Orten u. s. w. werken war

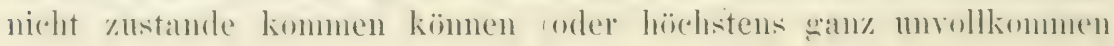

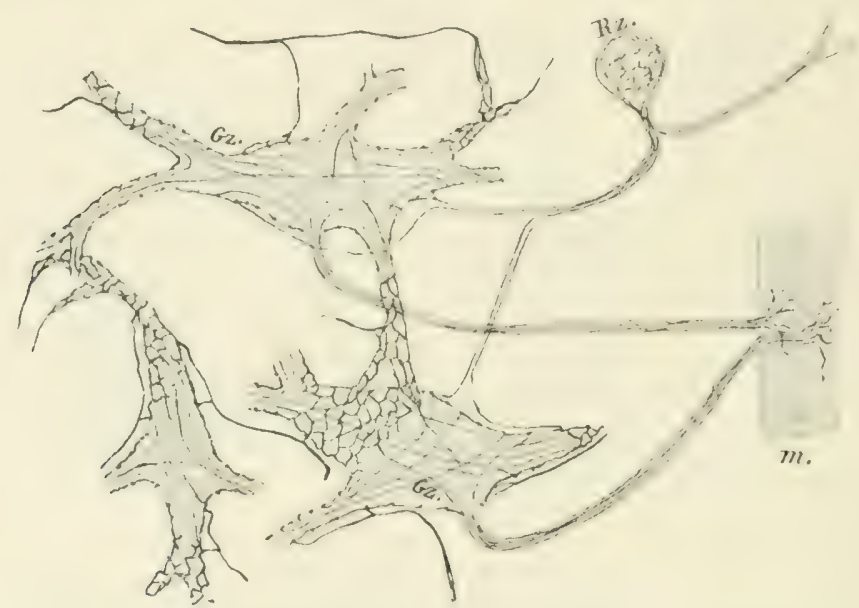

Fig. 43. Schema des Fibrillenverlaufs im Nervensystem der Wirbeltiere.

anf die Weise bewirkt werden kömnen, daß die Muskulatur an gewissen stellen eine ereringere lieizschwelle besitzt, als an andern.

Damit entferntere Partien des Körpers gemeinsam miteinander arbeiten kümen, mïsien die Fibrillengitter, von denen ans ihre Mus-

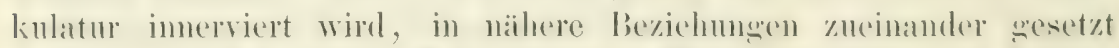

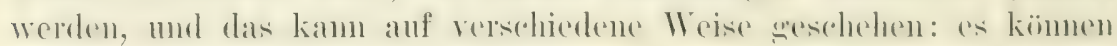
zwischen den enternten Fibrillengittern lange Fasem mit paralled verbanfenten fribrillen eingeschaltet werden, es kïmnen aber ande die

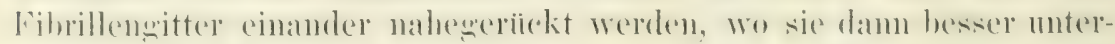
einander Fibrillen anstauschen können. Aber anch hierbei ist natiirlich die Ausbildung langer Fasern merlikßlich; sie werden in der Hauptsache vom Gitter zur reizanfnehmenden Fläche und zu den

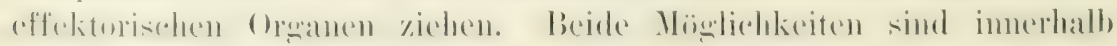

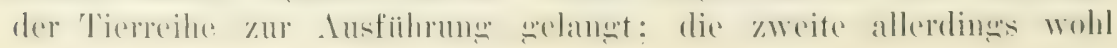


nirgends in reiner Form, sondern immer mit der andern vermischt.

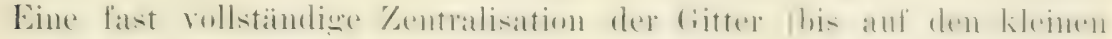
Rest von Nervemetz, der fast bei allen Tieren zu gewissen Zweeken

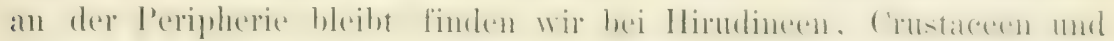
Wirbeltieren, wobei die Gitter sich mehr oder weniger von den Ganglienzellen emanzipieren; bei den niederen Wiirmern und den

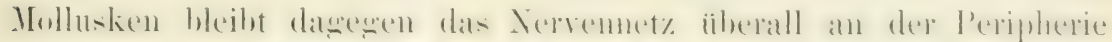

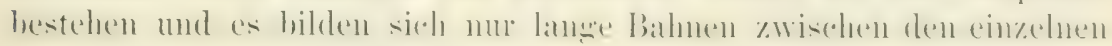

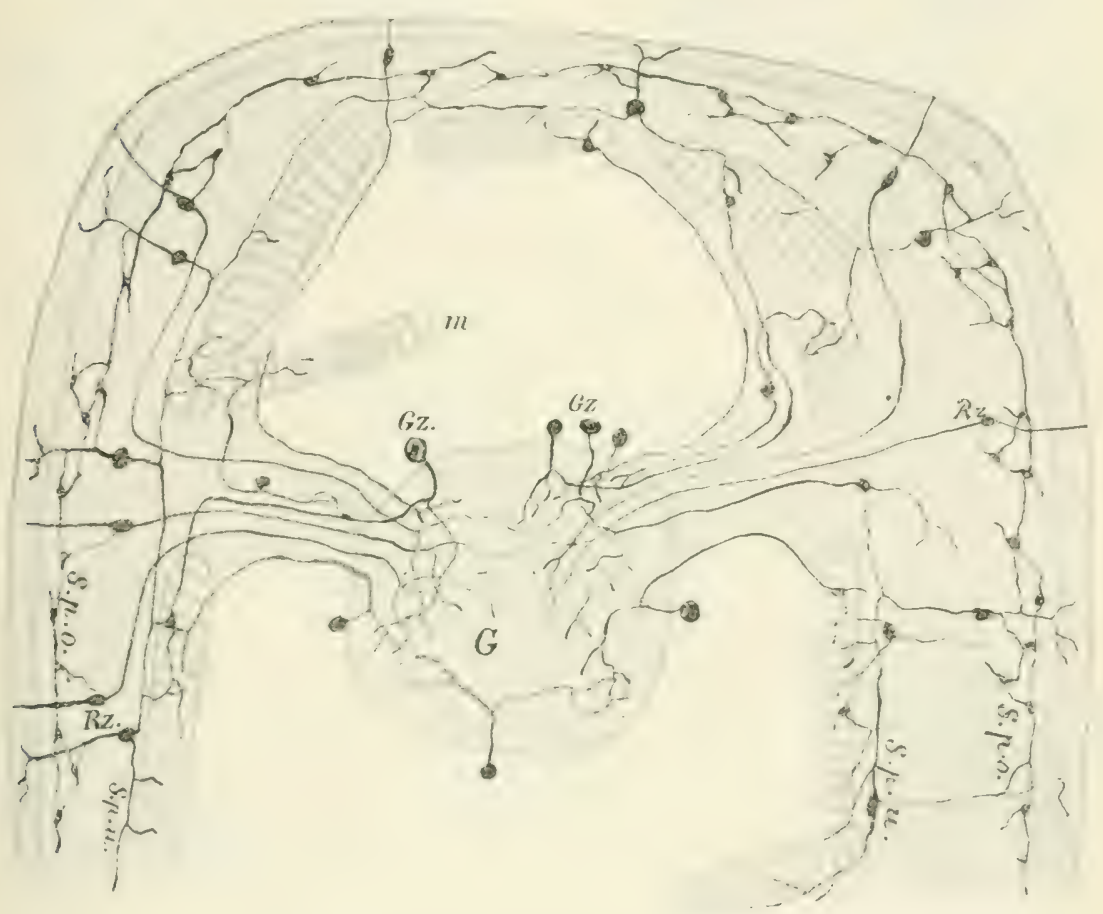

Fig. 41. Sehema des Nerrensrstems der Mollusken. G. Ganglion, Gr. Ganglienzellen desselben. S.p.o. oberflächlicher (subepithelialer), S.p.u. tiefer Nervenplexus, m. Muskeln, Rz. liezeptionszellen.

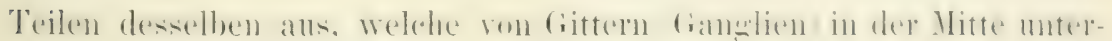
brochen werden (vielleicht sind anch die Echinodermen als Vertreter einer sehr niederen Stufe dieser Form hierher zu rechnen).

Die Figur 44 stellt einen Teil des Körpers eines Molluskes schematisch dar. Da ïber den Verlauf und die Verknïpfungsweise der

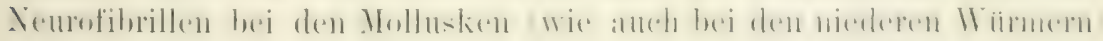
nur wenig bekannt ist, habe ich nur die plasmatischen Balmen in das Schema eingetragen. Daß dieselben Fibrillen enthalten und daß in

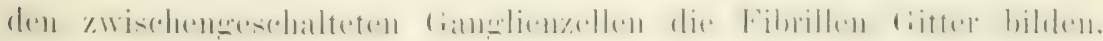
ist sicher, daß im Nemropil außerdem extracelluläre Gitter bestehen, 
ist selı wahrscheinlich. Man wïrde das Schema also leicht auf die

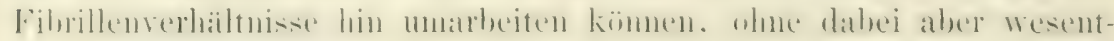
lich weiterzukommen. Unter dem Epithel breiten sich durch den ganzen Körper hin zwei Nervennetze aus, welche hier und dort miteinander in Verbindung stehen. Das eine liegt dem Epithel, das andre der Nuskulatu näher. Das letztere tritt zu Muskulatur dureh

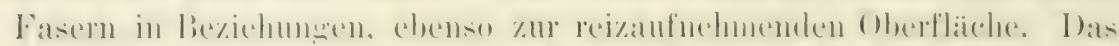

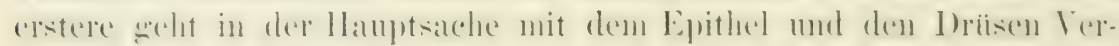

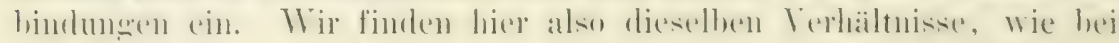

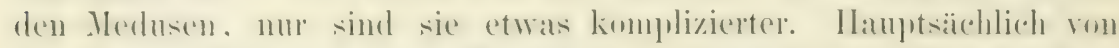

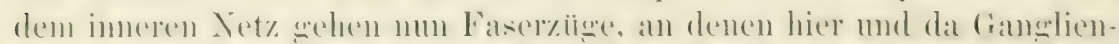

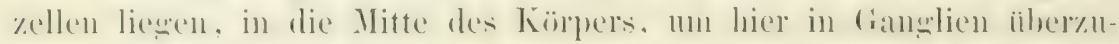

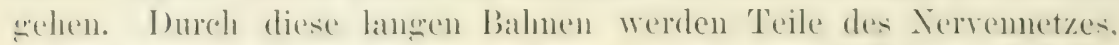

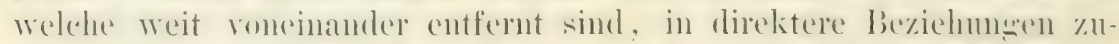

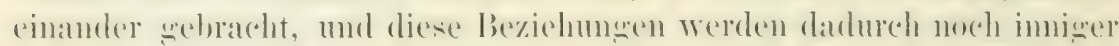

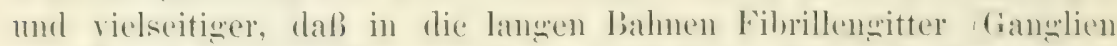
vom Typus hïherer Tiere, wohl anu ähnlichsten denen der Crustaceen, eingeschaltet sind.

Ebenso wie bei den höheren Wiümern, Crustaceen und Wirbeltieren, hei denen - wenisstens für dio bewewnsmuknkatur - kein

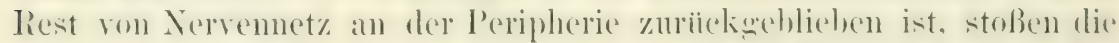
laneren, von der Peripherie kommenden und zur P'eripherie sohenden Fasern nicht in einem l'unkt zusammen. Es existiert nicht ein fianglim. sondern mehrere oder, wie bei den Wirbeltieren, cin langer Strang

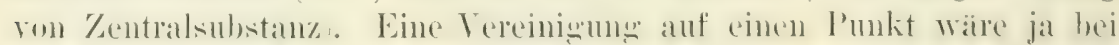

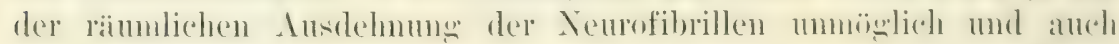
nicht zwerkentsprecolend, weil damn wieder alles in ähnlicher Wuise dilfus zusammenemeniseht wiole, wie bei den diffusen Nerrennetzen.

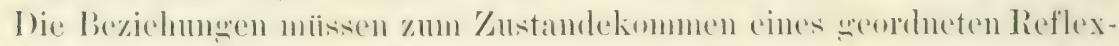
lebens bald inniger, bald lockerer sein. Wir sehen deshalb wieder innerhalb der zentralisierten 'Teile des Nervensistems lange balnem.

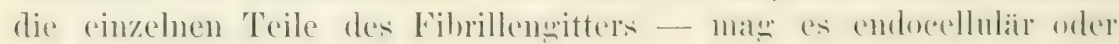

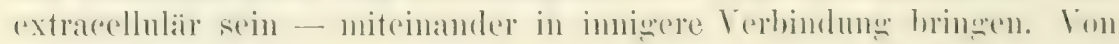

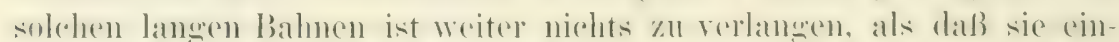

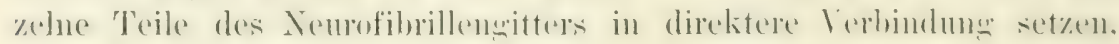
so daß also die unverzweigten Fibrillen, welehe bei den Crustaceen (Fig. 42) von einem Fortsat\% zum andern gochen und bei den Wirbeltieren Fig. 13, von einem l'rotoplasmafortsat\% \%um andern rerlanfen,

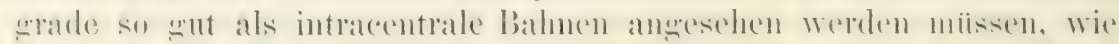

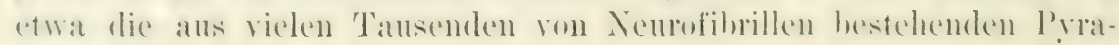
miclenbahmen.

Wenn man die Dinge so betrachtet, wie es hier geschehen ist, so liegrt es auf der Hand, daß ein Nerrensystem desto mehr lange 
Bahnen und deste reichliehere Fibrillengitter besityen muli, je komplizierteren und rielseitigeren Zweeken es dient. Es ist aber anch klar,

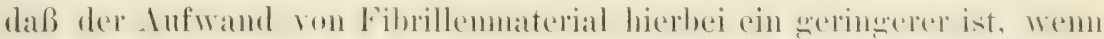
die Gitter extracellulär liegen, als wem sie in den Zellen liegen, be-

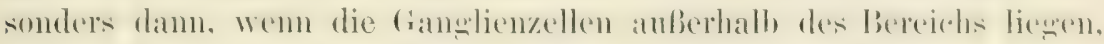
in dem die langen, von der Peripherie kommenden Fasern sich auf-
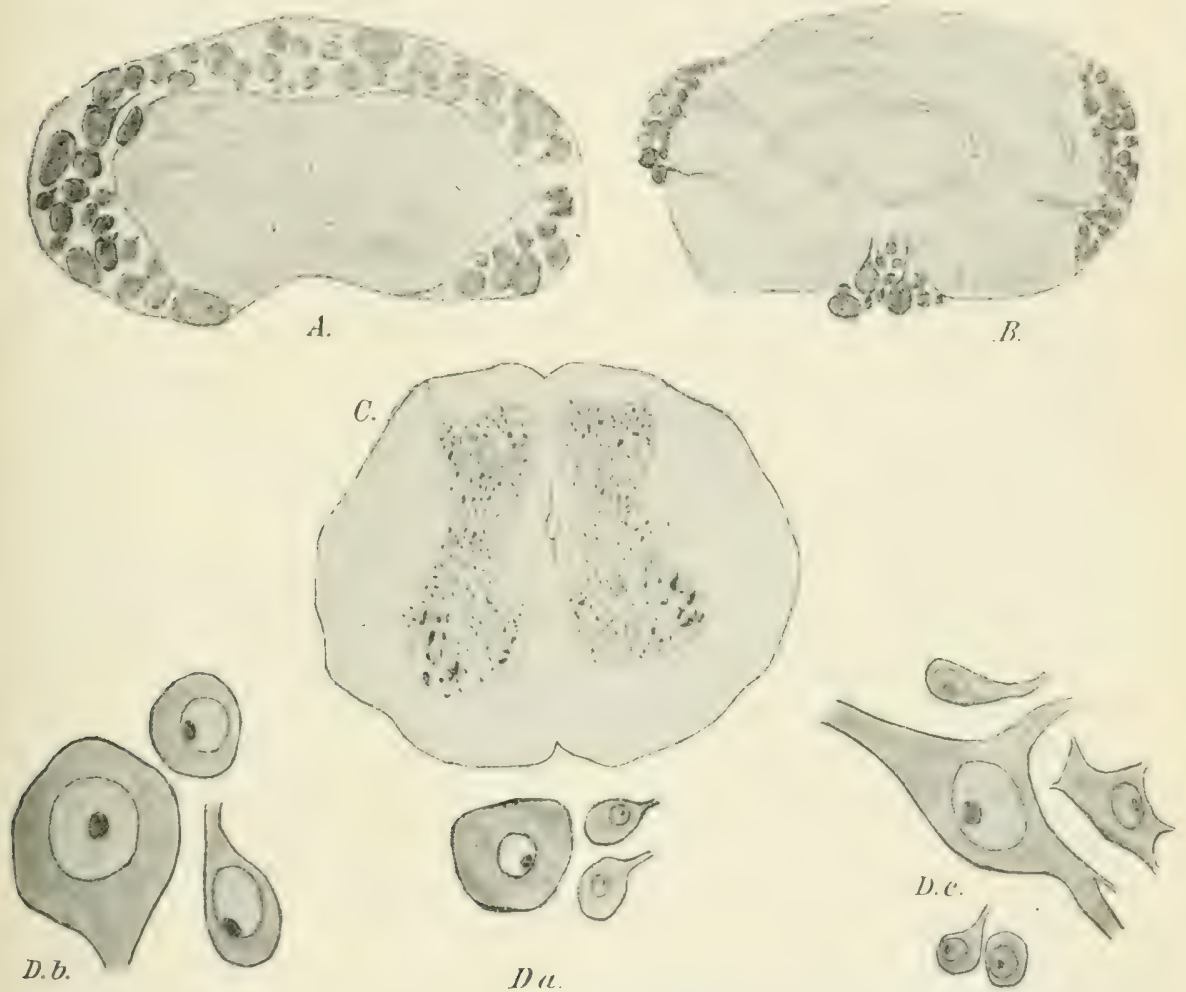

Fig. 45. A Querschnitt durch ein Ganglion ron Hirudo, $B$ durch ein Ganglion von $A$ stacus, $C$ durch das Rïckenmack rom Frosch. Die drei Quersehnitte sind durch verschiedene Vergrïßerung auf ungefähr gleiche Fläche gebracht; die Masse der Ganglienzellen ist mit IIlfe der Camera im richtigen Verhälnis zur Fläche der Schnitte gezeichnet. In $D$ sind verschieden große Ganglienzellen derselben Tiere bei gleicher Vergrüßerung gezeichnet, a Hirudo, $b$ Astacus, $c$ Froseh. (VergröBerung: 1140 mal, $B 42$ mal, $C 25$ mal, $D 450$ mal.)

splittern. Vit andern Worten: Je höher die nervösen $̈$ üßerungen eines Tieres sind, desto mehr wird die Masse der Ganglienzellen gegen die des Graus und derlangen, intrazentralen Bahnen zur ü ektreten. (Zu den langen Bahmen

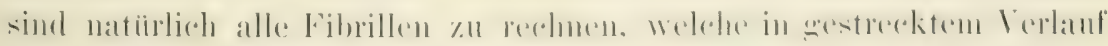

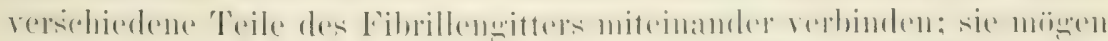

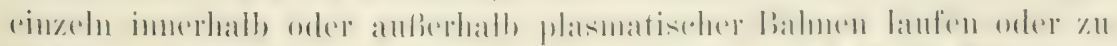

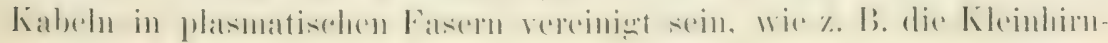


Seitenstrangbahnen, die Briicke u. s. w.) Wiurde man das Nervennet\% einer Meduse oder noch besser eines Seeigels zu einem Klumpen zu-

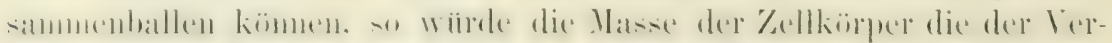

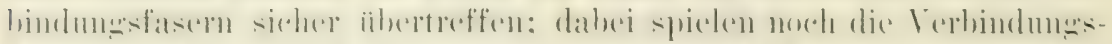

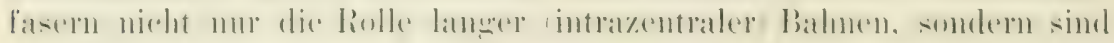
zum 'l'eil schon als periphere Fasem anzusehen, da sie viele Fibrillen

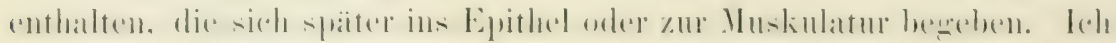
habe es unterlassen, hiervon eine Abbildung zu geben, da es sich nur

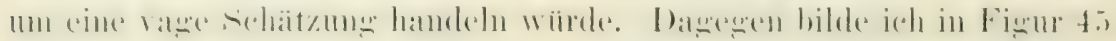
drei Schnitte ab, von welehen der erste eimem Ganglion ron Hirudo, der zweite einem Ganglion ron Astaeus und der dritte dem Riieken-

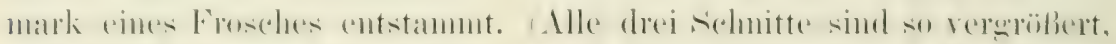

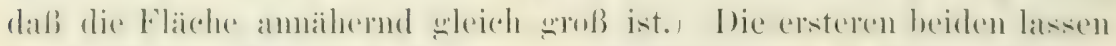

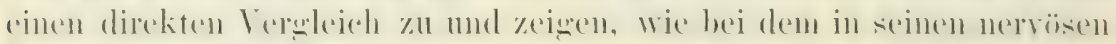

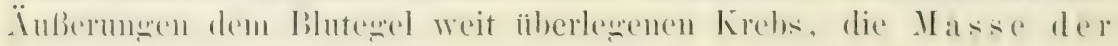
Ganglienzellen gegeniber der der Fasern und ihrer A ufsplitterungen relativ viel geringer ist, als bei diesem.

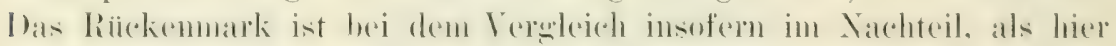

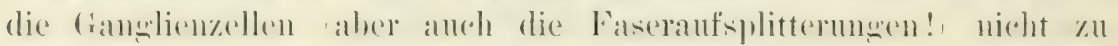
Ganglien vereinigt sind. Anch wemn man das in Rechumg richt, so ist doeh hier die relative Masse der Ganglienzellen (ich meine Masse, und nicht Zahl) noch viel geringer, als beim Krebs. (Bei höheren Wirbeltieren ist dies in meh höherem Malke der Fall. Daberi sind die Ganglienzellen des Frosehes im absoluten Hirudo, und kaum kleiner, als die von Astacus, wie die Zusammenstellung in Figur $45 \mathrm{D}$ zeigt; im Verbültnis zur Masse des ganzen Nervensystems sind sie aber außerordentlich viel kleiner.

Sehr instruktiv ist anch die Vergleichung andrer Zentralteile, und ich mache hier nochmals auf die Abbildungen Nissls (Fig. 25) anf-

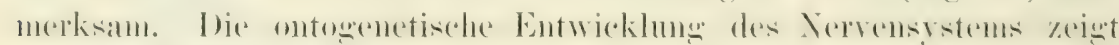

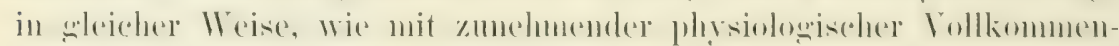
heit die relative Hasse der Ganglienzellen abnimmt. (Wenn man \%. 13. das Riickenmark eines jungen Hundes mit dem eines erwachsenen

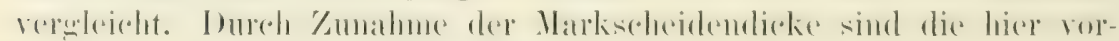
handenen Unterschiede lange nicht erklïrt.) Diese Tatsachen zeigen bereits, daß den Ganglienzellen unmöglieh die hohe Bedeutung fiir die nerrösen lrozesse zukommen kann, die ihnen von vielen Forschern zuerkannt wird.

Lei den Medusen sind noch alle Ganglienzellen gleichwertig. Jede

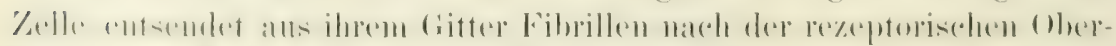

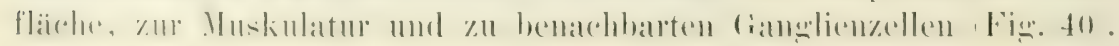


(Gamz ilhulich ist es auch bei den Nervennetzen im Gaumen des Frosches.) Jerle Zelle birgt also alle Qualititen in sich, welche wir bei

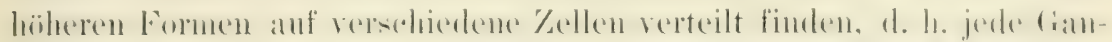

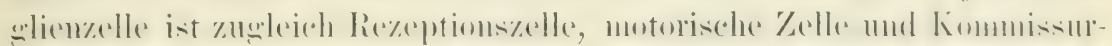

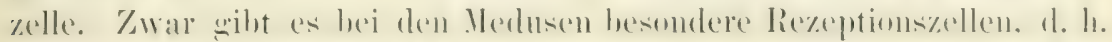

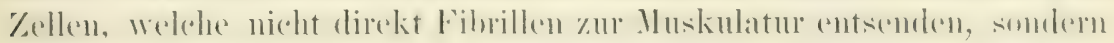
nur zu Oberfläche und zu benachbarten Zellen, aber diese kommen wenigstens bei den Acraspeden nu an gewissen Körperstellen vor

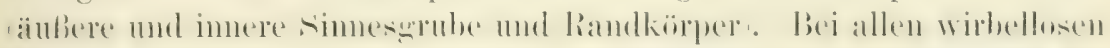

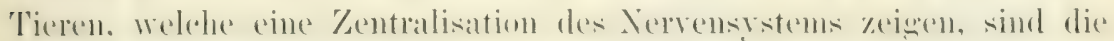

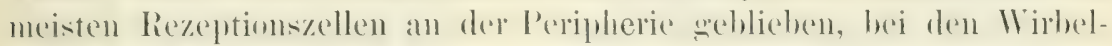

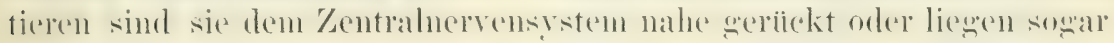
in ilnu spinalganglien ; num an wenipenstellen finden sie sich moch in

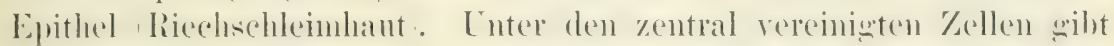

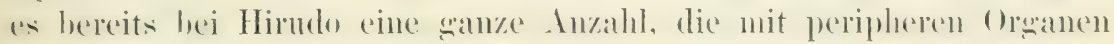
iiberhaupt in keiner direkten Verbindung stehen, d. h. die in ihnen

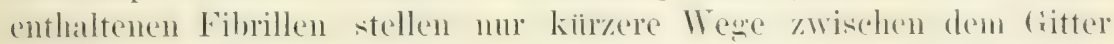
rerschiedener Zentralteile her und treten erst duroh diese mit peripher rerlanfenden Fibrillen in Terhinduns. Bei crustaceen mol Vertehraten ist ihre Zahl noch wesentlich größer. Solche ,Neurone" haben die direkt motorische und rezeptorische Funktion anferechen und sind mur noch Kommissurelemente. Indirekt sind sie aber ebensogut motorisch wie rezeptorisch, sowie anch die rezeptorischen Nemone indirekt motorisch und die motorischen indirekt rezeptorisch sind. Eine scharfe Grenze zwischen Rezeption und Motilitä im Bereich der nervösen

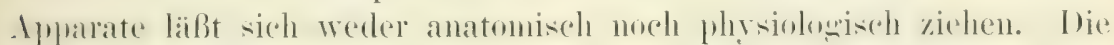
Unterschiede sind immer nur relativ und beruhen anf der Richtung, in der normalerweise die Reizleitumg geschieht. -

Es ist nun meine Aufgabe, zu zeigen, inwieweit die besprochenen

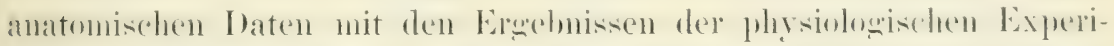
mente ïbereinstimmen. - Sach den anatomischen Befunden mul3 man

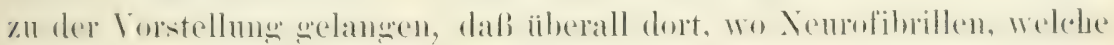
von der reizanfnehmenden Oberfläche kommen, mit solchen in emem Netz zusammenstoßen, die zu Muskeln gehen, die Bedingungen zu cinem Reflex gegeben sind. Da wir num bei den Tieren und Organen, welehe von Nervennetzen innerviert werden, ïberall solche Gitter rorfinden, so muß hier auch jedes kleinste Stiick reflexfähig sein; da anßerdem alle diese Gitter unteremander in Verbiudung stehen, so kamn nu bei rollkommener Kontintitätstrennumg die Leitung von einem Teil des Tieres (oder Oranes) zum andern aufgehoben werden. Dies bestatigt sich im rollsten Maße bei allen Nervennetzen, am leichtesten und elegantesten ist es aber bei den Medusen zu demonstrieren. 
Eine der auffallendsten Erscheinungen bei den Medusen sind die

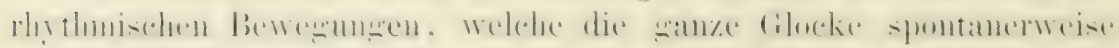

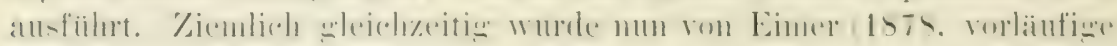
Nitteilung 1876) und Romanes (1876 und 1877) gezeigt, daß diese

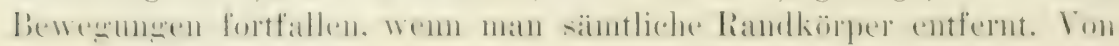

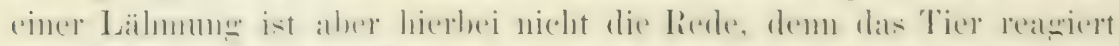

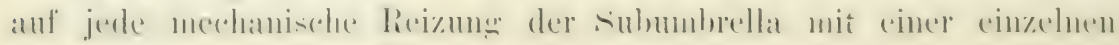

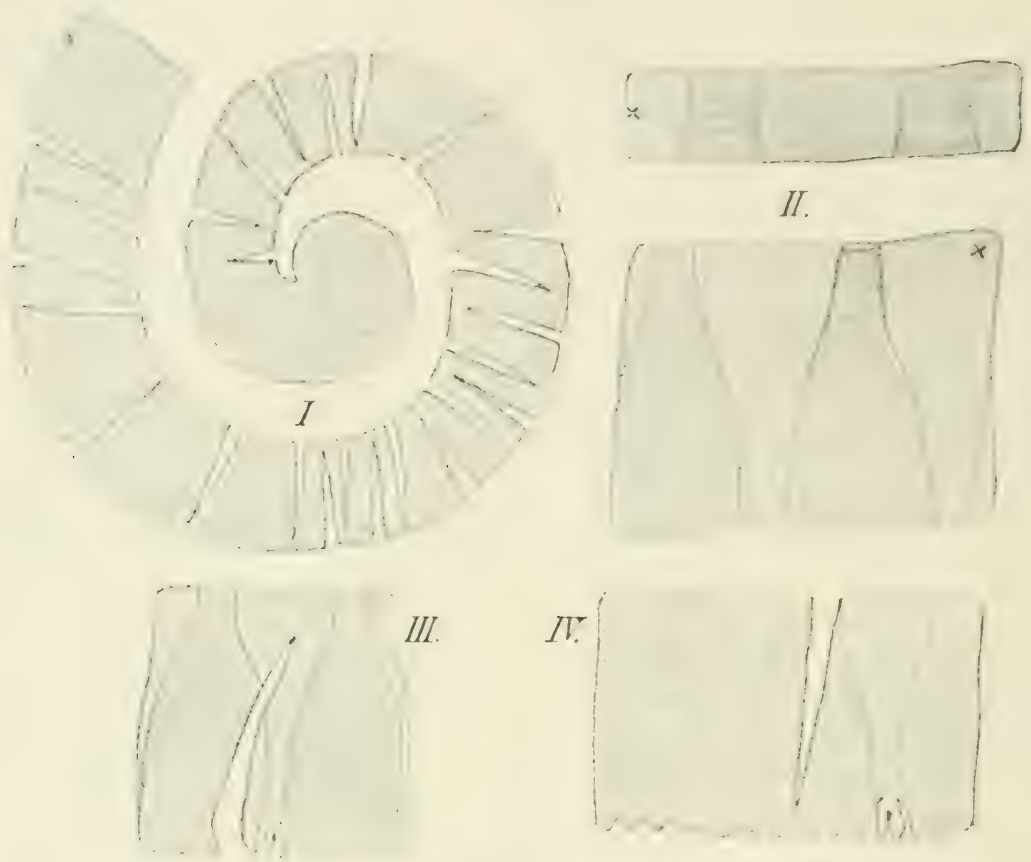

Fig. 46. Diagramme zu Versuchen über die Erregungsleitumg bei den Medusen. I. Versuch von Romanes. Der Körper ist zu einem langen Spiralband zersehnitten; durch abwechselnde Einschnitte ist ein Zickzackband hergestellt. Nur an einem Ende befindet sich noch ein Randkürper, von dem aus die Kontraktionswellen in rhythmischer Folge bis zum äußersten Ende laufen, wenn die Brïcken nicht unter 1-2 $\mathrm{mm}$ breit sind. II. Zwei Muskelfelder aus dem Schirm ron Rhizostoma (s. Fig. 35. S.90), welche nur durch muskelfreies Gewebe miteinander verbunden sind. Wird irgendwo mechanisch (oder elektrisch) gereizt z. B. bei $x$, so zucken stets beide Muskelfelder. III. Dureh den bis ins muskelfreie Feld gefiihrten Schnitt wird nicht verhindert, daß das linke Muskelfeld an den spontanen Kontraktionen teilnimmt, welche von dem Randkürper auf der rechten Seite ausgehen. 1I: Dasselbe zeigt sich, wenn der Schnitt vom Zentrum bis in den muskelfreien land gefuhrt wird.

Kontraktion der sanzen Glocke. Andauernde Reize irond weleher Art mechanische, chemische, faradische) lufen keine einche hon-

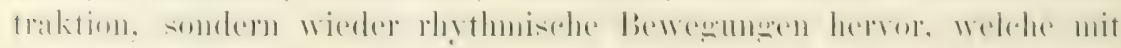
dem Schwinden des Reizes wieder aufhören. Das randkörperfreie Tier verhält sich also gradeso wie die, ganglienlose" Herzspitze. Die

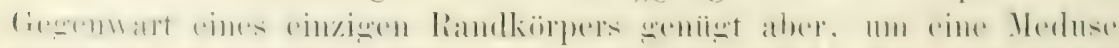

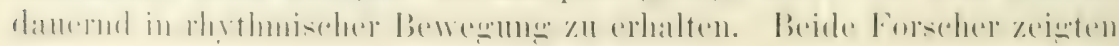


nun, daß radiäre Einschnitte \%wischen den Ramelkärpern die Kondination nicht oder kaum stören. Rollt man den ganzen Körper dureh einen

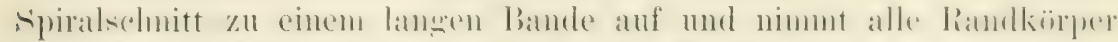

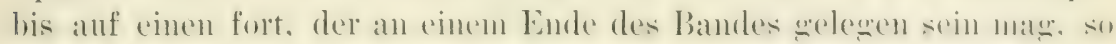
führt der wanze streifen seine rhythmisehen Kontraktionen ans: ja man kann aus dem Bande durch tiefe seitliche Einschnitte ein Zickzack-

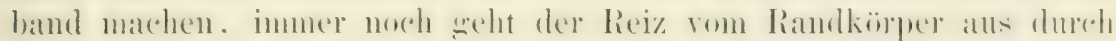
das ganze Band hindurch, wenn nur die Bricken noch eine Breite ron etwa einem Millineter halen Fis. 46 I. Wird der liandkinjer fortgeschnitten, so ist der Streifen wie gelähmt; sticht man aber an einem Ende mit einer Vadel hinein, so läuft eine Kontralitionswelle iiber den ganzen Streifen hin. Wie die Tiere zerschnitten werden ist

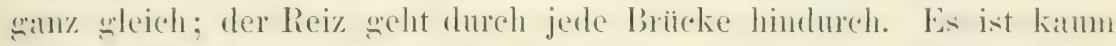

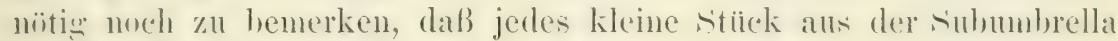
reflexfähig ist.

Wir finden also bei den Medusen die Eigenschaften ror, die man bei einem Nervennetz zu erwarten hat, nur ist es die Frage, ob das im Epithel wefundene Netz wirklich die Reizleitmm vermittelt ader ol, sie nicht etwa durch die Muskulatul selber besorgt wird, wie dies Engelnam is75, bei den wanz analowen Erscheinmenten an IIcrzen

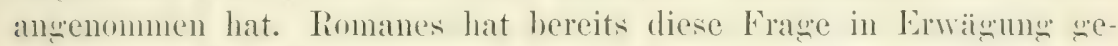
zogen und sich dahin ansegesprochen, daß wenigstens für die rhyth-

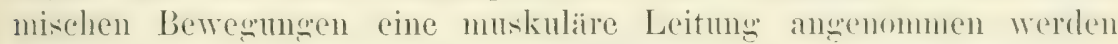
könne. Für die Berregungen der 'Tentakeln und einige andre Erscheinungen nimmt el dagegen eine nervöse Leitung an und sucht dieselbe experimentell zu beweisen. So sehr ich die Arbeiten ron

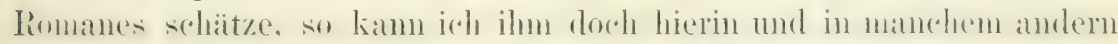

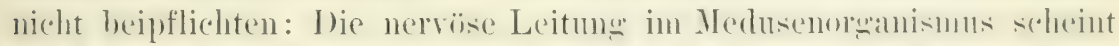

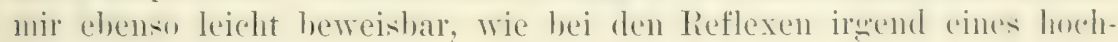
stehenden Wirbeltieres!

Bereits die Leitung von den Randkörpern, von denen ja ohne

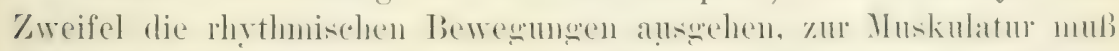
durch ein andres Elenent weschehen als durch Mnskelfasern, da, wie

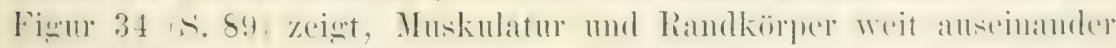

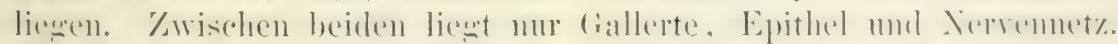

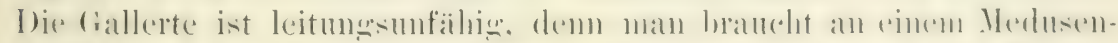

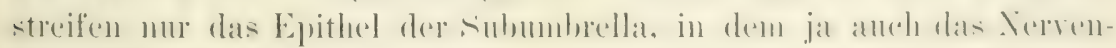
netz und die Muskulatu liegen, zu durchtrennen, dann zuckt bei Reizung einer Seite immer nu diese, trotzdem die Gallerte in ihrer ganzen Dicke beide Seiten miteinander rerbindet. Andrerseits kann

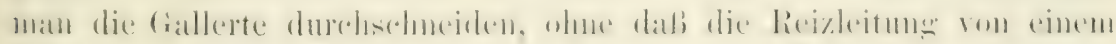

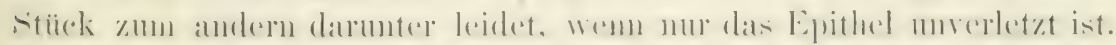

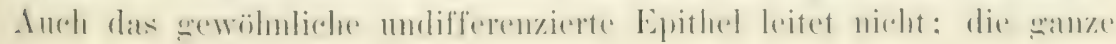


Lmbrella ist mit solchem bedeckt, aber man kam sie reizen so stark man will, nie wird man auch nur die leiseste Bewegrung in der Iluskulatur der Subumbrella oder der 'T'entakeh beobachten. Hier fehlt eben das als Nerrennetz angesprochene Gewebe vollkommen. Es kamn also nur das Nervennet\% sein, das den Reiz ron den Randkörpern auf die Muskulatur überträigt.

Bei den meisten Medusen kommt überall da, wo sich Nerven-

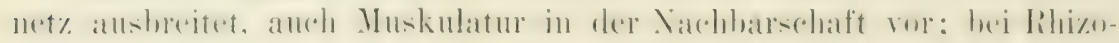
stoma wibt es aber große muskelfreie Felder, welche rom Nerremetz durchzogen werden (Fig. 35, S.90). Wenn man aus einem solchen

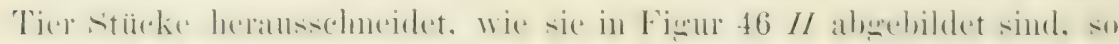
steht die Muskulatur beider siten nur dureh Nervenuet\% uiteinander in Verbindung. Wäre num die Leitung ron Muskelfaser zu Muskelfaser muskuliarer Natur, so dürfte bei Reiz einer Seite immer nur diese zucken. Das ist aber nicht der Fall: der Reiz geht bei jeder Art von Reizen anch auf die Muskulatur jenseits des muskelfreien Feldes ïber. ${ }^{1}$ ) Da die muskelfreien Felder bei großen Tieren eine Breite ron 1-2 cm haben, so ist jeder Irrtum ansgeschlossen: Die Leitung ist nervöser Natur!!

Es gelingt aber anch den Beweis zu liefern, daß nur das Nerren-

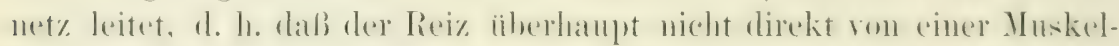
faser auf die andre übergehen kann. Berührt man ein randkörperfreies Stïck ron der Oberflaiche her, so zuckt unter gewöhnlichen

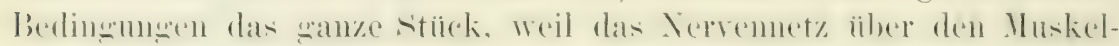
fasem liegt und entweder direkt oder durch Vermittlung der intra-

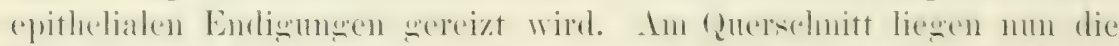
Mnskelfasern direkt zutage und man kamm dicht an der (iallerte direkt mit der Nadel ein Muskelbündel berïhren. Wenn der Versuch mit der nötigen Vorsicht ansgeführt wird, so sieht man immer, da 3 sich nur das Muskelbindel schnell zusammenzieht, das von der Nadel getroffen ist, wälrend alle iibrigen in rollkommener Kuhe verharen: Dieser Versuch gibt auch cinen sehr guten Beweis dafïr, daB der Reiz nicht imstande ist, rïckläufigrom II skel auf den Nerv ïberzugehen, eine Tatsache, die Kühne (1859) zuerst mit Hilfe des

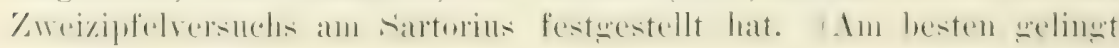

1) Die allerzentralsten und breitesten Teile der muskelfreien Felder sind fast nervenfrei; man darf also keinen Streifen aus dieser Gegrend benutzen. Auch am Schirmrand kann man demonstrieren, daß die Leitung nicht durch die Inskeln selbst hesorert wird. Ilier ist ein Streifen von mehreren Millimetern Breite vorhanden, Aer Nervennet\%e aber keine Muskeln enthïlt. (Der äußerste pigmentierte Rand fiilhrt anch keine Nerven mehr.) Fïhrt man einen Schnitt wie in Figur $4611 \mathrm{I}$. IV angegeben, so macht das linke Stiuck die rhy thmischen Kontraktionen des rechten mit. 
dieser Versuch bei Cotylorhiza, weil sich hier die Muskulatur faltim in die Gallerte einsenkt, während die Nerven iiber diese Falten shlatt fortziehen. Die Gefahr ist also hier gering, daß man mit der Nadel zugleich mit den Muskeln das Nervemetz beriihrt. Bei absterbenden

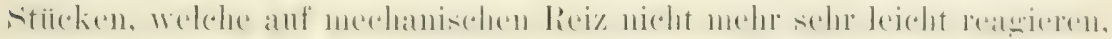
gelingt es auch ein einzelnes Bündel in der Weise zum Zucken zu

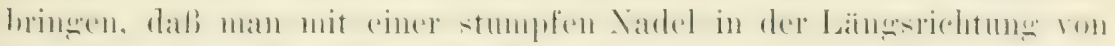
der Epithelseite her ïber die Faser streicht. Ist die Nadel scharf oder der Druck zu groß, so zuckt das ganze Stiick.)

Tach alledem kamn es keinem Zweifel unterliegen, daß bei den

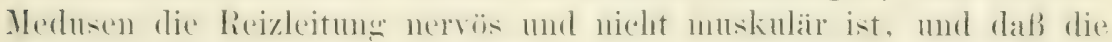
Xetze im Epithel diese peizleitende Funktion ansiben, wie es Einner und die Gebritder Hertwig nach den anatomischen Befunden von vornherein angenommen haben. Die Existenz ron ganz ähnlichen Nervennetzen in Herzfleisch im Verein mit den außerordentlich weitgrohenden Analogion zwischen den physiolngischen kischeinmenen, welche an den Medusen und am Herzen zu beobachten sind (siehe Kapitel 2.2', veranlasisen mich dazu, anzunchmen. dals die Redzleitung entgegen der Auffassung von Engelmann auch im Herzen eine rein nerröse ist. Es wäre sonst auch ganz unverständlich, was diese Unmasse von Nervenelementen, die ich und andre im Herzmuskel gefunden haben, zu bedenten hätten. Da ihre Anordnung im Herzen dreidinensional ist. so spricht der Engehmannsche Hanptrersuch, die Auf-

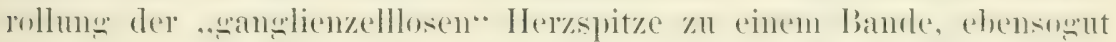
fïr eine nerröse Leitung, wie für die muskuläre. Da Engelmann annahm, daß die Nerrenfasern in der Kammer parallel nebeneinander mol ohne seitliche Verbindungen ron der Basis zur Spitze verliefen, so komnte er aus seinem Versuch den Schluß auf muskuläre Leitung im Herzen ziehen. Jetzt, wo die netzige und dreidimensionale An-

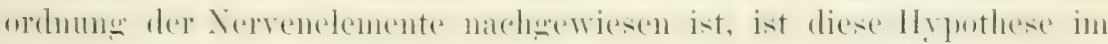
höchsten Grade zweifelhaft geworden. Auch ein andrer Beweis für

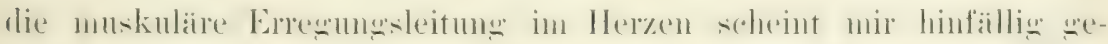
worden zu sein. Bowditsch, Aubert und Langendorff (1902, p. 284) klemmten im lebenden Frosch nach dem Vorgehen Bernsteins die Ilerzspitze ab, um dadureh die Nervenfasern zur Degeneration zu

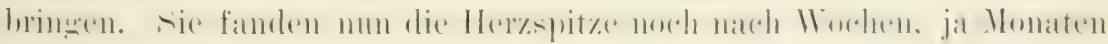
erregbar. Die ruhende Her\%spitze kontrahierte sich auf Reiz im ganzen. Dieser Beweis fält mit dem Nachweis von Ganglienzellen in der Herzspitze und dieser scheint mir gelungen. Aber abgesehen davon wäre der Beweis zweifelhaft, weil es marklose Terven zu geben scheint, die nicht degenerieren (siehe Kapitel 10). Weiter unten werde

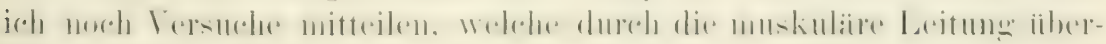
haupt nieht zu erkläiren sind. 
Ich habe schon oben angedentet, daß aus dem anatomischen Aufbau der Nervennetze nicht nur der Schluß zu zichen ist, daß ein

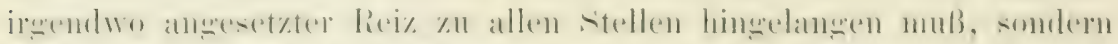

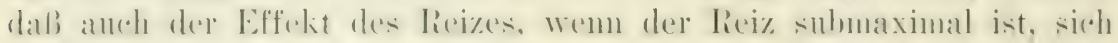

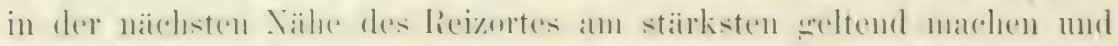
von da aus allmählich an Stärke abmehmen muß. Dies läßt sich an

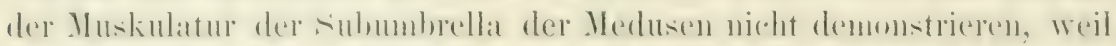

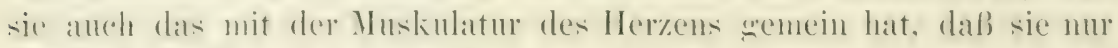

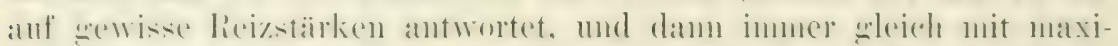

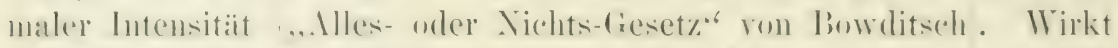

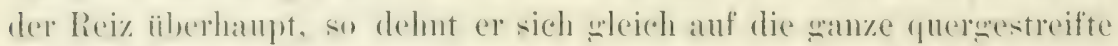
Muskulatur der Subumbrella aus. Anders ist es mit der Muskulatur des Masenstiels nund der der 'Tentakeln. Diese fülut lieine solunellen Einzelzurkungen aus, wie die Muskulatur des Her\%ens und der sub-

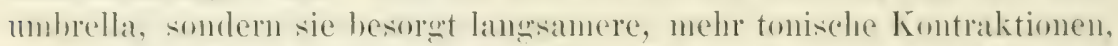
wie sie den Mnskeln der meisten Wirbellosen zukommen, mol ist audh dureh faradische Erregung in eine Art ron Tetanus zu versetzen.

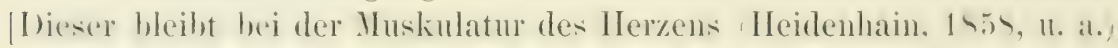
mormalerweise, ('yon, 19un. und hei der Muskulatur der subumbrella (Uexkiill, 1901, ich) anch bei stälister Faradisation aus; es kommt hier nie zu etwas anderem als zu rhythmischen Kontraktionen.] Das

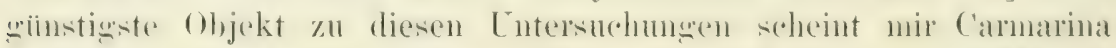
hastata mit ihren schönen langen Tentakeln nnd ihrem lanem Mastenstiel zu sein (auch die 'Tentakeln ron Polypen, besonders ron Cerianthus, geben ein giunstiges Objekt ab).

liereits Nasel 1 >94, hat ('amarina zu ähnlichen Versuchen henut»t und liesultate erzielt, mit denen sich die meinimen fast swanz decken:

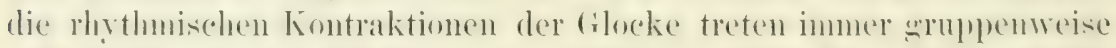

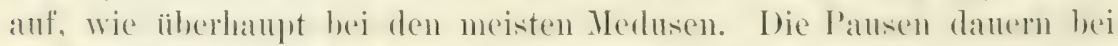

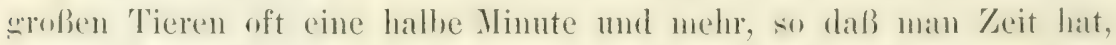
seinen Versuch waihrend derselben anzustellen. Berihlut man einen 'Tentakel z. B. in der Mitte ganz leicht mit einem Glasstaibchen, so tritt nur eine kleine lokale kontraktion, eine seringe lerelickuns, an demsellonen anf. Ist die Beriblume stäker, so enereft die Kontraktion auf weitere Teile des T'entakels über. Bei einem kleinen Stoß tritt solum ein Emporselnollen des sanzen Tentakels anf, welohes sich bei noch stärkerem Anstoß anf die beiden zunächst benachbarten Tentakeln und schließlich auf alle 'Tentakeln ausdehnt. Hierbei macht der Magenstiel bereits in der Regel eine schwache Bewegung nach der Reizstelle hin, die bei weiterer Steigerung des Reizes zu einem

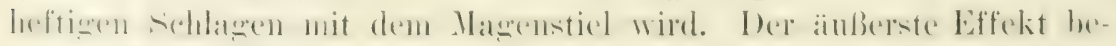

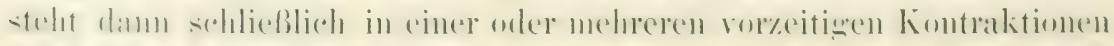

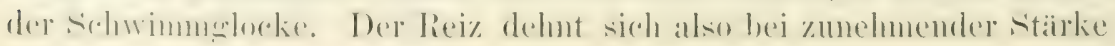


auf immer weitere Gebiete des 'Tieres aus; es geht aber auch aus

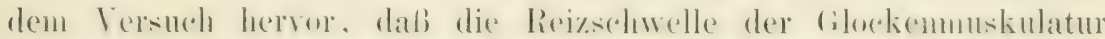

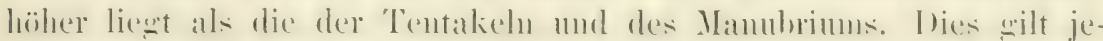
doch nur für Reize, welche ron außen kommen, denn bei den spon-

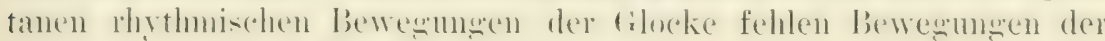
Tentakeln und des Magenstiels oft ganz.

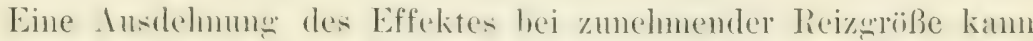
man auch, wie ja bekannt, an den ebenfalls ron Nervennetzen imnervierten Bhuterefiben der Wirheltiere beohadehten: ich meine die lokale

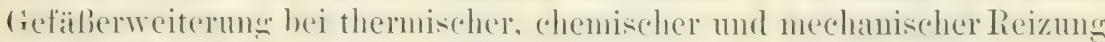
der Hant und die lokale fiefaßrerengerung hei Kialtereiz. Es wird ja zwar vielfach angenommen, dal diese lieize direkt anf die refäbmuskulatur wirkten und dab die Weiterleitung zu entfernteren Gefälpartien ron der Muskulatur selber besorgt würde; mir scheint diese Ansicht aber unhaltbar. Die erste Frage ist für mich wieder die:

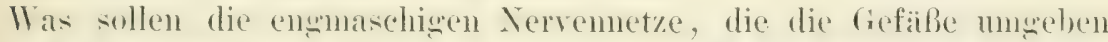

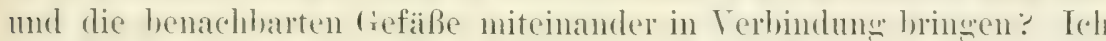
staube aber. daff man anch direkt durch das Experinent berreisen kamm, daß die Reizleitung hier nicht musknlär sein kamn. Da jeclorh meine dahin wehenden Versuche moch nicht abseschlossen sind, verschiebe ich ihre Veröffentlichung auf eine spätere Gelegenheit.

Nach meiner Meinung handelt es sich bei den lokalen Gefäßrerindermugen mu richtige Reflexe, und ich zweifle keinen Angenblick, daß es bei den Bewegungen des Darmes des Ureters u. s. w. kurz allen den Orwanen, in denen Enselmann und mit ihn viele andre eine muskuläre Leitung annehmen, grade so ist. Von den Erscheinungen, welche man bei Medusen zu beobachten instande ist, muterscheiden sich diese Jewesmumen nur dadurch, daß sie auber durch die Voreänge in Vervennet\% selber anch dureh solche hestimnt werden, welche in Zentrahnervensysten ablanfen das die Medusen nicht besitzen) und dem Nerrennetz durch lange Bahnen richtige Achsenzylinder, Fis. 27, äbrmittelt werlen. Es liexen bei diesen (1)wanen, wie mir scheint, Verhältnisse ror, wie sie uns bei den niederen

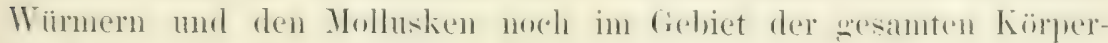
muskulatur in auberurdentlicher Klarheit enteresentreten: die Muskulatur ist hier wie bei den Gefäßen, dem Darm u. s. w. durch ein eingelagertes und mehr oder weniger modifiziertes Nervemetz in einem

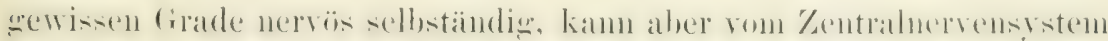

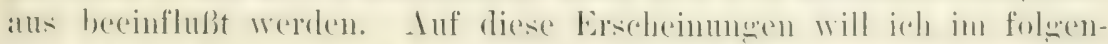

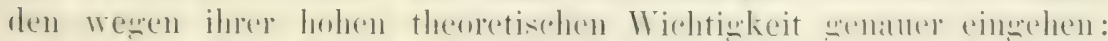

Von niederen Wïmern sind hauptsächlich Planarien untersucht

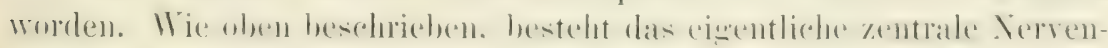
system dieser 'Tiere in zwei Ganglien, welche am rorderen Ende des 
Kiorpers gelegen sind und als Gehim bezeichnet werden. Von hier aus gehen aber Nervenfasem durch den ganzen Körper, welche von vielen Ganglienzellen durehsetzt sind und an der Peripherie höchst wahrschemlich in ein wirkliches Nerremetz übergehen. Zwischen Suißwasserplanarien und Seewasserplanarien zeigen sich nun nach

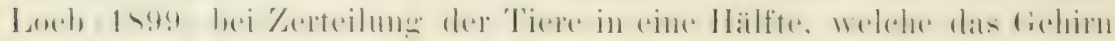

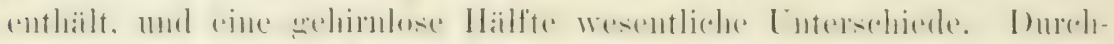
schneidet man eine I'lanaria torva (Süßwasserplanarie), während sie an Boden dahinkriecht, mit einem Messer in eine vordere und eine hintere Hailfte, so kriecht jede Hälfte für sich ruhig weiter. Bei Thy-

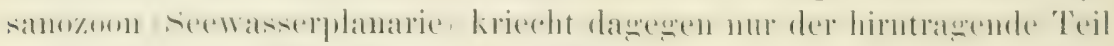
weiter, während der hintere 'Teil, auch wenn er viel größer als der rordere ist, keine Progressirbewegungen mehr ausfithrt.

Der Unterschied ist allerding's sehr groß, aber nach meinen Befunden nur quantitativer Natur. Anch bei Theranozon fand ich nech

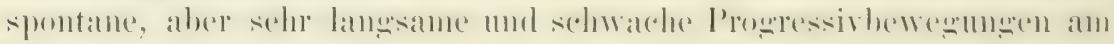
Hintertier, besonders dann, wenn man nur einen Randstreifen be-

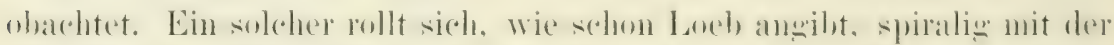

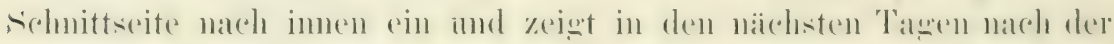
Operation kleine Wellenbewegungen, welche ron einem Ende zum

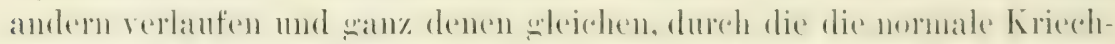

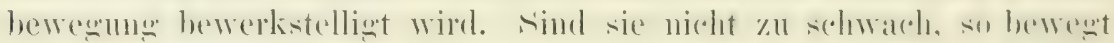

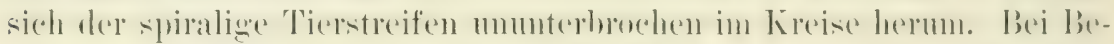

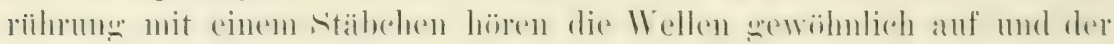

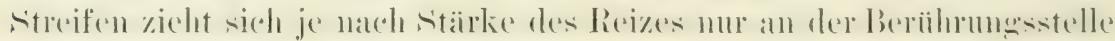

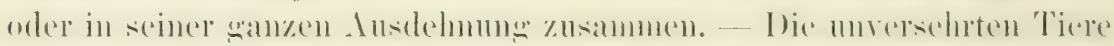
kriechen immer mit der hellen Bauchseite dem Boden zugewandt; dreht man sie anf den Rüicken, so drehen sie sich schmell wieder zur Banchlage zurück. Sie zeigen also, wie Loeb das nemnt, einen positiren Stereotropismus der Banchseite. Dieser ist anch noch, wie Loeb fand, an dem gehirnlosen Hintertier zu konstatieren. Ich selber habe mich davon ïberzengen kömnen, daß selbst ganz kleine Stiicke ans

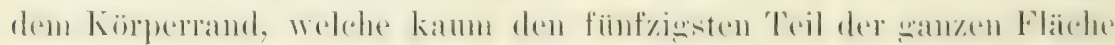
ansmathen, diese I'mdrehumg noch ansfïhren, allerdings in längerer \%eit als das ganze Thier oder hirnenthaltende Vorderteile. Wenn Loeb an diesen Versuch die Bemerkmg sehließt: „Wir sehen hier wieder, daß das Nervensystem nur der rascheren Reaktion dient", so befindet er sich, wie bei allen derartigen Bemerkungen, die von einer Ausschaltung des "Nervensystems" sprechen, in einem großen Irrtum. Es ist eben nur das zentralisierte Nervensystem, das System der langen Bahnen, das zwischen die einzehen Partien des peripheren Nervennetzes eingeschaltet ist, fortgenommen und das periphere Nervennet\%,

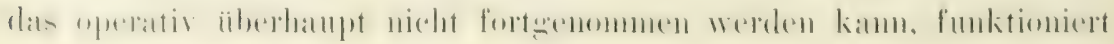


ruhig weiter, grade wie etwa beim herausgeschnittenen Darm eines Wirbeltiers. - Ungleich besser als an den Planarien lassen sich aber

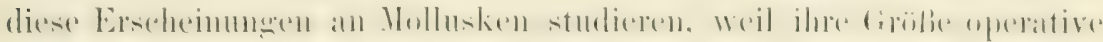
Eingriffe besser ermöglicht.

\section{Versuche an IIollusken.}

Als geeignetstes Objekt erwies sich mir zu diesen Versuchen der große marine Opistobranchier Aplysia (dentsch: Sechase), eine Nacktsehnecke, die eine Länge ron $30 \mathrm{~cm}$ und ein Gewieht ron $1 \mathrm{~kg}$ erreicht. Das \%entrale Nervensystem und der Verlauf der peripheren Nerven dieses 'Tieres sind in Figu 47 abgebildet. Um den Schlund herum liegen drei große Ganglienmassen, ron denen die beiden unteren aus je zwei Ganglien, dem Pedalganglion und dem Pleuralganglion (rorderen Visceralganglion) bestehen. Das obere Ganglion ist das Cerebralganglion. Untereinander stehen sie durch Kommissuren in Verbindung; rom rorderen Visceralganglion jeder. Seite geht auBerdeme eine Kommisim \%um hinteren Visceralsanglion, das an hinteren Körperende in der Nähe der Kiemen gelegen ist. Auf dem muskulösen Kropf liegen auBerdem noch zwei kleine Ganglien, die Buceal-

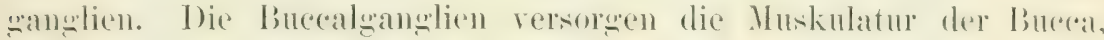
die hinteren Visceralganglien Kiemen, Herz und Atemsipho. Die

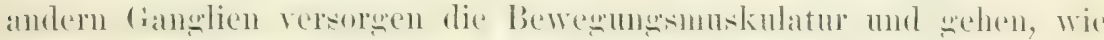
schon oben gesagt, an der Peripherie zum 'Teil in Rezeptionszellen, zum 'Teil in ein Nervennetz über; das mit der Muskulatur in Verbindung steht (S. 82).

Durch Injektion von Pelletierinsulfat (Schoenlein), das man gut

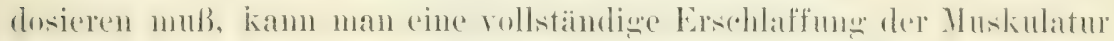
hervorufen, welche alle Operationen wesentlich erleichtert. Sie geht hei guter Dosierung nach einer halben bis einer ganzen Stunde voriiber. (Ich ziehe Pelletierin dem von Jordan empfohlenen Cocain ror.) Bei den Operationen ist nur zu beachten, daß man dureh Aufsackung vor der Eröffnumg der Leibeshöhle das Ausfließen von

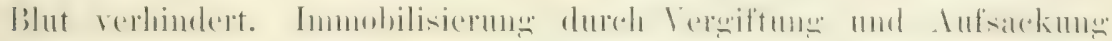
ist übrigens mu nötig, wenn man die T'iere lingere Zeit an Leben erhalten will. Grade für die hier zu bescheibenden Versuche ist die

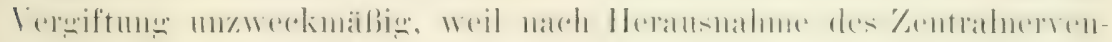
systems bald eine starke Tonussteigermong eintritt, welche die Beobachtung erschwert. (Ich komme auf dieselbe später zurick.) Wenn die Entgiftung eintritt, so bildet sich die Tounssteigermo zu sehnell aus, um genïgend '/eit zur beobachtung zu haben. Ich habe daher die 'Tiere entweder ohme Riicksicht auf den Blutaustritt zan\% aufgeschnitten oder nit einem Bindfaden den vorderen Körperteil, der den $x$ Bethe, Nervensystem. 


\section{Vergleichung des Zusammenlanges der nervösen Elemente u. s. w.}

die Ganglien heranswenommen. In noch andern Fillen habe ich nur

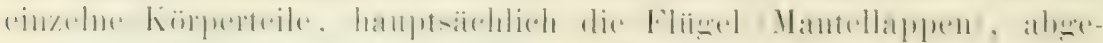

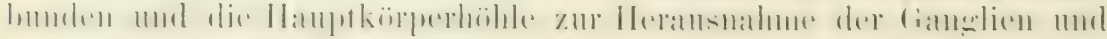
zur Reizung der Nerven eröfnet. Gut angelegte Limaturen verhindern

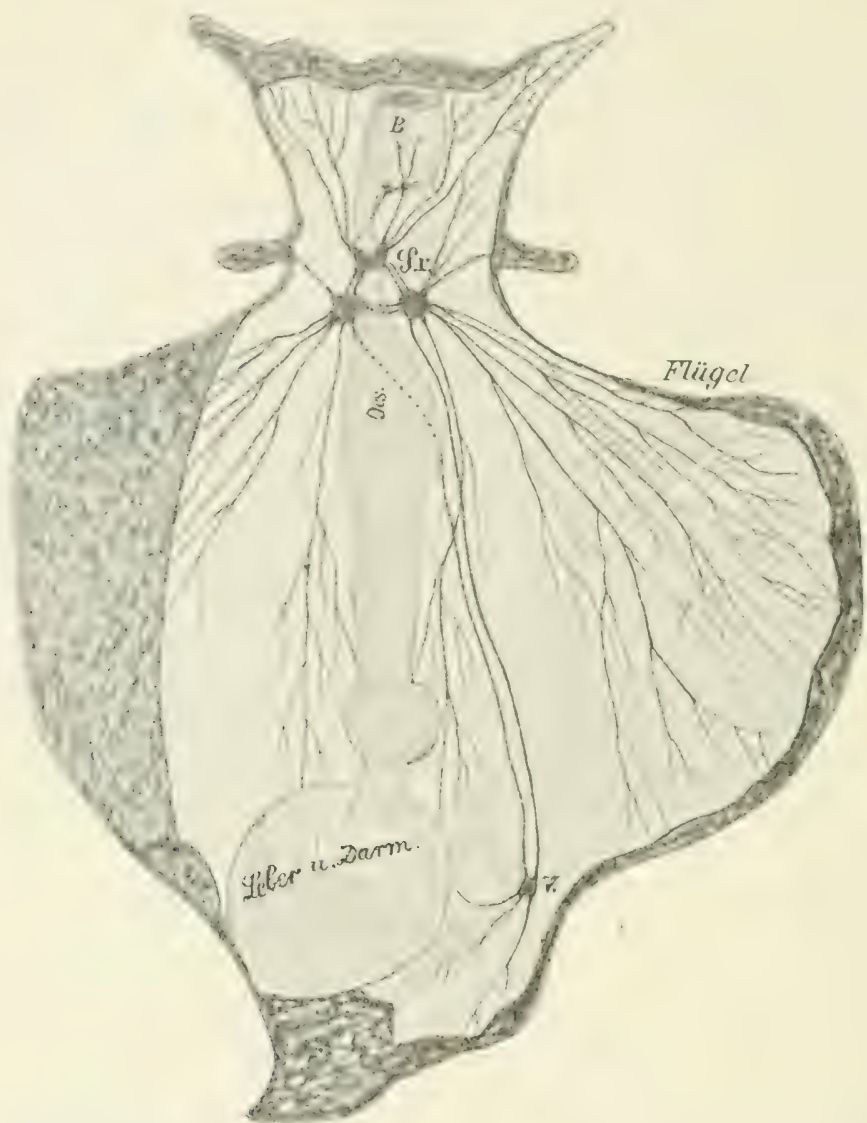

Fig. 47. Präparation des Nervensystems von Aplysia. Das Tier ist vom Rïeken aus aufgeschnitten. Oben der Kopf mit seinen lappigen Anhängen und den Tentakeln. Das Nervensystem ist seluwarz gezeichnet. S.r. der Schlundring (dorsal das Cerebralganglion; ventral beinahe zu ciner Masse vereinigt das Pleural- und Pedalganglion [paarig]). Nach vorne auf der Bucea $(B)$ die kleinen Bucealganglien. Durch Iange Kommissuren mit den Pedalganglien verbunden die Visceralganglien $\mathrm{I}$. Ocs. der Oesophagus. Der Darmtraktus ist sehematisch gehalten, Kiemen, Kiemendeckel und IIerz, welche die Visceralganglien verdecken wïrden, sind entfernt. (2/3 natïrlicher Grüße; die (ianglien sind verbältnismiißig etwas zu groß gezeichnet.)

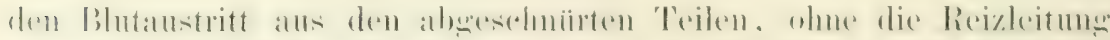

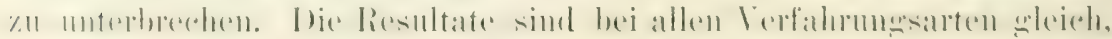

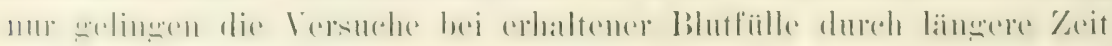
hindureh, weil, wie Jorkan (1901) nachwies, ein Vorrat von Flüssigkeit notwendig ist, damit die Muskulatu wieder ersehlaffen kann. Es 
pressen nämlich die Muskeh bei der Kontraktion einen großen Teil ilnes Wassers in das umgebende Gewebe (siche Kapitel 20).

Die normalen 'Tiere sitzen sehr häufig ganz ruhig im Bassin am Boden oder an der Wand. Bei genanerem Hinsehen gewaht man

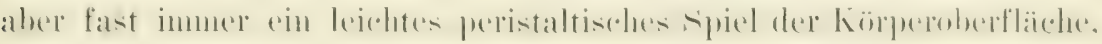
besonders an den Seitenrandern des Fußes; außerdem nacht der

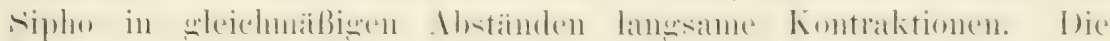

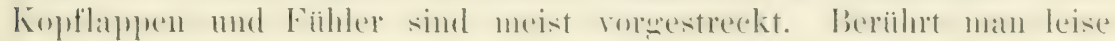
einen dieser Teile, so wird el ziemlich schmell zurïckgezogen, ebenso

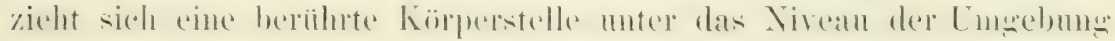
trichterförmig zuriick. Ist der lieiz starker, so dehnt sich der Effekt auf immer größere Partien des Körpers diffus ans. Es kann dabei schlieblich zu einer wollkomment seitlichen Verkrimmmmen des Tieres kommen. Statt dieser diffusen liaktion treten häiffin andre auf, hei denen ron der Reizstelle weit entfernte Teile ohne resentliche Reaktion der dazwischen liegenden in Berregung geraten. So z. B.

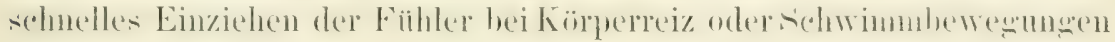
bei Kitzeln des Fußes. - Die Lokomotion der 'Tiere besteht in Schwimmen und Kriechen. Ersteres wird durch die Mantellappen besorgt, welche sich weit ausbreiten und langsame, gut koordinierte, schwin-

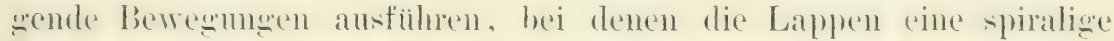
Form annehmen. IBeim Infwirtshewegen ist die sipirale in entwegengesetzten Sinn gerollt als bei der Abwärtsbewegung. Wie Jordan

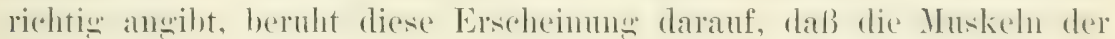
Flïgel sich nacheinander kontrahieren. Das Kriechen wird durch wellenfömnige Kontraktionen der soble des Fubes bewerkstellient. Die Wellen laufen ron vorn nach hinten ab (Jordan).

Hat man einem 'Tier nach einem der oben angegebenen Verfahren

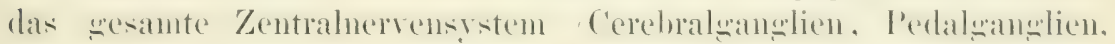
hintere und vordere Visceralganglien und Buccalganglien) herausgenommen, so ist das Tier durchaus nicht gelähmt (wie es Jordan

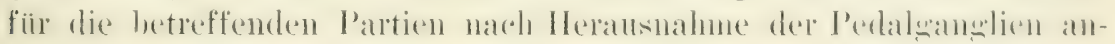
gibt), viehmehr zeigen sich sofort recht heftige peristaltische Bewegrungen der gesamten Körperoberfläche. Wie schon benerkt, fehlen dieselben anch am normalen, ruhig dasitzenden 'lier fast nie; hier zeigen sie sich auf eimmal wesentlich rerstärkt. Objektiv ist der Vorgang also aan\% ihnlich dem ron Goltz (1572) beobachteten

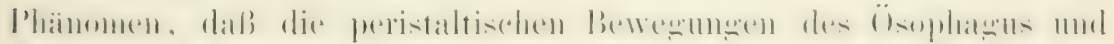

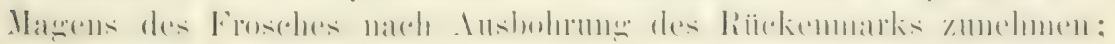
nur handelt es sich bei Aplysia mu beweg'ungen imnerhalb der Lokomotionsmuskulatur. Am stairksten und regelmäßigsten sind diese peristaltischen Bewegrugen an Fruß, besonders an den Seitenfläichen, wo die Wellenbewegungen wie nomal ron vorn nach hinten ablaten, 


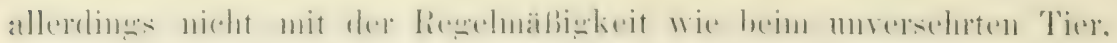
wemn es kriecht. In den Flïgeln sieht man meistenteils nur unge-

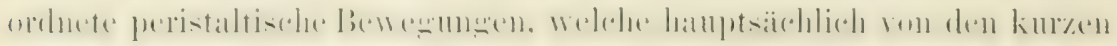
Muskeln ausogehen mögren; in eingon fällen habe ich aber hier Be-

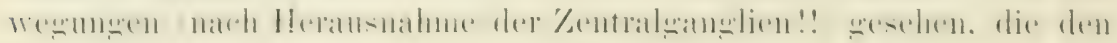
Schwimmbewegungen des normalen 'l'iers sehr ähnlich waren. Beide Fliigel dehnten sich a us und zogen sichunter Spiralbildung wieder zus ammen. Dies spiel trat in gleichmäßigen

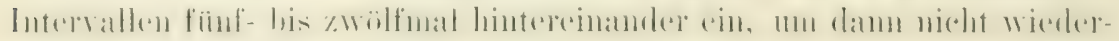
zukehren. Eine Koordination beider Seiten konnte dabei nieht festgestellt werden, jerle schlug für sich, aber immerhalb jedes Flügels war eine gewisse Koordination zu erkennen. - Nach einiger Zeit werden die peristaltischen Bewegungen schwächer, sind aber auch nach eingetretenem starkem Gesamttonus noch tagelang sichtbar (wem nü Schlundring und Buccalganglien heransgenommen waren und zugenäht wurde). (Nimmt man anch die hinteren Visceralganglien heraus, so sterben die 'Tiere bald, weil sie nur ungenigend atmen kionnen.

Die Fühler und Mundlappen sind gewöhnlich ansgestreckt. Beriblut man sie, so riehen sie sich je nach Stairke des Reizes mehr oder weniger zurick. Ist der Reiz stark, so greift er auf die Körpermuskulatur ïber; eine vollkommene Zusammenballung des ganzen Tieres kamn man allerdings nie erreichen, doch tritt dieselbe auch heim nolmalen T'ier anf lokalisierte Reize nur selten ein. Das Gleiche ist anch an andern Körperstellen zu beobachten: je stär ker der Reiz, desto weiter greift der Effekt um sich auch noch

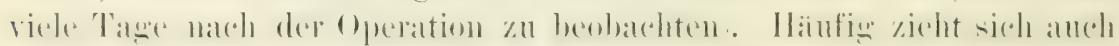
nur die gereizte Stelle ein, wähend in der Umgebung heftige peri-

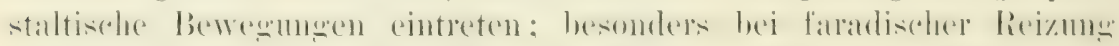
beobachtet man nicht selten, daß nach dem Aufhören des Reizes der

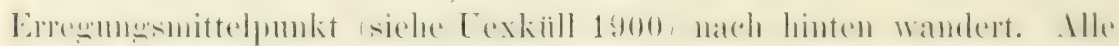

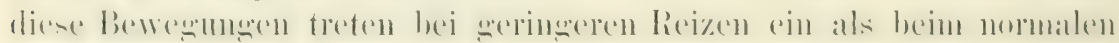
'l'ier und zeichnen sich dureh größere Leblattigkeit und längere D) alter aus.

Daß die Nervennetze unter dem Einfluß des zentralisierten Nervensystems stehen, geht schon daraus hervor, dal die l'eristaltik nach

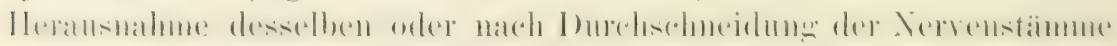
zunimmt. Dieser Zusammenhang mit den Ganglienknoten lät sich aber auf andre Weise noch viel besser demonstrieren: Bereits Jorlan

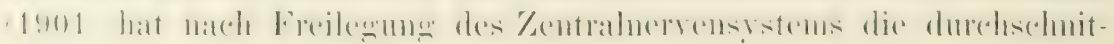
tenen Nerven gereizt, aber nur andanernde Lontraktionen erhalten. Offenbar liat er gleich zu starke Ströme angewendet und zu kure Zeit beobachtet. Die Sache liegrt nainlich riemlich kompliziert: Nur 


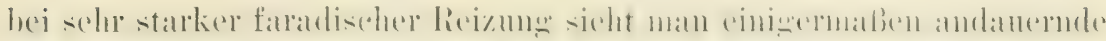
und damn selı ansgedelunte Kontraktion eintreten; bei allen sub-

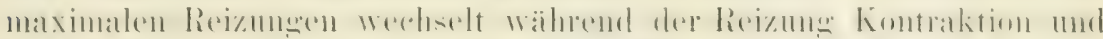

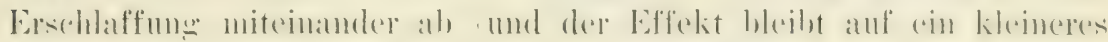
Gebiet beschriukt). lBesonder's an den Flïgeh ist dies gut zu beobachten, und hier kommt es bisweilen zu richtigen rhythmischen Kontraktionen; an der ibrigen Körperoberfläche sieht man in der

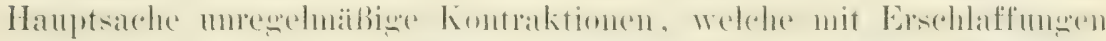
abwechsehn, oder sehr heftige peristaltische Bewegunen. Dasselbe tritt auch bei Reizung mit dem konstanten Strom wähend der Durehströmung ein. Ich komme später auf diese Dinge noch turick. Was mir hier die Hauptsache ist: Bei Reizung eines peripheren Nerren bleibt der Effekt nicht a die direkt innervierte nach Stäke des Reizes anf weitere 'T'eile und schlie Blich auf die ganze Inskulatur a us, trotzdem das gesamte zentrale Nerrensystem herausgenommen ist. Es hängt also jeder Nerr dureh das Nervennetzindirekt mit der gesamten Musklatur zusammen; die Nerven sind nur lange Bahnen, welche zwischen einzelnen 'Teilen des Nerrenuetzes kïrzere Verbindungen herstellen.

Ich beschreibe hier, um die Sache zu reranschanlichen, einen typischen Versuch: Eine große Aplysia wird rom Rucken her anf-

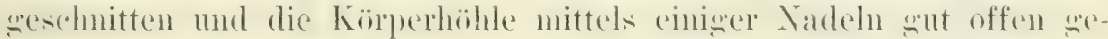
halten. Alle peripheren Nervenstämme werden dicht an den Ganglien durchschnitten, soweit wie möglich frei präpariert und die Ganglien heransgenommen. In jeden Flïgel gehen vier Nerven (die Zahl derselhen variiert zwischen zwei und vier). Von diesen wird der vorderste

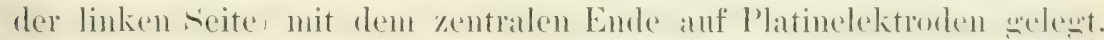

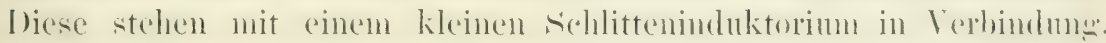
das mit einem Chromsämeelement setrieben wird. Die frei in der Luft schwebende Strecke des Nerven mißt $3 \mathrm{~cm}$. Der 'Tonus ist gering, aber die ganze Körperoberfläche ist in zienlich leblafter peri-

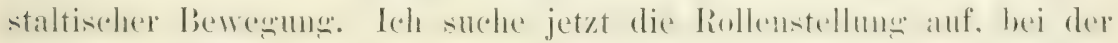
eben ein Effekt sichtbar wird (is cm Rollenabstand). licim Einbrechen der Ströme kontrahiert sich $n$ u der vordere Rand des Flügels und dehnt sich bald, trotz Fortsetzung der Reizung, wieder aus. Nach kumel Ruhepause (Aussetzen des Reizes) hat eine elnente Reizung den gleichen Effekt. Bei Reiz mit 17 em Rollenabstand kontrahieren sich anßer den rorderen P'artien des Fliigels anch die mittleren Teile beim begimn der Faradisation. Nach einigren Sekumden tritt Erschlaffung ein, welehe aber nicht andauert. Es tritt eine zweite Kontraktion ein, eine neue Erschlaffung und uoch eine 
1 is Vergleichung des Zusammenhanges der nervösen Elemente u. s. w.

dritte schwächere Liontraktion, nach der dauernde Ruhe folgt. Bei $16 \mathrm{~cm}$ Rollenabstand kontrahiert sich schon der ganze Flïgel und zwar volne zuerst. Der rhythmische Weehsel ron Kontraktion und Erschlaffumg ist dentlich ausgeprigt. In ganzen wurden 11 Bewegungen gezihlt. Die letzten beiden waren schwach und es folgte auf sie Rulie, trotzdem der Reiz andanerte. Nach einer Reizpause

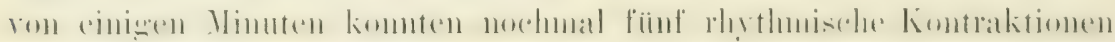
ausgelöst werden. 13ei $14 \mathrm{em}$ geriet der Fligel in cinen dauernden Kontraktionszustand, in welehem aber hin und wieder ein kleiner

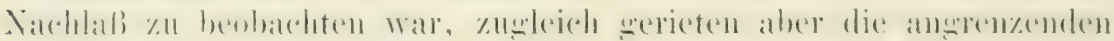
Partien des Fußes in sehr verstaikte wurnfömige Bewegungen. Schließlich bei $12-13 \mathrm{~cm}$ Rollenabstand war die Kontraktion des linken Flitgels stark und andanernd. Der ganze Köper war in lebhaftester peristaltischer Bewegug und der rechte Flïgel, der bis dahin ruhg geblieben war, machte eine lange Serie sehöner rhythmischer Bewegungen!

Es wurde dam der dritte der Fligelnerven aufgelegt. Bei schwacher Anfangsreizumg kontrahierte sich nur die hintele l'artie

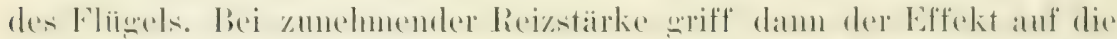

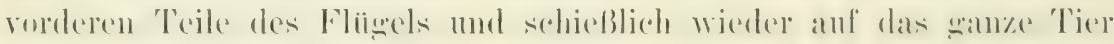
iiber. Der rechte Fligel zeigte dabei nur Kontraktion ohme wesent-

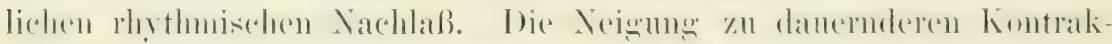
tionen wird ïberhaupt mit der Dauer des Versuches immer größer. - Nur die Kontraktionen der mit den Nerven in näherer Verbindung stehenden Muskeln erfolgen bei Begimn der Reizumg. Ton den zunächst reagierenden Partien aus sicht man die Reaktion sich nach allen Seiten verbreiten, so daß sich \%. B. der andre Flügel etwa 1\%. Sekmolen später zu bewegen anfängt als der gereizte. Hierans geht bereits hervor, daß es sich nicht m eine Wirkumg ron Strom-

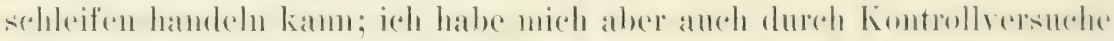

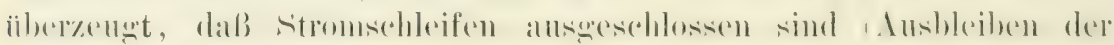
Reaktion nach Abbinden des Nerven unterhalb (ler Reizstelle 1. s. w.).

Die gleiche Ausbreitung des Reizeffektes rou der anfänglich allein reagierenden Muskelgruppe auf das ganze 'T'iel' kam man natiolich auch an andern Nerven konstatieren. Nach den Fliigelnerven sind hierzu besonders die Nerven des Fußes geeignet, weil sie auch auf längere Strecken (5-6 cm) hochgehoben werden kömen, allerdings nicht so leicht wie jene.

Sehr interessante Resultate eroibt anch die Untersuchung einiger Land-Nacktschnecken. Herr Seminarlehrer Kinnel hat mich hierauf aufmerksam gemacht und mil einige schöne Versuche an denselben gezeigt. Er selbst wird binnen kurem iiber dieselben berichten, hat mir aber auf meine bitte grestattet, sehon vorher dieselben hier zu er- 
wihnen. Ich verdanke diesem Herm anch einige Exemplare, an denen ich seine Befunde nachprifen und erweitern komnte. Bei den P’ulnonaten liegen alle Ganghlien dicht zusammen im Kopt. Die Lokonotion dieser 'Tiere wird, wie simroth (1875 und 1879) genaner untersuchte, durch einen streifen in der Mitte der Sohle besorgt, weleher wellenfömige Bewegungen ron hinten nach rorn ausfiihrt. Schneidet man nun einem solehen 'Tier (Limax cinereus oder variegatus) den Kopt ab, so zeigen sich die Wellen in un reränderter Regelmä Bigkit! Kunkel). Während bei Aplysia die Wellen immerhin

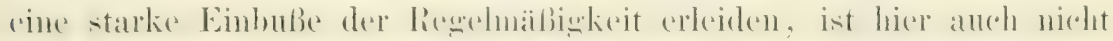
die geringste Störung in ihrer Koordination zul bemerken. Sie sind auch stark genug, um noch eine Fortbewegung des Hintertiers zu ermöglichen. (Übrigens hat bereits Simroth hauptsaichlich aus ana-

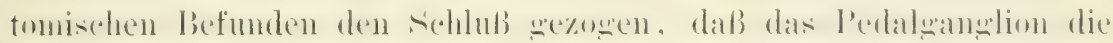
Lokomotionsberregumgen nur anrege.) - Schneidet man den langgestreckten Körper auf und reizt einen der langen Fußnerven mit Wechselströmen, so nehmen die Wellen an Heftigkeit noch zu. Präipariere ich einen solchen Nerven bis in die Nähe der Schwanzspitze, halte ihn hoch und reize das zentralste Ende (die Ganglien sind entfernt, so erhalte ich denselhen Effekt wie hei lphria: hei sohwathem

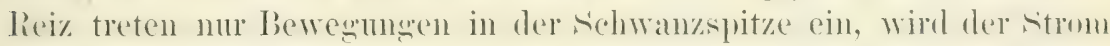
verstiilkt, so dehnen sie sich immer weiter nach rorme aus. Auch hier kann nan wieder konstatieren, dab os sich nicht un einfarele tetanische Kontraktion handelt, wie etwa bei der Reizung eines Froschnerven, sondern um eimen Wechsel ron Kontraktion und Erschlaffung. So

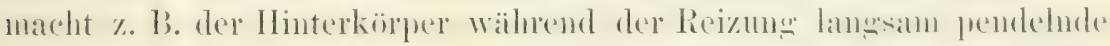

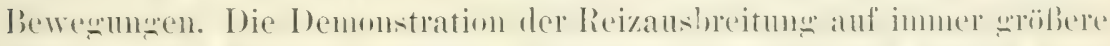

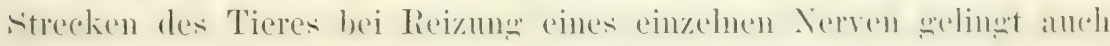
sehr g’ut bei den größeren Land-Nacktschmecken, z. B. bei Arion, während sie das Forthestehen von Lokomotionswellen noch weniger g'ut zeigen wie Aplysia. Es mag dies daher kommen, daß die 'Tonussteigerung nach Entfernung der Ganglien ganz besonders stark ist, die Lokomotionswellen aber zum guten Ablauf eines geringen 'Tonus der Muskulatur bediurfen. (Das normale Tier kriecht nur, wenn der

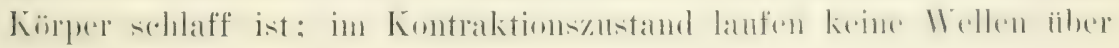
die Solnle.)

An Arion läßt sich auch sehr schön zeigen, da B die langen bahnen, welehe duch das Zentralnerensystemgehen, die Reize sehneller und leichter a uf weite strecken vermittelu, als es durch das Nervennetz möglich ist. Ich richte mil zwei Tiere hel: bei dem einen ist das manze '/entralnervensystem herausgenommen (anch die Nerven, soweit das möglieh ist); das andre ist in der Witte so durchschnitten, dali das Hintertier 
und Yordertier nu noch durch die beiden langen Nerven des Fußes

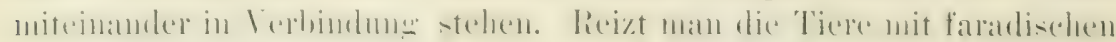
Strömen an Schwanzende, so entsteht lier eine Kontraktion und ver-

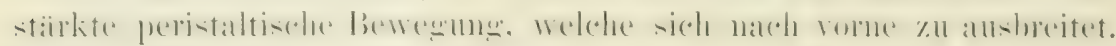
Bei dem 'Tier', dessen lange Bahnen erhalten sind, g’enigen num viel schwächere Ströme, un den Reiz bis zum Kopf gelangen zu lassen, und es verochen vom Moment des Reizanfanges bis zul Kontraktion des Torderendes nur etra $0,5-0,75 "$ ". Bei den Tier ohne Zentralnelvensystem muß man stäkere Ströme anwenden, 1 m den Effekt

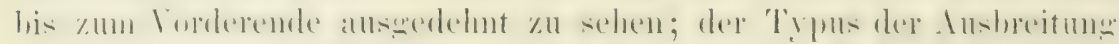

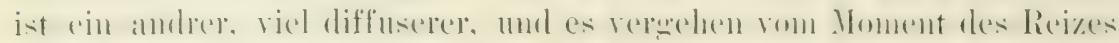
bis zur Ankunft der Kontraktionswelle an Vorderende 2-3", also etwa die vierfache Zeit. (Natirlich wurden ghleichlange Schnecken zum Verwleich ausgewaihlt. Die Länge der benutzten Tiere in gestrecktem Zustand betrug etwa $9-10 \mathrm{~cm}$. Beim nolmalen 'Tier geht

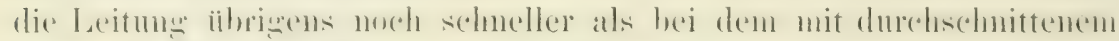
Körper. Man wiirte schon graphische Methoden zu Hilfe nehmen mïssen, um die Zeit zu bestimmen.

Wil sehen also bei den Mollusken genau das, was man aus den

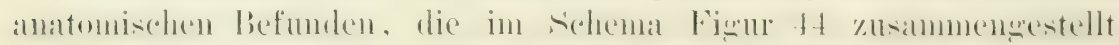
sind, vou volnherein annehmen muBte: die Muskulatur des ganzen

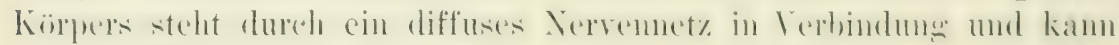
in ihrer 'Totalitait von jedem Punkt der Oberfläche erregt werden, auch dann, wenn das Zentralnervensystem fehlt. Das Kentralnervensystem stellt nur imnigere Terbindungen zwischen einzelnen, weit roneinander entfernten Punkten des Nervennetzes her; es ist nur lange Bahn!

Auch für die Existen\% zweier Nerrennet\%e unter der Hant der

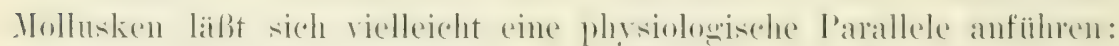

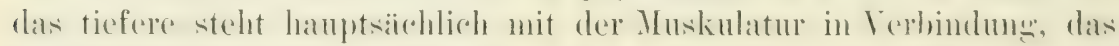

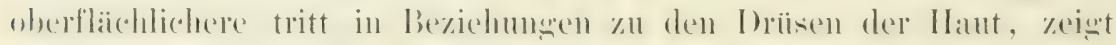
abel mit dem zentralen Nervensystem nur indirekte Verbindungen.

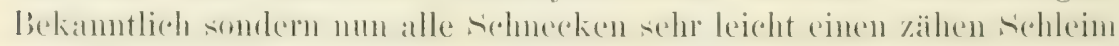
ab. Dies ist besonders bei Limax sehr ausgesprochen: Beriihrt man

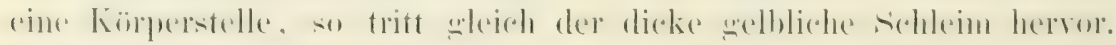
Ist der Reiz stärker, so bedeckt sich auch die weitere Unmebung mit

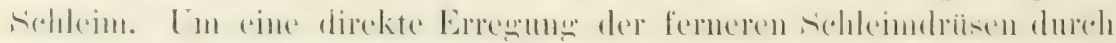
den Reiz selbst kann es sich nmmöglich handeln, denn dazu ist die Entfernumg zu groß; auch kann der Reiz nicht direkt von Drïse zu

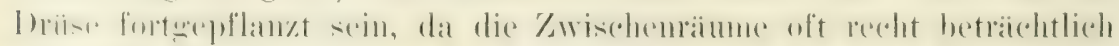
sind; die Übertragumg muB also dureh ein reizleitendes Gewebe besorgt werden. Nach Fortuahme des Zentralnerrensystems besteht die Erscheinung ruhig fort, rorausgesetzt, daß sich die Driisen bei der 


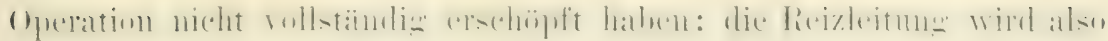
durch das Jerrenuet\% a wehen. Nun ist dureh Reizung der Jerrenstimme nur sehr sehwer Selietion der Hauthrisen zu erielen; erst bei Reizstïrken, bei denen schon die Muskulatur des ganzen Körpers in Bewegung ist, tritt sie ein. An einer Verschiedenheit in der Ansprechbarkeit ron Muskehn und Drüsen kimn dies nicht liegen, weil bei Hautreiz die Drisen eher leichter zu Sekretion gebracht werden, als die Muskeln zur Kontraktion (ror wie nach Herausmahme der Ganglien). Mir schent daher die Erklärung aus der anatomischen Ver-

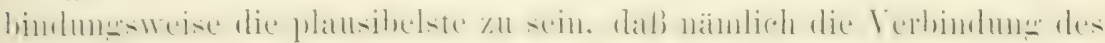
inneren Nervemnetzes, das die Muskulatur rersorgt, mit dem Zentralnervensrstem inniger ist, als die zwischen dem Zentralnerrensystem

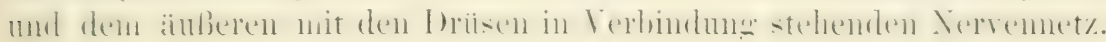

ITas hier bei den Mollusken im Bereich der gesamten Muskulatur ror sich geht, finden wil bei den Wirbeltieren nur noch in den $\mathrm{Ol}^{\circ}$ -

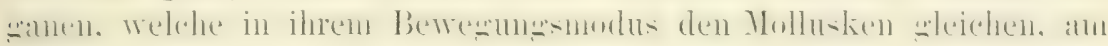
cklatantesten in den Terdaumgsorganen. Ich will mich hier auf diese beschrinken und nur iber die Tersuche berichten, welche Goltz (1872) am Magen und Ösophagus rom Frosch anstellte, Tersuche, die ja den

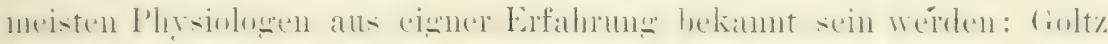
hängte curarisierte Frösche an der Schnauze auf, nachdem rorher Ösophagus und Magen freigelegt Waren. Toun Maul aus wurde num

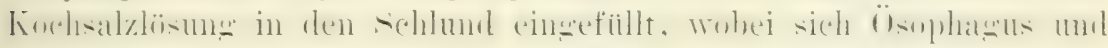
Iagen stark erweitern mol füllen. Entweder sind sie dann ganz glatt oder es laufen nu schwache peristaltische Wellen dariber hin. Wird

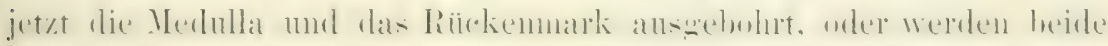

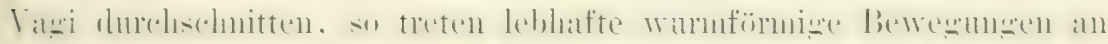
speiseröhre und Jagen auf, es kommt zu allgemeiner Kontraktion, bei weleher der größte Teil des Wassers durch das Maul ansfließBt. Erst beim Absterben tritt wieder Ruhe und Erschlaffung ein. Reizt man Ösophagus oder Magen nach der Zerstörung des Zentralnervensrstems, so werden die peristaltischen (und antiperistaltischen) Bewegungen noch wesentlich verstälkt und bleiben es fiur lange Zeit. leizung beim Tier mit unverletztem Zentralnerrensystem ruft chenfalls peristaltische Bewegunen hervor, sie sind aher schwäber, ron kiirzerer Daner und bediurfen zu ihrer Luslösung stälkerer Reize. Es ist also hier grade wie bei den Mollusken mach Ausschaltung des

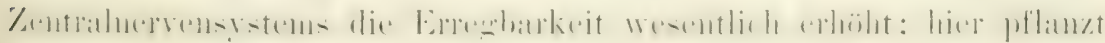
sich wie dort der Reiz ron jeder Stelle nach jeder andern lin fort. IVird beim aufgehängten Tier ein Vagus gereizt, so treten die lebhaftesten peristaltischen Bewegungen ein; aber niemals, wie im Gebiet 


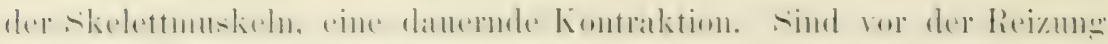
beide Vagi durchschnitten, so werden die bereits bestehenden Bewegungen verstäkt; auch bei sehwachster Reizung ist eine beruhigende Wirkmg nicht zu konstaticren. So wie die bewegungen vom Darmsysten direkt ausgelöst werden können, so können sie auch

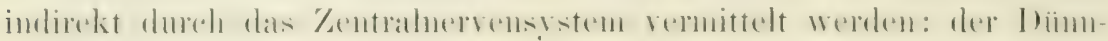
darm eines lieres mit mverletztem Zentralnervensystem wird abge-

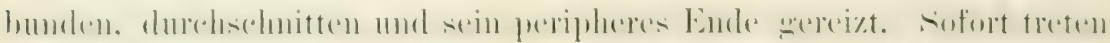

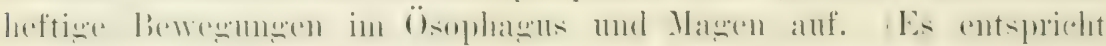
dieser Versuch dem bei Arion gemachten, wo Vordertier und Hinterfier nur noch durch zwei Nervenstämme miteinander in Verbindung stehen.) In gleicher Weise können Bewegungen von andern Stellen des Nerrensystems ausgelöst werden, so bei 'Tetanisation des Ischiadicus, beim Eintanchen der Beine in Schwefelsäure u. s. w. Aus alle-

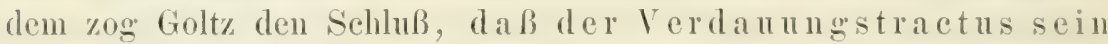
cigenes diffuses Reflexnervensystem in sich berge, welches zwar dureh das Zentralnervensystem beeinflußt wiile, aber nicht im an legenden, sondern im beruhigenden Sinn. (Unser Schema für die Mollusken [Fig. 44] kïnnte die nötigen anatomischen Bodingmengen erfïllen. Wenn das

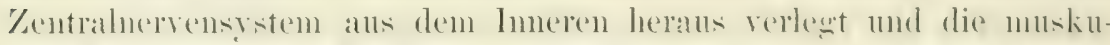
läre Kïprevand als I armwand anferefalit wiirle. loh komume später auf diese Dinge noch eimmal zuriek. ${ }^{1}$ )

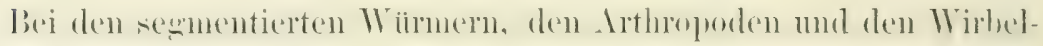
tieren, finden wir, wie oben gezeigt, Nervemetze nur im Bereich be-

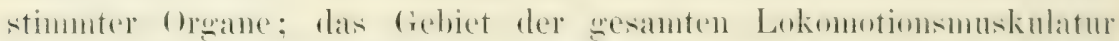

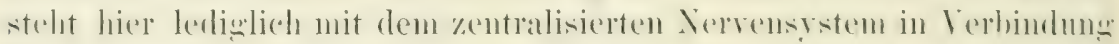
rign. $41-43 \%$ Hiemit steht die physologische Erfahrum in hestem

1) Die Ansicht, daß es sich im Darmsystem um muskuläre Erregungsleitung handelt, halte ich kaum noch fïr diskutierbar. Sie konnte nach meiner Heinung nur so lange Anlänger finden, als der enorme Nervenreichtum dieser Organe und die Analogien mit den niederen Tieren, bei denen von musknlärer Erregungsiibertragung gar nicht die Rede sein kamn, nicht bekannt waren. Außer den Awerbachsehen Plexus und den Gefïbnervennetzen finden sich im Darm richtige Nervennetze, welche schon öfter andeutungsweise gesehen sind. Sie scheinen mir einen Übergang zwischen den richtigen, breitanastomosigen Nervemetzen und den plasmatisch isolierten Neuronen zu bilden. Ls kommt hier zur Bildung einer richtigen Nervenfaser an jeder Zelle. Von dieser unterscheiden sich die andern Fortsitze wesentlich; sie gleichen mehr Protoplasmafortsätzen zentraler Zellen, endigen aber in ihrem plasmatischen 'Teil nicht blind, sondern verbinden sich nach mehrfachen Teilungen wenigstens zum Teil direkt mit denen andrer, gleichartiger Zellen. Doch sind meine Untersuchungen hieriiber noch zu spärlich, um 


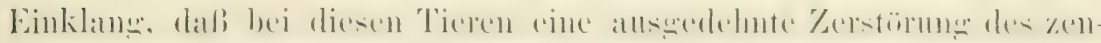
tralen Nervensystems vollkommene Reflexlosigkeit mach sich rieht. Das Zentralnervensystem ist eben hier in Gegensatz zu den Mollusken der einzige Ort, wo rezeptorische und effektorische

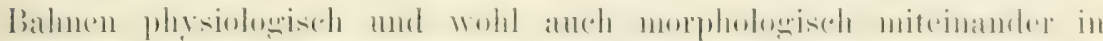
Verbindung stelen. Was hier vom ganzen Zentrahnervensystem gailt,

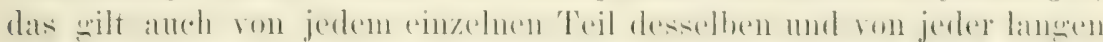

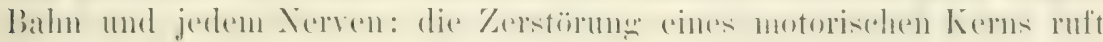
bei einem Wirbeltier dauernde reflektorische Lähmung in den zu-

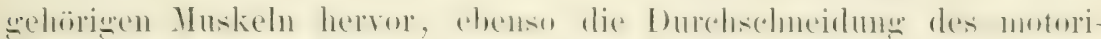
schen Nerven. Durchschneidung eines rezeptorischen Nerren macht das innerrierte Gebiet der Haut unfähig, Reflexe zu relmitteln; man mag reizen so sehr man will, es tritt keme Reaktion ein. Ebenso ist es mit der Durchtrennumg langer zentraler Bahnen. Hat man das Riickemmark eines Wirbeltiers oder die Kommissmen zwischen zwei

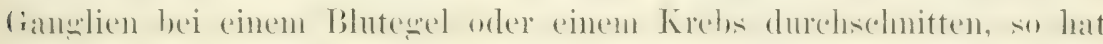
man das 'Tier in zwei getrennte Reflexwesen geteilt. Trotzdem alles iibrige zusammenhängt, reagiert auf Reiz rorue nur das Vordertier, auf Reiz hinten nur das Hintertier. Wie so ganz anders als bei den

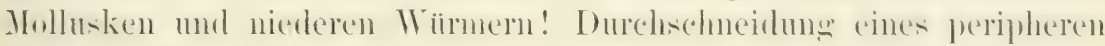
Nerven ruft hei diesen weder motorische mold rezeptorische Lähnumen im imnervierten Gebiet hervor; es zeigt sich mur eine geringe, manchmal gar nicht nachweisbare Beeintrachtigung. Ist die zentrale Verhindung zwischen Vorler- mul Ilintertier sanz unterhrochen, sind \%. Is. die Kommissuren zrischen dem Cerebralganglion und den Pedalganglien bei einer Aplysia durchschnitten, so zeigen sich zwar dent-

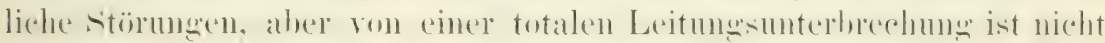
die Rede, wie ja schon aus allem rorher Gesagten entnommen werden kamn: Reizt man das Hintertier, so reagieren anch die ron Cerebral-

als abgeschlossen gelten zu können. Auch am Ureter finde ich iiberall Nervennetze mit eingestrenten Ganglienzellen. Man kömte dieselben zwar dem Blutgefiißsystem zurechmen, jedenfalls kann man sich aber nicht mehr darauf stiitzen, daß im Ureter Nervenelemente fehlten, durch die seine Bewegungen vermittelt werden könnten. Sollen hier die peristaltischen Bewegungen, die an andern Organen und andern Tieren nervös vermittelt werden, anf eimmal rein muskulair sein? Mir scheint das nuwahrseheinlich. Der Ablauf der Wellen nach beiden Seiten beweist nach meiner Meinung gar niehts gegen die nervöse Leitung. Die Leitung von jeder Stelle zu jeder Stelle ist ja grade das Eigentïmliche bei den Nervennetzen, wie doch wohl aus den Versuchen an Medusen mit urößter Sicherheit hervorgeht. Ich habe es ïbrigens nicht übersehen, daß Engehmann (1569 und 15is) nur für den eigentlichen Darm, aber nicht für Ösophagus und Magen eine muskulaire Leitumg amnimmt. Dats ron ilm als lieweis angegebene Fehlen von Nerven und Gamglienzellen am Fliegendarm hedarf jedenfalls der liestiitigung mit neneren Methoden, ehe es weiterhin ins Feld greführt werden darf. 


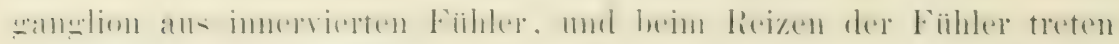
Bewegrungen in den Fliigeln, dem FuB, kurz in allen vom Pedal-

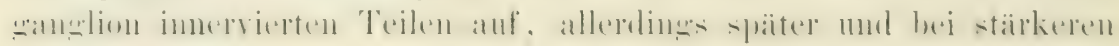
Reizen als beim normalen 'Tier.

Ob das zentrale Nervensystem durch Tiefenlagerung eines Teils des Nerrennetzes aus diesem entstanden ist und ob wir in den Mollnsken resp. den niederen Würmen ein Zwischenstadium zwischen dem Nervensystem der Coelenteraten und dem der höheren Würmer, Arthropoden und Wirbeltieren vor uns haben, oder ob es eine roll-

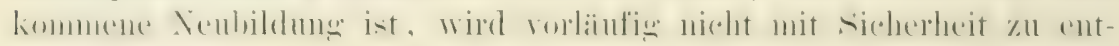
scheiden sein. Mir scheint das erstere allerdings das wahrscheinlichere. Man dürfte damn amnehmen, daß das periphere Nervennet\% sich mehr und mehr zuriiekgebildet hat, so daß schließlich alle Ver-

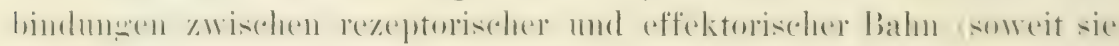
die Lokomotionsmuskulatur angehen) nur noch durech das zentrale

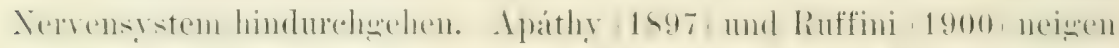

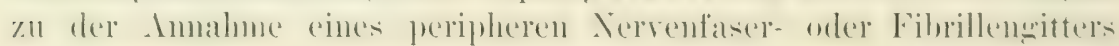
sowohl im Epithel als auch in der Muskulatur. Apáthy hat bei

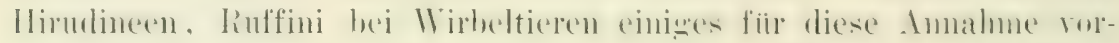
grebracht; bewiesen ist jedenfalls noch nichts. Wenn sich die Sache aber bestaitigen sollte, so würden wir in diesem Gitter ein Rudiment

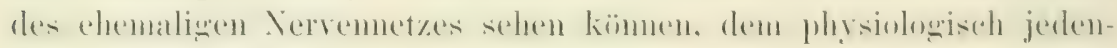
falls keine große Bedeutung mehr zukäme; das-können wir schon

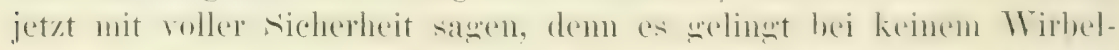

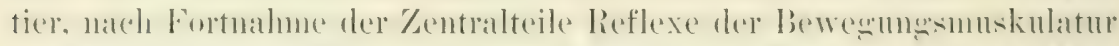

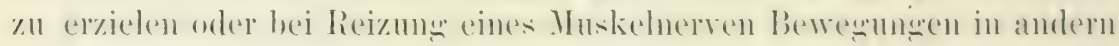
als den innervierten Muskeln zu konstatieren. Es kamn also dies ver-

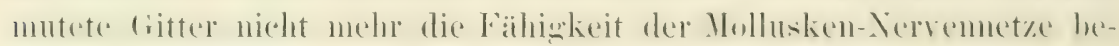
sitzen, eine diffuse Ausbreitung der Reize zu vermitteln. 


\section{ACIITES KAPITEL.}

\section{Die primäre Färbbarkeit der Ganglienzellen und der Neurofibrillen.}

Die primäre Färbbarkeit der Ganglienzellen S. 127-133. - Die primäre Färbbarkeit der Neurofibrillen S. 133-135. - Das Wesen der primären Fïrbbarkeit der Ganglienzellen und der Neurofibrillen S. 135. - Die primäre Firbbarkeit beruht auf Anwesenheit besonderer, löslicher Substanzen S. 139-1+1. - Die primär fïrbbare Substanz der Fibrillen ist von der der Nisslschollen verschieden S. 141-142. - Eigenschaften der Fibrillensiure S. 143. - Wie ist die Fibrillensiiure-an die Fibrillen gebunden? S. 144. - Scharfer Unterschied zwischen peripheren Nervenfaserm einerseits und den Nervenfasern und Zellen des Zentralnervensystems andrerseits S. 145. - Konkurrenzsubstanzhypothese: Im Zentralnervensystem bildet sich eine Konkurrenzsäure, welche bei Sauerstoffmangel die Eberhand gewinnt und die Fibrillensïure aus der Verbindung mit den Fibrillen herausdrängt. Erstere fehlt in den peripheren Nerven S. 146-14S.

Unter primärer Färbharkeit verstehe ich die Eigensolhaft mancher (iewehshestandteile sich in frischem oder mur durch Wirserentzichnily verinderten Zustande nit den meisten basischen Farhstoffen zon färben.

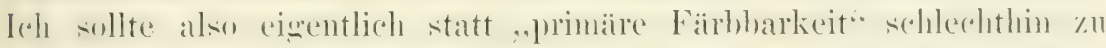
sagen, von einer ,primären Fïrbbarkeit nit basischen Farbstoffen" sprechen, doch ist dies deswegen umnötig, weil es fast keine Gerrebsbestandteile gibt, die sich nicht mit sauren Farben primär färben ließen. Wenn man also ron einer primären Färbbarkeit als etwas Besonderem spricht, so kann nur eine solche rermittelst basischer Farbstoffe gemeint sein. Der primären Färbbarkeit steht die sekun-

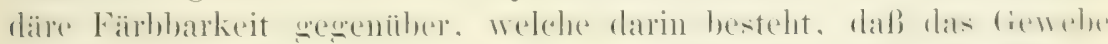
Coder die betreffenden Gewebsbestandteile) um den F'arbstoff anzunehmen in irgend einer Weise ehemisch verindert werden muß.

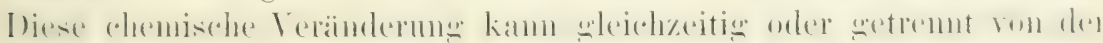

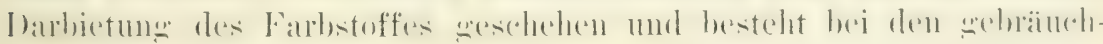
lichen Färbungsmethoden in der Regel in einer Beizung. Ich neme

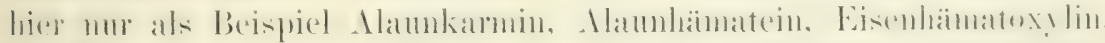

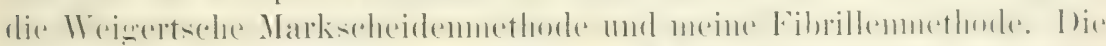

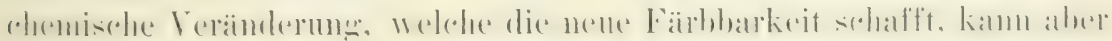
anch auf andre Weise z. B. dureh Jodieren, Nitrieren 11. s. W. bewirkt werden, Mittel, die bisher wenig oder gar nicht zweekhewußt angewandt sind, die aber doch, wie mir einige Versuche gezeigt haben, zu gruten Resultaten führen können, besonders, wem sie mit gewissen Beizungen kombiniert werden. (Bis zu einem gewissen Grade deckt sich meine ,primäre Färbung" mit der ,substantiven Farbung" von Rawitz.) 
Eine reine primäre Färbung kamn natiurlich nur damn zustande kommen, wem das Gerebe nicht oder nur soweit rerändert ist, als es

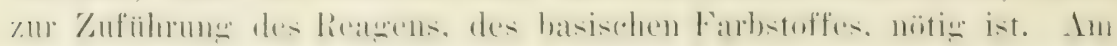
besten wird es immer sein, den Farbstoff anf das frische Gewebe einwirken zu lassen; in \%weiter Linie kommen Strichpräparate mit

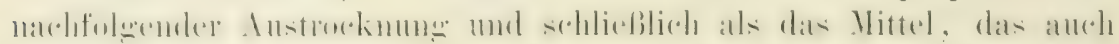
Schnitte zulaßt, Alkohol (resp. Ither) in Betracht. Alle Fixierungsmittel, welche Säuren enthalten, kömnen die primär bestehenden V er-

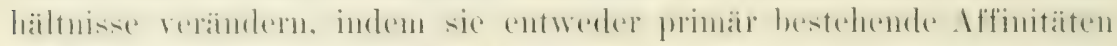

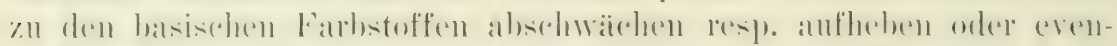

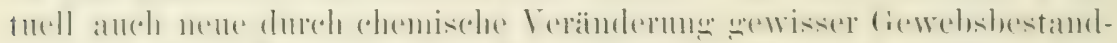

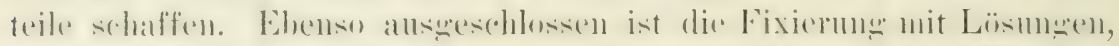

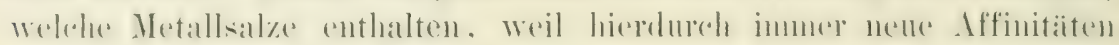

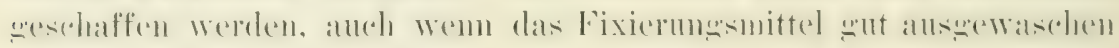
ist. Eine Aufhebung primäirer Affinitäten ist bei diesen allerdings

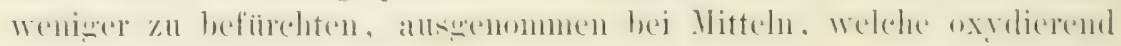
wirken, wie z. B. Chromsalze.

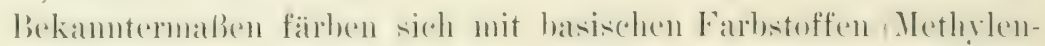
blau, Thionin, Tolnidinblau u. s. w.) in ungebeizten Schnitten der' meisten Gewebe nur die Kerne und zwar in diesen anch nur die als

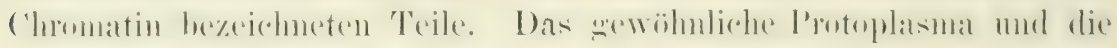

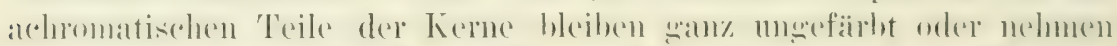

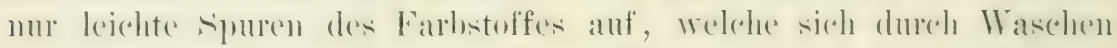

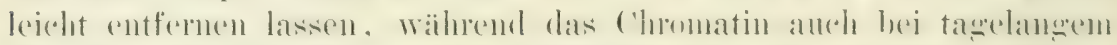

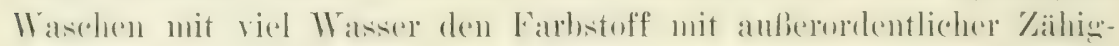
keit festhält. In gewissen Geweben kommen aber noch andre Formbestandteile (neben den Kernen) vor, welehe ohne irgend welehe Tor-

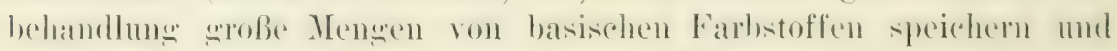

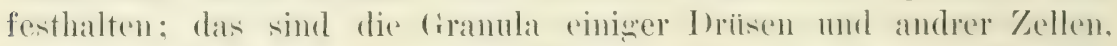
damm aber in den uns hiel beschäfigenden fiewehen gevisise bestandteile des Ideibes der Gamelienzellen, die Nemofibrillen und die Markscheiden.

Die primäre Färbbarkeit des Ganglienzelleibes ist, seit Nissl soine Methode zur Lntersuchung dersellnen publiziert lait, vielfateh

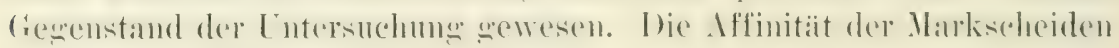
zul basischen Farbstoffen ist mehrfach erwihnt, aber nie genamer untersucht worden; sie ist anch nicht sehr stark und rerdient, soweit

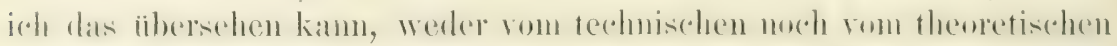

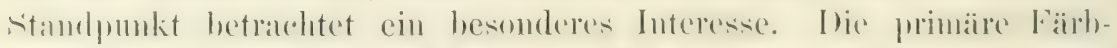

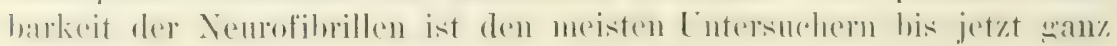

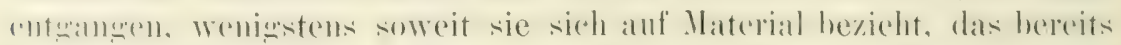
fixiert ist. Der Grund dafür liegt wohl darin, daß die läirbung beim Üherfiblen der Praparate in Alkohol verschwindet. Wie sich aus 
dem später Nitgeteilten ergibt, kamn diese primäre Färbbarkeit der

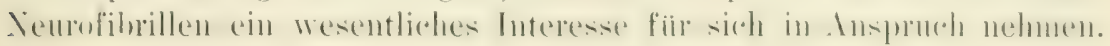

\section{Die primäre Färbbarkeit der Ganglienzellen.}

Nissl (1592 und 1894) läßt bei seiner Wethode zu1 Darstellung

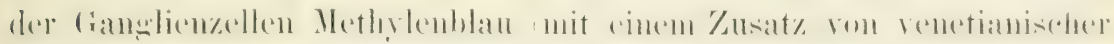
Seife) auf das in Alkohol fixierte Material einwirken. Nach der Färbung wird der überschüssige Farbstoff mit Anilinalkohol fort-

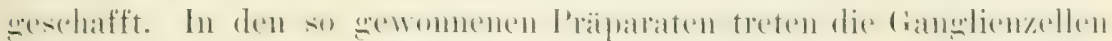
schon bei schwacher Vergrößermo dunkelblau auf fast farblosem

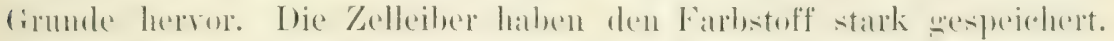

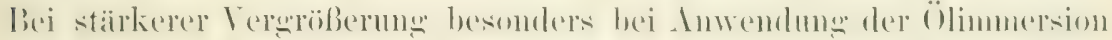
zeigt es sich aber, daß die Zellleiber nicht gleichmäßig blan sind. Besonders die größeren Zellen z. B. die Vorderhornzellen zeigen ein flerkimes dusiehen: dunkle sichollen, striche und P'unkte hehen sich ron fast farblosem Grunde ab; in manchen Zellen zeigt die färbbare Substanz auch eine netzartige Struktur. ${ }^{1}$ ) In allen diesen Fällen ist die färbbare sulstanz des Zellleibes seho donkel tingrert; in kleinen und kleinsten Zellen aber, wie sie z. B. die Substantia gelatinosa des Riickenmarks berölkern, macht sie sich nu als zarter Farbschleier hemerkbar. Soleher heller gefärbter Massen entbehren anch die größeren Zellen neben den dunkel gefärbten nicht. Bei den motorischen Zellen und einisen andern finden side die dhatakteristischeten Bilder. (Tafel Fig. II). Der Zelleib ist erfüllt von großen Schollen; in den Protoplasmafortsätzen finden sich Streifen und an ihren

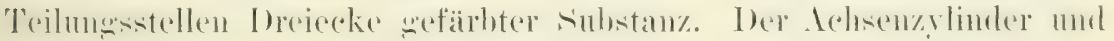
sein Ursprungshïgel bleiben stets ungefärbt. Auf Grund dieser rer-

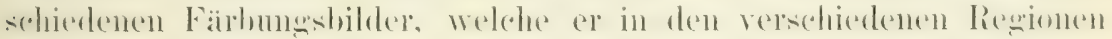
des Nerrensystems fand, stellte Nissl eine Nomenklatur der Nervenzellen auf, welche aber nur für die spezielle Nervenzellanatomie von Interesse ist, uns hier also nicht weiter zu beschäftigen hat.

Wir haben es hier also mit einer echten primären Färbbarkeit zu tun, welche uns wenigstens von einem Bestandteil des Ganglienzelleibes ein gutes Reaktionsbild gibt. Wemn ron andern Seiten Fixiering mit Metallsalzen \%. B. mit Sublimat (Lenhossék, van Giehuchten, Bühler) empfohlen ist, so bedentet dies eine Verkennumg dessen, was mit dieser ideal einfachen Methode erreicht werden soll

1) Diese geformten Substamzportionen der färbbaren Sulnstanz Nissls werden von manchen Autoren Flemming-Nisslsche Körjerchen (Flemming sah sie zuerst), Xissl-Schollen, Tigroid u. s. W. benamnt. Diese Bezeichmungen decken sich aber, wie Nissl mehrfach hervorgehohen hat, nur zum Teil mit der (primär) l'ärbbaren substanz. Sie treffen nur für gewisse Zellarten zu. 
und allein erreicht werden kamn. K/war kam cine solche mit Sublimat fixierte Zelle sie kamn aber unter L'mständen auch Dinge zeigen, die der primairen Reaktion fremd sind, weil eben das Metallsal\% einer sekundüren Färbung Vorschub leistet. Ganz ähnlich steht es mit der zuerst ron

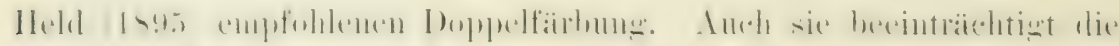

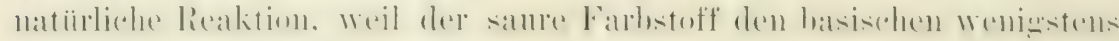

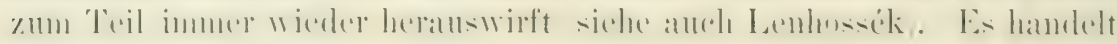
sich bei der Nisslschen Methode eben nieht, wie manche Autoren

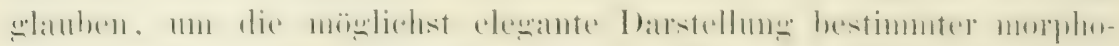
logischer Elemente, die auch auf andere Weise möglich ist, sondern um eine chenische Reaktion dieser Elemente. Reaktionsbild und

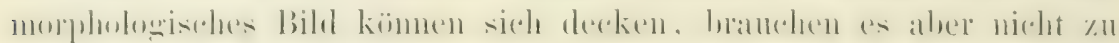
tun, wie ielı später zeigen werde. Ja, man kam direkt sagen: Dic

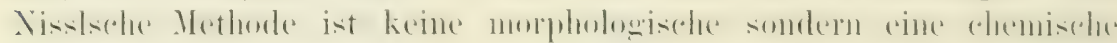
Methode. - Anders steht es mit der Wahl des Farbstoffes, der Art und Weise semer Applikation und der Art der Auswaschung. Hier

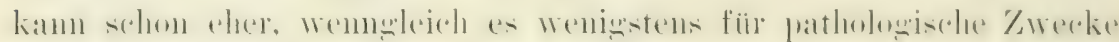
lö̈hst iiberfliissig ist, eine Ïndermg getroffen werden. Thionin,

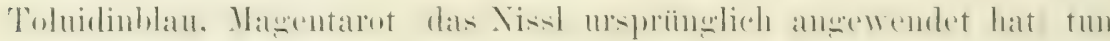
etwa dieselben Dienste wie Methylenblau. Die renetianische Seife scheint im wesentlichen nichts weiter zu tun als den Firbungsprozess zu beschleunigen, grade so wie die Erwämung beim Färben. Auch die Differenziermo mittels Anilin dient im wesentlichen der Zeit-

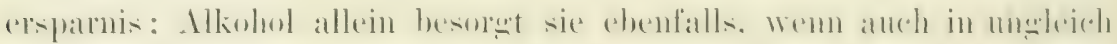
langerer Zeit. Fur methodologische Zwecke ziche ich sogar einfache Alkoholdifferenzierumg vor, weil dabei nie mehr ansgezogen wird als

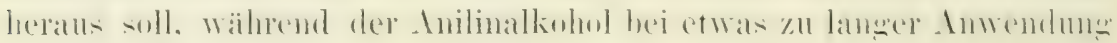
auch die fairbbare Substanz ihrer Farbe wicder beraubt.

Die Portionen der färbbaren Substanz lassen zwischen sich ungefärbte Bahmen frei, welche, wie Nissl schon lange hervorgehoben hatte, besonders in den großen Zellen nicht selten von einem lortsat\% der '/elle zu einem andern zu verfolgen sind. In diesen Bahnen vermutete er Fibrillen, und ich komnte später in der 'Tat nachweisen, daß diese Vermutung richtig war. Die Hauptfibrillenbahmen verlanfen in

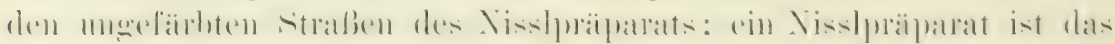

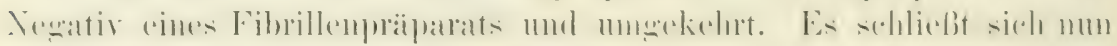
daran die Frage, ob diese Lagebezichung der beiden Elemente anch in der lebenden '/elle dieselbe ist. - Beror noch die Fibrillenfrage zu einer sicheren Entscheidung gelangt war, wurde die lirge, ob das bei seiner Methode sichtbar gemachte Bild der Ganglienzelle den natiulichen Verhaltnissen entspriche, ron Nissl selbst behandelt. Er muBte die Frage offen lassen, kam aber bei seinen Überlegungen zu 


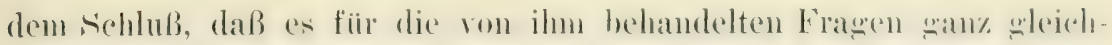
griiltig sei. Ihm kam es daranf an, eine Methode zu besitzen, welche

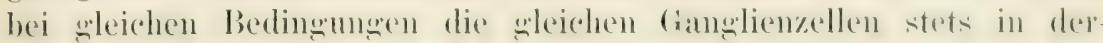

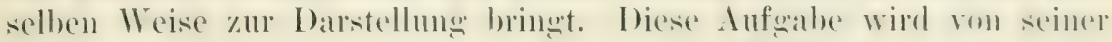
Methode in der Tat gelöst und er nemnt das Bild, das sich bei Anwendung derselhen mntel den Mikroskop zeign, das Nervenzellenäquivalent. Werden die bedingungen des Versuchstieres vor den Torde. verändert, wird das Tier \%. B. vergiftet oder eine Operation an ilm

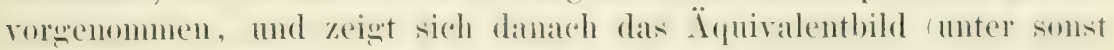

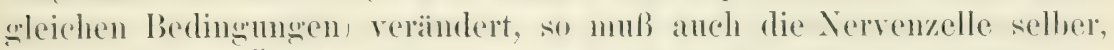
welder dieses İquivalenthild entspricht, ror dem Tode ron der normalen Zelle abmewichen sein. I)as İquivalenthild der nomalen (ianwhenzelle läßt nicht ohne weiteres einen Rückschluß auf das Ausiehen der mormalen Zelle selber zu, wohl aber die Lhweichmog vom mormalen Bilde hei Veränderung einer bedingung auf eine stattgehabte Veranderume des Crbildes infolge der Verändermug der betreffenden bedingmun. Die Äquivalenthilder der Ganglienzellen normaler mu in stets meicher Weise gretiteter Tiere, wie sie in langen systematischen Tersuchsreilen dureh Nissl festestellt sind, zeigen oft schom bei

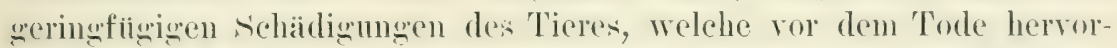
gerufen wurden, starke Verändermugen und so hat sich seine Methode als ganz besonders geeignet gezeigt, iiber funktionelle und pathologische

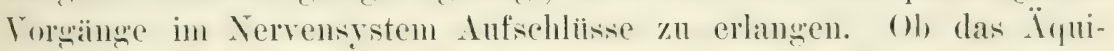
valenthild den Bilde der normalen (xamglienzelle wleicht oder ähnlich

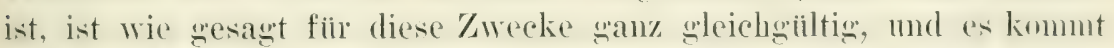
nur darauf an, daß den experinentellen Verändermugen Verandermugen des Trquiralentbildes parablel gehen. Inf die Art dieser Verinderungen werde ich an späteren stellen Gelewenheit haben zurickzukmmmen.

Ließ Nissl die Frage offen, ob die durch seine Methode darwestellten strukturen den Bilde der lebenden Zelle entsprialen, sin glaubte Held (1895) sie in einem bestimmten Sime beantworten zu

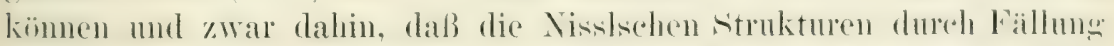
einer in der Cianglienzellfliissigkeit genësten substanz entständen. Mit andern Worten: Die fäbbare substan\% sollte rin Kumstumolulit sein. An und fiir sich muß natiullich eine Substanz da sein, welche die

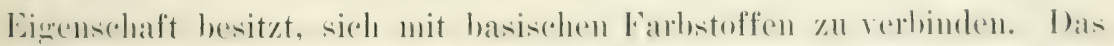

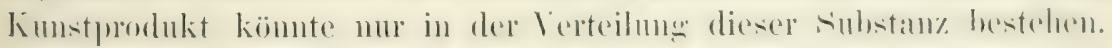

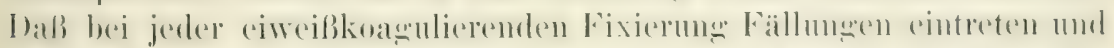

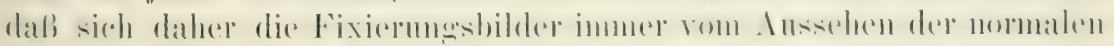

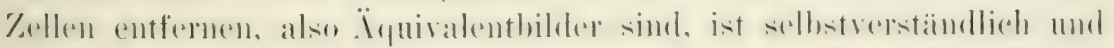
insofern ist immer eine starke Reserve angebracht. In der Regel wird man aber ammehmen diüfen, daß sich diese Abweichmgen vom normalen Ban immer nur anf die feinere struktur bezichen, dem es ist Bethe, Nervensystem. 


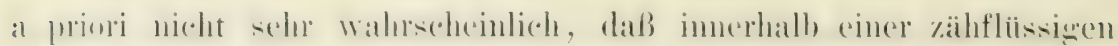

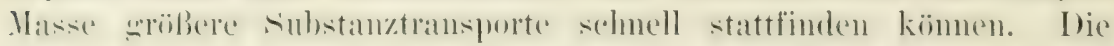
Mäglichlied ist natiolich nicht allswschlieben. Held stützt sich bei scince Behauptung anf zwei Aremuente: Die Nichtsichtharkeit ron

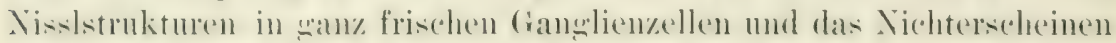

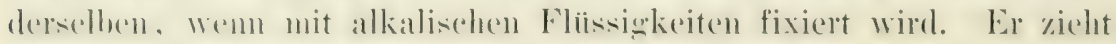
daraus den Sehluß, daß die bekamnten Strukturen durch saure Fixiermosmittel orler dureh postmortale sänerung des fiewebes anssefallt wiirden, demn sie wiirden cinige Zeit nach dem Torle sichthar, anch wenn kein Fixierumgsmittel angewandt worden ist.

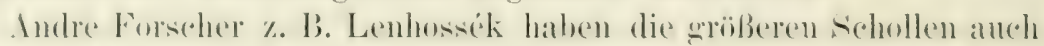

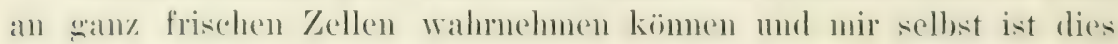
mehrfach an Vorderhornzellen vom Frosch gelungen, welehe wohl

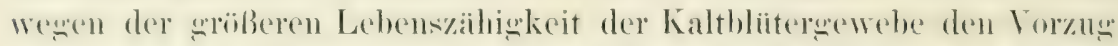

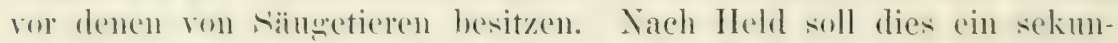
daires Stadium sein und ich will es nicht fiil ganz ausgeschlossen balten, daß Lenhossek und ich immel erst mosere Zellen unters Mikroskop bekommen haben, nachdem dies schom eingetreten war. Es muls

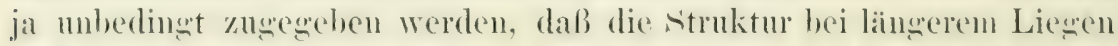
des l'rijuarats, besomders aber beim Zutritt vou Alkohol dentlichere wird. Wirklich in allen Einzelheiten dentlich wird die struktur aber (rst heim Fäben. Ich meine num mit biblhler 1898/, dab das-Dentlicherwerden heim Dbsterben med Fixieren den nicht widerspricht, dak die struktur von Anfang an vorhanden ist, dem es ist durchans denkbar, dak in der sanz frischen Zelle die Lichthrechungsverhailnisse so sind, daß dic an und für sich differenten substanzen allein durch die Lichtbrechung nicht sichtbar werden. - Noch weniger scheint mir Ilelds Versuch mit alkalischen Fixierung slässiskeiten zu herroisen.

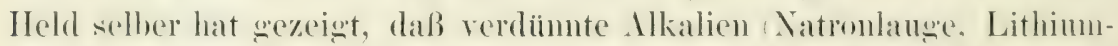
karbonat.) bereits fixierte Ganglienzellen in der Weise rerandern,

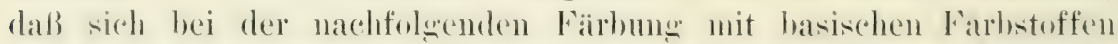
keine Nisslstrukturen mehr zeimen und dab bei nummelor erfoluender Färlung mit einem santen Farbstoff die stellen, an denen worher die

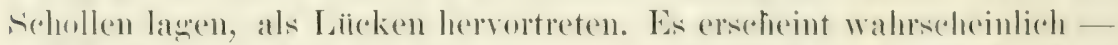
mol Held nimmt dies als sicher an - dals licrbej die primail färbhare

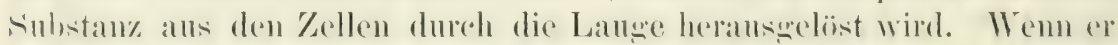
num hei der Fixierume frischen Gewebes statt sowöhnlichen Alkohols.

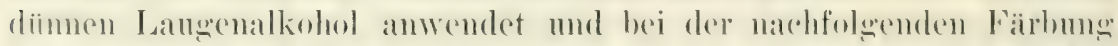
der sehnitte keine Nisslstrukturen sichthar werden, wohl aber in den

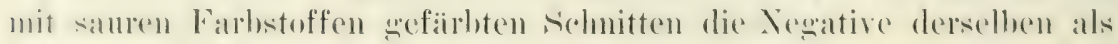

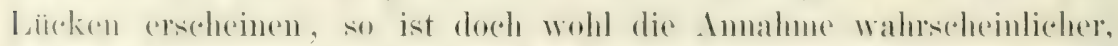

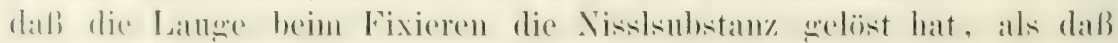
sie deren Fällung verhinderte. Dieselbe Meinung hat auch sehon 
Biihler ausgesprochen und darauf hingewiesen, daß dort, wo eine Liicke erscheint, etwas entfernt sein muß. Ein Beweis dafür, daß

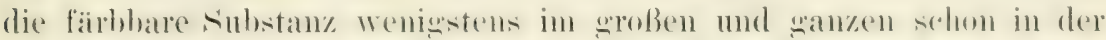
lebenden Zelle so lokalisiert ist, wie wir es auf den gefaibten Prii-

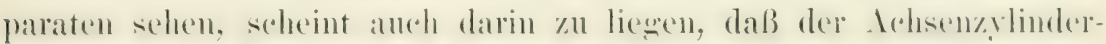

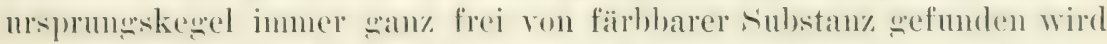

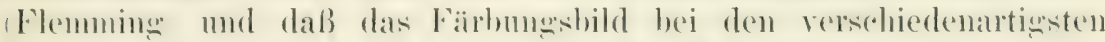
Fixierungen eine große Gleichmäßigkeit aufweist (Lenhossék).

Nach all diesem wiurde ich nicht daran zweifeln, daß das Äquivalentbild dem Bilde der nomaten tanglienzelle, wenigstens was die Verteilung der primär fäibbaren substanz anbetrifft, schr ähnlich sicht, wenn nicht eine Beobachtung von Becker vorläge, welche doch zu ciner sewissen Reserve reranlaßt. Ilerr Dr. Becker hat dieselbe ror einignen Jahren in Baden-Baden auf den Kongreß siidwestdentscher Nemrologen und Irrenärzte demonstriert, aber somst nicht publiziert. liecker injiziert lebenden Fröschen Nentralrot, nimnt nach einigner Zeit ("twas vom Ritckemuale heraus und zerquetscht es auf dem Objekt-

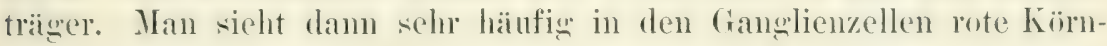
(·hen weichmäbien verteilt. Diese bewegen sich darin langsam hin und her und sammeln sich mit der Zeit an bestimmten stellen an, während sie an andern Stellen rerschwinden. Auf diese Weise entsteht mit der Zeit eine Zeichnung in der Ganglienzelle, welche einem Nisslpräiparat ziemlich ähnlich sieht.

Die Bezichungen zwischen den Fibrillenprijparat und dem Nisslprijparat sind offenbar. Es wäre nm möglich, daß die Lï̈cken, welche

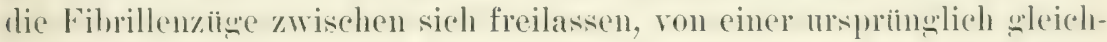
näßBis in der Zelle verteilten substanz beim Absterben resp. bein Fixieren erfuillt werden. Dieser Ammahme scheint sich mir aher manches

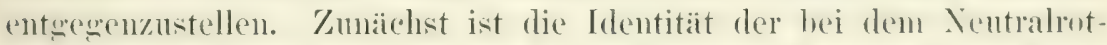
rorfahren wefärbten substanz nit del färhbaren substanz des Nisslpriparats zweifelhaft. Macht man nämlich das seledohe Experinent mittels Methylenblaninjektion, so sicht man oft in den Gans lienzellen (wenn nicht eine diffuse Fïrbung derselben eintritt) vou Anfang an das typische Nisslbild, außerdem aber eine ganze Inzahl von Körn-

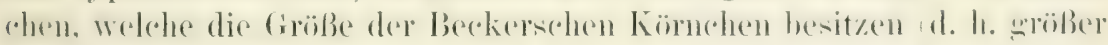

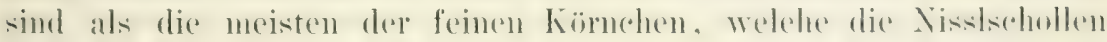

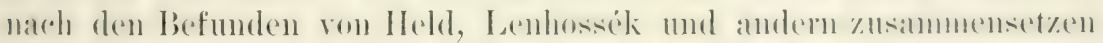
und ïber den ganzen Zelleib verteilt sind. Anch in vielen andern

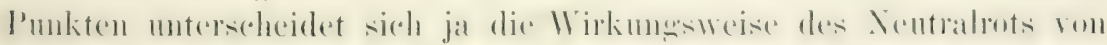
der des Methylenblans, 'Tohuidinblans 'u. s. w. sowohl bei der Applikation anf das lebende wie anf das fixierte Gewebe. - Die Fixierung

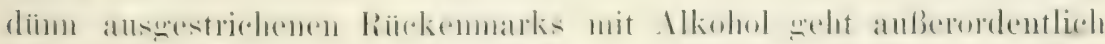

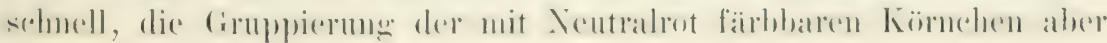




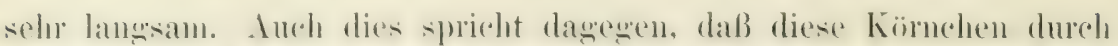

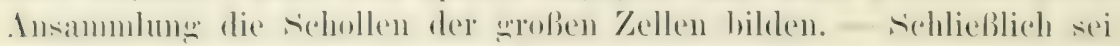

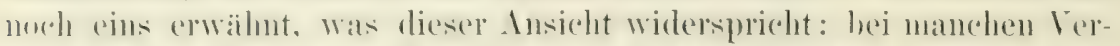

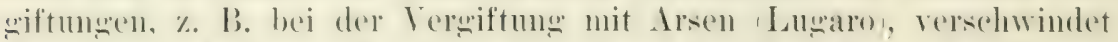

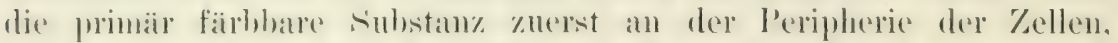

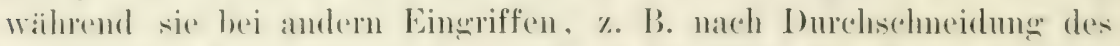

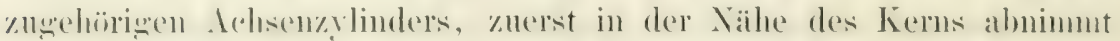

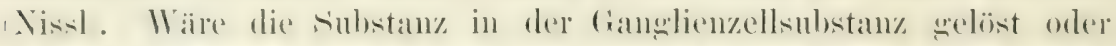

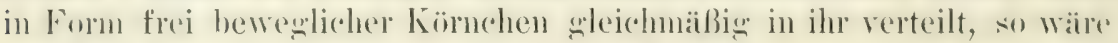
sall kein (irund rorlanden, weshall, die substanz, wenn sie erst nach-

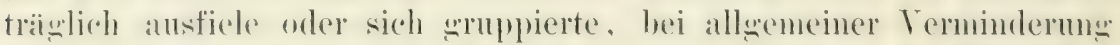
durol, einen pathologischen l'moels bestimmte stellen der zelle frei ließe. Man sollte vielmehr meinen, daß sie anch jetzt noch ibberall

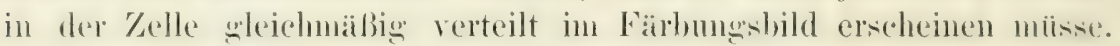

Grade diese letzterwähnte Ersoheinmos scheint mir entschieden dafïr zu sprechen, dah die primär färbbare substanz auch in der lehemden Zalle fest lokalisiert ist, d. h. dab das Äquivalentbild in der

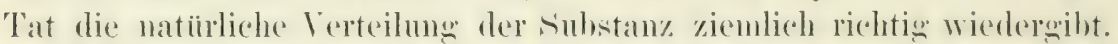
Daseren möehte ich die Beckerschen Kärnchen als otwas hisher noch wenig Bekanntes ansprechen, das frei in der Zelle verteilt ist, sich aber eventuell an die präormierten substanzhocken anlagert mul im Nisslpriparat mit ihnen zusammen gefarbt wird. - Weitere Aufklärungen sind hier aber jedenfalls noch abzuwarten, ehe man ein definitives Urteil abgeben kamm.

Wie schon elwähnt, ist die primäi färbbare Substanz sowohl in lezuc anf ihre räumliche Verbreitume innerhalh der fianchenzellen

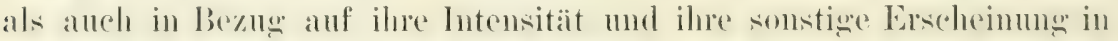
den rerschiedenen Zellarten versohieden. In manchen Zellen, besonders in den großen Zellen der Wirbeltiere, ist sie in großen. Brocken an-

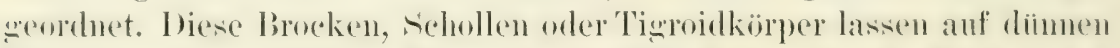

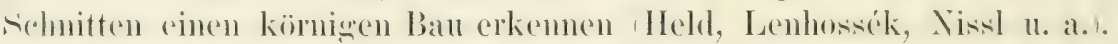
l) Kërnchen werden zusammengehalten von ciner homogen aussehenden Substan\%, welche die Farbe viel schwächer annimmt (Nissl). Bei

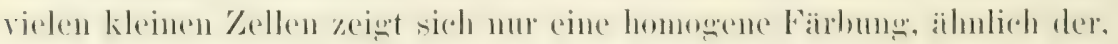

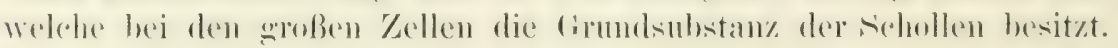
sie dehnt sich nicht durch die ganze Zelle ans, ist aber in der Begrenzung ziendich undentlich. Noch andre Zellen, \%. B. die Zellen

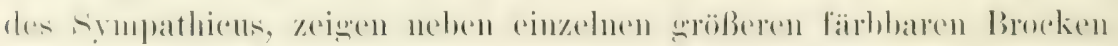
einen feinen gefirbten Staub. - Anch bei wirbellosen Tieren ist die prinäl färbbare Substanz weit rerbreitet. Bei Hirudo findet man sie

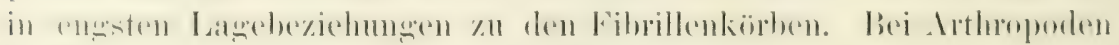
und Mollusken ist sie - wie die Fibrillengitter — durch die ganzen zellen ausgebreitet. Der Stamnfortsatz der Ganglienzellen ist hier 
wrade so wie der l'olkegel bei den wroßen $/ 4$ ellen der Wirheltiere frei von faibbarer Substanz. Die freie Zone ragt auch hier noch etwas in den Zelleib himein. Auch hier zeigen die Zellarten (ein und dersclhen Tierspezies, welche sich durelı GröBe mul Lokalisation unterscheiden, wesentliche Lntersoliche im primär gefiabten l'räparat. In vielen kleinen Zellen der Irthropoden sind wie in den kleinen Zellen der substantia selatinosa der Wirbeltiere nur efourbte śchleier, aber keine wirklich gefornten substanzportionen vorhanden. Die vielen kleinen zellen, welche, zu dichten Massen vereinignt, an den pilzhutförnigen Körpern G Glohnli, des Arthropodengehirns liegen, scheinen der prinär färbbaren substanz iiberhaupt sanz zu entbehren. Anch bei den Wirbeltieren kommen einige Zellarten vor, in welchen, obwohl sie als tanglienzellen anzusprechen sind, bisher keine primär fäbbare Substanz nacherewiesen werden komte, so \%. 13. in den Körnerzellen der Retina. Nach Bïhler sollen anch die Rindenzellen der Eidechse frei ron färbbarer substanz sein, doch möchte ich dieser Anwabe einises Mißtranen entgegenbringen, weil bei der von ihm šeibten Methode meist nur die swoben Mnsmmlungen der substanz sichtbar werken. Torlänfige wird man jedenfalls das Torkommen von prinäir fibbharer substanz als ein ziemlich allgemeines C'harakteristikm der Ganglienzellen ansehen diufen. Ihr Terhalten segen Chenikalien wird weiter unten besprochen werden.

Die primäre Färbbarkeit der Nenrofibrillen.

Ich habe bereits weiter oben davon gesprochen, daß sich bei der Applikation von Methyenblau auf das lebende oder iiberlebende (iewebe die Neurofibrillen färben. Selur häufig tritt, wie zuerst Ipáthy hervorechoben hat, bei der Methylenblaufäbung zunärhst eine Tinktion der Neurofibrillen ein, welcher erst sekundär — wenigstens in den Yervenfasern - die Färbung der Perifibrillärsubstanz folght. beim Verschwinden der Färbung sind es die Neurofibrillen, welehe am länsten den Farbstoff festhalten. Inf Grund dieses Verhaltens ist ('s mö̈lich, mit Hilfe der Ehrlichschen Methode gुute Fibrillenpriiparate

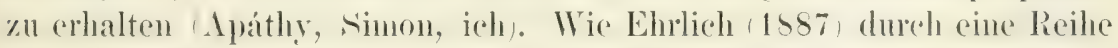
von Versuchen erwiesen hat, ist nun Methylenhlan nicht der ainzige Körper, welcher ,neurotrope“ Eigenschaften besitzt. Eine Anzahl andrel hasischere Farbstoffe, die dem Methylenhlan meh" oder wenigner nahestehen, zeisen dieselbe Eigenschaft, wenn anch meist wenienele ansuesprochen: Thionin, Inmethylthonin, Methyelenazur. Toluidinblan

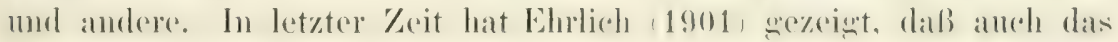

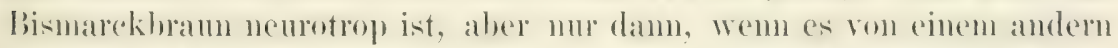
derartisen kïrper unterstiitht wirel. Bismarckloram allein injiziert wibt keine Nervenfärbung; injizierte er es aber zusanmen mit Methylen- 


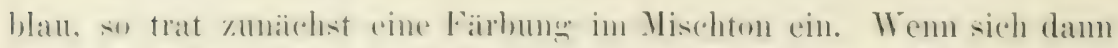

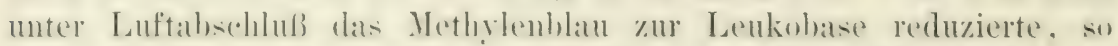
traten die Jerven in dem loranen Fathtom des bismarekbrauns lervor.

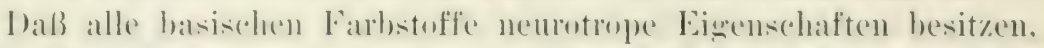

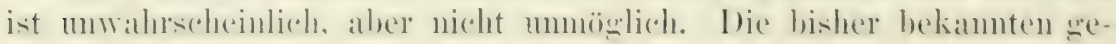

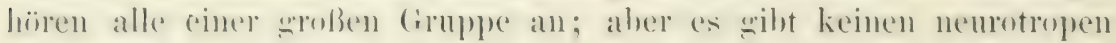

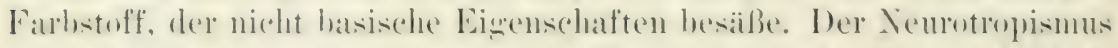
scheint mir num mehr oder weniser identisch mit der Verwandtschaft der Farbstoffe zu den Fibrillen zu sein. Das was die Dunkelheit und sichäife der erreichloaren Nervenhihler ansmacht, ist nicht die

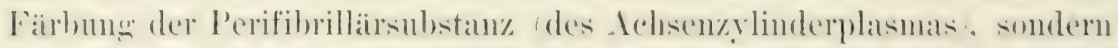
die der Nemofibrillen. I) I'erifibrillärsubstanz wirl zwar auch fast

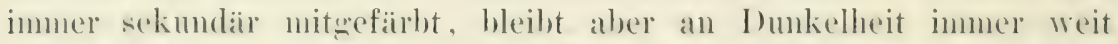
hinter der der Fibrillen zuriek. Dies kommt deswegen nur selten bei Wirbelticen zur Beobachtung, weil die Fibrillen bereits hein

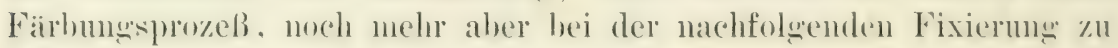
einem diunnen Strang zusammenschnuren.

Bisher hat man nun geglaubt, da $\beta$ die Verwandtschaft $z$ wischen Nervensubstanz (resp. Fibrillen) und den erwähnten Farbstoffen nurimlebenden oder wenigstens frischen Zustande des Gewebes rorhanden sei. Dies ist aber nicht der F 11 . Sie bleibt auch nach dem Fixieren mit manchen Fixationsmitteln erhalten, geht aber verhälnismäBịn leicht verloren, und die nach dem Fixieren zu erreichende Färbung verschwindet beim Passieren von Alkohol so schnell, dab man sie an montierten Prïparat nu dann zu sehen hekommt, wem man sie fixiert hat. An besten hleibt die Basophilie der Vemofibrillen in Alkohol erhalten. I)ies wilt aber nur für periphere Nerven und gewisse Fasern des Zentralnervensystems. In den Ganglienzellen, den stramefasem nud in Gran erhält man primäre Färomog der Nemofibrillen bei cinfaroher Ilkoholfixierune 11 ur auf Ausstrichpräuaraten, nicht aber. wenn

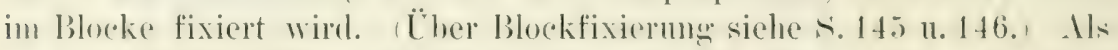
hasischen Farbstoff wende ich sewöhnlich nicht Methylenblan, sonderm Toludinhlau an, weil dieser F"abstoff die Fibrillen prinär metateloro-

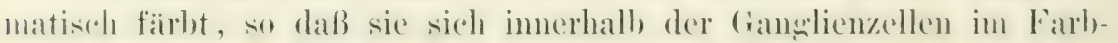
tom von den Nisslstrukturen unterscheiden. Methylenblan färbt die Fibrillen ungefäln ebenso blan, wie die prinär fähbare substan\% der

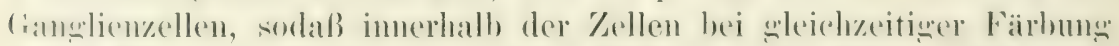

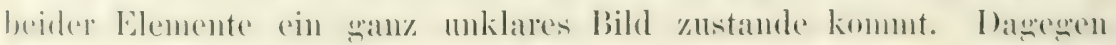

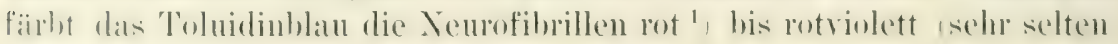

1) Diese Farbdifferenz kamn nicht darauf bezogen werden, daß etwa das Toluidinblau durch einen roten Farbstoff verumreinigt ist, denn man kann z, B. 


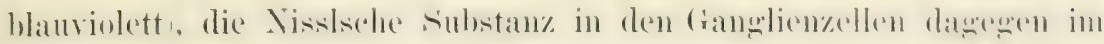

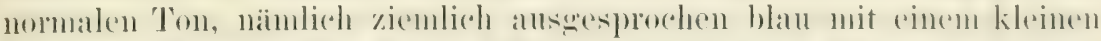
stich ins Violett. Die Farbendifferenz bleibt beim Fixieren arlablten.

Am einfachsten kamn man sich von der primären Fäbbarkeit der

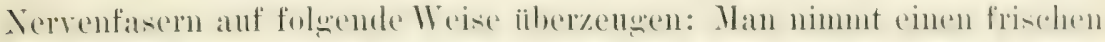

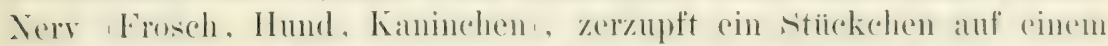

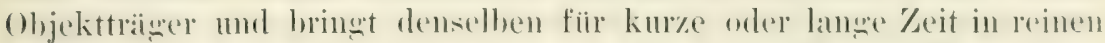
Alkohol. Nachden der Mlkohol wieder dureh destilliertes Wasser veredränst ist, wird der (Objekttriiger fiir 10-15 Minuten in eine Läsmlng

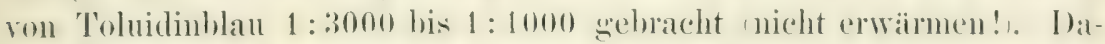
nach wird mit destilliertem Itassep einime Minnten mewaschen und das Praparat olme weiteres unter dem Mikroskop betrachtet. Man sieht damn die geschumpften Achsenzylinder tief rotviolett refäbt; häufiஹ口 haben aber auch die Markscheiden reichliche Farbmengen aufwenommen, so dab dadureh das Lehsenzylinderhild zum Teil verdeckt wird. Bringt man das Präparat in Alkohol, so rerschwindet die Fairbung vollkommen, sowohl aus den Scheiden, wie aus den Achsenzylindern. Dagegen läßt sich die Fäbnng leicht fixieren, wemn man das I'rijparat nach dem Waschen für eine halbe Vinute oder längel in eine Anmonimmmolybdatlösmog bringt. In Canadabalsan grebracht. treten die Achsenzylinder noch deutlicher hervor.

Die Jästige Nitfähmug der Markscheiden wird leicht dadurch vernieden, daß man die Objektträger vor dem Fäben für einige stunden in Xylol stellt. Das Xylol löst die färbaren sulstanzen der Markscheide der eingedampfte Rückstand eines Xylolauszuses von Nervensubstanz färbt sich mit Toludinblan ziemlich krätim zumleich mit andern Markscheidensubstanzen, nimnt den Achsenzylindern alser nicht ihre prinäre Färbbarkeit. Anf diese Teise herosestelle l'rijparate zeigen außer den Kernen nur die Achsenzylinder, und zwar treten diese in einer recht elesanten Weise hervor. Sind die Achsemzylinder stark zusammengeschnurt, so sieht man anch mit der Immersion nur einen dunklen strane. Betrachtet nan aber bei starker Vereroberune eine Achsenzylinderstelle, welche nicht geschrumpft ist - solche kommen fast in jedem Praiparat vor —, so sieht man ihn aus lauter diumen Fibrillen zusammenesesetzt. D)iese nit den Nemofibrillen identi-

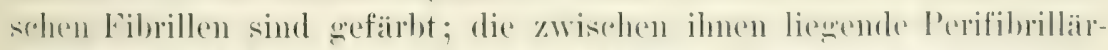

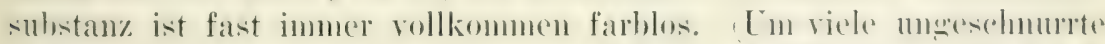

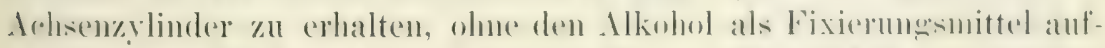

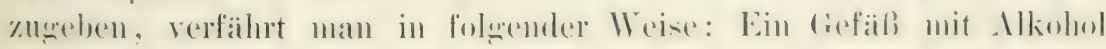

sehen (unter dem Mikroskop), wie sich die rötliche Fïrbung der Neurofibrillen in Alkohol mit demselben blaugrïnen Farbton löst wie die blane Farbe andrer Gewebsbestandteile oder des freien Farbstoffs. 
wird im Gefriergemisch bis auf $-10^{\circ}$ bis $-15^{0}$ abgekïhlt; damm entnimmt man einem Frosch ein Stiick des Ischiadiens und wirft es in den Alkohol. Es muß hierin in kumer Zeit steif gefroren sein.

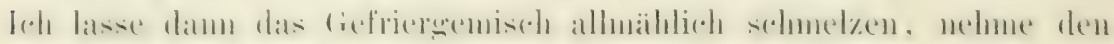
Nerven heraus, wenn die 'Temperatur etwa bis auf $+15^{\circ}$ gestiegen ist,

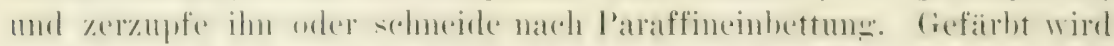

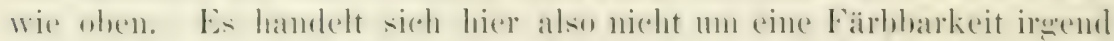

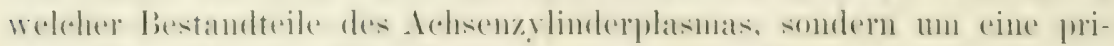

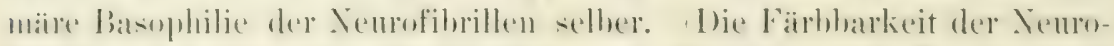
fibrilhen mit basischen Farbstoffen nach Fixiermon mit Osmimmsäme

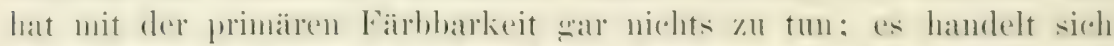

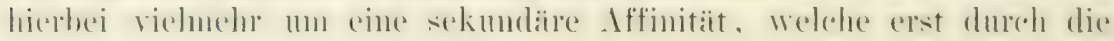
Osmimmsäturewirkmug geschaffen wird.

L'm Firbungsbilder vom Zentrahervensystem zu erhalten, benutzt

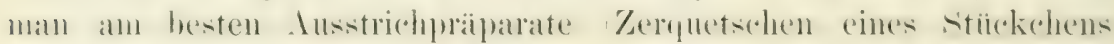

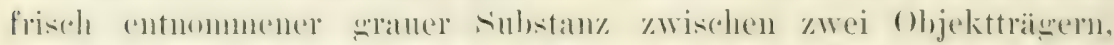

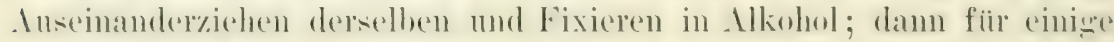
stmolen in Xylol. Anatoinisohe Einzelheiten mol Feinheiten sollen ja mit der Methode nicht heransgebracht werden; sie soll nur dazu dienen, iiber die reaktionellen Eigenschaften einizer Bustandteile des Nervensystems Nenes zu bringen, und dabei kam man sich ruhig dieser etwas rohen Methode bedienen. Nan findet dabei immer noch zellen genug, welche nicht zertrimmert sind.

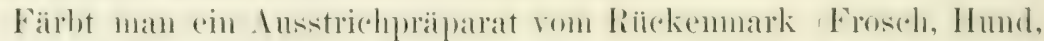

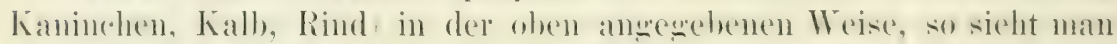

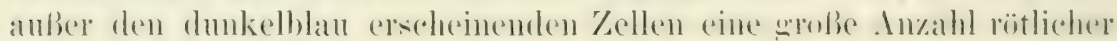
Fïden, welehe sehr verschiedene Dicke haben und sich bisweilen teilen. In diesen Fäiden erkennt man nach den Lagebeziehungen zu den Ganglienzellen und ihrem nehr oder weniger dichten Gefiige Achsenzylinder und Protoplasmafortsätze (Tafel I, Fig. I). Taucht man ein Priparat vor dem Fixieren in Alkohol, so rerschwinden alle

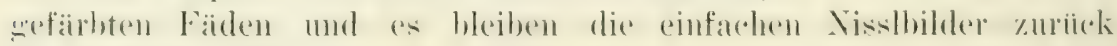
l'Tatel I, Fig. II).

In den nur mit Wasser gewaschenen Praparaten sind die Zellen sehr dunkel. Bei stiirkerer Verö̈ßerung erkennt man in ihnen den

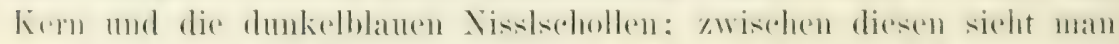

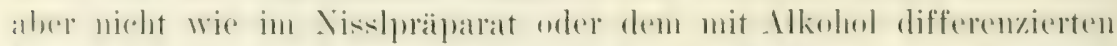
l'rip)arat helle Straßen, sondern alles was nicht blau ist, ist von einer

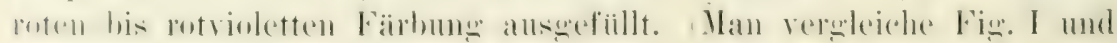
Fig. Il der 'Tafel.) Es sind dies die rotgefiabten Fibrillenbahnen, welche man aber bei der allgemeinen Dunkelheit der Zellen fast nie in die cinzelnen Fibrillen auflösen kann. Die Protoplasmafortsätze kann man oft sehr weit verfolgen. Besonders dort, wo sie nur noch 


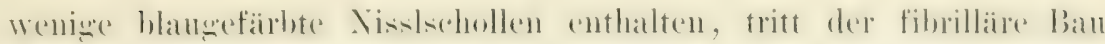

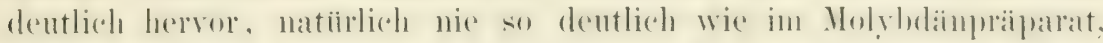
in welchem die einzelne Fibrille viel dunkler gefäbt ist als hier. lemerkenswert ist es anch, dab in diesen l'ripharaten die l'motoplasma-

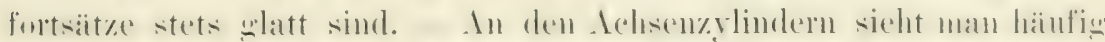

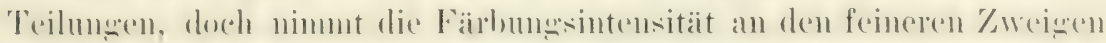

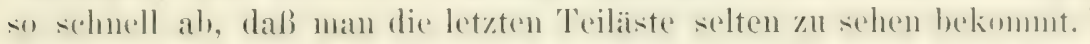

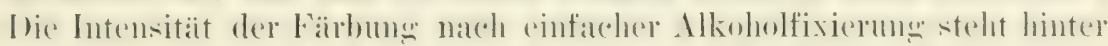

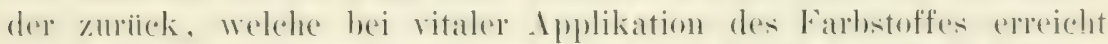

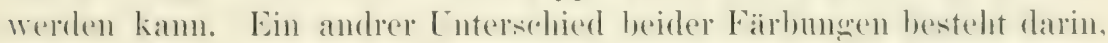
daß bei vitaler Applikation immer nu einige wenige Elemente gefarbt werden, wähend bei der Fäbung nach stattwehabter Fixierung, wie besonders die Untersuchung von Schnitten durch Nerven oder

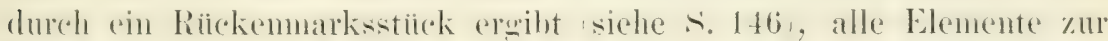
Darstellung welangen. Diese Lnterschede scheinen mir aber nicht dagegen zu sprechen, daß wir es in beiden Fällen im Grunde mit ein und derselben Reaktion zu tun haben. Bei der Fixierung kamı selı wohl etwas von der Färbungsaffinität verloren gehen; hierfür spricht schon das, dafs die Färbunge eingetrockneter nicht mit Ilkohol hohandelter, Ansitrichpräparate häufig so dunkel aufällt, wie die vitalgefübter, nur ist auch in diesem Fall die Färbung allgemein. Mir scheint es jetzt, als ob doch bei der vitalen Fairbung nur diejenigen Elemente sich färben, welche nehr onder weniger serchädizt

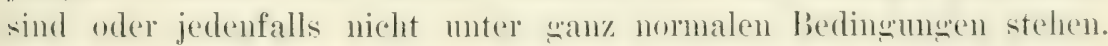
Hierfür spricht \%. B., daß die Zahl der gefärbten. Elemente nach Strychninisierumg größer ist als bei normalen Tieren, wie dies vor kurem von Wolf beschrieben wurde und mir schon seit etwa acht

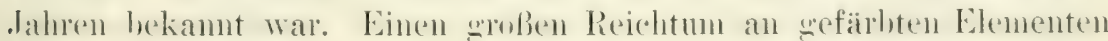
fand ich anch bei caroini, welche im stadium des Wämetetanus nit Vethylenblau injiziert wurden. Ist dies richtig, so ist es nieht zu

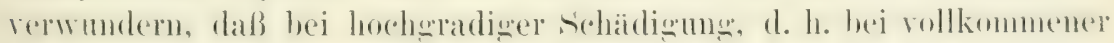

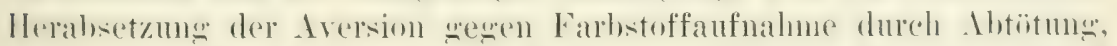

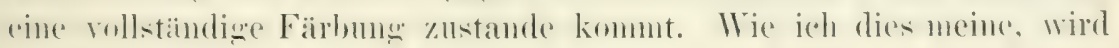
aus dem weiteren noch näher hervorgehen.

1) Kaplan (1902) hat eine schöne Methode zur Darstellung der mit Markscheide umgebenen Achsenzylinder mittels Anthraceneisengallustinte beschrieben. Diese ,Axostromafärbung" hat mit der primären Fïbbarkeit und iiberhaunt mit den Fibrillen nichts zu tun, da sie nur an myelinhaltigen Fasern zu erhalten ist. Was sich eigentlich bei der Kaplansehen Methode färbt, ist noch mklar. Dal ja die Grenzen der Perifibrillïrsubstanz der Nervenfasern über die mit Mark umfrehenen Teile hinausgehen, kam das "Axostroma" mit dieser nicht ohne weiteres als identisch angesehen werden. Es muß vorläufig angenommen werden, daf die Perifibrillïrsubstanz dort, wo die Nervenfasern von Mark umgeben sind, in hesonderer Weise differenziert ist (Kaplan). 
Die primäre Fairbbarkeit in lebendem, wie in mit Alkohol ab-

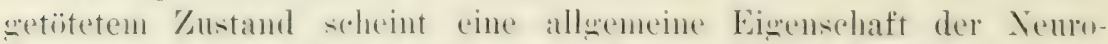

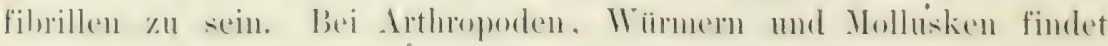
sie sich in golecher. Weise wie bei den Wirbeltieren, nur ist bei den meisten von mir anf diesen l’unkt untersuchten Wirbellosen der Inten-

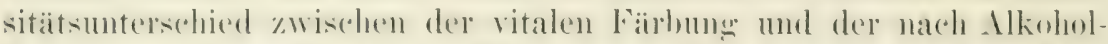

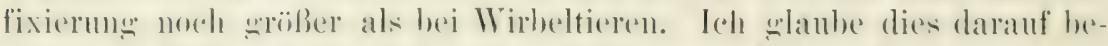

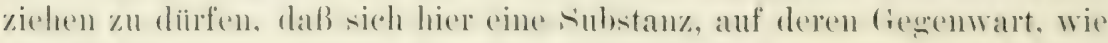

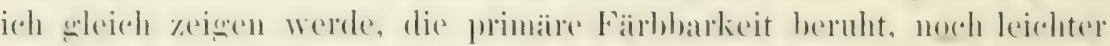
rom den Fibrillen abspaltet, als es hei den Wirheltieren der Fall ist."

Das Wesen der primären Fäbbarkeit der Ganglienzellen und der. Neurofibrillen.

Ich habe bereits emähut, dak die Eienensohaft der Xemofibrillen

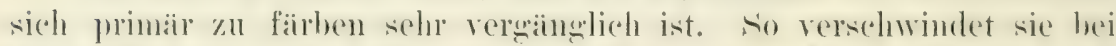
vielen Fixierungen, anch wenn sie anf das lehensfrische Gewebe cinwirken (Salpetersiume, Chromsalze u. s. w.). Auch nach Einwirkung von Erdalkalien auf Alkoholmaterial ist sie nicht mehr vorhanden. 'Totzdem sind dic Fibrillen als morpholonische Bestandteile noch da, wie ja schon daraus hervoroceht, daß sie bei der Molybolanmethorde

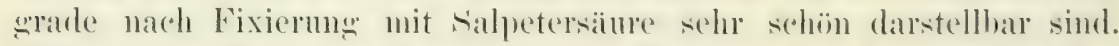
bie primaire Farbbarkeit ist also eine Fisensehaft, die rerschwinden kann, ohne daß das Substrat dabei zerstört wird.

Grade so verhält es sich anch mit der primären Färbbarkeit der Nisslstrukturen. Wir wollen mus dabei nur mit denjeniwen strukturen des Nisslpräbarats beschäftigen, welehe wohl weformt sind; das sind die ans Körnehen zusammengesetzten sichollen und striche, wie sio hanptsäbhlich in den motorischen Zallen und den spinalganglienzellen rorkommen und die anch als Flemming-Nisistsche sichollen oder Tigroid bezeichnet werden. Nach Held sollen diese Strukturelemente aus P'aiparaten, die mit Alkohol fixiert sind, nach Behandlumg mit Erdalkalien vollstandis rom der Bildfläele verschwinden d. h. sie sollen

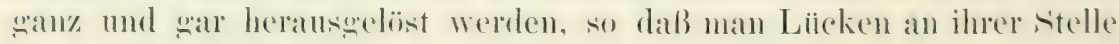
sieht. Dies ist nach meinen Befunden unrichtig. Es verschwindet

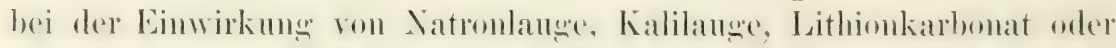
Satrimukarbonat nur die primäre Fäblotrkeit; es cutstehen aber an

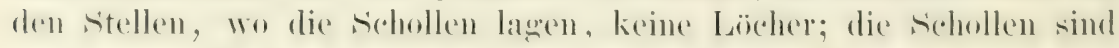
viehmehr noch als solche in den Zellen vorhanden. (Daß durch sehr

1) Bei Anwendung einer Modifikation der weiter unten beschriebenen $\ddot{A}$ thermethode hat Dr. Prentiss im hiesigen Laboratorium an Hirndo sehr schöne und ziemlich allgemeine Neurofibrillenfärbung erhalten. Danach kam es als gesichert gelten, daßs sich die färbbare Substanz bei den Wirbellosen besonders leicht von den Vibrillen abspaltet. 
lange Eimwirkung starker Lösungen von Mkalien vielledeht wirklielle

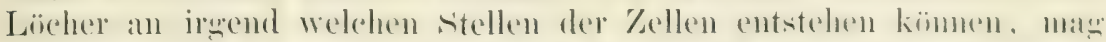

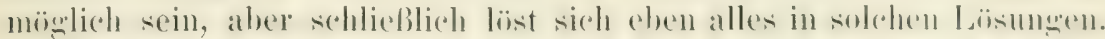
I) primaire Färbbarkeit rersehwindet ans śchnitten oder in . Ilkohol

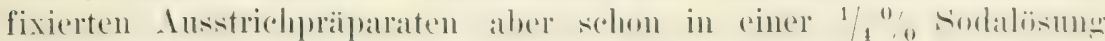
und bei einer Einwirkung von 10-20 Minuten.) Mit basischen Farl, stoffen kamn man nach der Bohandlume mit Alkalien so lamge mol so stark färben, wie man will, die śchollen fälben sich nicht mehr anch wenn man das Alkali ausgewaschen oder nentralisiert hat). Bei Anwendung von Eisenhämatoxylin, Molybdänhämatoxylin oder nach warm crfolenter Beizung mit Molybdänsaly nud darauf folgender Fäbume mit einem hasischen Farbstoff treten die schollen aber wieder garade

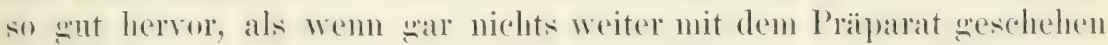
wäre. Auch nach Fairbung mit sauren Farbstoffen \%. B. mit Saiurefuchsin treten sie zu Tage. Wie in nicht mit Alkalien behandelten Präparaten heben sich die Schollen dunkler rot ron heller rotem Grunde ab. Dasselbe Resultat erhielt ich, wenn ich das Gewebstilck gleich mit La ngenalkohol nach Held fixiert hat te: Keine Lücken, aber vollkommener Fortfall der primären Fäblarkeit.

In derselben Weise wird die primäre Fäbbarkeit der Neurofibrillen durch Behandhung mit Laugen aufæehoben. Taucht man ein Ausstrichprajparat rom Räckemmark, das in Alkohol fixiert ist mud bei direkter Firbung mit 'Toluidinblau Nissl und Fibrillenbild geben wärde.

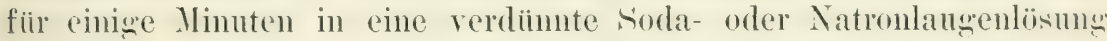
und färbt es damn, so treten. nur noch die Kerne hervor (anch wenn rorher neutralisiert ist). Beide primären Farbbarkeiten sind rerschwunden. Läßt man die Lanse noch läingere einwirken oder benutzt man stäkere Lamene, so rerschwindet auch die primäre Fäbbarkeit der Kerne. In solehen I'räparaten nimmt kein einziger Gewelshestandteil mehr basische Farben an, auBer wenn sie vor dem Firben mit Beizen hehandelt sind in diesen Fall spielt aber der basische Fartstoff nur eine sekundiire Rolle).

Entständen bei der Laugenbehandlung wirklich Lïcken. wir Mold eremeint hat, so wiirde man ohme weiteres den sichluß zichen kïnnen.

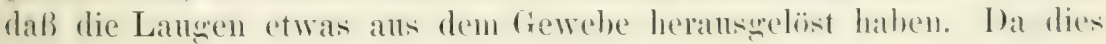
aber nicht der Fall ist, so branchen wir es nicht notwendigerweise mit einer Lösung zu tun zu haben. Möglicherweise kömnte es sich nur um eine physikalische oder chemische Veranderung der vorher

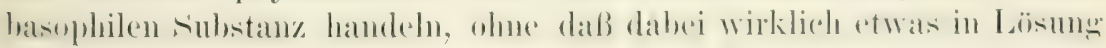
gegangen wäie. Es ist aber auch möglich, daß vor der Langen-

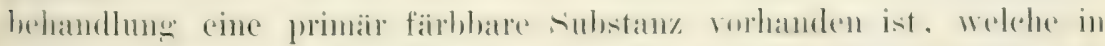

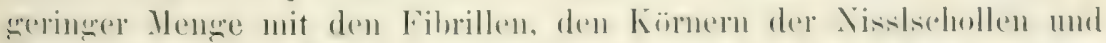

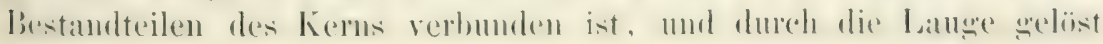




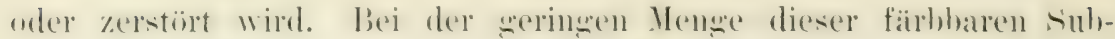
stanzen wiirde immer noch soviel von den Formbestandteilen zuriickhleihen, dali bei sichthamatehume dersellen mit andern Methoden keine Verringerung der Masse fuir das Auge zu konstatieren wäre. Mit andern Worten: Es ware möglich, dak die Fibrillen, die Nisslschollen und die Kerme aus einem Gemisch oder einer Verbindung ron Sub-

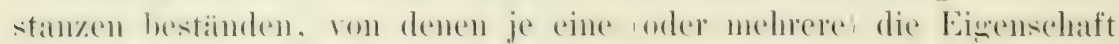
hesiblie, sich mit hasischen Fathstoffen zol verbinden und sich in Erel-

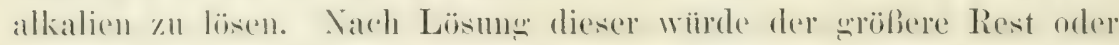

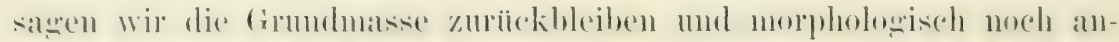

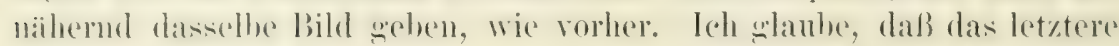

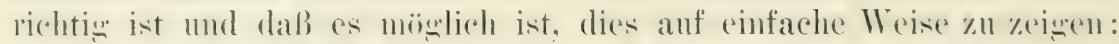

Eine große Anzahl organischer Körper (Basen, Amidogruppen ('uthaltende substanzen แ. a.) hesitzt die Fignenschaft sich mit sublinat zu verbinden. I)iese in Wasser meist nulöslichen Körper sind alkalibeständig, werden also, wemn sie eimmal gefäll sind, von Alkalien nirht wieder anfwelïst. Eine Inzahl andrer sinblimatrerbindungen \%. B. von. Diamidosiuren sind zwar in samem oder neutralem IVasser löslich, fallen aber aus, wenn die Lösmng alkalisch gemacht wird. Wemn wir es in dem hypothetischen, fähharen liestandteil der Fibrillen und Nisslschollen mit solehen substanzen zu tum hätten, so diufte die primäre Fäbbarkeit mach Behandlume nit sublimat nichot mehr in Langen zugrunde gehen. Tatsachlich ist dies der Fall: Man stellt sich eine Inzahl von Iusstrichpraiparaten her und fixiert sic in Ilkohol. Dann wird die Zeit bestimmt, welehe notwendig ist, 1 m aus einem

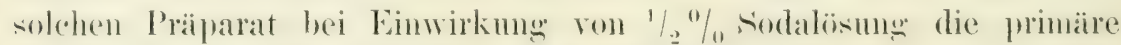
Färbbatkeit der Seurofibrillen und der Nisslschollen ganz zum Verschwinden zu bringen. Diese betrage zehn Minuten. Es wird nun ein andres Praiparat zunächst fü eine kurze Zeit in S nblimatIös $1111 g^{\circ}$ gebracht, gut ausgewaschen und damn fiur 24 Stunden in die Sodalösung gestellt. Bei der Fïrbumg (natiurlich nach voraus-

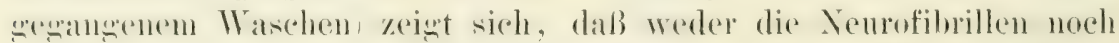

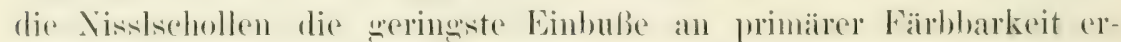
litten haben. Selost bei langer Einwirkug sehr viel stälkerer. Laugenlösungen verschwindet die primare Färbbarkeit nicht. Entfernt man aber dureh langes Waschen mit Jodlösung das Sublimat wierler aus dem Prijparat oder zerstört man die Verbindune dureh Einwirkme von viehwefolwasserstoff, so stellt sich die alte Empfindlichkeit für Langen wieder ein. - Im Augenblick wird man diesen Versuch nur so deuten kömnen: Das Verschwinden der primären Firbbarkeit der Neuro-

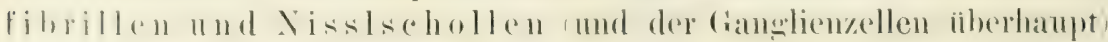
berul auf der Lösung einer fäbbaren Substan\%. Diese 
Substanz coder siubstanzen, ist an die Grumdmasse der Fibrillen mud der Schollen in irgend einer Weise chemisch gebunden.

Wie schon mitgeteilt, rerschwindet die primäre Färbbarkeit der Fibrillen weniestens in Zentralnevensistem, selu viel leichter als die der Nisslschollen, und die Fabbung selber ist nicht wie die der

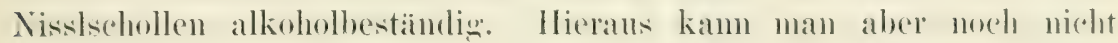
den Schluß ziehen, daß es sich 1 m zrei rerschiedene fïrbbare Substanzen handelt. Es könnte sich 1 m ein und dieselbe Substanz handeln und die Versehiedenheit ledighich daranf beruhen, dak die substanz mit der Grundmasse der Fibrillen in sehr viel weniger fester Verbindune stande als mit der der schollen. Daß es sich aber doch um zwei verschiedene Substanzen handelt, geht aus dem Verhalten zu Salzsäure und zu Ammoniak hervor.

Es werden eine Anzahl ron Ausstrichpräparaten rom selben 'Tiel' hergestellt und diese wie folgt behandelt: Zwei werden normal geefailbt. Sie zeigen Nissl- und Fibrillenbild (Tafel 1, Fig. I). zwei andre I'räpalate kommen fiur 24 stumden in eine Mischmmon won 1 T. HCl, 3 T. Wasser und 20 T. Alkohol (anf genaues Einhalten dieses Terhältnisses kommt es nicht an, werden dam sespiilt und gefarbt. Das Fibrillenbild ist vollkommen verschwnden und nur das Nisslbild und w war unvermindert vorhanden (Tafel I, Fig. II). - Zwei weitere Praparate kommen in eine Mischung von $1 \mathrm{~T}$. HCl und etwa 20 T. Wasser. Nach 24 Stunden wird gewaschen und gefäbt. Es zeigt sich keine Spur rou gefalbten Nisslschollen, die Kerne sind etwas blasser (oder invers), die Fibrillenfäbung ist aber rollkommen erhalt en. Da die Nisslschollen ungefaibt sind, so sieht man jetzt den Fibrillenverlanf in der ganzen Zelle (Tafel I, Fig. III).

Es ist also die fäbbare Substanz der Fibrillen in alkoholischer. Sal\%säre, die der Ganglienzellen in wässeriger Salzsä ure löslich. Handelte es sich in beiden Fällen 1 dieselbe Substanz, die das eine Mal nur leichter abspalthar wäre, so wäre anzumehmen, daß sie sich von den Fibrillen anch bei der Bohandlune abspaltet, bei der sie in festerobendenen falle ah-

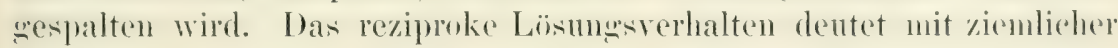
Sicherheit darauf hin, daß es sich $11 m$ zwei rerschiedene Substanzen handelt. Ich will die eine Substanz von num an die Fibrillensäure. die andre Nisslsäure nennen. Warum die Substanzen als Siumen anzusehen sind, wird aus dem Folgenden hervorgehen.

Durch Alkohol allein wird die Fibrillensäure ebensowenies ausgezogen wie die Nisslsäure dureh reines Wasser. Danach wird man

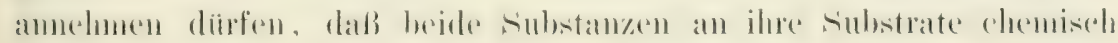
grebunden sind und daß die Salzsiure sie abspaltet. Man wird ferner 


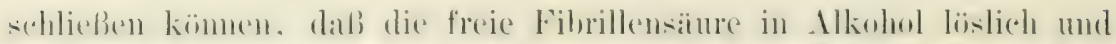

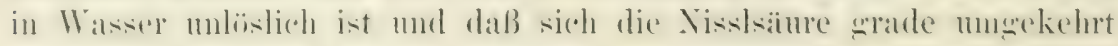
verhält (löslich in Wasser, mü̈slich in Alkohol).

Bringt man ein Praiparat zuerst in Salzsiumealkohol und dam in Wasser, so fiillt das Fäbungsresultat so aus, als wenn es nu in

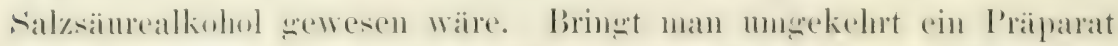
erst in rerdiunte Salzsaime und damn in Alkohol, so fäben sich

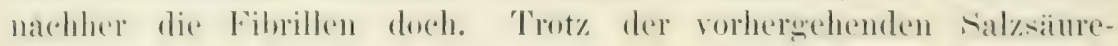

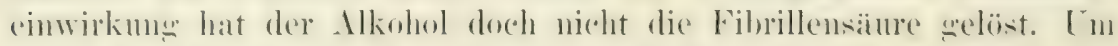

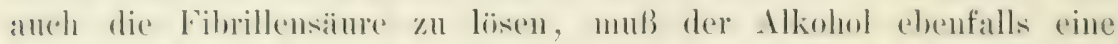

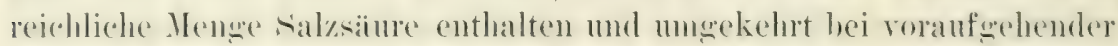

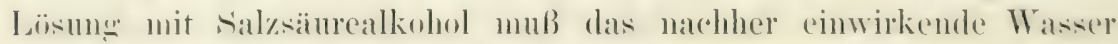

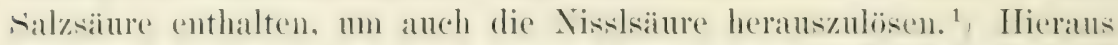
ist der Schluß zu ziehen, daß die Alspaltmm nu geschieht, wemm die Salzsilure in dem sereigneten Lösungsmittel enthalten ist. Eventuell ist die 'Tatrache aber anch dahin zu denten, daß die sibstanzen nul' bei saurer Reaktion der Lösungsmittel in Lösung gehen.

Ammoniak wirkt nur anf die Nisslsäme lösend; auch in starker Konzentration verändert es die primäre Färbbarkeit der Veurofibrillen worler in alkoholischer noch in wässeriger Lö̈sung. In alkoholischere

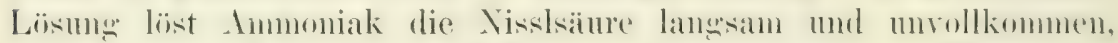

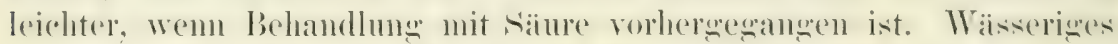
Ammoniak (1:10 bis 1:20) löst die Nisslsäme riemlich schmell. Da die Fibrillensiume erhalten hleibt, so treten in solchen P'rijuatraten die

1) Nach Held sollen sich die Nisslschollen weder in verdiimnten noch in konzentrierten Sïuren lösen. Wemn ich recht verstehe, sollen sie auch ihre Basophilie dabei nicht verlieren. Mir ist es nicht verstandlich, wie er zu diesem Resultat gekommen ist. Salzsäure löst die Nisslsiure in der Kïlte in einer Konzentration von etwa $2-3 \%$, im Brutschrank bei einer Temperatur von $40^{\circ} \mathrm{C}$. schon bei einer Konzentration von $0,4 \%$ und zwar innerhalb 2-3 Stunden. Nun sollen nach Held bei Verdauung von grauer Substanz mit Pepsinsalzsïure nur die Nisslschollen ïbrig bleiben und zwar unter Beibehaltung der Basophilie. Da letztere schon durch die Salzsïure allein zum Verschwinden gebracht wird, so könnte es sich bei diesem Resultat nur um eine durch das Pepsin erzengte sekundäre Fiarbbarkeit handeln. Ich habe aber weder mit frisch aus Sehweinemagen gewonnenem Pepsin, noch mit einem käuflichen Präparat zu dem Heldschen Resultat gelangen können. Auf die angebliche Nichtverdaubarkeit und den Befund von Phosphor in einem Verdaumgsriickstand hat dann Ileld die Vermutung anfgestellt, daß es sich in den Nisslschollen um ein Nukleoalbumin handle! Ganz abgesehen von der Kuilmheit dieses Schlusses ist es doeh etwas zu weit gegamgen auf den Nachweis von Phosphor in einer Substanz des Nervensystems etwas zu geben, wenn sie auf solehe Weise dargestellt ist. Lhosphor ist im Nervensystem in so vielen Substanzen vorhanden, daf man nur nach oftmaligem Umfaillen entscheiden kamn, ob eine Substanz wirklich Phosphor enthält oder ob der gefundene Phosphorgehalt nicht nur anf Verunreinigungen zuriickzufiihren ist. 


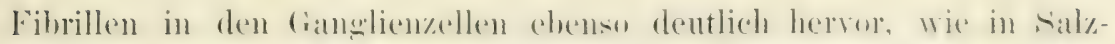

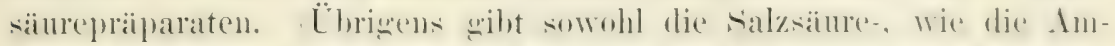

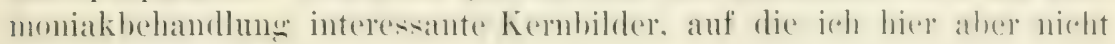
näiher eingehen will.

Die hier angefühten Versuche weisen den Weg, in welcher Weise

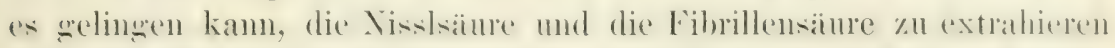

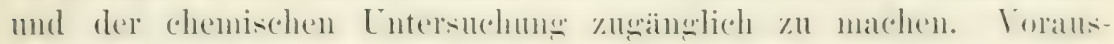

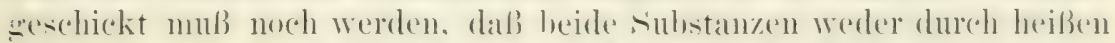
Alkohol, noch durch chloroform orler Ïther aus den Präparaten heraus-

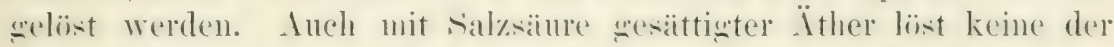
beiden Substanzen, so daß angenommen werden muß, daß sie in Ather ïberhanpt unlöslich sind.

Die ron mir angestellten 'Tersuche beide Substanzen rein darzustellen sind his jetzt ibler. Torversuche nicht hinansegenmene Ich

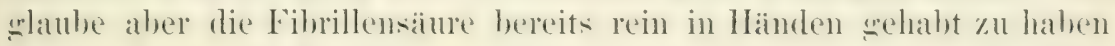
und auch bei der Nisslsäure nicht weit daron gewesen zu sein. Die Darstellung heider substanzen ist dadurch erschwert, dab sie anteren-

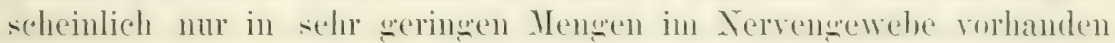
sind. Ton der Fibrillensäure habe ich zweimal aus etwa einem Kilo frischem ochsenrickemmark moefahr je zwei Zentigramm substanz rhlalten, von der Nisslsäure mehrere Dezisramm diese substanz wal aher vemutlich nicht frei von beimengumgen: Ich beschränke mich hier daranf einige Reaktionen und Eisenschaften beider substanzen zu beschreiben:

Die freie Fibrillensäure ist eine amorphe, fast ungefärbte Substanz, welche in trocknem Zustand eine hornige Konsistenz hat.

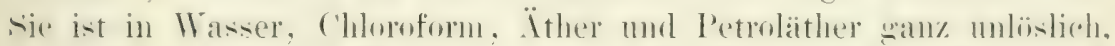

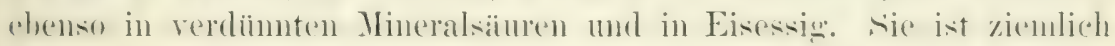
leicht löslich in Alkohol, besonders wenn er schwach angesäuert ist. Aus der alkoholischen Lösung fällt die Substanz bei Zusatz von Jatronlange oder Kalilanere oder der betreffenden kohlensanren salze als Alkalisal\% aus. Diese Salze sind in Wasser sehr leicht lïslich. Mit Sublimat bildet die Säure eine in Alkohol, Wasser und Laugen unlösliche Verbindung. Das Ammoniaksalz ist sowohl in Alkohol als auch in Wasser $110 \mathrm{n}$ ïslich.

Die frei in Wasser suspendierte Substanz fa $a l^{\circ}$ bt sich beim Kusatz

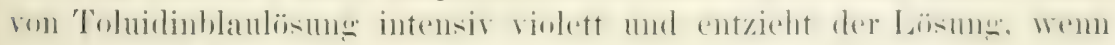
nicht zuviel Farbstoff zugegeben wurde, alle Farbe. Verset\%t man die Lösung des Alkalisalzes mit einem Tropfen Toluidinblau

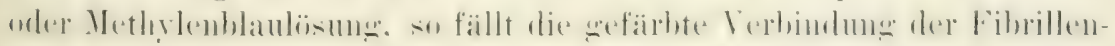
säure und der Farbbase sofort aus (veroleiche II. Heidenhain, 1902).

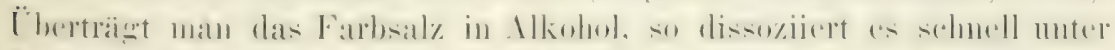

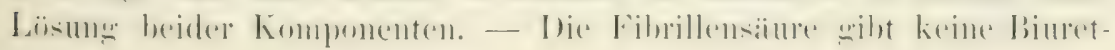




\section{Die primäre Färl,barkeit der Ganglienzellen und der Neurofibrillen.}

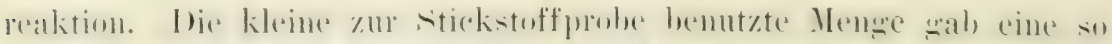
schwache Grïnfärbung, daß der Gedanke, sie riburte von einer geringen Verunreinigung her, nicht auszuschließen ist.

Die freie $\mathrm{N}$ is s ls it ure (:) ist in Wasser leicht löslich, in Alkohol schwer löslich. Mit Alkalien bildet sie leicht lösliche Salze. Ihre

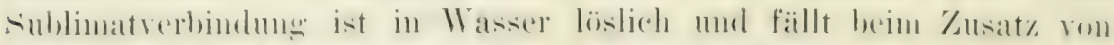

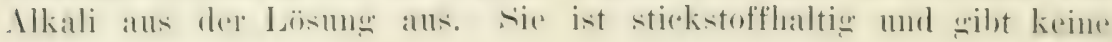
Biuretreaktion.

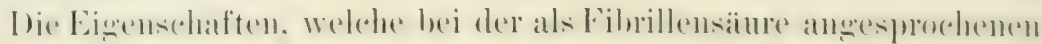

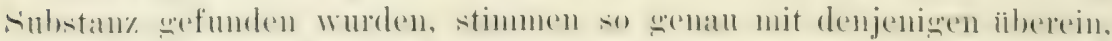

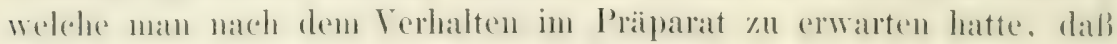
ich keinen Augenblick daran zweifle, daß beide Substanzen identiseh sind. Dafuir spricht auch, daß in der Lösungsfraktion.

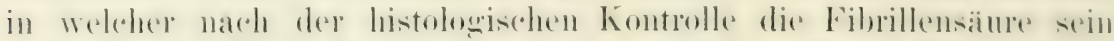

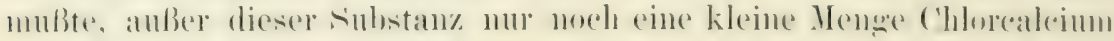
gefunden wurde. - Zweifelhafter ist es, ob die fäbbare Substan\%

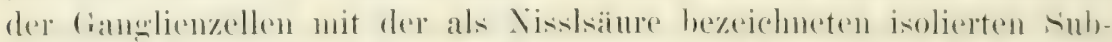
stanz identisch ist. Inber der histologeischen Kontrolle, dab die substan\% in der betreffenden Lösungstraktion sein mulite in der keine andere in Betracht kommende sinbstanz vorhanden war, kamn ich als

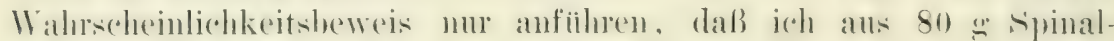

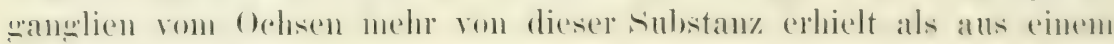
sanzen Kilo Gehirn.

Bei vitaler Injektion eines nemotropen Farbstoffes bekommt nan immer nur eine seringe Zahl von Nervenfasern gefäbt. Die Zahl derselben vermeht sich, wem das Vervensistem unter schlechten bedingungen steht, besonders, wenn es unter Zutritt ron Luft abstirbt. Ist das Gewebe mit Alkohol oder Ïther (siehe weiter miten) fixiert. so fairhen sich alle Fasern. Ich ziche hieraus den Schluß, daß die

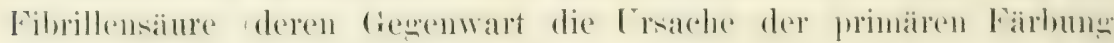
ist und welche, wie ich später zeigen werde, kein Abfallsprodukt der Fibrillen ist, sondern ihnen dauend anhaftet) mindestens zwei

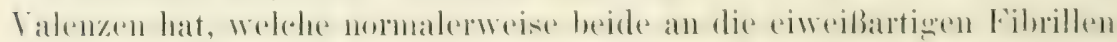
grebunden sind. Bein Absterben löst sich eine (same) Talenz und ist

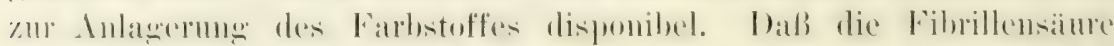

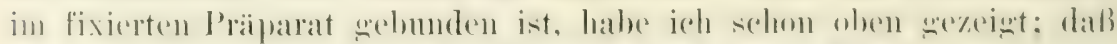

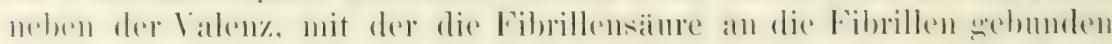
ist, eine zweite und zwar sa ure Valenz vorhanden ist, welche ron der

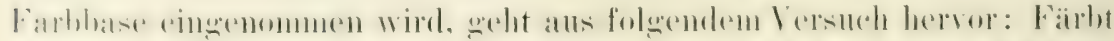

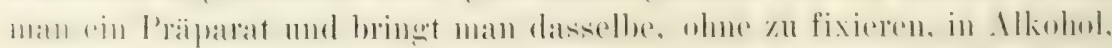
so rerschwindet die Färbmo wieder, wie oben angegeben. Das Praiparat ist jetzt aber einer ernenten Färbung der Achsenzylinder (resp. 
der Nemrofibrillen) fähig. Häte die Fibrillensäure nur eine sa ure Valenz, mit der sie an die Fibrille grebunden wäre, so miißte sie sich, um an den Farbstoff gehen zu kömen, ron der Fibrille abspalten:

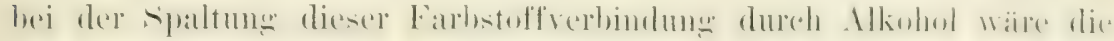
Fibrillensäitre damn frei und müßte sich in Alkohol lösen. Da sie dies nicht tut, sondern immer wieder färbbar ist, so muß die Talenz, welche den l'arbstoff aufnimmt, eine andre sein, als die, mit der die Fibrillensäure an der Fibrille luangt. - Unter Zugrundelegung der Ehrlichschen seatenkettentheorie kamm man sich die Verhältnisse wat rorstellen.

Ich habe gezeigt, daß die Fibrillensäure in den Fasern des Riickenmarks und in den Ganglienzellen nu dann nach Alkoholfixierung darstellbar ist, wenn das Gewebe vor dem Fixieren dureh das Quetschen der Luft answesetyt wird. Fixiert man in Block nit

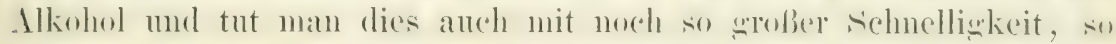

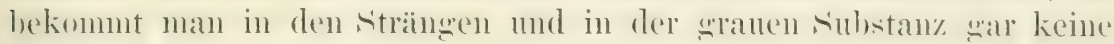
Färbung der Nervenfasern. In den großen Ganglienzellen zeigen sich höchstems spuren ron prinärer Färbung der Fibrillen und auch das nur in der Nähe der Blockoberfäche. Dageren sind hei einisermaßen frisch dem Tier entnommenen Stiicken stets die motorischen Wr urzelfasern innerhalb des Rückenmarks gefärbt und fast immer die hinteren Wurclfasern, anch in ihren anf- und alsteimenden Teil Tafel I, Fign. V. Wir finden also hier einen anffallenden Luter-

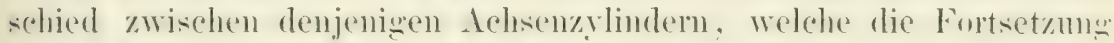
peripherer Nerrenfaseru sind und denen, welche einen zentralen Verlanf haben! Erstere rerhalten sich wie die Fasern peripherer Xerrenstamme, in denen sich auch noch viele stunden, ja Tage nach dem Toule die primäre Färbbarkeit dureh Alkohol erhalten laißt sielete auch die Wurzeln in der Fiz. Vi, letztere wie Ganglienzellen und prante substanz! Der Unterschied ist nach meinen bisherigen Erfalnumenen durchaus scharf.

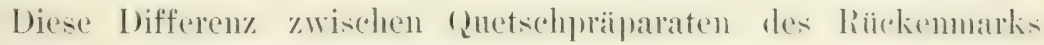
(es kann auch Gehim genommen werden) und in Block fixierten stiucken brachte mich auf den Gedanken, dak im Zentralnemensistem rine substanz vorhanden sei corler sich nach dem Tode hilde. Welche

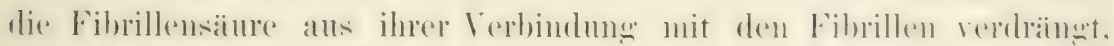
so daß sie als freie Sïure (siche oben) sich beim Fixieren in Alkohol auflöst. Diese - sagen wir - Konkurenzsubstanz wïrde im Leben

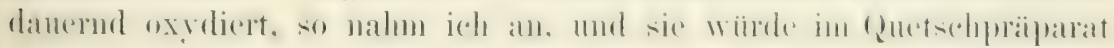

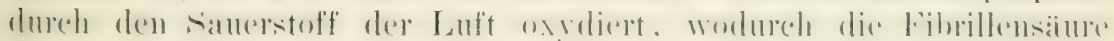
wieder in den Stand gesetzt wird, sich mit den Fibrillen zn verbinden.

Wäre diese Vorstellung richtig, so mïßte man die Fibrillensäure nherall anch in Block nachweisen kömnen, wemn man sich einel Bethe, Nervensystem. 
Methode bediente, bei der sich die freie Fibrillensäure nicht löst oder hei der sie in eine alkoholunlösliche Verbindung ïbergeführt wird. Hier»n darf natïrich kein Metallsalz angewandt werden, da dabei (ielegenheit zu sekundäirer Färbung entstehen kömnte.) Da die freie Fibrillensïure ja in Wasser unlüslich ist, so kam sic ihren l'latz nicht verändern, sondern muß an den Fibrillen liegen bleiben. Sach den Voruntersuchungen kamen hier zwei Wege in Betracht: entweder man vermied den Alkohol und ersetzte ihn durch Ïther, in dem, wie

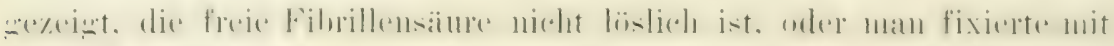

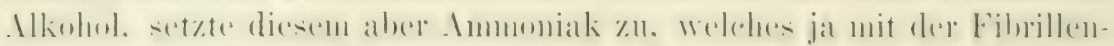

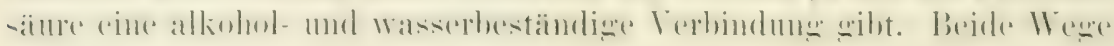
wurden mit vollem Erfolge betreten.

1. Alte Äthermethode. (Dieselbe ist unsicher und daher nicht empfehlenswert. Da ich aber mit derselben bei den spïter zu beschreibenden Versuchen gearbeitet habe und keine Zeit hatte, die Ergebnisse mit der nenen und sichereren Methode nachzupriifen, so muß sie hier beschrieben werden.) Das Gewebsstiick wird direkt in Ather iibertragen, und dieser mehrfach gewechselt. Nach etwa zwei Tagen wird es in eine Lösung von Toluidinblau 1:3000 gelegrt und an andern Tag mit Ammoniummolybdat ohme zu waschen fixiert. Danm wird eingebettet und geschnitten. Bei dem mangelhaften Eindringen der Farbe und infolge andrer Umstïnde versagt die Methode bisweilen ganz. In andern Fïllen bekommt man sehr schöne Bilder, besonders in den Achsenzylindern, deren Fibrillen oft gar nicht zusammengeschnurrt sind.

2. Nene Äthermethode. Übertragen des frischen Gewebes in Ïther. Entwiissern mit absolutem Äther. (Die von den Histologen meistenteils und merkwiirdigerweise angewandte Methode zur Erlangung von absolutem Äther durch einfaches Hineinwerfen von Chlorealeinm ist ohne Destillation für unsern Zweek mbrauchbar, weil immer Chlorealcium in Lösung geht. Am besten entwässert man mit metallischem Natrimm und destilliert, wenn die Wasserstoffbildung aufgehört hat, vorsichtig den abdekantierten Äther ab.) Übertragen in Xylol, Einbetten in Paraffin. Die mit Wasser aufgeklebten Schnitte werden durch Xylol und Ither $\left.(!)^{1}\right)$ in Wasser gebracht und wie sonst gefärbt und fixiert. ${ }^{2}$ )

3. Ammoniakmethode. Iran fixiert mit Alkohol, dem auf 7 -10 Teile 1 T'eil Ammoniak hinzugesetzt ist. Einbetten und Färben wie sonst.

Mit den beiden letzten Methoden bekommt man stets eine deutliehe

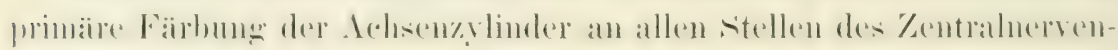
systems, anch wemn die Stiicke ziemlich alten Leichen entnommen

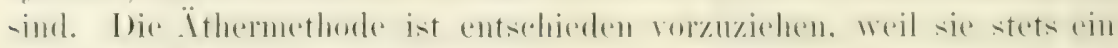

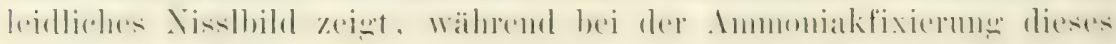
fast ganz verloren geht. Die Äthemethode läht, was die feineren Details angeht, oft zu wiinschen iibrig, weil leicht Vacuolenbildung,

1) Ein ganz kurzes Verweilen der Schnitte in Alkohol macht iibrigens nicht viel Schaden.

2) Äther zum Entwäissem anstatt Alkohol ist bei chemischen Untersuchungen sehon mehrfach angewandt worden. Wie ich höre hat Feinberg diesen Kunsts.riff bereits zu histologisehen Zwecken benutzt. (Deutsche med. Wochensehr. 1902.) 
ähnlich wie beim Vertrocknen, eintritt. Häufigr fehlt dies allerdings ganz und damn sieht man in den Zellen und den dickeren Achsen-

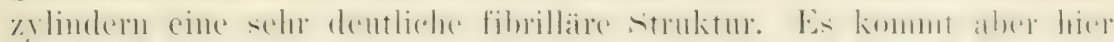
nicht anf Feinheiten an, soindern auf die Reaktion und in der Tat gibt diese Methode ein Reaktionsbild des Vervengewebes von einer solehen Empfindlichkeit, wie wir es bisher nur fï die Ganglienzellen in der Nisslschen Methode besitzen. Ich glaube, daß sie für die Pathologie gute Dienste wird leisten können.

In einem Schnitt des $R$ ii $\mathrm{ek}$ enmarks, der in der angegebenen Weise behandelt ist, ist die primäre Färbbarkeit der Neurofibrillen iiberall, im Gran, in den Ganglienzellen und in allen Strang forsern erhalten (Tafel I, Fig. IV). ${ }^{1}$ ) Es ist dadurch bewiesen, dak die Fibrillensäure dort. wo das Alkoholpräparat nichts zeigh Fing. V, nicht etwa fehlt, sondern nur in freiem Zustande rorhanden ist. Daß sie im $̈$ therpraparat wirklich frei ist, ist leicht zu zeigen. Man braucht nur einige Schnitte vor dem Firben für einige Stunden in Alkohol zu bringen, welcher ja freie Fibrillensäure löst, und man erhält nachher beim Fürben dassothe liesultat, als wem der Bhorek mit Alkolonl fixiert gewesen wäre (also etwa wie lig. V).

Es bliebe noch zu zeigen, daß die Fibrillensäure dort, wo sie bei den bisherigen Versuchen frei gefunden wurde, intra vitam wie in den peripheren Nerven an die Fibrillen gebunden ist. Ich komnte diese Versuche ans änberen Grïnden nicht zu Ende führen, flaulue aher, dab die zwei Tersuche, welche ieh semacht habe, wo kilar waren, daß sie eine Entscheidung der Frage bereits zulassen.

Wir haben Grund anzunehmen, daß bei der allmählichen Abkïhlung eines Granismus alle vitalen Prozese einschlafen, whe dals Veränderungen durch Oxydation us. s. w. eintreten. Wemn num im Zentrahervensystem eine Konkurenzuhstanz danernd webildet, aluer immer wieder durch Oxydation zerstört wird, so kann dieselbe sich

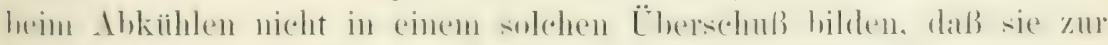

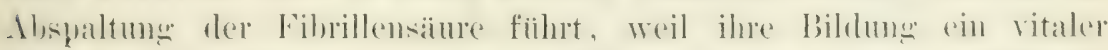

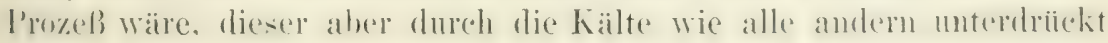
wïrde. Tch ließ num zwei Frösche allmählich einfrieren, meißelte das Rückenmark heraus und iibertrug es direkt in stark unter $0^{\circ}$ ab-

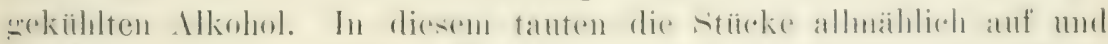

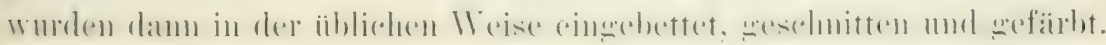

1) Von einer primären Färbung der Fibrillen kamn man auch da sprechen, wo man nicht die einzelnen Fibrillen, sontern nur den rötlichen Ton, sei es in Vervenfasern, sei es in Zellen, sieht, da diese rütliche Fïrbung nachweislich von der Fïrloung der Fibrillen lierrïlırt. 
Auf den Selnitten zeigte sich die primaire Färbbarkeit aller Strangasern, der Zellen und des Graus ebenso onterlualten wie im itherpriparat eines gew öhnlichen Frosehes. Die in Alkohol fixierten Rückemmarke zweier nicht ein-

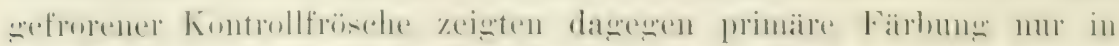
den II

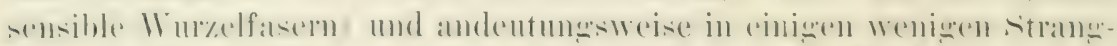

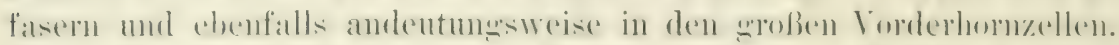

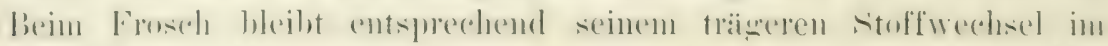

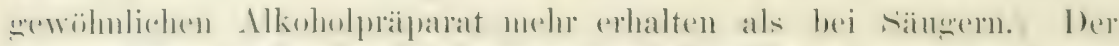

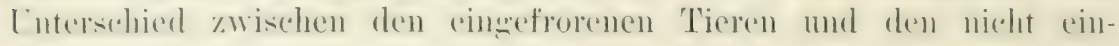
gefrorenen war auBerordentlich deutlich.

An Säugern habe ich nach dieser Richtung hin leider keine Versuche anstellen kömmen. Ich glaube aber, daß bereits aus diesen

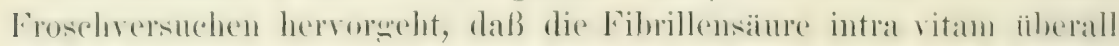

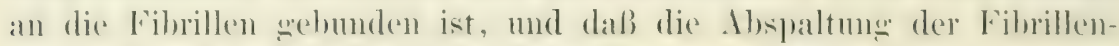

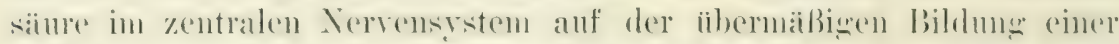
sulstan\% hermht, welehe dem peripheren Verven fremel ist. Eventuell

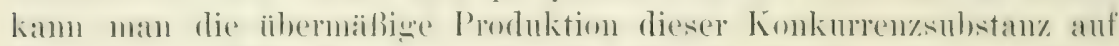

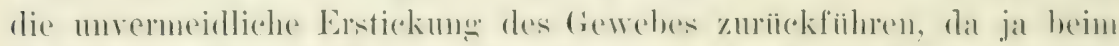

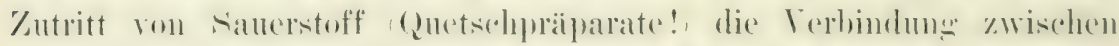
Fibrille und Fibrillensibue wieder heresestellt wirel, es sich also in

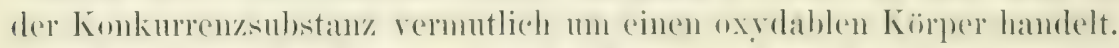
Eine Erstekung des (iewebes bei der Entualmo ans dem Tierkeirper ist

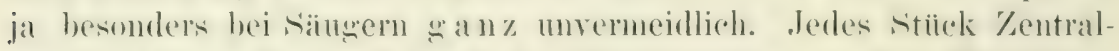
nervensystem, das man nach der Iteramsuahme ans dem 'Tierkïrper fixiert, ist erstickt; man mag so schnell verfahren, wie man will. Eine Fixierung des nicht elstickten fiewebes ist erentuell damm mö̈lich, wem man, wie Mann dies ausgefiihrt hat, intra vitam das Fixiermesmittel in die Blutbalm injiziert. Bei diesem Verfahren solemt Manm anch in der Tat bereits primäre Fäbune der Fibrillen in den fanclienzellen und strangfasem erhalten zu haben, someit man dats aus seinen kuren Publikationen elsehen kann.

Die Existenz einer Konkurenzsubstanz beim Absterben oder nach

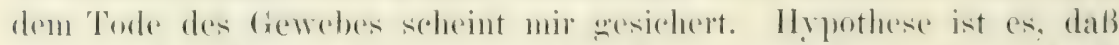

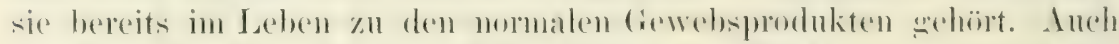

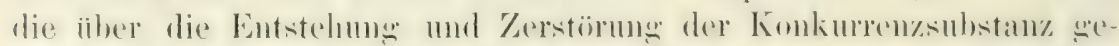
äuberten Insiolsten sind insofern hypothetisch, als sich die Tatsachen

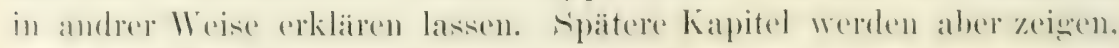
daß diese Hypothese nicht unfruchtbar ist. 


\section{Über einige andre Zellstrukturen und Zellbestandteile und die Veränderungen der Ganglienzellen nach intra vitam erfolgenden Eingriffen.}

Ton einigen Autoren sind innerhalb ron Ganglienzellen Centro-

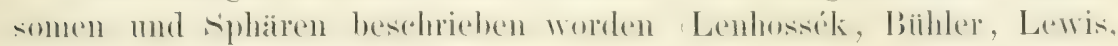
Joseph, studnicka und andere. An ïberzengendsten seheinen mir nocels

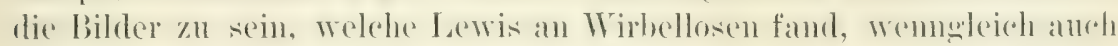

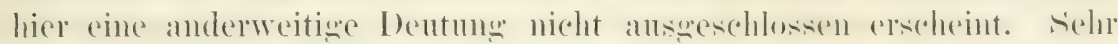

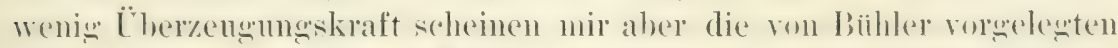
Abbildungen zu besitzen. IBilder, wie sie Lenhossek erhicelt, sicht man an sinualganglienzellen nicht selten; bei Hülnerembryonen vom secollsten his zehuten Tage sind sie soswar sehr dentlich und an jerler Zelle zur sehen. Etwas Analoges labe ich an zentralen \%ellen aber nie wahrnehmen können. Daß es sich bei diesen kugligen und ron konzentrischen sichichten mugebenen Gebilden num C'entrosonen handelt, scheint mir vorläufig zweifelhaft. Fül die hier behandelten Fragen ist es auch ziemlich gleichgilltig, ob die Ganglienzellen noch im ansgrebildeten Zustande Reste von Centrosomen besitzen oder nicht. Erwähnmon mag hier anch finden, dak in den Kernen mancher fanenlienzellen des Ionels Krystallö̈le enefunden worden sind Lenhosick. Sjörall).

Vor einigen Jahren erregten Befunde ron Golgi (1898 und 1899) ain herechtintes Aufsehen, durch welche wereist wude, dals der \%ell-

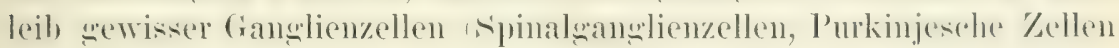

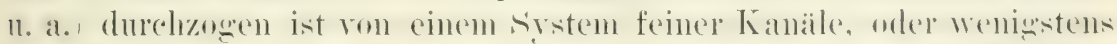

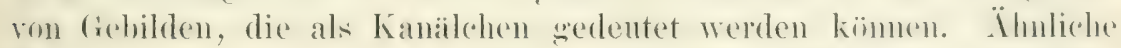
Kanälchen wurden auch von Nelis (1899) und Holmgren (1900) in

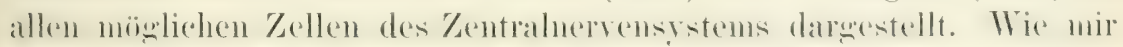

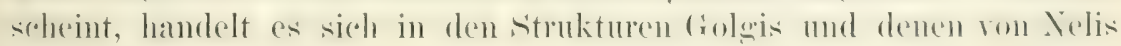
und Holmgren nicht $u m$ identische Gebilde (Bethe 1900). Eistere sind viel reicher verzweigt und sind nur anf den Zelleib selber be-

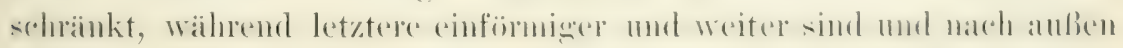
münden. Fïr den Neurologen haben diese Gebilde an Interesse verloren, seitdem ron beiden Strukturen gezeigt ist, daß sie anch in

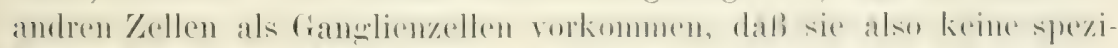

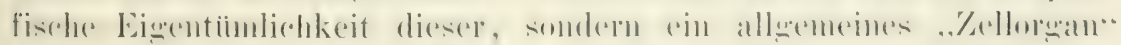
sind. (Siche Veratti und Holmgren 1902.) 
In vielen Ganglienzellen findet sich anch Pignment und zwar desto meln je älter das 'Tier ist, von dem die Praiparate stammen. Es werden mehrere Arten von Pigment in den Ganglienzellen untersehieden; an häufigsten findet sich das gelbe l'igment. [In Alkoholpraiparaten färbt es sich mit basischen Farbstoffen gar nicht oder sehr schwach. In diesem Fall wird die Farbe beim Passieren ron Alkohol wieder ansgezogen. Sind die Priparate mit Salpetersiure ron etwa $10 \%$ fixiert, so fairben sich die Pigmentansammhnngen mit 'Toludinblan lenchtend smaragdgriun. Ich fïlne dies deswegen an, weil wir es hier mit einem von den Fällen zu tum haben, wo ein

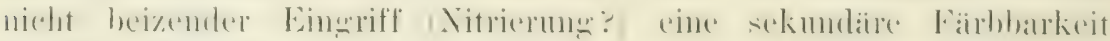
schafft.] Das Pigment ist weder in Sïuren noch in Alkalien löslich. Allgemein wird ihm kein aktiver Anteil an den Torgingen in der

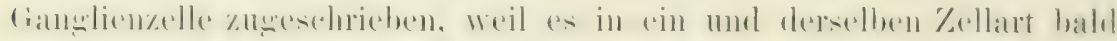
reichlich vorhanden ist, bald ganz fehlt. Man nimmt an, daß es sich

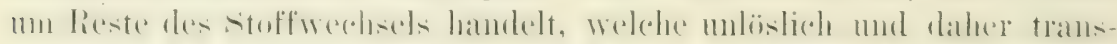

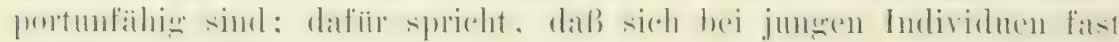
kein Pigment findet, während die Zellen alter Indiriduen oft davon strotzen. Einige Autoren lassen das Pigment aus Nisslschollen hervorgehen.

Eine ganze Anzahl von Forschern hat die Veränderungen studiert, welche sich an den Ganglienzellen im Zustande der Ermüdumg oder

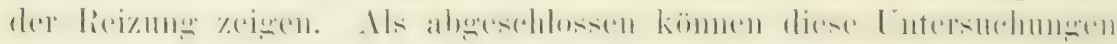

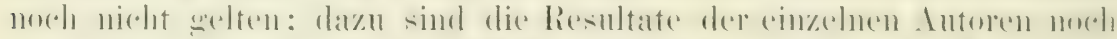

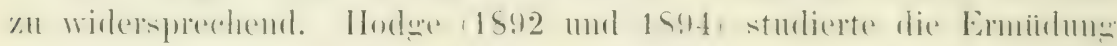
an Arbeitsbienen, welche am Abend cingefangen waren, und verglich ilıre Zellen mit solchen Tieren, die die Nacht über geruht lıatten.

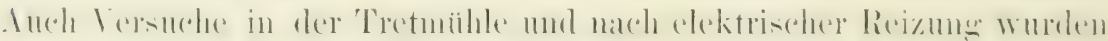

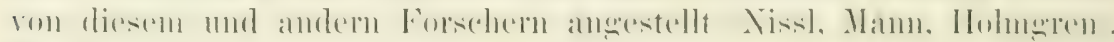
Der Kern soll kleiner werden, einen umegelmäßig zackigen Umriß\}

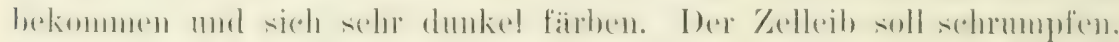

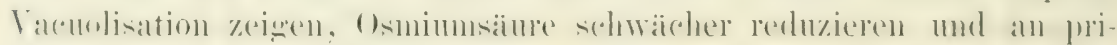
märer Fäbloarkeit abnelmen.

Eine große Anzahl höchst interessanter Versuche ist zu dem

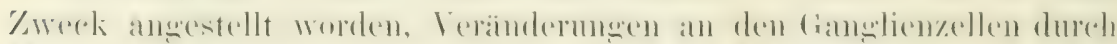

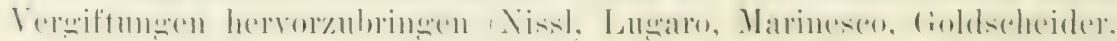
Flatau, van Gehuchten, Brauer и. a.). Als Untersuchungsmethode

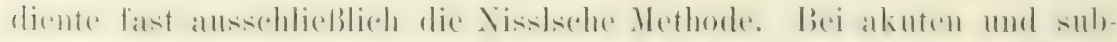

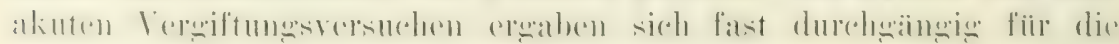

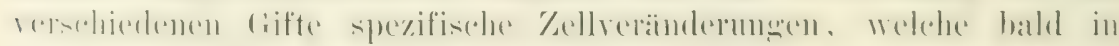
cinem totalen Verschwinden der primären Färbbarkeit (meist mit ror-

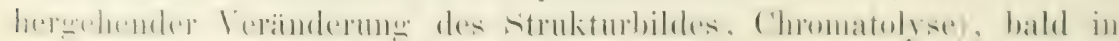

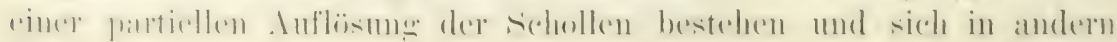




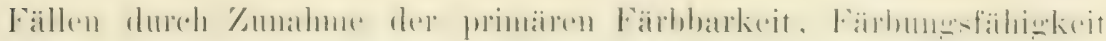
der in normalen Prịparaten ungefärbten Bahmen oder anderu Änderumgen des Strukturbildes kund tum. Derartige Versuche wurden mit Blei, Quecksilber, Arsen, Phosphor, Alkohol, Veratrin, Strychnin,

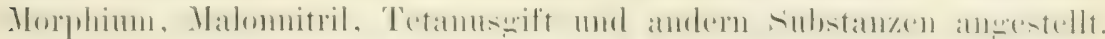

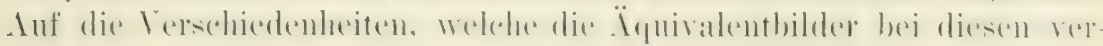
schiedenen Giften aufweisen, will ich hier nicht näher eingehen und

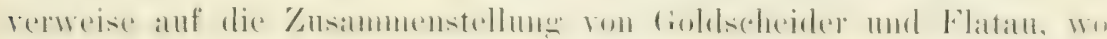
sie in ziemlicher Vollständigkeit anfgeführt sind. So wie die Zellreränderungen fiir jedes Gift spezifisch sind, so ist wenigstens bei manchen Giften auch die Zellart typisch, an welcher sich die Gift-

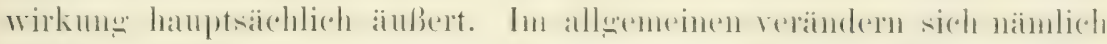
nicht alle Zellen des gesanten Nerrensystems, sondern bei manchen Giften wird diese Zellart, bei andern jene Zellart in erster Linie vom Zerstörungsprozeß ergriffen.

Bei dieser Sachlage lag es zunachst auf der Hand, die spezi-

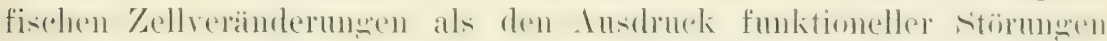

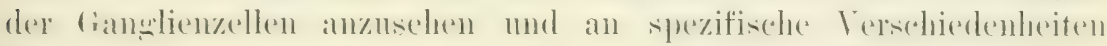
der Ganglienzellen zu denken. So wurde denn auch Nissl durch derartige Lntersuchungen dazn wefüht, die Lehe von den spezifischent Zellfunktionen aufzustellen. Weitere Lntersulehungen rom Nissl sellsst

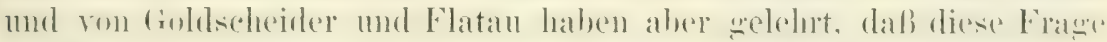
noch nicht so spruchreif ist, als es anfangs erschien (Nissl 1898).

Bei chronischen Vergiftungen, welche Nissl mit Alkohol, Veratrin,

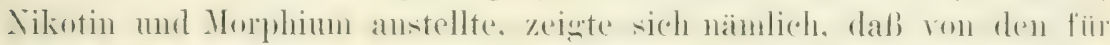
jedes rift sperifischen Vurindernugen, welches sich hei subakuter und akuter Tergiftung zeigen, nichts zu sehen ist. Das Vergiftungsbild war bei dieser Art der Einverleibung der Gifte in allen Fällen das

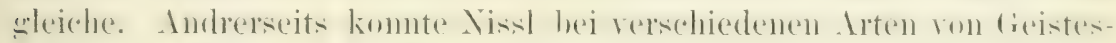
störumg und bei nicht Geisteskranken, die rol dem 'Tode deliröse

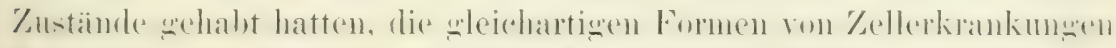

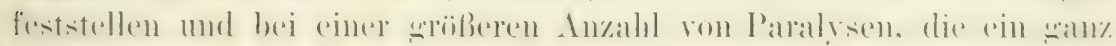

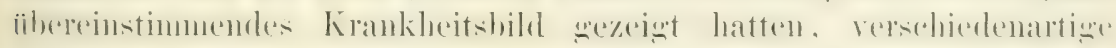

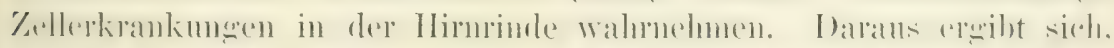

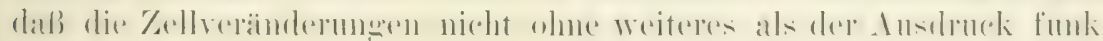
tioneller Störumgen und noch weniger als der Ausdruck bestimmter Störungen anzusehen sind. - Eine starke Inkongruenz zwisehen der Art der Zellverinderungen und der Stäke und Art der funktionellen Störungen geht auch aus folgenden Velsuehen hervor: Irird bei einem

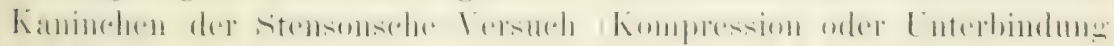

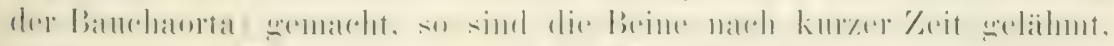

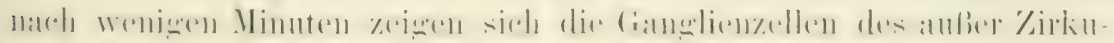
lation gesetzten Riickenmarkstickes deutlich verïndert. Hebt man 


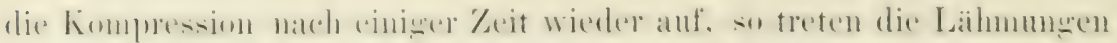

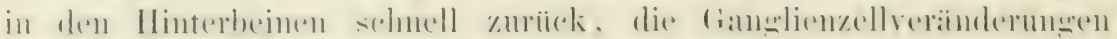
persistieren aber noch durch längere Zeit (Nissl). - - Vergriftet man

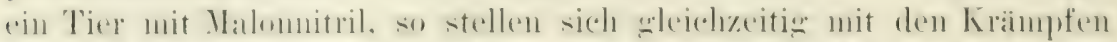

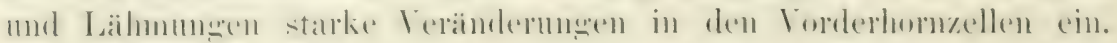

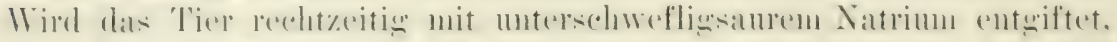

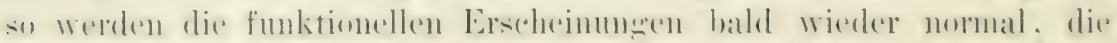

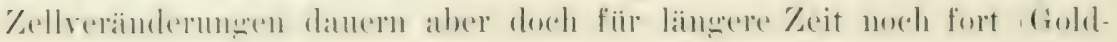
scheider und Flatau). - Bei der Tergiftung mit Tetanusurift stellen

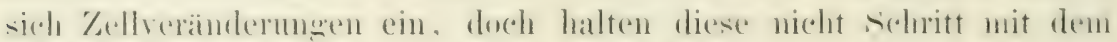

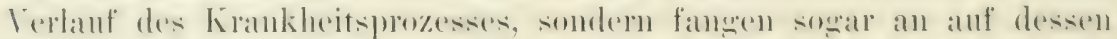

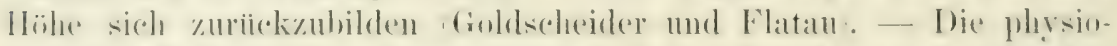

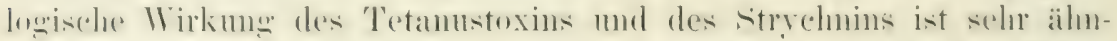

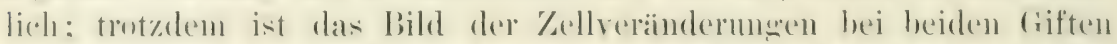

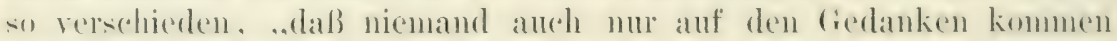

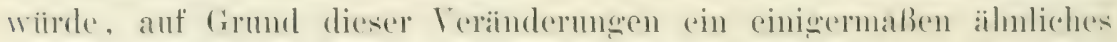
symptomenbild rermutungsweise anzunehmen" (Nissl).

Danach ist es wohl sicher, daß die Zellverändermgen, welehe

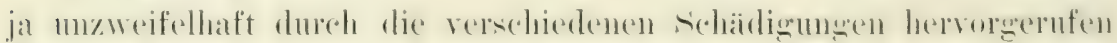

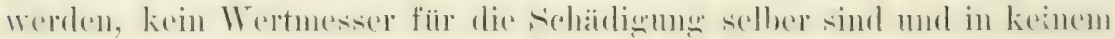

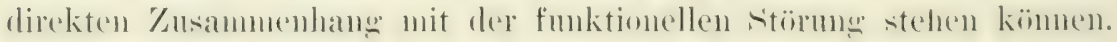
Sie sind, wie Nissl sagt, ,in erster Linie der Ausdruck del durch

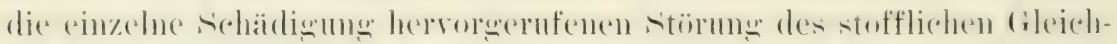
pewichts in der Nervenzelle". Damit ist gewiß nicht zuviel gesagt. Yielleicht wird man mit der Zeit, wenn erst genaner erforscht sein

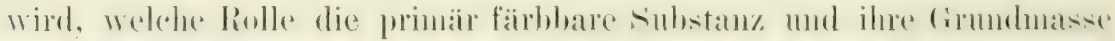

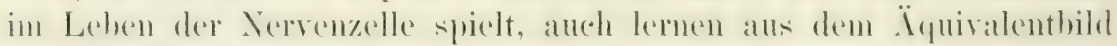

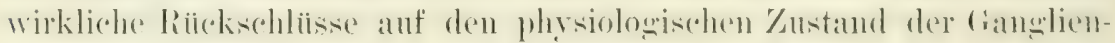
zellen zu ziehen. Im Angenblick ist über die Rolle, welehe die färbbare Substanz in der Ganglienzelle spielt, noch gar nichts zu sagen

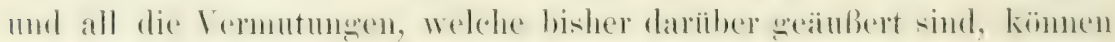
als in der Luft schwebend übergangen werden. 


\section{ZEHNTES KAPITEL.}

\section{Die Nervendegeneration.}

Die morphologischen Veränderungen bei der Degeneration S. 155-160. - Das Schwinden der primären Fïrbbarkeit am Anfang der Degeneration S.161-163. - Die Ursachen der Degeneration S. 163-175. - Tägliche Reizung eines durchschnittenen Froschnerven beschlemigt die Degeneration S. 164-166. - Die Degeneration mach Kontinuititstrennung ist nur trammatisch S. 167. - Traumen, die keine Leitungsunterbrechung hervorrufen, bewirken doch Degeneration S. 165-171. Leitungsunterbrechung zieht nicht notwendigerweise Degeneration nach sich S. $172-175$.

Bereits einem Autoren des achtzehnten Jahrhunderts, Arnemam (1787) fiel es auf, daß das periphere Ende eines Nerven einige Tage

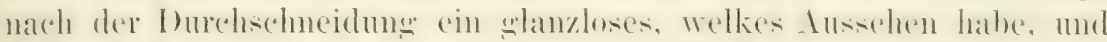
dab auf Reizung eines soldehen Xerven keine Zuckungen mehr in den

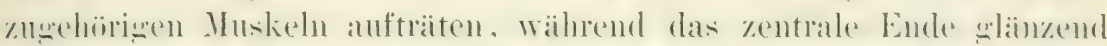

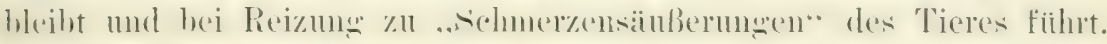

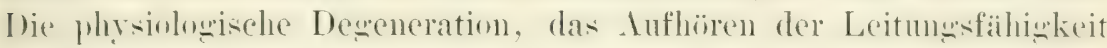
des Nerven nach der Abtrennung ron den Zentralorganen, wurde in den ersten Jahrehnten des nemzehnten Jahrhmoderts allseitig les. staitigt und gehört bis auf den hentigen Tag zu den gesichertsten hementuisen unserer Wistenschaft. IListologische Lutersuchungen an degenerierten Nerven wurden erst relativ spät, zuerst ron Nasse im Taltre 1539, muternommen. Eine Öberemstimnumy der Yeinumgen.

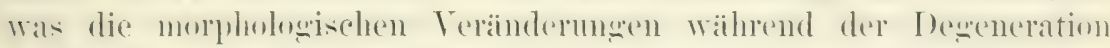
anbetrifft, ist erst in den letzten Jahren erreicht; in einigen Punkten steht sie immer noch aus.

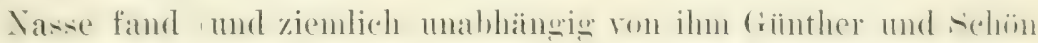
1840), daß einige Monate nach der Durchschneidumg eines Nerven (Froseh und Kaninchen) das Nerrenmark vollkommen verschwunden

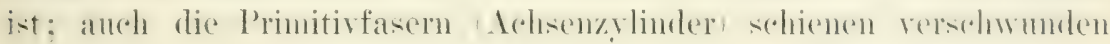
zи sein. Bei Untersuchung früherer Stadien rom Frosch kounte be-

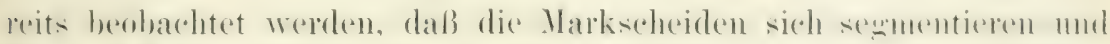
dann zu kleinen Fettröpfehen zerfallen, welde späterhin rerseduwinden. Diese Befunde wurden ron den meisten späteren Autoren (Waller,

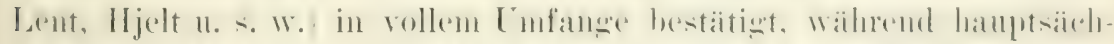

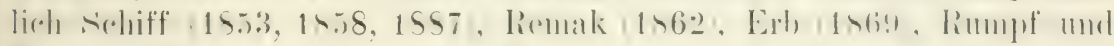
Korybett-Daskiewiez nur eine Degeneration der Markscheiden aner-

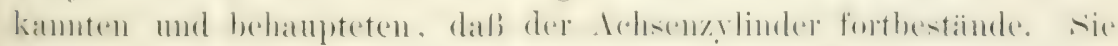
stiitzten sich hierbei in der Hauptsache auf die Untersuchumg peripherer Nervenstimpfe, welche mehrere Monate ror der Sektion ron den Zentralorganen abgetrennt waren und in denen sie noch deutlich 
Achsenzylinder wahrnehmen konnten. Andre streitpunkte bestanden darin, ob es sich um eine fetrige Degeneration des Markes oder um L'mwandlung desselben (Eichhorst, Tizzoni, S. Mayer), oder un Ver-

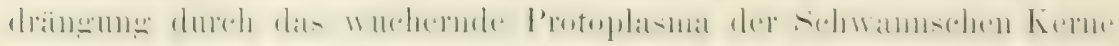
(Ranvier) oder schlieBlich mon phagoeytäre Prozesse handle. Auch ist bis auf den hentigen 'Tag lebhaft dariiber diskutiert worden, ob die

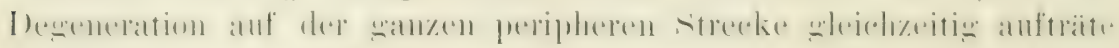
oder ob sie an der Verletzungsstelle resp. an der Peripherie ihren Anfang nähme und von da aus fortschritte. Es liegt nicht in meiner Absicht, die ansgerlehnte Literatur hier zu besprechen. Sie ist so gnut in den Arbeiten von r. Biingner (1591) und Ströbe (1893 und 1895 ) referiert, daß ich auf diese verweisen kann. Ein Teil der zur

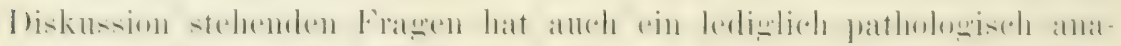

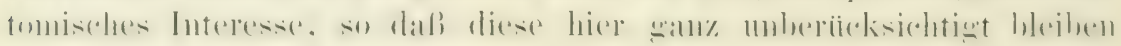
kimmen.

Einen der wesentlichsten Fortschritte machte die Degenerationsfrage dureh die Untersuchungen ron Waller (1852), die zur Auf-

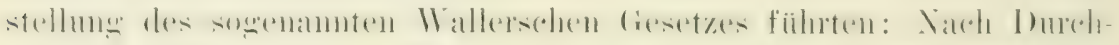
scheidung motorischer Wureln degenerieren die Nervenfasern nur nach der Peripherie zu und zwar nur die motorischen, die sensiblen bleiben intakt. Durchschneidet man eine sensible Wurzel, so bleiben die Nervenfasern im peripheren Nerven und in dem T'eil der

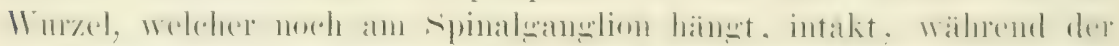
an Rïckemmark verbleibende Teil der Wurel degeneriert und zwar. wie wir jetzt wissen, noch weit ins Rüickenmark hinein (Hinterstrang-

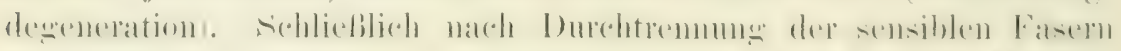

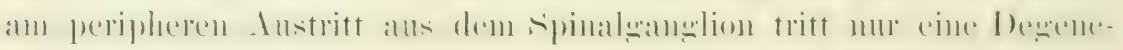
ration nach der Peripherie hin ein. Hieraus schloß Waller, da B die Degeneration der. Nervenfasern zustande kitme dureh Abtrennugroneinemutritorischen (trophisehen) Zentrum, welehes für die motorischen Fasern im Rüekenmark, für die sensiblen im spinalganglion grelegensei. Im Anschluß an die Untersuchungen von Wagner (1846) und Robin (1846), welehe den Zusammenhang von Ganglienzelle und Achsenzylinder znerst gesehen hatten, verlegte er bereits das nutritorische Zentrum in die Ganglienzelle.

Nan kamn diese Befunde und Dentungen, welche die Degenera-

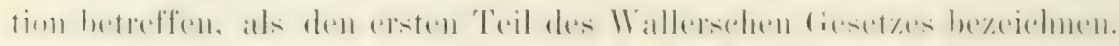
Der zweite Teil bezieht sich dam anf die Regeneration der Nervenfasern und kamn kur\% dahin zusammengefaßt werden: Die Rege. neration einer Nerrenfaser geschieht nurom trophischen (nutritorischen) Zentrum aus, indem der Achsen. zylinder ron der Ganglienzelle wieder in die alte Bahn 
hineinwächst. Dieser zweite 'Teil ist schon an und für sich eine Konsequenz des ersten Teils, für den Fall daß dieser auch in seinem theoretischen 'T'eil (d. h. in Betreft der trophischen Funktion der Ganglienzelle) richtig ist. Er wird uns aber erst im nächsten liapitel zu beschäfigen haben.

Das 'Tatsächliche des ersten 'Teils des Wallerschen Gesetzes fand fast allgemeine Anerkenmung. 'Znerst war es Schiff (1853), del die

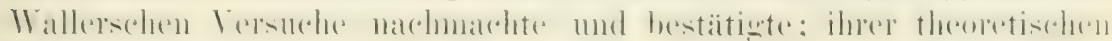
Dentung trat er aber entgegen, inden er ebenso wie Kölliker bei

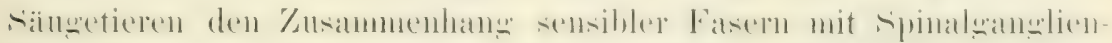
zellen lengmete. Später ist, wie bekannt, diesel Zusammenhang anch für die Sängetiere als sicher erwiesen worden, so daß von diesem

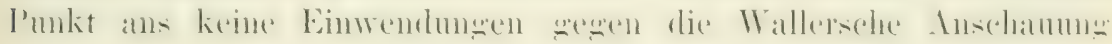
mehr gemacht werden kömnen. Andre Autoren - und ihre Zahl ist sehr groß - haben die Wallerschen Befunde bestaitigt, seine theoretischen Schlïsse angenommen und die GesetzmäBigkeit der Nervenfaserdegeneration auf das gesante Nervensystem ansgedehnt. Wo man auch eine Verletzung ron Nerrenbahnen bewirkt, immer geht das ron der Ganglienzelle abgetrennte Fasergebiet eine regressire Metamorphose ein; dieser Satz kam nach allem als feststehend betrachet werlen, wenigstens fïr alle markhaltigen Nervenfasem vom

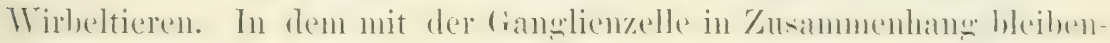
den Faserteil tritt zwar auch eine Degeneration ein, diese erstreckt sich aber normalerweise nur auf die nächste Umgebung der Terletzung. Eime ganz andre Frage ist die, ob sich diese Tatsachen

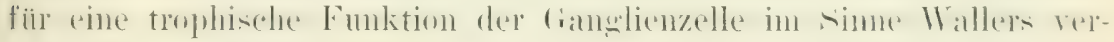
werten Iassen.

Das größte Interesse beansprucht unter den allgemeinen Veräin-

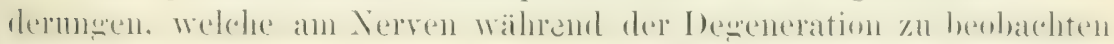
sind, das Verhalten des leitenden Elements, als welehes wir nach dem bisher besprochenen und anf Grund der weiter unten mitgeteilten Beweise die Neurofibrillen ansehen müssen. Außer einigen spärlichen Andentungen ron v. Büngmer und Stroebe liegen ïber diesen Punkt

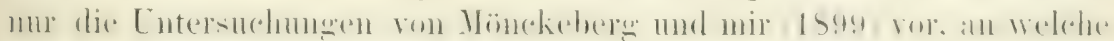
ich mich im wesentlichen halten werde. Einige nenere von mir grefundene Einzelheiten füge ich unsern damaligen Befunden bei. In Betracht kommen hier auch noch alle die Arbeiten, welche sich mit dem Verhalten des Achsenzylinders als Ganzen beschäftigen. Die

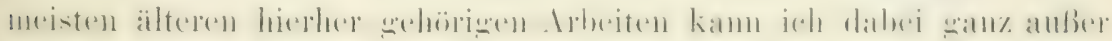
acht lassen, weil eine sichere Darstellung des Aehsenzylinders be-

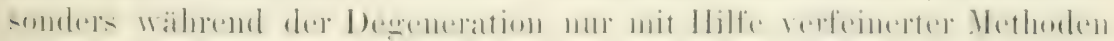
möglich ist. Als Ergebnis der neneren Entersuchumgen iiber dies Thema (Beer, v. Bïngner, Howell und Inber, Stroebe) kam nan 


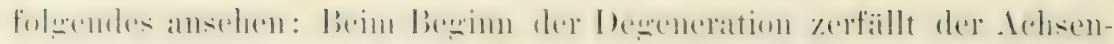
zylinder in einzelne Stiicke, welche mit zunchmender Degeneration rerschwinden, sodaß am Ende der Degeneration iiberhaupt nichts mehr rom Lehsenzylinder iibrig ist. Dabei mïssen also wohl auch die Fibrillen zerstiickelt nud rerschwunden sein.

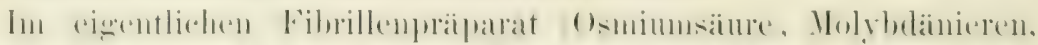

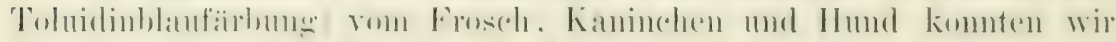

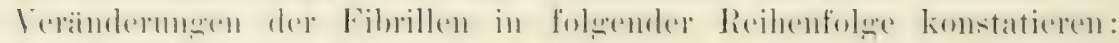

1. Die Fibrillen sind weniger gestreckt als normal. Auch bei

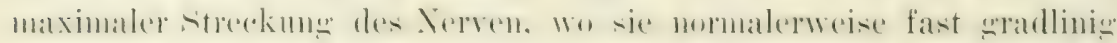

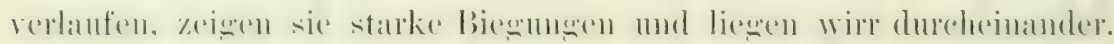

2. Die einzelne Fibrille ist nicht mehr glatt, sondern zeiot hier und dort körnige Verdickungen. Die Perifibrillärsubstan\% ist noch lomogen (Fig. 48 A).

3. Die Körnelung der Fibrillen nimmt zu und führt zu einem

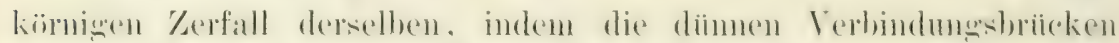

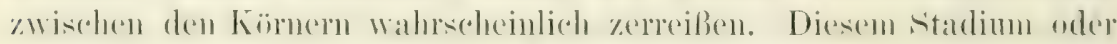
schon dem zweiten kann ein Zusammenschmuren dej Fibrillen zu einem Strange vorhergehen. Ist dies cingetreten, so kann man fest-

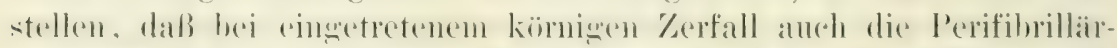

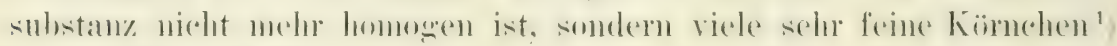
enthält (Fig. $48 \mathrm{~B}$ ).

4. Die großen Körner, welehe aus den Fibrillen entstanden waren, sind versehwunden. In ihrer Stelle finden sich kleinere Körner, wolehe von denen nicht zu mutersoheden sind, die in der Perifibrillatesubstanz auftreten (Fig. $48 C$ ).

5. Die Körnchen rerschwinden anscheinend durch Lösung. Die

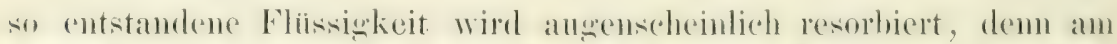
Ende der Inexeneration ist an stelle des weiten Hohlramms nur noch ein kleiner Spalt vorhanden.

Sehen wir num zu, wie sich die von den älteren Autoren be-

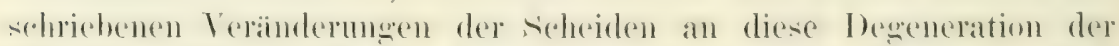
Fibriblen anfiigen: Wie bereits erwiblnt, hatte schon Vasse eine Zer-

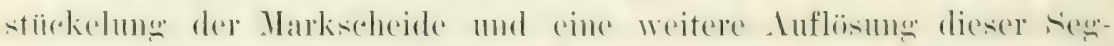

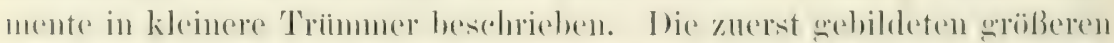

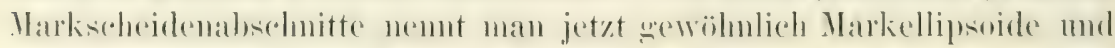

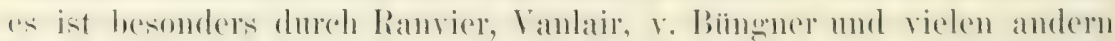

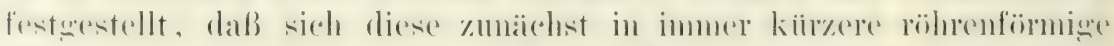
Stiicke teilen, welche sich an beiden Enden schließen und so den

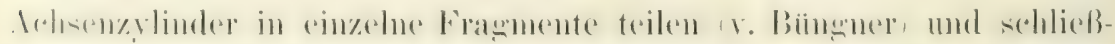

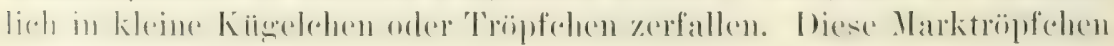

1) Diese Körnchen sind in der Reproduktion kaum sichtbar. 
liegen damm zwischen dem letzten Rest des Achsenzylinder's und del

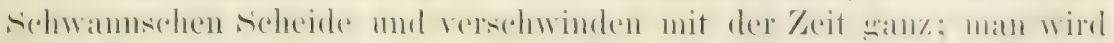
nicht fehl gehen, wenn man sagt durch Resorption, denn es bleilst nichts zuriek, was als Umwandlungsprodukt derselben angesehen werden kömnte.

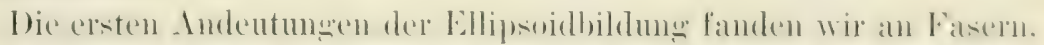

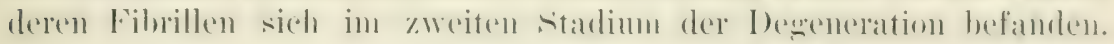
Es sind damn aber nur Einschnilrungen der Markscheide zu konsta-
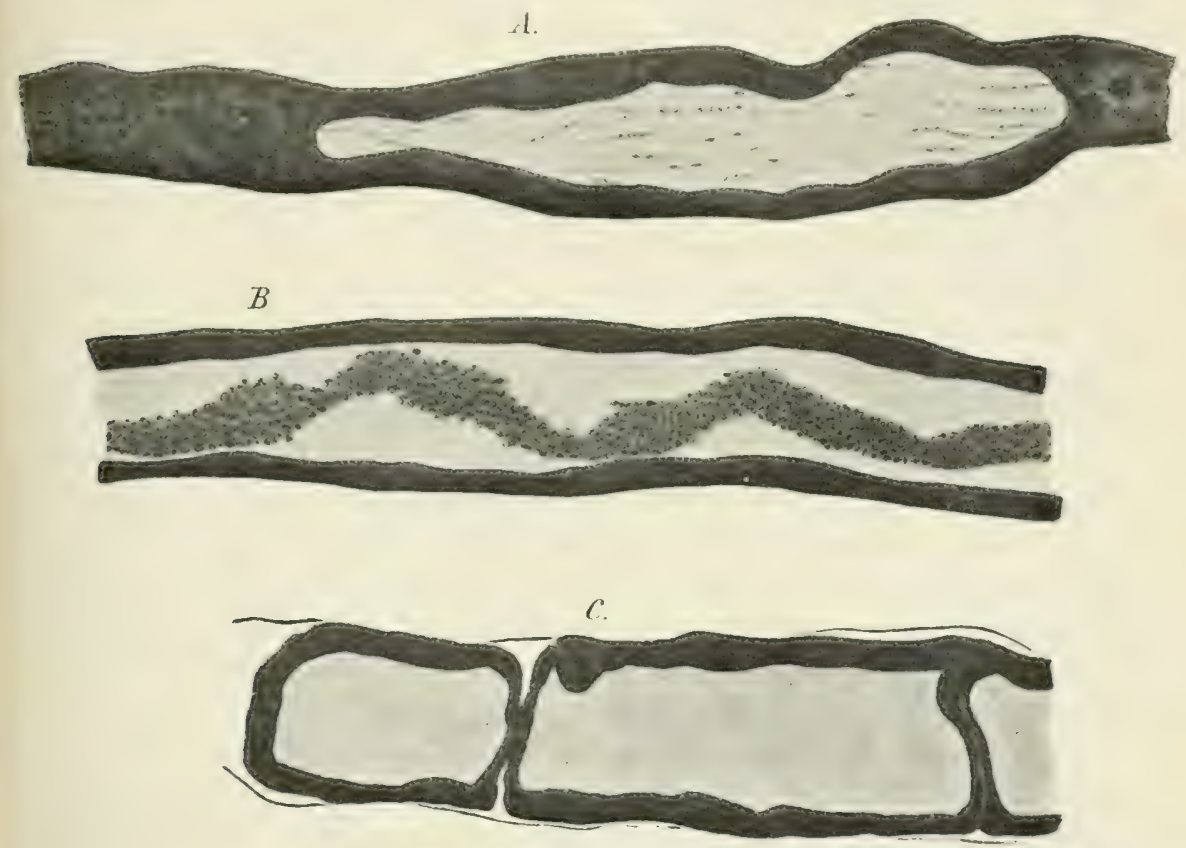

Fig. 48. Degeneration dex Neurofibrillen im markhaltigen Nerven nach Durchschneidung desselben nach Münckeberg-Bethe (1899). A Anfang der Körnchenbildung an den Fibrillen (Winterfrosch, 102 Tage nach der Durchschneidung). b Stadium der gemischten Körner (Kaninchen, sechs Tage nach Durchschneidung). $C$ Stadium der blassen Körner (aus dem Nerven desselben Kaninchens).

tieren, welche noch nicht his zur vollkommenen sichliebmus des Eillip)-

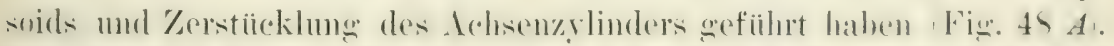

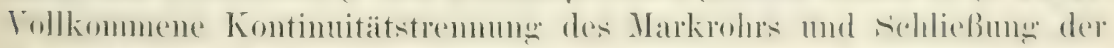
Rohne an den Enden. also lichtige Ellipsoidbildumen hahen wir immer rest dame gefunden, wem dire Fibrillendereneration hereits in das Stadium der großen Körner gretreten war. Niemals finden sich in

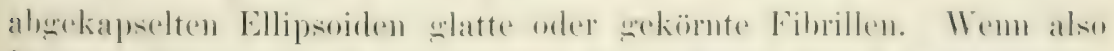
Beer, r. Büngner und andere eine Zerstieklung des Achsenzylinders gefunden haben, so war diesel Achsenzylinder nu noch ein Stran von Körnern. Übrigens geht der Segmentiermng der Markscheide 


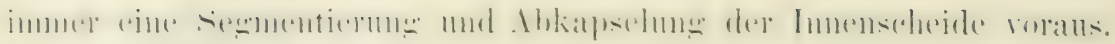
Wem die Ellipsoide zu Markkugeln zerfallen, so sind die Degrenerationsprodukte des Iehsenzylinders meist schon ganz resorbiert.

Der Infand der morphologischen Degeneration bestelit also in einer Terinderung der Neurofibrillen und \% wa in einem typischen körnigen Zerfall. Dieser folgt der Zerfall der Markscheiden allerdings sehr schmell. Aber ehe die

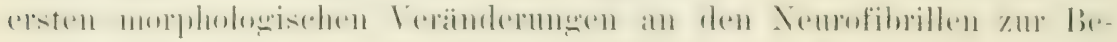
ohachtung kommen, ist die Leitungsähigkeit der Nerven bereits verschwuden. Die physiologische. Degeneration tritt also eher in Erscheinung als die morphologisehe Lntersuchung etwas e r kennen lä $\beta$ t; jedoch tritt riemlich gleichzeitio

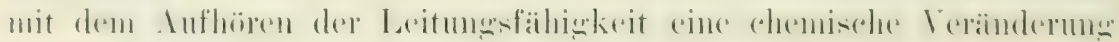
der Neurofibrillen ein. Ehe ich auf diese eingehe, muß ich aber erst den zeitlichen und örtlichen Verlauf der Degeneration nach Kontinuitiitstremmug besprechen.

Die Schnelligkeit der Degeneration zeigt bei den verschiedenen Tieren ankerondentliche Luterschiede. Bex Vïgehn findet man den Angaben von Ranvier zufolge schon zwei 'Tage nach der Operation

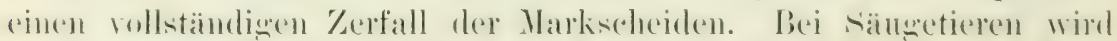

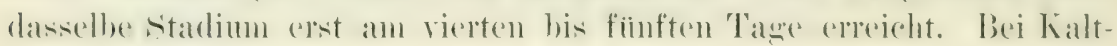

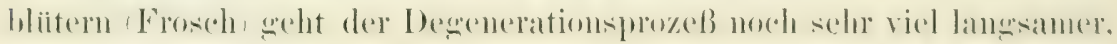

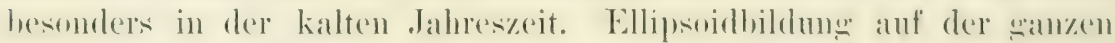
peripheren Nervenstrecke fanden wir an Winterföschen erst nach 1:30 140 Tagen, wähend derselhe status hei smmmerfröschen schon nach $30-40$ Tagen erreicht wird.

Besonders an diesen Tieren mit langsamem Degenerationsverlauf

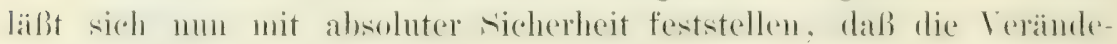
rungen sich nicht gleichzeitig im ganzen peripheren Abschnitt ein-

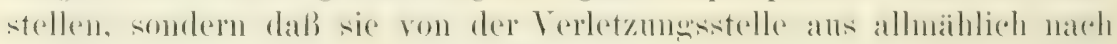
der Peripherie (und nach dem Zentrum) hin fortschreiten. Diese Beobachtung wurde zuerst ron Erb (1869) gemacht und in nemer / Leit besonders von v. Bïngluer bestaitigt (auch von v. Nothaft). Ranvier

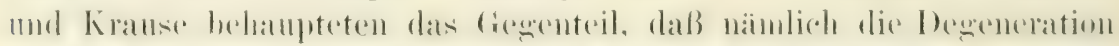

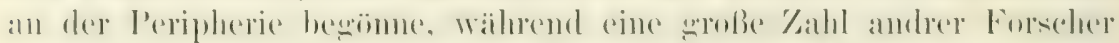

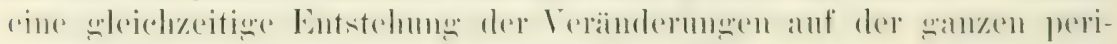
pheren Nervenstrecke konstatieren wollte. Diese letztere Ansicht ist in nenster Zeit mit besonderm Nachdruck von Stroebe vertreten worden. El stutht sich hierbei darauf, daß man häufig an ein und derselben

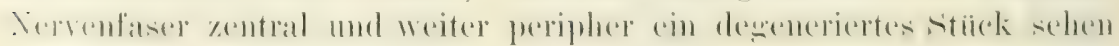
kiimme, wähend der Mittelteil noch ein normales Anssehen zeight. Es ist nicht zu bestreiten, daß man derartige Fasern nicht selten zu Gesicht bekonmit, wem man die Degeneration nur anf Markscheiden- 
präparaten oder an P'rïparaten mit geschrumpten Achsenzylindern mutersucht, an denen iiber den Zustand der Nemofibrillen nichts zu sehen ist. In Fibrillenpriparaten wird man aber in solchen Fällen immer konstatieren können, daß anch in den Mittelstiick ein vollkommener Fibrillenzerfall besteht. Der Markseheidenzerfall ist eben kein Wertmesser für die Hölie der Degreneration. Um ïber den wahren sachverhalt Aufklärung zu erhalten, muß man weit roneinander entfernte Nervenstellen miteinander vergleichen und, wenn man das tut,

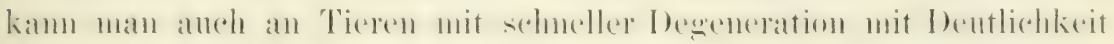
sehen, daß die Degeneration von der Verletzung ansgeht und nach heiden Seiten weiter schreitet.

Wie gesagt, sind diese Dinge beim Frosch an leichtesten zu sehen: Etwa 20 Tage nach der Laision findet man nur in der Nähe derselhen Ellipsoide. In etwas gröberel Entfermum sind die Markscheiden intakt nnd nur die Fibrillen in Degeneration, wïhrond weited nach der Peripherie zu noch ganz normal anssehende Fasem liegen.

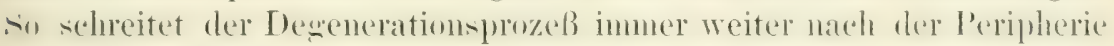
ror - der Fibrillenzerfall immer dem der Marksoheiden vorangehend - bis schließlich mach 100 und mehr Tagen die Degeneration bis zur :iuBersten Peripherie vorgedrungen ist. Gestört wird die Übersichtlichkeit des Bildes nur dadurch etwas, daß nicht alle Fasem grleich schmell dem Zerfall anheinfallen. Man sieht also im selben schuitt Fasern mit vollkommenen Fibrillenzerfall und Ellipsodbildungneben sanz nomalen. Besonders die diinnen Fasern sind ess. die dem

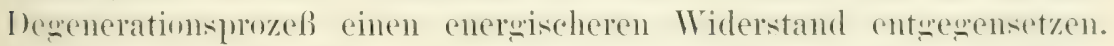

Ganz dieselben Verhälnisse, nur in schnellerel Anfeinanderfolder. sind beim Kaninchen zu konstatieren. Hiel konnten wir anch feststellen. dab die sensiblen Fasem sclumeller zerfallen als die motorischen.

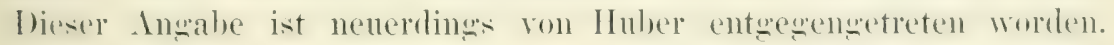
Ich glaube olme geniigende Grïnde.) - Beim Hund ist der Verlauf der Degeneration ein etwas andrer und ich glaube, daf sich dureh

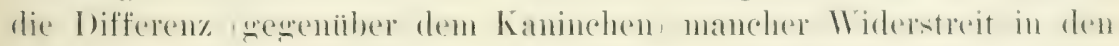

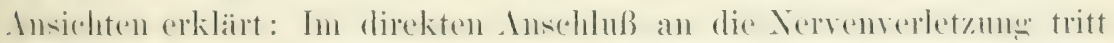
zunächst nur ein sehr langsam fortschreitender Zerfall in der Nähe der Wunde ein. Dies danert bis zur Mitte oder bis zum Ende des dritten, ja manchmal bis zum Infang des vierten Tages und dann schreitet die Degeneration in wenigen Stunden bis zur l'eripherie ror, so daß es den Ansehein erweckt, als wem die Degeneration im ranzen Verlauf der Nerven gleichzeition geschähe.

Wie im peripheren Stumpf so konnten wir auch im zentralen

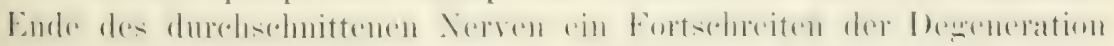
von der Laisionsstelle aus feststellen. Mehrere Autoren, und mit besondern Xachdruck Engelnam (1876), haben angegeben, daß die 


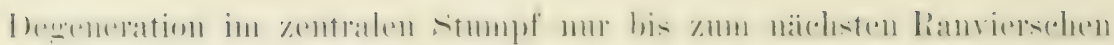
Schntiring «ehe, d. h. daß hier nur das angeschnittene segment zugrunde ginge. ${ }^{1}$ ) Wir haben dies ebensowenig wie Ziegler (1896) be-

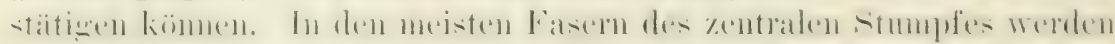
drei bis sechs Segmente von der Degeneration eroriffen; in andern reht sie oft noch viel weiter $(3-4 \mathrm{~cm})$ herauf. Bei einem 'T'ier, welches mach der Operation sich infizierte und unter septischen Er-

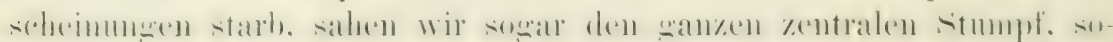
weit er heransenommen war, in vollstindiger Degeneration.

Jedenfalls degeneriert also anch der zentrale Stumpt trotz seines

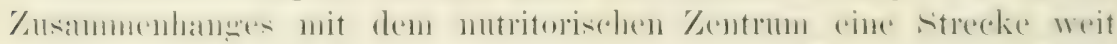
und zwar ron der Verletzungsstelle ans in der Richtung zur Zelle.

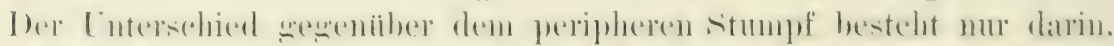

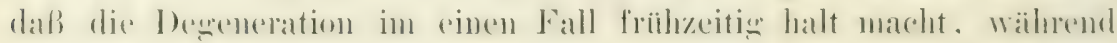
sie im andren bis zum letzten Ende des Nerven fortschreitet. Dieses

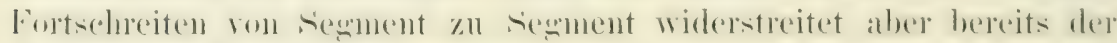
Thallersohen Vorstellume, welche die Xesuroutheorie mit in siroh anf-

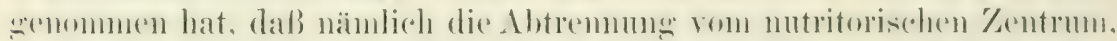
der Ganglienzelle, die Ursache der Degeneration sei. W it re die Faser bei der Kontinuitatstrennumgeinem trophisehen Einfluß entzogen, so miißte sich dieser Mangel anf der ganzen peripheren Strecke gleichzeitig geltend machen. Im zentralen Ende diufte aber ub r haupt keine Veranderung eintreten, weil es danernd unter dem tro. phischen EinfluB bleibt.

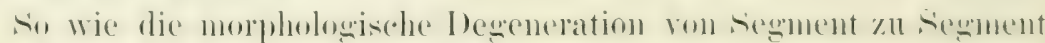

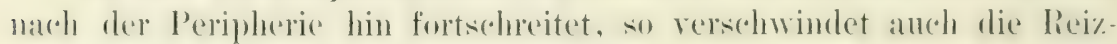

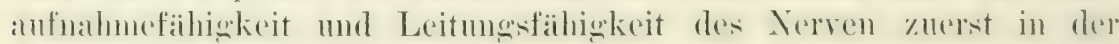

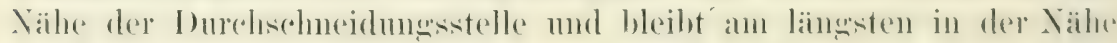

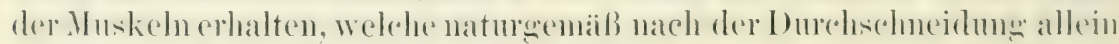

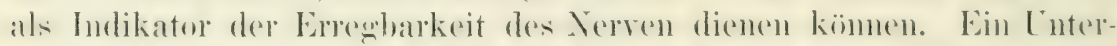

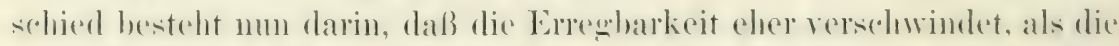

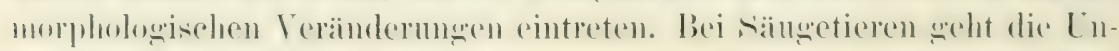

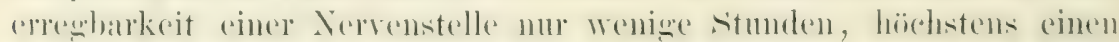

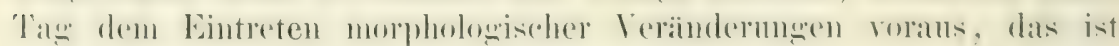

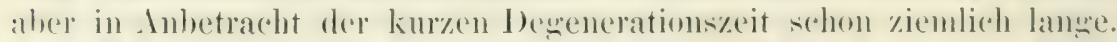

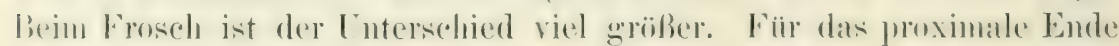

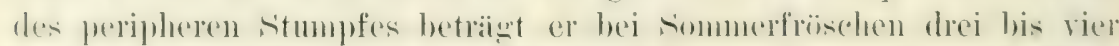

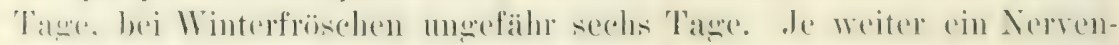

1) Nach Engelmam soll auch im peripheren Stumpf die Degeneration zunïchst am ersten Schnïrring Halt machen. Erst wesentlich später soll der Zerfałl in dem ïbrigren Teil des Nerven eintreten. Wir haben uns von einem Haltmachen des Yerfalls am ersten Schnïrring nieht ïberzengen kömmen. 


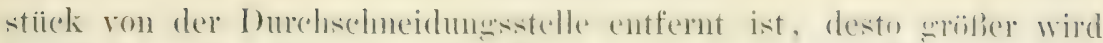
der Zeitram, weleher zwischen Linerembarwerelen und fibrillenzerfall

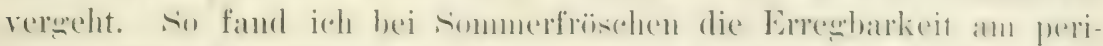

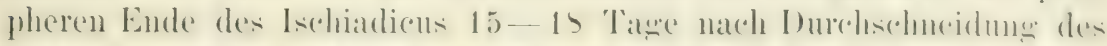

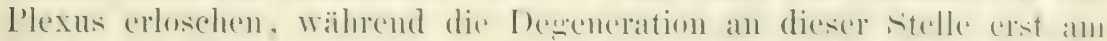
25. bis :30. 'Tage sichthar War. bei Winterfröschen fand ich die Es-

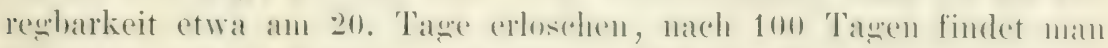
aber immer moch Fasern in feripheren Teil des Nerven, welehe moll

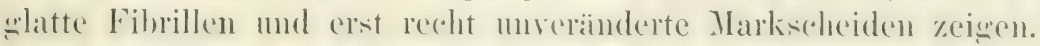

I)iese Verven der Winterföische sind wohl am sereignetsten um die

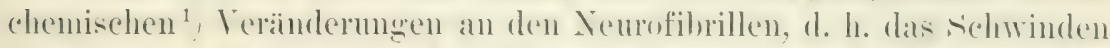
der primären Färbbarkeit rel. Katpitel b. zu zeisen, weil es hier an leichtesten ist, den richtigen Monent zu treffen. Ich stelle die Verstlche in folwender Weise an: Eince Anzahl ron Fö̈schen werden an seichen Tage beide Ischiadici hoch ohen am Oberschenkel durchschnitten. Tom 15. Tage nach der Operation an werden jeden Tag die Wunden geriffnet und die Erregharkeit geprift. Fängt sie an fering zu werden, so wird der eine Ischiadicus heranswenommen mud nach Komservierung in Alkohol an einfachsten an Zupfuraparaten. auf Fibrillensäure „2efärht. Es finden sich dann meistens schon einięe Faseru, in denen der Achsenzylinder sanz blaß ist. Den Ischiadicus der andern seite lasse ich noch einige Tagre nach Eintritt vollkommenel Unerresbarkeit in Tier. Von einem andren Frosch wird der erste Ischiadicus entfernt, wemn grade Lnerregharkeit eingetreten ist: Einime hasice Fasern, das (iros noch gefärlot, aber meist blasser als momal. Drei bis sechs 'Tage nach dem Eintritt der Uner rogarkeit-also etwa 23 - 26 'Tag'e nach der D urehschneidung' - finde ich dann meist alle Fasern bis zur Peripherie

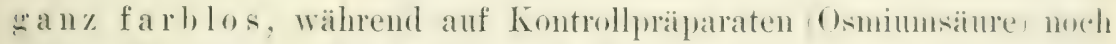
schöne Fibrillen zu sehen sind und oft sogar die ersten Infainge von Degeneration in a!len Fasem mit Insmahme der umnittelharen Nachlan-

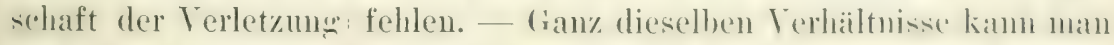

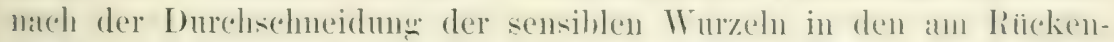
mark verhleibenden Wruzelstimpfen feststellen. Immer trift das Ver-

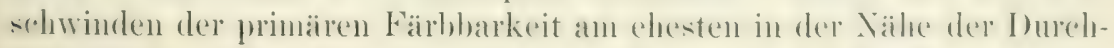

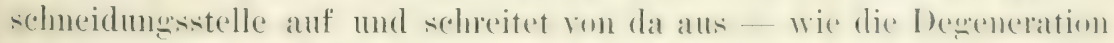
der Fibrillen und Markscheiden - cellulifugal fort.

Schon etwas schwieriger ist es bei Sommerfröschen den richtigen

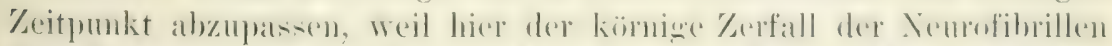

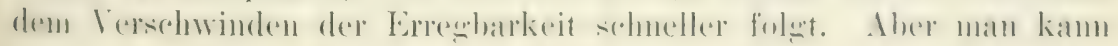

1) Über andre chemische Verinderungen wilhrend der Degeneration siehe die interessanten Untersuchungen von IJalliburton. 1901. 


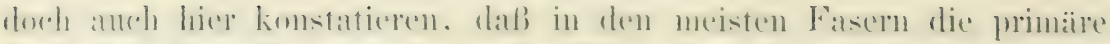

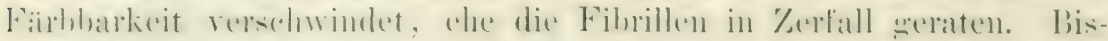

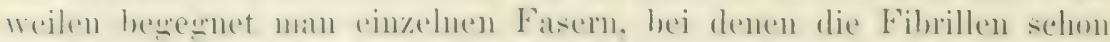

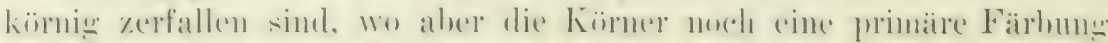

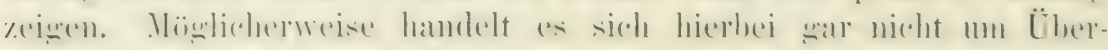

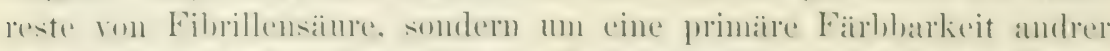

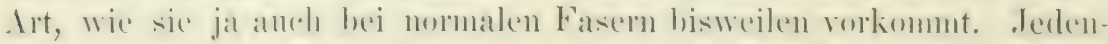

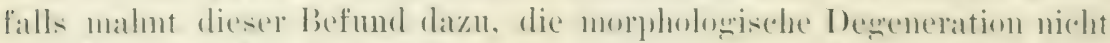

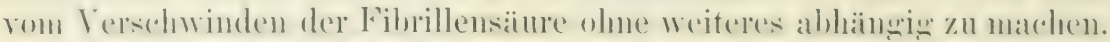

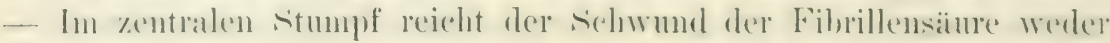

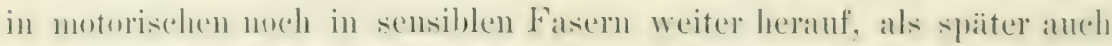
der Zerfall der Fibrillen und Markscheiden geht.

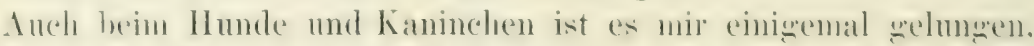
das rebwinden der primären Färbbarkeit vor dem Fintritt des kiornienen Zerfalls der Fibrillen festzustellen. Her anch hier tritt die

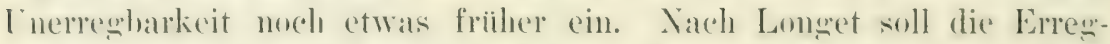
harkeit eines durehschnitenen Nerven beim Wambiiter vier 'Tatere nach der Durchschneidung anflären. Nach meinen Versuchen ist dieser Zeitram zu wrols. In der Remel fand ich beim Kaninchen schom nach

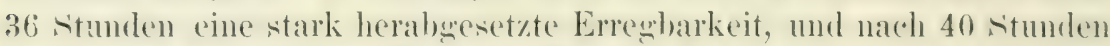
kamm sie bereits fehlen. Nach 48 stunden, spätestens nach jo stunden war sie auch nahe am Muskel stets vollkommen verschwunden. In zwei Fällen, wo sie ganz erloschen war (48 und 54 Stunden nach der ()peration, fand ich im Verlauf des samzen peripheren sitmmptes keine prinäre Fäbbarkeit, während sie in drei andern Fällen nur an proximalen Ende (etwa auf eine Strecke von $4 \mathrm{~cm}$ ) fehlte, weiter peripher aber noch in vielen Fasern vorhanden war. Bein Ilund tritt die Lnerrengarkeit später ein als beim Kaninchen. In der Reened ist die Erregharkeit erst nach drei T'agen, ja manchmal erst nach droi Tagen und zwanzig stunden bis zur Peripherie hin erloschen. Anch hied fand ich in den untersuchten Fällen which nach dem Lufhören der Er-

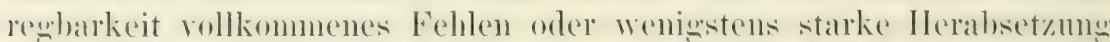
der prinären Färbbarkeit. Die kömigen Degenerationsprodukte der

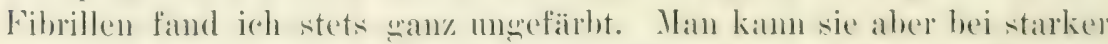

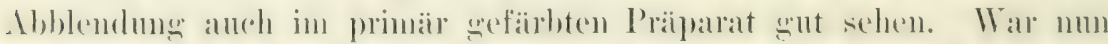
noch primäre Farbbarkeit in eimigen Fasern am unteren Ende ror-

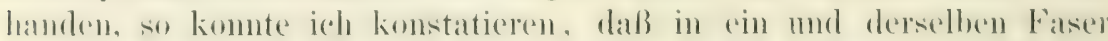

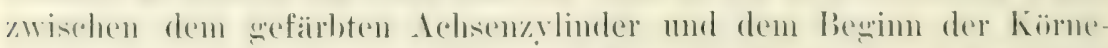

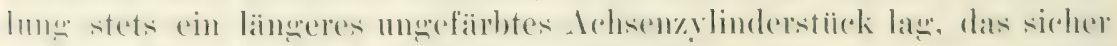

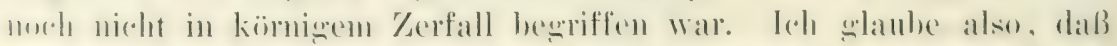

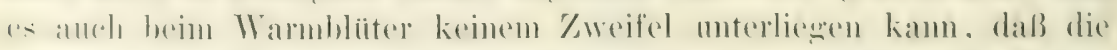

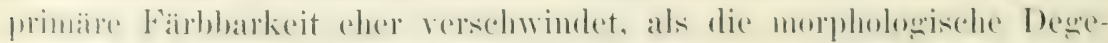

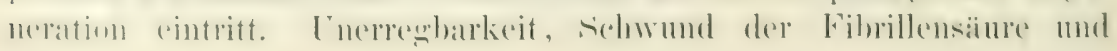




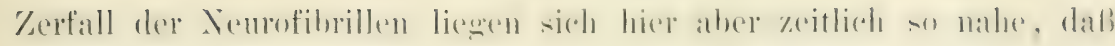
sie beinahe ineinander übergehen. Bei der langsamen, elnonischen

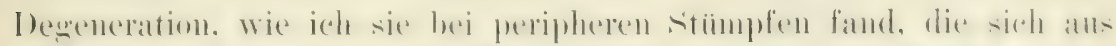

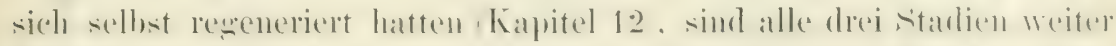

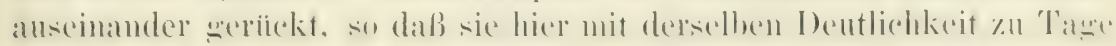
treten wie beim Frosch.

Sicher kamn ich sagen, daß niemals bei der Degeneration die

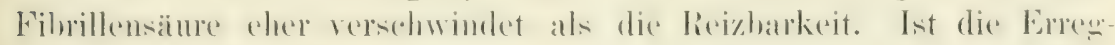
barkeit verschwunden, so ist die primäre Färbbarkeit meist schon verringert, und sie verschwindet bald nachher ganz. Wie die Erregbarkeit in der Nähe der Verletzung zuerst verschwindet, so anch die Fibrillensänre. Dieser Befund brachte mich zuerst anf den Gedamken.

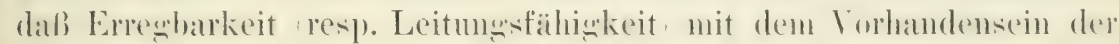
Fibrillensiane in einem innigen Zusanmenhang stände. I)ie weiter unten mitgeteilten Befunde werlen zeigen, dals dieser Grobuke sich noeh besser stiitzen läßt. ${ }^{1}$ )

Man hat sich iberlegt, in welcher Weise der trophische Einfluß der Ganghienzellen auf die periphere Nervenstrecke zu erklären sei. and hat vielfach zu der Annahme gegriffen, daß von den Zellen danernde Reize durch die Nervenfasern geschickt wïrden, deren Fehlen nach der Vervendurehschneidumg nu der Degeneration führte. I'm die später zu besprechende chromische Degeneration des zentralen Amputationsitumpfes und der zentralen Zellen zu crklïren, hat dam Marineseo 1592 , noch die Ammahme semacht, daß auch von den Endmganen danernde Reize zu den Zentralorganen strömten, deren Fort-

1) Das Schwinden der primären Färbbarkeit läßt sich auch im Rückenmark leicht nachweisen und kann hier zum frühzeitigen Nachweis von Degenerationen dienen. So konnte ich bei einem Hund mit total durchschnittenem Rïickenmark die Strangdegeneration nach oben und nach unten hin, soweit sie iiberhaupt geht, schon vier Tage nach der Operation recht deutlich darstellen. Bei einem andern sah ich die Pyramidenstrangsentartung fünf Tage nach Fortnahme einer motorischen Zone. Für Versuchstiere, die einem früh sterben, kömnte diese Hethode vielleicht manchnal ganz angenehm sein. Wartet man längere Zeit nach der Operation, so wird die Vermehrung der Glia in den entarteten Partien leicht stürend, weil die Färbung der Kerne den Ausfall der primären Fïrbbarkeit z. T. verdeckt. Überhaupt muß man sieh auf Quersehnittsbildern in acht nehmen, dafs man Kerne nicht für quergeschnittene Achsenzylinder hiilt. Bei 200 facher Vergrößerung sind sie schon leicht voneinander zu unterscheiden. Über die Techik siehe S. 146. - Das Schwinden der primären Fïrbbarkeit ist ubrigens, wenigstens im Prinzip, schon von Tuckett gefunden worden. Dieser beobachtete, daf sich marklose Nervenfasern (Remaksche Fasern des Kaninchens) nicht mehr bei vitaler Applikation von Methylenblau füben, wenn die Fasern einige Zeit nach der Durchschneidung leitungsunfähig geworden sind. Es ist dies nach seiner Arbeit das Hauptanzeichen, daß auch marklose Fasern in Degeneration verfallen. (Auf Fibrillen wurde - 1595 - noch nicht untersucht.) 
fall hier eine Degeneration herrorriefe.) Wemn diese Erklärung der degenerativen Prozesse richtig wäre, so sollte man meinen, daß man

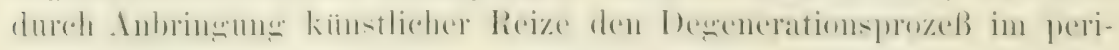
pheren Stumpf verhindern oder wenigstens verlangsamen könnte. Grade das Gegenteil ist der Fall: Die Degeneration wird dureh Reizung des peripheren stumpfes wesentlich beschleunigt! ${ }^{1}$ )

Die Versuche wurden in folgender Weise angestellt: Mehreren

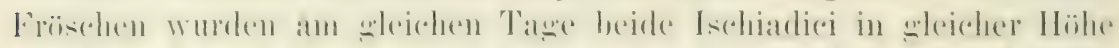

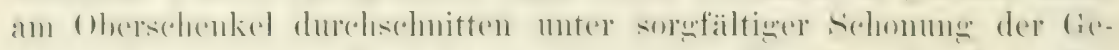

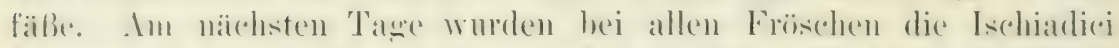

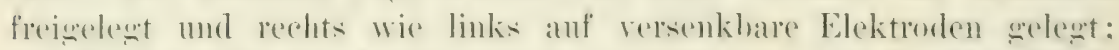

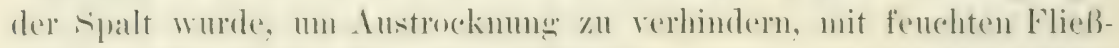
papperstreifen ïberdeckt. Ille Elektroden waren nit der sekundären spirale ein und desicellen sidhlitteninduktorimus verbunden; es komnten aber alle Elektoden, welche an den linksiseitigen Nerven lagen, ans-

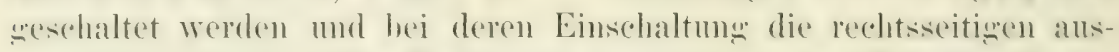
Eeschaltet werden. I) Ee Elektrorten waren immer an sielmittende der

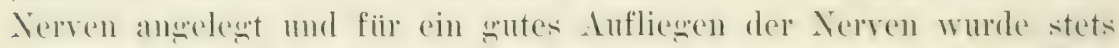

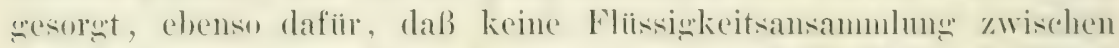
den Platindrähten stattfand. Es wurde nun zunäd hst täglich die Rei\%schwelle rechts wie links bestimmt und darauf der rechte Nerr für zwei bis drei stunden tetanisiert. Alle zedm Vinnten wurde ane Reiz-

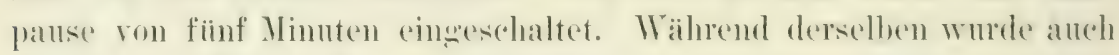
dureh eine Wippe der primäre Strom gewendet. Begommen wurde stets mit der Reizstäle, welche grade alle sichenkel in schwachen Tetanus versetzte; späterhin wurde der Rollenabstand immer in deer Weise verringert, dak der T'etanns anf sweicher Höhe bliels. Nach der lieizung wurden die Wunden jedesmal wieder vernäht. In dieser

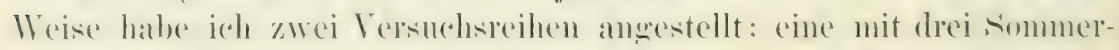
fröschen, die andre mit vier Winterfröschen. Das Ergebnis war in

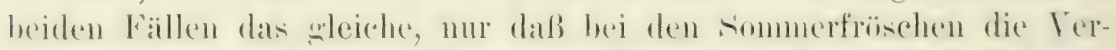
ändermug schneller wing. Bei jedem der Versuche ging ein Tier nach fünf

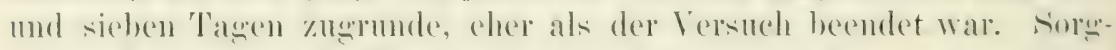
fältige Remhaltmug der Wounden und der Instrumente ist sehe wesentlich.

bei den Winterfröschen verhielt sich der Verlanf folwendermatien:

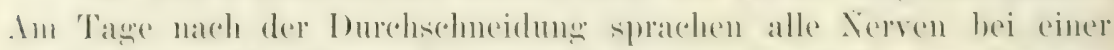

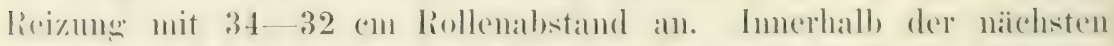

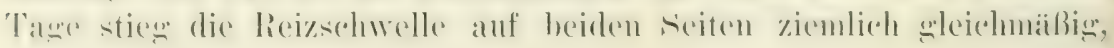

1) Langley und Anderson (1902) haben einer inzwischen erschienenen vorliiufigen IIitteilung zufolge keine Verzögerung der Degeneration bei täglicher Reizung des durchschnittenen Nerven gefunden. Von ciner Beschleunigung derselben sagen sie aber nichts. 
so daß nach acht bis nem Tagren ein Rollenabstand von $24-22 \mathrm{~cm}$ nötig war; um eine Erregumg hervorzurufen. Von num an sank in den

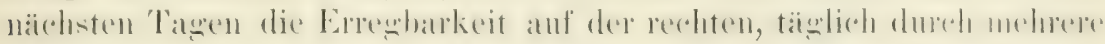
Stunden gereizten Seite sehr schnell, während sie auf der linken, immer nur probeweise gereizten Seite auf gleicher llöhe blieb! Am zwölften 'Tage lag die Reizschwelle links zwischen 22 und $24 \mathrm{~cm}$ Rollemabstand, rechts dagegen bei $11 \mathrm{~cm}$. Am dreizehnten Tage

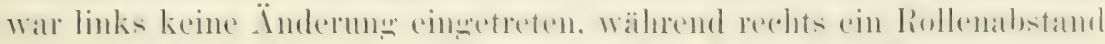
ron $10 \mathrm{~cm}$ nötig war, eine Reizstälke, bei weleher an Kontrollpräipa-

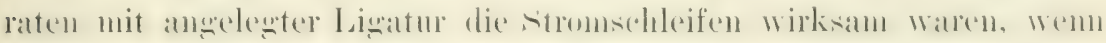
die untere Elektrode $6-8 \mathrm{~mm}$ ron der Umsehnurungsstelle entfernt war. Die Reizung wird also bei den Nerven der rechten Seite wohl nicht lokial gewirkt haben, somklen anf Vorvenstellen, welehe mehr peripher lagen; auch bei Reizung 6-7 mm unterhalb der frihheren Reizstelle war noeh ein Rollenabstand ron $11-12$ cm nötig. Erst viel weiter peripher fand sich cine Erresharkeit, welde der der linken

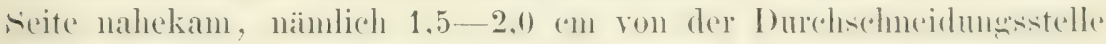
entfernt, wo die Reizschwelle bei $21-22 \mathrm{~cm}$ lag.

In diesem Stadium wurde der reehte Nerr ganz heransgenommen; vom linken Nerven wurde nur das der Durchschmeidungsstelle am

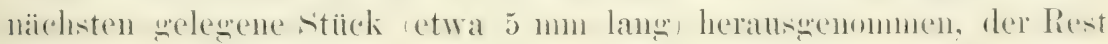
blieb noch im Tier, bis auch hier die Erregbarkeit bis anf $10 \mathrm{~cm}$ Rollenabstand gesunken war. Dies erfolgte am zwanzigsten bis z weiundzw anzigsten Tage. Damn wurde auch hier der ganze feriphere stumpf entfernt. Alle diese Nervenstiicke wurlen der Länge

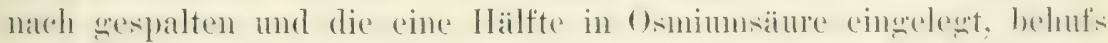
Intersuchung der Narksoheden nud der Fibrillen, die andre Ilälfte in Alkohol fixiert, um sie anf Fibrillensiture zu untersuchen. Die Unterschiede waren sehr eklatant: Im linken Nervenende (das am dreizehnten Tage heransgenommen war) bemerkte ich nur eine Spur

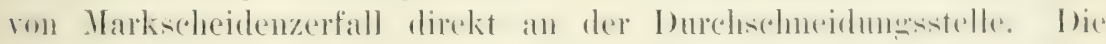
primäre Färbbarkeit ging bis dicht an diese heran. In rechten Nerv

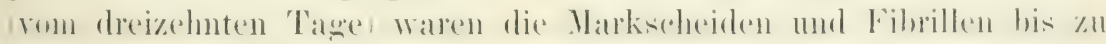

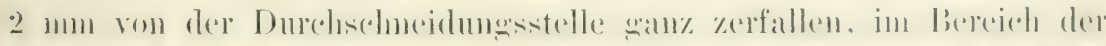

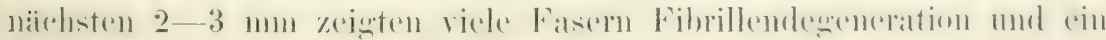
'I'eil anch Markscheidenzerfall. Auf dieser ganzen Strecke fehlte natiolich auch die primäre Farbbarkeit; auBerdem fehlte sie noch $2 \mathrm{~mm}$ weiter abwäts in den meisten Fasern und war im periphereren 'l'eil fast iberall viel schwïcher (heller) als normal und im obersten Ende des linken Nerven. Bei dem T'eil des linken Nerven, der erst am

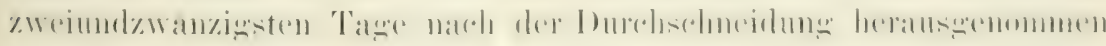
war, lag die zentrale Grenze der vollstandigen Degeneration und des

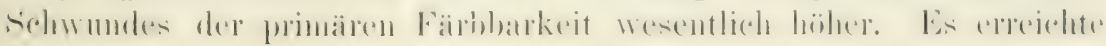




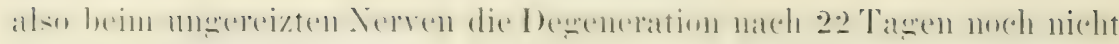
den Grad, den sie im gereizten Nerren nach 13 Tagen erreichte. -

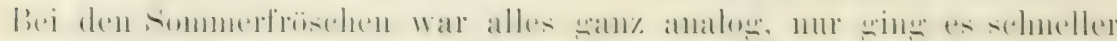
und die Degeneration des gereizten Nerren war noch ausgedehnter.

Beim täglich nach der Durehsehneidung gereizen Froschneren erliseht also die Eregbareit um mehr als ein Drittel frilher als beim geichbehandelten aber nichtgereizten Nerven; die Fibrillensäureverehwindet friber und die Degeneration verlat ft schneller.

Ich bin mir dessen vollständig bewußt, daß der elektrische Reiz den natiulichen wohl kam ersetzen kann, aber er ist derjenige, den man noch am ebesten benutzen darf. Da num der Vorgang im Yerven

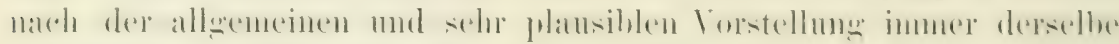
ist, gleichgiltig durch welche Art von Reiz el veranlaßt wird, so kamu man auf Grund dieser Versuche jedenfalls sagen, daß es der Mangel an Aktivitit nicht sein kamn, der die Nervenfasern zur Degeneration bringt. ${ }^{1}$ ) Die Aktivität fehlt ja nun zwar nach der Durchschneidung des Nerven nur in den motorischen Fasern, wie Goldscheider (1894) mit Recht hervorgehoben hat, aber es kömnte jemand sagen mol Lemhosite $[1595]$ lat dies in der Tat wetam, es

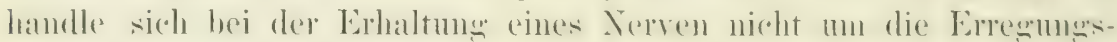
wellen, welche von der Peripherie kommen, sondern nur um solche

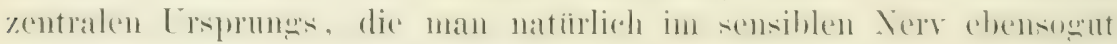
annehmen kann, wie im motorischen.

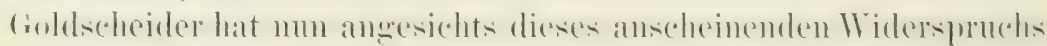

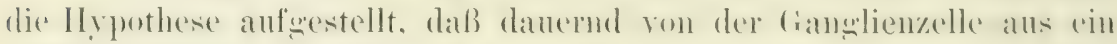

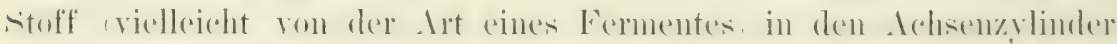

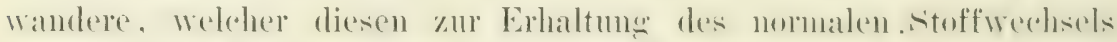

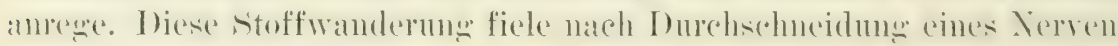
fort und deswegen degeneriere er. Lenhossék [siehe oben] setzt an

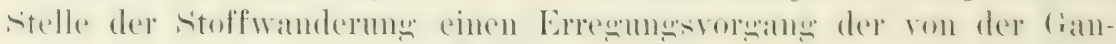

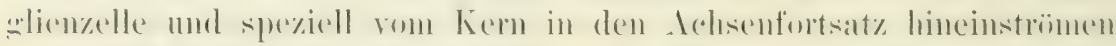

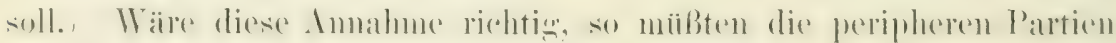
cines durchsehnittenen Nerven zuerst degenerieren, weil man doch

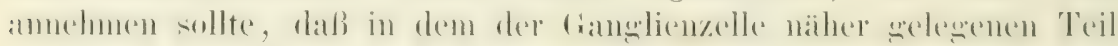
der Faser mehr von dieser Substanz vorhanden sei. Andrerseits wäe es auch schwer zu verstehen, warum bei dauernder Erregung des

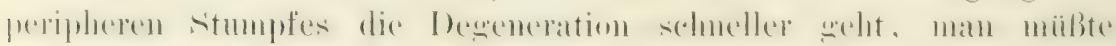

1) Wem atuch die Degeneration durch Faradisation des peripheren Stumpfes heschleunigt wird, so schadet es doch sicher nichts, wemn man nach wie vor bei Fïllen von Nervemaht elektrisiert. Zugrumele geht der periphere Stumpf zuniehst doch. Die Elektrisierung soll ja auch nicht den Nerven erhalten, sondern die Muskehn. 


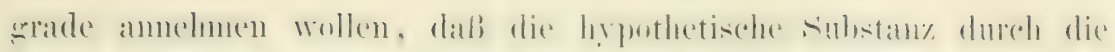
Erregungswellen nach der Peripherie him befördert wiirde. ${ }^{1}$ )

Wie ich oben beschrieben habe, geht die Degeneration bei Kontinuitätstrennmg von der Verletzung aus nach beiden Seiten. Von

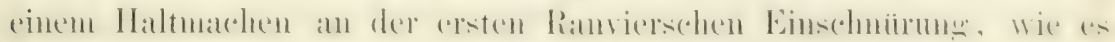
von Engelmann rertreten wurle, ist im allgemeinen nichts zu be-

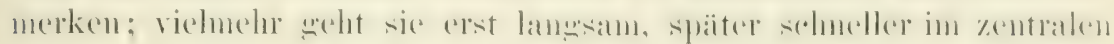
wie im peripheren Abschnitt olme sichtbare Haltepunkte von Faser-

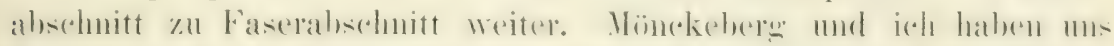

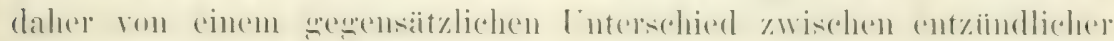
oder trammatischer Degeneration (welche nu das rerletyte Faser-

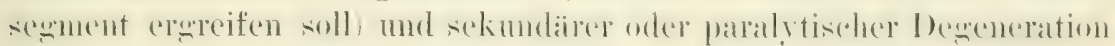
(die nur im periphereu Stumpf und hier iberall gleichzeitig in Er-

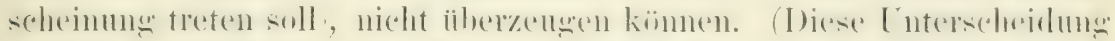

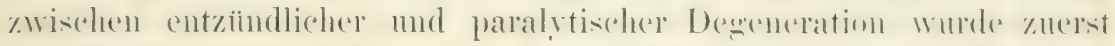

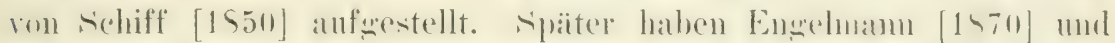
andre versucht, sie nnter dem Namen trammatische und sekundäre

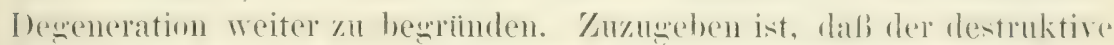

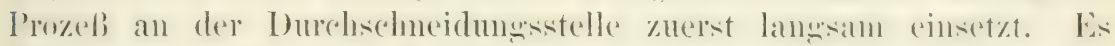

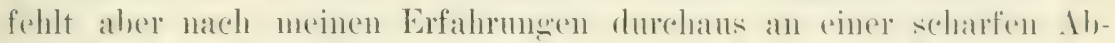
grenzung am nächsten Schniuring.)

Ich bin auf Grund meiner Versuche, besonders auch derer, welche an autogen regenerierten Vervenstïcken angestellt sind siehe Kaphitel 12,

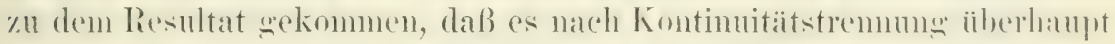
nur eine Art von Degeneration gibt und zwar nu u t a um a t is che. Die Schädigung', welche dureh das 'Trauma gesetzt wird, stört das

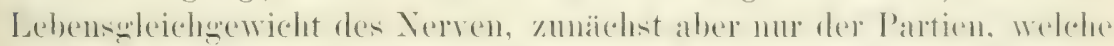

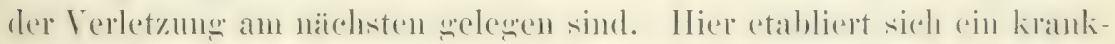
liafter, degenerativer Prozeß, welcher sich von 'Teilchen zu 'T'eilehen fortsetat, grade so, wie etwa eine Entzïndung rom P’unkt der ersten

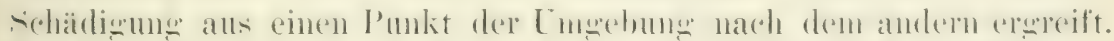
Nach der Peripherie zu pflanzt sich der krankhafte Prozeß bis ans Ende fort, nach dem Zentrum zu macht er frither oder spaiter lialt;

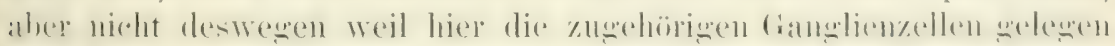

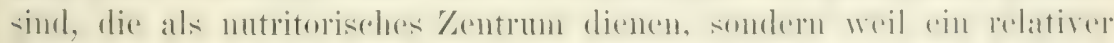

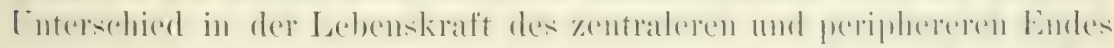
existiert, den man als eine Art ron Polarisation autfassen kann. Der

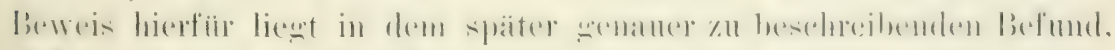

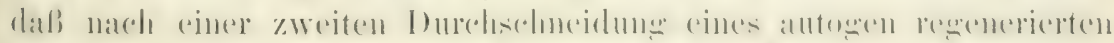

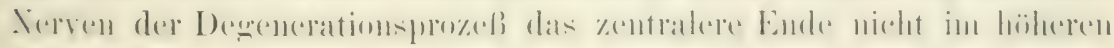

1) Diesen Einwïnden kömnte man dureh die gezwungene Annahme begegnen, daß die hypothetische Substanz nicht von der Zelle in den Achsenzylinder hineindiffundiere, sondern von den periphersten Enden aus hineingesogren wïrde. 


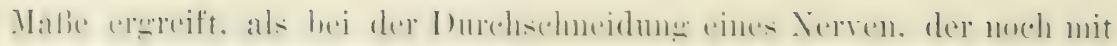

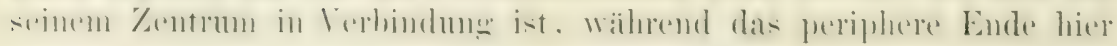
chenso einem vollstandigen Zerfall anheimfällt wie sonst.

Wemn diese Ansicht richtig ist, daß nur die Schadigung die

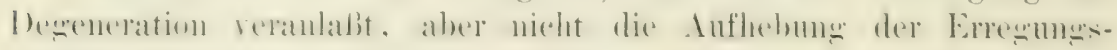
leitung (Paralyse) oder des nervösen Zusammenhanges mit dem Zentrum iiberhaupt, dann mu bei lokalen Sehädigungen des Nerven, welehe die Leitung noch nieht unterbrechen, eine Degeneration eintreten können und bei Leitungunterbrechunen, welche den Nerven nur wenign schädigen, die Degeneration ausbleiben oder l a ng an er eintreten. Beides lïbt sich zeigen:

Bei starker Kompression eines Nerren, wie sie grewöhnlich zu

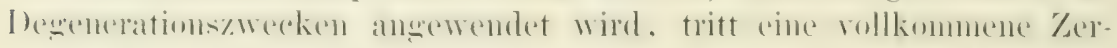
störung der Achsenzylinder ein und das obere und untere Ende des

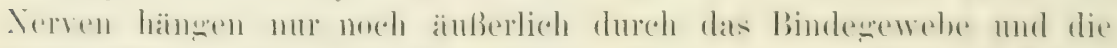

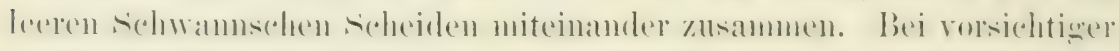

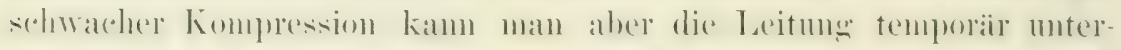
brechen; sie kehrt zurick, wenn die Kompression aufgehoben wird siche Kappitel 14. Dabei bleiben die Fibrillen intakt und nur die Mark-

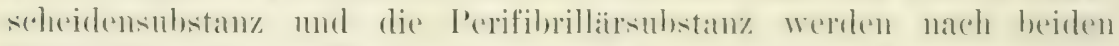

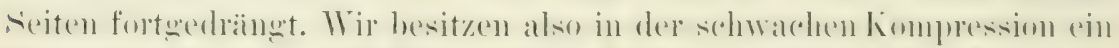

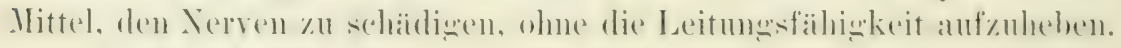

Um die Kompression in der richtigen Abstufung am lebenden 'T'ier vornehmen zu können, wurde folgender Apparat benutzt: Ein Elfenbeinstabchen, wie es in Figur 64 abgebildet ist, wurde mit der Rinne nach menten mit einer Klammer an einem Stativ befestigt. L̈bel dem Stäbchen war eine Rolle befestigt, eine zweite in derselben Höhe und Lage etwa 15 cm davon seitwails. Über die Rollen war ein Faden gelegt, an dessen einem Ende eine Schale fiir Gewichte hing, an dessen anderm, iiber dem Stäbchen befind-

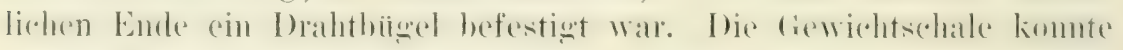
wie in Figur 64 unterstiitzt werden. Unter dem Stabehen stand ein nach unten und oben bewegliches Tischehen. Auf diesem wurde cin Frosch befestigt, der Ischiadicus unter Schonung der Gefäße freigelegt und ein Seidenfaden unter ihm hindurchgezogen. Die

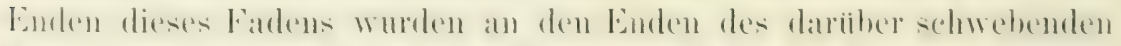

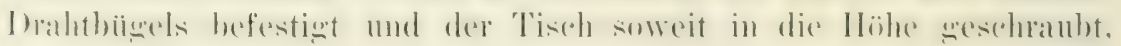
daß der Ischiadiens in die Rime des Stäbehens zu liegen kam.

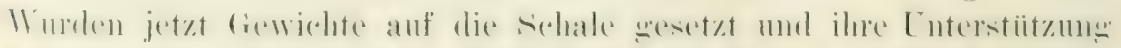

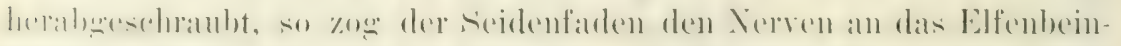

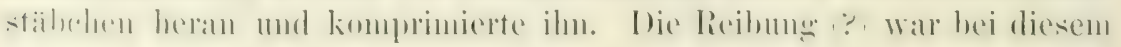
Apparat geringer als bei dem weiter unten beschriebenen, so daß 
schon Gewichte von 16-24 gen genïgten, um den Nerven bei einel Einwirkungsdauer von 30-60" undurehgängig zu machen.

Ich ließ das Gewicht stets eine Minute einwirken. Danach wurde

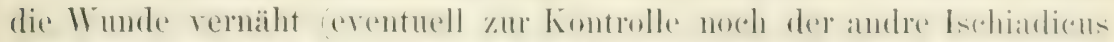

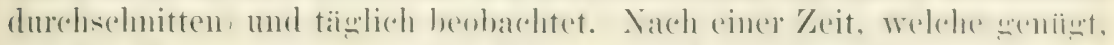

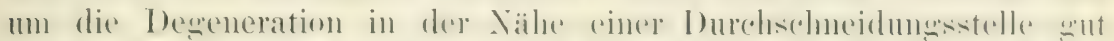

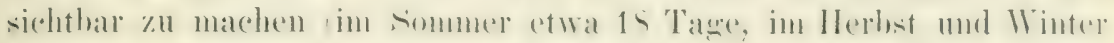
etwa 25 'Tage), wurden die 'l'iere getötet und die Nerven untersucht.

Es stellte sich num heraus, daß bei Kompressionsstärken, welche

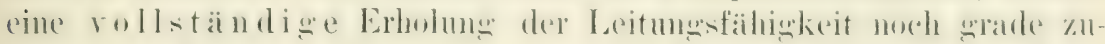

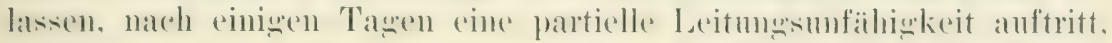
welche von einer teilweisen Itexeneration der Nelvenfasern des Nerven begleitet ist. Ist die Kompression etwas stärker, so daß keine voll. stäindige Erholung eintritt, so wird der Nerv nach einigen Tagen

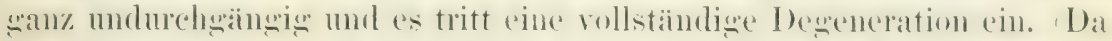
die kompresion nicht iberall im Nerven die sleiche stärke erepeht. so ist es nicht zu rerwundern, daß die Degeneration manche Fasern

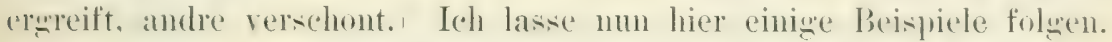

Frosch 1. (Die beschriebenen Frösche stammen alle von einer swöberen serie. sie wurlen an steichen Tage, 22. septenter 1902, operiert und am gleichen 'Tage, 17. Oktober, getötet.) Kompression mit 21 w : Erregharkeit oberhalb der Operationstelle wor mol nach der Kompression bei 21 cur Rollenalstand. Nach dem Nähen zoist sich die Rezeptionsfähigkeit und die Motilitait herabyesetzt, jedoch sind beide überall vorhanden. In den nächsten Tagen blieb das Bild dasselbe. Tom sechsten 'Tage an nahm die Motilität mul Rezentionsfähigkeit immer mehr ab. Nach zehn 'Tasen war keine Motilitiit mehr in den immerverten Muskeln zu hemerken, die Rezeptionstahigkeit war

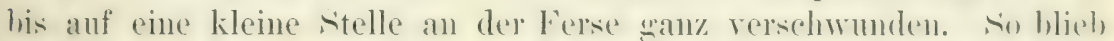

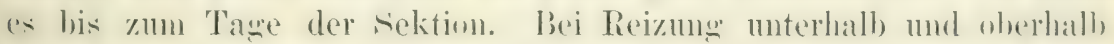

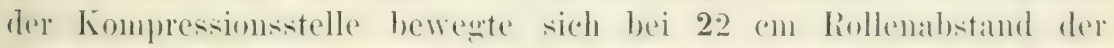
Gastronemins unch spurweise, alle andern Muskeh blichen in Ruhe.

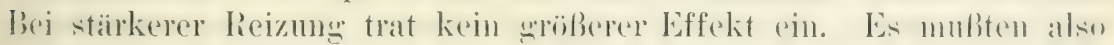
anch noch einige wenige motorische Fasern erlualten sein. - Nach

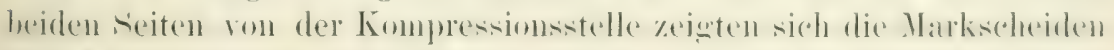

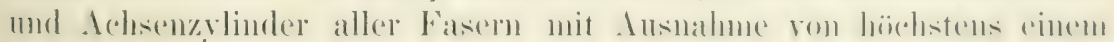
Dutzend auf eine Strecke von etwa $2 \mathrm{~mm}$ ganz zerfallen (Fig. $49 C$ ).

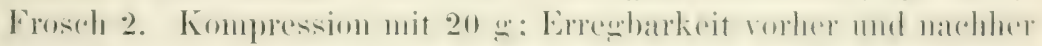
bei etwa $20 \mathrm{~cm}$. Nach der Operation ga nz normal. Lißit sich $\mathrm{Ab}_{\text {- }}$ duktion des Beines nicht gefallen. Nach zwei 'Tagen ist die Re-

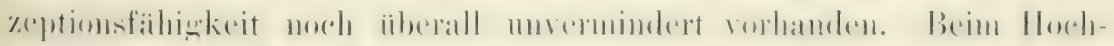
heben und Sitzen werden beide Beine grleich angezogren, doch ist die Mittelzehe des reehten (operierten Beines) manchual etwas $\mathbf{m}$ - 
ereschlagen. Tom sechsten bis zwölften Tage nimmt die Rezeptionsfähigkeit und Motilitait schmell ab. Am zwölften Tag ist die Re-

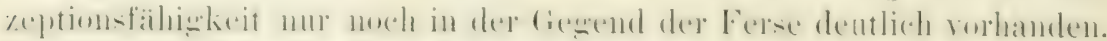
Das rechte Bein zeigt beim Sprung fast nur noch Bewegung im Obersehenkel; beim Sitzen wird der Unterschenkel nicht mehr angezogen, die Zehen sind gekrimmt. Beim Aufhängen hängt der Linterschenkel sehlaff herab. Der FuB wird bei Reiz an der Ferse noch unvollkommen bewegt, die Zehen gar nicht mehr. In den

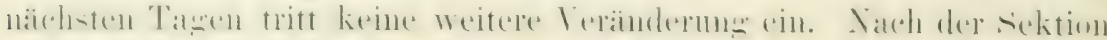

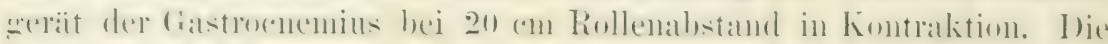

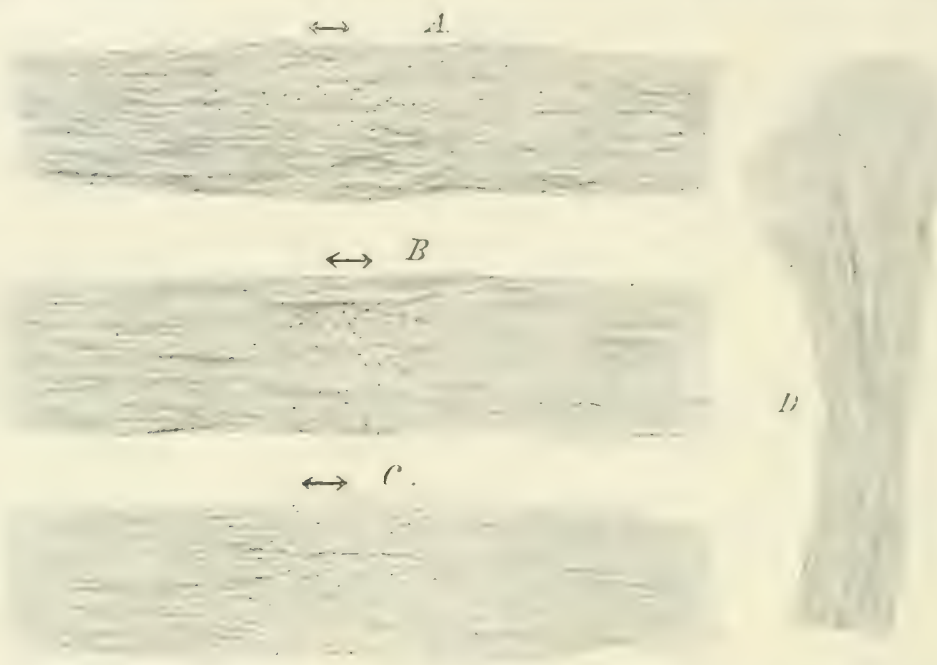

Fig. 49. Jegeneration Ton Froschnerven, welche $(A-C)$ unter Anmendung geringer Gemichte an iler mit Pfeilen bezeichneten Stelle komprimiert waren oder welche $(D)$ durchschnitten waren. Die Zeit ron der Operation bis zur Sektion betrug überall 25 Tage. Die Degeneration (Zerfall der Markscheiden, welcher durch Punktreihen angedeutet ist) ist noch auf die näichste Umgebung der Sehädigungsstelle beschränkt. Das zentrale Ende liegt auf der linken Seite. Niheres im 'Text. Vergrößerung $25 \mathrm{mal}$.

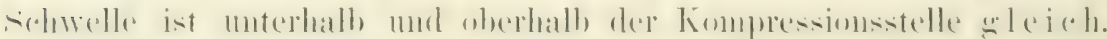
Die Strecker zeigen fast keine Reaktion (beim Reiz rom Nerven aus),

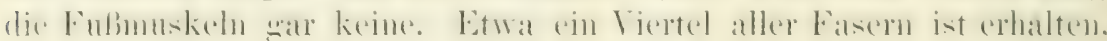
die iubrigen sind in Degeneration (Fig. $49 \mathrm{~B}$ ).

Frosch 3. Kompression mit $16 \mathrm{~g}$. Bis zur Sektion zeigen sich

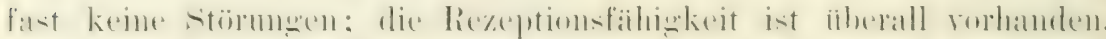
sprung und Haltung des Beines bis zuletyt fast ganz normal. Bei der Sektion zeigt sich volle Lrregbarkeit aller Muskeln rom Nerren ans. Trotzdem zeigen sich an der Kompressionsstelle etwa ein Viertel aller Fasern degeneriert (Fig. $49 A$ ). Lis kann also eine nicht unbedentende Zahl von Nervenfasern degeneriert sein, ohme dab sich 


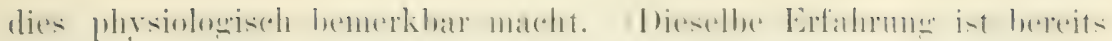
mehrfach ron Nemropathologen gemacht worden.)

AuBer den drei beschriebenen Fröschen habe ich noch eine Anzahl andrer hergestellt, welche sich zwischen diese drei einreihen wirden, auf deren Beschreibung ich aber verzichten kam. An andern

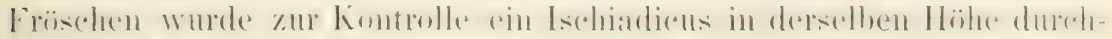

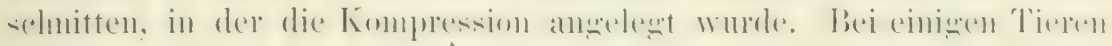
wurde auch auf der einen Seite komprimiert, auf der andern durch-

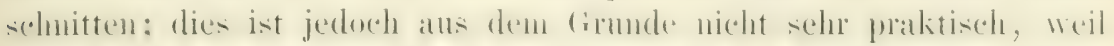

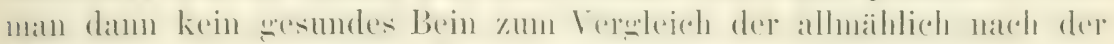

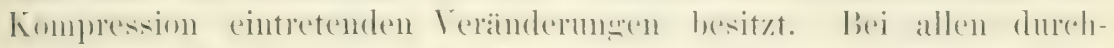

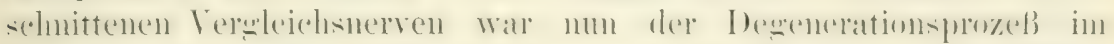

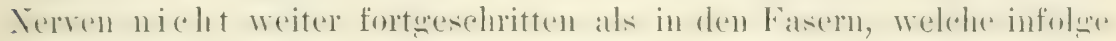
der Kompression in Degeneration rerfallen waren! (Fig. 52 D).

Am lehreichsten sind Frösche wie der unter 2 beschriebene.

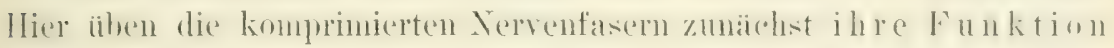
ganz wie bei einem normalen Tier ans, mit der Zeit tritt aber eine Funk tionsstörung (Leitungsunterbrechung) e in,

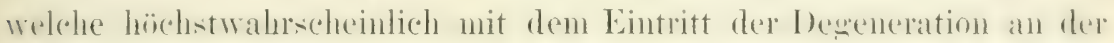

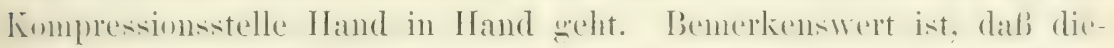
jenigen Fasern, welche der Deseneration nicht anheinfallen, hei der

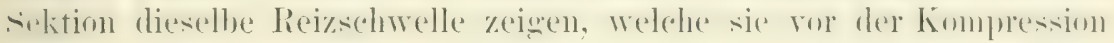
besaßen. Da außerdem die Menge der deg'enerierenden Fasern abhängig ist ron der Stärke der Kompression, da entzindliche Verinderumgen an der Kompressionsstelle fehlen und der Degenerationsproze $\beta$ ebenso schnell einsetzt wie nach Durchschneidung;, so wird man die Degeneration nicht als sekundäre

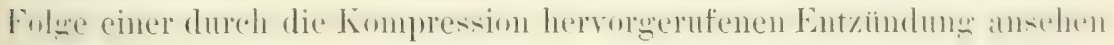
können. Man wird vielmehl anmehmen müissen, da $B$ die mä $B \mathrm{igge}$

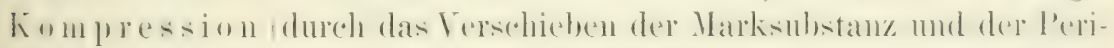
fibrillärubstanz) eine lokale Schäidigng der Nerrenfaseru (resp. der sie zusammensetzenden Zellen) beding t, welche z wa r z $u$ ä chst noch die physiologische Tätigkeit (Leitung zulïßt, mit der Zeit aber trotz der erhaltenen Leitum $\mathrm{g}^{\circ}$ fähigkeit zur Degeneratiou führt. Ich riehe also ans diesen Versuchen den Schluß, daß bei der Nervend urehschueidung nicht die Unterblechung der Leitung oder des Zusammenhanges nit den Ganglienzellen die Degeneration be-

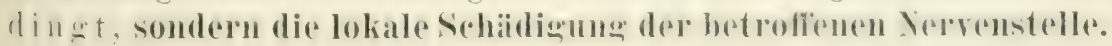

Man hat auf die verschiedenste Weise Nerven geschädigt, doch hat man bisher nach allen Verfahren und immer nach der greichen Zeit die Degeneration eintreten sehen. In allgemeinen fehlen zwar 


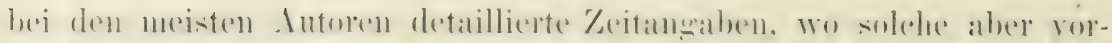

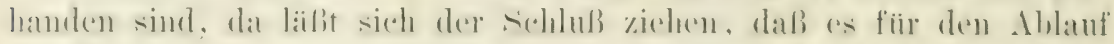

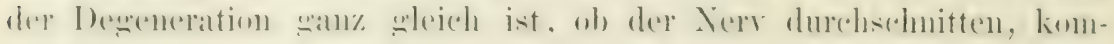
primiert oder veritzt wird. Ich selber habe meine Aufmerksamkeit anf diesen P'unkt gerichtet gehabt, weil es mir darauf ankan, eine

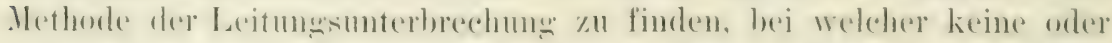

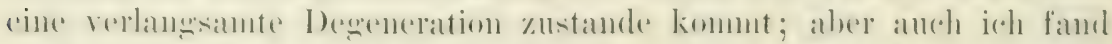

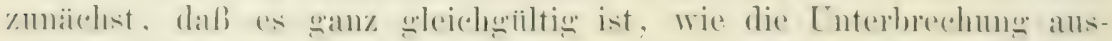

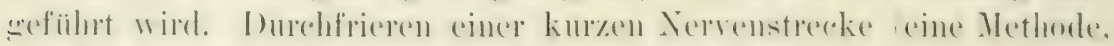

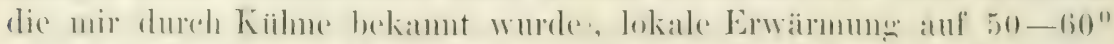

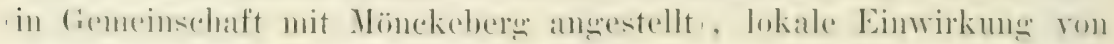
säuren u. s. w. - alle diese Unterbrechumgsarten brachten nach der

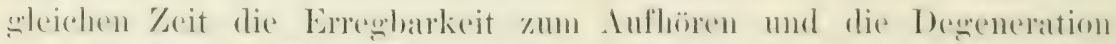

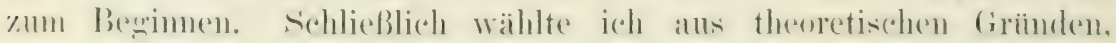

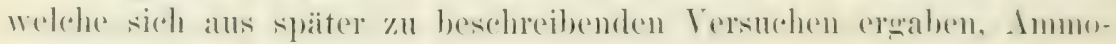
niakdämpfe - und diese führten zum Ziel! Die Zahl meiner Tersuche ist allerdings noch sehr klein - ich hatte keine Zeit längere

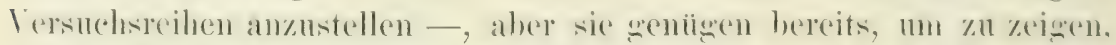

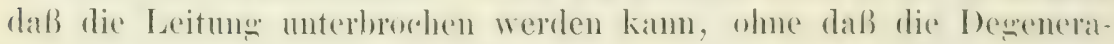
tion nach derselben Zeit eintritt, wie nach stärkeren Verletzungen (Durchschneidung, Kompression, Verbriihung' u. s. w.).

Es wurde ein Stïck Bambusrohr (1 cm dick) und ein Stïck Glas-

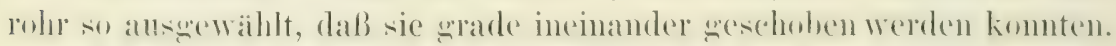
In das Bambuscohr wurden an Quersehnitt zwei sich gegentiberliegende

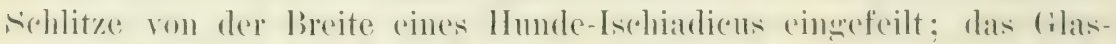

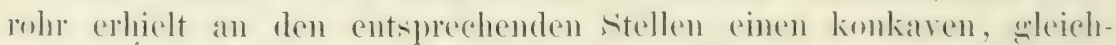
breiten schliff. Inf die freien Enden wurde je ein fimmoischlanch

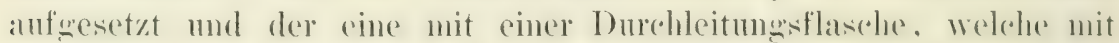

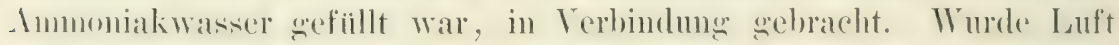
in die Flasche geblasen, so strömte natiolich mit Ammoniak geschwängerte Luft durels die aus den beiden inemander westoditen

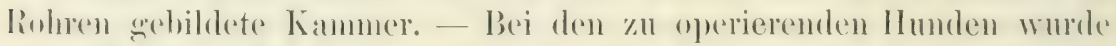

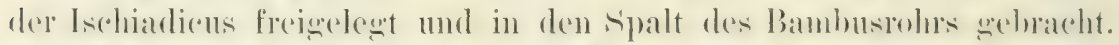

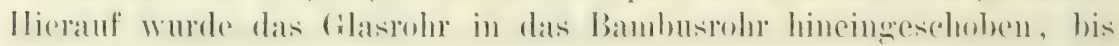
es dem Nerven gut anlag, ohme ihn zu quetschen. Der Versehluß ist

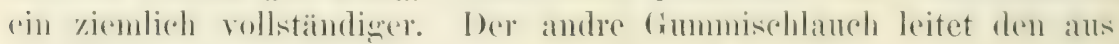
der Kammer ausströmenden Ammoniakdampf ab.

Ich bestimmte num zuerst den Rollenabstand eines Induktions-

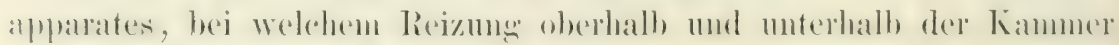

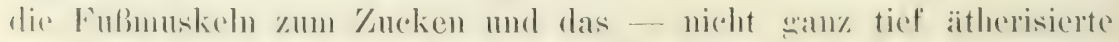

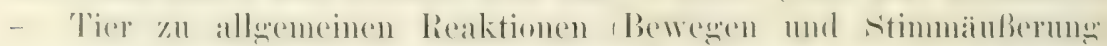

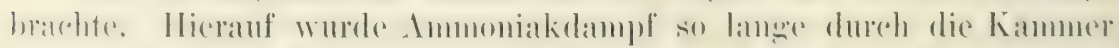

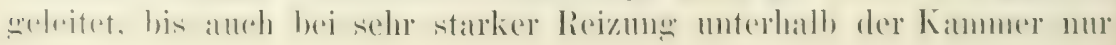




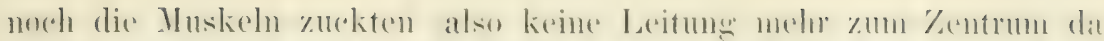
war) und bei Reiz oberhalb der Kammer nur noch allgeneine Reak-

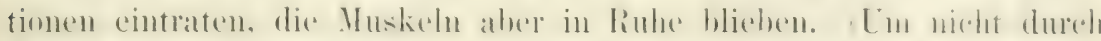

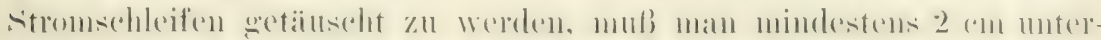

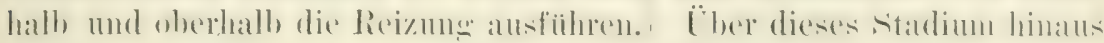
soll man nicht die Ammoniakeinwirkung fortsetzen; anch soll man nie zu starke Ammoniakdämpte anvenden.

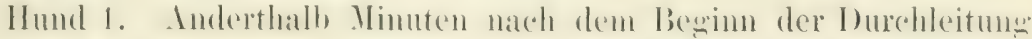

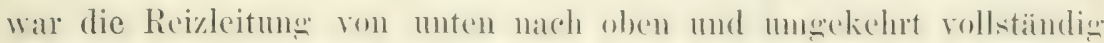

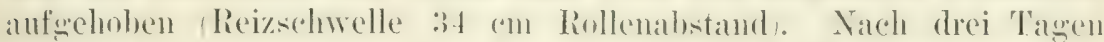

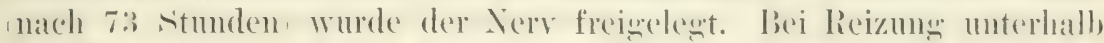
der Einwirkungsistelle zurokten die Muskeln des Fubes nund der (rastroenemins bei einem Rollemalstand vom ?2) (om. Inch bei lieizune mit maximalen strömen (5 com mol wenioner blieb es nur hierbei. Das Tier reagierte nicht. Auch oherhalh der Eimwirkmesstella mulite ich cinen Rollenabstand ron 18-20 cm anwenden, um ïberhaupt eine Reaktion zu erhalten; diese beschränkte sich aber auch bei stärksten strimen anf allgemeine Bewegnugen und stimmänberung. Ineh nicht die geringste Bewesung in den Muskeln des Lutersohenkels trat ein. Die Einwirkmngstelle des Ammoniaks war also noch absolut undurchwaing fö fü die Leitung; trotzdem war die periphere strecke noch wnt erreghar. Nach Inrchschneidung des Nerven und wleicher Wartezeit pflegt der Nerv beim Hunde bereits völlig unerregloar zul sein. Hörhstens zeight sich noch weit peripher sehwache Erregharkeit. In der Nähe der Durehschneidungsstelle fundet man stets auf eine sitrecke von mehreren Centimetern Fibrillen und Markscheidenzerfall. Bei diesem Ammoniaknerv wa a $\mathrm{r}^{\circ}$ ch nicht eine Spul vou Degeneration nach 73 stunden zu bemerken. Alle Fasern hatten bis an die Einwirknnesstelle und anch in dersellen primäne

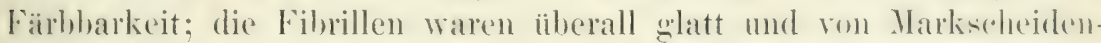

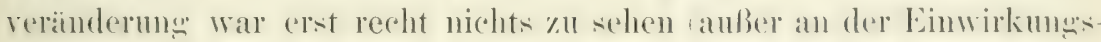
stelle, wo das Nark, wie man sagt, gerommen aussah).

Hund 2. Rechts und links Ischiadicus bis zur. Undurchlassigkeit

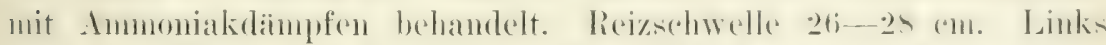

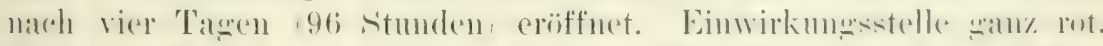

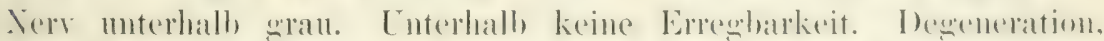
wie nach Durehschneidung. Offenbar hatte hiel das Ammoniak zu lange eingewiokt. - Rechts am z wölfte 1 Tage nach der Amuroniak-

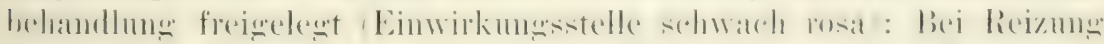

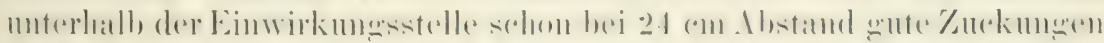

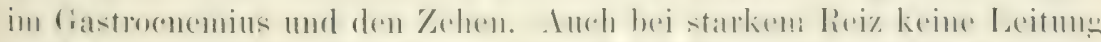

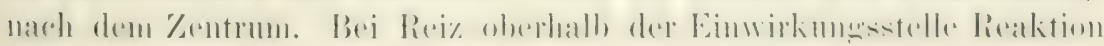
des ganzen 'lieres von $24 \mathrm{~cm}$ an. Bei ganz starken Reiz (10 cm Rollen- 
abstand) zucken auch die Zehen, a ber 11 ie der Gastrocnemins. (Rei\%stelle 3 em iiber der Einwirkungsstelle.) Von oben nach unten schien

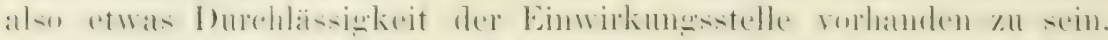
aber nur fïr einen 'l'eil der Fasern. - Befund: So weit die

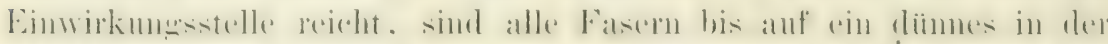

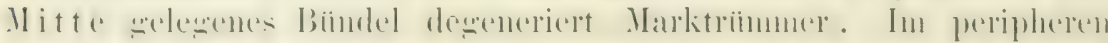
T'eil des Nerven finden sich mindestens dreimal soriel Fasern mit erhaltenen Markeheiden und Fibrillen, daneben ene

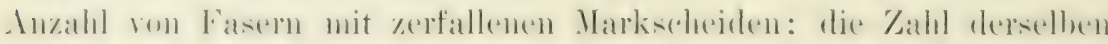
nimmt nach der, weiteren Peripherie zu immer mehr ab. Primäle Fäbbarkeit in rielen Fasern bis zur Einwirkungstelle vorhanden. Sicherlieh waren hier also eime Menge Fasern vorhanden, welche zwölf 'Tage lang rom Zen†rum neloös getrennt waren, ohne degeneriertzusein.

Hund 3. Rechts und links Ammoniakeinwirkung bis zur Undurchbissinkeit. Rechts wurde dam der Nerv einen Zentimeter oberhall, der Einwirkmosstelle durchschnitten. Rechts nud links nach vier Tagen freigelest 97 Stunden nach der Operations. Rechter Verr moterhalh der Einwirkmesstelle merreghar, aber noch von weiben Ansiehen, wahrend der kure stmmpf oberhall, der Einwirkungsistelle

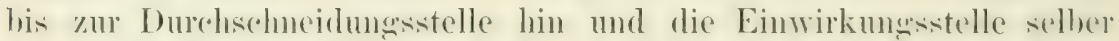
gelblichgrau waren. - Links Zuckungen der Muskeln bei Reiz mit 2:3 cm Rollenalstand, hanptsidchlich in den Zehen, weniwer in Gastrocnemius. Auch bei stäkster Reizung keine Durehgäing geit der Einwirkungstelle, weder von oben nach unten, noch von unten nach oben. - Befund rechts (wo der Nerv ander der Ammoniakwirkme anch durchschnitten war: In zentralen Ende coberhall) der Ammoniakemwirkme, De eneneration alle r

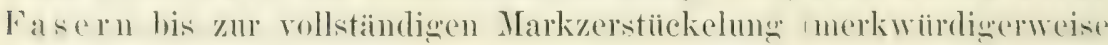
waren von dieser Iexeneration die allerzentralsten Enden der mosten Fasern ausonommen. Hier direkt an der Durehselmeidungsistella Waren die Markmhre besser erhalten. Die vollständioe I)eseneration sctzte sich noch ein stiock weit in die Finwirkmuseresend hinein fort: aber noch innerhalb dieser traten viele Fasern zu 'Tage, welehe ge-

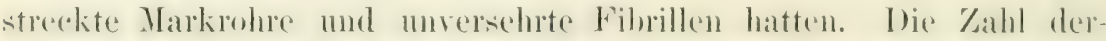

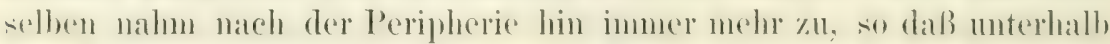
sler Finwirkmesstelle mol bis zur äuBersten Peripherie hin nur nods

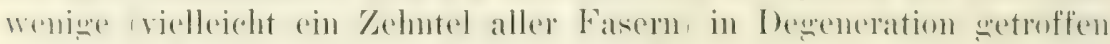
wurden. Alle andern waren im Auselien ganz normal.

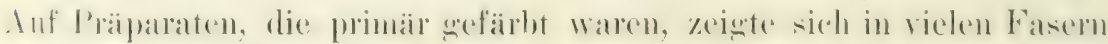

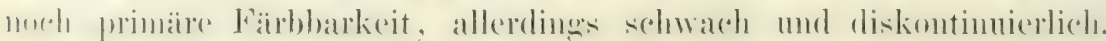
Dureh die Ammoniakeinwirkungar also sicherlich der degeneratire Prozeß, der von der Durehsehneidungs- 
stelle ausging, in den meisten Faseru kupiert worden, denn das Aufhören der Degeneration innerhalb der Einwirkungstelle wal ein ziemlieh sehroffes. Nach

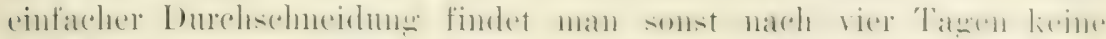

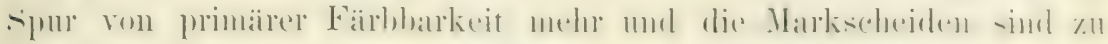
dieser Zeit bereits bis zur Peripherie hin in Ellipsoidbildung!

Befund im linken (nicht durchschnittenen) Nerven: In der Mitte

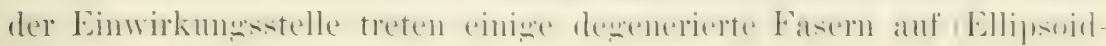

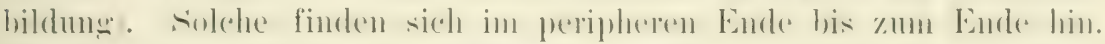
Ihre Zahl beträgt etwa ein Siebentel aller Fasern. Der Rest zeig t vollkommen erhaltene Markscheiden und Neurofibrillen. Primäre Färbbarkeit wurde in allen diesen Fasern gefunden, auch innerhalb der Einwirkungstelle.

Nach diesen Befunden mu zugegeben werden, daß die nervöse Leitung dureh riel längere Zeit hindureh unterbrochen sein kann, als zur vollkommenen Degeneration nach Totaldurchtrennung nötig ist. Es ist nicht die Leitungsunterbrechung, welche die Degeneration herrorruft. Ammoniak rerhindert fur lange Zeit die Leitung, ohne aber den Nerven so schwer zu schädigen, daß eine Degeneration eintritt. Es hindert auch den dewenerativen Prozeß, wem dieser sich von einer Kontinuitätstrennung aus fortsetzt. Bei zu starker Einwirkmon schädigt es aber den Terven so stark, dali die Deneneration sich normal entwickelt, wie nach Verletzmugen. Indrerseits ist bei schwächerer Einwirkmo die Leitumesmuterhechung nicht danemol. wie ans dem Befund an rechten Verren des Hundes No. 2 und speziall anf diesen l'unkt gerichteten Tersuchen lervorweht. Jedenfalls ist also die Degeneration nicht eine Folge der Aufhebung des funktionellen Zusammenhanges zwischen Faser und, nutritorischem" Zentrum. Vielmehr ist nach dem vorliegenden Tatsachenmaterial die lokale Schädigung des Ner. ren resp. der Zellen, aus denen er zusammengesetzt ist, also das 'Trama, als die einzige Ursache der mach Kontinuititstrennung t. s. W. eintretenden Degeneration anzusehen.

Bei toxischen Schädigungen, denen der Nerv in seinem ganzen Verla uf allswesetzt ist, scheint die Degeneration nach dem Tatsatehen-

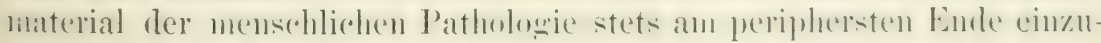
set\%en. Es wäre also dieses als punctum mininate resistentiar anzusehen.

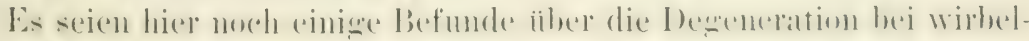
losen Tieren erwähnt: Bei Arthropoden treten nach Nervendurch-

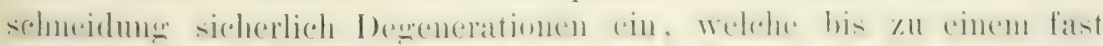

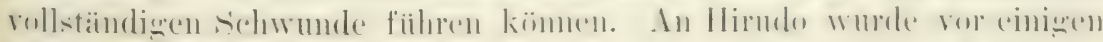

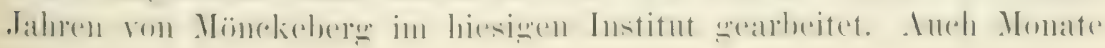




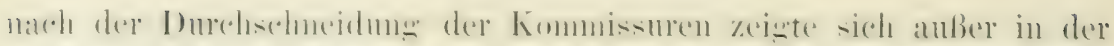

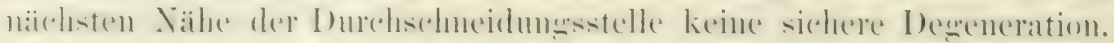

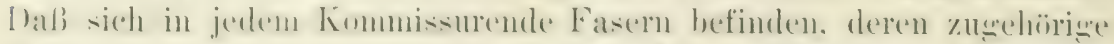

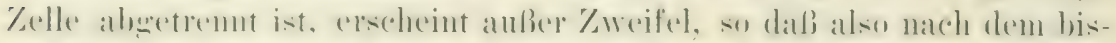

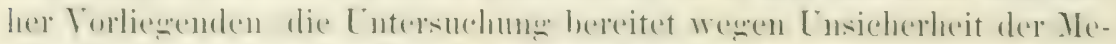

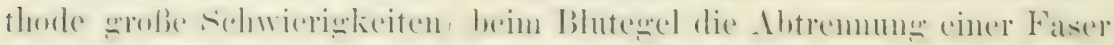

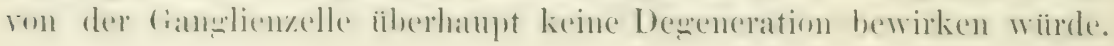

\section{ELF'JES KAPITEL.}

\section{Die retrograden Veränderungen der Ganglienzellen nach Verletzung der zugehörigen Nervenfasern und die chro- nische Degeneration der Nervenstümpfe.}

Nach dem Wallerschen Gesetz soll bei Verletzung einer Nervenfaser die Degeneration nu in collulifugaler Richtuns erfolgen: die [ris]rumstranglienzelle und der an ihr verbleibende Faserstumpt sollen aber verschont bleiben. Der zweite Teil dieses Satzes wurde zuerst erschiottert, als Dickinson 1869, fand, daß längere \%eit nach Amputation eines Siliedes vom zentralen Nervenstumpt nur noch ein kleiner Rest vorhanden sei, in dem kamm noch Nervenfasern zu erkennen sind. Bald daranf wurde von Dickson die Enteleckmug g̈emateht, daß in Riickenmark von solehen Lenten, denen vor längerer Zeit ein cilied amputiert war, das Vorderhorn auf der betreffenden seite verkleinert mor die Zahl der motorischen Gamglienzellen in demselben verringert ist. Beide Befunde sind oftmals bestatigt, so von Hayem, Darksohewitsch und Redlich; aine hesonders eingehende Bearbeitung erfulır

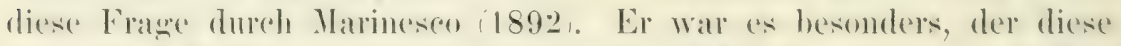

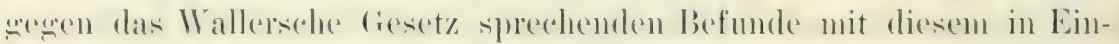

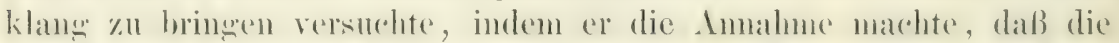

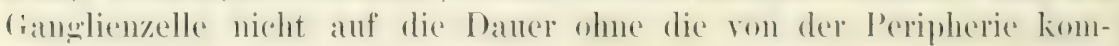
menden Erregungen existieren kömne; sie enthielte zwar das nutri-

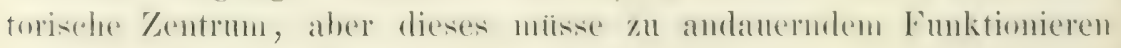
inmer von der Peripherie her angeregt werden.

Zu einem ähnlichen Resultat wie die Untersuchung Amputierter

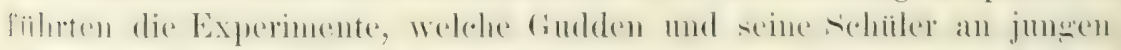

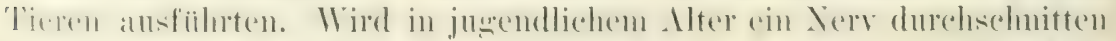

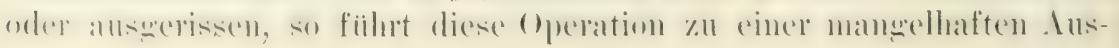




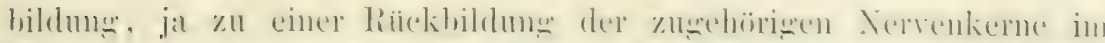

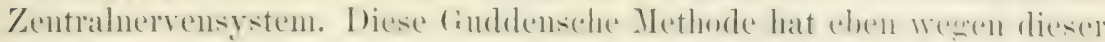

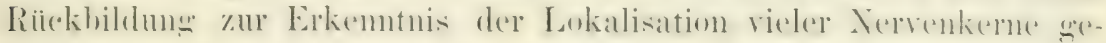
führt. Gudden selber neigte dazu, den Erfolg der Operationen auf

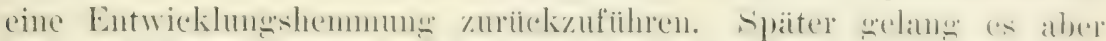

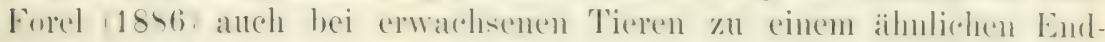

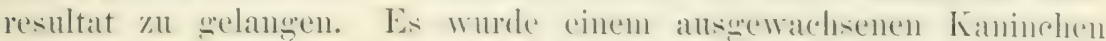
der Nervus facialis ansgerissen; nach 141 Tagen waren die Wurzelfasem des Jerven alle denenerient und die Gamplienzellen in Farbialis-

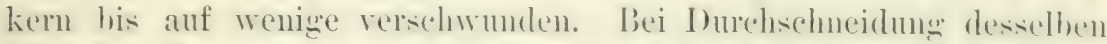
Verven wat chenfalls eine statie zentrale Deweneration rorhanden; sie hlieh aber hinter der nach Anseribung sefundenen erhehlich zuriek, worans Forel den sichluß zog, dali die Degeneration un so smöber sei,

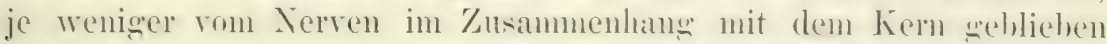
ist. Es zeigte sich durch diese Versuche, wie ja auch schon durch die Befunde an Amputierten, daf zentrale Teröindermen nach Vervenrerletzung nicht nur bei Nengelwrenen eintreten, dals es sich also auch bei der Guddenschen Methode wohl nicht nur um eine Entwicklungshemmung handelt.

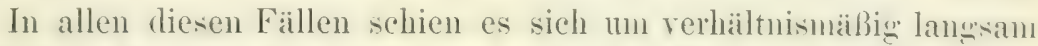
ahlanfende Prozesse zu handeln, welche das Wallersche Gesetz rom alleinigen Degenerieren des peripheren Faserahschnittes nicht allzustark erschiitterten. Demn in der Tat verläuft ja die Wallersche Deseneration inmerhalb weniger Tage, während es sich hei Anputierten in der Regel um Jahre, bei Forels Versuchen um Monate handelte. Man komnte diesen Tatsachen gegeniber zn Not nit der von Marineson aufortellen, ron coldscheider erweiterten Hypothese auskimmen, dab die Zellen und mit ihnen die zentralen Nervenstiunpfe ans Manger an peripheren ind zentralen, Reizen gewissermaßen an Inaktivitait zunlunde wingen. ${ }^{1}$ Diese Hypothese, welche die trophisele Funktion der (iancrienzellen aufrecht erhält, kamn aber gregreniber den lísultaten, welche Yissl i 1592), mit seiner Methode förderte, nicht stamblalten, demn mit dieser Nethode zeinen sich Veränderumgen an den L'rs]muns-

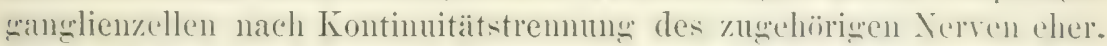

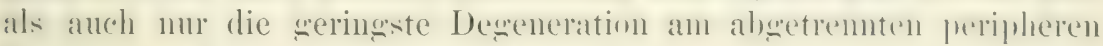
Nervenstumpf zur Beobachtung kommt.

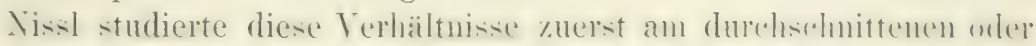

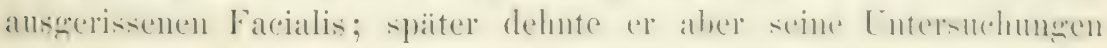

1) Hierher gehört auch die Ilypothese ron Lenhossék, daß die motorisehen Zellen wegen der Unmöglichkeit der licizabgalye zugrunde gingren, die sensiblen aber, weil ihnen keine Reize zugehen. Das scheint mir doch ein sehr uneinheitliches Erkliirungsprinzip! 
iiber das ganze Nervensystem ans und zeigte, daß eine regressive

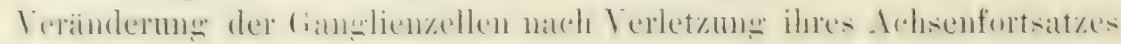
von allgemeiner Gesetzlichkeit sei. So wurde diese Methode der

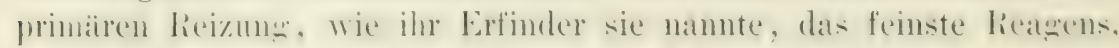

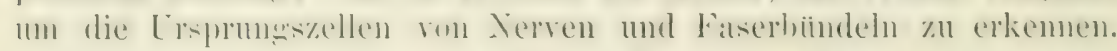

Schon $24 \mathrm{Stunden} \mathrm{nach} \mathrm{der} \mathrm{Nervenverletzung} \mathrm{zeigen}$ sich die ersten Veränderungen an den Ganglienzellen in einem cireumseripten Zerfall der fäbbaren Substanzportionen. Dieser Zerfall der fäbbaren Substanz dehnt sich in den nächsten Tagen ïber den ganzen

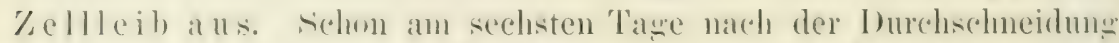
des Xerven ist die prinäbe Farbharkeit der vehollen fast wanz verloren

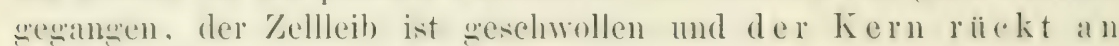
die Peripherie (Fig. 50). Im weiteren Verlauf kann der Kern

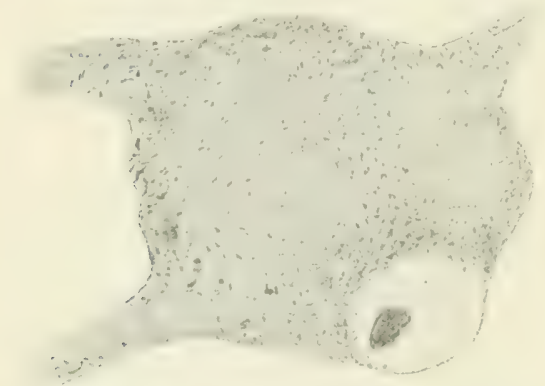

Fig. 50. Ganglienzellveräinderung nach Durchschneidung des zugebörigen Neuriten. (Chromatolyse und Wandständigkeit des Kerns.) ganz verloren gehen und der Zellleibzerfallen. Nicht in allen Zellen (des Facialiskerns) geht der Prozeß gleich schnell; auch führt er nur in einem Teil zum vollkommenen Zelluntergang. Am achtzehnten Tage ist der Prozeß auf höchster Höhe; etwa ein Drittel aller Zellen ist zugrunde gegangen, alle andern zeigen Schwund der fürbbaren Substanz und Kernverlagerung. Von nun an tritt, auch wenin keine Verheilung der Nervenenden eingetreten ist, eine Restitution der erhalten gebliebenen Zellen ein: Der Kem riìdkt wieder in die Mitte, der Zellleil, nimmt wieder normalere (iestalt an und es biddet sich wieder färbbare Suldstany in der normalen Anordnunk. ${ }^{1}$

1) Was die Neurofibrillen während dieser regressiven Zellveränderung anbetrifft, so liegen mir nur die Resultate, welche an einem Kaninchen is 'Tage nach Durchschmeidung des Facialis gewomnen wurden, vor. (Der Block wurde mir von Herrn Nissl giitigst zur Verfïgung gestellt. Ich hatte eine weitere Bearbeitung der Frage vor, komte sie aber bisher nicht zur Austiilurung bringen.) Danach fehlen in den Zellen, die noch erhalten sind, die Fibrillen jedenfalls nicht. Ihre Zahl scheint aber verringert und in manchen Fortsiitzen scheinen sie ganz. zu fehlen. Am auffallendsten ist, daß sie nicht mehr zu Bündeln angeordnet sind, sondern ziemlich wirr und gleichförmig die Zellen durchziehen. An Schnitten, die mit Molybdänhïmatoxylin gefärbt waren, zeigte sich der Zellkörper ganz blaf, woraus hervorzugehen scheint, daß nicht nur die färbbare Substanz in den Zellen verloren gegangen ist, sondern auch das Stroma, an dem die färbbare Sulsstanz haftet. 
Diese wichtigen Versuche sind vielfach wiederholt und an Tier-

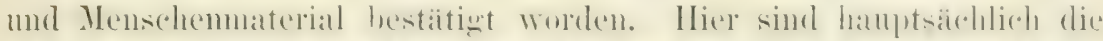

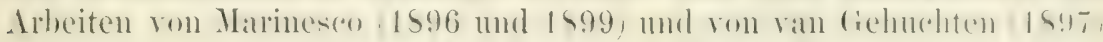

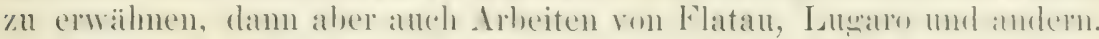

Nach den Befunden von Marinesco steht die Sehwere der retro-

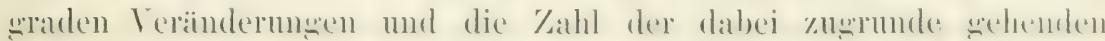
Zellen in einem bestimmenten Verhältnis zur Länge des alogetrenuten Nerven. Bei den Nervenkernen der Medulla, deren Nerven relativ kurz sind, ist die Schädigung sehwerer als bei den Kernen des liiekemmarks mit seinen relatir viel längeren Nerven; andrerseits ist in ein und demselben Xervenkern die Verainderung stärker, wemn der Nerv dicht am Ursprung abgetrennt wird, als wemn er weit an der Peripherie geschädigt ist. Kommt es zu einer Verheilung der Nervenstümpfe, so soll die Zahl der gleich zugrunde gehenden Zellen weringer sein, als wemn die Verheilung ver\%ïgert oder verhindert wird.

Eine Restitution der Zellen, welche nicht znyrumde gegangen sind, tritt immer ein, gleichwiltig ob eine Terheilung der Nervenstümpfe zustande komme oder nicht; darin stimme'n Marineseo und van (rehuchten Nissl vollkommen bei. Die Restitution hleibt nur ans, wenn sleich alle Zellen oder die meisten zugrunde gehen, was manchual rorkommt, besonders bei Ausreißung des Nerven.) Bleibt eine Vereinigung der stïmpfe dauernd ans oder wird sie dureh Imputation eines filiedes ganz. ummöglich gemacht, so fangen die Zellen in Lauf ron Monaten nach der Operation an allmählich zu atrophieren unrl eine nach der andern ganz von der Bildfläche zu verschwinden Marinescoi. Die Zellen würden also hei rerhinderter Vereinigun." folgende Veränderungen durchmachen: 1. Retrograde Zellmetamorphuse in ummittelbaren Anschluß an die Nervenverletzung cetwa vom ersten lis zum achtzehnten Tage danernd; dahei weht ein Teil der Zellen ganz zugrunde, Nissl. 2. Zellrestitution oder Zellerholung, hei weleher die Zellen wieder ein nahezt normales Aussehen bekommen (vom achtzelnten Tage bis etwa zum Ende des dritten Monats Nis-s. 3. Zellatrophie im Lanf der nïchsten Monate umd Jahre Marinesen. lsei den starken Zellschwund, der in Riickemuark alt Imputierter stefunden wird, hat man es also wohl nicht mit dem Endresultalt dee

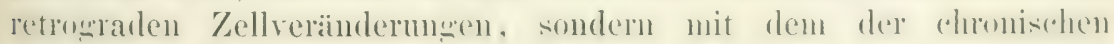
Atrophie zu tun.

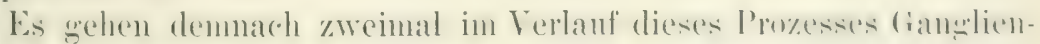

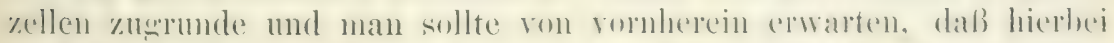

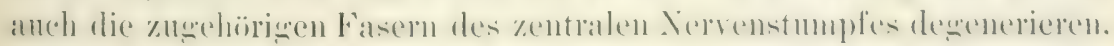
und zwar, da jetzt die Schädigung am zentralen Ende der Nervenfaser liegt, von hier ansgehend. Bei dem langsamen und all-

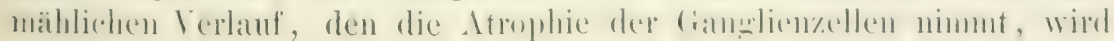




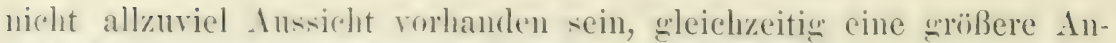
zalll dewenerierender Fasern hei dieser zu finden; die meisten werden 'ntweder bei der Entersurhung sehon bis zu Ende deneneriert sein uder noch nicht mit der I)osenelation besomen haben. So hat man

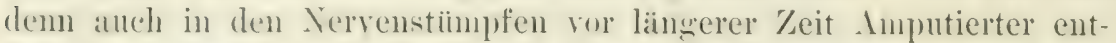
weder normale Fasern neben vielen degencrierten aber fast keine (legenerierenden) oder nur degenerierte gefunden.

Giinstiger liegen die Verhälnisse bei den retrogralen Zellverände-

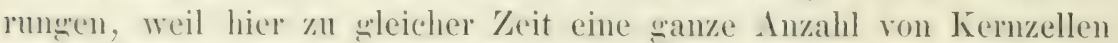

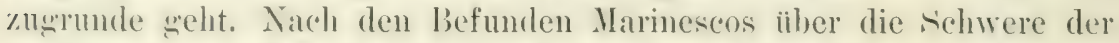
Zellaffektion 1113 auch hier das Resultat ein selu verschiedenes sein, je nachdem man Rückenmarksnerven oder Kopfnerven untersucht. In der 'Tat habe ich auch nach Inurehschmeidung des Ischiadiens bei Hunden und Kaninchen, welche ich an 20. bis 30. Tas nach der D)uchschuridung untersuchte, immer nur selı wenige frisch degenerierte Fasern anfinden kïnnen. Die cellulipetale Deweneration in zentralen stumpf, welche in direkten Anschluß an die Durchselneidung anftritt, ist zu dieser Zeit längst alogelanfen. Man findet nur noch Marktrimmer. Es treten aber mu diese Zeit inmer einige nene dengenerierende Fascrn (also frische Ellipsoidbildumb) auf, aher höelıstens in cinem Zwanzisstel aller Fasern. Der Rest behält mestreckte Markrohre nud primäre Färbbarkeit, trotzdem die \%ellverändermeg in diesen Augenblick auf dem Höhepunkt ist.

Inders ist es bei lopfnerven, besonders wemn sie kur amputiert oder ansgerissen sind, wie dies aus einer Arbeit von Bregmann (1592, hervorweht. Bregmann riß Kaninchen verschiedene Kopfuerven, besouders häufiær den Facialis, aus. 20 'Tase nach der Operation besamn die Inegeneration der Wurelfasem und zwar, wenigstens beim Facialis, inmer in der Nähe des Lrsprungskems, wie zu erwarten war. Von hier aus breitete sich der Prozeß nach der Peripherie zu aus. Am 5. 'Tag' sollen alle Wurzelfasern zerfallen sein, was sich allerdings wohl auf Marchipraiparaten nicht mit Sicherheit beuteilen läßt. Jedenfalls handelt es sich hier wohl un solche Fälle, wo die intensive śrobidigung, die das Ausreißen mit sich briugt, die Mehraalıl aller \%ellen zum primären Verfall geebracht hat frrade wie in dem Fall von Forel und einigen von Marineseo und van fiehuchteni. Auffallend

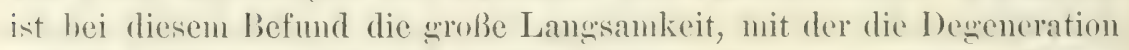
verlief. Während die cellulipetale Deweneration in wenigen Tagen herendet ist, zieht sich diese absteigende - oder besser gresast -,

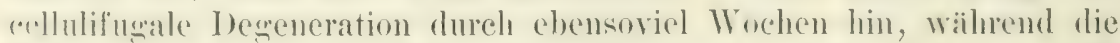

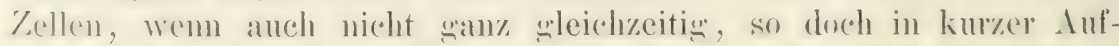

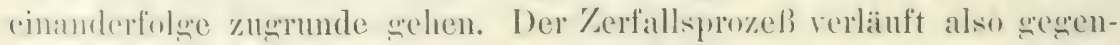
iiber dent akuten, der in direkten Anschlub an das Tramma einsetzt, 
ganz chronisch. Man könnte sagen: die śchädignum, Welche durch den wirklichen und natiulichen Ansfall des sogenamten trophischen Zentrums gesetzt wird, ist geringer als die von einem 'Tramma hervorgebrachte, daher erfolgt die I)eneneration anch schleppender (siche auch die Ammoniakversuche Ich hin aber in Tersuchumg, diese chronische Deweneration der Nervenfasern auf das Konto wirklicher Inaktivitait -- ein Wort, das wegen seiner vielfachen, mißhriachlichen Anwendun etwas in Mißkredit geraten ist - zu setzen, denn der degenerative Fortfall des trophischen Zentrums sollte nach meiner Meinume eine ehenso schnelle Degeneration des Nerven nach sich ziehen, wie seme operative Ansschaltumg. Folgende Befunde werden, wie mir scheint. diese Erklärung stiitzen können: 1. Überläßt nan einen antogen regrenerierten Nerven, der also war nicht mehr mit Ganglienzellen in Verbindung steht (siehe näichstes Kapitel, sich selber, so geht zunäichst die Leitungs - und Erregungäahigkeit wieder verloren und nun tritt eine sehr langsane durch Monate sich hinziehende chronische Degeneration ein, bei der angenscheinlich - so sagt man immer, wemn man keine bindenden Beweise hat - auch in der einzelnen Faser der degenerative Prozeß sich durch lange Zeit hinzicht. Sicher scheint mir. daß anch hier die chronische Degeneration am zentralen Ende beginnt, dem ich fand hier immer mehr in Zerfall begriffene Fasern als an der Peripherie. 2. Zwei jumgen Hunden durchschnitt ich zu andern Zwecken - ich komme später darauf zuriick - einen Nervus opticus in der Orbita. Beide wurden nach etwas weniger als elf Momaten retötet. In beiden Fällen fand sich die Retina vollkomm en entartet: nur noch ein bindegewehiges Häutchen war ïbrig gehliehen; ron Ganglienzellen war auch keine Andeutung mehr rorhanden. In beiden Fällen aber enthielt der Opticus eine sehr große Anzahl von mornaleu Nervenfasern, die sicherlich nicht neusebildet waren, sondern die alten Opticusfasern repräsentierten, dem es fehlte ihnen der für autochthom rewenerierte Fasem charakteristische Protoplasmahof. In dem einen fanden sich einige degenerierende Fasern durch die wanze Längre des Stumptes, hesonders aber in der Nähe der ehemaligen lietina. im andern waren nur einigge Ellipsoide an eben dieser stelle zu benerken. Ich slaube ammehmen zu diufen, daß die Lrspumescellen der meisten Opticusfasern, die Zellen der Fanglienzellschicht, seit .Hniten zu-

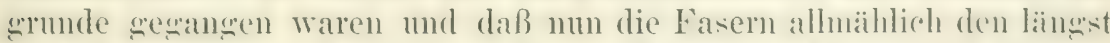

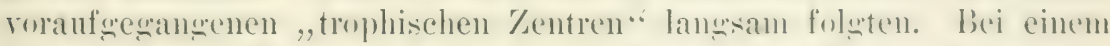

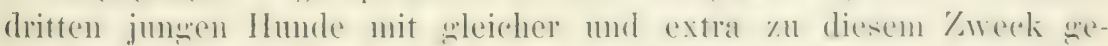

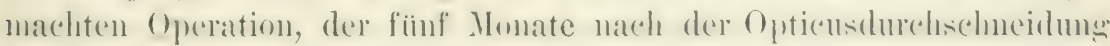

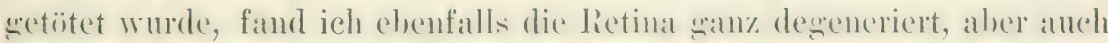

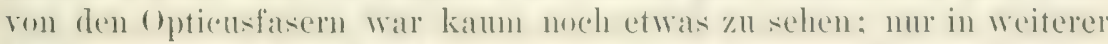

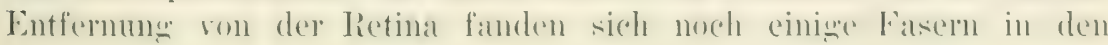


letzten stadien der Markscheidendeseneration. Sio dürfign diese Inwaben leider sind, su kïmnen sie doch wohl zu den Nachweis heitrasen, dall die Fasern hei der chronischen Degeneration von dem

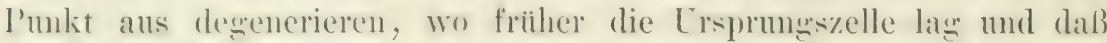
die Fasern iln ..trophisches Zentrum" wesentlich iilserdanern können.

\section{ZWÖLFTES KAPITEL.}

\section{Die Zusammenheilung durchschnittener Nerven und die Nervenregeneration.}

Historisehes S. 182-187. - Was kann der periphere vom Zentrum abgetrennte Nervenstumpf aus sich selber heraus an Regeneration leisten? S. 187-212. Methode der Untersuchung S. 189, 190. - Regeneration der peripheren Stïmpfe

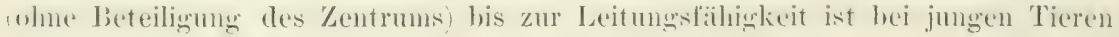
leicht zu konstatieren S. 190-195. - Eine zweite Durehsehneidung eines so (antugens) regenerierten Nerven fïlurt nur in peripheren Alschnitt zu ciner zweiten Degeneration; der zentralere Abschnitt bleibt intakt S. 195-197. - Die Leitungsfähigkeit der autoregenerierten Nerven geht nach einiger Zeit unter Verlust der primären Färbbarkeit der Neurofibrillen verloren. Daran schließt sich eine sehr langsame, chronische Degeneration S. 197. - Auch Nerven, welche noch nicht oder nicht mehr leitungsfähig sind, degenerieren bei einer zweiten Durchschneidung S. 198. - Autogene Regeneration an isolierten Nervenstiicken S. 195, 199. - Beschreibung der verschiedenen Stadien bei der Autoregeneration S. 199-205. - Bei alten Tieren treten an sich selbst überlassenen Nervenstümpfen nur die Anfänge der Autoregeneration auf S. 205-207. - Einfluß des zentralen Endes auf die Regeneration bei Zusammenheilung beider Stümpfe S. 20s. - Regenteration der Ilinterstrangfasern nach Fortnahme der spinalganglien s. 2on-210. - Autoregenerierte Nerven können anatomisch und funktionell zusammenwachsen S. 212. - Wird ein Nervendefekt nur vom zentralen Ende her iiberbruckt? S. 212-215. - Die Nervenfasern besitzen eine Wachstumspolaritait S. 217-224. Reflexartige Erscheinungen an autoregenerierten Nerven S. 224-227. - Neurotropismus S. 231, 232.

1776 machte Cruikshank die zufällige Entdeckmug, daß die Enden (ines durolschnittenen Nerven sich nach einien Wochen wieder ver-

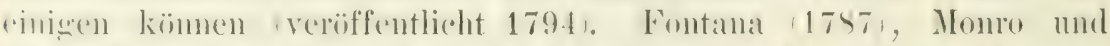

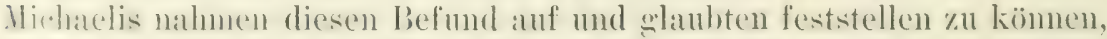
dali es sich un eine Überbriakmug des Defoktes durch wirkliche

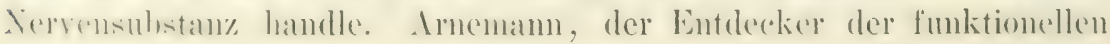


Degeneration, trat den entwegren 1757. In einer answerlelnten Versuchspeihe kumte er zwar hestatignen, daf die Nervenenden sich wieder rereiniwen, aher er fand anch nach mehr als zwei Monaten idie andern Antoren hatten schon nach wenigen Worhen ihre rektionen sentacht, die Verwachsungsstelle fuir Reize undurehgaingign und lomute in der Narbe nur Zellgewebe nachweisen. Heute wissen wir, daß die Wartezeit viel zu kurz war.

Die Mögliehkeit der funktionellen Wiederberstellung (das Wiedererscheinen der Leitungsfähigkeit, wurle zuerst von Iaighton (1795) erwiesen und dureh J. C. II. Meyer 1797), Gruithuisen, Sömmering, Bichat, Magendie und andre bestätiont. - Auf die Möglichkeit der Verheilung und der funktionellen Wiederherstellumg legten die damaligen Autoren den Hauptwert; iiber die Art des Vorganges, die ja auch ohne praktisches Interesse ist, machte man sich war keine Torstellumgen und man komnte das auch gur nicht tun, weil die degenerative Teränderung des Nerven nach der Durchschneidung noch gar nicht bekannt war. Wenn in diesen älteren Arbeiten von Nervenrexeneration esprochen wird, so wird darunter etwas ganz andres rerstanden als heute. Man nahm eine Neubildung von Nervengewebe nur für die Ausfiillung des Defektes in Anspruch, also nur für die Wiederherstellung der Verbindung zwischen zentralen und peripherem stumpf. Nur in dieser Ausfüllumg besteht bei ihnen die Regeneration.

Die Regenerationsfrage im hentigen simne komte erst auftreten, nachdem Nasse 1839 gezeigt hatte, daß das wanze periphere Ende des durchschnittenen Nerven in seinen Elementen zugrunde geht. Wie werden diese Elemente wiedergebildet (regeneriert), wie und von wo der Defekt zwischen beiden Nervenstimpfen ausgefüllt? Das ist eine Frage, die his in die letzten Jahre hinein die Histologen lehhaft beschäftigt hat. Sie hat eine Flut von Arbeiten hervorgerufen, bei denen es sich eigentlich immer mur mo die Entscheidung zwischen zwei Mäglichkeiten handelt: Werden die nenen Fasern an Ort und stelle nengebildet oder warhsen sie vom zentralen stumpf ans? IEine dritte Mäglichkeit, daß der Achsenzylinder gar nicht zugrunde ginge und nur die Narkscheide neu gebildet wïrde, eine Ansicht, die hanptsäichlich ron Schiff vertreten wurde, ist in nenerer Zeit in Wegfall gekommen, seitrlem man sioh mit den verbesserten Methoden anfs deutlichste äher\%eng't hat, daß auch der Ichsenzylinder immer zerfällt.

Nasse war noch ganz unbefangen und konstatierte nu, daß die nengebildeten Fasern diumer seien als die alten. Giinther mud frohön

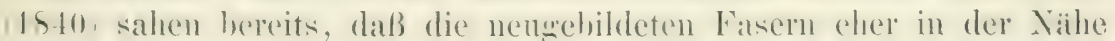

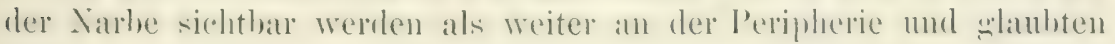
daher - allerding's mit Reserve - ammehmen zu diüfen, daß die Regeneration rom zentralen Ende ausginge. 
Der Kampf der Meinumen begann erst mit der Publikation der Wallerschen Arbeiten 1552\%. Nach diesen Autor sollte die Regeneration $1111 \mathrm{r}$ dadureh zustande kommen, daß die Fasern vom zentralen Ende d. h. ron der (ianglienzelle, ihıem nutritorischen Zentrum. in den peripheren stumpf hineinwüchsen. Es war eine grroßartige. cinheitliche Idee, die Waller in seinem Gesetz von der trophischen Funktion der (ianglienzelle niederlegte, wer aber seine Beschreibung rom Verlanf der Regeneration liest, der wird sich dem nicht verschlieben kïmnen, daß seine Dentungen, soweit sie sich anf die Regeneration beziehen, anf einem sehr dürfigen Beobachtungsmaterial fußen. Tatsächlich liegen die Verhältnisse auch so zweidentign, daß sie fiir sichiff und andre geniigend Anhaltspunkte boten, entgegengesetzte Ansichten zu vertreten. Nach Schiff komnte schon deswegen keine Rede ron einem zentralen Auswachsen der Fasern sein, weil der Achsenzylinder im peripheren stumpf überhaupt nicht zugrunde winge; demn er beobachtete - fünf und mehr Monate nach Iur.hschneidung des Nerven bei verhinderter Vereinizung der Stümpfe einen zentralen von einer nicht myelinhaltigen Sicheide ungebenen Achsialstrang in jeder Faser des peripheren Stumpfes. Da nun solche Nervenstümpfe nicht leiteten, gelangte er zu der Ansicht, daß dem Achsenzylinder die Leitungsfähykeit nach der Durehschneidung zusleich mit der Markseheide verloren sehe und daß bei zustande wekommener Verheilung die Leitungsfähigkeit unter dem Einfluß des Zentrums wiederkäme. Anch die Markscheide sollte sich nur unter dem Einfluß des Zentrums wieder bilden, aber loeo und nicht durch Answachsung vom Zentrum, denn er konnte sie einigemal unterhalh der Narbe eher beobachten als in derselben.

Den nächsten wesentlichen Fortschritt in der Regenerationsfrage sehe ich in der Entdeckmog Lents, daß sich nach der Nervendurehtrennung eine wesentliche Kernvermehrung einstellt. Sie wurde von IJjelt (1861) weiter verfolgt und er fand, daß diese Kernvermehrun von den Kernen der Schwannschen Scheide ausgehe. Er brachte anch bereits die Kernvermehrung mit der Bildung nener Fasem in 7, 1 sammenhang.

In Jahre 1559 traten Philipeaux und Vulpian nit Versuchsresultaten in die Öffentlichkeit, die mit allem, was danals bekannt war nud später sefunden ist, in offenbarem Widerspruch standen. Bei den Zeitgenosien erregten sie Zweifel, won der folgenden Generation wurden sie iiberhaupt kaum noch der Erwähnung für wert gehalten, und doch bedeuten sie den gröBten Fortschritt, der in der Rexenerationsfrage iblerhanpt gemacht werden komnte. Die beiden Forscher

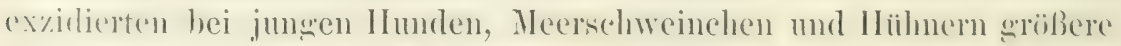
stiicke des Ischiadiens, Medianus, Mypoglosists onder Lingualis, so 
dak eine Zusammenwachsum vereitelt wurle. Wem sic nach cinigen Monaten die Nerven freilesten, so zeighten sie nicht das welke dussehen desenerierter Nerven, sondern waren wieder weils mul fest. Bei mechanischer oder elektrischer lieizme dieser peripheren Servenstimpfe erhielten sie 1 wem die Nerven motorischer Natum waren, Zuckungen in den imnervierten Muskeln, während das 'Tier selhel' nicht auf die Reizung reanierte. Lnter dem Miknsknp untersucht fanden sich in den Nerren cine swobe Anzahl richtiger Nervenfasern mit Markscheide mol Achsenzylinder; andre Fasem hatten noch ein anomales Ausselien. Wurde solch ein Nervenstumpf in seinem Terlauf zum zweitenual durchschnitten, so verfiel das periphere Ende ciner zweiten Degeneration, wähend das zentrale - nun isolierte Ende - intakt blieb. Daß es sich in diesen funktionstiichtigen Nerven nicht $u m$ undegeneriert wehliebene Fasern, sondern mu das I'rodukt einer a uto@̈enen Regeneration handelte, erschlosien sie daraus, dah bei Kontrolltieren wenige Tase nach der Durchschneidung wie bei Erwachsenen, [nerreghatkeit und vollkommene Deseneration eintrat. Sie zogen aus diesen Befunden den SchluB, daB bei jugendichen Individuen eine vollkommene, antogene Nervenregeneration möglich sei und daß aus diesem Grunde auch bei erwachsenen Tieren kein Auswachsen der nenen Fasem rom zentralen Ende anzunehmen sei.

Eine Bestaitigug fanden diese Versuche ron andrer sieite nicht. schiff machte nit negativem Resultat einige Tersuche an 'T'ieren ron fünf Monaten, sab aber zu, daß bei noch jüngeren Tieren vielleicht positive Resultate zu erzielen sein möchten. Alle andern Antoren hestritten die Möglichkeit einer antogenen Regeneration, welche bis

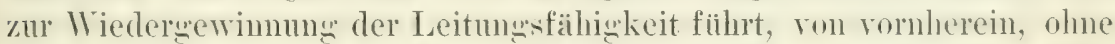
anch nur einen einzigen Versuch an jungen Tieren anzustellen. Non gerieten die Versuche in Verossenheit. 1874 kam Tulpian noch eimmal anf die Frage zurick. E machte neue Versuche an jumen Hunden, welche das Tatsächliche der alten Versuche durchaus hestatigten. Er dentete sie jetzt aber anders. Das ausschließliche Auftreten der zweiten Dexencration in peripheren Ende machte ihn stut\%i und fiilurte ilm zu der Inmahne, daß die nenen Fasern aus selur diimen.

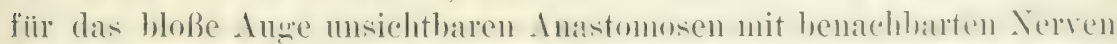

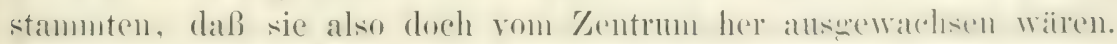

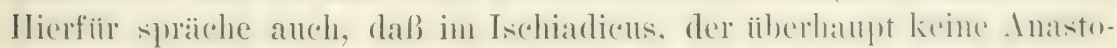

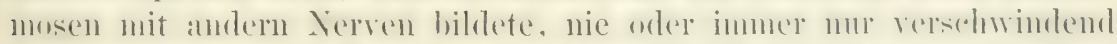

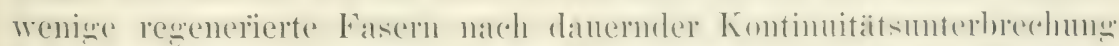

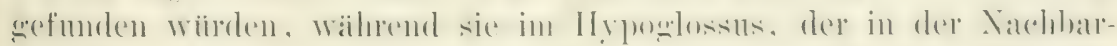
schaft vielel andrer Nerven verliuft, sehr zahlreich seien. Danach,

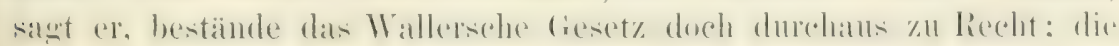




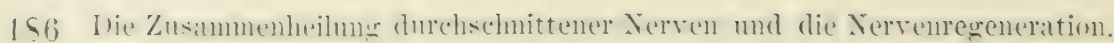

moturischen Fasern wïchsen rom Riuckemmark ans, die sensiblen

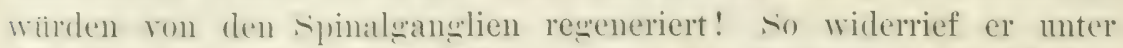

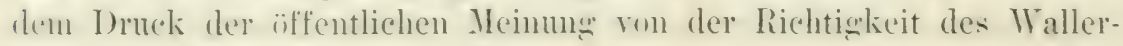
schen Gesetzes seine größte 'T'at.

Fast alle späteren Autoren machten den prinzipiellen, methodischen Fuhler, dals sie die Rerreneration an Nerven studierten, bei denen die Dexeneration durch Kompression oder eanfache Durchschneiduns nut haldiser Wiedervereinimung der stiunpfes hervorseloracht war. sie stellten war nicht erst fest, was der periplere stumpt olne lereinimung mit den /entrum aus sich selhst herans kann. - Die Hauptrertreter eines kontinuerlichen Auswardsens der neuen Fasern rom Zentrum aus waren Ranvier und Vanlair. Vou diexen faßte Ranvier die Vermehrune der Kerne nach der Durchschneidung als Lrsache der Degeneration auf, inden ihr wucherndes Protoplasma den Achsenzylinder zerstiickele; zur Regeneration stände sic in keiner bezichung. Eine diskontinuierliche Bildum der nenen Fasern wurle besonders ron dentscher seite behauptet, so von Koryhutt-I)askiewicz, Wolleres, Herz, Nemmam und andern. Nene Gesichtspunkte traten aber erst zutage, als es mit der Vervollkommmuma" der histolngischen Methoden gelang, den Achsenzylinder hesser darzustellen. Hier sind es besonders zwei Arbeiten, welche nene und

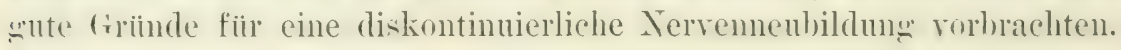
Sie stammen ron v. Büngner und von Howell und Huber.

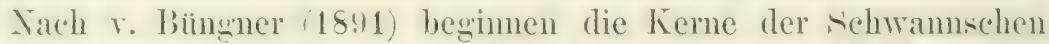
ścheide schon an vierten T'age nach der Nervenverletzun Ko Kompression mit ainem Faden oder Pferdehar oder partielle Durchschneidunges sich durch typische Mitose zu teilen. Das an ihnen liegende Protoplasma wrohert und bildet so spindelförmige Anschwellumgen, welche untereinander konfluieren und zur Bildune von Bandfasern führen. In diesen bildet sich in der Nähe der Kerne eine fibrilläre sitreifuns, ans. welche sich schlieblich durch das sanze band aushreitet. Die Kerne. welche anfangs in der Mitte der Fasern liegen, treten bei der weiteren I) ifferenzierun an die seite, so daß sie den nenen Fasern anliesen. Am zentraleren Ende des Nervenstumpfes zreht die Differenzierum der batmdiasern solmeller vor sich als weiter peripher, so dab man also in der Vähe der Verletzunsstelle stets weiterfortweschittenere Fasern

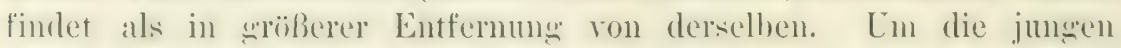
Fasem, die nit denen des zentralen Endes in Vephindung treten,

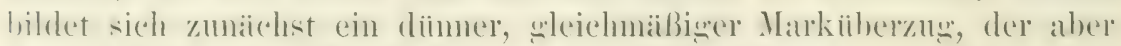
nirdet definitiv ist. Die definitive, viel dickere Markschedede bildet siceh

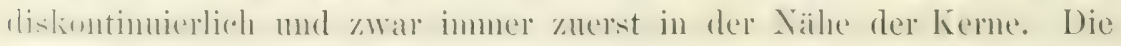
nenen Fasern werden also diskontinuierlich ans den Sehwannsehen Zellen gebildet, allerdiugs unter dem Einfluß des Zentrums. 
In den meisten P'unkten sehr ähnlich ist die lieschroibung, welche Howell und Huber (1892) von- der liegeneration geben: Sirhom an Anfang der Degeneration fangen die Kerne der šchwannschen ścheide an, sich durch Vitose zu teilen; ihr P'rotoplasma wollert und fliebt mit dem der benachbarten Kerne zu einem Bande zusammen. Auf diese Weise entstehen innerhall, der alten fichwamschen folleiden lange biander, welche reihenweise Kerne enthalten. In der Peripherie dieser Fasern bildet sich eine diinne sicheide, welche als spoutere schwamsche scheide angesehen wird. Zur Bildung solcher, emhryonaler Fasern" kommt es num auch damn, wenn die Vereinigung mit dem zentralen Stumpf verhindert wird; sie entwickeln sich dam aber nicht weiter; höchstens kommt es stellenweise zu einel Andeutumg von Myelin. Zu einer wirklichen Aushildung der Regeneration kommt es nu bei Zusammenheilumg des peripheren stmmpfes mit sen zentralen; anch die Bildung der embryonalen Fasern greht dam schmeller. Die Bildung (ler Markscheide soll (nach Verheilung) diskentinuierlich seschehen; die definitiven Achsenzylinder sollen aber rom zentralen stumpf in die embryonalen Fasern des peripheren Stmmpfes hineinwachsen, doch wird dies nicht mit sicherheit behamptet.

Gegen diese Antoren traten v. Nothafft und Ströbe (189:3 u. 1595) anf, welche, wohl nicht ganz unbeeinflußt rou Dogna der Neurontheorie, das Answaclisen der neuen Fasem vom zentralen Ende zu erweisen suchten. Besonders die Arbeiten Ntröbes sind reich an interessanten Details. Die Bandfasern bestätigt er, glaubt aber, daß sie mit den späiteren Achsenzylindern nichts zu tun hätten. Es seien eben nur Protoplasmawncherungen der Sobheidenkerne und diese seien nicht nerviser Natur / keine Neuroblasten, wie r. Büngner geneint, somdern Iindesewebskerne. v. Nothafft hat seine Ansicht suater etwas modifiziert und in vielen P’unkten zurïckgezonen. Eine vernittelnde stellumg, wenn auch durchaus nicht zu wunsten der Nenrontheoric, nimmt Ziegrler 1S!6, ein. Nach ihn soll die Regeneration alloin rom der letzten schwannschen Zelle des zentralen stumpfes ausuchen. Anker diesen Alpeiten ist noch die von Wieting $159 \mathrm{~S}$, weleher die

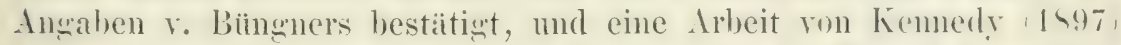
zu erwälnen, der eine autroene Reseneration an Nerven beobachet haben will, ron denen er aber nicht mit rollkommener sirherlest nachweisen kounte, daß sie wirklich ganz vom zentralen Stumpf unbeeinflußt waren.

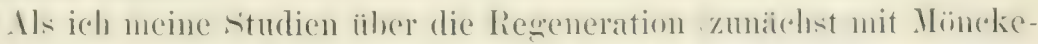

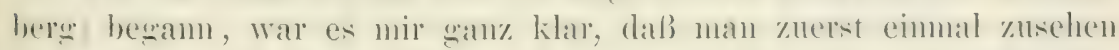
mïsse, was der vom Zentrum abgetrennte Nerv aus sich selbst heraus an Regeneration leisten kamn, wie dies ja, wenn anch nicht

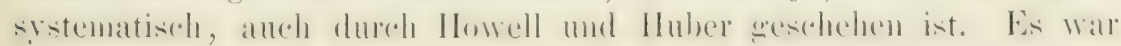


sehre sut mö̈lich, daßB die Wiederherstellung unter dem Einfluß des sugenamten Zentruns wesentlich sohneller winge als whe dasselbe, (n) daß die Verhailtnise immer molar bleilen müßten, wenn nan eine Einwirkmo des Zentrums, also eine Znsammenwarhsumg, zuliefe. Andrerseits war es wahrscheinlich, dab die besten Resultate bei jugendlichen Individuen z.n erwarten waren, demn es ist ja allwemein bekannt. daß junge Tiere rine wesentlich wrößere lexenerationskaft hesitzen als alte. Dals Philipeanx und Vulpian an solchen bereits pusition lesultate ergielt hatten, war mir damals noch unbekamnt, weil die Versuche fast nirgends erwilnt wurden. Der Gedanke, junge Tiere zur verwenden, war hei uns iibrigens nicht sanz primär, sondern entstand erst unter dem Einflub sines Befundes. Wrir hatten eine grobe Anzahl von Kaminchen operiert und warteten mit der Sektion so lange als mö̈lich in der Itoffnumg, daß sich nach langer Zeit auch im roll-

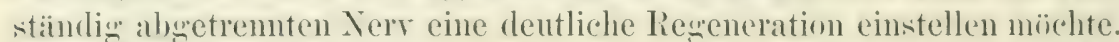
Die meisten Tiere statben uns nach etwa zwei Monaten infolge des unvermeidlichen Decubitus der FüBe, von dem ans, anch bei wuter Reinhaltumg, fast immer Infektionen entstehen. Das beste Tier erreichte ein Alter ron 100 Tagen, ein andres 86 Tage. Bei beiden wurde nichts weiter ron Regreneration gefunden als Bandfasern resp. Achsialstrangfasern. Bei einem andern Tier aber, das nur 56 Tatne nach der Operation lebte, zeigten sich die Fasem an vielen Stellen mit einer diumen, aber deutlichen Myelinscheide nmgeben: anch komnte an einimen stellen eine schwache fibrilläre streifung im Imeren der Fanern wahrenommen werden. Da dieses Kanmehen noch nicht ganz ansgewachsen war, während die andern iltere Tiere wewesen waren, sn machten wir die Jugend für das positive Resultat rerantwortlich und heschlossen, fortan nur noch junge Tiere zn operieren. Bei den mansgewachsenen Kaninchen zeigte sich nun die Mortalitait noch wröber als lei den erwachenen. Es gelang nur noch einen zweiten Fall mit Andeutung von Markscheide zu bekommen. - Nönckeherg mußte dann leider Straßhurro verlassen, und ich setzte die Versuche allein fort. Ia ich den Ischiardiens weren seiner leichten Zngänglichkeit nnd seines klaren, anastomosenlosen Verlaufs nicht als Versuchsnery aufgehen wollte, wandte ich mich der Gperation ron jungen IIunden zu, welche ja lrekamntermaken geeren alle Infektionen des täglichen Lebens viel widerstandsfähiger sind als Kaninchen. Ich habe hier nie einen 'Todesfall

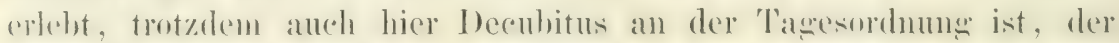

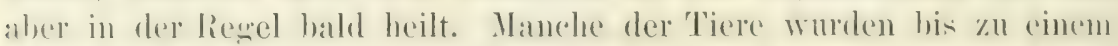
bahr ann Leben erhalten mol damn im besten fiesumdheitsustand pereschlachtet. Hier habe ich nun in der Tat eine ganze Anzalllvon Fiallen erhalten, in denen der ganzrom Zentrum getrennte Nerr nach einiger Zeit neugebildete Nerren- 
fasern in großer Zahl zeigte, Nervenfasern, die a uch die physiologischen Eigensehaften normaler Fasern hatten, nämlich leitungs fähig wa ren. Ieh uenne diese Regeneration mit P'hilipeaux und Vulpian autogene Regeneration.

Um die Verheilume des zentraten und peripheren Endes nach der Durohshoheidung zu verhindern, wurlen verschiedene Methoden an-

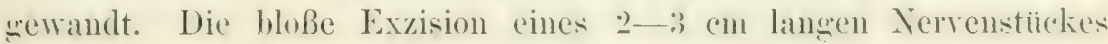
fiihrt nicht mit sicherheit zum Ziel, wie schon sichiff angerehen hat; wribere stïcke des Terven herauszmehmen, ist hei jumgen Tieren deswegen nicht sehr zweckmäßjig, weil man dam nicht mehr sehr viel Nerr übrig behält, um später den bloßgelegten Stumpf zu reizen. In einer Anzahl ron Fällen habe ich das ron schiff angegebene Verfahren angewandt, bei welchem del Ischiadicus an Foramen Ischiadici mit einel breiten Pinzette erfaßt und heransgerissen wird. Meistens grelingt es, den sanzen oberen Teil des Nerven mitsant den notorischen Wureln und den spinalganglien herauszuzichen; dieser Teil wurle dam bis zur Mitte des Oherschenkels abgeschnitten. Einigemal wurle er auch nach Alsschneidung der spinalganglien aufuremlt und dicht ïher der Kuiekehle rersenkt. Sind die Wrurehn mit herausmerissen, so finde ich bei der sektion niemals Fasem des zentralen stmmpfes außerhalh des Foramen Ischiadici. Entweder wachsen die motorischen Wuzeln gar nicht wieder aus oder sie finden nicht durch die Intervertebralkanäle hindurch. In einem Fall, bei dem die Wrumeln nicht mitkamen (der Stamm war, der Länge nach zu urteilen, am Iustritt aus der Wirbelsäule durchrissen), wuchs der zentrale stanm his zum Oberschenkel ans und verband sich mit dem peripheren stumpf, so dab der Fall mbranchbar war. In zwei andern Fallen hildete sich nach ebenfalls halbunißlungener Ausreißung eine diume Inastomose von wenigen Fasern aus.

Eine andre und ebenso sichere Methode besteht darin, daß man den Ischiadicots in der Mitte des (H)erschenkels durchsohneidet, den peripheren stumpe an seiner sitelle lïßt und den zentralen, nardulem man etwa is cun ron ihm abgetrennt hat, durch einen Muskel hindurehsterelt mud in einem anderu Muskelfach festnäht. Ev wä̈lsst dam in diesen fort und trifft nie anf sein peripheres Ende esewöhnlich wïchst

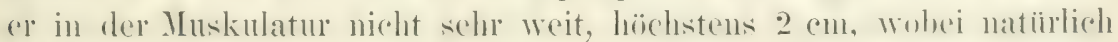

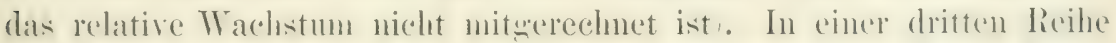

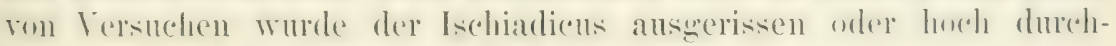
solnitten und das periphere Ende zu cinen hestimuten, später \%u beschreibenden Nebenzweck nach dem Damm zu verlagert.

Wenn nun anch die Art des Operationsverfahrens einen Einfluß

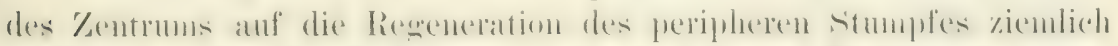

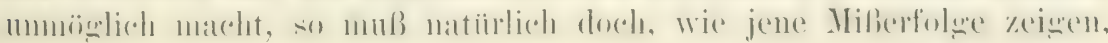




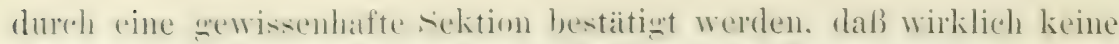
II iedervereiniwny nit dem zentralen Ende oder einem andern Nerven stattgefunden hat. Die sektion wurde in riniwen Fillen unter dem

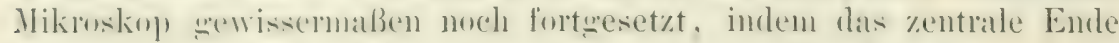
des prepipherent stmmpfes mitsant dem ungehenden ferwebe in serie

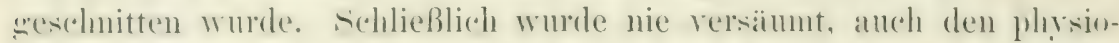
logrischen Xiachweis zu führen, daß sich keine . Mastomosen answebildet hatten, und diesem Nachweis scheint mir am meisten Gewichtzuzukmen: Bei Reizung des peripheren Stumpfes mit starken Induktionsströmen dufte das Tier ni cht reagieren bei halher Narkuse durfte das Tier beim Reizen weder heulen noch Abwehrbewegungen machen). Nur in den ron dem Stumpf innervierten II ukeln durfen Zuckungen eintreten.

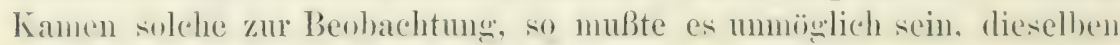
von andern Stellendes Körpers aus hervorzurufen, vor allem durften sie nicht auftreten, wem der zentrale manchmal ja erreichlore, Ischiadicositumpf gereizt wurde. In den Fällen, in welchen eine, wemn auch inmer nur partielle Leitung zwischen Zentrum und peripherem stumpf bestand, waren die Anastomosen stets anatomischlo darstellbar. Als gelungene Fälle wurden sie nicht betrachtet.

Gelungene Fälle, d. h. solche, in denen eine vollständige oder unvollstandige liegeneration des peripheren stmmpfes ohne irgend welehen Zusanmmenhang mit den Zentrum zustande kan, habe ich im stanzen 23 zи verzeichnen, außerdem zwei hallygelungene, bei denen kleine Anastomosen hestanden, und die beiden schon erwähnten Fälle bei Kaninehen. Die 23 guten Fialle rom Hund wurden an 15 Tieren inn Alter ron 8 Tagen bis 8 Wrochen gewomnen. IBei manchen Hunden wurde an beiden Beinen operiert. Ton den 23 Fiallen scheide ich noch zwei rorlinfig aus, welche nur an den Wurchn operiert waren. Es verbleiben also noch 21 Fälle. Siehe die Tabelle auf S. 191.

Daß hei jungen Tieren die Degeneration mit derselhen sicherheit wis bei erwachsenen der Durehsoheidung des Nerven folst, hat bereits Ranvier festgestellt; er konnte sogar zeigen - und ich kamn dies bestätigen - daß die Degeneration besomders schelnell vonstatten

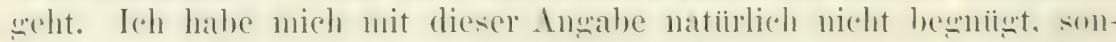
dern eigene Versuche angestellt, Welche jedesmal zu cinem positiven Resultat führten. Niemals wurde, wenn das Tier nach rier bis zehn Tagen getotet wurde, anch nur eine einzige nicht degenerierte Faser im peripheren stumpegefunden. Bei andern Tieren legte ich den Ischiadiens vier bis zehm Tage nach der Operation frei, stellte fest, daß er unerregbar war,

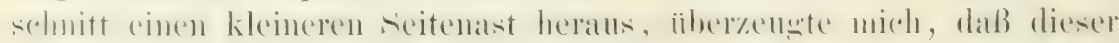
vollkommen degeneriert war, und nähte wieder zu. An den drei 


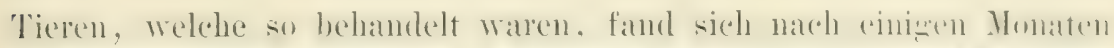

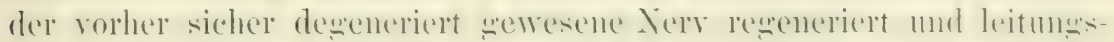

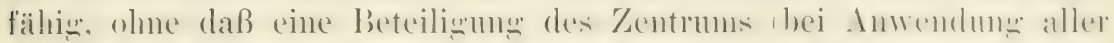

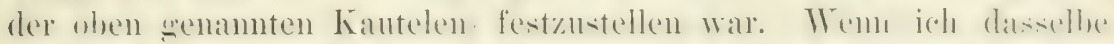

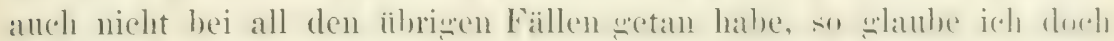

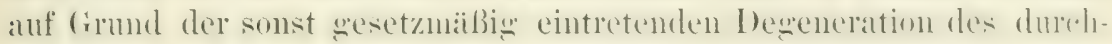
schnittenen Nerven ammehmen zu diurfen, da $B$ auch in all den andern Nerren, welche spätel leitungsfähig und mit beinahe normal a usehenden Faseru gefunden wudeu, zuerst eine Degeneration nach der. Durchschneidung stattgefunden liatte.

Tabelle der Hunde, bei denen Autoregeneration beobachtet wulde.

M. = Monat. $\quad$ T. $=$ Tag. $\quad 0$. = unerregbar bei der Sektion. $\quad x=$ schwach oder nicht in allen Iuskeln erreglar. $*=$ sehr leicht erregbar und in allen innervierten Muskeln starke Zuckungen veranlassend. $l_{0}=$ linker, $\mathrm{r}_{\text {. }}=$ rechter Ischiadicus.

\begin{tabular}{|c|c|c|c|c|}
\hline No. & $\begin{array}{l}\text { Alter am Tage } \\
\text { der Operation. }\end{array}$ & $\begin{array}{l}\text { Lebensdauer bis } \\
\text { zur Sektion. }\end{array}$ & $\begin{array}{l}\text { Erfolg } \\
\text { und Zah } \\
\text { ti }\end{array}$ & $\begin{array}{l}\text { der Reizun } \\
\text { hl der Opera } \\
\text { iionen. }\end{array}$ \\
\hline 1. & 3 Wochen. & $1 \mathrm{II} .24 \mathrm{~T}$. & I. 0 . & \\
\hline 2. & s Tage. & 1 M. $25 \mathrm{~T}$. & 1. $\%$ & \\
\hline 3. & 21 & 3 M. $3 \mathrm{~T}$ & r. $*$ & \\
\hline 4. & ־ Wochen. & 3 M. 25 T. & r. & 1. * \\
\hline 5. & $6 \quad$ & 4 II. $11 \mathrm{~T}$. & r. $\because$ & 1. $\because$ \\
\hline $\begin{array}{l}6 . \\
7 .\end{array}$ & $\begin{array}{c}3-4 \text {. } \\
32 \text { Tage. }\end{array}$ & $\begin{array}{l}4 \text { MI. } 15 \mathrm{~T} . \\
4 \text { M. } 24 \text { T. }\end{array}$ & 1. $x$ & 1. Ring \\
\hline $\begin{array}{l}8 . \\
\vdots .\end{array}$ & $2 \frac{2}{5}$ Wochen. & $\begin{array}{ll}5 & \mathrm{MI} \\
6 & \mathrm{MI} .\end{array}$ & $\begin{array}{l}\text { r. } \times \\
\text { r. } 0 .\end{array}$ & $\begin{array}{l}1 . \nsucc \\
1 . ٪\end{array}$ \\
\hline $\begin{array}{l}10 . \\
11 .\end{array}$ & $\begin{array}{ll}6 & \\
5 & \end{array}$ & $\begin{array}{lll}6 & \mathrm{M} . & \\
6 & \mathrm{M} . & 5 \\
\mathrm{~T}\end{array}$ & $\begin{array}{l}\text { motor. } \\
\text { 1. }\end{array}$ & Wurz. : \\
\hline 12. & 27 'T'age. & $6 \mathrm{MI} .20 \mathrm{~T}$. & 1. $\%$ & \\
\hline 13. & 7 Wochen. & $5 \mathrm{II}$ & 1. 0 . & r. 0 . \\
\hline $\begin{array}{l}14 . \\
15\end{array}$ & $\begin{array}{l}5 \\
5\end{array}$ & $\begin{array}{r}\text { S M. } 15 \text { 'I. } \\
10 \text { M. } 15 \text { 'T. }\end{array}$ & $\begin{array}{l}\text { 1. } \% \\
\text { 1. } 0 \text {. }\end{array}$ & \\
\hline
\end{tabular}

Bemerkungen.

Zweites Mal durchschnitten.

r. auch operiert. Aber Anastomose.

r. zweites Mal durehschnitten. 1. auch operiert. Aber Anastomose.

r. zum zweitemmal durchschnitten.

r. auferdem Ring. 1. zweites Mal durchsclnitten.

Spinalganglien herausgenomment.

r. zweites Mal durchschnitten.

Dem Nerven waren die mit ausgerissenen und abgeschnittenen Spinalganglien beigegeben.

Zweites Mal durchschnitten.

Nach vier Monaten le itend gewesen. 
Zn einer autogenen Regeneration habe ich es in allen operierten

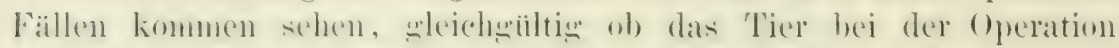
ache Tage ofler achit Wochene alt war. (Ültere Tiere habe ich nicht

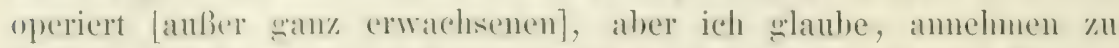
dïrfen, dalk die alutongene Reweneration anch now drei bis vier Monate nach der (iehurt bis zur Leitungsablhigkeit gelangen kann.) (oh es in

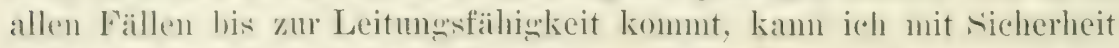
nicht angeben. jedenfalls ist dies aber wohl die Regel. Niemals sah iech alle Fasern regeneriert, mul die Zahl der vollkommen resenerierten Fasern schwankt in den einzelnen Fiallen recht stark. Man mulk hei der Benteilung dieser Verhältnisse aber in Betracht ziehen, daß einize Zcit nach stattgehahter Regencration imner wieder ein RückbildungsprozeB eintritt: Die schon dagewesene Erregbarkeit hört wieder anf und nach und nach gehen alle Fasern wieder zugrunde (siehe weiter unten). Mir scheint in dieser Beohachtung, welche ich mehrmals gemacht habe, ein se hr st ringenter Beweis dafür zu liegen, da $B$ die regeneriertgefundenen Fasern nieht vom Zentrum ausgewachsen waren, denn ein Nerv, der im Zusammenhang mit dem Rückenmark regeneriert ist, bleibt erhalten und leitungsähign, so lange das Tier lebt und geht nicht ohne erneute Verletzung schon wenige Monate nach der Neubildung eine zweite - und zwar ganzatypische - Degeneration ein. ${ }^{1}$ )

Ich will nun an einzehnen heransgegriffenen Beispielen zeigen. was an derartigen sich selbst iiberlassenen Xervenstiimpfen junger There zul Beobachtung gelangte.

Hund 4 der 'Tabelle auf Seite 191: Im Alter' von sieben Wochen wurde rechits und links der Ischiadieus hoeh an Becken durchsechnitten, durch die innere Oberschenkelmuskulatur durehgezogen und am Damm mit dem der andern seite zusammengenäht. Die Wunde heilte per priman in fünf Tagen. (Wie sich bei der Selition zeignte, hatte die Naht nicht wehalten. Beide Enden wurden an Damm 2 cm voneinander getremint gefunden.) Acht Tage nach der Operation wurde der linke

1) In einer kïrzlich erschienenen und - ich muß sagen - von sehr geringem Beweismaterial begleiteten Arbeit stellt Miinzer (1902) die Behauptung anf, daß es sich gar nicht $u m$ eine autogene Regeneration handle, sondern um ein Einwachsen markhaltiger Fasern, welehe aus benachbarten Muskeliisten stammen. Dieser Erklärung, die neuerdings auch von Langley und Anderson (1902) vertreten worden ist, widerspricht obiger Befund - außer vielen andern. Es wäre doch z. B. sehr merkwïrdig, wie anch IIaenel (1903) hervorgehoben hat, dat\} dies Hineinwachsen von Muskehnerven in die Narbe bei jumgen Tieren stattfindet, bei alten aber nicht. Auch der physiologisehe Befund widerspricht dieser Deutung durchaus. 
Nerr an Knie freigelegrt. Er hatte das bekannte, welke Answehen eines degenerierten Nerven. A uf faradische Reizungen traten keine Zuckungen in der innervierten Muskulatur auf.

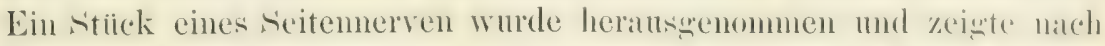

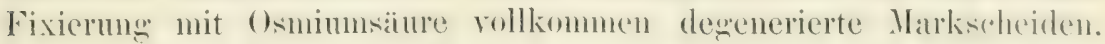
Drei Monate und 25 Tage nach der Operation wurden beide Nerven an Obersehenkel freigelegt. Sie hatten ein ghinzend weißes Aussehen und zeigten auch Fontanasche (Guerhänder. Rechts ergal, Re i -

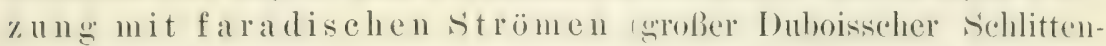
apparat mit kleinem Chromsäureelement s chon be einem Rollenabstand von 34 em tetanische Kontraktion im Gastrocnemius, den FuB- und Zehenmuskeln. Links waren etwas stärkere Ströme $(30 \mathrm{~cm})$ nötig. Bei $30 \mathrm{~cm}$ rechts und bei $28 \mathrm{~cm}$ links war die Kontraktion schon maximal und sehr kräftig. Bei starkstem Reiz traten linki keine Znekungen des Tieres ein. liechts waren bei übereinandergeschobenen Rollen kleine Reaktionen des Tieres bemerkhar, welche aber auf stromschleifen zu beruhen schienen. Von dem nur rechts erreichbaren zentralen Ischiadicusstumpf waren keine Zuckungen des Lnterschenkels und Fußes anslöshar. Desgleichen bliehen Zuckungen dieser Muskehn vollkommen ans, wenn das Lumbahmark mit sehr starken faradischen Strömen (von der Hant aus) durehströnt wurde, wobei alle andern Muskehn des Körpers in lebhafteste Bewegung gerieten! Bei der leichten direkten Erregbarkeit der Ischiadici wäre dies Resultat "2an z unverständlich gewesen, wem sie anf irgend einem Wege mit dem \%entrum zusammengehangen hätten. Der Gastrocnemins war schön rot und ziemlich dick. (Die Querstreifung der Muskelfasern war "zut erhalten.) bẹ direkter Reizung reagierte er erst bei $20 \mathrm{~cm}$ Rollenabstand. Die Reizun des Terven in einer Entfermung von 5 em komnte also den Muskel nicht direkt erregt haben, da von hier aus die Zuckungen schon bei 30 und $34 \mathrm{~cm}$ eintraten. (Außerdem svar beim Reizen eine diunne Gummiplatte unter den Nerv geschoben.) Der linke Nerv wurde mitsamt seinem zentralen Ende und dessen Longehnog heranswenommen und in Osmimusiare konserviert. Der rechte Nerv blieb noch vier T'awe im T'ier, nachdem er vorher in der IItte des Obersehenkels durchsedmitten worden war.

Der linke Nerv wies a uf Schnitten und Zupfpräparateu einen großen Reichtum an markhatigen Fasern auf

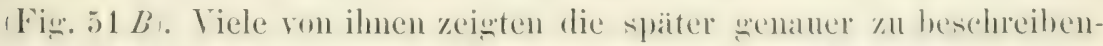
den ('haraktere regenerierter Fasern, manche waren aber von nomalen Fasern kaum noch zu unterseheiden. Sie hatten beinahe normale

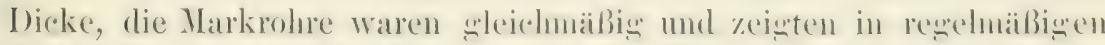
Abständen Ranviersche Einsehnilrungen. Dat nath dem \%entrum \%u 


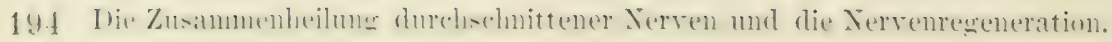

wericlitete Ende wurle in eine Längsserie zerlent. Anf diesen richnitten zeigte sich, daß der Nerr an der Spitze ron einem dichten perinemalen bindegewelne muschlessen war. Dor Xers selber war in der

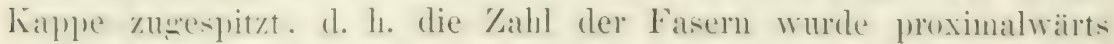
immer geringer (Fig. 51 A). Ton einer Anzahl rou Fasern komute

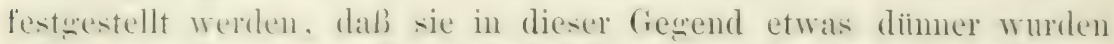
mol dimn mucrmittelt emeligten. Andre drangen noch in das perinemale Bindegewehe eim, rerließen dieses aber nicht nach atuben

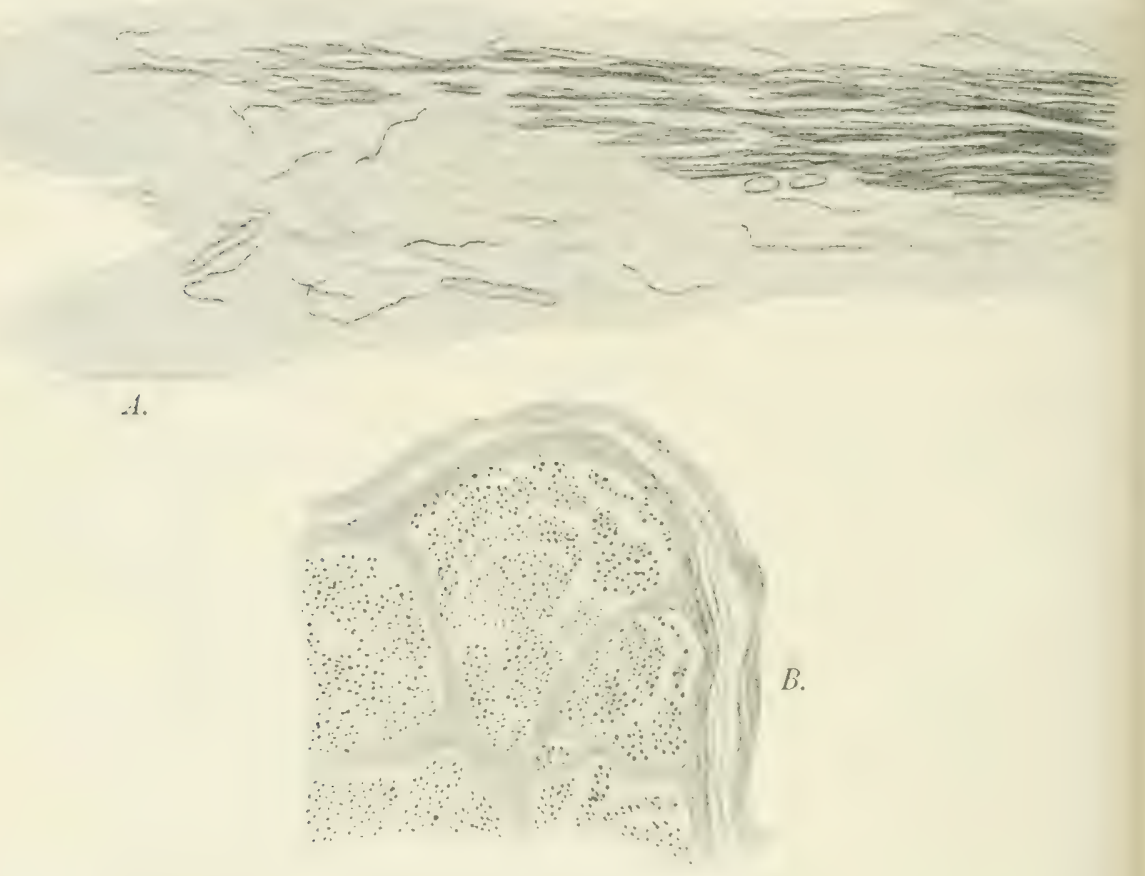

Eig. 51. A Längsschnitt durch das zentralgerichtete Ende eines autoregenerierten Nerren. (Leitz Obj. 1, Ocul. I. Einzelheiten sind bei stärkerer Vergrößerung nachgetragen; um das zu seluende zu verdeutlichen ist die Dicke der markhaltigen Fasern zum Teil übertrieben.) $B$ Querschnitt durch denselben Nerven weiter peripher. (Leitz Obj. 3, Ocul. I. Die Figur gibt eine Anschaung ron dem Verhältnis zwischen den rollständig regenerierten Fasern und denen, welche marklos geblieben sind oder gar nicht regeneriert sind.) - Beide Figuren sind auf $\% / 3$ verkleinert.

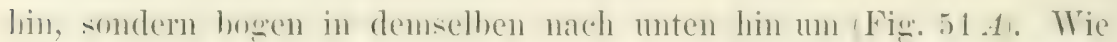
iroh unch weiter unten zeigen werde, wachsen die Nervenfasern ancen-

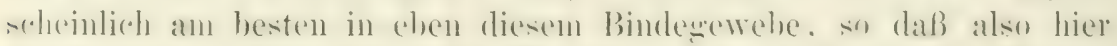

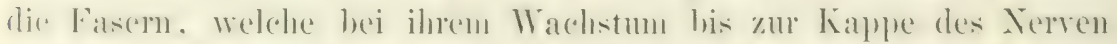

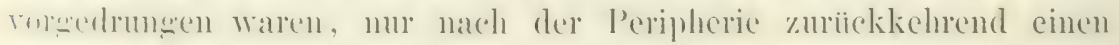
guten Mutterboden fanden. ${ }^{1}$ )

1) Derartige Fasern, deren Menge und Ausdehmungsgebiet häufig sehr viel grijłer ist, hat Miinzer (1902) rielleicht ror sich gehabt. 
Nerven, welche ohne Anschluß an das Zentrum bis zu vollständiger Erregharkeit regeneriert waren und dann immer eine grolle Anzahl markhaltiger Nervenfasern zeisten, habe ich im sanzen zwilf erhalten. Diese sind in der Tahelle mit einem stern bezeidelnet. Hhut 2, 3, 4, 5, 9, 11, 12 und 14. Bei Hund 13 war 4 Monate nach der ()peration Erregharkeit vorhanden, zur Zeit der siektion, d. h. natch S Monaten war sie wieder verschwunden.) Zu diesen zwälf komnen noch zwei Yerren von Ilund S und einer von Inund 6, bei denen die Erregharkeit geringer war und in denen nur eine geringere Zahl von Fasern Markscheiden besaßen. Schließlich ist hierher anch noch der Hund 10 zu rechnen, bei welchem nur die notorischen Wurehn durchschnitten waren. Die kiirzeste Zeit, nach welcher Erregbarkeit und sute Regeneration gefunden wurle, betrug 1 Nonat und 25 Tage (Hund 2). Die laingste Zeit, nach welcher noch Erregharkeit rorhanden war, betrug 10 Nonate (Hund 14).

Nach diesen Befunden mu es als sichergestellt betrachtet werden, daB ein peripherer, vom Zentrum dauernd abgetrennter Nerv sich aus sich selber heraus, also autogen, regenerieren kann. Der Nerv besitzt in sich die Fähigkeit, sich nach stattgehabter Degeneration vollständig und bis zur Leitungsfähigkeit zu regenerieren!

Bei allen darauf untersuchten Nerven waren nicht nur die Markscheiden und die Achsenzylinder nengebildet, sondern es waren auch wieder in den Achsenzylindern deutliche Neurofibrillen vorhanden und diese Nenrofibrillen besaßen wieder primä re Färbbarkeit letzteres in sechs Fillen untersucht und immer gefunden.

Wie schon oben erwïhnt, wurde bei dem beschriebenen Hunde der Nerr der rechten sieite zum zweitemmal durehschnitten. Dadurch zerfiel er in zwei Teile, einen zentraleren Teil $A$, der nun sainzlich isoliert war, und einen periphereren Teil $b$, der noch mit den Mnskeln zusammenhing. Nach vier 'Tagen wurde der Nerv freigelegt. Der Nerv zeigte sich jetzt in seinem peripheren Ende $(B)$ vollkommen unerregbar. Der zentralere Stumpf $(A)$ hatte wie vorher ein weißes Aussehen, der periphere stumpf $(B$ ) war etwas gelhorau verfürbt und

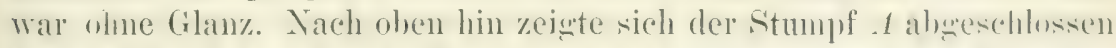
wie auf der linken sieite. I Ine letzten Ausläufer des zentralen stumpfes des Ischiarlicus endeten mindestens 4 an rom ihm entfernt in Mnskel. Auch das zentrale Ende von $A$ wurde in Serie geschnitten, welche

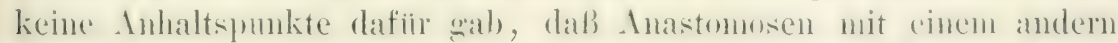
derven bestanden hatten; von bei weitem den meisten Fasern komnte nachgewiesen werden, daß sie innerhall, der perinemalen lsinderewebskappe endeten. 
Der Teil $A$ zeigte normale Fasern. Die Markscheiden waren statt und die Fibrillen whe Anzeichen von Degreneration. Nur in niichster Naihe der I) urehschmeidungstelle waren seringe Degenerationen zu benerken: sie reichten aber cher weniger weit nach oben, als es nach der weichen Zeit bei einem normalen Verren nach Konthuntätstremung im zentralen Ende der Fall ist. Das ganze peripherere (miterhall, der zweiten Durchschneidungsstelle gelegene) Ende, also der Teil $B$, zeigte starke Degeneration bis zum Ende hin ebenso der untere Teil $B$ des linken Nerven, welelser noch vier Tage nach Heransmahme des Teils $A$ in Körper greblieben war. - Eine solche zweite Durchschneidung wurde im ganzen viermal an autogen regenerierten und leitungsfähigen Nerven ausgeführt. Jedesmal degenerierte nur das peripher von der Durchsehneidungsstelle gelegene Ende, während das zentral davon gelegene Ende, das also mïnzlich isoliert war, erhalten blieb, srade wie bei einem Nerven, der noch mit seinem, "nutritorischen Zentrum" in Zusammenhang steht.

In einem Fall wurde außer der zweiten Durehsehneidung in der Vitte des peripheren stumpfes eine Loslösung des zentralen Endes desselben ausgefuihrt. Man komnte ja sagen, daß doch unsichthare Inastomosen zwischen zentralem und peripherem Stumpf hestinden: deshalb mußte ich versuchen, das obere Ende des peripheren Stmupfes whe Verletzung von der C'mgrebung abzulösen, wobei ja natiirlich alle diese unsichtbaren Verbindungsüden durchreißen müßten. In diesem Fall war num das zentrale Ende des peripheren stmmpfes stark ausgestrahlt (der Nerv war mitsant den Wureln ansgerissen zewesen und der zentrale stumpf war überhaupt nicht wieder ansgewachsen, wie die Sektion zeigte), so daß beim Loslösen eine große Menge dieser übrigens gut sichtbaren Nervenfädehen durehriss. Diese Durchreißungen fiihrten natülich Degenerationen nach sich, aber trotzdem fand ich im oberen Ende des peripheren stumpfes (Teil $A$ ) fünf Tage nach der Operation mehr als die Hälfte aller Fasern undegeneriert, wihrend in unteren Teil, also peripher von der zweiten Durehschmeidmngsstelle, alle Fasern vollstiindig degeneriert waren.

Aus diesen Befunden geht hervor, da $B$ ein a utogen regenerierter Nerv, der also keinen Zusammenhang mit dem Zentrum hat, bei einer zweiten Durchsehneidung nur in seinem peripher von der Unterbrechungstelle gelegenen Teil vollstänig degeneriert, wähend sein zentralwärts gerichteter Teil (außer in nächster Nähe der Wunde) von der Degeneration verschont bleibt, trotzdem

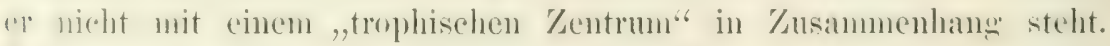
Es ist also bei der Durchschneidung eines normalen Nerveu nieht der Zusammenhang mit einem trophischen 
Zentrum, weleher das zentrale Eude vor der Degeneration bewahrt! (Vergleiche S. 175.)

Bis jetzt habe ich nur rom denjenigen Nerven gesprochen, woldhe

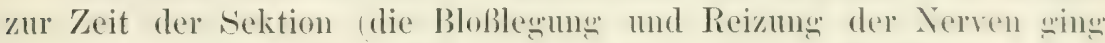
immer ummittelbar dem Töten voraus) erregbar zefunden wurlen. Diejenigen Jerven, welche ku\% ror der Sektion nicht errewhar werfumden wurden, können anatomisch einen ebenso holen firar del. Regeneration zeigen, wie die vollkommen erregharen. Manchmal ist sogar die Zahl der Fasern, welche nit einer schïnen Markscheide ungeben sind und gut differenzierte Fibrillen enthalten, grö̈ßel als bei solchen Nerven, die leitend gefunden wurden. So fiel z. 13. der a natomische Vergleich zwischen Hund 14 und 15 zu Lugunsten des Hundes 14 aus. In den Nerven beider Hunde wurden viele markhaltige Fasern gefunden, bei Hund 15 war ihre Zahl aber größer; trotzdem war der Nerr dieses Tieres ganz unerreghar, während der des andren (seines junger operierten und jünger getöteten Bruders) sehr leicht erreghar war. Ebenso enthielten die Nerven des Hundes 1:3 mehr markhaltige Fasern als die seines vier Monate frïher geschlachteten Bruders (Hund 4\% Nur die Nerren des letzteren waren zur Zeit der Sektion erregbar; die des andren waren es nicht (zur Zeit der Sektion), waren es aber vier Monate frulher (also zur Zeit, wo Hund 4 geschlachtet wurde) gewesen.

Die einmal schon vorhandene Leitungsähigkeit kann also wieder verschwinden, während der Nervim Markscheiden- und Fibrillenpräparat noch Iange Zeit nachler keine wesentlichen Unterschiede zeigt. Außer dem physiologischen Lnterschied ist aber doch noch ein andrer rorhanden: Die leitungsfähigen Nerven zeigen immer primäre Färbbarkeit der Neurofibrillen; bei den leitungsunfäigen aber doch regenerierten fehlt sie stets vollhommen! Bei diesen Nerven war die Leitungsähinkeit respektire Erregharkeit zur Zeit der Sektion schon wied er verschwmolen; ebenso wahrscheinlich bei dem einen Nerven des Hundes No. 9. Sie kann aber auch noch nicht dasein, trotzdem bereits eine anatomische Regeneration zu konstatieren ist. Wenigstens glaube ich so den Befund bein Hund No. 1 deuten zu müssen. Einen Monat und 24 Tage nach der Operation war der

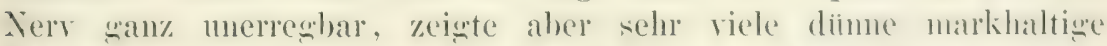
Fasern, welche deutliche Fibrillen enthielten. Inch hiel war vom

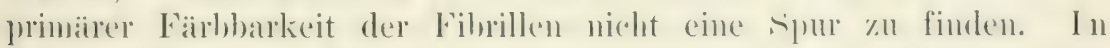
diesen Befunden sehe ieh einen neuen Beweis, da B die Funktion des Nerven mit der Anwesenheit ron Fibrillensaitue in engem Zusammenhang steht. 
Ls war ron wesentlichem theoretisehem Interesse zn erfahren, wie es hei solchen moch nicht wher nicht methe ereshaten Nerven mit einer zwciten Dexeneration steht. Wemn die Deweneration irwend etwas mit der Leitmesunterlorechung, also mit einer laralyse frerwleiche s. 17.5

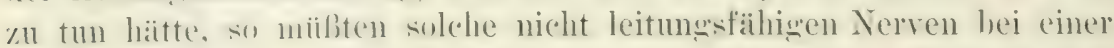
zweiten Inurdischneidung der Degeneration widerstehen. Dies ist aber nicht der Fall: Die Deseneration tritt seman in dersellsen Weise und in dersellsen Zeit ein, wie hei cinem der Leitung fähigen Nerven. Ich habe diesen Versuch zweinal angestellt, bei IIund 1 mol hei IIund $!$. Bei Hund 1 waren viele dünne markhaltige Fasern neben einer wroben Anzihlil noch nicht markhaltiger Fasern, welche aber schom schöne Filnrillen enthielten, vorhamden. Nach der zweiten Durehschneidung degenerierten beide Faserarten nur unterhalb der zweiten 1) urdechmeidungsstelle (also im Teil $D$ ), waihrend sie oberhalh der Verletzung (in Teil $d$ erhalten blieben. Bei Hund 9 imerregharer Xerw, fanden sich nu wenige markhaltige Fasem. Viele Fasem waren marklos, enthielten aber Fibrillen und noch andre standen anf dem Stadimm der Bandfasern (ob) noch oder schon wicder, kam ich nicht entscheiden). Die wenigen markhaltigen Fasern zeigten unterhalh der zweiten Durchschneidung. Markscheidenzerfall; oherhall, derselben waren die Markscheiden wlatt. Die marklosen Fasern zeigten unterhalh der Sichnittstelle kïrnige Degeneration, während sie oberhalls z.mu Teil homogenen Inhalt (Bandfasern), zum Teil fibrilläre struktur besaßen. Ich ziehe aus diesem Befund, der auch durch andre Befunde gestiitzt wird, den schluß, daß anch die Bandfasem nach einer zweiten Durchschneidung eine körnige Entartung ihres l'rotoplasmas eingehen können. I) Degeneration im oberen Ende [Teil A] beschränkte sich immer anl' die der V'erletzungsstelle direkt anliegenden Faserenden.)

Lm die antogene Regeneration noch sicherer zu stellen und allen Einwänden zu entgehen, habe ich zwei Versuche an ganz isolierten Nervenstïcken gemacht. IIan komte ja rielleicht noch gegen meine bisher beschriehenen Versuche Einwände folgender Art machen: Die snefundene Regeneration zelit war nicht von dem Nerren selber ans, sondern von versprengten Ganglienzellen, wie sie einigemal im Verlauf peripherer Nerven gefunden sind. Nun sind zwar sulche Zellen selten, und ich habe sie nur einigemal hei Froschneren wesehen, außerdem wirden sic als sanz offenbare Spinalganglienzellen nur der Nenbildung ron sensiblen Fasern dienen kïmen, aber man muß sich ron romherein wegen alle Arten von Einwänden schiitzen. Andre Einwände kïnnten dahin gehen, daß die Regreneration von den Endorganen, aber nirdit rom Nerven selber answingen. Alle derartigen Zweifel werden durch die Regeneration isolierter Nerrenstiicke zerstört. Ich wing leci der (fperation in folgender, mir von Iterm l'rofessor Ewald rol- 
geschlagenen Weise vor: Nach hoher Durchsehneidung des Ischiadicus mol Versenkung des zentralen Stumperes in ein andres Muskelfath wurde der Nery auch an der Knickehle durchschnitten. Das isolierte sitick wude nun an zentralen und peripheren Ende ron der Wuskulatur losgelöst, so daß es mur noch in der Mitte mit dem mulienenden (iewebe in Verbindunw war. Das obere Ende wurde num nach unten, das nutere nach oben museschlawen mod beide Enden durch mehrere Nähte miteinander vereinint. Inf diese Wreise entstand cin geschlossener Nervenring, der weder mit dem \%entrum noch mit der P'eripheric in Zusammenhaug stand. In heiden Fällen wurde der Nervenring nach etwas mehr als vier. Innaten freimelent und gereizt. Inch lei stärsten Induktionsströmen trat werler Reaktion des 'Tieres noch Bewegung in den Lnterschenkel- und FuBmuskeh ein. Reaktion des 'Tieres war aber in heiden Fällen ron dem aufgesuchten zentralen Ischiadieusstumpf, Bewegmg der Lnterschenkelmuskulatur nu in einem Fall rom peripheren mit den Luterschenkehmskeh in Verbindung stehenden Ischiadicusende hervorzurufen. D i e Nervenringe waren also physiologisch duchatu isoliert, ebenso anatomisch, wie eine sorofältige Präparation erabab. In beiden Fällen war der Ring vollkommen greschlossen, d. h. die Enden waren miteinander verwachsen. Bei der anatomischen Untersuchng zeigten sich beide isolierten Nervenstucke ganzbesonders reich an schön a usgbildeten Markfasern, welche deutliche Neurofihrillen enthielten. Die Ringe wurden in serie greschnitten und zeigten auch nicht eine einzige versprengte Ganglienzelle. Danach wird wohl nicht darau zu zweifeln sein, daß die autonene Regeneration ron den ,Tervenzellen" Kapitel 13, selber ausgeht, daß also wedel" das Zentrum noch die peripheren Endorwane dabei beteilint sind.

Ich will num den Vorgang der autogenen Regeneration, soweit mil iiber denselben etwas bekannt weworden ist, wenaner beschreihen. Mit bestimmtheit läßt sich darïher zur Zeit natiorlich noch nicht viel anssagen, und ich halte es eigentlich für ummoghlich, dies äherhanpt jemals zu kömnen, denn man wird niemals an ein mol dersolhen Faser beobachten können, in welcher Weise sie sich umformt. Bei den meisten solchen entwicklungshistologischen studien handelt es sich ja nur un die Konstatierung von Verschiedenheiten, dic nebenemander orler nacheinander anftreten. Bringt man sie in eine bestimute Reihe und nimmt nan an, daß diese Reile den sioh folgenden Entwicklung-sstarlien entspricht, so ist das immer ein sichlulf rom sein anf das Werden, der eventuell يan\% falsch ist. Wemn die versohiedenen stadien zeitlich ganz voneinander getrennt sind, damn kamn man bei voll-

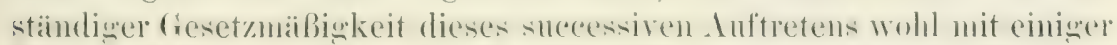
sicherheit die eine Form als die Vorstufe ciner späteren anschen, so- 
wie aber verschiedene Formen immer zur gleichen Zeit zur Beobachtung gelangen, wie das hier der Fall ist, so ist man im wesentlichen anf Vermutungen angewiesen, die vicle Histolognen und Embryologen fälschlicherweise als mumstößliche Tatsachen hinzustellen versuchen.

Sicher ist in vorliegenden Fall nur, daß der gäinzlich vom Zentrum setremnte, junge Yerv nach einigen Tagen einen vollständigen Zerfall der Markscheiden und der Neurofibrillen zeigt, daß nach zwei his drei Wochen kaum noch eine sjum ron Mark zu bemerken ist und der wanze Nerv ans kernhaltiwen Bandfasern besteht, und daß schließlich nach mehreren Monaten wieder markhaltige und marklose Fasern mit Nenrofibrillen vorhanden sind. Daß die Bandfasern ans den degenerierten Nervenfasern entstanden sind und die Markfasern wieder an. den Bandfasern, ist wahrseheinlich, aber nicht absolut sicher, weil diese Umbildung nicht direkt beobachtet werden kann.

Über die ersten Stadien kann ich an jungen Tieren sehr wenig sagen, weil ich nur je einen Fall von 4, 10 und 20 Tagen nach der Operation besitze. Der Ablauf der Degeneration und die sich an dieselbe anschließenden Terändermgen scheinen aber wanz ebenso zu sein wie bei erwachsenen Tieren, nur scheint alles etwas schmeller zu gehen. Wie schon von verschiedenen älteren Autoren, und zuletzt senaner von v. Büngner und Howell und Huber beschrieben ist, tritt etwa rom vierten Tage nach der Durchschneidung an eine lebhafte Vermehrung der Schwannschen Kerne ein, welche von einer Wucherun des zugehörigen Protoplasmas begleitet ist. Nach zehn Tagen fand ich die Kernvermehrung schon sehr stark. Neben den Resten der Markscheide (kleine Kü̈gelchen) und der Innenscheide ziehen sich imnerhalb der alten Schwannschen Scheide protoplasmatische Bänder hin, welche an den Kernen meist dicker sind. Eine solche Faser sicht also ans wie eine Reihe von Spindelzellen, deren spitzen miteinander verschmolzen sind. Andre Fasern sind dieker und zeigen bereits ein sleichmäBiges Kabiber (Fig. 52 B). Nach zwanzig Tagen waren die Marktrimmer fast ganz verschwumden, ebenso die Reste der Innenscheiden. I) Zellbänder waren dicker und die spindelförmigen Anschwellungen waren an den meisten Fasern answewlichen. Wir haben also hier die typischen Bandfasem v. Bünghers, die embryonalen Fasem Howell und Inbers vor wns. In manchen dieser Fasem untersoheidet no:n num schen dentlich einen imneren strang und einen :inßeren Mantel. dere innere strang zeigt anch bisweilen bereits in der Nähe der lieme rine lndentmer ron fibrillïrer Streifung, wie sie znerst von v. Büngner

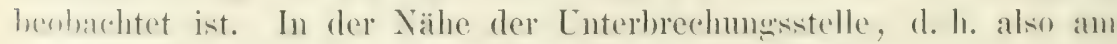

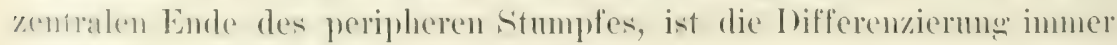
weiter ansgebildet als an der Peripherie. 
Derartige Fasern finde ich nun auch bei allen älteren Nerven neben solehen, die eine viel weitergehende Differenzierma zeisen; selbst bee dem Hund 14 waren sie 10\% Nomat nach der Kontinutiatsunterbrechung in reichlicher Menge rorhanden. Man wird rorlüufig ammehmen müssen, daß nicht alle Nervenfasem die Kraft haben, sich vollständig zu regenerieren und daß sie in dem stadium lange Zeit verharren, das sie eben grade noch erreichen kounten. Die Fasern, welche in Fig. $52 . A$ abgebildet sind, stammen ron diesem Tier, sic kümnten aber gradesogut (wenigstens a und b) ron dem Tier von 20 Tagen stammen.

In meiner Tierreihe ist hier eine große Lücke, demn das nüchste Tier wurde einen Monat und 24 Tage nach der Operation getïtet.
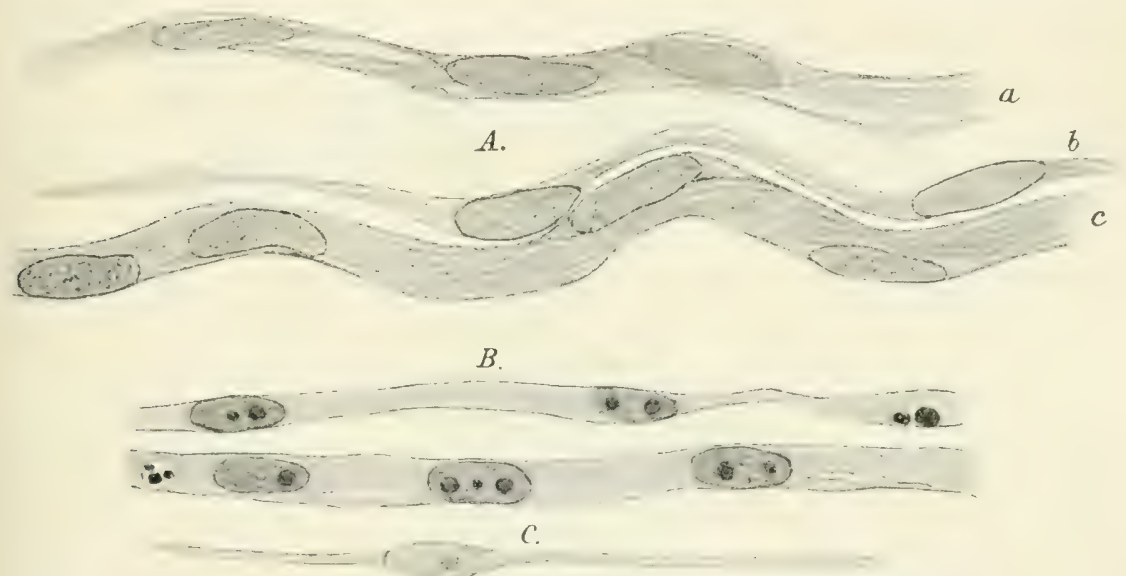

Fig. 52. 1 Drei Nervenfaseru in frühen Stadien der Autoregeneration. $B$ Bandfasern von einem jungen Hunde zehn Tage nach der Durchschneidung des Nerven. $C$ Eine Faser, wie sie vermutlich am Ende der Degeneration aussehen würde, wenn nicht der Anfang der Regeneration eintreten wïrde, ehe die Degeneration ganz abgelaufen ist. ( $A$ und $B$ gezeichnet mit Zeiss Apochromat 1 ,30 Kompensationsocular 6 . $C$ ist bei derselben Vergrößerung gedacht. $\mathcal{A}$ und $B$ mit osmium fixiert und zerzupft, Färbung nach der Molybäinmethode.)

Es war mir eben in der Hauptsache un die Feststellung der autogrenen Regeneration zu tun, nicht, oder weniger, um die Darstellung der einzelnen stadien, so daß ich das immerhin nicht wanz leicht zu heschaffende Material an jungen Hunden für die Erzenemen möglichst hochradig regenerierter Nerven benutze. Der Nerr dieses Tieres war unerreghar, zeigte aber eine zienlich starke Regeneration. Etwa die Hälfte aller Faseln besaß eine dentliche Markscheide: diese war aber nur selten über die sanzen Fasern answebreitet, sondern zeigte

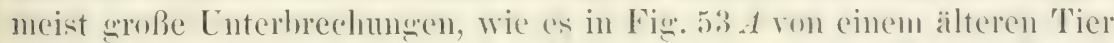
abowebildet ist. Da man die Markbildumg stets an den kernen findet,

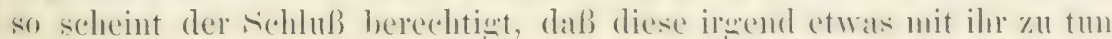


hablen. Die narkfreie strecke, an der also die Faser noch nackt ist, liegt gewöhnlich grate in der. Mitte zwischen zwei Kernen. Alle diese markhaltigen Fasern waren wesentlich climmer, als normale Fasern junger Hunde dieses Ater's zu sein pflewen, enthielten aber deutliche Nenofibrillen. - Vom den marklosen Fasern standen nur wenige auf dem stadiun undifferenzicerter Bandfasern; die meisten zeigten wenigstens eine Differenzierung in ein zentrales Band und eine plasmatische

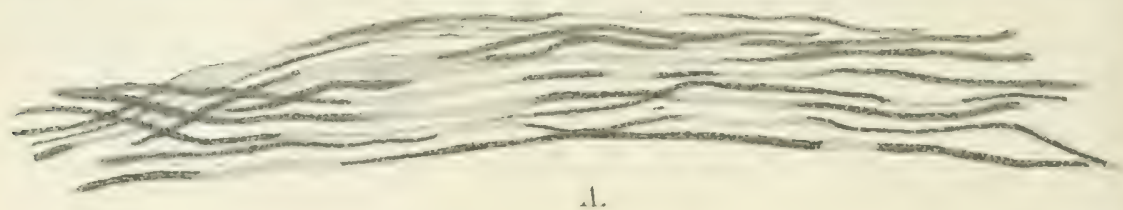

1 .
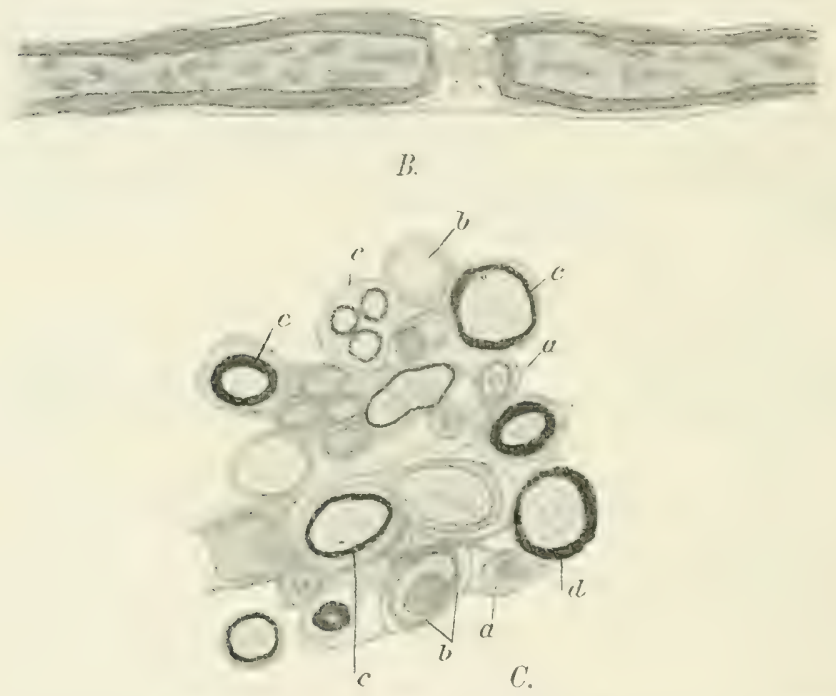

Fig. 53. A Autoregenerierte Nervenfasern mit Unterbrechungen im Markmantel. B lianviersche Einschnïrung einer vollständig autoregenerierten Faser. $C$ Querschnitt aus einem autoregeneriertem Nerven. Buchstabenerklärung im Text. ( $A$ Leitz $1 \times 3 . B$ und $C$ Zeiss Apochromat 1,30 , Kompensationsocular 6. Alle drei Abbildungen von Osmiumpräparaten; $C$ nach der Molybdïnmethode gefïrbt, $A$ und $B$ aus Zupfprïparaten.)

sicheide. In einem Teil dieser Fasern war wenigstens in der Nähe der Kerne eine dentliche fibrillïre s'treifung zu sehen, bei noch andern durchzogen die Fibrillen die sanze Lünge des Bandes. Eine solche

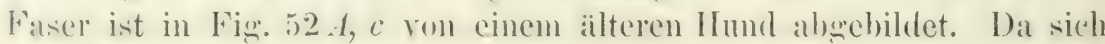
alle Zwischenstufen finden, so kömute man wanz gnt folwende Entwicklungsreihe anfstellen: 1. Bandfasern, 2. Differenzierung in achsialen Strang und plasmatische sicheide (Adehialstrangfisem), 3. Auftreten yon VFibrillen in der Näilıe der Kerme, 4. Versehnelzen der diskontinuier- 
lich webildeten Fibrillen zu fibrillären biandern, ๖. Auftreten fon Mark in der Xähe der Keme, 6. Ansbreitume des Marks wom hier ans nach

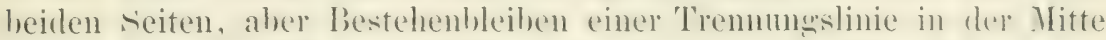
zwischen je zwei Kernen bildung der Ranvierschen Einschniirnnenten.

Dieses letzte Stadium war in dem Hund 1 noch fast nirgends erreicht, bei allen andern autogen rewererenten Nerven aher in neh oder weniger reichlicher Menge vorhunden. IJervoryhehen ist wn diesem Nerven noch, daß die Zahl der markhalticen Fasern in der Sähe der Durchsehneidumsstelle, also am zentralen Ende des peripheren stumpfes, wesentlich wrïber war als weiter nach der Peripherie zu. bei manchen der Inude, welche läntwere Zeit nach der ('peration geelelt hatten, war dies auch in auffäliger Weise zu sehen, bei andern war der Unterschied gering; dies waren meistens Fälle, in denen die anatomische und phrsiolowische Resceneration auf hörhster Höhe oder itber dieselbe hinaus war. Die Regeneration macht also am zentralen Ende des peripheren Stumpfes schnellere Fortschritte als in den peripheren Partien. Oderanders ausgedritckt: Die Regenerationskraft einel Nerienstrecke ist um so größer, je näher sie sich dem Zentrum befindet. Diese Tatsache macht es so schwer, an einfach durchschnittenen Nerren ein klares Bild ron der Regreneration zn gewinnen, weil immer die Berechtigung rorhanden ist, das friilere Auftreten vom rewenerierten Fasern in der Nähe der Durchschneidungstelle anf einen Einfluß des zentralen Stumpfes zu beziehen. v. Bimgner luat bereits die Tatsache ron der stïkeren Regenerationskraft zentralerer Tervenstellen an einfach durchschnittenen Nerven richtig erkannt, hat sie aber doch nicht nit solcher vicherheit erweisen kïmnen, daß ihn nicht elsen dieser Einwand ron nenronistischer feite ströbe, gentacht werden kounte.

Schon bei dem Hund 2, welcher nur' einen 'Tag' länger nach der Operation lebte als Hund 1, fanden sich eine Reihe von Fasern, welche his zur Aushildung Ranvierscher schninringe regeneriert waren. Dieser Hund, ein Bruder von No. 1, war im Alter von acht 'I'agen operiert worden, wälrend No. 1 zur Zeit der Operation bereits drei Wochen alt war. Es wäre aber vorschnell, wenn man das jugendlichere Mter allein für die stärore Rexpeneration rerantwortlich machen wollte (der Nerv von No. 2 war auch leitumgsfähig, der von No. 1 nicht). Der Nerr dieses IImudes miterschied sich nicht wesentlich ron dem aller späteren (No. 3-15). Es schwankten nur die Zahlen-

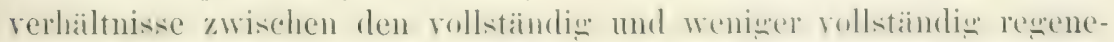

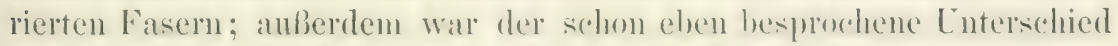
\%wischen den zentraleren und peripheren l’atien der rexenerierten

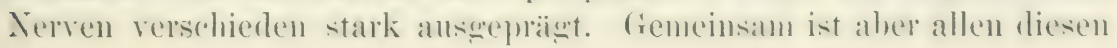


Aerven, dal sich alle stadien, welche vorher wenamnt wurden, nebencinander vorfinden, sleichuriiltiw. ol, die Terven leitend oder nicht mehr leitend waren. Bandfasern sind relativ selten, aber Fasem mit den Infängen der Fibrillenentwicklung sind iiherall häufig, ehenso Fasern nit answebildeten Fibrillensträngen, aber ohe Markscheide. Diese letzteren zeizen bei Nerren, welche leitend sind, fast immer primäre Färbbarkeit. Da nun in einigen Fallen bei guter Erresharkeit mur verhältnismäBi wenige markhaltige Fasem, aher viele marklose Fasem mit primärer Fäbbarkeit vorhanden waren, so muß ich den śchluß ziehen, daß anch diese marklosen Fasem mit gut differenzierten Fibrillen und primårer Färbbarkeit leitend sind.

In Fig. 538 gebe ich eine Abbildung won einer vollstaindig resenerierten Faser, welche eine wohl ansgebildete Ranviersche Einschnïrung zeigrt. Man kömte sie sehr gut für eine normale Nervenfaser halten. Bei dieser Faser, wie bei einigen andern, die ich fünf his zehn Nonate nach der Operation zu Gesicht bekommen habe, lient die Schwannsche scheide bereits der Markscheide beinahe an. Bei den meisten Fasern ist dies nicht der Fall; es zieht sich riehmehr zwischen beiden Scheiden eine mehr oder weniger breite Plasmaschicht hin, welche an den Kernen noch rerdickt ist. Dieser Lntersehied ron normalen Fasern, bei denen nur in der Nïhe del Kerne eine kleine I'lasmamenge vorhanden ist, macht es leicht, regenerierte Fasern noch lange Zeit ron nomalen zn unterscheiden. Am besten kamn man diese Verhailtnisse auf Quersehnitten sehen. Einen solehen bilde ich in Fig. $53 \mathrm{C}$ ab. Man sieht hier verschiedene stadien der Regeneration neheneinander. Mit $a$ sind diejenigen Fasern bezeichnet, welehe srade ïber das Bandfaserstadium hinans sind. Nan sieht hier eine sich dunkel färbende Lchse, musceben von einem helleren plasmatischen Inof. Die anfangs homogene Bandfaser hat sich also hier in zwei Komponenten, den achsialen Strang und die plasmatische Scheide differenziert. Bei andern Fasern ist der achsiale strang heller, und in demselhen sieht man die Querschnitte ron Fibrillen als kleine P'unkte (b). In diesem Stadium besitzt der Achsialstrang bereits alle morphologischen Qualitïten des Achsenzrlinders; man kann ihn also anch als solchen bezeichnen. Die Markscheide tritt num auf andern Fasern an der Grenze ron Achsenzylinder und plasmatischer scheide auf, zucrst als diume Lamelle $(c)$. Nach außen hin zeigt sich die Hasmatische scheide dentlich durch ein stairker färblores IIäutehen ahgegrent, welches man wohl als schwamnsche sicheide bezeichnen kann. Auf die Frage, ob wir es hier mit der alten Schwannschen

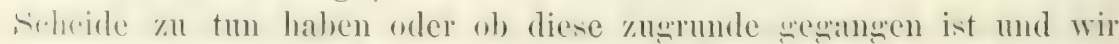
(eine nene vor uns haben, weik ich keinen Bescheid. Sichließlich sieht man an der Faser d die plasmatische seheide fast ganz versehwunden 
nud die Markscheide von ungefülı normaler IDicke. Es sei dam noch auf die stelle e lingewiesen, an weleher man drei junge markhaltige Fasem von einer gemeinsanen sicheide mugeben sieht. Fulche Bilder sieht man nicht selten: manchmal sind es nur zwei, manchnal aber auch vier Fasern, die in dieser Weise vereinigt sind. Man ist versucht in der wemeinsamen sicheide die alte sichwannsche sicheirle z.n sehen. Jedenfalls wird man derartige Gebilde mit andern Autoren als aus einer alten Nervenfaser hervorgegangen ansehen düren.

Ich hahe meinen standpunlit schom dahin präzisiert, daß solche Entwicklungsseihen, wie ich hier eine für die antogene Regeneration junger Nerven aufgestelit habe, nicht den Wert direkter Beobachtungen beanspruchen können. Sie repräsentieren um eine angenblickliche Wahrscheinlichkeit. So ist es wahrscheinlich, daß die Bandfasem ans den degenerierten Nervenfasern herorgehen, daß aus den Bandfasem wieder die Fasern hervorgehen, welche einen Achsialstrang und eine plasmatische ícheide hahen Achsialstrangfasern, und daß diese wieder die Vorstufe zu den markhaltigen und funktionsfähigen Nerrenfasern darstellen. Tatsachen, die dieser Auslegung der Befunde widerspriichen, liegen zur Zeit nicht vor. Wir werden also zur Zeit die Bandfasern und noch metr die Achsialstrangfasern dort, wo wir sie finden, als Anfänge einer Regeneration ansehen diurfen.

Sehen wir nun zu, was aus einem Nerven eines erwachsenen Tieres werden kamn, nachdem er danernd vom Zentrum ahgetrennt ist. - Das Versuchsverfahren war hier dasselbe wie bei den Nerven junger Tiere. Die Nerven wurden entweder auswerissen, oder es wurde ein stiick ron drei his vier Zentimeter Länge exzidiert, und der zentrale stumpe in ein andres Muskelfach eingenäht. Zn leitungsähigen Nerven gelangt man auf diese Weise nie; das muB unbedingt den älteren Experimentatoren zugegeben werden; da das zentrale Ende bei diesen älteren Tieren relativ ebenso stark a uswächst, wie bei den jungen, so kann man aus dem Nichtwiederkehren der Erregbarkeit den Schlußziehen, daß bei den jungen Tieren, wo sie wiederkehrt, dies nicht vom Zentrum aus geschehen sein kanu. - Der Nerv hekommt aher imnerhall, einiger Inomate eine struktur, welche der momalen wieder ähnlicher ist, als die, welche als bude der Itegeneratim angesehen werden mub. As Ende der Desencration mürohte ich das stardinm bezeichnen, bei welchen del Achsenzylinder rollstindiщn verschwnden und die Markscheide bis anf kleine Markieste, die noch lange persistieren kimmen, zerstïlt ist. In diesem stadlum ist ron

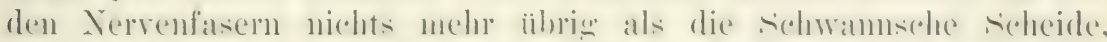

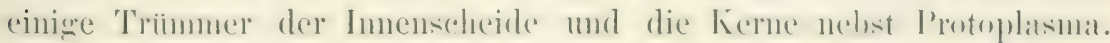

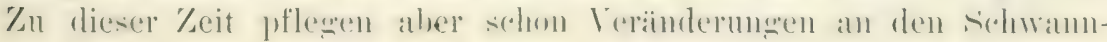


schen kernen und ilnem l'rotophlasmal eingetreten zur sein, die zur Doweneration nicht meln wut gerechnet werden kïmnen, nämlich Vermehrung der herne mol Wucherung des L'rotophasmas. Degeneration und liegeneration sreifen eben incinander, wie dies hereits v. Buingner

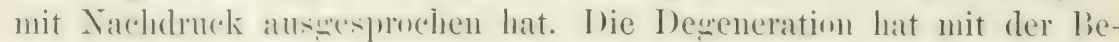
seitiwng des alten levemuaterials geendet, die liegeneration nit Vermehrung der keme und Wudherung des Protoplasmas begrmene Die Folge dieses Doppelpuzesses ist, dab man nie das reine Endresultat der Deseneration zu selien bekommt. In den Fasem, welche

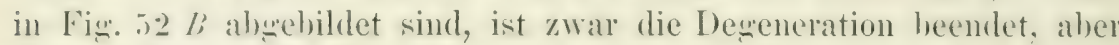
die Wucherung des Protoplasmas ist schom recht bedeutend. Alstra. hiert man bei diesen Fasern von der Kernvermehrumg und der P'rotoplasmabildung, so bekommt man das eigentliche theoretische Endbild der Iegeneration. Ich habe es in Fim. 53 C darustellen rersucht. Es kommt num, genau wie es v. Büngner und Ilowell und IIuber heschrieben haben, zur Bildung ron Bandfasern, indem sich das gewucherte Protoplasma der benachbarten Faserkerne miteinander verbindet. /u einer bildung ron Nark habe ich es an wirklich ausgewachsenen Tieren nicht kommen sehen /Tiere ron etwa ein bis zehn Jahrenj. Wemn Howell und Huber eine solehe sefunden haben, so handelt es sich wohl sicher un nicht ganz erwachsene Tiere. Dagegen sah ich auch hei wanz alten, schom zahnlosen Hunden stets und locinahe in allen Fasem eine andre Differenzierung eintreten, die ans den Bandfasern eine, normalen Fasern ïhnlichere, Struktur entstehen läßt; das ist die Bildung von Aclisialstrangfasern.

Der Achsialstrang ist anfangs düm, ehenso die scheide, aber sechs bis nem Inomate nach der Operation können die Fasern die Dicke der dümeren sorte normaler Yervenfasern erreichen. Wie die Fis. 54 zeigt, ist der Achsialstrang dentlich von der scheide absesetzt, welche letytere etwa die Dicke einer Markscheide hat. Im Achsialstrang kommt es aber nie zur vollständigen Ausbildung ron Fibrillen d diskmtinnierliche Indentungen fibrillärer Streifung sind nanchmal zu sehen, in der scheide nie zur Bildung ron Mark. Dic scheiden brätnen sich zwar in Osminmsünre, zeigen aber nicht die starke Reduktionskraft, welche den wirklichen Markscheiden znkommt. Diese Adhsialstrangfasem hat schiff , 1457, offenbar wesehen and abyebildet, wenn er behaujtete, dab der Achsenzylinder noch Monate nach der Vervendurehschneidung vorhanden sei: er hat aber nicht

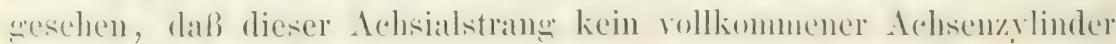
ist und dak bald nach der Operation ïberhaupt nichts ron einem

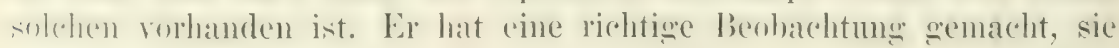
aber falsch gedeutet.

Wir sehen also, daB a uch bei den Nervenerwachse- 
Die Zusammenheilung ducrhschnittener Nerven und die Nervenregeneration. 207

ner Tiere eine autogene Regeneration eintritt; aber diese bleibt a uf habem Wege stehen. Es fehlt dem Nerren an Kraft, a us sich selbst heras die Regeneration zu vollenden. Je juinger der Nerv ist, desto mehr Fasern kïmnen sich ohne beteiligung des \%entruns iiber das stadiun der Bandfasem und Achsialstrangfasern hinats regenerieren, ja zu "rregungähigen Fasern werden. Ein Teil bleibt aber anch bei den Nerven junger 'Tiere auf der niederen situfe stehen. Die Regrenerationspotenz ist also in den verschiedenen Fasern schon fribzeitig verschieden groß und nimmit im Lauf des Lehens schnell ah, geht aher anch bei den ältesten Individuen nicht ganz verloren.
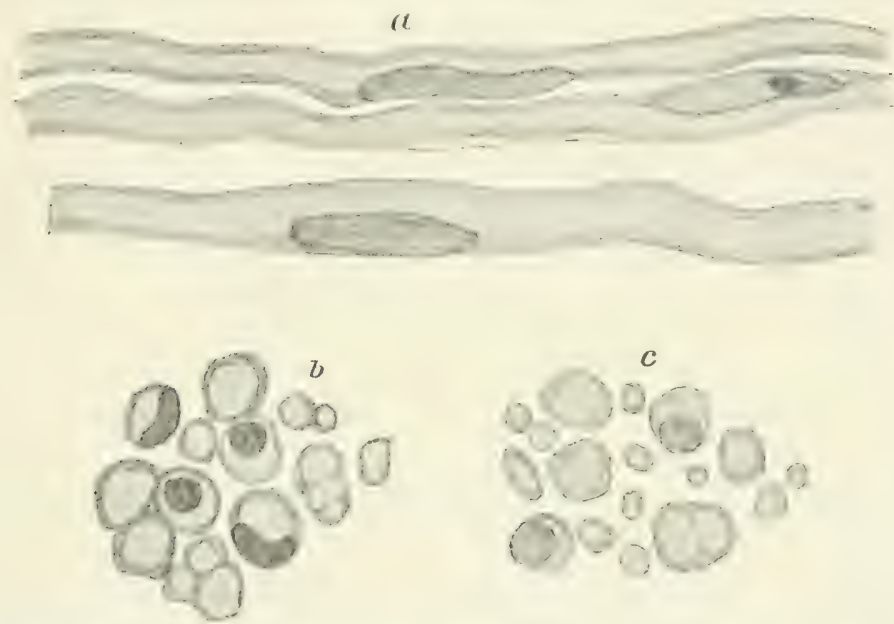

Fig. 51. Autoregeneration bei ausgewachsenen Tieren, $a$ und $b$ rom Hund, $c$ rom Kaninchen. (Zeiss Apochromat 1,30, Kompensationsocular 6.)

Der Vorgang bei der Regeneration gequetschter oder einfach durchschnittener Nelven ausgewachsener Tiere ist durch die L'ntelsuchumgen rou v. Biingner und IIowell und Huher zur freniige hekamnt geworden. Ich liamn die Befunde dieser Autoren bestätigen mol hahe ihnen nichts hinzuzufügen. Das Wesentliche, mu es nochmal zu wiederholen, ist etwa folgendes: 1. Deweneration des peripheren Stumpfes. 2. Wuchermog der Kerne mod ihres l'rotoplasmats. 3. Bildung von sipindelzellen, ans denen damn IBandfasern und weiterhin Iolsialstramefasem herorehen. 4. Inskontinuierliches Inftreten

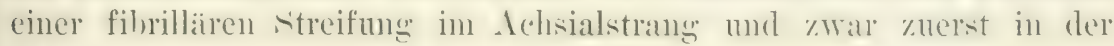
Nähe des zentralen Endes und ron da mach der Peripherie fortschreitend. 5. Diskontinuierliches Anftreten der Markischeide, ehenfalls zuerst in der Nähe der alten Lnterbredhungstelle. Wemn wir num sehen, dals bei verhinderter Zasammenheilum mit den /entrum in 
den Nerven junger Thiere fast momale und funktionstürhtige Fasern offentalr ans den Achsialstrangfasem hervorgehen und daß auch in

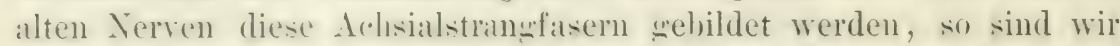
zu dem siblulb berechtigt, daß bei vollständiger Regeneration alter Nerven, welche nur unter dem Einfluß des zentralen Nervenendes möglich ist, eben diese Achsialstrangfasern das Material zu den definitiven Nervenfasern hergeben und daß sie nicht sekundär rom Zentrum auswachsen.

Solange man nicht wußte, was der Nerv aus sich selbst heraus kamm, komte der Befund, dak bei stattgehabter Verwachsung von zentralem und peripherem Ende die nengebildeten Fasern immer zuerst in der Sïhe des zentralen stumpfes auftreten, zn der Ansicht führen, dal die Fasem von diesem in den peripheren hinein wïchsen: jetzt ist das wohl nicht mehr gant möglich. Wir kïmnen, der alten s'chiffschen Anschaumg folgend, dem zentralen Stumpf bei der Regeneration des peripheren nur noch eine anregende Wrirkug zuscheiben. Der periphere stumpf regeneriert sich ans sich selhst, er allein wilot das Material dazu her; vom zentralen stumpf kommut nur ein grewisses Etwas, das die regenerativen I'rozesse kräftigt. Mancher wiurde hier zur Hypothese des Ferments greifen; ich riche es aher ror, die Frage des, Wie?" saur auf sich beruhen zu lassen, solange nicht mehr Anhaltspmikte vorliegen. Dieses .,gewisse Etwas" won der fanglienzelle herzuleiten und so die Lehre vom trophischen Zentrum neu zu beleben, liegt allerdings gnar keine Veranlassung ror. Wir haben ja gresehen, daß anch bei der autogenen Resreneration junger Nerven das zentrale Ende inmer den peripheren Teilen voraus ist, d. h. kräftiger und schneller reagiert; man wiirde also anch hier ein trophisches Zentrum in der Nähe der jeweiligen Cnterbrechungsstelle suchen kümnen, was natürlich alsurd ist. Ich waube daher, daß man mit der Ammahme auskommen kamn, daß der \%entrale stmupf relativ gesmud ist und deswescen dem peripheren stmmpf die Anregung geben kamm, die er zur Vollendung der Regreneration nötig hat. Xur in der Jugend hat der periphere stumpf diese Anregung nicht nütig.

Bisher ist nur von der Regeneration der Nervenfasern in peripheren Nerven die Rede gewesen; ich rerfige aber anch übë einen Fall, welcher die antogene liegencration ron Fisern des Räekemmarks mit Sicherheit erkennen läßt. Bei dem Hund No. 7 wurde im Alter von 32 Tagen der Reückeratskanal in der Beckengegend auf gehrochen. Daranf wurden anf der linken seite sechs spinalyanglien freigelewt, die hinteren Wurgeh derselben durehsehnitten und so nach der Seite serzecen, dafs sich das spinalganglion von der motorischen Wrurel 
ablöste. Unterhalb der Ganglien wurde wiederum duchsehnitten, so da $B$ sie num herausgenommen werden

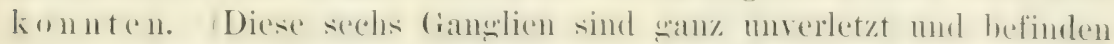

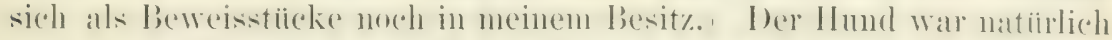
mateh dieser Gperation an linken Ilinterbein ganz ascusibel, während

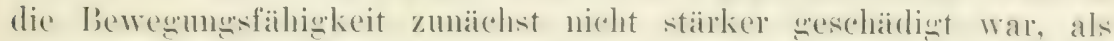

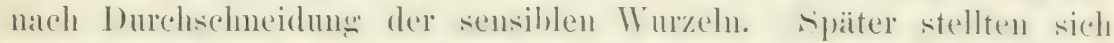
hei diesem Hunde mod nedreren anderin jungen Tieren, denen nur die semsiblen Wurgeh in derselben . Lusdehnung durchschnitten waren,

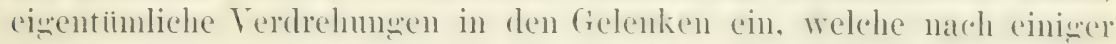
Zeit auch mit Gewalt nicht zu redressieren waren. Anffallend an

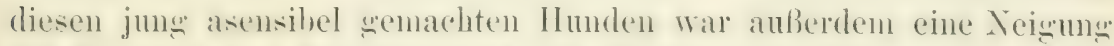
der Knochen zum Frakturieren. Da die spinalganglien wanz entfernt waren, so hag keine Möglichlicit vor, dali sich ron ilnen ans sensible Fasem regenerieren komnten. Bekamntlich degenerieren nun nach Verlet\%ng der sensiblen Wumehn die Hinterstränge des Rürekemmarlis und zwar nach einer so ausgedehnten Operation, wie sie hier aussefuilht wurde, so stark, dak der Ilinterstrang der betroffenen sieite inn dieloiet der Operation und noch weit hinauf sath\% dium wird und zilsammenfällt. Der Rückemnarksunerschnitt wird dadurch ganz asrmmetrisch. Als dieser Hund nach beinahe fünf Ironaten seziert witde, fand sich ron spinalganglien an den stellen, wo ich nperiert hatte, nichts ror. Die am Rïckenmark hängenden sensiblen Wureln endeten nach der Peripheriezu blind (sie waren

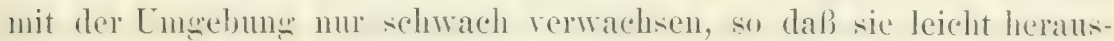
zmmehmen waren). Durch ihr weißes Aussehen fielen sie sofort auf. I) as Riickemmark reigte sich sut srmmetrisch and entbehrte des gellylichen streifens, der sonst nach einer derartigen (Jperation an IInterstrang der operierten seite zn sehen ist. I)ie mikmsopische Lntersuchung ergal folgendes: Die sensiblen Wurzeln, welche fiinf Monate lang ihrer Spinalganglien beraubt gewesen waren, enthielten viele markaltige Fasern, neben einer geringen Anzahl rou Bandfasern und fibrillärdifferenzierten Achsialstrangfasern. Diese markhaltigen Fasem waren diumer als die der nomalen hinteren 11 urehn

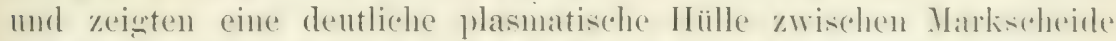

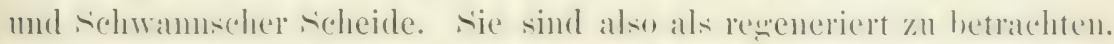
Das Rückenmark zeigte in der Lendenansehwellung (und a ueh in allen andern Gegenden) einen symmetrischen

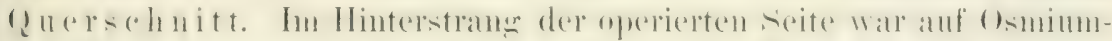

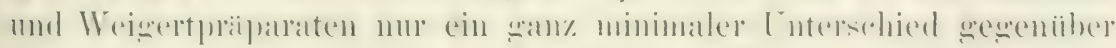
der normalen Seite zu sehen. Die Zahl der Fasern war, soweit sich

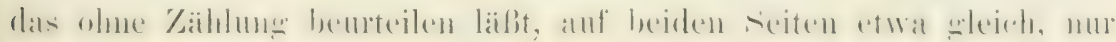




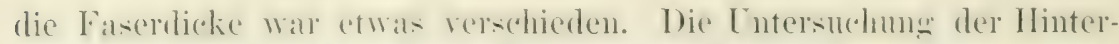

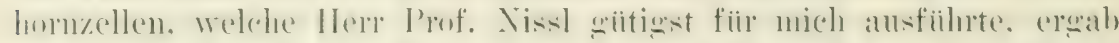

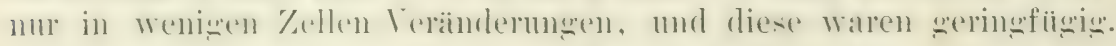

Diesen Resultaten stehen zum Vergleich die gegeniiber, welche

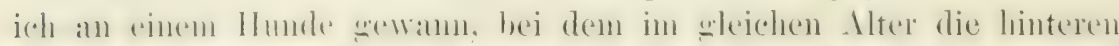

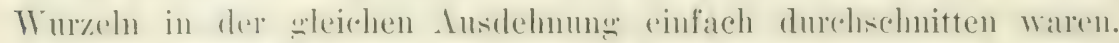
Er wurde dienfalls etwats weniger als fünf Monate nach der Operation getötet. Bei diesem bot sich das typische Bild, das man bei erwachsenen Tieren nach der Operation zul sehen gewolnt ist. Die

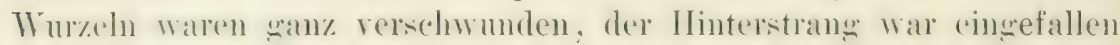
und enthicht nur noch wenige Xervenfasem; die Zellen der IInterhörner waren stark rarifiziert, die noch vorhandenen rerändert. Virmu in den einen Fall die autogene Regeneration eingetreten ist und in andern anshlieh, ist nicht zu entscheiden: bei dem vollkommenen Fehlen der zugehörigen sinalyanglien im ersten Fall wird aber wohl niemand zweifehn wollen, dak sich hier diesensiblen Wurzeln und die Hinterstringe antogen regeneriert haben. ${ }^{1}$ ) Nach diesem Befund wird man in Zukunft mit der Anwendung der Wallerschen Deweneration zu anatomischen Zwecken bei jungen Tieren etwas vorsichtig sein müssen.)

Einen ähnlichen Versuch hahe ich auch an motorischen Wruzehn answeführt. Bei einem sechs Wochen alten IIunde wurde das Riückenmark freigelest und extradural fünf motorische Wurchn durchschnitten und ein Stiick von $1 / 2-1$ (an herauspeschnitten. I)as linke IInterbein war motorisch ganz gelähnt, aber an allen stellen rezcptorisch. Nach zwanzig Tayen wurde der Ischiadicus freigelegt und gereizt. Dats Tier schrie, aher es traten nicht die seringsten Zuckumen in der immervierten Mnskulatur ein. Darauf wurde der Nerr durehsedmitten und die Enden nach Heransnahme eines kleinen Stiickes wieder durch Xaht rereinigt. (Das ausweschnittene stiick zeigte, wie zu erwarten war, viele sanz erlaltene Fasern [die rezeptorischen] und eine grobe Anzahl wanz degenerierter [die motorischen]., Die Rezeptionsfähorkeit

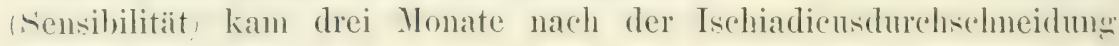

1) Nach den neueren Untersuchungen von Nissl (1903) liegen die Verhältnisse an den Spinalganglien nicht so klar, als man bisher angenommen hatte. Die

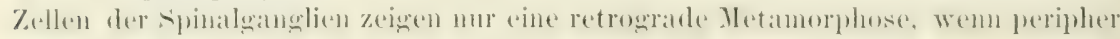
vom Ganglion durchschnitten wurde, dagegen bleiben sie intakt, wenn die sensible Wurzel durchsehnitten wird. Andrerseits degenerieren aber im letzteren Fall gewisse Hinterhornzellen. Diesem Befunde nach miißte man die Fasern der linteren Wurzeln als die Achsenfortsätze von Hinterhornzellen ansehen. Andrerseits spricht aber die Art und Weise, in der die Wurzelfasern degenerieren, dafür,

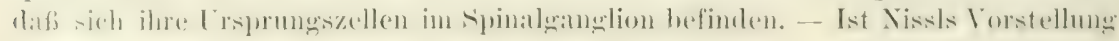
richtig, so erscheint der oben beschriebene Befund in einem andern Lichte. 
wieder. Die Beweglichkeit des Beines kehrtenichtzur ü k: a uch diestäksten Reize brachten keine reflektorischen Zuekungen in demselben herrol. Es hing stets ganz schlaff

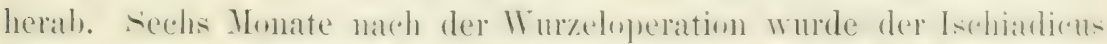

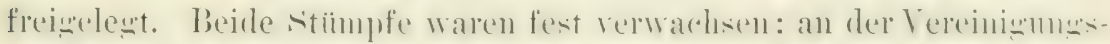

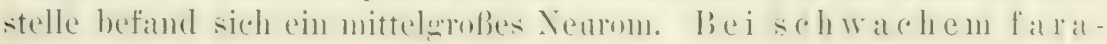
dischem Reiz unterhalb des Neuroms zuckten die Muskelindes Unterschenkels und Fu Bes. Um oberhalb des Neuroms

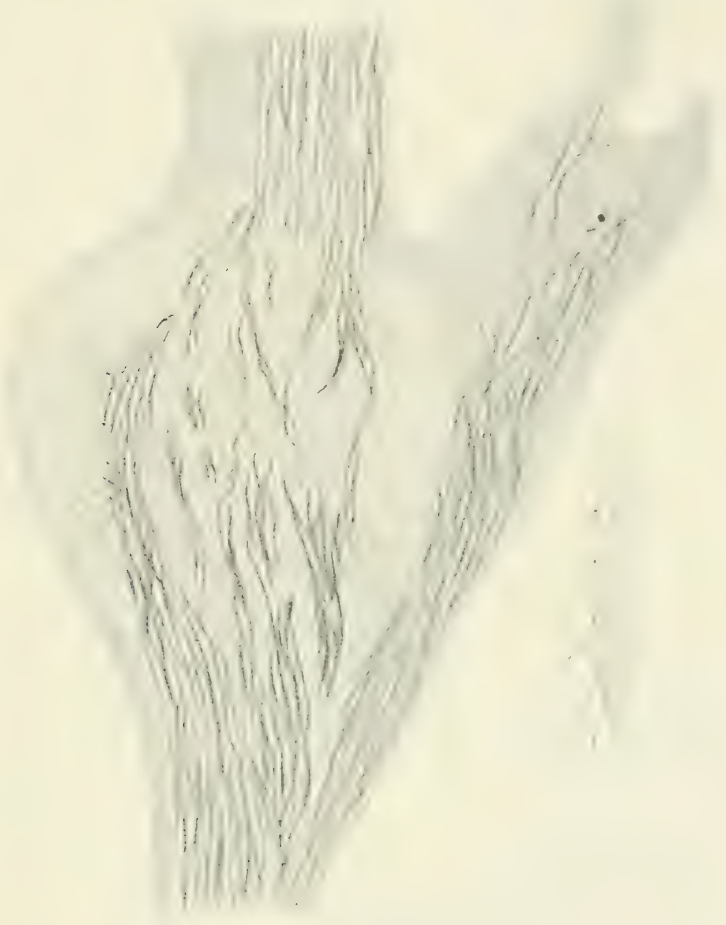

Fig. 55. Spinalganglion mit daran hïngendem peripherem Stumpf der motorischen Wurzel, welcher frei flottierte. Sechs JIonate nach der Wurzeldurchschneidung. - Unten rechts eine Skizze des Sektionsbefundes.

Zuckmugen in diesen Muskeln anszulïsen, muBten die Rollen $11 n$ a con senälert werlen. Ich komnte sie dann aber anch von den \%entralsten. moch creichbaren stellen des Nerven anslïsen die höchste stelle war

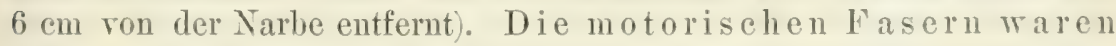
also im zentralen und peripheren Ende des Nerven autogen regeneriert und an der. Durehtrenuugstelle wieder zusammengewachsen, gradeso, als ob das zen. trale Ende noch mit seinen Ursprungsellen in Zu-

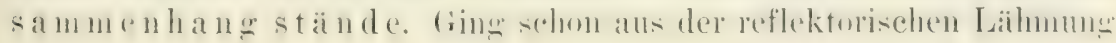


des beines hervor, daß lein Zusammenhang zwischen motorischen Fasern und Rïrckenunark bestand, so komnte dies noch durch den anatomischen Befund erhärtet werden. Zwischen den zentralen Enden der motorischen Wu\%eln und den periphleren stïmpfen derselhen lag

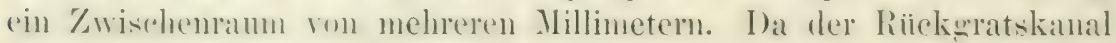
nicht von Varbengewebe erfüllt war, so lieb sich dies olne künstliche P'riparation feststellen: Die Enden der Wruzeln flottierten frei im Kanal Fig. 5.5); die zentralen Enden zeignten dicke Neurome. die peripheren waren zuseepitzt. Schnitte durch das spinalsanghlion nebst

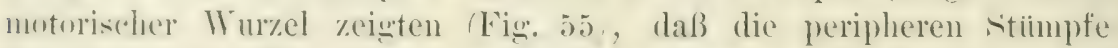
der motorischen Wurzehn nach dem Rüickenmark zu blind endeten und mit einer Kappe von l'erineurium hedeckt waren. Es kamm also nicht daran sezweifelt worden, daß antogene Regeneration voliewt. Was an diesem befund gexeniber den schon mitgeteilten neu ist, ist die Tatsache, dab getremute Nervenfasern anch bei der antogenen Regeneration wieder anatomisch und funktionell zusammenwachsen können! ${ }^{1}$ )

Dieser Versuch leitet zu der Frage ïber, in welcher Weise die Vereinimug durehsehnittener Nerven zustande kommt, von wo ans. der Defekt, wemn einer da ist, ansgefüllt wird. Er entscheidet sie schom in sewisser Weise nämlich dahin, daß z ur anatomischen, und funktionellen Vereinigung zweier Nervenstücke eine Beteiligung des sogenannten trophischen Zentrums, der Ganglienzelle, nicht notwendig ist, daß viehmehr den Vervenelenenten an sich die Fïhigkeit zukommt, sich nach Kontimuitästremung wieder miteinander zu rereinigen. Die bis jetzt herrschende Ansicht steht dem entagegen; sie behauptet, daß, wie die Regeneration iiberhaupt, so auch die Ausfüllumg des nach der Durehschneidung entstandenen Defekts lediglich vom zentralen Ende ans weschicht. IJervorerufen ist diese ältere Anschanung hauptsiichlich durch den Befund, daß nach Exzision eines größeren Nervenstiickes das zentrale Ende des Nerven ein beträehtliches stïck answächst, während das periphere keine Tendenz zeight, sich dem Zentrun wieder z.11 nïhem. Dieser Befund hat ja anch \%ur Ausbildung der Theorie heigetragen, dak die Fasern des zentralen stumpfes hei der Regeneration in den peripheren hineinwiichsen und ihn, wie sich Vanlair (1882, 1885, 1888) ausdriickt, neurotisierten.

Auch hier ist wieder der Unterschied zwischen zentralem und peripherem stmunf nur relativ; er ist allerdings bei crwathenen Tieren

1) Da die Wurzelstiimpfe frei flottierten, war es in diesem Fall ganz ansgeschlossen, daß von benachbarten Muskeln her Markfasern in die Stiumpe eingewachsen waren, wie dies Münzer (1902) annahm. 
so bedentend, daß man ihn ohme hesomders daranf gererolitete Entel-

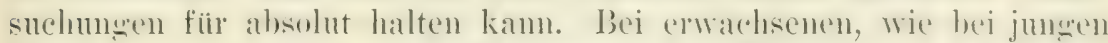

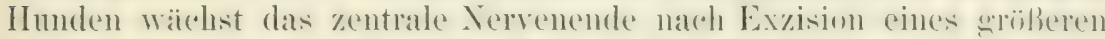

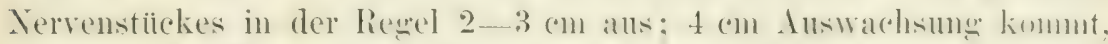
wie auch s'chiff schon angiht, nur solten rol. I)as Ïukerste, was ich beobachtet habe, sind 5 cun. In manchen fällen fand ich aber anch viel geringere Werte - $1 \mathrm{~cm}$ und noch weniger. Wie lang die einzehen answewachsenen Fasem sind, läßt sich natiulich schwer beurteilen, weil sie imnerhalh des Teuroms sehr geschlängelt verlanfen mud der Ort der Inrchschneidungsitelle nur dam hei der Sektion mit vicherheit festgestellt werden kam, wem man an derselben einen seidenfaden durcherezogen oder eine andre Narke angehracht hatte. Das Neurom selber wiht nur einen ungenanen Anhaltspunkt, weil es manchmal sehr mbestimmt abgenrent ist und die Lagne der Tremmungstelle manchmal, wie Tersuche nit reidenfärlen erwaben, an Anfang bisweilen aber anch beinahe in der Mitte des Veuroms welegen ist.) Wem man diese relativ kurzen Strecken, welche das zentrale Ende anszurachsen vermag falls es nicht auf sein peripheres Ende trifft, mit den strecken veroleicht, die es beim Zusammentreffen mit dem peripheren Stumpf nach der Ansicht von Wallers Anhängern ,neurotisieren" kann (50 cm und noch mehr), dann sollte man meinen, daß ron einer Auswachsungstheorie gar nicht die Rede sein könne. Die Anhänger dieser 'Theorie haben auch sehr wohl eingesehen, dab hierin ein IViderspruch liest und hahen deshalb zu der Anmahme gegriffen, daß der periphere stumpf des Nerven ein besonders gruter Sährboden für die rom Zentrum answachsenden Nervenfasern sei. Mir scheinen aber die dafür angefuibrten Tatsachen eine ganz andre Erklärung zuzulassen.

Charakteristisch für auswewachsene Nervenstümpfe ist, dath sic fast nie stmupf enden. sondern in eine, öfter mehrere lange spitzen answeznen sind. Diese oft fadenfïrmigen Gebilde enthalten nehen perineuralem Bindegewebe viele Vervenfasern. Trem num an peripheren Ende nach vollkommener Tremmmg vom Zentrum kieine Answachsung zum Zentrum hin stattfinde, so miißte der stumpf an der Jurchschmeidungsstelle auch nach Wrochen und Monaten keine Veranderumg darbieten. Das ist aber niemals der Fall. Bei jungen wie erwarlsenen Individuen findet man fast nie den peripheren stmmpef

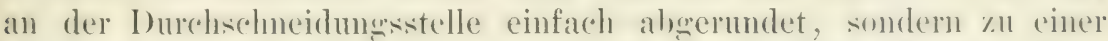

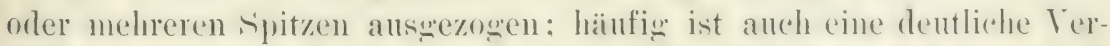

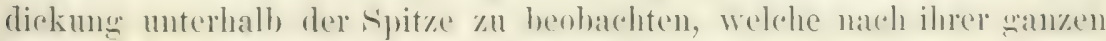
struktur als richtiges Nemon zu lezedohnen ist. Es erredeht \%wa nie die Dicke der Nemome, welele man an zentralen sitimpfen zu

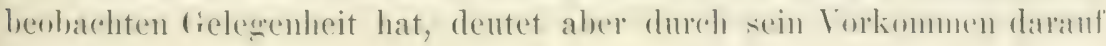


hin. daß auch an peripheren stumpf Wachstumserscheinungen auftreten. Besonders an den peripheren Nervenstiinpfen junger Tiere sind die fadenfömigen Ausläufer manchmal recht lang $11-2 \mathrm{~cm}$. -ie enthalten, wemn cine stäkere antogene Regeneration eingetreten ist, neben perinenralem Bindegewebe eine mehr oder weniger reichliche Menge markhaltiger Nervenfasern. Bei erwachsenen Tieren erreichen diese von der Inurehscheidungsstelle auswehenden Ausläufer meist nur eine ereringe Länge bis zu 1 cm). Man findet in ihnen neben Bandfasern reichliche Achsialstrangfaseru. Danach erscheint es auber Zweifel, dak auch an peripheren stumpf nach rollkommener lontimutiitsunterbrechung ein Answachsen der Fasern mach dem Zentrum \%.11 stattfindet. Ein weiterer Beweis hierfür liegt in der Beobachtung, dak fast durehgängign in der perineuralen Kappe dieser stumpfenden bei jungen Individuen! markhaltige Fasem gefunden werden, welche in dem Bindegewebe des Nerven ein ganzes Stiick imanchmal 5- i mm rïckwärts verlaufen (Fig. $51 A$ \&. 194. Da normalerweise keine oder nur außerordentlich wenige Nervenfasern immerhalb des Perineuriums sefunden werden, so muß angenommen werden, daß diese Fasern von der Durehschneidungsstelle aus in das Perineurium hineingewachsen sind. (1) anch bei den peripheren Nervenstimp,fen erwachsener Tiere Fasem vorkommen, welche in das Perineurim hineingewachsen sind, weiß ich nicht bestimmt zu sagen, weil die fäberische Differenzierung der Achsialstrangfasern zu sehwer ist, un einzehe Fasern mit sieherheit innerhalb des Bindegewebes nachzuweisen.

Danach wachsen also die Fasem des peripheren Stmmpfes gradeso iilser die Durehsehneidungsstelle hinaus wie die des zentralen Stumpfes, nur ist die Wachstumsenergie bei ihnen geringer als bei jenen. Das Auswachsen der Fasern ist Funktion des Verven und nicht der (ians.lienzelle. - Wie kommt es zustande? Hieriiber kamn man natiurlich nichts Bindendes anssagen, weil man es nicht direkt beobachten kam; aher man kann doch wenigstens Vermutungen aufstellen, die sich durch Tatsachen stiitzen lassen: Ebenso wie eine Kernvermehrung und P'rotoplasmawucherung immerhalb der Fasern des peripheren stumpfes und derjenigen Faserabschnitte des zentralen stumpfes, welche der Dexeneration unterliegen, stattfindet, so teilen sich auch die Kerne, welche direkt an der Inrehschneidungsstelle liegen. Inf diese Weise verlängern sich die Fasem im peripheren und zentralen stumpf iiber die Durchschneidungsstelle hinaus. Zunächst bestehen diese Verlängermugen aus Bandfasern, sie metamorphosieren sich aber in derselben Weise wie die ïbrigen Bandfasem anch: Im zentralen Ende werden sie in jedem lall zu markhaltigen Fasem, an peripheren nur bei junten Tieren; bei älteren beiben sie hier wenn keine Zusanmen-

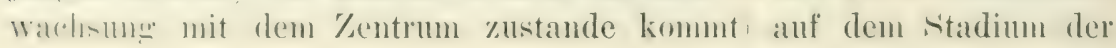


Ichsialstrangfasem stehen. Eine ganz ähnliche Ansielit ïher das Auswachsen der Vervenfasern - allerdings nur der des zentraten stumpfes - hat Ziegler (1596, aufurestellt. Nach ihm soll nach Kontinuitätstremung die liegeneration nur von zentralen Ende ansgelien, aber nicht durch Answachsen des Achsenzylinders von der Ganglienzelle, sondern durch Bildung rom Zellenreihen, welche sich nachtrïglich in Tervenfasern umbilden. Diese Zellenreihen sollen in der eben weschilderten Weise von dem periphersten Schwannschen Kern des zentralen Endes, dessen Fanserabsehnitt grade noch degeneriert ist, durch immer wiederholte Teilungen desselben ansgehen. Der Lnterschied gregen meine Ansicht besteht nur darin, daß Ziegler den P'rozel3 nur ron einem Kern jeder Faser ausgehen läßt und die ganze Regreneration auf die Vermehrung desselben zuriekführt, eine Ansicht, die angesichts der Tatsache ron der autogenen Regeneration wohl sicher falsch ist.

Stoßen Fasern des zentralen und peripheren Endes während ihres einander entgegengerichteten Wachstums zusanmen, so vereinigen sie sich miteinander, - so wird man wenigstens ammehmen mïssen. Ich mïchte glauben, daß diese Vereinigung aber nur so lange möglich ist, als beide zusammenstoßenden Fasern noch auf dem stadium von Bandfasern sind. Doch habe ich hierfür keine sicheren Beweise. - Daß durchschnittene Nerven wieder zusanmenwachsen kömen, ist seit dem Ende des achtzehnten Jahrhunderts durch so viele physiologische Experimente und klinische beobachtumgen (wegen der Literatur siehe Th. Kölliker, 159", und speiser, 1902, erwiesen worden, daß es keiner weiteren Belege bedarf. Hierbei handelt es sich aber meist um die Zusammenheilung eines zentralen Stumpfes und seines zugehörigen peripheren stmmpfes, also um das natuirliche Verhältnis. Siehr viel weniger ist untersucht worden, wie sich zwei fremde Nerrenstilcke zneinander verhalten, ob anch unter unnatiorlichen Verhïltnissen eine Vereinigung der Nervenquerschnitte stattfindet. Es erwibt sich hier gleich eine große Anzahl von Fragestellungen, welche bisher nur zum kleineren Teil Bearbeitung gefunden haben. Ich will nu einen Teil dieser Fragen hier besprechen.

1. Kamn das zentrale Ende eines Nerven mit dem peripheren eines andern, eventuell länzeren Verven zur Verwachsm gehracht werden? Ein derartiger Versuch wurde zuerst ron Flonmens an IJuhn

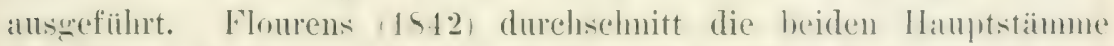
des Plexus brachialis anf einer sieite und vernälate die zentralen und

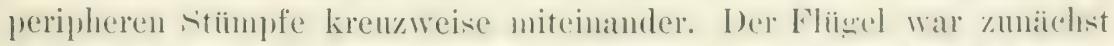
grelaihnt, wurde aber nach einigen Monaten wieder bewent mul komnte

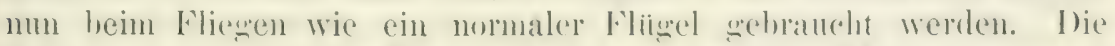

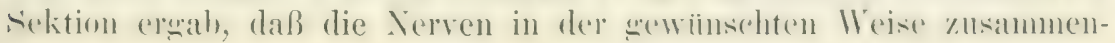


weheilt waren. Ïlmuliche Nervenkleuzungen sind won Rawa, stefani

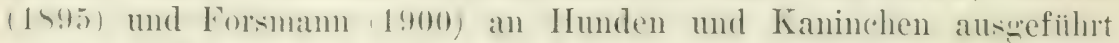
wrilen. Forsmam stellte anch Veroledohsersuche \%wischen natiu-

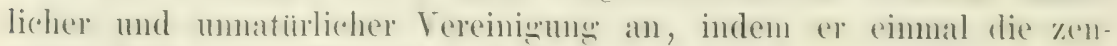
tralen Enden des Thibialis mol l'emens mit den zuselörigen peripheren Enden zusammenwaldsen lied, das andere Mal eine krenzweise

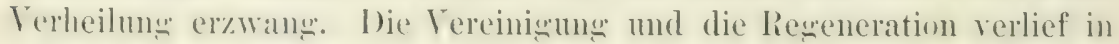
beiden Fällen seleich solunell. In andern Versuchen wurle der zentrale

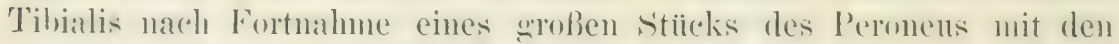
feripheren stimupten beider Nerven zusammengeluacht. Beide peripheren stimpfe wurden in weicher 1 reise von den einen rentralen

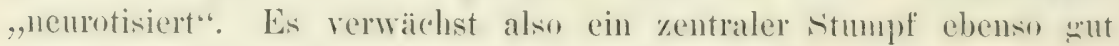
mit einem fremden peripheren Stumpf wie mit dem eignen.

Thie diese Antoren das Experiment zwischen den Nerven ein und derselben Extremitait anstellten, so machte ich es zwischen rechts mul links. Einem Hunde wurde der Ischiadiens anf der linken Fieite anı Kinie, auf der rechten Seite am Formmen ischiadici durchschnitten. Es wurde sodam der Damm aufüeschnitten und das periphere Ende des linken, zentralen situmpfes und das zentrale Ende des recliten, peripheren stumpes nach Durchsteckung durch die jederseitige, immere (Derschenkelmuskulatur an Damm miteinander vernäht. Inf diese Weise war also das zentrale Ende des linken Ischiadicus mit dem peripheren des rechten in Verbindung gebracht und die Nervenstrecke etwa nun die llälfte ihrer natiurlichen Länge vermehrt. Nach sechs Monaten stellten sich auf der rechten seite in dem rom Ischiadicons immervierten Gebiet Rezeptionsfähigkeit und Motilitait wieder her. Nach sieheneinhalh Ionaten wurde der Ischiadicus links ohen freigelegt und wereizt: Es kontrahierte sich nur die Muskulatur des Lnterschenkels und des Fußes der rechten Seite. Darauf wurde die Sektion gemacht, welche eine vollkommene Vereinigung des linken zentralen und rechten peripheren Ischiadicus ergah. Letzterer sah wieder schön weiß ans mul cuthielt sehr viele markhaltipe Nervenfasern. - Jan kamm also einen Nerven iiber das natürliche $\mathrm{Maß}$ verlängern.

2. Was wird aus einem Nerven, der an zwei stellen durchschnitten ist, oder in den nach Inurolsschneidung ein stitck eines andren Nerven ringesetyt ist? Es existieren iiber diese Frage mehrere Lntersuchungen.

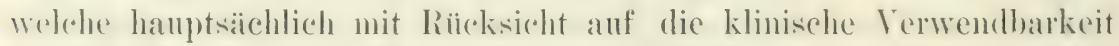

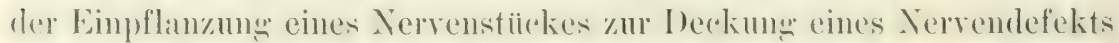
angestellt sind. Wrenen der diesteräglichen Literatur rerweise ieh ant

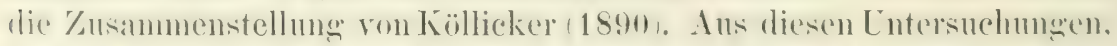

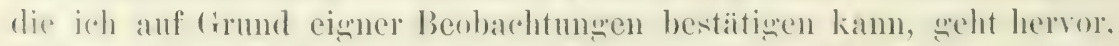

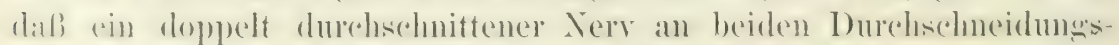

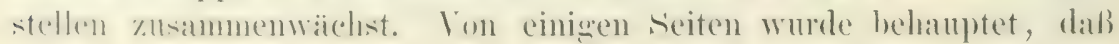


die Vereinigum an der periphereren ["nterbrechumgstelle immer erst damn eintrite, wemn die Rexeneration vom zentralen Ende answelend bis hierher vorgedrungen sei. So wie diese ganze Torstellung der

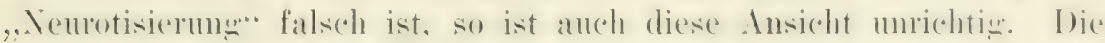

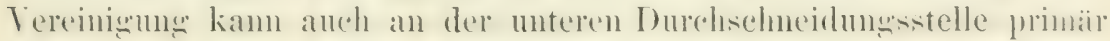
erfolgen. - Vou einigen Seiten ist angegeben worden, daß man zư beckung eines Defektes einen Verven von irend einem andern Tier nehmen kömne. Forsmam hat dem in nenerer Zeit lebhaft widersprochen und darauf anfunerkam permacht. daß ein Nerv cines andren 'Tieres ciner andren Art nur als Leitschnur für die wachsenden Fasern dient, die man grade so gut durch einen Faden ersetzen kann. Zur

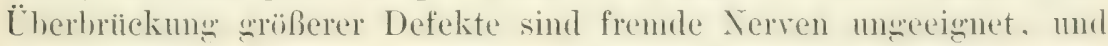
die Vereinizun kommt kamm anf gröBere strecken zustande als sie schom ohne Zwischenschaltung weschicht. Dageren ist die Zwischenschaltung aines Nervenstiokes von derselhen Tierart rom sehr wutem Fofoly hegleitet: dic Vereinigung des zentralen und peripheren Endes ist auf diese Weise auch bei wroßer Entfermung ilner Enden möglich. und es werden bei dieser Eimpflanzung Nervendefekte iiberbriickt, welche ohme ein derartises Mittel allein durch Answachsug der Situmpe nicht ausgeglichen wirden. Während hei Einpflanzung eines Tervenstiickes ron einer fremden 'Tierart (\%. B. Taube orler Meerschweinchen hei einem Kaninchen, die Fasem des zentralen stumbles nu l d u reh das Bindewew be des fremden Nerven hinduchwachen, nehmen sie in diesem Fall den Weg durch die Nerrenfasern des einseschalteten Vervenstüros. Formann steht auf dem Buden dex Auswachsungstheorie. Nach meiner Auffassme wachsen nicht die Faseln des zentralen situmpfes in die des eingeschalteten stiuckes linein, sondern zwingen sie, sich vollständign zu regenerieren, nachdem sie sohon volher ins Bandfaser- oder Achsialstrangfaserstadim getreten sind. Anch nach meinen Erfahruneen ist die Finpflanzung eines Vervenstiickes ron wesentlichem Vorteil, wenn es sich darmm handelt, spobe Zwischenräume zwischen zwei Nervenenden zu ïberbricken. Es scheint mir aber, daf man bei einer solchen Einpflanzung Irert darauf lewen muß, daB das eingepflanzte Stück die natioliche Orien-

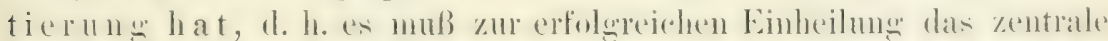
Ende des eingeschalteten Nerrenstiocks an das zentrale Ende des

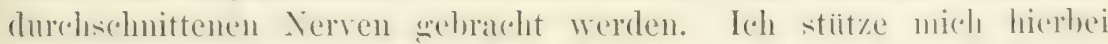
auf folgenden Versuch:

Einem jungen Hunde wurde in Alter von acht Wochen der Ischiadicus rechts und links freigelegt. Anf beiden Seiten wurde in der

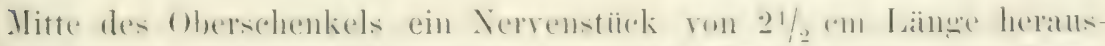

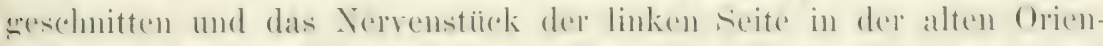

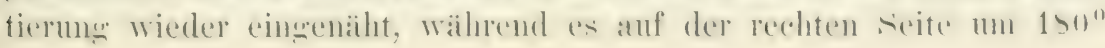


medreht und so nit dem zentralen und peripheren Vervenende in umgrekehrer (bientierung vernäht wurde. Die hierbei ansgeschnittene Torrenstrecke ist nicht so lang, daß sie nicht von zentralen Ende aus durchwachsen werden könnte. Ich habe sie mit Alsicht so gewählt, damit die Fasern des zentralen Endes anch auf der rechten seite das periphere, nit dem . In skel zusammenhängende stäck erreichen kïnnten. falls das eingeschaltete, mugekehrt polarisierte stiuck nicht in wirkliche Verwatchsun träte. Nach drei Monaten kehrte anf beiden seiten Intilitit und Rezeptionsfähiskeit wieder, nach vier Monaten war heides ganz normal. Es wurde nun auf beiden Seiten der Nerv zum zweitemual und zwar oberhalh der zentraleren Verwachsungsstelle durchschnitten. Nach weiteren vier Tagen wurde der Hund gretötet. Iuf heiden seiten war das Zwischenstiick anatomisch gut eingeheilt; auf der rechten Seite war es dicker als auf der linken Seite.

Auf der linken seite richtige Orientierungi zeigten sich fast alle Fasem des peripheren Endes bestehend ans einem kleinen stiick des früheren zentralen Endes $c$, dem Zwischenstiick $z$ z und dem ganzen friiheren peripheren Ende ( $p$ ) his zur Peripherie hin in starker Degeneration Ellipsoidbilduug. In $z$ und $p$ fanden sich ganz wenige Fasern, welche nicht degeneriert waren, in c gar keine. Anßerdem waren in : und $p$ einige Fasern vorhanden, welche auf dem Achsialstrangstadium standen, also nicht ganz regeneriert waren. - A uf der rechten Seite "Zwischenstiick $m$ 180" "zedreht, verhielten sich Stiick $c$ und $p$ grade so wie links, Stïck $z$ aber ganz anders. In $z$ waren hier neben vielen sanz degenerierten Fasern eine grobe Anzahl von Fasern vorhanden, deren Markscheiden vollstä ndi心 intakt waren, anßerdem fanden sich sehr viele Fasem, welche auf dem stadium von Achsialstrangfaseru standen. Auf Längsschuitten, wo sich die Verhältnisse allein beurteilen lassen, konnte ich folgende Zahlenverhältnisse feststellen ies wurden mehrere sichnitte (durchgezählt):

$\begin{array}{lccr} & \text { Markfasern (erhalten) } & \text { Markfasern (degeneriert) } & \text { Marklose } \\ \text { Stiick } z \text { links: } & 4-6 & 80-100 & 10-12 \\ \text { Stiick } z \text { lechts: } & 36-40 & 80-90 & 20-40 \\ \text { Stiick } p \text { links: } & 1-2 & 80-90 & \\ \text { Stiick } p \text { rechts: } & 2-3 & 80-85 & \end{array}$

Ich erkläre mir diesen Befund folgendermaßen: Die Nervenfasernbesitzen eine Art von Polaritat; sie wachsen in der liewel nux dam znsammen, wemn die l'olarisation der zusanmenstoßenden buerschnitte entegenengesetzt ist. Es verwächst also das zentrale Ende rines heransgeschnittenen Nervenstiockes / was die Fasern selber anberifft, mit den peripheren Einde eines zentralen stumpfes, aher 
nicht mit dem zentralen Ende eines peripheren stmupfes und unwekehrt. Auf der rechten seite meines Hundes war die l'olarität des Zwischenstückes nugckehrt; die Fasern desselhen komut(n sich also weder mit denen des zentralen stumpfes noch mit denen des peripheren veremigen. Da es sich aber um ein jumges 'Tier handelte, so komnten sich die Fasern des Zwischenstiickes antowen bis zum Markfaserstadium regenerieren. Als solche at togen regenerierten Fasern sehe ich diejenigen des Zwischenstickes an, welche nach der zweiten Durchschneidung nicht degenerierten. Sie konnten auch nicht degenerieren, selbst wemn ihre nach dem Zentrum zu gerichteten Enden iiber das obere Nenrom hinauswewachsen und bei der zweiten Iurchschneidung verletzt waren, weil es sich dabei re vera um eine Verletzung ibres peripheren Endes gehandelt hätte, welche nach den auf S. 196 besprochenen Befunden keine Degeneration ihres zentralen nur durch die Operation nach der Peripherie gewendeten Endes hervornfen könnte. - Auf der linken Seite, wo die Polarisation richtig war, haben sich die meisten Fasern des zentralen Endes mit denen des Zwischenstiicks mol diese wieder mit denen des peripheren sitiokes verbunten. Die wenigen Fasern, welche nicht zum zweitenmal deseneriert sind, sind solche, die keinen Anschluß gefunden haben und autogen regeneriert sind, ebenso haben die wenigen Achsialstrangfasern keinen Anschluh ereicht. Hier im linken $/ \mathrm{W}$ ischenstiick liegen fast alle Fasern innerhalb der alten Bahn; dagegen verlaufen im rechten Zwischenstiek sehr viele Fasern - und das sind ausschlieBlich degenerierte - a u Berhalb deralten Bahn im perineuralen Bindegewebe. Hier fanden die auswachsenden Fasern des zentralen Endes keinen Inschluf an die Fasern des rwischenstückes; sie wuchsen zwischen ihnen im Bindegewehe weiter, aher ebenso gut im Perineurim, wie im Endoneurium. Erst im peripheren Stumpf trafen sie a uf die richtige Polarisation der Fasern; sie konnten sich mit diesen verhinden wodurch ihrem Weiterwachsen ein Ende gesetzt wurde) und infolgedessen war die zweite Duchschneidung im peripheren Stumpf wie im ganzen liuken Nerven von einervollständigen Degeneration fast aller Faseln gefolgt.

Ich gestehe zu, daß es mißlich ist, die Hypothese der Nervenpolaritat nur auf einen Befund anfmubuen, und ich wiirde dies nicht enetan haben, wenn nicht noch andre Tatsachen durch dieselhe eine

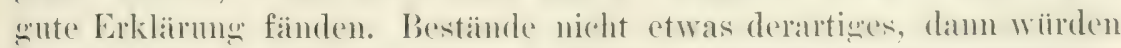

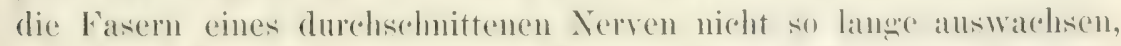
bis sic auf richtign polarisierte Fasern eines peripheren stumplest 
träfen, sondern sich unteremander verbinden. Auch das Nichtrerwatchsen zweier zentraler Xervenstïmpfe - anf das ich wleich zuriickkomme - läßt sich durch diese Hypothese leicht erklïren. (Im

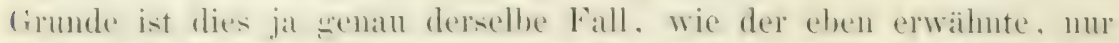
dak die Fasem zweier Verren statt eines Xerren ror die Mäglidheit grestellt sind. sich miteinander zu verbinden. - Schließlich sei nom

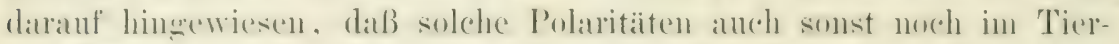
und I'flanzenreich rorkommen. liesmolers bei Pflanzen sind sie sehr

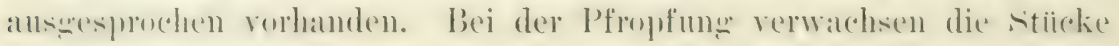
immer nur, wenn sie in der richtigen Polarisation eingesetzt sind.

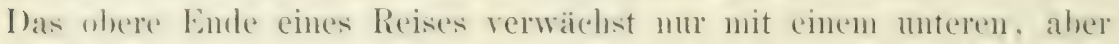
nicht mit einem andern oberen und mugekehrt siehe die Abhandlung von Vöehting, 1892).

3. Können zwei zentrale Nervenstümpfe miteinander verwachsen? Ein Versuch nach dieser Richtumg hin wurde zuerst ron schiff 1855, angestellt. Die Fragestellung war allerdings hei ilm eine etwas andre. Er wollte sehen. oh sensible Terren imstande wären rückwärts zu leiten. Zu diesem Zweek suchte er am Bein zwei Nervenäste auf, welche bei der Reizung nur reflektorische aber keine motorische Wirkung zeigten, die also rein semsibel waren. Er durchsolnitt beide und vereinigte die zentralen Enden durch Nibts. Nach einigen Inonaten wurden die Nerven wieder frei gelegt — sie waren verwathsen - und gereizt: dabei zeiwten sich wieder Reaktionen des Tieres von beiden aus. Es wurde num der eine Nerv so hoch wie möslich durehschnitten und sein peripheres Ende, das ja mit dem andern Verven zusammengewachsen war, gereizt. Anch bei starkem Leiz traten keine Reaktionen mehr ein. Lm diese wieder zu erhalte'n, mußte der Reiz an dem andern Nerr oder mindestens an der Narbe angesetzt werden. I)ie beiden zentralen Vervenenden waren also entweder nicht miteinander funktionell vereinigt oder die sensiblen Fasern waren nicht instande, riickwärts zu leiten. Die mikroskopisehe Lnter-

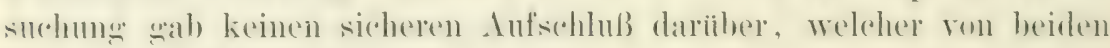
Schlïssen der richtige sei.

Außer diesem Versuch existieren, so weit mir bekannt geworden

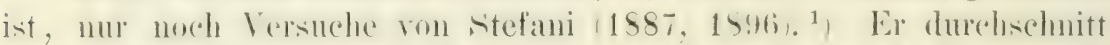
hei me-heren Hunden und Kanineloen den Radialis und Medianns und vereinigrte ihre zentralen Enden durch Naht. Nach zwei bis fünf

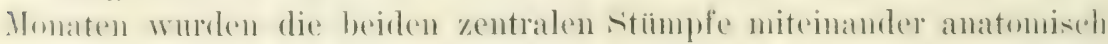
vereinigt gefunden. Es wurde nun einer der Nerven hoch durch-

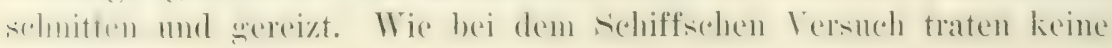

1) Inzwischen haben Langley und Anderson (1902) ähnliche Versuche mit demsellyen Resultat wie Stefani angestellt. 
Die Zusammenheilung durehschnittener Nerven und die Nervenregeneration.

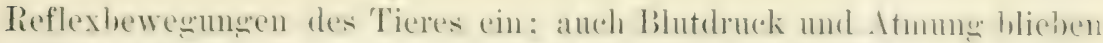
wähend der Reizung unverändert. Erst weun der Reiz die Narbe traf oder an dem unzertrennten Jerven angesetzt wurde, traten Reflexbewegungen u. s. w. ein. Die Narbe zwischen den beiden zentralen Nervenenden war also für Reize undurehgängig. — Bei zwei andern Hunden fïlnte stefani 1896 dieselle (l) pration ans, allem mit dem Lntersehied, dals er den Radialis nach der Vernähnum semes zentralen stmuptes mit dem des Mediamus hoch durchschnitt. Fs

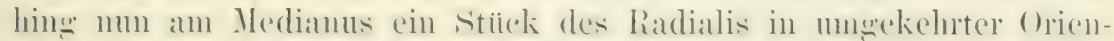
tierung. Sach zwei Monaten wurde die Wunde wieder seäffnet. Am Medianus hing ein kleiner rötlicher strang, welcher als der Rest des

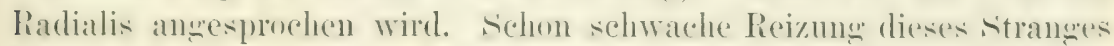

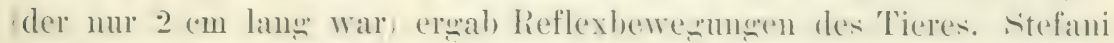
schliebt aus diesen Versuchen, dak zwei zentrale Nervenenden nicht zusammenheilen kimmen, wemn sic beide mit ihren Lrspruntsuanelienzellen in Zusammenhang stehen, daß aber eine Zusammenheilumestattfinder, wemn der eine Jery ron diesen Lrsprumesellen wetremit ist. Mir scheint dieser fichlub nicht zwingend zu sein. In ersten Fall bleilst immer noch die andre Erklärune, daß zwar cine Zusammmenheilumg stattegefunden hat, dab aher die Fasern nu einseitig leiteten.

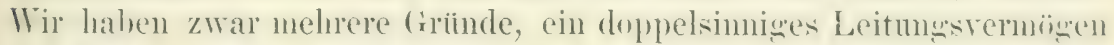
der Nervenfasern anzunchmen, doch scheinen mir dieselben nicht so alsolut heweisend, als es von den meisten Antoren ansenommen wirl. In жweiten Fall, wo der eine Nerv durchschnitten wurde, kann mall elonso wnt eine Luswachsumg der Fasem des Medianus in den un-

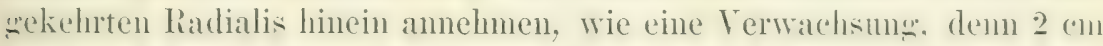
ist eine Länse, die auswachsente Fasern mit Leichtipkeit erreichen.

Um zu sehen, wie sich die Fasern zweier vereinigter zentraler stimpfe zueinander verhalten, hahe ich wieder dic Hethode der be. seneration angewandt. Lne die heiden Nervenduerselnitte hesser rinander adaptieren zu kïnnen, vereinimte ich nicht zwri Verven dersolhen folieduafe, somdern den rechten und linken Ischiadions. Inf beiden rieiten wurle hei einem zwei Monate alten Humle der Ischial-

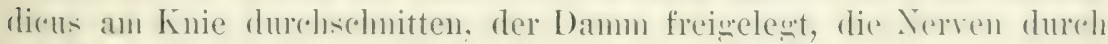

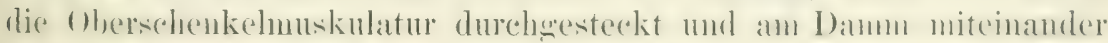

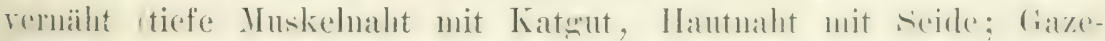

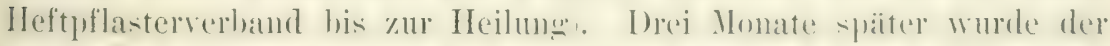

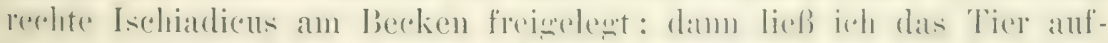

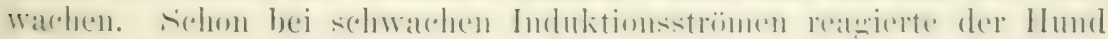
mit Schreien und Berregen des Körpers. Daranf wurde der Nerv durchschnitten. Reizung des zentralen Endes gab nach wie vor Schreien, Reizung des peripheren, wenn anch noch so stark, luatte gar keinen Effekt. Ich ließ den Hund noch vier Tage am Leben, 
eine Zeit, die nach meiner Erfahrung ausreicht, um alle Faser-

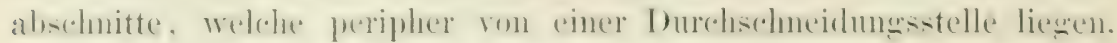
bis auf die Höhe des Markscheidenzerfalls zu bringen.

Vor der Tötung wurde der ganze Damm aufgesehnitten und das

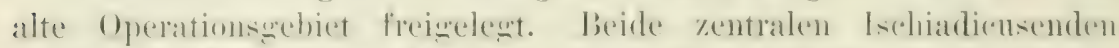

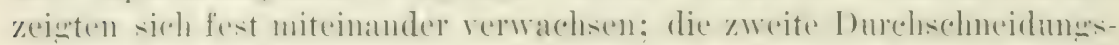
stelle des rechten war $4 \mathrm{~cm}$ ron der Narbe entfernt. Wurde dieser liest des rechten Ischiadicus fereizt, so fand wie rier Tage

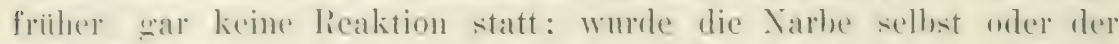
linke stanum wereizt. so trat sofont eine leftige liealition ein. Ilierin stimmt also mein Versuch ganz nit dem sichiffs mod denen stefanis:

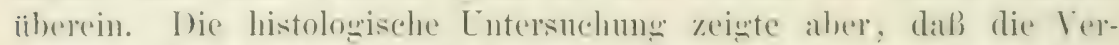

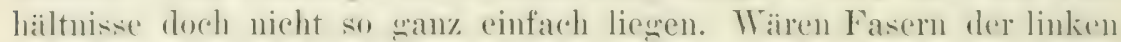
und rechten seite mit ihren Quersehnitten \%usanmengewardsen. so knmten sie sich entweder indifferent we weniihser einer zweiten Durchschmeidung verhalten oder aber ihre alte Dewenerationsalbhängigkeit von der Intaktheit ihres zentralen Absehnitts bewahrt haben. Im ersteren Fall wïrden sie nicht degeneriert sein, im zweiten würde man erwarten müs-en, daß die Fasem des rechen lechiadiens bis an die Xarbe degeneriert wären und hier unvermittelt in wohlbehaltene Fasem iilserwingen. Waren die Fasern nicht zusammenteheilt, damm komnten entweder die Fasem jeder side anf ihrer seite stebliehen sein oder sie komnten durcheinander sewachsen sein. In letzterem Fall mußte man desenerierte Fasern anf heiden seiten der Narbe vorfinden. Dies letztere war der Fall: in der Narbe fanden sich etwa gleichriel erhaltene und desenerierte Fasern. Die crhaltenen nahmen run dort ans in den rechten Nerven hinein inmer mehr al, fanden sich hier aber noch mehr als $2 \mathrm{~cm}$ ron der Narbe entfernt in erheblicher Zahl) und wurden in den linken Verven hinein inmer zahlreicher Fiw. 57 A S. 229); bei den degenerierten Fasern verhielt sich die

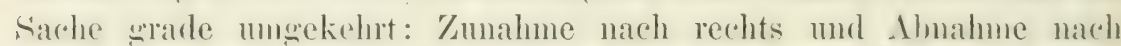
links. Nirgends aher sah ich ene degenerierte Faser sich direkt in rine erhaltene fortsetzen; sie endeten natch links hin immer blind, ehenso wie die erhaltenen Fasern auf der linken Seite unrermittelt abhachen. Zun erwähnen ist noch, daß die Fasern der fremden seite ulie degenerierten anf der linken, die momalen anf der rechten sich

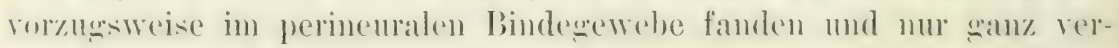
einzelt in den Nerrenstämmen selber.

Danach halte ich es allerdings für gesichert, daß sich die Fasern zweier zentraler stïmpfe nieht miteinander verbinden und erkläe dies auf Grund einer l'olaritat. Ine Fasern kionnen aber von einem stmmpt in den andern hineinwachsen, inden sie hier das Bindewewehe als Bahn bemutzen. 
Dies Auswachsen scheint aber nur bei den motorisehen Fasern statt-

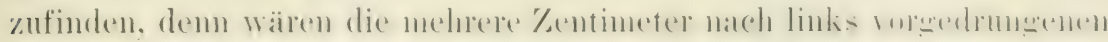
Fasern auch nu zu einem kleinen Teil rezeptorisch, so müßte das

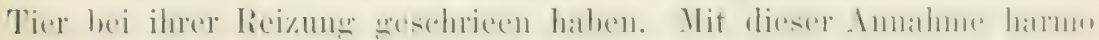
niert der Befund, daß auf beiden Seiten der Narbe die Zahl der erhaltenen resp. degenerierten Fasern größer war als in der Narbe und jenseits derselben. Ist der eine Verr durehsehnitten (und infolge-

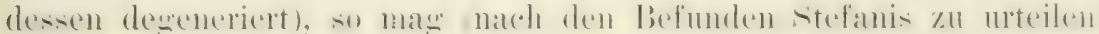
dies Wachstumhindernis der sensiblen Fasern fortfallen.

4. Kann das obere und untere Ende eines isolierten Nerrenstiickes verwachsen? Diese Frage komnte erst anfueworfon werden, nachdem die Tatsatche der antowenen Regeneration festwestellt wal dasselhe

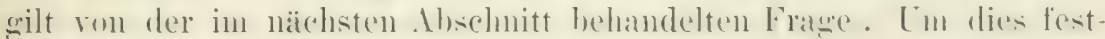
zustellen, isolierte ich in der bereits oben auf S. 199 angegebenen Woise zweimal ein stïck des Ischiadiens junger Itunde und remähte das zentrale und periphere Ende miteinander, so daß ein Nervenrin!-

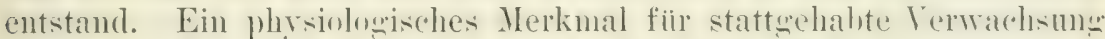
gibt es in diesem Fall nicht: man ist ledighich auf den anatmischen Befund angewiesen. In beiden Fällen waren die heiden Enten fest miteinander rerwachsen. Die Narbe wurde ron vielen Nerrenfasem durchzogen, wodurch wieder die Wachstmufähigkeit der Nervenfasern ohne beteiligung des Zentrums erwiesen wird. Iieraus komute aber matiirlich noch nicht mit sicherheit der sichnß gezomen werden. dall anch eine Terwachsung der Nervenfascrinuerschitte statterefunden hahe. Ich sriff deshall, im zweiten Fall zur Desenerationsmethode. Bei einem einfach isolierten stiick wïrde bei einer zweiten [)urchschneidung nur eine Degeneration des peripheren dhschnittes arfolgen: was

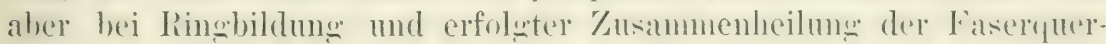
schnitte erfolgen würde, war nicht mit Sicherheit vorher zu sagen. I) ureh die Verwathsumg komnte eventuell das Degenerationstedualtnic ganz verschoben werden, so daß bei jeder Verletzung, wo sie auch angesetzt sein möge, immer eine Degreneration der wanzen fasem erfolgte. Es komnte aber das alte Verhälnis zwischen periphererer and zontralerer strecke erhalten bleiben, so dab bei ciner zweiten Inur.hschneidung secentiber der Sarbe die Fasern nur in ihren peripheren T'eil bis zur Narbe hin dem Zerfall anheimfielen. - Die zweite Dureh-

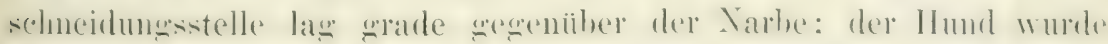
drei Tage und zwei Stunden nach derselben getötet. In dem mit

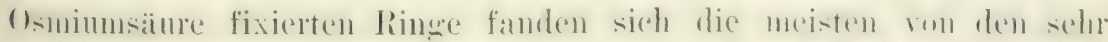

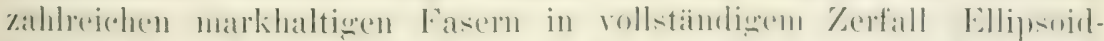

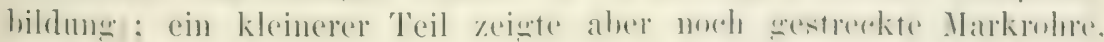
an denen hin und wieder Anzeichen von beginnendem Zerfall zu erkennen waren. Ich bin überzengt, daß ich sie am niichsten 'Tage 


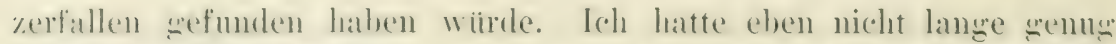
nach der zweiten Durehschneidung gewartet. Lamals wuBte ich noch

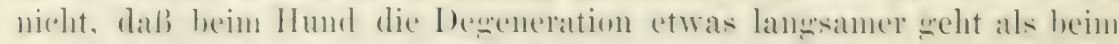

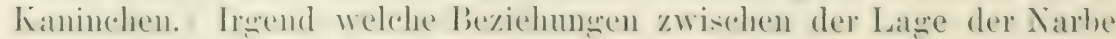
mad der Latge der erlaltenen Fatsern komnte ich nicht auffinden: sie fanden sich iilnerall: in der Yarbe, zentral und peripher von iln. Nir

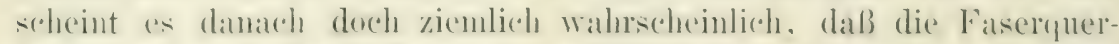
schnitte in der Varbe wirklich zusammenewatchsen waren und dall mit dieser Znsinnmenheilung die Fasern anfhörten, ein zentrales Ende zu haben, so daß sie nun auf jede Verletzung hin in ihrer Totalitit

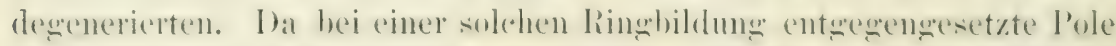
ancinander sechracht werdeng so wiirde anch dieser befuncl für die Polaritätshyothese sprechen. Ich will nicht rerschweigen, dall mam

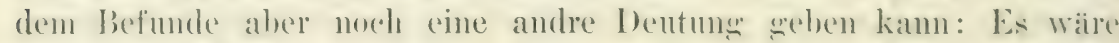
nämlich mü̈lich, wenn anch nicht sehr wahrscheinlich, dak der Nervenring in Zustande chronischer Degeneration war, dak also die Durehschneidung gar nicht die Veranlassmog zum Markscheidenzerfall gewesen ist.

5. Können die zentralen (guerschnitte zweier peripherer stimpfo miteinander verwachsen? Cun dies zu prifen, lable ielo an vier jungen

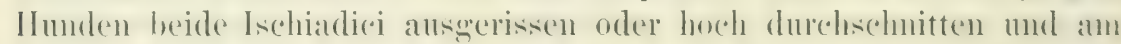
Dammı niteinander vernälıt, so daß num beide peripheren stämpte miteinander verbunden waren. In zweien dieser Faille waren die Nerren wohl etwas z.11 liur; die Nerremaht löste sieh und die heiden Ischiadici wurden bei der sektion roneinander wetrennt wefunden. In den beiden andern fällen blieben sie aneinander. In einen dieser Fälle watr die antowerne Regencration nur gering, die Xerven waren nicht leitungsfähig. Im andern war der eine Nerv, als ich nach vier Monaten äfnete, leitungsähig, es zuckten aber bei seiner Reizmn nur die Muskeln der weichen Seite. ()b der Nerv der andern seite zu dieser Zeit auch leitungsfähig war, weiß ich nicht. Als ich nach acht Ifonaten beide Nerven freilegte, waren as beide nicht; der linke nicht mehr, der rechte war es vielleicht nie enewesen oder nicht zu der \%eit. als ich den linken bloßlegte und reizte. Beide Nerven enthielten reichlich markhaltige Fasem, auch die hreite Nitrbe war von solehen ilurchsetz.t. Diese Fasem konnten aber von einem Nerven in den

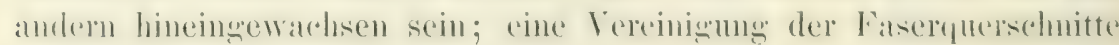
branchte nicht erfolgt zil sein.

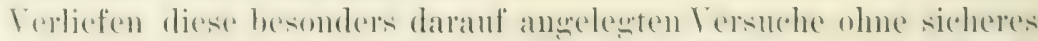

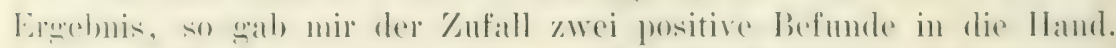

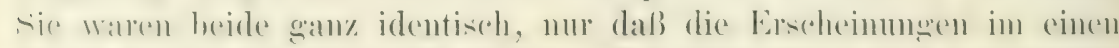

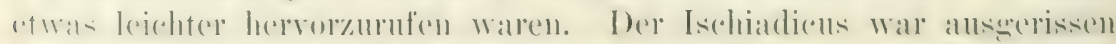

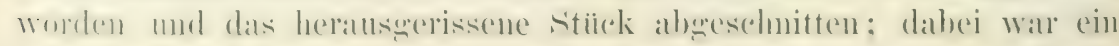




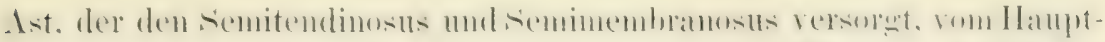
stamm abgetrennt worden. Nach beinahe sieben Monaten wurde der Nerr freigelegt. Seine Reizung eroab schöne Zuckungen im Bein, aber auch bei großer Stärke kein Selureien. (Das zentrale Ende war

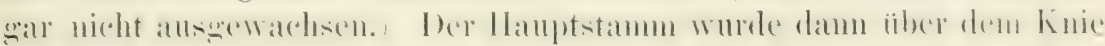
durchschnitten. Nach sechs Tagen wurde wieder eröfnet und nun ansgiebig das ganze Gebiet freigelegt (Fig. 56). Hauptstamm und Ist fiur Semimembranosus und Semitendinosus waren dureh eine sehr diinne Brỉcke rerbunden. Wrurde diese oder der Muskelast gereizt, so zuckten eben diese Muskeln. Sie zuekten aber a uch, wenn ich bei greichem Rollenabstand, del da grade wirksam war, am untersten Ende des Hauptstamms (bei + ) reizte! Um paradoxe Zuckung konnte es sich hier angesichts der guten Durchfeuchtung nicht handeln; auch das Experimentum crucis gelang leicht: schon bei geringem Druck mit einer Pinzette bei + traten die lebhaftesten Zuckungen in den Muskeln ein. Nach Zersehmeidung' der diinnen Verbindungsbricke bei $o$ war die Bewegung nicht mehr von + aus auszulösen. Hier war also wirklich eine rïcklänfige Verbindung vorhanden.

Man kïmute ja vielleicht daran denken, daß Fasern des Muskel-

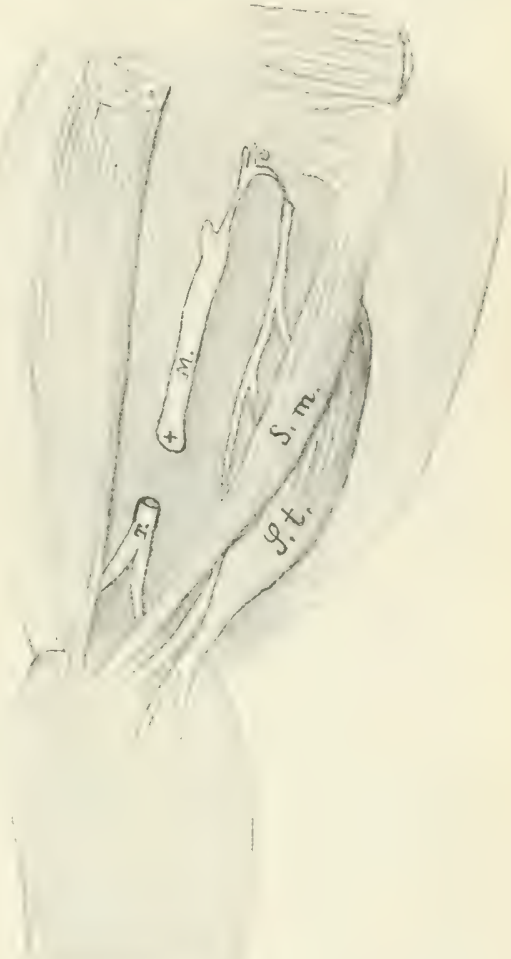

Fig. 56. Skizze eines IIundeschenkels, - bei dem der Nerv des Semitendinosus (S.t.) und des Semi-

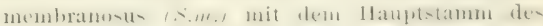
darehwehnittenen und aturenenerierten I-chiadicus verwachsen war. Der Isehiadicus war einige

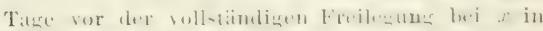

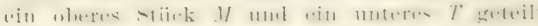
worden. o Terdickung in der dïnnen Faserbriicke. astes in den Hauptstamm hinein-

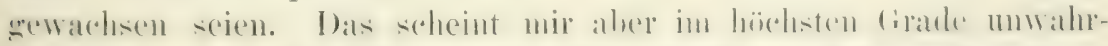

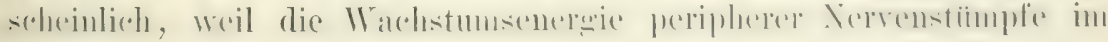
allgemeinen sehr gering gefunden wird und es sich hier mu ein Aus-

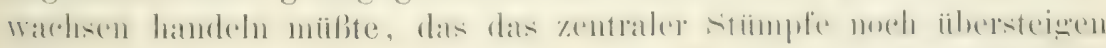
wiirde (etwa $6 \mathrm{~cm}$ ). - Die histologische Untersuchung zeigte, daß

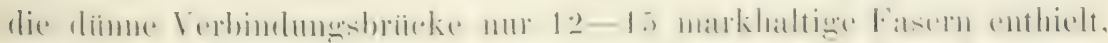

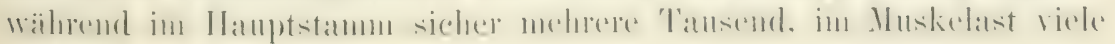




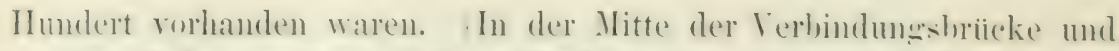
an der stelle, wo sie mit dem Muskelast zusammenstiel), fanden sich

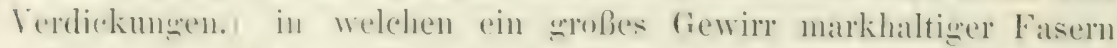

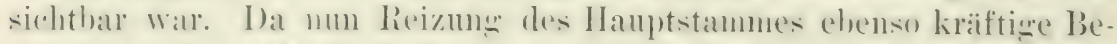

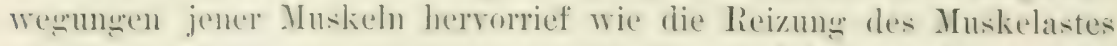
selhst. sn soldeint nir hierin cin zweiter leweis dafür vorzuliegen, daß es sich nicht mon eine direkte lieizung answewatehsener motorischer Faseme des Muskelastes hei Reizung des IJauptstammes handeln komnte. Revizung so weniger motorischer Fasem kamn nach sonstigen Erfalımuen keine maximale Muskelkontraktion zustande bringen. Eine

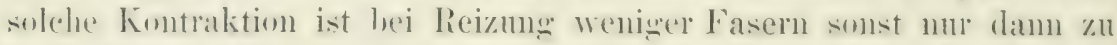

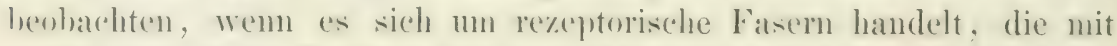
motorischen dureh Zentralsulstanz in Verbindmes steleen. Jeh bin daher

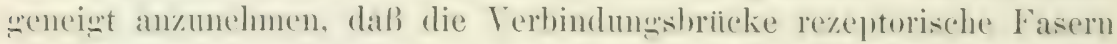
des llanptstanms e'nthiclt, welehe sich in den Anschwellungen mit einer viel wröberen Anzahl won motorischen Fasern des Mnskelastes rerhunden hatten, so dals num die Anschwellungen gewissermaken ein franmienzelloses Reflexzentrum vorstellten. Ich fasse also die rom Hanptstamm alls anslösbare Kontraktion des semitendinusus und semimembranosus - mit aller Reserve! - als eine Art ron Reflex auf, die olme Ganglienzellen vor sich ging.

Ein zweiter Fall zeigte ganz ähnliche Verhasltnisse. Der Nerr

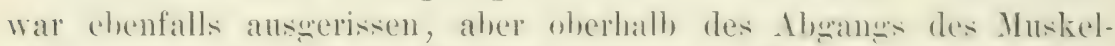
astes amputiert. Bei der Eröffnung reighte der IIauptstamm am Ende ein ziemlich großes Neurom. 3 cm unterhalb desselben ging der

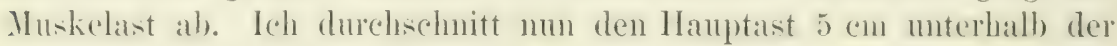
Algangsstelle und reizte hier. Auch in diesem Fall zuckten riicklä ufig beide Muskeln! Ein Urteil, wie viele Fasem des Ilauptstammes sich in Xeum mit Fasem des Yuskelastes verhunden Latten, ließ dieser Fall nicht zu.

schlieflich sei noch ein dritter Fall angeführt. In diesem lazen die Verhailtnisse etwas komplizierter. Ich hatte den Ischiadicos nitsimnt den Wrurehn und zwei spinalganglien heransererissen und den Nerr dann iiber dem Knie durehsehnitten. Darauf schnitt ich ron den sponalganglien so viel rom den Anhängsehn ah), daß nur noch ein kur\%'s stiick des Nervenstammes mid der Wurehn an ihmen hing mond lente sie so in die Wunde hinein, dali der Guerschnitt des monteren

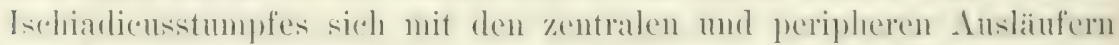
der dianglien beriilnte. Sach sechs Momaten wurde wieder geriffnet.

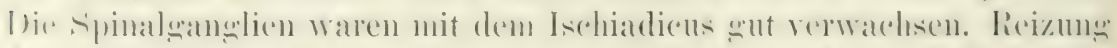

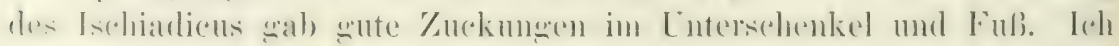
präparierte mir num am Untersehenkel einen Seitenzweig des P'eroneus auf eine Strecke ron mehreren Zentimetern frei (es war 
ein Hautast, also wohl sensibel), dur chschnit ihn 1 öglichst peripher und reizte sein zentrales, dem Hauptstam zugerichtetes Ende. Bei jeder Reizung traten deutliche Zuckungen in fast allen Muskeln des Untersehenkels und FuBes ein: gradeso, als ob ich ihre motorischen Fasem im

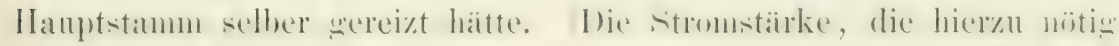

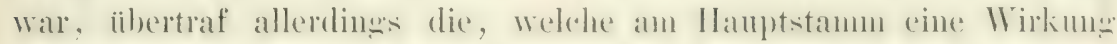
lervorzurufen imstamle war. Ftromschleifen waren allsweschlosisen.) Die histologische Lntersuchung des Ischiatdicusendes mit sant den

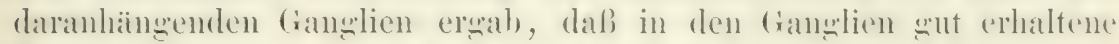

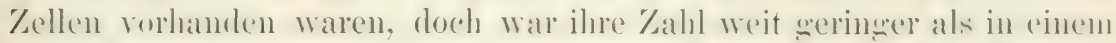

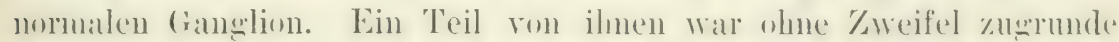

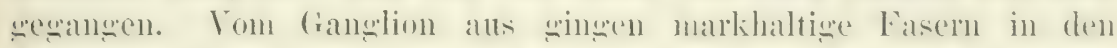
Hanptstanm des Ischiadicens, abel - soweit sich das hei den etwas schwierigen toposaphlischen Verhältnissen feststellen lief - nur vu seinem peripheren l'ol ans. Wemn nicht die beiden andern Fälle be-

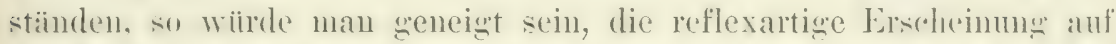

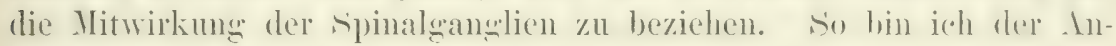
sicht, daß sie mit der Erscheinung gar nichts zu tun haben.

Nach diesen Befunden scheint es nicht zweifelhaft, daB sich am

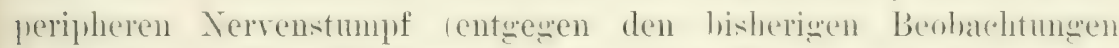
ani zentralen thumpf, Faselon ron sleicher l'olarisation miteinander verbinden können. Immel ist dies jedenfalls nath meinen hisherienen

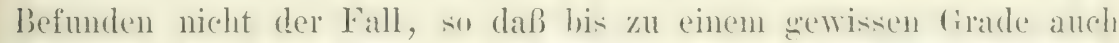

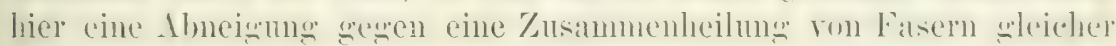
Polarisation besteht; außerdem scheint mir hier Grund zu der Annalme vorhanden, dal) es nur orler in erster Linic Fasern versohicedenter Funktion sind, welche sich miteinander verbinden.

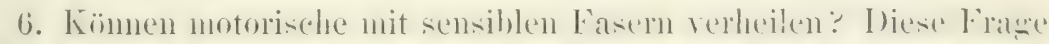

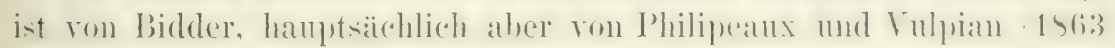
bearbeitet worden. Es wurde ron diesen Autoren der zentrale Stamm

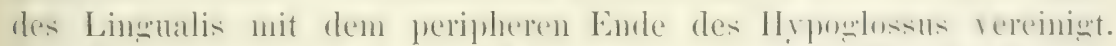

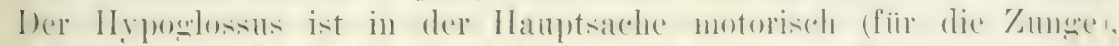

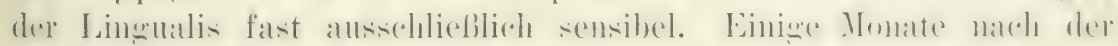
Operation wurde die Narbe freigelegt und der Nerv oberhalb und

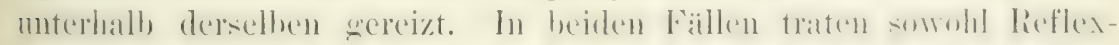
bewegungen des 'Tieres als auch Kontraktionen in der Zunge ein.

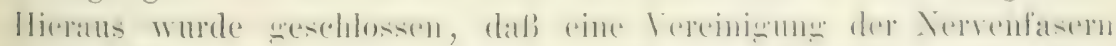
in der Weise stattgefunden habe, daß die sensiblen Fasern des Lingrualis den ihnen zugeführten Reiz auf die motorischen des Нypo-

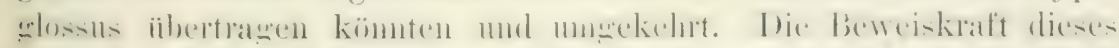

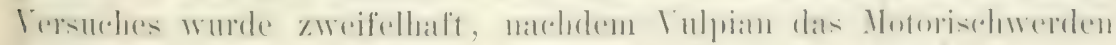

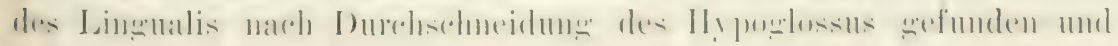




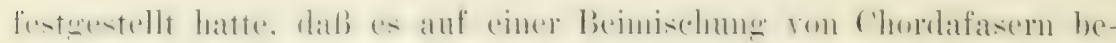

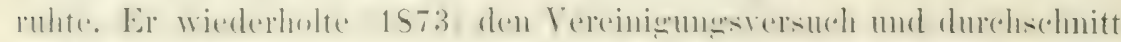

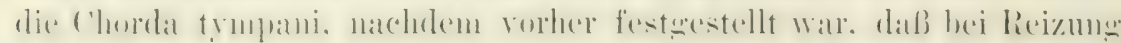
des zentralen Lingualis die Zunge zuckte. Einige Tage nach der

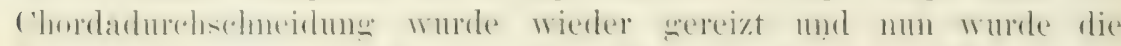
Reizung unwirksam gefunden. Die Chorda und einigge Fasern des

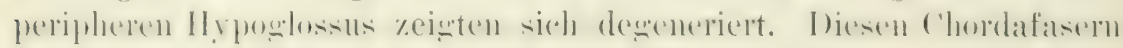
war also der Erfolg zuzuschreiben. Wie num Vulpian hervorhebt, waren im peripheren Hypoglossus sehr viele regenerierte Fasern

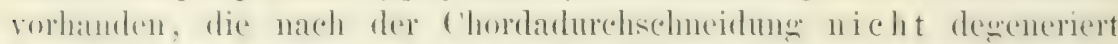
waren. Dat (re angenseheinlich an alten Tieren operiert hatte, komnte es sich nicht un Autorexeneration handehn; die Fasern multen also im Anschlub an die Fasern des Lingualis regeneriert sein oder von diesen ansgewachsen sein. Mir seheint das erstere das zutreffende zu sein: Einem inrofen, answewachsenen Ilunde wurde der zentrale IIypoglessus mit dem peripheren Ende des Lingualis vernïht, nachdem vom Iypoglossus das periphere, rom Lingualis das zentrale Ende, soweit erreichbar, exstirpiert war. Ich hahe ans leicht rrkemnloaren friunden den Versuch ungekehrt, als sonst iiblich, anenestellt.) Nach fünf Monaten wurde wieder eröfnet. Die Nerven waren fest vereinigt und der Lingualis wieder schön weiß. Es wurde

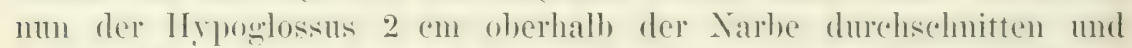
der Ifund nach vier Tagen getötet. Der Lingualisstunpf wall voll von frisch degenerierten Fasem: zwischen ilmen waren keine marklosen Fasern lbandfasem oder Achsialstrangfasern zu entelecken. Die Fasern des Lingualis waren also unter dem Einfun derer des Iypoglossus regeneriert und die vorefundenen markhaltiwen Fasern waren nicht in den peripheren Lingnalis hineingewatehsen, dem sonst hätte man die Reste der alten Lingualisfasern als Achsialstrangfasern finden miissen. Darans, daß die Degeneration sich nach der zweiten Inuch-

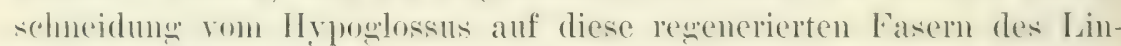
gnalis ansolehnte rig. $57 \mathrm{~B}$, geht hervor, dab die sensiblen Fasem des Lingualis, welehe wenigstens zum sammenheilung nit motorischen Fasem des Hypowlosus reweneriert sein müssen, ron der Intaktheit dieser motorischen Fasern jetzt in

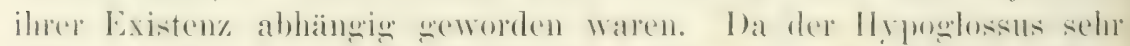

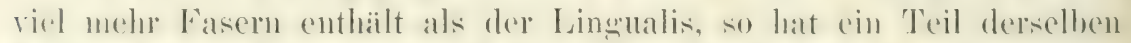

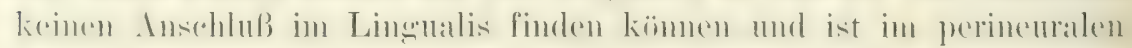
Bindegewebe weiter gewachsen $(F i g .57 B)$. Diese nun wirklich aus-

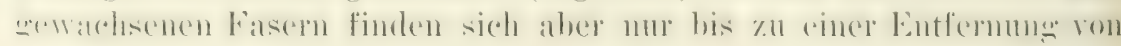
etwa 1 em ron der Narbe aus gerechnet. Große Strecken können eben auswachsende Fasern nicht zurieklegen. - Ilält man diesen

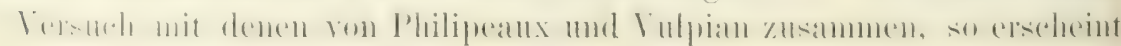




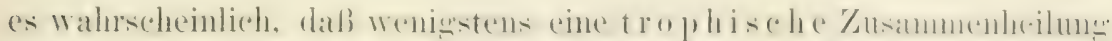

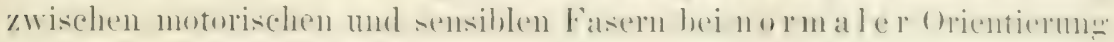

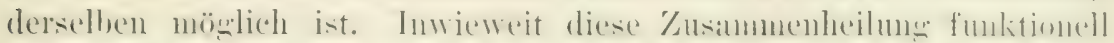

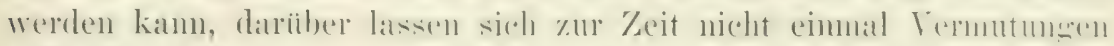

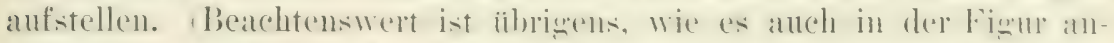

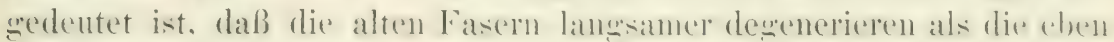

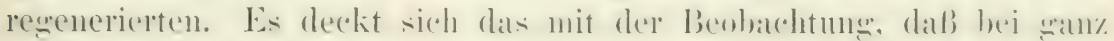

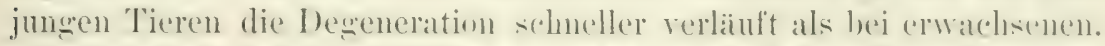

Ich habe anch den Versuch semuacht. das zentrale Ende des Lamus maxillaris superior des Trigeminus mit dem peripheren Ende des

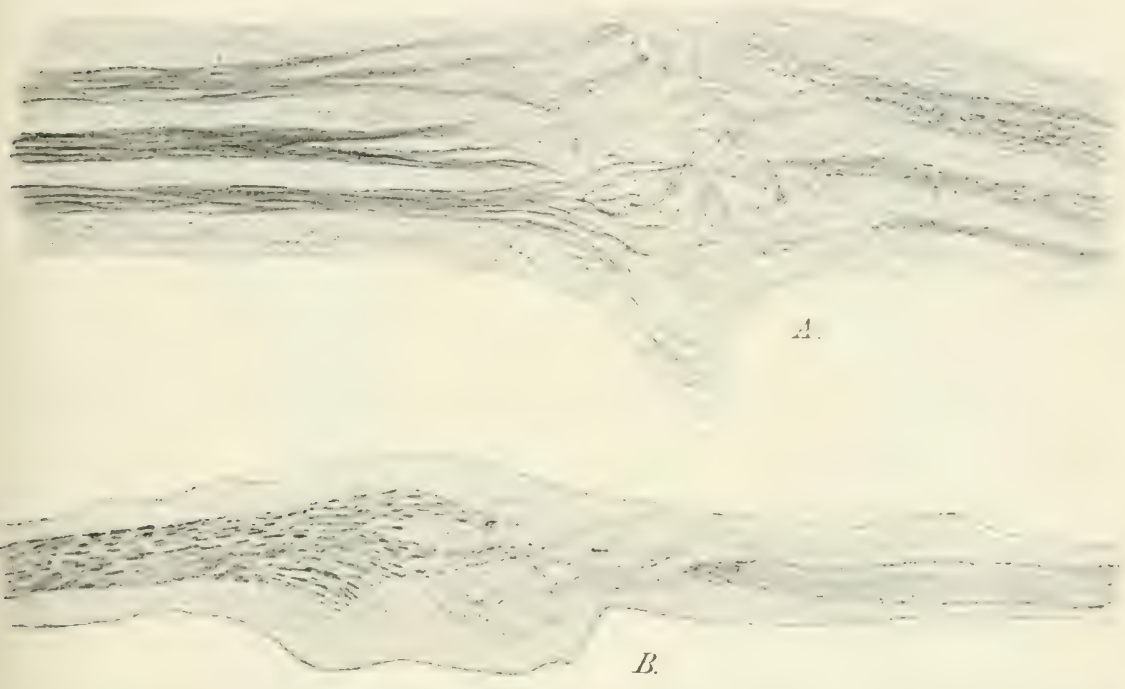

Fig. 57. A Zusammentachsungsstelle des rechten und linken zentralen Ischiadicusstumpfes nach weiter zentral gelegener Durchschneidung des rechten Ischiadicus. B Zusammenwachsungsstelle des zentralen Hypoglossus- und des peripheren Lingualisstumpfes nach Durchschneidung des Hypoglossus an einer mehr zentralgelegenen Stelle. (Osmiumschwärzung der Markscheiden.) Vergrüßerung 10 mal. Die Dicke der Fasern ist übertrieben.

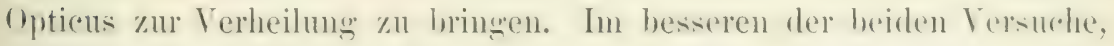
welche ich nach dieser Richtung hin anstellte, kam es aber nur zu riner rein äuberlichen Zusammenheilune: die Faserm beister Verven

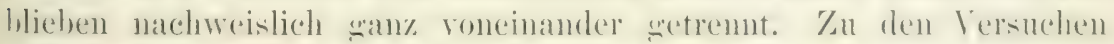

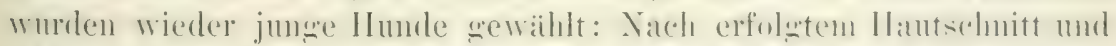

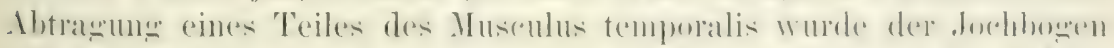

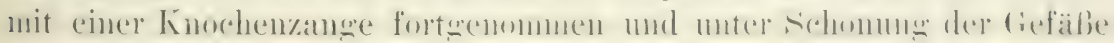
der Trigeminusast aufgesucht. Er wurde dicht am Eintritt in das

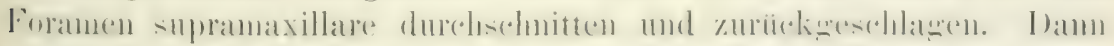

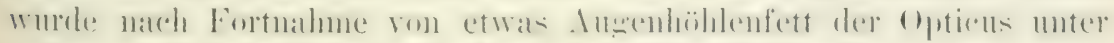
r. 


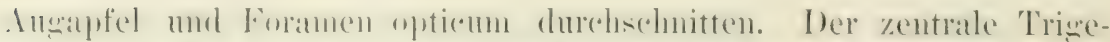

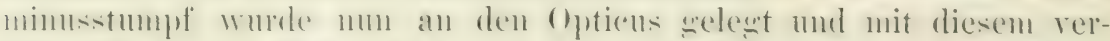
nailit. In heislen Fällen trat nateh einigen Wochen Truibune der Linse und des Glaskörpers ein. Nach etwa zehn Monaten wurde der eine Ilumb weteitet. Ther Bulbus der oprerierten seite war wesentlich kleiner

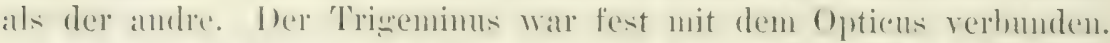

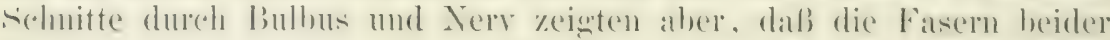
Nerven ganz getrennt waren. Die Fasern des Trigeminus waren im

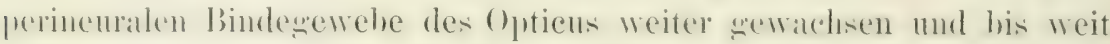
in die Selera eingedrungen. So umfaßten sie den sehr verküirzten

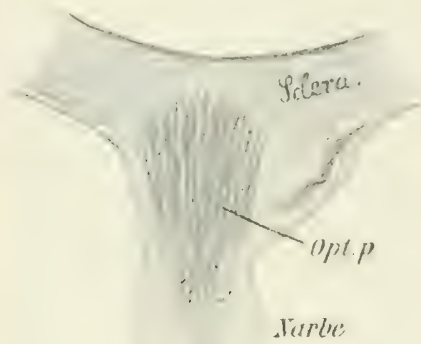

lipleculi:

$B$

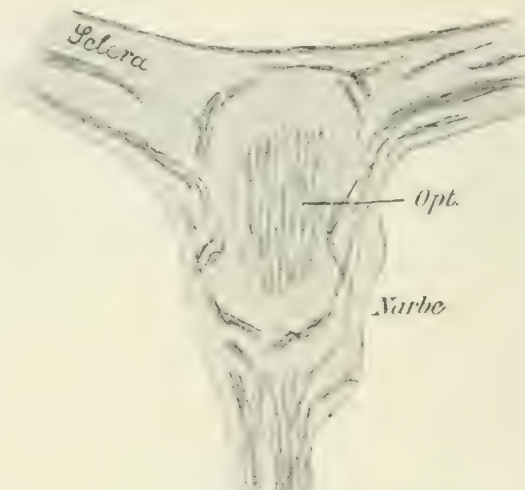

Frugemminus

A

Fig. 58. A Zusammenwachsungsstelle des zentralen Trigeminusstumpfes und des peripheren Opticus. L Zusammenwachsungsstelle des zentralen und peripheren Opticusstumpfes. (Etwas schematisiert.)

Opticosstmupf, welcher, wie schon anf $S .181$ angegeben, wute markhaltige Fasern bei vollkommener dhwesenheit einer Retina enthielt (Fig. 58 A). (Wie ans der Serie mit Sicherheit hervorgeht, sind die

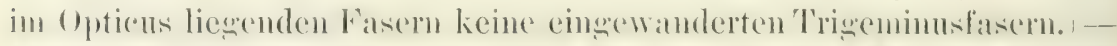

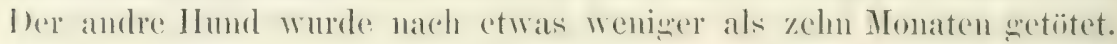

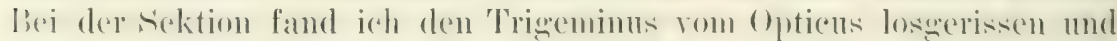
in seiner alten Lage fest mit seinem peripheren Ende verwachsen. Andrerseits hatten sich anchderzentrale und periphere Opticusstumpf wieder zusamengefunden und waren miteinander verwachsen. Die Verwachsungsstelle war deutlich

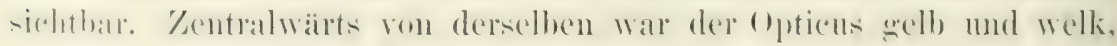
wiblurend er nach dem Ange zu glinzend weiß war. Die Schnitt- 


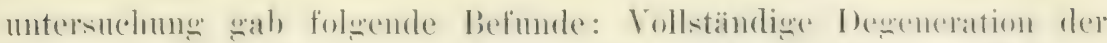

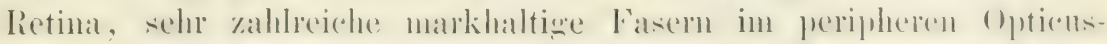

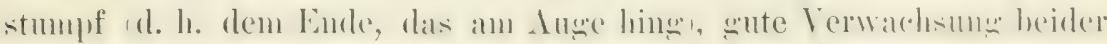

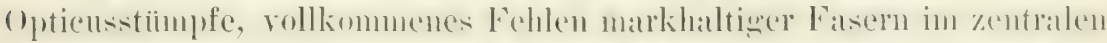

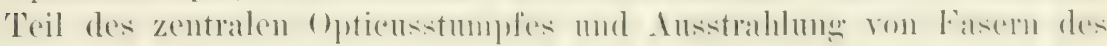

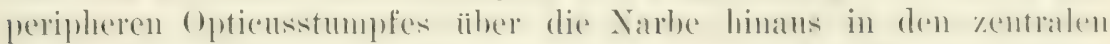
hinein $(F i g .58 \mathrm{~B}$ ). Jedenfalls kann also anch der Opticus, dieser

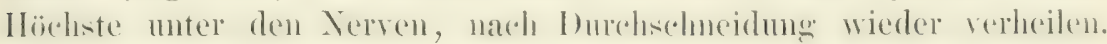
Wem man das nötige Tiermaterial opfern wollte, wïrcle man es vielleicht sogar in einen oder andern Fall wieder zu einem funktionstïchtigen Nerten bringen können.

Im Anschluß hieran seien noch einige andre Fälle von gelungener Servenverheilung erwähnt, deren Interesce allerdings mehr anf einem andern tiebiet als dem hier hehandelten liest, weil die anatomischen Verhältnisse bei den betreffenden Nerven zu wenig bekannt sind. Philipeaux und Vulpian gelang es, den zentralen Vagus und den peripheren IYpoglossus zusammenzuheilen. Rémun des Vagusanteils

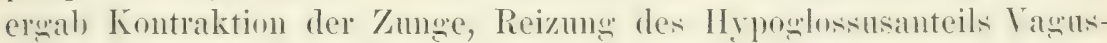
erscheinungen. Langley 1897, melang es, leei der Katze den zentralen Vagus mit dem Cervicalganglion des sympathicus zu V Verheilung zu hringen. Anch hier hatte Reizung des sympathicus Vagnsersehemungen

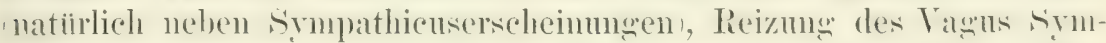
pathicuserscheinumen zur Folge. Es können also nach diesen Befunden Terven ron der verschiedensten physiologischen Wirkmo niteinander funktionell in Verbindung gebracht werden.

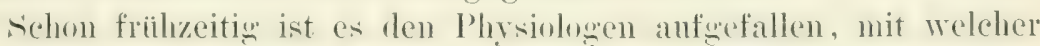
manchunal erstannlichen sicherheit sich die Enden durchschnittener

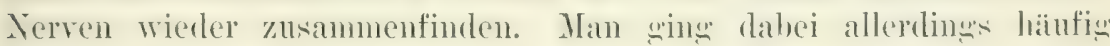
von der falschen Voranssetzune ans, dab jerle Faser sich mit der iln korrespondierenden wieder vereininte. vicherlich ist das nicht der Fall. Wie schon oben gezeigt, sucht ein zentrales Ende nur, sich iiberhaupt wieder mit einem peripheren Ende zu rereinigen, aber nicht grade mit seinem eignen. So wie die ganzen Nervenstamme nicht sehr wählerisch sind, so werden es auch die einzehnen Fasern nicht sein und man kamn annehmen, daß sich häufig sogar motorische Fasern des einen Stumpfes mit sensiblen des anderu rer-

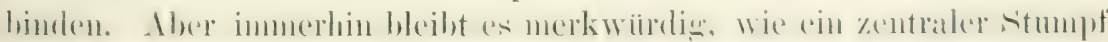

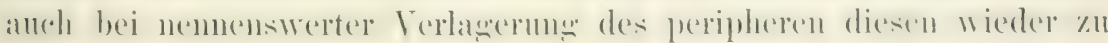
finden vermag. Es ist das Verdienst Forsmanns (1900), aus diesen

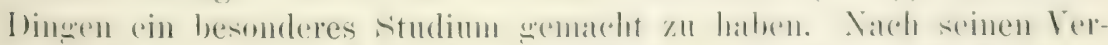

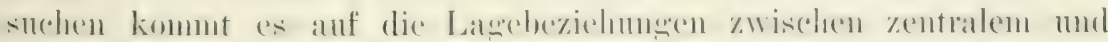
peripherem Stumpf gar nicht an, wie man leicht hätte annehmen

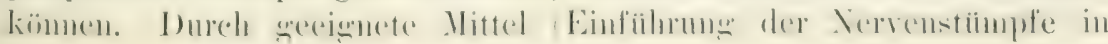


Kollodiumröhren, die nachher mitgeschnitten wurden) gab er den

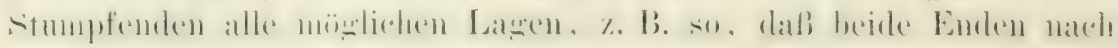
der Peripherie zu gerichtet waren, aber immer fanden sie sich gut zusammen. Er kam daher auf. den Gedanken, daß es sich hier um einen Chemotropismus handle und daß die Fasern des zen-

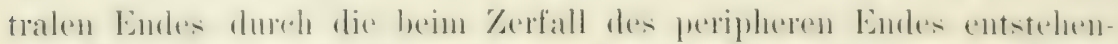

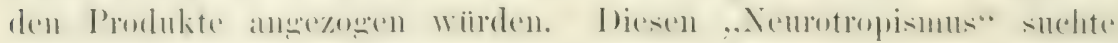
er durch folgendes sinnreiche Experiment weiter zu stiitzen. An das zentrale Ende eines durehsehnittenen Nerven brachte er \%wei Rährehen ron Kollodium, deren öffnumg preripher werichtet war: das

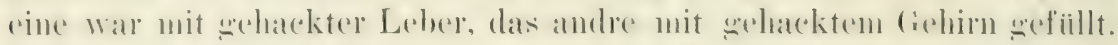
Die rom zentralem Ende answachsenden Fasern wuchsen num riek-

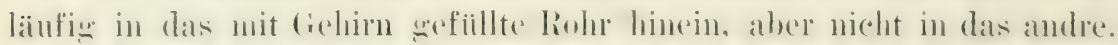

so heweisend dieses Experiment für die anf die answachsenden Faserni anziehende Wirkmo der zerfallemden Xervensulstanz zu sein seheint, so diufte nach meiner Heinumg der wahre siacherhalt doch etwas anders sein. Das, was die primäre Vereinigung zwischen den Enden eines durehsehnittenen Nerven herstellt, ist namlichnach meinen Erfahrungendas Bindegewebe der Nerven. Die Fasern wachsen erst sekundär auf diesem Boden weiter und treffen sn mubedingt anf das periphere Ende, wemn das bindegewelse den Anschluk erreicht hat. So fand ich z. B. schon zehm Tage nach Exstirpation eines 1 ('m langen Xervenstiickes beide Enden durch perineurales lindegewebe niteinander verbunden. Zu dieser Zeit haben aber die Fasem grade erst hegonnen ans\%uwadhen und sind höchstens 1 mm in dem Bindegewehe vorsedrungen. Ich slaube wohl, daß eine Art Chemotropismus bei dem Zusammenfinden eine Rolle spielt, glaube aber, daß er nicht den Xervenfasem selbst, sondern dem Bindegewebe zukommt; dieses wächst nach der Reizstelle hin und die wachsenden Tervenfasem folgen ihm nard. - Auch das wire Inreheinanderliegen der Fasern im Yeurom wird durch das Bindegewebe vorgebildet. Znerst wuchert es ganz wirr und arst allnählilich nehmen die Fasern eine geordnete und parallele Richtung an. Diese Irrwerge machen die answatchenden Kervenfasem nachlier getrenlich nach. Son konment es, daß man hei wröberen Defekten immer zwei Neurome reins an zentralen, eins an preripheren

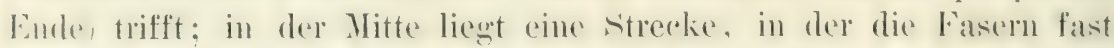

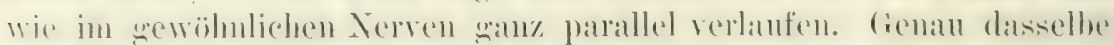
findet man aber schon wenige Tage nach der Operation im Binde-

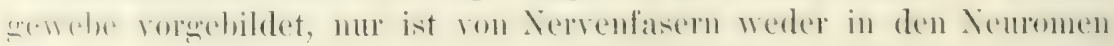
noch in der Zwrischenstrecke etwas zu finden. -- Ich habe schon

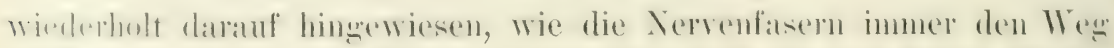

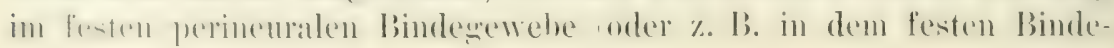




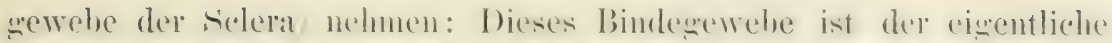

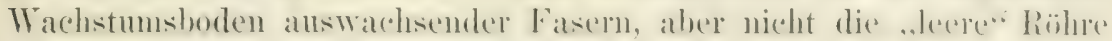
der alten fichwamschen šcheiden, wio Ranvier, Vanlair u. a. meinten. Diese sind, wemm die Fasem des zentralen Endes auswadelsen, nicht mehr leer mol wemn sie zutaillin in der falschen Grientiermen sind siehe s. 2 2!), so wachsen die Fasern des zentralen stumples, wite (2s scheint, an ihmen vorbei. Wo es sich um funktionstielitige Verbindung eines zentralen und eines mehr als einige Zentimeter langen peripheren Stumpfes handelt-so muB man nach meiner Meinung unbedingt sohließen — da sind nicht die zentralen Fasern in die peripheren hineingewaclisen, sondern sie haben sich mit ihnenverbunden und sie zur Vollendung der bereits angefangenen Regeneration angeregt!

\section{DREIZEHN'TES KAPITEL.}

\section{Über die Entwicklung der Nervenelemente.}

Es liegt mir ferm hier einen rollkommenen Überblick uiber die Entwicklumg des Vervenssstems mol seiner eimzelnen Elenente an weben. Nur einzelne P'unkte, die für die allogemeine Inffassung des Nervensystems von Wichtigkeit sind, mögen hier zur Besprechung kommen.

In dem vorhergehenden Kapitel wurde sezeigt, daß dic Reweneration verletzter Nerven nicht durch Inswarksmen der Nervenfasern rom zentralen stumpl her geschieht, somdern daß Reste des alten Nerven. wahrscheinlich die Zellen der sichwannschen sicheide, die nenen Verven-

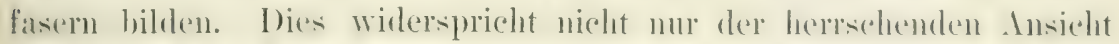

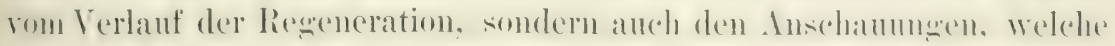

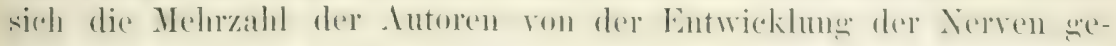
bildet hat. 'Zwar gibt es einige Falle, in denen die Regeneration

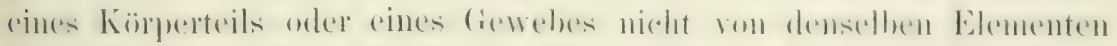

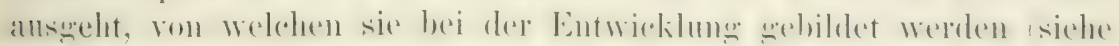

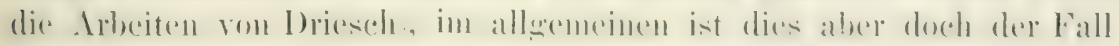
und so ist es dem von jeher ein berechtigtes l'ostulat gewesen, die

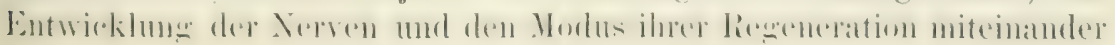




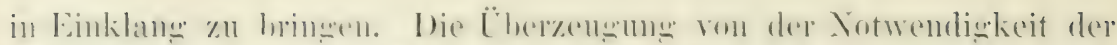

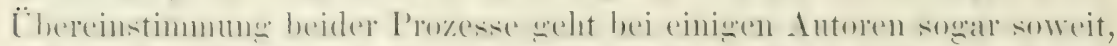

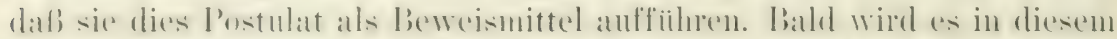

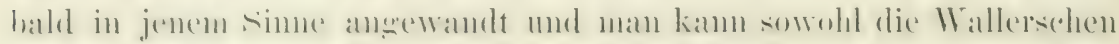
Sïze als Beweismittel für den ron His rerfochtenen Modus der Ent-

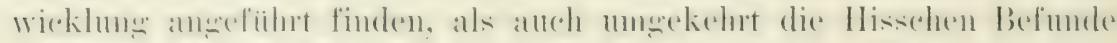

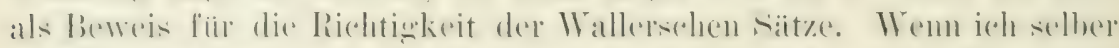

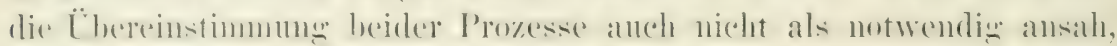

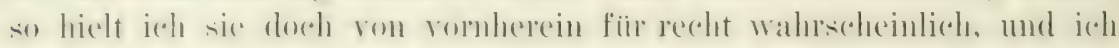
sah mich daher gezwungen, aus eigner Anschaumg ein Urteil ïber

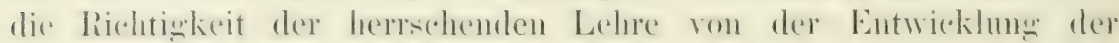
Nerven zu gewimmen. An diese Arbeit komnte ich um so mehr mit

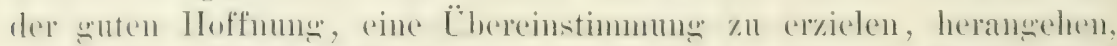
als jas die herrschende Ansieht nicht widerspruchslos dasteht und

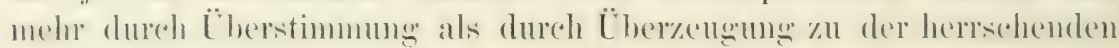
geworden ist.

Noch immer stehen sich zwei Ansichten ïber die Entwicklung der Nervenfasem serentiber: Die Remak-Kupffer-Hissche, dab die

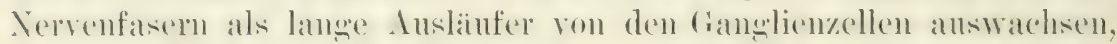
also mit der (ianelienzelle zusinmmen eine /elleinheit bilden, und die batfon- linald-Dohrusche uler sich Kupffer zeitweise angeschlosicen hat), daß sie aus einer ganzen Anzahl von Zellen entstehen, also multizellulären Lrsprums sind und mit der fanglienzelle nur sekundä etwas zu tun haben. Die Hensensche Ansicht könnte man noch als dritte nemmen, doch fällt sie für mos mit der Hisschen zusammen, weil as sich hier nicht darmu handelt, ob Kentrum und Peripherie ah oro mitcinander verbunden sind, somdern nur darum, ob die Nervenfascern 'Zellausläiffer oder zelluläre Gebilde sind.

Für die Auswachsumgstheorie werden von His $(1883,1886,1887$, 1559, 14:90, etwa folerende P'unkte anerefiilnt: Das Nemalrohr steht

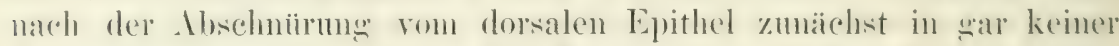

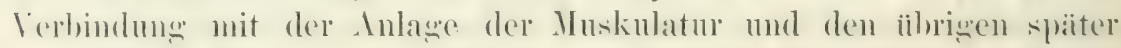

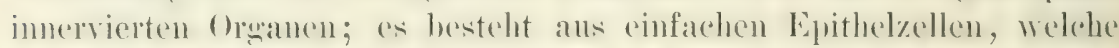

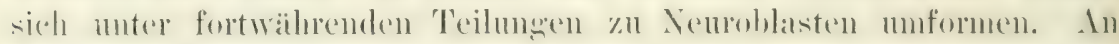
denjenigen Nenohlasten, welehe in der Xähe der spaiteren motorischen Wurzel liegen, bildet sich cin Fortsat\%, weleher die Membran des

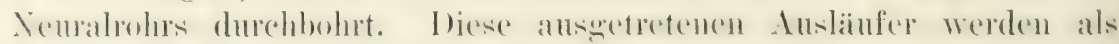

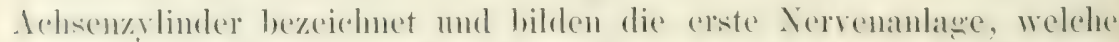
anfangs immer frei von Zellen sein soll. Je älter der Embryo ist, desto weiter sind die Fasern mach der Peripherie zu vorgedrungen.

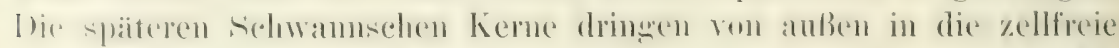

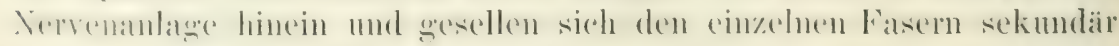
hinz11. Sie sind als Mesodermzellen anzusehen. 
Kölliker $(1886,1900)$ stïtzte die Ausläufertheorie durch Unter-

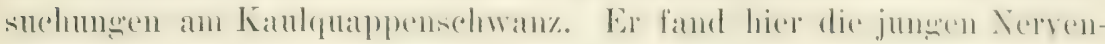
fasern zmäichst olme Kerne. Sie sollen sich erst später anlagern.

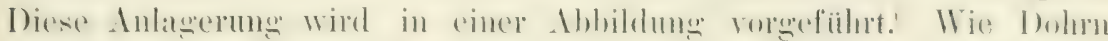

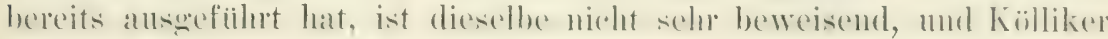
selber driickt sich in der Arbeit noch sehr zuriekhaltend ans. In

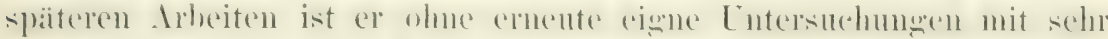

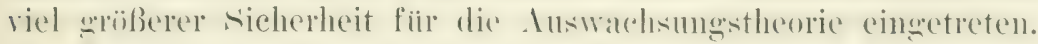

Eine starke Stibtze schien die Hissche Ansicht durch die von

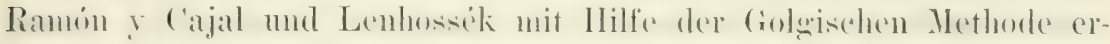
hobenen Befunde zu erhalten. Sie fanden im Riickenmark junger Hähnchen inkrustierte Xemoblasten, von denen ein immer verhälmismäbies sehr dicker Fortsatz die Memhran in der Richtume der vorderen

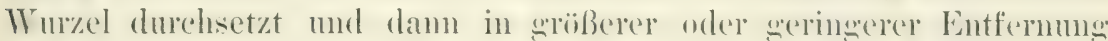
mit cinel moregehn̈ßigen Anschwellum endet. Diese Anschwellum wird als das Ende der vorwachsenden Tervenfaser antesehen und als Wachstumskeule bezeichnet.

Gurwitsch (1900) untersuchte die Bildumg der Schwamnschen Scheiden an Ischiadicus ron s'chafembryonen. Diei seinem friihsten Stadiun, das schon einer ziemlich späten Entwicklunssistufe entsprieht, findet 'r den Yerven aus Bimdeln feiner Fasern hestehend, welche von einer kernhaltignen Membran umeben sind und nur wenime Kerne enthalten. An einer andern Stelle sagt er, daß die jungen Nerrenbïndel wanz kernlos seien und sieht dies als hinreichenden fround an, sich der Ansläufertheorie anzuschließen. Aherehildet wird dieses kemlose Stadium nicht. Von den Kemen, welehe den jungen Nerven

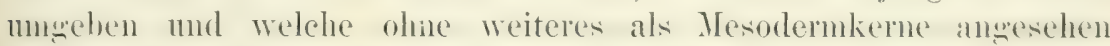
werden, sollen nun Kerne zwischen die Fasern treten und zu sichwamschen Kernen werden.

Die neneste Untersuchmmg, welche für die Auslïufertheorie eintritt, stammt von Harrison (1901) und ist an Salmonidenembryonen

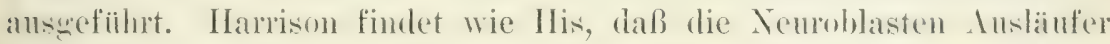
ansienden, welche die Rïekemuaksmembran durchbohren nnd mun

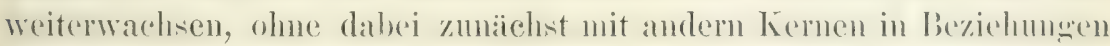
zur treten. Später macht die große Zahl von Mesenchymzellen das IBild unklar. Das Ende der vorwatehsenden Insläufer ist kolhige an-

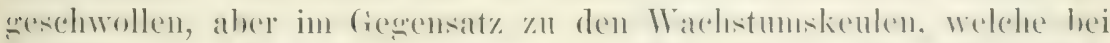

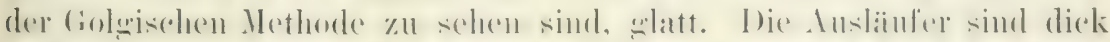
mod protoplasmatiseh. Mit Insmahme dine Faser wird keme andere ah-

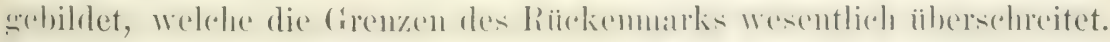

Wem man das Resultat aller dieser Arbeiten zusammenfaßt, so wird zwar dureh sie gezeigt, daß von den Neuroblasten Nuslaufer in

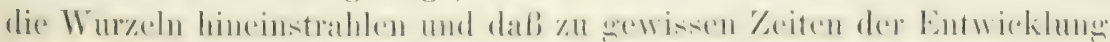




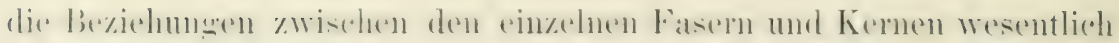

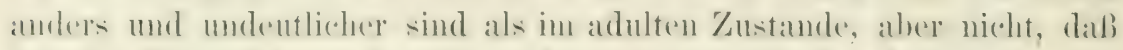
lwi der Entwioklung der Xervenfasern, speziell der Achsenzylinder.

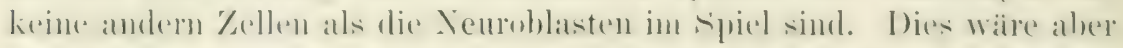
zu zeigen notwendig, wenn wirklich diese Ansicht von der Nerven-

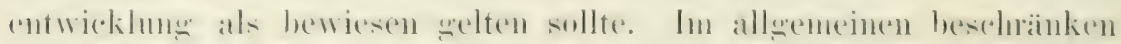

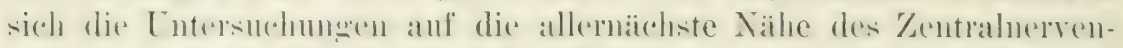

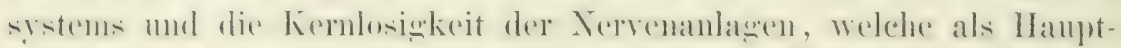
stiit\%punkt angesolen werden mülite. Autoren häufig nicht mit der wïnschenswerten Klarheit hervor.

Im Gegensatz zu den erwähnten Autoren lassen Balfour, Götte,

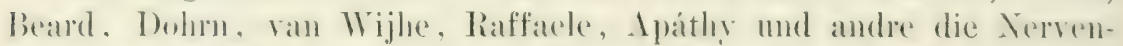
fasern ans zellerihen entstehen und beschereiben die erste Nervenanlage als eime nicht faserige, sondern zelluläre. Anch Kuptfere, der ja urspriunglich der liegrinder der Inswachsungstheorie war, veroffentlichte släter befunde, welche viehmelır für aine zelluläre Entstehumen der Nervenfasern sprechen. Er zeigte nämlich, daß hei Petromyzon die

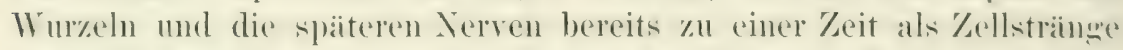
vorebebildet sind, zu der weder Fasern gebildet noch Hesenchynzellen rorlanden sind. Nateh Gïtte sollen die zellinen Elemente, welche die Nervenanlayen bilden, mesodemaler Herkmnft sein. Alle andern lassen sie vom Ektodorm alstammen. In der stelle, wo später die motorische

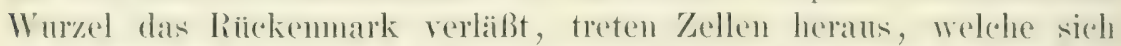

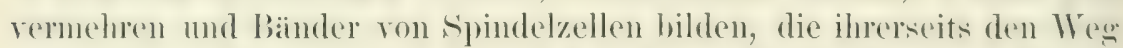
des späteren Xerven vorzeichnen. Ans diesen Zellbaindern oder Letten bilden sich damn erst die Jervenfasern. Als Lntersuchunswnaterial dienten hier vorzugsweise Selachierembryonen.

Man kann sich nicht verhehlen, daß manche der Arbeiten, welche die \%ellkettentheorie vertreten, besomders die älteren, mehr Vermutumenen als beweise vorbringen. Dies kann aber keneswess für die Arbeiten

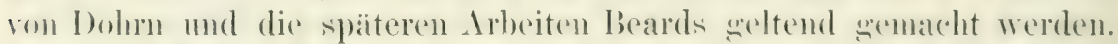

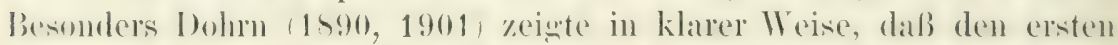
Inlagen der motorischen Wrurzeln von vornherein zelliwe Elemente

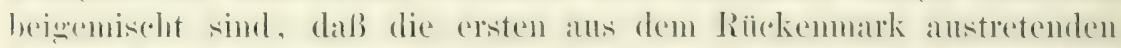

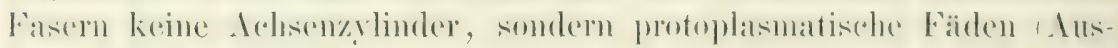

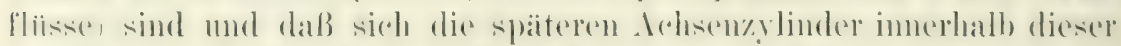

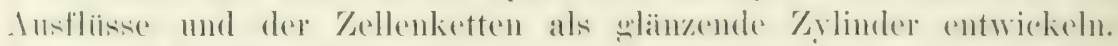

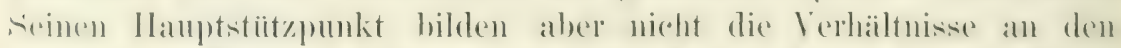

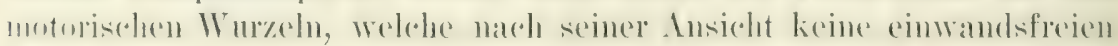

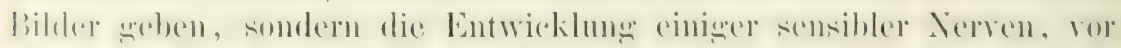

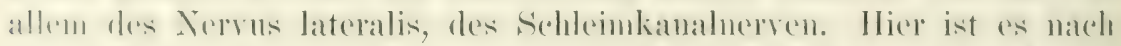

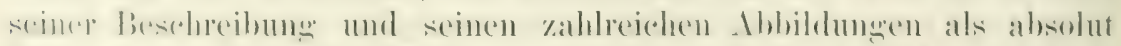

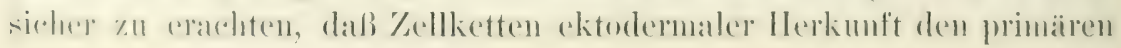




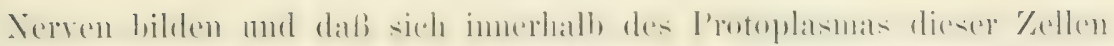

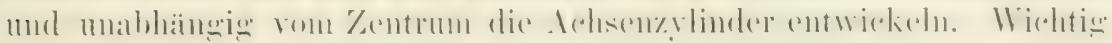
ist es auch, daß sich häufig mehrere Zylinder im Leibe ein und derselben Zelle zeigen.

Eine besondere Stellung nimmt Sedgrick (1895) ein, welche mir bis \%u einem gewissen Grade seho sympathisch erscheint. Fiu ihn

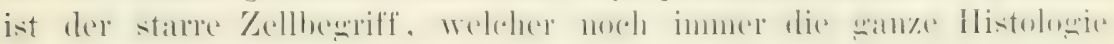
und Embryologie beherrscht, unhaltbar geworden. Der Leib eines

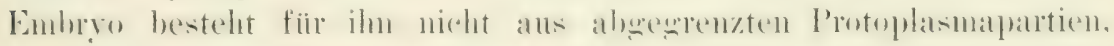
welche je einen Kerm enthalten und als Zellen angesehen werten kömmen, sondern aus einer großen Protoplasmamasse, welche vele Kerne enthält. In der Nähe der Kerne ist das Protoplasma dichter, so daß es anscheinend einen abgeschlossenen Leib um dieselben hildet. Während der Entwioklung nehmen diese Verdichtumgen immer mehr zu und gewinnen immer mehr Gestalt. So entwickeln sich die Gewebe des fertigen Tieres nicht dadureh, daß die ron An-

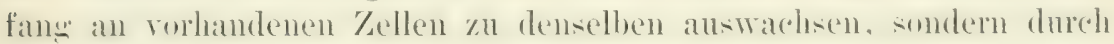

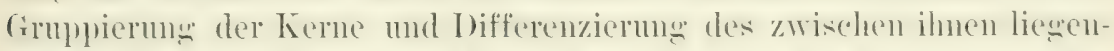
den indifferenten I'lasmas. Daher kamn fül ihn die Entwicklnum der Nerven nicht in einem Answachsen rom Zellfortsätmen hestimmter zentraler rellen bestehen, sondern nur in der Differenzierung einer substanz, welche bereits an Ort und Stelle ist. Diese Differenzierung' scheint vom Zentrum zull I'eripherie fortzuschreiten, es sind aber herne hei ihr beteilist, welehe sich hereits, ehe die Differenzierung berinnt, an der Stelle ihres späteren Auftretens angesammelt haben. Also anch hei rederwick ist die Entwicklumer der Nerven eine multinukleäre, wenn auch nicht eine multizelluläre.

Ich habe als Untersuchungsmaterial Hühmerembryonen benutzt und meine Aufmerksamkeit hauptsächlich den Rückenmarkswurzeln zugewandt. Sind die einzehen Elemente bei diesen Tieren auch kleiner als bei den Embryonen mancher andrer Tiere, so besteht hierin doch keine wesentliche Schwierigkeit, weil man mit Uilfe von Immersionssystemen zu vollkommen klaren Bildern gelangt, vorausgesetzt, daß man gute Färbungen erzielt hat. Nach einer ganzen Reihe ron Fixierungsversuchen habe ich für meine Zwecke die Fixierung mit 90\% Alkohol als die bei weitem beste erkannt. Ich bin darauf gefaßt, daß mir viele Embryologen die Benutzung von Alkohol als Kunstfehler amrechnen werden, bleibe aber dabei, daß sich Alkohol für das Studium der Nervenentwicklung besser eignet als die meisten bei den Embryologen iiblichen Gemische. Grade in der Eigenschaft, welche man dem Alkohol gewöhnlich rorwirft, daß er schrumpfend wirkt, sehe ich hier seinen Hauptvorteil. Die jungen Fasern werden dichter fixiert als \%. B. bei der Anwendung ron Sublimat und die zusammengehörigen Kerngruplen sind besser voneinander getrennt; die Fïrbung der darzustellenden Gebilde grelingt auch hesser als nach den meisten andern Fixierungsmitteln. Gefïbt wurde meistens mit dem Apathysehen IIämatein Ia, und zwar nach dem schmeiden. Zum Teil wurden diese Prïparate mit Säurefuchsin natchgefïbt. Anfjerdem gelangte Fïrbun mit basisehen Farbstoffen (Methylenblan oder Toluidinblau) mit oder 
ohne Nachfärbung mit sauren Farbstoffen zur Anwendung. Mit Beginn der Markscheidenentwicklung wurden auch in Osmiumsäure fixierte Priiparate untersncht.

Wie bekannt, findet man in den ersten Bebrïtungstagen die Entwicklung in den vorderen Segmenten stets erheblich weiter fortgeschritten als in den hinteren, welche sich erst später angelegt haben. Meine Zeitangaben beziehen sich stets auf die Gegend des Riickenmarks, in weleher sich die vordere Extremitit anlegrt.

leh begimne mit der Beschreibung von Embryonen vom Ende des dritten. 'Tages (2 'Tage und 19 Stunden, 2 Tage und 20 Stunden,

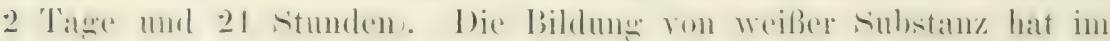

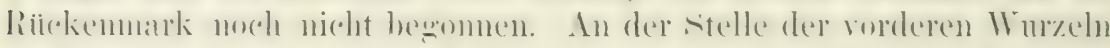
sind wenige (zwei bis fünf) Fasern zu sehen, welche die Membran des Riickenmarks durchsetzen. Auf diesem Stadium sehe ich die

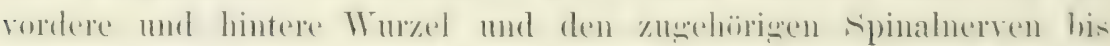
zum ventralen Liande des Muskolhblattes als deutliche Zellhä̈ndele angelegt (Fig. 59). Sie bestehen aus großen oralen Kernen, welche in der Richtung rom Riickemmark zur Peripherie gerichtet, und von rincm dunkel timgiorten, spindelfärmienen Hof von dichterem l'rotoplasma umgeben sind. Wenn ich auch mit Sedgwick der Ansicht

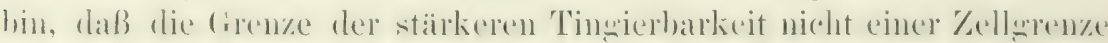

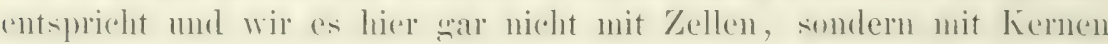
zu tun haben, an welehen sich das allgemeine Körperplasma etwas

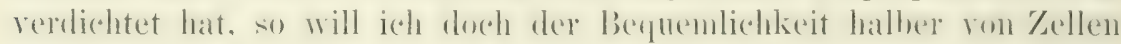

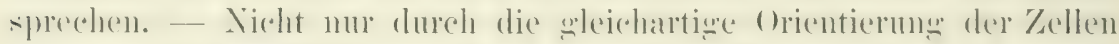
heben sich diese Zellbänder von der Umgebung ab, sondern anch dureh die Forme und struktur des Zelleibes und dureh die beschaffenleit der Kerne, welche mit ihren zwei Kernkïrperelen den Kermen der Xemoblasten anferorelentlich ähnlich selien. Nicht selten siont

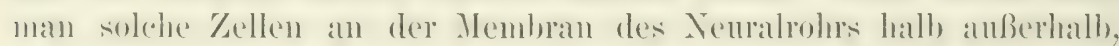
hall, immerhall, desichlen liesen. I) Fäden, welche die Membran des

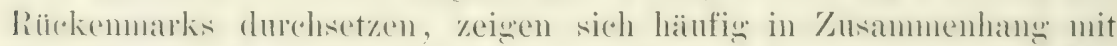

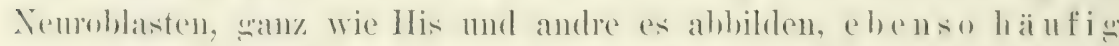
zeigen sie sich aber als Ausläufer der Zellender Nervenanlage, welche ich fortan mit Apathy als Nervenzellen (im Gegensatz zu den Ganglienzellen) bezeichnen will.

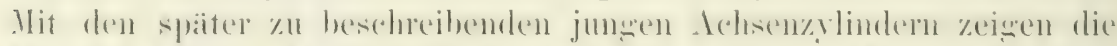

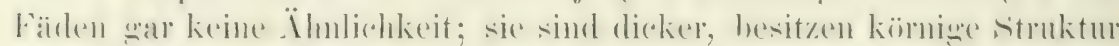

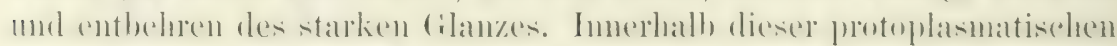

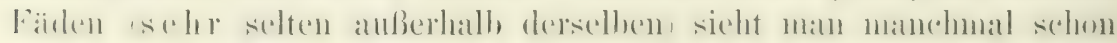

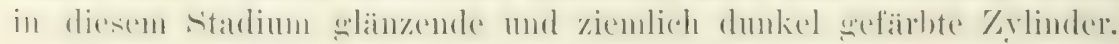

Dieselben Zellbändler finde ich num in der gleichen Ausdehmung

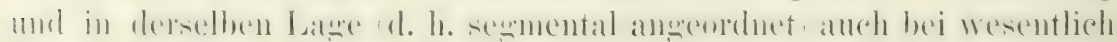
fribleren Stadien, doch fehlt bei diesen jede Andeutung von Fasexu, welche als spätere Achsenzylinder oder als Fortsätze der 
Vemoblasten anferefalit werden kïnnten. Ie jüngere diu starlien sind, desto weniger Zellen setzen die einzelnen Zellketten zusammen, so daß dadurch ihre Auffindung erschwert wirel. Bei Embryonen von der Mitte des dritten 'Tages sind sie schon sehr deutlich (2 'Tage 12 Stunden und 2 Tage 16 Stunden), aber auch am $\Lambda \mathrm{nf}$ fing des dritten 'Tages sind sie schon zu erkennen. Zweifelhaft erscheint es mir dagegen, ob gewisse aus wenigen Kernen zusammengesetzte Briicken, die ich sehon in del Mitte des zweiten 'T'ages zwischen Nemallohe und Mrotom fand, mit den suäteren \%ellketten etwas zu

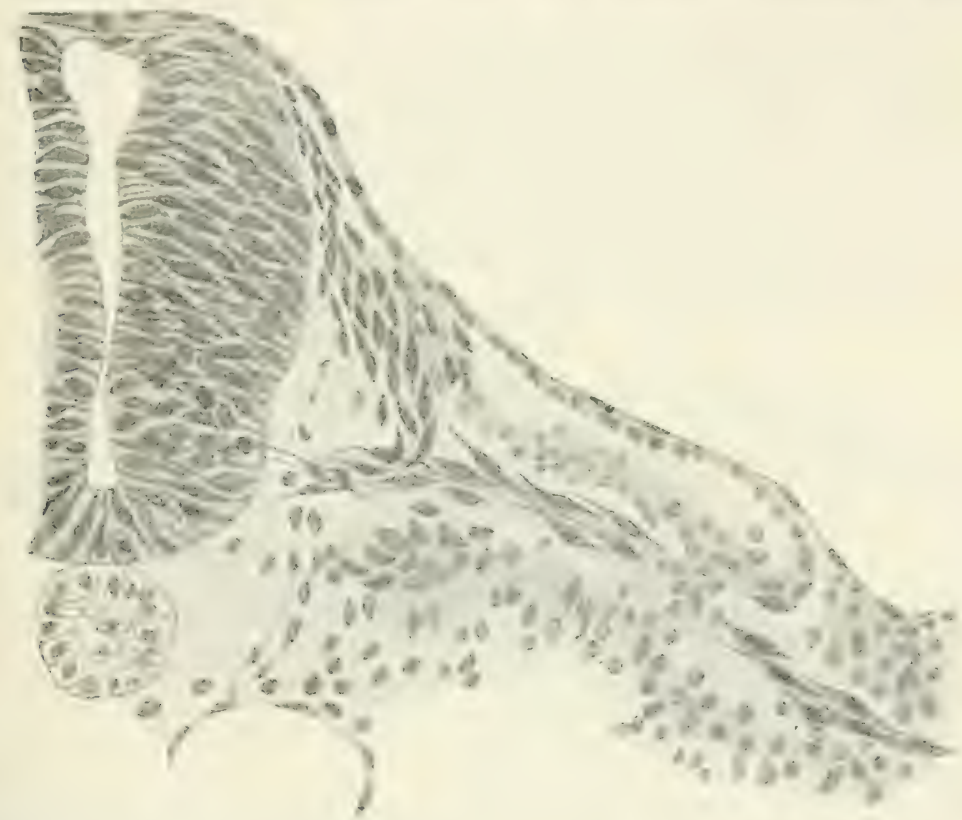

Fig. 59. Quersclunitt durch einen Hïhnerembryo von 2 Tagen und 21 Stunden Bebrïtung. Anlage der Wurzeln und des Spinalnerven in Form von Spindelzellen. Anfang der Embryonalfaserbildung. $($ Leitz $\mathrm{I} \times 5$.

tum haben, weil die Elemente hior noch nirblt die (hatraliteristikil hesitzen, welche sie in späteren Stadien vou andern Elementen unterscheiden. Tom Anfang des dritten Tages an ist dies in der Regel

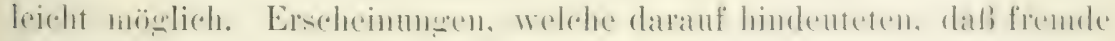

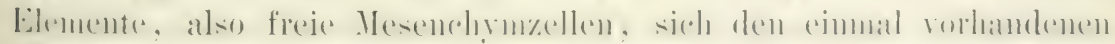

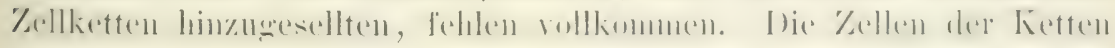
vermehren sich vielmehr nu l' aus sich selbst heraus durch häufige 'Teilungen, welehe immer in der Längsrichtung del Anlage vor sich gehen. Fast in jeder Zellkette sind mehrere Mitosen vorhanden.

Ehe sich also eine spur von Nervenfasern beim 1liilmelien zeigt, ist der Ort, an dem späiter der Nerv entsteht, durch Zellketten vor- 
gezeichnet. Woher diese Zellen stammen, kamn ich nicht sagen und es ist dies fïr mich auch mwesentlich. Jedenfalls glaube ich aber behaupten zu dirfen, da $\beta$ die erste $A$ nlage der Nerven beim Hühnchen nieht faseriger, sondern zellularer Natur ist.

An Ende des dritten und Anfang des vierten Tages treten sehr

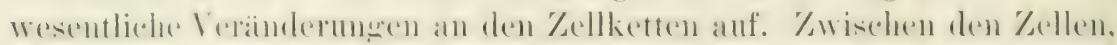

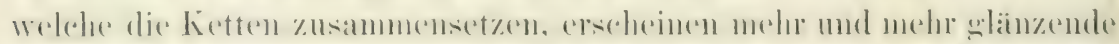

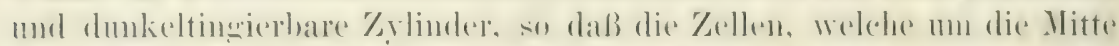

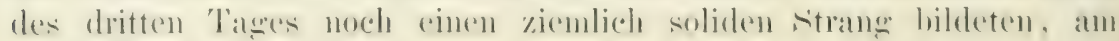
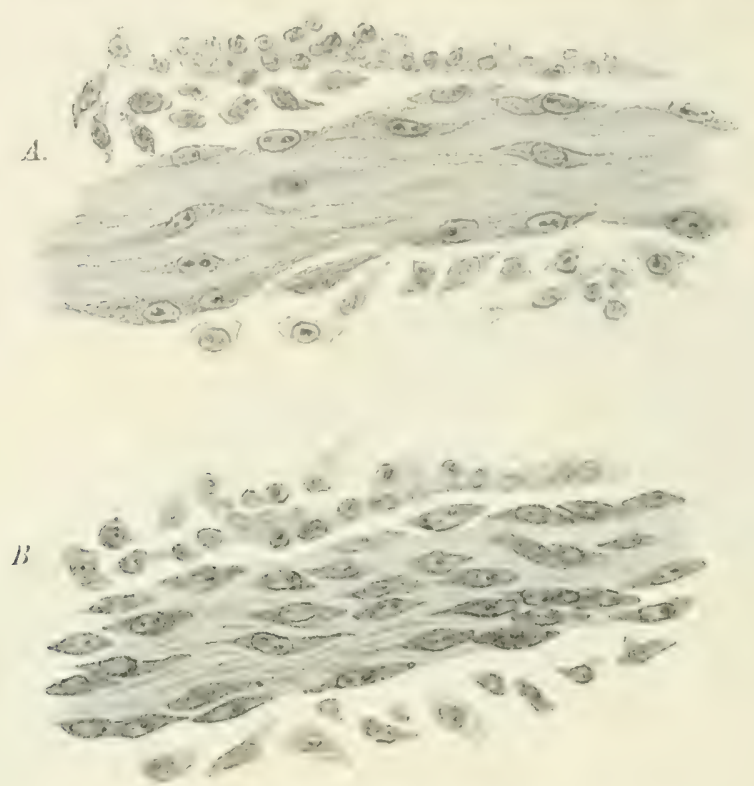

Fig. 60. Zwei aufeinanderfolgende Schnitte aurch einen Spinalnerren eines Hühnerembryos ron 3 Tagen 6 Stunden Bebritung. (Leitz I $\times 7$.)

Anfang und gegen Mitte des vierten Tages diese Zylinder röhren-

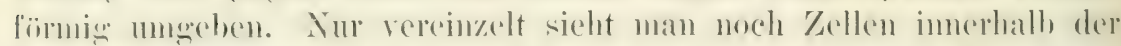

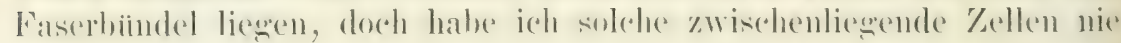
ganz vermißt. Figur 60 stellt einen Spinahnerven aus dem oberen

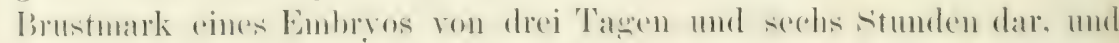
zwvar ist $A$ ein Schnitt, weleher mitten dureh den Nerven hindureh-

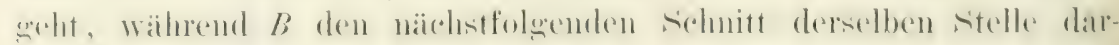
stellt, in welchem bereits die äußere Oberfläche getroffen ist. Auf Querschnitten durch eine solehe Nervenanlage sieht man das quer-

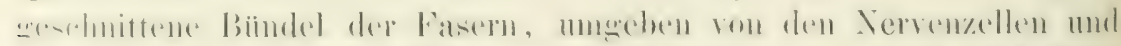

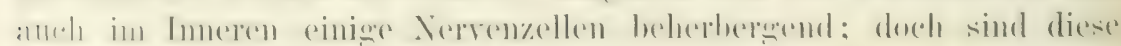

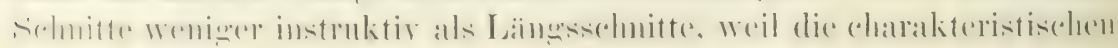


Enterschiede zwischen den Nervenzellen und andern zellen weniger deutlich herwortreten. Bilder dieser Art haben nach meiner Ileinunge

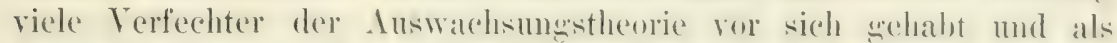
erstes stadium die Entwicklumg betrachet, ohne zu schen, daßs sie bereits ein sekundiires Stadium darstellen.

Es fragt sich nun, wie die glänzenden Zylinder in die Mitte zwischen die Nervenzellen sekommen sind: IDurch Eindringen von Ausliufern zentraler Zellen oder dureh Infferenziermug des nach der Strangmitte zu gelegenen l'lasmas der Xervenzellen? I) Le Lntersuchung mit stärkeren Vergrößerungen zeint, daß zwar manche Zylinder anscheinend frei zwischen den Nervenzellen liewen, $d$ a $B$ aber andre ganz deutlich in deren körnigem Plasmaverlaufen (siehe Fig. 61 und 62\%. Die anscheinend freien Zylinder liegen der nächst benachbarten Zelle meist ziemlich dicht an und bleiben anch zwischen den Zellspitzen zu kleineren Bündelehen vereinigt (Fig. 60). Sehr bemerkenswert ist es anch, daB in jeder Zelle rorwiegend an einer

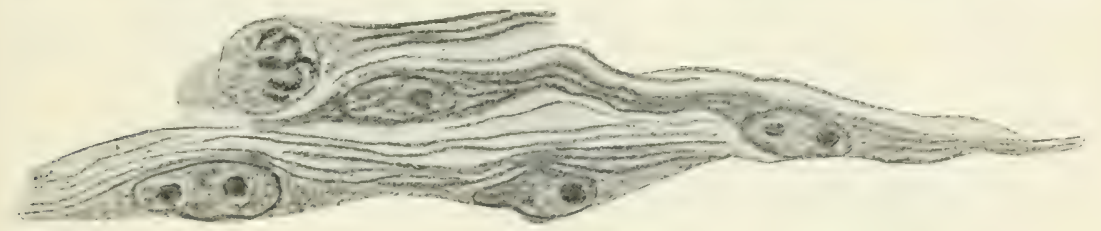

Fig. 61. Fünf Spindelzellen aus der Anlage eines Spinalnerven vom Hühnchen. Das Auftreten von glïnzenden Zylindern im Protoplasma der Zellen. (Bebriitung: 3 Tage 21 Stunden.) (Zeiss Apochromat 1,30, Kompensationsocular 6. Genau mit dem Zeichenapparat aufgenommen.)

Seite Zylinder im Protoplasma liegen und zwar an der der Mitte der Anlage zunekehrten Seite. Direkt nach anßen sieht man nie solche Zylinder und zwar weder im deutlich sichtharen Plasma noch außerhall, desselben. Am deutlichsten sind diese Terhältnisse bei Embryonen von 3 Tagen und 4-20 Stunden.

Zn dieser Zeit hat sich die weiße Substanz des Riickenmarks hereits zu bilden begronnen Fig. 62 . Die den vorderen Wryehn mahe gelegenen Veuroblasten zeigen zur Wurzel hin gerichtete fortsütze, welche zunächst protoplasmatisch sind, weiterhin aher das Ansisehen der oben beschriebenen Zylinder annehmen. In . Instritt der motorischen Wurgel aus dem Rïckemmark liegen stets eine wamze Inzahl von Nervenzellen, welche ihren zentral gerichteten, protoplasmatischen Ausläufer mehr oder weniger weit in das Riickenmark hineinerstrecken. In mo zwischen diesen Aus-

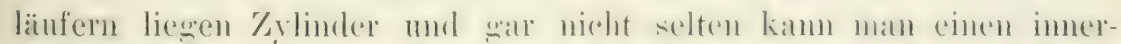

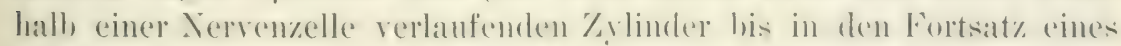

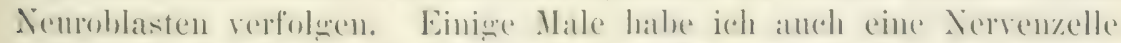

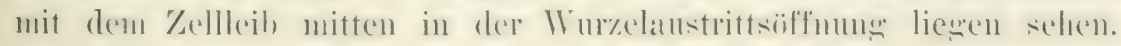
bethe, Nervensystem. 
Es sei auch nochmak hei der Finu 62 anf die Ïhnlichkeit zwischen Neuroblasten und Nervenzellen aufmerksam gemacht.

so, wie in diesen stadium die Verbälnisse an Rïckemmark liegen, kann nan zwar die Zylinder als Fortsätze der Xeuroblasten ansehen: aber ebenstogut kamm man sie für (iebilde halten, welche ans den Nervenzellen in die Nemoblasten hineinwatsen. Wahrscheinlicher als diese Auffassmegen scheint mir aber eine andre: Primä l bildet sich hein Embryo zwischen Rürekemmark und dem zu innervierenden Teil eine mehrzeilige Kette von Kernen, um welehe das Plasma

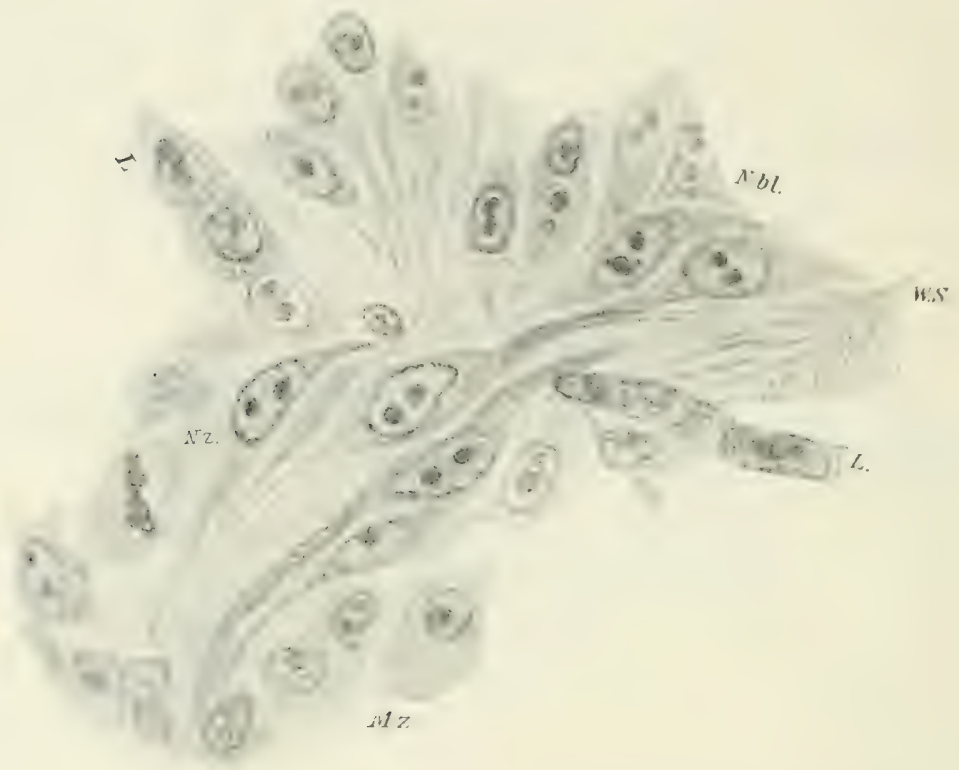

Fig. 62. Austrittsstelle einer vorderen Wurzel aus dem Ritickenmark eines Hühnchens von 3 Tagen 6 Stunden Bebritung. N.bl. Neuroblasten, $u, S$. weiße Substanz, L. Limitans des Neuralrohrs, N. Nervenzellen, M. N. Mesodermzellen. (Vergrößerung wie bei Fig. 61.)

verdichtet ist. In Grunde hamdelt es sich 1111 ein allsgedehtes synatium, in welehem die Kerne der Nenroblasten und der Nervenanlage liegen. Innerhalb des verdichteten Plasmas, welches als Leib der Nerventellen imponiert, differenzieren sich dureh Verdichtung Zylinder heraus, welehe vou einer Zelle zur näehsten und so fort bis zu den Verdiehtungen reichen, die als Neuroblasten bezeichuet werden. Die gebildeten zylinder seluieben sich immer weiter zur Mitte der Nervenanlage fort, wo sie dann anscheinend frei sind, tatsächlich aber noch im allgemeinen Plasma liegen, das aber wegen seiner ge- 
ringeren Dichtigkeit nicht mehr deutlich sichtbar ist. Da die Zylinder mit den Vemoblasten in festerer Yerbindume hleiben. so scheint es in etwats späteren stadien, als ob sie dustaufer derselben seien und mit ihren eigentlichen Bildumesollen nichts zu tun hätten. Wir sehen also hier beim Hühnchen, daß die $/ y^{2}$ inder im Plasma der Nervenzellen zuerst sichtbar werden und zwar meist

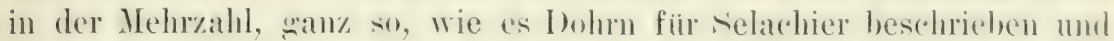
abgebildet hat.

Am Ende des dritten Tages, wo die Zahl der Zylinder noch gering ist, kamn man leicht Zählumgen derselben vornehmen. Ich zählte in ein und demselben Nerven die Zahlıl der Kylinder in dor Nähe des Rückemmarks und so weit von demselben entfernt als es möglich ist und fand in der Regel an Rückemmark etwas mehr als an der Peripherie. In etwa $30 \%$ der Fäle fand ich gleich viel und him und wieder sogar an der Peripherie mehr als am Rickenmark. Der letztere Befund, den ich einigemal mit voller Sicherheit feststellen komute, widerspricht der Auswachsumstheorie anfs entschiedenste, ist aber leicht zu verstehen, wenn man die Nervenzellen als Bildungsstaitten der Zylinder ansieht.

Während des Endes des vierten und des Anfangs des fünften Tages nimmt die Bildung von Zylindern immer noch stark zu. Da die Nervenzellen sich während dieser Zeit nur wenigr vermehen, das Faserbiundel aber an Dicke zmminmt, so ist das Faserbindel num die Mitte des fünften Tases nur von einem ziemlich spärlichen Mantel von Nerrenzellen umgeben. Um diese Zeit treten in den Nervenzellen wieder sehr lebhafte Teilungen zutag $\mathrm{g}^{\circ} \mathrm{e}$ Ohne dab eine Beteiligum andrer \%ellen als der Nervenzellen zu bemerken ist, ,mischen" sie sich unter fortwïhrenden Teilnneren inmer mehr unter die Fasern. Sie ,wandern", wie viele Autoren sich ausdriicken wiorden, in das Faserbiundel hinein. Von einem Windern ist natiulich nichts zu sehen; der Tatbestand ist nur der, daß man von

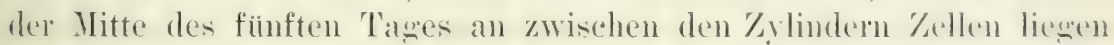
sieht (die an Zahl immer zunehmen), welehe den frïher als Nerren-

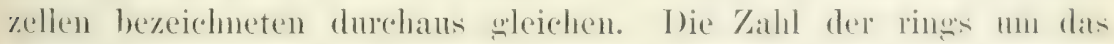

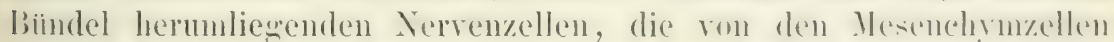

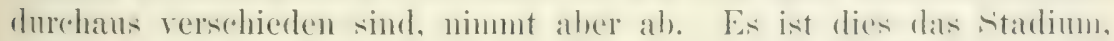

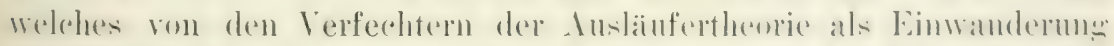
von Mesenchymzellen in die Nervenanlage bezeichnet wird. Wer die Jervenzellen von Anfang an kennt, wird aber nicht im $\mathrm{K}^{\circ}$ weifel sein,

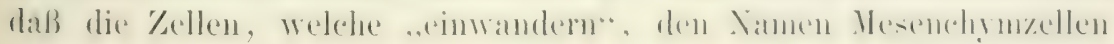
nicht rerdienen. Es sind rielmehr die dureh T'eilungen vermehrten Zellen, welehe die erste Anlage des Nerren bildeten. 
Die Lagebegichnngen zwischen den zylindern und den Verven\%ellen werden inmer innigrere, su daß ann Ende des sechsten und .nfang des siebenten Tatges an jeden Zylinder in weringen dbatanden je ein Kern liewt. Lon diese Zeit he winnt sich das Platina un Zylinder und zumehörigen Kem zin rerdichten, so dals wir jetzt Zylinder vor mis haben, wetehe vem einem Mantel mongeben sind, in dem hin und wieder neben dem Zylinder ein Kern liegr Fig. 63. A. Bei den häufig zu heobachtenden kernteilungen bleibt der Zusammenham zwischen Kern mol zylinder immer erhalten, aber wie mir scheint, zieht der Zylinder nicht wihrenddesien an Kern vorbei, sondern wird unsichtbar (Fig. 63 A). Bestaitigt sich dies, so ist es ein neuer Beweis für die Mhängizkeit des Zỵlinders von der Nervenzelle. Von dieser Zeit an kamn man das sanze Gebilde: Zylinder, umgebender Mantel und Kem als embryonale Vervenfaser bezedehen mol dem Zylinder den

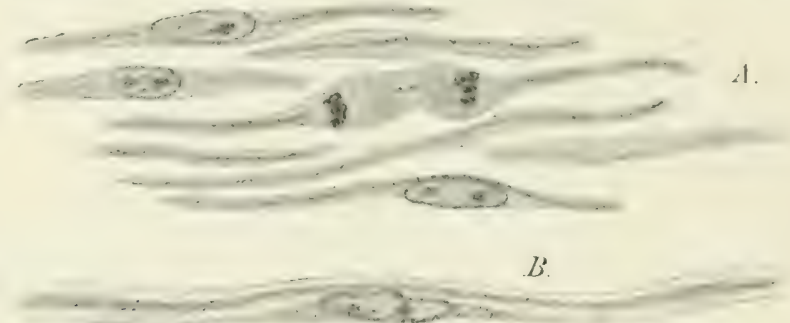

Fig. 63. A Embryonale Nervenfasern eines Hühnchens von 7 Tagen Hebrïtung. (Färbung mit Apathys Hämatein Ia. Dieselbe Färbung wurde bei den Fig. $59-62$ zugrunde liegenden Prïparaten verwendet.) $B$ Primärgefürbte Nervenfaser. Hïhnchen von 11 Tagen Bebriituag. Zupfprïparat. (Vergrößerung wie bei lig. 61 und 6\%.)

Nanen embryonaler Achsenzylinder geben, dem erst jetzt bildet er die Achse. Der Vergleich zwischen Figur 61 und 63 zeight, daßs die Nervenzellenkerne bei der Umwandlung zu Sehwannsehen Kermen wesentlieh an Gröbe abnehmen.)

Bei späteren Teilungen (nemter 'Tag') verschwindet der Achsenzylinder an der Kernteilungsstelle nicht nechr. I)iesem Stadlam entsprechembe Bilder sind von Källiker und Raffacte bereits allowehildet.

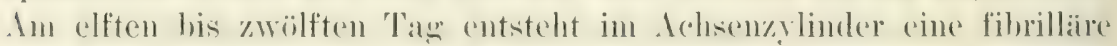
Streifung, welche an Dentlichkeit immer mehr zunimmt. Am dreizehuten bis vierzehnten Tag zeigen sich die crsten spouren rom Mark dicht am Achsenzylinder und umgeben ron Plasma, grade wie bei antorenererten Fasern. Zngleich zeigen die Fibrillen primäre Färbbarkeit (Fig. $63 B$ ), und zwar fällt ihr erstes Luftreten mit dem Auf-

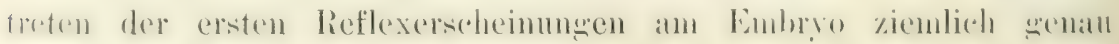
zusammen.

Für mich kamn es keinem Zweifel unterliegen, daß die Entwicklung der Nervenfasern multizellulär vor sich geht. Es entsteht aber 


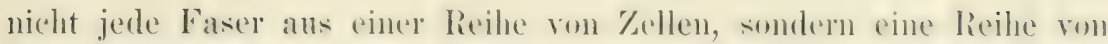

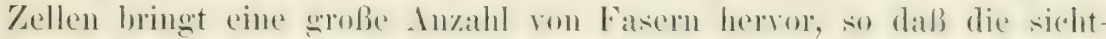
baren Bezichungen zwischen den Nervenzellen in wewisson stadien auberordentlich locker sind. Erst syäter vernohren sich die Nerronzellen stark und treten nun mit den einzelnen Fasern in nahere Beziehungen. Erst wenn dies eingetreten ist, fangen die nummehr zu Schwanschen Zellen mewordenen Vevenzellen an, mit den Zylindern zusammen ein abereshlosidnes Ganzes zu bilden. Dei diesem kompli-

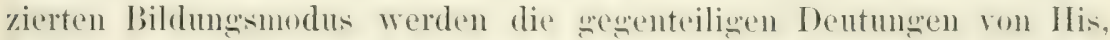
Kölliker, Gurwitsch und andern durchaus verständlich.

I)ie Lnterscheidum zwischen (ianshonzellen und Nervenzellen habe ich Ipathy entlehnt, der die Entstehumg der Tervenfasern und hesonders der Neurofibrillen von den Nervenzellen ableitet, die Ganclienzelle aber für ein eignes fiebilde ansieht, das erst sekundär ron den Nervenzellen aus mit Neurofibrillen versorot wird. , ̈̈ber die Entstehung der Ganglienzellfibrillen ron den Nervenzellen aus enthalte ich mich jeder ÄuBerumen, weil ich nichts dafiur und nichts dawider anzufïhren weib., Leider sind die (irundlawen für seine diesbezü»lichen Anschammen von Apáthy noch nicht ansfihrlicher mitweteilt. Nach Apathys bisherimen Mitteilungen enthält jeder Kern und jede Kommissur von Hirudineen nur eine große Nervenzelle, welche mit den Ganglienzellen sroße Öhnlichkeit hat! Der Hauptunterschied ist der, daß die Neurofibrillen an den Nervenzellen slatt vorbeiziehen, während sie in den Ganglienzellen Netze bilden. Von der einen Vervenzelle sollen die wesanten Neurofibrillen eines Nerven his ins Ganglion hinein welbildet werden. Die Einteilung des Nerven in einzelne Nervenfasem geschieht erst sekundär. Bei der Kür\%e der Hirudine(2nnerven kamn ein wesentlicher Lnterschied nicht darin wesehen werden, dah hiel nur eine zelle im Gegensatz zu einer wanzen Kette solcher bei den Wirbeltieren) vorhanden ist. Der Hauptunterschied scheint nir

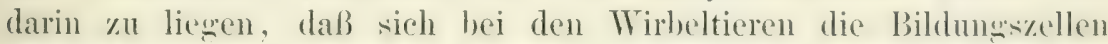
sekmolair vielfach teilen nud die Teilunesporodukte zu den einzelnen Nervenfascrn in engere Verbindme treten, während sie hei den Hirndineen auch in erwachenen Zustand das embryonale /ahlolenverhältuss beibehalten. Erwähnt sei noch an dieser Stelle, daß nach den Befunclen Apathys die postembryonale Vomehrung der Vomotibrillen bei Pontohdella, wahrseheinlich dureh Länestualtume zustande kommt.

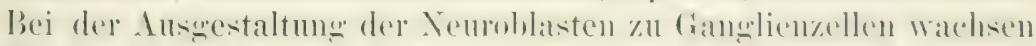

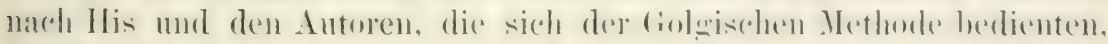

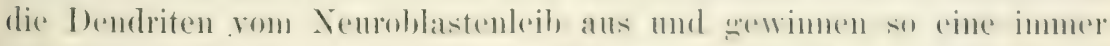

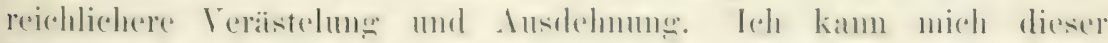

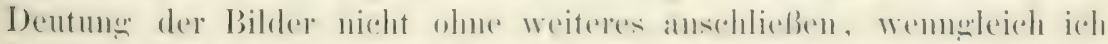

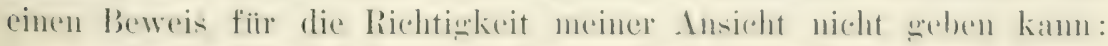




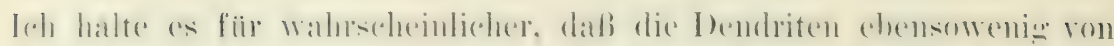

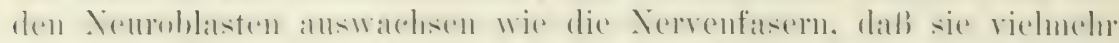

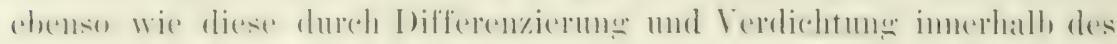

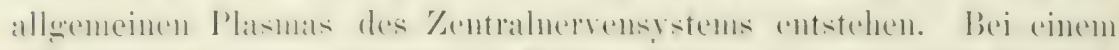

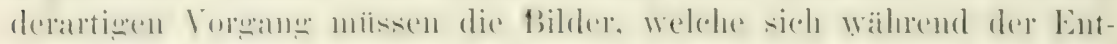

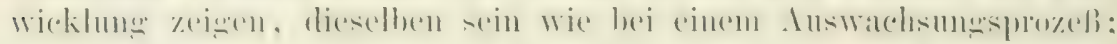
das Endresultat wird aber anf diese Weise einfacher und leichter erreicht. - Znerst ist der wahmehmbare Leib der Nemoblasten, soweit

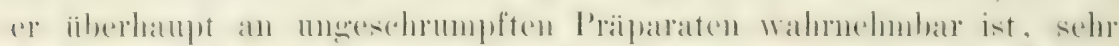

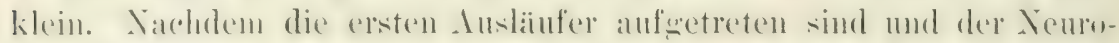

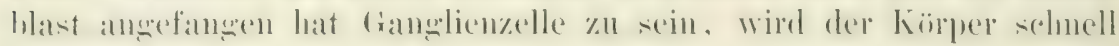
šößer und grenzt sich dentlicher von der Ungebung ab. Beim

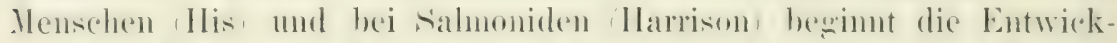

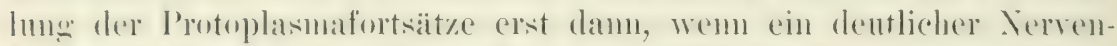

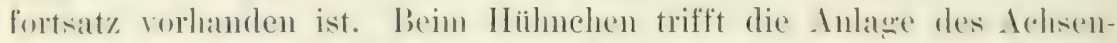
fortsitzes mit dem ersten Aufteren der I)endriten ziemlirh zusammen: Zur Zeit, wo die elsten Zylinder sichtbar werden mach der Mitte des dritten 'Tasers, sicht man auf meinen Prapuaraten bereits Semroblasten mit drei und vier Fortsätzen; bei einem Embryo von 2 Tagen und 19 Stunden sah ich sogar schon eine Reihe von Zellen, bei denen 2-3 Dendriten schon wieder Seitenzweige zeigten. Die Dendriten sind in der Nähe des Zellkörpers immer scharf rom umgebenden

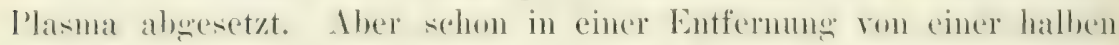
lis einer wanzen zellbreite zeigt sich ihe kontur verschwommen, mu bald ganz unter die Schwelle der Wahrnehmbarkeit zu treten. Von scharf absesetzten Enden, wie sie die Inswatsungstheoric erfordern wiilode, ist nichts zu bemerken.

Die Spinalganglienzellen sind, wie His gezeigt lut, zuerst bipolar und bilden sich erst mit der Zeit zu mipolaren Zellen mu. Dieser l'nzeß begrinnt bein Hiilnchen an Ende des fünften 'Tašes. Bei Fischen bleiben die spinaluanglienzellen zeitlebens hipolar.

In nenerer Zeit ist von italienischen Intoren die Lehre anfüestellt worden, daß die Ganglienzellen, besonders die moßen motorischen

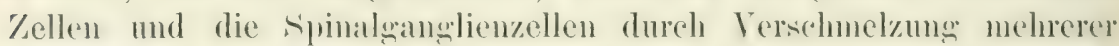
Nenoblasten entständen Frannito |1900, 19012], ('apolianco. Iels habe diesel Frage gleich nach den ersten Publikationen dieser Autoren meine Aufmerksankeit zusewandt, denn, wem sich ilore dngabe hestatigen wibde, so wäre sie ja der vortrefflichste Beweis fiir die Lnrichtimkeit der Nenronenlehre, den man sich denken kam. Der Prozeds wäıe auch nicht olıne Analoga, dem es entwickeln sich z. B. auch

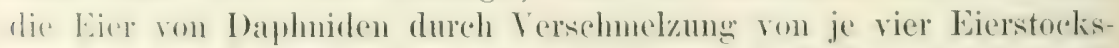

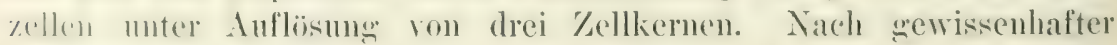

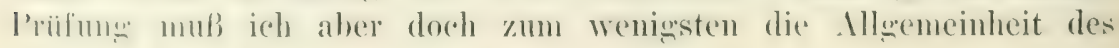


Prozesses anzweifeln. Fragnito hat seine Lutersurehungen hauptë̈chlich an Hühnerembryonen angestellt und gibt an, daß der Ver-

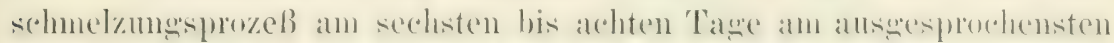

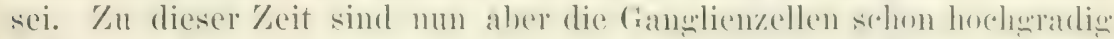

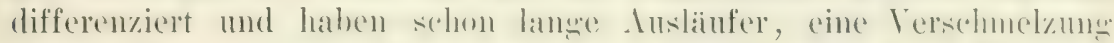

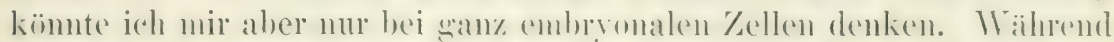
bis zum siebenten Tag die meisten (ianglienzellen sut roneinander

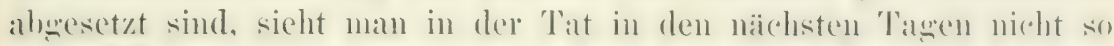
selten (iruppenbildungen eintreten, ähnlich wie dies Fragnito abbildet.

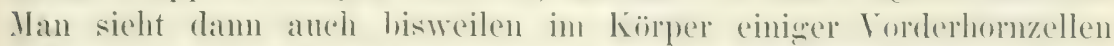
neben dem swroßen Kern kleinere dunklere, kernähnliche Gebilde. Wemm dies wirklich Keme sind, was mir nicht sicher erscheint, so kïmnte es sich aber wohl kaum um Neuroblastenkerne handeln, denn sie sehen ganz anders ans. Zwischenstufen zwischen den timpuen ron (ianglienzellen und diesen Zellen habe ich nicht finden kïmnen: ich rermisse sic auch in den Abbildungen der Autoren. Wron man num anch wirklich jene Gebilde im Zellleih, als wirkliche kerne ansieht, so ist doch die Zahl der Zellen, welche diesen Ban zeigren, viel zn gering, un die Bildung der groben Zellen aus vielen kleinen als allgemeinen Prozeß ansehen zu kömen. - Wäre die Ansicht Framintos und capolianeos richtig, so miißte die Zahl der Zellen im Kentralnervensistem rom sechsten his zum zehnten Tage etwa auf ein Drittel bis ein Fünftel der urspriunglich rorhandenen zusammenschrumpfen;

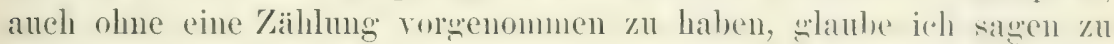
kömnen, daß dies sicher nicht der Fall ist. Am leichtesten wären Zühlungen jedenfalls im spinalganglion auszuführen, wo der gleiche Prozeß stattfinden soll ich habe allerdings dort nichits von Mehrkernigkeit entecken können: Fragnito schreiht auch in seiner letzten Arbeit, daf Capobianco Zählungen vorgenommen habe und eine Abnahme der Zellzahl gefunden habe. Solange aber nicht hestimmte Zahlen und die Methode der Zäihlung und der Berechnung mitweteilt sind, möchte ich auf die hlobe Tersichermon nicht allzuriel seden. Daß un den achten Tag herum in manchen (ianglienzellen junger IIühnchen eigenartige Prozesse vor sich grehen, die wert sind, norbly weiter studiert zu werden, webe ich gern zu, doch scheine'n mir die ron Fragnito und (apobianeo ans den objektiven befunden al)eveleiteten Schliusse vor der Hand etwas zu weitgehend zul sein. - (An dieser stelle sei noch erwähnt, dab Krohnthal die Gamplienzellen ans Winderzellen entstehen läßt!) 


\section{VIERZEHNTES KAPITEL.}

\section{Das Wesen der Nervenleitung.}

Die bisherigen Anschauungen ïber Nervenleitung S. 24S-254. - Über die Beweise für die leitende Natur der Neurofibrillen S. 255-261. - Der Kompressionsbeweis S. 259. - Bei aufgehobener Leitungsfähigkeit einer engbegrenzten Kom-

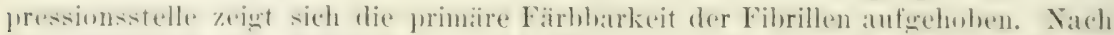
dem Anflären der Kimpression und Wiederherstellumg der Leitungsfihigkeit kehrt die primäre Färbbarkeit wieder S. 261-265. - Bei Einwirkung ron destilliertem Wasser auf einen lebenden Nerven wird die Fibrillensäure von den Fibrillen abgespalten. Bei toten Nerven bleibt sie an die Fibrillen gebunden S. 265-265. - Über die Wirkung des konstanten Stromes S. 272-292. - Histo-

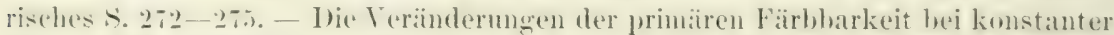
Durchströmung des Nerven S. 276-292. - Bei starken Strömen ist die primäre Fïrbbarkeit an der Anode aufgehoben, an der Kathode verstärkt S. 27s. - Abhängigkeit der Veränderung ron Stiirke und Daner der Durchströmung S. 279-2S1. - Einige Zeit nach Aufhebung der Durchströmung ist das Färbungsbild wieder normal S. 251. - Die Neurofibrillen selber werden bei der konstanten Durchströmung nieht verïndert S. 252, 253. - Extrapolar von der Anode läßt sich abgespaltene Fibrillensäure nachweisen S. 254-286. Die Hervorrufung von ,Polarisationsbildern " gelingt $n$ u $\mathrm{r}$ am lebenden Nerven S. 257. - In einer narkotisierten Nervenstrecke lïst sich kein Polarisationsbild hervorrufen. Die Narkotika hemmen also die Bewegungsfähigkeit der Fibrillensïure S. 257-259. - Kohlensäure verändert das Polarisationsbild S. 259. - Kiilte vermindert die Anodenveränderung, Wärme die Kathodenveränderung S. 291. - Besondere Versuche zeigen, daß die Ausbildung eines Polarisationsbildes nicht im sinne der Heringrehen Assimilations- mol Dissimilationshypothese gedeutet werden kann. An den Fibrillen befindet sich vielmehr eine heschriankte Jenge von Fibrillensianre, welche unter dem Einfluts des stromes wandert S. 293-297. - Veränderung der primären Fïrbbarkeit der Achsenzylinder durch Reizung S. 298-301. - Zur Theorie der Nervenleitung S. 301.

Vielfache Lntersuchumen älterer und newerer Autoren haben zu dem sicheren Erowehnis greführt, daß die Funktion des Nervensystems lediglich in der Reizleitung zu suchen ist. Während bei den einzelligen Vesen und den niedrigsten Metahionten noch allen Teilen des ()ranismus die Fähiskeit, Reize aufzunehmen, fortzuleiten und durch Bewernum anf dieselben zu reasieren, zukommt, tritt bei den hïheren Metazoen ein Gewelse auf, welches nur der Reizleitung dient, sumst aber nicht aktiy an den LehensänBerungen teilnimmt. Die meisten andern fiewche scheinen neben ihrer spezialfunktion die Eigenschaft der licizleitung beibehalten zu haben Muskelgewebe, Epithelgewelse monl deren lecrivate, nud nur in Nervengewebe sehen wir eine der [reisensoluaften des l'rotoplasmas remlich isoliert. Natürlich nub anch das Dervengewebe neben dieser cinen Eigensohaft noch alle die- 
jenigen besitzen, welche den nomalen bestand farantieren; es muß sich ans dem rom Blut gebotenen Material emähren und die stoffwechselprodukte wieder an dasselbe abgelien kömnen. Das sind aber Eigenschaften, olme die wir uns a priori kein lebendes dewehe denken kümnen, so daß wir sie als Mußqualitäten ignorieren kïmnen. Danach wiirden wir im Vervengewebe den cinfachsten siperialfall lebendigen Geschehens erwarten und nus hier am ehesten der Hoffnung hingeben dïrfen, einen Lebensworgang in seine Komponenten zu zerlegen. Das jedenfalls scheint außer allem Zweifel, daß der Vorgang im Nerrengewebe einfacher sein muß als die Prozesse in einem einzelligen Wesen, unter denen die Erregungsleitung nur einen kleinen Teil ausmacht. Die Ioffnum auf einen Einblick in die Natur der Erresungsleitung scheint um so berechtigter, als mancherlei dafur spricht, daß der Leitungsprozeß rom Ernährungsprozeß ziemlich unabhängig ist, so daß die Erkenntnis dieses nicht unbedingte Vorbedingung zum Verstaindnis des Leitungsvorganges sein muß.

Die anatomische und phrsiologische Einheitlichkeit der parallelfaserigen Nerrenstämme höherer Tiere sehen diesen zum studium des elementaren Vorganges der Leitung ron rornherein den Vorzug vor den Zentralorganen und den zellreichen Nerven vieler niederer Tiere. Schon der anatomische Aufbau dieser läßt rermuten, daß hier der Prozeß der Leitung nicht so rein hervortritt wie bei jenen. Auch der physiologische Versuch eroibt ja wesentliche Lnterschiede zwischen Nerveustämmen und sogenannten Zentralorganen, welche allerdings wohl nicht dazu berechtigen, prinzipielle Lnterschiede zwischen der Leitung dieser und jener zu konstruieren, wie das früher oft gescheheu ist. In Anbetracht der Kontinuität der Neurofibrillen in den Zentralteilen wird man amehmen dürfen, daß das Wesen der Leitum iberall dasselbe ist und es kömnte sich wohl nur darum handehn, dal in den Zentralorganen andre Faktoren zu dem einfachen Vorgang hinzukommen. Anch bei dieser Anffassung wird es nach wie wor praktisch richtic. sein, den Prozeß der Nervenleitung und alles, was mit ilm zusanmenlıängt, nur an den einfachst gehauten Nervenstimnnen zu studieren und die Zentralorgane zumächst ganz beiseite zu lassen.

Alogechen von einigen grolomechanischen Leitmosthenrien huldigte man bis geeren Ende des achtzehnten Jahrhumderts der Ansicht, dals in den Xerven ein Fluidum zirkuliere mol daß störmugen in desien

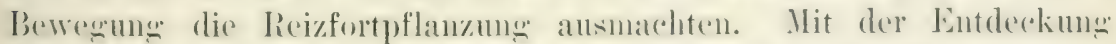

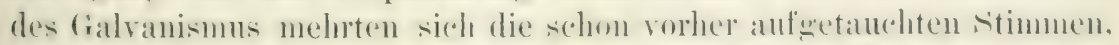

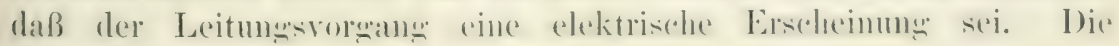
mangellafte Isolation der Nerven und die gegenïber der Fort-

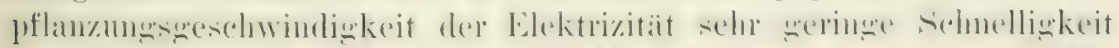

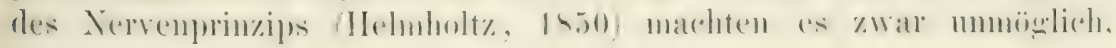


eine direkte Fortleitung von Elektrizitit in Nerven anzunehmen, jedoch zeigte Du Bois-Reymond, wie man trotzdem aus seinen großen Entdeckungen (Nervenstrom, negative Schwankung u. s. w.)

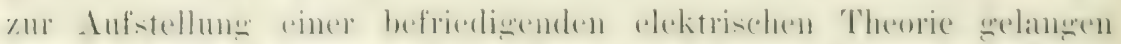

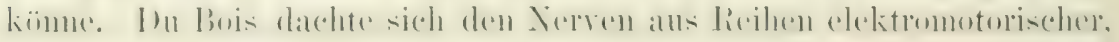
peripolarer Molekeln zusammengesetzt, welehe unter dem Linfluß

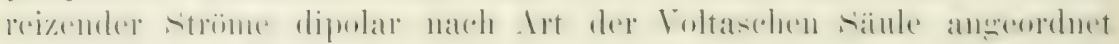
werden. Vom Reizort ans pflanzt sich diese Drehung der Molekeln

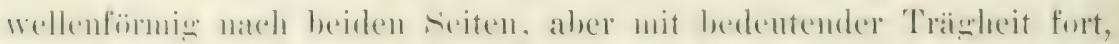

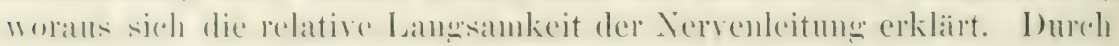
die Anordnung der Molekeln wurde anch der Nerrenstrom in hinreichender Weise begreiflich gemacht. Du Bois wollte mit dieser Theorie nur die olektrischen Vorwinge an Nerven erklären und wah sie nicht für eine Leitungstheorie ans, doch wurde später von seinen

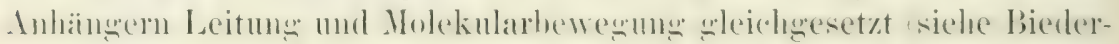

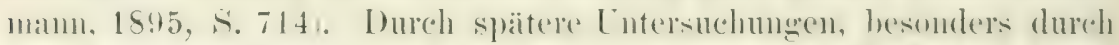

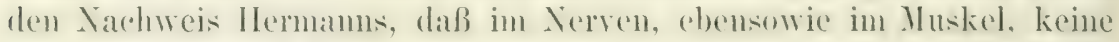
elektromoturiselren krafte prïexistieren, geriet diese Themrie in Wider-

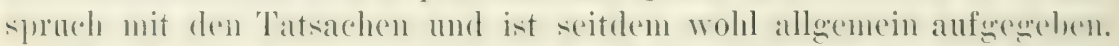

In Anschluk an seine glänzenden Lntersuchungen ïber die Herahsertmus der Erregharkeit des Xerven in ciebiet der Anode und die steigerung derselben in (ichiet der Kathode stellte Pflïger 1859 eine Thererie atuf, welche alle Erscheinungen an Nerven, hesonders hei clektrischer lieizung, verständlich macht, alser eigentlich mehr ein andrer Ausdruck der Tatsachen an der Hand eines mechanischen Beispiels als eine wirkliche Erklibung ist. Er stellt sich den Nerven als ans Reihen won Molekeln bestehend vor, welehe das dauernde Bestreben hahen, in bewegung zn geraten, aber dureh molekulare Hemmungen daran verhindert werden. Der Molekularepannmo steht also eine Iolckularhemmung gegenibler, welche sich im ruhenden Nerven das dileicharwicht halten. In Bereich der Anode werden nun die hemmenden Krafte verstäkt, an der Kathode vermindert oder anfwehoben. Herabsetzung und steigermug der Erregharkeit werden bei dieser Annahne leicht verstandlich, und anch die öfnumgsonckung, der Rittersche

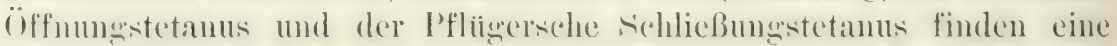

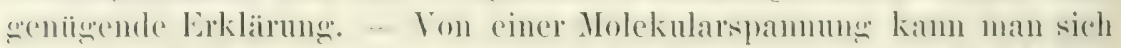
leidelt ein Bild machen, dagegen lat die Vorstellung einer Molekularhemmung ilre Schwierigkeiten und entbehrt der Analoga.

In wesentlichen physikalischer Natur sind anch die Anschanmgen, wrelche Hermann (siche die im Literaturer\%eichnis angefiihrten Arbeiten

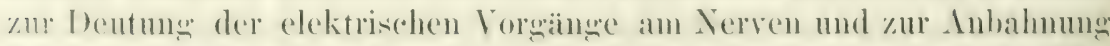
(eine Erklibung des Leitungsoromanges entwickelte, wenn er auch

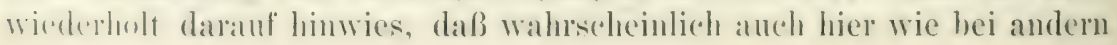




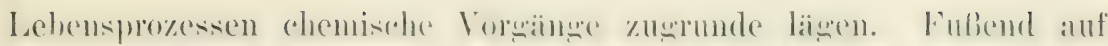

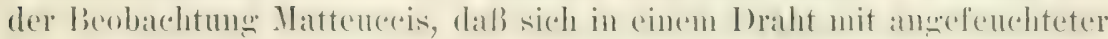
Wicklung ein an einer Stelle zugeleiteter Strom extrapolar nach Art des Elektrotomus amslowetet, komstruierte Hermam soin, liernleitermodell“6, an welchem er auffallende Analogien zu den elektrischen Erscheinungen an Nerven aufweisen konnte. (In einer langen Glas-

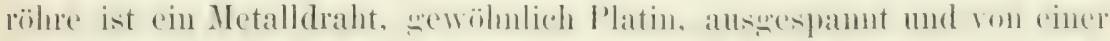

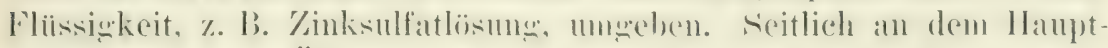

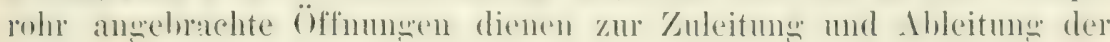
Ströme.) Wird der Hülle (dem fenchten Leiter) an einer Stelle ein strom zuneführt, so führt dieser an der tirenze ron Hülle und Kerm dem Metalldraht, zu einer Polarisation, welche sich nach heiden fieiten hin an der Grenzschicht ansbreitet. Leitet man von zwei Punkten der Iliille, welehe auf einer seite des zugeleiteten stroms extrapolar welegen sind, zum Galvanometer al, so wird ein dem zugeleiteten strom wherch«erichteter strom anwezeint. Wie bein Du Boisschen Elektotomus des Jerven nehmen die absoleiteten ströme an Intensitiit al), je mehr man sich mit den Ableitumsstellen vom zuseleiteten strom entfernt. Bedingung für das Zustandelommen der stromansbreitung in Kemleitermodell ist die Mönlichkeit emer Polarisation zwischen Kern mol Hiille und ein munterbrochener Verlanf des Kerns. Bei Kuleitumg kumer stromstöße und Ibleitung an einer weit entfernten stelle fand Hernamn, daf der Polarisationsstrom hier erst entsteht oder wenisstens rrst sein Maximm erreicht, wemn der ,Reizstrom" schom nnterbrochen ist. Woraus sich eroiht, dal der Polarisationsstrom sich wellenformum anshreitet. Die Ausbreitumg areschicht mit einer feschwindigkeit, welche der des Nervenprinzips ähnlich ist $(20-65 \mathrm{~m}$ in der Sekunde. Inßerdem zeinte es sich, daf die elektrischen Erobeinmmen an den Ableitunstellen sich aus zwei l'hasen zusammensetzen, einel stäkeren, den polarisierenden strom wleichwerichteten stromplase, und einer schwäheren, entwerengesetzt werichteten. Z̈hnliche ksschemungen treten bekamntich andeh bein Nerven in den phasischen Aktionsströnen in Esselieinmme. Hermamn erläuterte sodamn, wie man muter Amalne einer l'olarisation zwischen den Arhsenzylindern als Kern und den Markscheiden als Iliille, fül welche er in dem Lnter-

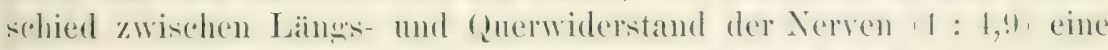
stiitze sieht, imstande sei, die meisten physikalischen Fischeinmuen am Nerven in befriedigender Weise zu erklïren.

IVenn Hermann anch immer wieder auf die rroße Öhnlichkeit

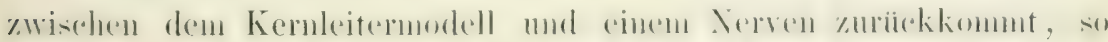

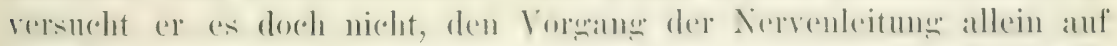

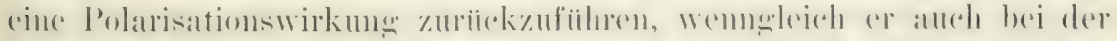

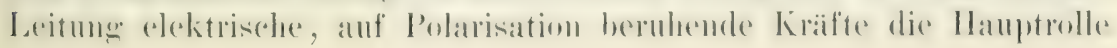




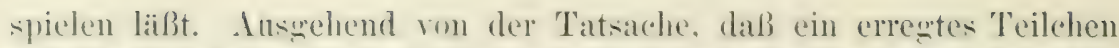

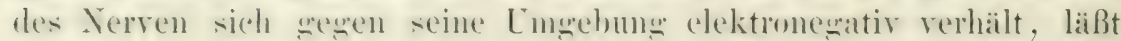
(er die von diesem ansonehenden, bei der mikroskopischen Kleinheit schr kräftigen strönchen auf die Sachbarteilchen erresend wirken, indem diese in hatelektrotonus versetzt werden, auf sich sellst aber beruhigend wirken, weil das erreste Teilehen durch eben diese strönchen in Anelektrotonus versetyt wirl. Anf diese Weise kam man

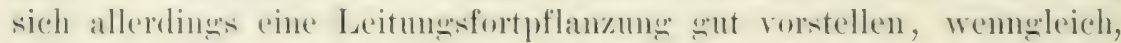
wie Hermam selhst zugibt, eine vollständige Leitumestheorie nicht

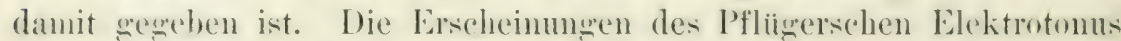

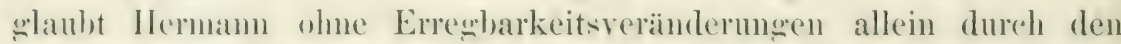
satz des polarisatorischen Inkrements und Dekrements erklären zu kömmen. Dieser — ein Ausdruck der 'T'atsachen — sagt aus: Der Aktionstrom ials Aushluck der Nerreneregung nimmt zu, wenn er sich auf positivere Nervenstellen zu- foder von negativeren fort-) bewegt und nimmt ab, wenn er auf negativere Stellen zu- (oder ron positiveren fort-) läuft. I Während der Iourchströmung läßt sich allerdings alles durch diesen Satz erklairen, doch zwingt die Tatsache, dak die Anode nach starker Durchstrümung häufig noch lange Zeit mureizhar und leitungsunfähig ist, dazu, wirkliche Erregharkeitsveräderungen im sinne Pflügers anzunehmen.)

Sehr viel radikaler als Hermann ist im Lauf der letzten Jahre Boruttau (1595-1902) für die Identifizierung des Leitumstoranganges mit den Vorgangen an Kernleitermodell eingetreten. Bei genïgend langen Abstand zwischen der stromzuleitmosstelle und der stelle, von welcher zum (xalvanometer, resp. zum Kapillarelektrometer, abgeleitet wird, fand Boruttau keinen dauernden, dem zugeleiteten gleichserichteten strom, sondern nu ein Nexativwerden der proximalen Elektrode und zwal bein schlieBen anf der soite der Kathode, heim

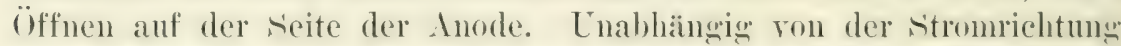
pflanzt sich also bei läneren strecken nur eine newative Trelle oder in Anschluß an die Berechnumen von ('remer) Psendowelle in Kernleitemudell fort. Noch besser kommet dies bei der Kuführumg ron Induktionsschlägen zul Vieltung, nur daß hier, mabhängign von der Richtung des schlages, sich die Nexativitait nach heiden seiten him anshreitet. I)as Auftreten dieser Erscheinuno, nämlich , die Beror-

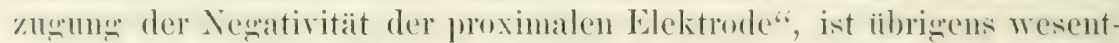
lich von der Art der Kernleiterkombination ahbängig Boruttan, 1902).

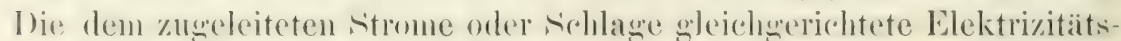

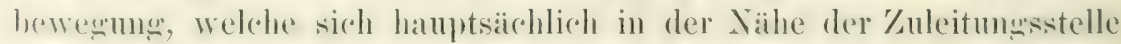

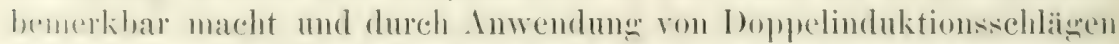

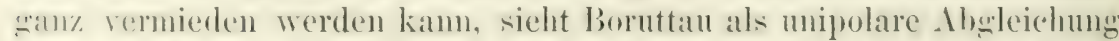
oder mit Hering und biedermamm als stromschleife an, welohe durels 


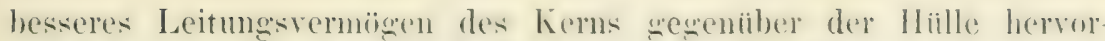
ererufen wird. Inas eigentlich Wesentliche an den Kemleiterversuchen

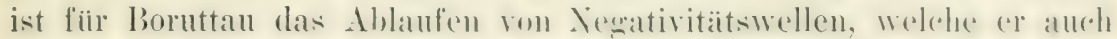

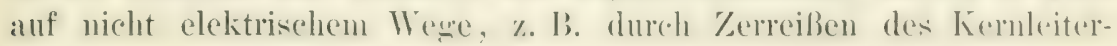
drahtes, hervorzurufen imstande war.

Wem Loruttan auch nicht die Vorwäne in phrsikalischen Modell mit denen in lebenden Nerven in allen Finzelheiten identifiziert, so hält el doch im Aumenblick 1902 einem Ablauf der Frregmun nach Art der Negativitatswelle in Kernleiter für das einzis: Wahrscheinliche, inden er Iktionstrom und Leitunswelle sleichzusetzen scheint. Ils Kern sieht er nicht, wie Hermann, den sanzen Achsenzylinder, sondern die Neurofibrillen an. Die Perifibrillärsbstanz wäre danach die In̈ille. In der 'Tat wïrde ja anch hei der Inemannschen Ammahme, daß die Markscheide die Hülle sei, die Kernleitertheorie nur für die mark-

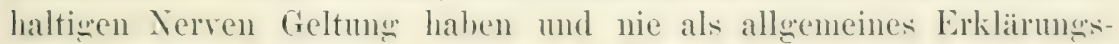
prinzip dienen können.

Eine andre, der Kernleitertheorie nahestehende phrsikalische Leitmustheorie, welehe von strong anf die Ammahme der alleminen Bewewlichkeit der nesativen Ionen aufgelout wurle, kann hier wewen ihrer rein spekulativen Natur übergangen werden.

sehen die bisher besprochenen Nerventheorien in der Leitung vorwiegend elektris che Vorgä $\mathrm{ge}$, so werden diese von Hering ind in Anschluß an diesen von Ijiedermann, Ilead, schoenlein ı. a. im wesentlichen als Begleiterscheinungen chemischer Vorw in $n$ we betrachtet. Nach Hering (1889, haben wir bei allen Lebensroräingen zwei Phasen, die Assinilation und die Dissinilation, zn unterscheiden; so auch in Nerven. Bei allen chenischen Vorwingen kïmnen nun elektrische Erscheinumenen auftreten; deren (ileichlreit oder Ïhnlichkeit berechtigt aber nicht zur Identifizierung der Vorwänge selber und dort, wo nur diese elektrischen Erscheinumeren zu 'Tate treten, besteht keine berechtigung, sie als das Wesentliche anzusehen. rie sind vielmehr als der Ausdruck der Issimilation mud bissimilation zu betrachten. In ruhenden Yerven halten sich Assimilation und Jissimilation das (rleichgewicht. Dieses wird mestïrt durch die An-

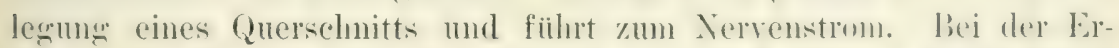

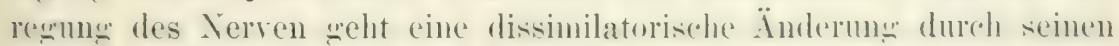

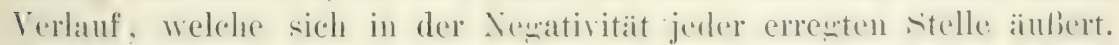

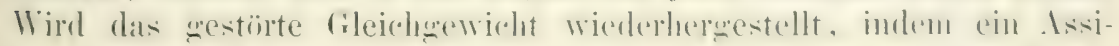

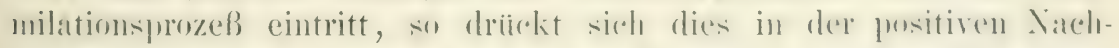
schwankung aus. (Diese wurde von Hering [188t] am Olfactorius

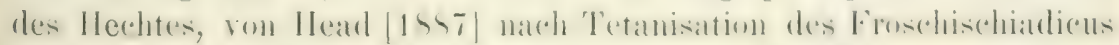

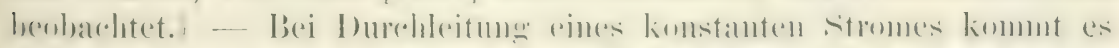

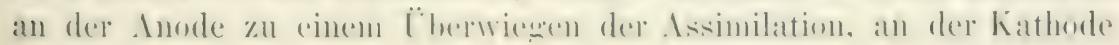


zu einer rerstäkten Dissinilation. Infoleredessen entsteht von der Kathode ans hei der sohliebung eine Erregmen, während sich die

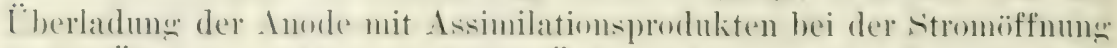

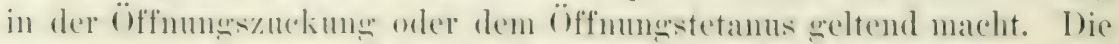

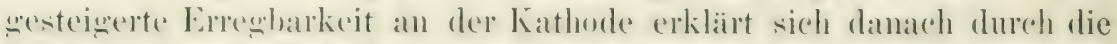

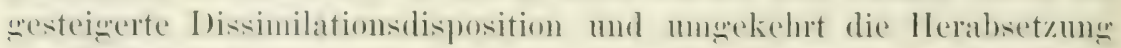
der Erresharkeit an der Anode dureh die remumblerte Dissimilation und remelnte Assimilationsdisposition.

('hemische und physikalische fiesielitspunkte werden schließlich in der alektrochemischen Molekulartheorie Bernsteins 1585, 1899, mitcinander verhunden. Fubend auf der vom P'flïserer entwickelten Anschaumen, daß in der lebenden substanz alle Molekïle durels intramolekularen sanerstoff rerknijpft sind, stellt er sich die leitencle vulstanz in Form rom aneinanderogereihten Molekiilen vor. I)iese Reihen sind polarisierbare Leiter. Bei der Durchleitung eines komstanten stromes werlen an der Kathode, welche einer immeren Inode der Faser entspricht, elektronegative Ionesn, und zwar wahrscheinlich sanerstoff,

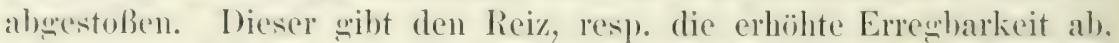
inden er anf die oranische substanz oxydierend wirkt. Die an der Inode abmeschiedenen elektropositiven Ionen wirken entwegengesetzt, indem sie die Stabilität der oxydablen Gruppen der leitenden Molekiile vermindern. (In weleher Weise siobl bei diesen Ammahmen die elektrischen Erschemungen erklären lassen, ist inn Origninal nachzulesen.) Anch von Ilömann (1599) wude ohme Kemutnis der Bernsteinschen.

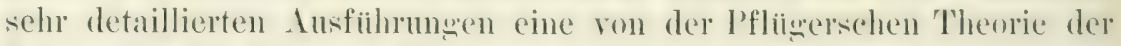
Kontinuitait der lebenden substanz ansgehende olektrochemische Theoric entwickelt. -

Wem man diese rerschiedenen Theorien miteinander veroleicht. so wirl man zugeben mitssen, daß eisentlich jede otwas für sich hat. l)em vollandenen Tatsachenbestand vermögen sic lanker den älteren Theorien, alle bis zu einem gewissen Grade gerecht zu werden. Genen

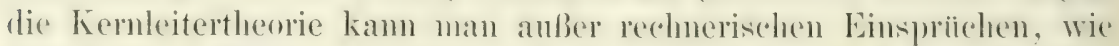

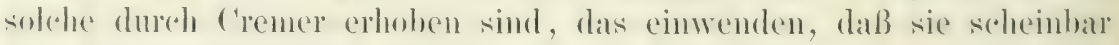

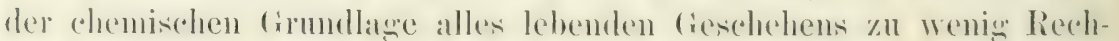
nung trägt, andrerseits wird von Boruttau gegen die elemischen Thererien eingewandt, dak man sich schwerlich einen cohemischen

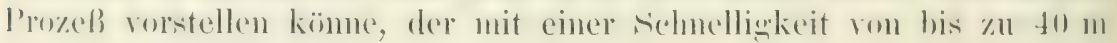
in der Sekunde fortschritte.

Ein Entscheid dürfte sich hier erst dann treffen lassen, wemn es

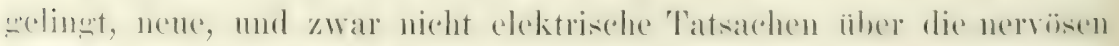

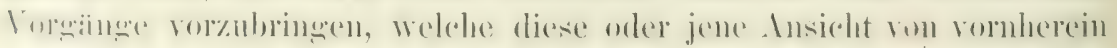

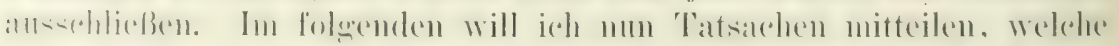

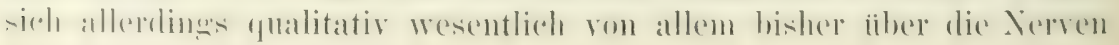




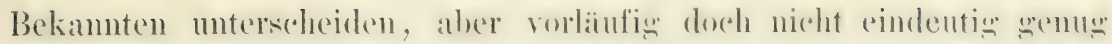

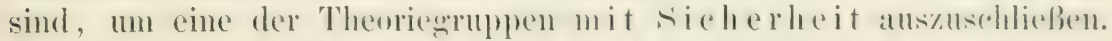

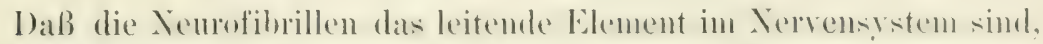

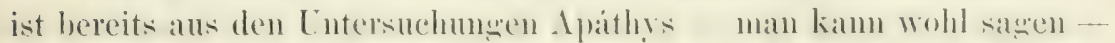

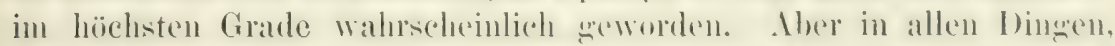
die mit herebrateden Vorstellungen irendwie kollidieren, verlangt man immer moch nateh beweisen, wemn längst keine mehr nötion sind.

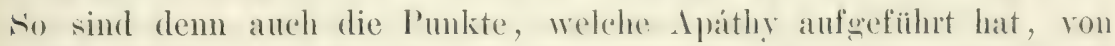
vielen nicht als æ̈eniigend angesehen worden mol denen, welehe ich zum Teil in Gemeinschaft mit Mönckeheron anforefuht habe, ist es nicht besser gegangen. Ich kam noich dabei allerdings nicht des Eindrucks erwehren, daß eine uewisse Voreingenommenhe it herscht, dem Antoren, welche sich vorher nicht engingiert hatten, haben sich leicht für die leitende Funktion der Neurofibrillen sूewimnen lasien. Ich will iibrigens dabei sleich benerken, daß ich anch diejenigen als Anhänger dieser Ansicht ansehe, welche die Fibrillen als Kern in einem Kernleiter ansehen. - Als Konkurrent der Fibrillen könnte höchstens die Perifibrilläsubstan\% ansesehen werden, also die substanz, welehe bei allen dickeren Nerrenfasern meben den sicheiden, den Haupthestandteil ansmacht. Anatonisch seheint aber diese Konkmrenz bereits neschlasen und zwar durch den Nachweis Apátlỵs, daß die Fibrillen an wewissen stellen der Perifibrilläsubstanz enthehren, und dureh die Tatsache, dak die Perifibrillärsubstanz an den Ranvierschen Einschniurmen muterbrochen ist, wailuend die Fibrillen slatt durch dieselhen hindurch-

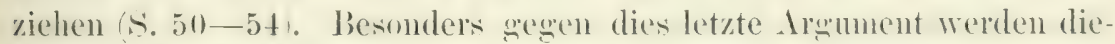
jenisen Einwände erheben, welche derartige membranoise sicheidewände nicht als Hindernis der Reiziblertragnug ansehen Engehnam, 1880); es ist ja auch nicht mit Sicherheit nachzuweisen, daß nicht sipuren von Perifibrilläsulostanz zusammen nit den Fibrillen durch die Membran hindurehtreten. Gegen beide Finwände wird man dam din Gegengewicht erlangen, wem nan zeint, daß dic Perifibrillär-

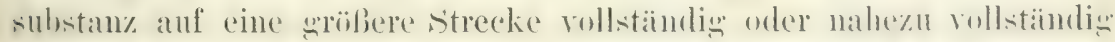

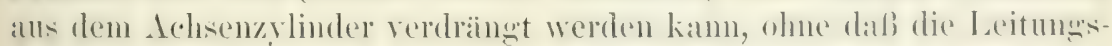

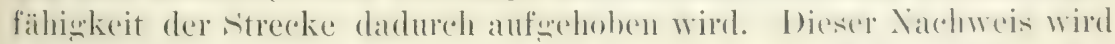

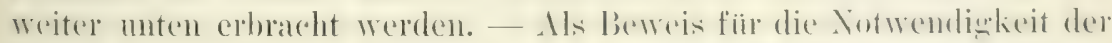
Neurofibrillen für die Leitung wird man auch die oben erwähnten Verhältuisse bei der Degeneration betrachten diurfen.

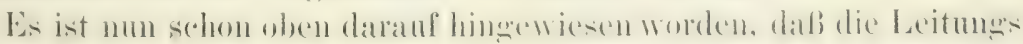

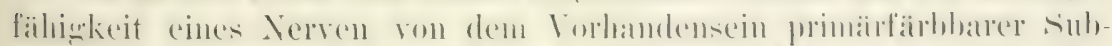

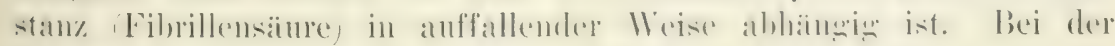
Degeneration latte sich lä ufig das Verseluwinden der primaren Färbbarkeit als erste sichtbare Veranderung 


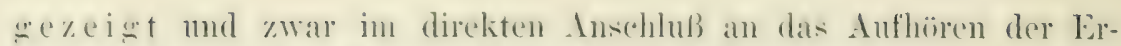

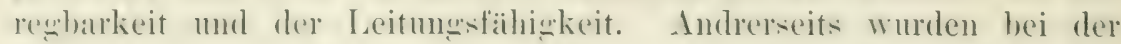
A utoregeneration Stadien gefunden, in denen zwar alle morphologischen Bestandteile normaler Nervenfasern vorhanden waren, die Neurofibrillen aber der primälen Färbbarkeit entbehrten. Diese Nerrenwaren nichteregbar. Waren aber die autogen regenerierten Nerien erregbar, so fehlte niemals die primare Fäbbarkit der Neurofibrillen. Nach diesen Befunden wurde es mir wahrscheinlich. dal die prinäre Färbbarkeit oder, mit andern Worten, das Vorhandensein von Fibrillensäure die Fibrillen erst leitungsäihig mache

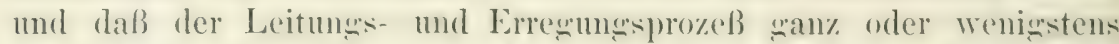
zun 'Teil in einer Werdselwirkune zwischen Fibrille und Fibrillensäure zul suchen sei.

Die ersten Versuche zur weiteren Begründung dieser Ansicht liegen melur als fünf Jahre zurieck. Ich hatte damals anch einige positive liesultate, doch wurde ich durch allerhand verfrubte Vorstellungen ïber das Wesen dieser Wechselwirkmes so in die Irre seführt, daß idh die sache wanz wieder aufüab. Bei einer ernenten Anfuahme der Arheit eroing es mir nicht hesser. Die anfanghelien positiven Resultate ïber die Einwirkmu des konstanten stromes auf die Verteihug der Fibrillensäure wichen gäinzlich newativen, so daf ich die ersteren auf Zufällighkeiten zurückführen zu müssen walubte mud auf eine Weiterführms der Tersuche verzichtete. Wie sich später heransorstellt hat, waren unsentïnende technische Vorrichtungen, ror allem die Benutzung von Metallelektroden, daran schuld. Eine ernente Durchsicht der alten I'räparate in Winter 1901 zeigte mir aber, daß ('s sich bei den heohachteten Veränderungen ummöglich um Zufiilliwkeiten handeln kïmnte und ich ging num zum drittenmal an die Arbeit, diesmal ohme störende theoretische Vorstellumen mud technisch hesser answeristet. Es šelang mir num anch endlich eine Reihe von 'Tatsachen zu finden, welche sich nutereinander sut vertraten und es

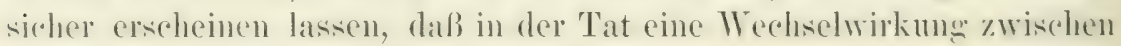
Fibrille und ribrillensäure besteht.

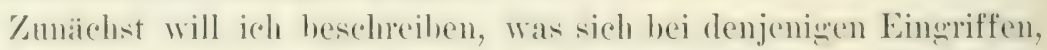

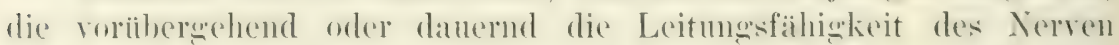
unterbrechen, in mikroskopischen Bilde mit den mir zu Gebote stelenden Mitteh crkemnen lält. Die Eineriffe sind: Kompression, Ein-

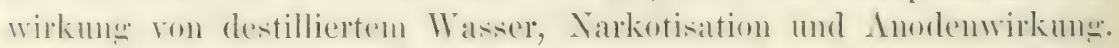

Die Nervenkompression.

Jede starke Kompression eines Nerven \%. B. dureh Zuzichen einer

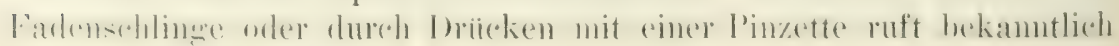




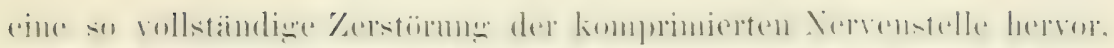

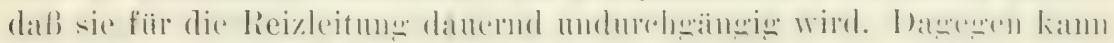

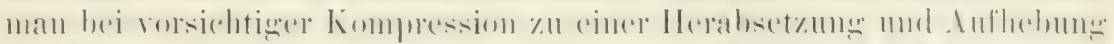

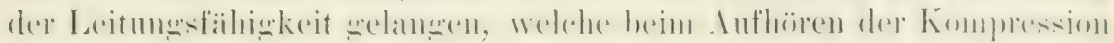
wieder verschwindet. Derartige Versuche sind von Gritzner, Efron, \%ederbanm, Ducceschi und andern angestellt worden. Während die meisten Autoren eine riemlich ausgedehnte Streeke des Nerven der
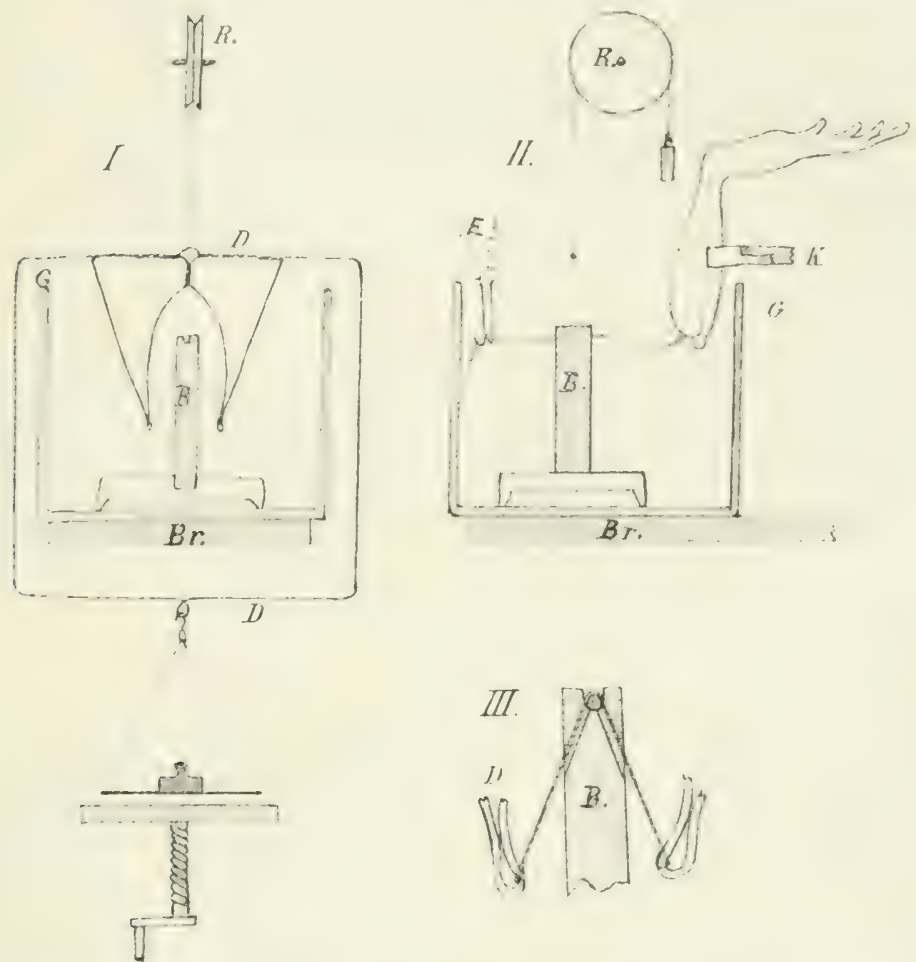

Fig. 6s. Apparat zur lokalen Kompression von Nerven wit Vorrichtung, um den Nerven wïhrend d̀er hompression zu fixieren. I. von vorne, II. von der Seite (beide $3 / 2$ natiirlicher Grüße). III. Kompressionsblack mit dem daraufliegenden Nerven und dem Faden in idealem Lüingsschnitt (etwas vergrüBert). $R$. Rolle, $D$. Drahtbügel, an dem unten die Gewichtsschale hängt, $L$. Kompressionshock, $C_{i}$. Glasschale, $B r$. an einem Statir befestigtes Brett, auf dem die schale steht, $K$. Klammer, E. Reizelektroden.

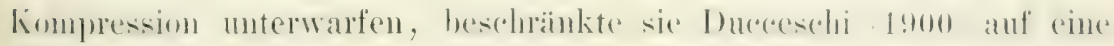
kleine Stelle, indem er einen dimmen Seidenfaden um den Nerren

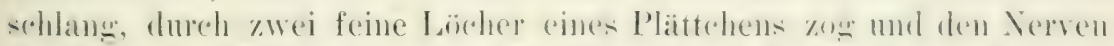

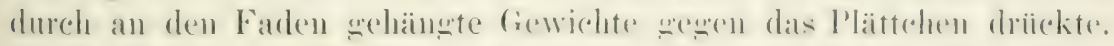

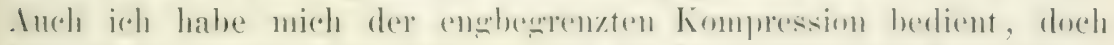

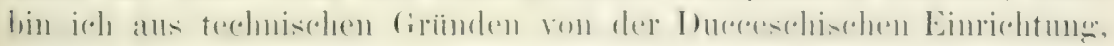
die ich zuerst benutzte, abgrekommen. Fiir mich war es nötiğ, die Terven wälend der Kompression zu fixieren, dem nur dabei 


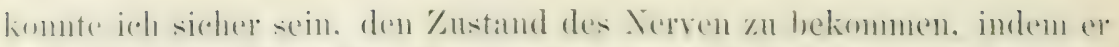

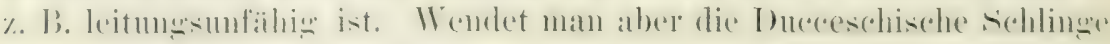
:m, so ist es nur sehr schwer möglich, ohme Verletzumg der komprimierten Stelle den Faden nach dem Fixieren zu entfernen. Sehr

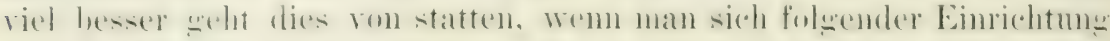

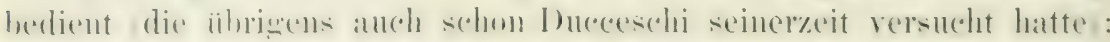

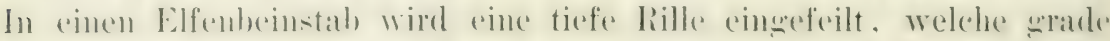

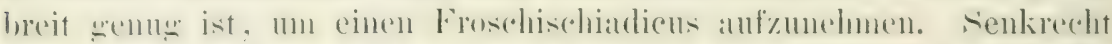

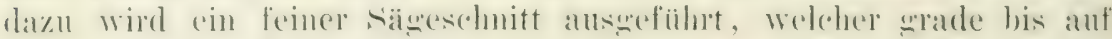
die Sohle der Rinne herabgeht und dann nach beiden Seiten hin

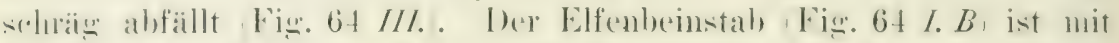
der limne nach oben anf einen bleiklot\% befestient: dieser wiedermu steht in einer Glasschale $(G)$. Un die Schale schwebt ein Drahtbiigel $(D)$. Von diesem ragt eine Gabel in die Schale hinein; diese mufalit denstah. Ihre moteren Enden sind durch cinen dimmen Faden verbunden, weloher sich in den sägeschnitt hineinleget Fis. 64. III. .

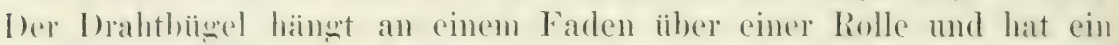
Gegengewicht. Unten ist an Biigel eine Schale zum Auflegen vou

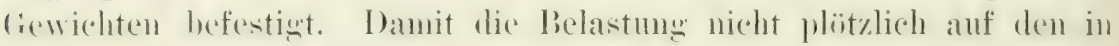
der Rimne liewenden Nerven einwirkt, wird die Gewichtsschale anfangdurch einen Schrauhtisch unterstiotz. D)ie Aufstellung des Praparats ist aus Figu $64 I I$. zu ersehen. Als Pribungsreiz wurden Einzelinduktionsschläge angewandt.

Was die physiologischen Daten anbelangt, so kamn ich num

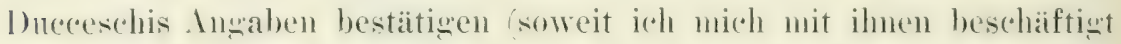
habe). Schon ein Gewicht von 15-20 g kann bei långerer Ein-

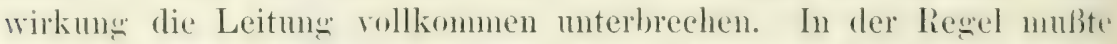
ioll bei dieser Aufstellumg aber zur rollkommenen Aufhehmug der Leitung eine Belastung von $30-50$ g anwenden. Häufiger als Incoeschi es angiht, sah ich hei weringen fiewichten eine erhöhte Erresharkeit eintreten, wie sie von all den Autoren swefunden wurde. die auf größere Strecke komprimierten.

Meine Versuche zerfallen in drei Gruppen: 1. Nerven, welche bei riner Belastume fixiert worlen, die die Leitume noch nicht muterhach. 2. Nerven, die fixiert wurden, wenn eine höhere Belastung die kom-

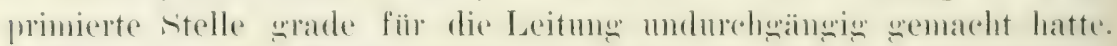

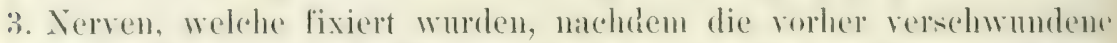

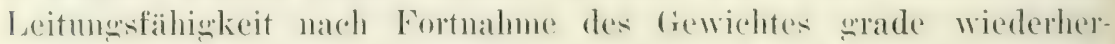
gestellt war. - Die Fixierung geschah in der Regel mit Alkohol: nur bei dieser Fixierung bekommt man ja ein gutes Bild von der

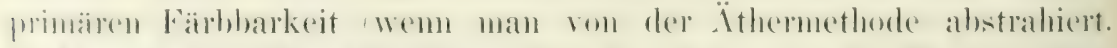

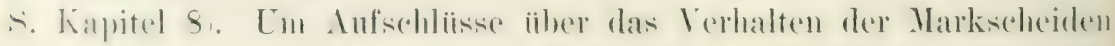
zul erlangen, wurde anch einige Nale, wie es Duceeschi (nach Anf- 
hebung der Kompression) tat, mit Osmiumsäure fixiert; diese Bilder sind jedoch zientich entbehrlich. Sie zeigen, was Duceeschi bereits

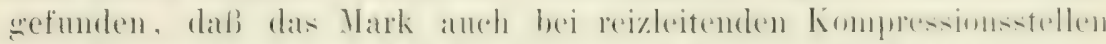

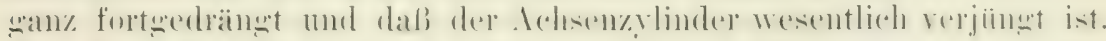
Wie dium der Achsenzylinder iibrigens dabei wird, kamn man nur be moilen, wenn wähend der Kompression fixiert wird, da el nach Aufhebung derselben in wenigen Minuten wieder an Dicke zunimmt.

1. Ich beschreibe einen bestimmten Fall: Reizschwelle vor der

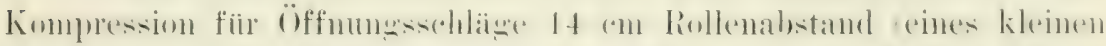

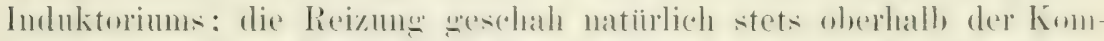

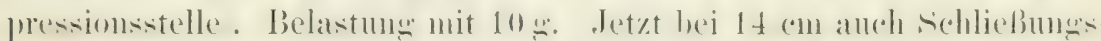
schläge wirksam. Damm $15 \mathrm{~g}$, schlieBlich $20 \mathrm{~g}$. Belastung. Jetzt Erregbarkeit wieder wie ror der Kompression. Die Erregbarkeit nimmt innerhalb zwei Ninuten Belastmo nicht weiter ab. Schale mit

Fir. 65. Noch leitungsfähige Kompressionsstelle während der Kompression fixiert im Läugsschnitt $($ Leitz III $\times 3)$.

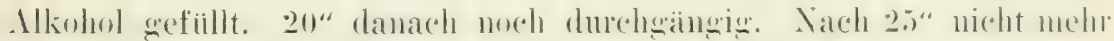
durchgaingig. Nach weiteren $45^{\prime \prime}$ die Belastung aufgehoben.

Der Nerr wurde zunächst längsgeschnitten, darauf neu ein-

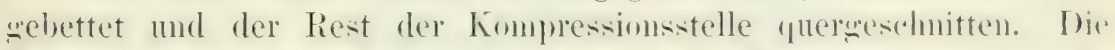

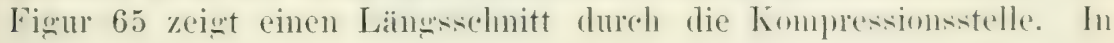
Figur $66 \mathrm{~B}$ sind Querschnitte dureh nicht komprimierte Fasern dieses Nerven aberehildet; $110 \mathrm{~m}$ in einer Faser ist der Iolsenzylinder

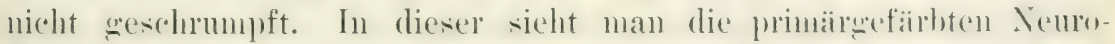
filmillen als P'unkte. In allen andern Fasem sind die Fibrillen dureds Alkoholwirkung zu einem Bündel zusammengeschntunft, das mun sehr

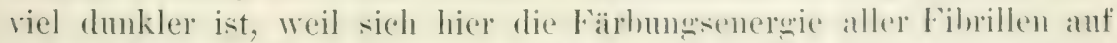

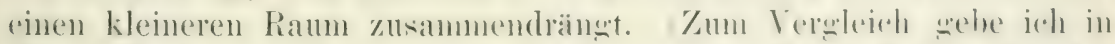

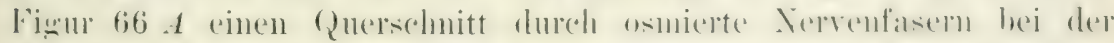

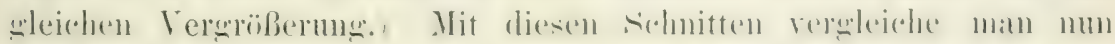
die Figur $66 \mathrm{C}$, welche einen 'T'eil eines $Q$ uersehnittes d uch die Compressionsstelle des beschriebenen Nerven bei go le i her VergröBerung wiedergibt. Die dunklen Punkte in der Mitte der

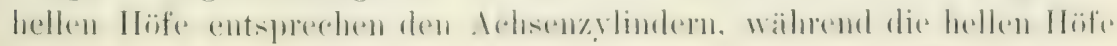


nicht mit dem hellen Hof der Fasern in Figur $66 \mathrm{~B}$ \% identifizieren

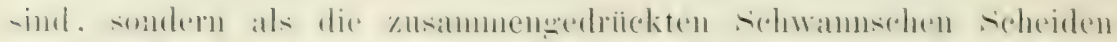

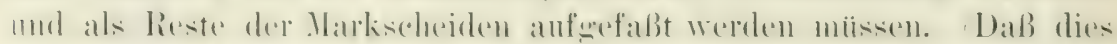

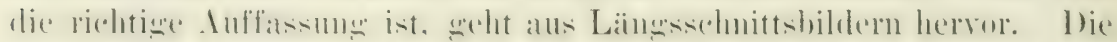

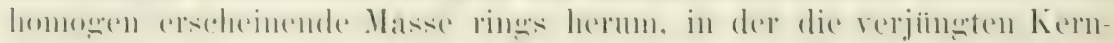

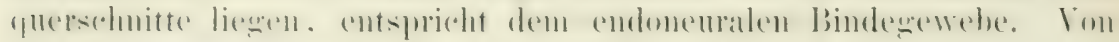
den Achsenzylindern ist auf dem Höhepunkt der Kompression nur noch das anf einen engen Raum zusammengepreBte Bündel von

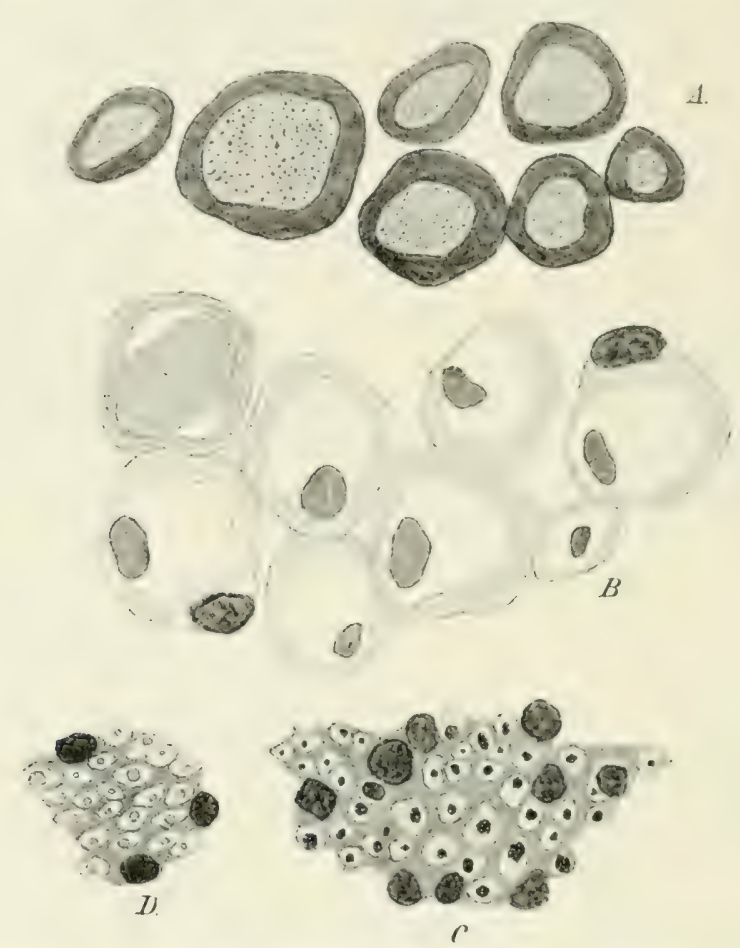

Fig. 66. A und $B$ Querschnitte durch normale Froschnervenfasern. I Nach einem ()smium-MolybdinToludinblan-Prïparat. $B$ (wie auch $C$ und $D$ ) nach einem Alkohol-Toluidinblat-Molybdinpriparat (primäre lärbung der Achsenzylinder). - $C$ und $D$ Querschnitte durch komprimierte Nervenfasern. ( leitungsfiihig, $D$ leitungsunfähig. Alle vier Figuren sind bei gleicher Vergrößerung (Apochromat 1,30, Kompensationsocular 6) mit dem Zcichenapparat gezeichnet.

Xenrofibrillen vorhanden, wihrend die l'erifibrillärubstanz, ganz oder

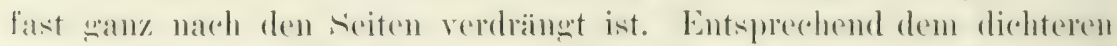
Aneinanderliegen der Fibrillen arseleeint das Bïndel wesentlich

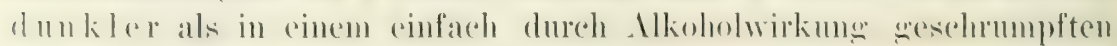
Achsenzylinder.

Da die Fibrillen gegenüber der Perifibrillärsubstan\% nur einen

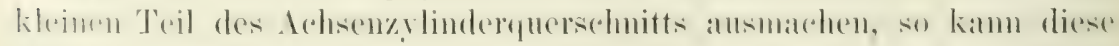
Größe vernachlässigt werden und die Fläche des normalen Achsen- 


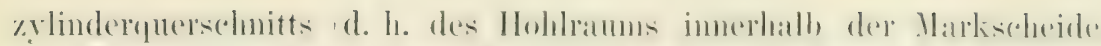

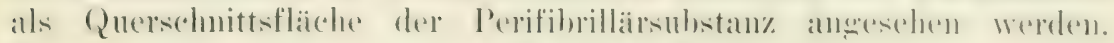
Wenn man nun als eventuellen Rest von Perifibrillärsubstanz an der

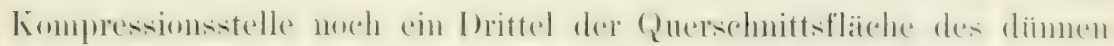

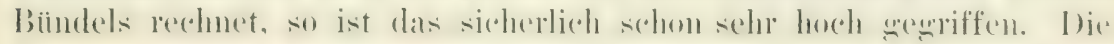

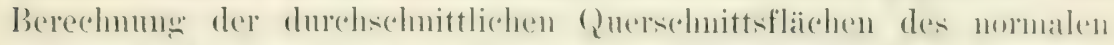

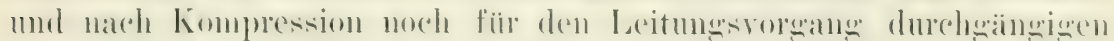
Achsenzylinders ergibt nun ein Verhailtnis ron 218:1. Da nun wie peraset der Rest rom Perifihrillärsulstanz nicht höher als ein Drittel veranschlagt werden kann, so verhält sich die Menge von Perifibrillärsubstanz (anf dem Querschnitt) in der normalen Faser zur Menge im komplimielten, noch leitungsfäligen Nelven wie 654: 1. Wenn man nun die Perifibrilliasubstanz als das Leitende ansicht, so miißte nan hehaupten, daß dor

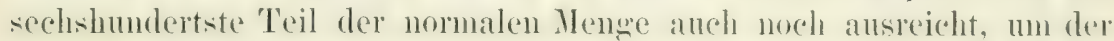
rollen Funktion zu genügen. Dies wird aber schwerlich jemand be-

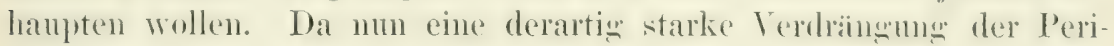
fibrilläsulstanz in meinen Versuchen auf eine strecke vom $0.2-0,3 \mathrm{~mm}$ stattfindet, so ist auch wicht mehr der Eimwand statthaft, der bei dere

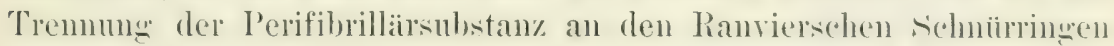
gremacht werden konnte. Nach diesem Befunde glaube ich die leitende Funtion der Nenrofibrillen gegeniber allen gemachten Einwänden als gesichert betrachten z ll dï r f en.

2. Fixation des Nerven im Augenblick, wo die komprimirte Stelle

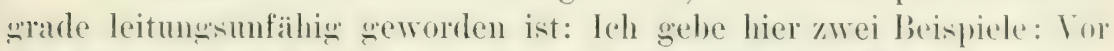
der Belastmog sohwelle bei 22 an Rollenabstand. Nach Belastmme mit 10 ge etwas eregharer. IBei $20 \cong$ Erregharkeit etwats remindert.

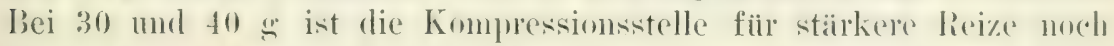

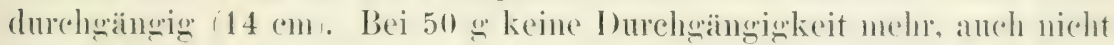
bei $5 \mathrm{~cm}$ Rollenabstand. Sofort fixiert, Gewicht nach einer halben

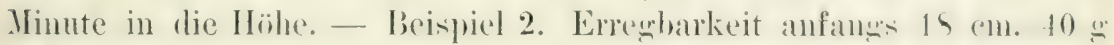

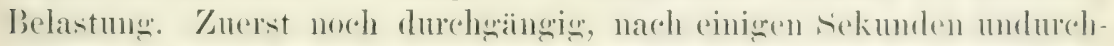
gräingig. Sofort fixiert; Gevicht in die Höhe nach einer Minute.

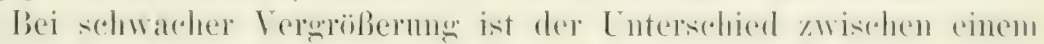
solehen Nerren und einem noch gut durehgingig gewesenen sehr

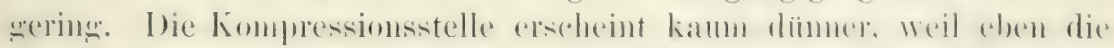
Ilauptmassen - das Mark und die Perifibrillärsubstan\% -- auch dent

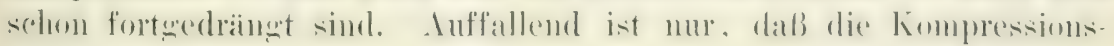
stelle weniger dunkel erscheint als dort.

Bei starker Vergrößerung ( Fig. 66 D) sieht man, daß die Querschnitte der Kerne noch kleiner sind als bei dem vorigen Stadium. auch die hellen Höfe und das endonemale Bindegewebe haben an 


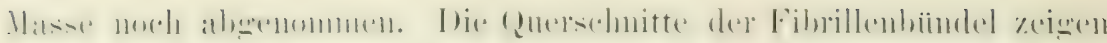
sich zwal auch noch ein wenig dumnel als bei leitungrähigen Kompressionsstellen, doch tritt dieser Unterschied gan\% gegen den in der Fairbunesintensitait zuriek! Wäl rend die B iindel bei leitungs. fähoen Kompresionstellen tief dunkel erseheinen (Fig. $66 C$ ), sind sie hier trot\% der ganz gleichen Behand$1 u n g$ stets gan bla B (Fig. 66 D). Die Querschnitte treten eigentlich nur dadureh noch deutlich rol der Umgebung hervor, daß ilıe

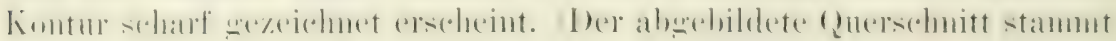
rou Beispiel 1.) In Figur 67 gebe ich drei Stellen aus einem Längsschnitt des Beispiels 2 wieder. Die Stelle $A$ liegt auBerhalb des Be-

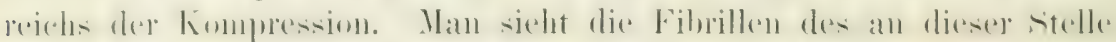
nicht

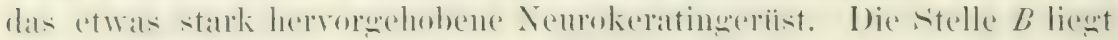

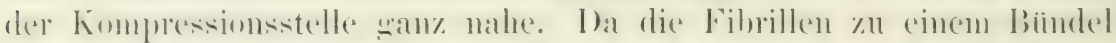

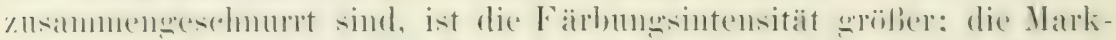

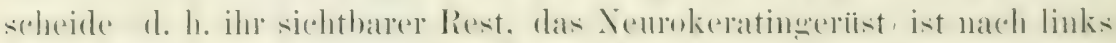

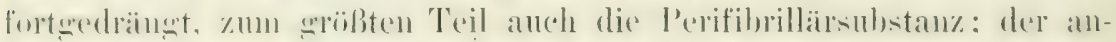

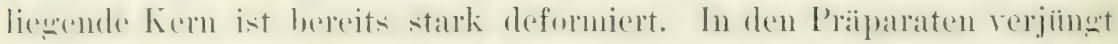

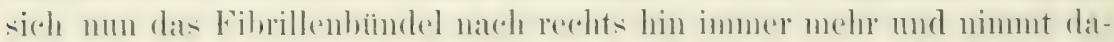

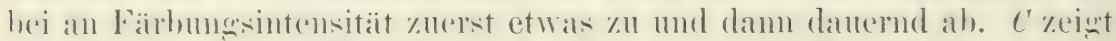

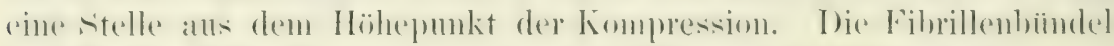

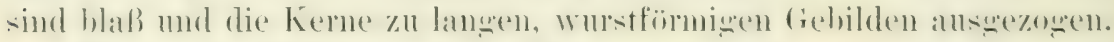

Wären die Fibrillen unverändert, so müßten die ans ihnen zu-

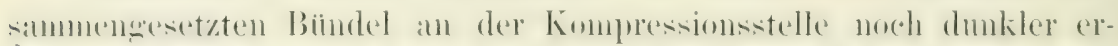

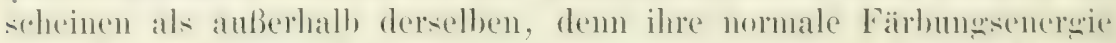

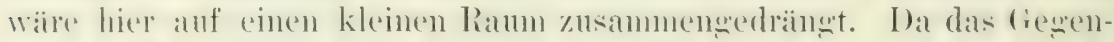
teil der Fall ist, so muß irgend eine Veränderung mit ilmen rorgegangen sein. Ehe ich diese zu deuten versuche, will ich erst das dritte Stadium beschreiben.

3. Nerven, welche fixiert wurden, nachdem sie wieder durch-

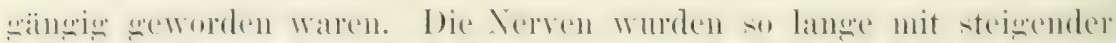

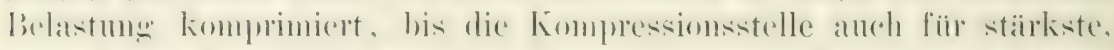

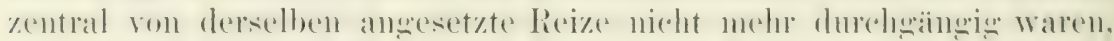
also bis zu dem Stadium, dessen fixiertes Bild soeben beschrieben wurde. Darauf wurde das Gewicht hochgehoben und num unter oft

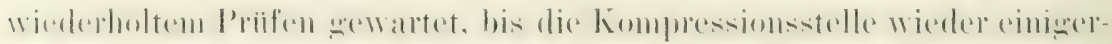

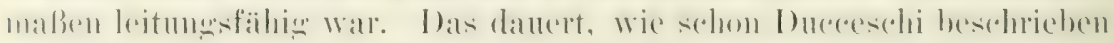
hat, oft nur wenige Sekunden. War dies eingetreten, so wurde fixiert. In diesen Fälen bot sich ein Bild, wie es für nur mäßig und nicht

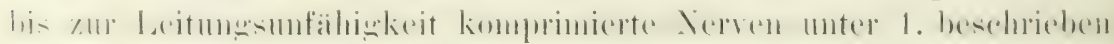
worlen ist. Die Figur 60 C kömnte gradeso gut ron einem solehen Jerven genommen sein! Die Hauptsache dabei ist, daß das Fibrillen- 
bindel an der Kompressionsstelle stets wieder tief dunkel fälbar ist, wenn die Leitungsähigkeit sich wieder-

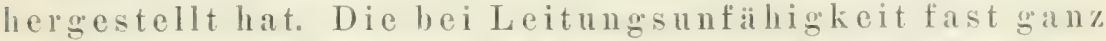
verschwndene primäre Fäbbarkeit kelut also mit ker Wiederherstellung der Leitungs ähigkeit zuriek!
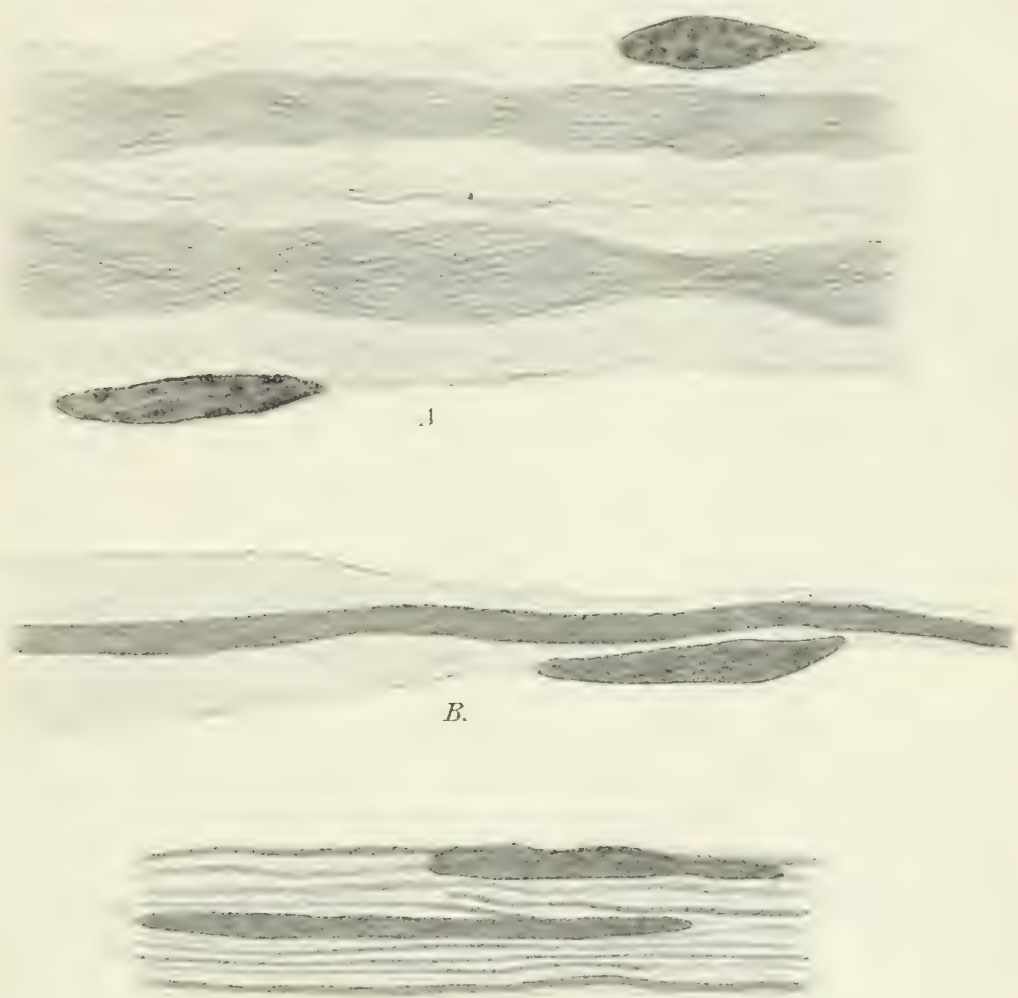

C.

Fig. 67. Fasern aus einem Längsschnitt durch einen bis zur Leitungsunfähigkeit kouprimierteı Nerven (Färbung und Vergrößerung wie bei Fig. $66 \mathrm{~B}, C, D)$. - $\perp$ Fasern ron normalem $A$ ussehen, $0,8 \mathrm{~mm}$ von der Mitte der Kompressionsstelle entfernt. Die Fibrillen ausnahmsweise nicht zu einem Strang zusammengeschrumpft. Die Integrität der Markscheide an dem Aussehen des Neurokeratingeriistes zu erkennen. $-B$ Beginn der Kompression. $0,5 \mathrm{~mm}$ ron 1 entfernt. Verdrïngung der Markscheide, Achsenzylinder geschrumpft, aber nicht ïber das gewöhnliche Maß rerjiingt, Kerı leformiert. - $C$ Mitte der Kompressionsstelle $(0,25 \mathrm{~nm}$ von $B$ entfernt). Achsenzylinder stark verjüingt, im Verhältnis zu $B$ nur ganz schwach gefärbt und dicht aneinander fepreßt. Kerne gan; in die Lüinge gezogen.

Ich habe noch den Beweis zu fülnen, dafs der färbbare oder nicht mehr färbbare Stab, welcher sich an der Kompressionsstelle zeigt,

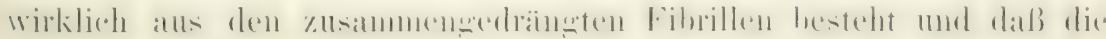
Fibrillen bei der Kompression ihre Individualitat nicht verlieren. Da in dem Stab die einzelnen Individuen nicht zu sehen sind, so kam dieser Beweis immer nu indirekt gefiihrt werden. Wie man fast an 


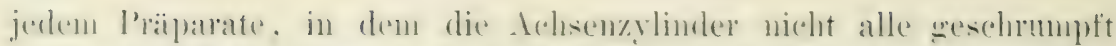

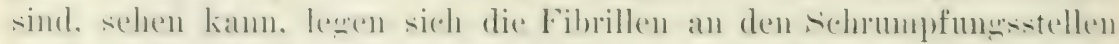

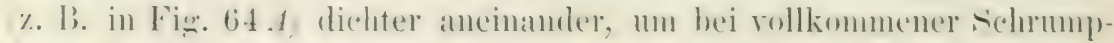

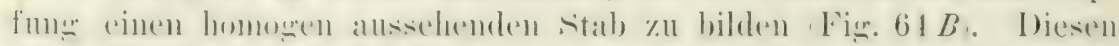

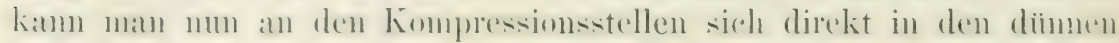
stah fortset\%on sehen, während der helle Hof., der den lest des Markscheidenhohlramms ausmacht und der zum 'Teil vou der krimlius-

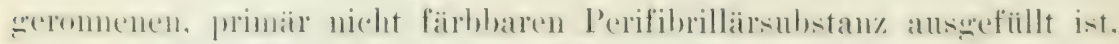

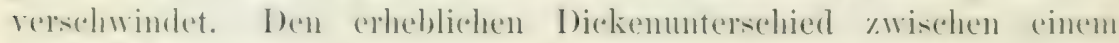

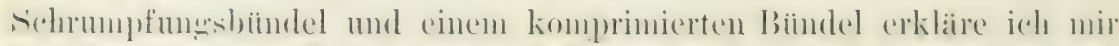
daulurel, dab in ersteren Fall noch eine Menene Perifibrillairsulstany. zwischen den Fibrillen liest; dahere sind diese biindel anch heller als die

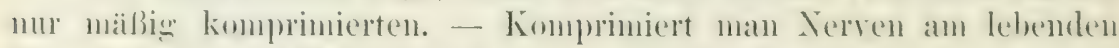

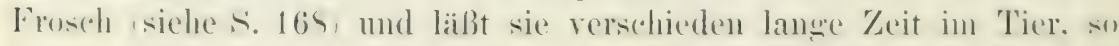
treten anber der oben heschriebenen eventuellen I)egeneration foldende lerandermmenen an der Kompressionsstelle anf: Sach rinem his zwed

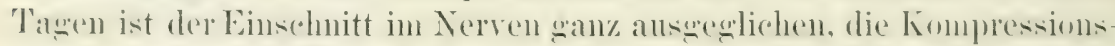

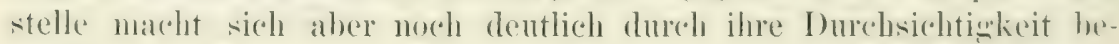
moklatr. In Osmimmprïparaten ist die Kompressionstelle selu solowar\%; die Markscheide ist nicht dentlich rom Achsenzylinder alowesetzt. denm

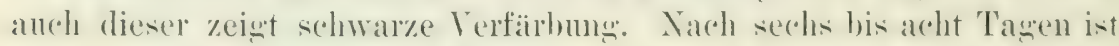
zwar immer noch eine starke Schwärzung des Achsemraums an del Kompressionsitelle vorhanden, aber man kann doch innerhalh desselben

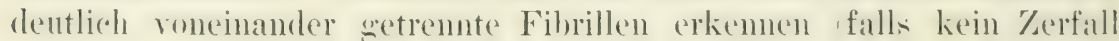
eingetreten ist). Da nun hier während der Kompression sicher ein ganz dïmner Stab rorhanden war, so schließe ich, daß sich dieser wieder in seine Komponenten zerlegt hat, d. h. daß die Fibrillen während der Kompresion ihre Individualität nicht anfzugeben hatten.

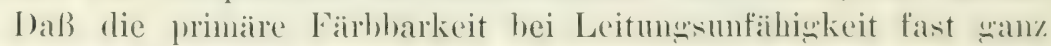
rersehwindet mol stets rorhanden ist, wem die Nervenstelle noch uder wieder leitumesfahiog ist, scheint mir nach meinen Tersuchen durchaus

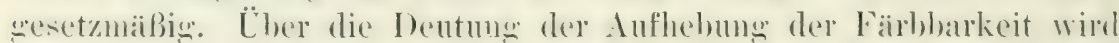
man aber nach diesen Versuch allein \%weifelhaft sein kömnen. Da

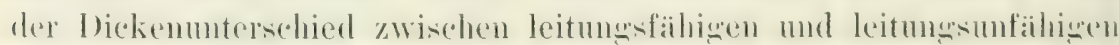

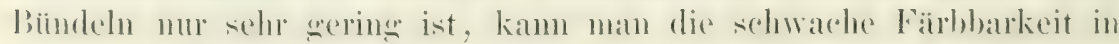
letsterem Fall nicht etwa allein auf den Dickenunterschied rurvick-

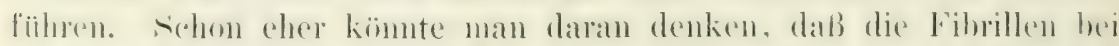

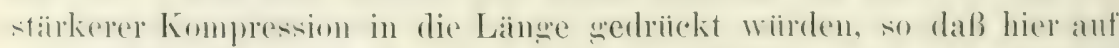

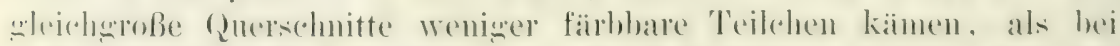

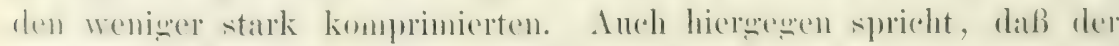

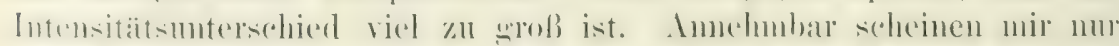

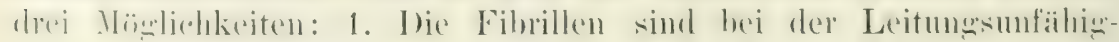
keit so stark aneinander gepreßt, daß der Farbstoff nur noch auf 


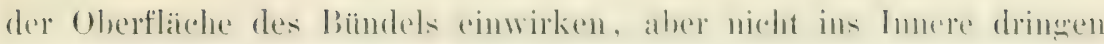
kann. Bei dieser Ammahme kömnte man die Abmahme der Färbbarkeit als etwas ganz Unwesentliches ansehen, man könnte aber auch die dhwesenheit der kapillairen spalten zwischen den Fibrillen, die sivel

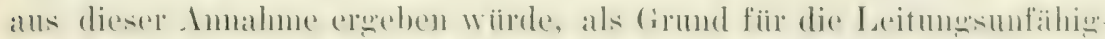

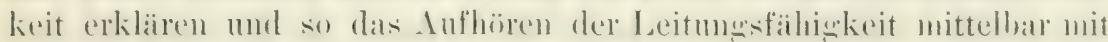
dem Aufhören der Färbbarkeit in Zusammenhang bringen. 2. Dic Fibrillensiane ist nicht mit den Fibrillen chemisch verhunden, somderm bildet nur mit andern Substanzen eine Hïlle 1 m dieselben. Bei der starken Kompression wird diese Hïlle, ebenso wie es mit der Peri-

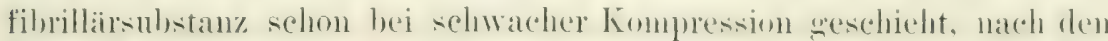

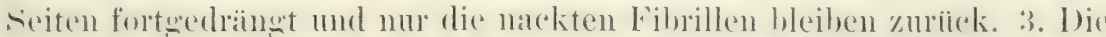
Fibrillensiure ist mit den Fibrillen in nomalen Zustand chemisch verhomden, wie ich dies in Kapitel 8 wahrscheinlich zu machen gexncht habe: diese ziemlich lockere Bindung wird abed dureh den Voreane der Kompresion gesprenent und da die freie Fibrillensiatue in dlkohol löslich ist, so wird sie beim Fixieren aus dem Nerven herausgelöst und kam nicht mehr fäberisch \%u Darstellung wehracht werden. Welche rom diesen Dentumen die Wahrscheinlichkeit für sich lat. wird, wie ich meine, aus späteren Versuchen hervorgehen.

\section{Einwirkung ron destilliertem Wasser.}

Nach einer alten, ich weiß nicht von wem zuerst gemachten Erfalıung wird die Erreghatieit eines Jeren durch Einwirkung wom destillierten Wasser and auch von hrpotonischen śalzlösmgen, schnell

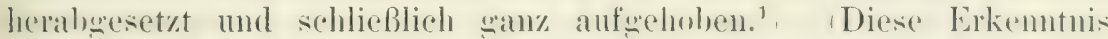

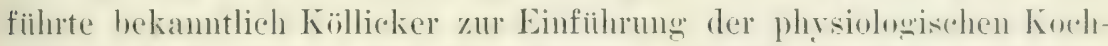
salzlösung, in welcher sich Froschmerven mehrere Tagre lang errentour "halten. Läßt man das destillierte Wasser nul anf eine ku\%e strecke

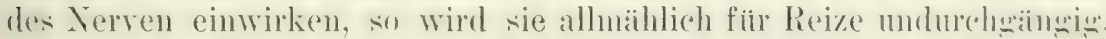
waihrend der Serr oberhalh und moterhalb dieser stelle sein Ldeitumsvermögen so lange hehält, als sich nicht die Wirkung des destillierten

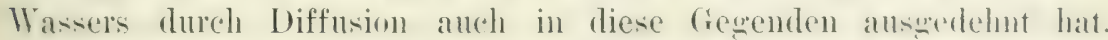

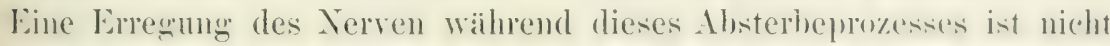
zu konstatieren, weniestens bleiht der Muskel bei Fintandomer des

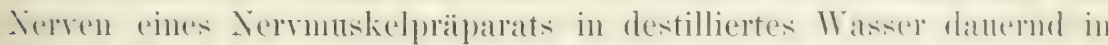

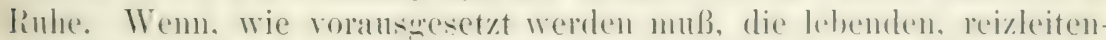

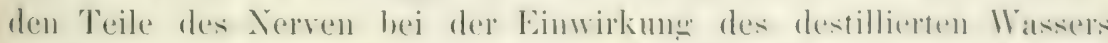

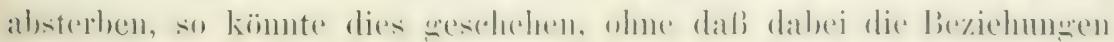

1) Bekanntlich ist destilliertes Wasser ein ganz allgemeines (rift fïr lebende Gewebe. Seine zerstörende Wirkung wird auf die Auslaugung der zum Lehen notwendigen Mineralsalze zuriickgefiuhrt. Infolge ihres hölıcren osmotisehen Druckes quellen alle Gewebe in destilliertem Wasser auf. 


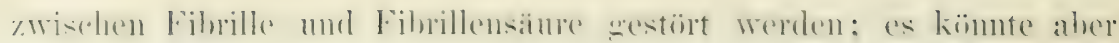
auch in diesen Beziehmngen eine Inderung eintreten der Art, daß die eiweißartige Fibrille beim Lbsterben die Verbindung mit der Fibrillensäure löst. Ein negativer Befund wiilde also nicht gegen

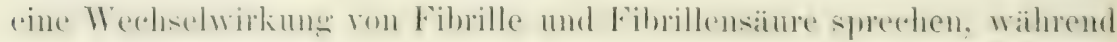
ein positiver Befund die Ammahme ciner Wechselwirkung befürworten wiircle.

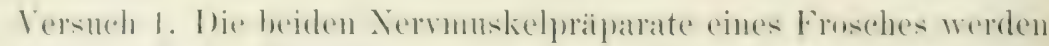

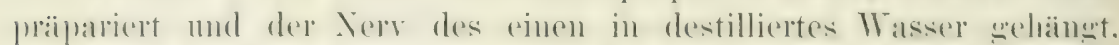

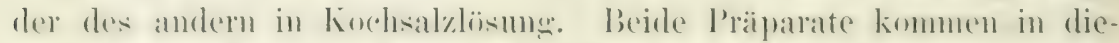

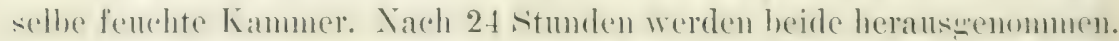

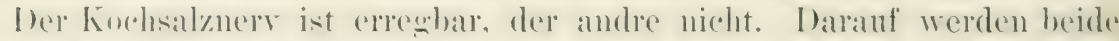

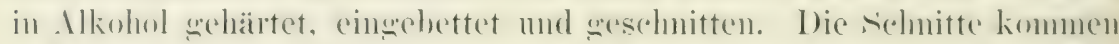

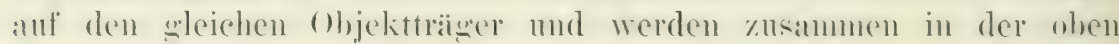
(S. 135) angegebenen Weise gefäbt. Der er egbare Kochsalznerryeigt, wie ein normales Präpart, sehöndunelgefärbte Achsenzylinder; die Achsenzylinder des Nerren, der im destillierten Wasser gelegen hatte, sind aber entweder ganz fablos oder zeigen nur eine sehwache primare Fäbloarkit. (Eimzelne Fasern sind bisweilen dunkler,

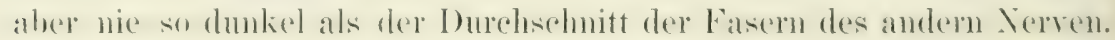

Versuch 2. In dasselbe Gefaß mit destilliertem Wasser kommt 1. ein frischer Nerr, 2. ein Nerv, der fiur einige Nimuten in Alkohol selegen hat und dam ausgewaschen wurde und 3. ein $N$ er $\mathrm{r}$ eines durch Erwäimen auf $55^{\circ}$ wäimestar gemachten Frosches. Nach 2t stunden werden alle drei in Mlkohol fixiert, zusammen weiterbehandelt und geschnitten. Die Achsenzylinder des ersten Nerven sind ganz bla $B$, wie beim vorigen Versuch. Die des zweiten (Nkohol) sind ron normaler D nnkelheit, ebenso die des dritten (wämestarr). (Die Achsenzylinder wämestarer Verven zeigen manchmal ein kömiges Inssehen, was abel nichts mit (ler Einwirkung des destillierten Wassers zu tun hat. Anf die Unter-

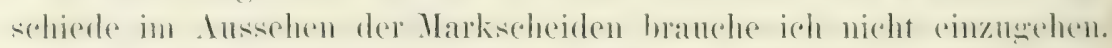
Aus diesem Versuch geht hervor, daß die A ufhebung oder I e r minderug der primären lärbbarkeit dureh destillier. tes Wasser nur dann zustande kommt, wenn der Nerv in lebendem Zustand hineingelegt wild. Zu bemerken ist

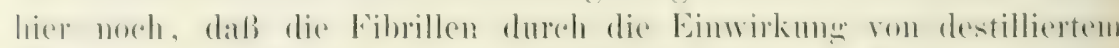

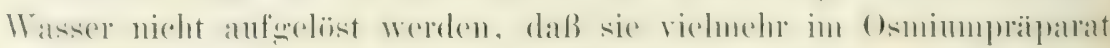
keinen Unterschied gegen normale Fibrillen aufweisen.

Versuch 3. Ein kleines Reagenzröhrehen mit destilliertem Wasser

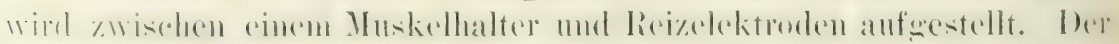

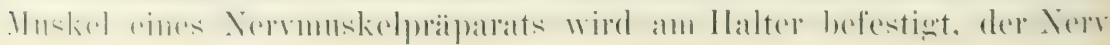




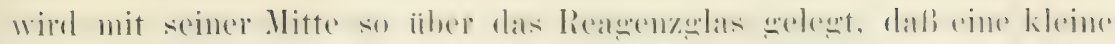
Schlinge ins Wasser hängt, und sein zentrales Ende wird über die Elektroden gebrickt, nachdem vor dem Eintanchen ins $\mathrm{W}^{\mathrm{asser}}$ die

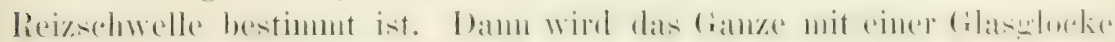

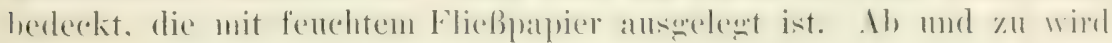
„2eprift, ob die eingetanchte Nervenstelle noch fiur den Reiz durchgringig ist. Beispiel: Anfangs Schwelle bei $40 \mathrm{~cm}$ Rollenabstand

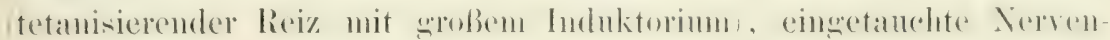
strecke ca. $1 \mathrm{~cm}$ lang. Schwelle mach 30 Minuten mverindert, nach 45 Minnten $35 \mathrm{~cm}$, nach 60 Minuten $20 \mathrm{~cm}$. Nach $1 \%$. Stunden ist

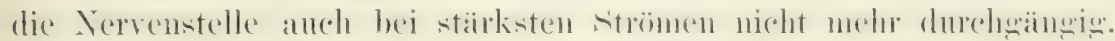
Reizung unterhalb der gewässerten Stelle gibt bei $38 \mathrm{~cm}$ Rollenabstand pute Muskelkontraktion. Hierant wurde in Mlkoluol fixiert.

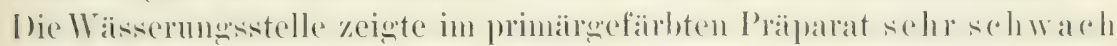

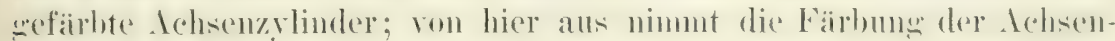

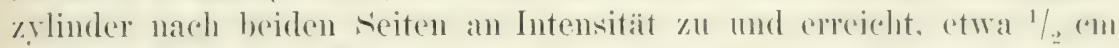
fon den Enden der Wässermusstelle entfernt, dieselbe Imnkelheit wiu das rom andern Nerven desselben Tieres heresestelle Normalpräparat. Die primäre Färbbarkit zeigt sich also an einer geWäserten Nervenstelle schon dann fast arfgehoben, wenn dieselbe grade erst die Leitung gähigkeit ein(1) ebii $\beta$ t hat.

Versuch 4. Wie oben gezeigt wurde, ist die Fibrillensåure nicht in Wasser, wohl aber in freiem Zustand in Alkohol löslich. Wem sie also durch das destillierte Wasser nur vom der Filnille aboespalten wiirde, so wiirde sie nach Beendismung des Versuches noch in Norven vorhanden sein und kïme im Alkoholpriiparat nur deswegen nicht zur

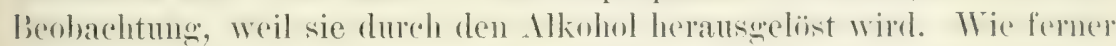
oben gezeigt wurde, ist die freie Fibrillensiume in Äther nicht löslich: wenn man also anstatt Ilkohol İtere anwendet mol don Verven ror dem Fairben nicht in Alkohol bringt, so muß man entscheiden kömmen, ob es sich hier um eine bloße Abspaltung oder um eine Veränderung der Fibrillensiture selber handelt: Ein Ners wird, wie hem

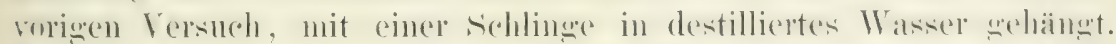
Nach etwa $1^{1} \%$ Stunden ist die Stelle fül Reiz undureligäingig und selber nicht mehr reizhat. Der Nerr wird num an der Mitte der

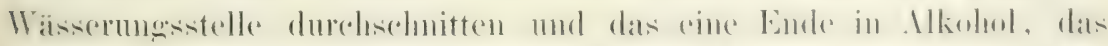

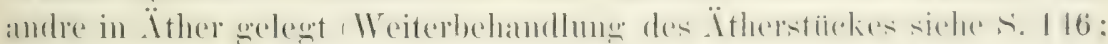

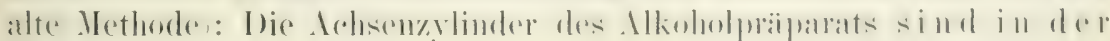
Wasseregion bla B, auBerhalb rerselben dukel. Im It herpräparat zeigen sie iiberall die greiche Dunkelle it; die einzelnen Fibrillen treten auch in der Wasserstrecke deutlich und dunkel hervor und sehen eradeso aus wie in nornalen Nerventeil. 
Das destillierte Wasser spaltet also die Fibrillensäure nur roun Nerren ab, verändert aber weder sie noch ibre Lage.

Die Einwirkung der Nareotica und andres.

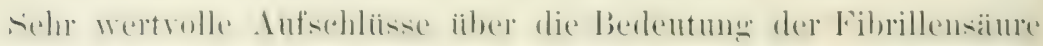
waren ron den Versuchen mit Nareoticis zu erwarten, weil diese die

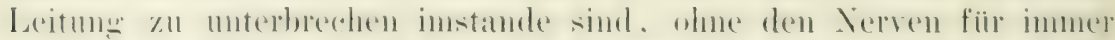
zul schädigen (wie dies beim destillierten Wasser der Fall ist). Da

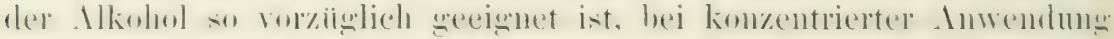

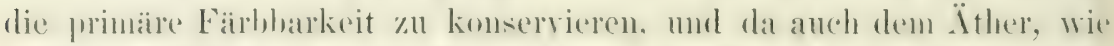

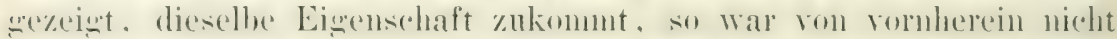

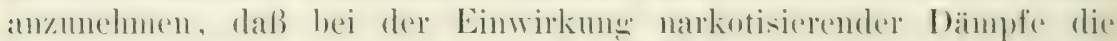

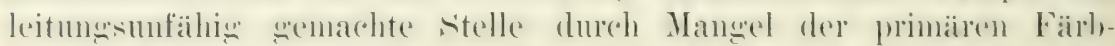

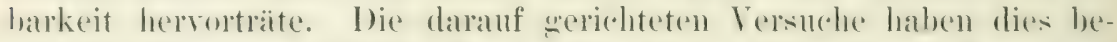

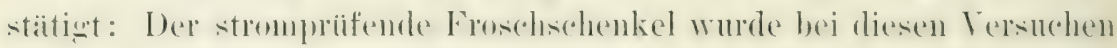
mit zwei Klammern gehalten und so an Rande einer Schale anf-

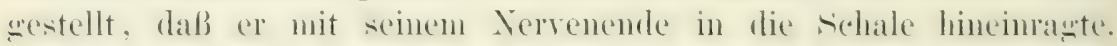

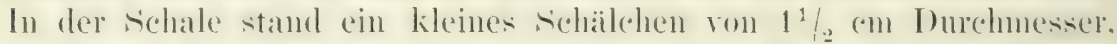
in desien Rand an zwei werenthberlienenden stellen kleine Korben aingeschliffen waren. In diese wnde der Verv hineingerentert mod das

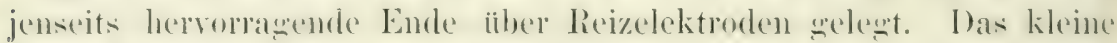
s.hälehen wurle damm mit einem Gimmerdeckel bedeckt, an dem anf

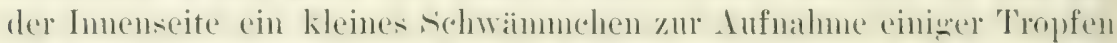

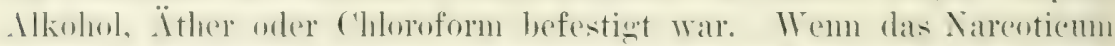
so weit eingewirkt hatte, daß anch bei starkster Reizung des zentralen Eudes keine Reaktion des redenkels mehr eintrat, dam wurde die

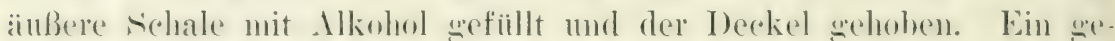

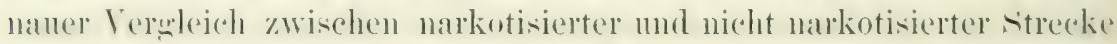
elogh nie Unterschiede. Wie ich weiter unten zeigen werde, ist aber doch das Verhälnis zwischen Fibrille mud Fibrillensiane immerhall, dep narkotisierten Strecke wesentlich verändert.

Den Nareoticis schließen sich eine Reihe andrer Stoffe und Eingriffe an, welche in melor oder weniger hohem Maße die Leitungs-

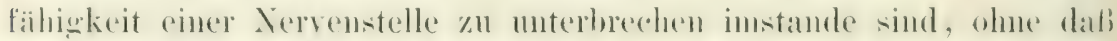

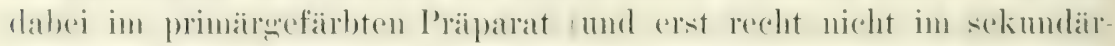

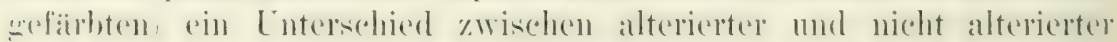
Strecke zu bemerken wäre. Ich nemne hier die Behandlung einer Nervenstrecke mit Ammoniak orler mit Kohlensïme und die lokale

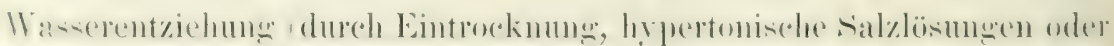

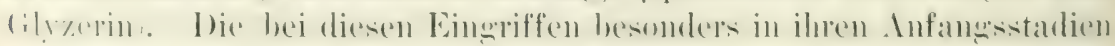

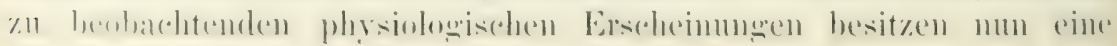


newisse Öhnlichkeit mit denen, welche sich hei hokaler Narkose des Jerven mit den eigentlichen Nareoticis zeigen. In einzelnen ergeben sich zwar quantitativ nicht unwesentliche Unterschiede, besonders zwischen Narkotisiermo und Wasserentzichmog, aber in den zwei Punkten stimmen alle diese Eimgriffe überein (soweit ich das aus der

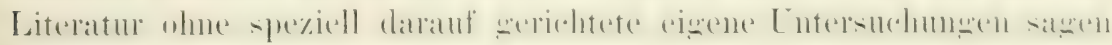
kann): Zunächst erhöhen sie die lokale Erregharkeit und weiterhin

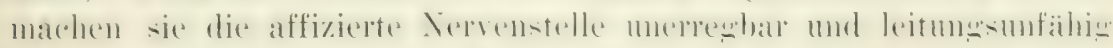
(oder setzen wenigstens die Leitungsfähigkeit herab).

Im stärksten ist die Zumahme der Erregbarkeit bei der Wasser-

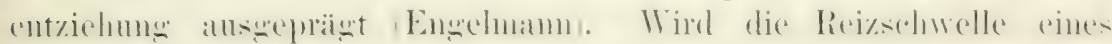
frischen Nerven bestimmt und läßt man diesen ganz oder nur an der Reizstelle eintrocknen oder entzieht man ihm mittels stärkerer Kochsalzlösung Wasser, so tritt hald ein Stadium ein, in welchem weit

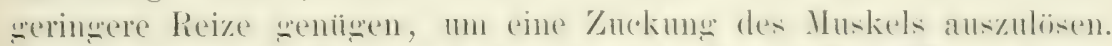

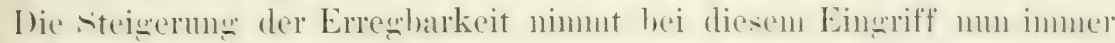
mehr \%u, his schließlich anch spontan erst einzehe Kuckimeren und damn Tetanus eintritt, Erscheinumen, die seit langem als lertrockumustetanus hekamnt sind. Alhü̈hlich nimmt die Errecharkeit wieder ah mond. wenn nur eine beschränkte stelle mit salzlïsmm behandelt ist. su wird diese schlieblich fiur weiter oben ansesetzte Reize unduredhçäingig.

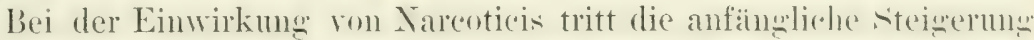
der Erregharkeit so stark in den Hintererumd gewentiber dem umwekehrten Prozeß, daß sie den ersten Beohachtern diünhazen, 1672.

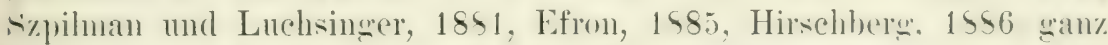
entgangen zu sein scheint. In den Untersuchungen dieser Antoren wird die interessante ron Grimhagen zuerst enteleckte Tatsache, dab die Errenbarkeit in der affizierten fegend eine Einbulie arlitten hat.

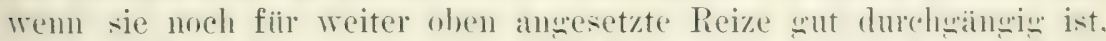

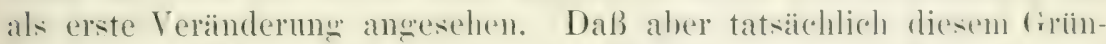
laacenschen Phänomen hesonders hei Jarkotisation nit Alkuhol- mol

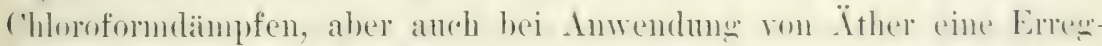

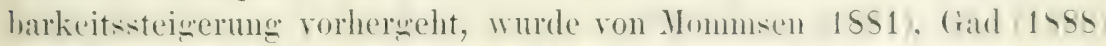

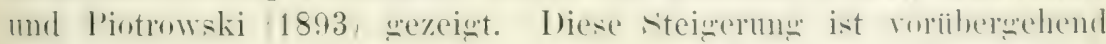

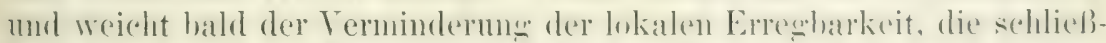

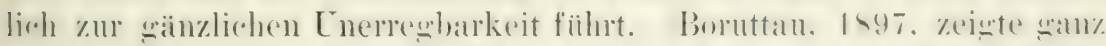

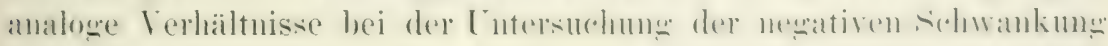
unter dem Einfluß von Nareoticis. Zuerst nimmt dieselhe an Stiuke \%, dam bis auf 0 ab. $\mathrm{CO}_{2}$ verstälkt die negative Schwankung erlieblich; bei Ammoniak nimmt sic yon Anfang an ab.) Am besten werden diese Vor wäinge nach dem von Griulıagen eingefiihrten Verfalren studiert: Der Nerv wird durch eine sonst rut wesehlosseno 
Kanmer von Glas, Horm oder Kork gezogen, in welche durch ein

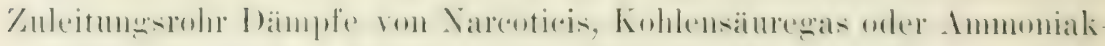
gas geleitet werden kümnen. Imnerhalb der Kammer liegt der Nerv auf einem oder mehreren Elektrodenparen; ein weiteres Paar von

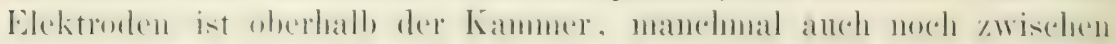
Liammer und Muskel am Nerven angebracht. Nachdem ïberall die Reizschwelle bestimmt ist, wird das Gas eingeleitet und yon Zeit zu

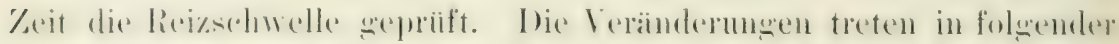

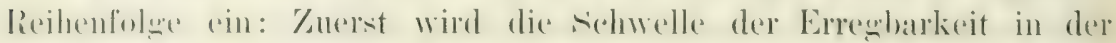

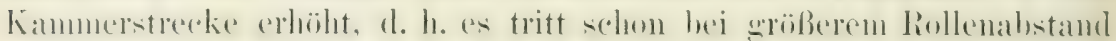

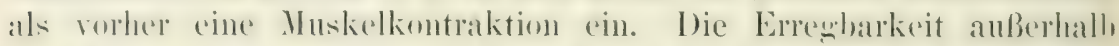

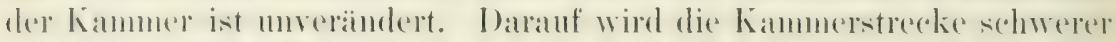

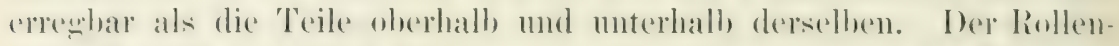

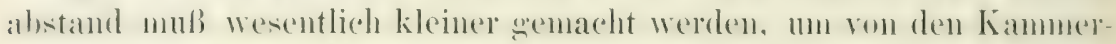

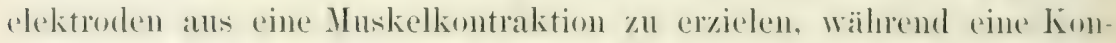
traktion von den oberen und muteren Elektroden schon bei wäberem Rollemabstand zustande kommt. Bei weitel fortgesetyter Gaszuleitum!n

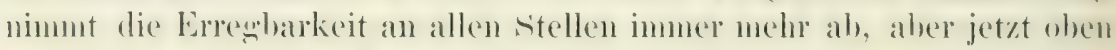
schmeller als in der Kammer, so daß zu einer gewissen Zeit die Reizung oberhalh, der Kammerstrecke, atuch wemn sie sehr stark ist. keinen Effekt mehr hat, während von der Kammer aus mit starken Reizen noch eine Kontraktion zustande kommt. Schließlich erlischt die Erresharkeit anch immerhall, der Kammer san\%. I Dendrinos, 1902.2. aitherisiert eine lange Nervenstrecke mit einem weit rentral- und eincen weit periphergedegenen Elektrodenpar. Znerst wird die Reizunz an zentralen Ende, dann am peripheren Ende mwirksam. Da beide Stellen gleich alteriert sein miissen, so handelt es sich nicht m ein Lnerresharwerden der Nervenstelle, sondern darum, daß sich die El-

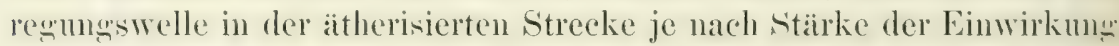
fribher oder später erschöpft. Diese Idee ist sehr einlenchtend. Bui starker Narkotisierung diufte aber doch wohl eine vollkonmene Lu-

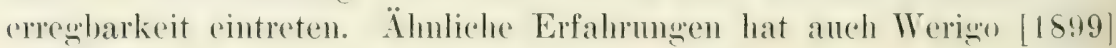
publiziert.

Die anfängliche Steigermen der Erregbarkeit ist, soweit die Lutersuchungen reichen, hauptsächlich bei llkohol mol chloroform sehr answesprochen, weniger bei Ïther und Kohlensiane. Bei kohlensibure

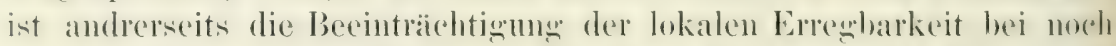

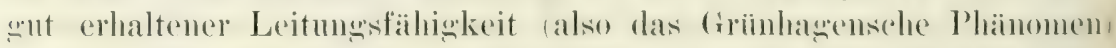

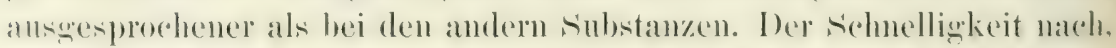

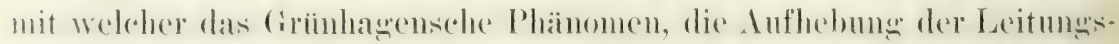

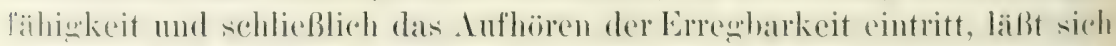

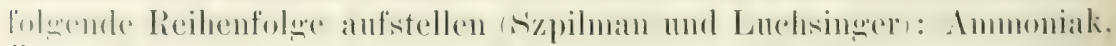

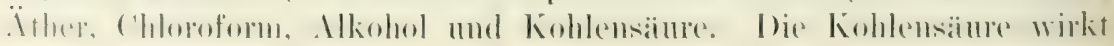


am schwäichsten. (Ich habe bei wirklich leiner Kohlensäime anch

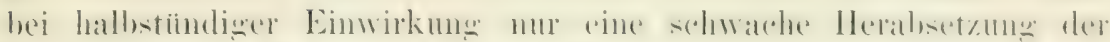

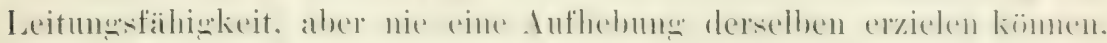

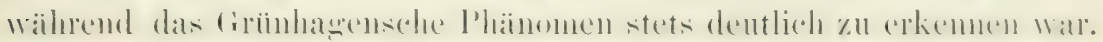
Waihrend bei Ammoniak, wenn es bis zur Leitungsunfahigkeit eingewirkt hat, keine Erholmg eintritt (oder erst nach vielen 'Tagen, siehe S. 174), kann sich der Nerr ron der Narkose mit Äther,

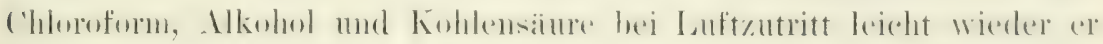
holen, vorausgesetzt, daß die Narkose nicht zul lange gredauert hat. Znerst kehrt die lokale Erregbarkeit wieder, dann erst die Leitungsfähigkeit (Efron, Pereles und Sachs, Dendrinos ${ }^{1}$ ).

Daß bei schwererer Schädigung die Reizung der zentraleren

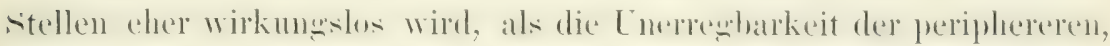
narkotisierten sitellen eintritt, entepricht durchants der natiurlichen Vorstellung, daß der Leitungsrorgang nur in einem Weiterschreiten der

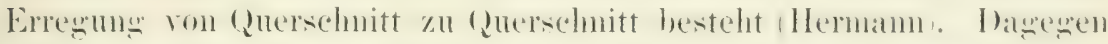
scheint das Grïnhagensche Phänomen dem zu widersprechen, denu hier ist bei einem gewissen Stadium der Einwirkmg die Fahigkeit

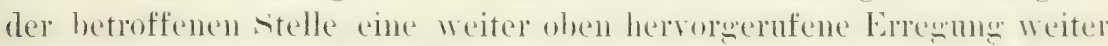
zu leiten größer, als die Fähigkeit, direkt in Erregung zu geraten. friinhagen und mit ihm sichiff und ande haben anch in der Tat diese

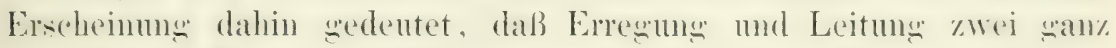
verschiedene Dinge seien. Diese Deutung wird uns weiter unten \%u beschäftigen haben.

Hier kam es mir hauptsächlich darauf an, auf die 'T'atsache anf-

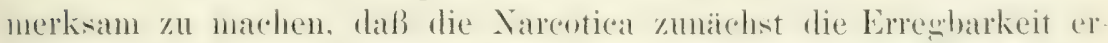
höhen, vor allen der Alkohol die andern sind nur moneniigend unter-

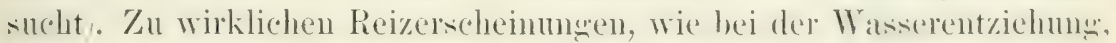

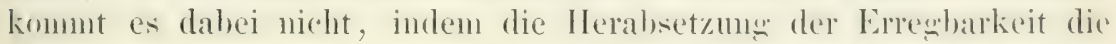
steigerung derselben zu sohnell ablist. Alkohol wirkt zwar in starkel Konzentration Kïhne, reizend, doch diufte diese Wirkung ant Wasserentziehung zu beziehen sein.

Dureh die anfänglich in mehr oder weniger hohem Maße gosteigerte Erresharkeit treten die hien hesprochenen Eingriffe in cienen-

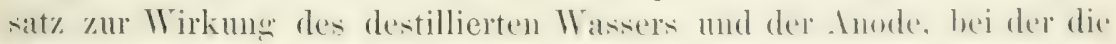

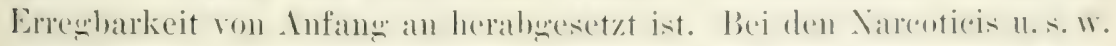

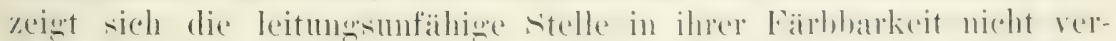
ändert; bei jenen verliert sie die primäre Färbbarkeit, wie dies jetzt fuir die Anode gezeigrt werden soll.

1) Nach Pereles und Sachs erlischt die Leitungstiihigkeit der sensiblen l'asem eher als die der motorischen. 


\section{Über die Wirkung deskonstanten stromes.}

Die ersten Andentungen, daß ein starker konstanter Strom beim

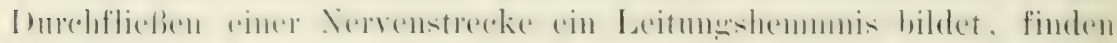
sich bei Valentin (1S48). Einen großen Sehritt weiter gelangte Eek-

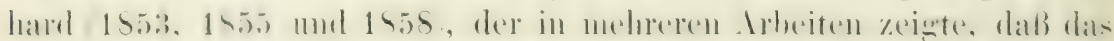

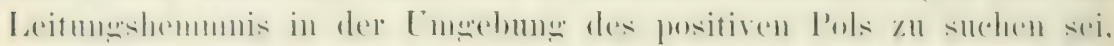
während in der Nähe des negativen Pols sograr cine gresteigerte Er-

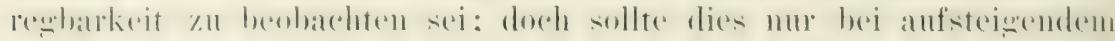
resp. absteigendem Strom der Fall sein. Z/u wirklicher Klarheit ge-

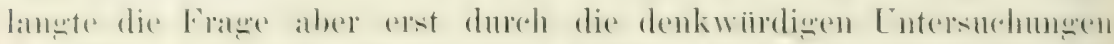

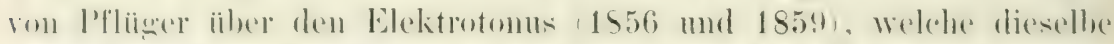

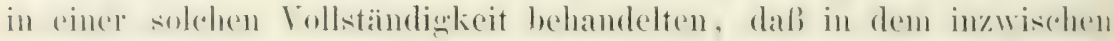

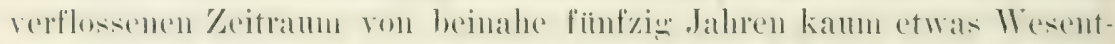
liches hinzugefiigt werden komnte.

Wie bekannt, ist das Resultat dieser Untersuchungen ku\% fol-

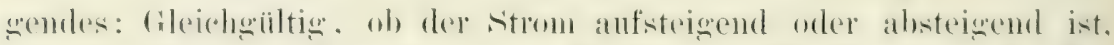
tritt immer in der Umgebung der Anode eine Herabsetzung der Erregbarkeit, in der Nähe der Kathode (des negativen Pols) eine Steigerung derselben ein. Diese Verinderung dehnt sich um so weiter extrapolar aus, je stäker der Strom ist; je weiter man sich von dem Pol entfernt, desto mehr nimmt die Verändermo an Intensitait ab.

Reizt man bei aufsteigender Stromrichtung zwischen der Anode und dem Muskel eines Tervmuskelpräparats tetanisch, so kam der lieiz, weleher bei nicht seschlossenem strom einen starken T'etanus hervorbringen wïrle, vollkommen wirkmgslos bleiben. Andrerseits kamn bei absteigendem Strom ein schwacher Reiz, der an und fiir sich keinen Effekt herorbringen wïrde, zu riner starken //uckunw coder einem 'Tetanus; wenn der Reis tetanisch ist), fuiluren, weil er sich im Gebiet der Kathode befindet.

Die Erregharkeitsisteigerung an der Kathode ist hei anfsteigendent Strom nur bei ganz schwachen Strömen zu konstatieren, weil die Herabsetzmne an der für den Reiz zu durchlanfenden Inode bei stailkeren Strömen so stark wird, daß sie zur vollständigen Leitung snnterbrechung fiilnt. - Die intrapolare Strecke wird dureh den prolarisierenden Strom in eine Sitrecke rom erhöhter an der Kathodes

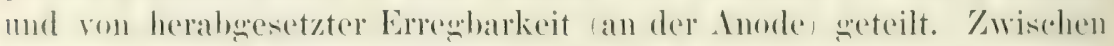

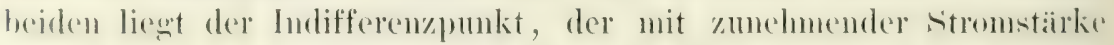
näher an die Anode zu liegen kommt. (In der intrapolaren Strecke kimmen elektrische Reize nur mit Vorsicht als Priifungsere verwandt

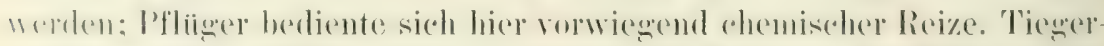

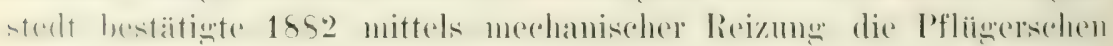
Aufstellungen in vollem Umfange. Dieses Gesetz der Erregbarkeits- 


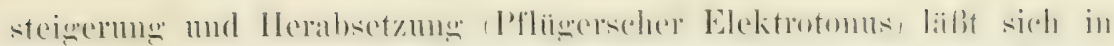
Form von Kurven (Fig. 68) darstellen, wobei die verminderte Erreg-

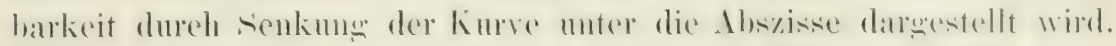

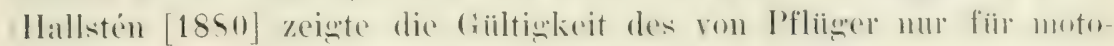
rische Fasern gepriften Gesetzes an sensiblen Fasern).

Die Erregloarkeitssteigerumg an der Kathode tritt sofort beim

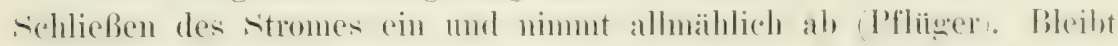
cin starker Strom lange geschlossen, so tritt in der kathodischen

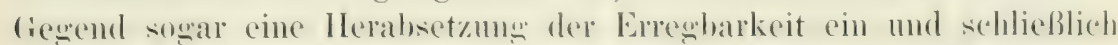

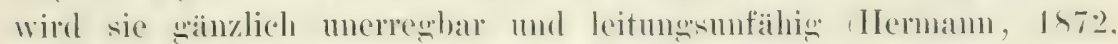

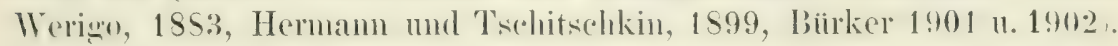
Andrerseits tritt die Errecharkeitsherabsetzmon an der Anorle nur allmählich ein und bleibt bis zun Ende der solnließungstaner erhalten

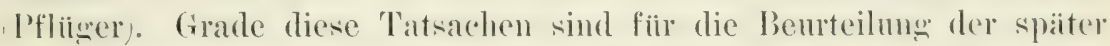
zu besprechenden Befunde von großer Wichtigkeit. ${ }^{1}$ ) - Nach der

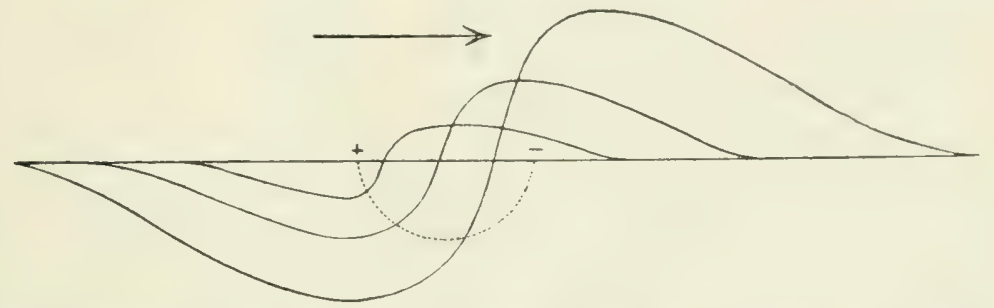

Fig. 6s. Kurvenmäßige Darstellung der Erregbarkeitsverhältnisse im Elektrotonus nach Pfliger. + Anode (Eintrittsstelle des Stromes), - Kathode (Austrittsstelle des Stromes). Die drei Kurven denten die Stärke und Ausdebnung der Erregbarkeitsveränderungen bei verschieden starken Strömen an.

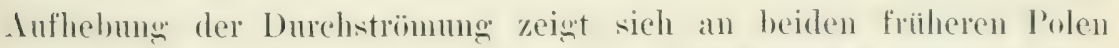
(rin mugekehrtes Erregharkeitsverhätnis: Die fribere Kathodenstrecke ist weniger erreghar resp. unerewhar und leitungsunfähiw, die Anoden-

1) Nach Wundt (1571), Tschirchew (15\%9) und andern pflanzt sich die Erregbarkeitsherabsetzung von der Anode aus mit einer geringeren Gesehwindigkeit als der des Nervenprinzips fort. Dagegen ist nach den Untersuchungen von Grimhagen und Baranowski \& Garré (1580), welehe unter Hermanns Leitung arbeiteten, eine Herabsetzung der Erregbarkeit (10-14 mm von der Anode entfernt) schon im Moment der Stromschließung zu beobachten. (Ein Anteil des polarisierenden Stromes wird durch die primäre Spirale eines Induktionsapparates greleitet, so daß gleichzeitig mit dem Schließen des Stromes dem Nerven an einer

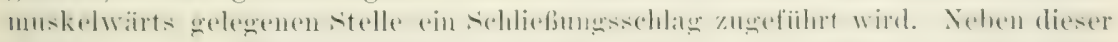
Griinhagensehen Methode wurden von Baranowski und Garré noch zwei andre angewandt, die im Original nachzulesen sind.) Bekanntlich entsteht im markhaltigen Nerven bei Zuführung eines konstanten Stromes extrapolar ein im Nerven gleichgerichteter Strom (Du Bois-Reymonds oder galvanischer Elektrotomus). Derselbe ist nach Ilering (1559) und Biedermann (1856) zum 'T'eil als aut ciner merkwïrdigen Ausbreitung von stromsehleifen basierend ammsehen, weil 


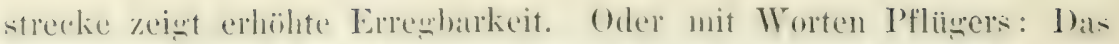

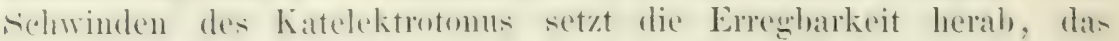
Schrinden des Anelektrotonus erhöht sie. An der friiheren Anode

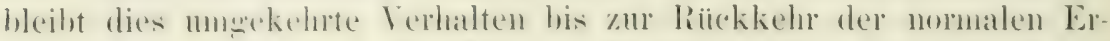
resharkeit erhalten: an der fribleren Kathode schwindet es bahl und

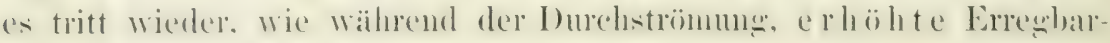
keit ein, welche damn allmählich verschwindet.

Durch diese 'Tatsachen findet bekanntlich das von Pflïger bei

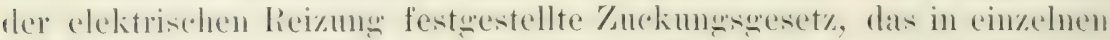
l'mukten sohon won litter mod Ileidenhain formuliert war siehe bieder-

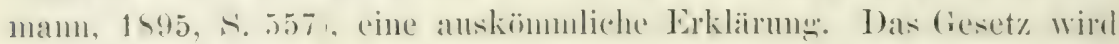

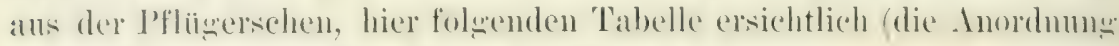
der 'Tabelle weicht rom Original etwas ab).

\begin{tabular}{|c|c|c|c|c|}
\hline \multirow[t]{2}{*}{ Stromstairke } & \multicolumn{2}{|c|}{ Aufsteigender Strom } & \multicolumn{2}{|c|}{ Absteigender Strom } \\
\hline & Schließung & Öffnung & Schließ3ung & Öffnung \\
\hline Schwach & Zuckung' & Rule & Zuckung & Rulie \\
\hline Mittelstark & Zuckumg & Zuckung' & 'Zuckung' & Zuckung \\
\hline Stark & Rulhe & Zuckung & Zuckung & Rulie \\
\hline
\end{tabular}

Nach Analowie der Erscheinumen an Mnskel wird angenommen.

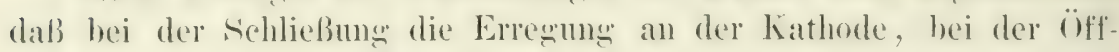
1mmb an der Anode stattfindet; diese Ammahme steht anch mit den Errecrbankeitsverhältnisien bej konstanter Durehströmung im besten

er im marklosen Nerven fehlte und an leblosen Röhren mit stärker leitendem Pliissigkeitskern ehensogut herzustellen sei wie an markhaltigen Nerven (natsoes

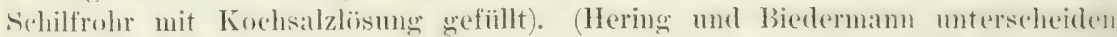
danatch zwischen einem physikalisehen und einem physologischen Elektrotonn. Letzterer soll nach Biedermamn [1sss] in der Äthermarkose verloren gehen, ersterex aber persistieren. Seitdem hat Boruttau (1597) gezeigt, daß auch an marklosen Nerven (Cephalopoden) elektrotonische Ströme zur Beobachtung kommen, die allerdings schwächer sind als an markhaltigen Nerven. Auferdem zeigte Waller [1895, 1896, 1897] und Boruttau (1897), daß die elektrotonischen Ströme bei der Natkose mol bei Anwendung andrer substanzen verschiedenartige Veranderungen erleiden. Nareotica, Säuren und Wärme vermindern mehr den Anelektrotonus. Alkalien und Kälte mehr den Katelektrotonus. Da aber immer noch eine reichliche extrapolare Stromausbreitung bei der Narkose iibrig bleibt, so wird man die Existenz eines physikalischen Elektrotonus nicht ganz leugnen kömen, wenngleich derselbe melı auf ordinäre Stromschleifen zu beziehen sein dürfte.) Die Resultate von Grünhagen und Baranowski und Garé sind möglicherweise (siehe Biedermann, 1895) auf diese Stromschleifen zu beziehen. - Untersuehungen

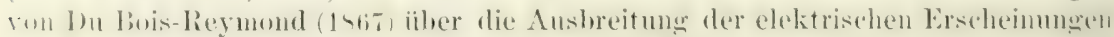
bei konstanter Durchströmung haben wie die Pflügerschen Untersuchungen zu dem Resultat geführt, daf der Katelektrotonus sich schnell entwickelt und riemlich schnell sinkt, während der Anelektrotonus allmählich ansteigt, einige \%eit anf der Höhe bleibt und dann langsam nachlïbt. 


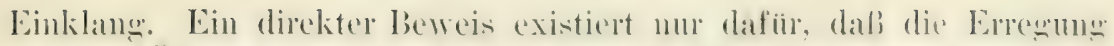

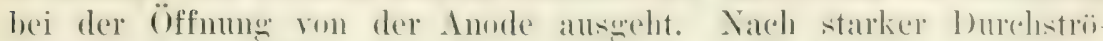

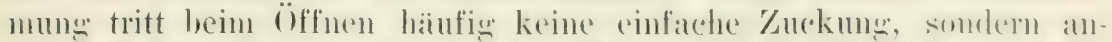

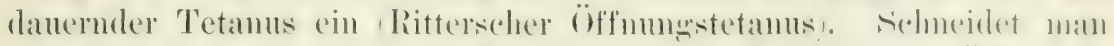

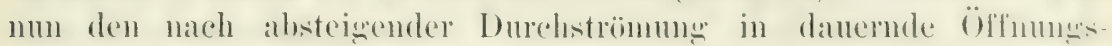

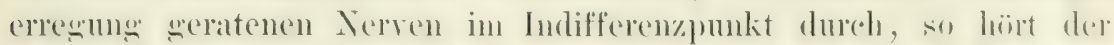
Tetanus sofort auf (Pflüger). Anch durch zeitmessende Versuche Bezold, 1561, wird die Richtigkeit des satzes schr Wahrscheinhich gremacht. Angenommen der Satz sei richtig - und es zweifelt wohl niemand an seiner Richtiokeit —, so erklät sich der zuerst paradox crscheinende Erfolg der Reizung mit starken Strömen einfach anf folgende Weise: Bei aufsteigendem Strom tritt an der Anode so

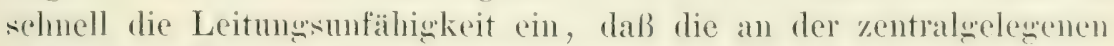
Kathode anftretende sichliebungserregnus nicht mehr hindureh gelangen kamm. Andrerseits tritt bei Öfnume des absteigenden stromes an der Kathode Leitmogsmofahiogkeit ein, so dab die von oben kommende. Öffunngserregung nicht zum Muskel gelangen kann.

Von rorn herein mußte es merkwiurdig erscheinen, daß der konstante strom bei șlejehmäBgen Fließen keine Erregung hervorbringt,

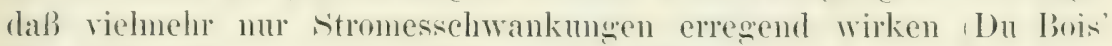
Gesetz der Nervenerresung, dem es muk doch angenonmen werden, dak der strom anch bein ruhigen Fluß wie somst iiberall danemol Veränderungen hervorruft. Es hat sich demn anch erezeigt, daß unter Lmständen eine danernde Erregung durch den konstanten strom lorevorerufen werden kamn und daß die wahrscheinlide mesetzten danernden Veränderung'en des Nerven in der Regel nur zu gering oder zu

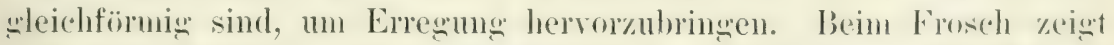
sich eine Danererregumg hauptsaichlich nach Abkühlume als I'fliiger-

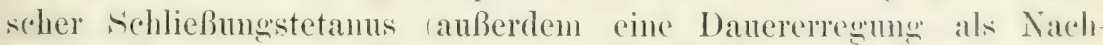
wirkmog im Ritterschen Öfnungstetanus. Bei manchen Tieren scheint ïherhaupt nur tetanische Erregung durch den komstanten strom her-

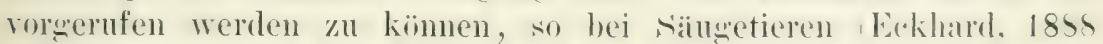
und manchen Wirbellosen ischerennery des frebses, Biedermam. 1888, und Nerven von Aplysia, Bethe). Auch die sensiblen Nerven

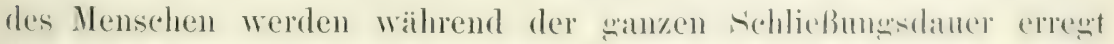
Volta: Ausstrahlen eines danernden trolumerzes in die Finere bei Infsetzung der Elektroden auf den Ulnaris).

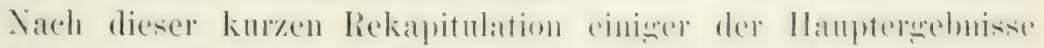
der bisherigen Forschung anf diesen Gebiet, will ich nun zur Be-

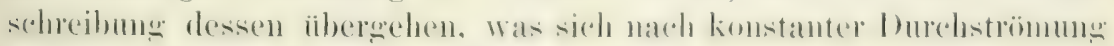
im primärgefärbten. Bilde wahmehmen läßt. 
Versuchsanor do $11 \mathrm{ng}$.

Zur 'Zuleitmug des Stromes bediente ich mich immer ,mmpolari-

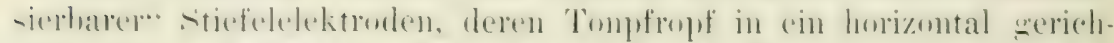

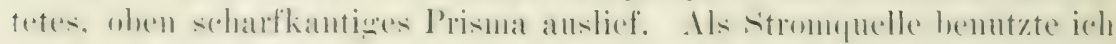
in der Regel fiunf oder sechs Daniells. Von den Elementen wurde

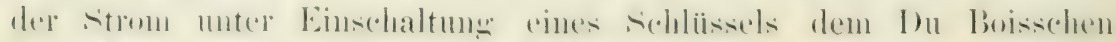

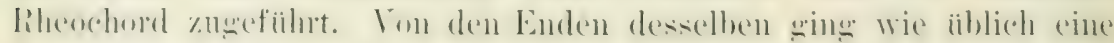
Nebensehließung durch cinen Stromwender zu den Elektroden. In

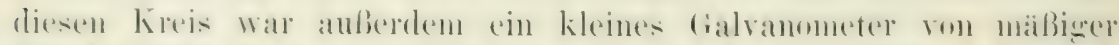

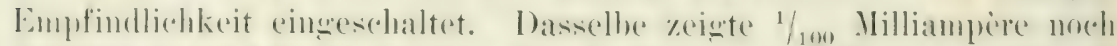

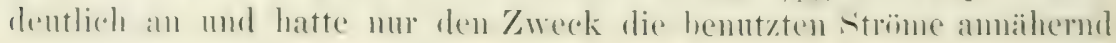

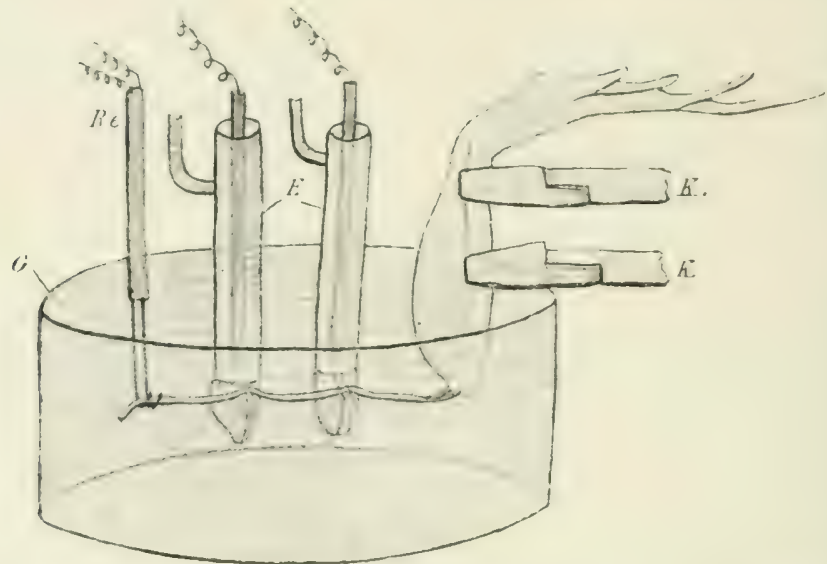

Fig. 69. Skizze der Aufstellung, welche benutzt wurde, um Nerren wïhrend der Polarisation zu lixieren. - E. unpolarisierbare Elektroden, R.e. Reizclektroden, $K$. Klammern, welche den Froschechenkel halten, $\boldsymbol{f}$. Glasschale, in welche die Elektroden mit dem darïberliegenden Nerven und (ler Schenkel hineinragen.

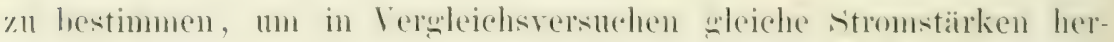
stellen zu können. Da es notwendig war wihrend der Durehströmung zu fixieren, so wurle die Anfstellume des Präiparats dem entsprechend gretroffen: In eine (ilasschale won etwa 10 cm I)mehmessel

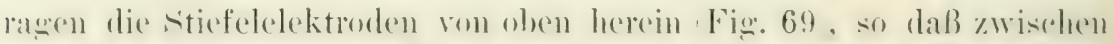
ihrem unteren Rande und dem Boden der Schale noch ein kleiner

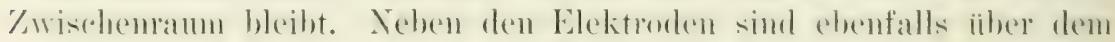

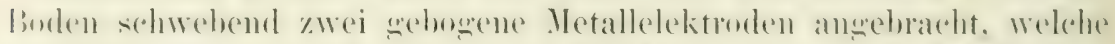

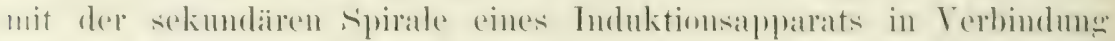
stehen. Termittelst dieser wird anf Undurehgängigkeit der Anode sceprift; ansserdem halten sie den Nerven in der richtigen Lage. Am entgegengesetzten Rande der Glasschale steht ein Gestell mit zwei

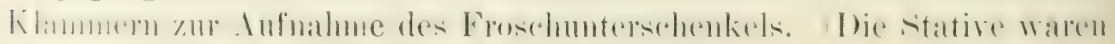
in den meisten Versuchen durch untergelegte Glasplatten gegen die 


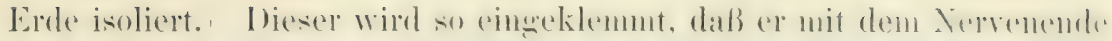

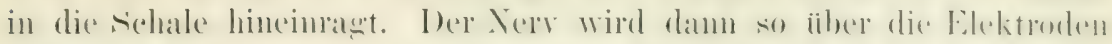

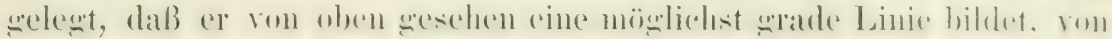

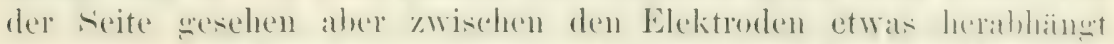

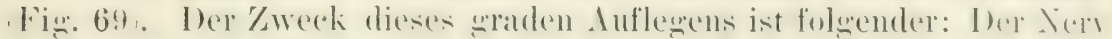

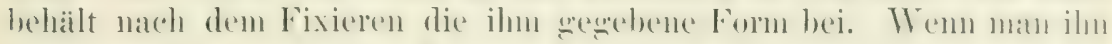

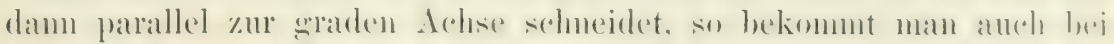

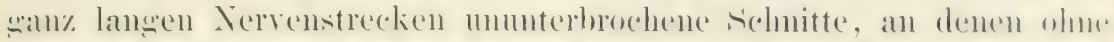

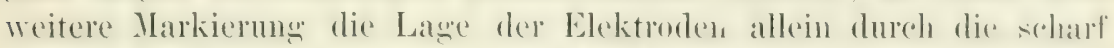

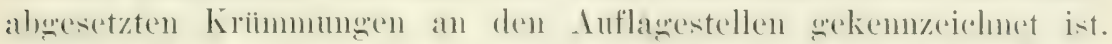

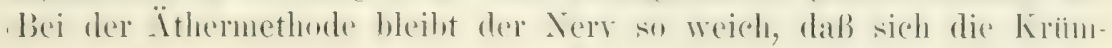
mungen beim Abnehmen von den Elektroden ansigleichen. Hier bestimme ich die Lage der Elektroden entweder dureh Ausmessung ron den sichnittenden aus oder duroh Markierung mit Zimmoberstand, der am eben fenchten Nerren in geniigenden Menge haften bleibt.)

Nachdem der Nerr gut über die Elektroden gelagert ist, lasse ich den Strom, je nach Art des Versuches, verschieden lange hindurchgehon mol fixiere damn in der Wreise, daß die Glassolate mit

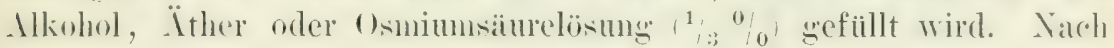
etwa einer Ninute wird dam der Strom geöffnet. Der Nerr ist dam bei Anwendum ron Alkohol und İther schon soweit verändert, dals eine Öfnumgserregung nicht nehr zustande kommt. Bei Inwendung. ron (Ismimnsäme mul man meist etwas länger geschlossen halten. bei länger ausnedehnter Durchströmung lege ich die schale mit fenchtem Fliebpapier ans und bedecke sie mit einem Deckel aus rilimmer, dele so ausgeschnitten ist, daß el nur die Elektroden und den tichenkel

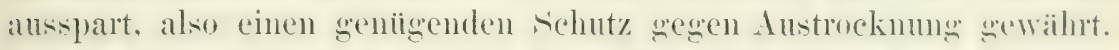
Jiei denjenigen Versuchen, hei denen die Anwendung einer fenchten

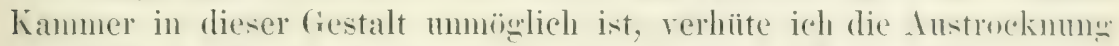
durch Befeuchten mit einem in phrsiologische Kochsal\%lösung wetauchten Pinsel.

\section{Anoden- und Kathodenhild.}

Versuch 1. Ein starker Strom, der bereits beim Schlicken sofort

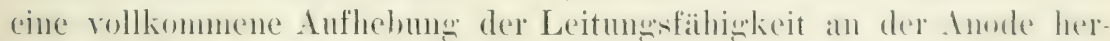
vorruft, wird zelm Minuten lang durch den Nerven geleitet. Ich be-

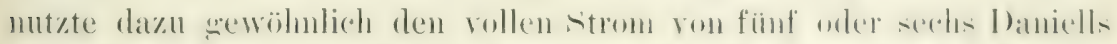

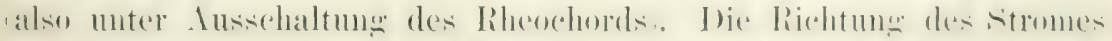

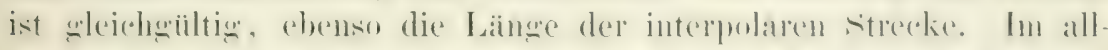

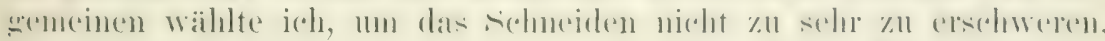
eine interpolare Strecke von $1-2 \mathrm{~cm}$. Je nach dem Widerstand der

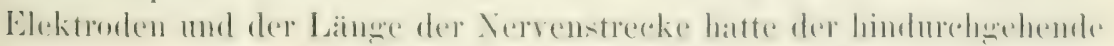
Strom eine Stäke ron 0,05-0,2 Villiampère. Aneh bei stärkstem, 
wherhalh der durchflussenen strecke angesetztem tetanischen Reiz darf ron Infang an leine lieaktion des schenkels eintreten. Nachdem der stron zehn . linuten hindurdegenangen ist, wird die sichale mit Ilkohol sefüllt mond damm, nach etwa ciner Vinute, der sitrom geriffnet. Daranf Entwässem mit alosolutem Alkohol, längeres Verweilen in Xylol mol Einhettun世 in Paraffin. Dic sehnitte werden, wie olsen is. 135, angegeben, gefürbt.

Das Fiidhungsesultat ist bei den vielen Versuchen, welche ich «emacht lıabe, immer das sleiche sewesen: Die Anode ist vollkommen farblos, die Kathode zeigt eine wesentlich stäkere Färbung der Achsenzylinder, als es an normalen Nervenstellen der Fall ist! Die Figur $70 I$ zeigte ein I'hotogramm eines, sehnittes durch einen solchen Nerven bei schwacher

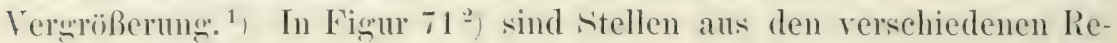
siomen dessellyen sichnittes bei stärkerer Verorïßerumg photosraphisch abuebildet. Der Lntersehied zwischen normaler Nervenstelle cinerseits und der Kathode und Anode andrerseits ist so dentlich, daß es einer Erklärums weiter nicht bedarf. In Präparat treten die Lnterschiede viel deutlicher hervor. Figur 70 II giht von einem andern sirchint eine schematische, aber nicht übertriebene Zeichumg. Durch die Färbung der Kerne und des Bindeswewehes wird der Lnterschied der versehiedenen stellen für das bloße Auge weniger auffälig, doch sind die Verschiedenheiten in der Fairbunssintensitait in der Resel schom mit bloßem Auge deutlich zu sehen.

Vonder Anode aus nimmt die Färbung nach dem extrapolaren Teil hin allmählich an Intensitat $\%$. (Bisweilen erstrecken sich, besonders wemn die Elektrode nicht scharfkantig war, einige gefäbbte Faseln von der extrapolaren sitrecke in die Anodenstelle hinein; solche noch sefärbten Fasem finden sich,

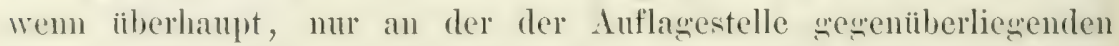
reite. Ohne daß eine Terstïlkum der Täbung jenseits der Anode zu benerken wäe, treten normale Verhältnisse in der extrapolaren Strecke ein (Fig. 70).

Jenseits der Kathode - etwa 2-2,5 mm ron der Mitte der Auflagestelle entfernt - nimmt die Intensitat der Färbung immer mehr ab und zwar unter das MaB eines normalen Nerven (Fig. $70 I I)$. Weiterhin nimmt dann die Färbung sintensität allmählieh wieder $z u$, bis sie $4-6 \mathrm{~mm}$ wn der Kathode entfernt mogefähr so intensiy ist, wie man es bei

1) Der anf der Platte deutlich sichtbare Unterschied zwischen Anode und Kathode kommt in der Reproduktion nicht heraus. Die Figur kann nur noch dizu dienen, die Form eines solchen Schnittes zeigen.

2) Figur 71 ist auf Tafel Il dem Buch hinten angefiigt. 


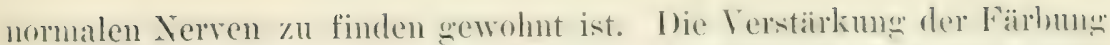
an del Kathode ist hei mittlere Temperatur siche s. 291, immer seh" auffallend, dagegen ist die Abmahme der Fübung jenseits derselben nicht immer deutlich walızunchmen, weil sie sehr alluählich einsetzt und nie bis zur vollkommenen Farblosimkeit iwie an der Anoder fiihrt. Je stärker der Strom war oder je länger er andauerte, desto deutlicher ist aber dieses Hellerwerden jenseits der Kathode zu sehen.

Wenn man von der Anode ans die interpolare Strecke verfolgt, so findet man zunälist noch alle dehsenzylinder san\% farblos bisweilen findet man einchlne schwach gefäbte Fasern, doch muß man
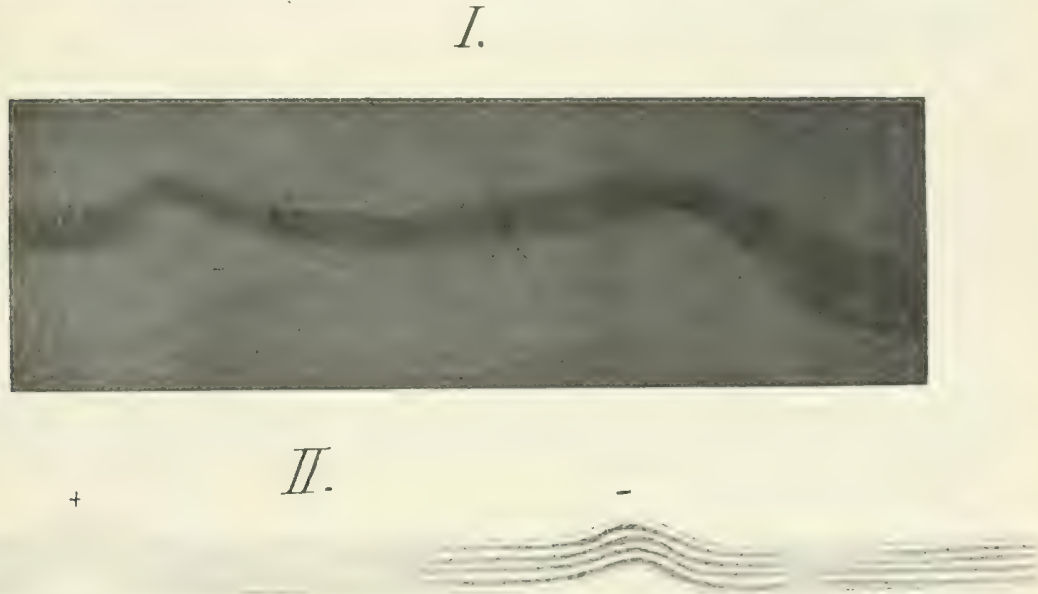

Fig. 70. I. Photogramm eines Längsschnittes durch einen Froschnerven, welcher zehn Minuten mit einem starken Strom ( 4 Daniel, voller Strom) polarisiert, mit Alkohol fixiert und auf dem Schnitt mit Toluidinblau 1:3000 (15 Minuten) gefärbt worden ist. (Vergrößerung etwa 10 mal). Links Anode, rechts Kathode. - II. Schnitt durch einen andern gleichbebandelten Nerren schematisch gezeichnet. Die Kerne sind wie in allen folgenden schematischen Figuren fortgelassen. Der Nerv ist verkürzt und nur aus wenigen Achsenzylindern ( 4 ) bestehend gedacht. Wert wurde nur darauf gelegt, die Dunkelheit der Achsenzylinder in den verschiedenen Abschnitten ihres Verlaufs müglichst genau (d. h. dem Präparat entsprechend) wiederzugeben.

sich ror del Verwechslung mit gefärbten Bindegewehsträngen hütenı. Wem man an der Mitte der interpolaren strecke angekommen ist urlel bereits etwas iiber dieselbe hinaus ist, so begimen die Ichsen-

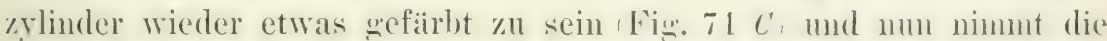

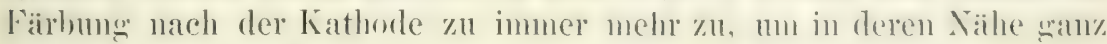
stark zu werden (Fig. $70 / I$ u. Fig. $71 \mathrm{~B}$ ).

Läßt man einen polarisierenden Strom von goleicher Stälke nul eine ku'ze Zeit geschlossen, \%. B. 10", und fixiert damn, so ist nichts von den bescolniebenen Verändermenen zu benerken. Die ersten dent-

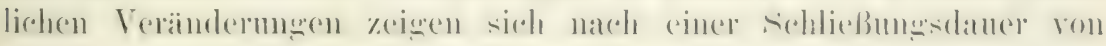
einer habben bis einer Minute. In der Anode sieht man eine kul\%

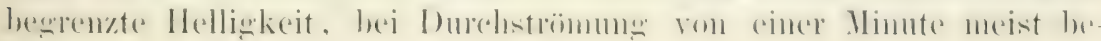


reits eine rollstandige Farblosigkeit (Fig. $72 A$ ). Die Kathode ist

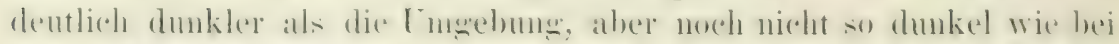

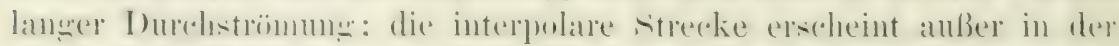

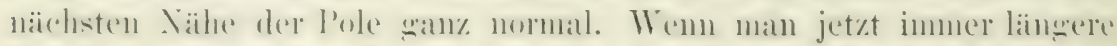

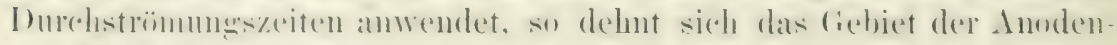

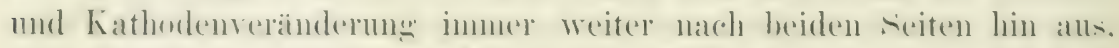

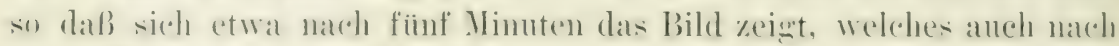
zelm Minuten langer Durchströmung zu sehen ist; jedoch ist die Kathode noch nicht ganz so dunkel als hei dieser Inurehströmungsdaneer

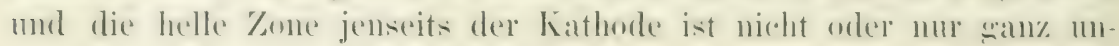
deutlich zu bemerken (Fig. 72 b).

Hierans scheint hervormgehen, dab die Fibrillensäure allmählich

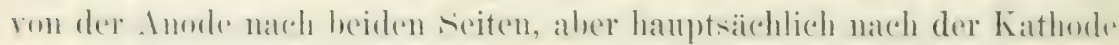
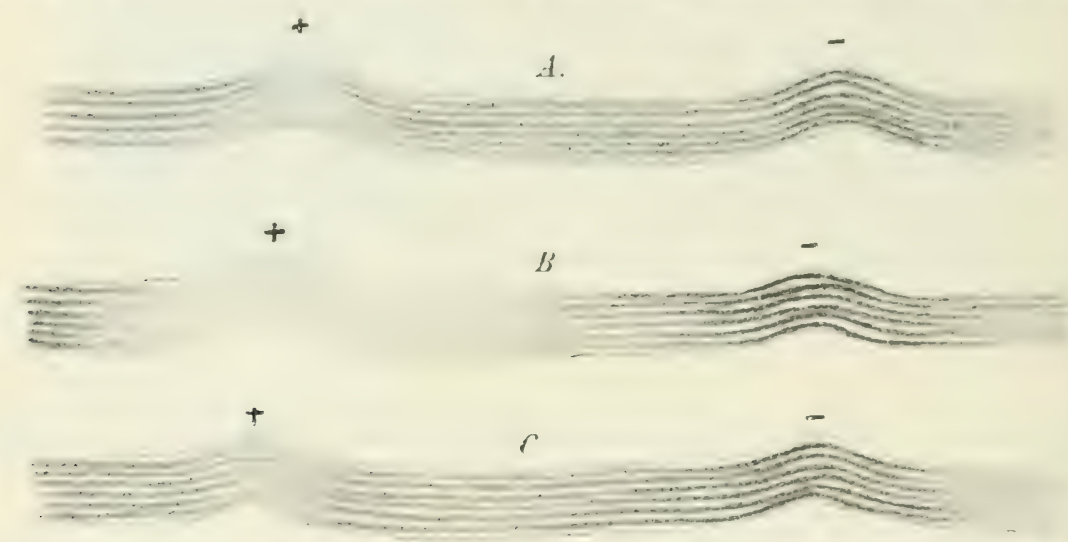

Fig. 72. Schematische Abbildungen des Polarisationsbildes unter verschiedenen Bedingungen. A Starker Strom, eine Minute durchströmt. B Bei gleichem Elektrodenabstand und gleicher Stromstärke fünf Minuten durchstrümt. C Bei schwachem Strom zehn Minuten durchströmt.

hin, verdrängt wird, während sie von der Kathode sowohl aus der interpolaren als anch aus der extrapolaten strecke antezogen wird und zwar ans der letzteren weniger intensiv. Bei langdanernder Ihurdströnum wird aber anch of viel Fibrillemsäure ans der extrat-

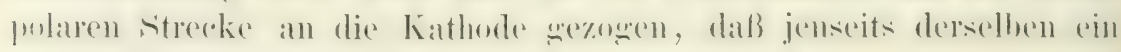
dentlicher Nangel entsteht.

Dieselben Effekte lassen sich num anch bei sehr viel schwächeren

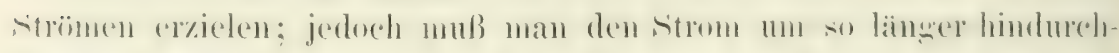
fließen lassen, je schwaicher der Strom ist. Bei eingeschaltetem

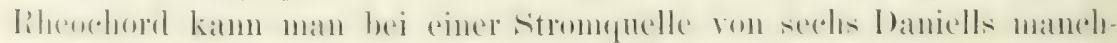

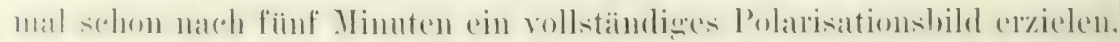
wenn anch nur die drei ersten Stöpsel herausgenommen sind, d. h. nach meiner approximativen Messung bei einem Strom ron etwa 0,02—0,03 Milliampère. 
Bei einer Stromstaike, wetche beim Schließen noch keine voll-

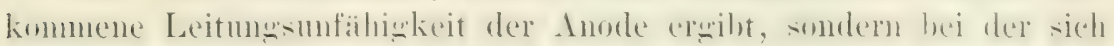
dieselhe erst nach etwa 201-30) sekmolen anshildet, hekommt man in 10-15 Minuten ein wohlausgebildetes Polarisationsbild mit voll-

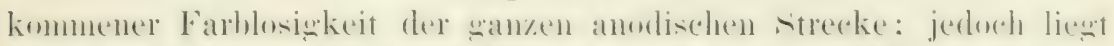

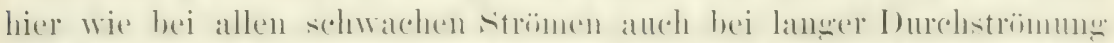
der färberische Indifferenzpmbl näher an der Anode. Inffallend ist

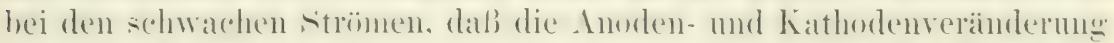

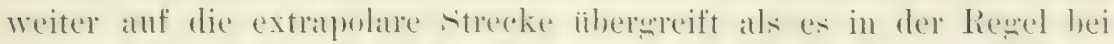
staken strömen der Fall ist. Fixiert man bei einem derartigen stron

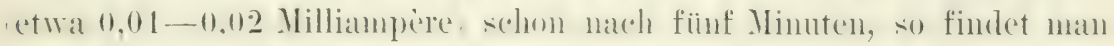
nur an der Kathode eine deutliche Veränderung, während die Anode noch ziemlich mrerändert erscheint. Bei noch schwächeren strömen ron weniger als 0.01 Milliamprere, sogenamte ,schwache

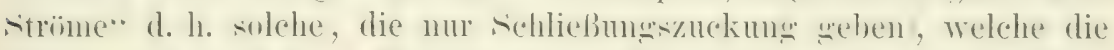

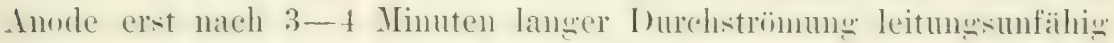
machen, kommt es auch hei länoster l)urchströnung 20 Minuten, in der liegel nicht zu einer vollständigen Farblosionkeit der Anode. Dieselbe zeigt sich zwar immer wesentlich heller als normale Nerrenstellen, behält aber in allen Fasern eine geringe Färbbarkeit bei. Dagegen zeight die Kathode inmer eine sehr dentliche Verdunklum

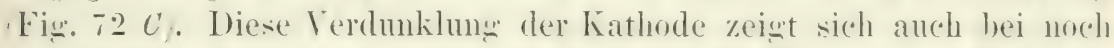
schwächeren strömen, welche erst nach 20-30 Minuten eine Endurchgaingigkeit der Anode herrorrufen und die die Anode auch nach 15-20 Minuten nuch nicht deutlich verändern. Hieraus erwiht sich, dali die Kathodenveränderung eher eintritt oder leichter hervormurufen ist als die Anodenreräindermng.

Öffnet man einen starken Polarisationsstrom, nachdem el etwa 10' weschlosien war, so tritt, wie bekinnt, die Leitmusfähiokeit der vorher anodisch owewenen strecke nicht sofort wicher ein, ja nach sehr starken und andanemdem Durchstrimen kamm der Nerr danernd oder für lange Zeit geschädigt sein. IV a r tet man so lange, bis der Yer wieder in allen Teilen leitun $\mathrm{g}^{\circ} \mathrm{s}$ a hig ist, und fixiert man iln jetzt, so sieht man stets alledureh den strom gesetzten Verïnderungen wieder a usgeglichen: Die Anode hat wieder normale Färbbarkit und an der kathode ist ron einer stäreren Färbung meist nichts mehr zu bemerken. Bisweilen findet man die Anode, nachdem sie wieder vollständig durehgängig ist, etwas d unkler als normale

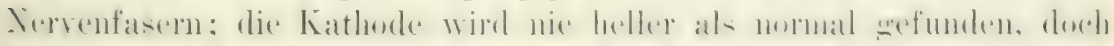

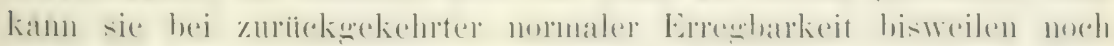
etwas dunkler als die Ungebung sein. (Mit Vorteil verwendet man zu diesen Versuchen Strome, welche eben wrade imstande sind, 


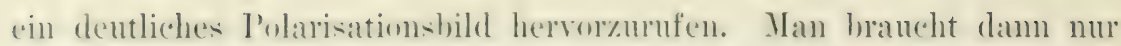
11-20) Yinuten zu warten und ist duch sicher, daß vorher eine Ver:indermy. bestand. Fixiert man nach öffnmen des stromes, noch ehe die Leitmofähirkeit der Anode wiederwekehrt ist, so findet man die Anode innmer now farblos oder wenigstens bedentend heller als normale Verrenstellen. Kü nach dem öffnen eines starken stromes findet man fast dasselle Bild, wie wemn während der Inrehstrümmn! fixiert ist; je linner man wartet, desto meln zeigt sich die anodische strecke des Firbungsbildes eingeengt und die kathodische strecke heller. Daraus geht herwor, daß die Fibrillensä̈ure alluählich ibre nomale Verteilung wiederowimnt. I lese Restitution nimmt selı viel mehr Zeit in Anspruch als zur Hervorrufung der Veränderung nöticwar. Andrerseits wird durch diese Versuche aber anch gezeigt, dah eine Nervenstreckenur dann leitungsfähig ist, wenn sie eine reichliche Menge Fibrillensäure in kontinuierlicher Verteilung besitzt. Die Anwesenheit von Fibrillensäure an den Fibrillen ist Bedingung der Nervenle itung!

Wie rerhalten sich num die Neurofibrillen geseniiher dieser offenharen Versehiehnug der Fibrillensäure? Daß die Fibrillen bei der konstanten Durchströmung nieht aufüelöst werden, läßt sich hereits aus den wewönlichen Alkoholpräiparaten ersehen, wem man die sichnitte

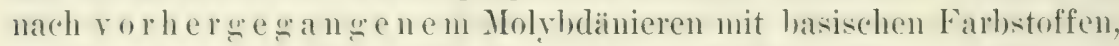
also sekundär, färbt. Hier zeigt sich der Schrump fung sstrang des Achsenzylinders überall gleich dunkel gefärbt und auch an der Anode nicht unterbrochen. Von dem im primärefärbten Präparat so deutlich hervortretenden Fäbungsunterschieden ist nichts zu sehen. Statt dessen zeigt sich aber ein morphologischer Lnterschied: Die gaeschrumpften Adrsenzylinder sind an der Anode wesentlich diunner als an nomalen Nervenstellen, an der Kathode aber etwas dieker letzteres ist nicht immer deutlich. Lm üher die Fibrillen genanere Aufschlïsse zu gewinnen, muß in Osmiumsäure fixiert werden.

Versuch 2. Ein Nerv wird wie beim Versuch 1 mit dem vollen

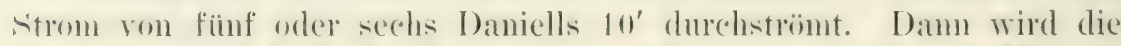
(ilasschale mit $1 \%$ Osmimmsäure sefüllt und nach 1-3 Minuten der Strom geöffnet. Nach 12-24 Stunden wird der Nery ron den Elektroden herabgenommen und in der bekamnten Weise aber ohme Reduktion weiter behandelt Mönckeherw und Bethe, 1699. Ein Treil

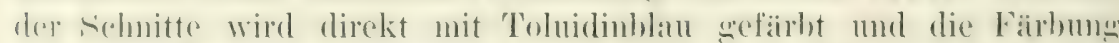
mar.h dem Iraschen nit molybdänsandem Ammonimm fixiert, ein andrer T'eil wird erst molybdäniert und dann gefärbt. Die Präparate zeigen keinen Untersehied untereinander. An allen 
stellen treten die Fibrillen mit der gleichen Scharfe und Deutlichkeit hervor; sie durehriehen die Anode ebenso glatt wie die Kathode und die interpolare strecke; sie sind an der Anode nicht dïnnerals normal und an der Kathode nicht dicker: kurz, man kann an diesen Präpaten nieht sehen, daB mit dem Nerven irgend ein Eingriff vorgenommen ist. Da auch das direkt nefairbte Präparat nichts ron ciner Inodenhelliwkeit und Kathodendunkelheit erkemnen lïßt, so kamn man schließen, daß die direkte Fäbluakeit nach Osmierume nichts mit der prinäiren Füblarkeit nach Alkoholbehandlung, also der Anwesenheit von Fibrillensibure, zu tum hat. Die Fibrillensäure geht hei der Osmiumsäurebehandlungr (vielleicht durch Oxydation?') verloren, wofür sich auch andres anfiilnen liißt.

Bei der konstanten Durchströmug werden also die Fibrillen, soweit sich das mit unsern Mitteln erkennen läBt, nicht verandert! Was geandert wild, ist die Verteilung der an ihnen haftenden Fibrillensäure. (Eine andle Auffassung der Befunde wird späterhin Berieksichtignng finden.) Da die Fibrillenhïndel in Alkoholpräparat bei sekundärer Färbune an der Anode dïmner grefunden werden als an der Kathode, die Fibrillen selber aber keme Verjüngmug an der Anode zeigen, so kïmnte nuan auf den Gedanken kommen, daß dieses Verhalten durch die Abwesenheit resp). Amwesenheit von Fibrillensiure hervorernfen wird. Dieser Schluß wäre aber verfrihit. Im Jahre 1868 wurde nämlich ron IIunk gezeignt, daß an durchströnten Nerven das Reusssche I'hänomen, nämlich Wassertransport von der Lnode zur Kathode, in Erscheinung tritt siehe auch Quincke, Ammalen der Physik mud

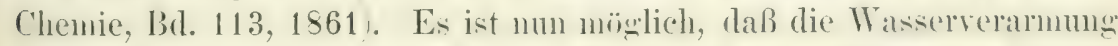
der Anodengegend sie greift nach Munk anf die extrajolate strecke

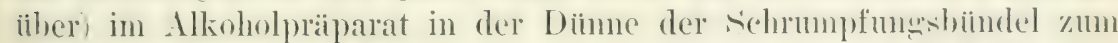
Ansdruck kommt, daß sie sich aber durch den langen Aufenthalt in

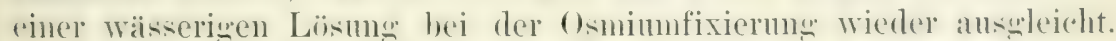
Es sei hier erwähnt, daf Munk den Wassertransport nit der physiolonischen Wirkung des konstanten stromes in Zusammenlang hringt.

Ins den bisher beschriebenen Versuchen kam man folgende Vorstellungen ableiten. Der konstante strom heht an der Inude die Ver-

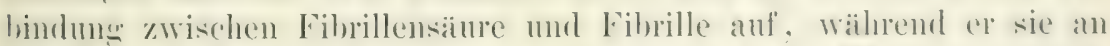
der Kathode festist; die Anode stäbt auBerden die Fihrillusäure ab.

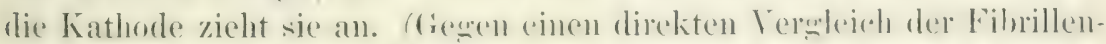

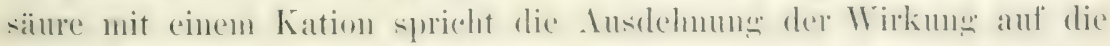
extrapolare Strecke.) Die Ansammlung an der Kathode wird sich anßer auf eine ganz andre Weise, auf die ich später zu sprechen komme, nur dureh eine Wanderung der Fibrillensäure erklären 
lassen. Dagegen könnte man das Fehlen von Fibrillensäure an del Anode anf folgende Weise erklären: Die Anode bewirkt zwar eine

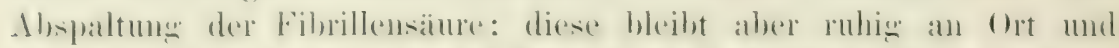

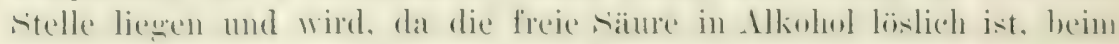

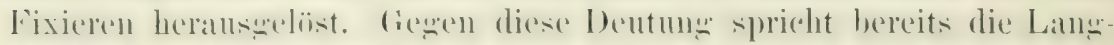

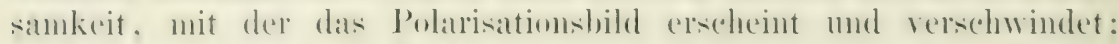

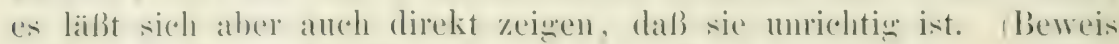

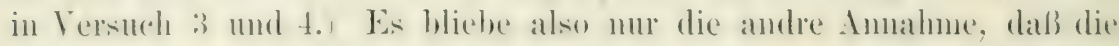
Fibrillensäure anch von der Anode fortwandert. Da num im Alkoholpräparat sich nicht nur die Anode selber, sondern auch ihre extra-

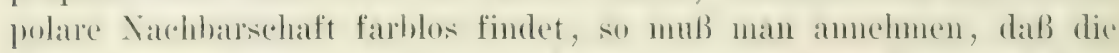
Fibrillensiture atch nach hierhin also in extrapolarer Richtmon fort-

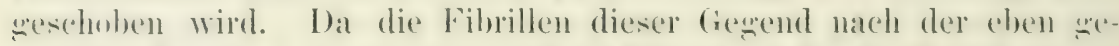

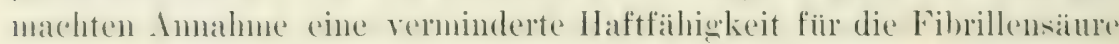
haben. so mub die extrapolarversehobene Fibrillensäure frei hleiben:

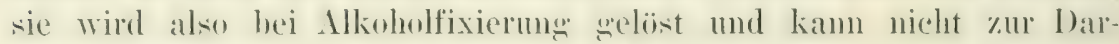
stellung welangen. Wendet man mu ein Mittel an, welches die Fibrillensibure nicht lïst, so mulb man die freie Fibrillensïne jenseds der Anode nachweisen kïmnen. Das Mittel, diesen /aweck zu erreichen. besitzen wir im $̈$ Äther.

Versuch 3. Ein Nery wird in der gewohnten Weise $10^{\prime}$ durchströnt und damn die sichale mit Ither wefüllt. Writere Behandlungsiehe S. 146.) In solchen Präiparaten sieht nan, wie erwähnt, dic Fibrillen zwar anch etwas zusammengeschnurt, aber in der liegel doch nicht so stark, daß sie nicht noch als Individuen zu sehen wären. AnRerordentlich störend bei der Lutersuchume ist die starlic Mitfärbung der eseromnenen Markscheiden. Nur mit Hilfe der (i)immersion ist eine Auflösmng möglich.) 1, Weit jenseits der Pole sieht man die Fibrillen normal gefärbt (Fig. 73 I.). An der Kathode nimmt die Fäbung der Fibrillen wesentlich zu und man kann deutlich sehen, daB das Plus an Fäbung wirklich a uf die Fibrillen und nicht etwa a uf die Perifibrillärsubstanz $z u$ bezielnen ist (Fig. 73 II.). Nach der Anode hin nimme die Färbung num in der interpolaren strecke immer medr ab. gan\% wie bei Alkoholpriparaten, bis die Fibrillen schließlich ganz farblos werden. So geht es fort bis iiber die Inode himans, wo die Fibrillen dam allnäblich wieder dunkler werden (Fig. $73 \mathrm{IV}$.). Extrapolar ron der Anode nnd noeh bis in die Gegend hinein, wo die Fibrillen schon wieder gefälot sind, sieht man 1 un

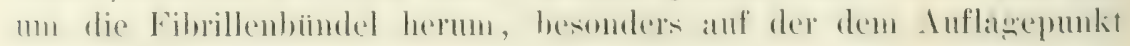

1) Dieser C̈belstand wird durch die nene Äthermethode (p. 146) gehoben. Ich habe aber bisher keine Zeit gefunden, die Versuche mit dieser Methode zu wisclerholen. 


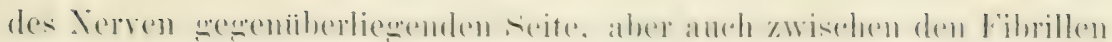
selber sehr kleine, dunkel gefarbte Körnehen, welche an

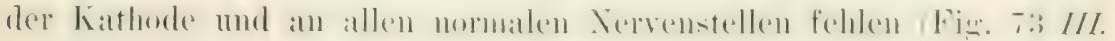

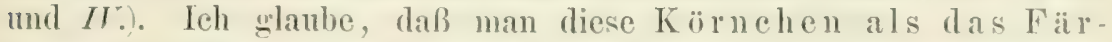
bungsprodukt der freien Fibrillensäule oder ihres Alkali salzes, denn sie verschwinden leicht, wenn der Nery vol dem Färon wewäissert wird) wird ansehen milissen!

AuBer an dieser Stelle habe ich sie aber manchmal noch an einel

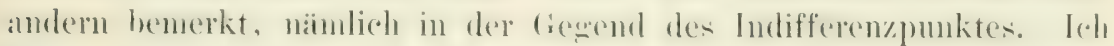
hatte dies theoretisch nicht vorausgesetzt, sehe aber, nachdem der liefund gemacht ist, ein, daß ein Vorkommen freier Fibrillensiiure
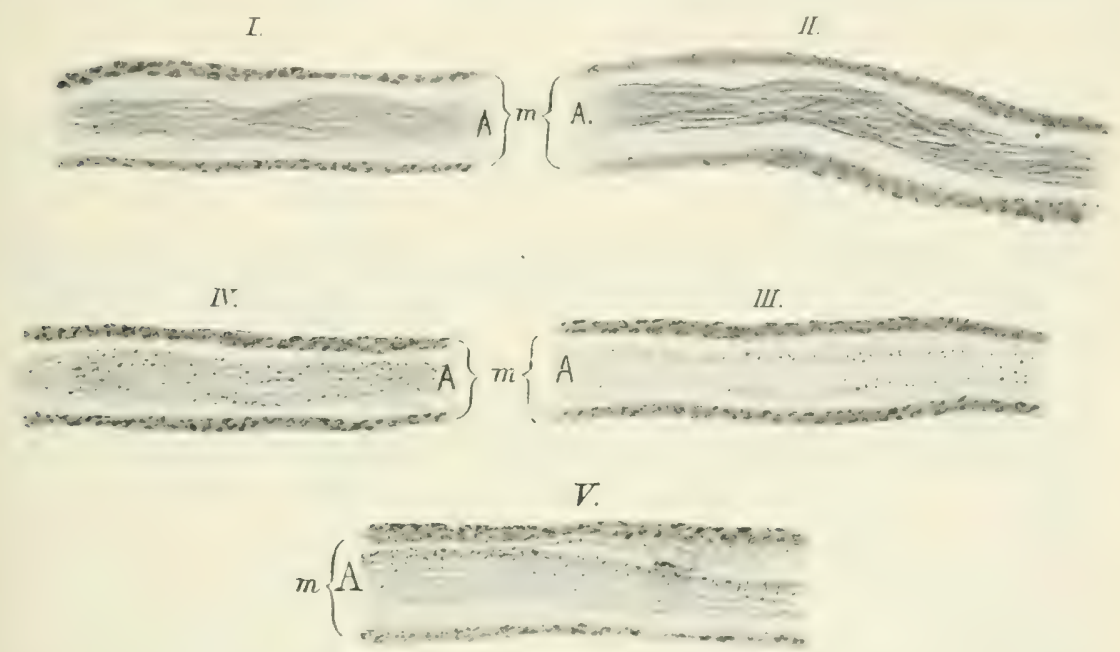

Fig. 73. Nervenfasern aus verschiedenen Gegenden polarisierter Nerven nach der (iilteren) $\ddot{A}$ thermethode behandelt. (Apochromat 1,30, Kompensationsocular 6, Zeichenapparat). m. die lïngsgeschnittene, körnige Markscheide. 1. der Achsenzylinder. - I. Aus einer normalen Yervenstelle. II. Aus der Kathodengegend. III. und $I \mathrm{I}$. Aus der Anodengegend, III. direkt ïber der Elektrode, II. etras mehr extrapolar. (I.-IV. aus demselben Schnitt). $\mathrm{F}$. Faser aus der Anodengegend ron einem Nerven, dessen positive Elektrode extrapolar während der Polarisation verschoben wurdr.

an dieser Stelle hätte erwartet werden können, denn wir haben ja anch hier mangelhafte Iffinitä der Fibrillen, so dab Fihrillensiatme, die

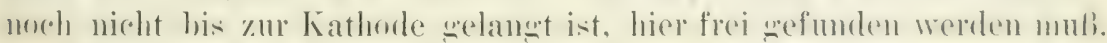

Wemn es richtig ist, daß die Anode die Fibrillensäure extrapolar verdrangt, so muB eine ansehnlichere Menge derselben extrapolar gefunden werden, wenn man die Anode Wähend der Durehströmug in extrapolarer Richtung versehiebt. Ein solchel Versuch wïrde, wenn er positir ausfiele,

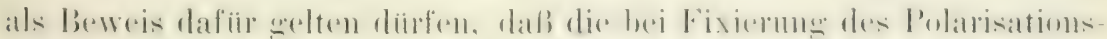

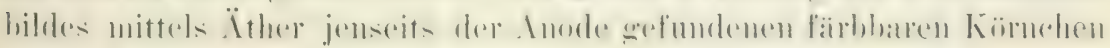
wirklich mit der freien Fihrillensiume zu identifizieren sind. 
Versuch 4. Die Aufstellung des Apparates erfolgt wie bei den friiheren Versuchen, nur wird die Anodenelektrole an edner schranbenspindel befestigt. an dab sie in der Lïngsachese des Nerven allnählich versehoben werden kamn. Übresens kam man die Versehiebung bei

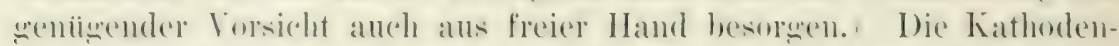
elektrode wirl nahe an Inskel an den Nerven angeleget. die Anodenelektrode etwa 1/2 em vori ihr entfernt in proximaler Lage. Der

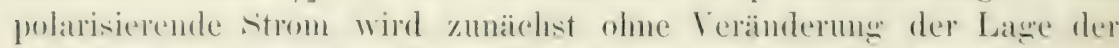
Elektroden zwei Minuten geschlossen scehalten; dann fängt man an die Anolenelektrode langsam proximalwärto zu bewergen. Anf jerlen Millimeter Versehiehmow hat man etwa eine Minnte zon rechnen. Wemn die Anode $u m$ 10-15 $\mathrm{mm}$ verschoben ist, füllt man die Schale mit

$I$.

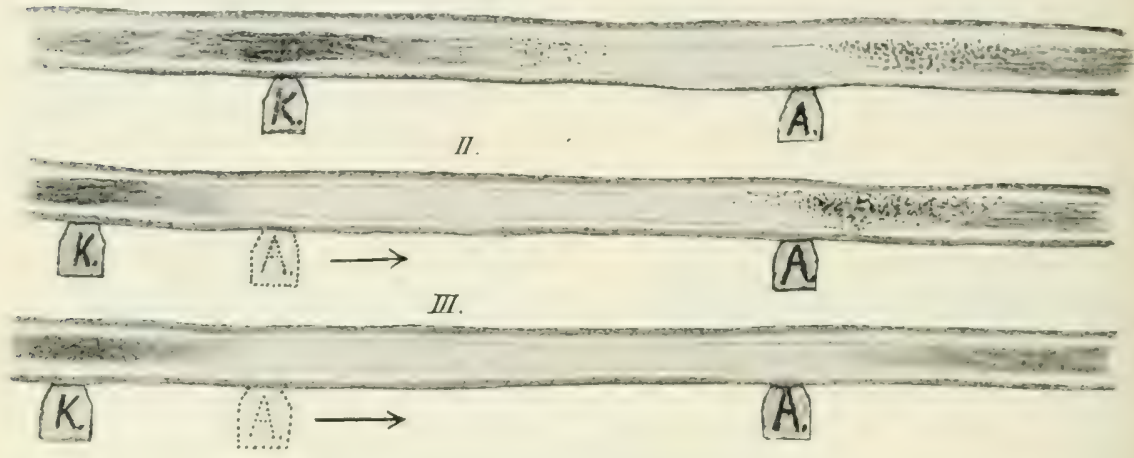

Fig. 74. Schematische Darstellungen des Polarisationsbildes. Der Nerv ist als eine einzige grobe Nervenfaser gedacht. Die dunkle Kontur bedeutet die Markscheide, der strang in der Mlte den Achsenzylinder. K..Kathode, A. Anode. - I. Die Elektroden stehen wihrend des Versuches fest. Ithermethode. II. und III. Die positive Elektrode wird wihrend des Versuches langsam in der Richtung des Pfeiles verschoben. II. Mit der Äthermethode untersucht, III. mit der $\Lambda$ lkoholmethode untersucht.

Ïther. In einem Kontrollversuch wird genan so verfahren, die lixation aber in der üblichen Weise mit Alkohol vorgenommen.

Zuniehst der Alkoholnerv: Die ganze Versehiebungsstreckeder anodischen Elektrode ist frei von Fibrillensä ure (Fig. 74 III.), jenseits derselben sieht der Nerv aus, wie wenı

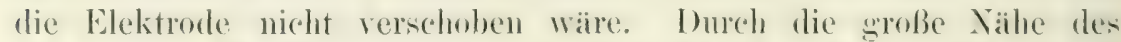
farberischen Indifferenzpunktes an der Kathode unterscheidet sich soleh Nerv von einem in gewöhnlicher Weise polarisierten. Ist zu schnell bewest, so bleiben einzehe Faserstellen gefärbt. C̈ber $1.5 \mathrm{~mm}$ filnrillensäurefreie strecke habe ich nicht eryiclen kïmnen, doch maty dies bei weiteren Versuchen gelingen.

Der Äthernerv zeigt dieganzeVersehiebungstreeke in gleicher. Weise frei von Fibrillensäure. An der Anode und jenseits derselben findet man aber in reiehlicher 
Menge färbbare Körnehen um die Fibrillenbündel herum und auch zwischen denselben. Hier ist fast immer das bereits erwähnte

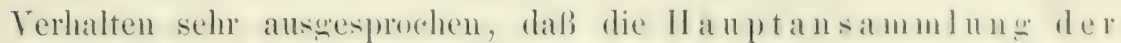
Körnchen anf der. Seite des Fibrillenbindels oder an de $\mathrm{r}^{\circ}$ and (ler Markscheide) liegt, welehe vou der A uflagestelle, also der snode, am weitesten entfernt wa $r^{\circ}$. Hierin scheint mir der beste Beweis dafür zu liegen, dals die Fibrillensäure ron del Anode abgestoßen wird. (Fig. 74 II. und Fig. $73 V_{\text {. }}$ )

Nach diesen Befunden \%eigt sich also die Möglichleit, die Fibrillensiine gewissermaben aus dem Nerven herausmunelken. Es soheint mir außerdem durch dieselben erwiesen zu sein, daB die Anode die Fibrillensäure nach beiden Seiten rerdrängt und die Fibrillen der Fähigkeit beraubt, die Fibrillensäure fest $z u$ halt en.

Es draing'en sich nun zunichst zwei Fragen auf: 1. 'Tritt die Veranderung des Färbungsbildes nul an lebenden Nerven auf:- 2. Wemn diese Frage mit ja beantwortet werden muB: Beruht der Effekt nicht ledisclich auf der durch den strom hervorererufenen Ansammlung von Anionen und Kationen?

Die Entscheidung der ersten Frage ist sehr einfach, die der zweiten bereitet Schwierigkeiten.

Versuch 5. Ein Frosch wird durch allmähliches Erwairmen eben wrade wämestare gemacht. I)er Hüfner wird damn freigedegt und anf seine vollkommene Lneregrbarkeit geprift. Ist diese rorhanden. so wirl el herauspläpariert und zehn Minuten ofler läner mit einem starken Strom durchströmt. - Die Schnitte zeigen a uch nach

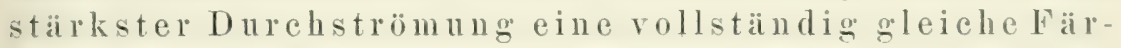
bung an allen Teilen der Nervenstrecke!

Versuch 6. Ein Froschnerv wird fül kume Zeit in Alkohol gelent, damn mit Kochsalzlïsmo auspewaschen und in weiroher Weise durchströmt. Auch in diesem Fall ist weder an der Anode noch an der Kathode eine Veränderung der Färbbarkeit zu bemerken.

Aus diesen Versuchen, die in mannigfacher Weise abgeandert werden können, geht mit Sicherheit hervor, daB der koustante Strom am toten Nerven keine Veranderung in der Verteilung der Fibrillensäure herorzurufen imstande ist. Wir haben es also bei dem Auftreten eines Polarisationsbildes mit

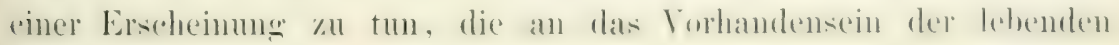
struktur gebunden ist.

In der Äthernarkose verliert, wie schon oben erwähnt, der Nerv die Eigenschaft zu leiten und erregt zu Werden. Wir miissen an-

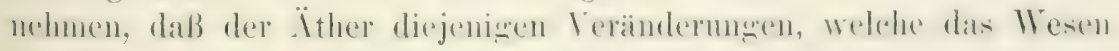
der Nervenleitung ausmachen, an ihrem Kustandekommen ganz ver- 


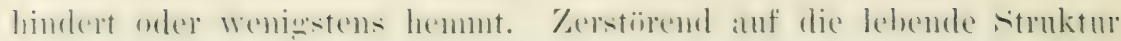
kann der Äther dabei nicht wirken, da ja nach dem Vertreiben des

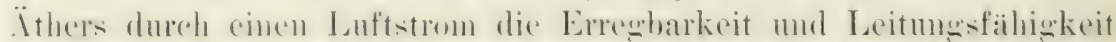

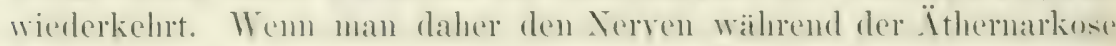

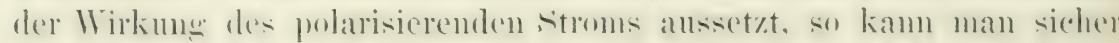

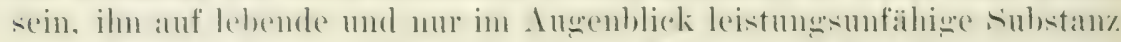
cinwirken zu lasion. Der elektrische Widerstand des Nerven steint wwar in der Äthernarkose, doch läBt sich dies durch Anwendumo stälkerer Ströme kompensieren.

Versuch \%. Die Aufstellung der Apparate muß \%u den Ïtherversuchen eine kleine Ändermen erfahren: Ich setze in die Giasschale

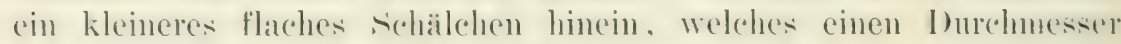
von ungefähr $2 \mathrm{~cm}$, eine lichten Höhe ron $7 \mathrm{~mm}$ hat. An zwei gegeniiberliesenden stellen ist der Rand des soloalchens soweit einerekerht, dals ein Froschnery bequem in dem Iussehnitt Platz hat. Senkrecht

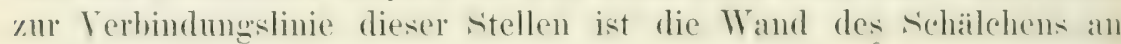
zwei Stellen, welche 1 cm roneinander entfernt sind, bis auf den boden und in einer Breite von 3 mm ansogeschliffen. Inf das schälehen paBt ein Flimmerdeckel, del an einer stelle ein kleines Inch hat, muter das ein stiockchen Watte sekleht ist. Läißt man anf das Loch ron außen einen Äthertropfen fallen, so wird dieser von der immenhefindlichen Watte sofort aufgesngen. Iuf diese Weise kam man die Narkose immerhalb der Kammer geniisend rewnlieren. Vor der Instellum

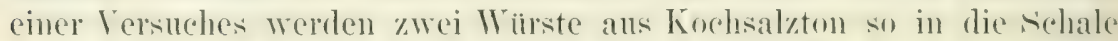

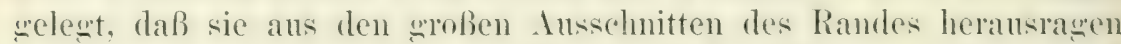
mol diese gerade verschließen. Inmerhalh der vichale werden sie anf den boden gepreßt nud prismatisch geformt. Die vorstehenden Ton-

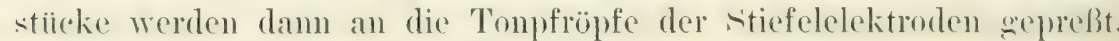
welche, wie bei den vorigen Tersuchen, in die große Schale hineinragen. Nachdem man sich dann davon iberzengt hat, daß nicht otwa durch Auflesen des fimmerleckels ein stromsehlub hervorecrufen

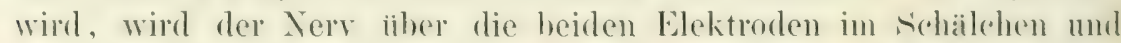

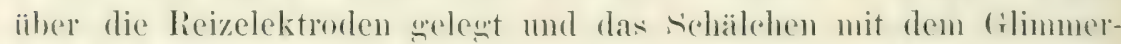
deckel bedeckt, dessen Wattehansoh mit einem 'Toupfen Öther heschickt ist. Von Zeit zu Zeit wird geprifft, ob die Ätherstrecke für den

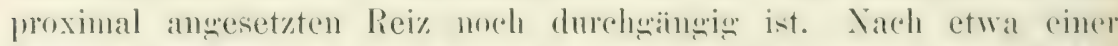
Minute pflegt anch bei stäkster Reizmug kein Erfoln mehr an Muskel einzutreten. Ich warte damn noch etwa eine halbe Minute und schlieke nun den Strom fuir zehn Minuten, wähend welcher Keit der Wattehallsch immer ätherfencht wehalten wird. Hieranf wirl der beckel

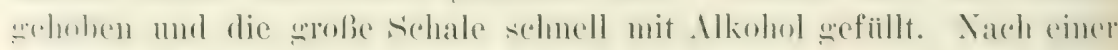
weiteren Minute wird der Strom geöffnet.

bie Schnitte so hehandelter Nerven lassen aneh 
nicht die greringten Anzeichen von einer Kathodenoder Anodenveranderung erkennen. Sie sehengrade so aus, als wenu der Nerv ïberhaupt nicht duchströmt worden wäre.

Schließt man den koustanten Strom grade in dem Angenblick, in dem der zentral antresetzte Reiz kemen Effekt mehr ausiibt, Wo also (in in der Kammerstrecke ansesetzter liciz noch ehen wirksan sein wiirde, oder gibt man mu weng Ither, so findet man an der Anode

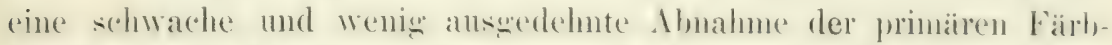

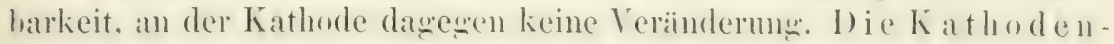
veräinderung wird also leichter dureh Ätherdämpe unterdriickt als die Anodenveräderung. (Daß ich mich davon ibsereug habe, daß die angewande stärke und Ibaner der Narkose den Nerven noch nicht tötet, sondern noch eine Erholung zuläßt, brauche ich wohl kaum zu erwähnen.)

(ianz dasselhe Resultat erhält man, wemn man statt Ïther Mlkohol, chloroform oder Ammoniak anwendet. Ist die Errembarkeit in der Kammerstrecke anfucholen, so tritt keine Veränderung des Färoungsbildes bei konstanter Durchströmung ein.

Aus diesen Resultaten scheint mir hervorzugehen, daß die Veränderung in der Verteilung der Fibrillensäure nicht nur das Vorhandenseinder lebenden Struktur, sondern anch die Funktionsfäligkeit der benutzten Nervenstreckezur Voraussetzung hat, und ich glaube nicht zu weit zu gehen, wem ich behaupte: Die Veranderung in der Verteilung der Fibrillensäure bei der Einwirkung eines konstanten Stromes ist ein Lebensvorgang. Die Narcotica heben die Bewegungabigkeit der Fibrillensäure auf, und die Bewegungsähigkeit der Fibrillensäule ist Bedingung fiu die Nelvenleitung.

Eine wanz andre Wirkmon zeigte sich bei der Polarisation ron Verren, welche sich in einer reinen Kohlensäme-Atmosphäre befinden. Es wurde hierzu eine besonders konstruierte Kanmer verwendet. Die Polarisation begram zwanzign Winuten nach dem Begimn der falsrinleitung., Bei den drei angestellten Versuchen zeinte sich die Anode viel weiter answedehnt als in gleich lange und wleich stark dureh-

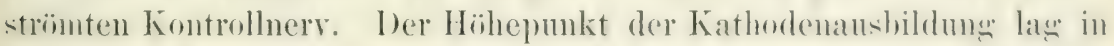
allen drei Fällen $n$ icht iber der Elektrode, sondern intrapola ${ }^{\circ}$ von derselben. Bei zweien der Nerven lag ein zweites Färbungs-

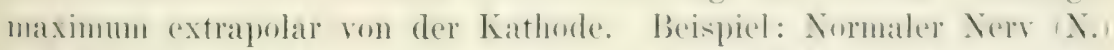

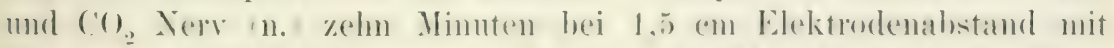

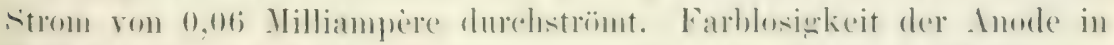
N. $3 \mathrm{~mm}$, in $11.5,5$ mm. Kathodenverinderung in N. an der Elektrode, 


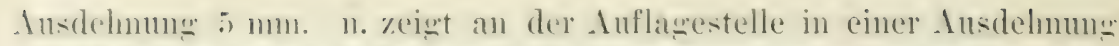
rom 1,2 mm normale Firhome. Fäbmesmaximum intrapolar davm 1,8 mm lang, extrapolar 2,8 mm lang.

Ich komme nun zu der Frage zuritick, ob die geschilderten Ver-

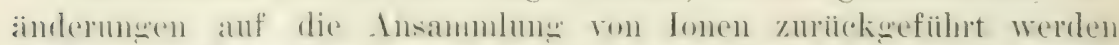
kimmen. Eine klare Vorstellme kïmnte man sich nicht machen, wie die Lonen in dieser IV eise wirken sollten, da die in Petracht kommenten Anionen ( $\mathrm{Cl}^{-}, \mathrm{PO}_{4}^{-}$und $\mathrm{CO}_{3}^{-}$) die Fibrillensäure nicht in Wasser

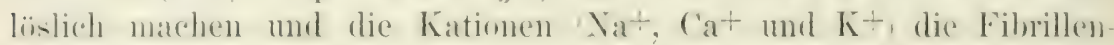
säire lösen. Hiernach sollte man eher erwarten, daß die Anode unreraindert, die Kathode aber farblos waire. Bei der Annahme einer imneren Polarisation im sime der Kernleitertheorie Anshildung einer

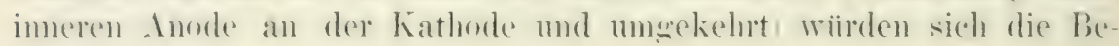
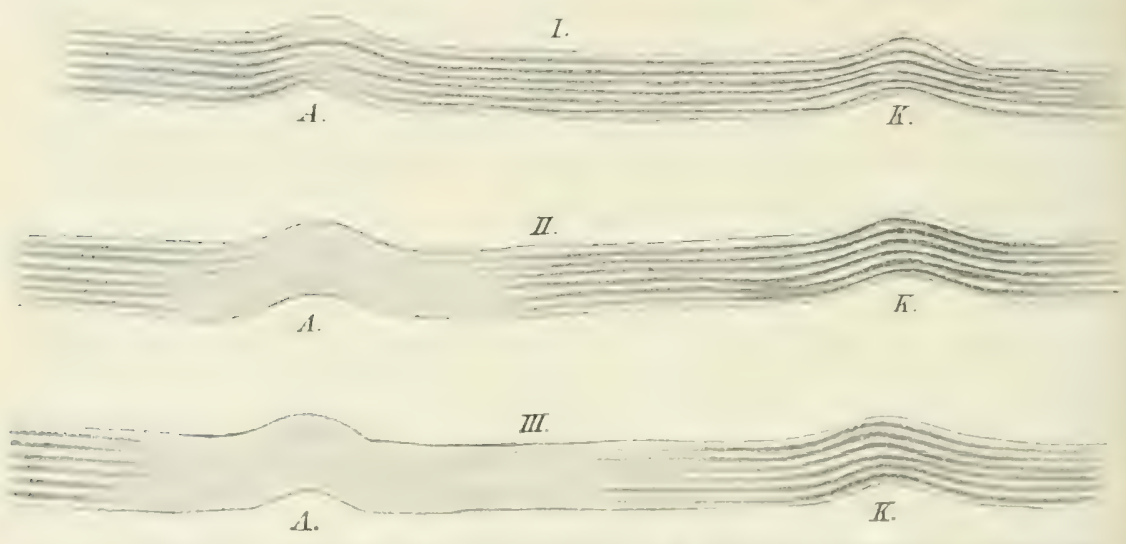

Fig. 75. Schematische Darstellung des Polarisationsbildes bei gleicher Stromstairke, gleichem Elektrodenabstand $(1 \mathrm{~cm})$. gleichlanger Durchstrümung (10 Minuten) und rerschiedener Temperatur.

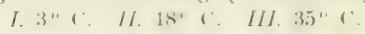

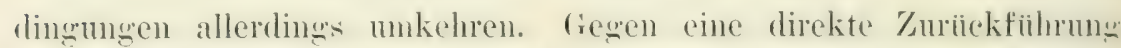

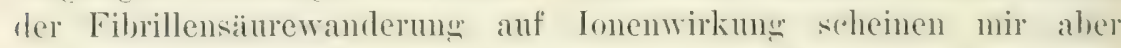
die Resultate am toten und narkotisierten Nerven zu sprechen. beim toten Verven tritt die Wamlermo der Ionen voransichtlich chensont ein wie an lebenden Nerven, vom einem Polarisationshibl ist abel nichts zu sehen. Äher und Alkohol behindern zwar die Bewerliclikeit der Ionen, aber bei der in den Versuchen angewanden Konzentration diufte die behindermug doch nicht swoh wenus sem. um eine Wanderung ganz zu verhindern, zumal bei sehr starken sitrimen.

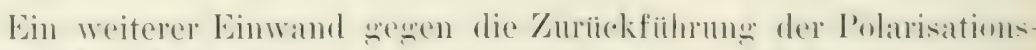

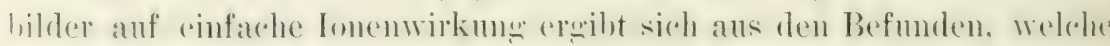
die Cutersuchung des Polarisationshildes bei versehiedener Temuperatm \%11 'Taşe forrdert. 


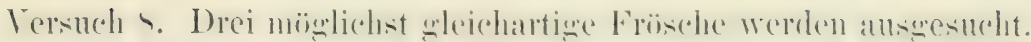

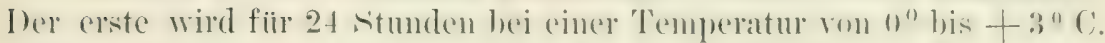

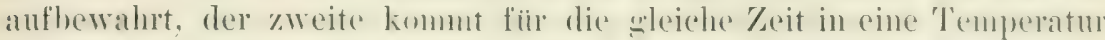
ron etwa $18^{\circ} \mathrm{C}$, del dritte wird etwa 12 Stunden vor Beginn des Versuches in einen Brutsehrank wesotzt, dere eine Temperatur won etwat $35^{\circ}$ C. zeigt. Zum Versuch werden die Elektroden in einen Raum westellt, der die selehe 'Temperatur hat, wie die znechiorisen Frösche. Der Abstand der Elektroden wird stets gleich gemacht und zur Polarisation ein solech starke stom rerwendet. I) Fixation orfolet

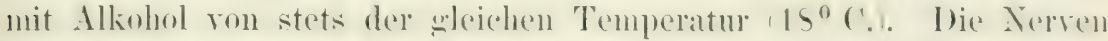
von allen drei Fröschen werden weich lanwa durchströnt. IIrei Versuchsreihen, an neun Fröschen angestellt, ergaben ganz gleiche Resultate.) - Der bei $3^{0}$ C. (Fig. 75, I) polarisierte Nerv zeigt nu eine geringe und enghenrenzte Inodenhelliwkeit, dagenen ist die

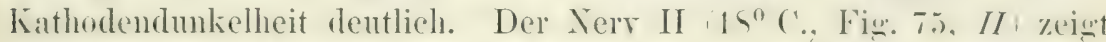

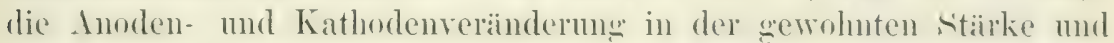
Ausdehmung. Der bei $35^{\circ} \mathrm{C}$. polarisierte Nerr (Fig. 75, III) zeigt eine starke und selur weit ansgedehnte Anodenhelliwkeit, dagegen ist die Kathodenverinderung nur eben angedentet. Die folmende Tabelle gibt die Ausmessung des abgebildeten Falles.

\section{Polarisationsdauer 10 Minuten, Strom von 0,05 Milliampere.}

Entfernung des färberischen Indifferenzpunktes ron der

Anodenelektrode.

\section{Anode}

$3^{0} \mathrm{C}$. nicht farblos

$18^{\circ} \mathrm{C}$. farblos anf $3,5 \mathrm{~mm}$

$35^{\circ} \mathrm{C}$. farblos auf $4,7 \mathrm{~mm}$ extrapolar intrapolar

$0,8 \mathrm{~mm}$

2,5 11111

$2,0 \mathrm{~mm}$

$2,8 \mathrm{~mm}$
$4,3 \mathrm{~mm}$

$4,7 \mathrm{~mm}$
Kathode

dunkel

dunkel

kaum dunkler als normale Stellen.

Niedere Temperatur behindertalso die Ausildun der Anodenveränderung, höhere die der Kathodenverändernng $g^{1}$ ) Dies Verhalten düfte sich nach dem, was über die Ionenverschiebung bekannt ist, nicht zu erklären sein. Es sei hier anch nochmals daranf hingewiesen, daß die Anoden- mol Kathodenveräinderung bei den polarisierten Jerven sich nicht anf die intrapmare strecke beschränken, sondern sich anch extrapolar ziemblich weit ausdehmen. Entsprechende Erscheinmengen sind hei der Elektmlises, su viel

1) Diese Befunde stehen in einem auffallenden Gegensatz zu der durch Waller und Boruttau gefundenen Tatsache, daß Kille den Katelektrotonus

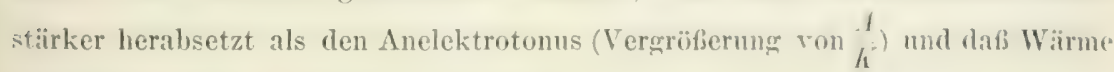
umgekehrt wirkt (Verkleinerung von $\frac{d}{K}$ ). 
ich weiß, nicht bekannt. Ich halte es demnach fiir sehr unwahr-reheinlich, dah die Verteilung der Fibrillensaiure durch den konstanten strom die primäre Wanderung der Ionen zur Ursache hat.

Sehr viel eher lassen sich die beschriebenen Erscheinungen, wenimstens in dinem Teil, mit dem I'hänomen der Konvektion in Zusammenhang hringen. Lnter Konvektion rersteht man siche Quincke 1861, Lehmamn 1s58, Warburg 1595, die Fortführung ron Flüssimkeit resp. fester Teilchen, die in Flïssimkeit suspendiert sind, durch den elektrisehen strom. I)iese kann in der Richtung des stromes IVasser. Terpentinöl, Toluol; Platin, Gold, (quarz u. s. w. in Terpentinöl suspendiert, aher anch entegen der Richtung des elektrischen stromes affolgen verunreinigter Alkohol, schwefel in Terpentinöl, (iasblasen in Alkohol [Quincke], Tonpulver in Wasser [Reuss] u. s. w.). Besonders geeignet zum studium dieser Erscheinung scheinen mir wefuollene und mit Farbstoffen imbihierte Gelatinestreifen $z, 11$ sein. Die Wasserbewegung ist bereits von Munk und andern an (ielatinestreifen studiert worden; andrerseits hat bereits smidt beohachtet, daß Methỵlenblau in wässerigen Lösungen zur Kathode wandert. An gefärbten fielatimestreifen kömnen beide Prozesse zugleich verfolgt werden.

Legt man einen mit Toluidinblan gefürbten felatinestreifen iiber „,unpolarisierbare" Elektroden und läßt den stron einiger Elemente hindurchgehen, so sieht man die Kathode trocken werden. Die dadurch bedingte Verdünnung des Streifens sehiebt sich num zur Anode, also entgegen dem strom, fort. Die Anode schwillt mit der Zeit etwas an. (Bei Anwendung von Platinelektroden wandert das Wasier, wie die Autoren angehen, mit dem elektrischen Strom.) Während dieser Zeit ist die Anode hell und die Kathode dunkler geworden. Die Anodenhelligkeit dehnt sich allmählich nach der Mitte der interpolaren Strecke zu aus und schiebt dabei Farbstoff vor sich her. Andrerseits bewent sich der Farbstoff in der Niahe der Kathode relativ schnell zn dieser hin. Die Folge davon ist, daß der streifen zon einer gewissen Zeit an der Kathode tief dunkel, etwas mehr nach der Anode zu heller als vor der Durchströmung, in der Vitte der interpolaren strecke wieder dunkler und in der Nähe der Anode san\% hell ist. Der Farhstoff bewegt sich also in der Richtung des elektrischen stromes, ehenso wie die Fibrillensiume. Beim Verven weht die Wasserbewegung im gleichen sime, beim Gelatinestreifen (wenigstrus bei Anwendung ,mupolarisierbarer Elektroden") im entgegenEresetyten Simne; dieser I'ntersehied diurfte aber rom keiner wesent-

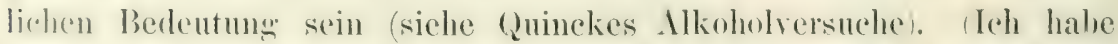
diese Versuche erst in allerletzter Zeit begomnen und sie noch nicht beenden kömen. In der Literatur habe ich bisher keine Angaben iiber ähnliche Versuche gefunden.) 
In der interpolaren Strecke zeigt demnach die Verteilung des Farbstoffes grobe Ïlnlichkeit mit der der Fibrillensiiture. Extrapolan rerhalten sich beide Erseheinumgen versehieden. Das Polarisationshilul des Nerven dehnt sich extrapolar aus; beim Gelatinestreifen zeigen sich extrapolar keine Verinderungen. Trotzdem staulse ich, dall wir es bei der Fibrillensäurewanderung mit einer Konvektionserscheinnnzu tum haben, aber es kommt zu dieser noch allerhand andres himzu. Wie rersehiedene der angeführten Versuche ergeben haben, ist die Fibrillensäure weder in der Nervenflüssigkeit gelöst noch in derselben suspendiert, sondern es ist anzmehmen, daß sie an die Fibrillen gebunden ist. Ehe sie gelöst odel suspendiert zur Konvektion kommen kann, mu sie also erst von den Fibrillen abgespalten werden (siehe die Narkoseversuche).

Bisher ist die stillschweigende Toransetzmng gemacht worden. daß ein Gehalt an Fibrillensäure dem normalen Zustand des Nerven entspraiche und daß dieser Bestand gewissermaßen mrerinderlich sei. Yan könnte die Dinge aber auch noch anders anffassen, nämlich in der Teise, daß die Fibrillensäure ein Dissimilationsprodukt der Fibrillen oder der Perifibrillärsubstanz sei, das sich in letzterem Fall erst sekundïr an den Fibrillen anlaserte. Den normalen Nerven könnte man sich dann entweder frei von Fibrillensäure denken und die in normalen Priparat gefundene Fibrillensäuremenge als durch Zersetzung während der Abtötmg entstanden, oder man wïrde auch an normalen Terven eine gewisse Ilenge von Fibrillensänre annehmen, welehe durch einen danernden geringen stoffwechsel in Nerven hervorehracht wiirde. Das letztere wäre wohl in Anbetracht der Narkoseversuche das wahrscheinlichere. Als Hilfsannahme wiirde damm noch himzısenommen werden müssen, daß die gebildete Fibrillensäure stets wieder fortgeschafft oder weiter zersetzt würde.

Bei Zugrundelegung dieser Deutung̨ kömnte man die Befunde an polarisierten Nerven leicht und olme wesentlichen Zwang im sinne der Heringselien Assimilations- und Dissinilationstheorie denten S. 25:3. Nach Ilering (1559, beruht die verminderte Enregharkeit an der Anode anf Herabsetzung der Dissimilation und Terstarkmue der Assimilatim. Lumgekehrt wird die gesteigerte Erregharkeit an der Kathode auf cine steigermo der I)issimilation (verbunden mit Henmmme der Assimilation. zuriiekgeführt. Das plötzliche Einsetzen der Dissimilation an der Kathouk

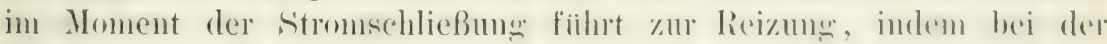

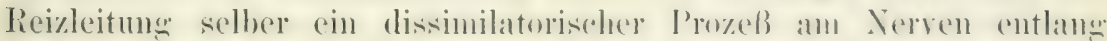
lïuft. In der Anode sind wïhrend des fieschlessensedins des strome-

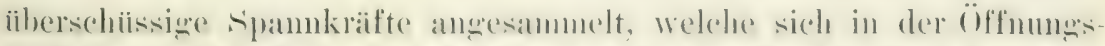
zuckungr und in der noch nachluer gesteigerten brrembarkeit kund tun. Die starke Ansammulung von fribrillensänre an der Kattherle wïrde 


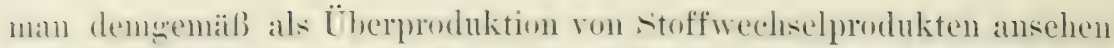
kïmen, während man den Vansel ron Fibrillensäme an der Anode auf

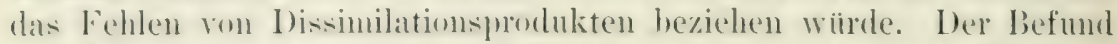
von froier onler wenigstens den Fibrillen nicht angelagerter Fibrillensiinre jenseits der Anode kïmnte man dahin verstehen, dak hier die frei-

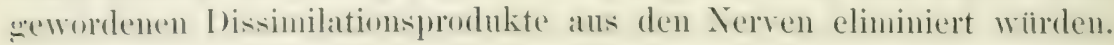

Da die Anode nach der Durchströmung sehr zur Dissimilation disponiert wire, so mïBte sie hei st trom 11 m ke lo in besonders hohem Mabe Fibrillensäme bilden kïmen, man miilite also die frühere Anode auBergewöhnlich dunkel finden. Wie der Versuch reigt, ist dies nieht der Fall.

Versuch 9. Der Nerv wird in der gewöhnlichen Weise auf die Elektroden aufecelent nud ein strom ron etwa 0,05 Milliampire drei bis vier Minuten lang hindurch geschickt. Dam wird der strom gewendet mol nach enleichlanger Einwirkungstaner Alkohol in die schale gregossen. - Ein Kontrolnery wird bei wleichem Elektrodenabstand mit cinem gleichstarken Strom die Hälfte der fresant\%eit in einer Richtung' durehströmt.

Der Kontrollnerv zeight die gewöhnlichen Verhältnisse: Die Anode ist farhlos, die Kathode dunkel; da die schließungsdaner nicht sehr lang und der vitrom nicht sehr stark war, so ist die räumliche Iusdehnumg der Polbilder nicht vollständig. - In andern Nerv, bei dem der strom sewendet wurde, ist die 1 node chenfalls farblos aber ziemlich engbegrenzt; rechts und links findet sieh eine dunkle Färbung der Achsenzylinder und zwar an Stellen, welche an der Kathode des andern Terven noch wa nicht dunkel sind Fig. 77 II, $5.296 \%$ Die K a thode also die urspringliche tnode zeigt sich etwas dunkler als normale Nervenstellen, aber nicht so dunkel wie die Kathode des Kontrollnerven. Rechts und links sind die Achsenzylinder heller als normal und ïher die Grenze hinaus, als es bei der Anode des Kontrollnerven der Fall ist (Fig. $77 I I)$. - Um bein Wenden des Stromes eine vollst ï ndi man den strom nach dem Wenden etwa doppelt so lange geschlossen halten, als es zur Hervorbringung des ersten Bildes notwendign war! 1 Ku\%e stromdaue und mittelstarke ströme wurden angewandt, mu dem Vorwurf zu entegehen, den Nerven zu sehr esesehädiont zu hahen.

Dats Resultat fält also nicht im simme dep Ilerineschen Theorie ans, sondern ist viel besser bei der Ammalme einer Wandermen einer rimmal vorhandenen Fibrillensäuremenge verstaindlich: I)ie nene Anode

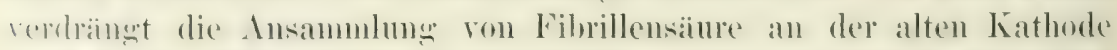
nards heiden seiten und zwar in fehiete, in welchen vorher sar keine Ansammlung gewesen war. Indrerseits entrieht die neue Kathode 
ihrer Sachbarschaft die spärlichen hier vorhandenen Menesen von Fibrillensäure. Da die fienend aber vorher frei davon war, so kamm sie sich nicht in derselhen Zeit dieselbe Menge verschaffen wie unter normalen Verteilungsverhäiltnissen.

Dalb die Fibrillensäure kein Dissinilationsporodukt ist, gacht noch besser ans folgenden Versuchen hervor:

Versuch 10. Eine Kathodenelektrode wird von zwei Anodenelektroden eingeschlossen und zwar in einen Fall von zwei dicht benachbarten (Fig. $76 \mathrm{I}$, Abstand zwischen beiden Anoden 4-5 1mm) und im andern Fall von zwei weit auseinandel stehenden (Fig. $76 \mathrm{II}$, Abstand $15-20 \mathrm{~mm}$ ). Dureh beide Nerven wird ein starker Strom
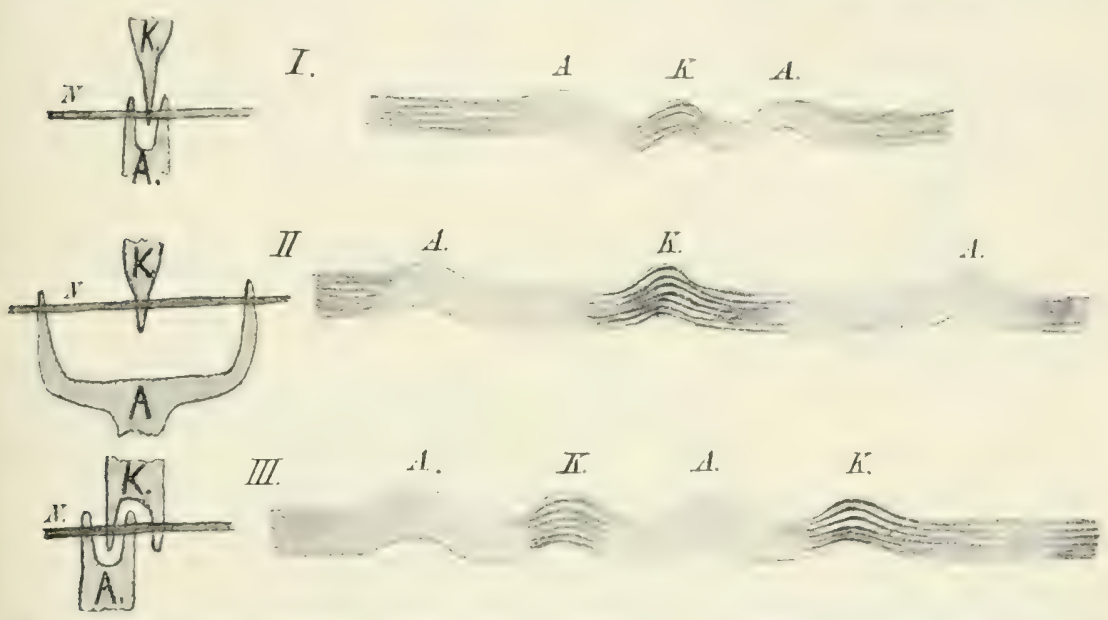

Fig. 76. Die bei der Benutzung gabelförmiger Elektroden entstehenden Polarisationsbilder. Auf ler linken Seite ist die Form und der Abstand der Elektroden, rechts das zugehörige Polarisationsbild angegeben. Niiheres im Text.

10' hindurchgeleitet. Für den Erfolg ist es gleichgỉltig, ob man heidemal einen gleichstarken Strom anwendet (also für II entsprechend dem größeren Widerstand eine stairkere strom urler dieselbe stromquelle benutzt, wobei die stromstaike im Falle II schwächer ist.

Im Fall $I$ ist die Kathode wenig dunkler als normale Nervenstellen, in Fall II ist sie seln dunkel. Ehenso ist in Fall III die ron \%wei Anoden eingeenote Kathode sehe viel wenimere dunkel als diu freie. Wäre die Fibrillensäure cin in loco gehildetes I)isimilationsprodukt, so wiirde es ganz gleich sein, ob sie von einer kurzen oder langen strecke produziert wird; hamdelt es sich aber in ihr 1 m eine rimual vorhandene Menere, welele wandert, so kamn die Kathode nur

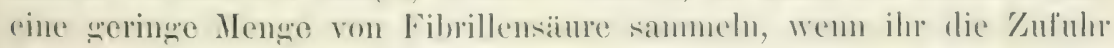
anf beiden Seiten von Anoden abgesehnitten wird. 
Versuch 11. An einen Nerven werden eine einfache Elektrode

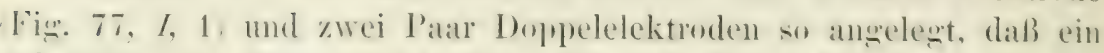
sichenkel jeder Ibeppelelektrode rechts und der andre links von der einfachen Elektrode liegt 2 mul :3. Die tichenkel des Patars 2 sind je $2 \mathrm{~mm}$ rom der Elektrode 1 ('ntfernt, die des Paars 3 je 10 nmm. Die Doppelelektroden sind so mit einem Doppelsehliissel verbunden, daß sie gregeneinander anserechelt werden kimnen. Der strom wird nun zunäichst etwa 10' so dureh den Yerven hindurelgedeitet, daß die Elektrode 1 eine Anode bildet, die Elektroden :3 je eine Kathode. Dadurch wird die Gregend der Anode uber die nicht eingeschalteten Elektroden 2 hinaus frei ron Fibrillensiure. Jetzt wird der stron gewendet und z.n greicher Zeit das Elektrodenpalar 2 für das Paar 3 in den stromkreis eingeschaltet. Jetzt ist die mittlere Elektrode Kathode; ein Zuströmen von Fibrillensäure ron den s'eiten her wird aher

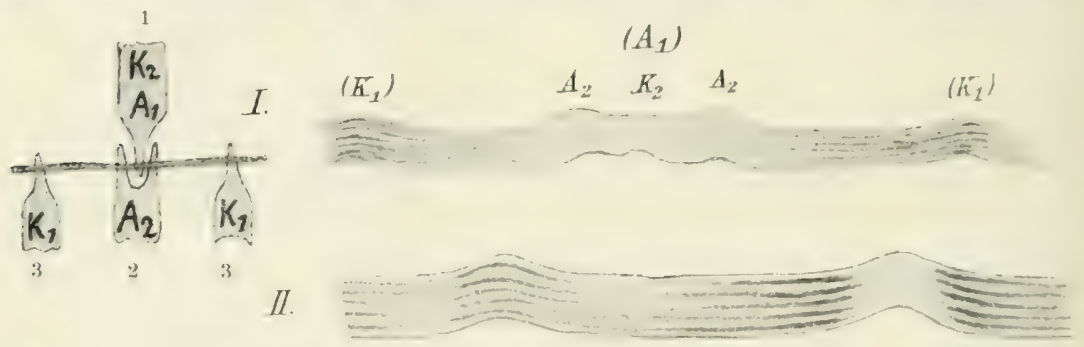

Fig. 77. I. Weaden des Stromes mit gleichzeitiger Einpferchung der Kathode. II. Wenden des Stromes bei normaler Lage der Elektroden. (Näheres im Text.)

durch die nahen Anoden verhindert. Sachdem der strom wieder lo' oder länger geschlossen war, wird fixiert.

Die Kathode, welche vorher Anode war, wird roll. kommen ungefärbt gefunden (Fig. 77 l). Wäre die Ammahme richtign, daß die Fibrillensäure Dissimilationsprodukt wäre. so mïßtr sie stark, zum mindesten aber etwas gefärbt werden.

Da die Kathode bei diesem Versuch wanz ungefärbt bleibt. so ist dies nur dahin zu verstehen, $d a B$ an den Fibrillen eine gegebene, in kurzen Zeiträuen weder merklieh zu-noch merklieh abnehmende Menge von Fibrillensäire vorhanden ist und daß die ganzen bisher beobachteten Erscheinungen nur auf einer versehiedenen Verteilung dieser Menge beruben.

Lis ist also nicht mö̈rlich die nenen befunde für die Heringsehe Thererie der Dissimilation und Assimilation in Anspruch zu nehmen: viel eher kömnte man in ihmen - natïrlich nur für den Nerven cincen bewreis geegen ihre Richtigkeit erblicken. Doch wäre dies wohl

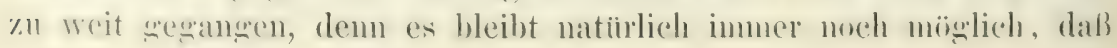




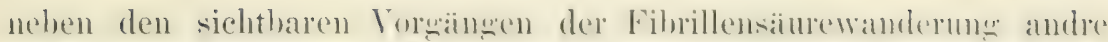

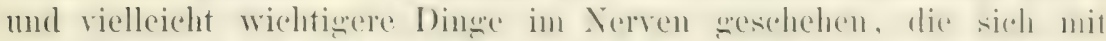
den Heringschen Amahmen decken. so seho ich friiles die Heringsche Theorie anch in ihrer Anwendung anf den Nerven geschaitzt habe, so wird es mir doch niemand verdenken, wemn ich mich jetzt an die beschriebenen sweifharen 'Tatsarehen halte mud nicht an das. was außerdem vielleicht noch sein kömnte. - Ehe ich aber auf die weitere Dentmon meiner befunde eingelse, will ich moh einize lersuche beschreiben, die eigentlich weiter oben lingehörten, dort aber vielleicht das Verständnis störend gewirkt hätten.

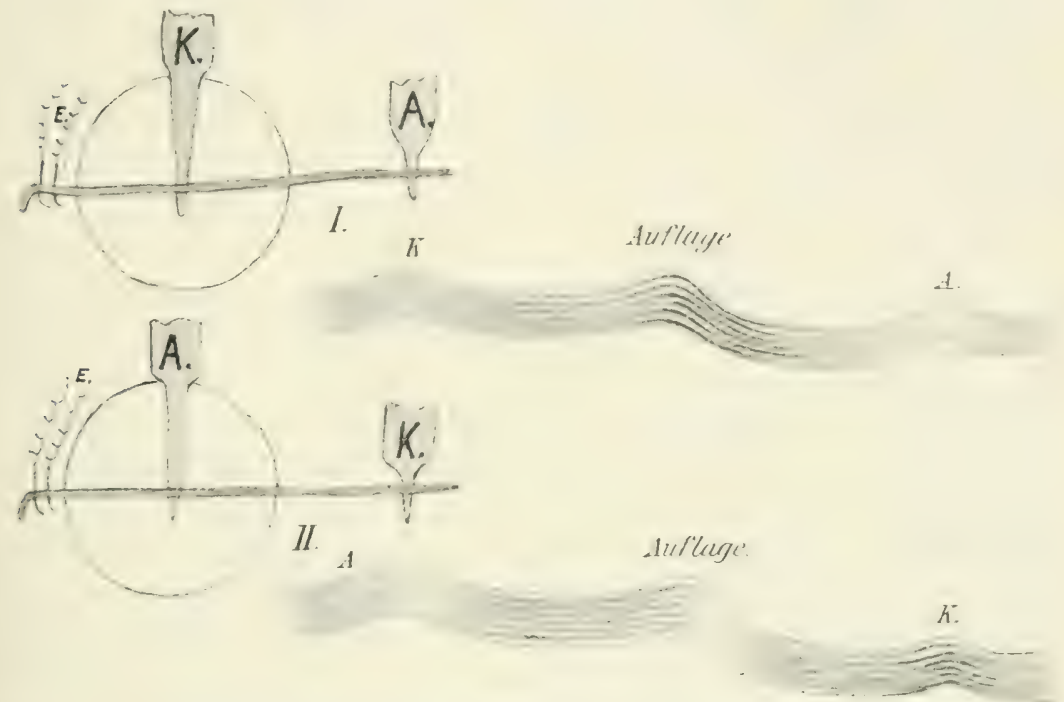

Fig. 78. Ätherisierung des Nerven in der Nähe des einen Pols. Der Kreis bedentet die Ätherkammer. A. Anode, $h$. Kathode, E. Reizelektroden.

Versuch 12. Ich hatte im. Versuch 7 gezeigt, daß die Narcotica die Bewernlicheit der Fibrillensäure aufleben. Es bliel) noch \%u mntersuchen, wie das Resultat ausfiele, wenn nur ein Pol in die nal-

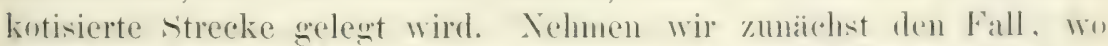

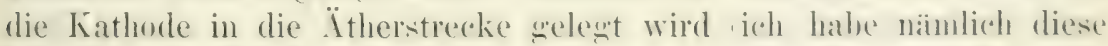

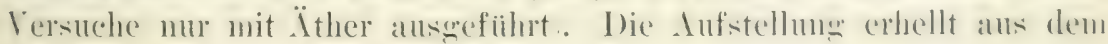
Schema in Figur $78 \%$. Die Ätherisierung braucht in diesem Fall gar nicht sehr stark zu sein, 1 m das typische Resultat zu erzielen:

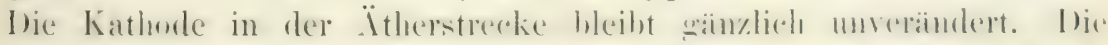

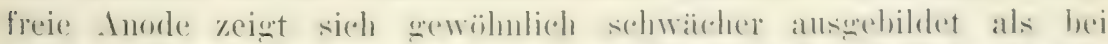

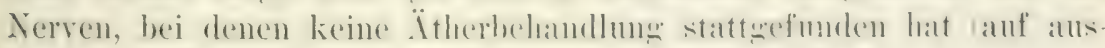

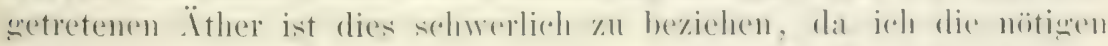
Yorkehrungen zur Fernhaltung des Äthers getroffen hatte). An de 
Stelle, wo der Yer zur Anode hin a us der ätherkammer a ustritt (sie ist durch einen Knick im Nerven markiert, weil der Verv hice anf dem rehälehemand anfliegt, ze igt sich das wohl a usgeildete Bild einer Kathode, nämlich dunle Fär bung der A chsenzylinder! Der Strom wird also da wirksam, Wo er anf nicht immobilisierte Fibrillensäure trifft, also an der Grenze der Äherwirkme. Wir haben also hier die physiologische Kathode im (iegensat\% zur physikalischen im Polarisationshild ror ms.

Versuch 13. Die Anode liegrt in der Itherstrecke, die Kathode frei Fis. is $/ I$. Während man bei ausceichender Narkose kein Inodenbild erhält, wemn beide Pole in Ïther lieşen, bekam ich in diesm Fall immer wenigstens eine Andentung von Anodenwirkmu. anch wemn die Ätherisierumg vollstandign war. Figur 78 II zeigt einen schnitt duch einen solchen Terven im śchema. An der physikalischen Anode zeigt sich ein schwaches mol begrenztes Anodenbild, dam folgen zur Kathode hin normale Fäbungsverhältnisse. I m Lustritt a us der Ätherstrecke folgt ein zweites Anodenhild physiologische Anode), aber anch ziemlich engbegrenzt, und dam schließlich eine mäßig gut ausgebildete Kathode.

Aus diesen Versuchen muß man den Schluß ziehen, daß der İther das Zustandekommen einer Anhäufung von Fibrillensäure an der Kathode vollständign zu nuterdrïcken vermag, daß dagegen die . Inodenwirkung bei Itherisierung noch in beschranktem Mabe zustande kommit. Ein ähnlicher schluß komnte schon oben daraus wezosen werden, daß bei Lagermmg beider Pole in die Ötherstrecke und bei unvollkommener Narkose nur das Kathodenbild sanz ausbleibt, wiihrend das Anodenhild noch in beschrinktem Maße zustande kommt und erst bei starker Narkose ebenfalls fortbleibt.

Veränderungen der primären Färbbarkeit der Achsenzylinder (resp. der. Neurofibrillen) dureh Reizung.

Die hier mitzuteilenden Versuche können nicht, wie die bisher mitereteilten, den Anspruch erheben, bis zu einem zewissen frade ah-

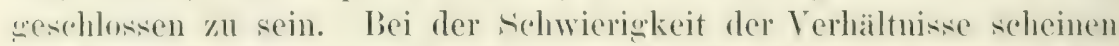
mir Irrtiomer nicht san\% ansogeschlossen und ich teile daher die befunde mit aller Reserve mit.

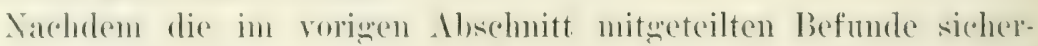
gestellt waren, draingte sich die Frage auf, ob im Zustande der

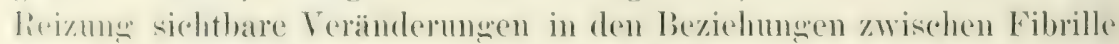
monl Fibrillensiatue zu beobachten sind. Wem wirklich Änderungen

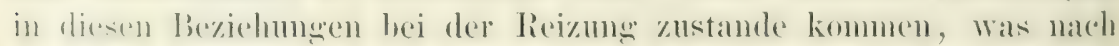
dens linherenehenden wohl vorallszusetzen war, so ist es a priori nicht 
allzu wahrscheinlich, daß dieselben auch faßbar sind. Tor allem stellen sich zwei sichwierigkeiten in den Weon: 1. Jeder licis bringt nach allen bisherigen Erfahrungen nur eine sanz voriberechende Veränderung des Nerven hervor. I)iese Verändermugen kam man schnell anf eimander folmen lassen, aber nicht in einen daucruden /astand rersetzen. 2. Kein Abtötungsmittel wirkt momentan und reizlos. fielbst beim Alkohol ist es zweifelhaft, oh el nicht reizend wirkt, so daß also unsre mugereizten Kontrollnerven eventuell schon den hö̈hsten Grad der durch Reize entstehenden Veränderungen zeieren. Vorauswesetzt aber, daß Alkohol nicht reizend wirkt, so kann er doch eine ('ventuelle T'eränderunğ dadurch verkleinern oder unkenntlich machen, daß er den Nerven narkotisiert und die Reizwellen aufhelot, ehe er sie fixiert. Hier konnte nur der Versuch entscheiden und der führte zu dem Resultat, daß sich sicherlich unter geeigneten Bedingungen Veräuderungen zeigen. Neme Reserve bezicht sich mehr auf die weiter unten gegehene Deutung der Befunde als auf die Befunde selbst.

Als Reiz konnten nur Induktionsstroome in Betracht kommen. Es war auch ron vornherein klar, daß man an ehesten auf einen Erfol心 rechnen konnte, wenn man die einzehnen Reize so schnell wie möglich (inander folgen ließ, un wo möglich eine Decknng der einzelnen Reizwellen zu erzielen. Die Tersuchsanordnung war folgende: Del Muskel eines Nerrmuskelpräparats wurle in einer Klammer befestignt. Ein bis zwei Zentimeter rom Muskel entfernt stand ein kleines L-Rohr, iiber dessen eine öffumng der Nerr so melegt wurde, daß ' mit einer schleife hineinhing. Jenseits des Rohrs wurde der Nerv ïber zwei P'atinelektroden geleg't, die so weit als möglich von diesen entfernt wurden. Die Elektroden standen mit der sekundären sipirale rines Induktionsapparats in Verbindung. Zur Lnterlorechung des prinären Stroms diente der Quecksilher-Turbinenunterbrecher der A. E. G., als stromquelle ein Chronsämeelement. Der Lnterbrecher unterbrah bei den meisten Versuchen den strom ungefähr 1200 nal in der siekunde. bei eben wirksanem Rollenabstand trat nul eine Anfangstuckung (Berm-

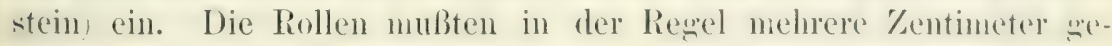

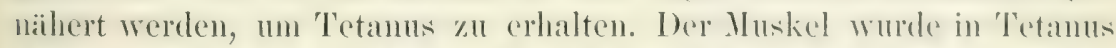

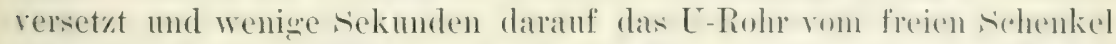

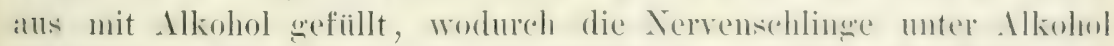

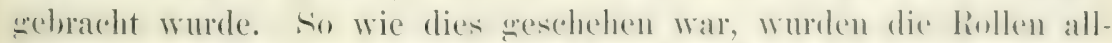

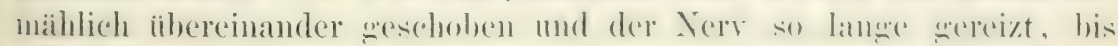
der Muskel nicht mehr reagierte. Etwa 2' später wurle dann der

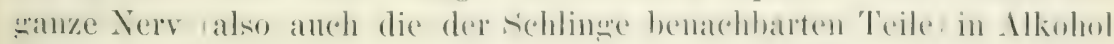
versenkt. Die Schnitte wurden in der iblichen Weise auf prinüre Faibloarkeit untersucht. 
Befund: In sechs ron sieben Faillen fand sich die wahrend der Reizung fixierte Nervenstelle im granen dumkler als die angrentenden erst nach der Reizung fixielten I'artien d. h. die einzelnen Achsenzylinder - manchmal alle, manchmal nur die Melomahl. hesomders die am Rande welegenen - Waren domkler und dichiter. Die Achsenzylinder latten also ein Aussehen. aibulich dem an der Kathode eines polarisierten Verren. In zwoi Fällen war der Untersehied an allen Fasern zut sehen und außerordentlich deutlich; in den iibrigen war es nötion die dunklen mud weniger dunklen Fasern in der föhlinge und anBerhall, derselben zu zailılen und ein Yerhältnis aufzustellen. Es kommen nämlich auch an und fïr sich dunklere Fasern in mormalen Nerven zur Beobachtmen. Diese Zahlen scheinen mir durchaus beweisend, hesonders im Hinblick darauf, daß bei s.leichbehandelten, aber nicht wereizten Kontrollnerven ain Interschied zwischen Schlinge und ïbriger Nervenstrecke anz fehlte.

Ein vollkommen andres und anch dentlicheres Bild zeig te sich, wenn gleich nach der Reizung oder wähend der Reizun In ersten Fall wurle wähend etwa zwei Minuten mit 1200 Lnterbrechungen gereizt, damn die Reizung unterbrochen und sleichzeitis: das L - Rohr mit Alkohol gefuillt. In zweiten Fall wurde fünfrigmal in der sekunde unterbrochen, sonst aber sanz wie oben rerfahren. Auch hier ist die Versuchszahl bisher nur klein: die Luterschiede waren abel stets deutlich und konstant (je acht Versuche).

Befund: Die wähend der Reizung (mit wenigen Reizen in der šekunde) oder wleich nach der Reizung fixierte Nervenstelle war stets dentlich blasser als die a $\mathrm{Ber}$ halb gelegenen Nervenpartien, die erst nach zwei oder drei Minuten, also nach einer Erholungspanse fixiert waren. Die Achsenzylinder waren etwa so sehwach sefärht reweniiber den normalen desselloen Terven, wie die Fasem an dex Anode eines zehn Minnten nit einen schwachen Strom polarisierten Xerven. (Täuschumen sind hier wie oben möglich, weil auch in normalen Verven Färlungsuter-

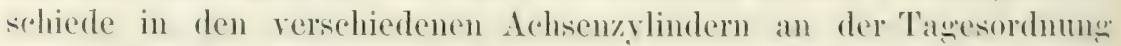
sind. Zum 'Teil mag dies auf der melir oder weniger schrumpfenden

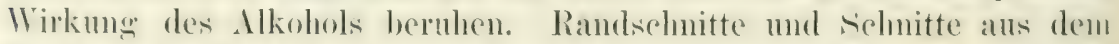
Zentrum des Nerven zeisen anBerdem nicht mowesentliehe Untersohiede in der Fäbumesintensitait. Auf alle diese Dinge muB man acht greben

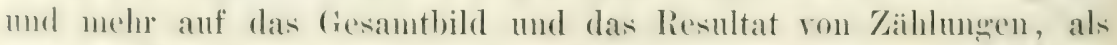

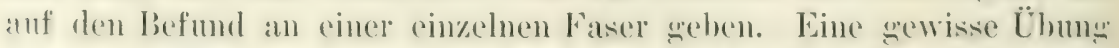

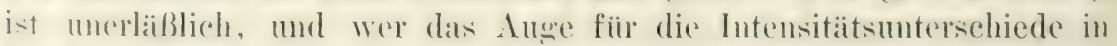

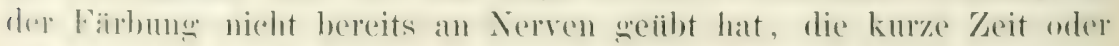
mit selmatchsten strömen polarisiert sind, wird leicht die Lutersohiedo 
ïbersehen. Diese Versuche wurlen an Winterfröschen angestellt. Vielleicht ist eine andre Jahreszeit geeigneter — oder noch weniger

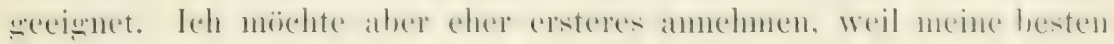
l'olarisationspräparate nicht von Winterföschen stammen.)

Das vorläufiğe Resultat dieser Untersuchungen lautet also: Beifrequenter Reizung zeigen die Achsenzylinder, was die primäe Firblarkeit anbelangt, ein kathodisches I 1 ssehen, bei wenig frequentel Reizung und kul' nach starker Reizun $\stackrel{\sim}{e}$ ein mehr anodisches A ussehen.

\section{"/ur' T'heorie der Nervenleitung.}

Die in vorhergehenden beschriebenen befunde machen es wahrscheinlich, daß bei der Nervenleitung eme Wechselwirkmw zwischen Filrille und Fibrillensäure stattfindet und daf in dieser Wechselwirkmug ein Hauptmoment des Nervenvorganges besteht. Die Hauptpunkte, anf die ich nich hierbei stütze, sind kn\% zusammentefabt folgende:

1. Bei der konstanten Durchströmung eines Nerven werden an der Anode und Kathode antagonistische phrsiologische Prozesse hervorzerufen. Ein antagonistisches Verhältmis findet sich anch in der Beziehung zwischen Fibrillensïme und Fibrille: An der Anode wird die Verbindunщ zwischen Fibrille und Fibrillensäure anfgehoben, an der Kathode wird sie verstärkt.

2. Diejenigen Eingriffe, welche eine Nervenstelle leitungsunfahign zu machen imstande sind, rufen stets eine Ändermog in den Bezichungen zwischen Fibrille und Fihrillensämre hervor. Diese Verinderung kamn bestehen in einer Anfhehung der Verbindung von Fibrillensäure und Fibrille Kompression [?], destilliertes Wasser, Anode

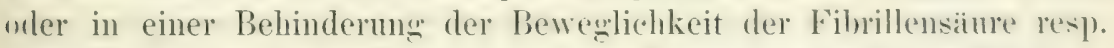
riner Behinderung der Zersetzung ihrer Verbindum nit der Fibrillensubstanz, Äther, Alkohol, Choroform, Anmoniak. Das Vurhandensein von webundener Fibrillensäure an den Fibrillen mol die Mäglichlieit

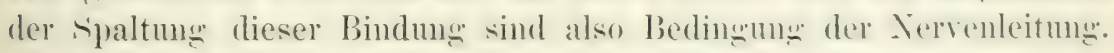

3. Während des Ablaufs einer Erregung im Nerven ist das Yerhältnis zwischen Fibrille und Fibrillensäure veräindert.

Ich will nun in folgenden versuchen die nenen Befunde unter lierieksichtigung des bereits Bekannten zu einer woliufigen 'Theorie der Nervenleitung auszubanen. Iroh hin mir dabei vollkommen lewalst. daf alles in Wirklichkeit fram\% anders sein kimm, als ioh es mir im

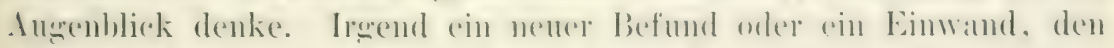

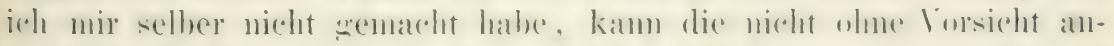
grestellte Gedankemreihe wieder zemeißen. In einer ganzen Anzahl 
ron P'unkten lassen die mir bekamnt gewordenen Tatsachen iiberhaupt noch keine bestinnten Vorstellungen \%, so daß in Bezun anf diess die Thenrie noch unvollständign bleiben muB. Schließlich bin ich mir anch selber bewnlit, dab die Dentumg, die ich hier sebe, nieht die eimzige ist, die sich ans den nenen Tatsachen entwickehn läßt; jal, ich habe mir selher zu verschedenen \%eiten sehr verschiedene ferdanken iiber diesethen gremacht. Ich bitte also, die hier folgende Theorie nicht als neine nuveränderliche Ansicht anfunfassen, sondern als eine vorlaiufige mit allem Vorbehalt auf das im Angenblick vorlandene Tatsachenmaterial aufgebaute Meinungsäußerung.

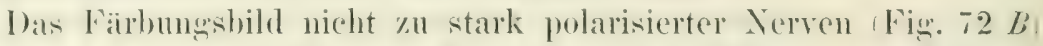
kïnnte man sehr gut für eine Darstellung des Pflï̈perschen Elektrotomus halten, bei der die Erregharkeitsrerhälnisse nicht, wie ïllich. durch eine Kurve, sondern durch Dunkelheitsgrade ausgedriickt sind. I) mittlere I)unkelheit der nomalen Achsenzylinder wïrde die normale Erregbarkeit darstellen, die größere Dunkelheit der Kathode die znesteigerte Erregharkeit derselben und die Helligkeit der Anode ilne his auf Null herabgesetzte Anspruchsfähigkeit und ilıre Leitungsunfähigkeit. Auch die intropolaren Erregharkeitsverhailtnisse wiirden in solchen Präparaten einen wuten Ausdruck in der von der Kathode zur Anode hin abnelmenden Intensitit finden. Den physiologischen Indifferenzpunkt würde man an der Stelle zu suchen haben, wo die Achsenylinder die normale Dunkelheit hesitzen. Bei den Vergleich der physiologischen Verhältnisse und der Färbungsbilder wärde hier anch das gut stimmen, daß der färherische Indifferenzpunkt bei schwachen Strömen in der Nähe der Anode liegt und sich gradeso wie der physiologisehe Indifferenzpunkt mit zunehmender Stromstirke zur Kathode hin versehiebt. Weniger gut wïrden die Verhältnisse in den extrapolaren Strecken übereinstimmen. Die Kathodendunkelheit und die Anodenhelligkeit dehmen sich zwar anch extrapolar ans und zwar. in gewissen Grenzen, num so mehr je stäker der strom ist, aber doch lange nicht so weit, als die Erregbarkeitsverändermugen bemerkbar sind.

Spricht schon dies nicht dafür, daß es angemessen ist, die Färbungwdifferenzen direkt mit den Erreghlarkeitsdifferenzen zu identifizicren, so sprechen andre Befumle direkt dasesen. Die Verindermun der Erregharkeit tritt im Ioment der stromschlieBmon oder bald narelsher ein und erreicht an der Kathode gleich ihr Naximum, an der chode allerdings erst nach einiger und bei schwarchen strömen of

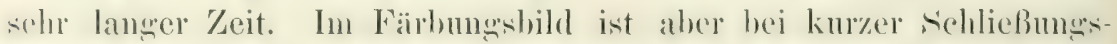
daner weder an der Kathode noch an der Anode eine. Ändermo zu benuerken. Das Farbungsbild beruht eben anf einer Wandermog der Fibrillensiume und diese nimmt nielot mbedentend viel Zeit in Inspruch. 
Ans dem Vergleich von Alkohol- und Ätherpriparaten geht unmittelbar hervor, daß auf der Höhe der Stromeinwirkung an der Kathode eine sesteigerte Iffinitiit der Fibrillen \%ur Fibrillensiure vorhanden ist, während sie an der Anode und iber dieselbe nach beiden seiten hinans so vermindert ist, dab die Fibrillen die in ilneer Nïhe vorhandene säure nicht festzuhalten vermö̈gen. ${ }^{1}$ I Ich mache hier nun die erste Amnahme, welehe dahin grelit, dals hereits im Moment des stromschlusses die Affinitit zwischen Fibrille und ribrillensiiume an der Kathode erhöht und an der Amode welockert wird. \%ongledeh mit diesem Wechsel der Affinität tritt das strömen der Fibrillensä̈me (zur Kathode hin und von der Anode fort) ein. In der Veränderung der Affinität und in der strömung (und zwar in deren Richtung, sehe ich den Anfang und einen Haupthestandteil des Elektrotonus. Gegen die Amahme der primären Affinitätsändermon wird man einwenden kïmen, daß sich wenigstens die Aufhebung der Affinitit im Präparat miißte hemerkbar machen. Ich habe gegen diesen Einwand nichts Positives zu erwidern mol kïnnte hörchstens mit der Ammahme kommen. daß die Entfernung der Teilchen anfangs so gering ist, dab die absterbende Fibrille (bei der Alkoholeinwirkung, die algespaltene säure noch wieder binden kann. Anch die Erklïmuy des Fïirbungsbildes an der Anode [frïheren Kathode] beim Weuden des stromes bereitet s'chwierigkeiten., Die gemachte Amnahme ist entschieden ein schwacher Punkt - das gebe ich ohne weiteres zu - man wird sie aber nicht mugehen kïnnen. An den sofortigen Eintritt der Fibrillensäurewandermg wird schon weniger auszusetzen sein, weil schon $1 / 2$. Minute nach Begrim der Durchströmung eine deutliche Verschiebung wahrzunehmen ist und das Tempo derselben mit der Daner der Durchströmung allmählich abnimmt, worans gefolgert werden kamm. daß sie beim Stromschluß am stairksten ist.

Fassen wir zunäichst einmal die Verhältnisse an der Anode ins Ange: Im Moment des Stromschlusses wird die Verbindung \%wischen Fibrille und Fibrillensäure nach unserer Ammahme gelorekert, und die Fibrillensäure strömt nach beiden seiten hin ron der Anode fort. Te näher ein Punkt der Anode liegrt, desto stärker wird die Iufheloung der Affinituit und desto enrößer die s'chnelligkeit sein, mit der sich die Teilchen bewegen. Damit stimmt iiberein, dath die Erreguarkeit in der Nähe der Anode am stärksten herabgesetzt ist und von da aus in extrapolarer Richtung sich immer mehr dep normalen Emenharkeit

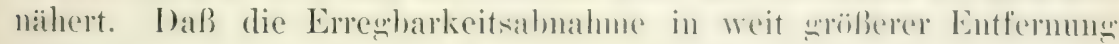
wahrnehmbar ist als die Veränderung der Affinität (im gefärbten

1) Ich bin mir wohl bewußt, daß es fiir eine derartige, graduelle Verinderung der Affinitait keine geniigenden Analogien giht. 
P'rij)arat, nimmt hei der seringen Empfindlichkeit meiner Methode, welche nur die gröberen Verïnderungen zeigt, nicht wunder. Wem hei der Erregung und Leitmm eine Werehselwirkmo \%wischen

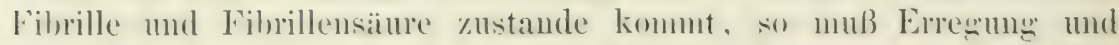
Laitung ummöglich sein, wenn die Fibrillensïure von den Fibrillen

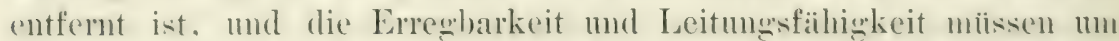

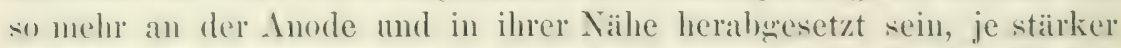
die Iffinitat zwischen Fibrille und Fibrillensiane herahesesetzt ist. Dies scheint der Fall zu sein.

In Moment des stromsehlusses tritt an del Kathode nach meiner Imalme, die durch das spätere Geschehen westiitzt wird, cine Verstäkung der Affinität zwischen Fibrille und Fibrillensäure und ein strömen der Fibrillensäure zur Kathode hin eim. Das zuströmende Material stammt num offenbar nicht nur aus der interpolaren, sondern anch aus derextrapolaren strecke. Dies kann nur auf die Weise zustande kommen, daB diejenigen Fibrillenteile, welche die stäkste Iffinität haben, ihrer Nachbarschaft Fibrillensiure entziehen und an sich binden. Diese Nachbarteile, die ebenfalls noch hohe Affinitait besitzen, entviehen wieder ihren Nachbarteilen von geringerer Affinität Fibrillensäure und so fort. Auf diese Weise werlen die Fibrillensäuremoleküle von Teilchen zu Teilchen weiterogeben und den stellen, welche von der Veränderum des elektrischen sitromes direkt nicht setroffen werden, und denen, welche nur schwach betroffen werden, entzogen. In der höheren Affinität der Kathodengegend nud in dem strömen von der extrapolaren strecke zur Kathode hin wird man die zwei Hauptfaktoren der erhöhten Erregharkeit sehen diufen. Beide Prozesse sind von Anfang an vorhanden; die westeigerte Iffinitait wird bleiben, aber das strömen wird mit der Daner der Durchströmung sehwächer und schwächer werden, weil eine sattigng der Fibrillen mit Fibrillensäiure an der Kathode eintritt, und weil es schließlich extrapolar an nenem Material fehlt. Hiernit stimmt ïberein, daß die Erreglorkeitssteigrerumg an der Kathode beim Stromschlul am stärksten ist und immer mehr abnimmt. Man kann sich vorstellen - und diese Vorstellung hat vielleicht ihre Vorteile -, daf die Fibrillen im nomalen

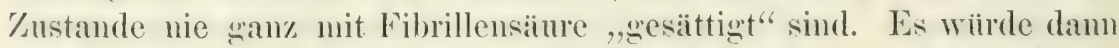
dic sesteigerte Affinitä der Kathode mur zu einer sättignn der freien "Valenzen" führen. Damit wïrle es gut zusammenstimmen, daß beim Öffuen des stromes kein Freiwerden von Fibrillensïure zur Be"harohtuns kommt (die Kathode wird nach ïfnen des stromes noch sunkel trefunden). Cubedingent muB man ammehmen, daß die ,Fibrillen norls zu leiten instande sind, wemn sie unter der Norm mit Fibrillen-

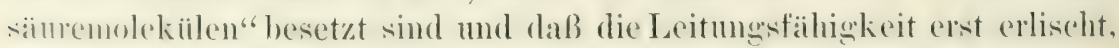

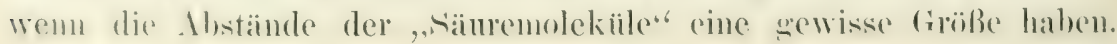


Außer dem Anfhören der Strömung komme aber noch ein andrer

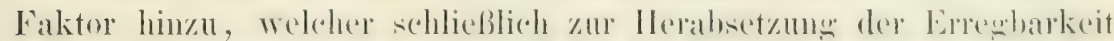

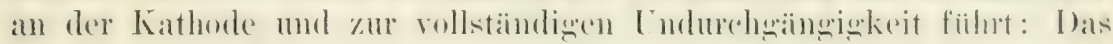

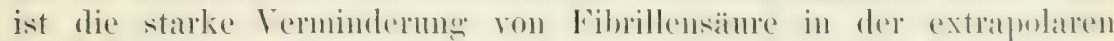

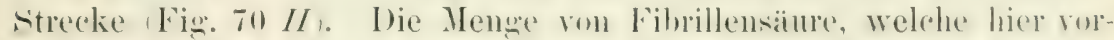

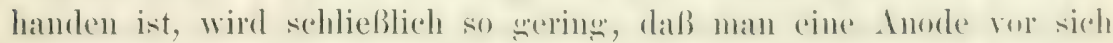
zu haben meinen kömnte; der Lutersehied zwischen einer soldhen stelle und einer wirklichen Anode besteht aber darin, dak an derselben keine freie Fibrillensiume vorhanden ist Fie. $74 /$. Diese Herabsetzumg der Erregharkeit an der Kathode mit darauf folgender vollkommener Lndurcheänowkeit findet bei allen bisherigen Nerventheorien keine senügende Erklärune, während sie dureh das Fehlen von Fibrillonsäure jenseits der Kathode leicht verstandlich wird. - I)ie dureh die Wanderung der Fibrillensiare sekundär zustande kommenden Veräuderungen führen also an der Anole zu einer immer weiterocehenden Herabsetzun

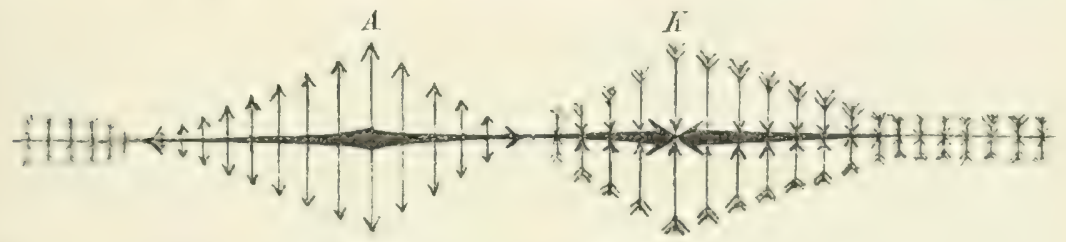

Fig. 79. Schematische Darstellung der vermutlichen Beziehungen zwischen Fibrille und Fibrillensiure wihrend der Polarisation. Die Abscisse bedeutet eine Fibrille. Die Ordinaten bedeuten die Stärke der Affinität zwischen Fibrille und Fibrillensäure und zwar je nach der Richtung der an ihnen angebrachten Pfeile, positive oder negative Affinitit. Die Richtung und Dicke der Pfeile auf der Abscisse bedeuten die Richtung und die Geschwindigkeit, mit welcher sich die Fibrillen-

siiure beregt. A. Anode, $K$. Kathode. Rechts und links ein Stïck normaler Nervenstrecke.

der Erregharkeit Terstäkmog der primären physiolocischen Ver-

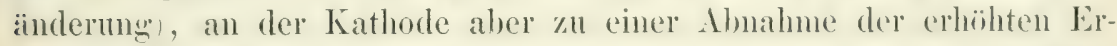
regharkeit also zur Absehwächume der prinären physiologischen Veräinderung').

In Fign 7 s sind die strömungs- nud Affinitaitsrerhältnisse dureh I'feile darsestellt, wobei die horizontal verlanfenden I'foile die Rirohtungr mur stärke des Fibrillensïurestroms andenten, die senkrecht aul die IIorizontale stolienden P’feile die erhöhte . Iffinitït mol die senk-

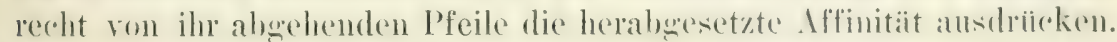
An der Hand dieses Schemas und unter der Voranssetzung, daß wir es immer mit sog. starken strömen dritter Fall des Zuckumessonetzest

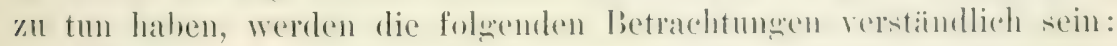

Wenn die Anode dem Erfolgsorgan zugewandt ist, so tritt beim

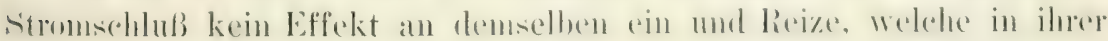
Nähe angesetzt werden, haben keine oder herabgesetzte Wirkung.

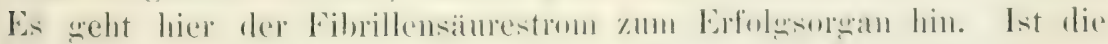

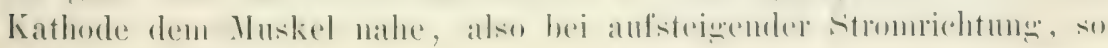


tritt ein Effokt hei stommschlub ein und die extrapolane sitrecke zeint (rhoihte Erregharkeit. Da hier der Fibrillensämestrom rom Erfoles-

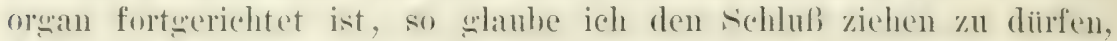

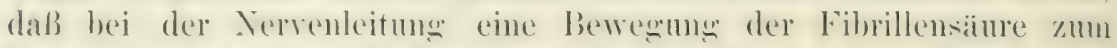

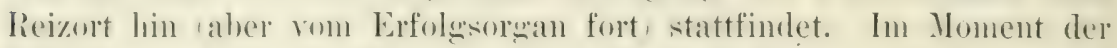

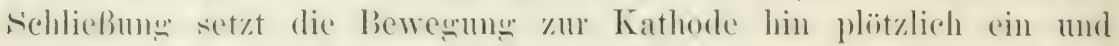
bewirkt eine Reizwelle. (Fiir die Auffassung, daß nicht nur die Iffinitätserhöhmme, sondern in der Hanptsache die Bewesmm der Fibrillensiane zum Reizort hin die Reizmug hervorruft, nehme ich anch die 'Tatsache in Anspruch, dab der Nerv hei reiner (Quedurehströmmnz"

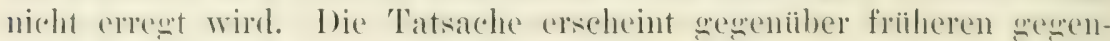

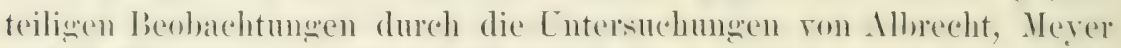

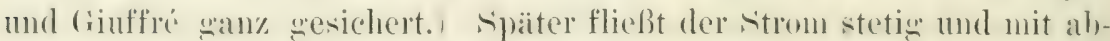
nehnender Kraft; daher hringt er keine weitere Reizung hervor. Bei manchen Tieren wirkt mun der konstante strom danernd erresend 1.Morhel, Krebs [liedermann, 1s56], und anch bei den 'Tieren, wo somst nul Öffnmms- und schließunwsuckung zu beobachten ist, tritt untel sewissen Bedingungen, hanptsäichlich nach läingerer Kälte-

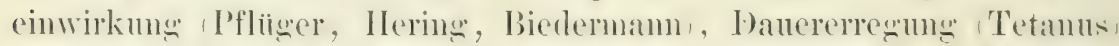
ein. Hiel ist mach meiner Vorstellumg die bewegnem der Fibrillensäure keine sheichnabise, sondern wewissermaßen eine ruckweise, indem die Beweghlohkeit der Fibrillensäme behmolert ist. Letzteres läßt sich auch tatsächlich bei Kälteeinwirkung nachweisen (S. 291).

Dort, wo ein kontinuierliches Fließen der Fibrillensäure zur Kathorle hin stattfindet, besteht natiolich eine Dispositim zur leichteren

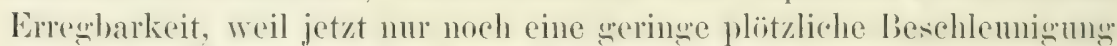

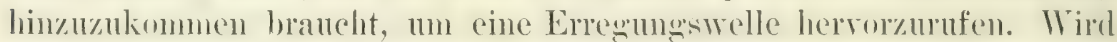

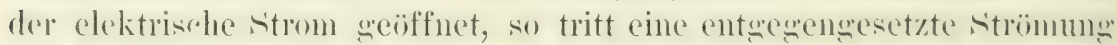
der Fibrillensiune ein, wie sioh dies ja anch hat nachweisen lassen. Diese Strömung geht zuerst schnell und nimmt immer mehr an Intensitit ab, so daB an der Kathode noch lange eine erhöhte Färbbarkeit zu komstationen ist. In diesel entwerenenesetzten strömung wird man

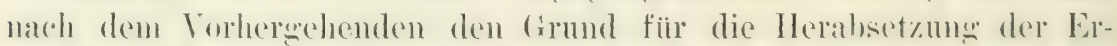

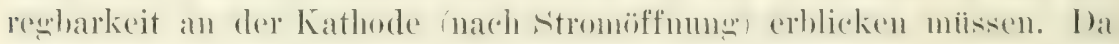

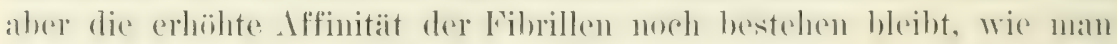

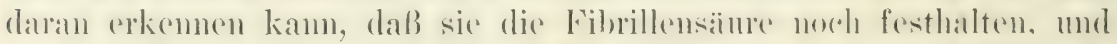

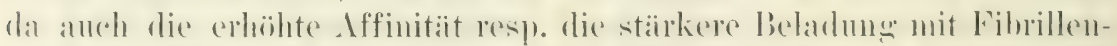

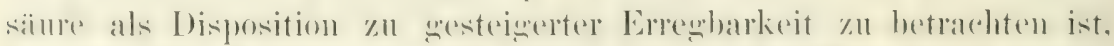

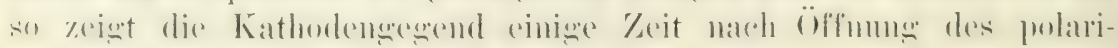
sicrenden Stromes w i eder erhöhte Erregbarkeit: Del Gegenstrom

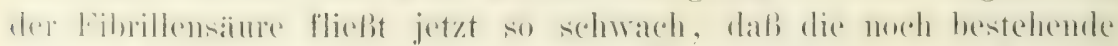

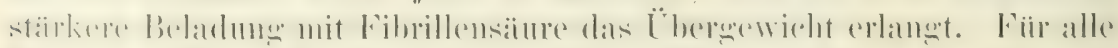

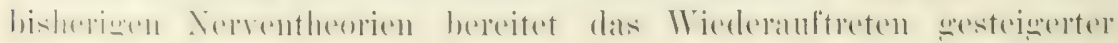


Errenbarkeit an der Kathode ein uniberwindliches Hindernis, während es sich hier olme weiteres direkt ans den Befunden von selbst erklärt.

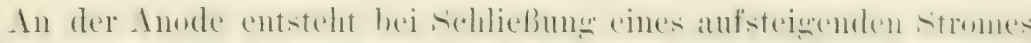

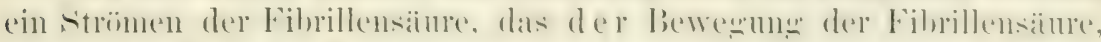

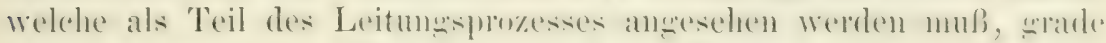

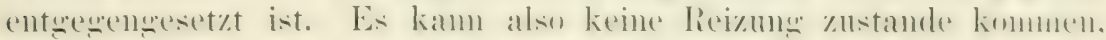

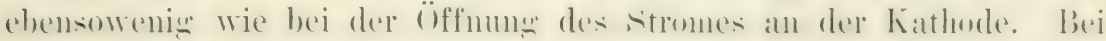
der Öffnung des Stromes findet aber an der Anode, wie sich dies zeigen lielh, ein Zuriekstrimen der Fibrillensiture zur Anede hin statt.

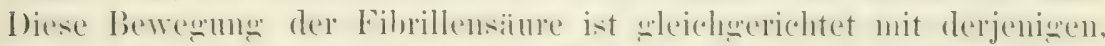
welche beim stromschlub an der Kathode bei absteigendem stom eintritt, sie muß also denselben Effekt haben wie dort d. h. zu einer

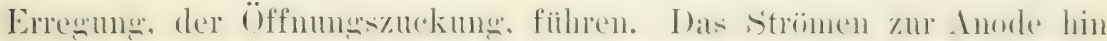

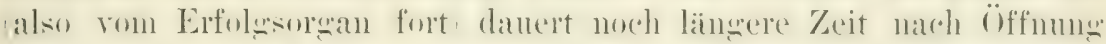
des Stromes an. Man wird also in ihm den Grund für die gesteigerte

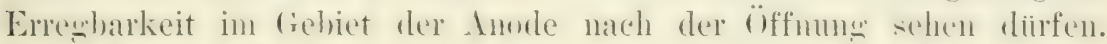
Da sich beim Zuriickströmen kein neues Minimum hilden kamn. sn

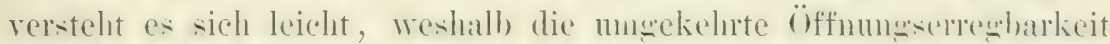
der Anode langsan in momale Errewharkeit iblereht, whe, wie es an der Kathede der Fall ist, noch eimmal ins fegenteil unzulschlasen.

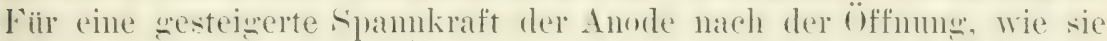
bei den meisten Verventhemien antenommen wird, wibt es in meinen

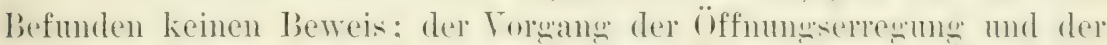

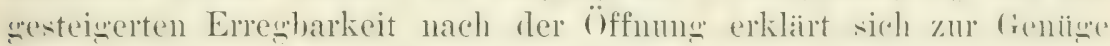
darans, daß die mit ihrer normalen Affinität behafteten Fibrillen

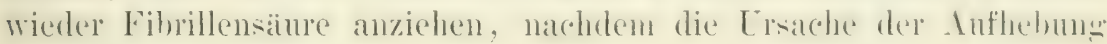
der Affinität geschwunden ist. -

Wir haben gesehen, dab sich hei schwachen strïnen viel leichter eine Ansanmulung von Fibrillensäure an der Kathode zeigt, als wine

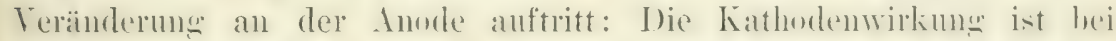
schwachen Strömen stärker. Hieraus erklärt es sich nach meiner

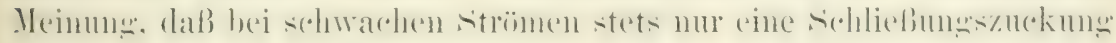
zustande kommt. - Bei sehwachen, mittelstarken Strömen muß man

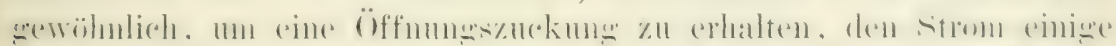

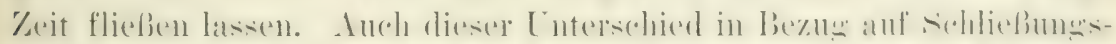

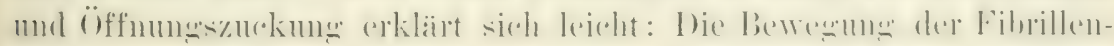
säme zul Kathode hin tritt auf jeden Fall sofort ein; damit die

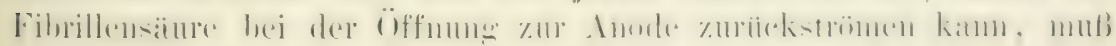
aber erst eine gewisse Menge von Fibrillensiure von der Anode fort-

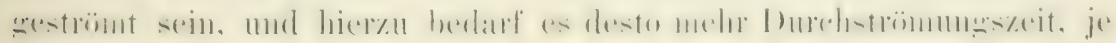
schwäicher der Strom ist.

Ist ein Strom längere Zeit geschlossen gewesen, so tritt beim Öffnen desselben besonders leicht, wenn er aufsteigend war (Rosen- 


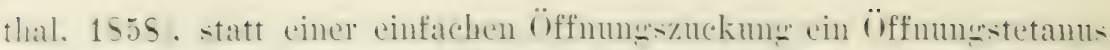

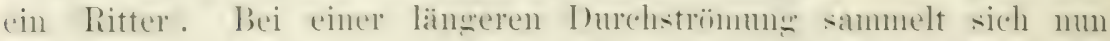

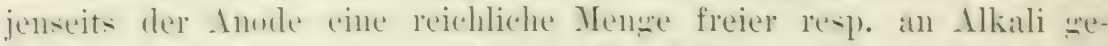
hundener Fihrillensilme an. Bei der stromöffnung kïmen die wieder

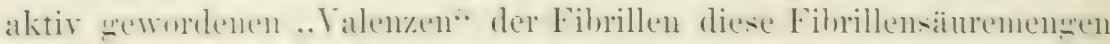
direkt in ren zur Anole hingerichteten Fihrillensïnestron hineinziehen mul hranchen die Fibrillensibure nicht erst weiter entfernten Teilen zu

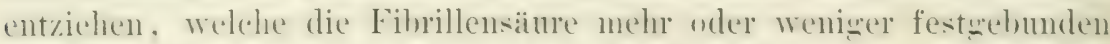

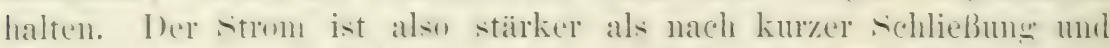
walırolueinlich auch disknntinuierlich. weil die freie Fibrillensäture den Fibrillen nicht direkt anlient. Jedenfalls sind die Bedingmenen an dex

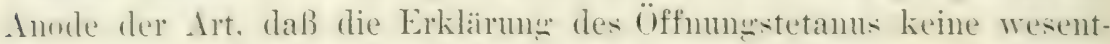
lichen sohwieripkiten hereitet. - Engelmann führt den öffnumsmul sichliedungstetanus auf latente Reize zurïck, welche nur bei "rhöhter Reizbarkeit wirksan wïrlen. Diese Erklärung kamn natiu-

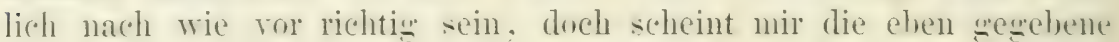
plausibler, weil man hier etwas Greifbares vor sich hat, während man sich nuter einem latenten Reiz vorläufing nichts Bestimmtes rorstellen kamn. Ist ein (iffumbstetanus ansgeblochen, so kamn der-

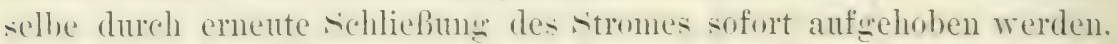

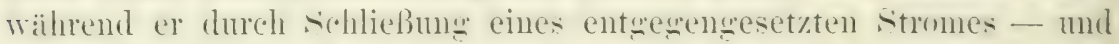
dieser hrancht nicht stark zu sein - verstäkt wirel Rosenthal, 15.,s.

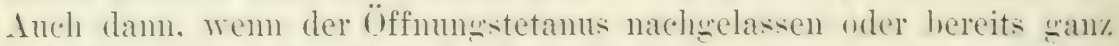

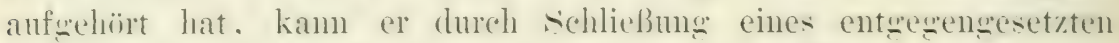
strones wieder anefofacht werden Posenthal. I'flïger und andre. Leide Befunde finden leicht eine befriedigende Erklärung: Bei ernenter

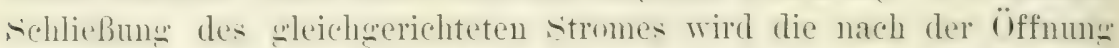
cingetretene normale. Iffinitat wieder aufweholen: bei schließum des contwenenesetzten stromes wird die Affinitait der Fibrillen erlöht. und

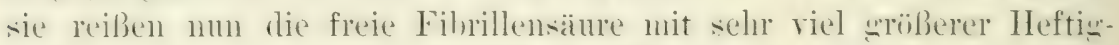
keit an sich, wodurch natiirlich der Tetanus rerstärkt resp. wieder' hervorerufen wird. falls nämlich die strönumg schon zu lang-ann wing. In derselben Weise erklaint sich die Toltasche Alternative.

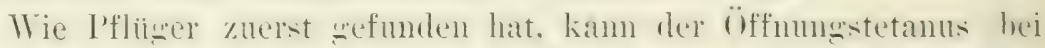

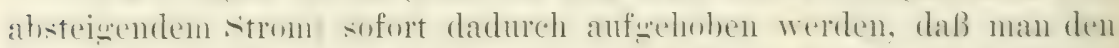

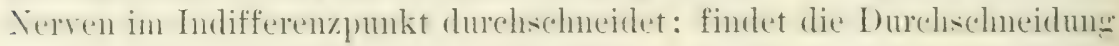
zwischen dem Indifferenzpunkt und der Anode statt, so geht der Öfnungstetanus ruhig und zwar unsermindert weiter. Ich glanbe nun, daß der Reiz hierbei gar nicht von der eigentlichen Anode aus-

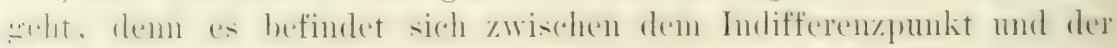

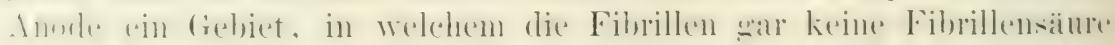
zur T'erfigung haben, also anch nicht den ron der Anode ausschenden Reiz zum Muskel hinleiten kömnen. Nachdem nämlich 


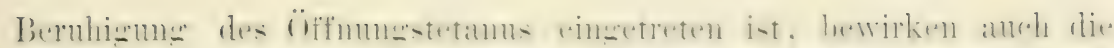
stairksten zentral ron der Anode angesetzten Reize noch durch längere Zeit hindurch keinen Effekt am Muskel. Es ist vichmehr anzunelımen, daß der Öffunngstetanus nach absteigender Dureh-

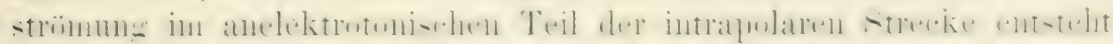
und zwar in der Nähe des Indifferenzpunktes. Hier findet sich wie

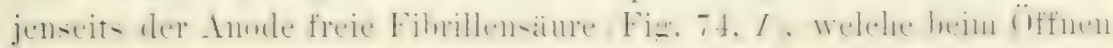
des Stromes ron den Fibrillen angerissen wird, so daß nun eine Fibrillensätureströmung zur Anode hin (also rom Muskel fort) ent-

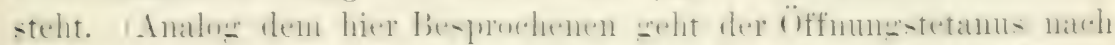

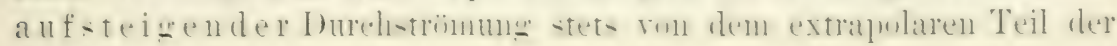
Anode aus.

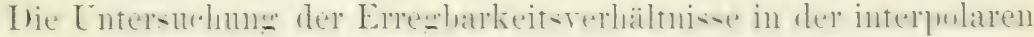
Strecke hat Pflïger Schwierigkeiten bereitet. Sicher hat er (bei chemischer Reizung nur feststellen können, daß in der Tählie der

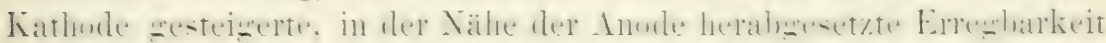

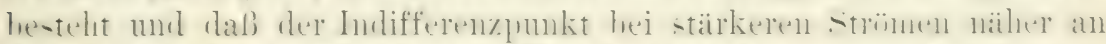

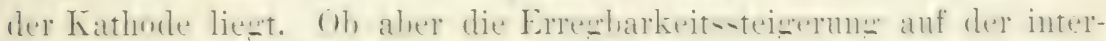
polaren und extrapolaren Seite der Kathode gleich groß ist, hat er

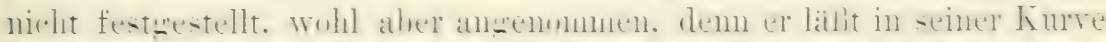

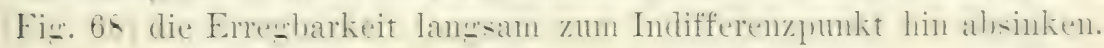

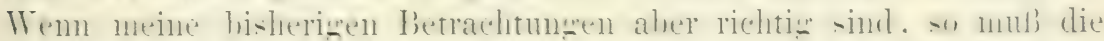

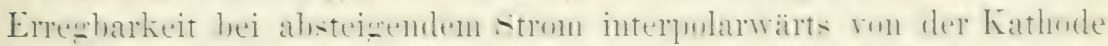

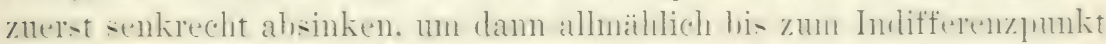
auf die normale Erregrbarkeit zu sinken. Der Grund hierfür liegt darin, daß in dem interpolaren Teil der kathodischen Strecke die

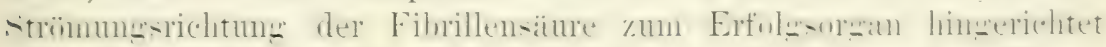

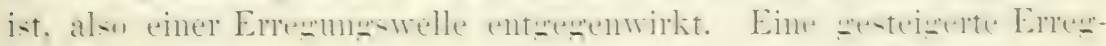
barkeit kamn hier trotzdem rorhanden sein, sie beruht dam aber nur noch auf der erhöhten Affinität. Tegen der Terschiedenheit der

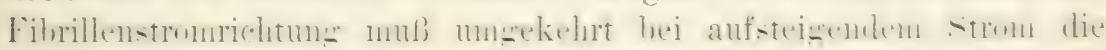

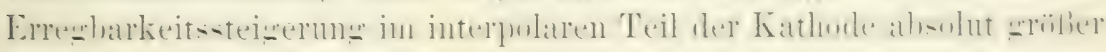
sein als im extrapolaren.

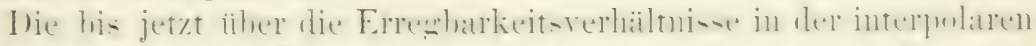

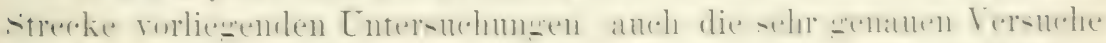
von Tigerstedt, 1582) geben auf diese Frage keinen Bescheid, weil eine quantitatire Vergleichung der interpolaren und extrapolaren Katloden- und Anodenstrecke nie vorgenommen wurde. Die Frage bleibt also zunächst offen.

Die Lnerregbarkeit hochgradig narkotisierter Nerven wird bereits znr Genige dadurch erklärt, daß die Fibrillensäure nicht mehr wanderungsfähio ist. Die Tatsache, daß bei etwas schwächerer Narkose nur noch an der Anode, nicht aber an der liathode eine Ver- 


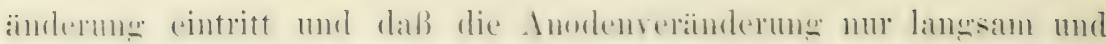

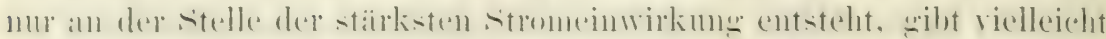

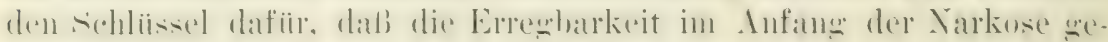

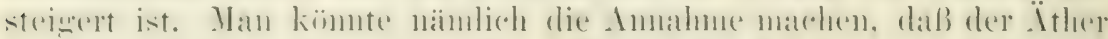

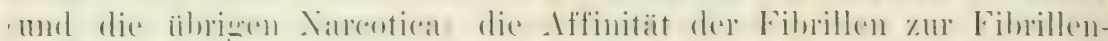
siiure erhöht. Gesichert ist ja nur, daß die Beweglichkeit der

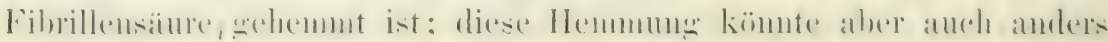

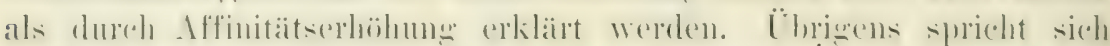
anclı Werlenski (1900) auf Grund merkwiirdiger Befunde bei An-

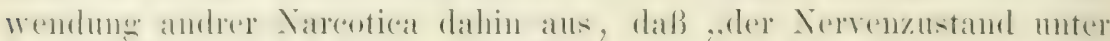

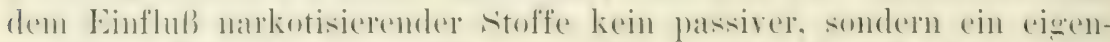

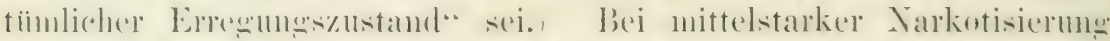

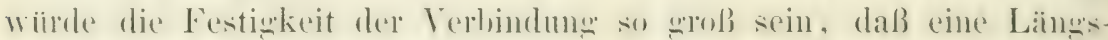

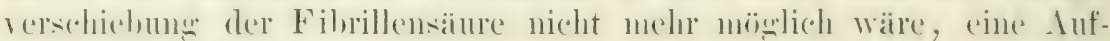
hebung der Verbindung aber grade noch an der Anode zustande

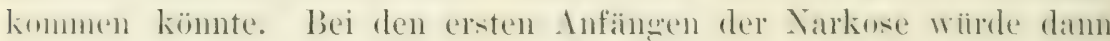
nur eine schwache Erhöhung der Affinitait bestehen, welche etwa

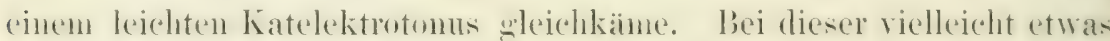

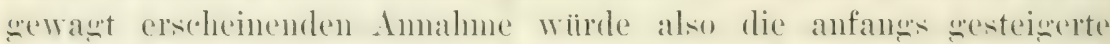

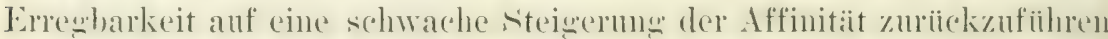
sein. Da letztere aber bald zunimmt, so wird es rerstandlich, daf nach einiger Zeit zwar immer noch Reizharkeit am muskularen Ende der Itherstrecke rorhanden ist, dab sich aber die Rerizwelle durch rine lanese strecke crhöhter Affinitat nicht nehr hindurcharbeiten kamn, wie dies Dendrinos enefunden hat. Dariber kam ja kein Zweifel

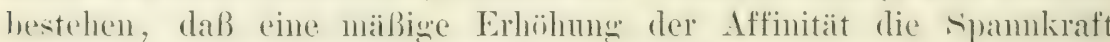
steigern, eine starke Erhöhung aber einen wesentlichen mol schlieblich unïherwindharen Widerstand hervorbringen muB. Hiernit witrde es g'ut iibereinstimmen, daß, wie Bortuttau (1897) nachwies, sich

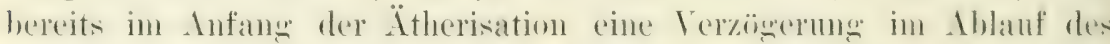
Aktomsstroms nachweisen läßt nud das el später wanz ansbleibt. In dersellyen Weise wïrde sich anch die Erresharkeitsiteigerung hei Wasserentziehung (Engelmann) erkläien lassen.

Wenn wir bei der Narkose einen 'T'eil der katelektrotonischen

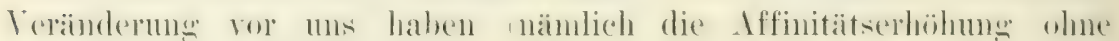
Strömung der librillensäture), so mïssen wir in der Wirkung des destillierten Wasters auf den Nerren einen Teil der anclektrotoniselesu

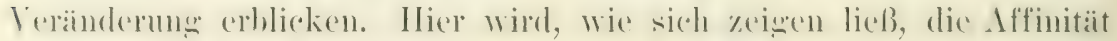

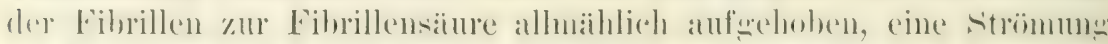
der Fibrillensäne findet dabei aber nicht statt: sio bleiht vielmehr so

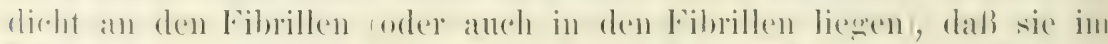

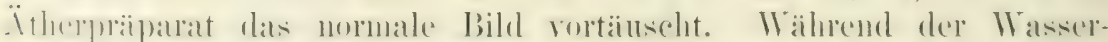

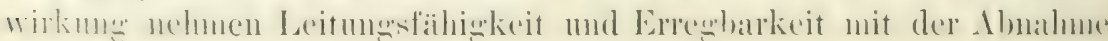


der Affinitait danernd ab, olme daß sich dazwischen anch nur die leiseste Andentung von Erreglarkeitssteigerung zeigt.

Ansgehend von der Idee, daß die Herabsetzmg der Lrregharkeit in der Nahe der Anode anch eine Verlangsamung der Nervenleitung

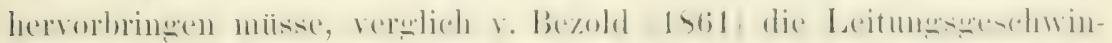

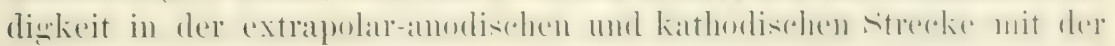
einer normalen Nerrenstrecke und kam dabei zu dem Resultat, daß

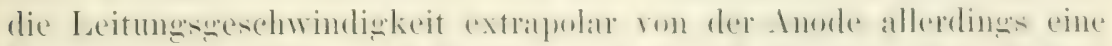

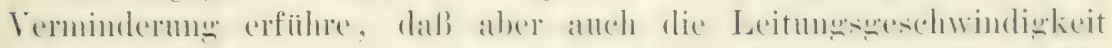

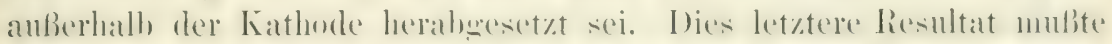

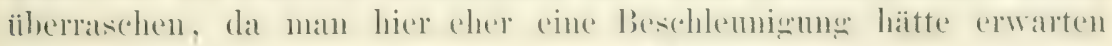
sollen. Dezold benutzte num hei diesen Lntersuchumeren relatis selor

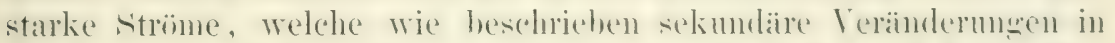

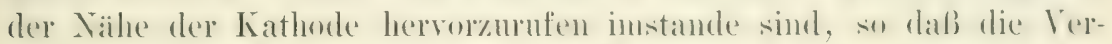

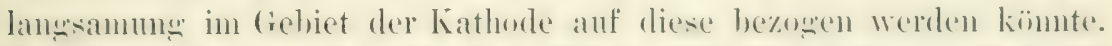

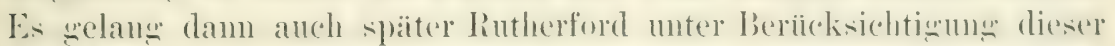

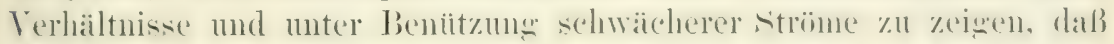

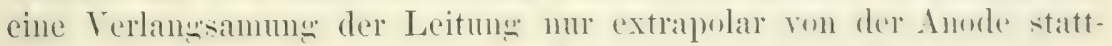

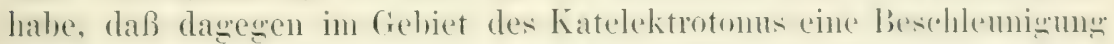
der Leitung zur Beobachtung gelange. Wenn wir ms rergegenwïrtigen, dab zwischen Anode und Muskel eine strïmung der Fibrillensäure zum Muskel hin stattfindet, also eine Bewegung, welche der der Leitung enterengesetzt ist, so kamn man als frumd der Verlang-

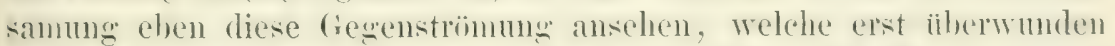
werden nuß, mol man kamn sich denken, daß der Fibrillensämestrom

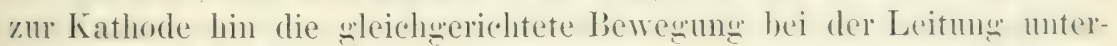
stiitzt und beschlennigt.

Ich komme nun zux Besprechung der elektromotorischen Elscheinmeren an Nerven. Dn linis-liermond enteleckte den Nerven-

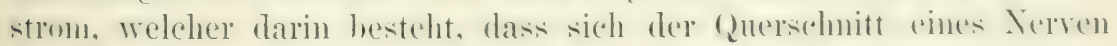

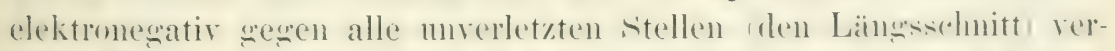

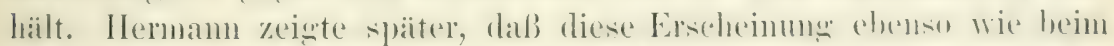

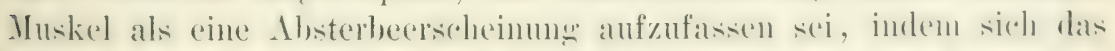

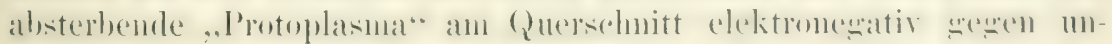

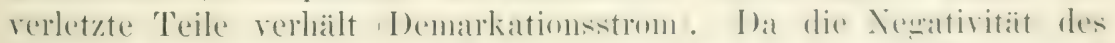

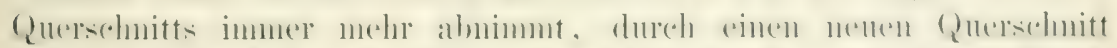

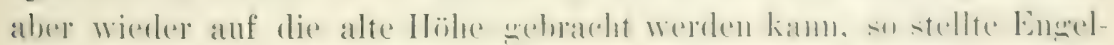

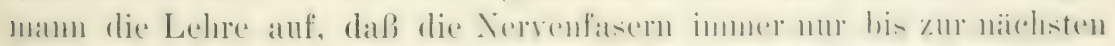

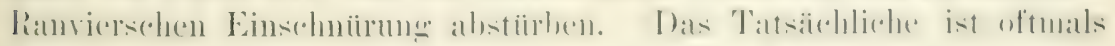
besonders von Head bestätigt.) Da sich aber Nerven, welche keine

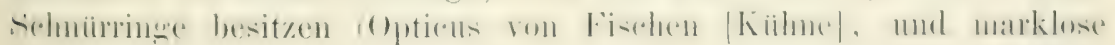
Nerven [Biedermamn]) ihlnlich verhalten, so liegt doch, wie Bieder- 


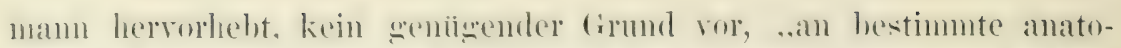

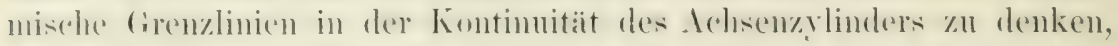

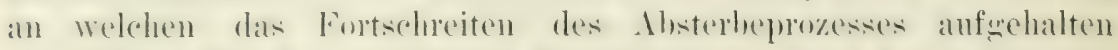

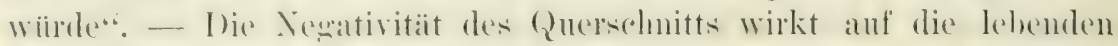
Nachbateile ein mol rersetzt sie in Katelektrotomus, so dab ein Nerv in der Nähe der Querschnittsstelle immer erregloarer ist, als im weiteren Verlanf (Hermann).

Da der Absterbeprozeß sehr langsam geht und voraussichtlich immer nur an enghegrenzter Stelle rorhanden ist, so kann er direkt nicht mit meiner Methode untersucht werden. Was ich untersuchen kann, ist nur das Resultat des Absterbens, das Abgestorbene. Es zeignt sich, dab die Fibrillensiane nach dem Alsterben an die Fibrillen sehumblen ist so lange nieht sekmudäle Prozesse eintretent und dureh den knnstanten strom nicht mehr zur Wranderunge webaraht werden katmo: rein mechanisch geedacht ist also die Iffinität zwischen dee toten Fibrille nud der Fibrillensïure stäker als normal. Es tritt also beim Lbsterben ein Zustand ein, der dem bei der Narkose ähnlich ist. Trenn hierin zwar noch keine Erklärung der Negativitait hein Dhsterben liegt, so kamn man doch eine gewisse Parallele erkennen. Die einfachste Inentung scheint mir num folgende: Die normale Fibrille hesteht nicht nul an Fibrillensubstanz und Fibrillensäure, sondern es hefinden sich in diesem Komplex, wie in jeder eiweibartigen Materie

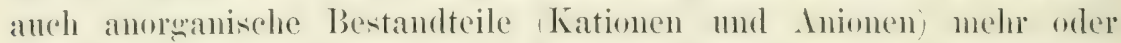

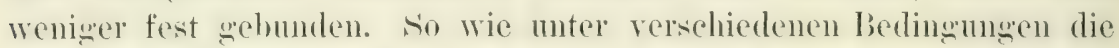
Beziehmegen zwischen Fibrille und Fibrillensäme in verschiedener Richtung beeinfluBt werlen kömnen, so kann auch eine verseliedene Beeinflusing der Kationen und Anionen, welohe in den Komplex mit aufgenommen sind, angenommen werden. Man könnte sich z. B. denken, dals mit einer Verstärkmg der Iffinitait katelektrotonischer rastand, eine Ibscheidung von eletronegativen Ionen talso Inionen, nit der Vermindermon der Iffinitat rzwischen Fibrille und Fibrillensaitue, anelektrotonischer Zustand) eine Ibscheidung elektropositiver Ionen , Kationen IIand in IIand ginge. Hierdureh kimen Konzentrationsdifferenzen im Sinne von Oker-Blom (1901) zustande, welehe nach ihm als Grund der clektromotorisehen Veränderungen angesehen werolen miissen. Wenn also beim Absterben eine Verstirkmng der Affinitit zwischen Fibrille und Fibrillensäme entsteht, so wiiblen die dabei frei-

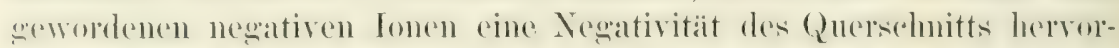

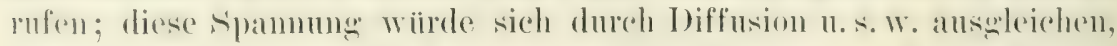
liverhöhte Affinitiat winde aber bestehen bleiben, weil die Fibrille nirht melur restitutorischer l'rozesse fähig ist, und sie mulh sich daher,

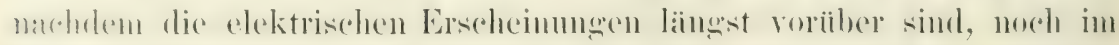

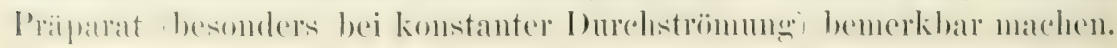




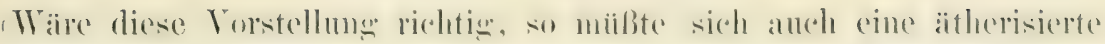

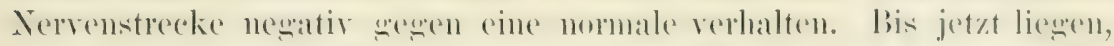
so viel mir bekannt, keine diesbezïglichen Untersuchumgen vor. Die

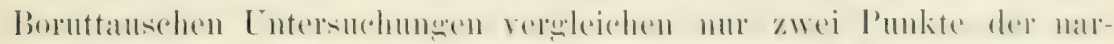

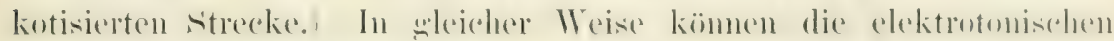
Ströne eine Erklairung finden.

1543 beschrieb du Bois, daß der Ruhestrom des Nerven bei weitentfernter tetanischer Reizung ahmimnt, nul seitdem ist diese

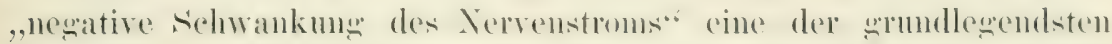
Tatsachen der Physiologie, weil sie anber dem natiirlichen Erfolon eines Nervenreizes bisher das einzige Mittel geblieben ist, iiber die Leitungsvorgainge im Nerven etwas zu erfahren. Bernstein (1871) lehrte dureh seine Rheotomversuche die Form der negativen sichman-

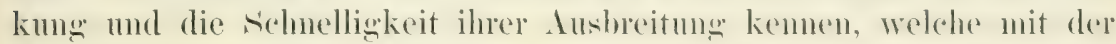

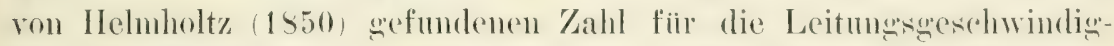
keit des Nerven nahezu ïbereinstimmt. Später gelang es Hermamn (1878, 1881) zul zeigen, daß die negative Schwankung (wie beim Muskel) nur eine 'T'eilerscheinung ist. Jede erregte (im Augenblick leitende) Tervenstelle verhält sich zu einer unerescten nicht in Leitung begriffenen elektronegativ. Bei Ableitum ron zwei Länssischnittpunkten wird daher der der Reizstelle zunäthst gelegene zuerst nesativ, weiterhin der andre. Da anf diese Weise zwei entgegengesetzte ströme hei einfacher Länesschnittsableitung und tetanischer Reizmum zum Galvanometer gelangen, so heben sie sich auf und bringen keinen Ansschlag der Nadel hervol. I Lm die Existenz zweiphasischer Alitinsströme nachweisen zu kömen, benutze Ifermann die Rheotommethode und rerlangsante die Leitume durch Kältecinwirkmen. Wird abed

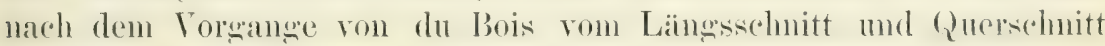
abyeleitet, so gelangt die Erregung nicht his zur zweiten Elektrolle, weil der Nerv hier abgestorben oder sterbend ist. Es wird bei jedem Reiz immer nur die Lämssohnittselektrode negativ beeinflubt, so dak sich die Wirkmong der tetanischen Reizmon summieren mul anf die Magnetnadel wirken kömnen. Auf diese Weise kommt bei der negativen śchwankung nur die erste Phase der zoreiphasischen Mktionsströne zom Ausdruck, allerdings reiner als bei den zweiphasischen, weil bei diesen die zweite Phase bereits beginnt, wenn del aufsteigende 'Teil der ersten noch nicht beendet ist. (In Figur 80 ist

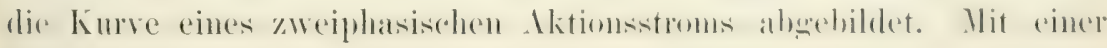
dimnen Linie ist gezeichnet, wie die Phasen eigentlich aussehen wiirden, wenn sie sich nicht störten. Kömnte man die Mbleitungselektroden gentigend weit anseinanderricken, so wiirde man beide P'hasen in voller Ausdehnumg und in ammähernd richtiger Form darstellen kömnen; doch wird dies durch äubere Faktoren verhindert.) 
Die Negativitait einer erregten d. h. leitenden Stelle tritt also

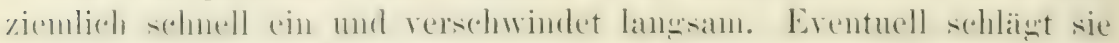
ins Gegenteil um, doch wïrde dies bei Ableitung ron zwei Längs-

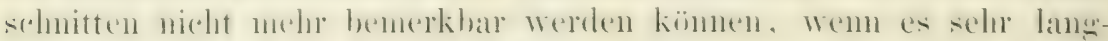

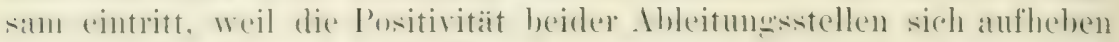

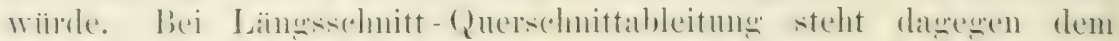

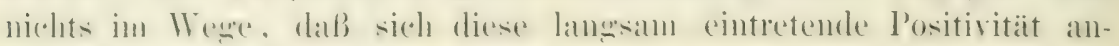
zeig- indem sich die Quersehnittelektrode nicht an dem Vorwang heteiligen wiirde. In der Tat hat auch Hering (1884) und nach ihm

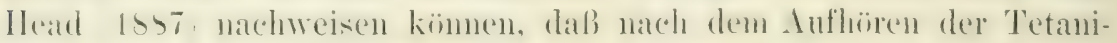
sation eine positive Nachsehwankung eintreten kann.

Un zu zeigen, daß es sich bei der negativen Schwankung (resp).

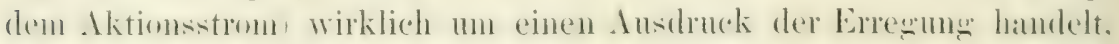
hat bereits du bois sich beniöht, den soleichen Vorwang nit andern

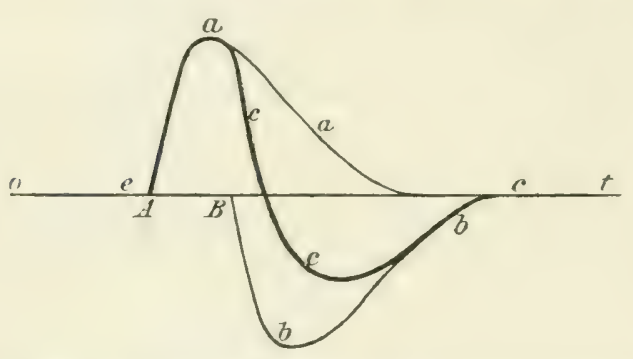

Fig. 80, Zweiphasischer Aktionsstrom nach Hermann aus

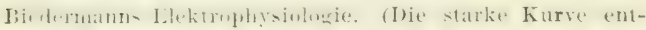

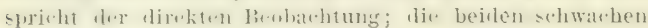
Kurven bedeuten die Konstruktionen jeder einzelnen Phase.)
Reizen als elektrischen hervorzurufen. Es ist ihm das nur in sehr bescheidenem Maße gelungen. In nenerer Zeit ist es aber Griitzner (1881) bei chemischer Reizung, Steinach (1894) bei mechanischer Reizung (an Kaltfröschen) gelungen. Besonders bemerkenswert sind die von Boruttan 1901. 1902) mit Hilfe des Kapillarelektrometer's bei me(hanischer Reiznne und im strychnintetanns gewomnenen Kurren.

Man sollte demnach kaum einen Zweifel hegen können, daß die Aktimsströne Hermanns, negative schwankung du Bois", Reizwelle lonsteins, Negativitätwelle Borntans, in einem imnisen Znsanmenhang mit dem Leitungsprozeß stehen. Trotzdem ist wiederholt besonders in letzter Zeit rersucht worken, die Alitomströne als etwats mele oder wenimer vom Leitunsworwang Lnablängiges hinzustellen: Her\%en (1899) packte einen Teil des Nerven zwischen Chloralosepulver und reizte ab und zu diese Stelle und eine zentral daron

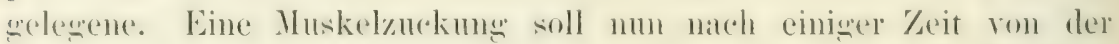
Chloralosestrecke nicht mehr zu erzielen sein, wälnend der Reiz von der zentral gelegenen lieizstelle aus die affizierte stelle noch

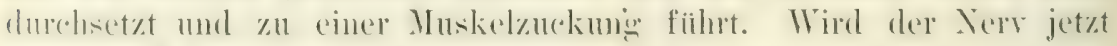

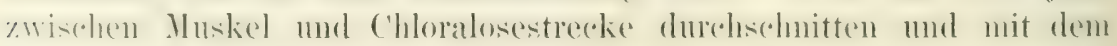
Galvanometer verbunden, so soll bei Reiz der Chloralosestrecke

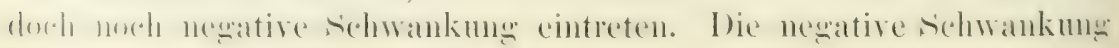


soll also bestehen bleiben, nachdem die Erreglorkeit bereits anfgrehört liat.

Wedenski (1900) und Boruttau (1902) haben diesen Versuch nachgeprift und sind zu dem Resultat gekommen, daß das Herzensche

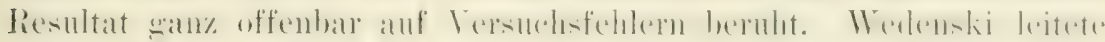

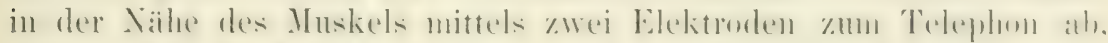

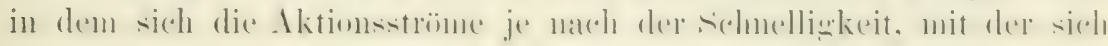
die Reize folgen, in einem höheren oder tieferen Ton kund geben.

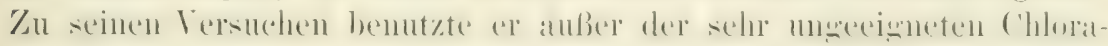
lose eine sanze Anzahl andrer Narcotica und kam dabei zu dem

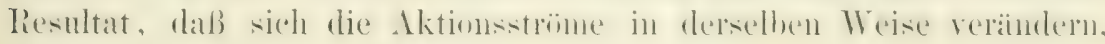
als der Reizerfolg an Muskel geringer wirt.

Auf die ron Gotsch und Burch (1899) gegen die Notwendigkeit

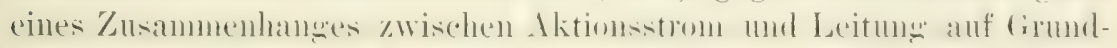

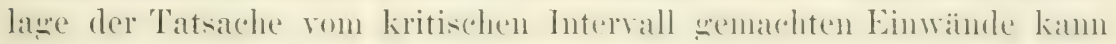
ich hier nicht weiter eingehen, doch scheint es mir, daß sie durch die Nachuntersuchung ron Boruttau (1902) als beseitigt zu betrachten sind.

Es liegt also kein Grund dafür vor, den Aktionsstrom vom Leitungsrorgang zu tremnen, rielmehr muß derselbe als eine 'T'eil-

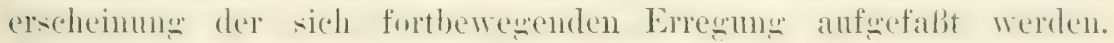
Wie ich nun ohen beschriehen habe, zeigen die Achsengylinder eines Terven, welcher während der lieizung nit sehr sohnell sich folsendron IVechselströnen fixient ist, Ïhnlichkeit nit der Katholengenend eines

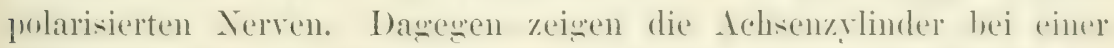

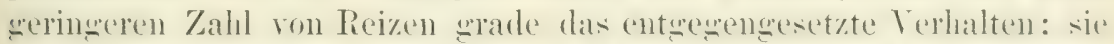

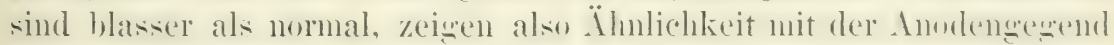
eines polarisierten Nerven. - Nun pflanzt sich nach den Linter-

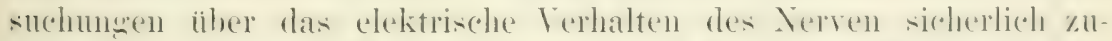
nächst rine negative Welle hei der Leitnug dureh den Verven fort. dil diese aber von kurzer Dauer ist, so kann die mit ihr erentuell Hand

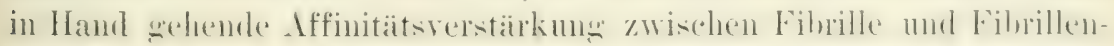

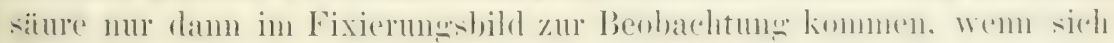
die Reize und somit die negativen Wellen sehr schmell folgen. Ich

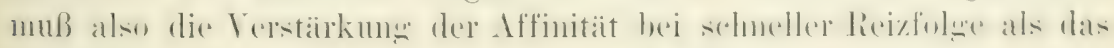
eigentliche Bild des erregten sive leitenden Zustandes ansehen.

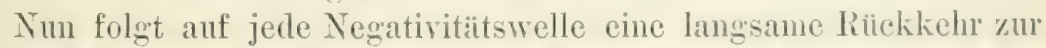

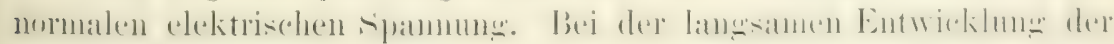
restitutorisehen Phase ist es, wie oben angedentet, sehr gut möglich, daß sie in eine wirkliche Positivität umschlägt, die aber wegen des

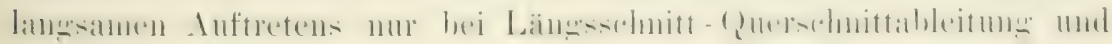
erst nach Auflören der Reizung zur Beobachtung kommt. Je weiter (in gewissen Grenzen) die Reize ansemanderliegen, desto besser wird 
sich diese Phase entwickeln kömnen, desto mehr wird ihre eventwelle Grundlage im Präparat erkembar sein. Ich sehe also in der

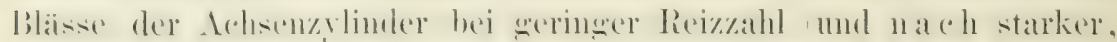

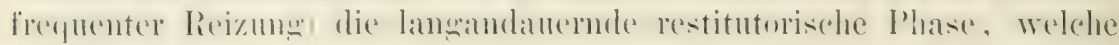

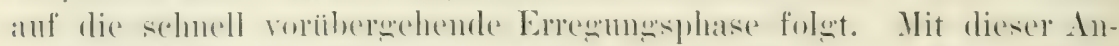

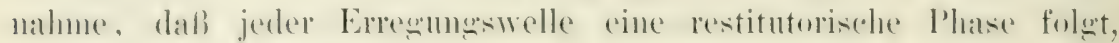
bei weleher jede Nervenstelle in einen anodischen Zustand gerëit,

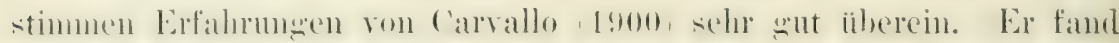

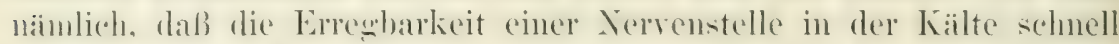
abnimmt, beim Erwämmen aber wiederkehrt, und daß warme Verven

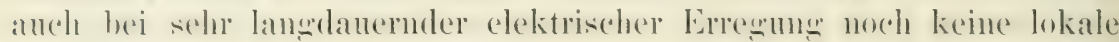
,Ermidnug' zeigen. Wie ich num oben gezeigt habe, wird beim

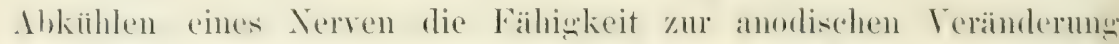
stark gehemmt, bein Erwämen gesteigert. Der Kaltnerv wird also sehr viel meln Zeit gebrauchen, um sich ron jeder cinzelnen Reizwelle in der restitutorischen Phase zu erholen, als der Warmmerv.

Als Anfangsstörtmg habe ich eine Verstäkung der Iffinitait am Reizort verbunden mit einer Verschiebung von Fibrillensäure zum Reizort hin auf Girundlage der Verhailtnisse an der Kathode bei der Schließung') und an der Anode (bei der Öffnumg') angesprochen. ${ }^{1}$ ) Wemn nun mit der Verstäkung der Affinitä ein Freiwerden von elektronesativen Ionen Iand in Hand weht, so entstehen vitrönchen, welche an der eresenten stelle in die Fibrillen eintreten, in den Nachbar-

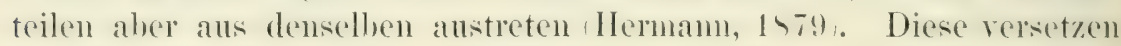
also die ruhende Nachbarschaft in Katelektrotonus nud bringen hiel wieder Affinitätserhöhumg hervor, welehe nit lokaler Lbgabe von negativen Ionen verbunden ist. In dieser Weise könnte man sich ein Fortschreiten der Erregung nach dem Vorgange von Hermamn vorstellen. Neu ist dabei nur, daß als primäre Verinderung die Affinitätserhöhnmg angesehen wird und dals an stelle der Polarisation zwischen Kern und Inille eine alleinise Terandermes der Fibrille enestzt wird, eine Veränderuns, hei der die Hiille die Perifilorillailsubstanz oder was sonst grade die Fibrille umgibt) nur eine ganz sckmoläre liolle spielt. Inch bei dieser Vorstellung wiirle sich die Nesativitatswelle in derselben Weise ansbreiten und änBern, wie im Kernleitermodell, wenngleich die Ursache nicht in eine einfache

1) Eine Zunahme der Affinität läßt sich anch bei mechanischer mol chemischer lieizung gut denken. Ich will zugeben, daß eine "lokale Konzentrationsänderung ron Ionen" die Anfangsstörung bei allen möglichen Reizarten leichter erkliirt, doch kann ich Boruttau (1902) nicht zugeben, dał dies die einzige Möglichkeit ist. Im Grunde habe ich aber auch nichts dagegen einzuwenden, daß man als Anfangsstörung immer eine Konzentrationsïnderung ansieht. Es kommt dabei anf das gleiehe hinaus. 


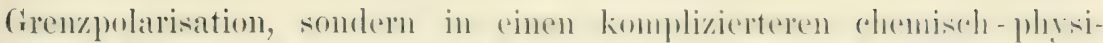
kalischen Prozeß verlegt wiirde, zu dem bis jetzt kein Analogon ron

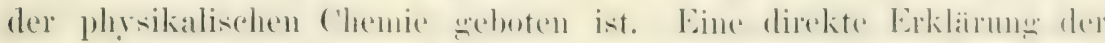
nemen Befunde anf Grund der hisherimen rein physikalischen Kermleitertheorie, wie sie von Hermann und Boruttan ausgebildet ist, scheint

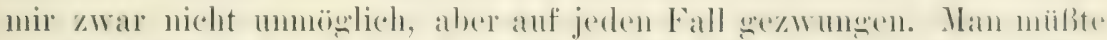

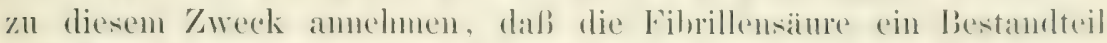

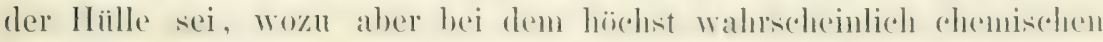

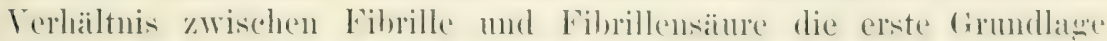

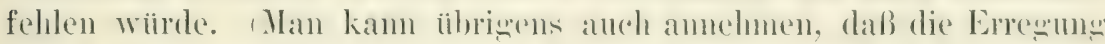
von Teilchen zu Teilchen dadureh forteneplanzt wird, dab das errecente Teilchen infolge seiner hïheren Iffinitiat dem meresenten Fibrillensäure entzieht und dieses hierdurch in Erregung gerät.)

Wemu also die negatir gewordene erregte Stelle zur Ausbildung ron Strömchen führt, die sich durch die Lnechung aberleichen und die nächst gelegenen Fibrillenteile in Katelektrotonus, die croporte Stelle selber aber in Inelektrotonus versetzen, welcher sich ans cinenen Kräiften der Fibrille langs am steigert, so muß dieser anelektrotonische Zustand damn an besten inn gefärbten P'räparat zum Ausdluck kommen und die katelektrotonische Iffinitatserhöhnng wanz hinter ilm zuricktreten, wenn nur selten eine nene Welle iiber die Fibrille hinläuft. Nach Beendigune der anelektrotonischen orler restitutorischen Phase wiirde jede Fibrille wieder ihre normale Iffinität zur Fibrillensiinre haben und die im erregten Zustand abgegebenen negativen lonen wieder ersetzt haben. - Folgen die Reize sehr schnell hintereimander, so kann die Erholung nicht eintreten: die Fibrille bleilst in einem andauernden Zustande erhöhtel Iffinitä, sie kimn also anch der Leitum nur noch in motereordneten Make dienen. Ich shanbe. daß dies mit einer Anzahl von 'Tatsachen sehr gut harmoniert: Bei frequenten und nicht zu starken Reizen tritt, wie Bernstein (1571)

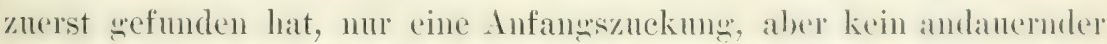

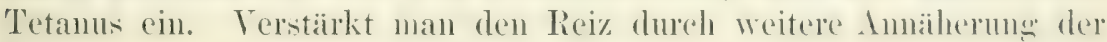
Rollen, so tritt zwar ein dauernder 'Tetanus ein, doch ist dieser auch bei stärksten Strömen nie auf die Höhe zu bringen, die man bei

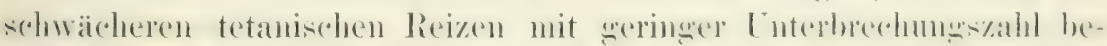
obachtet. Der 'Tetanus bei sehr frequenter Reizung' ist anch nie so

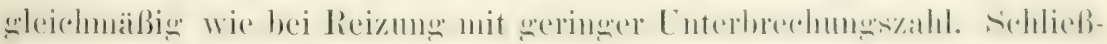

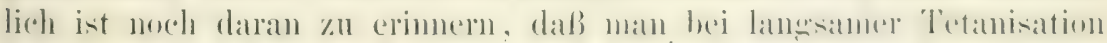

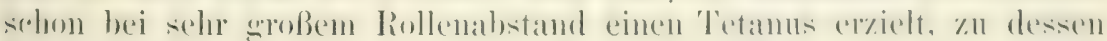

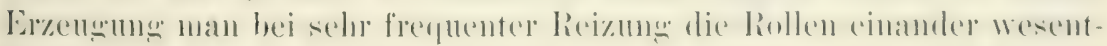
lich nähern muß.

Aus dem Gruenhagensehen Phänomen (S. 269) und ans Unter-

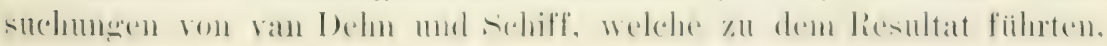




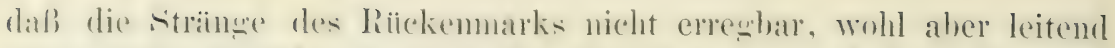

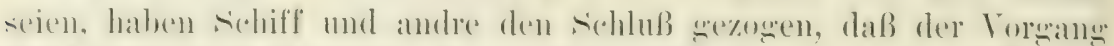

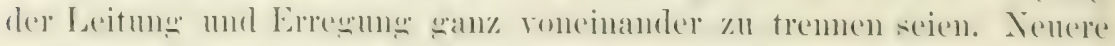
Untersuchungen (Fick, Biedermann u. a.) haben ergeben, daß die

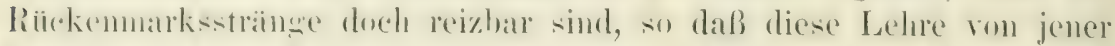

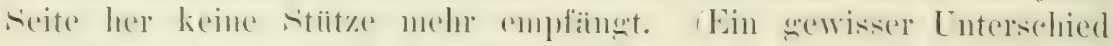

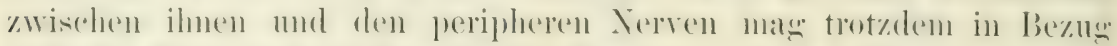

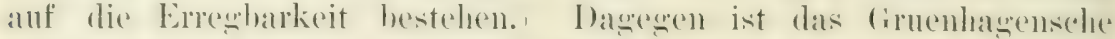

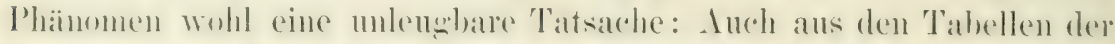
nenesten, sich wegen diese Tremmung richtenden Arheit ivon Wredenski [1900]), geht hervor, daß zu einer gewissen Zeit der Narkose die Reizschwelle zentral von der affizierten Stelle geringer ist als an dieser Stelle selber. Die ganze Frage ist aber durch diese Arbeit

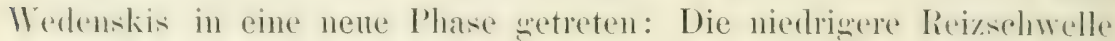
uherhall, ler affizierten stelle ist nämlich mur bei schwäroheren Reizen z11 konstatieren. Nähert man die Rollen, so tritt bei dem jetzt stärkeron lieiz ein niedriserer 'Tetanus mol schlieblich nur noch eine

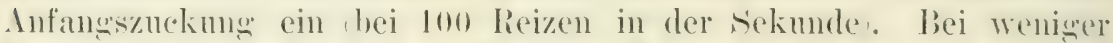
frepuenter hoizung macht sich dieser Lnterschied zwischen starken mol schwachem Reiz nicht bemerkbar. Man kamn sich rorstellen, dak bei der ohmehin in narkotisierten Neren bestehenden erhöhten Iffinitait, die duroh den Reiz sesetzte Erhöhmug so langrsam zuriick-

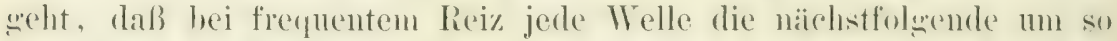
mehr stört, je stärker sie ist. - Im ïbrigen wird man mit Hermann

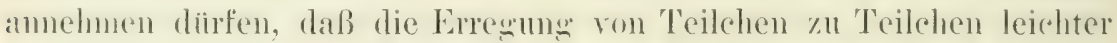
von statten geht als von außen. Nachdem ich gezeigt, daß sich bei der Leitung meist dasselbe Bild zeigt, wie an der Kathode eines polarisierten Nerven, wird wohl kaum noch daran zu zweifeln sein, daß Leitung fortgeleitete Erregung ist (Hermann). Auch

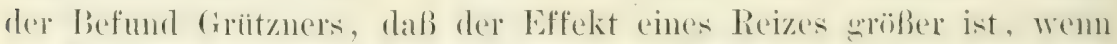

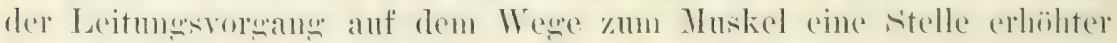

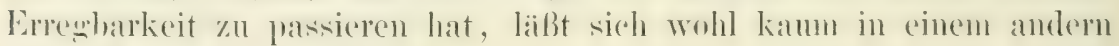
sime deuten.

Zuerst hat Bernstein (187T) den Versuch gemacht, die Ermiidbarkeitsverhätnisse des Nerven zu studieren. Er fand nach starker, tetanischer Reizung einer Nervenstelle diese für weiter oben an-

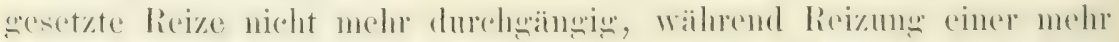

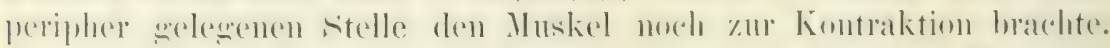

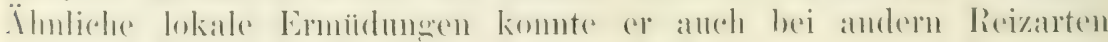
konstatieren. In den meisten Fillen tritt nach einiger '/eit Restitution ein. Für stairkere tetanische Reizungen läßt sich dieser lefund leicht konstatieren, ja es genügt bei hoher Spanmug ein cinziger Induktionsschlag $u$ eine Nervenstelle (anch beim Warm- 


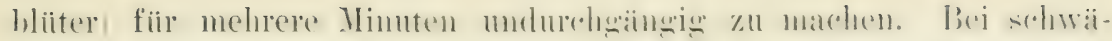
cheren Reizen tritt etwas ähnliches anch bei langer 'I'etanisation nicht ein, so daß man doch wohl an eine schwerere Schädigung zu denken hat. Im primärgefärbten Praiparat habe ich bisher keine wexentliche Veränderune an suldelen lieizstellen sehen kiinnen, die

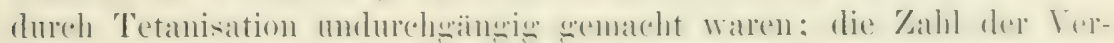
suche war jedoch noch nicht groß genug, um ein definitives Urteil fäillen zil können.

Bei Reizung mit Induktionsströmen ron zulässiger Stärke el-

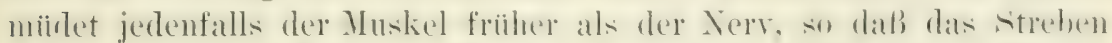

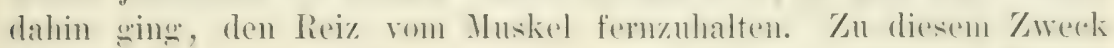
benutyte bereits bernstein einen kmotanten strom, weleher den Norven

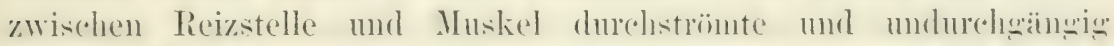
machte. Da aber das lange Flielenen eines starken stromes den Verrent

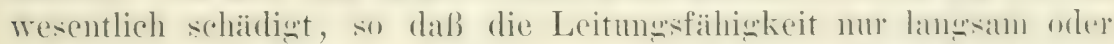
snar nicht wiederkehrt, so hatte bernstein nit diesen Versuchen keinru wnten Erfol心. - Wedenski 1584, henutzte das whiche Verfahren, schloß aber nur anf kurze Zeit einen starken Strom (bis der Nerv undurchgäingig war) und schwächte ihn dann stark ab. Aus (nach

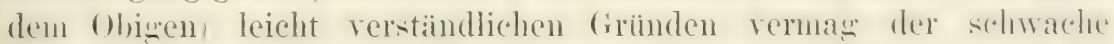

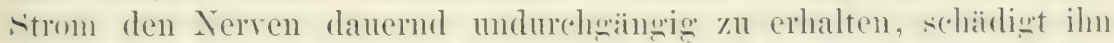

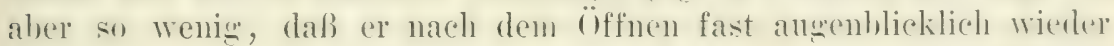
durchgängig wird. Er reizte nun den Nerven oberhalb der durchflosienen strecke bis zu 6 stunden manfhoirlich: wurle der pularisierenule strom dann geöffnet, so seriet der Muskel sofurt in Tetanus.

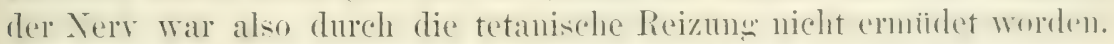

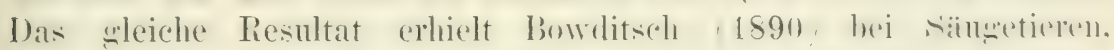

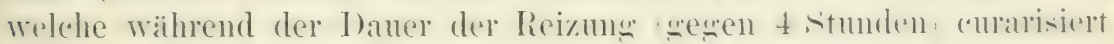
waren. Temn die Curarewirkung wich, so fing der Muskel an, zu reagieren.

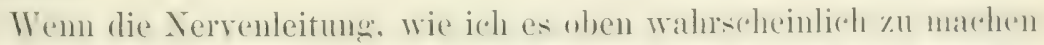

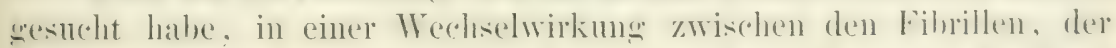

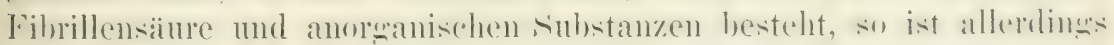

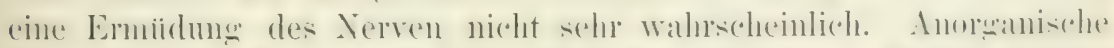

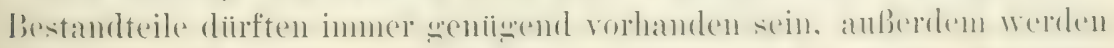

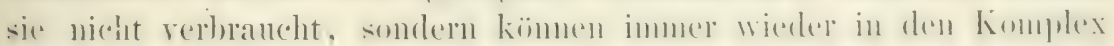

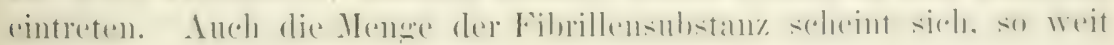
meine Versuche reichen, nicht zu vermindern; sie wird also, wie es

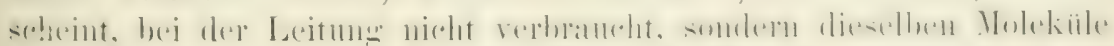
treten inmer wieder in Aktion. Über die Fibrillen selbst kann ich nichts aussagen und es ist möglich, daß diese bei der Leitung auf die Daner in Mitleidenschaft sezomen werden (eventuell in erhöhte

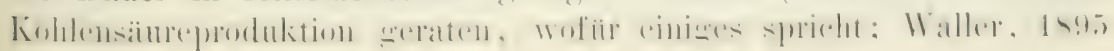




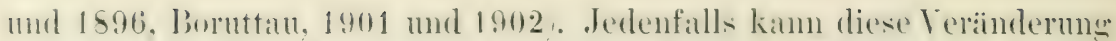
nateh den obigen Versuchen nur minimal sein. Dic weringere Mengere ron Energie, welehe für den Nerven durch die nach außen sich ab-

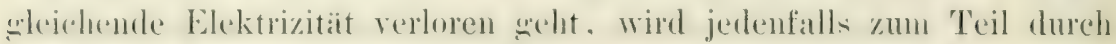
den Zuwachs ron Energie gedeckt, welehe mit dem Reiz in den Nerven hineingelangt. Für einen, wenn auch wohl sehr geringen

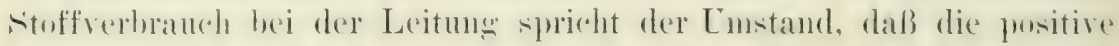

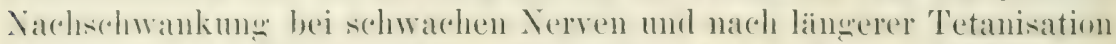

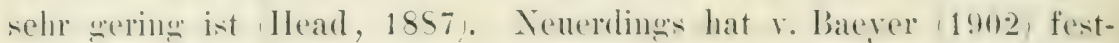

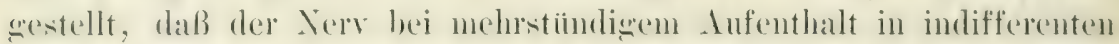

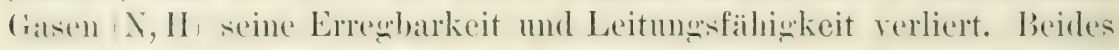
kehrt nach Wieder\%lussumer you šanerstoff in wenienen Minuten wieder. I)anit waire also, enteregen friberen beobachtungen, festerestellt, dab

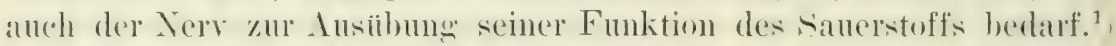

Ich fasse noch eimmal kurz zusammen: Der Komplex yon Neurofibrille, Fibrillensiture und gewisien anorganischen vubstanzen Elektrolyten) ist das leitende Element im Nervensystem. Bei konstanter Durchströnung wird die Affinitat zwischen Fibrille und Fibrillensiume an der Kathode erhöht, an der Anode herabosetzt: welehzeitio strïnt die Fibrillensäure zu Kathode hin und von der Anode fort. In dem

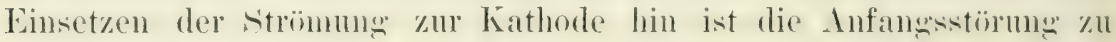
sehen, von weleher eine Reizwelle ausgeht. Ungekehrt gibt das

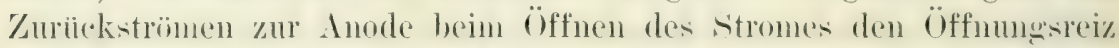

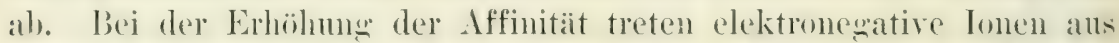
dem Komplex aus, bei Herabsetzmog onder Aufhebung der Affinität elektropositive.

Die Reizwelle besteht in einer wellenförmig fortschreitenden Affinitäserhöhmm nit Versehiehnng von Fibrillensäuremolekiilen zum Reizort hin. Ficichzeitien mit der Iffinitätserhöhme treten inmer an der betreffenden vtelle elektronesative Ionen aus dem Komplex aus. welche zum Iuftreten einer Negativitatswelle Aktionsstrom, negative

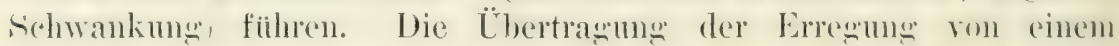
Quorschnittsteilchen zum andren geschieht dadureh, dab die klenen.

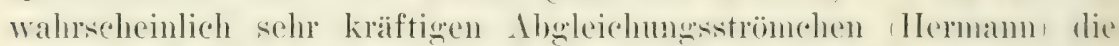
merregten Nachbarteilohen in Katelektotomus versetzen. Vielleireht

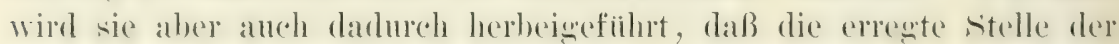
uncresenten Nachbarschaft Fibrillensianre entrieht und diese dadureh erregt.

1) Der frihhere Eintritt von Unerregbarkeit an Stellen, welche weiter vom Muskel entfernt liegen, diirfte doch wohl lediglich daranf zu bezichen sein, daß die Reizwelle eine längere, verïnderte Strecke zu durchlaufen hat, als bei Reizung an einer periphereren Stelle. Hier von einer zentrifugalen Entwicklung der Erstickung zu reden, dürfte wohl unangebracht sein. 
Nachdem die Affinitätserhöhung ihren höchsten Punkt erreicht hat, tritt eine restitutorische Phase langsan ein, bei welcher ein an-

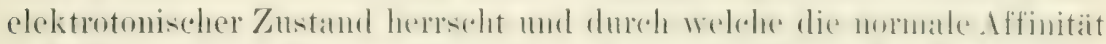

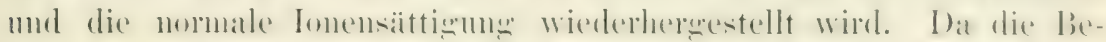

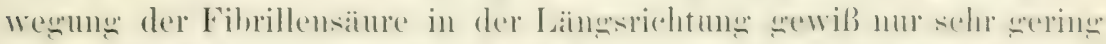
ist, so ist anzmehmen, dill jerles fribrillensïmremolekïl sich hei der Restitution wieder an seinen alten Platz begibt.

Ich sehe also den ProzeB, welcher sich im Nerven fortpflanzt,

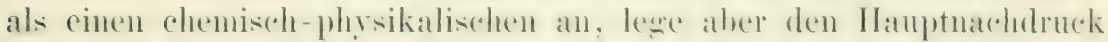

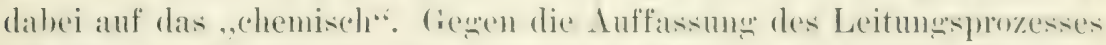

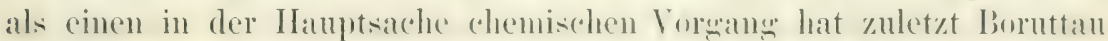
1902. eingewantt, dal es keine chemischen Vorwinge suibe, wetche sich mit einer Geschwindigkeit von $30-60 \mathrm{~m}$ in der Sekunde fortpflanzten. Das schließt aber nicht in sich, daß derartig schnelle

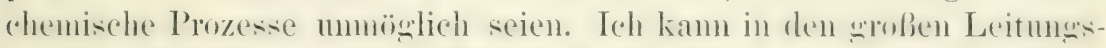
greschwindigkeiten mancher Terven keinen Einwand wewen meine Vorstellungen sehen, erblicke aber mugekehrt in den niedrigen Leitungsweschwindigkeiten mancher Nerven Eledone 50 ('n1 bis 1 m in der sckunde [Cexküll, 1594], Anodonta circa 1 cm in der sekunde [Fick, 156:3], einen Einwand gesen rein physikalisele Theorien der Nervenleitung. Anch die schnelle lestitutionsfähigkeit und der sicher minimale Stoffwechsel in Nerven sind gegen die chemische Natur des Leitung-srorganges ins Feld geführt worden. Beide Einwände kommen in Wegfall, wem man den chemischen Vorwang nicht in einer Verhemung sondern, wie das hier geschehen ist, in einer Ändermme der chemischen Affinität sieht.

\section{FÜNFZEHNTES KAPITEL.}

\section{Die Eigenschaften des Zentralnervensystems im allgemeinen.}

Unterschiede zwischen den peripheren Nerven und dem Zentralnervensystem S. 325. - Die Ganglienzellhypothese S. 326-334. - Ihre Widerlegung durch das Carcinusexperiment S. 325-330. - Widerlegung der Einwände, welche gegen dasselhe erhoben sind S. 332, 333.

Die durch Nervenleitung vermittelten, am unversehrten 'Tier auf-

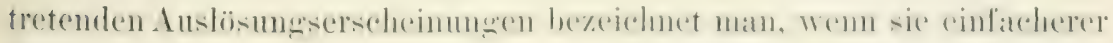
Natur sind, nach dem Vorgange von Prochaska (1800) als Reflexe. 


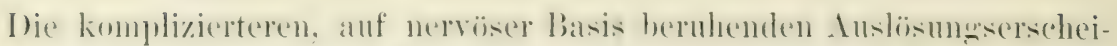
nungen, wie sie beim Menschen und vielen lı̈heren 'Tieren neben

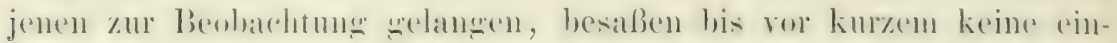

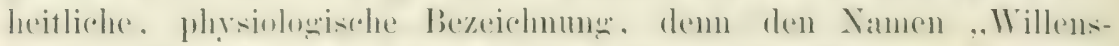

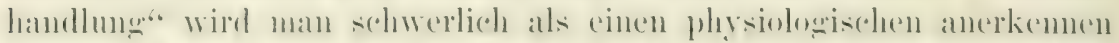

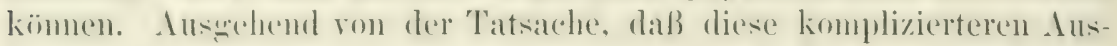

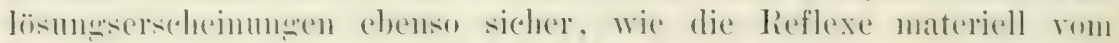

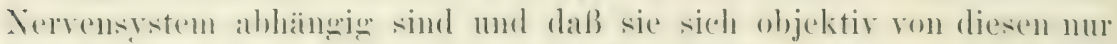

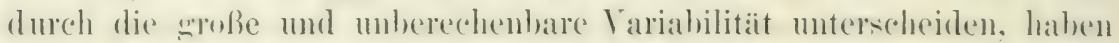

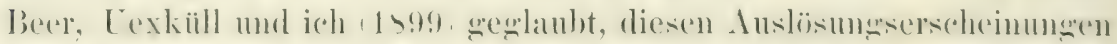

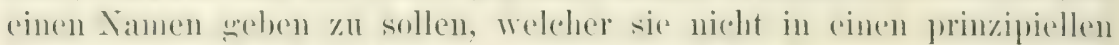

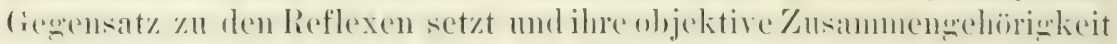
mit diesen zum Ausdruck bringt. Wir durften dies um so eher tun, als wir zu der Überzengung gelangt waren, daß das psychische Element, welehes man so rielfach auch in der Physiologie als in-

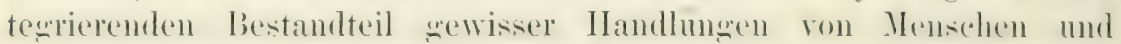
'Tiepen angesehen hat, stets etwas subjektives bleiben wirl und nie Objekt exakter Wissenschaft werden kamn. Was wir beobachten kionnen, sind eben stets nur bewentuserscheinmogen und nichts weiter, und diese unterscheiden sich bei den sogenannten Willens. landlumenen nicht wesentlich von denen bei den Reflexen. Wir fassen daher säntliche nervösen Antwortserscheinmmen muter den Samen „Antikinesen" zusammen, behalten für die gresetzmäßig wiederkehrenden Reizbeantwortungen den Namen ,Reflex" bei und bezeichnen die Reizbeantwortungen, in welchen ein variabler Faktor enthalten ist, als, Antiklisen", durch welches Wort weiter nichts priisumiert wird.

Bei allen Antikinesen spielt das Nervensystem vor allen Dingen die Rolle des leitenden Vermittlers zwischen der reizanfnehmenden ()herfläelse und den meln oder weniger weit entfernten effektorischen ()ranen. Wenn wir den Vervensistem anBer der leitenden Funktion keine weiteren Eigenschaften zuschreiben, so ist bereits die große

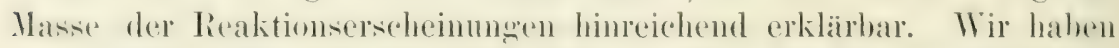
ja geselen, dial bei den verschiedenen Tierarten die rezeptorisolen mol cfektorischen Fibrillen miteinander nuter Gitterbildume in Verbindung treten. Bei den Tieren, welehe cin sehe anfates und diffuses licflexleben füluen, sind diese Gitter ganz diffus answebreitet, während bei allen höher stehenden Tieren, welohe lokalisierter Antikineson

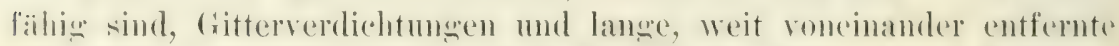

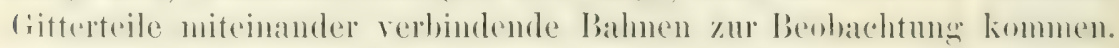

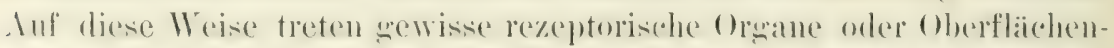

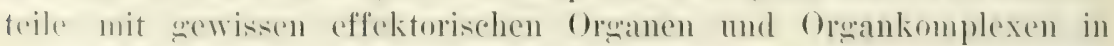

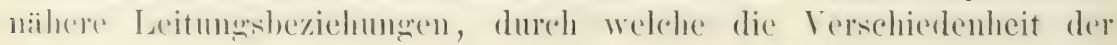


Reaktionen hei lieiz diesel und jener kïrperstelle aine ziendich hefriedigende Erklarmog findet. In der Tat ist es jat seit lattenem das

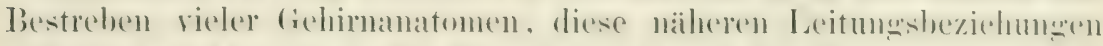

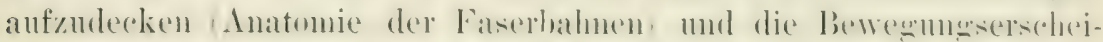

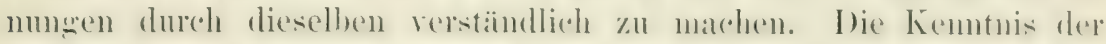

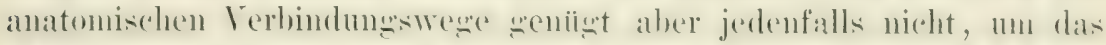

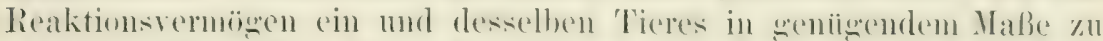
erklären. Hieranf hat Loeh 1599, in cince interessanten sichrift nachdriicklich aufmerksam gemacht.

Loeb hailt, wie es scheint, ron bestimmten anatomischen Verhindungen zwischen zusammenarbeitenden rezeptorischen mul effektorischen Organen nicht sehr viel. In der Tat gribt es Fälle genug;, wo sich die stïmugen nach Verletzung wewisser ballnen wanz wieder ansoleichen, su daß also diese Bahnen zum Zustandekmmen der be-

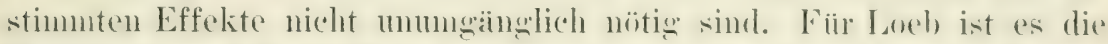
Hauptsache, dab iiberhaupt ein Leitungwren vorhanden ist; die wenanere IBeschaffenheit desselhen ist in ziemlich weiten (irenzen wheich-

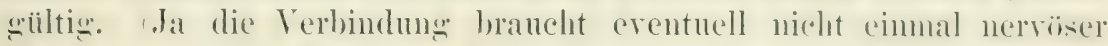
Natur zu sein?. Bestimmend für den Mblanf eine Antikinese ist in erster Linie nicht die Art der Leitungswege, sondern die Art und Beschaffenheit der effektorischen und noch mehr der rezeptorischen Apparate. Diese (Orone sind es im wesentlichen, welche die Eigentïmlichkeiten in den Reaktionen der verschiedenen Tiere bedineren. An und für sich ist die starke Werteinschätzung der Rezeptionsorwane nicht neu, derartig extrem ist sie aber bisher wohl nie reltreten worden.

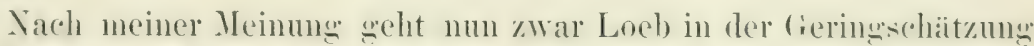
der bahmen und der anatomischen Details zu weit, doch wable iols ihm insoweit zustimmen zu müssen, daß das Zustandekommen be-

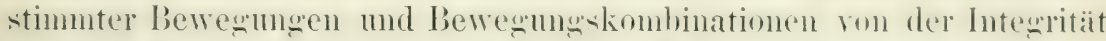
serwisier langer Bahmen in viel höherem Mabe unahlängig ist, als den Anatomen lieb sein kann. Dies wird aber immer nur damn der Fall

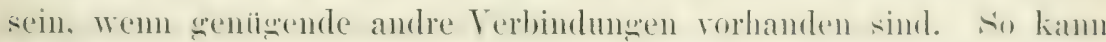

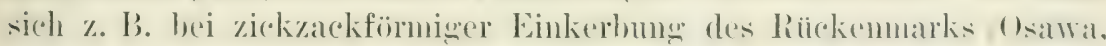
1882) die Längsleitung von vorn nach hinten und von hinten nach

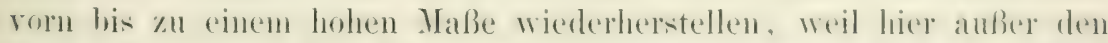

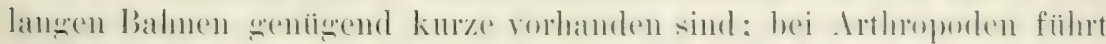

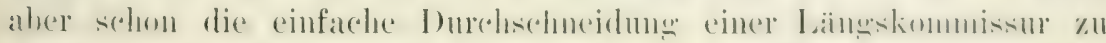

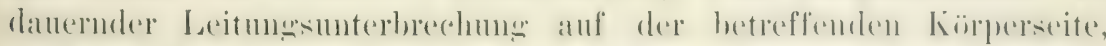

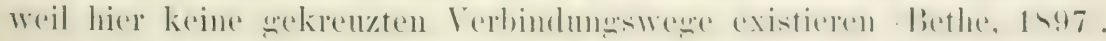

Ich glaube, daß man auf die Art der nervösen Verbindungen nach wie vor einen hohen Wert wird legen nïssen, dem es gibt kein

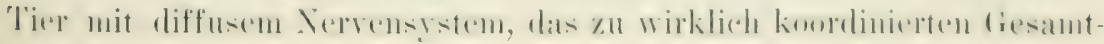




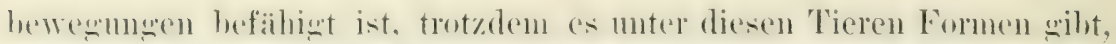

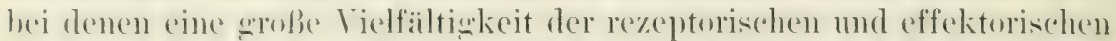

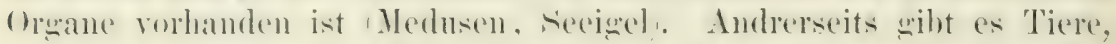

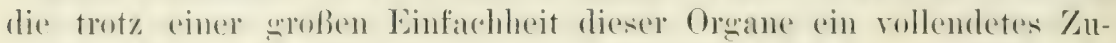

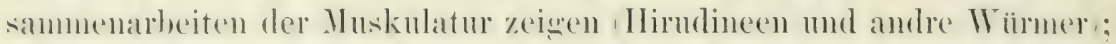
ich kamm dies nur daranf sohieben, dab ihr Nervensystem zentralisient ist mul redoliche lange bahmen besitzt. Ohme Zweifel ist aber dee

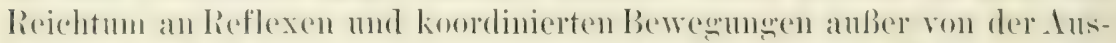

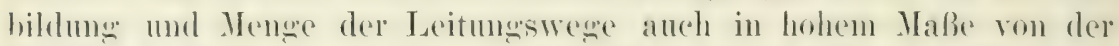

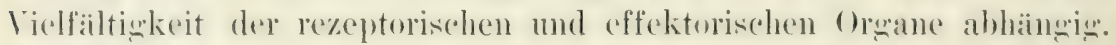
Ein 'Tier, das nur eine Art von rezeptorischen Organen (z. B. nur

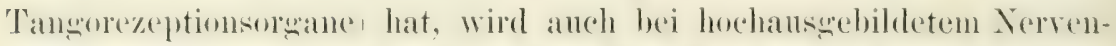
system nicht so Vielseitiges leisten kömmen, wie es mit allen Arten von liezeptionsorenanen answerïstet leisten wïrde. Siein Reflexleben mul) ämer sein. Andrerseits wiude einem 'Tier, das an effektorischen

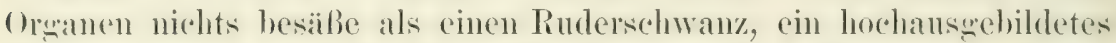
Nervenststem und eine Fülle versehiedener Rezeptionsorane wenig nützen.

Die 'Tatsache, daß derselhe Reiz, an verschiedene Körperstellen angesest, verschedene Effekte zur Folge haben kann mud daß verschiedenartige Reize gresonderte Esscheinungen hervorufen kïnnen, wird genilgend verständlich, wemm man dem Nervensystem nur Leitfähıkeit und den Rezeptionsoronen spezifische Elektionsfahionkeit zuschreibt. Die Verschiedenheit in anatomischen Aufhau des zontralen und peripheren Nervensystems, wie sie uns bei höheren T'ieren entwerentritt, wird dabei hinreichend erklärt, dem sie beruht ja vor allem darauf, daß hier die Fibrillengitter, welche die Ausstremung der Reize besorgen, von der Peripherie her an einen Ort zusammengezogen sind (S. 100$)$.

Bein diffusen Nervensystem (den Nervennetzen der Medusen, des

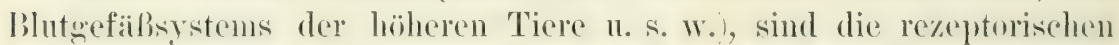
und effektorischen Bahnen anBerordentlich kurz; die Übertragunesstellen liegen iiberall in nächster Nähe, sind deshalb aber auch wanz zerstrent. Die anBerordentliche Verlängerung der rezeptorischen und effektorischen Bahnen bei den höheren 'T'ieren nud ihre räumliche

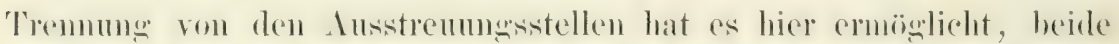
Teile getrennt vomeinander zu nutersuchen, Versuche, die z. B. an Medusen undenkbar sein wiurden. Diese Untersuchungen haben num zu Resultaten weführt, welche eine Gexensitzlichkeit zwischen den offek-

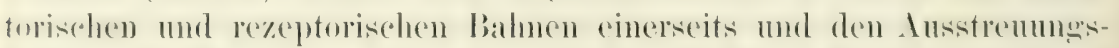

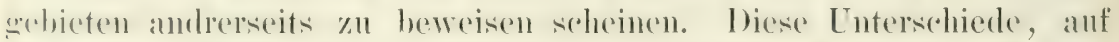

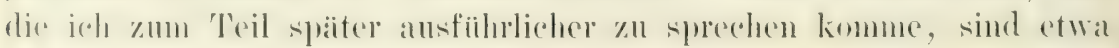
folgende: 
1. Der periphere Nerry (also die effektorischen und rezeptorischen

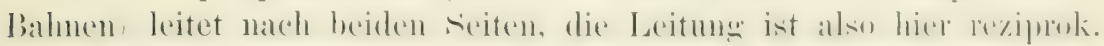

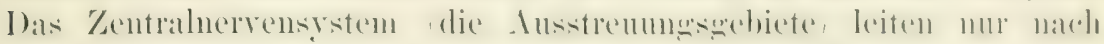
einer Richtung, die Leitung ist also irreziprok. (Bei Reizung des zentralen Stumpfes einer motorischen Wurzel treten keine Reflex-

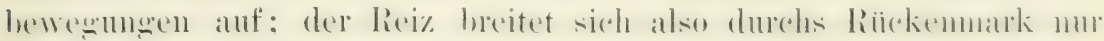

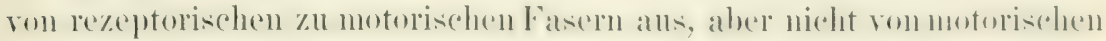
z11 motorischen.)

2. Der motorische Nery reagiert gleich gut auf Einzelreize und tetanische Reize. Reflektorisch wirken tetanische lieize moledeh bessele als Eimzelreize. Das Zentralnervensistem setzt dem Einzelreiz

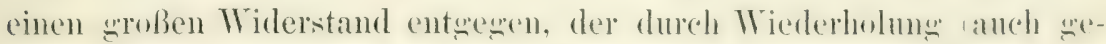
ringer Reize) ïberwunden wird. Erscheinung der Summation.

3. Die Ausbreitung der Erregung wird beim Passieren der grauen Substanz stark rerlangsamt.

4. Das Zentrahnervensastem ïht einen danemolen Einfluß auf die Muskulatur aus, der mach Durchschneidune der motorischen Nerren fortfillt. Muskeltonus.

5. Alle schädigenden Einflüsse wirken viel stärker auf das Zentrahervensystem als auf die Nerren. so beeinflussen die Nareotica zunaichst nur das Zentrahervensystem; sie machen die Antikinesen schon zu einer Zeit unmöglich, wo die peripheren Nerven noch gut erreghar sind. Strychnin, Nikotin und viele andre Gifte entfalten ilne Wirkmng an Zentrahnervensistem und sreifen dio peripheren Nerven erst viel später oder gar nicht an. (Andre Gifte wie Kurare und Kokain setzen mit iher Wirkmo hauptsäbllich am peripheren Vervenencle an; es gibt aber keme (iffe, die zuerst die Nerremstamme selher

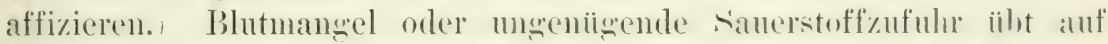
die peripheren Verven fast keinen Einfluß aus, wälorend das Zentral-

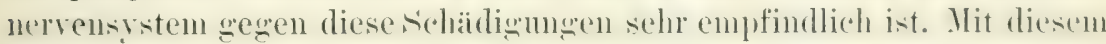
offenbaren, hohen sianerstoffhediirfuis der bentralorwane stelit der ana-

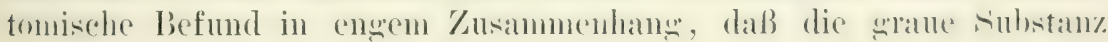
auberordentlich reich an BluterefäBen ist, Wälorend die prepipheren Nerven und die stränge des rentrahnervensystems nul spioliche Bhotgefïße enthalten.

6. Das Zentralnervensystem kann der Ausgangspunkt ron automatischen Berregungen sein, die Nervenstämme aber nicht.

Diese Unterschiede, welche ich so referiert habe, wie es den

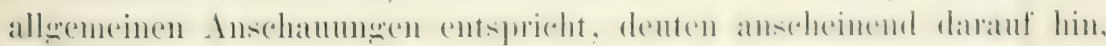

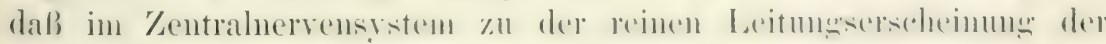

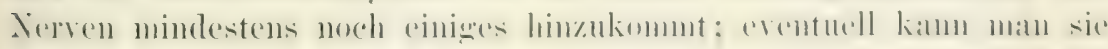
aber auch so deuten, daß der Vorgang in Zentralnervensystem iiberhaupt ron dem im peripheren Nerven versehieden ist. 
Fast so lange, als man die Ganglienzellen (und ihren Zusammen-

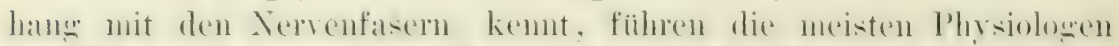
die Eigentünlichkeiten der Zentralorwane anf diese zuriek. Es bil-

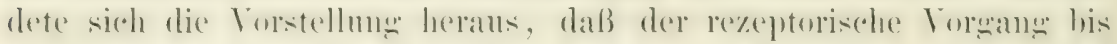

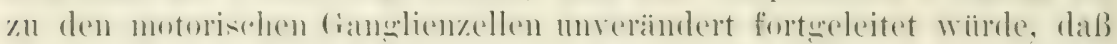
er aher hier eine nene Erscheinumg anslioste. Welche als motorischer Impuls dem Muskel zugeleitet wiurde. Es sollte also in den motorischen fanghienzellen eine Iuslïsung ron spannkräten zustande

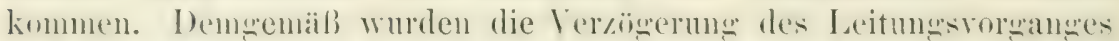

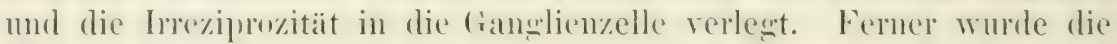
Wirkmng der Vervengifte dahin gedentet, dal sie den stoffwechsel der (ianglienzellen schädigten, und das hohe sanerstoffbediufnis der Zentralorgane wurde nur auf die Ganglienzellen bezogen.

Es ist ganz selbstrerstandlich, daß alle älteren Autoren bei diesen beduktionen unter Ganmlienzelle inmer nur das verstanden habren, was man damals (ianglienzelle oder canglienkugel namnte, nämlich den Kern mud den ilm zunächst mugehenden I'rotophlasmaleib; Achenzylinder mol l'rotoplasmafortsïte wurden damals he wrifflich noch rollkommen von der Ganglienzelle getrennt. Seitdem in der Neuronentheorie die Lehre aufgestellt wurde, daß Achsenzylinder und l'rotoplasmafortsitze nur Teile der Ganglienzelle seien, hat sich diese Anffassung bei den Physiologen nicht rerändert: Es wird immer noch die Ganglienzelle im alten Sinne als die Reflexvermittlerin angesehen. Wenn auch einige den Anatomen darin folgten, daß sie das gesante Xeurom als physiologisehe Einheit ansprachen, so rerlegten sie doch - wie sollte es anch anders sein! die Leitungserzögermug, die (iffwirkmgn.s. w. in Kern-P'rotoplasmaleib und bezeichneten diesen komplex nach wie vor als (ianglienzelle. Ja es wurde von streng neuronistischer Seite der Versuch zurilickgewiesen, das Wort Ganglienzelle (resp. Nerrenzelle) seiner alten Bedentung zn berauben und mit dem Nemronbegriff zn identifizieren. [Lenhossék (1895), p. 105: „... und es ist daher ohne Frage gerechtfertigt, wenn man die Bezeichnumg Zelle nur für das kernhaltige Protoplasmaklümpchen reserviert...".]

Ich will hier einige Beispiele anführen, welche zeigen sollen, was in der Literatur allgemein Ganglienzelle genamnt wird. Vielen wird dies überfliissige erscheinen; ich muk es aber tun, weil mir selbst von physiologischer. Seite der Vorwurf gemacht worden ist, ich hätte in dent greich zu beschreibenden Versuch etwas als fianglienzelle bezeichet, was in der That nur ein Teil der Ganglienzelle sei:

Rosenthal (1875), p. 13: „Wir sind berechtigt anzunehmen, daß die eigentlich wirksamen Elemente des Atemzentrums in ... den Ganglienzellen zu suchen sind." 
Wundt, Psychologie, 1893, p. 273: „Die Ganglienzellen sind die rigentlichen Werkistitten. . In den Xerrenfasern werden diese stoffe

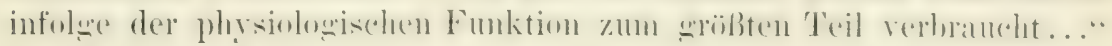

Verworn $(1900,2)$, p. 107: „Die motorischen Vorderhornzellen

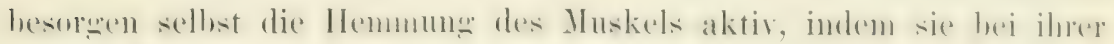
eignen Hemmung einen aktiren Hemmungsvorgang ... dem Muskel durch ilıren Achsenzylinder iibermitteln."

Derselbe $(1900,3)$, p. 169: ,Je länger die Ganglienzelle arbeitet, um so mehr entwickehn sich Lähmungserseheinungen."

Derartige Beispiele ließen sich zu hunderten anfïhren: Aus allen geht immer wieder hervor, daß a uch in neuerer Zeit kaum ein

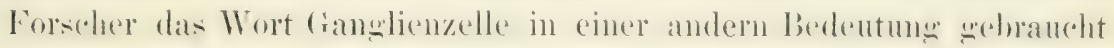
hat, als in der von Anfang an gebrätuchlichen. Wenn vor allem in physiologischen Schriften von der Ganglienzelle als dem wahren Zentralorgan, dem eigentlichen Reflexzentrun secprochen wird, so ist nie(:) etwas andres gemeint als der Kern mit dem ihm zunäichst anliegenden I'lasma; auch die Iendriten sind in den allermeisten Fällen ron dem berriff ., (ranglienzelle" answeschlessen, weil sie ehenso wie der Achsenzylinder der Ganglienzelle als Gegensatz gegeniibergestellt werden. Bis ror kuzem hat niemand den Intum hegangen, die Eigenschaften der Zentralorgane in das gesante "Neuron" z.n verlegren, denn es unterscheiden sich num mal phrsiologisch die zentralen Teile des ,Yeurons" rom peripheren, und für diese Lntersehiede werden eben von denen, die sie lokalisieren wollen, die Ganglienzellen verantwortlich gemacht.

Nun liegen irgend welche positicen Beweise fuir die zentrale Natur der Ganglienzellen nicht vor; was vorgebracht wurde, waren nur Vermutungen, basierend auf der sicherlich ïbertriebenen Wertschitzunn, welche der Kern und die Zelle seit Schleiden, schwamn und Virchow

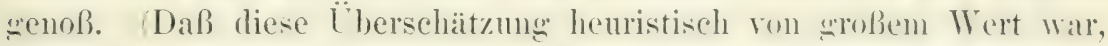
lengne ich natürlich nicht.) Ein Beweis für die zentrale Natur der (ianglienzellen war deswexen nicht erbracht, weil sämtlehe angehlich heweisenden Experinente am ganzen Zentrahnervensstem angestellt wurden, dieses sich aher bon den peripheren verven anber durch den Gehalt an fianglienzellen auch durch versohiedenes andere, vor allem

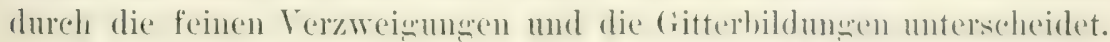
Zwei wrobe l'hysiologen haben verweblich anf das unzuredehende

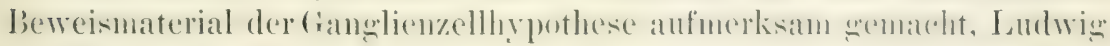
und Eekhard. Ludwig schrieb 1852 in seinem Lehrbuch der I'hysiologie (p. 124), nachdem er die ,Beweise" für die zentrale Natur

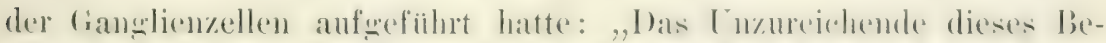
weises lenchetet aber soghleich ein, wemn man sich vor die Augen führt, dab keineswegs die einzige anatmmische Verschiedentseit, zwischen den 
()rten. Welche jene Eignentünlichkeiten darbieten nud denjenieren, welohen sie fehlen, in der Gegenwart der fanchlienkïrper lient. Noch weniswer wird man aber seneigt, jenen belauptungen dilabben beizumessen . . ."

Eckhard schreibt 27 Jahre später in IIandhuch der Physiologie

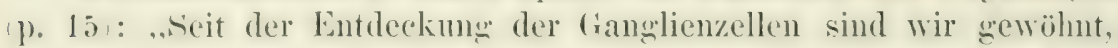
diesen alle diejenigen 'Tätiskeiten zuzuschreiben, welche wir aus den uns bekannten Leistumgen dex Nervenöhren nicht begreifen kïnnen. Diese (iewohmheit hat bereits eine solche Macht über ms bekommen, daß wir kamm noch danach frapen, wie fest der firmul unseres Verfalmens ist, und wir sind anBerordentlich froh, eine solehe Zuflucht zu haben."

Die Lagel)eziehungen zwischen Ganglienzellen und Teuropil bei den Krustazeen ließen in mir Zweifel an der Richtigkeit der (ianglienzellhypothese aufkommen und gaben mir zu gleicher Zeit die Mönlichkeit, die Richtigkeit dieser Hypothese experimentell zu prifen. Bei diesen 'Tieren lieğen die langgestielten, mipolaren Ganglienzellen (S. 27) außerhalb derjenigen Gebiete, in denen sich die Nervenfasem rerzweigen. Wenn jeder Reiz durch die Ganglienzelle hindurehgehen miißte, so wiirde die Erregungswelle den langen stielfortsatz zweimal passieren mïssen, eimmal auf dem Wege zur Zelle hin und eimmal auf dem Wege zum Muskel. Einerseits wäre dies nicht sehr ökonomisch, andrerseits wiurde man nicht verstehen, was die Fibrillen für eine Bedentung hätten, welche unter Lmgehumg der Ganglienzellen direkt rom Neuropil ans in die motorischen Fasern iibergehen siehe Fig. 12, ^. 35). Die Möglichkeit einer Nichtbeteiligung der unipolaren (ianglienzellen an Reflexvorgang ist vor mir sehon von Nansen, später anch ron Ramón y (ajal ansgesprochen worden.)

Lm die Wertigkeit der Ganglienzellen für die Reflexrorgänge experinentell zu prifen, wählte ich das zentrale Gebiet der zweiten Antenne ron Carcinus Maenas (Bethe, 1597 und 1595). Dieses Gebiet liegrt dicht an der s'chlundkommissur und nimmt den unteren Zipfel des Gehims ein (Fig. 8, s.. 27). Die von der rezeptorischen Oberfläche der zweiten Antenne kommenden Fasern (deren Rezeptionszellen peripher unter den Rezeptionsharen liegen) verlaufen durch den Nerven der zweiten Antenne bis in dieses Gebiet, um sich hier zu verzweigen (Fig. 8\%). AuBer diesen rezeptorischen Fasern füht der Nery anch die motorischen, welche mit zwei (ranglienzellpaketen am Gehirn in Verbindung stehen (Fig. $8 c_{1}$ und $c_{\mathrm{o}}$ ). (Wie aus einem besumderen Experiment hervoroht, wehören die Elemente $c_{1}$ den Bengeru, die Elemente $c_{2}$ den Streckern der Antenne an.)

Wird der Nery der zweiten Antenme dicht am Gehirn durch- 
solmitten, so ist die Inteme danemel selähnt. Während sie mormaler

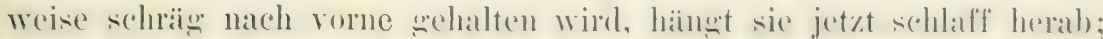

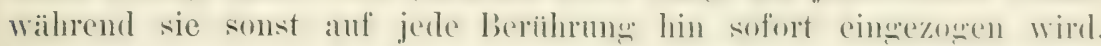
kamn man sie nach der I) urehschneidung des Neroen so stark reizen,

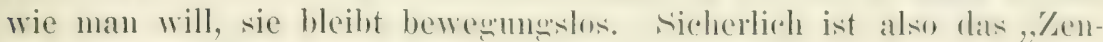
trum " der Antennenberegung im Gehirn gelegren!

Ich trug num in einel Anzahl von Fällen untel der binokulären Lupe und mit Hilfe eines winzigen Messers das Zellpolster c, mud a. ab und trenute, 1 m einen eventuellen Einfluls andrer (ranshienzellen anszuschlieben, das ganze zugehörige Neurphil vom iibrigen folim und rom bauchmark (Durchschneidume der betreffenden sehlundkonmissur) ab. (Der schnitt wurde in der anf Figur s punktierten Linie eeführt.) Es hängt also mit dem Terren der zweiten Antemne in den wnten Fälen nur noch ein stiick Nemopil zusammen, das frei rom Ganglienzellen ist. Alle Terbindungen mit dem iibrigen Zentralnervensystem sind aufgehoben.

Direkt nach der Operation ist nicht nur die Antemne selber, sondern auch jedes andere rom Gehirn aus innervierte Oroan reflexlos. Es ist dies eine Folge der Freilegung. Am Tage nach der Operation stellen sich die Reflexe wieder ein. Absesehen ron vielen mißgliekten Fällen, bei denen das am Nerven hängende Nenopilstiick in der nach der Sektion angefertigten schnitserie noch eine subbere oder kleinere Zahl von Ganglienzellen enthielt, gelang es mir in drei Fällen alle franglienzellen zu entfernen. In diesen drei Fällen komnten nach der Erholung ron der Operation folwende Erscheinmugen an der vom einem ganglienzellosen Stïck Zentralsubstanz innervierten Intenne beobachtet werden:

Die Antenue hängt nicht schlaff herab, wic nach Durchschneidung des Nerven, sondern wird in der normalen Lage gehalten. De r Tonus ist also vorhanden. Beim Beriuhen wird die Antenne flekticert und dam wie bei einem normalen 'Tier wieder worestreckt. Die Reflexereglorkeit ist also ebenfalls erhalten. retzt man hintereinander mehrere sehwache an sich muwirkinne lieize an, so tritt ein Reflex ein. Das ganglienzelllose Neulopilstuek ist also noch der Reizsummation tälig. Nls einziger Cuterschied weren ein nomales Tier zeinte sich wine wesentliche brhöhung der Reflexerregbarkeit.

In den nächsten Tagen nach der Operation nimmt die Reflex-

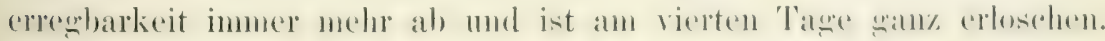
Die Ganglienzellen (wem man will der kerntragende 'leil des

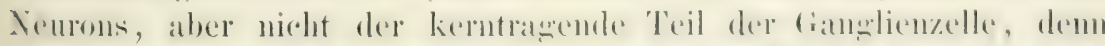

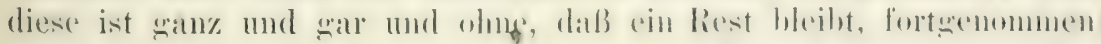
sind also zu den wesentlichsten Erscheinungen des 
Zentralorgans nicht notwendig; 'Touns, Reflexvermittlung und Reizsummation sind auch ohne Ganglienzellen möglich. - Ein dauerndes Bestehen von Reflexen ohme

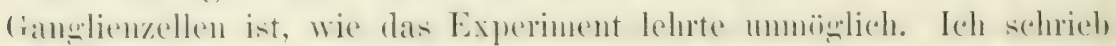

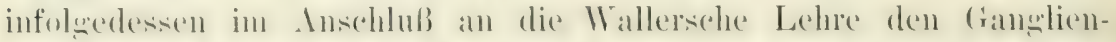

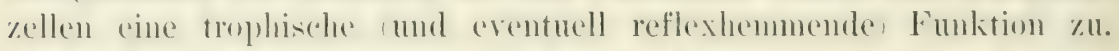
Vach den oben mitereteilten befunden liapitel 12, ist anch diese trophische Funktion höchst zweifellatt, so dalb also anch diese Eigenschaft den tramelienzellen senommen werden kam. Das Eintreten der

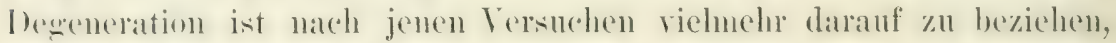
daß der Komplex, den man Nemon nennen mag", an einer relatir hollen sitelle verletzt ist, so dab alles I'eripherere der Deweneration verfallen 1 muß.

Ein Jahr nach der Publikation meiner Versuche reröffentlichte Strinach 1599, angenscheinlich olme Kemntnis meinel Arbeit) befunde, ans denen er den śchluß zieht, daß die Npinalyanghen zur

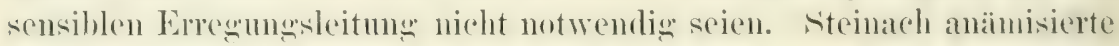

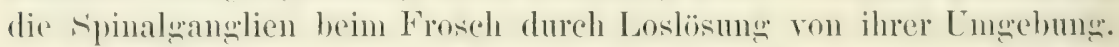
Die Wurchn wurden tänlich freigelest und oberhalb wnd unterhallo des (iannlions gereizt. Mit der \%eit nimmt die reflektorische Errewharkeit des Ganglions ab; dasselbe ist aber noch zu einer Zeit fiur die unterhalb angesetzten Reize gut durchgingig, wo sich die Spinalganglienzellen, wie die histologische Untersuchung zeigte, bereits in einem Stadium hochgradigen Zerfalls befinden. Dies ist nach etwa 14 Tagen, aber atuch schon friiher der Fall. Steinach ist der Meinung, daß diese Zellen nicht

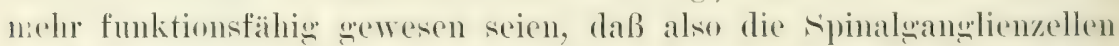
an der Reizleitumg direkt nicht beteilint seien. In einigen Fälen hat "le anch die (xanglienzellen, nachlem die Anämisiermug hereits einione 'Tage sewilkt hatte, mit einem Messer abgeklatzt (in einem Fall waren alle Zellen bis anf zwei stark verinderte entfernt und die bleibende dimne Britcke noch reizleitend gefunden.

(Beim. Hund fand van Gehuehten [1899] die mit Nikotin verwifteten sinalyanglien zu einer \%eit, wo die Nervenfasern noch nicht

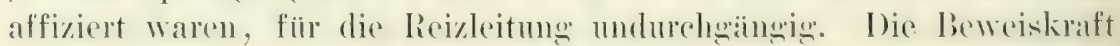
dieses Versuches für die Wichtienceit der Ganghenzellen ist nicht sehr groß, weil bei den Säugetieren, wie es scheint, alle Fibrillen durch

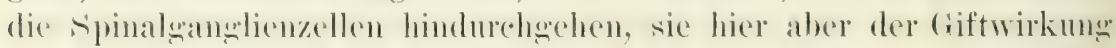
viel mehr ausgesetzt sind als in den Nervenfasern, wo sie durch die Hiillen geschiitzt sind [siche weiter unten]. Bein Frosch habe ich dateren, wem anch nicht sehr dentliche Inhaltspunkte dafiur gerefumben, dak rin Teil der Fibrillen direkt rom peripheren Fortsaty der Zellen in den zentralen hineinzieht, ohne also in den Stamm- 
fortsatz und die Zelle einzutreten. Wenn sich dies bestiitigt, so ist

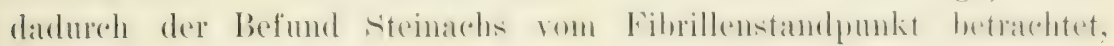
durchaus verstaindlich.

So interessant das Steinachsche Experiment ist; so greift es doch die Ilauptfrage nicht an, weil die sininalwanglienzellen mit dem Reflexvorgang nur mittelbar zu tun haben. Sie nehmen iberhaupt andern

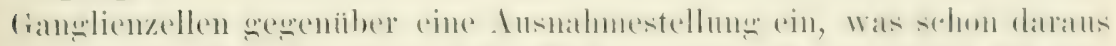

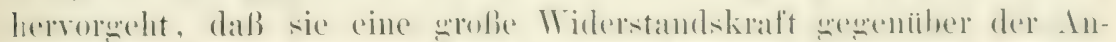

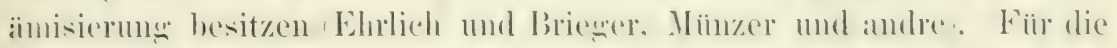
zentralen Prozesse - Reflexvermittlung, Tonus, Summation u. s. w. sind sie wohl nie in Anspruch genommen worden. Der Linwand Verworns 1900 , daß die Kellen in den steinachesenen Experinenten doch noch funktionsfähig gewesen sein kömnten, weil es von einigen andern Zellarten feststeht, daß sie trotz starker histologiseher Ver:inclerungen noch funktionieren kïmnen, dürfte dech wohl nicht fïr

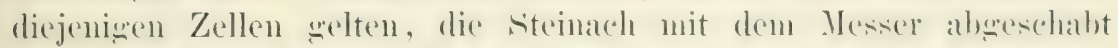
hat. Leider hat steinach diesen Versuch nicht anch an wanz mormalen spinalganglien answeführt. Es stehen dem vielledeht terchnische Schwierigkeiten im Wege.)

Jisher sind meine und Steinachs Versuche die einzigen, die wirklich an Ganglienzellen ausgeführt worden sind. Vergleiche die Versuche auf

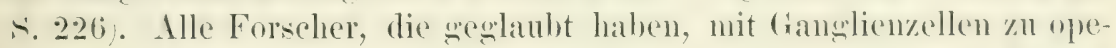
rieren und deren Eigenschaften zu studieren, befinden sich, wie sichenk $10102)$ in seiner kritischen trbeit über die Xeuronentheorie ausfïhrt, ..in einer wroßen Selhsttänschung.", weil sie nur an den nervösen zentren arbeiteten, die unter anderm auch Ganglienzellen enthalten. - Hier liewen positive Befunde ror und diese zeigen, dab die Ganglienzelle mit den Ilanpteigenschaften des Zentralnervensystems, welde hisher in sie

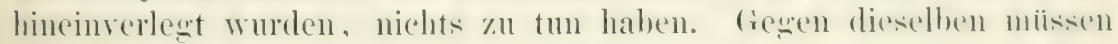
alle theoretischen Erwägungen zuriektreten - wenigstens für diejenigen, welche nicht Xaturphilosophen, sondern Xaturforsehere sind.

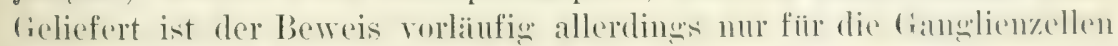
ron Careinus Naenas. Da aber die Ganglienzellhypothese bei allen iibrigen Tieren auf grade so schwachen l'iben stand, wie hei diesem Tier, so muß dieser eine positive Beweis, der für Wirbeltiere dureh

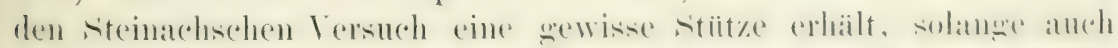
für die übrigen Tiere als maßgebend angesehen werden, als nicht

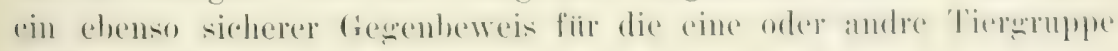
vorgebracht ist. ${ }^{1}$ )

1) Denen, welche an der Exaktheit meiner Beobachtung zweifeln, steht es frei den Versuch nachzumachen. Bis dahin verzichte ich darafi, ihnen entgegenzutreten. - Auch das mitleidige Achselzucken, mit dem manche Wirbeltierphysiologen allem begegnen, was an Wirbellosen gemacht ist, dürte hier wohl 
Als ich meinen Versuch beschrieb, hielt ich es für gainzlich aus-

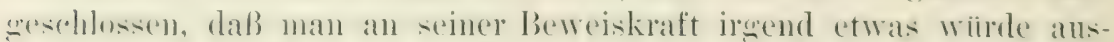
setzen kömmen. Zu meinem Erstamen ist er nur von wenigen als beweisend anerkannt worden (Nissl, 1898, 1903, F. Uexkïll, 1900,

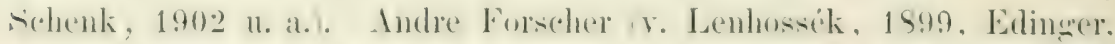

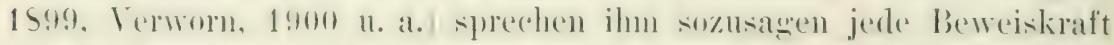

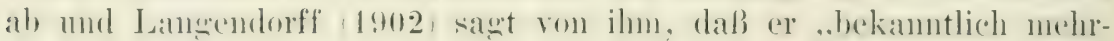
dentig" sei. Außer daß meinem Versuch die Wirbellosigkeit des

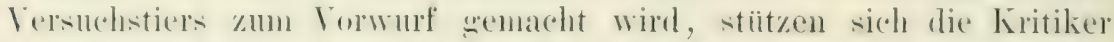

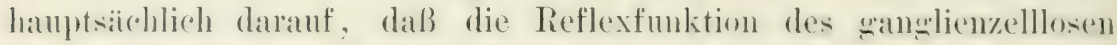

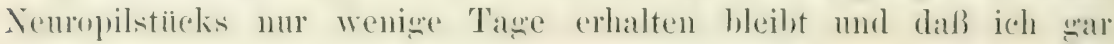
nieht die Ganglienzelle, sondern nur einen 'Teil derselben fortgenommen hätte.

Man beruft sich auf bekannte Versuche an Protozoen, in denen sichl zeiste, daß das Leben von kernlosen Tierstiucken noch einige Zeit erhalten bleibt, und man zicht aus dieser Tatsache den fichluß, daß mein ('arcinusexperiment nichts wesentlich Nenes zu Tawe refördert liäte. "Es ist also", schreibt Verworn (1900), ,gar keine aufallende Erscheinung, wie auch Fdinger und Lenhossik schon hemerkt haben, wem durch kernlose Massen von Gancrienzellprotoplasma bei manchen Kalthliitern noch einige wenige Tage lang Reflexe vermittelt werden können." Da ich selber zugegeben hätte, daß ich nur den ,kernhaltignen 'Teil des (ranglienzellkörpers" fortgenommen hïte ich habe wesast ,die Ganglienzellen d. h. den kerntragenden Teil des Nenrons", was ein sehr moRer Lnterschied ist, so sei der zanze Versuch, vïllig belanglos" sic!?. Mit Recht fragt hierauf S'chenk 1902, warum die Vertreter der Nemonenlehre nicht schon vor mir , die lonische Konsequenz aus jenen Kemutnissen wezogen" hätten und warum man die Iypothese Nansens, daß die Ganshlienzelle im wahren simne für den Reflex unnötig sei, aufs energischste bekämpft habe.

Tatsächlich ist bei meinem Tersuch dasjenige vollstandien und ohne Rest entfernt, was Verworn und Lenhosick selber Ganglienzelle nemnen (siehe die Zitate auf S. 325), nämlich der Kern mit dem hermuliegenden Protoplasmaklümpehen; ror allen Dingen: es ist das entfernt, was alle Physiologen (und nach den obigen Zitaten zu schliefen anch Verworn, Anatomen, P'sychiater mod Nemologen als

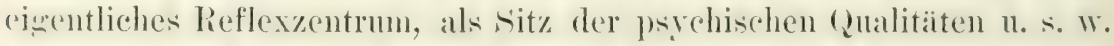
angesprochen haben! Jieser Versuch, der die Lnrohtigkeit der (ian-

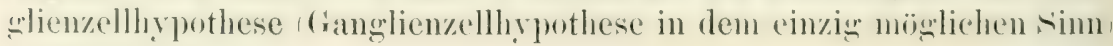

sehr wenig am Platz sein. Der Reflexvorgang mit allen seinen Eigentiimlichkeiten ist etwas so Elementares und fast durch die ganze Tierreihe bis auf Einzelheiten Gileichförmiges, daß seine physiologischen Grundlagen wohl ohne weiteres ibberall als gleich angesehen werden können. 
zeigt, wird ron Verworn, der dieser 'Theorie nach seinen letzten Ar-

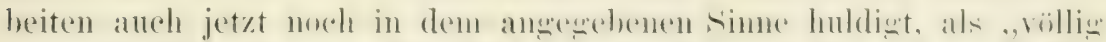

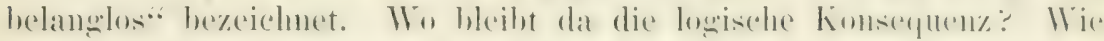
ist dies möglich? Dadurch, daß man meinem Versuch gerrenüber und nu in diesem Fall - die Ganglienzelle als das ganze ,Neuron" auffaßt. Es wiirde dies ja konsequent sein, wenn wirklich das ganze Neuron eine Zelle repräsentierte dies ist aber wie oben gezeigt höchst zweifellaft); jedoch hat diese Konsequenz mit der zur Diskusion stehenden Frage gar nichts zu tun,

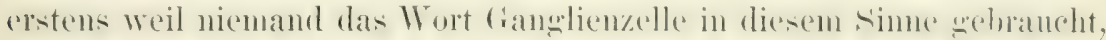

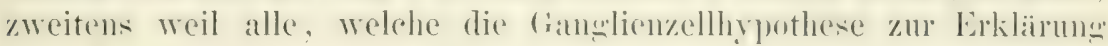
der Sonderlieiten des Zentralnerrensystems (im Gegensat\% z den Eigenschaften der Vervenöhen, henuten, mit der Ganglienzelle immer nur das meinen können, was ich total fortgenommen liabe. ${ }^{1}$ )

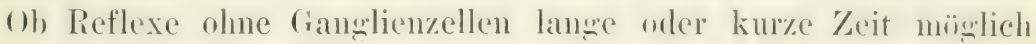

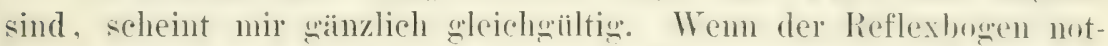
wendiserweise durch die Ganglienzelle swine, wenn die summation nur in der Ganglienzelle zustande käime u. s. w., dann miißten diese Inge in demselben Yoment nmö̈lich werden, in dem die ranglienzellen fortgenommen werden. Ebenso rerhält es sich mit der von

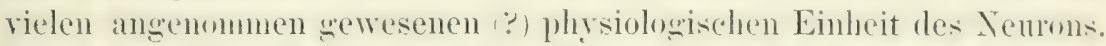
Ist es eine Einheit, wie etwa eine [Hir, so muß die Funktion aufhören in dem Angenblick, wo ich die Einheit störe (z. B. bei der Uhr das Gewicht abhebe. Da aber die Funktion nach Fortuahme der (ianglienzellen noch weiter geht, so kann von einer Einheit (in dem logisch allein möglichen Sinne) nicht mehr die Rede sein.

Selbstrerständ lich ist die Ganglienzelle insoweit zum Reflexrorgang nötig, als sie Leitungsweg;, d. h. Durehgangspunkt ron

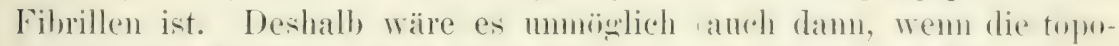
straphischen Verhältuisse es nicht verhinderten cin analowes Expreriment an Vorderhornzellen von Wirbeltieren zu machen, weil man nit fortnahme der Zellen alle Verbindungen zerstären wirde. Fihen dassellue träfe fïr Hirudineen zu. Ich behaupte nur, daß die Anhäufung be-

1) Da Verworn in seinem lieferat iiber die Neuronentheorie außer an den Stellen, die gegen meinen Versuch gerichtet sind, fast durchgehend das Wort Ganglienzelle im alten Sinne gebraucht, so scheint es mir, daß er seine ILeinung iiber das, was als Ganglienzelle anzusehen ist, ad hoe verindert lat, sich aber in der Eile noch nicht ganz an diese neue Auffassung hat gewöhnen kömen. Die Ganglienzellhypothese, welche ja grade die Unterschiede zwischen den Zentren und peripheren Nerven erklïren soll, hïtte bei der Anffassung Verworns gar keinen Sinn, und ich läitte, wenn ich die Ganglienzellen Verworns für ïherflïssig erklärt hätte, behauptet, daß das Nervensystem keine nervösen l'unktionen hätte. 
smolers differenzierten l'asmas und der Gamelienzellkern für den Reflexrorgang an sich unnötig ist, und ich halte dafür, daß das, was man hisher in die damelienzellen an sich rerlent hat, Eigenschaft

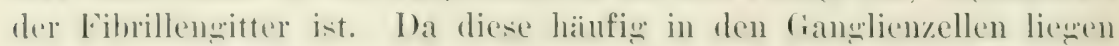

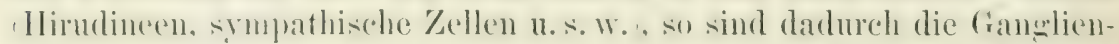
zellen manchmal sekmulär aber nicht durch ihre Zellheschaffenheit. Reflexrermittler, 'lonusorgane u. s. w., kurz Zentralorgane.

IVen man die Sonderheiten des Zentralnervensystems in die

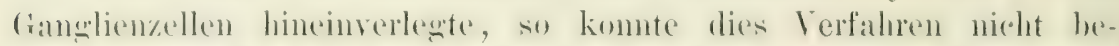
anspruchen, die Vorwänge dem Verständnis wesentlich näher eneriakt zul hiben. Dere einzige lorteil der (ianedienzellhypothese war der, dab sie die den Verven fremden Exscheinumgen an bestimmte stellen der zentralteile velegete, und zwar an stellen, die sich anatomisch ron den Fasern stark unterscheiden. Es ist aber sehr die Frage, ob die Jotwendigkeit eince strengen Lokalisation vorhanden ist mol ob nicht alle deratigen Versuche mehr anatomischen als funktionell-hiologischen

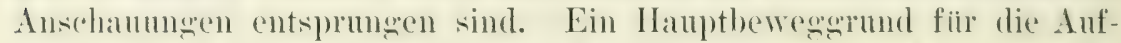
stellume und Vertedigme dieser Hypothese war jedenfalls das Bediufnis, die Erinnermosbilder irgendwo an einem hestimmten I'laty

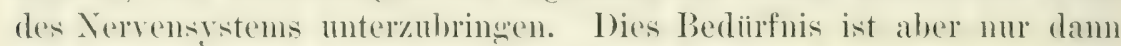
berechtigt, wemn man die Erimnermeshilder als etwas danernd Vorhandenes ansieht. Da man aber die Erinnerung mit gutem Recht anch als ein freschehen anselıen kamn Bethe, 1898, und hicrbei eine

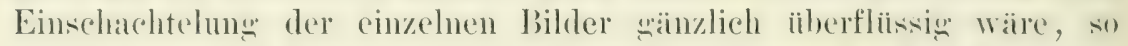
scheint nir ein Ersatz der Ganglienzellhypothese dureh Iufweismon eince andren, streng lokalisierten und nit hesonderen änberlichen Merkmalen ausgestatteten struktur nicht notwendig. Ich galaube, dal sich alle Eigentiumlichkeiten des Zentrahervensistems ebensogut oder ebensoschlecht wie bisher verstehen lassen, wenn man das nervöse Geschehen hier wie im peripheren Nervensystem in das leitende Element, die Xemofibrillen hineinverlegt. Ilifsamalmen werlen sich allerdings dabei ebensowenig verneden lasion, als die Gandienzenthypothese ohme solche ausgekommen ist. Inwieweit solche Hilfsammahmen zu machen sind, kann sich aber erst zeigen, nachdem das vorhandene Material kritisch hesprochen nud eine Inzalil nemer befunde beschrieben ist. 


\section{SECHZEHNTES KAPTTEL.}

\section{Die Reflexumkehr.}

Die Reflexersebeinmgen sind in den Ilanptpunkten so allgermein bekannt, daß ich auf ihre dufzilhlung und detaillierte beschereibungrergichten kamn. Natülich verstehe ich unter Reflex resp. Antikinese

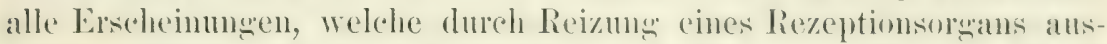
seliist werden mol nach Fortleitung des Erregungsworwanes durch Zentralteile hindureh an einem effektorischen ()ran \%ur beobachtum "welangen. Hierbei muB, ,Zentralteil" im weitesten sime des Wortes genommen und jede stelle als soleher angesehen werden, an der eine C̈herleitung von rezeptorischen Bahnen auf effektorische möglich ist. Ich wiirde an stelle ron Zentralteil Reflexbogen sagen, wemn nicht mit diesem Wort bereits eine sehr detaillierte und nach meiner Meinung unrichtige und zu spezielle Vorstellung verknipft wäre. Als Reflexbogen sieht man nämlich in allen Lehrbiichern ein ,sensibles", an der Haut endigendes und ein motorisehes mit einem Muskel verbundenes Nenron ahgebildet, welche sich berïlren. Falsch ist nach meiner Meinmo an diesen sichema, daß die Erregrmgsleitung in das Nemron als Ganzes verlegt wird, daß die Erregmosleitmo unterbrochen ist und daß die Ganglienzellen in ihm eine wesentliche Rolle spielen. $\mathrm{Zu}$ speziell ist diese Vorstellung, weil es bei manchen Tieren, z. B. den Iedusen, Übergänge von rezeptorischen Bahnen auf effektorische gibt, bei denen der Reiz nur eine Zelle passiert.

Bei den gewöhnlichen Reflexpraiparaten vom lrosch zeigen sich die Reflexe nur in einfachen Zuckungen des Schenkels ebenso ist bei den meisten lieflexen, welche in der l'athologie cine Rolle spielen, der Torgann eine Zuckung). Diese sehnelle und raseh vorïhergehende Reflexaktion, die Reflexznckung, ist eine Eignentimlichkeit der wan speziell modifizierten Muskulatur einiger Tierklassen (Tertebraten. Arthropoden, schwimmglockemmuskulatur der Medusen u. s. w.. Sic findet sich ïberall da, wo ein schnelles Reaktionsiemö̈wen ron Vorteil ist. IBei sehr vielen andern Tieren ist die Bewermonsmoknlatur mur langsan eintretender und langsan schwindender Kontraktionen fähiz: bei diesen Tieren haben anch die Reflexe stets einen mehr tonischen ('harakter. Dassellse gilt fiur die innere Muskulatur der T'iere, deren

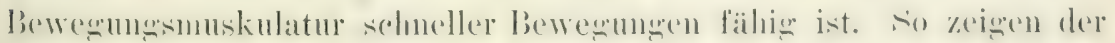
Darm, der Ureter, die Iris und andre Organe nur tonische Reflexe. Während die schuelle Muskulatur anf Vhomentanreize reflektorisels

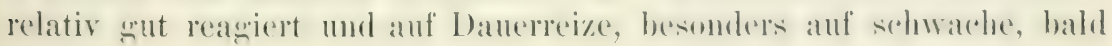


die Funktion einstellt, reaniert die Tomlismuskulatur auf reflektorische Monnentanreize wie auch direkt nur in serinem Maße oder sar nicht, auf Ibuerreize daseren, auch wemn sie sehwach sind, stark und andanernd. Dite andern effelitorischen (1):ane, vor allem die Iriisen scohlielien sich in ihrem Vorhalten der 'Tommsmuskulatur an. Im Ciebiet der schnellen . Wuskulatur treten anch tomische Erscheinungen zu 'Tage, doch spielen sie hier eine geringere Rolle.) -

Man war bis jetzt ziemlich allgemein der Ansicht, daß ein und derselise anf bestimmte Nervenendigunen wirkende Reiz nur immer ein und denselhen Effekt anszuliisen instande sei. Wenn man \%. D. anf eine Zehe eines ruluis dasitzenden Frosches einen welinden Druck ainwirken läßt, sn findet zunäichst nur eine leichte Zuckung in den beimmukeh statt. Wird der Reiz verstirkt, so kommt es zu einem

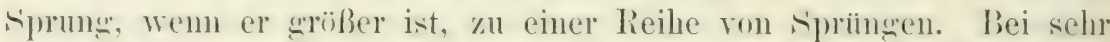
starker Erregum kam dieselbe eventuell auf andre srsteme überwreifen, es kïnnen Angenbewegunen und andre Erscheinumeren hinzutreten, aber nie kommt es zu Erscheinungen, die dem Effekt schwacher lidimng srade entgegengestat sind. Bei Steigerung der Reizstailie findet hier also nur eine steiserum des Effektes statt, aber keine qualitative Teränderung der Erscheinung. Dies ist mun nicht bei allen 'Tieren der Fall. Es wurde nämlich ron Uexkïll (1896, 1899 und 1s00, gefunden, daf schwache und starke Reize bei reeineln diametral entwegnenesetzte Effekte anszuliosen imstande sind. Dieselhen werden ron ihm als die starke und schwache Form des Reflexes bezeichnet.

Wie schon oben erwähnt, sind anf der sewölhten Kïrperoberfä̈rhe dieser Tiere mehrere Arten von beweshehen Orwanen in sroßer Anzahl angehracht. Die auffallendsten, welche den Tieren auch zu ihrem Tannen verholfen haben, sind die stacheln, welche mit Kunelscolenken der schale inseriert sind und durch einen doppelten Mantel von Mnskulatur nach allen sieiten hewegt werden kïnnen. Zwischen diesen stehen die Pedicellarien. Dies sind dreighedrige Zanæen, welche an stielen befestiont sind, die ihrerseits wieler anf kugelnelenken im Verhältnis zur schale beweot werden kïnncn. Morpholonisch und

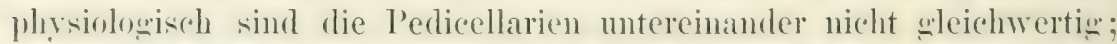
hei den meisten Irten lasien sich leicht vier Irten muterscheiden, welche v. Cexkiill als (iftzangen, Klappzanenen, BeiBzanwen und Put\%zangen hezeichnet zonlowisch werden sie als wemmiforme, tridaktyle, ophicenhale und trifoliate l'edicellarien untersohieden. Z/u diesen

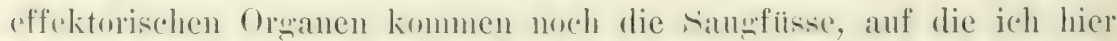
nicht weiter eingehen will. Vit Alsmalme der Giftzangen hesitzen alle diese, reflektorisch ziomlich voneinander mabhäneigen Oroane die schwarhe und starke Form des lieflexes. An leichtesten laibt sich 


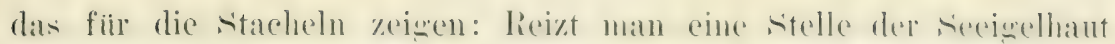

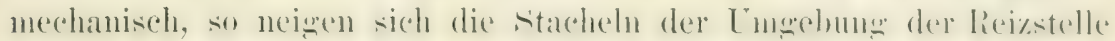
z11. Je weiter ein Stachel ron der Reizstelle entfent ist, desto

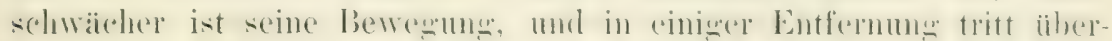
haupt keine Reaktion mehr ein. Das Dekrement, das die Erregung im Nerrennetz erfährt, ist also sehr groß. Bringt man jetzt an die-

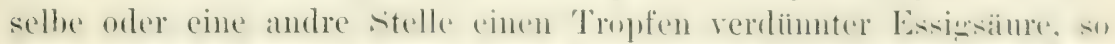
fahren die stacheln auscinamler, neigen sich alsn rom lieizort fort.

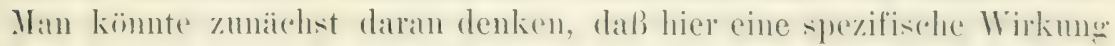

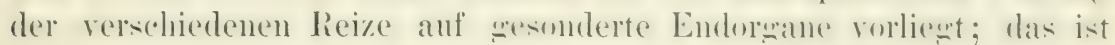
aber nicht richtig. Benutzt man nämlich statt der Essigsäure eine diinne Ammoniaklösung, so tritt wie beim mechanischen Reiz der positive Effekt der schwache Reflex = Ilmmeigunw zum Reizont ein, ist die Ammoniaklösmng stärker, so tritt der negative Effekt, der stalke

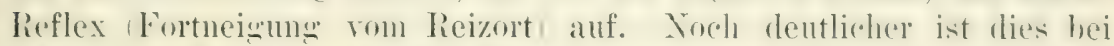
tetaniseher Reizung: Leichte Tetanisation einer Inatstelle wirkt wie ein mechanischer Rei\%, starke Tetanisation wie Essinsüure. beri liex-

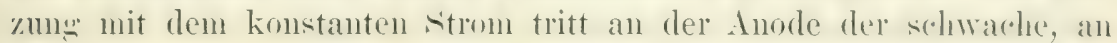
der Kathode der starke Reflex ein. Mechanischer Reiz wirkt stets als schwarher Reiz, die Applikation gewisser Chemikalien stets als starker Reiz \%. B. Essigsäure; bei Anwendune andrer chenischer licize, z. B. ron Ammoniak, erhailt nan bei schwacher Konzentration den schwachen Reflex, bei starker Konzentration den starken lieflex.

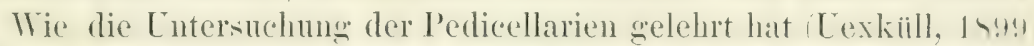
ist hei diesen mutereinander und in Verhältnis zu den stachehn die sichwelle, an der der schwache lícflex in den starken muschlägt, sehr

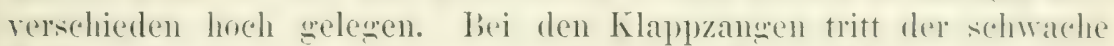
Reflex schon hei srant leichten mechanischen Reizen Anhranden ciner kleinen Welle ein: ein etwas starkerer mechanischer lieiz lieriihren der Hant) ruft schon die starke Form des Reflexes herror. An den Beißzangen tritt der schwache Reflex erst bei den mechanisehen

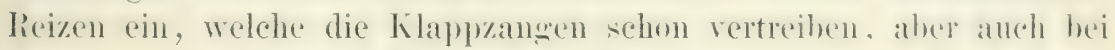
diesen tritt der starke lieflex noch in Bereich nechanischer licime desto

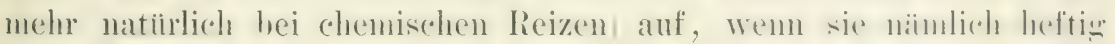

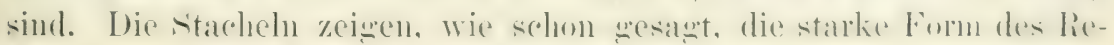

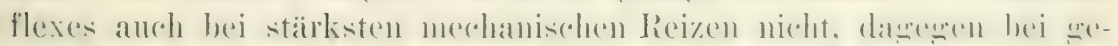

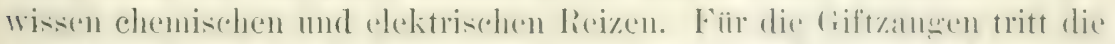

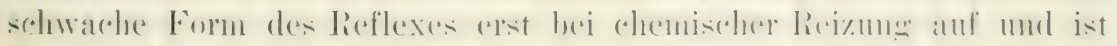

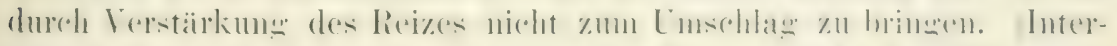

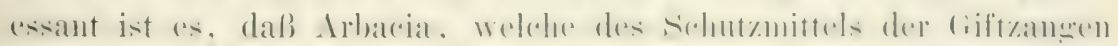

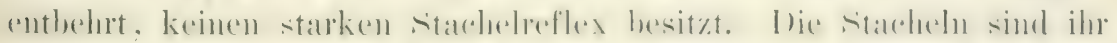

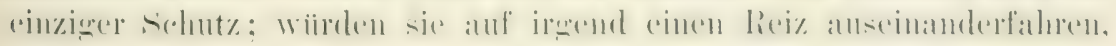
so wiirde die Haut allen Angriffen ungeschiitzt gegeniiberstehen. bet he, Nervensystem. 
Leider muß ich es nir versigen anf die speziellen Lefunde Lexkïls einzugehen, welche einen so tiefen Einblick in das Leben dieser Ieflexrepubliken gewähren, wie wir ihn vom katum einer andren Tierart besitzen.)

Zum Verstandnis der schwachen und starken Reflexform sind

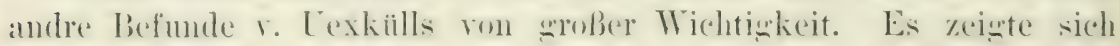
nänlich, dalb bei beiden Formen die wheichen Teile der die stachelbasen ungebenden radiair angeordneten Mnskeln in Funktion treten. Ein Infunktiontreten der Antionnisten ist zwar nicht ausweschlossen, aber es geht jedenfalls olne den: Wie ans anatomischen [ntersuchumen hervorehe ist jeder stachel an seiner basis von einem ans Xervenfasern und Zellen bestehenden Ring" unzelsen, der mit dem allwemeinen Nervennet\% der IIant in Verbindung steht. Jeder stachel besitzt dadurch seine eimen lieflexzentren, so daß anch ein kleines stiick sichale mit einem einzigen stachel alle Erscheinnugen zeigt. Wird num an einen solchen schalenstück die stachelhasis durch mehrere Radiärschnitte, welche bis auf das Kalkgeriist herahgehen und auf der sichale weitergeführt werden, in mehrere sektoren zerlegt, so werden dadurch auch die nervösen Terbindungen zwischen den einzelnen sicktoren auforehoben. Wird jetzt an einem der Dbschnitte an der sichale ein mechanischer Reiz angesetzt. so neigt sich der stachel der licizstelle wie normal zu. Das ist nicht weiter crstaunlich, weil man den Reflex so wie so auf eine Kontraktion der Stachelmuskulatur zuriekfuihren wïrde, welche der Reizstelle zunaidehst liegt. Wird num aher in derselben Weise ein chemischer Reiz angesetzt. so tritt anch wie nomal der starke Reflex ein, d. h. Fortneisen rom der Reizstelle. Da der Reiz zur andern Seite nicht gelangen kamn, so kamm der Effekt nur darauf beruhen, daß der Tonus der dem lieizort zunächst selegenen Mnskelpartie wesunken ist ïher den Tonns: Kapitel 201. Es werden also durch die rerschieden starken Reize dieselhen Muskehn

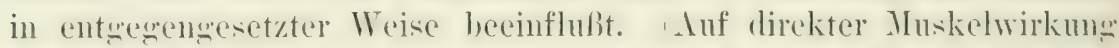
kamm der Effekt des zweiten Versuchs nicht beruhen, da alle die substanzen, welche auf die seeigelmuskulatur direkt wirken, immer nur zu einer Tomusteigermog fuiluen. Das Nervensistem ist also bei der starken Form des Reflexes beteiligt.)

Die Tatsache, dab bei mechanischer Reizung ciner Hautstelle sich

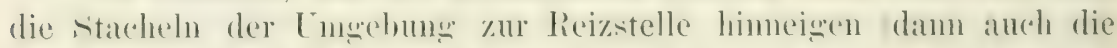

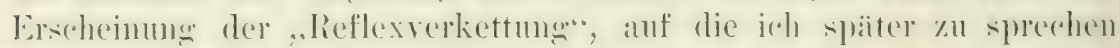
komme), hat Uexküll zu der Annahme veranlaßt, daß in der Haut nich mur e in Vervennetz existiert, sondern deren nehere. welehe von-

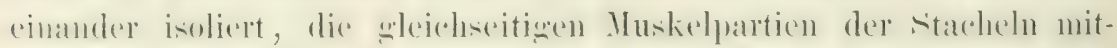
cinander verbinden, so daß also \%. B. alle linken und alle rechten, alle wheren und alle unteren Radiairmuskedn der stacheho miteinamer 
in Verhindung stehen. Olne /weifel ist auf diese Ireise dir Erklairmug der Erscheinungen an leichtesten zu luwerkstelligen. Es wird dabei

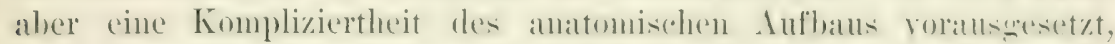

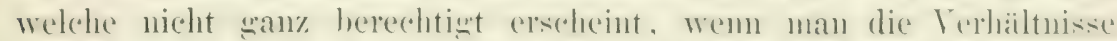

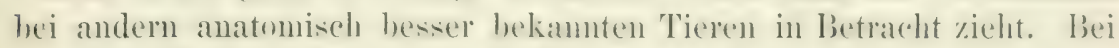
manchen Jedusen f'ambarina, bei denen sicher nur ein einziges Nervennetz existiert, limmmen licflexe vor, die mit dem Ilimeigenn der

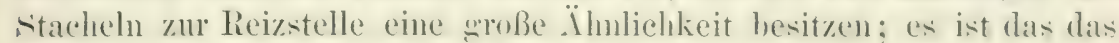
Hinfahren des Magensticls zu einel beriihrten sitelle der subumbrella. Ich staube, daß sich dieses Verhalten anch olme bestimmte bahnem dadurch erklärt, daß der Reiz, welcher sich im Nerremetz diffus ausmreitet, diejenigen Muskelteile des Masenstiels an stäksten trifft, welche mit der Reizstelle anf dem seichen Rarlius lienen. Inf diesolhe Weise düfte sich das Himeigen der vitacheln zum licizort el-

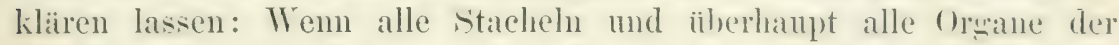
(b)effäiche nur durch ein einziges Nerreunctz rerhunden sind, so wird jeder von einer stelle des Netzes ansgehende Reiz dirjenigen Teile der Muskulatur jedes stachels am stärksten treffen, welche dem Reizort am naichsten liegon.

Die Verschiedenheit zwischen schwacher und starker lieflexform erklärt Cexkïll mit Zuhilfenahme einer besonderen Einrichtum: der Zentralteile, eventuell der Ganglienzellen, welche er 'Tonusichalter' nemnt. Tritt der Tonusschalter in Funktion, so tritt Ruhen des Er-

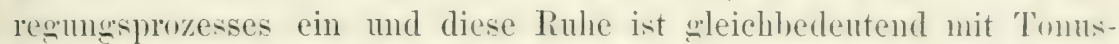
fall. Als phrsikalisches Teroleichsoljekt dient das P'orlal dines Klaviers. Der Tomusschalter wird Aurch den im Nerven ablanfenden Prozeß selber in Tätigkeit sesetzt und hindert diesen, wemm ich recht rerstehe, bis zu den betreffenden Mnskeln rorzudringen. Je nach Art des imnervierten effektorischen Oreans, ist das Eintreten der

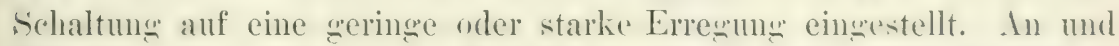
für sich tritt also auf jeden Reiz 'Tomusteigerung vin, wird der 'Tumus-

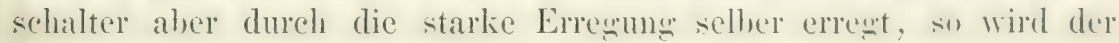
Reiz wirkungslos durch diesen.

Uexkiill ist sich wohl bewußt, daß es sich hier nul um einen Vergleich handeln kann, der — das muß zugegeben werden — aller-

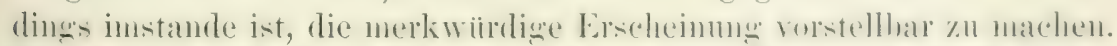

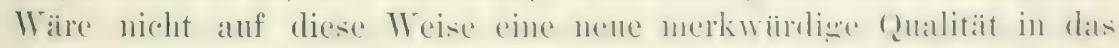

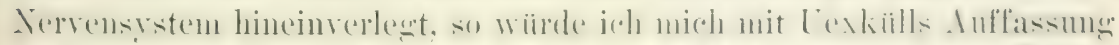

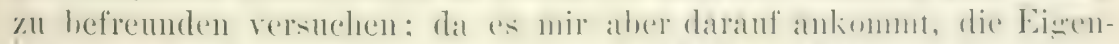

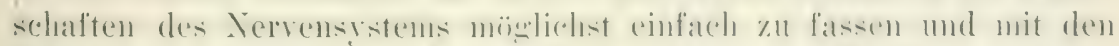

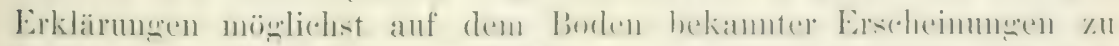

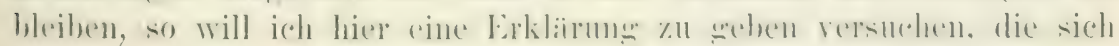
auch bei andern Gelegenheiten als branchbar erweisen diirte. 
Ich habe es oben wahrscheinlich zu machen gesucht, daß wir im Nerven zwei Prozesse anzunchmen haben (wie dies auch schon in etwas andrer Wrise Hering answesponchen hat, namlich eine Platse, welche relativ solnell eintritt und in einee wellenföming sich ansbreitenden Iffinitatserhöhung zwischen Fibrille und Fibrillensïure mit

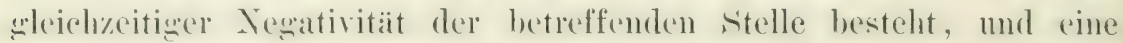
zweite langsam sich entwickehule, restitutorische Phase, bei weleher die Iffinitit zwisclıen Fibrille und Fibrillensäure remindert ist. Man wird die erste Phase als die errexende ansehen miissen, ist aber herechtint, anch der zweiten l'hase eine Wirkume anf die immervierten Orenane, also in diesem Fall auf die Muskeln, einzurämen. Wemn die erste Phase erregend wirkt, so wird die zweite Phase, da sie entegengensescetzter Natur ist, hemmend wirken kïmuen, also dort, wo es sich ını 'Tomusmuskulatur handelt, tonuslösend. Es steht num der Ammahme nichts in Wege, dah der Muskel bei dauerndem Wechsel beider Phasen, wie wir einen solchen bei allen Dauereizen imechanischen nud vor allem chemischen, voraussetzen kömmen, verschieden reagiert, je narhlem die Phasen stark oder schwach sind. Es ist denkbar, dab hei schwachem lieiz die erste P'hase wirksamer ist, bei starkem die zweite. Die stäke des Reizes, bei weleher die zweite l'hase die erste an Wirksankeit ïbertrifft, wird natürlich wesentlich von der Natur des Mnskels abhängrg sein. Man wïrde also das frible Iuftreten des starken Reflexes bei den Klappzangen darauf zuriickführen, daß ihre Muskulatur leichter auf die zweite Phase reagriert als \%. I. die Muskulatur der Stacheh. - Bei dieser Auffassung ist es nieht mehr als natiolich, daß es Muskulaturen wibt, bei denen ein Überwiegen der zweiten I'hase nuter gewïhnlichen Verhältnissen nic zum dusdruck kommit (Bewegnugsmuskulatur der Wirbeltiere, stachelmuskulatur von Arbacia u. S. w.). Daß es gestattet ist, derartige Unterschiede in die Muskulatur zu verlegen, folgere ich vor allem ans den interessanten Befunden, welche Biedermann (1885, an der Krehsschere gemacht hat. Es lassen sich auch Beispiele anführen, wo ohne Zweifel bei Veränderung der Proportion und Stärke zweier zusammeneinwirkender Rieize der Effekt sich indert. Ich erimnere hier nur an den Dichroismus: Dureh eine dïnne wie durch eine dickere sichicht von Chlomphyllïsung grehen sowohl rote wie griine strahlen hindureh, wie die spektroskopische. Entersuchmon lehrt. I)urch die

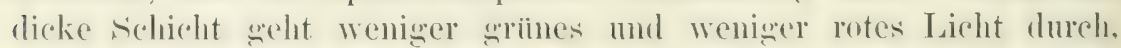

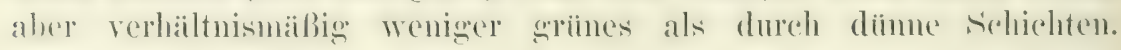
Sehen wir durch die dünne Schicht, so haben wir eine reine Griul-

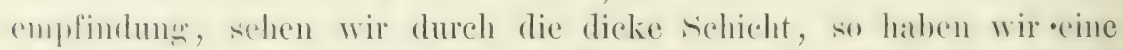

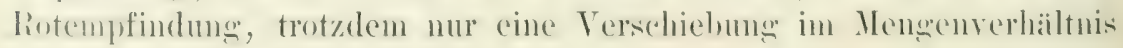
der roten und grüuen Strahlen vorliegt. 
Die seeigel sind nun durehaus nioht die cinzigen 'Tiere, bei denen sich eine Reflexumkehr konstatieren laißt; die Erscheinmmen diuffe vielnehr eine ziemlich häufige sein, nur läßt sich in vielen andern raillen nicht sicher entscheiden, oh nicht hei der stairkeren licizmm andre rezeptorische Elemente entroffen werden wie bei der schwaten. In ciniwen Fällen dürte dies allerdings auspeschlossen sein. Derartige Fälle waube ich in einer Anzahl ron somenannten Tropismen sehen zu diurfen, hei denen häufign bis zu sूewissen Reizstäken ein positirer Effekt zu beobachten ist, del dam hei stäkerem Reiz ins Gerenteil

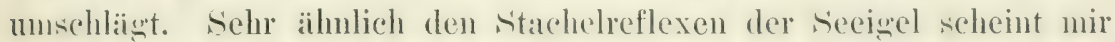
das Verhalten der Seheren von Krebsen zu sein Careinus, ('ancer, Astacusi. Tem man an die Innenseite der seriffneten schere cinen Genenstand bringt, so klappt die Fehere zusammen und bleibt langre geschlossen. Benutzt man als berïhenden fegenstand die eine branche einer stahlernen Schere, so wirl wie sonst die Krehsschere onshossen. Drïckt man jetzt die stahlschere zu, wobei es nicht eimmal nöig ist ein sitück von der Krebsschere abzuschneiden, so öffnet siroh die Krehsschere auf diesen starken Reiz hin sofort. Dasselbe läß3t sich bei tetanischen Reiz erreichen: Bringt man die bis anf die suitzen mit Lack iiberzogenen Nadelelektroden so zwischen die weöfnete Krabsschere, daß kein Ast derselhen beribut wird (das Versuchstier liegt in flachem Wasser) und läßt num bei mäßigem Rollenabstand den Induktionsapparat gehen, so wird die Schere geschlossen. Verstäkt man den strom plötzlich, so wird die Sichere sofort wë̈ffnet. - Ieh glanbe kaum, daß diese Erscheinumg durch Reizung verschiedener rezeptorischer Faseru, vou denen die einen einen rehließungsieflex, die andern einen Öffnumesreflex hervorufen, wird erklärt werden miissen, sondern ich bin der Ansicht, daß hier heidenal ein und dieselhen Fasern gereizt werten, dah hier also eine schwalche und eine starke Reflexform vorliegt. 


\section{Die Irreziprozität der Zentralteile und die Leitungs- verzögerung in denselben.}

Sieitrlem durch Bell, Mascendic und viele spätere Lutersucher festwestellt ist, daß die hinteren Rïrkenmarkwnyeh sensibel, die vorderen motorisch sind, besteht fiur diese Tiere das fresetz ron der Leitunsirueziprozitait des Zentralnervensystems, wenn es auch nicht steich in voller sichärfe aufzestellt worden ist. I) allein motorische Funktion der vorderen Wureln komnte ja nur damn erschlosisen werden, wemn Irreziprozität lestand; bestande keine, so wiirde die Reizmug des zentralen stumpfes einer vorderen Wruzel Reflexzuckum erweben und nu aus der Tatsache, daß hierbei lieflexzuckmenen ausbleiben, wurde daranf „2eschlossen, daB sie frei von zentripetalleitenden Fasern seien. - Der konsequente Schluß aus den Resultaten der Wurzel-

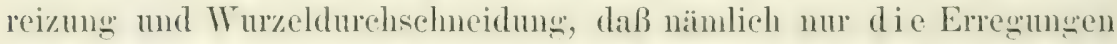
das Zentrahnervensystem durchsetzen, welche auf dem Wegre zentripetaler isensibler, rezeptoris(her) Fasem cintreten, dah also die Leitung einseitig ist, wurde, so weit ich sehe, zuerst ron Joh. Miiller gezogen. Um zu sehen, ob die Einseitigkeit der Leitung wirklich absolut oder nur relativ ist, vergiftete Joh. Miiller Frïsche nit Opium und durchschnitt ilnen dann die hinteren Wurceln. Wem dam die Reflexerrewarkeit so stark westiegen war, daß schon bloßes Erschüittern heftige lBewesunen hervorief, dam reizte el den freigelegten Ischiadicus der operierten seite durch Zerschneiden mechanisch, erhielt aber trot\% der großen Empfindlichkeit der Frösche und trotz des starken Reizes keine Reflexaktion. Dadurch war es bewiesen, dab die motorischen Fasern absolut nicht imstande sind, cinen ihnen zuefefïhten Rei\% durch das zentralnervensystem hindureh auf andre motorische Bahnen zu iibertragen.

Der Mïllersehe Versuch ist dam später von verschiedenen seiten mit den smeichen Erfolg. wiederholt worden (hesonders unter In-

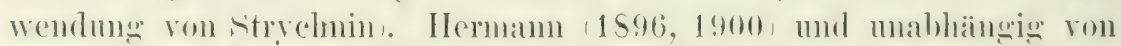

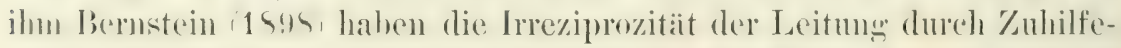

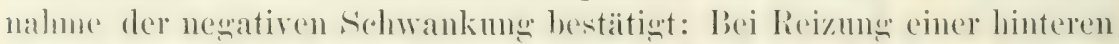
IIn\%el wurle negative fichwankmo an vorderen Wu\%ch erhalten, aber nicht umgekehrt.

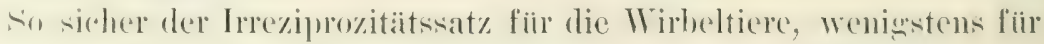
ihr zentralisiertes Nervensystem gilt, so kann ich ihn doch rol- 


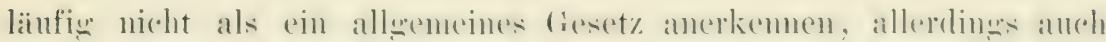

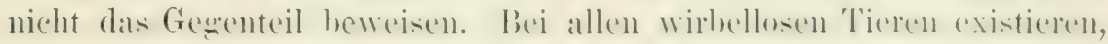
soriel ich weiß, nur wenige Beispiele für rein rezeptorische Nerven und kein einziges für einen rein motorischen Nerren. D. h. es sind bisher bei diesen Tieren keine Verven bekinnt, deren zentraler stumpt bei der Reizung nicht Reflexzuckungen auslöste. Hier ist also ein

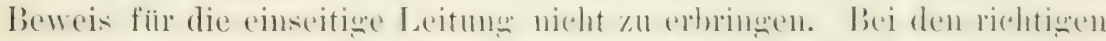
Nervennetzen, wie wir sie z. B. bei den Medusen finden, scheint es mir höchst wahrscheinlich, daß sie in jeder beliebigen Richtung zu leiten imstande sind, und ich werde weiter unten iiber Befunde ron Uexkïll berichten, welche wohl kaum anders, als durch die An-

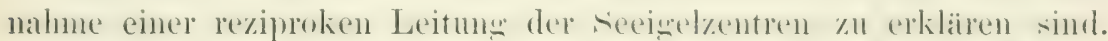

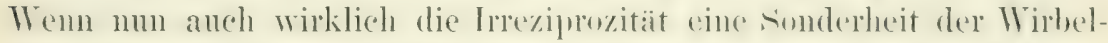
tiere sein sollte, so wïrde dies die Pliysiologie nicht der Aufgabe iiherhehen, dieselbe rerständlich zu machen. Inwieweit ist cin solches

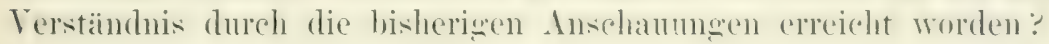

Als eine wirkliche Erklälung ist die Anschaumng ron Wundt (1976) anzusehen. Er nimmt an, daß die Ganglienzellen aus zwei Zonen bestehen, einer peripheren, welcher die Reize zngeführt werden, mol einel zentralen, welche die Reize latent macht und num anf wiederholte oder sehr starke Reize das Latenterwordene durch den Achsenzolinder abonibt. (Durch diese Einrichtume findet hei Wrundt anch die Terzögrame der Leitung und die summation ilue Erklärung., Leider baut sich diese Ansicht auf friihere Annahmen auf, die sicher unrichtig sind, so daß ihre weitere Erörterung iiberfliisim escheint.

Seit die Neuronentheorie in Aufnahme gekommen ist, glaubt man merkwürdigerweise in ihr den Schliussel zur Erklärung der Irreziprozität zefunden zu haben. Man meint nämlich die Lrsache der einseitigen Leitung an die Stelle legen zu kömmen, wo nach der Neuronentheorie nur Kontakt besteht. Ohne eine weitere besondere rentilartige Einrichtume an dieser stelle wäre alder bei besteltender. blober

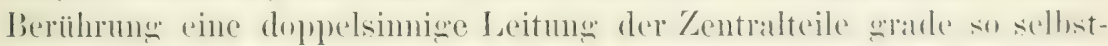

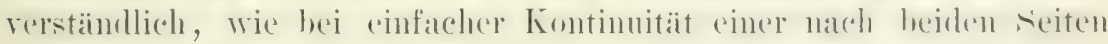
leitenden Substanz. Wenn ich in dem oft angewandten Bilde sich ladender Konduktoren bleibe: Der Funke springt grade so gut ron einer Kondensatorkugel zu andern, wie ron der andern zur ersten. $\left.{ }^{1}\right)$ Ichkann also durehaus nicht zugeben, daB die Kontiguitästheorie in diesem Punkt den geringsten Vorzug vor der Kontinuitatslehre hat. Sie muB ebenso wie diese Hilfsannahmen machen, um den 'T'atbestand zu

1) Zum Vergleich mit der Entladung zwischen einer Spitze und einer Kugrel fehlen die anatomischen Vorbedingungen. 
crklären: dia nun aber, wie oben wereigt, alle neneren anatomischen [utersudhungen cine hontinnitait des leitemden Elements hiöchst wahrsoheinlich machen mul hei manchen objekten mit sicherheit beweisen,

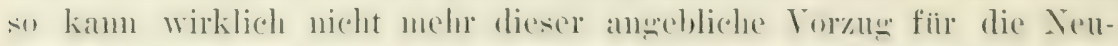
ronentheoric ins Feld gefïhrt werden. (In sehr klarer Weise hat

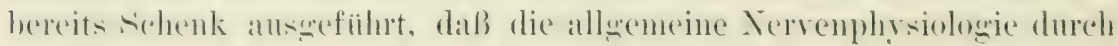
die Neuronentheorie nichts gewonnen hat.)

Wemn man anf Grund der Irreziprozitait einen Gegensatz zwisehen peripheren Verven und \%entralteilen anfstellt, so sieht man es als sellstrerstindlich an, daß der periphere Nerv nach beiden sieiten hin sweich sut leitet. - Der satz der doppelsimigen Leitumg wurde auf verschiedene Weise zu beweisen gesucht; ron den viclen Versuchen. die zu seiner sicherung angestellt sind, haben sich die allermeisten als nicht beweisend erwiesen Paul Berts Ratte, Verheilungsersuche zwischen motorischen und sensiblen Nerven. Als swïltige Beweise werden im allgemeinen nur die Fortpflanzung der negativen sichwankung nach beiden seiten und der Kühnesche Zweizipfelversuch angesehen.

Die Lntersuchum der negativen Schwankmog an beiden Enden eines gemischten Xerven hat natürlich gar keine Beweiskraft. In rein motorischen oder rein rezeptorischen Nerven sind aber, so viel mir bekannt, nur wenige Versuche angestellt \%. Is. Küihne. Sie ergaben, daß die neerative Schwankung nach beiden seiten verläuft. Dasselloe wurde von Pereles und sachs bei der Reizung des Ischiarliens und Wheitung ron der motorischen Wurel und bei lieizmng der semsiblem Wurehn und Dbleitme vom Ichiadieus konstatiert. Eine quantitative Vergleichung hat aber bisher niemand unternommen. Es wiire num doch sehr grut möglich, daß ein Dekrement in der Líchtung der normalen Leitung sanz fehlte, wïhrend in der muntïrlichen Richtung ein starkes Dekrement vorhanden wäre. L'm die doppelsinnige Leitung als absolut hinzustellen, hätte man erst zu zeigen, daß sich die nexative schwankmo in reinen Neren nach beiden seiten hin mit frleicherstärke ansbreitet. Nir scheint einiges dafür zu sprechen, daß dies nicht der Fall ist. Hierbei habe ich ror allem die ron du Bris-Reymond entdeckten und ron Mendelsolun IS5.) weiteruntersuchten Achsialströme im Auge, welche doch zu beweisen scheinen, daß ein Lnterschied zwischen dem Ende, nach dem ein Verv physiologisch hinleitet, und dem Ende, ron dem er fortleitet, existiert. Leitet man von beiden Guersehnitten einer motorischen oder semsiblen Wurcel,

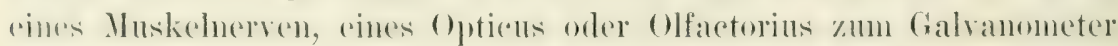
ab, so bekommt man einen Strom, der nach Mendelsohn der physiologisehen Leitungsrichtung entgegengesetzt ist.)

Der Zweizipfelversuch ist, wie Kühne (1586) selbst ausgeführt hat, nur unter gewissen Voranssetzungen beweisend für die doppel- 


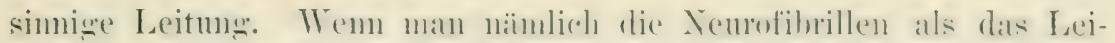

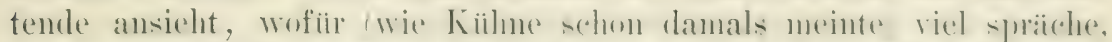

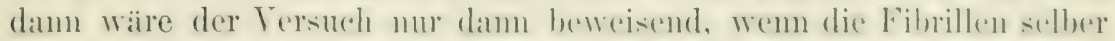
sich an den Teilumsstellen der Jervenfasern trilten. Es kiinnte abler

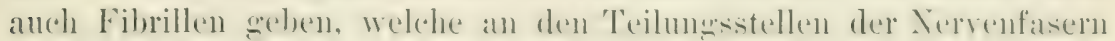
von einem Muskelzipfel zum andern verliefen nut wewissermalien inter-

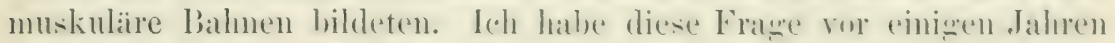

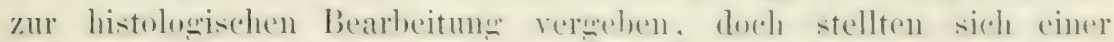

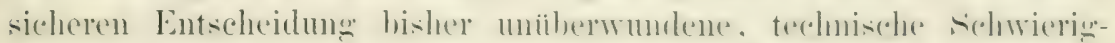
keiten in den Weg. Die Beweiskraft des Zweizipfolversuchs bildet also noch eine schwebende Frage. Nehmen wir aber an, daß wirkliche riickläufige Leitumg vorlient, so ist anch hier iaher die ynantitativen Verhältnisse nichts gesagt.

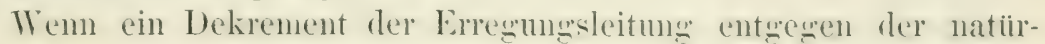
lichen Leitungsichtmug iiherhanpt existiert, so steht der Ammahme nichts im Wege, daß es sich wesentlich rereröbert, wenn die Fibrillen sich teilen, wie dies sicherlich in Zentrahnervensistem secholit. Der firmel hierfür ist leicht einzuselen. Man kamn sich rorstellen, daß das Inekrement beim C̈berwang anf immer weitere 'Teilungen so stark wirl, daß eine riickläufige Leitum von motorischen Fasern auf sensible oder andre motorische, mmögheh gremacht wird. In der normalen Leitungsichtung, wo das Dekrenent fehlen wïrde, wiilde dagregren einer Ausbreitung des Reizes nichts im Wege stehen. Diese Erklärung wiirde natiolich durch eine andre zu ersetzen sein, wemn nene L'ntersuchungen zeigren würden, daß ein solches Dekrenent in Jerren nicht zu konstatieren ist. C̈brigens halte ich es nicht für auspeschlossen. daß die Irreziprozität nur habituell ist.

\section{Die Leitungsterzögerung in den Zentralteilen.}

Die deschwindigkeit der Vervenleitune in den markhalticen Nerrenfasern, welche zu querostreiften Muskeh führen, hetrignt nach

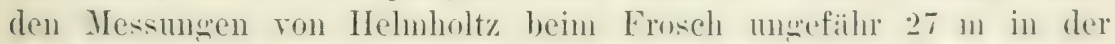

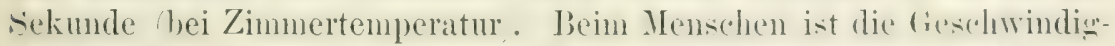

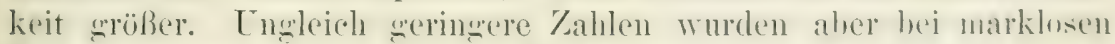

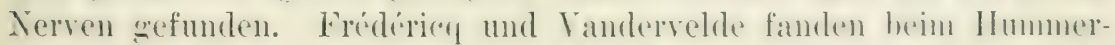
nerven nur eine Geschwindigkeit ron 6-8 m, Uexkiill (I 894 ) bei Eledone von $0,4-1 \mathrm{~m}$, Nicolai (1901) beim Olfactorius rom Hecht

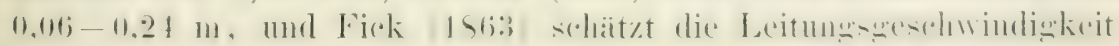
der Kommissurnerven ron Anodonta nur auf $0,01 \mathrm{~m}$ in del Sekunde.

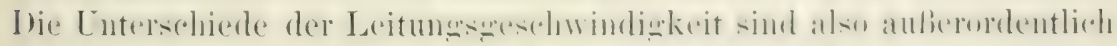
groß und zwar nicht nur bei den verschiedenen 'Tierarten, sondern auch bei den verschiedenen Nerven ein und dessethen 'Tieres. Auch

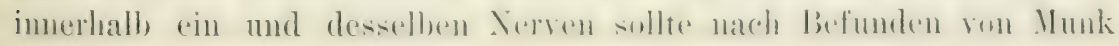


mud Rusenthal die Leitungseschwindirkeit an verschiedenen Stellen versehieden stop soin: doch scheint dies nach den unfangereichen

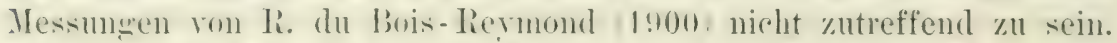
Wenn nun vielleicht anch die Leitmusweschwindirkeit in den rezeptorischen Xerven eines Tieres nicht so Eroß ist, wie in den motorischen, wie dies Helmbultz, Windt, Exner mon andre in ihren Versuchen

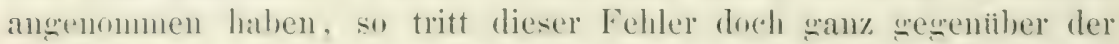
groben Leitungserziigerung zuriick, welche sich beim Reflexprozeb in den Zentralteilen herausgestellt hat.

Die ersten derartigen Versuche wurden von Ifelmhloltz i 5.59 in der Weise angestellt, dab er bei einem dekapitierten mol strychninisierten Frosch sensible Verven reizte und die Latenz maß, welche zwischen lieiznnment und Zuckung eines schreibenden Inskels verweht. Zum Teresteich wurde der motmiscle Nerv direkt gereizt und die I) ifferenz der Latenzzeiten berechnet. Sie ergab sich zur ${ }^{1} / 30^{-1} / 10$ Sekunde. ..Die C̈bertrag"ung der Reizung in Riickemmark" nimm danach ,.eine mehr als zwölfmal so swrobe Zeit in Anspruch, als die Leitmo in den betreffenden sensiblen und motorischen Nerven".

Exner, 1574, snchte die Reflexzeit hein Wensehen zu bestimmen und benutzte den Lidschluß des Menschen als Reflexzuckung. An den Lide des einen Auges war ein Hehel angebracht, welcher die Bewegmo auf der Kinnographiontrommel aufzeirhnete. Das Lid des andren Auges wurde durch einzelne Induktionsschligge sereizt, mud der Reizmoment ehenfalls markiert. IBei einem Rollenabstand rom 9 cm betrum die Reflexdaner im Vittel 0,0662", hei einem Rollenahstand ron $5 \mathrm{~cm}$ nur 0,0578". Exner nimmt für die Länge der Leitungsbahnen, welehe diesen Reflex remitteln, 3.5 ('m an; bei einer Leitungmeschwindigkeit ron $32 \mathrm{~m}$ in der sekunde würden für diese strecke (1,0057" verbraucht. Die Muskellatenz nimmt er halh so wrob an wie heim Frosch, nïmlich zu 0,00:"." Zieht man diese Zeitmengen rom den gefundenen Reflexzeiten ab, so hekommt man als, „redurierte Tieflexzeit" d. h. als diejenige Zeit, welehe der eigentliche zentrale Vorgang in Anspruch nimmt, 0,047-0,055". — Diese Zeiten sind

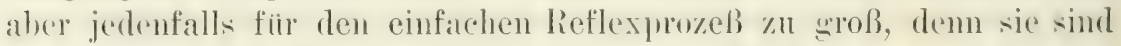
schon beim Froseh geringer (siehe unten). Erstens ist eine gewisse Latenzzeit der liezeptimsorwane der Haut anzmehmen, zweitens ist

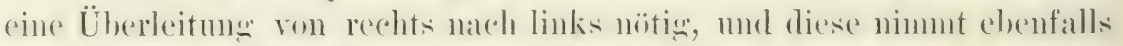
mehr Zeit in Anspruch als reine Nerrenleitung.

An genanesten ist die Reflexzeit von Wundt (1876) in einer

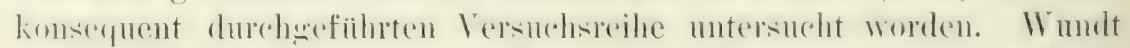
bemutze Reflexpraiparate rom Frosch; der Gastrocomemins ciner seite

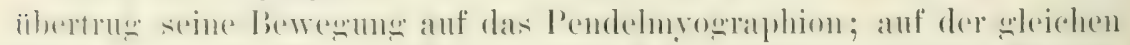

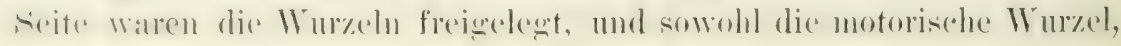


von welcher der diastromemins immerviert wirl, als ande cine weichseitise, dicht henachbarte hintere Wurel waren mit Elektwolen amiert.

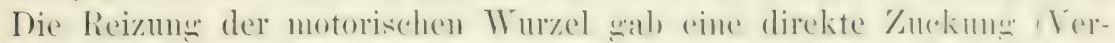

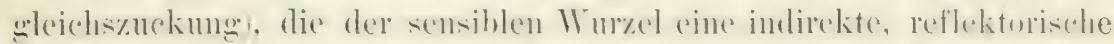
Zuckung. Es wurde nun die Latenzzeit bei direkter Reizung ron

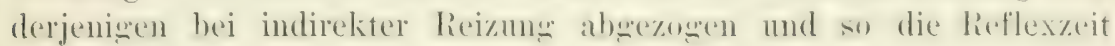
ermittelt. Einen wirkliehen Sehluß auf die Reflexzeit lassen die Kurven nur dann zu, wemn beide Kurven gleich hoch sind; da nun

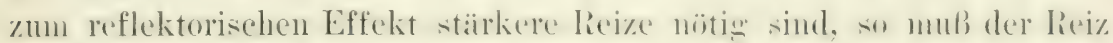

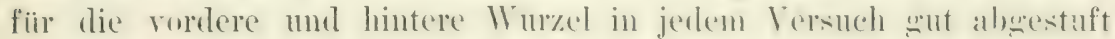
werden. Die totale Latenz (rom Reizmoment bis zum Anfang der

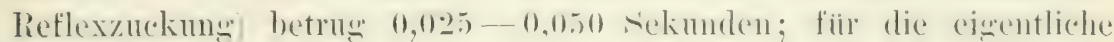

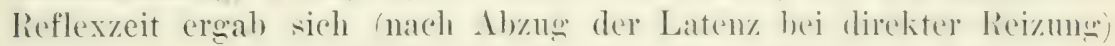
ein Wert ron 0,008-0,015". Wird der Reiz für beide Reizpunkte rerstärkt, so wird die totale Latenz sowohl fuir die direkte, wie für die reflektorische Zuckung verkïrzt, die I)ifferenz beider, d. h. die eigentliche Reflexzeit, bleibt aber ziemlich gleich.

Die Schnelligkeit, mit der der Muskel auf den ihn vom Nerven

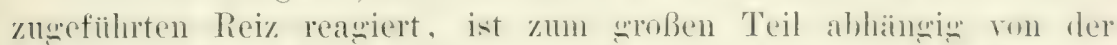
Staike des zugeführten Reizes. Nach den Untersuchungen von ๖. Vintschen wird aber anch die Geschwindigkeit der Nervenleitung mit zunehmender Reizstäke größer. Eine Folge dieser heiden Faktoren ist, daß bei ungenitwender Bbstufune beider Reize in Reflexversuch eine Differenz zwischen der totalen Latenz bei direkter mol indirekter Reizung entstehen kann, welehe der eigentlichen Reflexzeit nicht antspricht. Wrundt nennt diese Zeit die Differenzzeit. Ist der direlite Reiz stark, der reflektorische lieiz schwach. wohei dic licflexkmre niedriger aufällt, als die Verweichskure, dam ist die Inilfurem\%zeit „rüber als die Reflexzeit. In mongekehten Fall wird sie kleiner, und es gelang Wundt in einimen Fällen die Differenzmit nicht nur sheide sull, sondern sogar newativ zu machen. Wemm man also jede

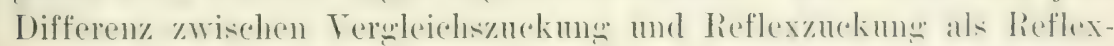
zeit ansehen wiurde, dann wiirde man zu dem Paradoxon gelangen,

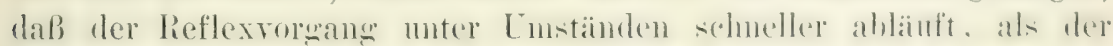
Reiz gebratcht, $11 \mathrm{~m}$ ron der motorischen Wurzel bis zum Muskel zu

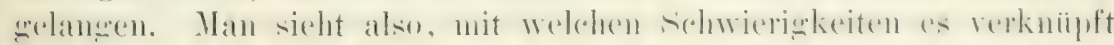
ist, die wirkliche Reflexzeit zu ermitteln, und es erscheint möglich,

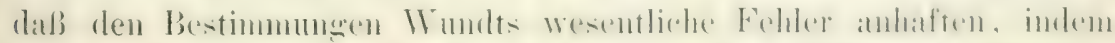

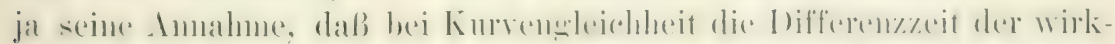
lichen Reflexzeit entspraiche, nicht absolut zwingend ist. Das wird

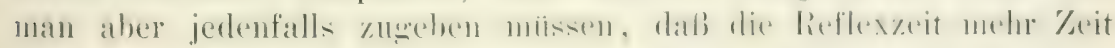
in Anspruch nimmt, als bei einfacher Leitung in parallelfaserigen

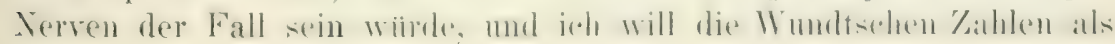


im wesentlichen richtig himnehmen. Il. h. etwa $1 / 100$ sekunde als Verzögerung beim einfachen Reflex des Frosches.

Da der Reiz beim Reflexrorgang, wie der Ursprung motorischer Vervenfasern ans den motorischen Vorderhomzellen lehrt, dureh cian-

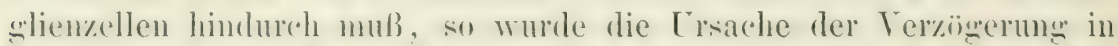
die (ianglienzellen hineinverlegt. Wir wisen jetzt, daß der Reiz aber anch durch ein Filntilengitter hindurch muß, un ron der re\%eptorischen IBahn anf die effelitorische zu gelangen, und da die spezifische Beteiligun der (ianglienzellen an den Reflexvorwingen nach meinen Versuchen hörchst zweifelhaft ist, so werden wir anch die Lrsache

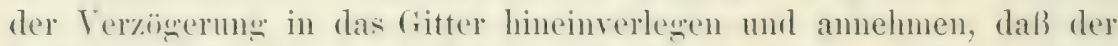
Leitmonspozed hier einen Widerstand erfährt. Daraus eroibt sich als Konserpuenz, daß der Widerstand wächst, wem die Reizwelle mehrere

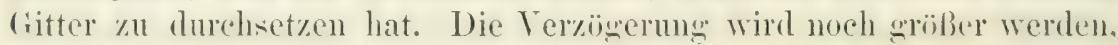
und der anslïsente Reiz stärkel sein müssen. Dak dies richtig ist. zeigen Experimente, welehe unter dem Einfluß der Gamglienzellhypotliese angestellt sind, und welche unter anderm beweisen sollten. daß die Verzögerung größer ist, wemn mehrere Ganglienzellen durehsetzt werden nuïssen. Da nun Gitter und Ganglienzellen immer in enger Ibziehmo zucinander stehen, so gelten die anf die Ganglienzellhypothese stimmenden Versuche grade so sut für die Fibrillengitterhypothese.

Wundt (1876) rerglich die Dauer der einfachen Reflexzuckung. (beim Frosch) nit der wekrenzten Reflexzuckum und derjenigen bei Längskleitung. (Eine sensible Wurzel der linken sieite wurle gereizt

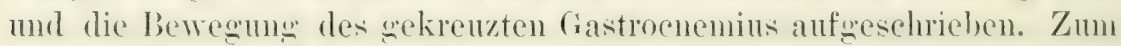
Vergleich wurde eine sensible Wurzel der rechten Seite gereizt. In andern Falle wurde ein Reiz an rechten Vorderam angesetzt und der rechte fastrocuemins schreiben gelassen. somohl bei (querleitung. wie bei Lïngsleitung fand sich die Reflexzeit um etwa 0,004" länger als bei einfacher Reflexzuckung.

Einen recht instruktiren Versuch hat Exner (1874) nach dieser Rirhtung hin angestellt: Er ließ den fatstrocnemins eines Frosches schreiben. Dieser stand mit dem gesamten heranspriparierten Zentralnervensystem durch den Ischiadicus in Verbindung. Es wurde num das Nervensystem successive rom Großhim anfangend mit einem fallenden Hebel zerquetsedit. Der Zeitmoment des Falles worle unter

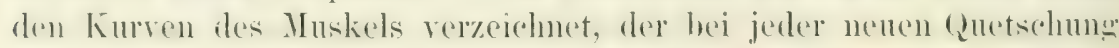

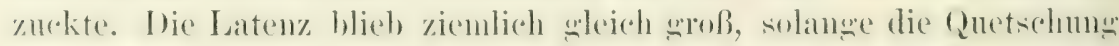
im Bereich des Gehirns stattfand. An der Medulla sank sie ziemlich plitzlich ab, $1 \mathrm{~m}$ diann beim C̈hereang anf den lerven noch eimmal abzufallen. Hieraus wird es wahrscheinlich, daß der Reiz in der Medullagegend Zellen resp. Gitter zu passieren hat. 
Hierher wären auch all die vielen Versuche zu rechnen, welche

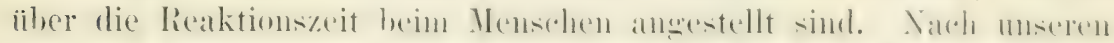

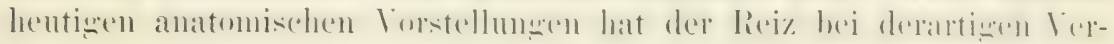
suchen eine große Anzahl ron Zellen resp. Gittern zu passieven, und

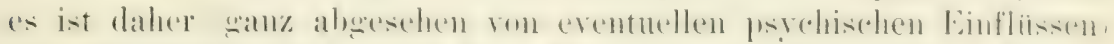

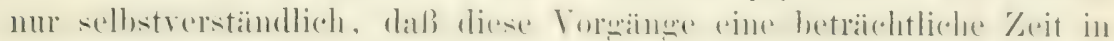
Anspruch nehmen. Bei starkem Reiz und guter Übung kamn man es

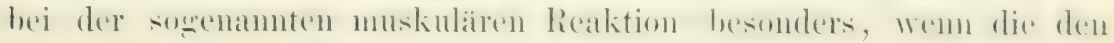
Kontakt lösende Hand den Reiz selber in Form eines Induktionsschlages empfängt) bis auf etwa $0,08^{\prime \prime}$ herunterbringen. Die sen-

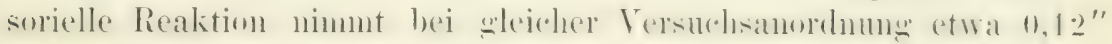
in . Inspruch; bei schwachem Reiz noch wesentlich mehr. wiehe hieriiher die Lehrbüeher der Psychologie.

Die Versuche, welche gemacht worden sind, um zи zeigen, daß die Verzögerung in die Ganglienzellen zu verlegen ist, können als zweidentige angesehen werden, wenn man die neneren Erkemutnise nit in Betracht zieht. Mls nur aus (xanglienzellen bestehende Durcheange-

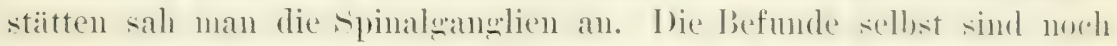
nicht ühereinstimmend, inden Exner 157\%, keine Ver\%ögermug in

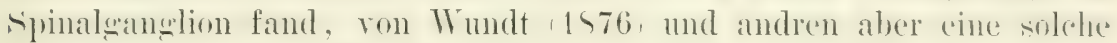
konstatiert, wurde. Wenn es sich herausstellen sollte, daß hier wirklich eine Verzögerung stattfindet, so ist damit nichts gegen meine

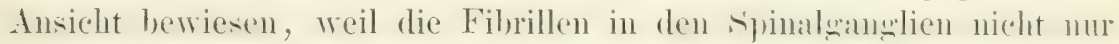
Zellen passieren, sondern anch innerhalb dieser Zellen (itter bilden.

Wir haben bereits gesehen, daß die Geschwindigkeit der Nervenleitmon nicht nur bei verschiedenen Tieren, smotern anch immerhall,

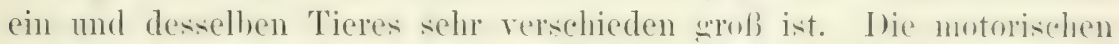
Nerren des Hechtes dürften wohl ebenso schnell leiten wie die des

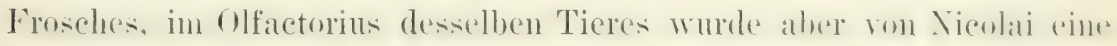

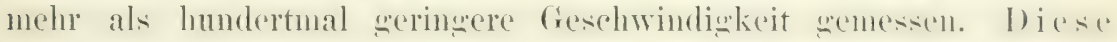
schon in den peripheren Nerven bestehenden, enormen Unterschiede berechtigen uns inden Fibrillengittern cine ebenso langsame Leitung anzunehmen, und allein durch diese Übertragung bekannter Eigensehaften mancher Nerven auf dieZentralteile wird dieverlangsamte Leitung derselben auch ohne geheimnisvolle Eigensehaften der Ganglienzellen genügend erklärt. 


\section{ACHTZEHNTES KAPITEL.}

\section{Reizsummation und Bahnung.}

Um einen Wirbeltiermuskel rom Nerren aus zu erregen, genügt

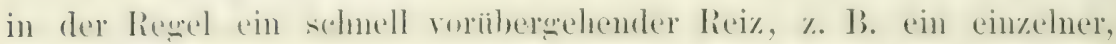
schwacher Induktionsschlaw. Je steiler die stromschwankmug ist, desto sicherer ist der Erfolg. Folgen nehrere Reize schnell hintereinander,

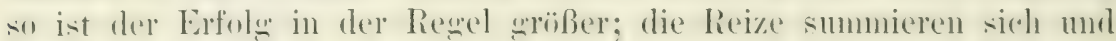
der Muskel gereait in einen mehr oder weniger vollkommenen Totanns. der allnählich zu voller Höhe ansteignt. Wirkt der einzelne Instantanreiz nicht anf den motorisehen Nerven direkt, sondern wird er an einem sensiblen Nerven oder an der Haut angesetzt, so daß die Zentral-

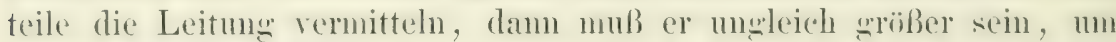
ïherhaupt emen Effekt anszulösen. VerhältnismäBig schwache Reize, welche anch weniger schroff sein kömnen, bringen dawegen einen ansgectehnten reflektorischen Erfolg hervor, wemn sie sich wiederholen. I) Reizsummation ist hier nahezu Bedingmon, damit ein Effelit zustande kommut. Dieser (iegrensatz zwischen direkter und reflektorischer Errewny wïrde aber nur dann von prinzipieller bedeutung sein, wem es nicht Xerven wähe, die ziemlich dieselben Reizbedingwnen rerlangen, wie die Zentralteile.

Während beim Frosch die steileren öffnmmsinduktionswehlïge wirksaner sind als die weniger steilen schließnugsichläge, ist dies bei der Kröte nicht mehr der Fall (Schott und Griitzner). Bei rielen wirbellosen Tieren ist eine Erregung durch einzehe Induktionsischläge iiberlanpt nicht möglich. Auch die stairksten sichliage greben keine Znckung. Dagegen wirken mohrere einander folgende schlïge auch damn gut, wemn sie relatir schwach sind. Tetanische Reize wirken gut, einzelne Reize wenig oder gar nicht. Bei Anwendung des konstanten stromes ruft eine kure schließune elsenfalls keme liealition hervor, während längere Durchströmung des Verven eine statke Wir-

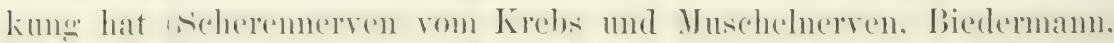

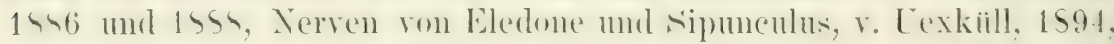
Nerven ron Aplysia und Nacktschnecken, Bethe). (Bei Mollusken

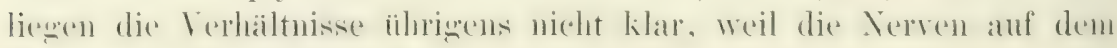
Wege zum Muskel von Zellen unterbrochen sind.

Da es hauptsächlich die Nerven mit langsamer Leitung sind, welche starke Summationserscheinmgen zeigen, so könnte man rer-

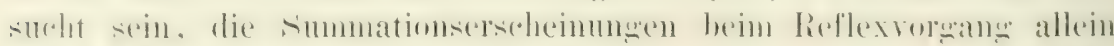

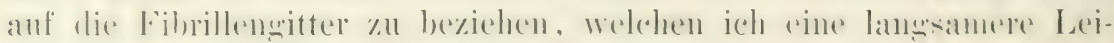

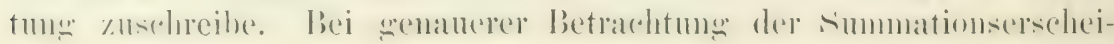




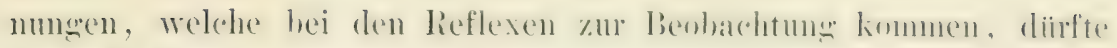
diese Erkläirung aber nieht als genügend erscheinen:

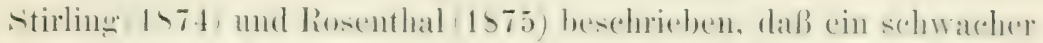

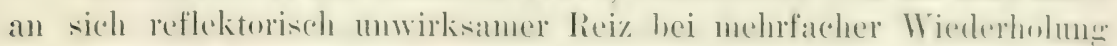

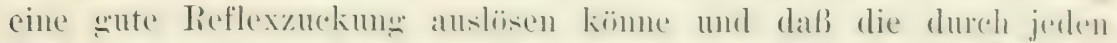

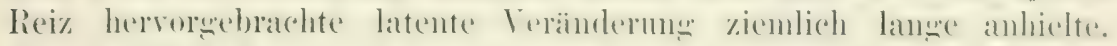

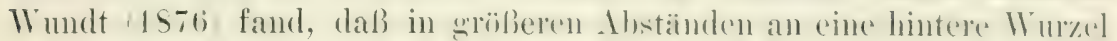

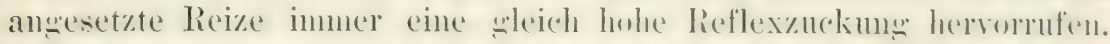

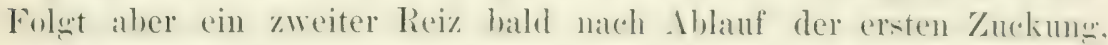
so ist die zweite Zurokmo höher mol werlehnter. Noch dentlicher tritt dies hervor, wemn die Wurel vor dem zweiten Reize schwach tetanisiert wird. Inie Nachwirkmon des, ,nodifizierenden Reizes" war atroh in diesen Experimenten eine ziemlich lange.

Genanere Angaben iiber die Daner der Nachwirkung verdanken wir der Arbeit ron Ward (1880). Bei Reizen, welche unter der schwelle blichen, die also an mul für sich in eröberen Mbsäinden anģesetzt, noch keinen reflektorischen Effekt hervorriefen, konnten Simmationserscheinmoren noch konstatiert werden, wemn dic einzelnen Reize Induktionsschläge, his zu $1^{\prime \prime}$ auseinandel lagen. Bei cincm Reizintervall ron $0,05^{\prime \prime}-0,40^{\prime \prime}$ zeigte sich nun eine ganz gesetzmäBige Erscheinmog: I) Reflexuckung tritt nämlich bei ein und demselhen Frosch stets nach der orleichen Anzahl von Reizen auf. In

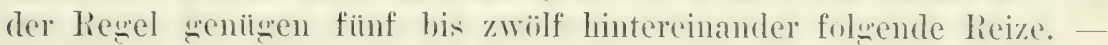
Nach diesen Befund zu schliefen, bleiht also der durch jeden Einzel-

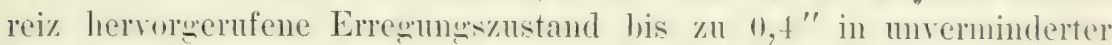

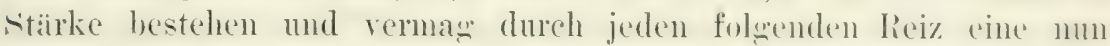
wieder ehenso lange anhaltende steigerung zu erfalnen. - Es fragt sich, ob diese lange Nachwirkung rorherewangener Reize dureh die Eizenschaften lans-san leitender Fibrillen wenïgend erkliat wird und ol nicht vielleicht den Wirlerstand in den Z/2ntralteilen besondere Eigenschaften zuzuschreiben sind.

Wie schon erwähnt, ist der Widerstand in den Zentralteilen in

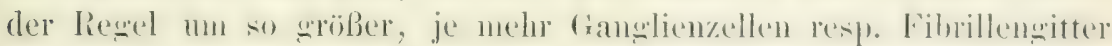
der Reiz zu passieren hat. Diese Eigentiumlichkeit war im Prinzip

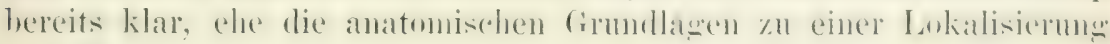
des Widerstandes gegeben waren. Johamnes Miiller sprach bereits den Satz aus, daß bei Reizmng einer Körperstelle zmächst die ihr

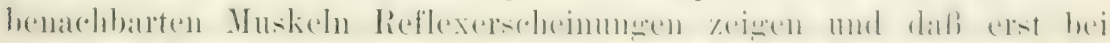

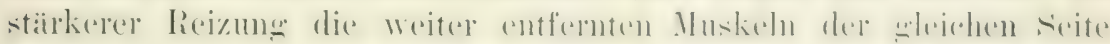
umd die Muskeln der gekreuten Seite in Aktion treten. Weiter aus-

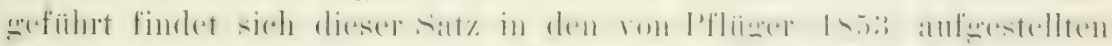

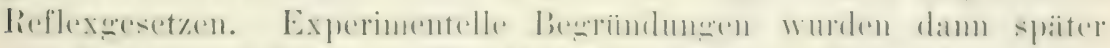

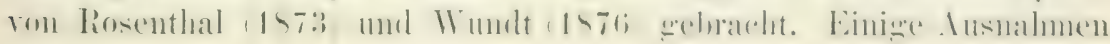


von diesel liewel sind seit langem bekannt. So kamn \%. B. hei süngetieren ein weit antfernter rezeptorischer Reiz cher eine T'upillenreaktion und eine alleneneine blutdrucksteigerung herorrufen, als die dem Reizort an nächsten verbundenen Muskeln in Aktion treten. Ein sehr

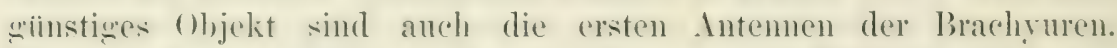
Diese sind in ständiwer zurkender bewennm. Wird irmendwo an Kïrper ein lieiz ansesetzt, der noch keine weiteren heflexe ausliist, so werden doch, falls el nicht allzuschwach ist, die Antemnen fiir einen Monent wanz eingezomen. Diese Insmahmen kömen aber wohl

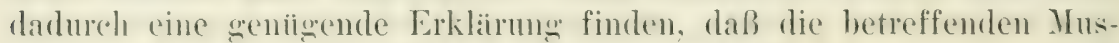
keln besonders leicht reflektorisch erregbar sind.

Den Iiderstand in den Zentralteilen kamn man sich nun eventuell in folmender Weise rorstellen: In den Zentralteilen befindet sich in der Nähe der Fibrillen auBer der ihmen iiberall angelagerten Fibrillensäure eine andre substanz, welche mit der Fibrillensäure in Konkuren\% mu die Iffinitätsvalenzen der Fibrillen tritt. Diese Substanz maџ von einem substrat immer neu sebildet werden, zu ihrer bildum sianerstoff hediüfen und dureh s'auerstoff wieder zerstört werden, kur\% eine sehr labile Substanz sein. Wenn diese einen T'eil der Fibrillenvalenzen in den \%entralteilen imne hat, sic selbst aber zur Fortleitun:des Leitungsprozesses nicht taugt, so wird sie es verhindern, daß jeder kleinste lieiz und jede kur\% roriberohende Zustandsïnderum

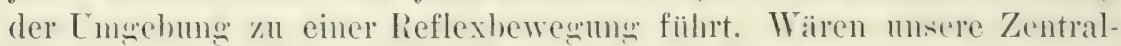
teile ebenso empfindlich wie die peripheren Verven, hesiiben sie alsu keine T)ämpfung, damn wïrden unsere Muskeln in cinem damernden Tanz begriffen sein. Wenn nun jede, durch einen rezeptorischen Verven zugefühte Erregunswelle einen Teil der Konkurenzsustanz verdringt und dieser Zustand des Verdrinertseins einiwe Zeit anhält. so muB die Fibrillenbahn hei mehmaliger Wiederhohms des Reizes schließlich sanz frei ron dieser dämpfenden substanz werden und der

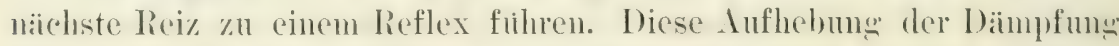
hält dann für einime Zeit an und natht sich darin geltend, dab in kurzen Intervallen wiederholte und anfanws mwirksame Reize jedesmal zu einem Effekt führen. Kommt längere Zeit kein neuer Reiz, so wird die Konkurenz wieder wirksam.

Diese IIypothese soll nul den Widerstand in den Zentralteilen ror-

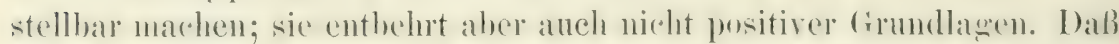

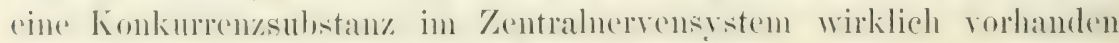
ist, scheint mir aus den in Kapitel S mitgeteilten 'Tatsachen mit

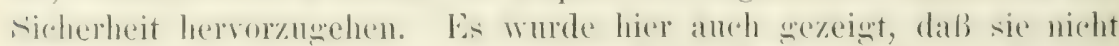

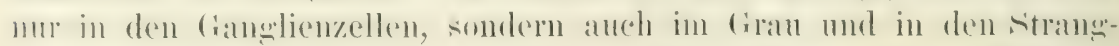
fasern (aber nicht in den peripheren Nervenfasern) ime Wirkung

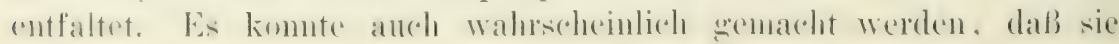


durch Sanerstoff zerstört wird. - In den Ganglienzellen wïrde als Konkurrenzsubstanz eventuell die Nisslsäture in Betracht kommen. In der 'Tat kömnte man eine Anzahl von Daten hierfïr anfihhren: Zn1-

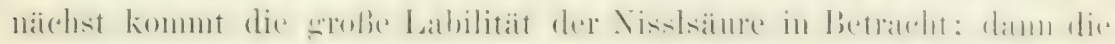
großen Schwankungen in ihrer Produktion und in der Masse ihres Substrates und vermutlichen Erzengers, der Schollen. Die Bilder,

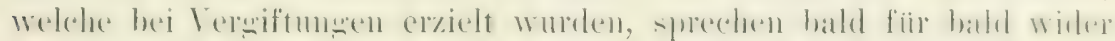

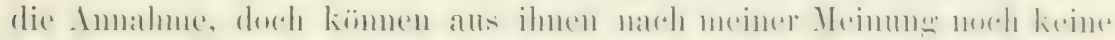

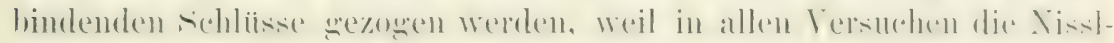

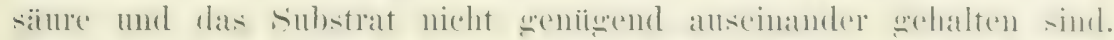

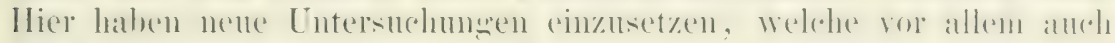
die Löslichkeitsverhältnisse der Nisslsäure mit in Betracht riehen.

Eine Stiitze der Annahme sehe ich in folgenden Erscheinungen: In den Vervemetzen der Medusemsubunbrella und der Herkinnmer.

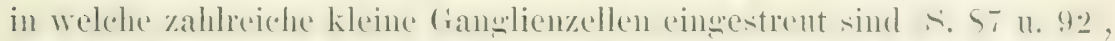
ist kein Dekrement der Erregung zu konstatieren. Ist das Netz an

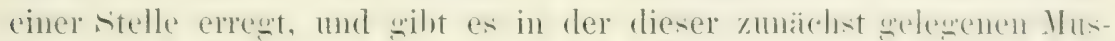
kulatur eine Zuekung, so dehnt sich die Erregrung anch mit sicherheit auf die ganze Subumbrella resp. die ganze Herzkammer aus. In diesen Zellen fehlt aber, soweit ich sehe, jede Spur ron Nisslsäure (d. h. primärfärbbarer Zellleibsubstanz). - Legt man das Riickenmark eines Frosches oder eines Hundes frei, ohne eine weitere Operation zu machen, so zeigt sich, wie bekannt, fast immer entweder direkt oder nach einem stadiun der Depresion eine andierendentlicher

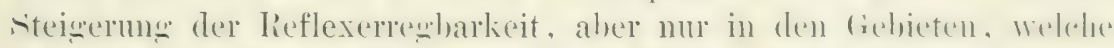

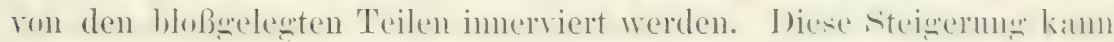

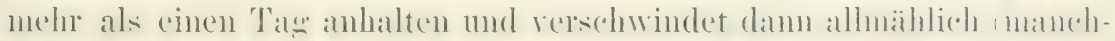
mal tritt sie erst an 'Tage nach der Operation ein). Bei einer (ler-

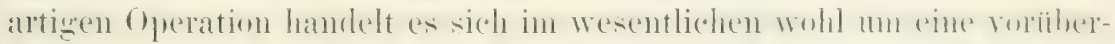

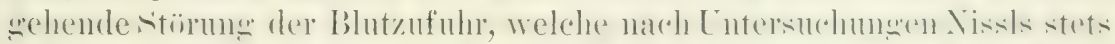

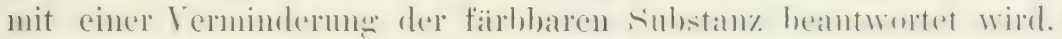

Neben der Nisslsämre - wenn dieselbe überhaupt als Konkurenz substanz aufzufassen ist - wïrde aber jedenfalls noch eine andere

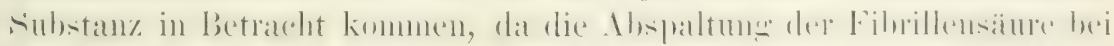

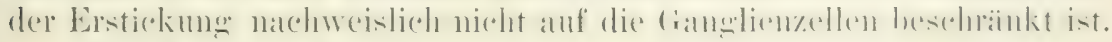

Bei dieser Auffassung der Summationserscheinumgen seheint mir die Annalıme von Exner (1582), daß die Summation nur ein spezieller Fall der Bahnung ist, sehr plausibel. Jeder Reiz bahnt eben dureh

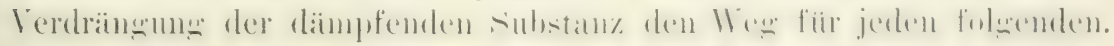
Unter Bahmung im engeren Sinne rersteht Exner das leichtere An-

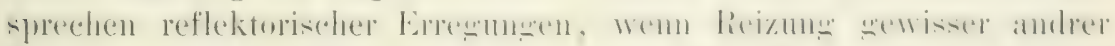
Rezeptionsorgane oder Nervensystemteile voranf gegangen ist oder gleichzeitig geschielıt: 
Exner reizte hei Kraninchen gleichzeitig oder kur\% nacheinander die Hirninde und eine P'fote. Sind beide Reize nnter der Schwelle, so geben sie zugleich angesetzt eine Zuckung: Dasselbe ist der Fall, wenn sie bis zu $0,6^{\prime \prime}$ nacheinander angesetzt werden. Gibt

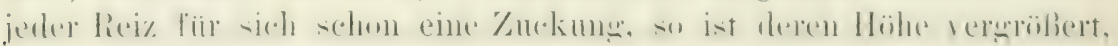
wenn beide Reize zugleich oder ku\% hintereinander erfolgen. Auch bei Kombination ron Schallreiz und Pfotenreiz oder ron Schallreiz und Rindenreiz ließ sich Bahmung konstatieren.

Wie mix scheint, haben wir es bei der Bahnumg im engeren Simme mit einel sehr weit rerbreiteten und für viele nervöse Prozesse höchst wichtigen Erscheinung zu tun. So fand \%. B. Y. Lexküll (1599), daß

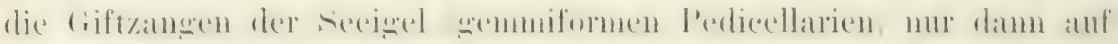

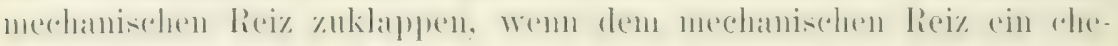
mischer vorhergeht. Merzbacher $(1900)$ sah beim Frosch an sich wn-

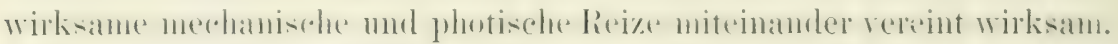
- Bei vielen Tieren z. B. beim Frosch und bei den Crustaceen ist zum

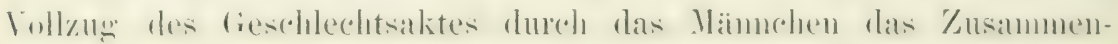
wirlen chemischer mol mechanischer lieize motwendiz. Leim Frosch

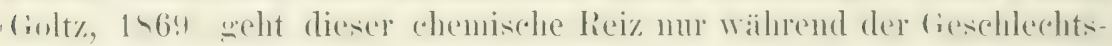
reife vom Weibchen aus, beim Carcinus (Bethe, 1897) nur dann, wemn

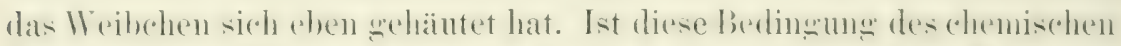

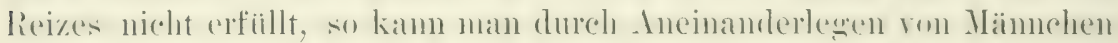

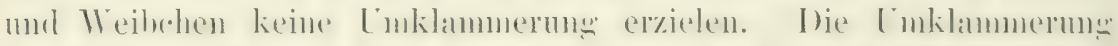

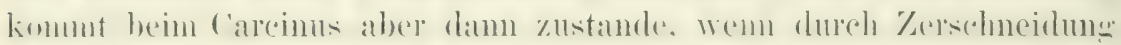

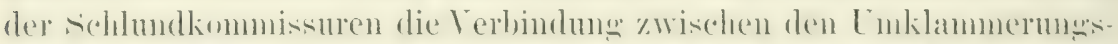

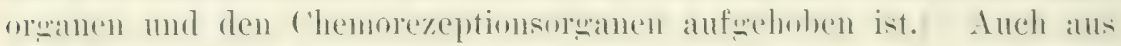

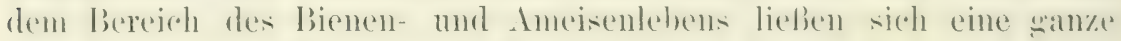
Anzahl derartiger Beispiele anführen.

In allen diesen Fälen wird man sich mit der Erklärung durch

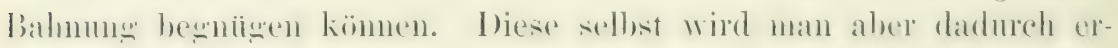
klären kömnen, daß der bahnende Reiz dämptende Hindernisse an den Fibrillen hinwegräut. 


\title{
NEUNZEHNTES KAPITEL.
}

\section{Die Wirkungen von Giften auf das Nervensystem.}

\author{
Steigerung der Erregbarkeit durch Alkohol bei den Medusen S. 359.
}

Es liegt nicht in dem Plane dieses Buches, in eine Besprechung: der rerschiedenen Nervengifte einzutreten; ich muß dies auch schon deshalb unterlassen, weil meine Kenntnisse in der Hauptsache aus der Literatur geschöpft sind und sich nur in wenigen Punkten auf eigne Beobachtungen stützen kömnen. Daher beschränke ich mich darauf, zu untersuchen, ob meiner Auffassung rom nerösen Ge-

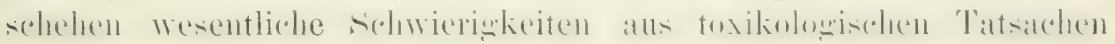
erwachsen.

So verschieden sich die Wirkmngen der einzelnen Nerrengifte außern, so kehren doch immer zwei Erscheinungen wieder: Erreg-

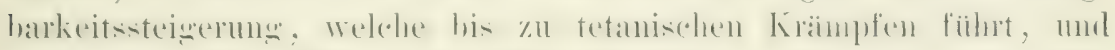
Liahmung. Beide Wirkungen finden sich fast nie granz roneinander

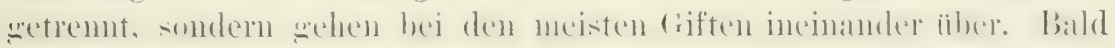
tritt die eine Erscheinung, bald die andre melı in den Vordergrund.

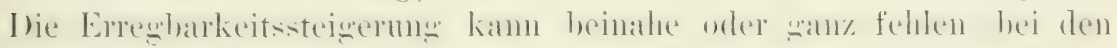

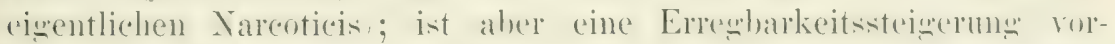
handen (bei Ammoniak, Strychuin rr. s. W.), so geht sie bei stairkerer Eimwirkung des Giftes stets in Lïhmung über.

Der primäre Angriffspunkt der meisten Gifte liegt in den Zentralteilen; einige wenige (Curare u. S. w.) wirken anscheinend in der

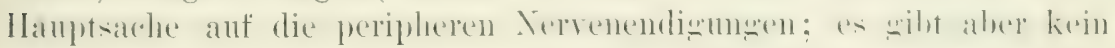
Gift, dessen Wirkung sich zuerst an den Nerven selber bemerkbar

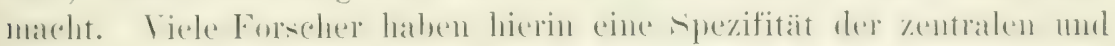

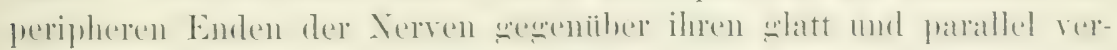
lanfenden Teilen sehen wollen. Mir will es aber scheinen - und

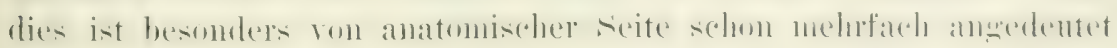
worden - daß der Grund der Berorzugung nicht unbedingt in spezi-

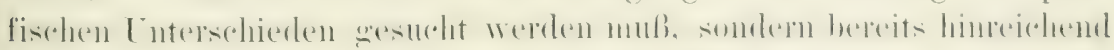
dureh mechanische Verhältuisse erklärt werden kamn.

Bei sämtlichen Tieren ron den Wïrmern aufwärts (vielleicht auch noch abwärts) sind die eigentlichen Nerrenfasern d. h. diejenigen

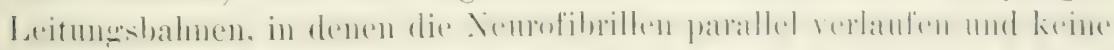

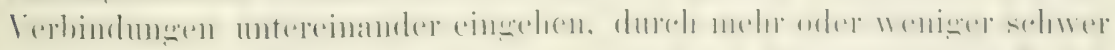

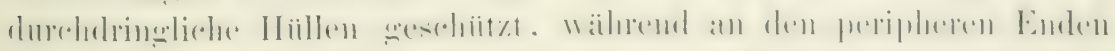
und im Neuropil die Nervenfasern resp. die Fibrillen bloßliegren. Am besten geschütat sind die markhaltigen Nerrenfasem der Wirbeltiere, wovon man sich leicht ïberzengen kann, wenn man die frischen lasem 


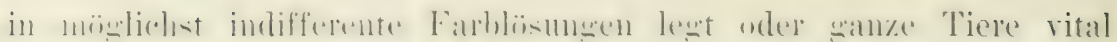

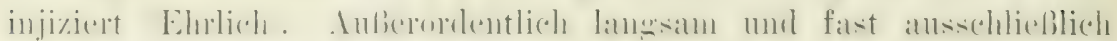

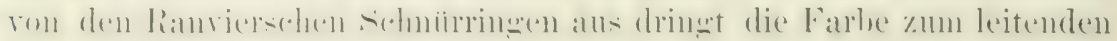
Element, den Neurofibrillen, ror. Außer, daß die Markscheiden bei

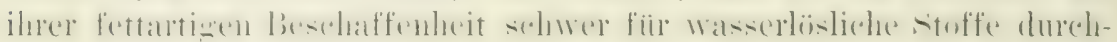
dringlich sind, wirken sie auch, wie mir scheint, insofern schiitzend, als sie nicht nur manche Farbstoffe, sondern auch andre Stoffe z. B. Nareotica aufspeichern und so, wenn die Menge derselben nicht zu

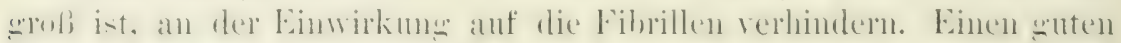
Schutz gewähren anch die Hüllen der sympathischen Fasern. Viel

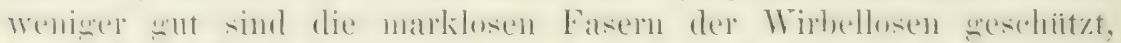

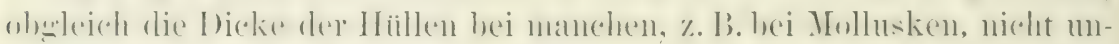
erheblich ist. In der granen Substanz (dem Neuropil) und in den finclienzellen sind die Fihrillen in cremensatz zu den peripheren

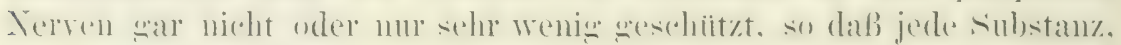
die der Blutstrom mit sich führt, sehr leicht an sie herangelangen kann. Zu diesen Lnterschieden kommit noch, daß die Nerren der Wirbeltiere nur schwach mit Blut rersorgt werden, während die Vascularisation der Zentralteile sehr stark ist. Bei niederen Tieren ist der Untersehied in der Blntrersorgung meist nicht sehr groß.

Es gibt nun, so weit ich ans der Literatur sehe und ans eigner

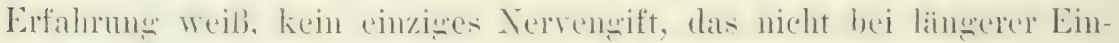

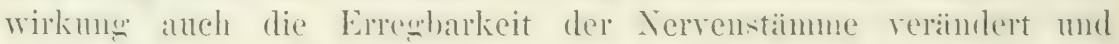
schließlich für immer oder voribergehend vernichtet. Dabei ist es nicht einmal immer nötig, wesentlich mehr Gift zuzufuihren, als zur Iferonrufung maximaler Giftwirkungen in (iebiet des Zentralnervensystems nötig ist, sondern man muß nu länger warten,

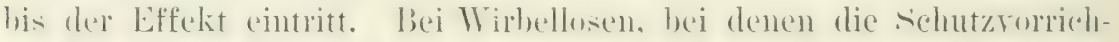
tungen der Nervenfasern nicht so stark ansgebildet sind, wie bei

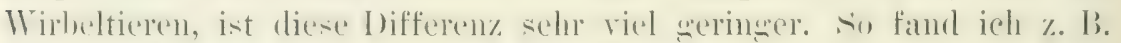

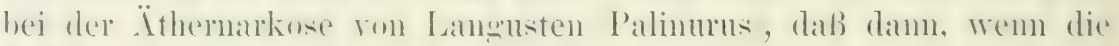
lieflexe vollkmmen erfuselen sind, hereits aine hedentende IBecin-

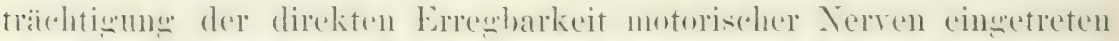

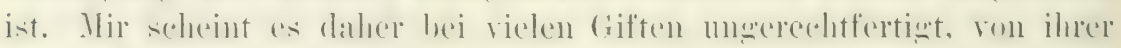
spezifischen Wirkung anf die Zentralteile zu sprechen, und ich

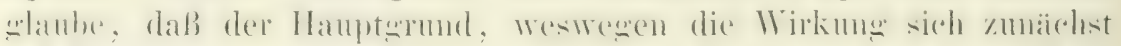

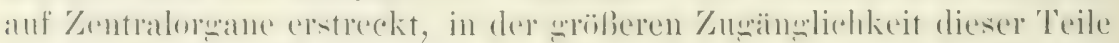

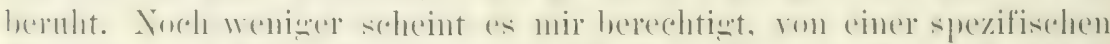

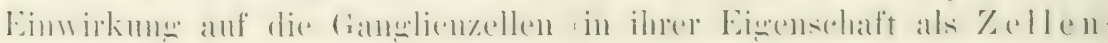

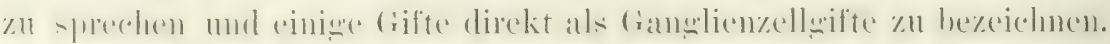
Man dürfte dies nur dann tun, wenn man den Nachweis geführt, daß

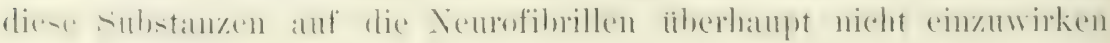
imstande sind. 
Wemn wirklich, wie ich meine, die Eigensehaften des leitenden Elements durch das ganze Nerrensystem hindurch im P'rinzip die

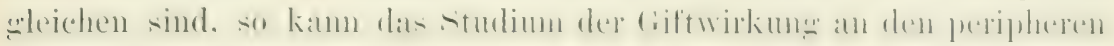
Nerven entschieden ron Nutzen sein, um dem Wesen der Giftwirkung näher zn kommen, weil bei diesen Teilen des Nervensystems alle Maßnahmen einer besseren Kiontrolle unterliegen. Wemn man die

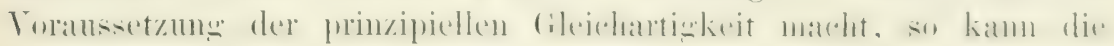
Tatsache, daß bei der Vergiftung eines normalen Tieres die Gift-

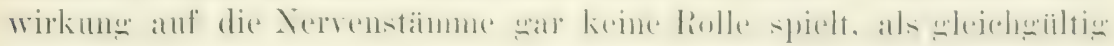
angesehen werden. Bis jetzt hat aber grade diese Tatsache die

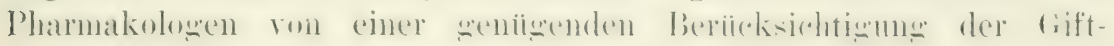
wirkung anf die Nerren abgehalten, weil sie von vormherein ron der prinzipiellen Verschientenheit zwischen den peripheren Verven and den Zentralteilen uiberzengt waren. An den peripheren Nerven kann fest-

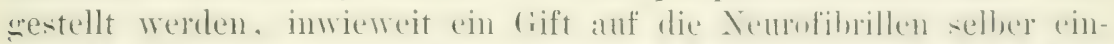

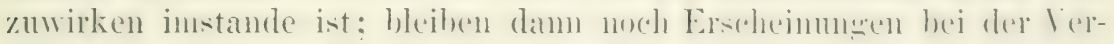
giftung des ganzen 'Tieres ubrig, welche sich nicht dureh die am

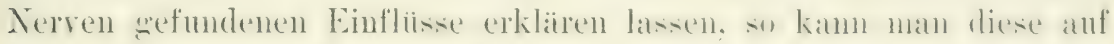

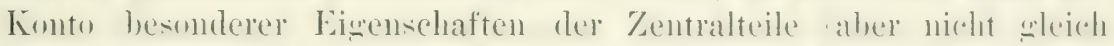
der (ranglienzellen setzen, su weit sie nicht dureh periphere IV irlungen

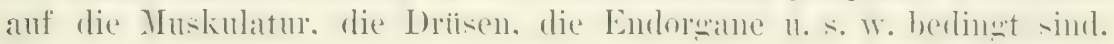
Da wir eine spezifische, in den Zentralteilen dimplente sulstan\% angenommen haben, so kann es matiirlich anch Gifte geben, welche speziell diese angreifen. Es kann aber andre wethen. welehe iblerall. wo sie auf Fibrillen treffen, auf diese und auf sie allein einwirken: an stairksten wird dies natiorlich dort der Fall scin. Wo die Fibrillen

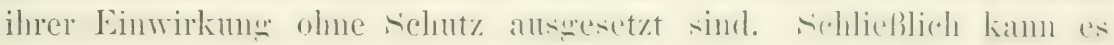
Substanzen geben, welche sowohl auf die Fibrillen selber, als auch auf die rorausgesetzten Dämpfungen Einfluß haben.

Als Gifte, bei denen wir nur eine allgemeine Einwirkung auf die Filsillen sether anzunehnen hranchen, moirehte ich in crster Linie die

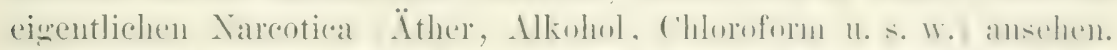

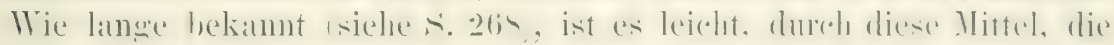

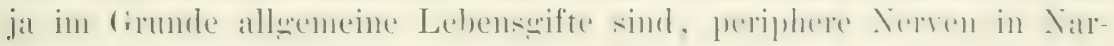
kose zu rersetzen. Es kommt dabei für uns weniger auf die Herab-

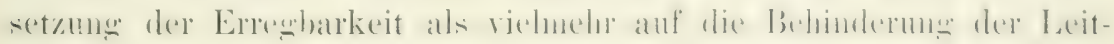
fähigkeit an. Je länger die narkotisierte Strecke ist, desto greringere Grade der Narkose reichen aus, $u m$ die Leitung auch fiir stärkste Reize zu unterbrechen. Die Erregungen aber, welche bei den Reflexen fortgeleitet werden, erreichen wohl nie die Stïrke derer, welche hei unseren künstlichen leizen zustande kommen, wie man wohl daraus ersehen kamn, daß die reflektorisch rermittelten Erregungen

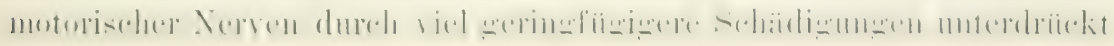




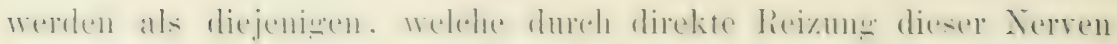
hervorgebracht werden. (S'o fand z. B. Ducceschi, 1900, daß schon

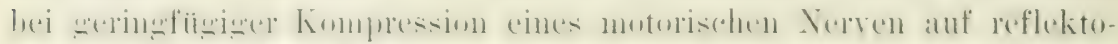

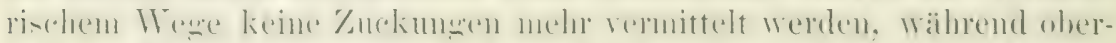

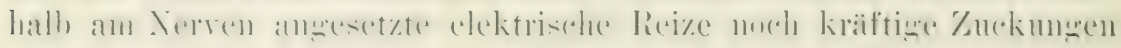
rermitteln.) Demmach steht der Ammahme niehts im Wege, da $B$ die bei der Nakose eintretenden zentralen Lähmungen a uf einer Narkose der im Lentrum freiliegenden Fib) rillenbaltnen berulen.

Wie ich auf Seite 289 gezeigt habe, besteht die Wirkung der

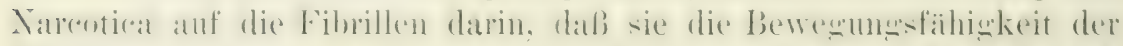

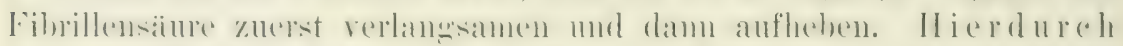
ist ein Weg gegeben, wie mansich ilberhatpt die Wirkung der Narcotica rorstellen kann. - In den letzten Jahren haben Hans Meyer (1899) und Orerton (1901) die Beobachtung gemareht, laf alle narkotisierenden sulstanzen in Fett lïslich sind mul

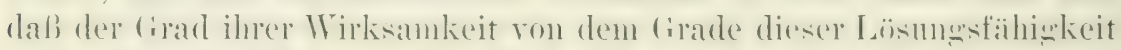

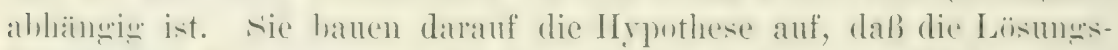

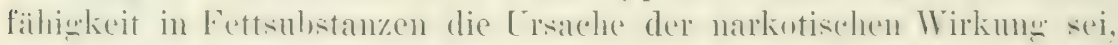

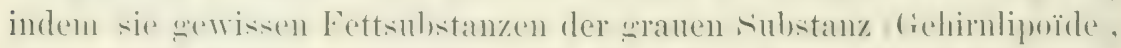
romehnlich der (ianglienzellen, eine Rolle bei den zontralen Prozessen

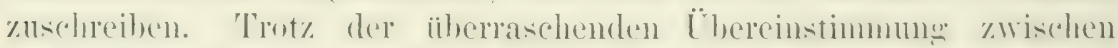

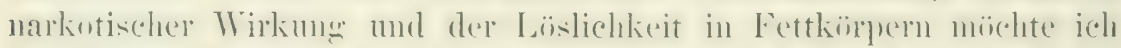

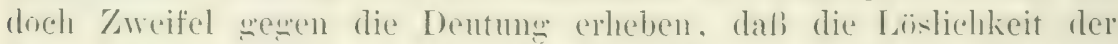

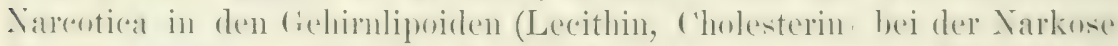

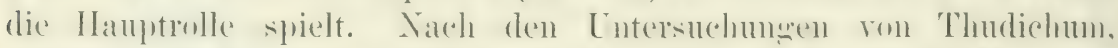
welohe einen Inspruch auf (iemanigheit erheben diufen, ist die Masse an ätlerlïslichen sulstanzen, Kephlalin, Lecithin, cholesterin in der wranen

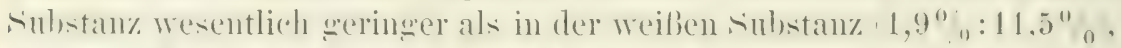

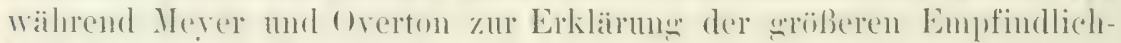

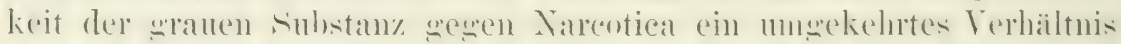

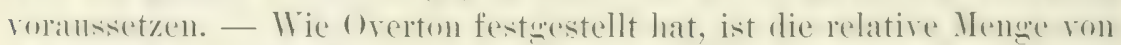

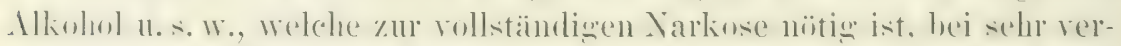

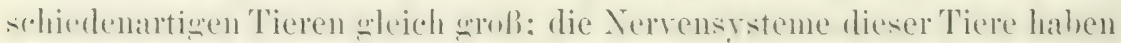
aber sicherlich einen sehr verschiedenen relativen Gehalt an ätherlöslichensulstanzen; bei krustazen ist der der Itheransum\%. l). minimal.

Schließlich sei noch angeführt, daß die Substanzen des Nerven,

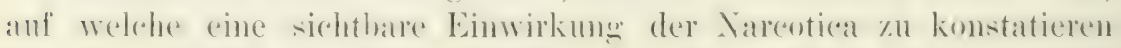
ist, die F"ibrillen und die Fibrillensibure keine Fettsulstanzen sind.

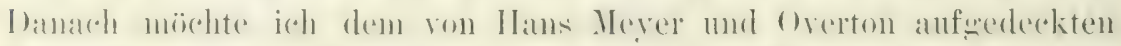

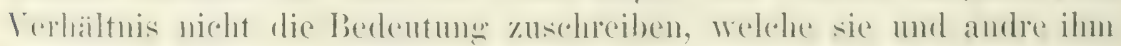

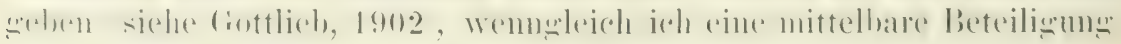
der ,Gehirnlipoïde“ hei der Narkose für wahrscheinlieh halte. 
Am peripheren Nerven laißt sich im Infangstadinm der Narkose stets eme Steigerung der Lregloakeit nachweisen, welehe erst allmählich in das depressive Stadium iibergeht.

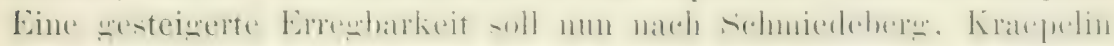
und andern bei der Narkose des zanzen Menschen oder 'Tieres nicht existieren. Die zu heobachtenden Exaltationen Beranschter und schwach Narkotisierter werden ron diesen Autoren auf Lähmung

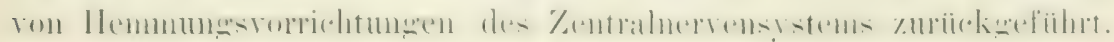
Diese Erklämo ist zwar durchaus ausreichend, aher sie ist doch

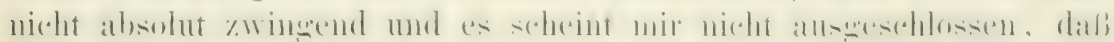

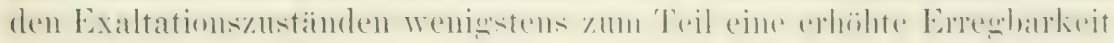

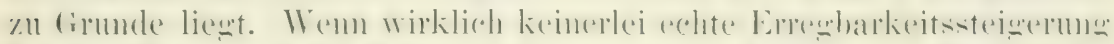

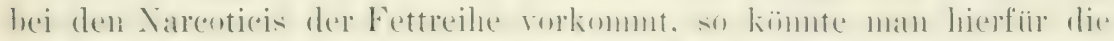

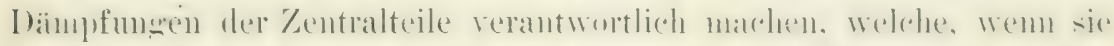
mrerändert fortbestehen, sehr wohl die erhöhte Erregbarkeit der

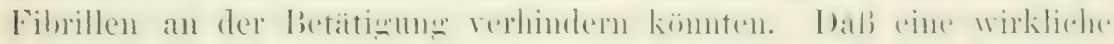

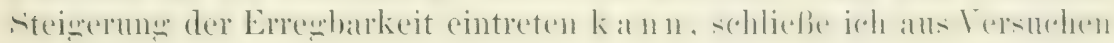
hei Medusen.

Bekamntlich (s. anch S. 106) erlöschen die spontanen rhythmischen

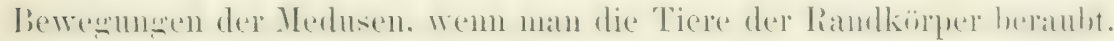
Anf Einzelreize treten einzelne Kontraktionen ein. Wird tetanisch an

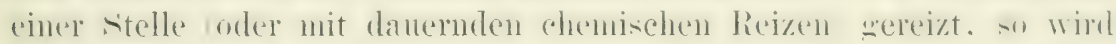

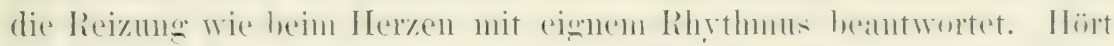
der Reiz auf, so werden anch die rhythmischen Bewegungen wieder eingestellt und bleiben bis zum Gewebstode aus, weun keine nenen Reize einwirken und das Wasser frisch erhalten wird. - Zur Be-

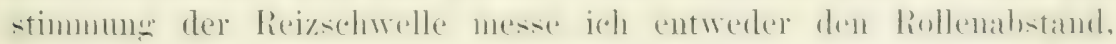

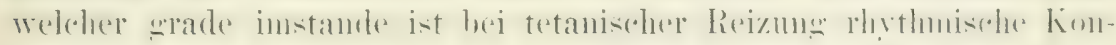
traktionen hervorzubringen, oder ich lasse auf das flach auf dem Riicken liegende und eben mit Meerwasser bedeckte 'Tier Wassertropfen von. gleicher Größe fallen und bestimme den Abstand, bei

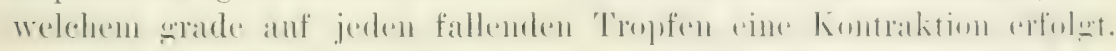

Nachdem bei einer randkörperfreien Cotrlorrhiza die Reizschwelle bestimmt ist, wird dieselbe in Seewasser gebracht, dem ein halbes Volumprozent Alkohol zugesetzt ist. Nach etwa einer Minute faingt die Erregbarkeit fast immer an bedeutend $z u$ steigen, so daß man die Fallhöhe der 'Tropten um nehrere Zentimeter veringern resp. die Rollen weiter voneinander entfernen kam. (\%. B. Fallhöhe vorher $20 \mathrm{~cm}$, nachher $12-15 \mathrm{~cm}$ : liollenahstand vorher $12 \mathrm{~cm}$, nachher $15 \mathrm{~cm}$.) Sehr viel auffalliger ist aber die Neiguno der Alkoholtiere (NB. ohne Rantkimper!) a uf einmaligen Reiz, ja sogar spontan rhythuische Kontraktionsreilien a $u$ s\% ufillren, wie sie sonst nur hei Tieren mit 


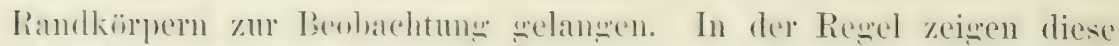
Kontraktionen cine meringere Konelination als bei momalen Tieren

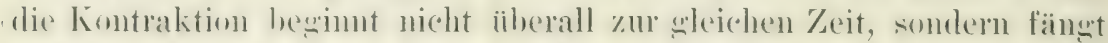

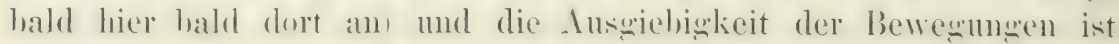
geringer.

Bei manchen Exemplaren kommt es auf jeden leichten, mechanischen Reiz nur zu 3-4 Kontraktionen, bei andern treten aber Pe-

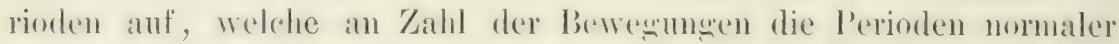
Tiere iblersteigen. Dic normale cotylorrhiza macht wewöhnlich nur serien ron 20 - bo Kontraktionen, auf dic Ruhepansen von rersohicelen

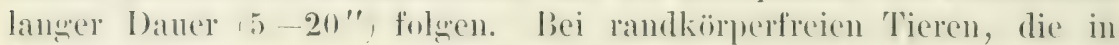

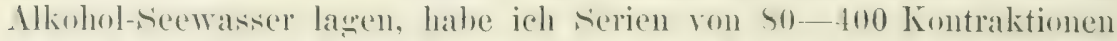

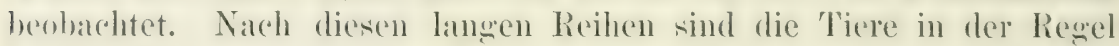

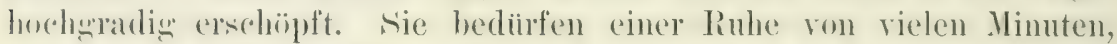
num eine nene lontraktionsreihe besimnen zu kimnen mol reasieren in der elsten Zeit hainfig nicht eimmal durch Einzelkontraktionen, wenn

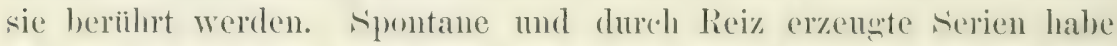
ich noch nach sechsstiundigem Anfenthalt in Ilkohol-secwasser beobachtet. Bringt man die 'Tiere in reines Seewasser zuriek, so geht die Fäigkeit auf Eimzelreize mit Serienzu antworten wieder verloren und die Reizschwelle steigt wieder zur alten Höhe. - Die Alkoholkonzentration kamn bis zu anderthalh, Prozent steigen, ohne daß der Effekt geändert wird. Bei höheren Konzentrationen macht sich eine depressive, narkotische Wirkung geltend, welche bis zur vollkommenen Reflexlosickeit führt; in reinem seewasser kann Elholung eintreten.

Da Alkohol bei lokaler Applikation gar keine oder nur sehr geringe Ricizung bei den Medusen hervorruft 1-3 Prozent, da ferner die mesteigerte Erregharkeit erst nach einer Latenzzeit von einer oder mehreren Minnten eintritt, eine \%eit, die genïgen diüfte, mu den Alkohol his zur Servensohicht vordringen zu lassen, da solulieblich die sesteigerte Frresharkeit stundenlane erhalten bleibt, so shlaube iob rine reizende Vimwirkung anf die epothelialen Nervenendignngen, also rine lieflexerregung, aussohlieben zu dürfen, und diese Versuche dafiil anfiilıren zu kïnnen, lab der. Mlkohol onnd vielleicht anch andre

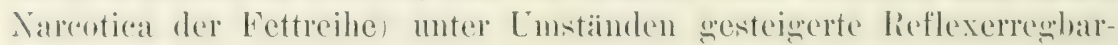
keit er\%engt. -

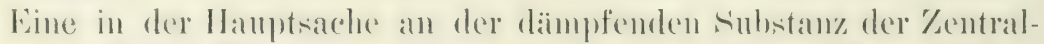

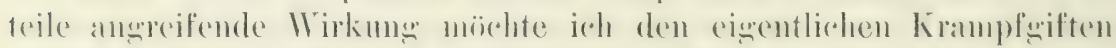
zuschreiben, vor allem dem Strychnin. Ich glaube, daß es keine Schwierigkeiten bereitet, sich dies rorzustellen. Ich habe oben die

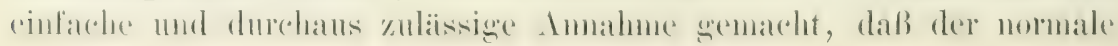




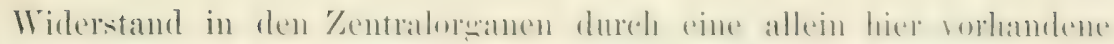

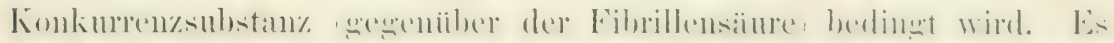

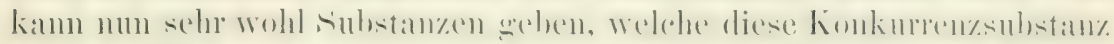

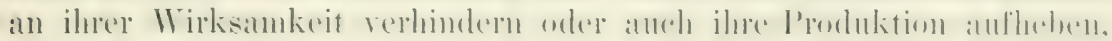

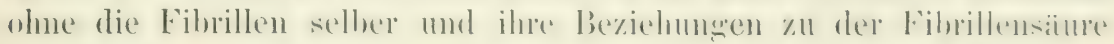
wesentlich zu verädern. Dadurch wiirte den zentralen Gibrillen-

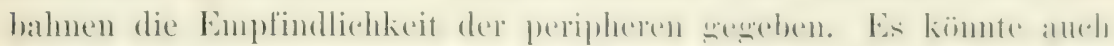
der kleinste Reiz zu einem Effekt füluren und es stände der Ansbreitung jedes Reizes bis in die entfentesten Gebiete des Nerrensystems nichts im Wege. Da das Strychnin anf die Fibrillen selber

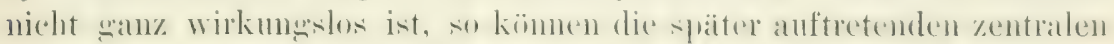

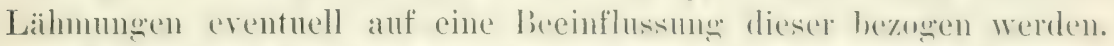

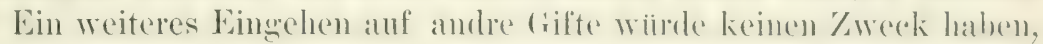

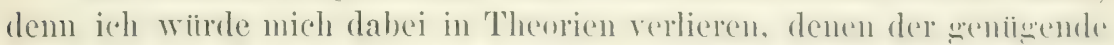

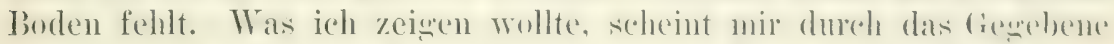
"rreicht, daß sich nämlich ron toxikulowischer seite meinen Idern keine Hindernisse in den $\mathrm{Weg}^{\circ}$ stellen, daß durch sie sogar eher klarere Vorstellumen erlangt werden, als die herrschenden Ansichten ("münwlichen. Herrorzuheben ist nur noch folgendes: Man wird mir einwerfen, dals die rerschiedenen (ifte in den Zentralteilen ilne I'rärlilektionsstellen haben: wemn \%. I). die Sareotica in erster Linie auf das Großhirn wirken, so kömme dies nicht anf den ja iiberall gleichen Fibrillen beruhen. Dagegen ist zu erwidern, daß die Bevorzugung immer nur graduell ist und daß sich bereits an saimtlichen andren

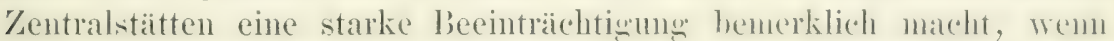
das fiensorium zu schwinden anfänet. In der versehiedenen I)icke der

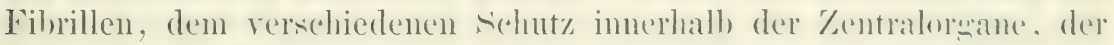

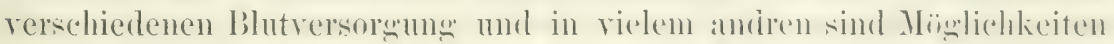
genug gegeben, un diese Untersehiede verständlich zu machen. -

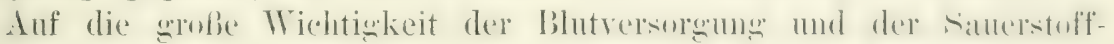

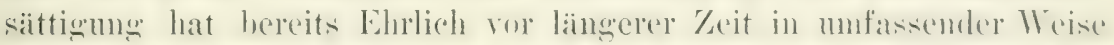

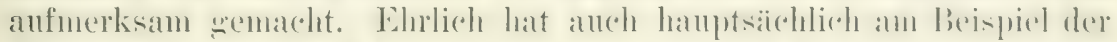

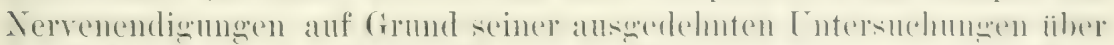

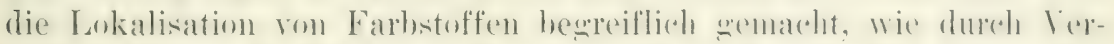

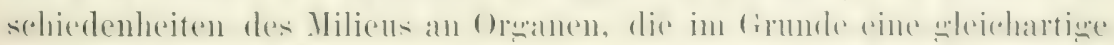

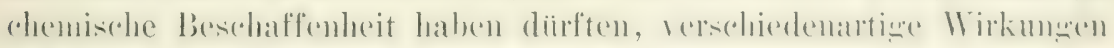
anf die gleiche Ursache hin eintreten können.

Einen schwer zu iiberwindenden Einwand gegen die Ansicht, daß

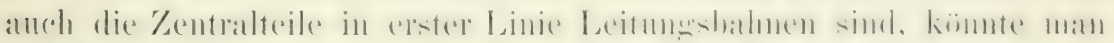

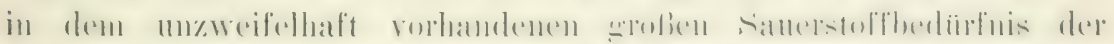

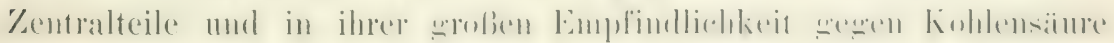
sehen. Ieh habe diesen Untersehied gegeniber den peripheren Nerven

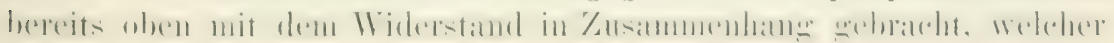




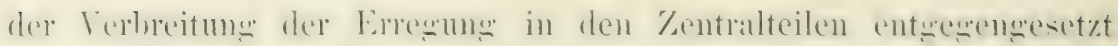

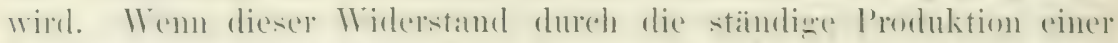

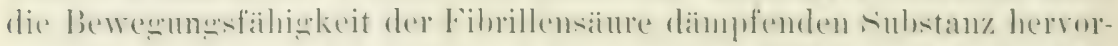

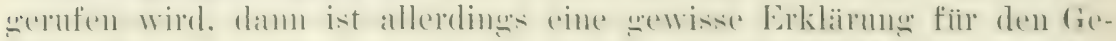

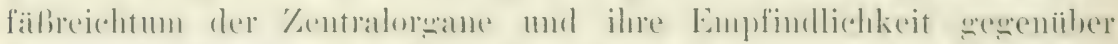

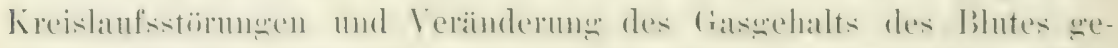

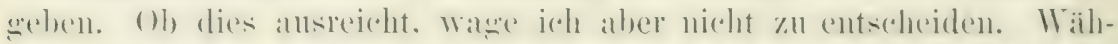

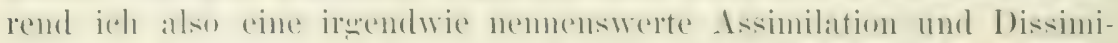

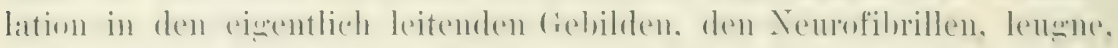
nul

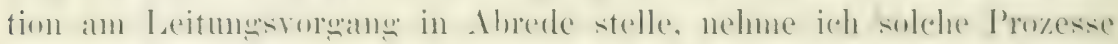
in den \% /

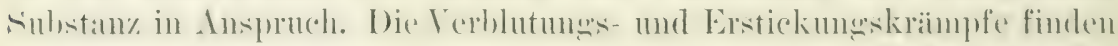

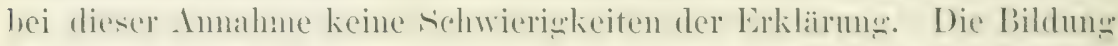

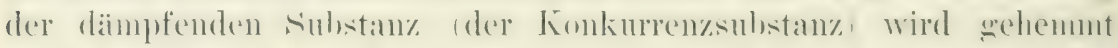

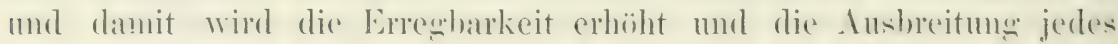
Reizes auf das gesamte Nervensystem findet keinen Widerstand.

IVie $11 m$ ans den in achten Kapitel mitweteilten Befmulen hervor-

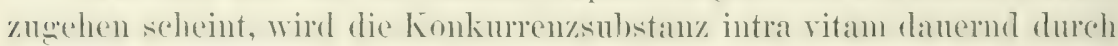
Oxydation zerstört. Diese Oxylation fält led Erstickung oder Verblutume fort. Wenn num die Bildume der Konkurenzsulstanz in der ersten Zeit mach der sianerstoffentziehung \%war vermindert ist, aber noch fortelanert, sn muli die Konkurrenzsubstau\% das Überwewicht bekommen und die Fibrillensïure ïberall in Zentralnervensisten ans

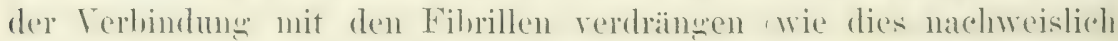
der Fall ist; siehe S. 145 u. f.). Dadurch wird die Leitung im Central-

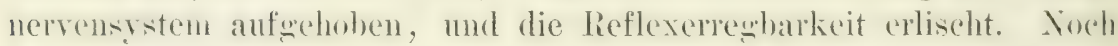
lange, nachdem dies eingetreten ist, werden die peripheren Verven

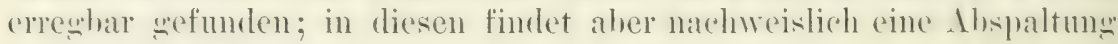
der Fibrillensäure nicht statt.

I ch füle also das Sauerstoffbediufuis resp. die stark Blutrersorgug der Zentralorgane a uf die Produktion und Regulierung einer Substanz zuriek, welche, nur hier vollanden, der. Damptung der Reflexe dient. ${ }^{1}$ )

1) Diese Anschauungen scheinen mir mit den neuerdings von Winterstein (1900) und Verworn (1900) gemachten Befunden nicht zu kollidieren. 


\section{ZWANZIGSTES KAPITEL.}

\section{Der Tonus.}

Versuche ïber den Tonus bei Aplysia S. 365-372. - Bei der Kontraktion tritt IIasser aus dem Muskel aus S. 365. - Nach Herausnahme des Zentrahervensystems tritt starke Tonussteigerung ein, welehe bis zum 'Tode andauert S. 370 , 371. - Der Tonus ist ein liuhezustand S. 371. - Fortleitung des 'Tonusfalls bei seeigeln S. 372 .

Am Anfang des vorigen Jahrhunderts war vielfach die Meinumg

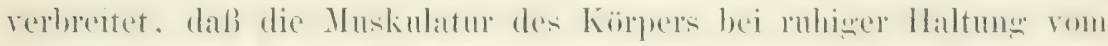

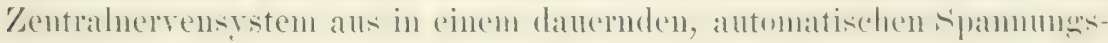

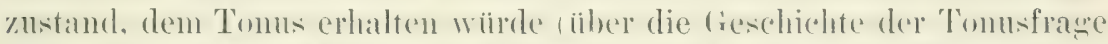

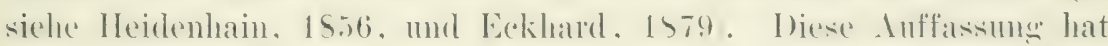
sich insofern als falsch erwiesen, als rom einer automatischen Funktion der Zentralteile hier wohl keine Rede sein kann. Daß aber ein wirklicher Tonns existiert, daran kamn schon lange kein Zweifel meh existieren, demu ohne eine dauernde und koordinierte spannums wäre es nicht möglich, daß ein Nensch und ein Hund ruhig stehen, ein Krebs danernd seine Intennen vorgestreckt halten, ein sectimel seine starchehn ron sich strecken könnte. Xach Ansichaltumg des Nervensystems hricht ein IImbl zusammen, sinken die Antemnen des krebses, und hängen die stachehn des seceigels schlaff herah. Der Tomus als physiologisches Phänomen ist weblieben, aber die Ansichten iiber sein Zustandekommen haben sich geändert.

Seit den Untersuchungen von Brondgeest (1860) ist die Tonnsfrage sehr viel klarer geworden: brondgeest durehselnitt dekapitierten Fröschen einen Ischiadicus und hänghte sie damn senkredit anf. Das

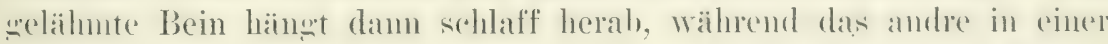

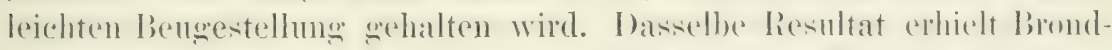

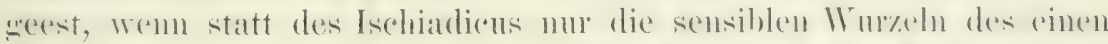

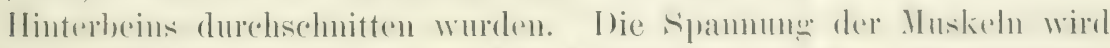

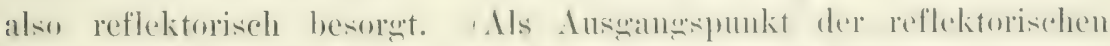

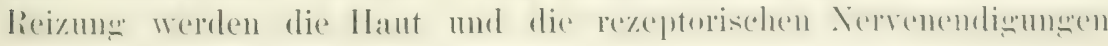
(ler Sehnen und Muskeln angesehen.)

Hermamn (1861) fand, daß beim Brondgeestschen Tonus nur ge-

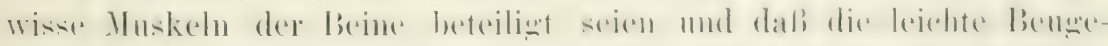

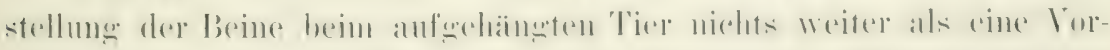
stufe zu der normalen Bengehaltung im Sitzen sei. Wäre diese beim sitzenden Tiere erreicht, so höre der Touns auf. Durch diese Be- 


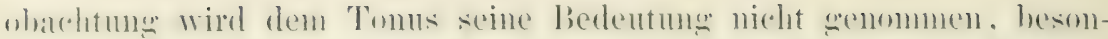
ders da bei vielen andern Muskelermplen cine Erschlaffung fast nue eintritt, wie z. B. bei den Antennemmuskeln der Krebse. Sie kamn nur dort eintreten, wo bei luhiger Ilaltung eine geniigende Unterstiitzumg dureh die Cuterlage stattindet. Diese fehlt beim Frosch

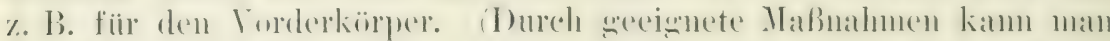

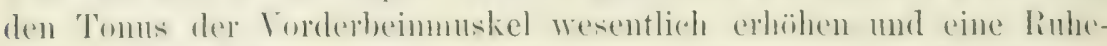

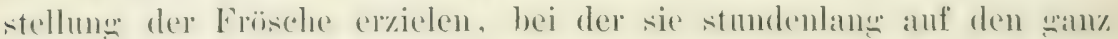
gestreckten Vorderbeinen ruhen. Verworn, 1897.)

Bevor der Brondgeestsche Versuch veröffentlicht wurde, hatten

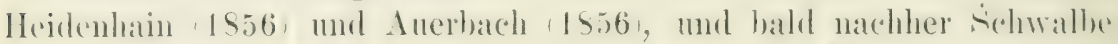

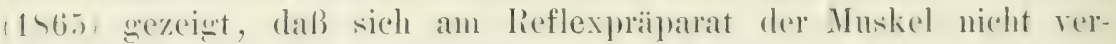

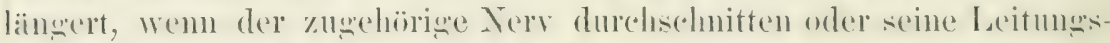

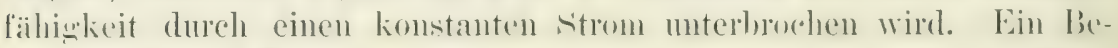
weis gesen die Existen\% eines Tomms kamn jotzt nicht mehr in diesen Versuchen weselien werden. sie beweisen mur, daß ein antomatischer Tonus wohl nicht existiert und daß der Reflextonus etwas sehr Versaingliches ist und die Mißhandlungen nicht erträgt, welche die Ilerrichtume solcher Präjparate mit sich hringt. Der Tonus hält eben bei all den Muskeln und Muskelpruppen, welche unter natiurlichen Lunstanden nie sehr lange Zeit in 'Toums verharen, anch unter nunatiolichen Bedingungen nicht lange an.

Ein großer Teil der reflektorischen Erregungen, welche den T'mus bestimnter Muskeln, z. B. der Iinterbeimmuskeln von Hunden und Fröschen, remitteln, stammt jedenfalls ans denjenisen Gebieten, in welchen der 'Tonus stattfindet. So haben eine ganze Anzahl ron Arbeiten der letzten Jahre ereceben II. F. Hering, 1597, Bickel, $1>97$, und andre), daß der 'Tomus \%. I). in den Ilinterheinen wesentlich herah)-

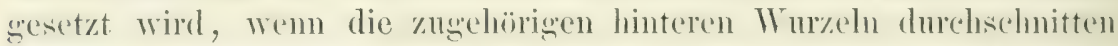
werten. Da ein 'I'onus aber' auch nach Ausschaltumg dieser rezeptorischen Bahmen noch forthesteht, so gecht daraus hervor, dali er anch, wenigstens zum 'Teil, durch rezeptorische Erregungen andere Gebiete remittelt wird. Die Arbeit von Merohacher (1902) iiber die hesultate

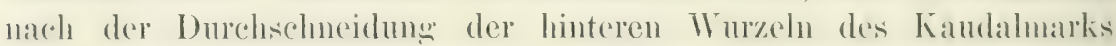
von Hunden hat sogar ergeben, daß eine Änderung in Tonus des Schwanzes nicht zu bemerken ist, wenn derselbe anch ganz arezeptorisch gemacht ist.

Eime Hauptquelle der Erregungen fiur den Reflextonus stammt nach den ausgedehiten Untersuchumgen von I. R. Ewald (1892) aus

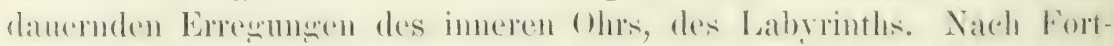
nathor beider Labyrinthe zoigt sich besonders bei lauben, aber andels

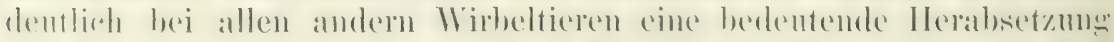

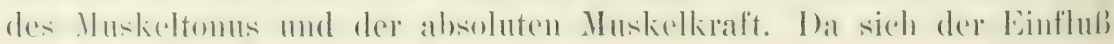




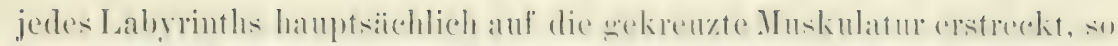

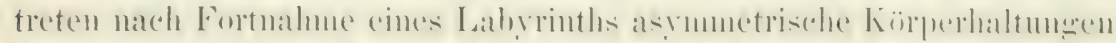

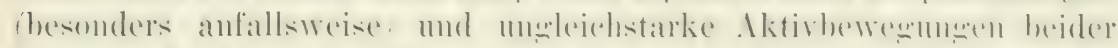

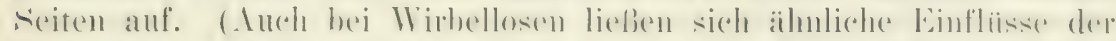

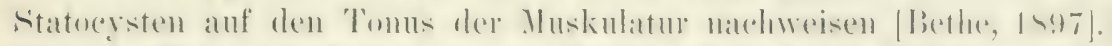

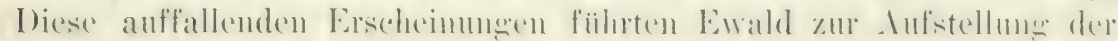
Hypothese vom 'T'onuslabyrinth. Die dauernde Erreg'ung' del Mus-

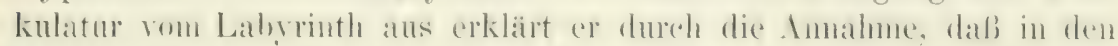

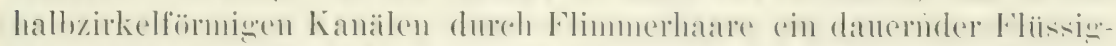

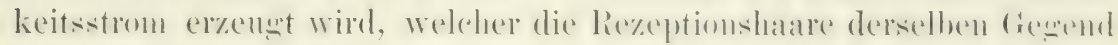
in eine dauernde Erregung versetzt. Von hier wird sie dam durch das Zentrahnervensystem zu den Muskeln fortgeleitet.

Besonders starke tonische Erscheinmoren sind bei Wirbeltieren an den sphinkteren der blase und des Mastolams zu hemerken. Man

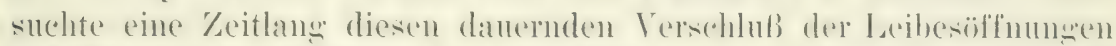
anf Elastizitätserhailtnisse zurïckzufïhren, weil dersellue anch nath dem Tode des Individumus noch forthesteht. Seit den Lutersuchumenen

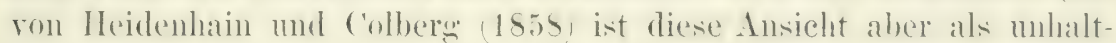
bar erwiesen. Diese Autoren maßen zunächst den Druck, weleher beim normalen Kaniuchen grade nötig ist, um den Verschluß des Fphincter vesicae zu sprengen. d. h. hei welchen stade Harntränfeh eintritt. Darauf wurden die Tiere durch Verbluten orler durch Blausiime setoitet, wohei der Gegendruck des siphinkters allmählich al)nimunt, his auf einen seringen Rest, der anclo nach dem Tude bleiht. Manchmal wird wahrend des Verhlutungskanpfes Flissigheit anssetriehen.) - Vielfache Lntersuchunsen sohienen zu erebehen, dab del Tumus der sphinkteren allein durch das liuckemmark remittelt werele

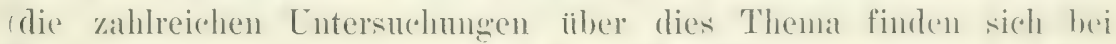

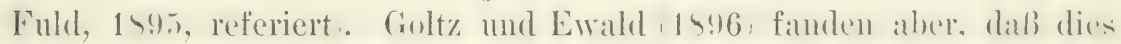

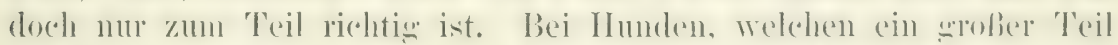

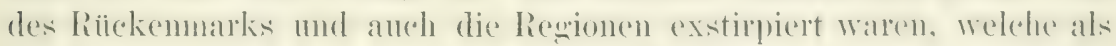

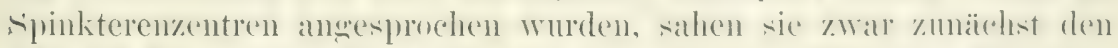

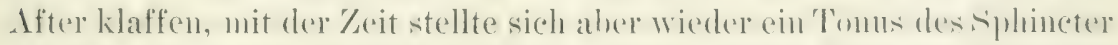

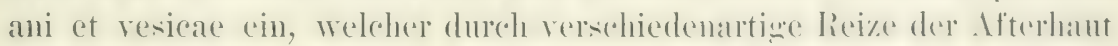

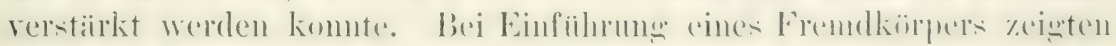

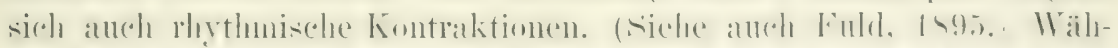

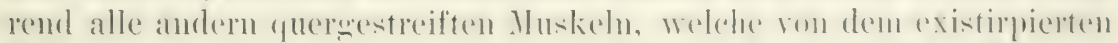

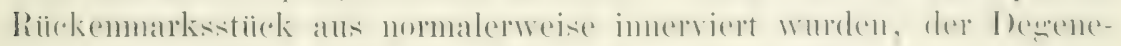
ration anheimfielen, blieb der Sphincter externus erhalten.

Diese Versuche deuten olme Zweifel darauf hiu, daß die sphinkteren außer vom Riickenmark noch von einem andren Kentrum ablä̈ngig sind, das vermutlich in der Nähe derselben gelegen ist. Ob es sich num bei dem sich wiederherstellenden Sphinkterentonus um 


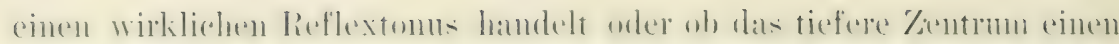

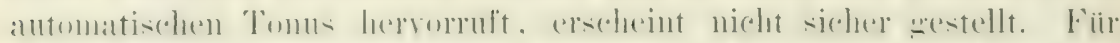

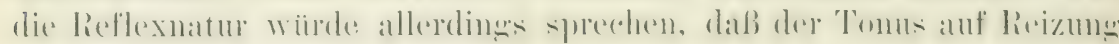
der Anusschleinhaut zunimmt. Soweit der Sphinkterentonus rom

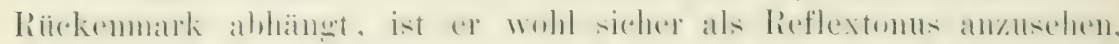

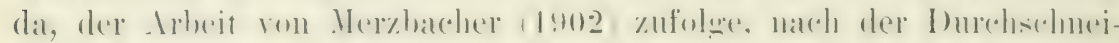

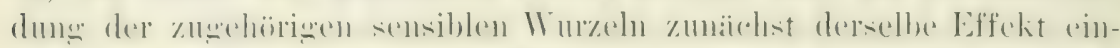

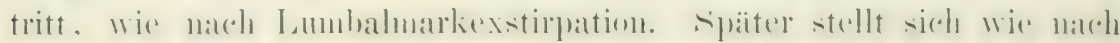
dieser der 'Tonus des Sphineter ani wieder her. (Klaffen des Anus

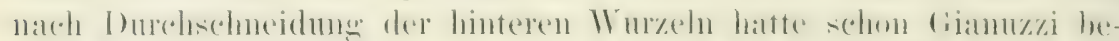

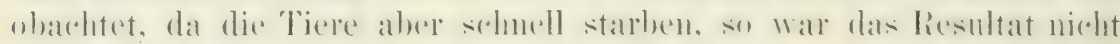
eindentig; siche Fuld, 1895.)

Bei den bisher besprochenen 'Tatsachen (mit teilweiser Ansuahme der letztgenamnten) hatten wir es mit dem 'Tonus von Muskulaturen zu tun, die nu schwer in einen tonischen Zustand zu rersetzen sind.

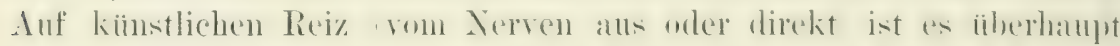
kaum möglich, einen queröestreiften Muskel in rinen /ustand danernder, sohwarher Kontraktion zu resetzen. Es ist dies wohl ein Hauptgrund, weswegen sich so viele Physiologen anfangs so ablehnend

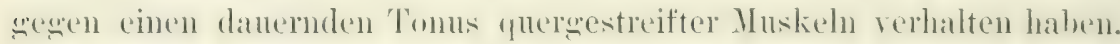
- Wesentlich anders liegen die Verhältnisse bei vielen (aber nicht

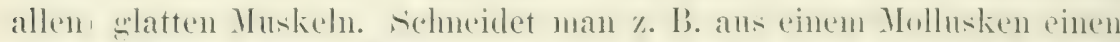

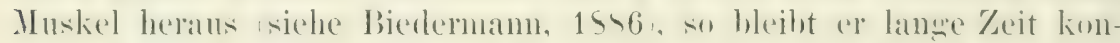
trahiert und geht häufie erst beim disterlon ofler hei Anwendumen

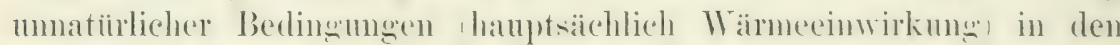

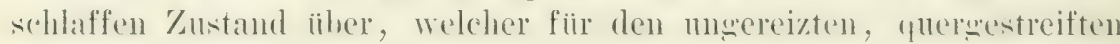
Muskel der natürliche ist. Auf Reizung tritt beim glatten Muskel wieder tonische Kontraktion ein, welche nur langsam weicht.

Diese 'L'onusmuskulatur tritt uns bei rielen wirbellosen Tieren (aber auch bei Wirbeltieren z. B. an den Gefaßen und dem Ureter) entgegen. Besonders ausgebildet findet sie sich bei den Seeigeln. Dic hier obwaltenden, hördst interessanten lerhältuisse haben r. Lexküll zur Anfstellung der Frage bewogen, ob denn ïberhaupt der schlaffe Zustand der oder der einzige Ruhezustand der 'Tonusmuskulatur sei.

Wir sind so gewöhnt, daß unsere eigne Muskulatur erschlafft, wenn wir sie nicht innervieren und daß die meisten Muskeln der

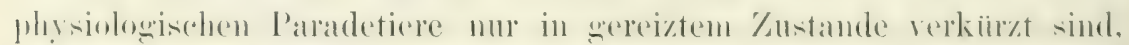

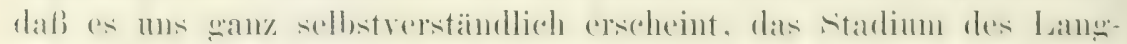

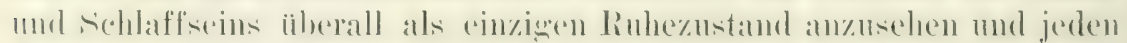
Zustand von Verkürztsein auf Reizung zuriekzuführen. Wem wir

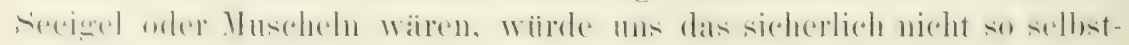
verstandlich vorkommen. Unsere Bewegungsmuskulatur, an der so 
viele das Wesen der Kontraktion zu ergrinden gesucht haben, stellt eben nux einen ganz einseitig entwickelten spezialfall formwechselfähiger lebender Substanz dar, und es ist sehr die Frage, ob wir die

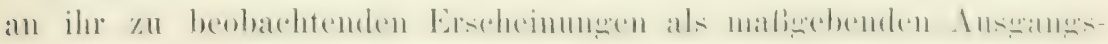
punkt für allgemeine Betrachtumgen ïber den Formwechsel werlen benutzen dürfen.

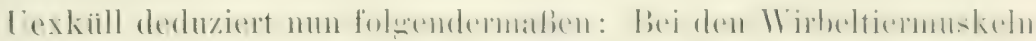

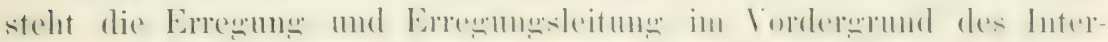
esses, bei den Seeigeln tritt beides in den Hintergrumd gegen den

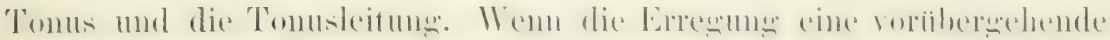

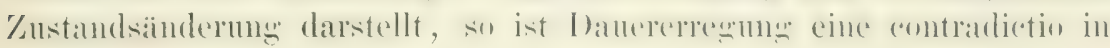
adjecto. Dieser Ausdruck fiu die tonische Muskulatur mu daher

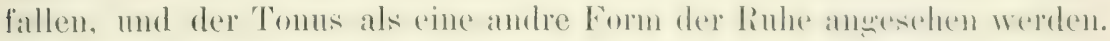
„Das einzige, was wir von der Lebensintensität einer Zelle zu sehen bekmmen, ist der Teil, der nidet zur Weiterführum des Lebens dient,

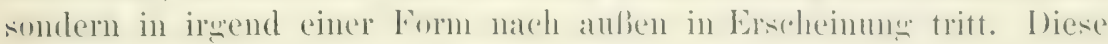
Überproduktion an Energie nemmen wir Tonus" (beim Muskel).

Nach dieser Auffassung würde, wenn ich recht verstehe, ein tomusahiger Muskel in dem /sustand weiter verharem, in den ihn die letzte Erregung rersetzt hat; er wiirde zwar nicht mehr erregt sein, aber doch Arbeit leisten, indem er mehr Energie produzierte als bei

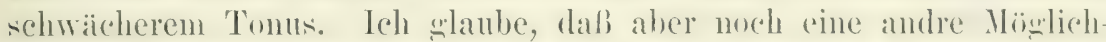

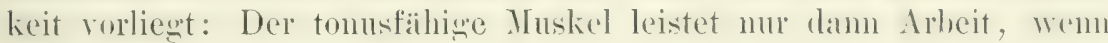
er aus einem Zustand in den andern iibergeht. Dem Zustande des

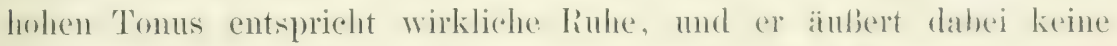
höhere Lebensintensitit nach außen als in schlaffem Zustande.

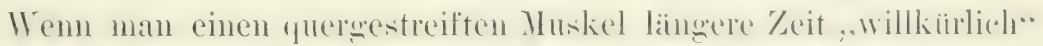

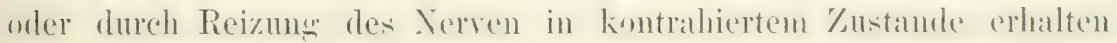
will, so verbraucht der Muskel dabei sehr viel Material und gerät

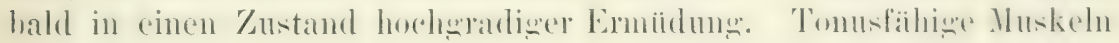
können aber stunden- und tagelang im Zustande der Verkiir\%ung bleiben, ohne Emuihdung zu zeigen. Wïrde hierbei dauernd Arbeit

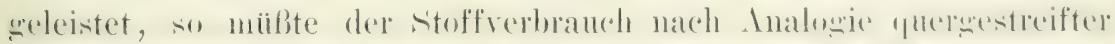

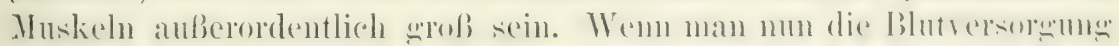

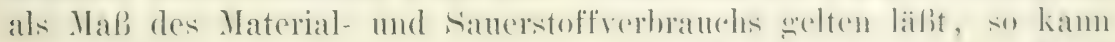

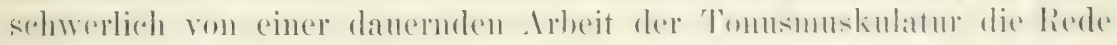
sein, denn ihre Blutversorgung ist in der Regel geringer als die der

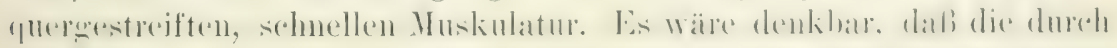

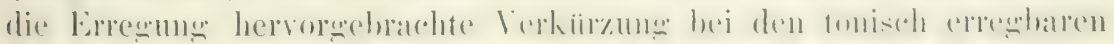

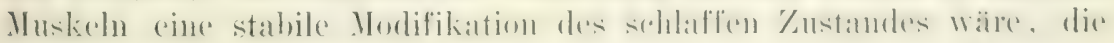
ohne Arbeit der Fasern fortbestände und nur anf neme Kustandsanderungen hin in andre stabile Runhelagen ungeändert wiirde.

Diese Ansicht schweht nicht so in der Luft und steht nicht so 


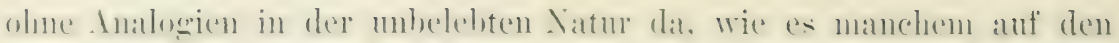
ersten blick seheinen möchte. Schneidet man eine Aplysia auf, so kehrt nach kurzer starker Kontraktion die mittlere Schlaffheit der

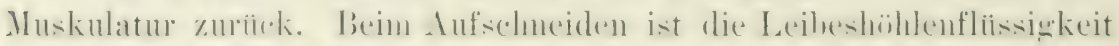
ausorelaufen. Lieigt man num nach Herausuahue des Zentrahnervensystems oftmals die derven. so wird ams deresole jedesmal für laingere

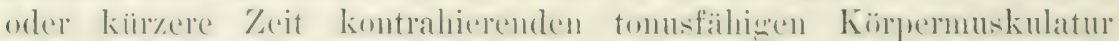

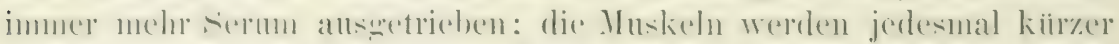

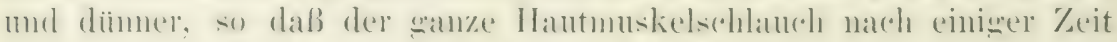
nur noch ein Drittel oder ein Viertel der Fläche eimmimmt, als nach dem Aufsehmeiden. Während dieser Zeit ist die Muskulatur immer härter geworden und sie ist jetzt der Erschlaffung iiberhaupt ni cht mehr fähig. Versucht man einen Streifen der Muskuktur ans dem sohbuch herauszuschneiden, su zieht er sich heftig zusammen und treibt eine Menge Wasser a us; die stärkste Verkïzung wird erreicht, wenn man versucht das Körper-

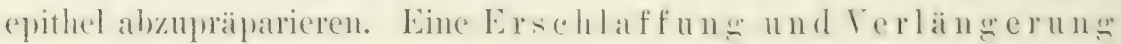
ist $n \mathrm{icht} m \mathrm{ehl} m \ddot{\mathrm{g}} \mathrm{lich}$, auch damn nicht, wenn man das Stiick in Serum legt. - Alle diese Beobachtungen, die ïbrigens auch an manchen andern Mollusken mehr obler weniger leicht welingen. hat schon Schoenlein gemacht, wie er mir seiner Zeit mitteilte, als ich

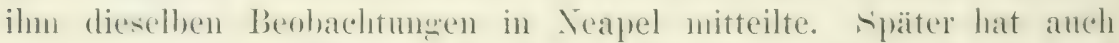
Jordan (1901) ähnliches beobachtet. Wie dieser Autor fand, wird beim mornalen 'Tier Wasser aus den Muskeln hei jecler Kontraktion unter die Haut gepreBt und ron da aus wieder in die Mnskeln anf-

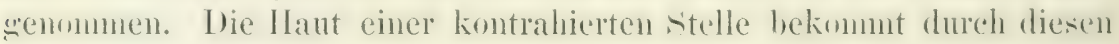
Wasseraustritt das bekannte warzige Aussehen, das bei der Erschlaffung verschwindet. - sicher wird iibrigens anch serum in die

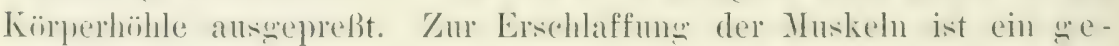
wisser positiver. Druek in der Körperhöhle nötig, woron ich mich mehrfach überzengt habe. TVenn nicht sofort nach dem Aufschneiden stare und danernde Terkiirzung der Muskeln eintritt, se lat dies wohl darin seinen firund, dab in den I)irertikeln der Känpere-

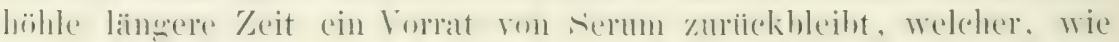

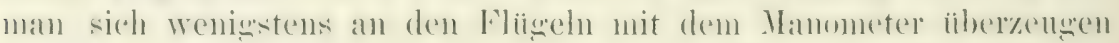

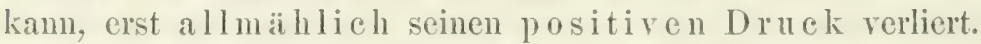

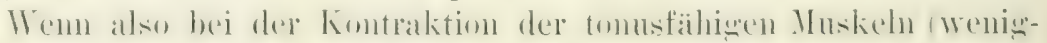
stens bei diesen 'Tieren) Wasser oder Serum ausgetrieben wird, so ist es sehr gut denkbar, daß der dadureh bedingte Ver-

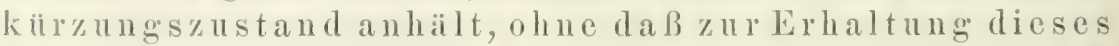
Zustandes eine aktive Arbeit geleistet werden mu.

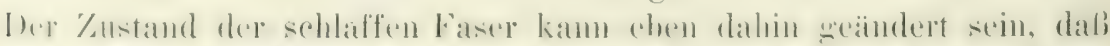

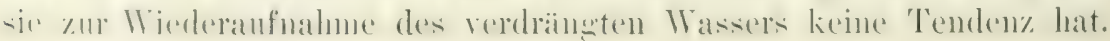


Den bei den Reizungsrorgäingen einiger Pflanzen beobachteten

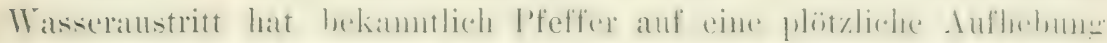

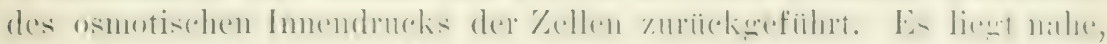

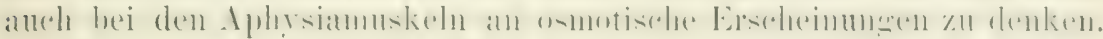

Die normale Aplrsia befindet sich stets in einem schwachen 'Jonus.

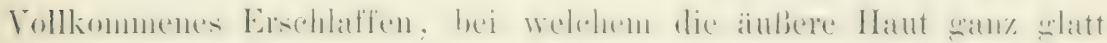
wird, kommt unter normalen Bedingungen gar nicht oder nur an be-

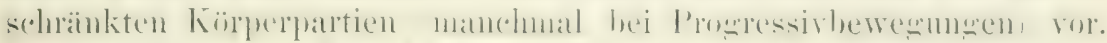

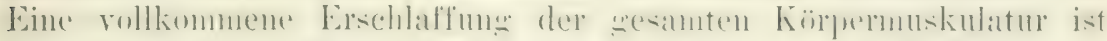

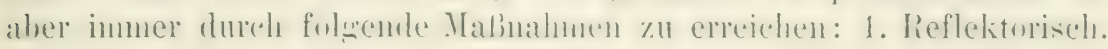
Zu diesem Zweck nimmt man ein 'Tier, olme es zu drieken, in die IIand und schiittelt es einigemal leise im Seewasser hin und her;

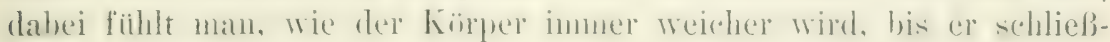
lich eine ganz schlaffe Masse bildet. ${ }^{1}$ ) 2. Durch Vergiftung. Injiziert man einem Tier l'elletierinsulfat rehoenlein, $1 \checkmark 44$, wler rovain, Nicotin, Morphin ${ }^{2}$ ) H. s. w. (Bottazzi, 1899), so tritt eine vollkommene Erschlaffung ein.

Um einen Ausdruck fiul die Stälke des Tonus zu gewimnen, benutzte ich ein einfaches Flibsiolieituanometer. Eine spitze filas-

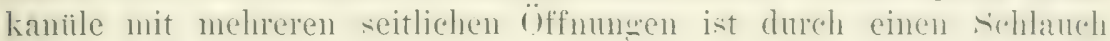
mit dem Manometer verbunden mul wird der Aplysia rom hinten leer

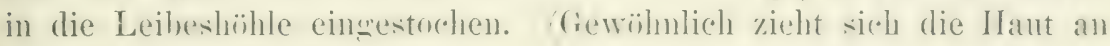
der Einstichsöffnung so fest um die Kanïle zusammen, daß eine

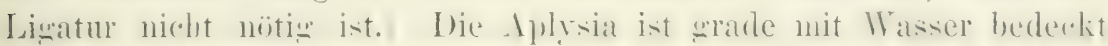

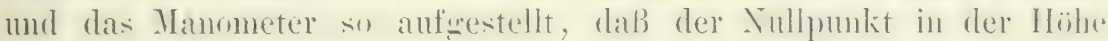
des Wassemiveaus liegt. - Beim nomalen I'iel (A. limacina) fand

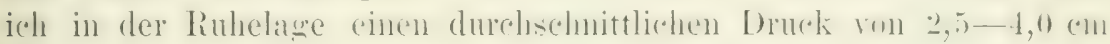
Wasser (je nach Individum rerschieden). Bei A. depilans ist der

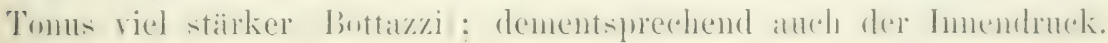

1) Man könnte es nicht fïr ausgeschlossen halten, daß dieser Tonusfall gar nicht auf der peripheren schwachen Erregung beruht, sondern durch passive Dehnung der Muskulatur hervorgerufen wird, wofür Analoga durch Uexküll (1900) hei Seeigeln bekannt geworden sind. Mran kam aber auch eine Erschlaffung durch Anbrandenlassen leichter Wasserwellen hervorrufen, was wohl mehr fïr eine periphere Reizung spricht. Drïckt man das Tier wilhrend des Schwenkens, so tritt statt Erschlaffung Kontraktion ein.

2) Diese Substanzen wirken ïbrigens nicht, wie Schoenlein ron Pelletierin meinte, nur auf das Zentrahervensystem ein und auch nicht, wie Bottazai zu meinen scheint, nur auf die IInskulatur. Die Wirkung hetrifft bei jeder Dosierung immer sowohl das Nervensystem, wie anch die Ifuskulatur resp. die peripheren Nervennetze, was nicht sicher zu entscheiden ist. licpinsehn der freigelegten Ganglien mit $1^{\%}$, Pelletierinläsung ruft hereits Erschlaffung hervor, wenn anch keine ganz maximale; Injektion nach Herausuahme des gesamten Zentralnervensystems bewirkt noch Erschlaffung (siehe auch Jordan).

Bethe, Nerrensystem. 
Ich habe bei dieser Spezies aber nur wenige Tersuche angestellt.

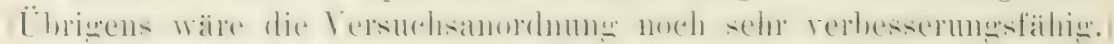

Der Normaldruck bleibt bei ein und demselben 'Tier stets anf der

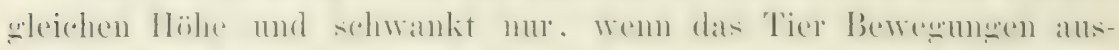
führt. So steigt der Druck bei jedem spontanen Flïgelschlag um 0,5-1,0 cm, bei spontaner Retraktion des lioptes $11 \mathrm{~m} 1 \mathrm{~cm}$ oder mehr.

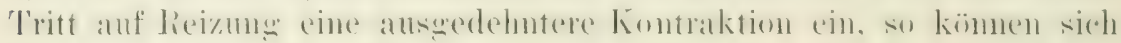
Drueksteigerungen ron $2-3 \mathrm{~cm}$ zeigen.

Wird num in der oben angegebenen Weise der 'Tonus dureh

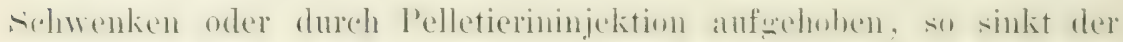
Innendruck bis auf $1 \mathrm{~cm}$, manchmal bis auf 0 herab. - Wäire der

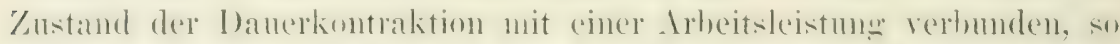

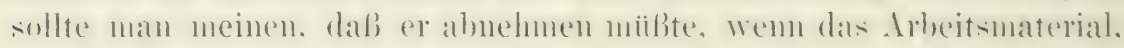
die Nahrung, entzogen wird. Dies ist aber nicht der Fall. Laßßt man ein 'Tier wochenlang' humgern, so tritt keine Verringerung des Tonts ein; derselbe nimmt sogar eher an Stäke etwas zu. Man

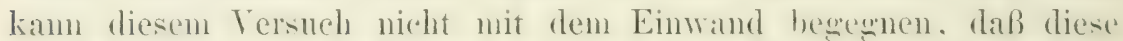
Tiere wrobe Reservestoffmengen in sich heresen. dem das Nahrunsbediufnis der normalen Tiere ist sehr groß. (In den ersten T'agen der Karenz findet eine sehr starke fewirhtsabmabme statt, welche

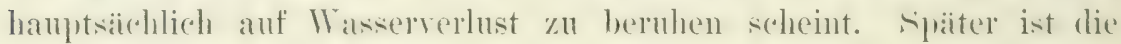
Gewichtsabnahme nur noch gering'; der 'Tonus besteht aber fort.)

Sehr viel auffallender werden diese Verhältnisse, wemn man den Tomms kimstlich steigert. Dies kamm, wie bottazzi gezeignt latt. dureh

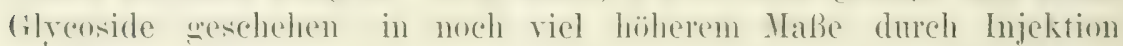
ron etwas Seewasser, in welchem Chloroform gelöst ist), doch ist dies Terfahren für uns nicht brauchbar, weil diese Vergiftungen mu voriberehend wirken, inden sie entweder zum Torle fiihnen oder Erholung zulassen. Sehr viel besser für unsere Zwecke brauchbar ist die Tonnssteigernun, welehe nach Fortuahne des gesanten \%entralnervensstems ${ }^{1}$ eintritt. liald nachdem diese Operation answefiihnt ist (siehe S. 113) fängt der Touns an, stark zu steigen. Da die

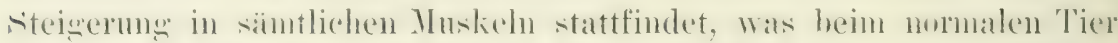

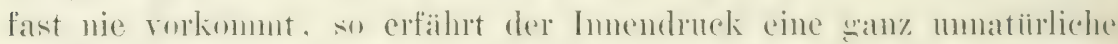
Erhöhung. Gemessen habe ieh Innendrucke ron $11-13 \mathrm{~cm}$ Wasser, wahrscheinlich ist der Druck aber oft noeh höher. Diese 'Tomushöhe ist zwar nicht das ereichbare Maximum, denn bei Berỉhrung der

1) Sie ist fïr die Kopfteile ron der Fortnahme des Cerebralganglions, fuir den größten 'Teil des übrigen körpers von der fortnihme der Pedalganglien abhïngig. Die unteren Visceralganglien milsen im lier bleiben, weil es sonst nicht atmen kamn. - Ich habe diese Befunde bereits 1595 in Neapel gemacht, aber nicht veröfentlicht. Inzwischen hat anch Jordan (1901) die partielle Tonussteigerung mach fortnahme der Pedalganglien beobachtet. 
Haut treten noch mehr oder weniger weit ansgerlehnte Retraktionen

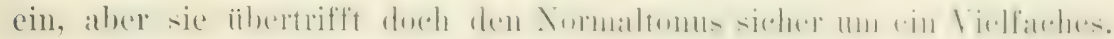
Erhält man solche 'Tiere am Leben, so tritt bis zum 'Tode ${ }^{1}$ ) kein $\mathrm{Ab}^{\mathrm{b}}$ sinken des 'lonus ein; er bleibt stets auf gleicher Höhe, wird durch

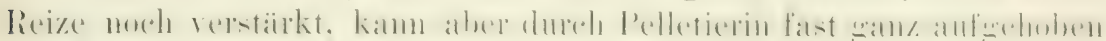

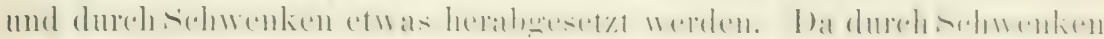
und auch durch sanfte Massage niemals ein vollkommener oder auch nur starker 'Tounsfall hervorgerufen werden kann, wie dies bein normalen 'Tier der Fall ist, so möchte ich doch den Tonusfall beim Schwenken füx reflektoriseher Natux halten.

IVem man bedenkt, wie groß die Arbeitsleistmo sein miißte, um den so hervorgerufenen starken Tonus aufrecht zu erhalten, wenn er durch fortgesetzte aktive Tätigkeit bedingt wäre, damn wird man zugeben müssen, da $B$ d ie Tonusmusklatur wohl andern Gesetzen unterworfen ist, als die Bewegunguskulatur und daB der Kontraktionszustand dieser Muskelneine andre Form. Wirklicher Ruhe ist.

Es ist nun die Frage, in welehem Abhängigkeitsverhältnis rom Nerrensystem der Tonus bei diesen Tieren steht: Jordan ist der Ansicht, daß die Tonussteigerung sofort nach der Herausuahme der Ganglien auftritt. Ich kann mich dem nicht anschließen, verstehe aber, wie man zu dieser Ansicht kommen kann, wenn man die liere bei der Operation rergiftet; weicht nåmlich die Giftwirkung, dam ist der Effekt schon da. Um die Frage zu entscheiden, sah ich rou einer Vergiftung der Versuchstiere ab und verhinderte den Austritt

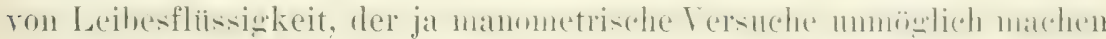

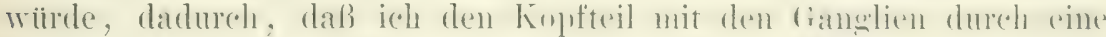

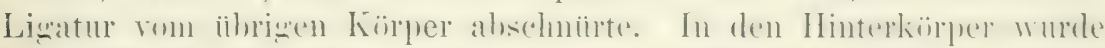

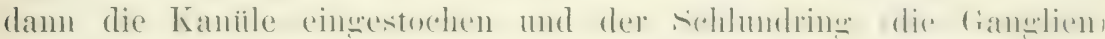
durch einen Schnitt in den Kopf freigelegt. Liegt dic Ligatur gut,

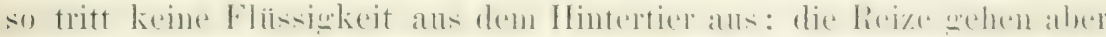

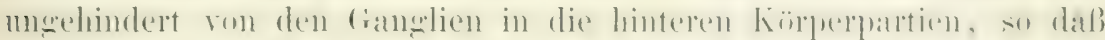

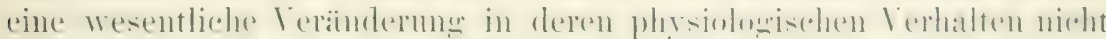

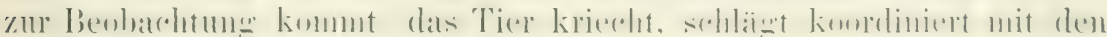
Fliigeln 11. S. w.).

Nachden sich der Innendruck auf eine gleichmäßige Höhe ein-

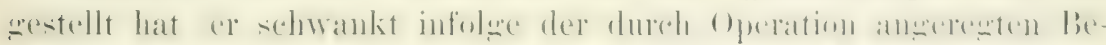

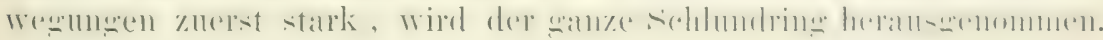

1) Ich habe solche Tiere bis zu zehn Tatgen am Leben erhalten, wïlrend welcher Zeit sie natiirlich keine Nahrung nehmen konnten. Jordan gelaner es. 'Tiere, denen beide Pedalganglien extirpiert waren, iiber einen Monat am Leben zu erhalten. Sie zeigten den erhöhten 'Tonus in den betroflenen fiebieten bis zum T'orle. 
Der Innendruck bleibt zunaichst meist normal. Manchmal sinkt er

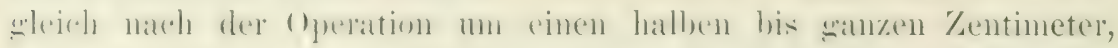
niemals aber steigt er direkt und steil in die Höhe. (Wenn die

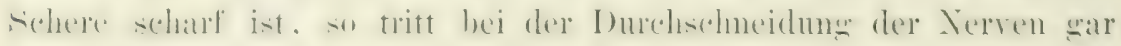
keine Reaktion, also auch keine Drucksteigerung ein.) Funf bis

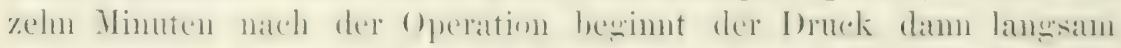

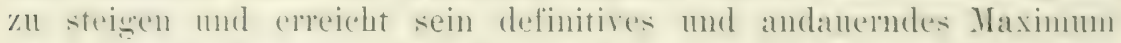

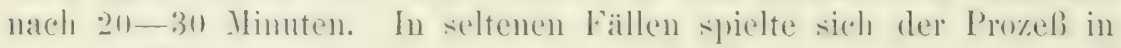
wenigen Minuten ab. Dies schien damn der Fall zu sein, wenn nach

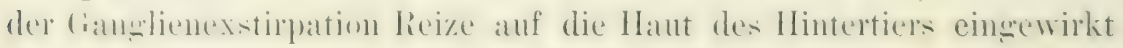
hatten. Besonders darauf gerichtete Versuche mußten leider aus

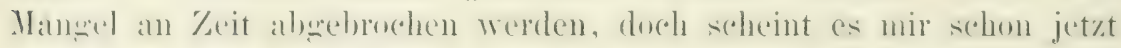
ziemlich sicher', daß der 'Tomms sich 1 mo so schneller entwickelt, je stäkere Reize anf die Hant einwirken.

Demmach seloeint hei diesen Tieren das periphere Nervennetz der Hamptremittler des Reflextonus zu sein. Das Hatutnerrenststem scheint aber nur in selur weringem Mabe die Fähigheit zu haben, die so leicht durch dasselbe vermittelten Tonussteigerunsen audh wieder zu lösen. T'onuslösung seheint also hiel eine Hauptfunktion der zentralen Ganglien zu sein. (Auf die ron

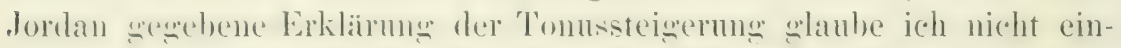

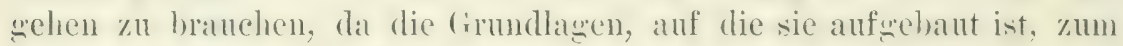
Teil auf Irrtimern beruhen.)

Ganz besondere Verhältnisse in Bezug auf den Tonus hat Uexkiill 1900, bei den reciogehn wefunden: Dic stacheln der meisten

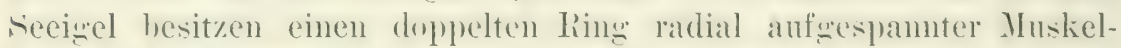
fäden. Die Fasem des einen linges bewegen sich riennlich schmell mol zeigen nur geringen T'onus, die andern weraten leicht in hohen Tomns mol halten ihn lange fest. Alle bewronmen des stachels kïmnen von der solmelleren Muskulatur ausgefiiht werden. Bringet

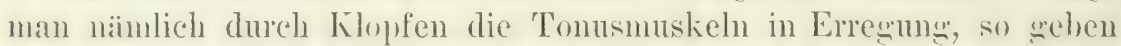
die stacheln auf Druck nicht nach; wemn man sie mit Gewalt zu hewegen sureht, so brechen sie entweder ab oder die 'Tomusmuskulatur zerreilit. Ist letzteres aeschehen, so sind die stachehn leicht hexwewlich und die ïbrimbleibenden schnellen Muskeln kïnnen noch alle Reflexe starlie und sehwache Form n. s. W. ansfiilnen. Nur die starlien Tommerscheinungen bleiben aus.

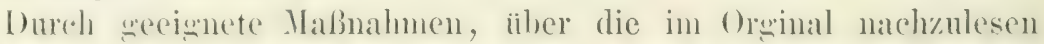
ist, kamn der T'omus der Tomusmuskulatur stark heralugesetzt werlen. Die Stacheln sind jetzt leicht beweglich. Driickt man nun einen sitadhel leicht und langsann nach einer seite, so wird dadurch die Muskulatur auf einer Seite gedehnt. Diese Erscheinung ist aber nicht rein passiv, denn, wenn man mit dem Druck 
nachläbt, so bewegt sich der Stachel in derselben Richtung weiter und kehrterst allmählich in die Ruhelagezurück. Die passive Dehnung bringt also den Tonus zum Sinken und el sinkt nachträglich noch weiter. Das

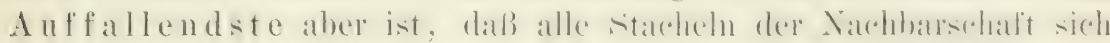
nach derselben Seite himneigen. Ls folgt also auf den 'Tomusfall

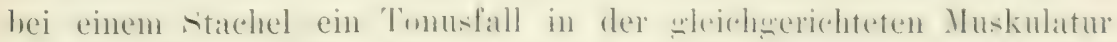

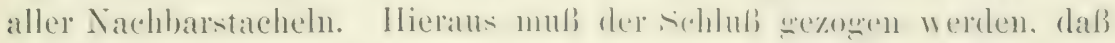
bei diesen Tieren die Erregung im Ner ren \%uliekfließen kann, wenn man nicht grade amnehmen will, daß hier besondere rezeptorische Fasern tätiщn sind. C̈ber die liedeutung dieses Plä̈nomens für das Tier Uexküll nemnt es Reflexrerkettmug muß ich auf das

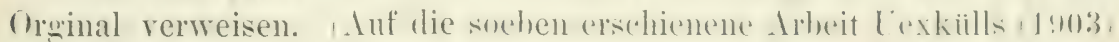
konnte leider nicht mehr eingegangen werten.)

\section{EINUNDZWANZIGSTES KAPITEL.}

\section{Die Hemmung.}

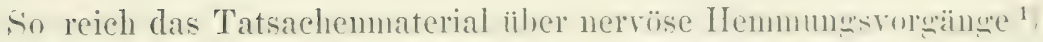
auch ist. so gehourt dies Kapitel, was die Deutume anhetrifft, doch zu flen dunkelsten und an meisten umstrittenen. Kum wefaldt bestehen

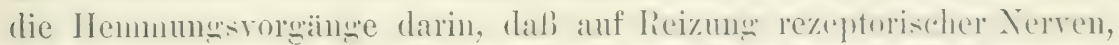

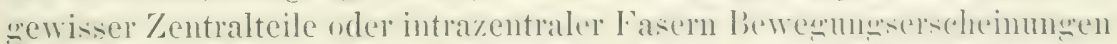

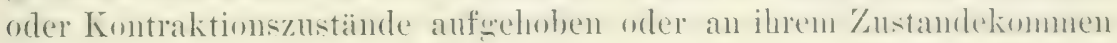
verhindert werden.

Die Existenz derartiger Ersoheimungen beim Menselen ist schom

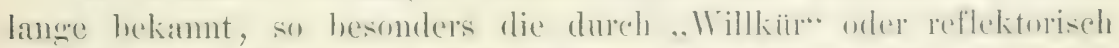

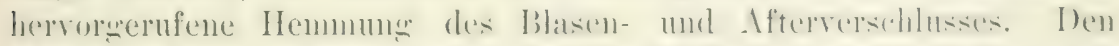

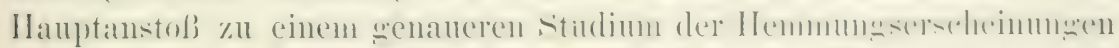

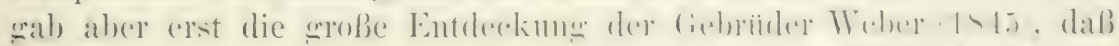

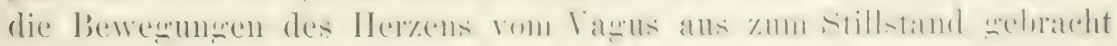
werden kömnen. Hentzutage wäre es rerfehlt, diesen historischen

1) Ein die Literatur ziemlich vollstïndig beriicksichtigendes Referat ïber die Ilemmungserscheinungen ist vor kurzem von 11. K. Hering (1902) publiziert worlen. 


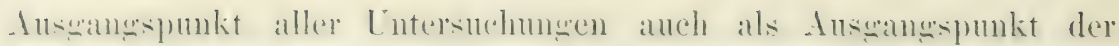

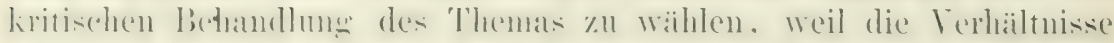
an Herzen an und für sich sehr kompliziert liegen und ron vielen

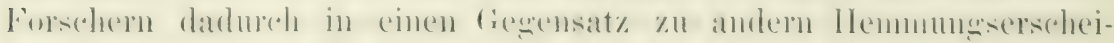
numgen gesetzt werden, daß sie die Herzbewegungen als rein mus-

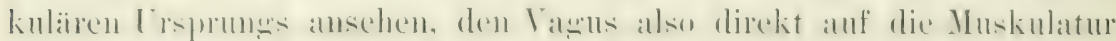
wirken lassen. Da im allgemeinen Nerven, welche mit Muskeln in

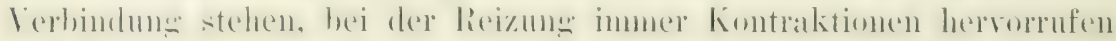

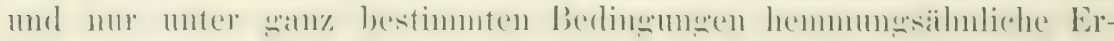

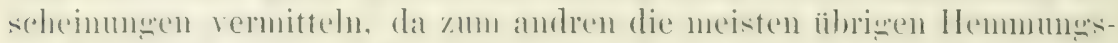

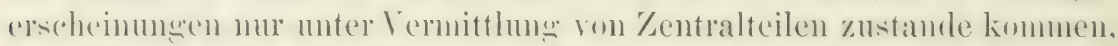
so wiirde bei der Herohemmung etwas wank andres vorliegen als bei diesen, voranswesetz, daß dic Herzaktion in Wirklichlieit rein myogener Natur ist. Ich für meine Person bin num zwar ron der Unrich-

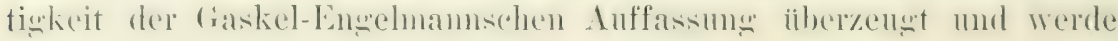
weiter unten meine Gründe hierfür aufweisen, so lange aber diese Frage noch zur Diskussion steht, wird es jedenfalls zweckmäbig sein, bei der Erörtermus der Hemmungserseheinmenen in allgeneinen von andern Tatsachen anszugehen. Aus ähnlichen Gründen ist die im

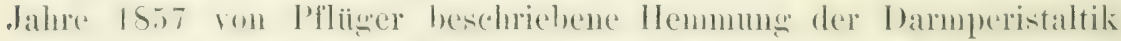
durela splanchnicusedzung in der Dentung schwierig, weil hier ebensowenig wie bein ILeren eine Möglichleeit rorhanden ist, die Eigen-

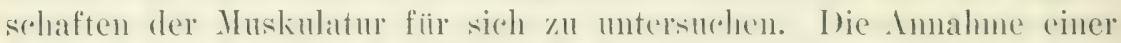
direkten Einwirkung der Vervenfasern udes splanelunicuss anf die Muskulatur dürfte hier allerding's wohl nur noch wenig Anklang finden, da jetzt die meisten forscher geneiwt sind, die eigentliche Inarmperistaltik auf nervöse Lrsachen zurückznführen siehe Starling, 1902).

Für die genanere Analyse der Hemmungsvorgänge sind die Beobachtumen an weeignetsten, welehe sich auf mumstrittene, durch das Zentrahnervensistem remittelte lieflexe beziehen. leh will zur Illustration ron den vielen hicherwehörigen Tatsachen nur einige wenige Borispiele anführen: Wie Golt\% l 469 fand, kam man einen

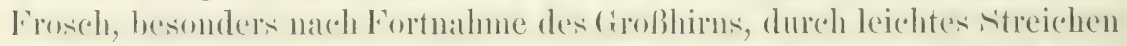

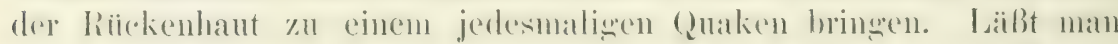

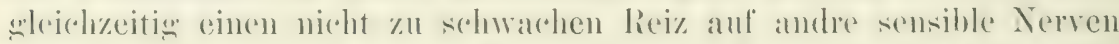

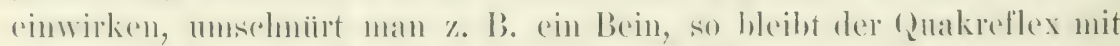

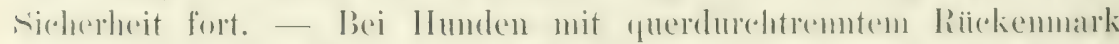

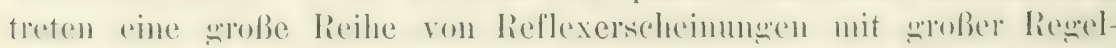

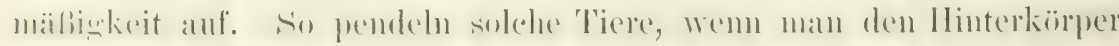

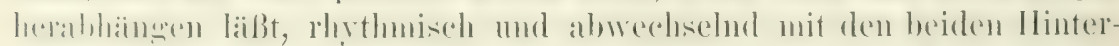
beinen. Drückt man den Schwanz oder streicht man sanft über einen Oberschenkel, so hört das Pendeh sofort auf, im einige Zeit nach 


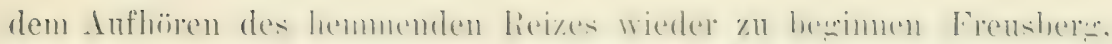

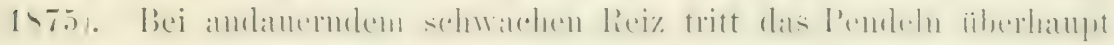
nicht ein. - Hat solch ein Hund ein Bein angezogren, das andre gestreckt und reizt man num das gestreckte, so wird dieses angezogen, zugleich sinkt aber anch das angezogene herab. Derselbe Versuch

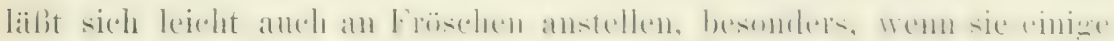
Zeit im Kalten gewesen sind (Biedermann, 1900). - Sehr prompt traten bei großhimlosen Hunden eine ganze Reilıe von Reflexen ein, welche beim normalen 'Tier nur unsicher zu erzielen sind, wie Goltz (1576-1592) gezeigt hat. Alle diese Reflexe, z. B. der auf Krabbeln der Körperseite cintretende Kratzreflex und der auf Kitzeln des

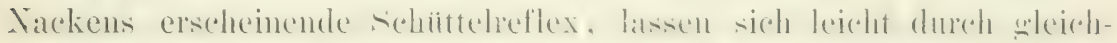

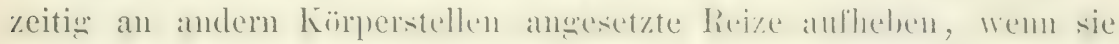
schon eingetreten sind, oder am Eintritt verhindern, wenn der auslösende Reiz erst später angesetzt wird.

In allen diesen und vielen andern Fällen wird also die normale

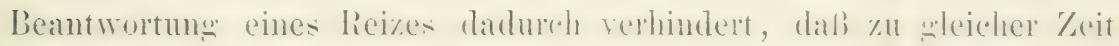
nit dem Reflexreiz (den wir beim Pendeln nicht g’enau kennen) an einer andern Körperstelle ein Reiz einwirkt. Während der Reflex seller nul ron bestimuten stellen answeliost werlen kamn, der krat\%-

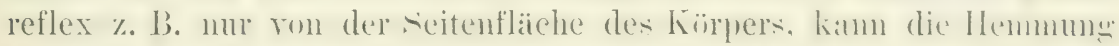

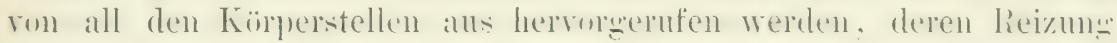
nicht eben zu diesem Reflex führt. Soweit mir bekannt, ist es nicht möglich einen Reflex ron derselhen peripherenstelle ans zu hemmen,

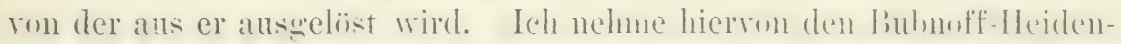

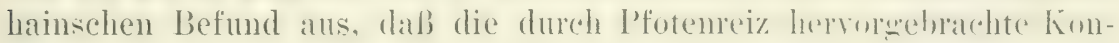
traktion durch Streichen der Pfote nachträglich wieder gelöst werden kann.) Systematische Untelsuchungen iibej diesen I'unkt existieren wohl nur ron Wundt (1876). Wurde beim Reflexpräparat (siehe S. 346) die Zuckung des Gastrocnemius ron einer hinteren

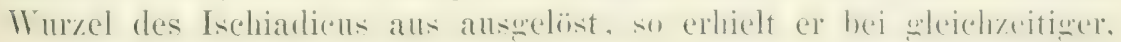
leichter 'Tetanisation einer benachbarten hinteren Wruel stets Verstärkung der Zuckung. Je weiter die tetanisicrte Wurzel vom Ursprung des Ischiadicus entfernt war, desto häbliger trat rine leminderung der Reflexwirkung, also Hemmung ein.

Manchmal miissen die hemmenden Reize stark sein: viele Reflexe lassen sich aber durch relativ schwache Reize unterdricken. Der

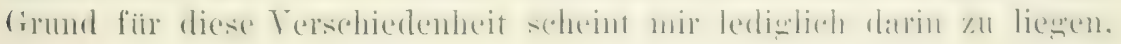
daß die einzelnen Reflexe sehr verschieden stark sind und diese Unterschiede in der Stäre sind zu einem guten 'Teil von der physio-

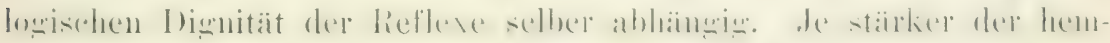
mende Reiz ist, desto mehr Reflexe fallen aus, bis schließlich bei sehr starken lieimen anch die notwendiesten lieflese anshleibun umb 
eine rollständigre Reflexlähnung (zum Teil identisch mit dem Begrriff Shok) eintritt.

Experimental kann eine sulche lieflexlähnumg l,isweilen dureh Tetanisation eines Ischiadiens und durch andre starke licize heim

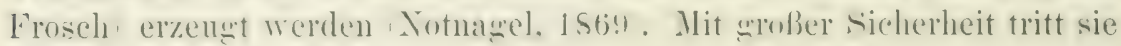
stets dadureh ein, dak man einem Frosch cinige Tropfen mednprwentiger Konchsal\%lïsmme unter die liückenhaut bringt. ${ }^{1}$, Fast momentan stellt sich anf diesen Kingriff hin eine vollknmmene lieflexlosimkeit ein: Die (rlieder hïngen schlaff heral) (seltener hefinden sie sich voriiberwehend in einem Zustand tonischen kranpfes, und werden anch anf starkes Kneifen nicht angezogen. Die Atmmg stelit still, die Zunge kann heransezogen werden und sogar der cornealreflex kamn fehlen. Selhstverständlich latsen sich die Tiere in diesen Zustand jede Lagee, auch die litickenlage, gefallen. Dieser Zustand danert aber nur wenige Minuten, dann kehren die Reflexe allü̈hlich wieder. Veranlaßt man die 'Tiere zu einigen starken liewegungen, so tritt gewöhnlich die Reflexlïhmung noch einigenual für ku\%e Zeit ein. Auch durch lieiben der Ríickenhant kam man nene Anfälle rom alsoluter Reflexhemmung hervorrufen. Nach etwa einer Viertelstumde sind die

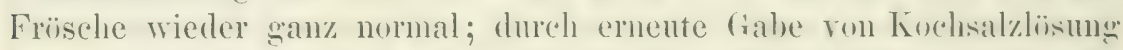
kann aber der alte Zustand wieder hervorgerufen werten. - Die allgemeine lieflexhenmung komnt hier offenbar dureh den starken all-

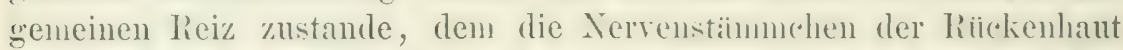
unterworfen werden. Ist das Kochssalz resorhicrt, so hören die Erscheinungen auf.

Lm allgemeine Reflexhemmung hervorzurufen, muß der hemmende Reiz erstens sehr stark und zweitens sehr auswedehnt sein, also viele Nervenhahnen zugleich treffen. Sichwache allg̈encine licize und starke lokale Reize kïmnen wohl die Reflexerregharkeit in allwemeinen herabsetzen und einiwe schwache Reflexe sanz an Zustandelommen verhindern, aber eine vollkommene Reflexlähnumy rufen sie nie hervor. Je lokaler ein Reiz ist, desto mehr wirkt er reflexauslösend und desto weniger reflexhemmend; je mehr er sich über weite Körperstrecken anshreitet, desto mehr wirkt er reflexhemmend mul desto weniger reflexauslösend. Der Lnterschied zwischen den anf

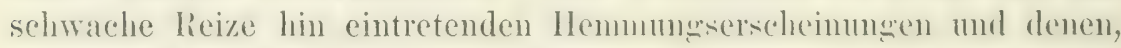
welche auf starke (und melur allgemeine eintreten, ist also nur graduell, so daß mir die Aufstellung einer gewissen (iegensitzlichlieit, wie sie II. E. Hering vornimmt, ziemlich willkïrlich zu sein scheint.

1) In der Literatur habe ich diese Erscheinung bisher nicht erwiihnt gefunden. Aus persönlichen Mitteilungen habe ich aber erfahren, dafi sie in verschiedenen Laboratorien hekannt ist. 
Eine scharfo tirenze zwisehen mehr physiologersehen Henmmmers-

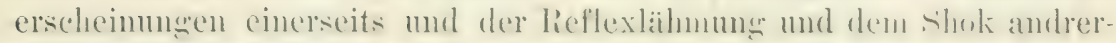
seits existiert nicht.

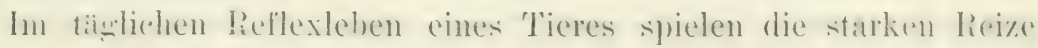
als hemmende Faktoren nur eine untergeordnete Rolle. Auch die

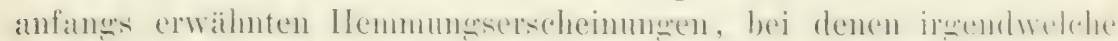

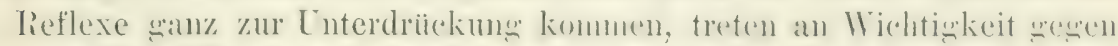
partiellere Hemmmonen zuritck. I)iesen verdankt wohl das kondinierte

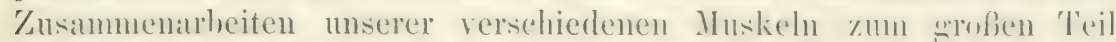

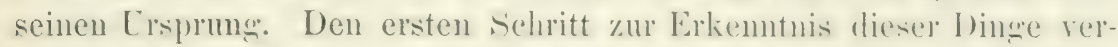
danken wir E. Hering and Breuer (1868).

Nachdem 'Traube (1847) gezeigt, daß die Atmung bei Reizung

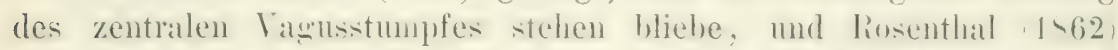

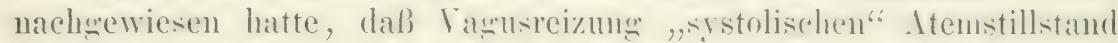
liontrahiertes Zwerchfell, Leizung des Laryngans superior , diastolischen" Atemstillstand schlaffes /werchfell, herroment, wurle wom Hering und Bremer daretan, dals derartige Hemmungen durch zen-

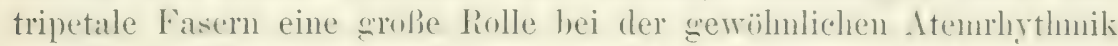
spielen. Ifei der Inspiration wirl die Lunge gedehnt und hierelureh werden zentripetale Faseru gereizt, welche die Inspirationsmusknlatur in der weiteren Iktion hemmen, "sie also zum Erschlaffen bringen; andrerseits wird durch das Kollabieren der Lunge bei der

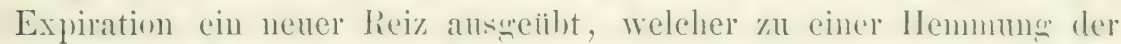
Expiration füht. Zumbich werden jedesmal die entwenengestrten Muskeln angeregt; siehe S. 398). „Wir haben es hier," schreibt H. E. Hering, ,nit der ersten experinentellen 'Tatsache zu tun, welehe uns zeiste, dals auf natülichem Wrege erreste zentripetale Verven in

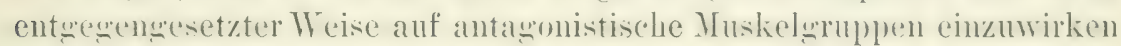
vermögen."

Bereits Charles Bell (1836) hatte die entgegengesetzte Innervie-

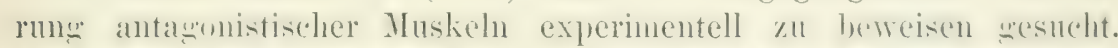
Er latte die selme eines Muskels ritreckinuskel, durelscelmitten und

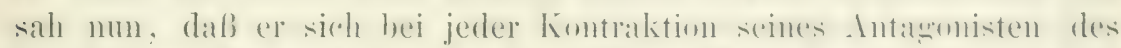

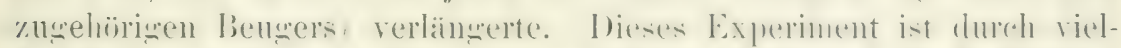

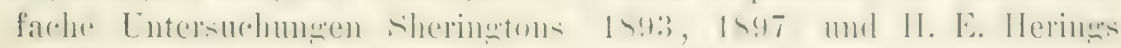

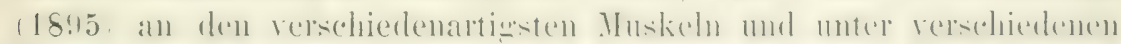

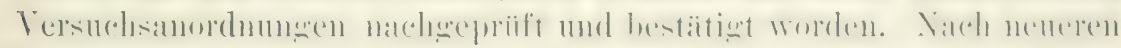
Untersuchmogen von R. du Bois-Reymond (1902) scheint die Hemmung eines Agonisten bei Kontraktion seines Antagonisten und umgekehrt zwar nicht so spezifisch zu sein, wie es ron Sherington

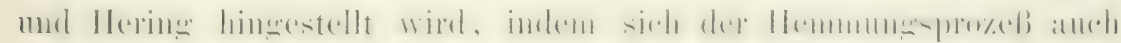
auf alle möglichen andern Muskeln erstreckt; in Prinzip wird man

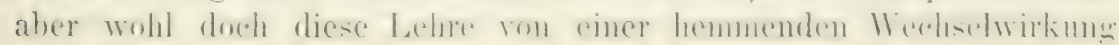


aufrechterhalten diurfen. Man darf sie nur nicht zu sehr schematisieren.

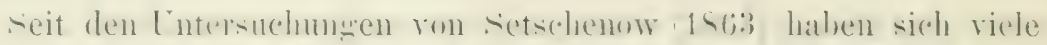

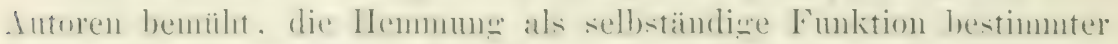

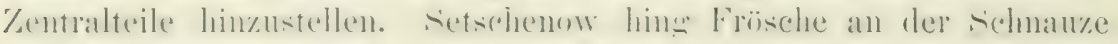
auf und tanchte eine Pfote in rerdiunnte Schwefelsäure. Es wurde

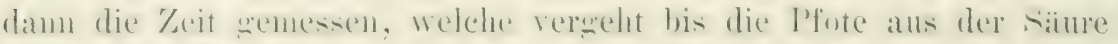

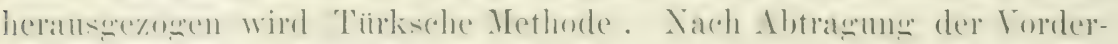

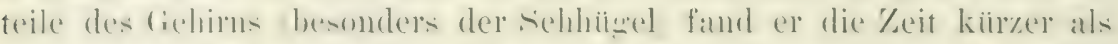

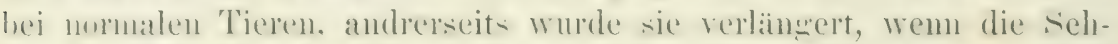

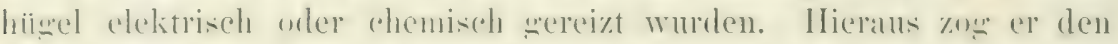

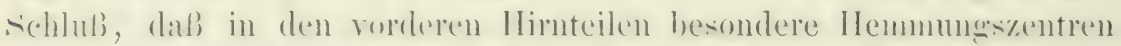

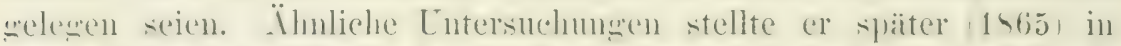
finemschaft mit l'aschutin an. Eine reflexhemunende Funktion sollte danach nur dem Gehirn, aber nicht dem Riickenmark zukommen.

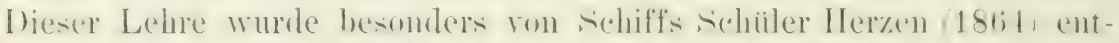

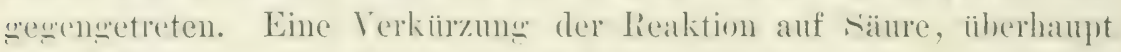

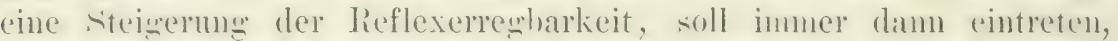

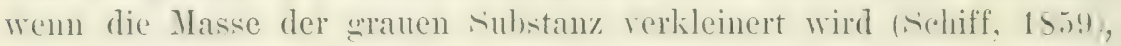

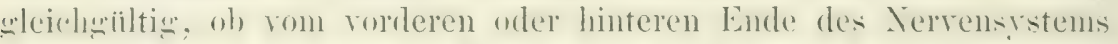
sulstanz fortenommen wird. Leider sind diese lundinteressanten Versuche in nenerer \%eit nicht wieder anfwenommen worlen. Eine

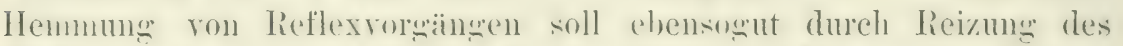

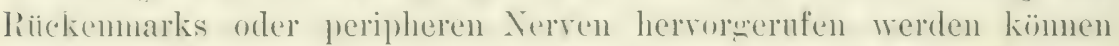

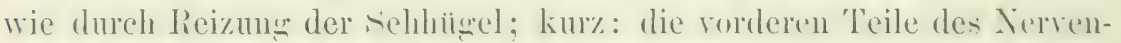
systems hätten, was die Hemmunwsoreange anbetrifft, nichts Wesentliches vor den iibrigen roraus.

Weun, wie oben gezeigt wurde, am unverstümmelten lier um so leirhter eine Reflexhemmunz zu er\%ielen ist, je answedehnter die weroizten l'artien sind, dam hat es nichts Merkwiildignes an sich, dak

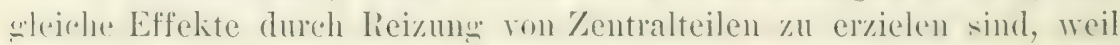
ja hier an den meisten Stellen ein Zusammenfluß sehr vieler le reipherer bahnen statfindet. Man reizt hier an einer sohembar

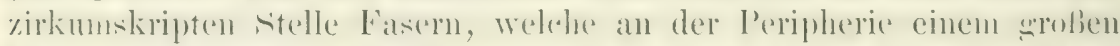

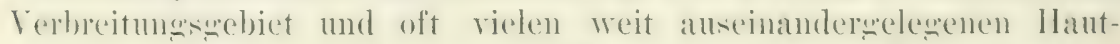
stellen entsprechen. An meisten Fasern, welche weit anseinander-

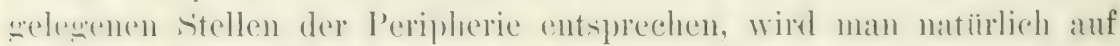
kleinstem Ratum an den stellen des Zentralnervensystems reizen, wo alleneneine simmelstellen sind, also bei Wirheltieren in firoblim mul

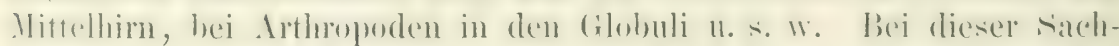

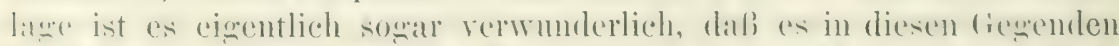
frellen wibt, deren kiinstliche lieizun die ja nie lokal sein kamm zu positiven Erfolgen führt (motorische Zonen). 
Daß es im simne von setschenow hemmende Zentren gibt, ist wohl allgemein aufgegeben. Wohl allgemein hegt man jetzt die Insicht, daß alle physiologischen Hemmungen auf außeren Reizen beruhen, grade so wie samtliche Bewegungserscheinumgen dieses Ur-

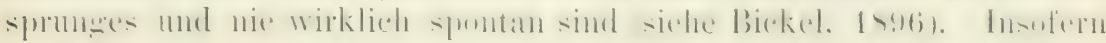
wird man aber noch immer ron Hemmmogszentren sprechen kömmen, als gewisse Zentralteile höherer 'Tiere zu rezeptorischen Nerven, von

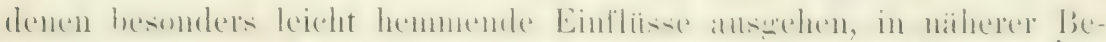

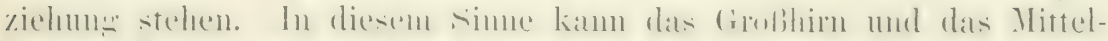

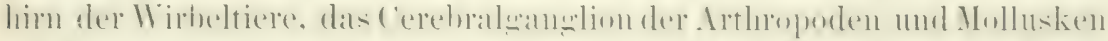

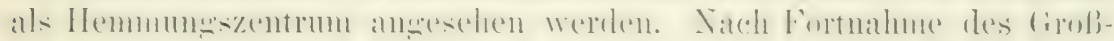
hirns sind bei Fröschen (Groltz, 1869, Schrader, 1887), 'Tauben (Schrader, 1889) und Hunden (Goltz, 1892) alle Reflexe sehr viel

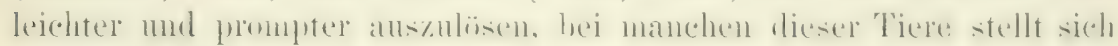
atch ein fast andaternder Bewegungstrieb ein. Dasselbe ist nach

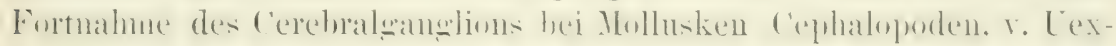
kiill, 1595, Aplysia, Jordan, 1901, ich) und bei Arthropoden (Bethe,

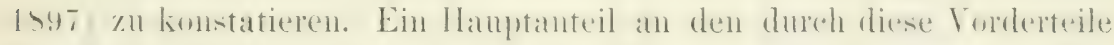

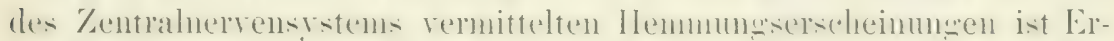
regungen zuzuschreiben, welche dauernd rom Auge aus zum Nerrensystem gelangen. So komnten Langendorff (1877) und Merzbacher

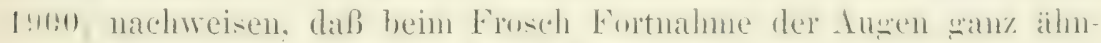

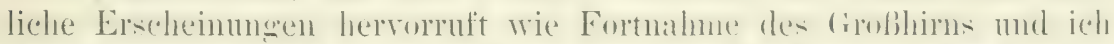

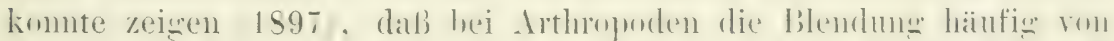

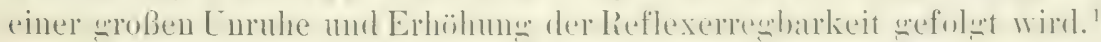

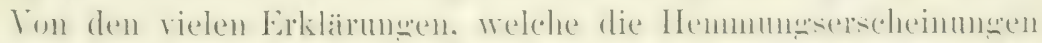

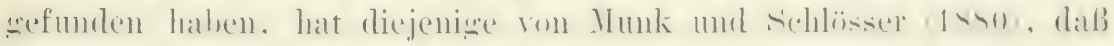

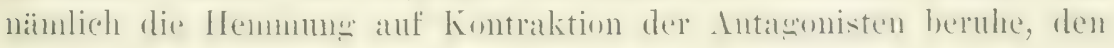

1) Eine große Anzahl von Tatsachen, welche ein mehr spezielles Interesse haben, will ich hier iibergehen. Kurz erwähnt mögen noch folgende Beispiele werden: Bubnoff und Ifeidenhain (1ss1) liefen nach Freilegung der motorischen Zonen den Extensor digitorum communis von IIunden seine Bewegungen aufschreiben. Auf Streichen der Pfote oder auf lindenreizung trat häufig eine Kontraktur des Iuskels ein. Diese konnte durch leichtes Streichen der P'fote oder durch schwache Tetanisation der motorischen Zone aufgehoben werden. Bromn-Séquard (1554) komnte durch Reizung nicht motorischer lindenfelder bei Hunden und Kaninchen die Reizharkeit der motorischen Zonen für mehrere Jinuten aufheben; er grlaubt es hier auch mit einer Hemunng zu tun zu labben. Libertini (1595) maß die Reflexzeit eines isolierten Muskels rom IHunde (auf I’fotenreiz) vor und nach Exstiruation der motorischen Zonen. In letateren Fall fand er sie verkiirzt und sehloß darans, daß vom Großhirn ans eine damernde Hemmung anf die Iuskulatur ausgeiibt wïrde. Der hemmende Einfluf auf die vordere Extremitit ist stïrker als auf die hintere, weil bei dieser die V'erkiirzung der Reflexzeit nach der Gehimoperation weniger ansgesprochen ist. 
Vorzug der Einfachheit. Es sprechen aber zu viele Grinde gegen

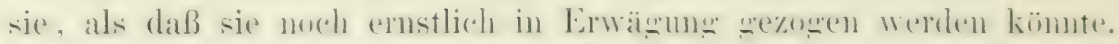

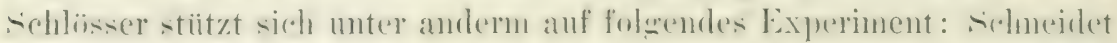
man einem Quakfrosch den Unterkiefer ab, so sieht man, daß bei

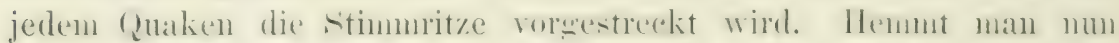
den Cuakroflex durch eine liemlinatur. sn wird der kehllingf stark

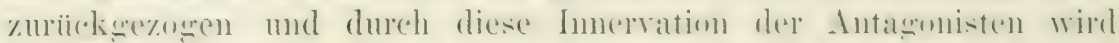

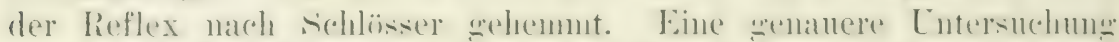

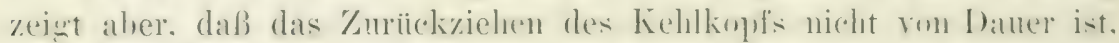

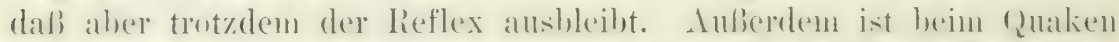
die enome Anspammung der banchpresse viel wesentlicher als die

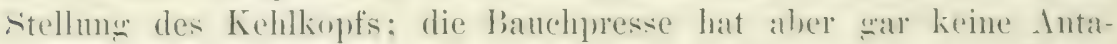

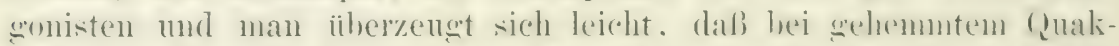
reflex anch nicht die mindeste Kontraktion in der Iianchmusknlatur eintritt. Inf solche Iemmungen, welche an Muskeln zur lieoharchtum,-

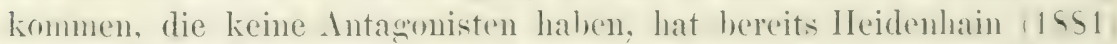

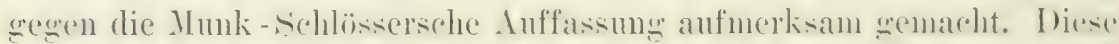
Beobachitungen und beobachtungen an isolierten Muskeln, wie sie ron ihm selher und spaiter wom sherington und llering siehe oben s. :37

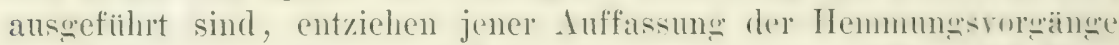
den Boden und zeisen, wie Heidenhain sayt, zum mindesten, dah siu keine allgemeine Giiltigkeit haben kanu.

Offenbar handelt es sich also bei der Hemmung darum, daß entweder bereits bestehende hontraktionen aufechohen werden orler das Inaktiontreten von Muskeln rerhindert wird. Über das Wie dieser

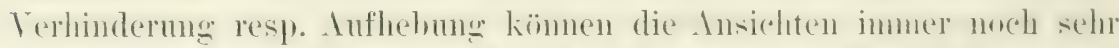

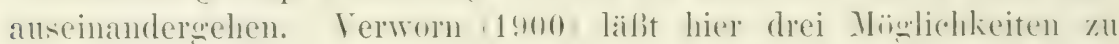
(rielleicht wälen noch mehr rorhanden): 1. Der motorisehe Impuls wird zum Aufhören gebracht resp. an Eintreten verhindert das ron

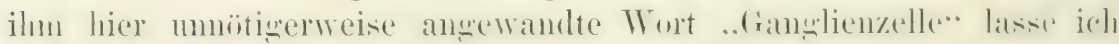

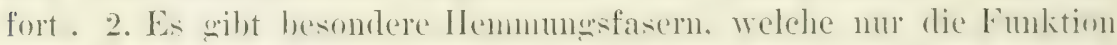
haben, weun sie erregt werden, die Kontraktion eines Muskels aufzuhuben oder an Eintritt zu verhindern. 3. Es whibt keine hesmoleren

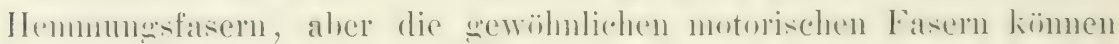

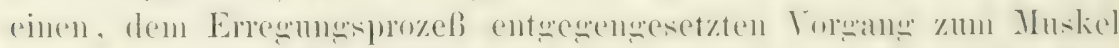

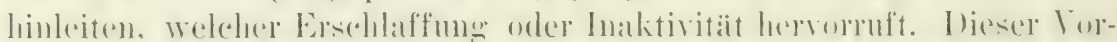

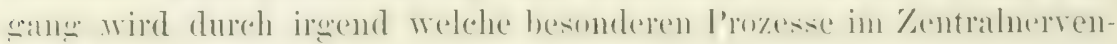
system (es braucht nicht gleich wieder die Torderhornzelle zu sein) hervorererufen.

Verworn glaubt, daß es keine Schwierigkeiten haben kïme,

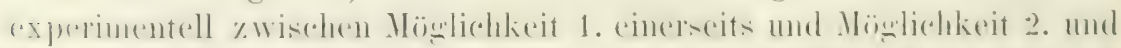

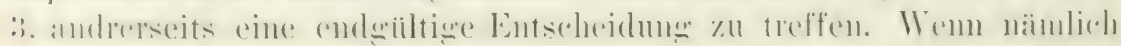
die Hemmung in einem aktiven zum Muskel geleiteten Prozeß be- 
stainde, wie es 2. md 3. ammehmen, so miliBte nach seiner Ansicht die Zuckungskurve eines Muskels, der direkt rom Terven aus von Zeit zu Zeit mit einem Induktionsschlag von stets grleicher und submaximaler Stäke sereizt wird, niedriger werden, wenn zugleich ein

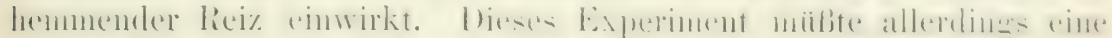

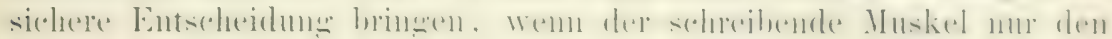

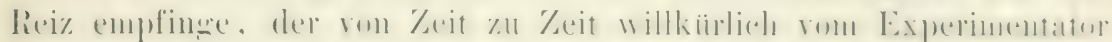
am Nerven angesetzt wird. Nun lüngt aber der Muskel durch seinen Nerven mit dem Zentralorgan zusammen, welches ja den eventuellen hemmenden Vorgang dem Muskel remitteln soll. Ton hier aus kam

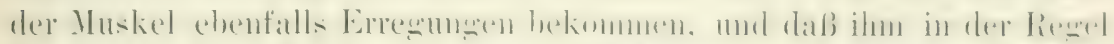

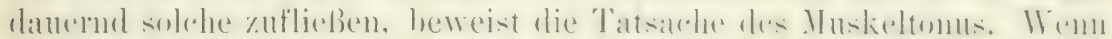

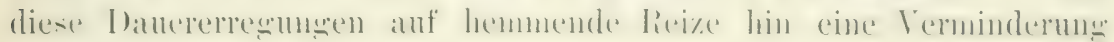
erfahren, so muß zum mindesten die Abszissenachse absinken; man

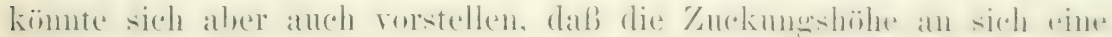

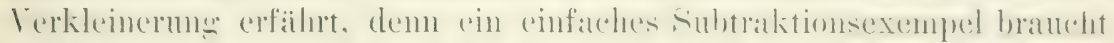
nicht rorzuliegen.

Toch andre Erscheinungen sprechen dafür, daß die Einflïsse, welche auf den Muskel einwirken, weun er noch mit dem Zentralnerrensystem in 'Zusammenhang' steht, nicht so ganz einfach sind. Harleß gab im Jahre 1860 an, daß die direkte Erregbarkeit des

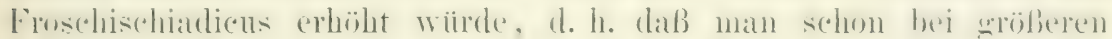

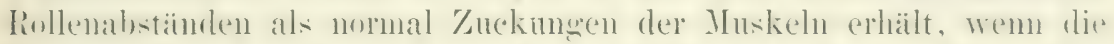
hinteren Wurzeln durehschnitten sind. (In einem Fall z. B. fand $\mathrm{el}^{\circ}$

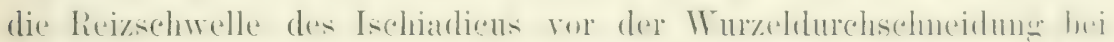

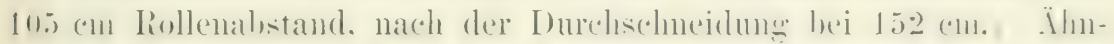
liche Resultate erzielte Mareacei (1882). Zu dem grade entgegen-

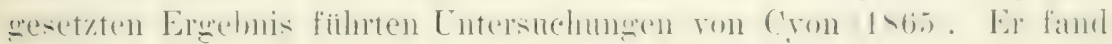
die Erreglbarkeit der rorderen Wurzeln beim Frosch nach Durch-

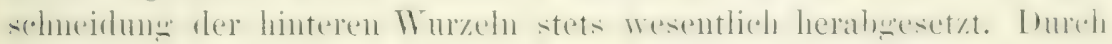

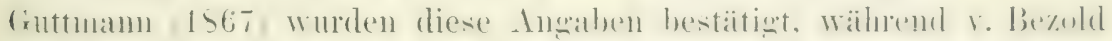
und Uspensky (1867) und G. Heidenhain (1871) eine Herabsetzung der Erregbarkeit lengneten orler sie, wenn vorhanden, auf Anämie

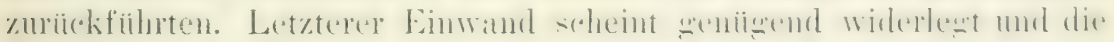

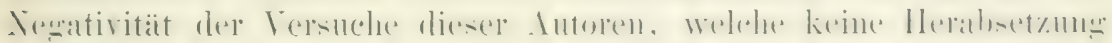

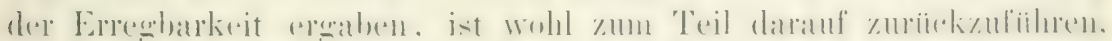
daß sie das Versuchsrerfahren Cyons nicht eimhielten. In nenerer Zeit ist die Frage durch italienische Autoren wieder aufrenommen und besonders durch Belmondo und Oddi (1590) im Simne Cyous beantwortet worden. Diese Autoren glauben auch den Grund dafiur grefunden zu haben, weswegen Harleß und Mareacei eine Erhöhung:

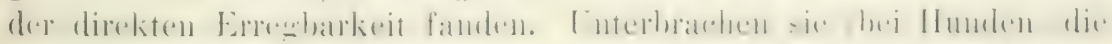

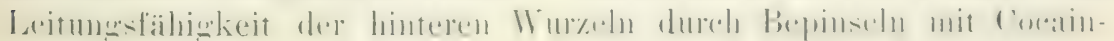




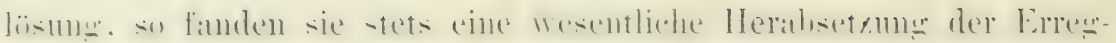

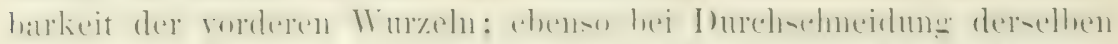

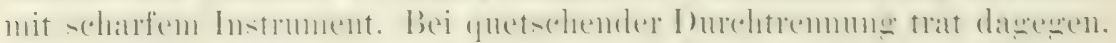

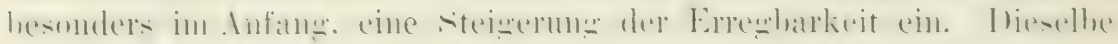

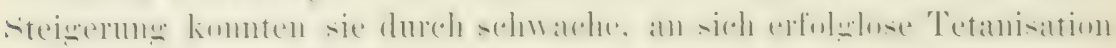
hinterer Wureln erzielen.

Wenngleich diese neneren Lntersuchungen in technischer Beziehung nicht ganz einwandsfrei sind, so scheint mir doch, den belegenden Kurven nach zu urteilen, etwas an der sache dran zu sein und ich möchte sie nicht so kurzer Hand beiseite schieben und unbeachtet lassen, wie dies ron Seite mancher Autoren greschehen ist, die der Meinung sind, daß man nur in Dentschland und England physiologisch zu arbeiten rerstehe. Jedenfalls ist eine nene Nach-

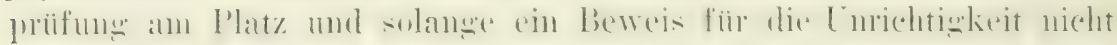
erbracht ist, müssen die positiven Angaben in Erwäimng gezogen werden.

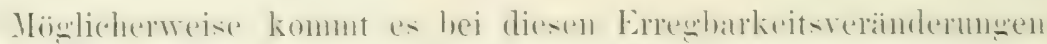

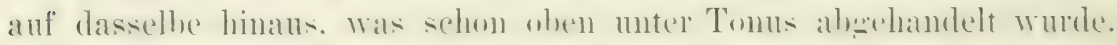

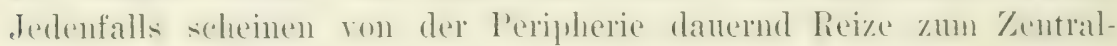
nervensystem und ron hier zu den Muskeln zu gelangen, welche z $и$ Teil den Tonus berirken. Es bleibt dam aber, wenn ich

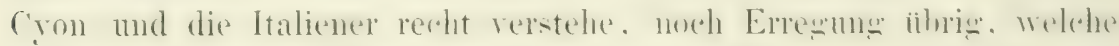
zur keiner weiteren Verkiirzung des Muskels führt, welche sich aber bei stärkeren Reizen — und auch solchen, die den Nerren direkt treffen - zu diesem addiert. Fehlt diese Danerregung, wie dies nach Durchschneidnug der hinteren Wu\%ch der Fall ist. so m iissen stärkere Reize auf den Nerren direkt einwirken, um dieselbe Wirkung zu erzielen, wie vorher. Da bei Vor-

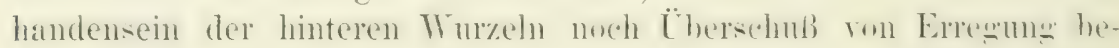
steht, so muß ihre Ausschaltung nicht nur in einem Absinken des

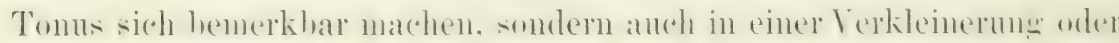

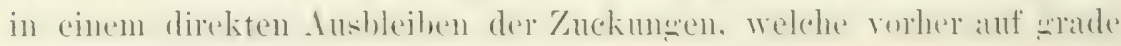
ansleichende Reize eintraten.

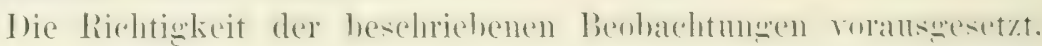
kaun - theoretisch betrachtet - die durch direkte Erregrumg des

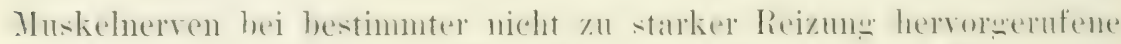

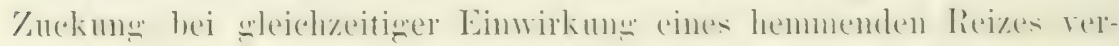
kleinert werden oder ganz rerschwinden, oln $\mathrm{e}$ da $\mathrm{B}$ di e II e m m un in einem aktiren zum M usel geleiteten l'rozel besteht:

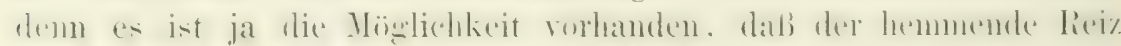

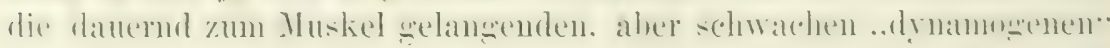
Reize (ein Ausdruck, der, soweit mir bekaunt, ron Brown-Séquard

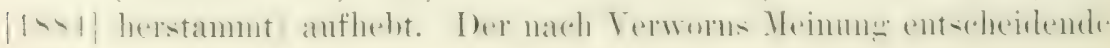


Versuch kamn also unter Umstanden ein zweifelhaftes Resultat ergeben.

Versuche dieser Art wurden zuerst von Oddi (1895) am Hunde angestellt. Die zu dem einen prïparierten Gastroenemins (welcher seine Zuckungen aufzeichnete) gehörige vordere Wurzel wurde freigelegt, mit Elektroden amiert und (nit Hilfe eines Metronoms) in

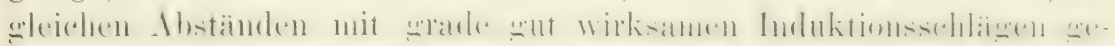

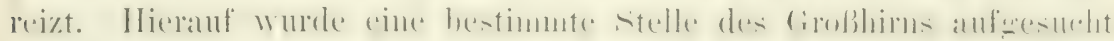
und faradisch gereizt. Während der GroBhirmreizung wurden die

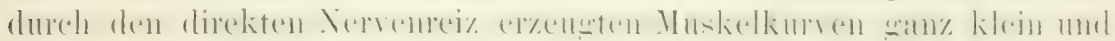
hörten in manchen Fällen sogar ganz auf. Tomusfall trat bisweilen

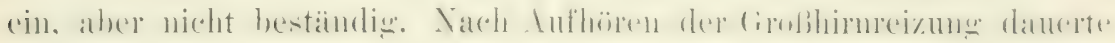
die Depression einige Sekunden an; damn kehrte die anfïngliche Kurrenhöhe (resp. die alte Nerrenerregbarkeit) wieder. Noch deut-

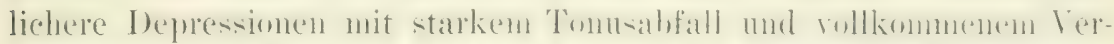

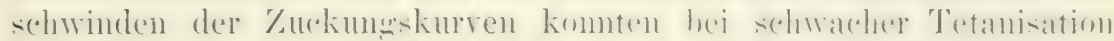

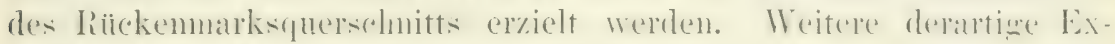
perimente wurden ron Oddi im Jahre 1898 und ron P'olimanti 1895 reröffentlicht.

Manelli (1896) vermied die Bloßlegung des Riickemmarks und

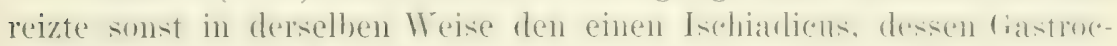
nemius schrieb. Bei faradischer Reizung des andern Ischiadicus

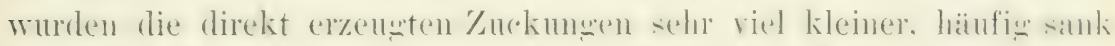
auch der Tonus selu stark ab. Die depressive Wirkung trat nicht sofort ein (was auch Oddi hervorhebt) und ïberdanerte die Faradisation des andern Ischiadicus oft riele Sekunden. Um während der Depression die gleichen Zuckungen wie rorher und nachher zu erzielen, mußten die Rollen oft $\mathrm{um}$ mehrere Zentimeter einander genähert werden (Katze). ${ }^{1}$ )

1sys hat damm starke, whe die Lntersuchnmeren der italienischen

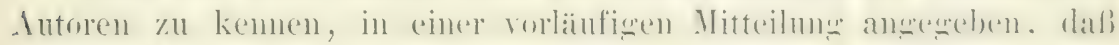

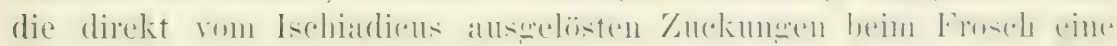
Eniedrigung erfahren, wemn das Großhirn gereizt wird. An diese Publikation knïpte Verworn (1900) an - auch er erwaihnt die oben

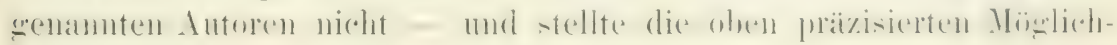
keiten auf.

1) Patrizi (1596) reizte rhythmisch die Nervi plurenici und zeichnete die Zwerchfellbewegungen aul. Wurde gleichzeitig der zentrale Vagusstumpt gereizt, so wurden die Zwerchfellhewegungen kleiner oder hörten auf. Inzwischen hat Ilering (1902) gezeigt, daß diese Wirkung auf Imnervation ron Antagonisten beruht. Dadurch wird zwar dieser Spezialfall ron der Diskussion ausgeschlossen, den Versuchen Oddis, Manellis 11 . s. w. aber kein Abbruch getan, da ja bei ihren Experimenten eine Einwirkung yon Antogonisten ausgeschlossen war. 
Verworn suchte sich in seinen eignen Versuchen ror allem ror

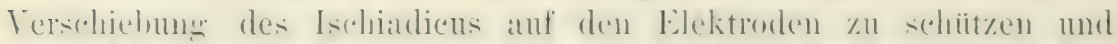

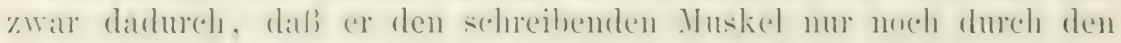

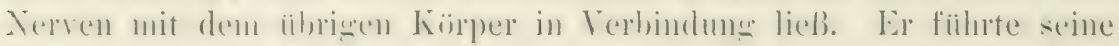
Versuche an Fröschen und Hunden aus. Als hemmenden Reiz be-

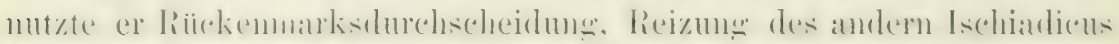

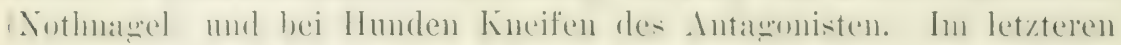
Fall bekam er Absinken des Tonus, aber keine Verkleinerung der

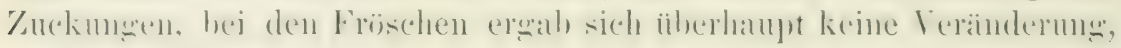
anch kein 'Tonusabfall.

Verworn zieht ans diesen negativen Versuchen den Schluß, daß

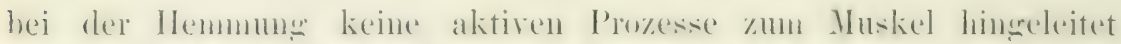

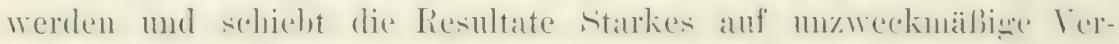
suchsinordnum, speziell auf Verschiehnum des Serven anf den Elektroden, wodureh ja, wie jeder weik, sehr leicht Ïndermugen in der Anspruchsfähigkeit entstehen können.

Inureh diese Lntersuchunen Verworns scheinen mir die pusitiven Resultate der italienischen Autoren - wegen die er sich allerdings gar nicht wendet - nicht aufgehoben; die Frage scheint mir vielmehr einer weiteren Bearbeitung zu bedürfen. Die Resultate der italienischen Forseher wïrlen sich whe Amnahme besmolerer hemmender Fasern oder den druanogenen entwegentesetzter l'ruzesse in den sewöhnlichen motorischen Fasern leicht dadurch erklären lassen, dab andanemel dymanowene Reize zmu Muskel welangen, welche sich zu einem Teil (aber eben nur zum 'Teil) im Muskeltonus äußern. Diese werden durch hemmende Reize aufwehoben ivie es ja für den 'Tomus sicher feststeht, so daß eine Vermindermen der Anspluchsfähigkeit des Nerren in Erscheinung tritt.

Soweit sie sich dariber ïberhaupt auslassen, scheinen anch die italienischen Antoren dieser Dentung ihrer Versuche zumeigen. Dals sie ans ihnen Versuchen anf besondere Hemmungsuervenfasem oder entgegrengesetzte I'rozesse in den motorisehen Fatsern schließen, habe ich nicht heranslesen kïmnen. Dieser Öberschuls an latenten lieizen scheint nach ihren Versuchen auberordentlich leicht durch Henmumwen in seiner Wirkung beeinträehtignt zu werden. Nun ist aber solon jode Fesselung ein starker hemmender lieiz, der sich in ganz hesonders

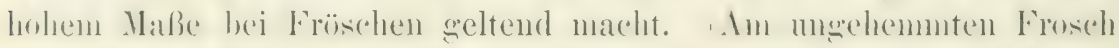
kann man eigentlich nur experimentieren, wem er wanz frei anf dem Tisch sitzt.) Unter diesen Umständen ist es nicht zu verwundern, dalf in den Versuchen Verworns, wo dureh die rersediedenartizsten Vorsichtomaliregeln eine enome liasse ron hemmenden Reizen anfresetzt wurde, das licsultat der italienischen Forscher nicht zum Iusdruck kam. 
Da Verworns Frösche noch einer weiteren Hemmung - zil der zwreifellos bereits in starkem Maße vorhandenen - fähig waren und da hierbei eine Verkleinerung der Kurven nicht zu konstatieren war,

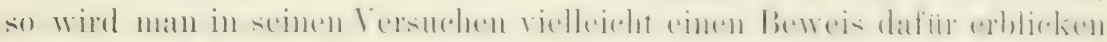

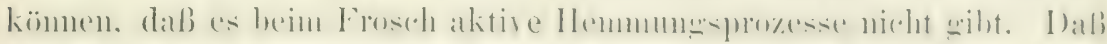

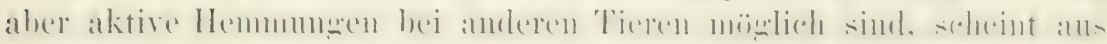

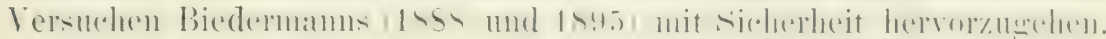

Biedermann durehschnitt an Krebsscheren den Öffnung'smuskel. Befand sich nun der SehlieBmuskel in schwachem Tonus, so er-

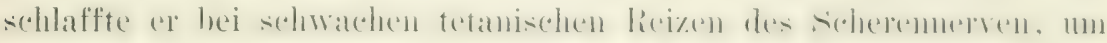
erst bei stärkeren tetanischen Reizen in Kontraktion zu geraten. Da die Nervenfasem sich im Krebsmuskel direkt zu den Muskelfasern begeben (ohne rorher Zentralteile zu passieren), so kann es sich hier nur darum handeh, daß dem Muskel zwei verschiedene Prozesse iibermittelt werden. Ich halte es allerdings nicht, wie Biedermann es tut, für zwingend, daß im Scherennersen zwei verschiedene Fasergattungen, motorische und hemmende, rorhanden sind. Man wiurde aluch mit einer cinzigen Faserwattung anskommen, wem man die when

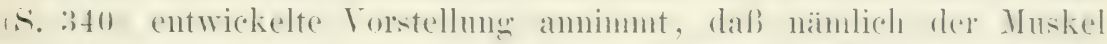
anf die heiden remutlich rorhandenen Phasen des Nerenerrentulsprozesses rerschieden reagiert.

Weniger klar als bei der Krehsochere liewen die Verhiiltnise heim Muschelschließmuskel, wo Pawlow 1555 ein ähnliches I'hänomen hewhachtete, beim starken lieflex der seeigel ['exküll, siehe s. :3:36

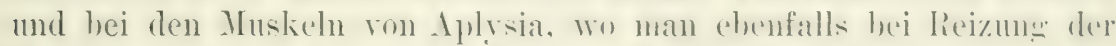

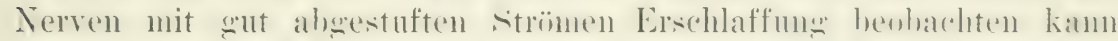
(S. 117). In allen diesen Fällen gehen die Nerrenfasern nicht direkt

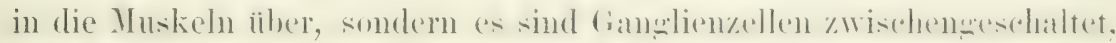

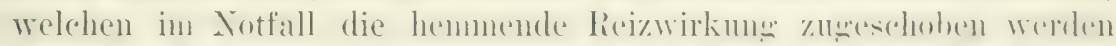
kamn. - Wirkliche Itemmung fasern, die direkt anf die Muskulatur einwirken, werden auch von allen denen, welche sich der Lngelmann-

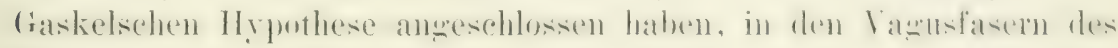
Herzens gesehen. Hier liegt aber der l'all nicht anders, wie bei Seeigehn und Mollusken, demn es scheint mir kein Zweifel dariber zu

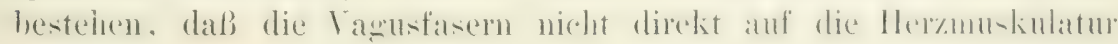
einwirken.

Demnach wäre der Biedermannsehe Befund an der Krebsschere der einzige Fall, wo eine direkt anf einen Nuskel iibertragene Nerrenerregung hemmend wirkt. Wenn aber solch ein Fall existiert, so darf er nie aus dem Auge verloren werden.

Trotzdem es nun wohl in manchen Fiallen eine am Muskel selber

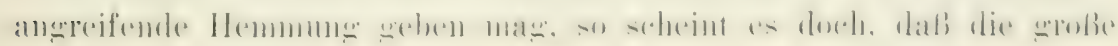




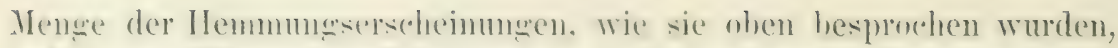

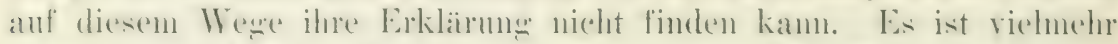

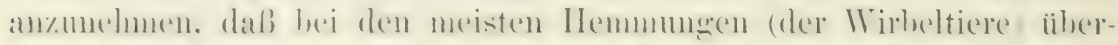

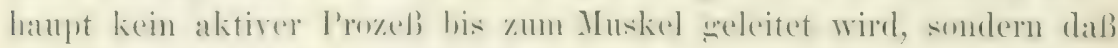
die Hemmung sich intrazentral abspielt. Sie würde also darin be-

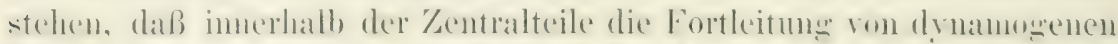
lieizen zu den Mnskehn rerhindert wirl, also in etwas rein Nexativen.

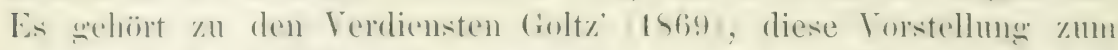

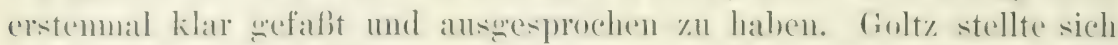

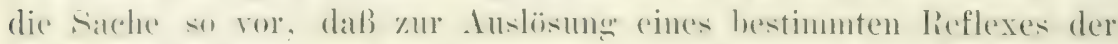
liei\% vom hestimmten l'mukten ansogehend den Muskel anf einem he-

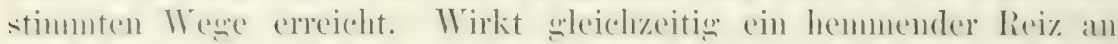
(ince andern stelle ein, so krenzt el den Wren des reflexamsliosenden

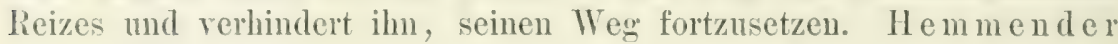
und reflexa us ösender Reiz wïrden sich also a ufheben, indem sie gewissermaßengegeneinander an rennen. Ns

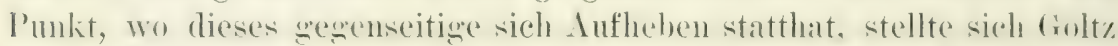
die Canmlienzelle vor, aber nur, wie dentlich ans seinen Worten hel'-

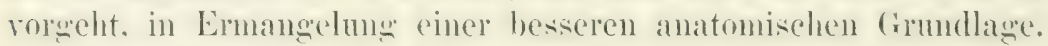

Diese Vorstellung hat sich als sehr fruchtbar erwiesen und ist nit einigen Erweitermonen zu ziemlich allowener Inerkemung ge-

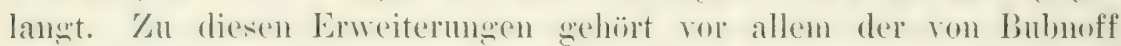
und Heidenhain (1881) und dann ron Brown-Séquard (1881) aufgestellte Satz, daB die Hemmung immer am eluesten an den Muskeln zum Ausdruck kommt, welche im Stadium der Verkïlzung sind, wäluend ruhende Muskeln auf den gleichen Reiz hin zur dynamogenen 'Tatigkeit neigen.

Die Ganglienzelle als spezifisches Organ scheint mir auch hier enthehrlich zu sein, und ich glanbe, man kamn dantit auskommen, dab die gerencentige Iufhehmeg der Reize in Fibrillengitter zustande kemmit. Sicherlich hat aber die coltzsche Vorstellung, dak die Henmung in allen Zentralteilen zustande kommen kamn und zur Erklärung keiner spezifiseher Zentren bedart, sehr viel

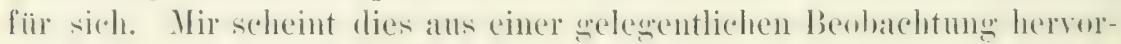
zugeden, welohe iroh an Medusen, also bei 'Tieren mit cinfachst entwickeltem Nervennetz, zu machen Gelegenheit hatte.

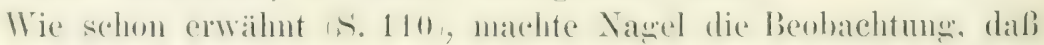
('almarina mit den Masenstiel nach einer heriilenten stelle der suln-

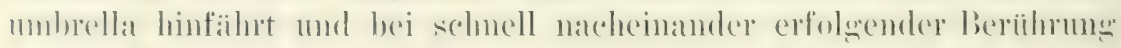
zweier Punkte erst nach dem einen und damn nach dem zweiten.

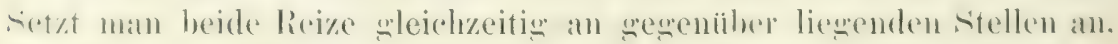

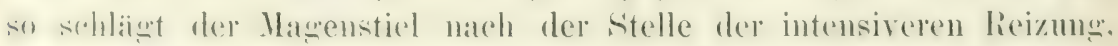
aber immer mit geringerer Intensitait, als es der Fall sein wiirde, 


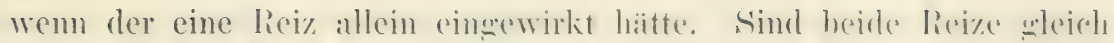
stark, was sehwer zu erreichen ist, so findet gar keine Bewegung

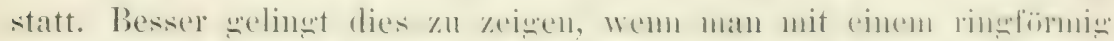

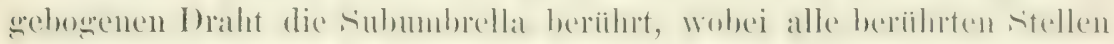

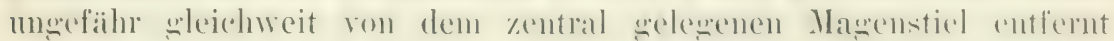
sein miissen. Ist die Beriihnung gut ausgeführt, so findet nur eine Kontraktion der Glocke statt; der Magenstiel bleibt aber ga $\mathrm{nz}$ lo hig und, wie mil scheint, schlatf, so daß der Bewegungs-

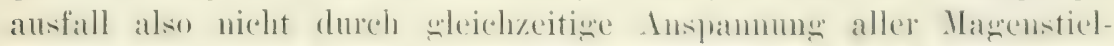
muskeln erklairt werken kamm. I)a Hemmunessentren hei diesen Tieren schwerlich anzunchmen sind, so bleiht nur die Erklärmmen, daßs sich

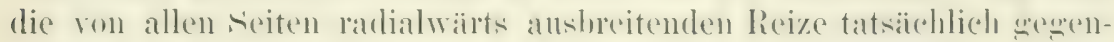

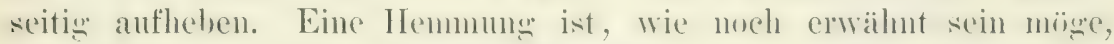

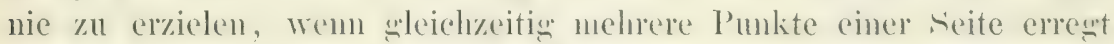

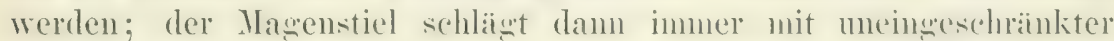
Kraft in der Richtune der liesultante. Es ist also hier Erfordernis, daß die Reize, mm sich grenenseitig aufzuhchen, von möglichst entgegengesetzten Punkten ausgehen.

Über die Art und Weise, wie sich die Reize untereinander anfheben, liegen bisher mur Vermutungen vor. Man hat versucht, sie als (infache Interferenzerscheinum hinzustellen und analoge liefunde an Nerven zu erheben. Es soll hier auf die betreffenden Versuche nux kurz hingewiesen werden, denn es ist zur Zeit noch morewiß, ob es am Terven eine wirkliche Interferen\% der lieize gribt oddi, 159s, Kaiser, 1891, Fuld, 1900), oder ob die Erscheinungen, welche zur Beobachtung gelangen, auf andre Weise zu exkläen sind Inilya, 1902, Amaya und Hoffmann, 1902, Boruttau, 1902). 


\section{ZWEIUNDZWANZIGSTES KAPITEL.}

\section{Die rhythmischen Bewegungen.}

Die Atemrhythmik S. 393-405. - Bei Fischen bewirkt Kohlensäurevergiftung keine Dyspnoe S. 395. - Der Rhythmus ist hier vou der Gasspammung des Blutes unabhäingig S. 395. - Durch Lähmung der Nervenendigungen in der Mund- und Rachensehleimhaut mittels Cocain läßt sich die Atmurg ganz zum Stillstand bringen S. 401-403. - Die Atmung der Fische ist ein peripher ausgelöster Reflex S. 403. - Reizsummation und Refraktïrstadium der \%entralteile in ihren Beziehungen zu den rhythmischen Bewegungen S. 405-405. - Die rhythmischen Bewegungen des Wirbeltierherzens und der Medusen S. 40s-456. Der normale Rhythmus und seine Abhïngigkeit von besonderen Teilen S. 405 bis 410. - Die Reaktionen des sinuslosen Herzens und der randkörperfreien Meduse auf kïnstliche Reize S. 410-423. - Treppe und ,Alles oder Nichts-Gesetz S. 411. - Rhythmische Kontraktion des sinuslosen Herzens und der randkörperlosen Meduse auf kontinuierliche Reize S. 413-422. - Refraktäres Stadium, Extrasystole und kompensatorische Ruhe (bei Herz und II eduse) S. 423-427. Die Störung der Synchronität beim Auftreten einer Extrasystole S. 427-432. Die Reizleitung im Herzen und in der Merluse S. 432-445. - Die Schnelligkeit der Kontraktionswelle im Hundeherzen S. 445. - Dasselbe im Medusenkürper S. 439 bis 442. - Beweise dafür, daß die Leitung im Herzen nerrös ist S. 442-446. Die. Koordination der Herz- und Merdusenbewegungen S. $445-450$. - Über die Natur des Refraktärstadiums S. 451. - Ursachen und Wesen der rhythmischen Bewegungen des Herzens und der Medusen S. $452-456$.

Mit einem großen Teil der rhythmischen Bewegungen ist seit langen der Begriff der Autonatie fest rerbunden. Sie sollten automatisch sein, weil man keine hinreichende Lrsache in der änberen Lunghumg entrecken komnte. So wurden die rhythmischen liewegnugen bei der Atmung, die liewegungen der Blut- mol Lymphherzen, die rhythmischen Kontraktionen der Medusen und andre derartige Bewegungserscheinungen für antomatisch ancesehen und werden es zum Teil auch moch heute. Bekanntlich ist das Vorkommen rhythmischer bewegungen ebensowenig auf die mit Xervensystem hewalnten Tiere beschränkt, wie das Vermögen iiherhaupt mit bewewngen anf Zustandscrändermoen zu reagieren: es hancht nur anf die rhyth-

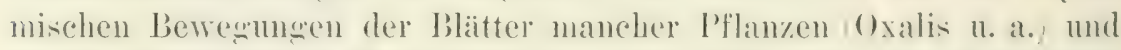
an die rhythnischen kontraktionen sewisen Vacuolen ron Infusorien. Amöben und einzelligen Pflanzen erinnert zı werden.

Noch am Anfang des vorigen Jahrhunderts glanbte man es hier mit sanz rätellaften Ligenschaften der lehenden (1)ranismen zu tum zu haben, hauptsïchlich aus dem Grund, weil man sich nicht vorstellen konnte, wie ohne rhythmische Lrsachen rlythmische Wirkungen zustande kommen kïmnten. Spriter hat man sich dam erimnert, dah 


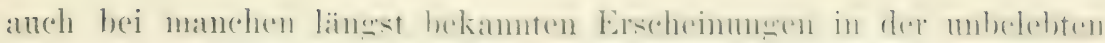

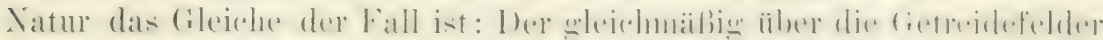

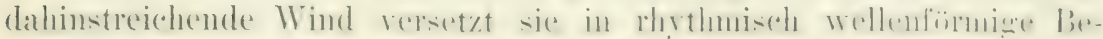
wegung. - In dunnem Strahl kontinuierlich aus ciner Öffnumg aus-

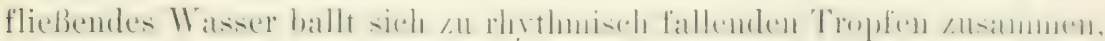
weil das Wassel erst abfallen kam, wenn seine Masse größer ist als

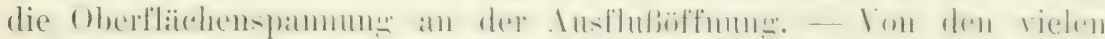

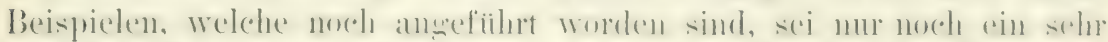

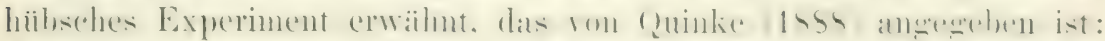

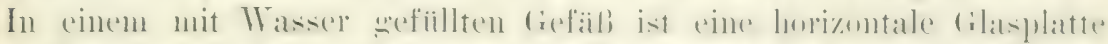

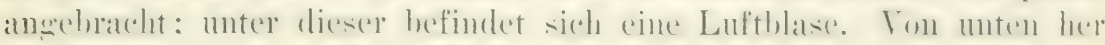

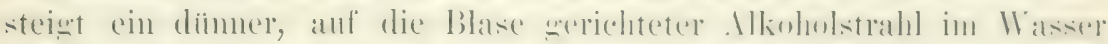
auf. Dadurch, daß der Alkohol die Oberflächenspannung an der

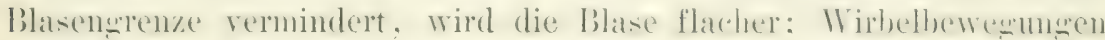

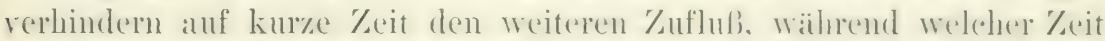

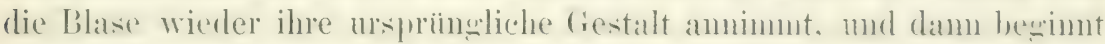
das Spiel ron nenem. Auf die WVeise kann ein sehr regelmäßiges Pulsieren der Luftblase hervorgerufen werden.

Der Yergleich mit derartigen Erscheinungen hat es nahegelegt,

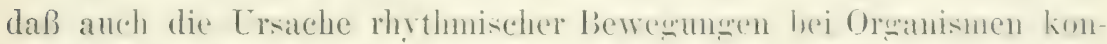
tinuierlicher Jatur sei orler weniestens sein kam. Dall erentuell aureh

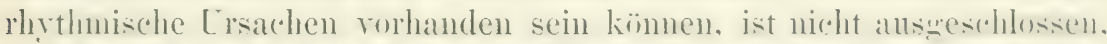

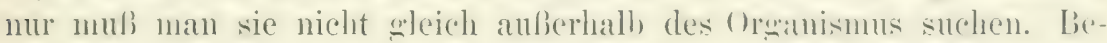
steht floch immer die Mighlichlieit, daf bei eimmal eingeleiteter liewegmen jede Kontraktion den Reiz zur nächstfolwenden abwibt. In den meisten Fällen haben sich zwar Firklarmusrersuche dieser Art alo nn-

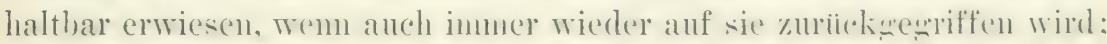
in andern Fällen, so bei der Erklämug des Itemrlythmus, haben sie sich aber bis zu einem gewissen Grade aussichtsroll gezeigt. Auch

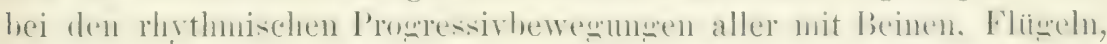
Ruderschwänzen แ. S. W. begabten Tiere wird wohl allgemein jede

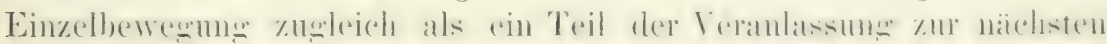

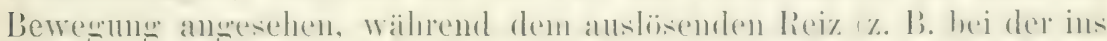

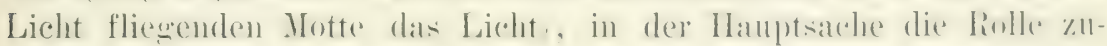
gesprochen wird, die ganze Masehinerie in Gang zn setzen. Ab-

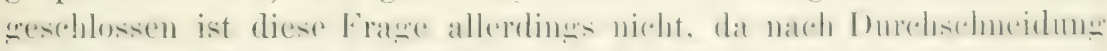

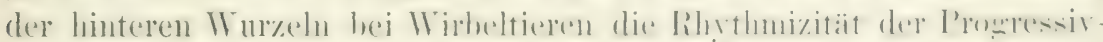

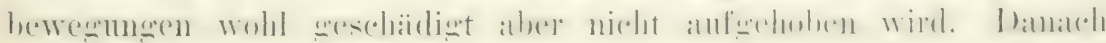
möchte es scheinen, als ob der immer wieder rhythmisch an der P'eri-

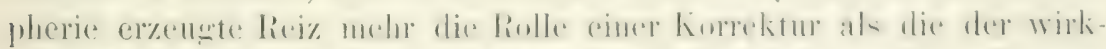

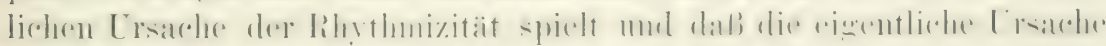

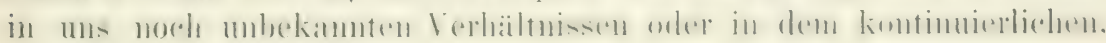
auslïsenden Reiz besteht. 


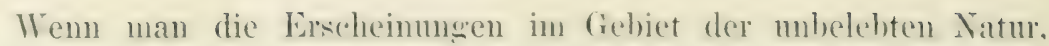

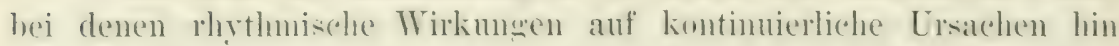
entstehen, mitereinamber veromleiclit, so kimmt man zu dem Resultat,

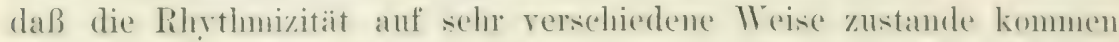
kamn. Auch in den belebten Mesen lient die Möglichkeit herfür rar: 1. Die kontinnierliche Ersache kann eine änfere und eine innere sein. 2. Die sitelle, an der die kontinuierliche Lrsache den Rhytlmus an-

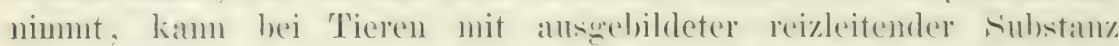
in dieser selhst, aber atroh in der effektorischen substanz, speziell der kontraktilen Substanz gelegen sein.

Wie schon besprochen, kommen sicherlich bei Lebewesen, die eines Nervensystems aber vielleicht nicht besonderer leitender sitrukfuren, enthehren, rhothmische bewenumen vor. In nenerer Zeit mehren

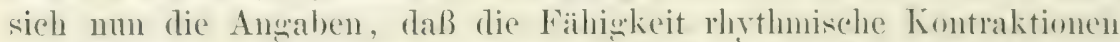
anszuführen eine allgeneine Eigenschaft der kontraktilen substanzen ist. Am längsten besteht diese Anmalme wohl für die Mnskulatur des Ilerzens, welche auf chenische Reize, anf Ausdehmun und Teta-

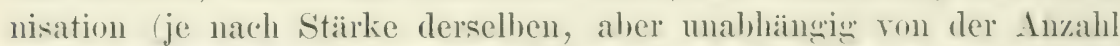
der Lnterlorechungen, mit rhythnischen Bewewnum antwortet. reit die refraktare Phase des Herzens bekaunt ist Marey, 1876), auf der ja anch die Lnfähigkit der Her\%muskulatur beruht, unter nomalen Verhälnissen in Tetanus zu geraten, hat diese Erscheinnne an Rätselhaftiokeit eingebüBt. Da man wenigstens gewisse 'leile des Ierzens, besonders die Herzspitze, für frei von Nervenfasem und Ganglienzellen hielt, so sah man die Rhythmizitait (ebenso wie die Leitung von Element zu Element) als Qualitit der Muskulatur au. Wie jetzt sicher steht, gibt es aber kemen Teil der Herzmuskulatur, der nervenfrei ist und, wie ich oben gezeigt habe, ist auch das Experiment, bei welchem die Nerven zur Desencration sebracht werden sollen und hei dem sich dic Leitunesähigkeit mol die Rhythmizitä erhalten zeiste, nicht beweiskrätign, daß es sich hier mu rein muskuläre Figenschaften handelt s. 109\%. Die Mönlichkeit, daß die Nervenelemente in Heren mit der Rihythmizitait zu tum haben, bleibt also noch bestehen mod ist später weiter zu diskutieren. (ienan wie bei der Itermuskulatur liegen die Verhälnisse bei der Muskulatur der subumbrella der Medusen, auf die ich später ansführlicher eingehen werde.

Sachdem bereits liohet $1 \$ 82$, anf rhythuische Erschlaffumen des Krebsmuskels während der Tetanisation anfuerksan swemacht latfe, die mit der Periode des errewenden lieizes nichts zu tum haben. meinfe schoenlein 1582, daß anch die Muskeln der Wasserkafer bei

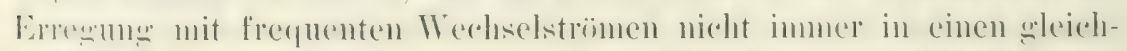

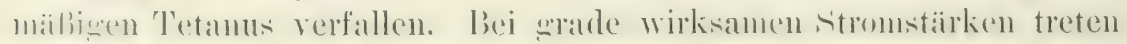

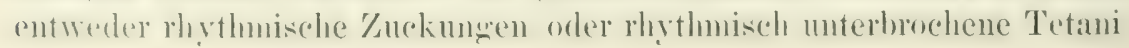




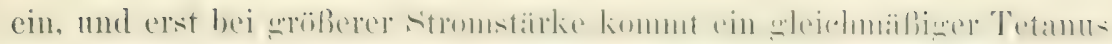
zur Entwicklumg. Da diese Muskeln wohl frei ron Zentralteilen sein düften, so wird man hier die Lrsache der Rhythmizitait in der Muskulatur selber suchen mïssen. Das gleiche gilt von den rhythmischen

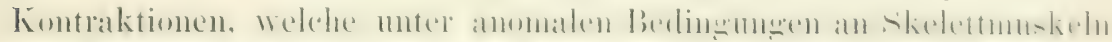

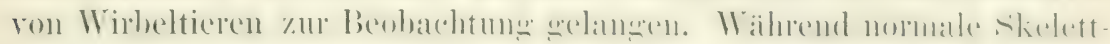

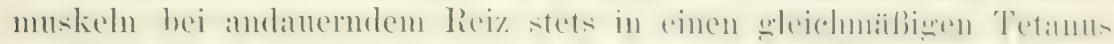

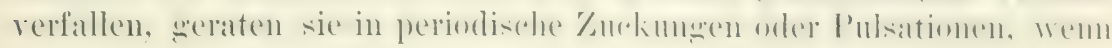

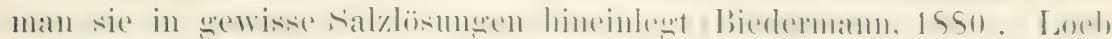

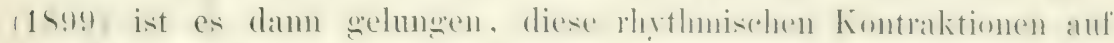
die Wirkung bestimmter Ionen (Na, Li, Cs u. s. w.) zurïckzuführen. Von andren Ionen, besonders $K$ und Ca, fand er, daß sie dem Auf-

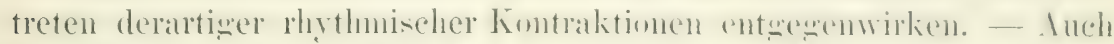

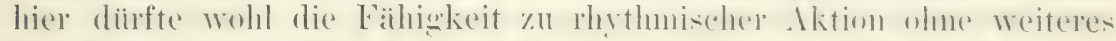

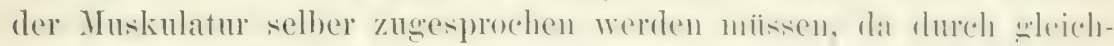
artione isolierte Behandlung der Muskehnerven ein ähnlichler liffekt hisher nicht erzielt ist.

Weniger gesichert ist die myogene Natur der an glatter Muskulatur spontan und auf Reizung eintretenden rhothnischen hontraktionen. Yur hei wanz wenigen der zur L'ntersuchum benutzten l'rijparate sind

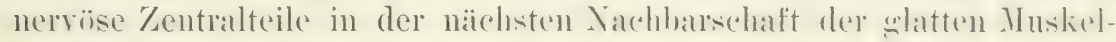
fasern bisher nicht nacherewiesen; das sind ded lietrartor penis rom I'ferd, an welchem sertoli spontane rhythuische Kontraktionen wahlnalmm, und der Retraktormuskel vom sipunculus nudus, an dem IBottazi die sleiche Erscheinme beoharchtete. (1) sie wirklich frei daron sind, ist eine andre Frage. Dagegen enthalten die von vielen Autoren an-

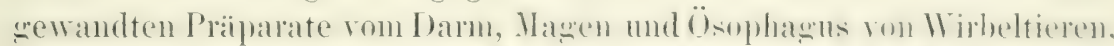

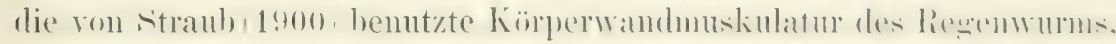

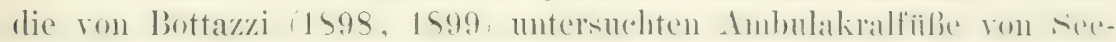
sternen und der Ösophagus ron Aplysia mehr oder weniger reich-

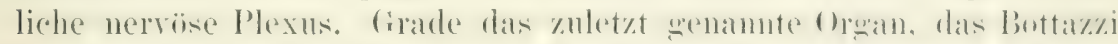

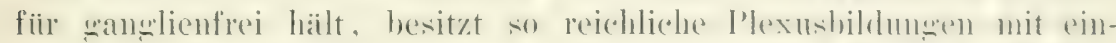

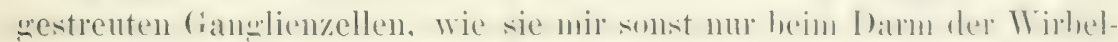
tiere bekannt sind.

Ein T'eil der Antoren, besonders IBottazizi und Straub halten es

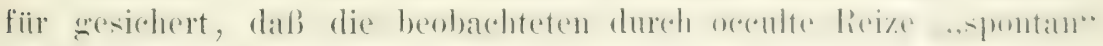

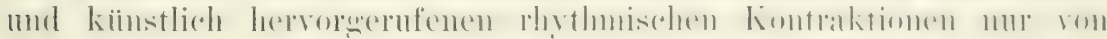
der glatten Muskulatur selber ausggehen, wälnend I’. Schultz (1597) dieselben fiur nervös rermittelt hält, weil sie auf behandlung mit

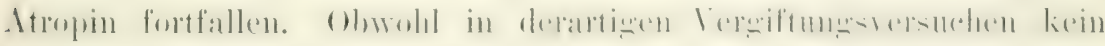
sicherer Beweis gesehen werden kann, weil nie eine Schädigung der muskulösen Elemente ausgeschlossen ist, so mu man ihmen doch

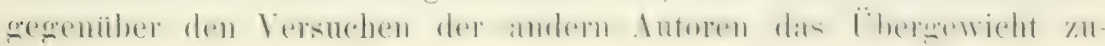


erkennen, weil bei diesen das als Beweis angefübrte Fehlen ron

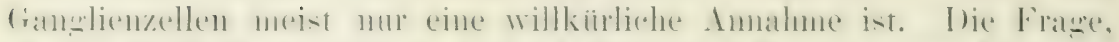

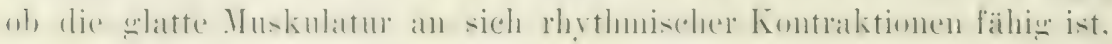
wircl also noch als offen bezeichnet werden miissen. (Siehe auch Biedermamn, 1902.)

Daß Pflanzen und Einzellige rhythmische Kontraktionen ohne

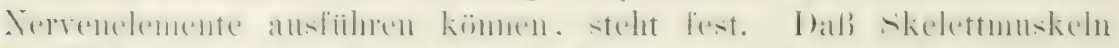

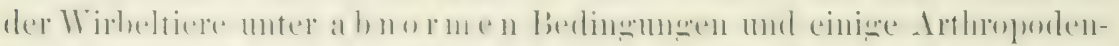
muskeln bei gewissen Reizstären sich rhythmisch kontrahieren

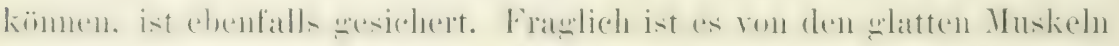

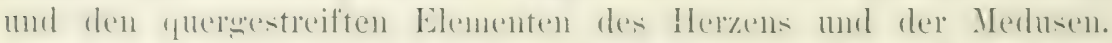

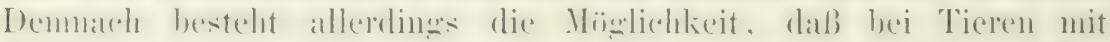

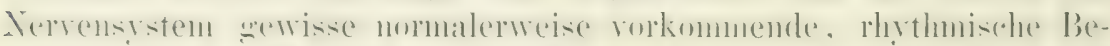

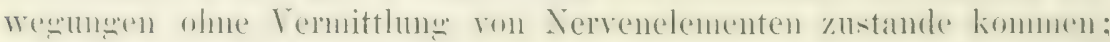
ich sehe aber keinen Zwang, daß dies notwendigerweise oder auch

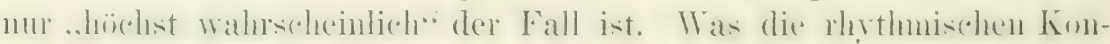
traktionen anletrifft, welehe man kïnstlich hei skelettmuskeln rom

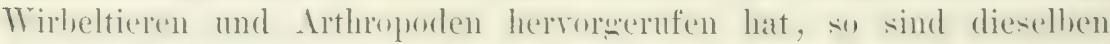

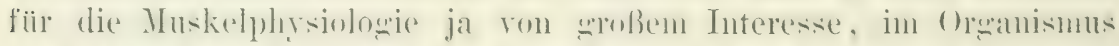

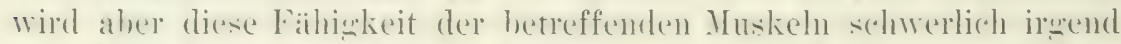

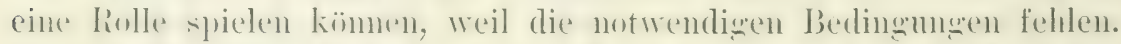
Gesctzt den l'all, daß die whitte Muskulatur an sich rhythmischer

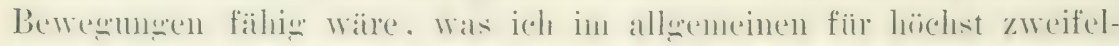

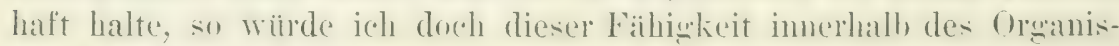

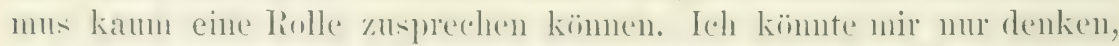
dali sie unter normalen lerhälnisien hesmolers hei den 'Tieren, deren bew e

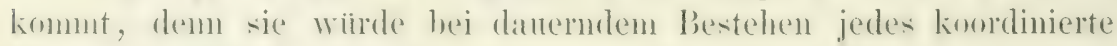
Znsammenatheiten rerhindern oder eines besonderen Hemmungsistems bediirfen. Auch für die inneren Organe (Darm u. s. w.) wiirde ich sie für unresentlich halten, weil die Erklärung der hier zu beohachtenden Erscheinungen schwerlich ohne Zuhilfenahne des nun eimual iiberall in reicher Ausdelnume vorhandenen Nervenplexus möglich ist.

Angängrig scheint es mir nur dort zu sein, die rhythmische Fähig-

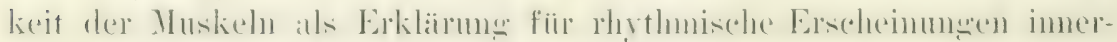

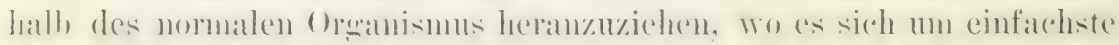

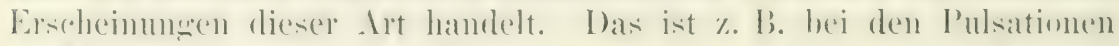

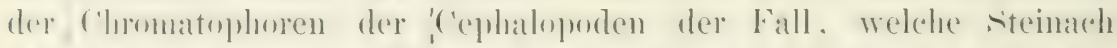

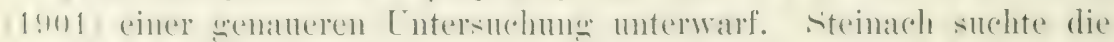

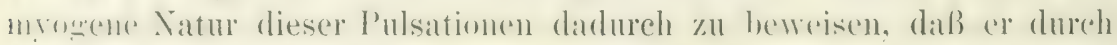

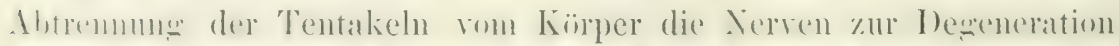

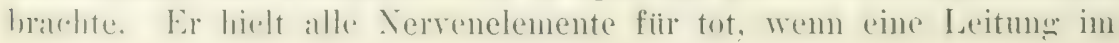


Tentakel nicht mehr zu konstatieren war. War dies eingetreten, so pulsierten die Chromatophoren noch weiter. Ich kamn allerdings in

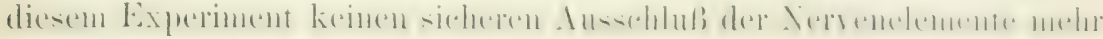
sehen, seitdem ich weiß, daß die Zählebigkeit der Nervenelemente sehr verschieden groß ist. (Dasselbe habe ich anch gegen Straubs Degenerationsexperiment beim Regenwurm einzuwenden.)

Auf die eventuelle Möglichkeit die P'ulsationen des Herzens und

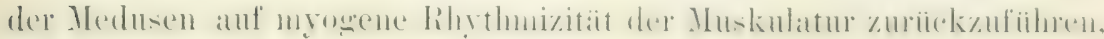
werde ich an späterer Stelle eingehen.

Ieh will num zunachst einen Fall yon rhythmischer Täitigkeit

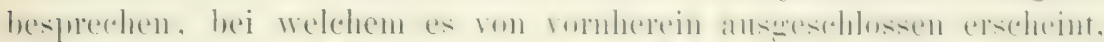

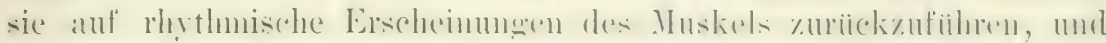

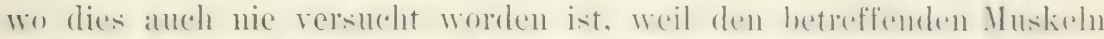

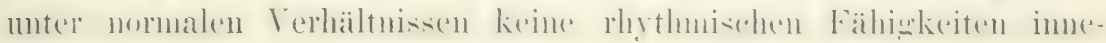
wohnen, nämlich die Atembewegungen der Wirbeltiere.

\section{Die Atemrhythmik.}

Bei allen höheren Wirbeltiereu (Säugetiere, Vögel) hat mau in

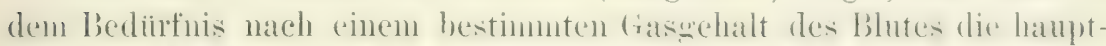

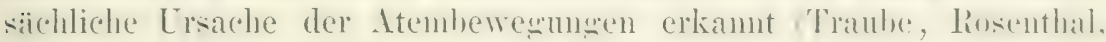
Kullmaul. Ifflïger und viele andre. Linginntige Iseschaffenheit des Blutes (zu wenig O, zu viel $\mathrm{CO}_{2}$ und wohl auch ein Gehalt an andern Stoffwechselprodukten des Kürpers erregen direkt diejenigen Toile de's Zentrahnerensystems, won welchen die Innervierung der Atronmuskeln besorgt wird. Dieses sogenannte Atemzentrum liegt, wie hekame, in der Medulla whlongata. ${ }^{1}$. I'eriphere licize kommen, wie

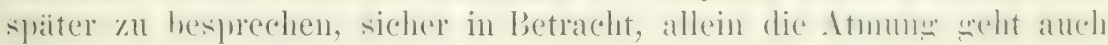
vor sich, wenn alle zentripetalen Nerren, die in Betracht kommen, durchschnitten sind (Rosenthal).

Ganz anders liegen die Verhältnisse bei niederen Wirbeltieren

1) Daß MIangel an Sanerstoff resp. Überschuß an Kohlensïure den Reiz für die Respirationsbewegungen abgibt, hat man mit Sicherheit aus folgenden 'Tatsachen erschließen können: Bei Mangel an Atemluft oder bei unzureichender Ausclehnungsfïhigkeit der Lungen (Pneunothorax, starkem pleuritischem Exsudat 11. s. .) wird die Zahl der Respirationen vermehrt und die accessorischen Atemmuskeln treten in Tätigkeit. Dieser dyspnoische Zustand tritt auch ein, wenn die Atemluft zu wenig Sauerstoff oder zu viel Kohlensïure enthailt. Dyspmoe tritt auch bei der Verblutung ein. Im Gegensatz dazu hören die aktiven Atembewegungen auf, wenn das Blut durch starke kïnstliche Atmung gut durchliiftet wird. Sistiert man die kïnstliche Respiration, so bleibt das Versuchstier lïngrere Zeit, olme zu atmen, liegen und beginnt erst wieder mit denselben, wenn das Blut aufhört, ïberarterialisiert zu sein. Stark 0 -haltiges Blut iibt also keinen Atemreiz aus (Zustand der Apnoe). - Beweisend dattïr, dâf das venöse Blut direkt zentral gelegene Gebiete reizt, sind folgende Versuche gewesen: Bei Unter- 
Fischen und Amphibien. Bei diesen ist der tiasuehalt des Bhutes

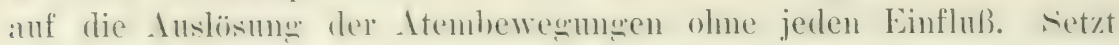
man einen Froseh in eine reine kohlensämeatmosphäre oder in

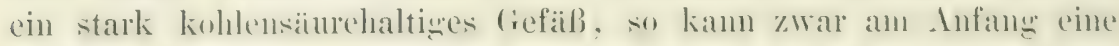

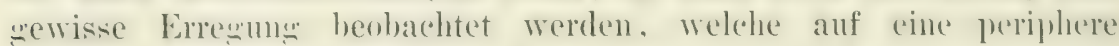
Reizung zuritek\%uführen ist IVinterstein, lago, bald werden die

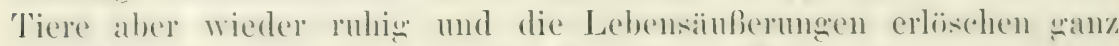
alhü̈hlich, ohne dab es zu der für höhere Wirheltiere so colaralite-

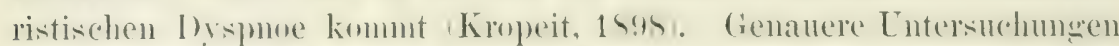

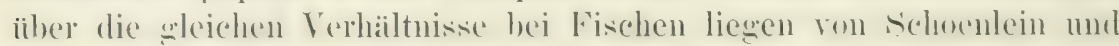

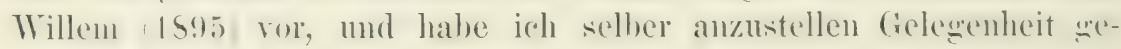
nonmmen.

Fohoenlein und Willem stellten bei Relachiern, Torperlo und Seyllium, fest, dab die Zahl der Respirationen in einer wesontlichen Abhängi心keit von der Wassemenge steht, welche den T'ieren zugefuilnt wird. Das Atemwasser wird hei diesen 'Tieren durch die sipritzlicher mittels aktiver Erweiterung des Mundrams mol Kiemenkorbes anf-

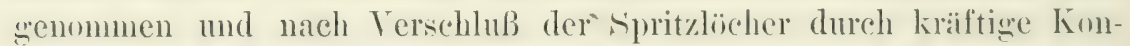
traktion des Kiemenkorbes aus den seitlichstehenden Kienenspalten heransgepreßt imanche cielachier offnen auch bei der Inspiration das Manl, doch scheint mir dabei keine Kommunikation mit den hinteren Rachenraum heroestellt zu werden. Bei der Lntersuchung wurlen

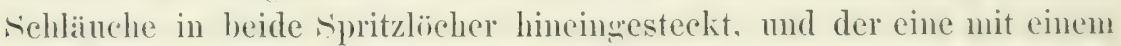
mit Wasser gefüllten Druckgefäß, der andre zur Regristrierung der Atembewegumen mit einer Maresschen Trommel verbunden. Flof das Wasser langsam, so war die Zahl der Respirationen gering, flof es schmeller, so rermehrten sich die liewegnugen bis zum Dopplelten und noch weiter. Bei zu starken Zufluß hören die aktiven Bewewnenen schließlich anf und es tritt 1 hwehr, speien und dauernde ciffumus des Maules ein. Wird der Zuflub sanz unterbochen, so entstehen noch wenige teils schwache, teils krampflafte Exspirationen bei aus-

bindung der Gehirnarterien tritt Dyspnoe auf, ebenso bei Verlegung des venösen Abflusses. Am instruktivsten ist folgendes von Fredericq (1900) ausgefuihrtes Experiment: Die Carotiden von zwei nebeneinander liegenden Hunden werden wechselseitig miteinander verbunden, so daß das Herzblut des einen dureh Gehirn und Medulla des andern strömt und umgekehrt, während jeder Hund seinen iibrigen Körper mit dem eignen Blut versorgt. Wird jetzt dem Ilund A die Luftzufuhr abgesperrt, so geriit der IIund 13 dadurch in Dyspnoe, weil das venös gewordene Blut des Hundes A sein Zentralnervensystem reizt. Der IIund B arterialisiert infolge der Dyspnoe sein Blut sehr stark, kommt aber nicht aus der Dyspnoe heraus, weil seine Zentralorgane von dem Blut des IIundes A gespeist werden. Das Iauptblut des IIundes A wird immer mehr venös, seine Medulla empfäingt aber das überarterialisierte Blut des liundes B; infolgedessen gerät der Ilund $\mathrm{A}$ in Apnoe! 


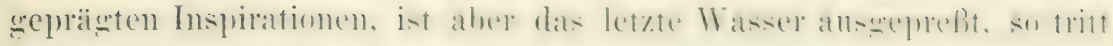
rollkommener (und zwar passiver) Atemstillstand cin.

Ging schon aus diesen Tersuchen hervol', daß die Ursache der

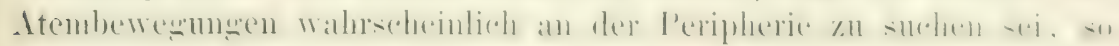
wurde eine zentrale Lrsache derselben noch weiterhin dadurch nn-

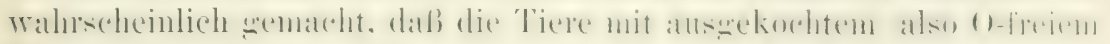
Wasser ïber zwanzign Minuten (reiter wurde del Versuch nicht ans-

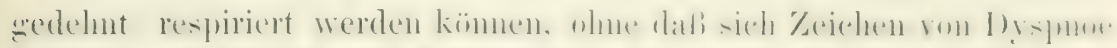

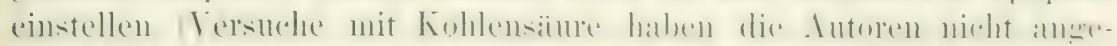

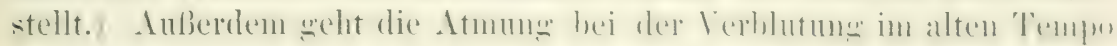
weiter. Daraus schließen die Yerfasser, daß die Atembewegnugen

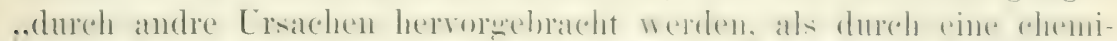

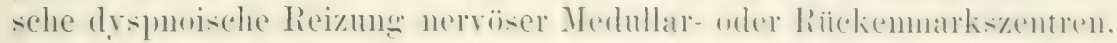
und vielmehr reflektorischer Natur sind".

Ich kamn diese Angaben in rollen Umfang bestätigen und habe

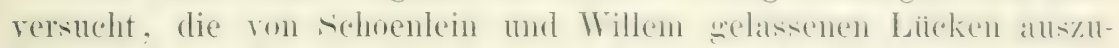
füllen. Weine Versuche simb nur an sirollimu catulus und raniroula answitellt: ein Luterahierl in den liesultaten wurle nicht humerkt. Die Tiere wurden auf ein besonderes Brett aufgrebunden, eine mit mehreren öffnumen relsehene Glaskaniile dureh das eine suritzloch

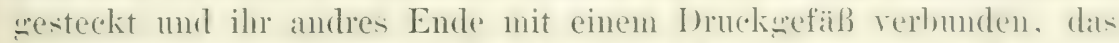

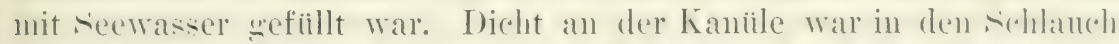
ein 'T-Rohr sesetot, dessen dritter sohenkel nit einer Mareysolen Trommel in Verbindung stand. Diese schrieh die Atemschwankungen

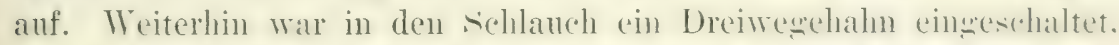
mit dessen Hilfe statt des reinen sienassers andere Flïsickleiten zugeleitet werden komnten.

1. Zuleitung ansekochten Wassers: Mehrere Liter texwasco worlen

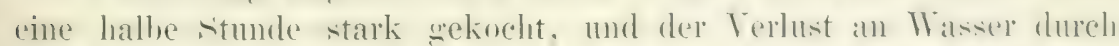

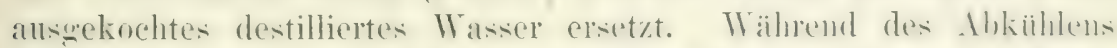

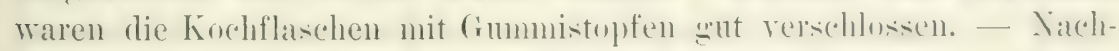
dem der Zufluß rou normalem Seewasser so reguliert war, daß das

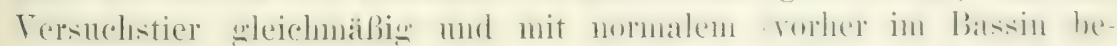

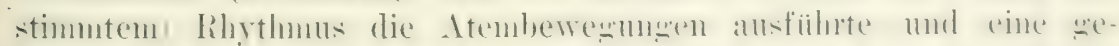

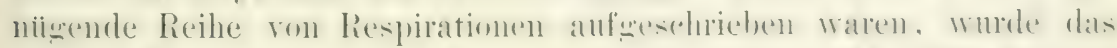

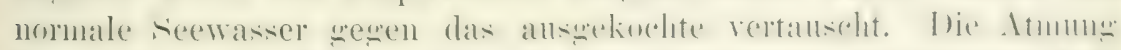

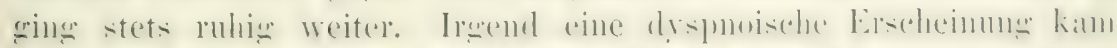

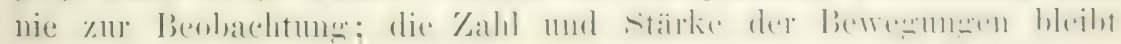
während der nächsten $30-40$ Ninuten muerändert. Nach efwa 40 Minuten oder später fangen die Atembewegrumgen an schwäicher und langsamer zu werden. Bisweilen, besonders anfangs, wird die

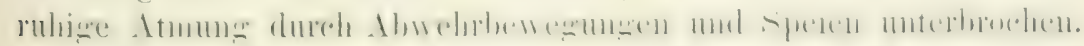

2. Respiration mit kohlensảuregeschwangertem Wasser: Durch 


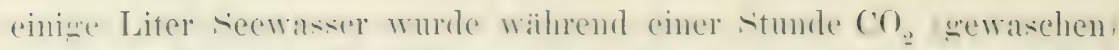

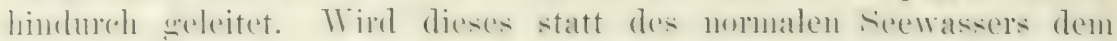
Hai zugefülıt, so beginnt el stets im Moment, wo es in den Mund

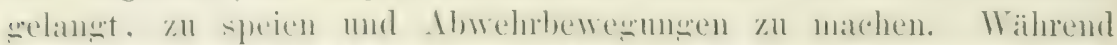

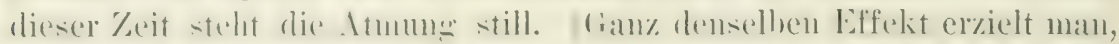

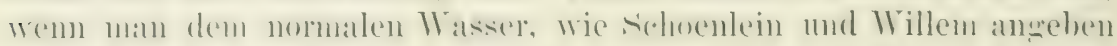

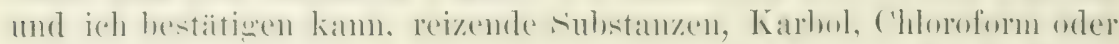
Alkohol zissetzt oder wenn man Siißwasser zuleitet.) Nach kurzer

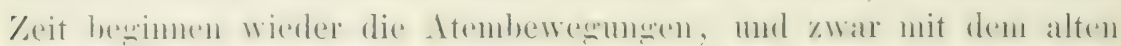

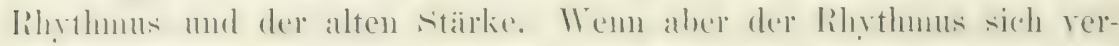
aindert zeigt, so ist er stets verlangsamt! Dazwischen treten neue

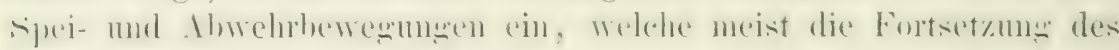

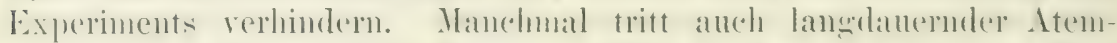
stillstand ein bis zu l'inf Minuten. Wird jetzt wieder nommales see. wassor zuseloitet. so bleiht del Atemstillstand gewoihnlich moch mehrere

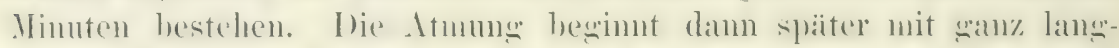

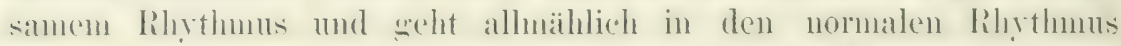

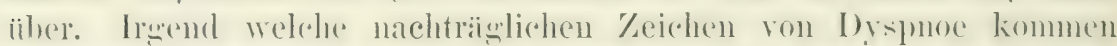

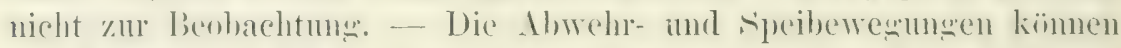
als drspmoisole reichen nicht antweselen werden, weil sie eintreten,

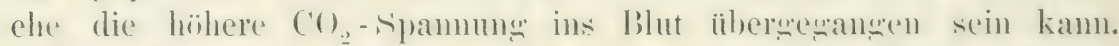
()ffenbar handelt (s sich, wie anch heim answekuchten Wasser, darum, dal) die Veräuderume in der Wrasserepualität einen peripheren lieiz hervoruft, der reflektorisch diese Erscheinmenen und anch den Itemstillstand auslöst. (Auch bei Fröschen tritt zuerst in einer $\mathrm{CO}_{\text {- }}$ Atmosphäre meist Erregung ein. Siehe oben.)

Oa ein rollkommen befriedicender liesultat bei direktem Wechsel zwischen normalem Seewasser und $\mathrm{CO}_{2}$ - Wasser nicht zu erreichen war, wurde ein Verstuchstier in eine Wamme mit normalem Seewasser golegt und in dieses $\mathrm{CO}_{2}$ eingeleitet. Der Fisch nahm selbst sein

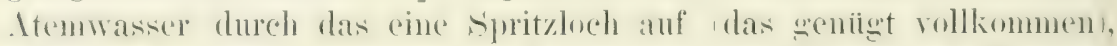
während das andre dureh einen sehlanch mit der Mareyschen Trommel verbunden was. speibewegungen und Abwehe treten hei dieser lere

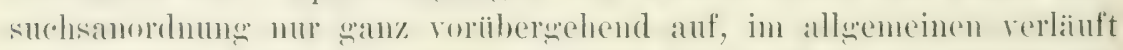
der Versuch somst wanz whatt: anfang-s bleiben Zahl mol stälie der liespirationen wan\% nurerändert. Mlnühlich wird die Zalıl hei zu-

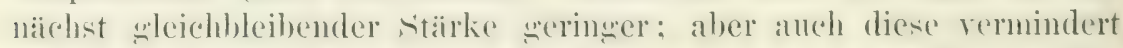
sich späiter, so dalf schliedblich die liesprirationen sanz anfhören. Er-

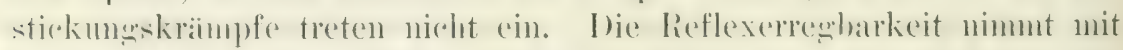
der Zeit immer mehr ab und erlischt schon vor dem Aufhören der liespirationen sanz. I) Tiere sind damn steif wie in der Totenstare.

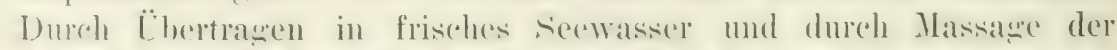
Kiemen kamn das Leben wieder angefacht werden, die Atmumg he- 
ginnt sehr langsam von neuem und wird allmählich wieder nomal,

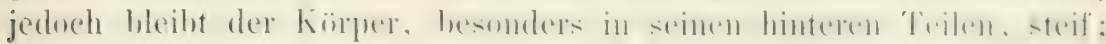
mir ist es aber nicht gegliekt, derartige 'Tiere dauernd am Leben zu erhalten; sie sterben nach einigen Stunden.

Als Beleg gebe ich hier von einem Tier dic Zeitangaben und Ausschnitte aus den Kurven (Fig. 81): Normale Respirationszahl 5 in der Minute. Zuleitung ron $\mathrm{CO}_{2}$ \& h 25; 1 h 50 Respirationszahl $($ Respz. $)=48,2$ h Respz. $=40$. Die Respirationen beginnen flacher zu werden. Zwischen 1 h 50 und 2 h 10 einigre Speiberregrungen. 2 h 18 Resp\% $=30,2$ h 25 Resp\%. $=26$, 2 h 50 Respz. $=18$. Das Tier begimnt steif zul werden. 3 h 5 Respz. = 1s. Ganz steif und hinten reflexlos. Gleich daranf Aufhören der Atmung. 3 h 25 in normales Seerasser. 3 h 35 die ersten schwachen Atemberregumgen.

3. Zuleitung von sauerstoffgesättigtem Wasser. Eine reichliche Menge Seerrasser wurde ausurekocht und dann durch dieselbe während einer Stunde ein kräiftiger Strom ron reinem Sauerstoff durchgeleitet. Nachdem die Respirationen längere Zeit bei normalem Seewasser aufgeschrieben waren, wurle das 0 -gesättigte Wasser zugeleitet. Eine Änderung in del

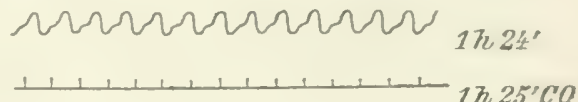

$1725^{\prime} \mathrm{CO}_{2}$

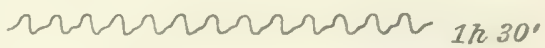

$1 \hbar 30^{\circ}$

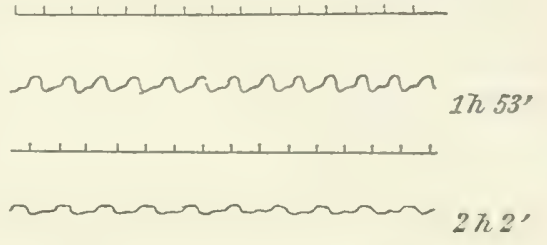

2750

Fig. 81. Atmungskurven ron Seyllium. 1 h 21 normal. 1 h 25 wird $\mathrm{CO}_{2}$ ins Bassin eingeleitet. Die Respirittionen werden flacher und langsamer und hören ohne dyspnoische Erscheinungen schlieblich ganz auf. Zabl und Stäke der Respirationen trat im einen Fall nicht ein. Im zweiten Versuch wurde eine geringe Zunahme der Respirationszahl festgestellt, welche aber

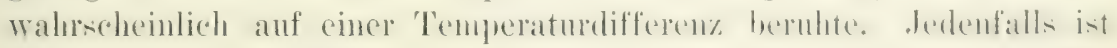
aber von einer Apnoe auch nicht die geringste Andentung zu be-

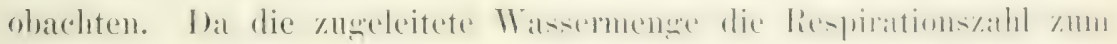
großen 'Teil bestimmt, so wurde der Versuch auch in der Weise angestellt, daß das Tier in normaler Weise das Wasser aktir aufnahm, wie dies auch unter 2. fü kohlensäurehaltiges Wasser besehrieben wurde. Das Tier lag zunäelist in einem Bassin mit normalem Seewasser. Darauf wurde es in die dameben stehende! Wame mit O-gesättigtem Wasser gelegt, in welehes noch wälnend des ganzen Versuchs 0 eingreleitet wurde. Auch hier wa keine Spur vou Apmoe zu bemerken. 
Wenn man diese Versuche mit den von Schoenlein und Willem Fefundenen Tatsatehen zusammenhält, so wird wohl kein \%weifel mehr bestehen können, da $B$ die Respirationsbewegungen der Fische (speziell der Selachier) nieht dureh ehemische Reize des Zentralnervensystems rerursacht werden. Der Gas-

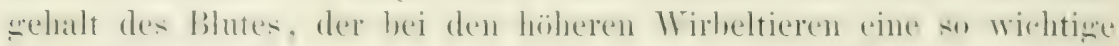

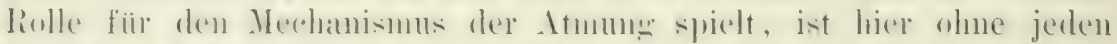

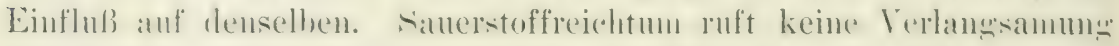
der Respirationen herror (gesehweige demn Apnoe), noch erzengt

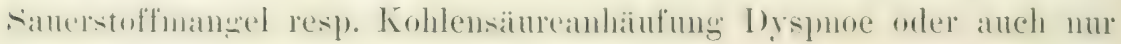
eine Andentming ron Atembeschleunigung.

Ehe ich anf die Respiration der Fische weiter eingehe, will ich die hei hühne'n Wirbeltieren hekannt wewordenen peripheren Ililf:ursachen der Atemberregungen besprechen.

Nachdem dureh Traube (184i) und Rosenthal (1861) die hervorragende Dedentung des Tagus fiur die nomale Itmumg erkamnt war, stellten Ilering und Brener 1565 , die Lehre anf, daß jede Exspiration sich selhst hemme und die niidehste Inspiration anslïse, wiahremd jede Inspiration ihrerseits den Anston zur Exspiration gebe und eine weitere Inspirationshewewng verhindere. Der anslösende Reiz sollte in einen Fall der bei der Exspiration zustande lommende Lungenkollaps, im andern Fall die durch die Inspiration er\%engte Lungendehnum sein, und heide lieize sollten rom rler Junge durch den Vagus zun \%entralorean meleitet werden. Die Inauptheweispunkte für diese Insicht bestanden darin, dak bei experimentell herbeigefiilutem killaps der Lunge stets eine starke Innerviermy der Inspirationsmuskeln zur Beobachtumg kommut, während bei künstlicher Aufhlasumg der Lunge das Umgekehrte der Fall ist.

(iegen die Richtigkeit dieser Hering-Erenerschen Theorie ron der sellststenermu der Atmum wurden ron (inttman 1875. Bedenken erhohen, weil er ans seinen Versuchen schließen zu mïssen whubte, daß Lungenansdehnung eine inspiratorische Wirkmng hätte. Gad wies damn 1550, natcl, daß Guttman seine Versuche falsch sedentet habe, und daß in der Tat Lmenendehmme wie Lmmenkollaps in dem ron Hering und birener angegebenen sinne wirkten. Sieitlem sind diese Versuche oftmals bestätigt und nach vielen lichlungen hin erweitert worden. Siehe wegren der Literatur boruttaus Zusammenstellumgr ron 1902.)

Danach kann es jedenfalls nicht zweifelhaft sein, daß die Mö̈mlichleit einer silhststenerung der Atmung im simme IJering-Breners hesteht. Viel nustritten ist aber norde die Frage, inwieweit bei der nomalen Atmmo der höheren Wirbeltiere diese selloststenermon in Betracht knmmit. Als IIauptfaktor hei der normalen Atmung wird 


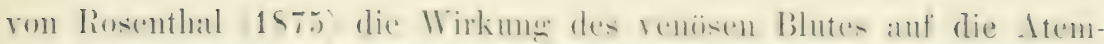

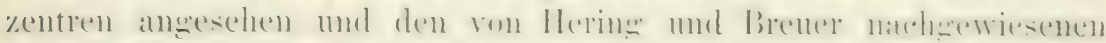

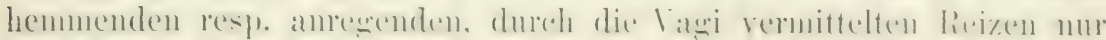

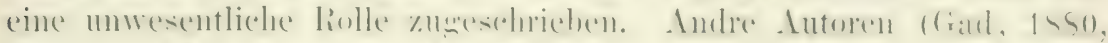

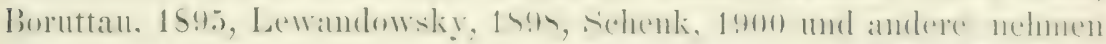

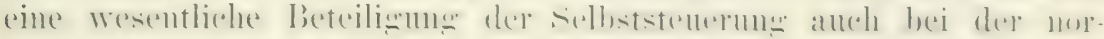

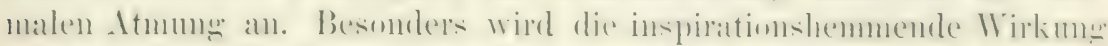

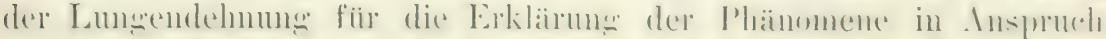

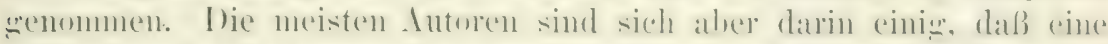

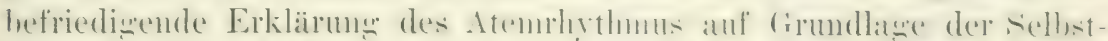

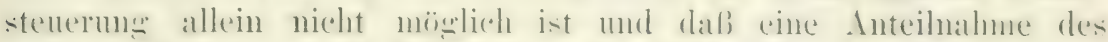

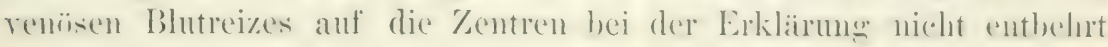
werden kann.

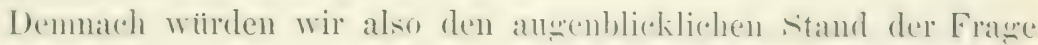

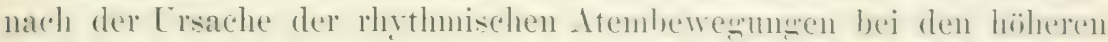
Wirbeltieren dahin präisieren kimmen: Die Lrsache der Atmunn ist eine doppelte. Erstens wirkt auf die Atemzentren der kontinuierliche Reiz des renösen Blutes eim. In welcher Weise dieser zu rhythuischen Wirkmugen führt, darïber bestehen zunäloht nur Vernutungen. Dieser lieiz genitst, num den Atemrhythnus wemu anch nicht in normaler Wrise, zu erhalten Vawotomie. Zweitens wirken

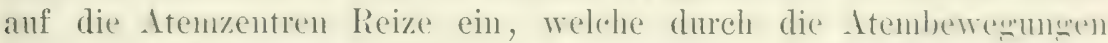
sellst in rhythnischer Folge herropebracht in den Vagi zentralwairts geleitet werden mol die bewewng, welche im Gang ist, hemmen

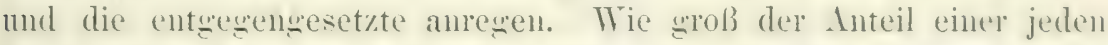
Reizonttung bei der nomalen Atmumg ist, dariber herrscht keme Einigkeit.

Wie wir sesehen haben, ist bei den Fischen mul Amphibien ein

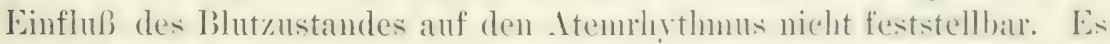
war daher die rom sichoenlein und Wrillem anferestellte aber nu unvollkmmen bewiesene, Ansicht zu prifen, didj der Itemmythmos

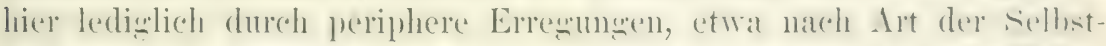

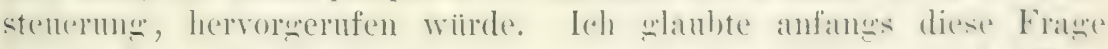
mittels Nervendurehschneidungen entscheiden zu kïmmen, habe diese

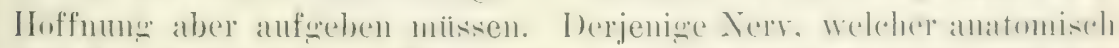

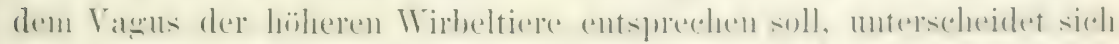

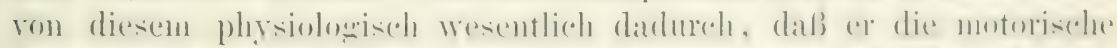

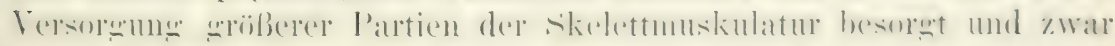

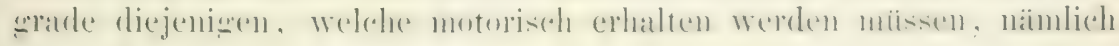
einen 'I'eil der Kiemenbögen.

Weder Durchschneidungsversuche des Vagus, welehe in größerer Anzahl angestellt wurden, noch Reizung des peripheren Vagusstammes liefen mich mit Sicherheit feststellen, wie viele Kiemenbügen allein vom lagus innerviert 
werden; deswegen nicht, weil bei der starken Spannung der Haut eine passive Mitbewegung zustande kommen kann. Als sicher kam ich angeben, dats die hinteren Kiemenbögen motorisch und sensibel allein rom Vagus innerviert werden und daf der erste Kiemenbogen und das Spritzloch rom Vagus ganz mabhingig sind und ihre motorische Innervation rom Facialis erhalten. Möglicherweise wird auch der zweite und dritte Kiemenbogen allein vom Vagus versorgt, doch scheint es mir besonders für den zweiten nicht ausgeschlossen, daß er neben Vagusfasern motorische Fasern rom Facialis erhält. Was die Wirkung auf das Ilerz anbetrifft, so entspricht der Vagus der Fische dem der höheren Wirbeltiere; er allein enthält herzhemmende Fasern. Nach doppelseitiger Vagusdurchschmeidung, welche die Tiere bei guter Operation tagelang überleben, indem die Atmung mit dem vordersten Kiemenbogempaar zur Erhaltumg des Lebens genügt, kam das llerz durch keinen Reiz der Peripherie oder der Medulla mehr zum Stehen gebracht werden. Sind die Vagi erhalten, so gelingt die Hemmung des Herzens sehr leicht. Schon bei mäßig kräftigem Streichen ïber die Haut kann vollständiger Stillstand eintreten. Die auffallende Korrelation zwischen Atembewegungen und Herzbewegungen, welche Schoenlein und Willem beschrieben haben, fällt nach doppelseitiger Vagotomie fort.

Haie, denen beide Vagi durchschnitten waren, atmeten noch rollkommen rhythmisch, mobei natiorlich die selähnten hinteren Kienen-

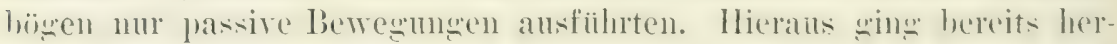
vor, daß der Vagus nicht allein derjenige Nerv sein konnte, dureh den die anemommenen peripheren Reize zun Zentralorwan wedeitet werden. Daß der Vagus aber auch bei diesen 'Tieren als Vermittler

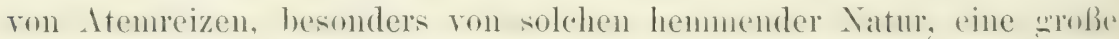
liolle spielt, secht aus Versuchen hervor, bei denen Haie rom und natels der Vacotomie anf Itemhemmung untersucht wurlen. Wälurend hei Tormaltieren sofort Itemstillstand cintritt, wenn das seewasser mit siißwasser orler mit karholhaltigem Wasser vertauscht wird, atmen diese Tiere zunächst ganz ruhig weiter und stellen die Atem-

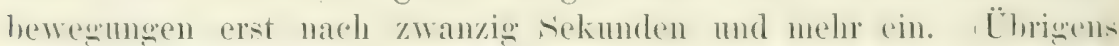
fancen normale 'Tiere bei liespiration mit siißwasser nach cinimere Zeit wieder zu atmen an. Dazwischen kommen wieder Stillstande und Dbwehlowernmen, aber man kamn manchmal ganz lange Itemperioden beobachten.) Auf Absehneidung der Wasserzufuhr reagieren dagegen die ragotomierten Tiere ebenso prompt, wie normale, mit Atemstillstand. Es ist also nu die Wirkung gewisser Hemmungsreize herabgesetzt.

Gleich hier muß bemerkt werden, daß man die Atmumg auf die versohiodenste Wreise hemmend und fördernd heonflussen kamn. Bei

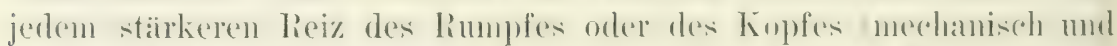

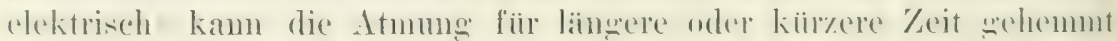

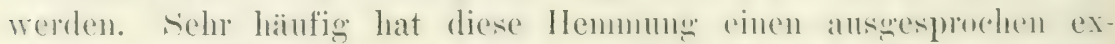
spiratorischen Charakter. In besten zeist sich dies bei Tioren. die mit

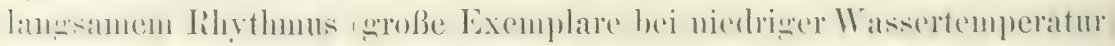
atmen. Ist elen eine Exsporation abmelanfen, so tritt hei kraftiscem 


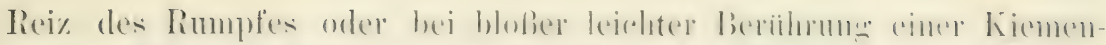

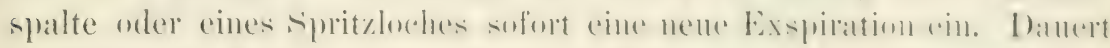
die Reizung fort, so löst sich die Kontraktion des Kienenkorbes langsam, und die Atmung bleibt noeh einige Zeit ohne bemerkbare Aktivstellung des Atemapparats untephorelem. Ist die licizume num momentan, so dehnt sich der Ḱiemenkorb gleich wieder aktiv aus, mol es erfolgt nach einer etwas verlängerten Pause die nächste Ex-

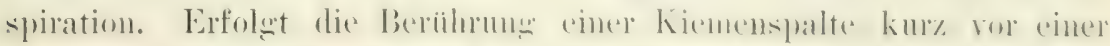

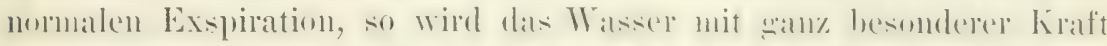

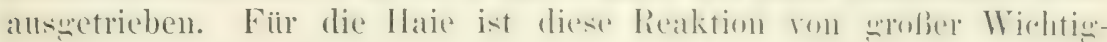
keit, weil sie die Kiemen vor Verunreinigung schuitzt. Sie tritt stets ein, nachdem die Tiere gefressen oder erbrochen haben, wozn sie sehr neigen sinchoenlein mol Willem, und hefördert die in Kienenkorts

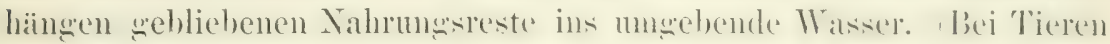

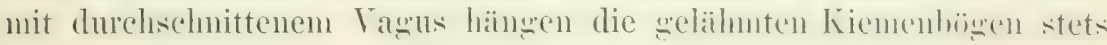
roll ron Speiseresten und Schleimflocken.)

Da eine gesonderte Luterbrechung der rezeptentischen Bahnen de: Vagus und der die vorderen Kiemenbögen und das Spritzloch vorsorgenden rezeptorischen Xerven mangels einer sernizgenden anatr-

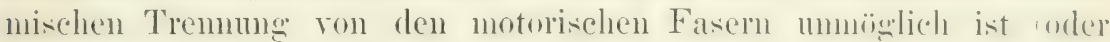
wenigstens im Augenblick unmöglich scheint), so mußte ich auf anderm Wege versuchen, periphere Atemreize antuschalten. Es ist mir dies in überraschend leichter Weise mit Hilfe von Cocain gelungen.

Cocainversuch: Ein Hai wird in der oben beschriebenen Weise herererichtet und mit seewaser respiriert. Mit dem dritten sichenkel des Dreiwegehahns ist ein Gefäß verbunden, das etwa 200 cem

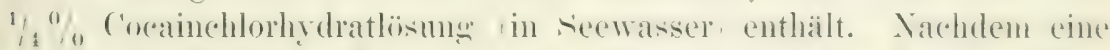
wenïgende Zahl ron Respirationen anfweschriehen ist, wirl dats secewasser durch die Lösung des Cocains ersetzt. Die Atmung geht zunaichst ruhign weiter. Sineibewegmen kanen zwar einigemal \%u lieobachtung, aber nie gleich beim Begimm; auch waren sie nie von Atemstillstand begleitet. Etwa nach 1,5'-2' werden die Atem-

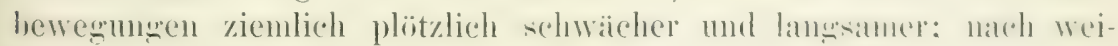
teren $10-20$ " erfolgen nur noch einige schwache Exspirationen in Abstinden von 5-6" und dann hören di e Bewegungen ganz

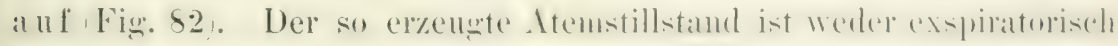
noch inspiratorisch, sondern ganz passiv. LäBt man etwa eine halbe Minute nach Eintritt des Stillstandes wieder frisches Seewasser zufließen, so bleibt der Atemstillstand noeh viele Minuten erhalten. Dam zeigen sich zuerst

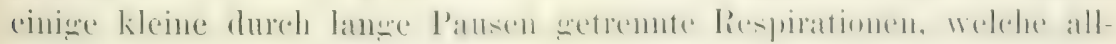
mählich an Stärke und Frequenz zunchmen. Die ursprüngliche Bethe, Nervensystem. 
Stäkeder Respirationen kehrt schneller wieder als die urspritugliche Frequenz.

Versuch rom 21. Oktober 1901. 1 h $19^{\prime}, 36$ Respirationen in der Minute. 1 h $20^{\prime}$ Cocain $1 / 4 \%$; es fließen bis 1 h $22^{\prime} 40^{\prime \prime} 190 \mathrm{cem}$ durch die Kiemen. Die Atmung geht zuerst ruhig weiter. 1 h $20^{\prime} 25^{\prime \prime}$ Speien. 1 h $22^{\prime \prime}$ Verlangsamung und

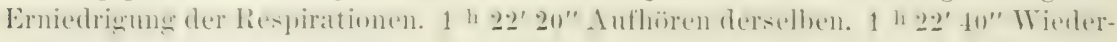
zulassen ron Seewasser. Der Atemstillstand dauert an bis 1 h $40^{\prime}$ (1S Minuten). $1 \mathrm{~h} 40^{\prime}$ die erste schwache Respiration. 1 h $50^{\prime}$ lespirationen ziemlich kriftigr, aber nur 30 in der Minute.

A.

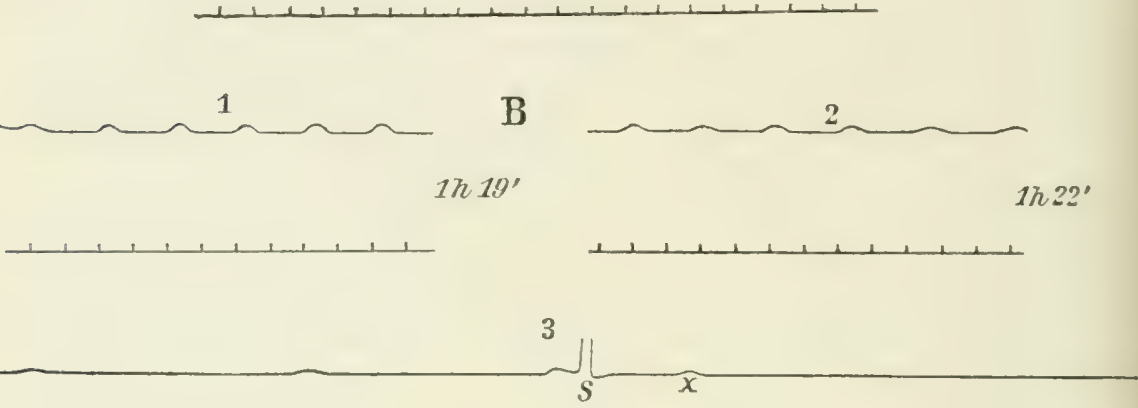

$1 h \cdot \frac{1}{22^{\prime}} 20^{\prime \prime}$

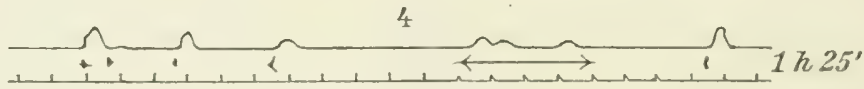

Fig. 82. Atmungskurven ron Scyllium. Cocainversuche. A Ziemlich unvermittelter Stillstand der Atmung 80" nach Zuführung von Cocain. - B Stillstand nach voraufgehender Verlangsamung. 1. vor Zuführung der Cocainlösung. - 2. Verlangsamter Rhythmus, - 3. Letzte Respirationen vor dem Stillstand. ( $\mathrm{I}=$ letzte Iiespiration. $S=$ Spuckberegung. $)$ 4. Während des Stillstandes durch mechanische $($,$) und faradische Reizung (<)$ von der Brust aus ausgelöste Respirationsberegungen. Erstere sind steiler und böher. Bei $<$ wuxden die Elektroden nur einen Augenblick aufgesetzt, bei $\longleftrightarrow$ blieben sie längere Zeit angesetzt (Alternieren von Inspiration und Exspiration). Am Anfang sind zwei mechanische Reize schnell hintereinander angesetzt, der zweite ist noch fast wirkungslos und ergibt nur eine ganz schwache Exspiration.

Daß es sich hier mo einen reflektorisclen Atemstillstand handelt, ist schom dadureh gam\% answeschlosisen, dab delselhe nie momentan

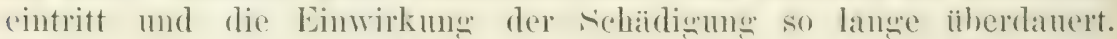
Man kimnte aber meinen, dah es sich hier mu eine zentrale Verwiftume handelt. Das ist abel anch sicher nicht der Fall: Während des dromstillstandes ist die lieflexemegharleit nicht nachweishar ver-

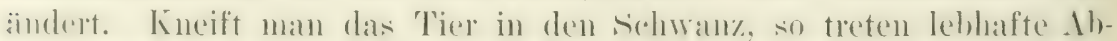

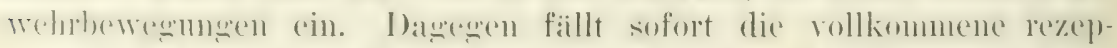

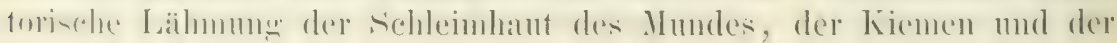


Spritzlöcher auf, kurz all der' 'Teile, welche ron der Lïsume' direkt bespiilt werden. Während sonst bei loerihlung der Kiemensehleimhat sofort eine heftig Expiration eintritt, kann man dieselbe jetztmeelanischmaltratieren, ohne einen Effekt $z u$ erzielen. Absolut berreisend ist aber

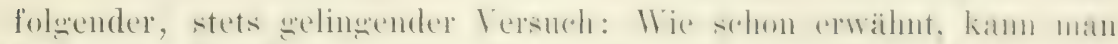

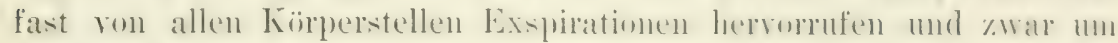
so leichter, je näher die geroizte Stelle den Kiemen liegt. W enn man nun den in Cocain-Apnoe daliegenden Fiscll am Ange, an der. Selnauze, an einer Brustflosse oder a Ba uch stark zwickt oder miteinem leichten Induktionsstrom reizt, so sielit man bei jedem derartigen Reiz eine rollkommen koordinierte Exspiration eintreten

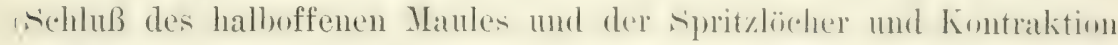
des Kiemenkorbes. Der zentrale Innervationsipplarat, wie aluch die motorischen Apparate müssen also ganz in Ordnumg sein.

Höchst bemerkenswert scheint mir noch folgender, allerdings aus Jangel an Zeit nur zweinal erholene liefund zu sein: Mrorlen während der Cocain-Apnoe zwei mechanische Reize kurz hintercimander angesetzt, so ruft nur der erste eine Kontraktion des Kinurnkorbes herror. Damit anch der zweite wirksam ist, muß eine goewisse Zeit vereangen sein rig. 82, 4). Bei andanernder tetanisinender

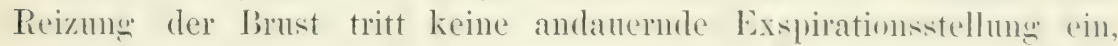

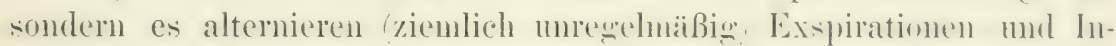
spirationen (Fig. 82, 4). Es besteht also nach jeder Respirationsbewegung ein a us gesprochenes Refraktästadium.

Werdendureh Cocaindieperipherenrezeptorischen Endigungen der Kiemen und der Mundsehleimhaut gelähmt, so ist die Atmung a ufgehoben. Nach diesen Tersuchen halte ich es für bewiesen, daß die Atmung der Fische (Haie) allein duch periphere Reize rerursacht will.

Ehe ich auf die Natur dieser Reize eingehe, muß ich noch einige

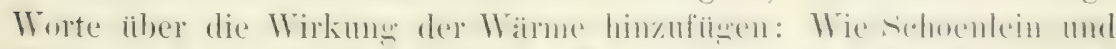

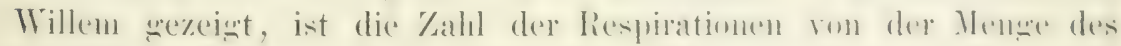

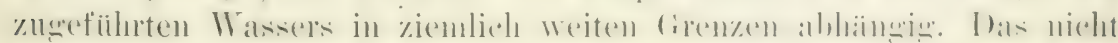

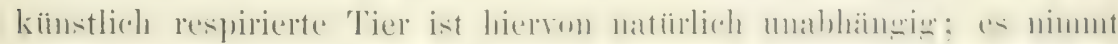
immer nur eine bestimmte Wassermenge anf. Das Tolum desselben

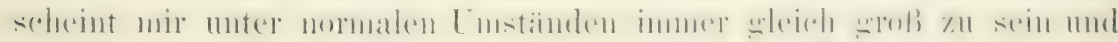
nur die Zahl der Respirationen zu sehwanken. Diese ist aber abhängrig und, wie mil seheint, allein abhängig' von der 'T'emperatur.

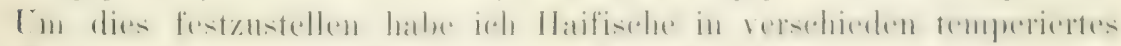
Wasser gesetzt und die liespirationen teils gezihlt, teils graphisch 


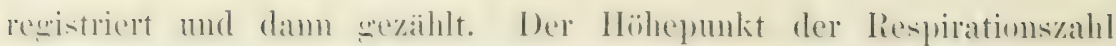
liegt, wie es scheint, bei etwa $20-25^{\circ} \mathrm{C}$. Dariber hinaus wird

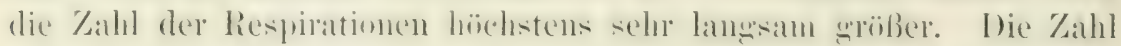
selber ist bei rerschiedenen Arten und in derselben Art bei verschieden großen 'Tieren recht rerschieden. Unter $20^{\circ}$ nimmt die zahl der Respirationen sehr schmell ab. So zällte ich bei einem 'Tier in Wassel von $19,5^{\circ} 42$ Respirationen in der Minute, bei

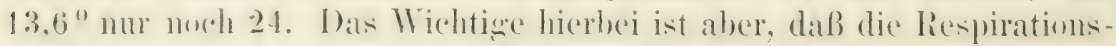
bewegungen nicht in dem Moment schneller werden, wo das Wämere Wasser die Kiemen berïhrt, sonderndaB die Beschleunigung sich ganzallmählieh im Lauf vou II inuten a usbildet. In seleher Weise tritt die Verlangsammug heim C̈hertragen in kälteres Masser allmählich ein. Ist die Tenperaturdifferen\% sehr swo B, so fänent die Ändermon in der liespirations\%ahl sehon nach etwa einer halben Ninnte an und erreicht in wenipen Minuten ihr Maxinum; je geringer die Differen\%, desto lanswanter

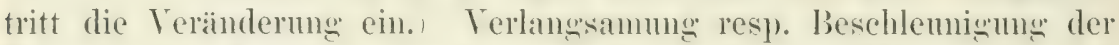
Respirationen kam man aber anch bei konstanter Temperatur des Atemwassers erreichen, wem man dem in flachem Wasser liesenden 'Tier ein Stiick Eis resp. einen warmen Schwamm auf den heradsragenden 'Teil des rehädels legt. Ich emeichte in diesen Versuchen weniger grobe Zahlendifferenzen als bei der andern Versuchsanordnung.) Ich zielie aus diesen Versuchenden SehluB, da die Temperatur nicht peripher (wie die Wassermenge), sondern zentral auf den Atemrhythmus wirkt (eventuell auch auf die Nuskeln). Eine Veränderung der Frequent tritt crst dann ein, wenn das Gehiln die Temperatur der Umgebung angenommen hat.

Auf Grund dieses Versuches und der zuerst von Schoenlein und Willem festwestellten Tatsache, daß die Respiration bei Mbsehmeidunw der Wasserzufulur aufhört, wemn das letzte Wasser ausgepreßt ist anßerden auf frund einiger andern Beobachtungen, welehe ich ror der Veröfentlichung noch einisemal wiederholen möchte), komme ich zu dem S'chluß, daß die periphere Ersache der Atmume der Haie wenigrstens zun 'Teil in einem kontinnierlehen Reiz hesteht. Diesen kontinnierlichen Reiz sehe ich in dem die siohlemhant beribrenden Wasser und zwar in seiner Qualitait als Flüssiskeit. Neben diesem kromstanten Reiz wird man wohl anch rhythmische Reize annohnen diirfen, welehe ähnlich wie bei den höheren Wirbeltieren dureh die

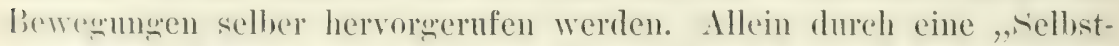

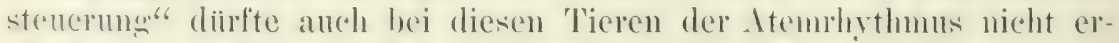

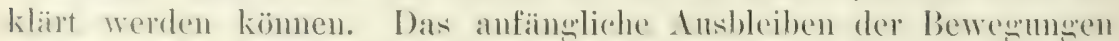
an der Luft, die vollstandige Lureschnäiskeit derselben, wenn sie 
nach längerem Verweilen an der Luft wieder eintreten, die Be-

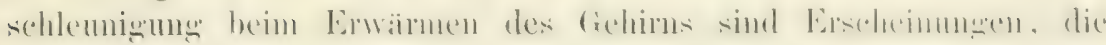
ich mir nicht erklären könnte, wenn die durch jede Inspiration resp.

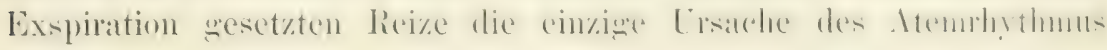
wären.

Diese Erscheinungen werden aber plausibel, wenn man in der

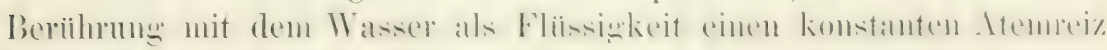

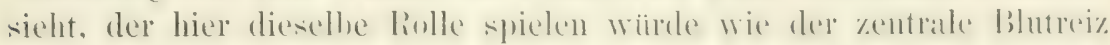
bei den höheren Wirbeltieren. Fïr die höheren Wirbeltiere ist bei

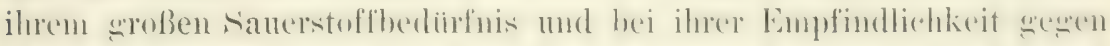

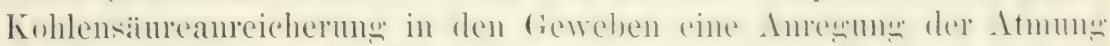

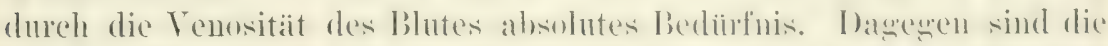

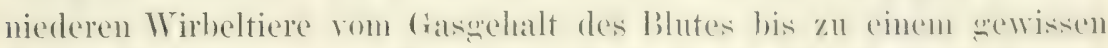

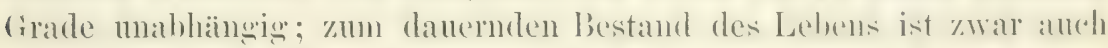
hier sanerstoff und Fortschaffung der kohlensäure notwendiz: aber die

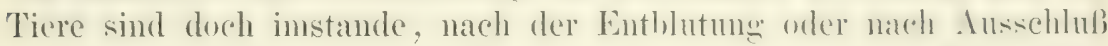
von Sanerstoff noch viele Minuten in ziemlich normaler Weise ilure

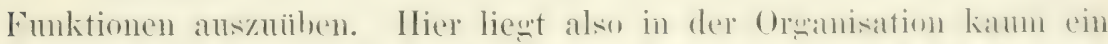
Berlürnis, jedenfalls nicht die Notwendigheit vor, dials die Itmung dureh die Blutheschaffenheit angerent wird. Vor der liespiration schlechten Materials, welche sie auf die Dance schädligen wiirde, sind

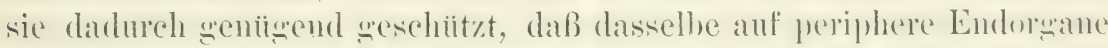
reizend wirkt, Atemstillstand resp. Ansspeien hervoruft und zulluchtbewegungen Anlaß gibt, welche erst aufhören, wenn bessere Bedingungen erreicht sind. Deim Haifiseh kann man sich hiervon leicht uiberzengen, wemn man in ihrer Nähe schädliche Stoffe ins Wasser bringt: Sowie das hiermit vermischte Wasser in den Mund gelangt, speien sie und suchen davon freie Wassergegenden auf. Diese Lrscheinung tritt auch bei stark $\mathrm{CO}_{2}$ haltigem Wasser prompt ein. Im iibrigen liegen derartige bedingungen mer nomalen Vorhältnissen (wenigstens für die Meeresbewohner) wohl iiberhaupt nie ror. -

Weder die Atemmuskulatur der höheren, noch die der niederen

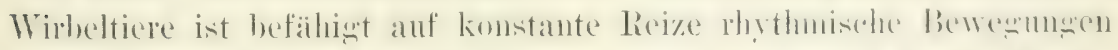
anszufuihren. Bei tetanischer lieizung treten wenisstens immer l)anerkontraktionen ein. Um nun die Umwandlumg des konstanten Blut-

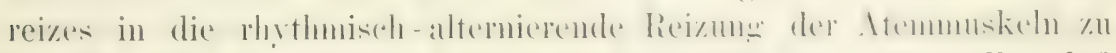
erklairen, hat Rosenthal (1862 u. 1875) die 'Theorie aufgestellt, daß in den Atemzentren ein Widerstand vorhanden sei, der nur zeitweise

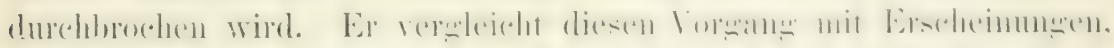
die \%. B. an einem Behälter zur Beobachtung kommen, der unten mit einem federnden Ventil versehlossen ist und in den kontinuierlich Wasser hineinfließt. Iat das Wasser in dem Gefäß eine bestimmte Druckhöhe erreicht, so wird der Widerstand der Feder iiberwunden 
und ein gewisses Quantum Wasser flieBt dureh das Ventil ab. So

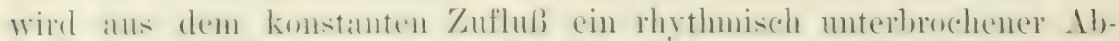

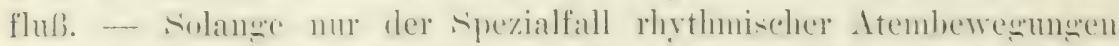
hekannt wall, dele hei lon hïheren Wibleltieren vorliest, war ein An-

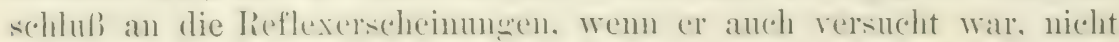

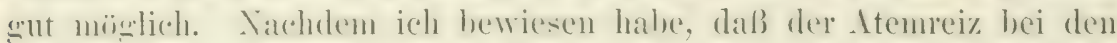

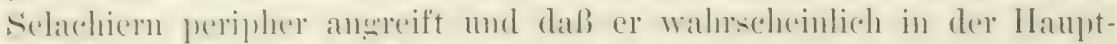
sache, wic hei den hïheren 11 irheltieren, kemtinuerlicher Satur ist,

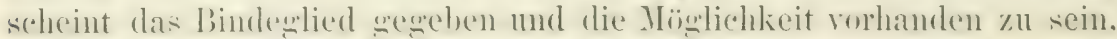

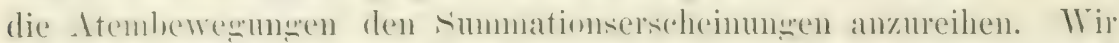

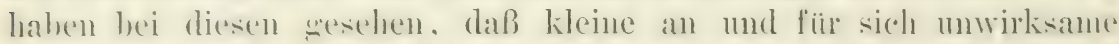
liontinuierlich oder rhythmisch wiederkehrende, Reize sich sumnieren

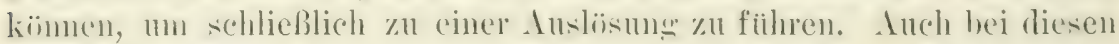
(s. 352, nubten wir ja einen Miderstand in den Kentraloreanen annehmen, so dak sich die nene Vorstellumg von der Rosentlaals nicht weit entfernt. Bei den Haien bietet es keine Schwierigkeit die

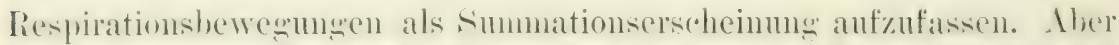
altol, bei den hïheren Wirheltieren ist dies möngeh. Von der Peripherie ist hier die Antriffstelle des Reizes, don Bediurfnissen entsprechend, ins 7entrum seriekt. ()h der kontinuerliche Reiz dort an fanclien-

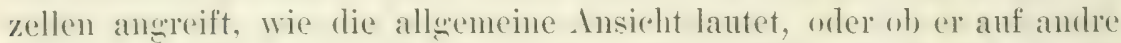
sitellen des firans, eventuell auf hesomdere, bisher noch mbekannte

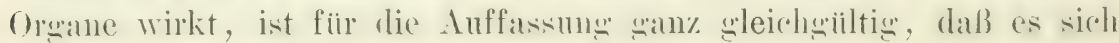
anch hier um eine Summationserscheinung und um eine Art ron

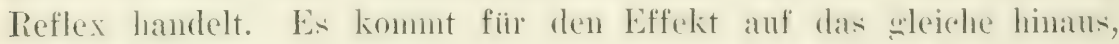
ob der Widerstand dadureh durehbodehen wird, dab wie hei den we-

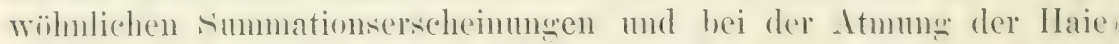
rin kuntimuierlicher Lei\% ron der Peripherie her zuneleitet wird, oder ol, oine konstante, in den Zentralorsanen selher gelegene Lisache den Widerstand von Zeit zur Zeit aufluebt.

Ich komme danach zu folgendem Schluß: Sow eit die rhythmische Bewegung der Atmung auf einer kontinuierlichen Ursache beluht, handelt es sich um eine Summationserscheinung und nicht um eine a utomatische, den Reflexbewegungen fremd gegenuberstehende und geheimnisvolle Eigenschaft der Ganglienzellen.

Bei den gewöhnlichen Summationserscheinungen, wie sie z. B. am lieflexpräbatrat des Forsohes studiert sind, hleiht dio eimmal ein-

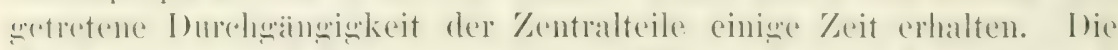

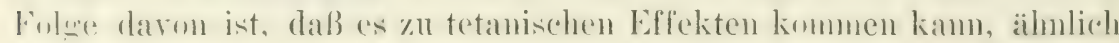

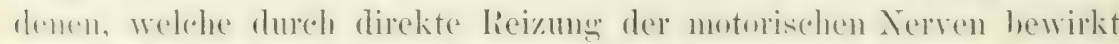

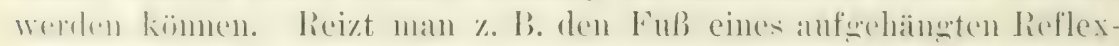

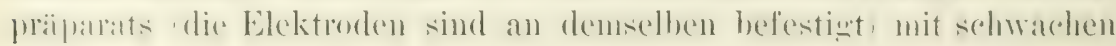




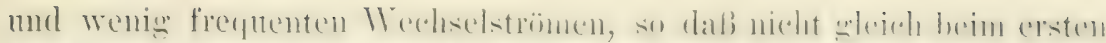

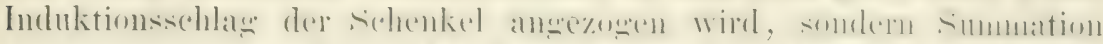

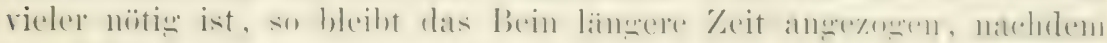
der Effekt eingetreten ist. Der Erfolg ist also ein dauernderer, als

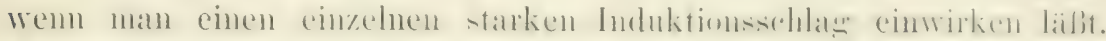

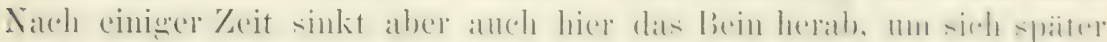
fiur kiurzere Zeit wierler zu heben. Ob es dabei zu einem wirklichen rhythmischen Alternieren kommen kamn, habe ich weder ans der Literatur noch aus den wenigen eignen Versuchen ersehen kïmnen.

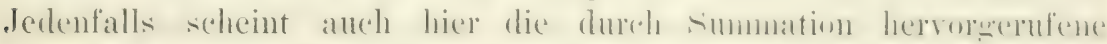

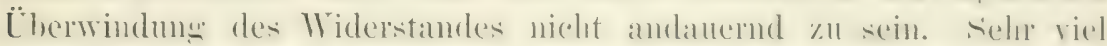

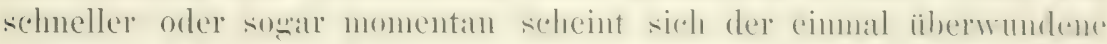

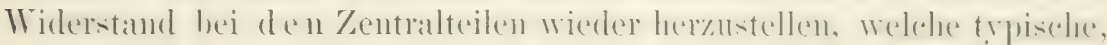
rhythmische Bewegungen vermitteln.

Für die Atmung der höheren Wirbeltiere liegen, soweit mir be-

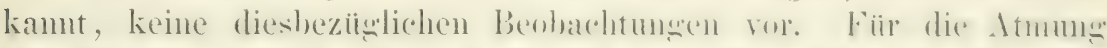

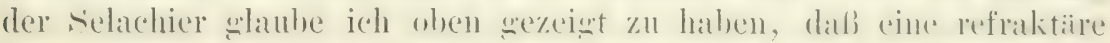
Periode existiert. Fs folst, wie es scheint, anf jede Durdibrechumw des Widerstandes ein Stadium vollkommner Unerregbarkeit.

Einen Fall von sehr typischer refraktärer Periode hat Zwaardemaker 18!n, bein LidschluBreflex gefunden. Inselle wurde dureh

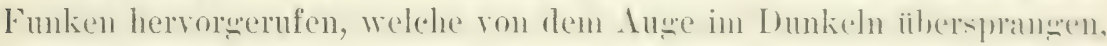
oder auch durch wames Anblasen. Folgten zwei Reize dicht anfeinander, so war der zweite stets mwirksam. Das Stadim roll-

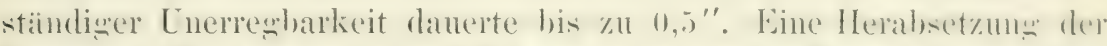

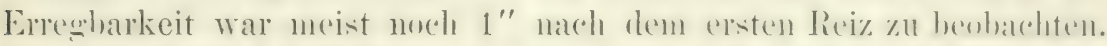

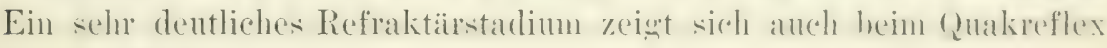
des Frosches.

An dieser Stelle möge noch folgende Beobachtung Errähnung

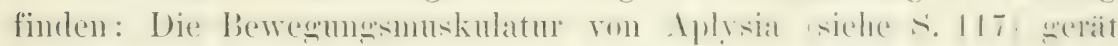
bei starker direkter oder indirektel Reizung (rom Nerven aus) zwar

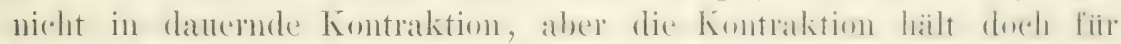
Minuten mit kleinen Schrankungen an. Als Reiz kann in golehel

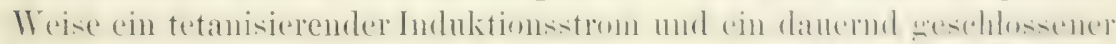

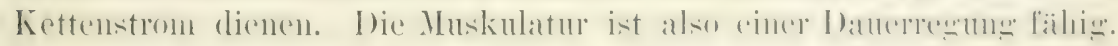
Reizt man num nach Fortnalme des Kentralnervensystems nit grut

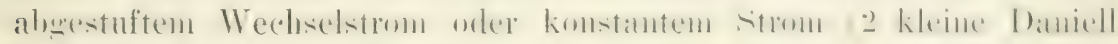
und 0,4-1 Ohm im Hauptkreis) cinen Fligelnerven (zwisehen Nerv

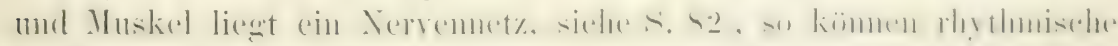
Kontraktionen des Fligels eintreten, bei denen ein schwacher líon-

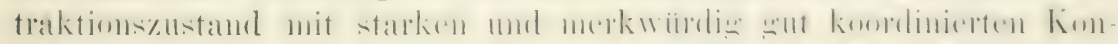
traktionen in regelnäßigen Pausen abwechseln. Die Kabl dieser rhythmischen Bewegnngen ist allerding's immer gering $(1-7)$; die 


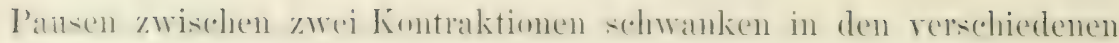
Versuchen zwischen 3 und 20 Sekunden. Um eine nene Reihe zu

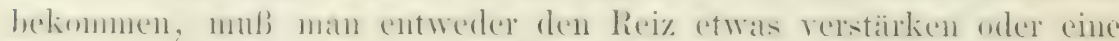

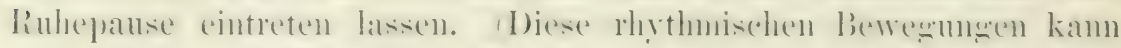

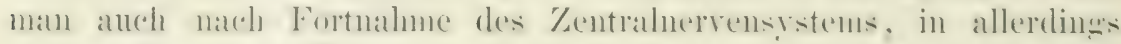

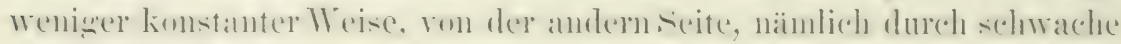

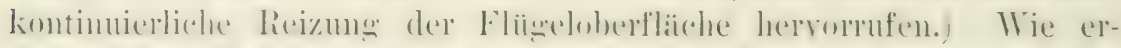

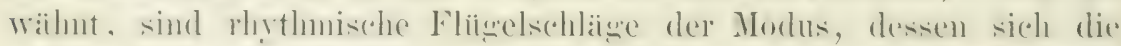
Aplysien beim sidewimmen bedienen: dureh diesen Versuch wird die

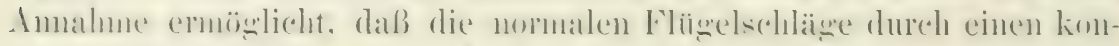
timuierlichen liciz hervorgerufen werlen, der vom Zentrahnervenststem dem Nerremnet\% zugeleitet wird, und daß erst hier durch einen

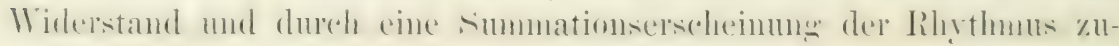
stande konmt.

Durch das Vorhandensein einer relativen und manchmal absoluten Refiaktäphase in den Zentraloreanen bekomme die oben entwickelte Inffasing der rhythmischen Atembewegurgen einen festeren IIalt, und die Entstehmo rhythnischer Effekte auf kontinuerliche Anliisse hin erscheint weniger rïtselhaft.

\section{Die rhythmischen Bewegungen des Wirbeltierherzens und der Medusen.}

Der Vergleich zwischen den Bewegungen des Herzens und denen der Medusen wird hier nicht zun erstemual angestellt. Zuerst tat dien

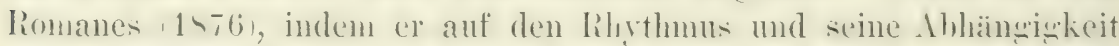

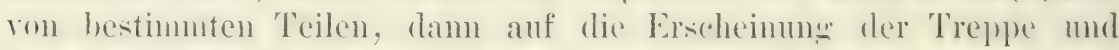
des in beiden Fillen zutreffenden ... Illes oder Xidhts-(iesetzes" hin-

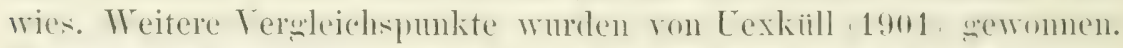
Eingehende lieschaiftigung mit den Medusen und dem Herzen halren mir gezeigt, daß die Analogie in der Tat noch viel weiter geht, so weit, daß ich sagen kann: Es gibt in der ganzen Tierreihe nicht zwei Erecheinumen, die sich bei gleicher Lomplikation und hei an-

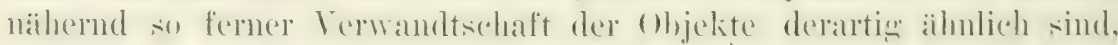
wie Her\%- und Medusenberregungen. Um einen, besonders fïr ver-

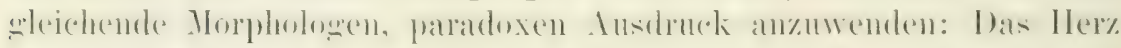
ist gleichsam eine in sich geschlossene und organgewordene Meduse.

Der normale Rhythmus und seine Abhängigkeit rom besonderen T'eilen.

Seitdem Stamnius (1852) gezeigt hat, daß das Frosehher\% stehen bleibt, weun man eine Ligatur zwisehen Sinus venosus und Vorhof 
anlegt, hat man fast allgemein die Ansicht angenommen, daß die normalen Herkkontraktionen rom Sinus ihren Ausgang nehmen. (Den gleichen Effekt erzielt man, wem der Sinns rom Vorhof ganz abge. tremnt wird.) An dieser Ansicht ist dureh den Nachweis nichts geandert worden, daß das Herz in der Regel einige \%eit nach Sinus-

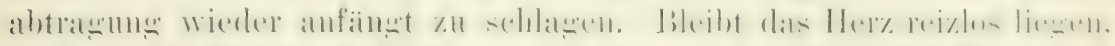

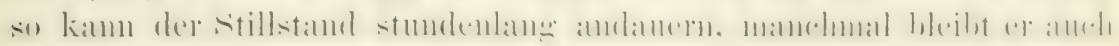
bis zum Absterben erhalten. (Dieser lange Stillstand sehließt es aus, daß er anf hemmender Vagusreizung berulht, was einige Zeit besonders ron Volkmann behauptet wurde.) Golt\% (1861 und 1862) glaubte den späteren Wiederbegim der P’ulsationen anf Reize beziehen zu müssen, welche durch die Berührung mit der Luft auf das Herz einwirken, weil es ihm gelang, bei Sinusabschmeidung unter öl den Stillstand dauernd zu machen. Hiergegen ist allerdings - und vielleicht mit Recht - eingewandt worden, daß das Her\% im öl erstickte, aber jedenfalls ist nie der Beweis geführt worden, daß die Ansicht Goltz' falsch ist.

Sicher ist, daß das simuslose Herz dureh Reize wieder zu l’ul-

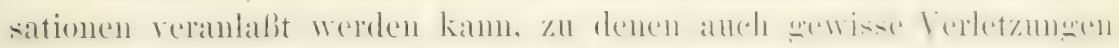
(die dritte Stamniussche Ligatur, die Munkschen Stiche, 1866 und

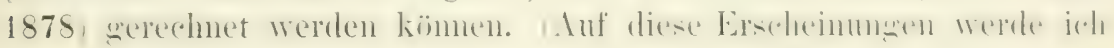
später ansführlicher zuriekkommen.) Da diese Reize seln schwach sein kömnen, so ist es durehaus nicht ansgeschlossen, daß anch die nach sinnsabtragung anseleinend spentan wider anftretenden l'ulsationen dureh Reize okkulter Art hervorgerufen werden. Gewisse Teile des Herzens, vor allem die sogenannte Herzspitze, zeigen aber nie wieder spontane oder spontan erscheinende Pulsationen, so daß wenigstens für diese absolut feststeht, daß sie die Reize zu ihren normalen Bewegungen von andern Herzteilen crhalten. Wenm num

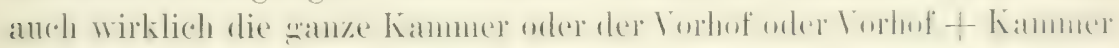
(nach Abtremnung des Sinus) unter Umständen ohme erkemubaren

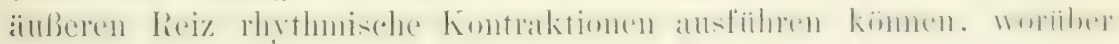
hier nicht diskutiert werden soll, so ändert dies doch nichts daran,

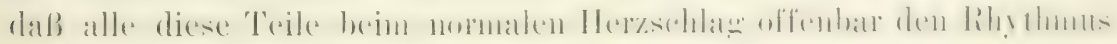
nicht selbst erzengen, sondern auf Erregungen reagieren, die ihnen vom Sinus zugefülut werden (Engelmann und andre).

In granz analoger Weise bilden bei den Medusen, wie Eimer und Romanes gezeigt haben (siche S. 106) die sogenannten Randkörper

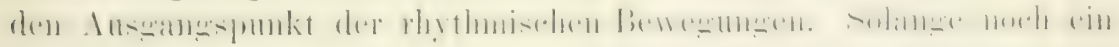
Randkörper vorhanden ist, gehen die rhythmischen liontraktionen weiter, ist auch dieser entfernt, so ist der im Vergleich zu den fortgenommenen Teilen so außerordentlich viel größere Rest wie gelaihmt. Bei den craspedoten Medusen danert der Stillstand nach Romanes bis 
zum Tode; nach Loebs Angabe (1899) treten aber nach etwa

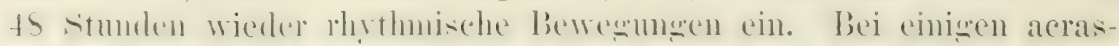

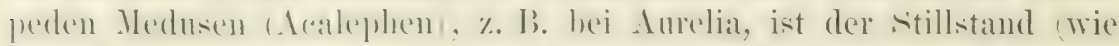

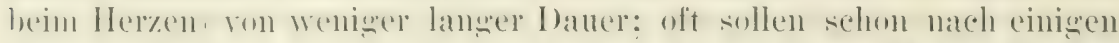

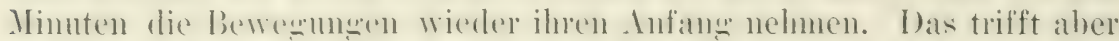

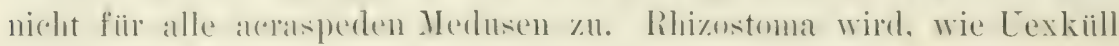
zeigte, dauemd in Ruhe versetzt; dasselbe gilt ron Cotylorhiza.

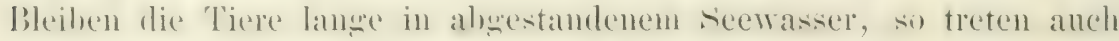
hier manchmal wieder rovthmische Komtraktionen ein, welche aber nach Lexkiill and lèize zurïckzuführen sind, welche von alsterbenden Hantpartion auswehen. Inureh stets frisch gohaltenes Wasser kamn

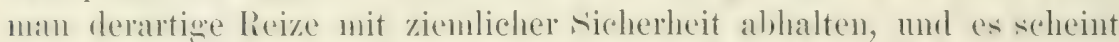
nicolt allswerchlosicen, dah sich die ohige Angabe Loebs anf sohlechtes Massole beziehen läbt. Es wäre dam tatsächlich der stillstand nach Fortmalme der liandkïrper ein danernder, falls andre Reize ferngehalten werden. Dies deckt sich mit der von Goltz für das Her\%

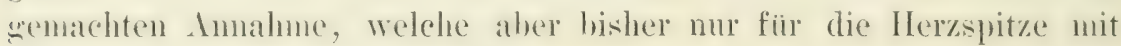
Sicherheit bewiesen werden konnte.

Unter normalen Umständen schlägt das Her\% der Wirbeltiere an-

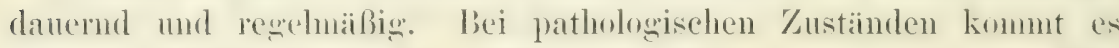
aber zu rerschiedenartipen Lnegehnäigkeiten, vor allem zum Ausfall cinzelner oder mehreper P'ulse und zu Gruprenbildungen. Das Anftreten solcher (iruppen ron P'ulsationen lient bei den Medusen in der normalen Breite. Die Länge der Gruppen und der Pausen schwankt unter verschiedenen Umstïnden und vor allem bei den verschicdenen Arten. Bei lihizostoma bestehen die (iruplen ans Hunderten

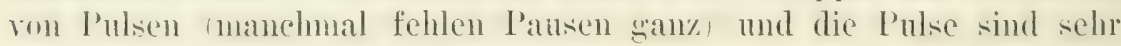
rewolnabie (Fi心. S7). Lei cotylorhiza komme es selten zu mehr als s) - lou anfeinander folenden Kontraktionen. Dann tritt mexist eine Panse ron dem IVert ron 3-20 I’ulsen ein. IIinfig sind die (iruppen viel

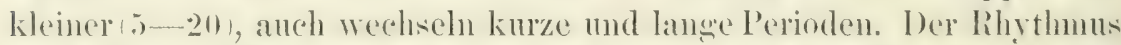
ist bei diesem Tier anch weniger reselmäbign als bei Rhizostomat das

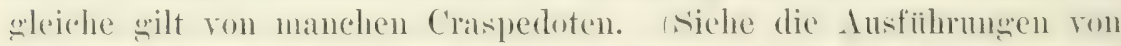

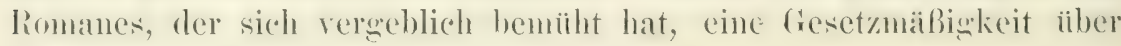
die Periodenbildung aufzustellen.)

Die Reaktionen des sinuslosen Herzens und der randkörperfreien Meduse auf künstliche Reize.

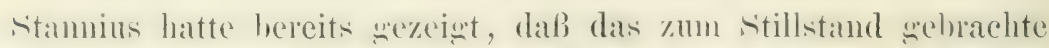
Froshlier\% auf jeden mechanisohen Einzelreiz nit einer einfachen Systole antwortet. Das Gleiche gilt, wie rielfache spätere Unter-

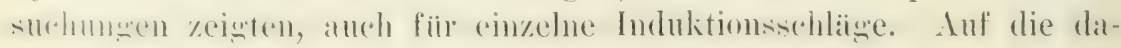




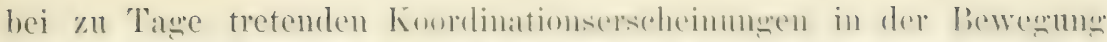

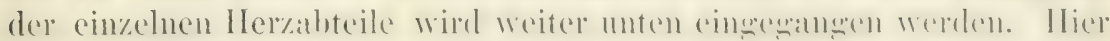
ist es für uns nur wesentlich, daß sich der Effekt stets an allen mit

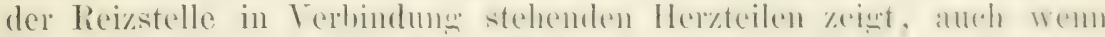

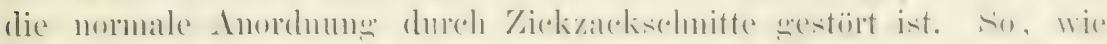

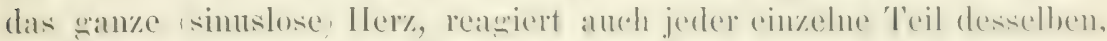
selbst die spontaner Bewegungen unfähige Herzpitze.

Ganz das Gleiche läßt sich, wie Eimer mol Romanes zuerst ge-

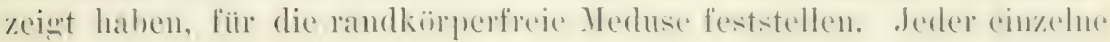
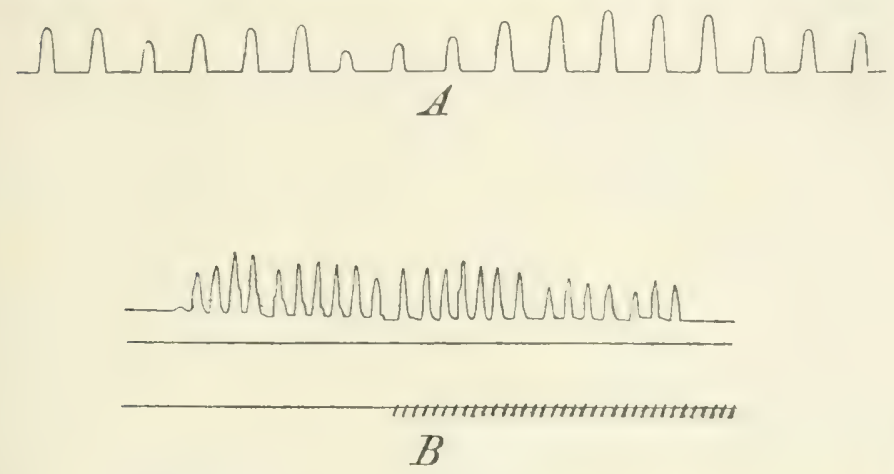

Fig. 83. Treppenbildung. A von Rhizostoma, $D^{3}$ von Cotylorhiza. (Beide im Verlauf normaler Pulsationen). $C$ von Carmarina durch elektrische Reize von gleicher Größe am randkörperlosen Tier erzeugt. Zeit $=0,5$ ".

mechanische Reiz und jeder iiberhaupt wirksame Induktionsschlag" löst eine Kontraktion des ganzen 'Tierrestes aus, gleichgiiltig, ob sich alles im normalen

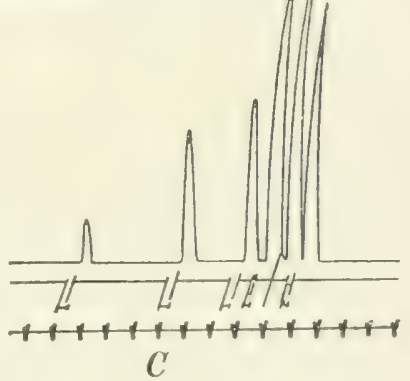
Zusammenhang befindet oder ob der

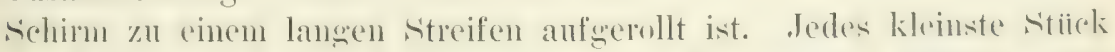

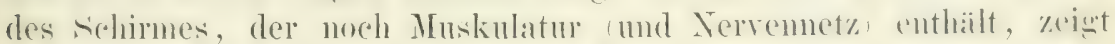
das Gleiche (siehe S. 106).

1871 zeigte Bowditsch, daß das sinuslose Her\% (oder irgend ein

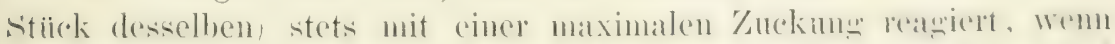

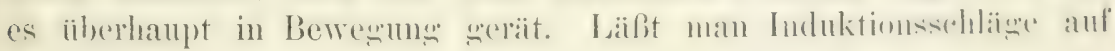
das Herz einwirken, und verstërkt man dieselben langsam von un-

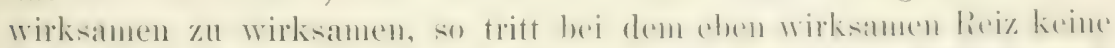

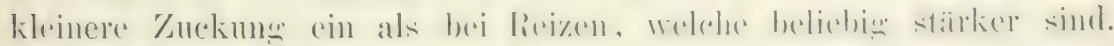
Dieses Phänomen ist unter dem Namen, „Alles oder Nichts-Gesetz" bekamut. (Über Ausmahmen von dem Gesetz siehe Kronecker 1SS3.)

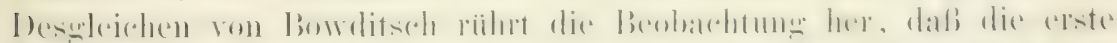

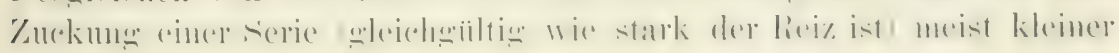


ist als die näbliste mol diese wioler kleiner als die folsende mol son

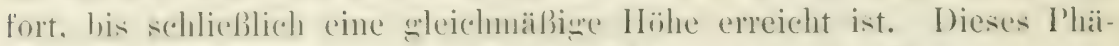
monen wird als Treppe hezeichnet und kommt anch hei sikelettmuskeln zur Beobachtung.

Das ,Alles oder Nichts-Gesetz" gilt, wie Romanes gezeigt hat, und wie ich mich selber durch viele Versuche iiberzengt habe, in

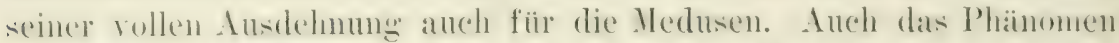

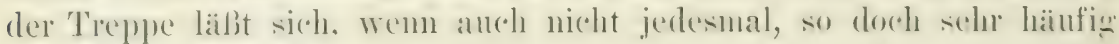
kmotaticren. Es lommot anch beim nomalen, selbständiw pulsierenden

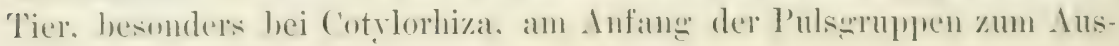
druck (Fig. 83).

Die Bewegungen der Medusen wurden auf folgende Weise aufgeschrieben: Das Tier wurde in Riickenlage in eine flache, mit Wachs ansgegossene Schale gebracht und mit einigen Stecknadeln nach Bedïrfnis am Boden befestigt (meist genïgen zwei bis drei Nadeln durch den nicht kontraktilen Mittelteil). Der Magenstiel wird als überflissig entfernt. Daranf wurde die Schale soweit mit Seewasser gefüllt, daß der Schirmrand sich frei berregen komnte. In den Schirmrand wurde an einer Stelle ein Haken eingesetzt und der daran befestigte Faden iiber eine Rolle zu einem mit Anschlag versehenen Hebel gefiilırt. Sollte zu gleicher Zeit ron einem zweiten Punkt des Sehimmandes geschrieben werden, so wurde der Faden von der zweiten Stelle meist nicht direkt zu der iiber dem IIebel befindlichen Rolle geführt, sondern zunäichst uiber eine zweite dicht am Schirmrand angebrachte Rolle. Dies geschah, wenn der zweite Punkt dem ersten gegenïber lag. Waren die ziehenden Kräifte, wie in einigen späteren Versuchen, senkrecht zueinander gerichtet, so mufte der Faden sogar iiber zwei Hilfsrollen gefiihrt werden. Bei der Größe und Kraft der Bewegungen spielen die eventuell zu erwartenden Fehler, wie ich mich iiberzeugt habe, keine wesentliche Rolle. (Zwei iibereinanderstehende Hebel, mit feiner Einstellung und festangebrachten Rollen fand ich auf der zoologischen Station in Neapel vor. Yon wem sie angefertigt sind, ist mir unbekannt.)

Die angegebene Fixierung des Objektes genïgt bei selbständig schlagenden Cotylorhizen und bei randkörperlosen Stiicken aller Arten. Gute Kurven von selbstïndig schlagenden Rhizostomen und Karmarinen erhält man jedoch aut diese Weise nicht, weil sich diese Tiere aufs energischste gegen die liückenlage wehren, solange sie Randkörper besitzen! Dagegen schlägt besonders Rhizostoma selır ruhig und gleichnäßig, wenn man sie in Bauchlage fixiert, wobei aber darauf zu achten ist, daß der Schirmrand nirgends anschlagt. Nachdem der Magenstiel entfernt ist, steche ich einen Draht melurfach ron oben nach unten und wieder nach oben durch das nervenlose Glockenzentrum und wickele die Enden iiber einen Stab, welcher über einem großen Behälter mit Seewasser so befestigt ist, daß das Tier grade mit Wasser bedeckt ist. Die Übertragung geschieht wie olven.

Die mechanische Reizung bereitet keine Schwierigkeiten, dagegen muß beim Reizen mit dem konstanten Strom oder mit Induktionsschlïgen darauf geachtet werden, daß die Elektroden bis zur Berïhrungsstelle mit der Subumbrellat gut isoliert sind. Am besten kam ich immer zustande, wemn ich elektrisch nicht unter Wasser reizte. Das ganze Tier befand sich im Wasser bis auf eine oder zwei kleine Stellen, an welchen die Elektroden angelegt wurden. Bei den in Banchlage befestigten Tieren wurde zu diesem Zweek der Schirmrand an einer 
Stelle nach oben gebogen und so in Zwangslage aufer dem Wasser gehalten. Die Erregharkeit erleidet dabei in lingerer Zeit keine Einbuße.

1858 zeigte Heidenhain, daß die nicht pulsierende llerzspitze resp. das \%

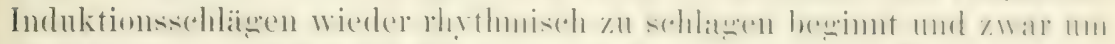

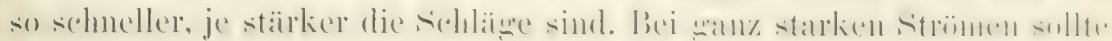
es zu tumultuarischem 'I'etanus kommen. Der. Versuch ist später oftmak wiederholt siele Marey, G G

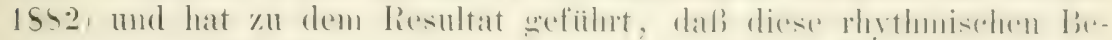

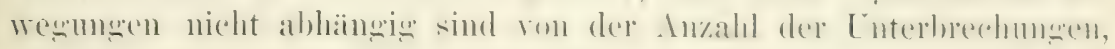
sondern nur von der Stärke des Reizes; allerding's konmt die Zahl

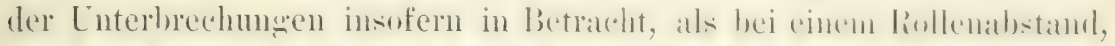

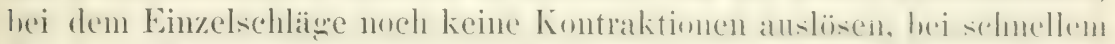

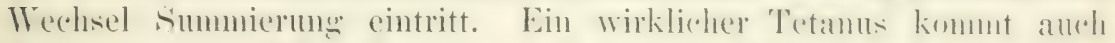

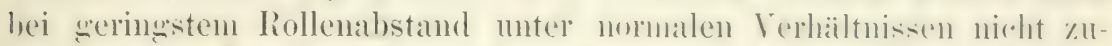
stande. Die Kurve behält stets Zarcken, die in rhothuischer licihenfolse anfsitzen, jedoch sinkt die kurve zwischen den linzelhementungen

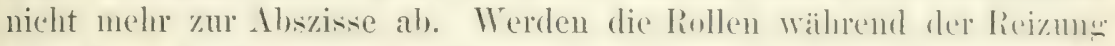
allnählich ïbereinander geschoben, so nimmt die Kahl der Kontraktionen bis zu einem bestimmten Punkt zu; dann kann durch noch

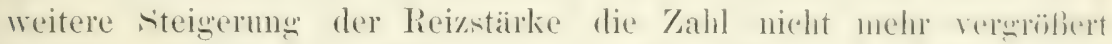
werden. Bei niedriger Temperatm ist diese Maximalzahl kleiner als bei höherer (Eng’elmann).

Dieselben Verhältnisse zeigen sich anch bei den Medusen. Bei faradischer Reizmog treten an randkörperlosen 'Tier wieder rhythmische Kontraktionen ein lionnanes, nud zwall steight ihre Zahl mit der Stärke der Ströme, führt aber auch hier nie zu vollkommenem Tetanus (ron Uexkiill). Die Maximalzahl ist wie beim Herzen bei

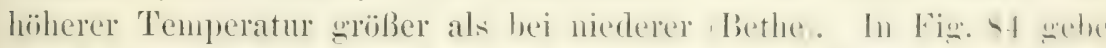
ich Kurven, welche die Abhängigkeit von der Reizstairke zeigen.

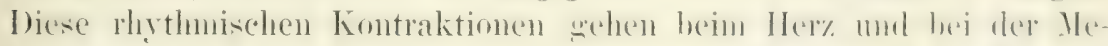
duse stets von der gereizten Stelle aus, so daß sich z. B. bei Reizung der Her\%kammer diese zuerst kontrahiert. Wird das normale Her\% oder

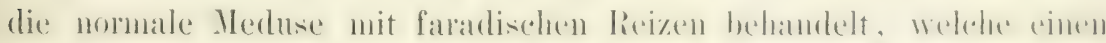

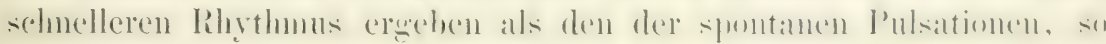
tritt nur der erstere zu Tage (Heidenhain, Bethe). In der Regrel

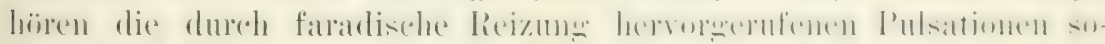
wohl beim Herzen wie bei den Medusen in dem Angenblick auf, wo die Reizimg beendet wird. Gelegrentlich kam man aber am sinuslosen Herzen beobachten, daß die P'ulsationen noch einige Zeit nach dem Aufhören des Reizes fortdatern (S'cherhey, 1S50, Bethe). Bei den meisten von mir untersuchten Medusenarten labe ich eine derartige Nachwirkung, welche auch beim Ileren immer eine Insuahme 


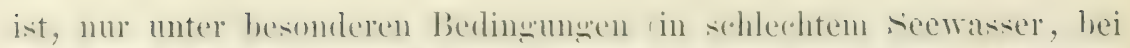

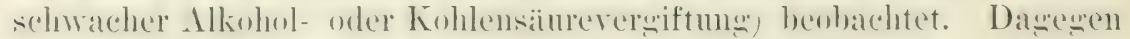
scheint sic bei carmarina stets vorhanden zu sein, wemn dep rorher-
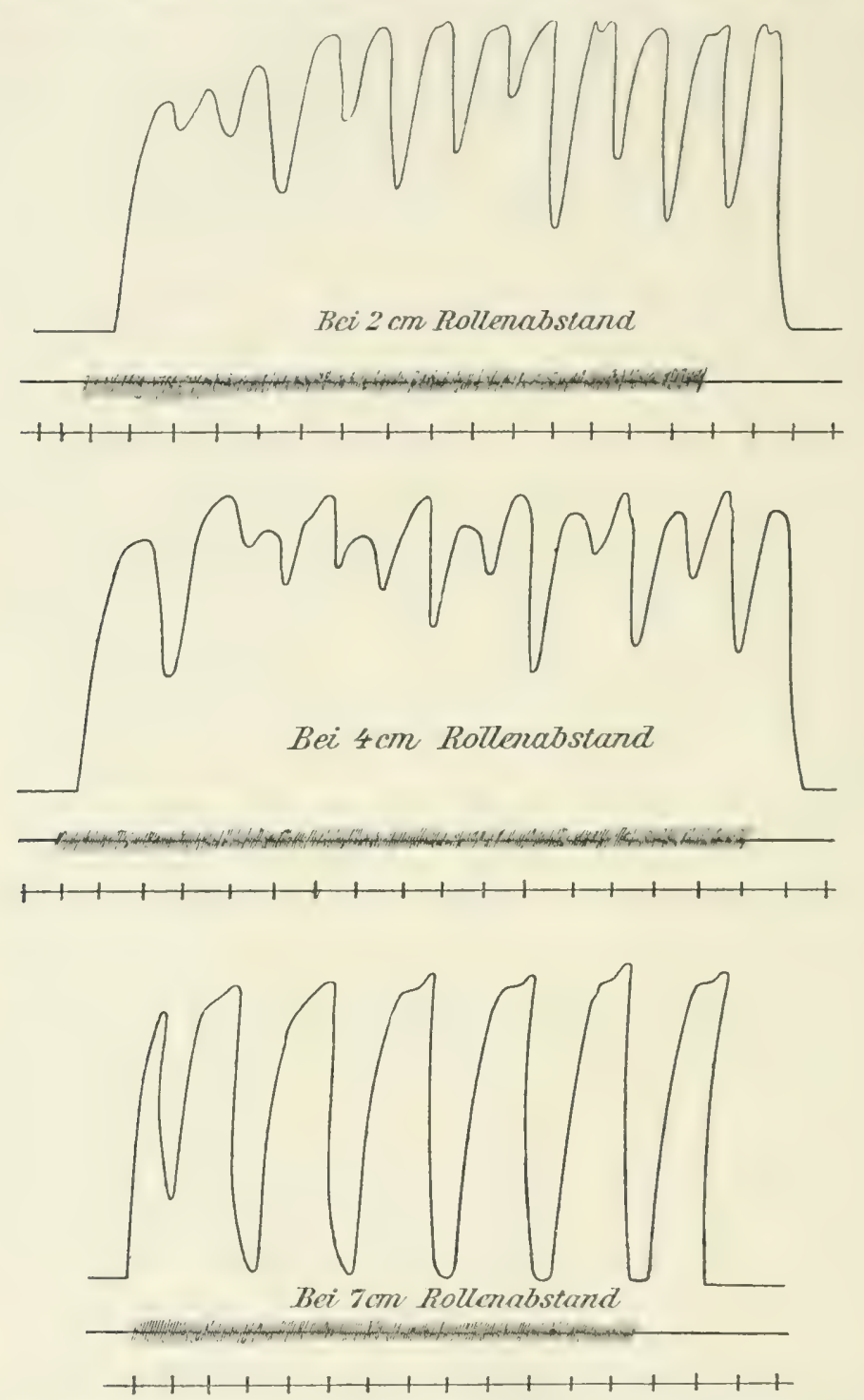

Fig. 81. Rhythmische Kontraktionen, welche bei einer randkörperlosen Cotylorhiza durch faralische lReizung bei verschiedenem Rollenabstand erzengt sind. Der Zcitschreiber gibt halbe Sckunden an.

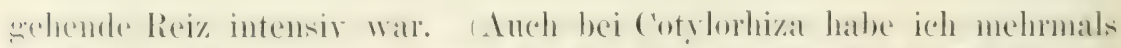

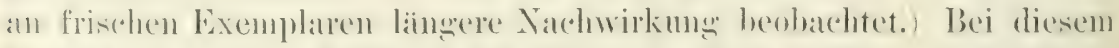

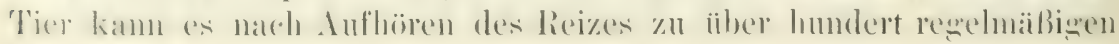


Pulsen kommen, auf die dann wieder danernde Ruhe folgt. Man kömnte geneigt sein, die Nachwirkung auf eine Verainderung an der

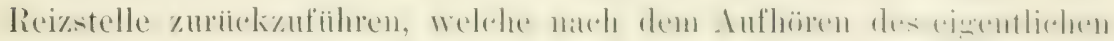
Reizes erregend wirkt. Das ist aber bei Cammarina sicher nicht der Fall: Schneidet man während der Nachwirkung die randkörperfreie Carmarina in zwei Hälfen, vondenen die cine die Reizstelle mit der ganzen Umgebung ent-
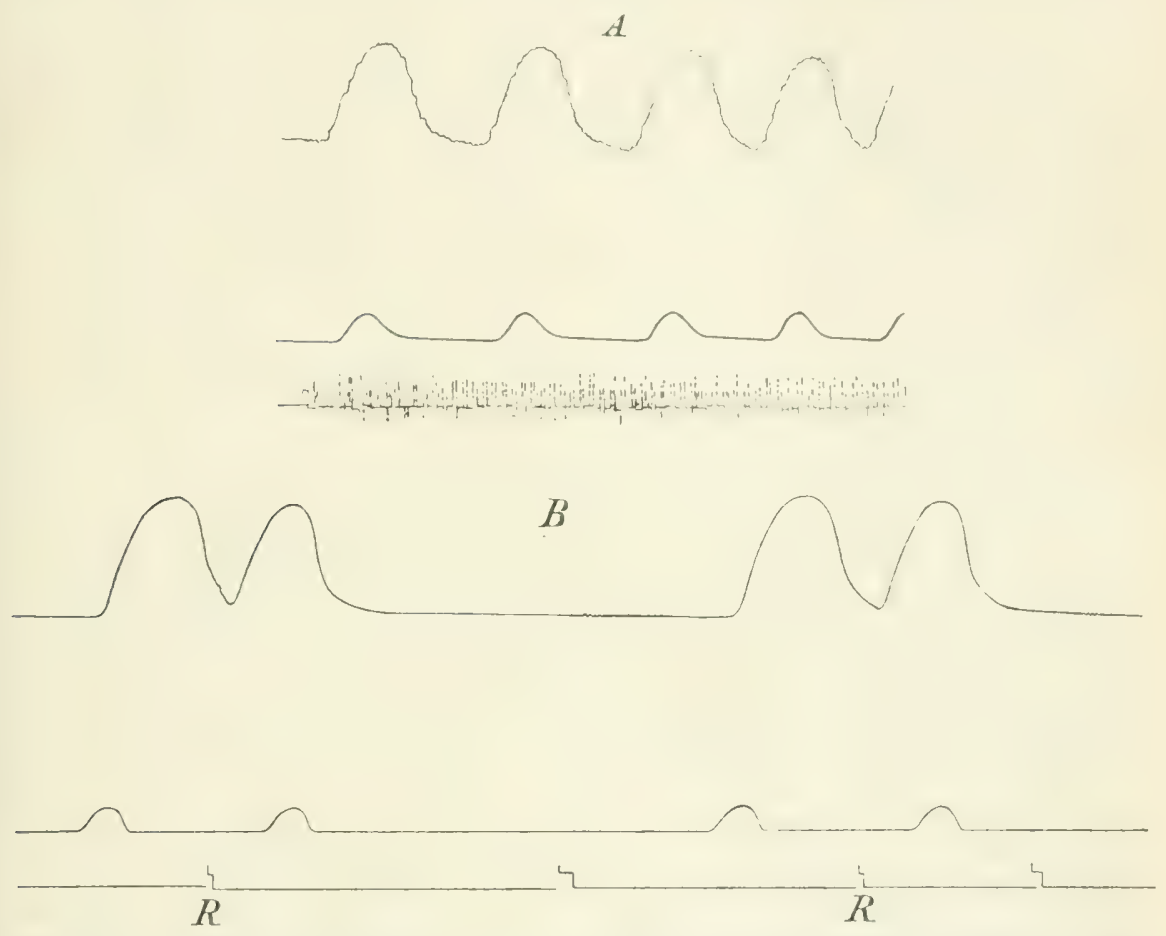

Fig. 85. Mechanische Reizung des Froschherzens mit dem elektrisch angetriebenen lieizhïmmerchen. A Tetanische Reizung des stillstehenden sinuslosen Herzens. B Hervorrufung von Extrasystolen bei einem sehr langsam schlagenden Herzen. - Der Reizapparat ist beide Mal auf der Kammer angesetzt. Unten Reizmarke, in der Mitte Vorkammer, oben Kammex. In $B$ erkennt man, daß das Fallen des Hammers $(R)$ fast keine Veränderung der Kurve gibt.

hält, so dauern die Pulsationen (in beiden Stücken) fort, um nach einiger Zeit in beiden Stïcken ziemlich gleichzeitig zu erlöschen. (Durehsehneidung gibt nie dauernde Pulsationen.)

Was bei frequenter elektrischer Reizung gilt, gilt auch sowohl für

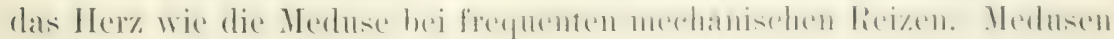
werden, wie schon auf S. 359 erwähnt, leicht durch T'ropfen erregt, welehe auf die Subumbrella fallen. Lüßt man die 'Tropten langsam auf das randkörperfreie Tier fallen, so folgt auf jeden 'Tropfen eine 


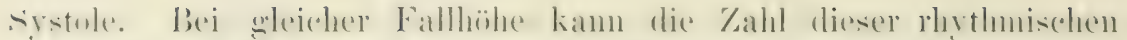

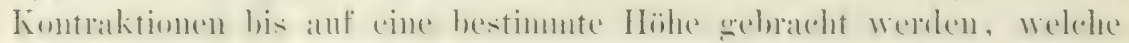

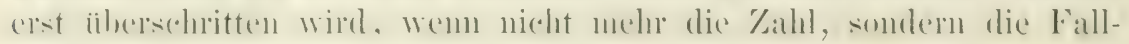
höhe (also die Reizstäi ke) gesteigert wird.

Nach einem mechanischen Reizverfahren, das weiter unten beschrichen ist, hathe ich den ersten Teil anch fiirs Jerz sicher stellen

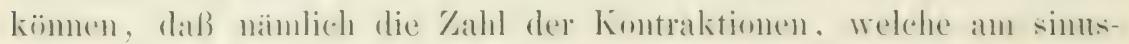

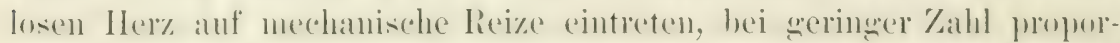
tional der lieize ist, daß aber von einer varierenden Pulsationszalil

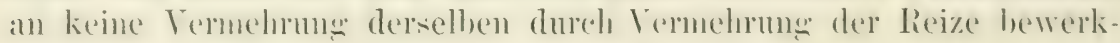
stelligt werden kamn. Bei Verstarkung der Reize, welche nur in ge-

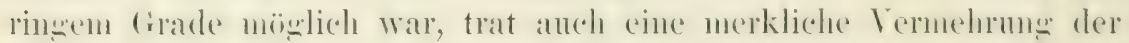

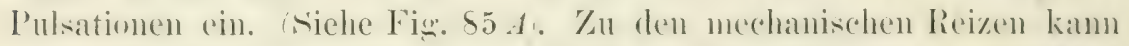

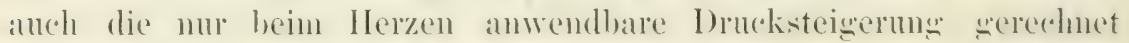
werden. Wird der Druck in simuslosen Herz oder in der Herzspitze vermelnt, so treten wieder rhythmische Kontraktionen ein, deren Frequenz abhängig' ist von der Stäike des Druckes (Roßbach, 1874, Ludwig und Luchsinger, 1881).

Zur Methodik der Herzversuche: Die größte Zahl meiner Herzversuche sind am ausgeschnittenen Organ ausgeführt. Zum Schreiben habe ich in der Regel ansbalancierte Fïhlhebel benutzt. Ich gebe dieser älteren Methode vor dem jetzt moderneren Suspensionsverfahren iiberall da (auch beim Herz in situ) den Vorzug, wo wiihrend des Versuchs gereizt werden soll, weil die Pelotten gestatten, den Reiz an denselben Stellen anzusetzen, welche ihre Bewegung dem Hebel mitteilen. Wenn man von zwei oder gar drei Stellen schreibt und von ebensovielen Stellen imstande sein will, Reize einwirken zu lassen, so ist fuir das Anbringen der Reize an gesonderten Stellen nur wenig Platz. Einige andre Vorteile der Fühlhebel, in der von mir benutzten Ausfïhrumg, ergeben sich von selbst. -

Zur elektrischen Reizung waren die Pelotten folgendermaßen konstruiert: In zwei dïnne Kapillarröhren war je ein Platindraht eingeschmolzen, welcher am Ende hervorsah. Beide Röhren waren mit den Längsseiten aneinander geschmolzen und hatten unten eine gemeinsame Verdickung von $1,5 \mathrm{~mm}$ Durchmesser. Aus diesem Knopf ragten die zugespitzten Drahtenden 1/2 mm hervor. Diese Doppelröhrehen wurden verschieblich an Hebel befestigt. An die oberen Enden der Platindrähte wurde je ein Lamettafaden angelötet, der am Drehpunkt des Hebels in einen isolierten Kupferdraht iiberging. Die beiden Kupferdrähte wurden damn zur sekundären Spirale oder zu einer galyanischen Kette geführt. Die unteren Spitzen dringen bis zum Glasknopf ins Herz ein und garantieren eine stets gleiche Reizung. Sie verhindern auch, daß das Herz sich verschiebt, so daß man bei Anwendung mehrerer derartiger Pelotten kaum noch nötig hat, rlas Herz auf der Korkplatte zu befestigen.

Für die mechanische Reizung wurde die Tatsache verwertet, daß ein freibeweglicher Eisenkern in eine durchströmte Spirale hineingezogen wird. Eine Kapillare von $0,5 \mathrm{~mm}$ Lumen und $1,5 \mathrm{~cm}$ Lïnge wurde mit zwei kleinen Spiralen umgeben, einer unteren und einer oberen. Das eine Linde der unteren Spirale wird mit einem Ende der oberen Spirale verbunden, und die so iibrigbleibenden drei Drähte werden wieder mit Lametta wie oben verbunden. Mit Hilfe eines 
in geeigneter Weise geschalteten Telegraphentasters, kann der Strom eines Elements bald durch die eine, bald durch die andre Spirale geschickt werden. (Es ist darauf zu achten, daß die Pole der Spulen gleichgerichtet sind, damit der Eisenstab nicht ummagnetisiert zu werden braucht.) Um Eindringen von Serum in die Kapillare zn verhindern, wird sie am unteren Ende mit sehr dïnner Kordon-Membran ïberbunden. Ins Innere kommt ein Eisenstiibelien von auszuprobierender Länge. Geht der Strom durch die obere Spirale, so schwebt das Stïbchen frei, wird der Strom umgeschaltet, so wird es gegen die Membran geschlendert und gibt so einen Reiz auf diejenige IIerzstelle ab, auf welcher der mit dem kleinen Instrument armierte Ilebel ruht. Dureh Variation der Stromstïrke, welche natïrlich bei der Diinne des Drahtes sehr beschränkt hleihen

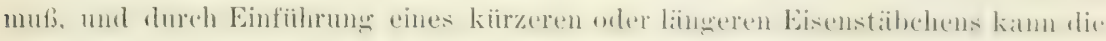
Anschlagskraft verändert werden. Da man den Schliissel bis zu siebenmal in der

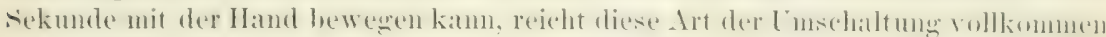
aus, um für das Herz eine tetanische, mechanische Reizung zu erzielen. Da die Dämpfung ziemlich stark ist, zeigen die Kurven heim Hermuterfallen des stiahelests (also im Reizmoment) nur eine minimale Kniekung, welche nicht stört. Eine

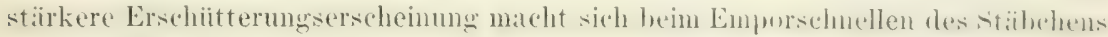
geltend (Fig. 85 B). Häßlich sind diese kleinen Zäekchen nur bei frequenter Bewegung des Eisenteils (Fig. 85 A). Das Gesamtbild der Kurve wird jedenfalls bei diesem Verfahren sehr viel weniger gestört, als bei dem meist angewandten Stechen mit einer Nadel. Auferdem ist die Mlethode sehr schonend, indem man dieselbe Stelle sehr oft reizen kamn, ohne daß der Effekt ausbleibt. Die Reizung greift sicher nicht mehr als einen halben Millimeter auf die Umgebung ïber.

An längsten ist als Erzenger rhythmischer Kontraktionen hem stillstehenden Her\% der konstante strom hekannt i Eckliard, 1 s5s. Wreiter answefiihrt ron Bernstein, 1871, scherhey, 1s 5 , und anderen. LäBt man den konstanten Strom durch das sanze stillstehende Ilow oder durch einen Teil hindurch gehen, so tritt hei schwachen strïnen nur beim öffnen und sichließen eine einfache sirstole cin. Bei stäl. kerem Strom - anch wenn das Präparat in denselben hineinmeschlichen wird (Bernstein) — setzen rhythuische Kontraktionen ein.

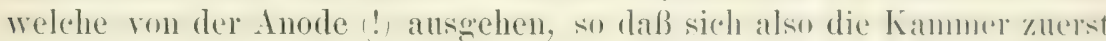
kontrahiert, wenn der Strom von der Kammer zum Vorhof geht. Hierson sollen besomders bei schwächeren strimen Insmahnen roskommen.! Beinn šchließen und ïffnen des stromes murken Vurhof

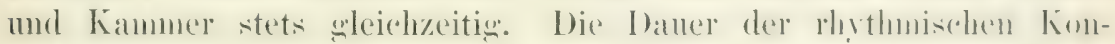
traktionen und ihre Frequenz hängen bis zol cinem swewisisen dirale von der Stromstärke ab. Bei schwachen Strömen sind die Pulse langsam und hören bald auf, bei stälkeren folgen sie einander schneller und dauern länger an.

Sowohl die reizende Wirkumg der Anode (beim Nerven und

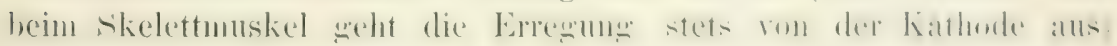
als auch die Er\%eugung eines Rhythmus dureh einen konstanten

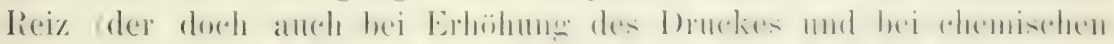

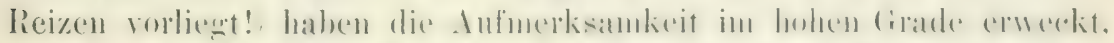

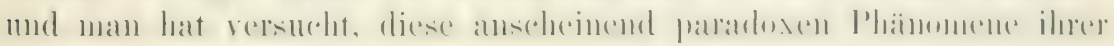


sumberstellung zu entriehen. Die Wirkmu世 der Inode hat Bermstem daratuf zuriickfüluren wollen, daß hemmende Apluate in Inelektrotomus versetzt wiirden, und Kaiser 1594, hat die Wirkung des konstanten stroms als rhythmisehe Erregung des Herzens zu interpotieren eresucht, inden das Iler\% durch die erste Kontraktion eine Miderstandsverïndermug er\%enste, welche hein Aufhören den Reiz fïr die nächste

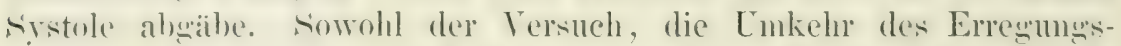
enesetzes die iblogens nach Terworn anch bei Protisten besteht als eine scheinbare hinzustellen, als anch das Bestreben, die Wirknug des konstanten stroms auf rhythmische schwankungen desselben zuriokzufiihren, diurten schwerlich der 'Tatsache segeniiber aufrecht erhalten werlen kïmnen, daß es war nicht nötig ist, das wanze Herstiick zu durchströmen. Wenu man irsendwo an stillstehenden Her\%en zwei Elektroden anfsetzt, deren Alstand nux $0,5 \mathrm{~mm}$ beträ口t, so treten bei derselben stromstälie rhythnische Pulsationen ein, bei der man sio bei Durchströnung des sanzen Her\%ens erhält. Man kamn den Versuch anch mit dèm gnleichen Erfolg̈ in der Weise ausführen, daß man von der Kammer oder Vorkammer einen langen, dümen vitreifen su abtrennt, daß el nur durch eine diumme Brỉicke mit dem Rest zusammenhäng und das periphere Ende desselben durchströnt. Grenen die Auslegume Kaisers sind anch von Langendorf 1994 und 1895 , nurl Trendelenhur@ 1900) sewiehtige Bedenken erhoben. Vor allen dïrte sie durch den von Trendelenbury geführten Nachweis widerlent werden, daß die rhythmischen Kontraktionen die Öffnung des stromes hisweilen lange iiberdanern. Danach wirl man also im konstanten strom an sich einen Reiz sehen diufen, der durch die strukturen des Herzens selber in einen rhythmischen mugewandelt wird. Die rhythmische Aktion ist hier angenscheinlich dureh dieselben Vonente bedingt, welche auch andre kontinuierliche Reize mit rhythmischen Effekten heantworten lassen. Ich erimnere hier noch eimmal daran, daß auch bei Reizung der Nerven von Aplysia mittels des konstanten stroms rhythmische Kontraktionen zustande kommen [A. 407]. An eine Änderumg des Leitungswiderstandes wird hier jedenfalls nicht gedacht werden können.)

Einige Versuche, die ich mit konstanter Durchströmung bei cotylorhiza anstellte, fïhrten zu einem riemlich nangellaften Resultat. Ciffunum und sohließung lösten Kontraktionen aus; wälnend der S'chließung traten aber nur vereinzelte P'ulsationen ein. Ich bat dam llerm v. Uexkiill noch einige Versuche für mich anzustellen, welohe (P) heitwilligst an Rhizostoma ansfïhrte, wofiur ioh ihm hier nochmals

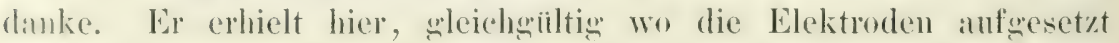
wurlen, bei rinem Elektoolenalstand von I an mol von einer stromstiolie von 20 Nillianpere ab rhythmische Kontraktionen des sanzen 
Tierstiicks. (Ich rermute danach, daß ich seinerzeit bei meinen Versuchen zu geringe Stromstairken angewandt hahe.) Also auch

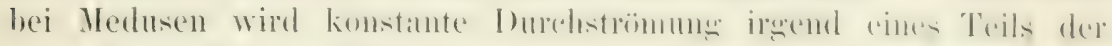

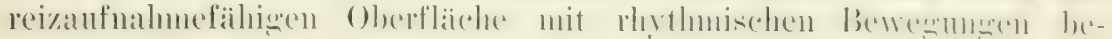
antwortet.

Auch auf chemische Reize hin führt sowohl das zum Stillstand

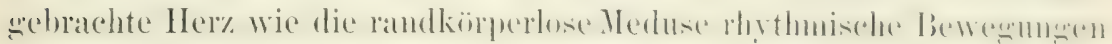
aus. Für das Herz liegen viele derartige Angaben vor; so können

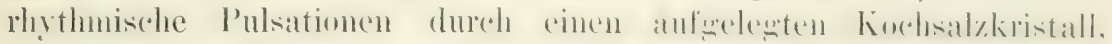

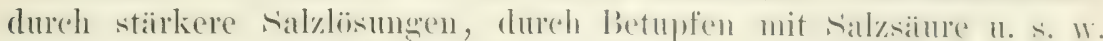

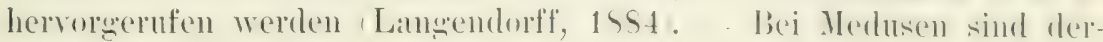
artige Versuche zuerst ron Loeb (1900) ausgeführt worden. Loeh

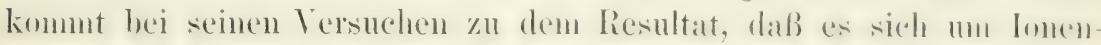
wirkmgen handle, mol zwar wäbe es rhythmusanrexpende lonen wor allem Xas und rhythmushindernde Fonen $k$ und ('a). Wird eine (ioniennema in zwei Teile geschnitten, von denen der eine den Randring enthält, der andre aus dem Glockenzentrum besteht, so schloigt in Seewasser, wie wir oben gesehen, nur der erstere weiter. Bringt er nun das Zentrum in isotonische Kochsalzlösmug, so füng̈t es wieder zu schlagen an; wird dagegren der Rand in eine Lösmng grehraleht, welche viel Car und $\mathrm{K}$ enthält, so hört er mit den rhythmischen bewermugen auf. Außerdem zeigte sich, daß das normale 'Tier um so mehr Kontraktionen in der Minnte ansfiburt und dab die P'ulsationsteihen un so lïnger sind, je mehr $\mathrm{NaCl}$ das Wasser im Verhältnis zu Ca und K enthält. Er zieht den SchluB, dak in den Randliörperne, rom denen normalerweise der Rhythmus ausgeht, das Verhältnis rom Nal ('a + K größer sei als in den übrigen Teilen der Glocke.

So interessant diese Versuche sind, so glaube ich doch, daß Loeb

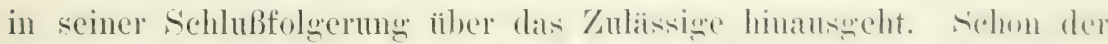
Cunstand, dalh die 'Temperatur und gewisse Reize anf den Rhythunueinen starken Einfluß haben, durfte, soweit sich dis in durenblick ïherblicken läßt, einer so cinfachen dhemisch-physikalischen Er-

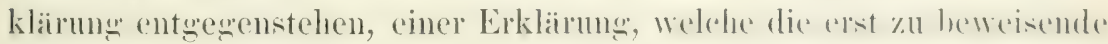
Ansicht zur Grundlage hat, daß der Rhythmus in der Hauptsache

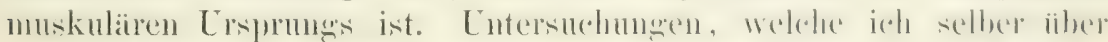

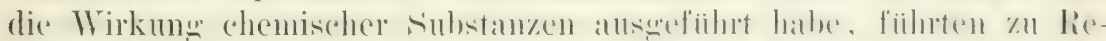

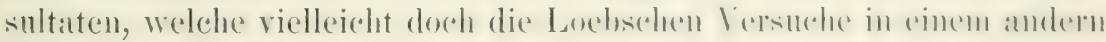
Licht erscheinen lassen.

Da ich Gonionema nicht zur Verfïgumg hatte, habe ich meine Versuche an Carmarina, Cotylorhiza und vor allem an Olindias Miillerii ausgefilitrt. Unzweifelhaft richtig erscheint es mir, daf $\mathrm{NaCl}$ am meisten geeignet ist, um rhythmische Kontraktionen an randlosen Tieren auszulösen. Die Zahl derselhen ist aber bei manchen Arten nur gering (Cotylorhiza, Carmarina), wem man das Tierstiick: 
wie Loeb es tat, in eine dem Seewasser äquimolekulare Lösung bringt. Wie bereits $r$. Uexkiill gezeigt hat, treten aber auch wieder Pulsationen auf, wenn nicht das ganze Tierstiick der $\mathrm{NaCl}$ - Wirkung ausgesetzt, sondern nur an einer

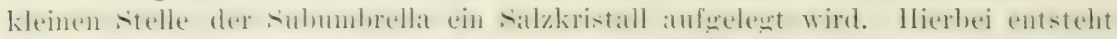
natürlich an der betreffenden Stelle cine hypertonische Lösung, man erreicht aber auch denselben Effekt, nur mit geringerer Wirkungsdauer, wenn man mit dem P'insel auf eine freiliegende Stelle eine Lösung von Kochsalz heraufbringt, welche isotonisch oder schwach hypertonisch ist. Daraus geht zunïchst hervor, daß $\mathrm{NaCl}$ jedenfalls nebenbei auch die Fähigkeit hat lokal zu reizen. Diese Eigenschaft einen lokalen Reiz alozgeben, kommt auch Kalimmsalzen Acetat und Chlorid) und andern Salzen zu.

Vermehrung des $\mathrm{KCl}$ soll nach Loeb normale Tiere zur Ruhe bringen und zum stillstand getrachte Tiere nicht zu Kontraktionen anreizen. Ich habe dies für Carmarina, besonders aber für Olindias nicht in vollem Maße bestätigen können. Wurde der Gehalt des Seewassers an $\mathrm{KCl}$ auf $1 \%$ gebracht, so wurde die Zahl der rhythmischen Bewegungen normaler Tiere zunächst nicht unerheblich vermehrt, wurde dann geringer und war nach ein bis zwei Minuten gleich 0. Randkörperlose Tiere begannen in derselben Lösung meist wieder zu pulsieren - bis zu 25 großen Pulsationen - um nach spätestens einer Minute wierler stillzustehen. Dieser Stillstand berult nun aber nicht a uf einem Nangel an Anregung zu rhythmischer Bewegung, sondern auf direkter Lähmung. Während sonst bei stillstehenden Medusen jede Beriihrumg und jede faradische Reizung mit sicherheit Kontraktionen hervorruft, kamm man nach einem zwei Minuten langen Verweilen in der KCl-reichen Lïsung so stark reizen, wie man will, es treten keine Kontraktionen ein. Diese Lähmung wird aufgehoben, wenn man die Tierstiicke (oder die ganzen Tiere in nomales seewasser zurückloringt. Daß die normalen Tiere bei Wiederkehr der Erregbarkeit nach dem Zuriickbringen in Seewasser ihre rhythmischen Bewegungen wieder aufnehmen, kamm nicht befremden; a uffallend ist es aber, daß auch die randlosen Stücke eine Zeitlang pulsieren. Dies tritt mit größerer Sicherheit ein als beim Verbringen in die KClreiche Lösumg. (Es kamen in einzelnen Fïllen 50-70 große und regelmäßige Pulsationen zur Beobachtung.)

Längere Reihen von rhythmischen Bewegungen bei randlosen Olindias erzeugte ich, wenn ich sie in Seewasser, dessen KCl-Gehalt nur um $0,25 \%$ vermehrt war, brachte. Hier können bis zu 75 Pulsationen erfolgen. Nach dem Aufhören derselben bleibt die Erregbarkeit noch eine Zeitlang erhöht, so daß man auf einen einzelnen mechanischen Reiz, auf den sonst nur eine Systole erfolgt. Reihen ron drei his fünf Kontraktionen erhiilt. Anch faradische Reizung, welche bei Olindias somst nie eine Nachwirkmng erosih, giht hier nach Anfhebung des Reizes eine Nachwirkung ron drei bis acht Kontraktionen. Allmählich tritt damn auch hier eine depressive Wirkung ein, welche aber nie bis zu vollkommener Unerregbarkeit führt.

Danach muß ich die Behauptung aufstellen, daß eine verhältnismäßige Vermelırung des KCl-fichalts z un ä chst reizend wirkt (Pulsationsvermehrung oder Anregung zu solchen) und daß sich erst weiterhin die von Loeb beschriebene, depressive Wirkung kund tut. (Die exzitative ist nur bei wenigen Arten ausfreprochen vorhanden und seheint ihm daher entgangen zu sein.) Die depressive Wirkung besteht aber in einer Erhöhung der Reizschwelle, welche bis zur vollkommenen Lnerregharkeit fiihren kam. (iegen die Lasehsche sichluffolgermog, dafs die Na-Ionen das anregende Element seien. oder wenigstens gegen ihre fe-

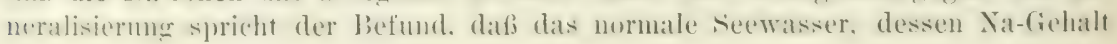


ja nach Loebs Ausicht nicht ausreicht, um das randlose Tier in Pulsationen zu versetzen, nach voraufgegangener Behandlung mit zuviel $\mathrm{KCl}$ eine ganze Zeitlang rhythmische Kontraktionen auslöst.

Mir scheint aus diesen und den folgenden Versuchen hervor-

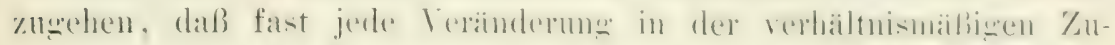

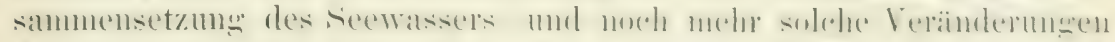

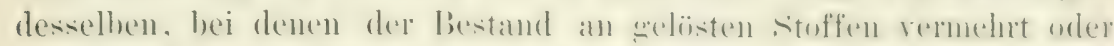

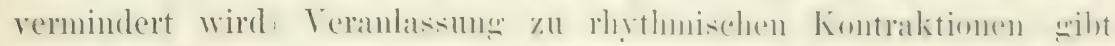

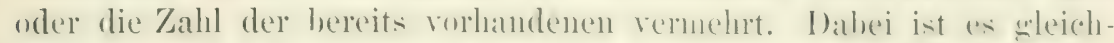

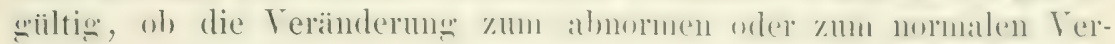
hältnis hin stattfindet. Bei manchen Arten kommt es nicht zu wirk-

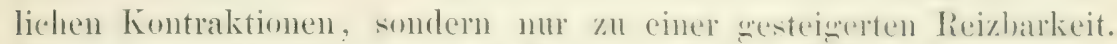

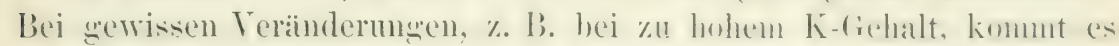
sekmudär zu einer depressiven Wirkmon, weloles bei almom lohem

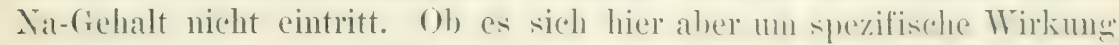
der Metallionen handelt, scheint mir zweifelhaft, weil sich älnuliche Wirkungen, wie mit KC'l anch mit nichtionisierten Körpern und mit Kohlensäure erzielen lassen:

Bei Einleitung von $\mathrm{CO}_{2}$ in ein Bassin, in dem sich normale und randlose Medusen befinden, wird das Tempo der normalen zunïchst erhöht und die bis dahin unbewegten Stiicke zeigen schwache rhythmische Kontraktionen oder wenigstens erhöhte Erregbarkeit. Nach einigen Minuten wird die Erscheinung schwächer und schließlich (nach etwa $20^{\prime}$ ) hören auch die normalen Tiere auf zu pulsieren. Zunächst ist noch schwache Erregbarkeit vorhauden, die in wenigen Minuten ganz erliseht. Einige Zeit nach dem Zuriekbringen in gutes Seewasser fangen die normalen Tiere wieder an sich zu bewegen, machen dann ein Stadium durch, in dem die Zahl der Kontraktionen weit über die Norm vermehrt ist, $1 \mathrm{~m}$ dann schließlich wieder ihr altes, der Wassertemperatur und Tiergröße entsprechendes Tempo aufzunehmen. Bei den randlosen Tieren zeigt sich stets (nach dem Wasserwechsel) ein Stadium erhöhter Erregbarkeit, in dem häufig einige selbstïndige Kontraktionen zustande kommen.

Bei Zusatz von Rohrzucker zum Seewasser geraten normale Carmarinen und Olindien in wilde Kontraktionen, die bald in Lälımung ïbergehen. Desgleichen werden randkörperlose Tiere zu lïngeren Pulsationsreihen $(50-60)$ veranlaßt. Beim Zurückbringen in reines Seewasser treten zunäichst wieder Pulsationen ein, die der normalen Ruhe weichen. Die nötige Zuckermenge ist so gering, daß die Veränderung des osmotischen Drucks wohl kaum eine Rolle spielt. Versuche mit äquimolekularen Lösungen habe ich leider nicht ausgefuihrt. (Nach Loebs Angaben haben nichtionisierte, indifferente Körper keine Wirkung auf den Rhythmus.) Daß Alkohol rhythmische Kontraktionen anslösen kann, ist schon oben erwähnt (S. 359); von Essigsaiure ist es bereits durch Romanes festgestellt.

Sicher ist aus dieser Zusammenstellung ersichtlich, daß die zum Stillstand gebrachte Meduse in ebenso vollkommenem IraBe wie das IIerz duch che- 
mische Becinflussung zum ermeuten Schlagengebracht werden kann. Innerlath, dieser Mittel wird man jedenfalls 11 nterscheiden mïssen zwischen solchen, welche in derselben Weise, wie der faradische Strom, als lokaler Reiz wirken und denen, welche die Erregbarkeit des Gewebes erhöhen. Eime ledig-

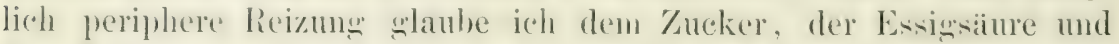
der Kohlemsïure, vielleicht auch dem Kalinmehlorid zusprecehen zu

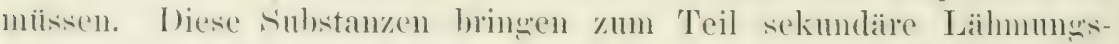
ersoheimungen hervor. Dadureh, daf sie als peripherer Reiz wirken. hewirken sie mittelbar eine gesteigerte Erreglarkeit. Ilkohol wirkt in schwachen Dosen sicherlich nicht als peripherer Reiz, weil die Kontraktionen erst nach längerer Zeit eintreten. Ich walube annehmen zu diufen, dab hier eine imnerliche nud direkte steigermung der Erregharkeit vorlient. Sowohl reizend, als anch direkt die Errex-

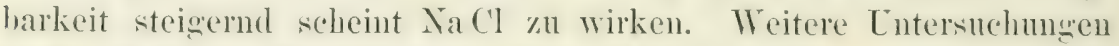
sind hier aber jedenfalls noch sehr wiinschenswert.

Ich fasse noch einmal zusammen: Beim nicht pulsierenden Herzen (oder Teilen desselben) und bei stillstehenden Medusen und Medusenstücken wird jeder einmalige Reiz, sei er mechanisch oder elektrisch, nur mit einer einzigen Kontraktion beantwortet. Dauereize, gleichgiiltig, ob sie aus einer schnellen Aufeinanderfolge ron Einzelreizen bestehen faradische und wiederholte mechanische Reizung', oder kontinuierlich sind (konstanter. Strom, chemische und osmotisch Reize), rufen rhythmische Pulsationen hervor. Die Zahl derselben ist in gewissen Grenzen von der Starkedes Reizes abll ä $1 \mathrm{~g} g$ i g:

Jeder 'Teil des Herzens und der Meduse ist also rhythmischer Bewrenumen fähig, wenn ihm nur genïgend starke Reize zusefülnt werden. Das nötige Reizquantum ist bei den einzelnen Abteilungen des Herzens und den verschiedenen Regionen des Medusenkürpers, noch mehr bei den rerschiedenei Mednsenaten sehr verschieden swob, und hierauf scheint es zu beruhen, daß manche Medusenarten nach Fortmahne der Randkïrper und das IJe\% ohne vinus anscheinend ron selber wieder anfangen zu schlasen, während dies bei andern drten and bei der sogenannten Herzspitze nicht der Fall ist. Man wird vermuten diufen, wie das Goltz zuerst für das Herz getan hat und wie dies für manche Medusenarten bereits bewiesen ist, dab okkulte Reize den Wierlerbeginn der P'nlsationen versehulden. Eine weitere

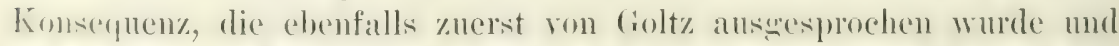
diu suater von Rosenthal akzeptiert worden ist, ist die, dab anch die

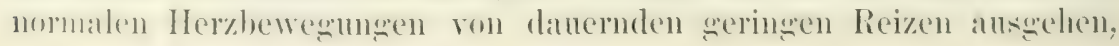




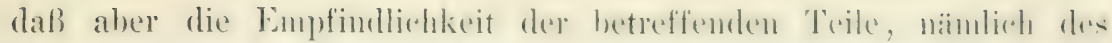
Sinus, so groß ist, daß es nicht gelingt, alle Reize von ihm fern zu

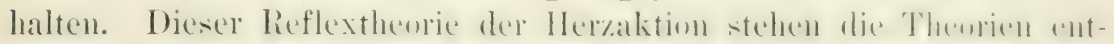

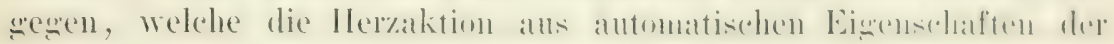
Herzganglien (Volkmann, Langendorff und viele andre) oder aus

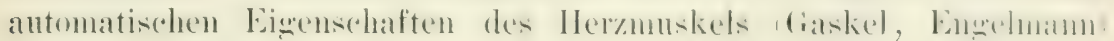
erklairen wollen.

Es soll weiterhin gezeigt werden, inwiefern die Merhsen ge-

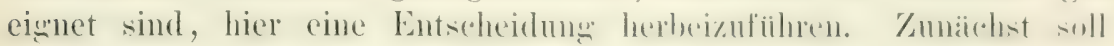
aber die Analogie zwischen Her' und Meduse noch weiter durchgefuilırt werden.

Refraktäres Stadium, Extrasystole und kompensatorische Ruhe.

Im Jahre 1876 zeigte Marey, daß das Herz während einer gewissen Zeit der Pulsation nicht reizhar ist. Die Ansdehnume dieses Refraktärstadiums sehwankt individuell und ist in hohem Malje rom der 'Temperatur und der stärlie des Reizes ablüngly. Marey stellte diese auBerordentlich wichtigen Tersuche in der Wreise an, dab er dis normal schlagende, im Körper befindliche Froschler schreiben livb und der Kammer in den verschiedenen stadien der Yuckumskinve einen Induktionsschlag rersetzte. Traf der lieiz das Her\% während der Systole (bei mittlerer Temperatur), so war el mwirkam; er rief aber eine nene Systole (systole provonué, Extrasystole) heror, wem er an Anfang der Diastole angevetzt wurde. Je suäter der Reiz angesetzt wird, desto schneller tritt die Extrasystole ein und destor arober ist ihre stälie. Bei höherer 'Temperatur nimmt die Anslehnung des Refraktärstadiums ab.

Diese Befunde wurden ron Engelmann, Lowén und andern bestätigt und erweitert. Die Erscheinmgen treten anch am answeschnittenen, sinuslosen Herzen in Erscheinumg. Folgen zwei Roize dicht anfeinander, so ist der zweite unwirksan, solange er in das liefruktailstadium der durch den ersten hervoruerufenen Znckung fällt Fig. s(i).

Die Kurven wurden in folgender Weise hergestellt: Die isolierte Kammer lag auf einer Korkplatte und war mit einem Schreibhebel versehen, durch dessen Pelotte Induktionsschläge zugefïhrt werden konnten. Am Kymographion waren zwei Kontakte angebracht, welche mit zwe getrennten Induktionsapparaten in Verbindung standen. Die bei Aufhebung der Kontakte entstehenden Öffnungsschläge wurden den Herzelektroden zugefuihrt. Der eine Kontakt stand fest, der andre komte in seiner Lage zu ersterem durch eine Sehraube versehoben werden, so daß beide Schlëge mehr oder weniger rasch aufeinander folgten. Um den Moment der zweiten Reizung auf der Kurve zu markieren, wurde die Methode angewandt, einen Induktionsfunken von der Spitze des Schreihhebels zur Trommel des Krmographions durehschlagen zu lassen. Diese in Deutschland wenig angewandte Methode hat den großsen Vorteil, daßs man keine Projektion 
auf den Kurven vorzunehmen hat, weil der Funke sich auf der Kurve selbst als

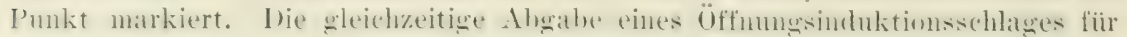
das Herz und für die Reizmarke wurde in der Weise bewerkstelligt, daß der

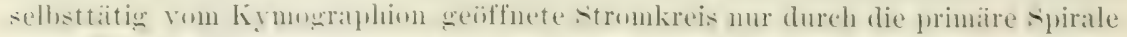

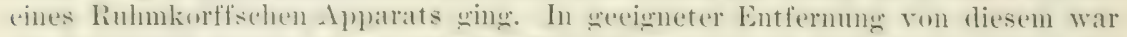
die sekmolïre spirale eines einfahen Induktimsilpluarats anfuestellt, welehe mit den Herzelektroden verbunden war. Auch mit Hilfe des Apparats für mechanische Reizung ließen sich Extrasystolen gut hervorrufen (Fig. 85 B.).

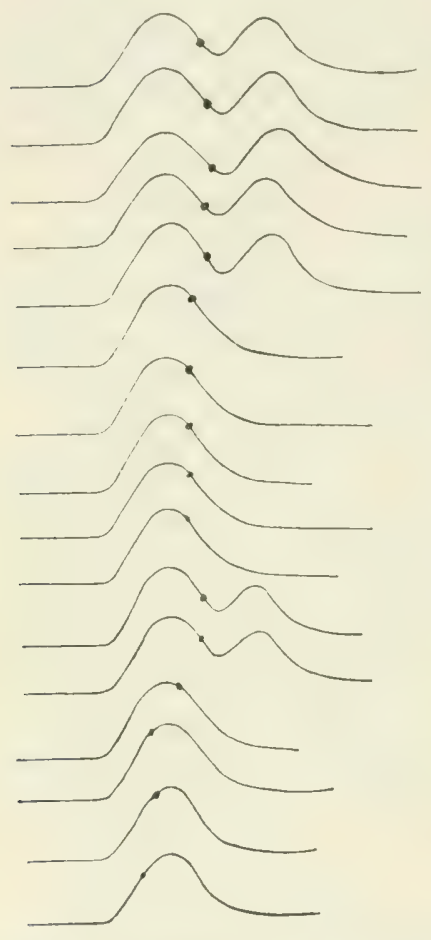

Vig. S6. Bestimunume der Ausclehnung lee Iefraktärstadiums an der isolierten Kammer von Rana temporaria bei $14^{\circ} \mathrm{C}$.

Durch die Entdeckung des Refraktiirstadiums ist es Marey gelungen, die meisten der im vorigen Abschnitt besprochenen Erscheinungen verstaindlich zu machen. Daß das Her\% bei konstanten und tetanischen Reizen mit rhythmischen Pulsationen antwortet, daß die Zahl der Pulsationen nur von der Stärke des Reizes, aber nicht von der Anzahl der Unterbrechungen (beim frequenten elektrischen und mechanischen Reiz) abhängt, daß die Maximalzahl der Pulsationen beim Erwärmen zunimmt, alles das ist durch die Feststellung, daß ein Refraktairstadium existiert und von Temperatur und Stärke des Reizes in seiner Ausdehnung abhängt, erklärlich geworden. Gewisse Schwierigkeiten bietet aber ein andres Phänomen, welches Marey gleichzeitig mit dem Refraktärstadinm beschrieben hat: die kompensatorische Ruhe.

Narey fand, daß anf jede Extrasystole (beim spontan schlagenden Herzen) eine verlängerte Panse (kompensatorische Ruhe) folgt, und zwar ist dieselbe $u m$ soviel länger wie eine gewöhnliche Panse, als die Extrasystole die vorhergehende Panse verkïrt hat. Vit andern Worten: vom Begimn der letzten Srstole bis zum liegimn der nïchstfolgenden vergeht grade soviel Zeit, wie zwei normale Frstolen mitsant den zugehörigen Diastolen (und P'ausen! in Anspruch nehmen (Fig. 5!). l)as , grrade soviel" muB natiurlich nicht allzn genan genommen werden. Yanchmal stimmt es zwar, soweit sich das mit unsern Mitteln fest.

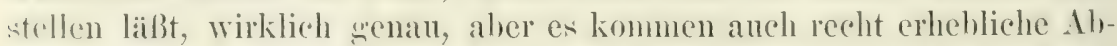
wrichungen ror siehe Lowén, 1866 und Engehmam, 1495). In der Rewel werden diese aher noch später ausgeglichen. Ist $z$. I3. die kompensatorische liuhe zu kury, so ist meist anch die nächste Panse noch verlingerert. 


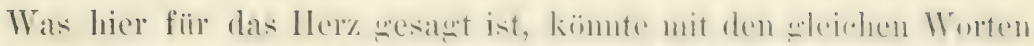

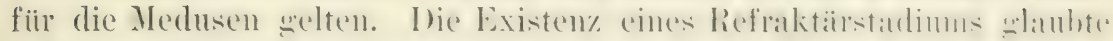
ich zwar nach Versuchen, wie sie im vorigen Abschnitt besehrieben

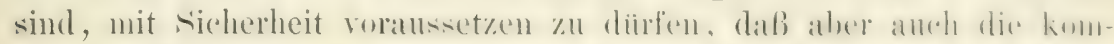

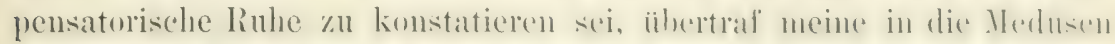
gesetzten Hoffnungen. ${ }^{1}$ ) Ein Refraktärstadium wa bei allen

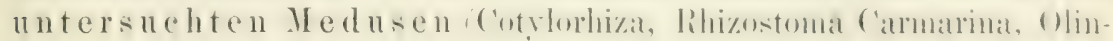
dias) mit Sicherheit zu konstatieren, und zwar nimmt es bei normaler Wassertemperatul stets zum mindesten die manze sistole ein. Die Latenz ist anch, wie beim Herzen, $n \mathrm{~m}$ so größer, je $n$ äler der Reiz dem Ende des Refraktästadium liegt. Bei normal schlagenden Tieren ist auch nach jeder Extrasystole eine kompensatorische $R u h e$ zu beobachten, jedoch kommen

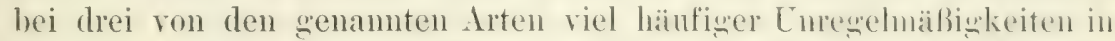
ilner Daner vor, als beim Ilerzen. Das liegrt wohl in der Hamptsache

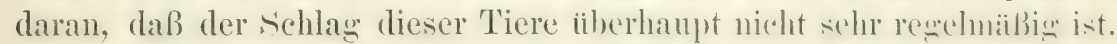
Bei Rhizostoma ist dagegen die Dauer der kompensatorischen Ruhe grade so gesetzmäign, wie beim Herzen.

Systematische Lntersuchungen iiher die Ausdehnung des licfraktärstadiums komnte ich bei den Medusen nicht vornehmen, weil ('s mir an geeigneten Aplaraten fehlte. Die Tatsache an mol fur sich kumbe aher mit vicherheit konstatiert werden isiehe Fis. 57 \% - Auch bei den Medusen ist die Ausdehmum des Refraktärstadiums hei starken lieizen kleiner als hei schwachen, eben wirkamen Reizen. Dei höherer Temperatur erfäht die Daner des Refraktästadims eine weitere und starke Einschrainkung. Das Refraktärstadium läßt sich wie beim Herzen mit der gleichen sicherheit bei nomalschlagenden 'Tieren und bei randkörperlosen stïcken, denen in rerschiedenen Lbä̈nden \%wei Reize zugeführt werden, feststellen. Extrasystolen sind auch hier greich gut durch Induktionsschläze und mechanische lieize hervorzirufen.

Was die kompensatorische Ruhe anhetrifft, so rerweise ich auf die in Fig. 87 segebenen Kuren. Kur Erklärung sei hier now folsendes linzugefiigt: I)ie drei normalen, einer Lxtrasytole vorans-

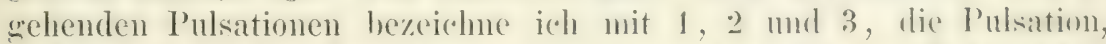
während deren der Reiz angesetzt wirl, nit a, die dere Extrassstole mit $b$, die nächste mit $c$ und so fort. In Kuve $A$ u. $C$ ist $a+b=1+2$ $=2+3=c+d$. In Kurve $E$ ist $a+b<2+3$; dagegen ist $1+2+3=a+b+c$. In Kuve $B$ ist cin Fall abgebildet, der

1) Nach den Vorstellungen, welche Engelmann (1595) iiber das Wesen der

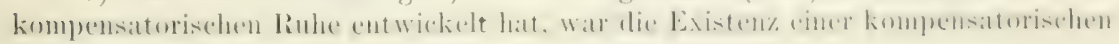
Ruhe bei den Medusen wohl nicht zu erwarten. 


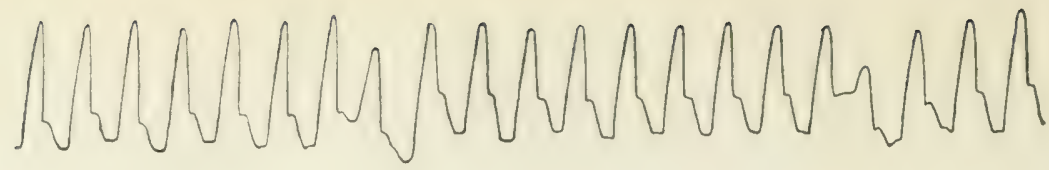
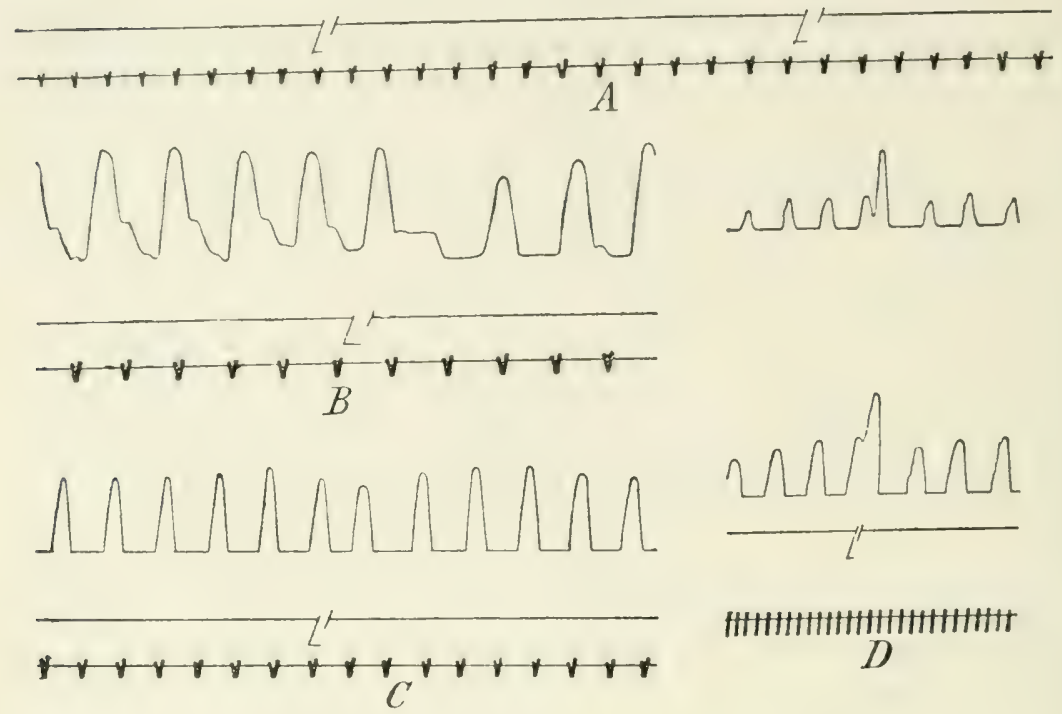

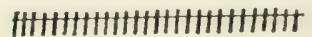
$D$
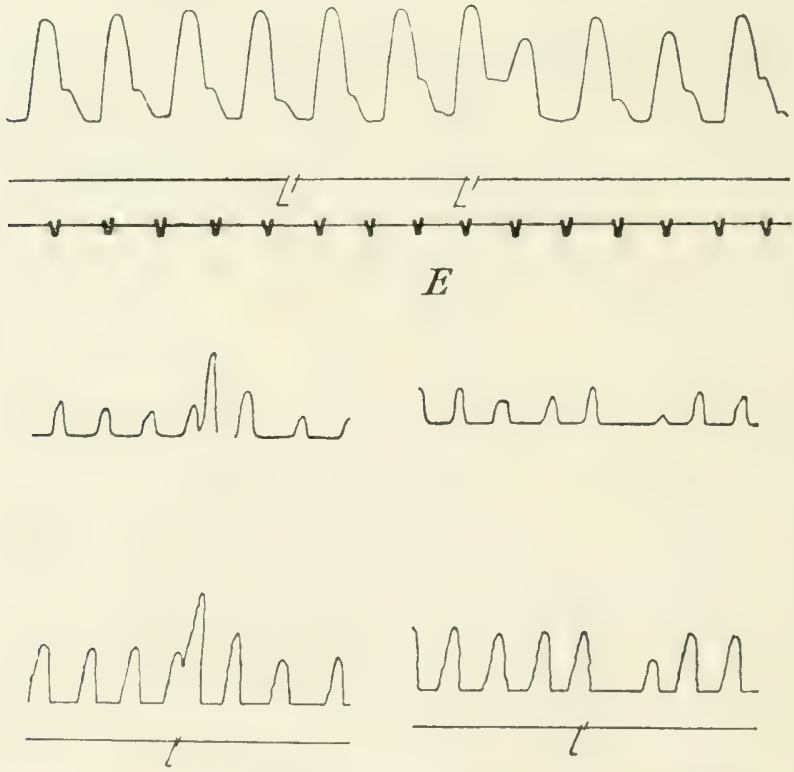

H+1+1+1+1+1+1+1+1+1+1+1+1+1

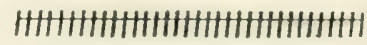
F $G$

Fig. 87. Extrasystolen durch öffnungsschlïge erzengt bei Medusen. $A, B, C$ und $E$ von Rhizostoma, nur von einem Punkte des Randes geschrieben. In $A$ und $C$ entspricht die Länge der kompensato- 


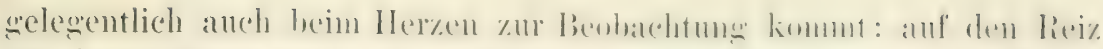

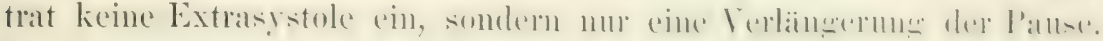
Die Superposition, welche bei cinigen Kurven ron Cotylor\}iza zum

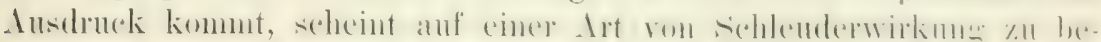
ruhen, doch kam ich dies nicht sicher beweisen. Bei Rhizostoma

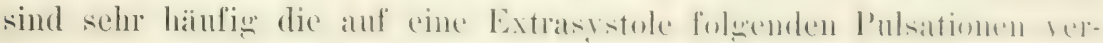
kleinert und steigen treppenartig wieder zur Nolmalhöhe an.

Die Störung der Synchronitat beim Auftreten einer Extrasystole.

Bei spontan schlagenden Medusen, welche von zwei gegeniibel-

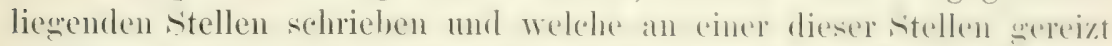
murlen, richtete sich zuerst meine Infmerksumkeit anf cine Erschoinung, die ich daraufhin anch beim Heren wiederfinden komnte. sulange die Mednse, sich sellst ïberlassen, ihre l'ulsationen ansfiihnt, begiunt jede Systole an allen Stellen des Schimes gleichzeitig und der Verlanf zweier ron verschiedenen stellen anfgenommenen Kurven ist gnanz parallel. Kleine Abweichmugen kommen an den Kurven zur Beobachtung, lassen sich aber immel darauf zu-

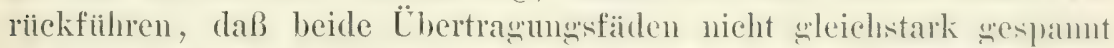
sind. (Ist der eine Faden etwas loser, st) zeichnet die entsprechende

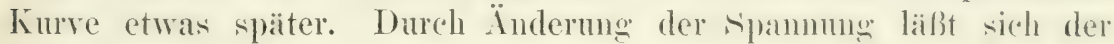
Fehler ausgleichen oder ins Gegenteil reråndern.) Wird nun a n der. einen'Stelle ein wirksmer. Induktionsschlag angesetzt, so tritt die Extrasystole an dieser Stelle wesentlich frïher ein, als an der gegenïberliegenden. Bei der nächsten oder ähemächsten Nomalpulsation ist die sirnchronitait wieder hergestellt. An Kurven, welche mit langsamer Trommelbewegung geschrieben sind (Fig. ST, D und Fr), kinnmt dic Störung darin zum Auselruck, daß an der nicht wereizten sitelle die Extrassstole der Kurve der rorhergehenden l'ukation an riner tieferen stelle anfsitzt. Infolge des späteren Eintrifts ist hier elie Extrassistole meist anch größer als an del direkt gereizten seite. liei schunllerer Trommelbewesum komment der zoitliche Listersehied deutlicher zur Geltung.

Da die Pulsationen bei den Medusen sicherlich von den Rand-

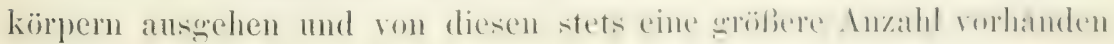

rischen Ruhe durchaus dem fïrs Her\% aufgestellten (aler auch hier nicht immer erfiillten) (iesetz.

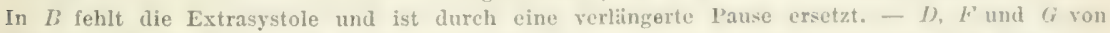
Cotylorhiza. Es ist von zwei gegeniuberliegenden l’unkten des Iankes geschrichen. 1)er liciz wirkt auf die Stelle, welche der unteren Kurve entspricht. In $D$ ist die kompensatorische liuho deutlich. in $G$ fehlt die Extrasystole und ist dureh eine verlängerte Pause erselat. Der Vergleich. der oberen und unteren Kurve in $D$ und $F$ zeigt. daB die fiix gewöhnlich bestehende Syneluronitait beim $A n-$ setzen ciner Extrasystole gestürt wird. Zeit $=0,48 \prime$. Darïler die Ireizmarke. 
ist, so hat sich schon Romanes die Frage gestellt, ob immer alle limulkürper zn wleicher Zeit in Tätigkeit sind. Für uns sind an dieser stelle mur die Versuche interessant, anf (rrmud deren er dies für wahrscheinlich hält: nalum Romanes alle Randkïrper his anf einen fort, so sah er, dab die Kontraktionswelle ron den einen noch vorhandenen Randkïrper sich ïber den iibrigen 'T'eil der (ilocke anshreitete. Besonders deutlich wurde dies, wenn er den Medusenkïrper zu einen langen Iand anfrollte, an dessen einem Ende der Randkörper saß. - Es ist mzweifelhaft richtign, daß in dem letzteren Fall das randkörperfreie Ende in der liesel viel spaiter zur Kontraktion kommt, als das andre Ende. Bisweilen kann man, das gebe ich zu, a uch ohne A ufrollung eine Störung der Synchronität beobachten, derart, daß die sieite, wo der Randkörper sitzt, sich etwas frïher kontrahiert als die wegenuberliegende. Dies ist aber nur dam der Fall, wem hei der Randkürperfortnahme srößere und radiärwärts tief einschneidende Verletzungen des schirmrandes stattgefunden haben; sind die dem Rande nahegelegenen Partien intakt, so bleibt die normale Syn('hronität, soweit das mit unsern Mittehn festzustellen ist, erhalten. Weiter unten werden Befunde mitweteilt werden, die diesen Entersehied zu erklären instande sind.) Wem aber auch ein Lntersehied in Einsetzen der Systole an der Stelle des Randkörpers und an der gregeniberliegenten Stelle des Schimes zu konstatieren ist, so ist dieser niemals auch nur annähernd so groß wie derjenige, welcher beim Hervorufen einer Extrasystole auftritt, wleichgïltig, ob sie rom randkörperfreien Ende oder in der Nähe des Randkörpers ihren Ursprung nimmt (Fig. 88, A).

Instruktiv ist auch die Kurve 85 B. Gelegentlich beobachtet man, daß ein 'Tier mit nur noch einem Randkürper oder ein großer, breiter 'Tierstreifen, an dessen einem Ende noch ein Randkörper sitzt, seine Kontraktionen ganz einstellt oder durch sehr lange Pausen unterbricht. Es sieht gewissermaßen so ans, als ob die im Randkörger sich ansammelnde spannkraft nicht mehr geniigt, das ganze Tier in Bewegung zu versetzen. ischneidet man nämlich den größten Teil des Körpers fort, so füht der kleine, am Randkörper verbliebene liest meist wieder für sehr lange Zeit scine Pulsationen aus.) Bei solchen Tieren genïgt nun die Zuführung eines kleinen lieizes, un wieder (eine oder wenn der lieiz konstant ist, mehrere Pulsationen anszuliosen. fretzt man einen an sich anch für ein randkörperloses Tier wirksunen Reiz am randkörperfreien Ende an, so sieht man eine Kontraktion zum Randkörper hinlaufen, kurz darauf antwortet aber das ganze 'Tier mit einer zweiten synehronen Zuekung, welehe stets ausbleibt, wenn der liandkörper entfernt ist. Der Reiz geniigt also dazu, eine Kontraktion aus- 


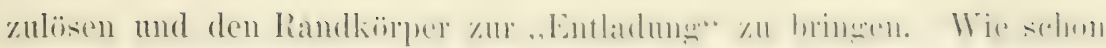
gesagt, zeigt die erste Kontraktion den Charaker einer Extrasystole (keine Synellonitä), die zweite deneiner Spontankontraktion Synchronitait des ganzen Tieres oder strei-
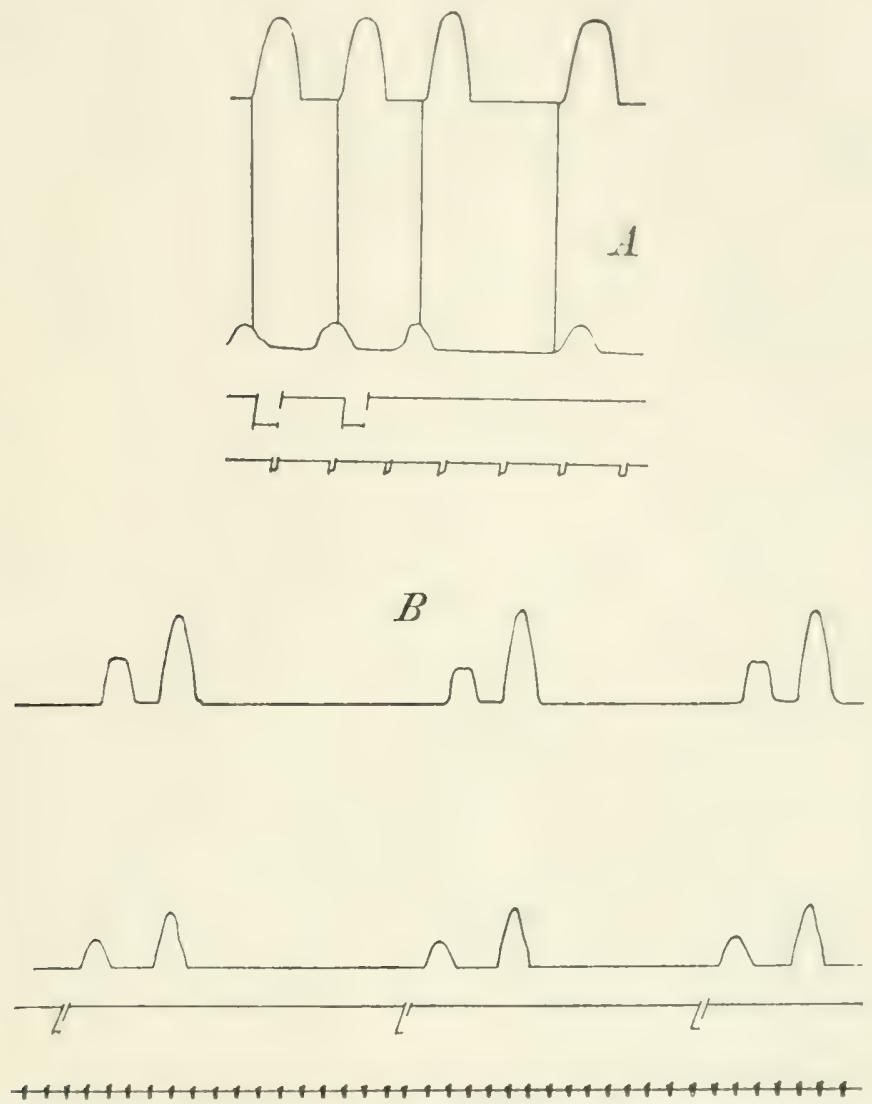

Fig. 88. Störung dex Synchronität bei kiinstlichem Reiz. Cotylorhiza. A Tier mit nur eincm Landkörper dicht an der Stelle, welche der oberen Kurve entspricht. Die untere Kurve ist von der gegenüberliegenden Randstelle gesehrieben; an dieser wird auch der kïnstliche Reiz angesetzt. Dic ersten drei Pulsationen sind durch künstlichen Reiz hervorgerufen: Die gereizte Stelle kontrahiert sich wesentlich früher als die gegenüberliegende (obere). Die vierte Pulsation ist spontan und zcigt vollkommene Synchronität beider Schreibstellen. - I $14 \mathrm{~cm}$ langer Streifen einer Cotylorhiza mit Randkürper an einem Ende. Von diesem Ende aus ist die obere Kurve gesehrieben. Die untere Kurve ist rom entgegengesetzten Ende gesehrieben, an welchem die Reizelektroden liegen. Aui jeden Reiz entsteht eine Zuckung asynchronen Charakters und eine zweite reflektierto Zuckung, welche synehron ist.

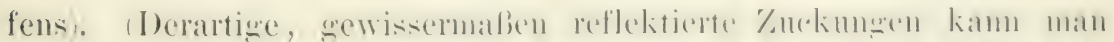

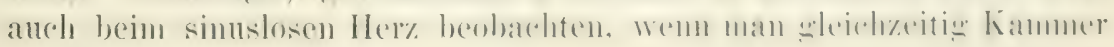
und Vorkammer reizt.)

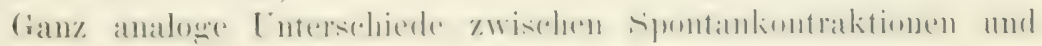


Extraststulen halle ich anch beim Ileren feststellen kömen, nur sind

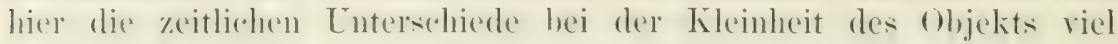
zeringer. Vielleicht sind die Lntersohiede in Wirklichkeit auch hier zienlich wrobs, werden aber dadureh verdeckt, dab durch rein mechanische

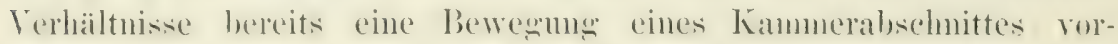
seteizuscht wird, wo er noch in Ruhe verharrt. - Beim spontanen Her\%-

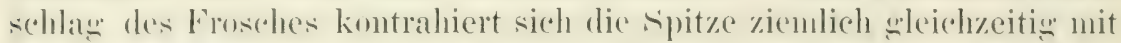
der Kinnmerbasis oder etwas später. I Bein sängetierher\%en sind Fälle heschriehen worden, wo sich die sipitze friiher kontrahierte als die Basis. Diese fiur die 'Theorie sehr interessanten Fälle sollen später gewüirdigt werden.) Groß ist der Untersehied nie. Nun geht die Anrewme \%ur Kimmerkontraktion ja sicherlich vom sinus ans und wird der Kammer dureh den Vorhof vermittelt. Der Reiz wird also auf jeden Fall zuerst zur Basis gelangen und erst spaiter zur spitze. Wenn es sich nun um einen einfachen Leitungsvorgang handelte, so müBte das zeitliche Verhältnis zwischen Basiskontraktion und Spitzenkontraktion nicht verschoben werden, wenn an der basis dureh einen meehanischen oder elektrischen Reiz eine Extrasystole hervorgerufen wird. In Wirklichkeit findet aber eine Veranderung der Art statt, daB die Basis bei kïnstlicher Reizung im Verhätnis zur Spitze früher sich kontrahiert, als wenn der Reiz von der Vorkammer zugeleitet wird (Fig. 89, $B$ und $C$ ). Weniger beweisend ist die Veränderung, wemn sie durch Reiz der Her\%spitze hervorgerufen wird, anch wemn vorher Basis und Spitze synchron schlugen. Dagegen wird eine Aufhehmw der synchronitait dann den Verwleich mit den Medusenbefunden zulassen, wemn sie bei Aufsetzung zweier Hebel anf symmetrisehe P'mkte der Kammerbasis und Reizung des einen Punktes zustande kommt (Fig. 89 A).

In den al)gebildeten Fällen, denen ich eine ganze Reihe ïhnlicher Knurven an die seite stellen kömnte, ist zwar die zeitliche Terschiebung" zwischen der Kontraktion beider Auflagestellen der Hehel nicht so dentlich wie bei den Iledusenkurven (was auch gar nicht zu erwarten gewesen wäre), aber ich glaube doch, daß sie olme weiteres zul elkemmen ist; yor allen Dingen scheint mir die verhältnismäßiæ weringere Höhe der Extrasystole an der direkt erregten stelle in mehreren Fällen deutlich. Iroh golaube nicht, dab sich die geringere Itöhe der Extrasystole an der direkt erregten stelle anf die ,Lokale Diastole“ Rossbachs und Auberts zuriickführen läßt.)

Diese Befunde zeigen, dab der natioliche Reiz sowohl beim IIer\%en wie bei der Veduse einen sanz andern lontraktionsmodus herorruft. als der kinstliche lieiz. Letzterer ist sicher instantan, or wirft 

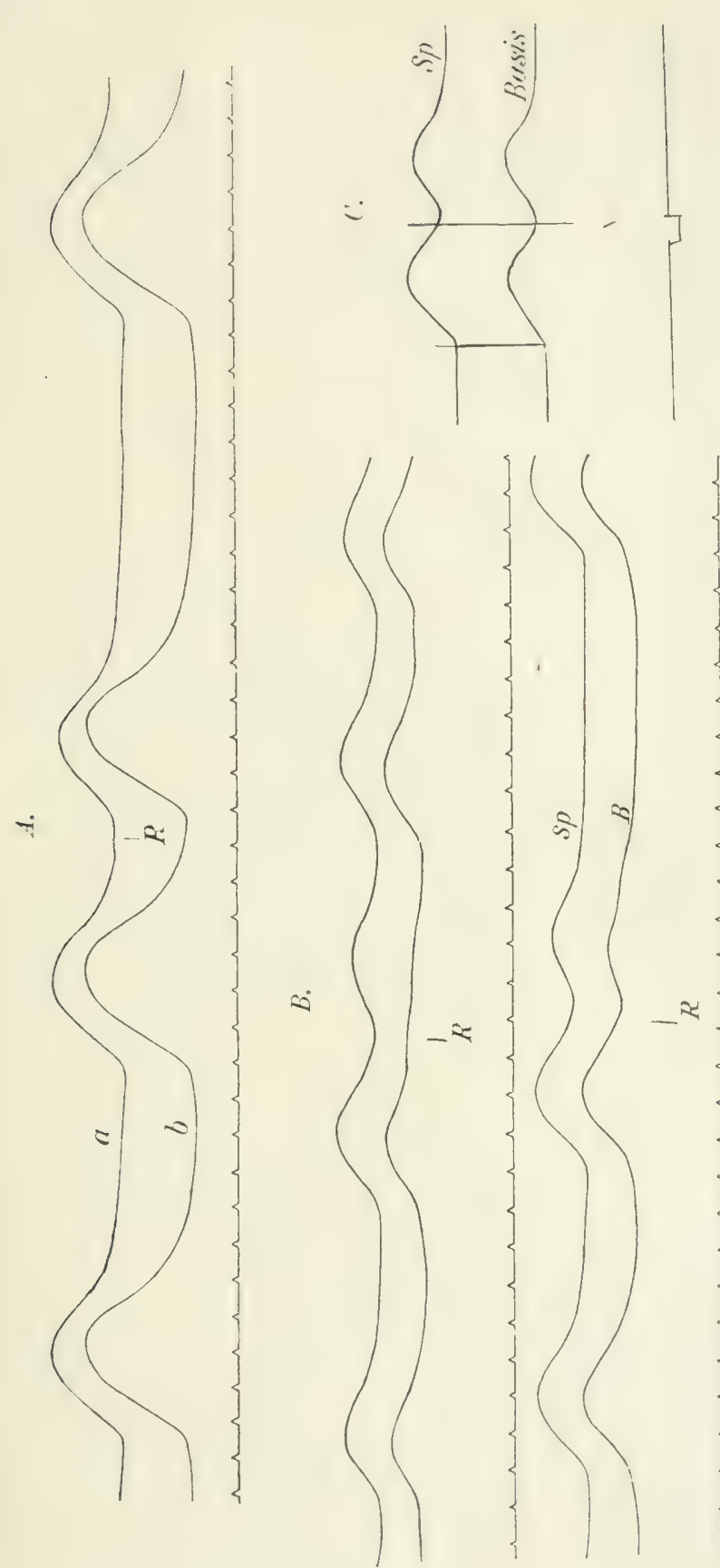

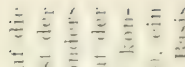

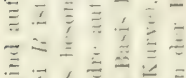

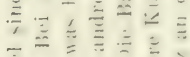

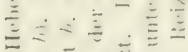

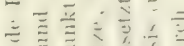

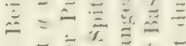

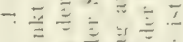

言言言

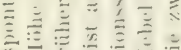

$=$

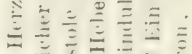

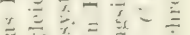

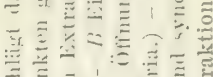

产.

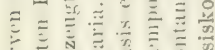

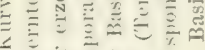

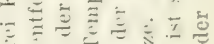

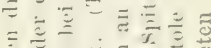

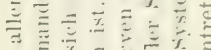

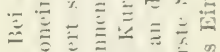

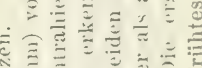

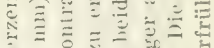

政田

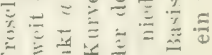

出

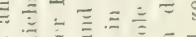

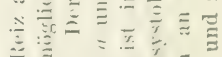

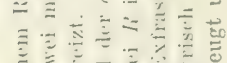

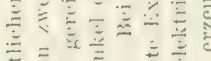

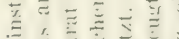

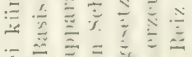

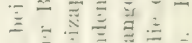

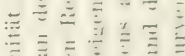

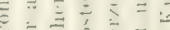

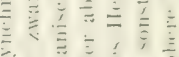

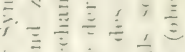

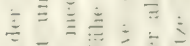

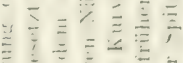

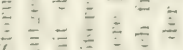

3
$z$

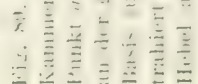


auf einmal an eine stelle des (iewebes eine wroße Menge Reizenergie. Ich nehme an, dal der natioliche Reiz einen andern Verlauf hat, daß er sich mïmlich danernd aber schwach in das fiewebe ergießt und es sewissermaßen in allen Teilen, welche in engerem Zusammenhang stehen, fiillt. Die Entladung kam damn ïherall nahezu wleichzeitie erfolgen. Der Instantanreiz bringt dagewen anf einmal großen Anstoß in das (iewebe, so daß die Entladumg an der Applikationsstelle frïher erfolgt, als der heiz (relegenheit gehalot hat, sich über das ganze Gewebe ansudehnen. Diese Fïllungshypothese scheint mir in andern Versuchen eine Bestaitigung zu erfahren. Ich möchte aher die Veroffentlichung derselben auf eine spätere Publikation verschieben, weil ich noch weiteres Material zu beschaffen hoffe.

Mag nun diese Deutung richtig sein oder nicht, jedenfalls zeigen diese Versuche, daß anch in diesem Punkt eine weitgehende Analogie zwischen Her\% und Meduse hesteht. Nach all dem mitgeteilten Material diurfte der anfang's aufgestellte Satz gerechtfertigt erscheinen, daß Her\% und Meduse physiologisch eine merkwürdige Ähnlichkeit zeigen. Ich halte vom Analogieschlıß sehr wenig; jedenfalls werde ich in ihm nie einen wirklichen Beweis sehen. Inmerhin wird man aber bei einer so weit sehenden Analogie zu der Vermutumg berechtigt sein, daß die materiellen Grundlagen der aufgeführten Erscheinmngen sich sehr ähnlich sehen oder sogar gleichartig sind.

Die Medusen sind physiologisch handlicher und anatomisch besser zuginglich. Wir werden daher zuzusehen haben, inwieweit sich hier eine Erklärung für die angezeigten Erscheinmmen geben läßt, und wenn dies gelingt, werden wir priffen mïssen, ob die Erscheinmngen heim Herzen demselben Prinzip unterworfen werden kömen. Ieh begrime zunäichst mit der Frage, ob die Reizleitung in diesen Geweben nervöser oder muskulärer Natur ist.

Die Reizleitung im Herzen und in der Meduse.

Ich hahe bereits oben den Beweis geführt, daß die Leitumg im Medusenkörper dureh ein besonders, nicht mit der Muskulatur identisches fewebe besorgt wird (S. 86 und 106). Es lieb sich zeigen, daß gewisse Teile der Subumbrella keine Muskulatur besitzen, wohl aber die Fihligkeit Reize zu leiten. Durch Veroleich dieser stellen mit der Glockenoberfläche, welche ïberhaupt nicht reizhar ist, wurde ein hestimmtes, von der Muskulatur und dem gewöhnlichen Epithel ganz verschiedenes Gewebe als dasjenige erkannt, welches die lieizleitung remittelt. Dieses (iewebe breitet sich netzförmig mit eingestrenten zanlen überall da aus, wo Leitungrsfaihigkeit vorhanden ist, auch zwischen den Muskehn selher. Der histologische C'harakter dieses Netmorelis gestattete, es als wahres Nervengewebe anzusprechen, und 


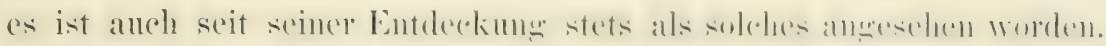
Fur die Medusen liegt also gar kem Zweifel an der nervösen Natur der Reizleitung vor. - Daß das Leitungsvermögen der Muskeln bei

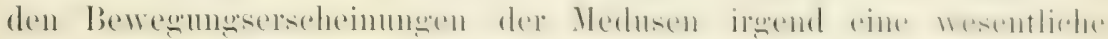

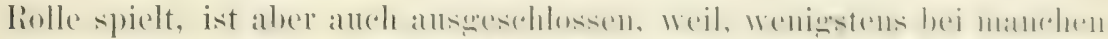

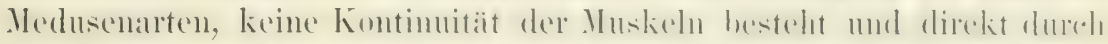

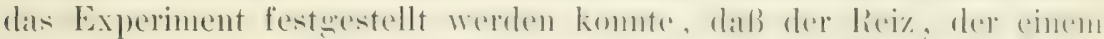

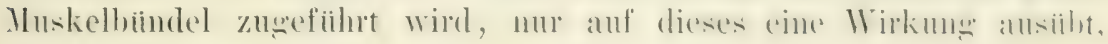
aber nicht zu andern fortgeleitet wird (S. 108).

Auch beim Herzen haben wir neben der Muskulatur ein selı reiches Nervennetz; dariber kann jetzt gar kein '/weifel mehr bestehen (S. 91). Es wirrde dem Unbefangenen nur natiulich erscheinen, wenn wir anch hier dem Nervennetz die Eigenschaft del lieizleitum zuschreiben und ammehmen, daf der liciz nicht direkt mon

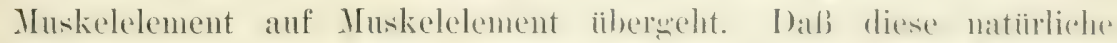
Amnahme ron bei weitem den meisten Physiologen und Klinikern nicht gemacht wird, ist nur ans der historischen Entwioklung zu ver-

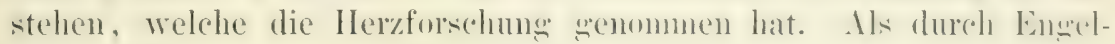
mann (1875) gezeigt wurde, daß man die Kammer eines Frosches in

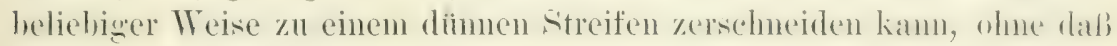

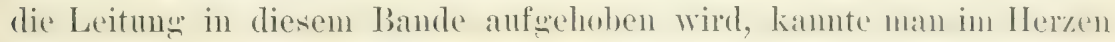

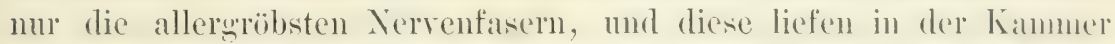

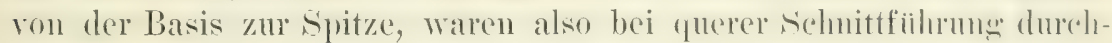
schnitten. Ton einem Nervennetz, einer nervösen Organisation, die

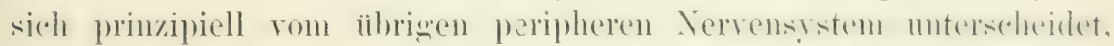
hatte man noch keine Ahnung. Man durfte also ammehmen, daß die Leitung ron der Muskulatur direkt besorgt wiirde, weil man rou

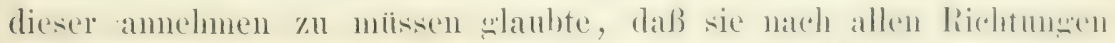
in Znsanmenhang stände. Indere liefunde wurlen fïl die muskuläre Leitung ausgenutzt, Befunde, die aber nur zeigten, daß im Herzen andre Verhälnisse vorliegen, als im skelettmuskelsistem mol dio grade so gut auf eine Besonderheit der Herzuerven, als auf Merkwïrdigkeiten des Herzmuskels schließen ließen.

Als damn die Nervennetze im Herzen durch lianvier, Dogiel, Heymanns und Demoor und andre beschrieben wurden, hatte die Beweiskraft des Engehmannsehen Zickzackrersuchs in Wahrheit ausgespielt, demn es war nun sicher gestellt, daß die nerröse Terbindung:

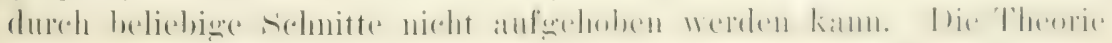
der rein muskulären Reizleitung in Herzen verlor nach diesen l'ublikationen aber nicht an Inhingerschaft. Im Gegenteil! Sic rermehrte sich noch nach dieser Zeit zusehends. - Was denn noch eine so eigenartige Nervenversorgung anderes zu tum haben sollte, als lieize ron Muskelelement anf Muskelelenent zu iibertragen, auf diese Frage 
sind alle Verfechter der Muskeltheorie die Antwort sehuldig seblieben. Entweder wurde die Existenz des Vervemetzes ismoriert, oder es wurke der ehemalige Hamptheweis für die muskuläre Leitume als mwesentlich angesehen und der Acrent jetzt anf die beweise selent.

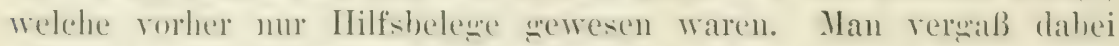
franz, daß diese Hilfsheweise doppelsinniw sind und dab ilmen andre Tatsachen, meist phamalsologischer Xatur gegeniblser stehen, welche ziemlich einsimnig für eine nervöse lbeteiligung sprechen. In der Tat hat die Engedmann-tiaskelsche Theoric unter den Phamakologen anch am wenigsten Anhänger gefunden.

Prüfen wir num die früheren Hilfsbeweise und jetzigen Hauptbeweise für die muskuläre Natur der Leitung genauer:

Der alteste dieser Beweise stammt rom Rudolph Wagner ision, der iiherhanpt der, echte, aber fast veressene Vater der Theoric rom der rein muskulären Natur der Ilerhewegungen ist. Das Hew der Hühmerembryonen fänget an zweiten bis dritten Tag der Bebriitmeg zu schlagen an. Zu dieser Zeit fand Wagner aber noch nirgends in Körper Nerven. Diese treten erst viel später auf und sind zunïchst leitungsunfahig. Noch am achten Tage fehlen Reflexe. Hieraus zieht er den schuluß, daß das embryonale Herz pulsiert, ehe Nerven rorhanden sind, und er schreiht daher den Muskehn die Rolle zu, sich automatisch zu bewegen und den Reiz von Teilchen anf Teilchen zu iilhertragen. Bei diesem Schluß bleibt er aber nicht stehen, sonderm er folgert weiter, ,daß auch der gewöhnliche Modus der Herzhewegnung bei erwachsenen Tieren ohne Vermittlung der Nerven zustande kommen kann" und daß der hier vorhandene Nervenapparat wahrseheinlich die Bewegmaen nur modifiziert, ohme sie hervorzubringen! , Übrigens wird schon hier anch für die Bewewngen des Darmes eine muskuläre Leitung in Anspruch genommen.)

Der Wagnersche Beweis für die myogene Natur der Leitum im embryonalen Herzen erweist sich bei näherer Betrachtung als sehr zweidentig. Weil noch keine Nerven leiten, muß die Leitung muskulär sein! Was aher den Nerven recht ist, ist den Muskehn hillig: erst ann achten oder neunten Tame kam man auf Reiz die ersten schwachen Inskelkontraktionen erzielen, das Herz kontrahiert sich aber schon am zweiten. Danach wirde man grade so gut den Schluß ziehen kimmen, daß auch die Leitung und Kontraktion, nicht muskulïren Lrsprung ist, oder man gibt zu, daß im Herzen auch die Nerven eine Ansnahme machen.

Sehr schöne und genaue Untersuchungen ïber das embryonale Ifer\% liegen von Fano (1590) vor, welche von His jun. 1 1893 , hestitigt mond durch histologisch-entwicklungsseschichtliche Lntersuchungen und (einige nene physiologische Versuche vervollstandigt wurden. Durch 
den Nachweis, daß die Herzganglien in das Herz hineinwandern und dort erst anlangen, wemn bereits eine Koordination der Her\%abschnitte zu beobachten ist, glaubt His bewiesen zu haben, daß die Ganglien an der Koordination keinen Anteil haben. Dies ist eine Frage, die uns später erst zu beschäftigen hat. His nimmt num an, daß sich die Terven im Herzen noch später entwickeh, indem sie von den

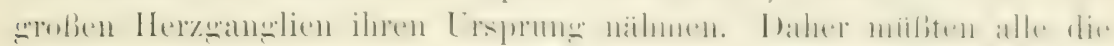
Erscheinungen, welche das embryonale Herz bietet, muskulären Lrsprungs sein.

Dieser Schluß geht sicherlich zu weit. IBei der Dürftigkeit der

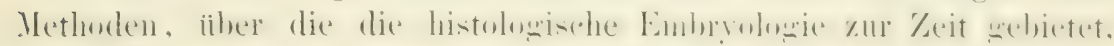
komnte His eigentlich nu über die Herkunft der großen Ganglienzellen etwas aussagen, über die später markhaltigen Fasem schon

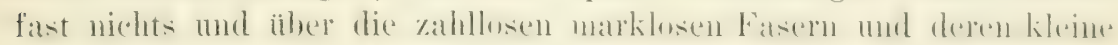

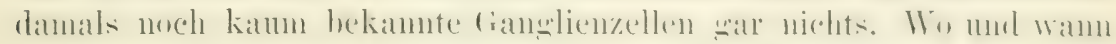
diese entstehen, ob sie einwandern oder in loco gebildet werden, dariiber ist nichts bekannt, und ehe dies nicht feststeht, kamn nicht be-

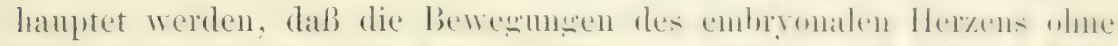

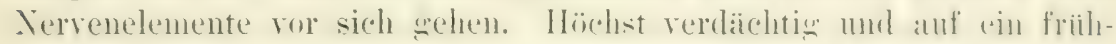
zeitiges Vorhandensein von Vervenelenenten deutend ist der ron llis

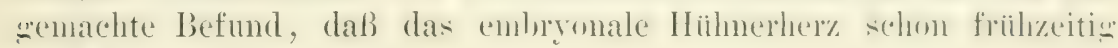
auf Muskarin reagiert!

Der Hissche Beweis für die muskuläre Natur. der embryonalen Herghewegungen hat aber noch einen andern schwachen P'unkt: \%u der Zeit, wo das Herz anfängt zu schlagen, besitzt es noch gar

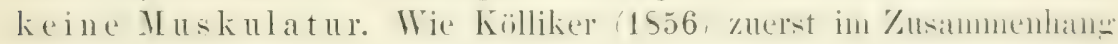
mit der vorliegenden Frage nachwies, besteht das Herz der Vögel und rephalopoden zu dieser Zeit nur erst aus Zellen. Mnskelfisem treten erst viel später auf (nach His jum. beim Hühnchen am vierten bis fünften Tag!). Ich bin wenigstens der Meinung - und glaube damit im Sinne vieler zu sprechen —, daß man nicht alles, was kontraktil ist, Muskel nennen darf. Ob sich später eimmal aus den

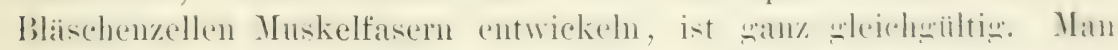
kann also mit rollem Recht sagen, daß die Leitung im embryonalen Herzen nicht muskulär ist; His wollte aber grade das Gegenteil beweisen.

Wie dem aber anch sei: die Verhailtnisse im embryonalen Ilerzen sind so sehr von denen des erwachsenen Tieres verschieden, daß aus

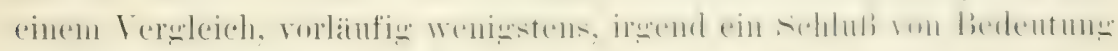
nicht gezogen werden kann.

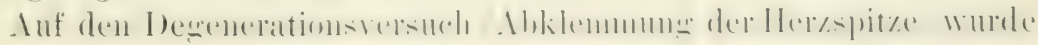
schon oben (S. 109) eingegangen und gezeigt, daß ihm Beweiskraft nicht zukommt. 


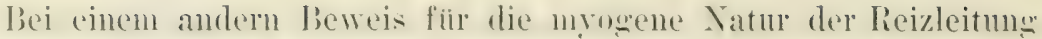

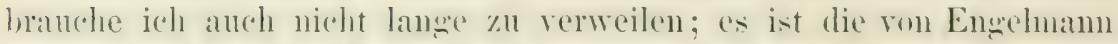

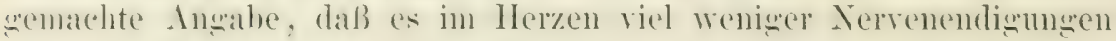
gaibe als Muskelzellen. Diese Frage lat jetzt ein ganz andres Ge-

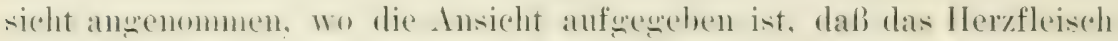
aus lanter kleinen Muskelzellen besteht. AuBerdem darf man wohl

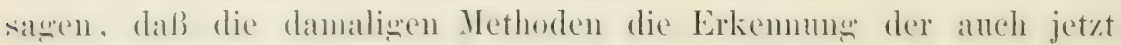
noch umbekamnten Nervenendigungen nicht schließen.

Es bleibt noch ein Beweis, auf den Engehmann zur Zeit auch das Hamptgewicht zu legen scheint, daß nämlich die Leitumg im Herzen für eine Leitung vermittels Nerven viel zu langsam gehe.

Engelmann zerschnitt die Herzkammer ron Fröschen zu einem langen bande nnd nal\} die Zeit, welehe zwischen dem Ansetzen eines Reizes am einen Ende und der Kontraktion des andern Endes ver-

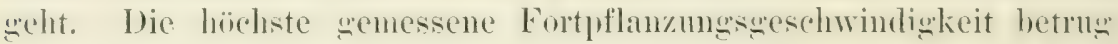
30 mm in der sekunde, eine Geschwindigheit, die also tansendmal kleiner ist, als die Fortpflanzmugreseschwindignkeit im markhaltignen Froschnerven. Engsehnam zieht hieraus den Scohluß, daß die Leitung nicht nervöser Natur sei, sondern von den Muskelelementen selber hesorgt wiurde. Den ersten Schluß, daß es sich nicht num nervöse Leitung handelt, kam ich rerstehen, den zweiten aber nicht. Wemn Enselnam die eventuellen Hermerven nit den markhaltignen Nerven verolich, so mußte er anch den Itermuskel mit den queresestreiften Juskeln verwleichen, dem die wanze Form der Znckmuskine, die lieizharkeitsverhätnisse mud die histologische beschaffenheit lassen mit

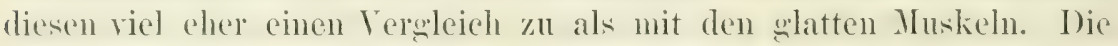
Fortpflanzmoseschwindigkeit in den queresestreiften Muskeln ist aber

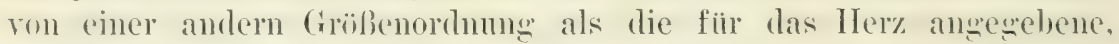
wenn sie auch hinter der der Nerren zuriekbleibt. (Fiir den Frosch-

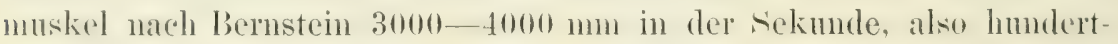
mal soviel als im Herzen; beim Menschen nach Hermann sogar 10000-13000 mmm). Damals nahm man allerdings noch an, daB der Hermmskel ans kleinen epetrennten Muskelzellen hestände; Engelunam hält aber noch hente an der Beweiskraft seines Versuches fest. Deshall, darf ich vom hentigen histologeischen standpunkt aus sagen: Man

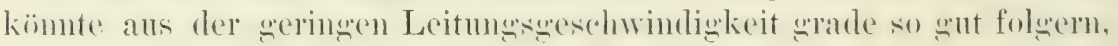
dalj die Leitung anch nicht muskuläl sein kïmme, sondern von ainem dritten noch unbekamnten Element besorgt wïrde.

Engelmann hat aber noch zweierlei ausser acht gelassen: Es ist

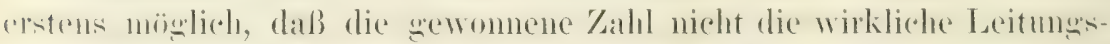

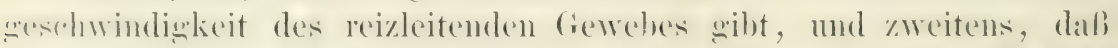
nir.lit alle Nervenelemente onleichschnell leiten. Ioh habe oben is. 4:32. rime Insicht entwickelt, welehe ich Fiillungshypothese namote. loh 


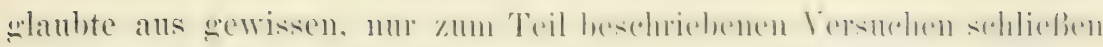
zu müssen, daß sich die kontraktile Substanz mit dem Reiz gewissermaßen anfüllt und erst losschlägt, wenn die Fiullung eine gevisse Höhe erreicht hat. Diese Höhe wird iiberall gleichzeitigr eintreten kömnen, wenn der Reiz sich mit geringer Intensität, aber ständig ins

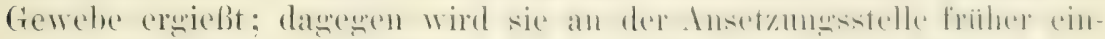
treten, wenn sich plötzlich eine große ,Reizmengec ins Gewebe er-

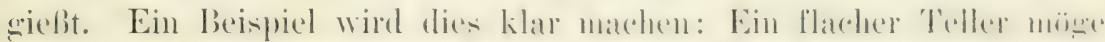

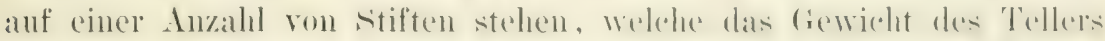
und noch etwas mehr tragen kömen. Wenn man langsam Wasser oder besser eine zähere Flissigkeit auf den 'Teller grießt, so wird es

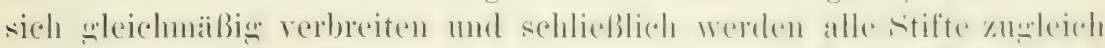

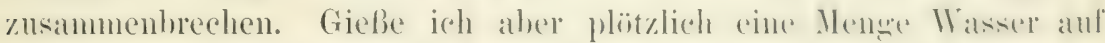

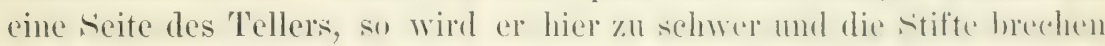

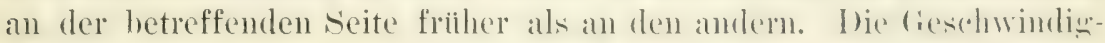

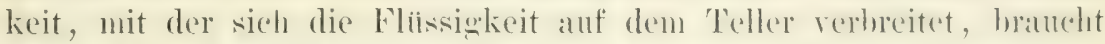
mit der (ieschwindigkeit nicht identisch zu sein, nit der der /usammenbruch von der einen Seite zur andern fortschreitet. Wenn a l so n eben den Muskelelementen eine spezifisele, reizleitende Substanz im Herzen vorhanden ist, so ist höchst wahrscheinlich die Geschwindigkeit der Kontraktionswelle nicht mit der Leitung sgeschwindigkeit dieser substanz identisch!

Engelmamn erwähnt, daß beim Frosch eine so geringe Nerven-

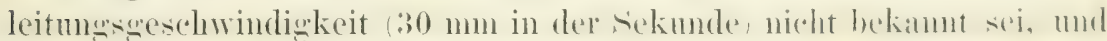

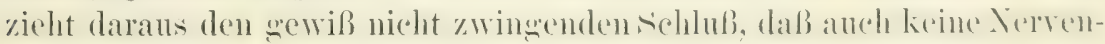
geschwindigkeit so geringer Größenordnung zu erwarten sei. Unter-

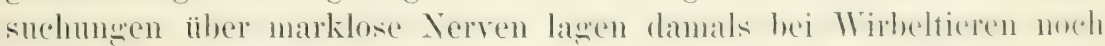
nicht vor; es war aber bereits bekamnt, daß im Herzen viele marklose

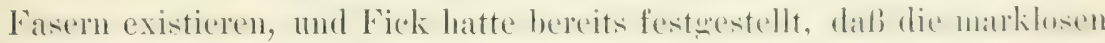
Fasem der Muschel nur mit einer Geschwindigkeit ron etwa $1 \mathrm{em}$ in der sekmule leiten, einer Geschwindiencit, die also noch seringer ist als die der Kontraktionswelle im Herzen. Bekamnt war anch damals

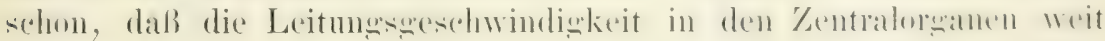
geringer ist als in markhaltigen Nerven. Allerdings schob man diese

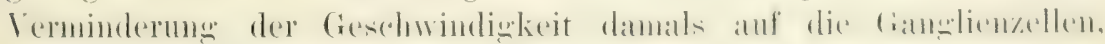
welche Engelnann in den unteren 'Teilen der Kammer vermißte.

Ich habe es oben wahrscheinlich zu machen gesucht, daß die

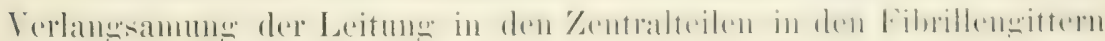
geschieht. Solcher Fibrillengitter passiert der Reiz beim zentralen

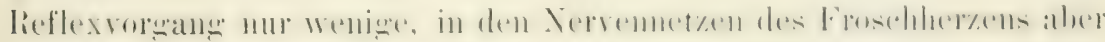
sicherlich schon anf kur\%er Strecke hunderte. Wir haben also bereits

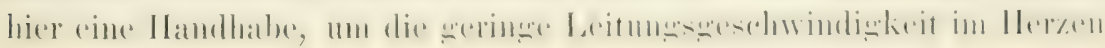




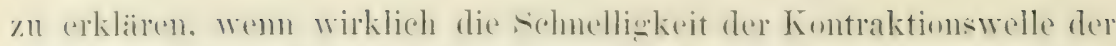

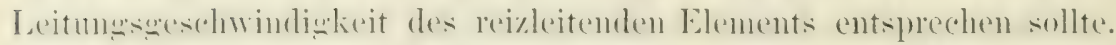

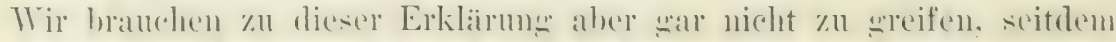
Xicolai 1901, naldewewiesen hat, dabschom der parallelfaserige, markluse olfactorins des Ifechtes also uhne zwischengeschaltete Fibrillensitter) nur 5-20 cm in der Sekunde leitet. Das wissen wir jetzt

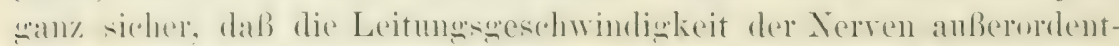
lich verschieden sein kamn und daß sie offenbar nach den lokalen

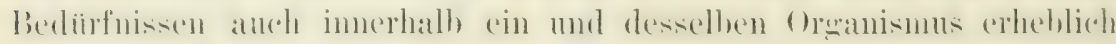
schwankt. Für das kleine Froschherz liegt, das kann man wohl zul-

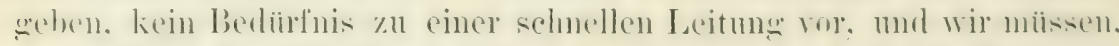
wenn diese Bediurfuisfrage richtign ist, erwarten, dab die Leitunesgeschwindigkeit bei größeren Herzen größer ist.

Ehe ich auf diese Frage übergehe, komme ich noch einmal auf die Ceschwindigkeit der Kontraktionswelle im Frochherzen zurieck. Engelmann hat im Jahre 1894 den Beweis zu fuiluren gesucht, daß anch die Leitung imnerhalh des Vorhofs und rom Vorhof zum Kammer muskulärer Natur sei und sich dazn elonfalls des Verfahrens bedient, die ..Leitmusesesthwindigneit" zu bestimmen. Er findet für die Leitung in Torhof wesentlich höhere Zahlen, als 1575 fïr die Leitung immerhalh, der Kammer. nämlich 90 - 200 $\mathrm{mm}$ in der sekunde. sicherlich sind seme frïheren Zallen für die (ieschwindiukeit der Kontralitionswelle in der Kammer zu niedrig, wie er auch selbst jetzt angibt.

Über die Geschwindigkeit der Kontraktionswelle bei größeren Herzen liegen, soweit mir bekamnt ist, nur Untersuchungen von Schliiter (1902) am Hundeherzen vor. Dieser Autor benutzte ein indirektes Verfahren, indem er durch die Aktionsströme des IIer\%ens zwei Froschschenkel in Berregung setzte, deren Nerren je an der basis und an der spitze des durchbluteten und spontan schlagenden Herzens aufwelent waren. Die zeitliche Inifferenz zwischen dem Bewimm beider Zuckungen ersab eine Geschwindigkeit ron 2-4 m in der Sekunde. (Die Versuche sind deswegen nicht gan\% eindeutig, weil manchmal war keine bifferenz vorhanden war und in andern Fällen der auf der sipitze liegende sehenkel eine Zeitlang zuerst zuckte, nachdem er vorher später gezuckt hatte.)

Wohl bewußt, daß man zu genauen Zahlen nicht gelangen kam,

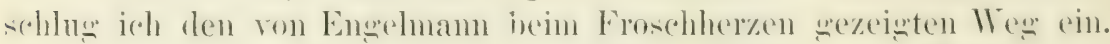
Ich entnahm dem ätherisierten oder dureh Stich in die Medulla ge-

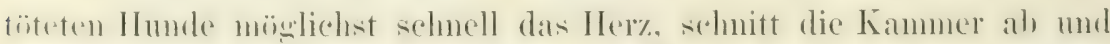
rollte sie zu einem 8-15 em langen Rande auf. Nach dem Fixieren anf riner korkplatte kan jedes Ende muter einen selureihhehel, durch

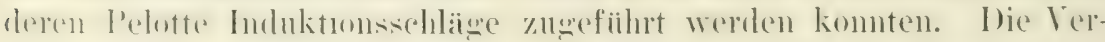

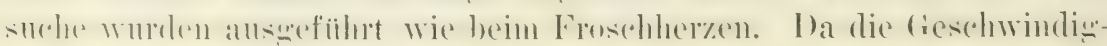




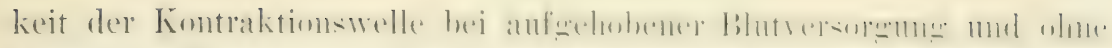

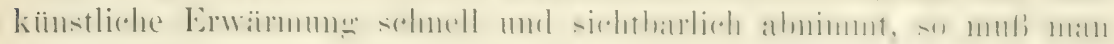
sich natiirlich eilen und alles vorher gut vorbereitet haben. Buei se-

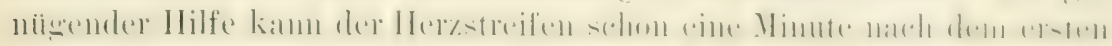

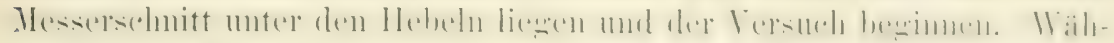
rend 2-3 Minuten kömnen dam gewöhnlich Kuren aufgenommen werden. Die Ausmessung der Kurven ergab im Anfang des Versuches

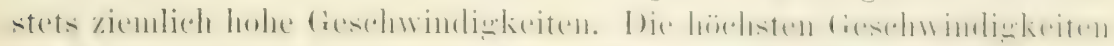

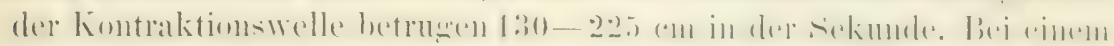

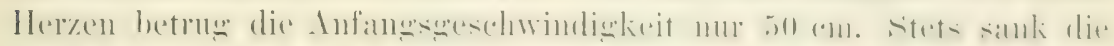

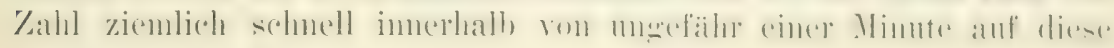
Größe herab. Es konnte auch stets ein sehr wesentlicher Unterschied zwischen schwachen, whate wirksanen Reizen derselben Art gefunden werden. So betrug die anfängliche

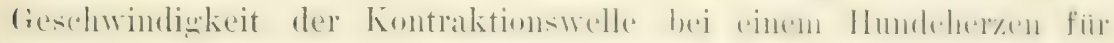
schwache Reize $56 \mathrm{~cm}$, für starke Reize $225 \mathrm{~cm}$. Daß es sich hier nicht um ein Übergreifen des Reizes auf weiter entfernte Partien

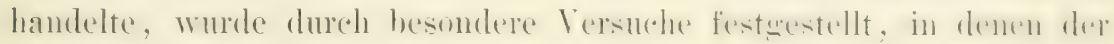
Streifen 2 mm ron der Aufsatzstelle der Pelotte entfernt durehschnitten wurde.

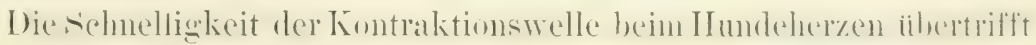
also die des kleinen Froschherzens $n$ mehr als das zehnfache und

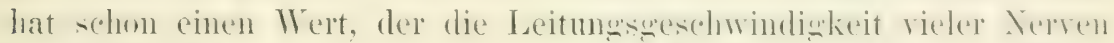

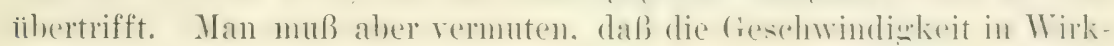

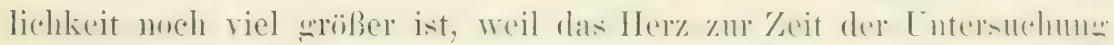
schon unter sehr ungiinstigen Bedingungen steht.

Der Wert dieses Vergleichs zwischen großen und kleinen Herzen

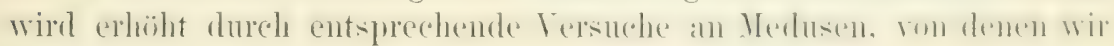
bestimmt wissen, daß die Reizübertragung auf nervösem Wege ror sich geht. Das Tersuchsverfaluen entsprach dem beim Frosch- und Hundeherzen angewandten. Auch hier wurde bald das eine und

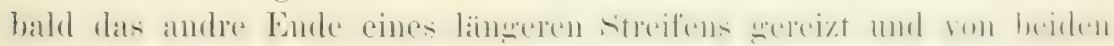
Enden geschrieben. Der Haken wurde stets so eingesetzt, daß nur die Kontraktion der Radiärmuskulatur in Betracht kam. Bei andern Versuchen wurde nur eine Kurve von einem Ende greschrieben und an einem nahen und einem fermen l'unkt gereizt. Die Geschwindigkeit der Kontraktionswelle ist auch hier, wie beim Herzen, wering. wenn die Streifen schmal sind; man muß also die Streifen (nach (btragung der Randkörper') so breit wie möglich wählen, d. l. nur eine Zirkumferenz nehmen. Bei großen Tieren kam man leicht Streifen ron 20-40 $\mathrm{cm}$ gewinnen. Da die Selmelligkeit wesentlich von del 'T'emperatu abhängig ist, so muß hieranf natiolich geachtet werden. Auch die Stärke des Reizes und die Schmelligkeit, mit der er vieder- 
holt wird, spielen eine Rolle. Bis zu cinem wewissen Grade nimnt die

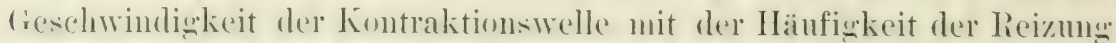
zul und wird hei zu schneller Infeinanderfolge wieder geringer. Wird derselbe Reiz nach längererer Panse in wleiehen. nicht zu zroßen Abständen immer wieder angesetzt, so nimmt die sichnelligkeit bis zur Erreichung eines Maximums zu.

An Cotylorhizen ron ungefähr $12 \mathrm{~cm}$ Durchmesser fand ich bei einer Temperatur ron $19^{\circ} \mathrm{C}$. eine durchsehnittliche Geschwindigkeit ron $300 \mathrm{~mm}$ in der Sekunde.

Lun den Einfluß der Temperatur zu zeigen, sei hier folgende Znsammenstellung wegeben. Bei einem streifen ron $26 \mathrm{~cm}$ auswenutyter Länge und bei stets shleichen, auseichendem Öffnungsschlag wurden je 12-20 Mesinngen semacht. Der Reiz erfolgte in sleichen Intervallen. Der streifen wude zunïchst hei Aquariunstemperatur untersucht $\left[\begin{array}{lll}19,50 & \mathrm{C} .\end{array}\right]$, dann für zehm Minuten in Wasser von $13,5^{\circ} \mathrm{C}$. weloracht und hier untersucht; darauf wurde das Wasser anf $25^{\circ}$ C erwämnt und wieder nach 10 Minuten seprift. Die IJöhe der Kurven betrig $2,7 \mathrm{~cm}$.)

Inrchschnittswesehwindiwkeit in Zentimetem $\begin{array}{ccc}13,5^{0} & 19,5^{0} & 25,0 \\ 25,4 & 30,0 & 49\end{array}$

Latenz der direkt gereizten Partie . . . . 0,368" 0,24" $0,16^{\prime \prime}$

Daurer der Zuckumg' . . . . . . . . $0,80^{\prime \prime} 0,55^{\prime \prime} 0,45^{\prime \prime}$

Figur 90 zeigt zwei Zuckungskurven bei verschiedener Temperatur.

Nrie man sieht, nimmt die Geschwindigkeit nicht in demselben Verhältnis zu, in dem die Latenz abnimmt. Weun man die gering whte Zahl gleich 5 setzt, so verhalten sich

\section{die Geschwindigkeiten wie $5: 6: 8,4$}

die Latenzen aber wie $11,5: 7,5: 5$.

Mir scheint auch dies Verhalten nur dann erklärbar zu sein, wemn kontraktile und reizleitende substanz voneinander getremnt sind.

(Hier sei noch eine Tabelle mitgeteilt, welche zeigt, wie nach längerer l'ause bei whleich srobem und in sleichen Intervallen erfolwenden Reiz die śchnelligkeit der Kontraktionswelle zunimmt. Das Intervall betrug gegen ", $9 "$. Die Zahlen geben die Zeit in sekmolen an, welche zwischen dem Ansetzen des Reizes und der Zuckung des denu

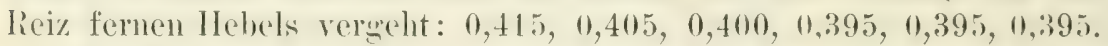

Die Zahlen liegen also zwischen der Geschwindigkeit der Kontraktionswellen beim Herzen des Frosches und dem des Hundes. Interessant und ron wesentlicher bedentumge ist num dex leider nur cimnal angestellte Vorpleidh zwischen einem groben und mittelgroben

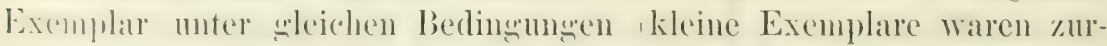
zeit nicht zu haben'. Das eine Exemplar hatte einen Durehmesser von 
etwa $20 \mathrm{~cm}$, das andre von $12 \mathrm{~cm}$ (Cotylorhiza). Die 'T'emperatur betrug $19,50 \mathrm{C}$. Der Reiz war gleichstark. Bei dem mittelgroßen

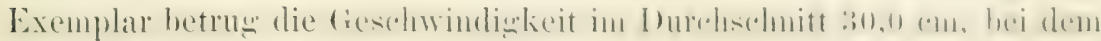
großen Exemplar 47,2 cm!

Leider habe ich keine kleinen Cotylorhizen und auch keine kleinen Medusenarten untersucht. Ioh werele dies hald natehluelen und

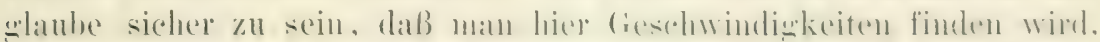

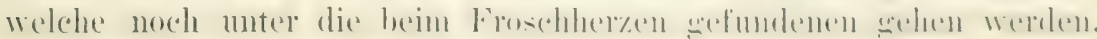
Ich muß auch sonst ansdrieklich hervorheben, daß diese Unter-

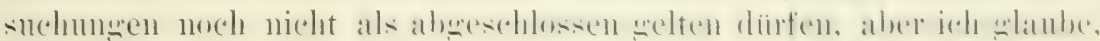
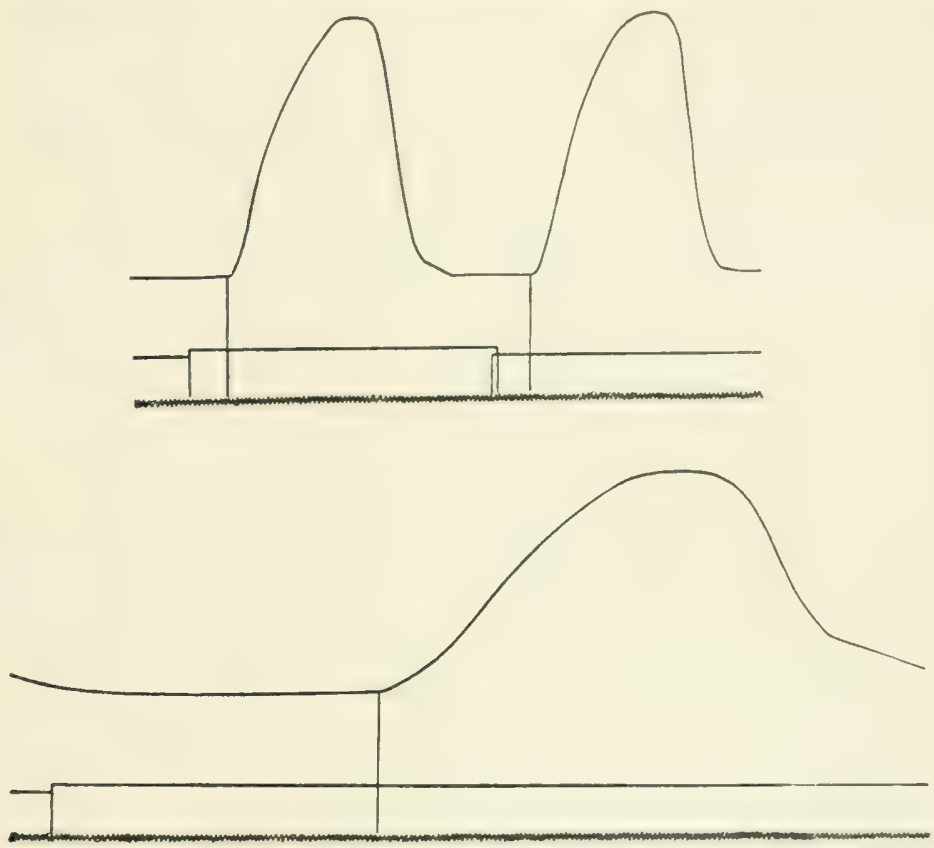

Fig. 90, Kurven zư Bestimmung der Geschwindigkeit der Kontraktionswelle bei Cotylorhiza bei verschiedener Temperatur. Entfernung des Reizortes ron den schreibenden I’unkt 26,7 cm. Obere Kurven bei $24^{\circ} \mathrm{C}$., untere bei $12,5^{\circ} \mathrm{C}^{1}$ )

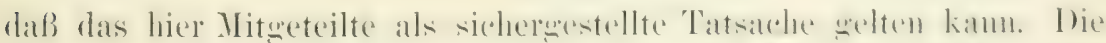

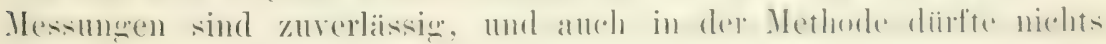
verfehlt sein. Es wäre nu möglich, daß ich noch nicht alle Bedingungen klar erkannt habe, ron denen die Gesehwindigkeit der

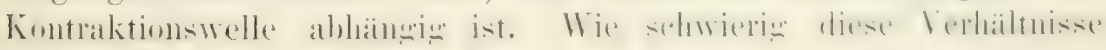

1) Alle beigegebenen Kurven sind von einem Zeichner der Verlagslutuchhandlung nach den Originalen gepanst. Hierdurch sind kleine Unregrelniibigkeiten und Fehler entstanden. Letztere sind aher sicher nirgends im Sime einer Verdeutlichung ausgefallen. 


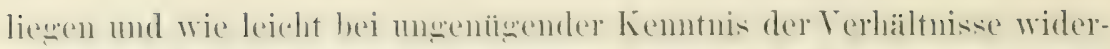
streiteme liesultate antstehen kimmen, wird ans folgendem ersichtlich: Die Gesehwindigkeit der Kontraktionswelle ist größer in den Randpartien, geringer in größerer Näle des Zentrums, und zwar sind diese Unterschiede groß. Bei einem Tier ron $19 \mathrm{~cm}$ Durehmesser wurde der muskulöse Teil der Blocke \% und Zirkuliarmuskulatur bis anf eine 1,.5 ('m breite briicke gespalten siehe Fig. 91 . An diesem Ende waren zwei sidereibhebel and den beiden

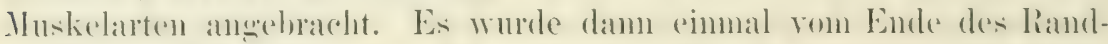
streifens mul ditum von dem des zentraleren streifens gereizt. Die Temperatur betrug mehrere Grade iiber $20^{\circ} \mathrm{C}$. (Die genaue Angabe ist

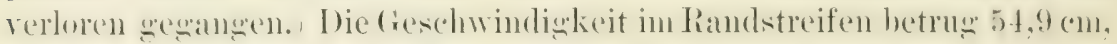
in mehr zentralen streifen, welcher die Radiärmuskulatur enthicelt, nur 28,1 cm. Dieser enorme Untersehied erklärt sich darans, daß das Nervennetz an hande reichlicher vorhanden ist und hier anch Ansit\%e von langen Bahnen enthialt. Es erklärt sich hieraus die weiter oben mitgeteilte Tatsache, daß die symehronität nach Fortnahme aller Randkiorper [his auf einen] ziemlich stark gestiort ist, wem die Randpartien hei der Fortnalno erheblich sesechïdigt wurden. Man sieht, dab hei Cnkemntnis dieser Verhältnisse leideht ein Lnterschied in der schnelliwkeit der Kontraktionswelle zwischen zwei verschiedenen Exemplanen sefunden werden kamm, olme dak er in Wirkliclukeit da ist. Weitere Fehler kïnnen entstehen, wenn man die Latenzverhältnisse nicht kemnt. anf die ich spaiter zurïckliomme. Ich solatbe aber bei meinen definitiven Messungen alle diese Fehlerinellen vermieden zu haben, die anch mir anfangs große Schwierigkeiten bereiteten.

Wir sahen beim Froschherzen eine langsame Fortpflanzung der Kontraktion, leim Hundeher\%en eine viel ströBere. IBei den Medusen. wo die Leitung sicher nervös ist, lernten wir eine mittlere (ieschwindin-

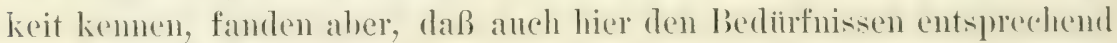
die Geschwindigkeit bei groben Tieren swröber ist, als bei kleinen. I) anit fällt aluer der letzte Beweis Engelmams für die muskulaire Natur der Reizleitung in sich selbst zusammen.

Wenn ich mich bis hierhin bemüht habe, zn zeigen, daß die Leitumg im Herzen nervös sein kann, so will ich jetzt Beweise aufführen, welche darauf deuten, daß sie nervösein mu. Sie sind mit der myogenen Theorie unvereinbar oder nur dann mit ihr in

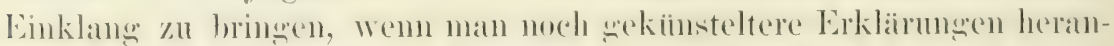

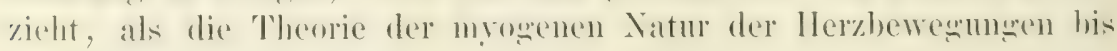
jetzt schon gezeitigt hat.

Engehanm besehriel in Jahre 1894 einen Fall, weleher ihn selloed

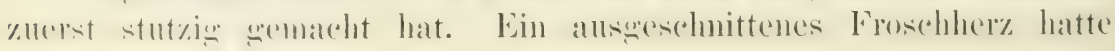


aufgehört von selbst zu schlagen. Als er dasselbe an Torhof reizte liontrahierte sich dieser nicht, wohl aber die Kammer und zwar nach einer so langen Zeit, daß direkte Kammereizung auscreschlossen war (bei direkter Kammerreizung ergab sich eine entsprechend kitrzere Latenz). Wie war dies zu erklären, daß der ruhende Vorhof zu leiten imstande war, ohne sich selbst zu kontrahieren? Das schien der myogenen Natur der Leitung zu widersprechen. Um diesen Widerspruch zu lösen, fußte Engelmaun auf der von Biedermann nach-

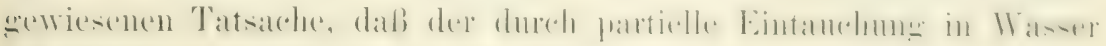
zur Hälfte wasserstar gemachte Muskel noch zu leiten imstande ist.

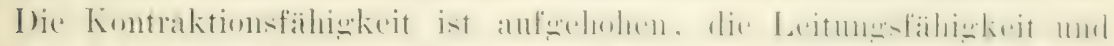

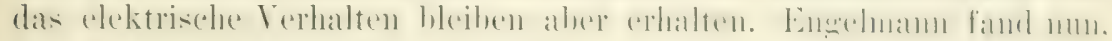
daß der wasserstare Vorhof ebenfalls noch zu leiten imstande ist und sieht hierdurch jeden Einwurf gegen seine Theorie beseitiont. Er entwickelte sogar im Anschluß an diesen und andre Befunde die An-

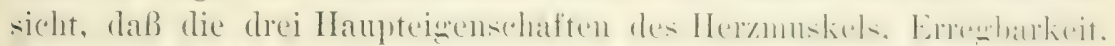

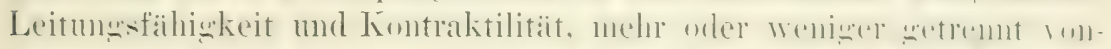

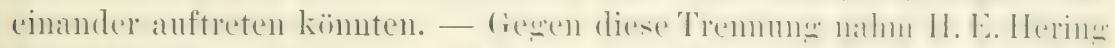

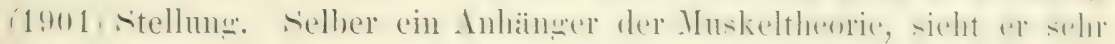

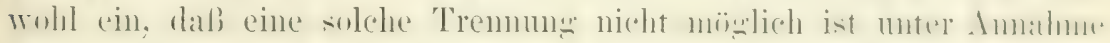
eines eimheitlichen Substrats. Er sucht daher zu berreisen (um die

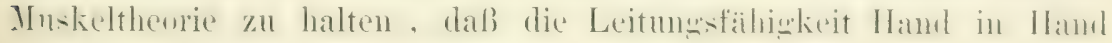
mit der Kontraktilitait abuähme. In der T'at reigt sich bei der Wasserstare ein starkes Dekrement der Leitung, und er nimmt an.

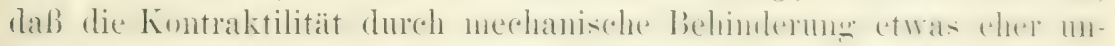
sichtbar wird, als auch die Leitungsäuhigkeit aufgehoben ist. Dementsprechend nimmt er an, daß bei noch erhaltener Leitumg, aber auf-

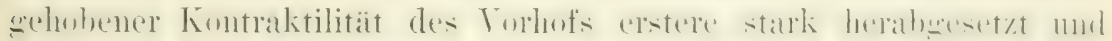

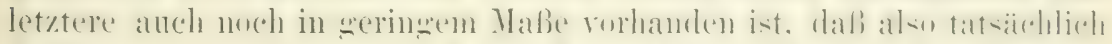

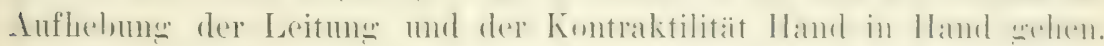
Num zeigte schon Hofmann (1898), daß man die Kontraktionsunfähigkeit des Vorhofs bei guterhaltener Leitungsfahigkeit (zur

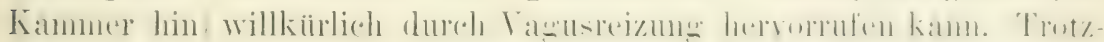
dem er ein Anlänger der Engelmannsehen 'Theoric ist, sieht er' in dieser 'Tatsache eine Selnwierigkeit für dieselbe. - In sehr viel hequemerer Weise kam man dic Kontraktionsunfahigkeit des Vorlinfs bei der Vergiftung mit Muscarin herrorrufen. Ist die Dosis (ich henutzte ein Präiparat, das mir Herr Dr. Faust fremdlichst zur Verfügune

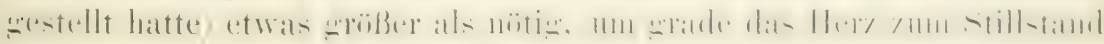
zu bringen, so tritt bald ein Zustand cin, in dem auch bei stälistem

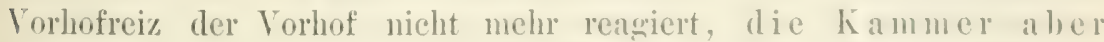
noch sehr gut anspricht. Der Latenzunterselied zwischen Vorhofreizung und Kammereizung in Bezug anf die Kontraktion der Kammer 
ist stets sol grob, dab an eine direkte Kammererregung bei Vorhofreiz nicht zu denken ist. Diesem Einwurf wurde anch dadurch begeenet, dab ich leviznngen mit neinem mechanischen Reizapparat ansführte. Ich hahe num bei relativ gut erhaltener Leitmesäahigkeit des Vorhofs diesen mit den stärksten zulässigen Vergrößerungen wäh he nd der Reizung beobachtet und anch nicht die allergeringste Bewegung whrnelımen können. (Wie bekannt, wird ja auch die Kanmeromtraktion bei stäkeren Veroiftungen nit der Zeit immer kleiner. In!n schlieblich anch auf starke Reize ansubleiben. Man kimnte also sagen, (laß bei erhaltener Leitmuswidhiskeit doch noch eine weringe bewegung der Vorkammermuskeln stattfände. Dies ist aber nicht der Fall.) Die Vorkammer kann al so leiten, ohne eine mit den besten Mitteln nachweisbare Bewegung a $u$ s zuf fïhren.

Hat nun Engelmamn durch die Heranziehung der Wasserstarre den Widerspruch sehoben, in welehem diese Erscheinmus zur Theorie der munkulären Leitung in Herzen steht! Ich slauhe nicht! Bei der Wasserstare ist die Reaktionsfahliwkeit der Muskeln, wie aus den ron Hering mitgeteilten Tatsachen hervorgeht, nicht vollkommen aufgehohen, sondern es ist nur das Zustandekommen einer Kontraktion in

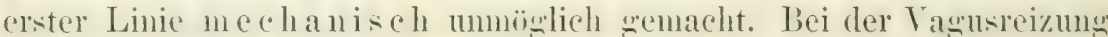
und bei der Muscarineinwirkung wird aber der Muskel nicht mechanisch an der Kontraktion rerhindert, sondern er ist nur wehemmt. Jeden Angenblick kann er seine Kontraktionsfähigkeit durch Lufhebung der Reizung oder dureh einen Tropfen Atropin wieder erlangen. Wir haben es also mit zwei ganz verschiedenen Dingen z.11 tun: Das eine Mal leitet ein Muskel, der noch bis zu einem gewissen Cirade reagiert, dies aber durch äußere Behindermü nechanisch nicht mehr änBern kann, das andre Mal soll nach Engehmam ein Muskel leiten, der überhant nicht in Reaktion tritt. IDaf ein gehemmter Muskel überhanpt nicht in Aktion tritt, ist wenigstens die allgemeine und durehans berechtigte Ansicht.)

Ich muß danach Engehnann geweniber II. E. Hering vollkommen recht seben, daß Leitung und Kontraktilitiit ronemander getrennt sind, kamn mich aber durchans nicht seiner Ansicht ansehließen, daß beide Funktionen von demselben Gewebe besorgt werden. Mir scheint viehnehr in diesem Versuch ein klarer Beweis dafür zn liegen, dak ein Gewebe im Herzen existiert, welches leitet, ohne sich zu kontrahieren, und solehe Gewebe pelegen wir nervös z, 1111 e $1111 \mathrm{e} \|$.

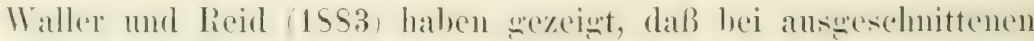

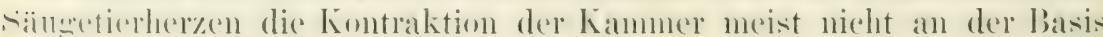
berimnt. wo der lieiz olne \%weifel in die Kannmer eintritt, sondern 
an der Spitze. Dieser Befund ist vou Schliiter am durchbluteten Katzenherzen bestitigt. Langendorff (1902) sieht hierin mit Recht

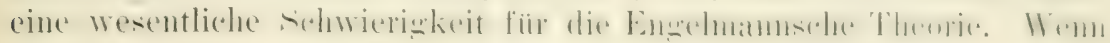
der Reiz durch die Muskelelemente weiter geleitet wird und die

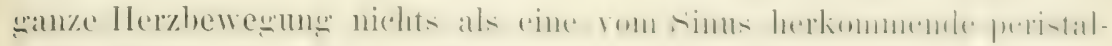
tische Welle ist, dann muß unter allen Unständen verlangt werden, daß die Basis sich immer zuerst kontrahiert. Es kommt also nur auf das Faktum an, daß die Kontraktion an der Spitze beginnen kann: ob dies unter natürlichen Verhältnissen der Fall ist oder, wie es den Inschein hat, nur beim absterbenden Herzen, ist olne jede Bedentung:

Ich habe dasselbe Faktum in noch unzweidentigerer Veise an zwei Streifen konstatieren können, die aus der Kammer von Hundeherzen geschnitten waren. Die Streifen waren an beiden Enden mit Fühlhebeln armiert und wurden an einem Ende (1) mit Öffnungsschlägen gereizt. Nachdem zun ä chst die Kontraktionswelle immer ton $A$ a usegangen war, kontrabiertesich beim nächsten Reiz das reizferne Streifenende B zuerst, und die Kontraktionswelle lief ron da a us neh Reizstelle A zuriek. - Diese Inversion bestand so lange fort, als ich mit gleichstarken öffnungsehlägen reizte. Ich rerstälkte dann den Reiz, worauf sofort wieder die Kontraktion bei A begann.

Ich erkläre mir diesen Befund in folgender Weise: Die Erregbarkeit war ans unbekannten Grïnden an beiden Enden rerschieden.

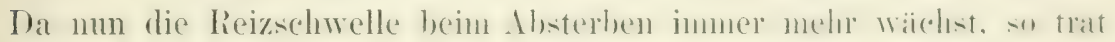
ein Noment ein, wo der Reiz fiur A nicht mehr genighte, um eine Kontraktion auszulösen. Der Reiz pflanzte sich aber im Nervenuetz nach $\mathrm{B}$ fort und komnte bei der hier rorhandenen höheren Erreg bar-

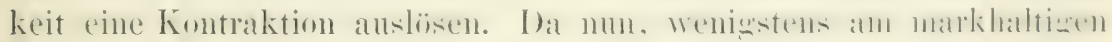
Nerven, die Reizwelle einen Zuwachs erfährt, wenn sie ein Gebiet

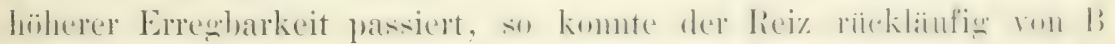
aus auch die Stellen ron geringerer Erregbarkeit (bei A) zur Kontraktion bringen. Nachdem der Reiz verstarlst war, geniighte er wieder, um anch das weniger empfindliche $\Lambda$-Lnde direkt zu erregren.

Dieser Versuch liegt ganz klar und dïrfte bei der Ammahme einer

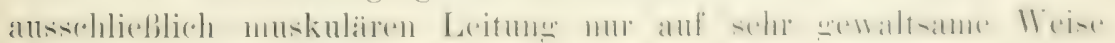
erklairt werden kömnen. Mir scheint er unbedingt dara $\mathrm{f}^{\circ}$ hinzureisen, daß neben der Muskulutrein reizleitendes Element besteht. Als dieses will man selbst-

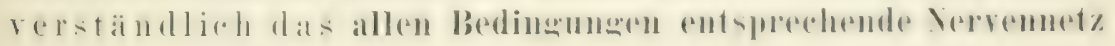
anselien miissen.

Analoge Faille hat bereits Romanes bei der Meduse Amelia be- 
schrieben. An einem Randstreifen dieses 'Tieres befand sich nur ein

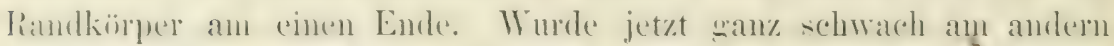

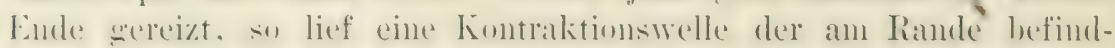

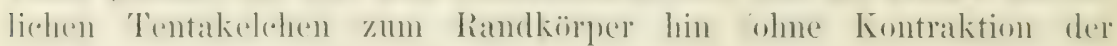
Glockenmuskulatur), ron wo dam eine Kontraktion der Glocken-

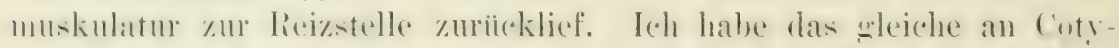

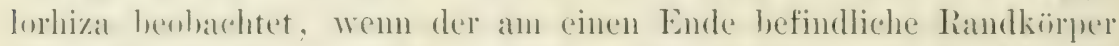
keine Lontraktionen mehr ans lïste, aber immer noch die kleinste Reizsehwelle hatte (siehe S. 428). Bei starkem Reiz lief die Kontraktimswelle zum Ramdkïrper hin und errente hier eine zweite riokläufiger Welle. War der Reiz schwach an randkörperfreien Ende angesetyt, su fehlte die erste Welle und nur die rïckläufige kan nuch montande. - Folgender befund von Williann IS58; kamn ehenfalls nur erklïrt werden, wem ein besonderes reizleitendes fiewehe in Ilerzen rorlanden ist. Bei einem alsterbenden Kaninchenler\%en gibt Kammerreiz Kontraktion der Kammer; dann folgt eine Kontrakion der wroßen Venen, an die sich erst die des Vorhofs anschließt!

Wie ich bewiesen zu haben glaube, und wie ja immer noch viele Forscher ammehmen, gibt es also eine nerröse Leitung im Herzen. spielt nehen dieser die vielleicht anzunchmende muskuläre Leitm!n eine Rolle? Bei den Medusen, wo die Muskelbündel roneinander getrennt sind, sicher nicht. Ich wlaube aher, daß anch in Her\%en die Wahrecheinlichkeit nicht sehr groß ist. Beim Herzen des Frosches stehen die einzelnen Trabekehn, woranf schon wiederholt von andern aufmerksam gemacht ist, in einem oft sehr lockeren Zusammenhang.. Nicht selten liegt eine dicke schicht von elastischen Fasern zwischen zwei Trabekehn, welche rom Herzhunen his zum Pericard zieht und, soweit sich das auf schnitten feststellen läßt, nirgends einen wesentlichen Austausch von MInskelfasem zuläßt. Des weiteren erimnere ich an die ron Ileidenhain (1901) sichergestellte Tatsache, daß die Muskelfibrillen nicht miteinander anastomosieren, sondern parallel nebencinander herlaufen, wie im skelettmuskel. Daß dies ein greeinnetes Mittel ist, den Reiz ron Fibrille anf Fibrille zu iibertragen, ist mir unwahrscheinlich.

Nach der Anschaumg von Engehmann und Gaskel soll anch die Leitung vom Vorhof zur Kammer muskulärer Natur sein. Diese Leitung wird von Gaskel (1884) den sogenannten Blockfasern zuweschrieben, Muskelfasem ron embryonalem Charakter, welehe bei niederen Wirbeltieren nach Stanley Kent eine direkte Verbindung: zwischen der Muskulatur des Torhofs und der der Kammer herstellen sollen. Ia die Leitung beim embryonalen Iterzen langsaner ist, als bein erwatedenen, so wird diesen Fasern die liolle zugesehrieben, die rom Vorhof zur Kammer verlanfende peristaltische Welle auf- 
zuhalten und so die Koordination der Herzteile her\%ustellen. Wie schon oben (S. 92) benerkt, ist es mir im hö chsten Grade zireifelhaft, daß diese Elemente eine wirkliche Kontinuitit herstellen. Nach meinen Beobachtungen sind sie ron den Wuskeh der Kammer uberall durch elastisches Gewebe getrennt. Ich habe bei der Betrachtumg meiner l'rïparate auch nie Zweifel unterdrieken können, daß es sich hier wirklich um Muskelelemente handelt. Anch bei Siingern hat

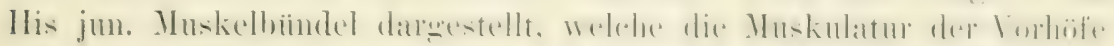
mit der der Kammern rerbinden. Ieh zweifle nicht an der 'Tatsache,

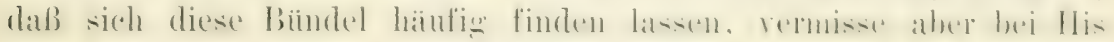
den Beweis, daß sie eine wirkliche Anastomose in dem Sinne her-

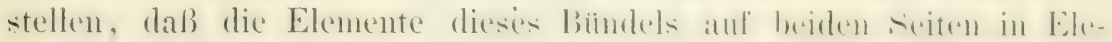

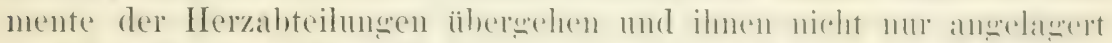

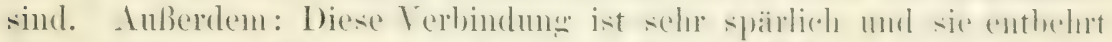
des embryomalen Charakters, kimm also fül die Erklärome des likoks

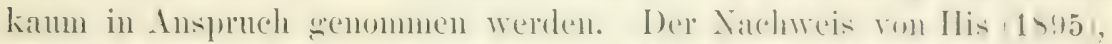

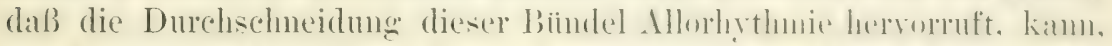

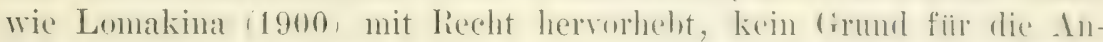

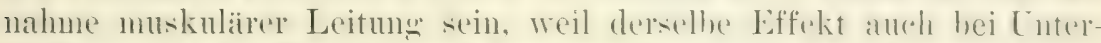
bindum der die Vorhöfe und Kammern verbindenden Jerren aintritt.

Die Muskelleitungstheorie steht hier also auf sehr schwachen anatomischen Grundlagen; dasegen wissen wir sicher, dafi all den Klappen entlang eine Lnzahl von Tervenfasem in die Kammer lineinziehen und hier direkt in das Nerremnetz übergehen. Bei dieser Latere der anatomischen Verhältnisse ziche ich es unhedingst ror, diesen die Üherleitumg des Reizes \%urnscheiben. Das Experiment kamm liere, someit es operativ rorocht, keine sichere Entsoheidung hringen. Schneidet man rom Vorhof oder ron der Kammer ans die Klappen heraus (Löwit, 1881), so nimmt die Kammer nicht mehr an den Pulsationen des lorhofs teil und, wemm man nach lhtratume des sinns den Vorhof oder die Kammer reizt, so antwortet stets nur der ge-

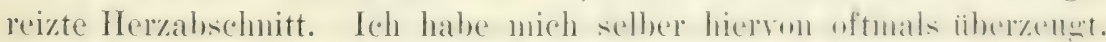

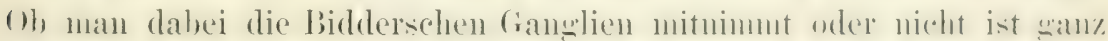

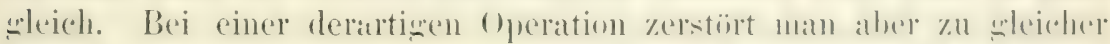

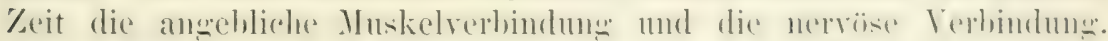

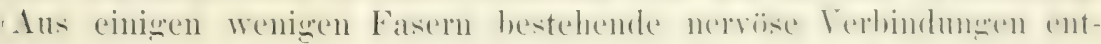
fernt von den Klappen [S. 96] sind jedenfalls als Ansmahmen an-

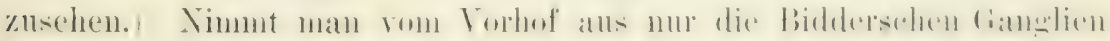
herans (r. Wittich), so tritt in der Regel der grleiche Effekt ein; ich

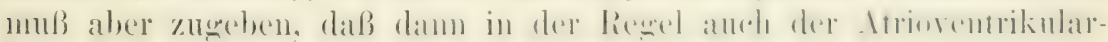
trichter stark geschädigt ist. Einige Autoren geben an, daß nach

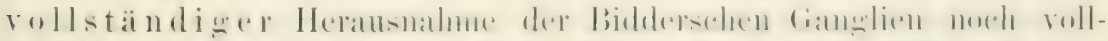
kommene Leitung zwischen Torhof und Kimmer bestehen könme. 


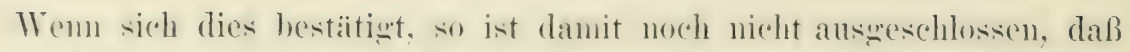
die Leitume nervös ist, da wir noch nicht wissen, ob alle zur Kammere ziehenden Nervenfasern die Bidderschen Ganglien passieren.

\section{Die Koordination der Herz- und Nedusenbewegungen.}

Wie zuerst Stamnius gezeigt hat, kamm bei Reiz der Kammer eine

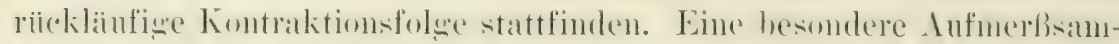

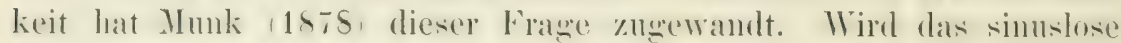
Her\% an der Kammer sereizt, so zurekt sie zulerst mul damm nateh dem bekamuten Interall von 0,1-0,03" der Vorhof. Bei Reiz des bulbus zuckt erst dieser, damn die Kammer, dann der Vorhof. Bei sehr langsinn schlagenden Hermen kamm nan diese Inversion anch ohne vinusfortuahne bewirken, so dab sich \%. B). bei bulbusciz die Kontraktionsfolge grade umgekehrt verhält wie normal. Wird an gewisen stellen eine Verletzums answefïhrt istammius, 1552, Munk, 1566 und 1875, so kommt es bei sinuslosen Herzen zu längeren inversem Pulsieren. Löwit (1881) hat auch eine ganze Reihe derartiger Versuche answefïht. Vielleicht nen ist folgende Modifikation: Man schneidet an Simus entlang einen streifen ron der Vorkanmer und der Kammer ab, so daß der Sinus durch ein kurzes Vorhofsstiick verhmulen direkt an der Kammer hängt. Es schlägt zuerst der sinns, dann die Kanmer, dam der smohe Vorhofisest nud kur\% darauf der Bulbus. Ina die nomuale Reizquelle vorhanden ist, schlasen solche Herzen sehr lange. Ist die Operation gut ausgefiihrt, so muß nach Abschmeiden des Sinus Stillstand eintreten.

In dieser Tatsache der Reziprozität der Herzkoordination sieht Engelnamn ebenfalls eine stïtze der Mnskelthenrie, weil keine riickläufienen lieflexe bekannt seien. Jetzt sind sie bekannt! Sowohl die

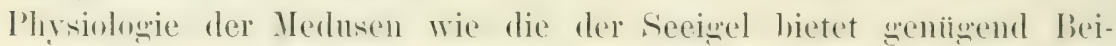

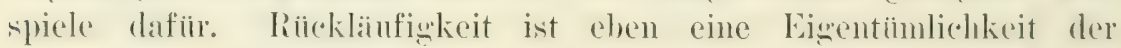
Nervennetze. Also anch von dieser Seite steht dem nichts im Wege, die Herzbewegungen auf nervöse Prozesse zuriickzuführen.

Auch bei manchen Medusen gibt es etwas, was der Koordination

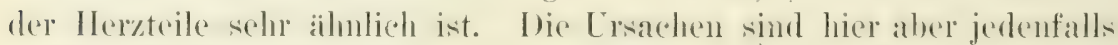
ganz andre. Cothylorhiza und verschiedene andre Nedusen haben

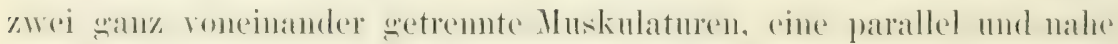
dem Rande verlanfende Zirkulirmuskulatur und eine die zentraleren

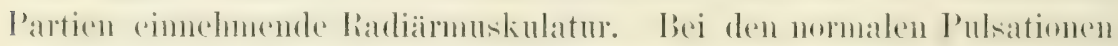
und auch bei der küustlichen Reizung kontrahiert sich zuerst die

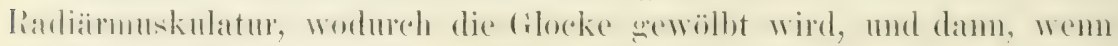

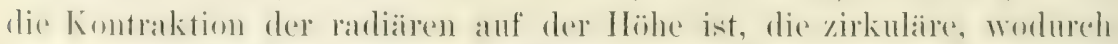

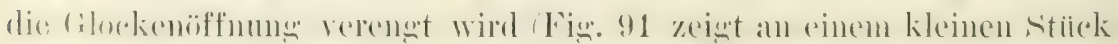

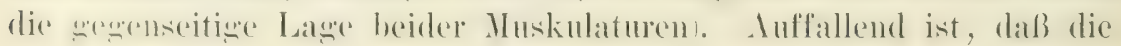


Muskulatur, welehe den Randkïrpern, won denen ja siched die Kuntrak-

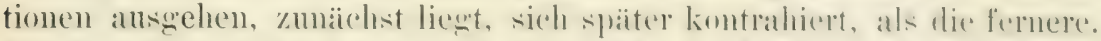

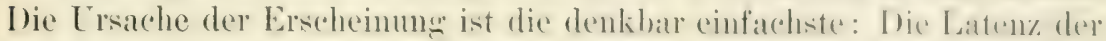

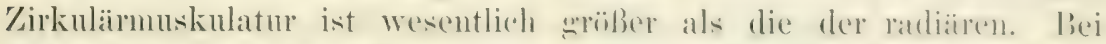

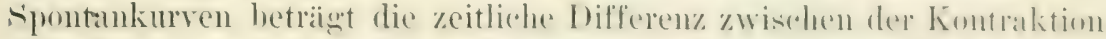

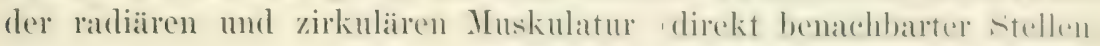
zwischen 0,3 und $0,5^{\prime \prime}$ (bei etwa $20^{\circ}$ C.). Nimmt.man einen kleinen randkürperlosen sektor und sclureiht ron der zirkulïren und radiären

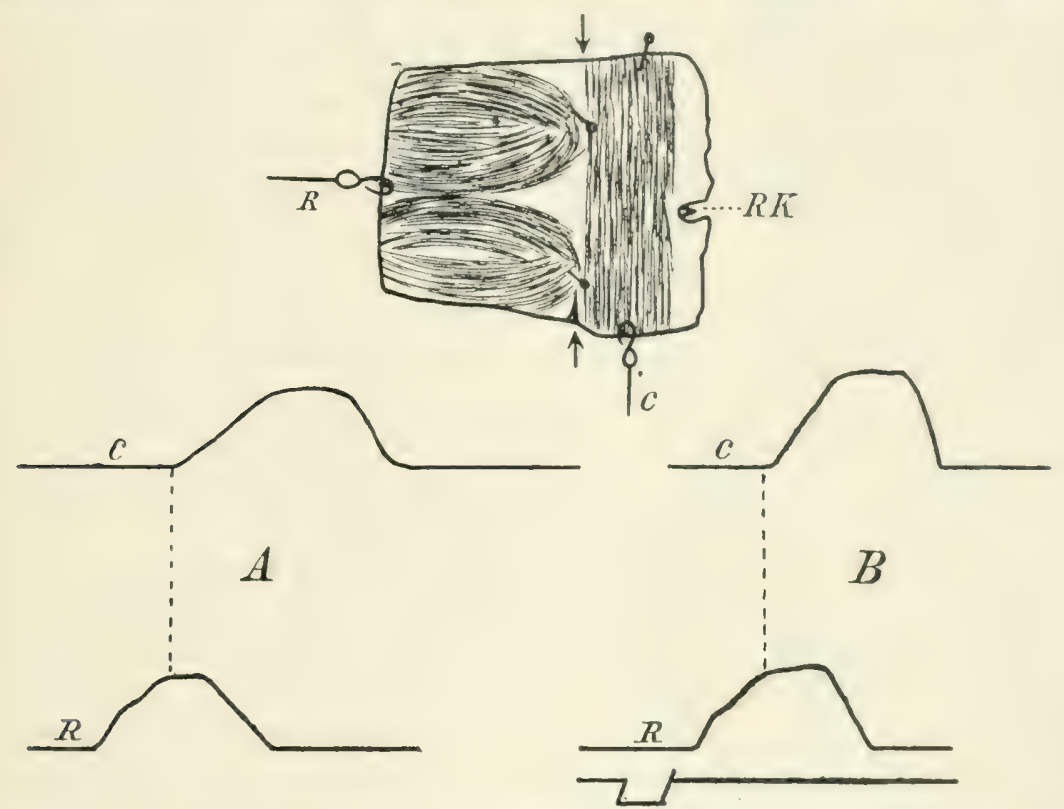

Fig. 91. Cotylorhiza. Oben: Aufstellung des Präparats. Unten links: Spontane Kontraktion. Die liadiärmuskulatur $(R)$ kontrahiert sich friiher als die Zirkulärmuskulatur $(C)$. - Unten rechts: Die zirkuläre Muskulatur ist durch einen Schnitt in der Richtung der Pfeile (oben) von der raditiren getrennt. Der Randkörper $(R K)$ ist außerdem fortgenommen. Soust ist das Präparat unverindert. Durch ein und denselben Induktionsschlag sind beide Stücke gleichzeitig erregt. Das anch jetzt noch zu beobachtende Nacheinander in der Kontraktion beider Muskelarten beruht also auf einer Verschiedenheit in der Latenz.

Muskulatur getrennte Kurven, so bekommt man nahezu wleiche Zeitdifferenzen, wenn man den Reiz das eine Mal iiber der Zirkulärmuskulatur, das andre Mal iiber der Radiamuskulatur ansety. I) De Latenzen schwanken matiulich je nach der 'Temprentur, ver:inderm sich aber auch in noch nicht genauer untersuchter Weise bis zu $15 \%$ o wem der Reiz oft wiederholt orler verscheden stark wemarht wird.

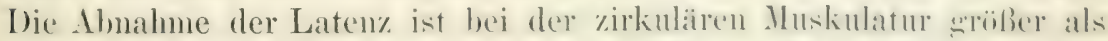

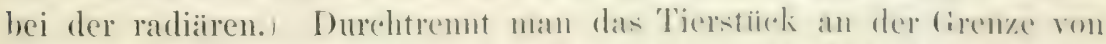

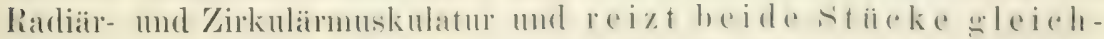
zeitig, so bleibt das \%eitliche Verhältuis das ghleiche. 
Beide Muskulaturen hahen also verschiedene Latenz falls nicht nervöse Verhälnnisse im spiel sind, was mir aber unwahrscheinlich erscheint [siche Fig. 91]).

Ein derartin einfacher Modus der Konrlination ist natülich für das Her\% mit seinen vier Abteilungen mmöglich. Hier muls die Lrsache in nervösen Einrichtumen wesucht werden, wie das von allen Anhängern der (ianglientheorie setan wird. Vorläufig liegt kein wesentlicher frumd ror, den wroken franglienzellen, welche in den rersehiedenen Alsteilungen liegren, die Anteilnahme an der Koordination zu- orler abzusprechen. Gegen eine Anteiluahme derselben kinnte man hördsstens ins Feld führen, daß an Überonen der Kanmer in den Bulbus solche großen \%ellen fehlen. Wenn die wroßen Ganglienzellen etwas mit der Koordination zu tun haben, dam kam man ammehmen, daß in ihnen ein Widerstand gelegen ist, der das Weiterscheiten der

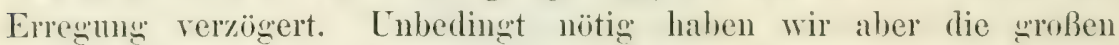
Gandelienzellen nicht, un die Koordination auf nervïsem Wege zu erklären, und es ist sehr gut möglich, daß sie mit derselben grar nichts zu tum haben. EngeImann hat zuerst gezeigt, daB die Kontraktionswelle im Herzfleisch ïberall da eine große Verzögerung erfäht, wo sie eine schmale Briake zu passieren hat. Stehen mehrere Teile der Kammer duch ditnne Bribken miteinander in Verbindung, so pulsiert jede (bei erhaltenem Zusammentang mit dem Vorhof) gewissermaBen für sich. Ganz dasselbe beobachtete ich bei den Medusen, wo ja die Leitung ganz sicher nervös ist. Sehr instruktir ist es, diese Versuche an Rhizostoma anzustellen, weil man hier vor der Einmischung der Muskulatur sich sehïzen kann. Stehen zwei Muskelfelder Á. 89 und 108, durelı das breite muskellose stiick in Zusammenhang, so kontrahieren sich beide bei Reiz des einen so schnell nacheimander, daß man nit bloßem Ange keinen Unterschied wahmimmt. Reduziert man die Verbindung jetzt auf eine schmale, muskelfreie und nur Nerven enthaltende Brilcke, so fängt das nicht gereizte Muskelfeld erst zu sehlagen an, wenn das gereizte seine Kontraktion fast beendet loat. Wir haben num gesehen (S.95), daß sich die vom Vorhof in den Ventrikel eintretenden Nervenfasern dort vielfach teilen, Sicher tritt dabei eine ungeheur Vervielfachung der Faseru cin. Wir haben also etwas ganz ähnliches vor uns (was den nervösen Apparat anbetrifft, wie bei dem Versuch mit der dimnen Brïcke, und ('s hesteht die Möglichkeit allein hieraus die Krordination des Hermens und ihre Reziprozität zu erklïren. 
Über die Natur des Refraktärstadiums.

Im allgemeinen wird olme weiteres angenommen, daß das Re-

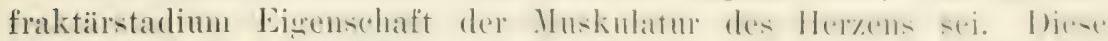

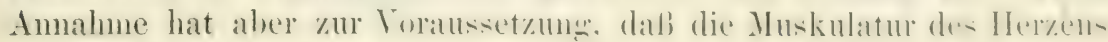
direkt und zwar leicht reizbar ist. Dies ist eine unbewiesene Hypothese. Es ist sehr gut möglich, daß die direkte Erregbarkeit der Herzmuskeln eine sehr geringe ist und daß die Muskulatur viel leichter vom Nerrennetz her anspricht. In diesem Fall ist es möglich, daß das Refraktäirstadium Eigenschaft des Nervennetzes ist, wie dies bereits Uexküill für das Refraktärstadium derMedusen angenommen hat. Ich glanbe hierfuir einen Versuch anfühıren zu können, der allerdings nicht absolut beweisend ist und der bei denen, welche der Muskeltheorie huldigen, eine ganz andre Erklärung finden wird. Setzt man an der Kammer oderVorkammer eines sinuslosen Herzens in größeren Pausen einen Reiz an, so antwortet jede der beiden Abteilungen mit einer Kontraktion mit einer zeitlichen
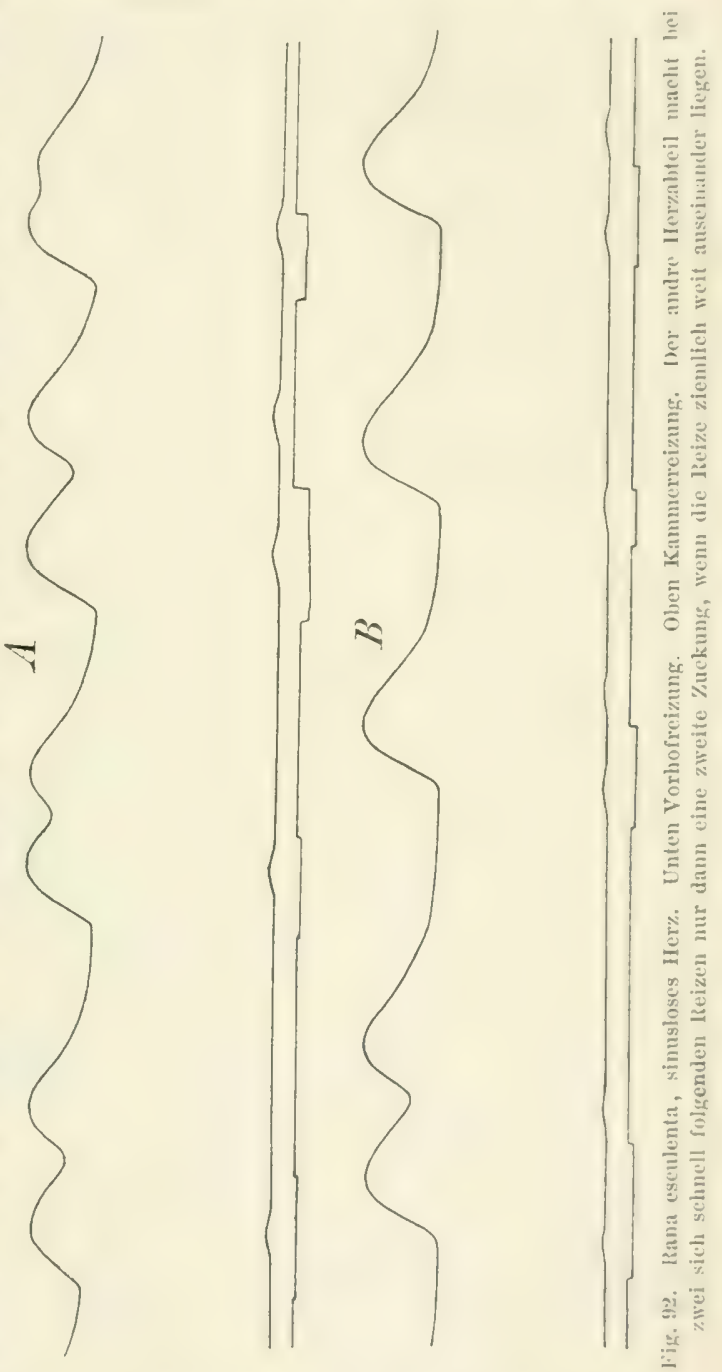
Differenz von $0,1-0,3^{\prime \prime}$.

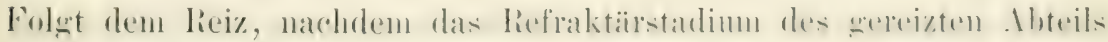

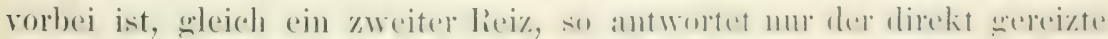

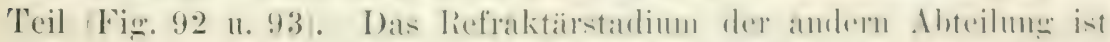

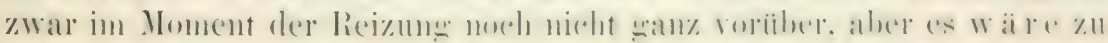


der Zeit roriiber, zu welcher der Reiz bis zu ihr gelangt sein sollte. Wäre the Muskelleitungstheorie richtign, so miißte eigentlich anch die andre
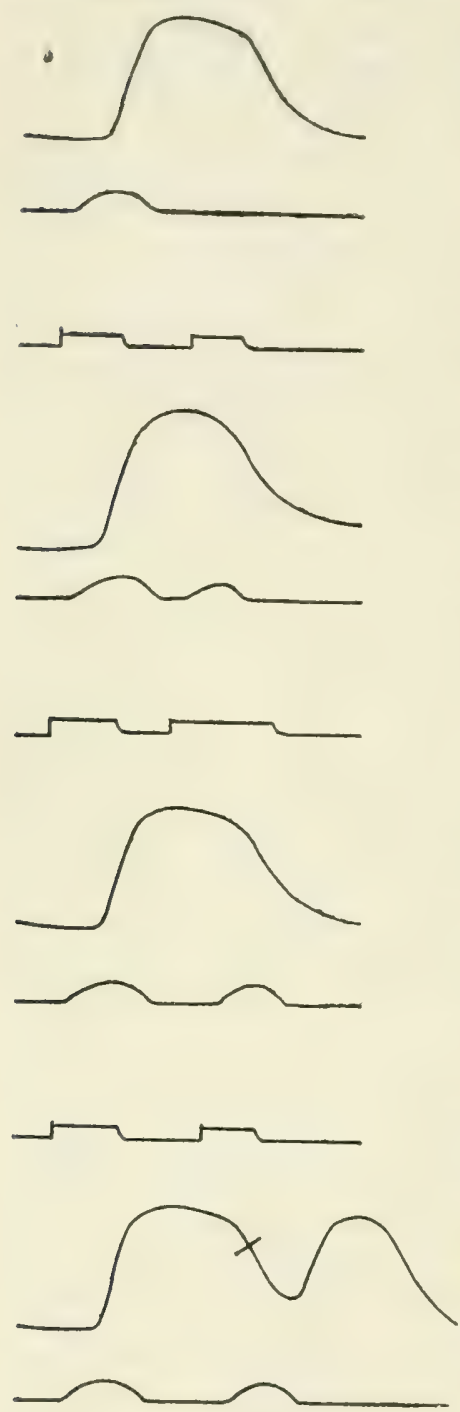

Fig. 93. Wie Fig. 92. Vorhofsreiz. Abteilung zucken, weil ja die Fortleitung. in einer peristaltischen Welle gesehen wird, die natürlich immer zustande kommen muß, wenn die gereizte $\mathrm{Ab}$ teilung sich ïberhaupt kontrahiert.

Das Refraktärstadium wird nun noch weiter rerändert, wenn man in folgender Weise vorgeht: Vorhof und Kammer sind mit Schreibhebeln und Elektroden rersehen. Zuerst wird die eine Abteilung gereizt, z. B. die Kammer. Die Kammer kontrahiert sich, und nach der bekannten Latenz auch die Vorkammer. Reizt man nun diese, wenn ihr Refraktärstadium grade roriiber ist, das ist zu einer Zeit, wo das Refraktärstadium der Kammer längst verschwunden ist, so reagiert nur die Vorkammer, die Kammer bleibt aber ganz ruhig (Fig. 94 u. 95). Erst bei sehr viel später erfolgendem Vorkammerreiz reagiert auch die Kammer mit einer Kontraktion. Durch die, die Diastole noch ïberdauernde Verminderung der Erregbarkeit, welche Engelmann beschrieben hat (1894), läßt sich dies Faktum nicht erklären, weil ich öffnungsschläge von ziemlich bedentender Stärke angewandt habe. Mir scheint, daß diese Erscheinung sich besser bei der Annahme erklïren läßt, daß das Refraktärstadium Eigenschaft des Nervennetzes ist.

Ursachen und Wesen der rhythmischen Bewegungen des Heryens und der II edusen.

Jedes Stück Herz und jedes Stiuck Neduse, das Muskel und Nervensubstanz enthialt, anckt bei einmaligem Reiz. Diese Erscheinmog hat durehaus den ('harakter eines Reflexes; in der Tat sind anch alle fiur einen Reflex 

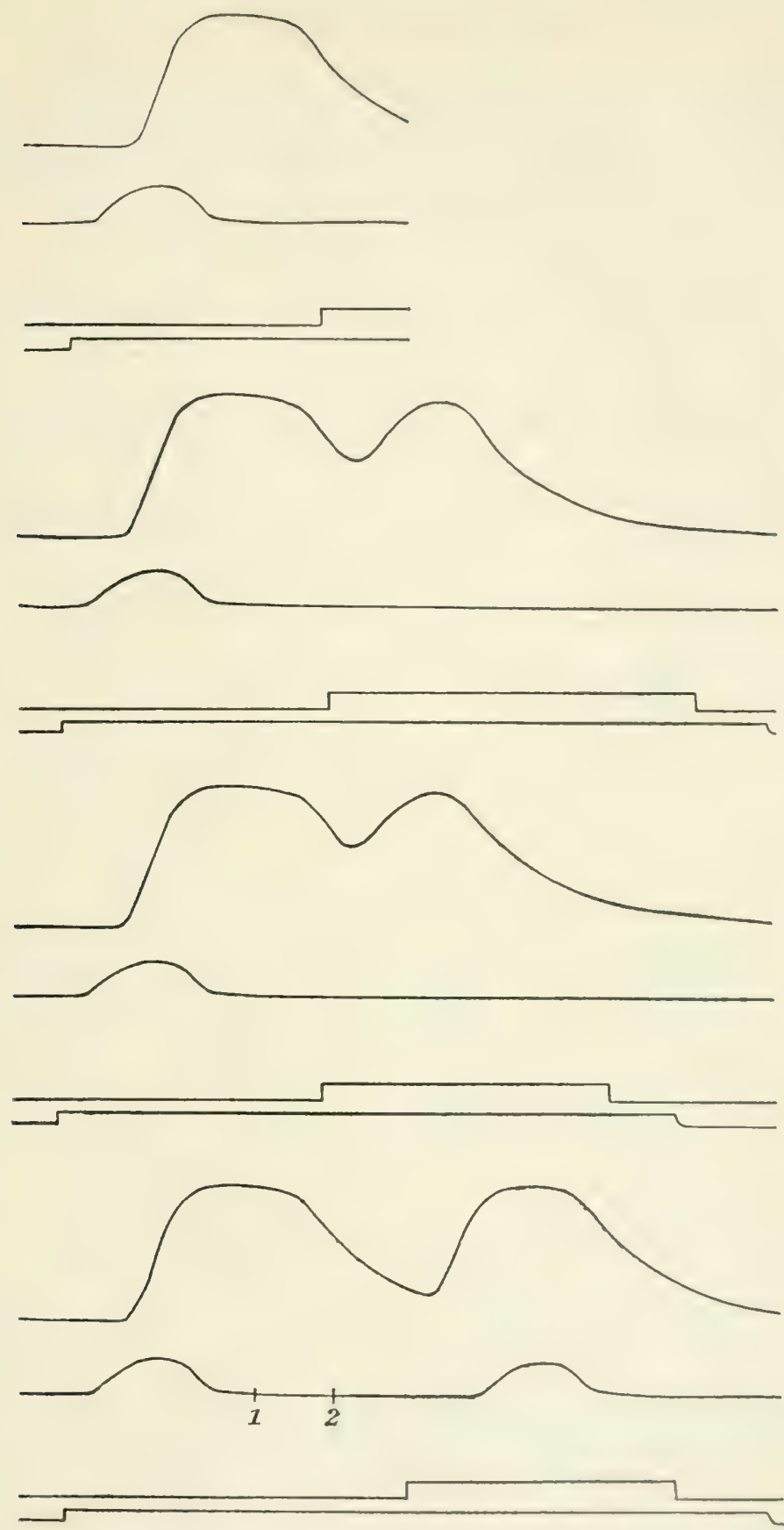

Fig. 94. Sinusloses Herz von Esculenta. Obere Kurve Kammer, untere Vorhof. Obere laeizmarke $=$ Kammerreiz, untere $=$ Vorhofreiz. Es ist in varierten $\Lambda$ bstinden orst der Vorhof und dann dio Kammer gereizt. Auf der untersten Kurve gibt 1 den l’unkt an, wo im vorliegenden Fall der Vorhof bei direkter Reizung einer neuen Kontraktion fähig war, 22 den L'unkt, wo er bei zwei aufeinander folgenden Kammerreizen wieder erregbar war. 
notwendigen anatomischen Bedingzungen erfült. Es ist daher durchaus herechtint diese Erscheinung, wie es vornehmlich Goltz getan, als Reflex zul bezeichnen. An einer stelle wird ein Reiz antesetzt, dieser wird
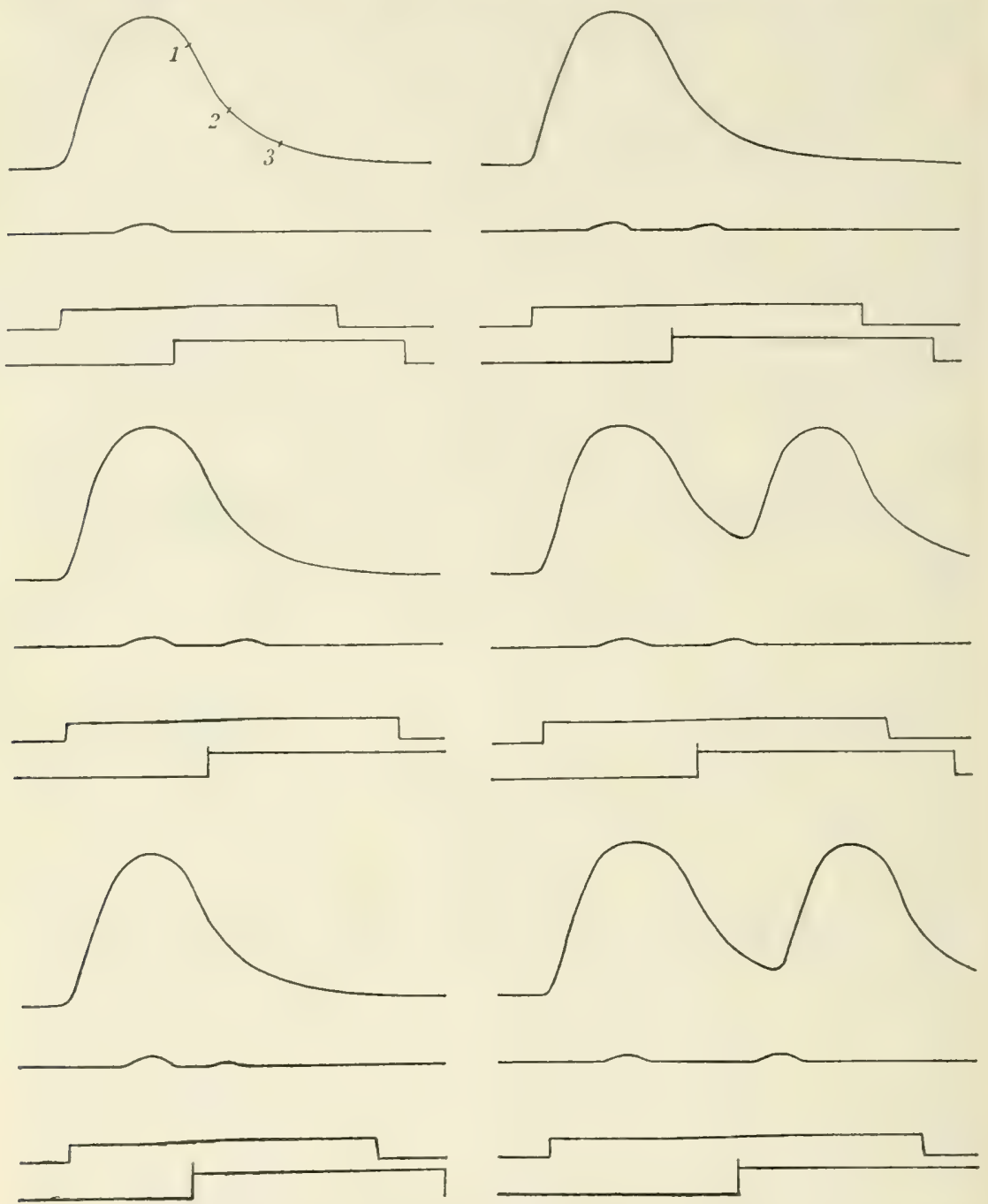

Fig. 95. Wie 91, nur daß der Kammerreiz dem Vorhofreiz vorausgeht. In der ersten Kurre bedeutet 1 den Punkt, wo im vorliegenden Fall die Kammer für einen zweiten Reiz zugänglich war, 2 den Punkt, wo sie bei zwei Vorhofreizen wieder einer Zuckung fihig war, und 3 den Punkt, wo sie bei der angewandten Anordnung erst wieder reagierte.

bei Medusen sicher, beim Herzen hïchst wahrscheinlich von Nerven aufgenommen, auf nervösem Wege durch ein Netz hindurch idas anch fanglienzellen enthält, was aber gleichgültig ist weiter geleitet und auf Inskelelemente unter Ausstremug übertragen. Eine andre De- 


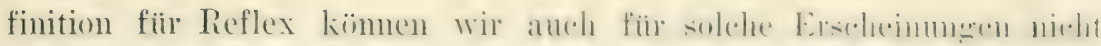

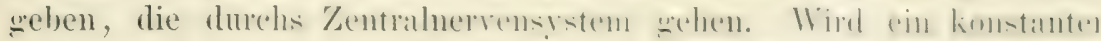

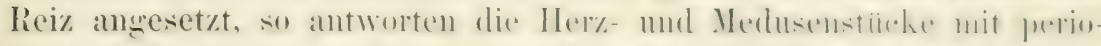

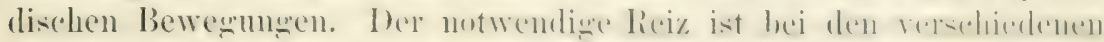

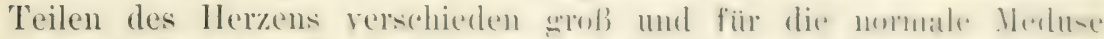

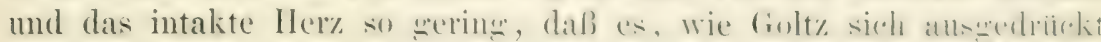

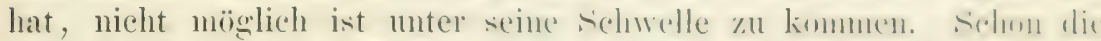

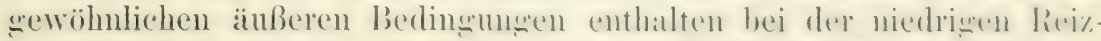

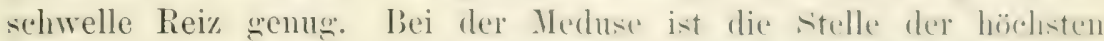

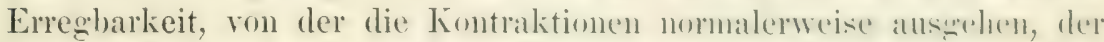
(die) Randkörper, beim Herzen der Sinus. Ein Unterschied besteht zwischen den einzelnen Herz- und Medusenteilen also nur betreffs de Reizschwelle.

Das, was bei der normalen Pulsation den Reiz abgibt, ist fiur das Her\% unbekannt, und es hat keinen Zweck olne Inhaltspunkte dariiber

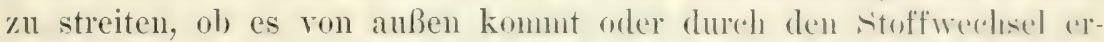
zengt wird. Nur möchte ich die Meinung aussprechen, daß es in den Muskeln des simus, wie die Engehman- Gaskelsche Themie will, nicht angreift, dem die Ïhnlichkeit des Herzens nit der Merluse läßt vermuten, daB auch beim Herzen der Reiz nicht rom Muskel auf die Nerven übergehen kann (vergleiche S. 108).

Bei den Medusen ist der normale Reiz zum Teil durch eine P’ublikation Lexkiils (1901) bekannt seworlen. Lexküll fand, dali eine Rhizostoma, der el nu einen Randkïrper gelassent hatte, diu Kontraktionen für längere Zeit einstellte, wenn el den liandkürper verhinderte zu schlenkern, daß die Kontraktionen aber wieder hesamnen, wenn der Randkörper freigegeben nud angestoken wurde. Die s'chwingungen, welche die Otolithen in den Randkiirperm durch jede Bewegung erfahren, sind jerlenfalls als reizendes Moment an-

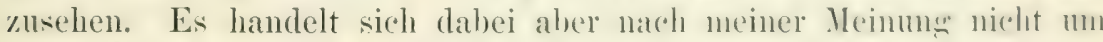
einen Momentaneiz - und anch Lexkiill soleint dieser Insioht nicht

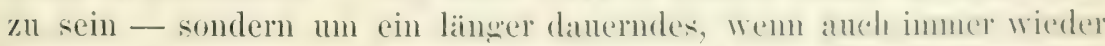
erzeugtes Vibrieren. Beweismaterial datiil hoffe ioh suäter rimmal veröffentlichen zu können. Dies Vibrieren der Otolithen sive Statolithen ist aber sicherlich nicht der cinzien lieiz, de anf die liamb-

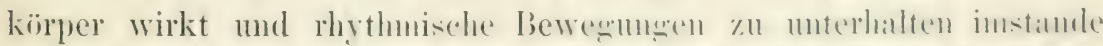

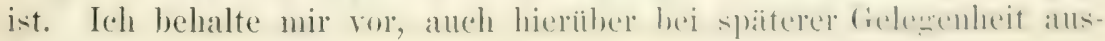
fiilurlicher zu berichten.

Die Ursachen der rhythmisehen Bewegungen sind rermutlich in

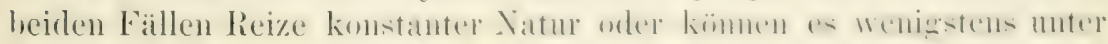

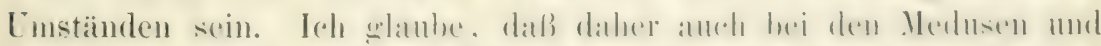

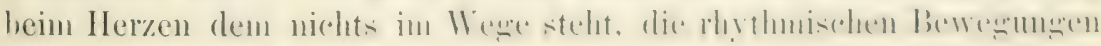


als Reflexe anzusehen, bei denen ein konstanter Reiz durch summation zu rhythmischen Entladungen führt. Durch das Vorhandensein eines starken Refraktärstadiums wird das Entstehen rhythmischer Erfolge gefördert, vielleicht erst möglich gemacht. Da wir ein liefraktairstadium als eine häufige Eigensehaft nervöser Zentralteile (resp. Fibrillengitter, kemen gelemt haben, so dürfen wir anch hier die refraktaire Periode anf das Konto der nervösen Elemente setzen!

\section{Berichtigungen.}

Seite 27, Figurenerklärung, Zeile 4: Statt "Atenne" lies "Antenne".

" 167, Zeile 16: Statt "1850" lies "1958“; statt "1970" lies "1876".

" 226, " 3: Statt „.) " lies „,". - Zeile 4: Statt „." lies „)."

"264, " 3 und 4: Statt "Fig. 64" lies ,Fig. 67".

"265, "2: Statt "vom Nerven" lies "von den Neurofibrillen".

. 269, 270,271 und 273: Statt „Grimhagen" lies „Gruenhagen“.

"273, Zeile 11: Statt "1901" lies "1900".

. 279, Figurenerklärung, Zeile 2: Statt „Daniel“ lies „Daniell“.

" 299, Zeile 13 von unten: Statt „Chronsäureelement" lies "Chromsïureelement".

" 377 und 350: Statt "Sherington" lies "Sherrington".

"418, Zeile 21: Statt "Langendorf" lies "Langendorff".

"428, „13 von unten: Statt „Randkörger" lies "Randkörper".

"436, " 8: Statt "schließen" lies "zuließen".

"438, "4 4 von unten: Statt "Rande" lies "Bande". 


\section{Literaturverzeichnis.}

Mit Ausuahme der mit zwei Sternen (**) ror dem Titel versehonen Nummern haben aile hick aufgefihrten Arbeiten im Original vorgelegen. Da die Separatabziige von Arbeiten, die in Zeitschriften publiziert sind, häufig fehlerhafte oder unvollständige Angaben ïber Bandzahl, Jahygang u. s. w. geben, so ist durch ein Sep. linter der Literaturangabe kenntlich gemacht, falls die Arbeit nur in einem Separatabzug vorlag. - Ein Stern (*) vor dem Titel bedeutet, daß die Literaturangabe nicht direkt rom Original (das friher eimmal eingesehen wurde) abgesehrieben worden ist. p. bezieht sich auf die Seitenzahlen der angefuhrten Literaturnummer, S. auf die Seiten dieses Buches, To dif Arbeit zitiert ist.

Allen, Ed. J.: Studies on the Nervous System of Crustacea. (Quarterly Journal of microscop. science Vol. 36, part. 4. - New ser. 1894. I, p. 461. II, p. 453. III, p. 492.) S. 26,30 .

- - Studies on the Nervous System of Crustacea. (Quarterly Journal of microse. science Vol. 39, p. 1. - New ser. 1896, p. 33.) S. 8, 26, 28.

Albrecht, Meyer und Giuffrè: Untersuchungen über die Erregloarkeit der Nerven und Muskeln bei Längs- und Querdurchstrümung. (Pfliigers Arch. IBd, 21. 1850 , p. $462-478$.) S. 306.

Amaya, S.: Über scheinbare Hemmungen am Nervmuskelprïparate. (Pflïgers Arch. Bd. 91, 1902, p. 413-424.) S. 387.

A páthy, St. v.: Studien über die Histologie der Najaden. (Biolog. Centralblatt Bd. 7, 1887-1888, p. 621.) S. 16.

- - Nach welcher Richtung hin soll die Nervenlehre reformiert werden? (Biolog. Centralblatt Bd. 9, 1889-1890, p. 527, 600 u. 629.) S. 16.

- Kontraktile und leitende Primitivfibrillen. (Mitteil. d. zool. Stat. zu Neapel Bd. 10, 1892, p. 355-375, Taf. 24.) S. $16,26$.

- Erfahrungen in der Behandlunge des Nervensystems fïr histologische Zweche. I: Methylenblau. (Zeitschrift für wiss. Mikrosk. Bd. 9. 1592, p. 15-37.) S. 33. - - Das leitende Element in den Muskelfasern von Ascaris. (Arch. f. mikr. Anat. Bd. 43, 1894, p. 886-911, Taf. 36.) S. 41.

- - Über das leitende Element des Nervensystems und seine Lagebeziehungen zu den Zellen bei Wirbeltieren und Wirbellosen. Compte-Rendu des síances du troisième Congrès international de zoologie. Leyde 1595. p. 132. S. 16.

- Das leitende Element des Nervensystems und seine topographisehen Bezichungen zu den Zellen. (Erste Mitteilung.) (Mitteilungen d. zoolog. Station zu Neapel Bd. 12, 1897, p. 495-748, Taf. 23-32.) S. 16 u. f., 26, 2S, 35, 40, 84, 124, 133, 236, 245, 255.

- - Die postembryonalen Veränderungen der leitenden Elemente des Nervensystems. (Ertesitö. Bd. XX. B. 1898, p. 107. Sep.) S. 245.

- - Über Neurofibrillen. (Proceedings of the international congress of zoologry, Cambridge 1898. Sep.) S. 16.

- - M. Ieidenhains und meine Auffassung der kontraktilen und leitenden Substanz und iiber die Grenzen der Sichtbarkeit. (Anat. Anzeiger Bid. 21, 1902, p. 61.) S. 14 .

Arnemann: Versuche iber die Regeneration an lebenden Tieren. Güttingen 1787. S. $153,152$. 
An hert. H.: Lntersuchungen ibler die Irritabilitit und Rhythmizitait des nervenhaltigen und nervenlosen Froschherzens. (Pflïgers Arch. Bd. 24, 1s81, p. 357.) s. 430 .

A uerba ch: Über den Muskeltonus. (Jahresber. d. schlesischen Ges. f. raterländ. Kultur 1856, p. 127-130.) S. 364 .

A uerbal ch. L.: Nervenendigung in den Centralorganen. (Nenrolog. Centralblatt.) 1S9S, No. 10. Sep.

Bateyer, H. von: Das Sauerstoffbediurfnis des Nerven. (Zeitschr. f. allgem. Physiol. Bd. 2, 1902, p. 169-179.) S. 320.

Bálint, S.: Neurofibrillen im Facettenauge der Insekten. (Értesitö, Sitzber. d. med. naturw. Sektion des Siebenbiirgischen Museumvereins. Abt. II. Revue. Bd. XXI, 1699, p. 1S-19. Sep.) S. 41.

Baranowski und Garrè: Über die Geschwindigkeit, mit welcher sich der Elektrotonus im Nerven verbreitet. (Pfliigers Arch. Bd. 21, 1880, p. 446 bis 462.) S. 273 .

Beard, J.: Morplological studies. II. The Derelopment of the peripheral nervous system of vertebrates. (Quart. Journ. of microsc. sciences Vol. 29, 1889, p. $153-227$, Taf. $16-21$.) S. 236 .

Beer, Bethe und v. Uexkiill: Vorschläge zu einer objektivierenden Nomenklatur in der Physiologie des Nervensystems. (Biolog. Centralbl. Bd. 19, 1899, p. $517-521$.) S. 2, 322 .

Belmondo, E. e 0 ddi, R.: Intorno all' influenza delle radici spinali posteriori sull' eccitabiliti delle anteriori. Rivista sperimentale di Freniatria e di Medicina legale Vol. XVI, 1590. S. 381 .

Berkley, H. J.: On complex Nerve terminations and Ganglion Cells in the muscular Tissue of the Heart Ventricle. (Anat. Anz. Bd. 9, 1894, 1. 33-42. 11 Abb.) S. 91.

Bernstein, S.: Lntersuchungen iber die Natur des elektrotonischen Zustandes und der negativen Schwankung des Nervenstroms. (Arch. f. Anat. u. Physiol. 1566, p. 596-637.) S. 299 .

- - Entersuchungen iiber den Erregungsvorgang im Nerven- und Muskelsysteme. Heidelberg 1871. S. 299, 313, 317, 417.

- - Über die Ermiidung und Erholung der Nerven. (Pflitgers Arch. Bd. 15, 1877$, p. $289-327$.$) S. 318$.

- - Nene Theorie der Erregungsvorgänge und elektrischen Erscheinungen in der Nerven- und Muskelfaser. (Unters. aus d. physiol. Inst. zu Halle. Heft 1, 1888.) S. 254.

- - Uber reflektorische negative Schwankung des Nervenstroms und die Reizleitung im Reflexbogen. (Pfliigers Arch. Bd, 73, 1898, p. 374-350.) S. 342.

- - Zur Kunstution und Reizleitung der lebenden Substanz. (Biolog. Centralbl. Bd. 19, 1899, p. 259-295.) S. 254.

Bethe, A.: Studien ïber das Centralnervensystem von Carcinus Maenas u. s. w. (Areh. f. mikroskop. Anat. Bd. 44, 1595, p. 579-622.) S. 26.

- - Der subepitheliale Nervenplexus der Ctenophoren. (Biolog. Centralb]. Bd. 15, 1595, p. $140-145$.$) S. 12,21$.

- - Die Nervendigungen im Gaumen und in der Zunge des Frosches. (Areh. f. mikrosk. Anat. Bd. 44, 1895, p. 185-206.) S. 79.

- Eine neue Methode der Methylenblaufixation. (Anatom. Anz. Bd. 12, 1596, p. 435.) S. 91.

- - Ein Beitrag zur Kenntnis des peripheren Nervensystems von Astacus fluviatilis. (Anatom. Anz. Bd. 12, 1596, p. 31-34.) S. S1. 
Bethe, A.: Vergleichende Untersuchumgen ïber die Funktionen des Centralnervensystems der Arthropoden. (Pflügers Arch. Bd. 6s, 1597, p. 449-545.) \$. 323.

- - Über die Primitivfibrillen in den Ganglienzellen vom Uenschen und andern Wirbeltieren. (Morpholog. Arb. Bd. 8, 1597, p. 95-116.) S. 19.

- Das Nerrensystem ron Carcinus Maenas. (Arch. fomikrosk. Anat. Bd. 50, 1597 , p. $460-546,559-639$ u. Bd. 51, 1598, p. 352-452.) S. 26, 133, 325, 354.

- - Die anatomischen Elemente des Nervensystems und ihre physiologische Bedeutung. (Biolog. Centralbl. Bd. 18, 189S, p. S43-874.) S. 323, 32S, 334.

- - Über die Neurofibrillen in den Ganglienzellen von Wirbeltieren und ihre Beziehungen zu den Golginetzen. (Areh. f. mikrosk. Anat. Bd. 55, 1900, 1). 513 bis 558.) S. $19,63,73$.

- - Einige Bemerkungen iiber die intracellulïren Kanälchen u. s. w. (Anat. Anz. Bd. 15, 1900, p. 304-309.) S. 149.

- - Über die Regeneration peripherischer Nerven. (Arch. f. Psychiatrie Bd. 34, Heft 3, 1901.) S. $15 \%$.

Bezold, A. von: Untersuchungen über die elektrische Ëregung der Nerven und Muskeln. Leipzig 1861. S. 275, 311.

v. Bezold und Uspensky: Über den Einfluß der hinteren Rückenmarkswurzehn auf die Erregbarkeit der vorderen. (Centralblatt f. d. medizin. Wissenschaften Bd. 5, 1867, p. 611 u. 819.) S. 381.

Bickel, A.: Beiträge zu der Lehre von den Bewegungen der Wirbeltiere. (Pflügers Arch. Bd. 65, p. 231, 1896.) S. 379.

- - Über den Einfluß der sensiblen Nerven und der Labyrinthe auf die Bewegungen der Tiere. (Pflïgers Arch. Bd. 67, 1597, p. 299-344.) S. 364.

Bidder und Volkmann: Die Selbständigkeit des sympathischen Nerven. Leipzig 1842.

Bi d der, F.: Über funktionell verschiedene und räumlich getremte Nerrenzentren im Froschherzen. (Arch. f. Anat. u. Physiol. 1852, p. 163.) S. 94.

Biedermann, W.: Rhythmische, durch chemische Reizung hedingte Kintraktionen gestreifter Muskeln. (Sitzber. d. Akademie Wien Bd. S2, Abt. III, 1880.) S. 391 .

_- Über die Erregbarkeit des Rückenmarks: (Sitzber. math.-naturw. Kl. Akad. Wien Bd. 87, Abt. 3, 1883, p. 210-242.) S. 318.

- U Über das elektromotorische Terhalten des Muschelnerven bei galvanischer Reizung. (Sitzber. Akademie Wien Bd. 93, Abt. III, 1886, p. 56-9S.) S. 273, $274,306,350,366$.

- - Über die Innervation der Krebsschere. (Sitzber. math.-naturw. Ǩl. Akad.

(1. Wissensch. zu Wien Bd. 97, Abt. III, 1885, p. 49-82.) S. 275, 306, 350, 385.

- C Üher die Einwirkung des Ithers anf einige elektromotorische Lrscheinumgen

an Muskeln und Nerven. (Sitzber. d. Akademie Wien Bd. 97, 1558, p. 84-123.)

S. 274 .

_ - Über den Ursprung und die Endigungsweise der Nerven in den Ganglien wirbelloser Tiere. (Jenaische Zeitschr. f. Naturwissenschaften Bd. 25, 1591, p. 429, Taf. $17-23$.$) S. 8, 26, 30, 33$.

-_ Elektrophysiologie. Jena, 1895. S. 250, 253, 274, 311, 318, 355.

- - Beiträge zur Kenntnis der Reflexfunktion des Rückenmarks. (I’flïgers Arch. Bd. 80, 1900, p. 408-469.) S. 375.

- Elektrophysiologie. (Ergebnisse der Physiologic. Abt. I, 1902, 1) 120 his 196.) S. 392.

Blanes, T.: Sobre algunos puntos dudosos de la estructura del bulbo olfatorio.

(Revista Trimestral Microgrifica. Tomo III, 1895, p. 99.) S. 62. 
Bochenek, A.: Contribution à l'étude de système nerveux des gasteropodes. (Le Nevraxe, p. 85, vol. III, 1901.) Sep. S. 40.

Bois-Reymond, E. du: Lntersuchungen ïher tierische Elektrizitiit. Berlin, 1sts, 1549,1854 . S. $250,311,313,344$.

- Über die elektromotorische Kraft der Nerven und Muskeln. (Arch. f. Anat. u. Physiol. 1867, p. $417-497[441-452]$.) S. 274.

- R. du: Über die Geschwindigkeit des Nervenprinzips. (Arch. f. Anat. u. Phys. 1900 , Supplementband, p. 68.) S. 346.

- U Über das angebliche Gesetz der reciproken Innervation antagonistischer Muskeln. (Arch. f. Physiol. 1902, Supplement, p. 27-44.) S. 37 .

Boruttau, H.: Neue Untersuchungen uiber die am Nerven unter der Wirkung erregender Einflïsse anftretenden elektrischen Erscheinungen. (Pflïgers Arch. Bd. 58,1894, p. 1-68.) S. 252.

- Untersuchungen über den Lungenvagus. (Pflügers Arch. Bd.61, 1595, p. $39-76$.$) S. 399$.

- Fortgesetzte Untersuchungen über die elektrischen Erscheinungen am thätigen Nerven. (Pflügers Arch. Bd. 59, 1895, p. 47-60.) S. 252.

- Nochmals iiber den Lungenvagus. (Centralbl. f. Physiol. Bd. 10, 1596, p. 817-822.) S. 399 .

- Weiter fortgesetzte Untersuchungen ïber die elektrischen Erscheinungen am tätigen Nerven. (Pflügers Arch. Bd. 63, 1896, p. 145-170.) S. 252.

- Der Elektrotonus und die phasischen Aktionsströme am marklosen Cephalopodennerven. (Pflügers Arch. Bd. 66, 1897, p. 285-307.) S. 252, 27 .

- - Ủber temporäre Modifikationen der elektrotonischen Ströme des Nerven. (Pfliigers Arch. Bd.68, 1897, p. 351-388.) S. 269, 274, 291, 310, 313.

- - Die Theorie der Nervenleitung. (Pflügers Arch. Bd. 76, 1899, p. 626-633.) S. 252 .

- - Die Aktionsströme und die Theorie der Nervenleitung. (Pflïgers Arch. Bd. 84, 1901, p. 309 u. Bd. 90, 1902, p. 233.) S. 252, 310, 314, 317, 320, 387.

- - Innervation der Atmung. (Ergebnisse der Physiologie, Abt. 2, 1902, p. 403 bis 408.) S. 398.

Bottazzi, Ph.: Richerche fisiologiche sul sistema nervoso viscerale delle Aplisie e di alcuni Cefalopodi. (Rivista di scienze biologiche Vol. 1, 1899, No. 11-12.) Sep. S. 370,391 .

- C Contribution à la physiologie du tissu des cellules musculaires. (Arch. italiennes de Biologie Vol. 31, 1899.) S. 391.

- - The action of the vagus and the sympathetic on the ösophagus of the toad. (Journal of Physiology. Vol. 25. 1899. p. 157-164.) S. 391.

Boveri*: (Abhandl. k. bayer. Akad. math.-phys. Kl. 1885.) S. 49.

Bowditseh, H. P. : Cher die Eigentimlichkeiten der Reizbarkeit, welche die Muskelfasern des Herzens zeigen. (Ber. k. sächs. Ges. Wiss. zu Leipzig. Math.phys. Kl. 1871, p. 652 .) S. $110,411$.

- Does the apex of the heart contract automatically? (Journal of Physiology Vol. 1, 1878, p. 104-10\%.) S. 411.

- Über den Nachweis der Unermüdlichkeit des Såugetiernerven. (Arch. f. Physiologie 1890, p. 505-508.) S. 319.

Fireman, E.: Experimentelle aufsteigende Degeneration motorischer und sensibler Hirnnerven. (Jahrbiich. f. Psychiatrie Bd. 11, 1592, p. 73-97, Taf.6-S.) 1). 180 .

Brener: Die Selbststeuerung der Atmung durch den Nervus vagus. (Sitzber. Akad. d. Wiss. zu Wien Bd. 5s, 1868, p. 909.) S. 398. 
Brondgeest, P. J.: Untersuchungen ïber den Tonus der willkïlichen Muskeln. (Arch. f. Anat. u. Physiol. 1560, p. 703.) S. 363.

Brown-Séquard: Existence de l'exeitabilité motrice et de l'excitahilité inhihitoire dans les régions occipitales et sphénoidales de l'écorce cérébrale. (Compt. Rend. de la Société de Biologie. Série 8, t. 1 (36), 1554, p. 301.) S. 379.

- - Dynamogénie. (Dietionnaire encyclopédique des sciences médieales série I, t. 30, p. 756 , Paris 1554.) S. 352 .

- - Inhibition. Dietionnaire encyclopédique des sciences médicales. Série IV, t. 16, Paris 1559.) S. 382,356 .

Bubnoff, N. und Heidenhain, R.: Über Erregnngs- und Hemmungsvorgänge innerhalb der motorischen Hirncentren. (Pflïgers Arch. Bd. 26, 1551, 1\%. 137.) S. 379 .

Bïhler, A.: Untersuchungen ïber den Bau der Nervenzellen. (Verhandl, d. physik.-med. Gesellsch. zu Würzburg. N. F. Bd. 31, 1895, Nr. 8, 2 Taf.) Sep. $\therefore 127,130,133$.

Biingner, 0. v.: Über die Degenerations- und Regenerationsvorgiinge am Nerven nach Verletzungen. (Zieglers Beiträge z. pathol. Anat. Bd. 10, 1591, p. $321-357$, Taf. 16 и. 17.) S. $154,155,158,186,200,207$.

B iirger, 0.: Beiträge zur Kenntnis des Nervensystems der Wirbellosen. Neue Untersuchungen über das Nerrensystem der Nemertinen. (Mitteil. d. zool. Stat. zu Neapel Bd. 10, 1891, p. 206, 2 Taf.) S. 26.

Bïrker, K.: Beiträge zur Physiologie des Elektrotonus. (Pflïgers Arch. Bd. S1, 1900 , p. $76-102$.) S. 273.

- Beiträge zur Physiologie des Elektrotonus. II. (Pflïgers Arch. Bd. 91, 1902 , p. $373-412$.) S. 273 .

Bütschli: Untersuchungen über mikroskopische Schäume und Protoplasma. Leipzig 1592. S. 48.

Carvallo, II.: Influence de la température sur la fatigue des nerfs moteurs de la grenouille. (Journal de Physiol. et de Pathol. génér. Bd. 2, 1900, p. 549 bis 556.) S. 316.

Cla us, C.: Der Organismus der Phronimiden. (Arbeit. aus d. zoolog. Inst. zu Wien Bd. 2, 1879.) S. 8.

Cremer, M.: Über Wellen und Pseudowellen. (Zeitschr. f. Biol. Bd. 40, 1900, p. $393-418$.$) S. 252$.

Cruikshank, W.: Versuche ïber die Nerven, besonders über ilıre Wiedererzeugung und ïber das Rïckenmark lebendiger Tiere. (Reils Arch. f. Physiol. Bd. 2, 1797, p. 57-71.) (Übersetzt aus: Philosoph. Transact. 1795, part 1, 1) 17\%.) S. 152 .

Cy o n, E.: Über den Einfluß der hinteren Nervenwurzeln des Rückenmarkes auf die Erregbarkeit der vorderen. (Berichte ïb. d. Verhandl. d. kgl. säichsischen Gesellschaft der Wissenschaften zu Leipzig. Math.-phys. Kl. Bd. 17, 1565; 1. - -5.) $\therefore .3-1$.

- - Über den Einfluß der hinteren Wurzeln auf die Erregbarkeit der vorderen. (Centralblatt f. die medizin. Wiss. Bd. 5, 1867, p. 643.) S. 381.

- - v.: Myogen oder Neurogen? (Pflitgers Arch. Bd. Ss, 1901, p. 225-294.) S. 423.

- - Le tétanos du cour. (Journ. de Phys. et de Pathol. grínér. 1900, p. 395 bis 404.) S. 110 .

Deiters, 0.: Untersuchungen über Gehirn und Riickenmark des Mensehen und der Sïugetiere. Braunschweig 1565. S. 5, S, 9, 13, 65. 
Dendrinos, G.: Über das Leitungsvermögen des motorischen Froschnerven in der Äthernarkose. (Pfliigers Arch. Bd. 58, 1902, p. 98-106.) S. 270.

Dickinson*: (Journal of Anat. and Physiol. Tol. 3, 1869.) S. 176.

Dickson: (Transact. of Pathol. Soc, of London Bd. 24, 1873.) S. 176.

Diet I, M.: Lutersuchungen ibler die Organisation des (iehims wirbelloser Tiere. (Sitzber. Akad. d. Wiss. Wien Bd. 77, 1878.) S. 8.

Dogie I, A. S. *: Über die nervösen Elemente in der Retina des Menschen. (Arch. f. mikrosk. Anat. Bd. 38, 1891.) S. 10.

- - Die Nervenendigungen in der Haut der äuferen fenitalorgane des Menschen. (Arch. f. mikrosk. Anat. Bd. 41, 1893.) S. 79, S0.

- Die sensiblen Nervenendigungen im Herzen und in den Blutgefäßen der Sängetiere. (Arch. f. mikrosk. Anat. Bd. 52, 1895, p. 44-69, Taf. IV-VI.) S. 79.

Dohrn, A.: Studien zur Urgeschichte des Wirbeltierkörpers. Nr. 17: Nervenfaser und Ganglienzelle. (Mitteil. d. zool. Stat. zu Neapel Bd. 10, 1891, p. 255 bis 341, Taf. 16-22.) S. 236.

- - Studien zur Urgeschichte des Wirbeltierkörpers. Nr. 20: Die Schwannschen Kerne, ihre Herkunft und Bedeutung. (Mitteil. d.zoolog. Stat. zu Neapel Bd. 15, H. 1 u. 2, 1901, p. 138-186.) S. $236,243$.

Donaggio, A.: Contributo alla conoscenza dell'intima struttura della cellula nervosa nei Vertebrati. (Rivista sperimentale di Freniatria Vol. 24, 189s. Sep.) S. 66.

- Nuove osservazioni sulla struttura della cellula nervosa. (Rivista sperimentale di Freniatria Vol. 24, 1899. Sep.) S. 66.

Duceschi, V: C̈her die Wirkung englegrenzter Nervenkompression. (Pflïgers Arch. Bd. 83,1900, p. $38-72$.) S. $257,262,358$.

Ebner, ron: Über die "Kittlinien“ der Herzmuskelfasern. (Sitzber. kais. Akad. Wien Bd. 109, Abt. III, 1900, p. 700-711.) S. 92.

Eckhard, C.: Der galvanische Strom als Hindernis der Muskelzuckung. (Zeitschrift f. rationelle Medizin N. F. Bd. 3, 1853, p. 198.) S. 272.

- Physiologie des nerfs et traitement du tétanos. (Recueil de travaux lus à la Société médicale allemande de Paris, Paris 1855, p. 1.) S. 272.

- - Ein Beitrag zur Theorie der Ursachen der Herzbewegung. (Eckhards Beiträge zur Anatomie u. Physiol. Gießen 1858, p. 147.) S. 417.

- - Über den Einfluß des konstanten Stromes auf die Erregbarkeit des motorischen Nerven. (Eckhards Beiträge zur Anat. u. Physiol., Giessen 1858, p. 25.) S. 272 .

- Allgemeine Physiologie der Ganglienzelle. (Handbuch der Physiologie. Herausgegeben von L. Hermann. 1s79, Bd. 2, II, p. 15-23.) S. 328 (363).

- Z Zur Kenntnis der erregenden Wirkungen des konstanten Stromes. (Eckhards, Beiträge zur Anatomie und Physiologie, Gießen 1858, p. 219 -226.) S. 275.

Edinger, L., und Wallenberg, A.: Bericht über die Leistungen anf dem Gebiete der Anatomie des Zentralnervensystems wïhrend der Jahre 1597 11. 1895. (Schmidts Jahrbiicher Bd. 262, 1899.) S. 332.

Efron, S.: Beitrïge zur allgemeinen Nervenphysiologie. (Pfliigers Arch. Bd. 36, 1585, p. $467-517$.) S. 257,269 .

Elirenberg, C. G.: Struktur des Gehirns und der Nerven. (Poggendorfs Annalen der Phys. u. Chem. Bd. 28, 1533, p. 449.) S. 4, 5 .

- Beobachtung einer auffallenden, bisher unerkannten Structur des Seelenorgans bei Menschen und Tieren. (Berlin 1836.) S. 4.

Elrlirh und lirieger: Cher die Ausschaltung des Lendenmarkgrau. Zeitschr. f. kilin. Merl. Mrkl. 7, 145t.) S. 331. 
Ehrlich, P.: Über die Methylenblaureaktion der lehenden Nervensulstumz. (Biolog. Centralbl. Bd. 6, 1857, p. 214-224.) S. 133.

- Farbenanalytische Untersuchungen zur Histologie und Kinik des lihtes. Berlin 1891.

_ - Über die Beziehungen ron chemischer Kionstitution, Verteilung und plarmakologischer Wirkung. (v. Leyden-Festschrift Bd. 1, 1901. Sep.) S. 133, 361.

Eichhorst, H.: Über Nervendegeneration und Nervenregeneration. (Virchows Arch. Bd. 59, 1574, 1) 1.) S. 154 .

Eimer, Th.: Die Medusen, physiologisch und morphologisch auf ihr Nervensystem untersucht. Tiibingen 1875. S. 9, 85, 106, 409.

Embden, G.: Primitivfibrillenverlauf in der Netzhaut. (Arch. f. mikrosk. Anat. Bd. 5\%, 1901, p. 570. Sep.) S. 10.

Engelmann, Th. W.: Zur Physiologie des Ureter. (Pfliigers Arch. Bd. 2, 1869, 1. 24:3.) $\therefore .123$.

- Über die Leitung der Erregung im Herzmuskel. (Pflïgers Areh. Bel. 11, 1575, p. 465.) S. $90,107,109,374,423,433,450$.

- - Über Degeneration von Nervenfasern. (Pflügers Arch. Bd. 13, 1576, 1) 4 it bis 491, Taf. 4.) S. $159,167$.

- - Vergleichende Untersuchungen zur Lehre von der Mnskel- und Nerrenelektrizität. (Pflïgers Arch. Bd. 15, 1877, p. 116-14s.) S. 311.

- - Zur Theorie der Peristaltik. (Areh. f. mikrosk. Anat. Bd. 15, 1575, 1). 255.) S. 123 .

- CUber die Diskontinuität des Achseneylinders und den fibrillären Bau der Yervenfasern. (Pflügers Areh. Bd. 22, 1580, p. 1-30, Taf. 1.) S. 50, 255.

- - (mit Hartog und Verhoeff): Der Bulbus artac des Froschherzens. (Pfliigers Arch. Bd. 29, 1882, p. 425-468.) S. 413.

- - Beobachtungen und Versuche am suspendierten Herzen. II. (Über die Leitung der Bewegungsreize im Herzen.) (Pflïgers Arch. Bd. 56, 1594, p. 149 bis 202.) S. $109,374,438,442,452$.

- - Refraktäre Phase und kompensatorische Ruhe in ihrer Bedeutung für den Herzrhythmus. (Pfliigers Arch. Bd. 59, 1895, p. 309-349.) S. 109, 423, 424.

- Über die Wirkungen der Nerven auf das Herz. (Arch. f. Physiol. 1900, p. $315-361$.) S. 443.

- - Über die bathmotropen Wirkungen der Herznerven. (Arch. f. Physiol. 1902, Supplement, p. 1-26.) S. 443.

Engelmann, W., und G. van Brakel: Über die peristaltische Bewegung, insbesondere des Darmes. (Pflügers Arch. Bd. 4, 1871, p. 33.) S. 123.

Erb, W.: Zur Pathologie und pathologischen Anatomie peripherer Paralysen. (Deutsches Arch. f. klin. Medizin Bd. V, 1869, 1).42-94, Taf. 1 11. 2.) S. $153,155$.

Ewald, J. R.: Physiologische Untersuchungen iiber das Endorgan des Nervus octarus. Wiesbaden 1592 . S. $364,365$.

Exner, S.: Experimentelle Untersuchung der einfachsten psychischen Prozesse. Abh. II. (Pflügers Arch. Bd. 8, 1874, p. 526.) S. $346,34 S^{\circ}$

- - In welcher Weise tritt die negative Schwankung dureh das Spinalganglion? (Arch. f. Physiol. 1577, p. 567-570.) S. 349.

- - Zur Kenntnis von der Wechselwirkung der Erregungen im Centralnervensystem. (Pfliigers Arch. Bd. 2S, 1552, 1). 457.) S. 353.

Fano, G., und Badano, F.: Sulla fisiologia del cuore embrionale del pollo nei primi stadi dello sviluppo. (Archịvio per le scienze mediche 13d. 14, is!l0, p. $113-162$.) S. 434 . 
Fick, 1.: Beitrige zu1 reroleichenden Physiologie der irritabilen Substanzen. Braunschweig 1563. S. 321, 345 .

Flemming, W.: Vom Bau der Spinalganglienzellen. (Beitrïge zur Anatomie und Embryologie. Festgabe für Henle. Bonn 1882, p. 12-25, Taf. II.) S. 127.

-.- - Dic struktur der Spinalganglienzellen bei siungetieren. Areh. f. Psychiatrie Bd. 29. Sep.) S. 56.

Flourens, P.: Recherches expérimentales sur les propriétés et les fonctions du système nerveux des animaux vertébrés. Paris 1842. S. 215.

Fontana, F.: Abhandlung iiber das Viperngift u. s. w. (Aus dem Französischen iibersetzt.) Berlin 1787 , p. $362-375$. S. 5, 182.

Forel*: Einige himanatomische Betrachtungen und Ergebnisse. (Arch. f. Psychiatrie Bd. 18, 1886, p. 191.) S. 177.

Forsmann: Zur Kemutnis des Neurotropismus. (Zieglers Beiträge Bd. 27, 1900.) S. $216,231$.

Fragnito, 0.: Lo sviluppo della cellula nervosa e i canalicoli del Holmgren. (Annali di Nevrologia, anno XVIII, 1900. Sep.) S. 246.

_ - Lo sviluppo della cellule nervosa nel midollo spinale di pollo. (Ammali di Nevrologia, anno XX, 1902.) S. 246.

Fredericq, L.*: Sur la cause de l'apnée. (Arch. de biologie Bd. 17, 1900, p. 561 bis 576.) S. 394 .

Freidenfeld, T.: Das centrale Nervensystem von Anodonta. (Biolog. Centralbl. Bd. XVII, 1897, p. 807-814, 2 Abbild.) S. 30.

Freusberg, A.: Über die Erregung und Hemmung der Täitigkeit der nervösen Centralorgane. (Pflügers Arch. Bd. 10, 1875, p. 174.) S. 375.

Frey, II. von: Über die tetanische Erregung von Froschnerven durch den konstanten Strom. (Arch. f. Physiologie 1883, p. 43-56.) S. 308.

Frommann, C.: Über die Färbung der Binde- und Nervensubstanz des Rïckenmarkes durch Argentum nitricum und iiber die Struktur der Nervenzellen. (Virchows Areh. Bd. 31, 1864, p. 129.) S. 13.

- - Zur Silberfärbung der Achsenzylinder. (Virchows Arch. Bd. 31, 1864, p. 151.) S. 13.

Fuld, E.: Über das Verhalten des Sphincter ani bei Hunden mit extirpiertem Lendenmark. (Dissertation, Straßburg 1695.) S. 365.

- - Üher gegenseitige Beeinflussmng (Interferenz) zweier Erregungen im Nerven. (Pflïgers Arch. Bd. 51, 1900, p. 381-398.) S. 387.

Funke, 0.: Über die Reaktion der Nervensubstanz. (Arch. f. Anat. u. Physiol. 1859 , p. $835-846$.)

- - Über Säurebildung im Nerven. (Centralbl. f. medizin. Wissensch. 1869, p. $721-723$.

Gad, J.: Die Regulierung der normalen Atmung. (Arch. f. Phy siol. 18s0, p. 1.) S. 399 .

- - Über Trennung von Reizbarkeit und Leitungsfähigkeit des Nerren nach Versuchen des Herrn Sawyer. (Arch. f. Physiol. 1588, p. 395-402.) S. 269. 269.

- "Wher Leitungsfihigkeit und Reizharkeit der Nerven in ihren Beziehumgen zur Läings- und Quererregbarkeit" nach Versuchen des Herrn Dr. Piotrowski. (Arch. f. Physiol. 1889, p. 350-361.) S. 269.

Gaskell, W. H.: On the innervation of the heart, with especial reference to the heart of the tortoise. (Journal of Physiology Bd. 4, 1854, p. 43-127.) S. $374,423,446$. 
Gedoelst*: (La Cellule Bd. 5, 1859.) S. 50.

Gehuchten, van*: L'anatomie fine de la cellule nerveuse. (XII. Congres international de Médicin à Moseou 1597.) S. 150, 179.

- - Conduction cellulipete ou axipète des prolongements protoplasmatiques. (Bibliographie anatomique, 2, 1899. Sep.) S. 330.

Gehuchten, van, et Biervliet, van we: Le noyan de l'oculo-moteur commun, 16, 19 et 21 mois après la resection du nerf. (Le Nevraxe Vol. 2, fase. 2.) S. 179 .

Gerlach, J.: Von dem Riickemmark. (Strickers Handbuch der Lelıre von den Geweben Bd. 2, Leipzig 1872, p. [665] 677-655 [693].) S. S, 9.

Gerlach, Leo: Über die Nervenendigungen in der Muskulatur des Froschherzens. (Virchows Arch. Bd. 66, 1876, p. 187-223.) S. 91.

Goldscheider, A.: Zur allgemeinen Pathologie des Nervensystems. (Berliner klin. Wochenschr. Bd. 31, 189t, p. 421-425 11. 444-147.) S. 166, 17.

Goldscheider, A., und Flatau, E.: Normale und pathologische Anatomie der Nervenzellen. Berlin 1898. S. 150, 152.

Golgi, C.: Untersuchungen über den feineren Bau des centralen und peripherischen Nervensystems. (Aus dem Italienischen iibersetzt von 'Teuscher. Jena 1594.) S. 9, 47, 68, 79 .

-- - Sulla struttura delle cellule nervose dei gangli spinali. (Bollettino della Societả medico-chirurgica di Pavia 1598. Sep.) S. 65, 149.

- - Intorno alla struttura delle cellule nervose. (Bollettino della Societi medicochirurgica di Pavia 1898. Sep.) S. 65, 149.

- Di nuovo sulla struttura delle cellule nervose dei gangli spinali. (Bollettino della Società medico-chirurgica di Pavia 1899. Sep.) S. 149.

Goltz, Fr.: Über die Bedeutung der sogenamnten automatischen Bewegungen des ausgeschnittenen Froschherzens. (Virchows Arch. Bd. 21, 1861, p. 191.) S. $409,423,454$.

- Über die Ursachen der Herztätigkeit. (Virchows Arch. Bd. 23, 1862, p. 45\%.) S. $409,423,454$.

- - Beiträge zur Lehre von den Funktionen der Nervencentren des Frosches. Berlin 1869. S. $354,374,379,386$.

- Studien ïber die Bewegungen der Speiseröhe und des Magens des Frusches. (Pfliigers Arch. Bd. 6, 1872, p. 616-612.) S. 115, 121.

- UUber die Verrichtungen des Großhirns. (Pfliigers Areh. Bd. 13 u. 14, 1876. Bd. 20, 1879. Bd. 26, 18s1. Bd. 34, 18s4. Bd. 42, 18s5. Bd. 51, 1892.) S. 375,379 .

Goltz, Fr., und Ewald, J. R.: Der Hund mit verkürtem Riickenmark. (Pfluigers Arch. Bd. 63, 1896, p. 362-400.) S. 365.

Goteh, Fr.: The submaximal electrical response of nerve to a single stimulus. (Journal of Physiol. Vol. 28, 1902, p. 395-416.)

Gotch, Fr., and Macdonald, J. S.: Temperature and excitability. (Journal of Physiol. Vol. 20, 1896, p. 247-297.)

Gotch, Fr., and Burch, G. J.: The electrical response of nerve to two stimuli (Journal of Physiol. Vol. 24, 1899, p. \$10-126.) S. 315.

Gottlieb, R.: Theorie der Narkose. (Ergebnisse d. Physiologie Jahrg. 1, Abt. II, 1902 , p. $666-679$.$) S. 358$.

Gïtz, St.: Über die feinere Struktur des Nervensystems von Astacus fluviatilis. (Értesitö, Sitzber. d. med.-naturwiss. Sektion d. Siebenbïrgisehen Museumvereins Abt. II, Revue, Bi. XXI, 1s99, 1. 21-22. Sep.) S. 39.

- J.: Adatok az Astacus fluviatilis. (Értesitio Bd. XXI, 1900, p. 63-71. Sep.) S. 39 .

Bothe, Nervensystem. 
Gruenhagen, A.: Versuche über intermittierende Nervenreizung. (Pflïgers Arch. Bd. 6, 1S72, p. 157-181, v. 150.) S. 269.

Gruithuisen, P. v.: Über die Empfindungen und Gefühle durch einen aloge-

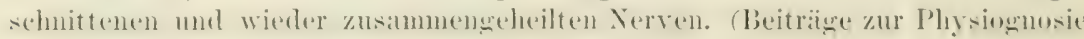
und Eautognosie, Mïnchen 1812, p. 74-79.) S. 183.

Gruitzner, P.: Über die negative Schwankung des Nervenstromes bei nicht elektrischer Reizung. (Pflügers Arch. Bd. 25, 1851, p. 255-281.) S. 314.

- - Über die Reizwirkung der Stöhrersehen Maschine auf Nerv und Muskel. (Pflïgers Areh. Bd. 41, 1887, p. 256-281.) S. 350.

Günther und Schön: Versuche und Bemerkungen über Regeneration der Nerven und Abhïngigkeit der peripherischen Nerven von den Zentralorganen. (Mïllers Arch. 1840, p. 270.) S. 152.

Gurwitsch, A.: Die Histogenese der Schwamnschen Scheide. (Areh. f. Anatomie. 1900, p. S5-94.) S. 235.

Guttmann, T.: Zur Lehre ron dem Einfluß der hinteren Riickenmarkswurzeln auf die Erregbarkeit der vorderen. (Centralbl. f. d. medizin. Wissenseh. Bd.5, 1567, p. 659.) S. 381 .

- Z Zur Lehre von den Atembewegungen. (Arch. f. Physiol, 1875, p. 500.) S. 398 .

Ha ene1, H.: Gedanken zur Neuronfrage. (Berliner klin. Wochenschr. 1903, No. 8 u. 9. Sep.) S. 192.

Haighton, J.: Versuche uiber die Reproduktion der Nerven. (Reils Arch. f. Physiol. Bd. 2, 1797, p. 71-86.) (Übersetzt aus: Philosoph. Transact. 1795. part 1, p. 190.) S. 183.

Hall, Marsha11: Abhandlungen iiber das Nervensystem. Übersetzt ron Kürschner. Marburg 1840.

Halliburton, W. D.: On the chemical side of nervous activity. Croonian lectures, London, John Bale, 1901. S. 161.

Hällstén, R.: Elektrotonus in sensiblen Nerven. (Arch. f. Physiol., 1880. p. 112.) S. 273.

Hannover, A.: Recherches microscopiques sur le système nerveux. Copenhague, Paris \& Leipzig, 1544. S. 6.

II arless, F.: Briefliche Mitteilung über die Gamglienkugeln der Lobi electrici von Torpedo Galvanii. (Miillers Arch. 1s46, p. 282.) S. 6.

- Molekuläre Vorgänge in der Nervensubstanz. I. Abhandlung S. 313. II. S. 529. III. S. 683. (Abhandl. d. math.-physik. Kl. bayer. Akad. d. Wissensch. Bd. S, 1860.) S. 381 .

Harrison, R. G.: Über die Histogenese des peripheren Nervensystems bei Salmo salar. (Arch. f. mikrosk. Anat. Bd. 57, 1901, p. 354-444, Taf. 18-20.) S. $235,246$.

Havet, J.: Note préliminaire sur le système nerveux des Limax. (Anat. Anz. Bd. XVI, 1899, p. 241-248.) S. 25, 26.

- Contribution à l'étude du système nerveux des Actinies. (La Cellule. T. 18, 1901, 1. 357-419, 6 Taf. Sel.) S. 21.

Head, H.: Über die negativen und positiven Schwankungen des Nervenstromes. (Pfliigers Arch. Bd. 40, 1857, p. 207-273). S. 253, 314, 320.

Heidenhain, G.: Über den Einfluß der hinteren Riickenmarkswurzeln auf die Erregbarkeit der vorderen. (Pflïgers Arch. Bd. 4, 1871, p. 435.) S. 381.

- MI.: Über die Struktur des mensehlichen Herzmuskels. (Anat. Anz. Bd. 20, 1901, p. 49-78, 2 Taf., 13 Abbildungen.) S. 446. 
Il eidenhain, MI.: Über chemische Umsetzungen zwischen Eiweißkïrpern und Anilinfarben. (Pfliigers Areh. Bd. 90, 1902, p. 115-230.)

- R.: Historisches und Experimentelles iiber Muskeltonus. (Heidenhain : Physiolog. Untersuch., Berlin 1556, p. 11-45.) S. 363.

- - Erörterungen ïber die Bewegungen des Froschherzens. (Arch. f. Auat. u. Physiol. 1559, p. 479.) S. 110, 113 .

- Über Erregung und Hemmung. (Bemerkungen zu einem Vortrage, des Herrn H. Munk.) (Pfliigers Areh. Bd. 26, 1581, p. 546.) S. 350, 356.

Heidenhain, R., und Colberm, A.: Tersuche iber den Tonus des 1Basenmuskels. (Arch. f. Anat. u. Physiol. 1855, p. 437.) S. 365.

If eld, H.: Beiträge zur Struktur der Nervenzellen und ihrer Fortsïtze. Erste Abhandlung. (Arch. f. Anatomie. 1595, p. 396-416, Taf. 12 u. 13.) S. 4S, 129, $132,135,142$.

- - Beitrïge zur Struktur der Nervenzellen und ihrer Fortsïtze. (Areh. f. Anatomie. 1897. Sep.) S. 65, 69.

- - Über den Bau der grauen und weißen Substanz. (Arch. f. Anatomie. 1902, p. 159-224, Taf. $12-14$.$) S. 71,74$.

Helmholtz, H.: Jessungen über den zeitlichen Verlauf der Zuckung animalischer Muskeln und die Fortpflanzungsgeschwindigkeit der Reizung in den Nerven. (Arch. f. Anat. u. Physiol. 1850, p. 276-364.) S. 249, 313, 345.

- Messungen iber Fortpflanzungsgeschwindigkeit der Reizung in den Nerven. (Arch. f. Anat. u. Physiol. 1852, p. 199-216, Taf. 7.) S. $249,345$.

- - Über die Geschwindigkeit einiger Vorgänge in Mruskeln und Nerven. (Terhandl. Akad. d. Wissensch. zu Berlin 1554, p. 328-332.) S. 249.

- - Über die Geschwindigkeit einiger Vorgänge in Muskeln und Nerven. (Terhandl. Akad. d. Wissenseh. Berlin 1859, p. 328.) S. $249,346$.

Hensen, Y.: Über die Entwicklung des Gewebes und der Nerven im Sehwanze der Frosehlarve. (Virchows Arch. Bd. 31, 1864, p. 51.) S. 234.

Hering, E. Über positive Nachschwankung des Nervenstromes nach elektrischer Reizung. (Sitzber. Akademie Wien Bd. S9, Abt. III, 1854, p.137-155.) S. 253.

- Z Zur Theorie der Jorgänge in der lebendigen Substanz. (Lotos. Bd. 9, 1589, p. $35-70$.) S. $253,273,293,314$.

Hering, H. E.*: Beiträge zur Frage der gleichzeitigen Tätigkeit antagonistiseh wirkender Muskeln. (Zeitschr. f. Heilkunde Bd. 16, 1595.) S. 377.

- - Über Bewegungsstörungen nach centripetaler Lähmung.' (Arch. f. exper. Pathol. 11. Pharmakol. Bd. 38, 1897, p. 266-283.) S. 364.

- - Über, die gegenseitige Abhängigkeit der Reizbarkeit, der Kontraktilitiit und des Leitungsvermögens der Herzmuskelfasern und ihre Bedentung für die Theorie der Herztiitigkeit und ilırer Störungen. (Pfliigers Arch. Bd. S6, 1901, p. $533-555$.) S. 443,44 .

- Die intrazentralen Hemmungsvorgïnge in ihrer Bezichung zur skelettmuskulatur. (Ergebnisse der Physiologie Abt. 2, 1902, 1).503-533.) S. 376.

Hermann, L.: Beitrag zur Erledigung der Tonusfrage. (Arch. f. Anat. u. Physiol. 1861, 1. 350-360.) S. 363.

- - Über eine Wirkung galvanischer Ströme auf Muskeln und Nerven. (Pfligers Arch. Bd. 5, 1872, p. 223-272 u. Bd. 6, 1572, p. 312-360). s. 250. 273.

_ - Das galvanische Verhalten. einer durchflossenen Nervenstrecke wiihrend der Erregung. (Pfliigers Areh. Bd. 6, 1572, 1) 560-567.) S. 250.

- Fortgesetzte Untersuchungen iiber die Bezichungen zwischen Polarisation und Erregung im Nerven. (Pfliigers Arch. Bd. 10, 1875, p. 215-239 [226-231]). S. 250 . 
II r m in n n. L.: Lntersuchumgen üher die Aktionsitrüme des Nerven. (I. Pfliigers Arch. Bd. 18, 1878, p. 574-586. II. Pfliigers Arch. Bd. 24, 1881, p. 246-294). S. 250,313 .

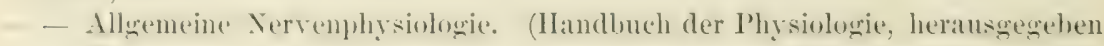
yon Hermann, Bd. II, Teil 1, Leipzig 1879, p. 3-196.) S. 250 f., 271, 311, 316. - - Zur Theorie der Erregumgsleitung und dar elektrischen Erregung. Pfliigers Arch. Bd. 75,1899, p. $574-590$.) S. $250,31 \%$.

- - Die Irreciprocitït der Reflexiibertragung. (Pflïgers Arch. Bd. 80, 1900, p. $41-47$.$) S. 342$.

Hermann, L., und Weiss, 0.: Über die Entwicklung des Elektrotonus. (Pfliigers Arch. Bd. 71, 1898, p. 237-295.) S. 273.

Hermann, L., und Tsehitschkin, A. W.: Die Erregbarkeit des Nerven im Elektrotonus. (Pfliigers Arch. Bd. 78,1899 , p. 53-63.) S. 273.

Hertwig, 0., und R.: Das Nervensystem und die Sinnesorgane der Medusen. Leipzig 1878. S. 9, 21, 85.

Herzen, A.: Expériences sur les centres modérateurs de laction réflexe. (Dissertation [Berne]. Florence 1864.) S. 378.

- - Ist die negative Schwankung ein unfehlbares Zeichen der physiologischen Nerventiitigkeit? (Centralbl. f. Physiol. Bd. 13, 1899, p. 455-458.) S. 314.

Hesse, R.: Über das Nervensystem und die Sinnesorgane von Rhizostoma Cuvieri. (Tüibing, 'zool. Arbeiten 1. Bd. p. 55, 1895, u. Zeitschr. f. wissensch. Zoologie Bd. 60. Sep.) S. $86,88$.

Heymans et Demoor: Etude de l'innervation du cœur des vertébrés à l'aide de la méthode de Golgi. (Mémoir. couronnés etc. publiés par l'Acad. roy. de médec. de Belgique T. 13, 1894, fasc. 5, p. 1-55, Taf. 1-25.) S. 91.

Hirschberg, E。: In welcher Beziehung stehen Leitung und Erregung der Nervenfasern zueinander? (Pfliigers Arch. Bd. 39, 1886, p. 75-95.) S. 269.

II is, W.: Untersuchungen iber die erste Anlage des Wirbeltierleibes. Die erste Entwicklung des Hïhnchens im Ei. Leipzig 1868. S. 234.

- C Ther das Anftreten der weißen substanz und der Wurzelfasern am Rückenmark menschlicher Embryonen. (Arch.f. An at. 1883.) S. 234.

- Zur Geschichte des menschlichen Riickenmarkes "und der Nervenwurzeln. (Abh. math.-phys. Kl. kgl. sächs. Ges. d. Wiss. Bd. 13, Leipzig 1s86, p. 479 his 514, 1 Taf., $\therefore .234$.

- - Die Entwicklung der ersten Nervenbahnen beim menschlichen Embryo. Übersichtliche Darstellung. (Arch. f. Anat. 1887, p. 368-378.) S. 234.

- - Die Neuroblasten und deren Entstehung im embryonalen Mark. (Arch. f. An at. 1889, p. 249-300, Taf. 16-19. Auch in: Abh. kgl. sächs. Ges. d. Wiss. zu Leipzig Bd. 26.) S. 234.

- - Histogenese und Zusammenhang der Nervenelemente. (Arch. f. A na t. 1890, Suppl. p. 95-117.) S. 234, 246.

His, W. jun.: Die Entwicklung des Herznervensystems bei Wirbeltieren. (Abh. d. math.-phys. Kl. kgl. sächs. Ges. d. Wiss. zu Leipzig Bd. 18, 1891.) S. 434. - - Die Tätigkeit des embryonalen Herzens und deren Bedeutung für die Lehre von der Herzbewegung beim Erwachsenen. (Arbeit. d. mediz. Klinik zu Leipzig, Herausgeb. Curschmann, 1893, p. 14.) S. 434.

- - Centralbl. f. Physiol. Bd. 9, 1895, p. 469.) S. 447.

IIjelt: Über die Regeneration der Nerven. (Virchows Arch. Bd. 19, 1861, p. 352.) S. 153,184 .

Hoche, A. Die Neuronenlehre und ihre Gegner. Berlin 1899.

II odge, C. F.: A microscopical study of changes due to functional activity in nerrecells. (Journ. of Morphology Vol. 7, 1892, p. 95-168.) S. 150. 
Hodge, C. F.: Die Nervenzelle bei der Geburt und beim Tode an Altersschwälche. (Anat. Anz. Bd. 9, 1594, 1).706-710, 4 Abbild.) S. 150.

H ofmann, F. B.: Über die Funktion der Scheidewandnerven des Froschherzens. (Pflïgers Arch. Bd. 60, 1595, p. 139-172.)

- Beitriige zur Lehre von der Herzimnerration. (Pflïgers Areh. 13d. 72, 1595. p. $409-466$.) S. 443 .

- Studien über den Tetanus. (Pfliigers Areh. Bd. 93, 1902, p. 186-235.) S. 357 .

II of mann, F. B. und Amay a, S.: Über scheinbare Ilemmumen am Nervenmuskelprïparate (H.) (Pfliigers Arch. Bd. 91, 1902, p. 425-433.) S. 357.

Holmgren, E.: Studier öfver Hudens och de Körtelartade Hudorganens MLrfologi hos Skandinaviska Makrolepidopterlarver. (Kgl. Svenska VentenskapsAkademiens Handlinger Bd. 27, 1895, 9 Tafeln.) S. 81.

- Zur Kenntnis des Hautnervensystems der Arthropoden. (Anat. Anz. Bd. XII, 1896, p. 449-457, 7 Abbild.) S. 12, S1.

- Zum Aufsatze W. Schreibers: „Noch ein Wort iiber das peripherische sensible Nervensystem bei den Crustaceen." (Anat. Anz. Bd. XrV, 1895, p. 409.) S. 81 .

- Studien in der feineren Anatomie der Nervenzellen. (Bonnet-Merkels Anat. Hefte Bd, 15, 1900. Sep.) S. 149.

- Weitere Mitteilungen iiber die Saftkanälchen der Nervenzellen. (Anat. Anz. Bd. 18, 1900. Sep.) S. 149.

- - Nervenzellen. (Anat. Hefte H. 59, S. 269, Jahrg. 1901. Sep.) S. 149, 150.

- Über die "Saftkanälchen" der Leberzellen 11. s. w. (Anat. Anz. Bd. 22. 1902 , p. $9-14,3$ Abbild.) S. 149.

Hörmann: Die Kontinuität der Atomverkettung, ein Strukturprinzip der lebendigen Substanz. Jena 1899. S. 254.

Howell, W. H. and $\mathrm{Huber}$, G. C.: A physiological, histological, and clinical study of the degeneration and regeneration in peripheral nerve fibres after severance of their connections with the nerve centres. Journal of Physiol. Vol. 13, 1892, p. 333-406, Taf. 12-17 u. Vol. 14, 1893, p. 1-51.) S. 155,186 , 200,207 .

Jordan, H.: Die Physiologie der Lokomotion bei Aplysia limacina. (Dissertation. Bonn 1901, u. Zeitschr. f. Biologie Bd. 41, 1901, p. 196-235.) s. 113, $115,116,368,370,371,379$.

Ka iser, K.: Eine Hemmungserscheinung am Nervenmuskelpriparat. (Zeitschr. f. Biologie Bd. 2S, 1891, p. 417-432.) S. 357 .

- - Untersuchungen iiber die Ursache der Rhythmizitiit der Iferzbewegungen. (Zeitsch. f. Biologie Bd. 30, 1894, p. 279-316.) S. 418.

Kallius*: Untersuchungen über die Netzhaut der Süugetiere. (Anat. Hefte Bd. $3,1894$.$) S. 10$.

$\mathrm{K}$ a nellis: Influence des racines sensitives sur l'excitabilité des racines motrices. (Comptes rendus de l'Académie des Sciences Bd.96, 1553.) S. 351.

Kaplan, L.: Nervenfïrbungen. (Arch. f. P'sychiatrie Bd. 35, 1902, II. 3, T'af. 20. Sep.) S. 137 .

Kennedy: On the regeneration of nerves. (Philosoph. 'Transact. Vol. 155 B, 1897.) S. 187.

Kent, Stanley, A. F.: Researches on the structure and function of the mammalian heart. (Journal of Physiology Vol. 14, 1593, 1. 233-254, 'T'af. 12.) S. 446 . 
Kïlliker, A.: Die Selbstindigkeit und Abhängigkeit des sympathischen Nervensystems. (Akademisches Programm, Ziirich 184t.) S. 6.

- - Physiologische Untersuchmgen iiber die Wirkung einiger Gifte. (Virehows Arch. Bid. 10,1556, p. 1 u. 235.) S. 435.

- Ilandbuch der Gewebelehre des Menschen. 3. Aufl., Leipzig 1859. S. 4,9.

- Histologische Studien an Batrachierlarven. (Zeitschr. f. wissensch. Zoolog.

Bd. 43,1586 ). S. $235,244$.

- I Iandbuch der Gewebelehre des Menschen. 6. Aufl., Bd. 2, Leipzig 1896.

s. $10,47,67$.

- - Gegen die Entstehung von Nervenfasern aus Zellenstrïngen. (Anat. Anz.

Bd. 1S, 1900, p. 511 u. 512.) S. 235.

Kölliker, Th.: Die Verletzungen und chirurgischen Erkrankungen der peripherischen Nerven. (Deutsche Chirurgie. Heransgegeb. von Billroth u. Luecke, Lief. 24 b, Stuttgart 1890.) S. 215, 216.

Korybutt-Daszkiewicz: Degeneration und Regeneration der markhaltigen Nerven U. S. w. (Dissertation, Straßburg 1878.) S. 153.

Kreh 1, L., und Romberg, E.: Über die Bedentung des Herzmuskels und der Herzganglien für die Herztätigkeit des Säugetiers. (Arbeit. aus d. medizin. Klinik zu Leipzig. Herausgegeb. v. Curschmam 1893, p. 50-95.)

Kries, von: Über summierte Zuckungen und unvollkommenen Tetanus. (Berichte der naturforseh. Gesellsch. zu Freiburg i. B. Bd. 2, 1887, p. 37-43.)

Kronecker, II., und Stirling, W.: Die Genesis des Tetanus. (Arch. f. Physiol. 187s, p. 1-40.)

Kronecker, H. (Mays, Th.): Über Änderungen der Leistungsfähigkeit und (ler Erregbarkeit des ermiidenden Froschherzens. (Arch. f. Physiol. 1883, p. $263-268$.) S. 411.

Krontha1, P.: Von der Nervenzelle und der Zelle im allgemeinen. Jena 1902. s. 247 .

Kropeit, A.: Die Kohlensäure als Atmungsreiz. (Pflïgers Arch. Bd. 73, 1898, p. $438-441$.$) S. 394$.

K ïhne, W.: Untersuchungen über Bewegungen und Veränderungen der kontraktilen Substanz. (Arch. f. Anat. 11. Physiol. 1859, p. 564-642.) S. 108.

_ - Über die chemische Reizung der Muskeln und Nerven und ihre Bedentung: für die Irritabilitiatsfrage. (Arch. f. Anat. u. Physiol. 1560, p. 315.) S. 108.

_ - Über das doppelsinnige Leitungsvermögen der Nerven. (Zeitschr. f. Biologie Bd. 22, 1886, p. 305-353.) S. 344 .

Kithne, W., und Steiner, S.: Beobachtungen über markhaltige und marklose Nervenfasem. (Untersuch. aus d. physiol. Instit. zu Heidelberg Bd. 3, 1880, p. $149-170$.$) S. 311,344$.

Kupffer*: (Abhandl. d. kgl. bayer. Akad. matlı.phys. Kl. 1s83.) S. 15, 47.

Langendorff, O.: Über Reflexhemmung. (Arch. f. Physiol. 1877, p. 96-115). S. 379 .

- Die Beziehungen des Sehorganes zu den reflexhemmenden Mechanismen des Froschgehirns. (Arch. f. Physiol. 1877, p. 435-442.) S. 379.

- - Studien ïber Rhythmik und Automatie des Froschherzens. (Arch. f. Physiol. 1884, Suppl., 1. 1-133.) S. 419.

- Zur Lehre von der Rhythmizitït des Herzmuskels. (Pflïgers Areh. Bd. 57, 1894, p. 409-417.) S. 418 .

- Die Reaktion des Herzmuskels auf Dauerreize. (Pflïgers Areh. Bd. 61, 1895$, p. $333-339$.$) S. 41$ S. 
La ngendorff, 0.: IIerzmuskel und intracardiale Innervation. (Ergebnisse der Physiologie 13d. II, 1902, p. 263-3.15.) S. 109, 332, 423, 415.

Langley, J. N.: Note on the experimental junction of the Varns nerve with the cells of the superior cervical ganglion. (Proceed. royal Soc. Vol. 62, 15!7, p. 331 .) S. 231 .

- - Stimulation and paralysis of Nerve-Cells and of Nerve-Endings. (Journal of Physiol. Vol. 27, 1901, p. 224-236.)

Langley, J. N., and Anderson, II. K.: Ohservations on the remeneration of nerve-fibres. (Proceedings of the I'hysiol. Society. Dee. 13, 1902. Sommal of Pliysiology. Vol. 29.) S. 164, 192, 220.

Leeuwenhoek, A.: De structura cerebri cpistola. (Delftac 16s\$, Op. II, 1) 35.) $\therefore 4 . ;$.

- Epistolate physiologicae. (Epistola XXXII, XXXVI u. XLY. Delphis 1719.) S.5.

Lehmann, 0.: Molekularphysik. Leipzig 1S8s. Bat. 1, p. 824-834. S. 292.

Lenhossék, M. von: Ursprung, Verlauf und Enidigung der sensiblen Nervenfasern bei Lumbricus. (Arch. f. mikrosk. Anat. Bd. 39, 1592, p. 102-136, Taf. 5.) S. 26,30 .

- - Der feinere Bau des Nervensystems im Liehte nenester Forschungen. 2. Aufl., Berlin 1595. S. 10, 47, 67, 166, 235, 326, 332.

- Centrosom und Sphïre in den Spinalganglienzellen des Frosches. (Arch. f. mikrosk. Anat. Bd. 46, 1595 , p. $345-369$, 'af. 15 u. 16.) S. 149.

- Kritisches Referat iiber die Arbeit A. Bethes: „Die anatomischen Elemente des Nervensystems und ihre physiologische Bedentumg." (Nemrolog. Centrall)l. 1899. Sep.) S. 332.

Leontowitseh, A.: Nene Tatsachen über Hantsimn. Teil 1: Innervation der Menschenhaut (russisch). (Mémoires de l'Académie impériale des Sciences de St. Pétersbourg 1900, Vol. 9, No. 9.) S. So.

Lew andowsky, I.: Über den Lungenragus. (Centralbl. f. Physiol. Bd. 10, 1S96, p. $601-606$.$) S. 399$.

- U Über die Sehwankungen des Vagusstromes bei Volumänderung der Lunge. (Pfliigers Arch. Bd. 73, 1895, p. 258-296.) S. 399.

Lewis, Margaret: Centrosome and sphere in certain of the Nerve Cells of an Invertebrate. (Anatom. Anzeiger Bd. 12, 1896, 1. 291.) S. 149.

Leydig, Fr.: Vom Bau des tierischen Körpers. Tübingen 1s64. S. S.

- - Zelle und Gewebe. Bom 15s5. S. S.

Libertini, G.: Sulla localizzazione dei poteri inibitori nella corteggia cerebrale. (Arehivio per le scienze mediche Vol. 19, p. 337, 1595.) S. 379.

Loeb, J.: Einleitung in die vergleichende Gehimphysiologie und vergleichende P'sychologie. Leipzig 1599. S. 23, 25, 112, 323, 410.

- Über Ionen, welche rhythmische Zuckungen der Skelettmuskeln hervorrufen. (Festschrift für Fick: Beitrïge zur Physiologie. Braumsehweig 1 s!9. Sep.) S. 391.

- - On the different effect of Jons upon myogenie and neurogenie rhy thmical contractions and upon embryonic and muscular tissue. (American Journ. of Physiology Bd. 3, 1900, p. 3S3-396. Sep.) S. 419.

Lomakina, Nadine: Über Terlauf und Bedeutung der Herznerven. ('Leitsehr. f. Biologie Bd. 39, 1900, p. 377-129.) S. 447.

Lovén, Chr.: Üher die Einwirkung von einzehen Inductionssehligen anf den Vorhof des Froschherzens. (Mitteil. vom physiol. Labor, des Carolin. Instit. in Stockhohn Heft $4,1886$.$) S. 123$.

Löwit, M.: Beiträge zur Kenntnis der Imnervation des Froschherzens. (l’lïgers Arch. Bd. 23, 1850, p. 313.) S. $90,417$. 
Lijwit. II.: Beitriige zur Kemtnis der Imervation des Herzens. (Pfligers Arel. Bd. 25, 1881, p. 399.) S. $447,448$.

Longet, F. A.: Traité de physiologie. Paris 1569. S. 162.

Ludwig: Lehrbuch der Physiologie des Menschen. Heidelberg 1552. S. 327.

L udwig, J. II., und Luchsinger, B.: Zur Physiologie des Herzens. (Pfliigers Arch. Bd. 25, 15s1, p. 211.) S. 416.

Lugaro, E.: Sulla struttura delle cellule dei Gangli spinali nel cane. (Rivista di Patologia nervosa e mentale Vol. III, 1998, p. 433. Sep.) S. 56, 132, 150.

Manelli, M.: Sopra aleuni fatti di inibizione riflessa osservati sui nervi periferici. Livista sperimentale di Freniatrial e di Jfedicina lenale Vol. XXII. fasce. I. 1896. Sep.) S. 383.

II ann, G.: Histological changes induced in sympathetic, motor, and sensory nerve cells by functional activity. (Journal of Anat. and Physiol. Vol. 29, 1894, p. 100-10s, Taf. 1. Sep.) S. 150.

_ - Die fibrillïre Struetur der Nervenzellen. (Verhandl. der anatom. Gesellsch. in Kiel. 1898. Anatom. Anz. Bd. 14. Ergäinzungsheft, p. 39-40). S. 50, 148.

Marcacei, A.: Nuovo fatto in farore della sinergia funzionale delle paia spinali. (Archivio per le Scienze mediche Vol. V, 1552, p. 253.) S. 381.

Marchand, R.: Beiträge zur Kenntnis der Reizwelle und Kontraktionswelle des Herzmuskels. (Pfliigers Areh. Bd. 15, 1877, 1) 511.)

- Der Verlauf der Reizwelle des Ventrikels bei Erregung desselben rom Forhof aus und die Bałn, auf der die Erregung zum Ventrikel gelangt. (I'liigners Arch. Bd. 17, 1878, p. 137.) S. 447.

II are y, E. L.: Des excitations électriques du cœur. (Travaux du Laboratoire de Narey 1576, p. 63-86.) S. $390,413,423$.

MI a rkwald, M., u. Krone cker, H.: Über die Auslösung der Atembewegungen. (Arch. f. Physiol. 1850, 1). 441.)

Narinesco, G.: Über Verïnderungen der Nerven und des Rüickenmarks nach Amputationen; ein Leitrag zur Nerventrophik. Neurologisches Centralbl. Bd. 11, 1892, p. $463-467,505-508$ 11. $564-574$.) S. $163,176$.

- - Phénomènes de réparation dans les centres nerveux après la section des nerfs périphériques. (Société de Biologie 1896. Sep.) S. 179.

- - Recherches sur la biologie de la cellule nerveuse. (Arch. f. Physiol. 1899, p. 89-111, Taf. 4. Sep.) S. $150,179$.

- - Recherches cytométriques et caryométriques des cellules radiculaires motrices. (Journal de Neurologie. 1900. Sep.) S. 179.

- E Etudes sur l'évolution et l'involution de la cellule nerreuse. (Revue neurologique. 1899. Sep.) S. 179.

- - Sur une forme particulière de réaction des cellules radiculaires après la rupture des nerfs périphériques. (Revue neurologique 1902, 3 Fig. Sep.)

Matteucei, M. Ch.: Essai sur les phénomènes électriques des animaux. Paris 1840. S. 000 .

Ma yer, Sigmund: Über Vorgänge der Degeneration und Regeneration im unverletzten peripheren Nervensystem. (Zeitschr. f. Heilkunde Bd. II, 1s51.) s. 154 .

Me Clure, Ch.: The finer structure of the nerve cells of invertebrates. (Zoolog. Jahrbuicher, Abt. f. Anat, p. 13, Bd. 11, 1597. Sep.)

Me TVilliam, J.: On the rythm of the mammalian heart. (Journal of Physiology Vol. IX, 1885, p. 167-195.) S. 446.

Mendelss ohn, M.: Über den axialen Nervenstrom. (Arch. f. Physiologie 1ss5, p. $381-399$.$) S. 344$. 
Merzbacher, L.: Über die Beziehungen der Simnesorgane zil den Reflexbewegungen des Frosches. (Pfliigers Arch. Bd. 81, 1900, 1). 222-262.) S. 379.

- - Die Folgen der Durchschneidung der sensiblen Wurzeln im unteren Lumbalmarke, im Sakralmarke und in der Cauda equina des IIundes. (Pflïgers Areh. Bd. 92,1902, p. $555-604$.$) S. 364,366$.

Meyer, J. C. H.: Über die Wiedererzeugung der Nerven. (Reils Arch. f. Physiol. Bd. 2, 1797, p. 449-467, Taf. 6.) S. 183.

Mejer, Hans: Zur Theorie der Alkoholnarkose. 1. Welche Eigenschaft der Anästhetica bedingt ihre narkotische Wirkung? (Arch. f. experim. Pathol. u. Pharmakol. Bd. 42, 1599, p. 109-11S.) S. 35 .

- - Zur Theorie der Alkoholnarkose. 3. Der Einfluß wechselnder Temperatur auf Wirkungsstïrke und Teilungskoefficient der Narcotica. (Arch. f. experim. Pathol. u. Pharmakol. Bd. 46, 1901, p. 335-3.46.) S. 355.

N eyer, S.: Über eine Verbindungsweise der Neuronen. (Arch. f. mikrosk. Anat. Bd. 47,1896, p. $734-74$ S.) S. 63 .

- Über die Funktion der Protoplasmafortsätze der Nervenzellen. (Berichte d. mathematisch-physischen Kl. d. kyl. siichs. (ienellsch. d. Wis.s. zu Leiprip. 1897 , p. 175. Sep.) S. $65,73,77$.

- Eine Eisenimprägnation der Neurofibrillen. (Anat. Anz. Bd. 20, 1902, p. $535-543$.$) S. 56$.

M $0 \mathrm{mmsen,J.:} \mathrm{Beiträge} \mathrm{zur} \mathrm{Kenntnis} \mathrm{von} \mathrm{den} \mathrm{Erregbarkeitsverïnderungen} \mathrm{der}$ Nerven durch verschiedene Einflüsse, insbesondere durch "Gifte". (Tirchows Arch. Bd. S3, 1881, p. 243-258.) S. 269.

II ̈̈nckeberg, G., und Bethe, A.: Die Degeneration der markhaltigen Nerven-

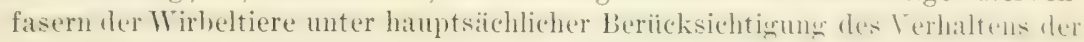
Primitivfibrillen. (Arch. f. mikrosk. Anat. Bd. 54, 1899, p. 135.) S. 49, 155, 255.

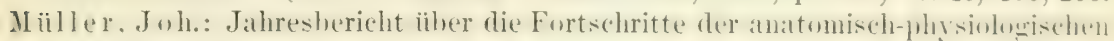
Wissenschaften im Jahre 1836. (Müllers Arch. 1837, p. I.) S. 4.

- - Handbuch der Physiologie des Menschen. 4. Aufl., 1S44. S. 342, 351.

I unk, H.: Untersuchungen iiber die Leitung der Erregung im Nerven. (Arch. f. Anat. u. Physiol. 1860, p. 795.)

- - Untersuchungen über die Leitung der Erregung im Nerven. (Arch. f. Anat. u. Physiol. 1862 , p. $1-46$.)

- - Untersuchungen zur allgemeinen Nervemphysiologie. (Arch. f. Anat. u. Physiol. 1866, p. 369-390.)

- - Untersuchungen über das Wesen der Nervenerregung. Leipzig 1568. S. 253.

- - Zur Mechanik der Herztätigkeit. (Verhandl. d. Berliner physiolog. Gesellschaft 25. II. $1876 \mathrm{im}$ Arch. f. Physiol. 1579, 1. 569.) S. 409, $44 \mathrm{~s}$.

Nünzer, E., und Wiener, H.: Beiträge zur Anatomie und Physiologie des Zentrahnervensystems. (Areh. f. experimentelle Pathol. u. Pharmakol. Bd. 35, 1895, p. 113-128.) S. 331 .

Miinzer, E.: Kritische Bemerkungen zur Lehre von den Neuronen. (Wiener klinische Rundschau 1899, No.6. Sep.).

- Gibt es eine autogenetische Regeneration der Nervenfasern? Ein Beitrag zur Lehre vom Neuron. (Neurolog. Centralbl. 1902, p. 1090-1098.) S. 192, 194.

Nagel, W. A.: Experimentelle simnesphysiologisehe Untersuchungen an Coelenteraten. (Pfliigers Arch. Bd. 57, 1894, p. 495-552.) S. 110, 386.

Nansen, Fridtjof: Die Nervenelemente, ihre Struktur und Verbindung im Centralnervensystem. (Anat. Anz. Bd. 3, 1s5s, 1). 15i-169.) S. 32S.

Nasse: Über die Veränderungen der Nervenfasern nach ihrer Durchschneidung. (Miillers Arch. 1839, p. 405.) S. 15.3, 1S.3. 
Telis, C.: Un mourean détail de structure du protoplasme des cellules nervenses. (Bull. de l'Acad. roy. de Belgique 1599. Sep.) S. 149.

Seumann, E.: Über Degeneration und Regeneration zerquetschter Nerven. (Areh. f. mikiosk. Anat. Bd. 15, 1550, p. 302-344, Taf. 16.) S. 156.

Nicola i, G. Fr.: Über die Leitungsgeschwindigkeit im Riechnerven des Hechtes.

(Pfliigers Areh. 13d. 55, 1901, p. 65-55.) S. 345, 349, 435.

Niss1, Fr.: Über die Terïnderungen der Ganglienzellen am Facialiskern des Kaninchens nach Ausreißung des Nerven. (Allgemeine Zeitschr. f. Psychiatrie Bd. 4 , 1 S92, p. 197-19S.) S. $127,132,177$.

- Über experimentell erzeugte Verinderungen an den Vorderhornzellen des Rückenmarks bei Kaninchen. (Allgem. Zeitschr. f. Psychiatrie Bd. 45, 1592, p. $675-652$.) S. 177 .

- Über die sogenannten Granula der Nervenzellen. (Neurolog. Centraibl.

Bd. 13,1594, p. $676-685,781-759$ u. $810-\$ 14$.) S. $127,129,132$.

- - Über eine neue Untersuchungsmethode des Zentralorgans speziell zur Feststellung der Lokalisation der Nervenzellen. (Centralbl. f. Nervenheilkunde u. Psych. Bd. 17, 1594, p. 337-344.) S. 127.

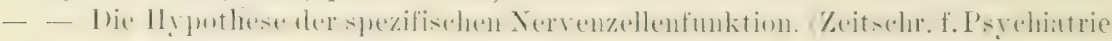

Bd. 5t, 4 Taf. Sep.) S. 150.

- Nervenzellen und graue Substanz. (Mïnchner med. Wochenschr. 1598. Sep.) S. 66, 75, 104, 152, 332 .

- Die Neuronlehre rom pathologisch-anatomischen und klinischen Standpunkt. (Verhandlg. d. Gesellschaft deutscher Naturf. u. Ärzte, 1900. Sep.) - - Die Neuronenlehre und ihre Anhïnger. Jena 1903. S. 11, 15, 62, 61, 210. Nothn a ge l, H.*: Bewegungshemmende Mechanismen im Riickenmark d. Frosches.

(Centralbl. f. medizin. Wissensch. 1869.) S. 376.

Nusbaum, J., und Schreiber, W.: Beiträge zur Kenntnis des peripherischen Nervensystems bei den Crustaceen. (Biolog. Centralbl. Bd. 17, 1997.) S. S1.

Oddi, R.: Il cervello ed il midollo spinale come centri di inibizione. (Roma 1595, Rendiconti della R. Accademia dei lincei Vol. IV, Serie 5 a. Sep.) S. 353.

_- L'inibizione dal punto di vista fisio-patologico, psicologico e sociale. (Torino 1898, Biblioteca antropologico-giuridica Vol. XXXIV, Serie II.) S. $353,357$.

Oddi (e Belmondo) siehe B.

Oker-Blom, MI.: Tierische Säfte und Gewebe in physikalisch-chemischer Beziehung. IV. (Pfliigers Arch. Bd. 84, 1901, p. 191-259.) S. 312.

Osawa, R.: Untersuchungen über die Leitungsbahnen im liückenmark des Hundes. Straßburg 1882. S. 323.

Overton, E.: Studien über Narkose. Jena 1901. S. 358.

Pawlow, Joh.: Wie die Muschel ihre Schale öfnet. (Pfliigers Arch. Bd. 37, 1545, 1. (i-31.) >. 34.5.

Pereles, H., und Sachs, M.: Über die Wirkung von Äther, Chloroform und Alkohol auf das Leitungsvermögen motorischer und sensibler Yervenfasem des Frosches. (Pfliigers Arch. Bd. 52, 1592, p. 526-534.) S. 269.

Pflüger, E.: Die sensorischen Funktionen des Riickenmarks der Wirbeltiere nebst einer nenen Lehre iiber die Leitungsgesetze der Reflexionen. Berlin 1853. S. 351.

- - Über die durch konstante elektrische Ströme erzengte Veränderung des motorischen Nerven. (Allgemeine medizinische Centralzeitung Bd. 25, 1556, p. 169 u. 449.) S. $250,272$. 
Pflüger, E.: Über das IIemmungs-Nervensystem für die peristaltischen Bewegungen der Gedirme. Berlin 155\%. S. 374 .

- - Über die Ursache des Öffnungstetanus. (Areh. f. Anat. u. Physiol. 155!), p. $133-149$.) S. 250,30 s.

- Untersuchumgen iiber die Physiologic des Elektrotonus. Berlin 1559. S. $250,272,305$.

Philipeaux et Vulpian: Fote sur des expériences démonstrant que des nerfs séparés des centres nerveux peuvent, apres s'être alteres completement, se régénérer tout en demeurant isolés des centres, et recourrir leurs proprietés physiologiques. Comptes rendus, 1559. (Journal de la P'lysiol. de l'Ilomme et des Animaux, Paris 1560, Bd. 3.) S. 154, 159.

- Recherches expérimentales sur la réunion hout i bout de nerfis de fonetions différentes. (Jomrual de la Physiologie Tome 6, 1863, p. 421-155 u. 474-515.) S. 227, 231.

Piotrowski, G.: Über die Trennumg der Reizharkeit und Leitungsfilhigkeit des Nerven. (Arch. f. Physiol. 1593, p. 205-290.) S. 269.

Polimanti, 0.: Influenza che le radici spinali posteriori esercitano sulla eccitabilita delle anteriori. (Bullettino della R. Aceademia medica di Roma, 1595 bis 1596, Fase. 5 11. 6. Sep.) S. 3 S3.

Prochaska, G.: Operum minorum anatomici physiologici et pathologici argumenti. Pars II. Viennae 1500. S. 321.

Purkinje: Untersuchungen aus der Nerven- und Ilimanatomie. (Bericht iib. d. Versamml. deutseher Naturforsch. u. Ärte zu Prag 1837, P'an 1838, p. 17\%.) S. 4 .

Quincke, G.: Über periodische Ausbreitung an Flïssigkeits-Oberflïehen und dadureh hervorgerufene Bewegungserscheinungen. (Sitzher. d. Akad. zu Berlin 1sss, II., p. 791 -s04.) S. 359 .

Raffaele, F.: Per la genesi dei nervi da catene cellulari. (Anat. Anz. Bel. 1s, 1900, p. 337-34t, 11 Fig.) S. 236, 244.

Ramón y Cajal, S.*: La rétine des Vertébrés. (La Cellule 1893.) S. 10.

- El Azul de metyleno en los centros nerviosos. (Revista trimestral micrograf. T. 1, 1896, p. 151-203.) S. $69,77$.

- Leyes de la morfologia y dinamismo de las células nerviosas. (Revista trimestral micrograf. 'T. 2, 1897 , p. 1-25.) S. 32 .

- - La red superficial de las células nerviosas centrales. (Revista trimestral micrograf. T. III, 1595, p. 199.) S. $66,71$.

- Estudios sobre la corteza cerebral humana. (Revista trimestral micrograf. T. IV, 1599, p. 1-63 [45].) S. 63.

Ranke, J.: Weitere Versuche iiber die Reaktionsänderung der Nervenfisern durch Tetauns. Centralbl. f. medizin. Wissensch. 1569, 1).97-101.)

Ranvier: Leçons sur l'histologie du systeme nerveux. 1578. S. 15s, 156, 190. - - Leçons d'anatomie générale. Paris, Baillière 15so. S.91.

Rath, 0. vom: Über die Nervenendigungen der IIautsinnesorgane der Arthropoden nach Behandhung mit der Jfethylenblau- und Chromsibermethode. (Berichte d. Naturforsch. Gesellsch. zu Freiburg i. 13. 13d. IX, Heft 2, Talf. I1. Sep.) S. 31.

Rawitz, B. *: Das centrale Nervensystem der Acephalen. (Jenaische \%eitschr. f. Naturwissensch. B(l. 20, 1557.) S. 30 .

Redlich, C.: Zur Kemntnis der Riickenuarksverindermgen nach Amplutationen. (Centralbl. f. Nervenheilk. u. Psychiatr. Jalırs. 16, 1593, 1. 1-i.) \&. 176. 
Remak, R.: Vorläufige Mitteilung mikroskopischer Beobachtungen über den inneren Bau der Cerebrospinalnerven und über die Entwicklung ihrer Formelemente. (Müllers Arch. 1836, p. 145). S. 5.

- - Weitere mikrosknische Beobatchtungen über die Primitivfasern des Nervensystems der Wirbeltiere. (Frorieps Notizen Bd. 3, 1537, p. 36.) S. 5.

- Neurologische Notizen. (Frorieps Notizen Bd. 3, 1537, p. 216.) S. 5.

- Observationes anatomicae et microscopiae de systematis nervosi structura. Dissertation. Berolini 1835. S. 6, 13.

- - Neurologische Erläuterungen. (Müllers Arch. 1844, p. 463.)

- Über multipolare Ganglienzellen. (Verhandl. d. kgl. pr. Akad. d. Wissensch. zu Berlin 1554, p. 26.) S. $7,000$.

- - Über den Bau der grauen Säulen im Rüickenmarke der Säugetiere. (Dentsche Klinik Bd. 7, 1855, p. 295.)

- Über die Wiedererzeugung von Nervenfasern. (Virchows Arch. Bd. 23, 1862, p. 411.) S. 153.

Retzius, G.: Zur Kenntnis des Nerrensystems der Crustaceen. (Biologische Untersuch. Neue Folge, Bd. I, 1890, p. 1.) S. 8, 26, 2 S.

- - Zur Kenntnis des Nerrensystems der Würmer. (Biologische Untersuch. Neue Folge, Bd. II, 1891.) S. 8, 26.

- Zur Kenntnis der motorischen Nervenendigungen. (Biologische Untersuch. Nene Folge, Bd. III, 1892, p. 41-52, Taf. XIV-XX.) S. 91.

- Das sensible Nervensystem der Crustaceen. (Biologische Untersuch. neue Folge Bd. VII, 1895.) S. 31.

- - Zur Kenntnis des Gehirnganglions und des sensiblen Nervensystems der Polychäten. (Biologische Untersuch. Neue Folge, Bd. VII, 1895.) S. 26.

- Zur Kenntnis des sensiblen und sensorischen Nervensystems der Würmer und Mollusken. (Biologische Untersuch. Nene Folge, Bd. IX, 1900.)

Ritter*: Beiträge zur näheren Kenntnis des Galvanismus, 1802. S. 30 .

Robin, Ch.: Sur la structure des ganglions nerveux des Tertébrés. (L'Institut

T. 15, 1847, I. Section, p. 74 [No. 687 vom 3 Mars 1847].) S. 6, 154.

Romanes, G.: Preliminary observations on the locomotor system of Medusae. (Philosoph. Transact. Vol. 166. 1876, p. 269.) S. 106, 409.

- Further observations on the locomotor system of Medusae. (Philosoph. Transact. Vol. 167,1877, p. 659.) S. $106,107,409,412$.

Rosenthal, J.: Üher Modifikation der Errewbarkeit dureh geschlossene Ketten und die Voltaischen Abwechslungen. (Zeitschr. f. rationelle Med. Bd. 4, 1855, p. 117-141, Taf. 11. Kürzer in: Honatsber. d. Berliner Akad. 1857, p. 639 bis 641.) S. 308.

- - Die Atembewegungen und ihre Beziehungen zum Nerrus vagus. Berlin 1862. S. $377,398$.

- - Untersuchungen iiber Reflexe. (Sitzber. d. physik.-med. Societiit zu Erlangen 1873 u. 1875.) S. 351.

- - Bemerkungen über die Tätigkeit der automatischen Nervencentra, insbesondere iiber die Atembewegungen. Erlangen 1875. S. 326, 399, 406.

- - Neue Studien über Atembewegungen. (Wirkung der elektrischen Vagusreizung auf die Atembewegungen.) (Arch.f. Physiol. 1850, Supplement p. 34.) S. 399 .

Rossbach, M. J.: Beitrige zur Physiologie des Herzens. (Verhandl. d. physik.medizin. Gesellsch. zu Würzburg Bd. 5, 1874, p. 183.) S. 416.

- Über die Wirkung direkter Herzmuskelreizungen. (Pflügers Arch. Bd. 25, 1881, p. 181.) S. 430. 
Ruffini, A., e Apaty, St.: Sulle fibrille nervose ultraterminali nelle piastre motrici dell' nomo. (Rivista di Patologia nervosa e mentale Tol. 5, 1900, p. 433. Sep.) S. $54,124$.

liffini, A.: Ise fibrille nervose ultraterminali nelle teminaioni nervose di senso e la teoria del neurone. (Rivista di Patologia nervosa e mentale Vol. 6, 1900$, p. $70-82$.$) S. 54,124$.

Rutherford, W. Elektrotonus. (Journ, of Anatomy and Physiol. 2. ser., No. 1, Nor. $186 \pi$, p. 8\%.) S. 311.

Schenk, F.: Über den Einfluß der Apnoë auf die vom Tagus ausgelösten Atemreflexe. (Pfliigers Arch. Bd. 83, 1900, p. 99-119.) S. 399.

- - Die Bedeutung der Neuronenlehre für die allgemeine Nervenphysiologie. (Würzburger Abhandlungen aus d. Gesamtgeb. d. prakt. Medizin Bd. 2, 1902, p. 183-20s. Sep.) S. 331, 332.

Scherhey, J.: Zur Lehre von der Herzinnervation. (Arch. f. Physiol., 1850, p. 255.) S. $413,41 \%$.

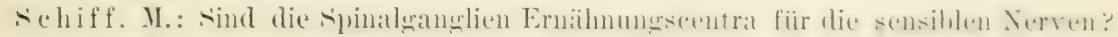
(Arch. d. Vereins fo gemeinschaftl. Arb. zur Förderung d. Heilkunde, Güttingen 1853, Bd. 1, p. 609, u. Schiffs Gesammelte Beiträge z. Physiol. Lausanne 1894, Bd. 1, p. $676-652$.) S. 153,155 .

- - Lehrbuch der Physiologie des Muskel- und Nervensystems. Lahr 1855 bis 1859 . S. $153,16 \pi, 189,220,37$.

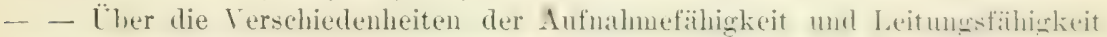
in dem peripherischen Nervensystem. (Gesammelte Beitr. z. Physiol. Lausanne 1894, Bd. 1, p. 755-757; Anhang dazu: p. 758-789. Heule u. Pfeuffers Zeitschr. 1866.) S. 271, 318.

- Über die Erregbarkeit des Rüickenmarks. II. (Pflïgers Arch. Bd, 29, 1582, p. $537-598$.$) S. 318$.

- - Sur la dégénérescence paralytique des nerfs. Sur quelques conditions de la régénération des nerfs sectionnés. (Semaine médicale 185\%, 1. 262 u. p. 350; mit Zusätzen rom Jahre 1594 in: Gesammelte Beitr. zo Physiol. Lausanne 1894, p. $706-726$.$) S. 153,183,206$.

Schlösser, W.: Untersuchungen ïber die Hemmung von Reflexen. (Arch. f. Physiol. 1880, p. 303.) S. 379.

Schlïter, Fr.: Die Reizleitung im Säugetierherzen. (Pflügers Arch. Bd. 89, 1902, p. 87-111.) S. 438,445 .

Schmiedeberg, 0.: Grundriß der Pharmakologie in bezug auf Arzneimittellehre und Toxikologie. Leipzig 1902. S. 359 .

Schoenlein, K.: Über rhythmische Kontraktionen quergestreifter Muskeln anf tetanische Reizung. (Arch. f. Physiol. 1852, p. 369-386.) S. 390.

- Über das Herz von Aplysia limacina. (Zeitschr. f. Biologie Bd. 30, 1594, p. $187-220$.) S. $213,369$.

Schoenlein, K., und Willem, V.: Beobachtungen iiber Blutkreislauf und Respiration bei cinigen Fischen. (Zeitschr. f. Biologie Bd. 32, 1595, 1). 511 bis 547.) S. 394, 401.

Schrader, M.: Zur Physiologie des Froschgehirns. (I’fliigers Arch. Bd. 41 , 1857, p. 75-90.) S. 379.

Schrader, II.: Zur Physiologie des Vogelhirns. (Ptliigers Arch. Bd. 46, 1559, p. 175-238.) S. 379 .

Schultz, Paul: Die lïnsgestreifte (glatte) Muskulatur der Wirbeltiere. (Arch.

f. Physiologie, 1597 , 1. $307-321$ u. 1) $322-32$.) S. 391 . 
Schultze, H.: Die fibrilläre Struktur der Nervenelemente bei Wirbellosen. (Arch. f. mikroskop. Anat. Bd. 16, 1879.) S. S.

Schultze, M.: Observationes de structura cellularum fibrarumque nervearum. (Bomer Universitïtsprogramm, Angust 1868.) S. 1 .

- - Allgemeines iiber die Strukturelemente des Nervensystems. (Strickers Handbuch d. Lehre von d. Geweben Bd. 1, p. 108-136, Leipzig 1571.) S. 14, 4 \%. Schwalbe, G.: Zur Lehre rom Huskeltonus. (Untersuch. physiol. Laborat. zu

Bomn, herausgegeb. von Pflüger, Berlin 1865, p. 64-79.) S. 364 .

Schwann: Mikroskopische Untersuchungen über die Übereinstimmung in der Struktur und dem Wachstum der Tiere und Pflanzen. Berlin 1838. S. 4.

Sedgwick, A.: On the inadequacy of the cellular theory of development, and on the early development of nerves etc. (Quart. Journ. of microse. Sciences Vol. 37,1895, p. 87-101.) S. 237.

Sertoli, E.: Contribution ì la physiologie générale des muscles lisses. (Arch. Italiennes de Biologie Bd. 3, 1583, p. 75-94.) S. 391.

Setschenow, J.: Pliysiologische Studien über die Hemmungsmechanismen für die Reflextiitigkeit des Riickemmarks im Gehim des Frosches. Berlin 1563. A. 37s.

Setschenow, J., und Paschutin, B.: Neue Versuche im Hirn und Riickenmark des Frosches. Berlin 1865. S. 378.

Sherington, C. S.: Further experimental note on the correlation of action of antagonistic muscles. (Proceed, of the Royal Society Vol. 53, 1893, 1. 407.) S. 377 .

Sherrington, C. S., and Hering, C. H.: Antagonistic muscles and reciprocal imnervation. (Proceed. of the Royal Society Vol. 62, 1897, p. 153.) S. 377.

Simon, Clı.: Recherches sur la cellule des ganglions sympathiques des Hirudinées. (Journ. internation. d'Anat. et de Physiol. Bd. 13, 1896. Sep.) S. 133. Simroth, H.: Die Tätigkeit der willkïrlichen Muskulatur unserer Landschnecken. (Zeitschr. f. wissensch. Zool. Bd. 30, 1878, p. 166-224.) S. 119.

- - Die Bewegungen unserer Landschnecken, hauptsächlich erörtert an der Sohle des Limax cinereo niger Wolf. (Zeitschr. f. wissensch. Zool. Bd. 32, 1579, p. $284-322$.$) S. 119$.

Singer, J.: Über die Veränderungen am Rückemmark nach zeitweiser V'erschließung der Bauchaorta. (Sitzber. d. math.-naturwissensch. Kl. Akad. Wien Bd. 96, Abt. III, 1887 [1888], p. 136-155, 2 Taf.) S. 331.

Smidt, H.: Die Sinneszellen der Mundhöhle von Helix. (Anat. Anz. Bd. XVI, 1899, p. 577-584, 6 Abbild.) S. 25.

- Die intraepithelialen freien Nervenendigungen bei Helix und ihre Beziehungen zu Sinneszellen und Drüsen. (Anat. Anz. Bd. XX, 1902, p. 495 bis 506,8 Abbild.) S. $25,31,82$.

Smirnow, A.: Über freie Nervenendigungen im Epithel des Regenwurms. (Anat. Anz. Bd. 9, 1594, p. 570-578, 3 Abbild.) S. 26, 31.

Soury, J.: Le système central etc. Paris 1899. (Bd. 2, p. $1721 \mathrm{f}$.)

Speiser, P.: Über die Prognose der Nervennaht. (Fortschritte d. Medizin 1902 , p. $145-162$.$) S. 215$.

Stannius: Zwei Reihen physiologischer Versuche. (Areh. f. Anat. u. Physiol. 1852, p. 85.) S. $408,448$.

Starke; J.: Über den Einfluß des Zentralnervensystems auf die Erregbarkeit der motorischen Nerven. (Centralbl. f. Physiol. Bd. 12, 1898, p. 596-599.) S. 383 .

Starling, E. H.: Überblick über den gegenwärtigen Stand der Kenntnisse iiber die Bewegungen und die Innervation des Verdauungskanals. (Ergebnisse der Physiol. Abt. 2, 1902, p. 446-465.) S. 374 . 
Stefani, A.: L'incrociamento dei nervi ete. (Rivista clinica. Bologna 1555. Sep.) S. 216.

- Se possono unirsi fra di loro le superficie centrali di sezione delle filure nervose. (Academia di Ferrara 7. Juli 15s\%. Sep.) S. 220.

- Della proprieta delle fibre nervose di mantenere isolati i loro monemi centrali. (Atti del R. Istituto Veneto di scienze, lettere ed arti Tom. VIII, Serie VII, Venezia 1596-1597. S. 220.

Steinach, E.: Über negative Schwankung des Nervenstromes hei nicht elektrischer Reizung des Nervenstammes oder der Wurzeln. (Pfliigers Arch. 13d. 55, 1594, p. 487-507.) S. 314.

- - Über die centripetale Erregungsleitung im Bereiche des Spinalganglions. (Pflïgers Arch. Bd. 78, 1899, p. 291-314, Taf. 19.) S. 330.

- - Studien über die Hautfärbung und ïber den Farbenwechsel der Cephalopoden. Nebst Versuchen über die autogene Rhythmizitit der ChromatophorenMuskeln. (Pfliigers Arch. Bd. 87, 1901, p. 1-37.) S. 392.

Stilling, B.: Nene Untersuchungen über den Bau des liiickemmarks. (Cassel 1859.)

Stirling, W.: Über die Summation elektrischer Hautreize. (Berichte d. Verhandl. d. kgl. sächs. Gesellsch. d. Wissensch. zu Leipzig. Math.-phys. Kl. Bd. 26,1874, p. 372.) S. 351 .

Straub, W.: Zur Muskelphysiologie des Regenwurms. (Pfliigers Areh. Bd. 79, 1900, p. $379-399$.$) S. 391$.

Stroebe, H.: Experimentelle Untersuchungen ïber Degeneration und Regeneration peripherer Nerven nach Verletzungen. (Zieglers Beiträge z. pathol. Anat. Bd. 13, 1893, p. 160-279, Taf. 7 u. 8.) S. $154,155,187$.

-- Die allgemeine Histologie der degenerativen und regenerativen Prozesse im zentralen und peripheren Nervensysteme nach den neuesten Forschungen. (Centralbl. fo allgem. Pathol. u. pathol. Anat. Bd. 6, 1895, p. 849-960.) S. 1.5. $15 \%$.

Strong, W. M.: A physical theory of nerve. (Journ. of Physiol. Vol. 25, 1900$, p. $427-442$.$) S. 253$.

Strümpell, A.: Zur Lehre von der progressiven Afuskelatrophie. (Deutsche Zeitschr. f. Nervenheilkunde Bd. 3, 1893, p. 471-501.) S. 175.

Studnicka, F.: Beiträge zur Kenntnis der Ganglienzellen. (Sitzber. d. kgl. böhm. Ges. d. Wissensch. in Prag 1900.) S. 149.

Szana, A.: Beitrag zur Lehre von der Unermidlichkeit der Nerven. (Arch.f. Physiol. 1591, p. $315-320$.) S. 319.

Szpilman und Luehsinger: Zur Beziehung von Leitungs- und Erregungsverı̈̈gen der Nervenfasern. (Pflügers Arch. Bd. 24, 1s51, p. 347-357.) S. 269.

Szymonowicz, L.: Über den Bau und die Entricklung der Nerrenendigungen im Entenschnabel. (Areh. f. mikroskop. Anat. Bd. \$s, 1596 , p. 329-35s, Taf. XIV.) S. 55.

Tigerstedt, R.: Die durch einen konstanten Strom in den Nerven hervorgerufenen Verïnderungen der Erregbarkeit, mittels mechanișcher lieizung untersucht. (Mitteil. r. physiol, Labor. d. Carolin. med.-chir. Instit, herausgeg. v. Lovén, Heft 1, Stockholm 1882. Auch in: Bihang till k. Srenska Vet. Akad. Handlingar Bd. 6, No. 22, 1852.) S. 272.

- - Zur Theorie der Öfmungsuckung. (Mitteil. vo physiol. Labor. d. Carolin.Instit. in Stockholm Heft 2, Stockholm 1852. Anch in: Bihang till k. Srenska Vet. Akad. Handlingar Bd. 7, No. 7.) \$. 272. 
'Traube: Zur Physiologie des Nervus vagus. (Medizin. Ztg. Berlin 1847, p. 20.) $\therefore 37 \%, 394$.

Trendelenburg. W.: Zur Frage der rhythmischen Fähigkeit des Herzmuskels bei Durchleitung konstanter Ströme. (Pfliigers Arch. Bd. S2, 1900, p. 268 bis 288.) S. 418.

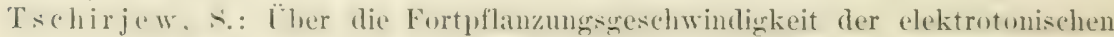
Vorgainge im Nerven. (Arch. f. Physiol. 1879, p. 525-552.) S. 273.

Tuckett, J.: On the structure and degeneration of non-medullated nerve fibres. (Journal of Physiol. Vol. 19, 1895-1896, p. 267-311, Taf. 1-4.) S. 163.

Tumänzew und Dogiel, Joh.: Zur Lehre' iiber das Nervensystem des Herzens. (Arch. f. mikrosk. Anat. Bd. 36, 1890, p. 483-506, Taf. 20-22.) S. 90 .

Uexkiill, J. von: Physiologische Untersuchungen an Eledone mosehata. III. (Leitschr, f. Biolog. Bd. 30, 1594, p. 317-227.) S. 321, 345, 350.

- - Physiologische Untersuchungen an Eledone moschata. IV. Zur Analyse der Funktionen des Zentralnervensystems. (Zeitschr. f. Biolog. Bd. 31, 1595, p. 584 bis 609.$)$ S. 25 .

- Über Reflexe bei den Seeigeln. (Zeitschr. f. Biolog. Bd. 34, 1896, p. 298 bis 332.) S. 336 .

- Die Physiologie der Pedicellarien. (Zeitschr. f. Biolog. 1599, Bd. 37, p. 334 bis 403.) S. 336,354 .

- Die Physiologie des Seeigelstachels. (Zeitschr. f. Biolog. Bd. 39, 1900, p. $73-112$.) S. $116,332,336,366,369,372$.

- Die Schwimmbewegungen von Rhizostoma pulmo. (Mitteil. a. d. zoolog. Stat. zu Neapel 1901, Bd. 14, p. 620. Sep.) S. $110,413,455$.

- Studien über den Tonus. I. Der biologische Bauplan von Sipunculus nudus. (Zeitschr. f. Biologie Bd. 44, 1903, p. 269-344.) S. 373.

Valentin, G.: Über den Verlauf und die letzten Enden der Nerven. (Nova Acta physico-medical Academiae Caesareae Leopoldino-Carolinae. Breslan und Bonn, Bd. 1s, 1836, p. 51.) S. 4.

- Lehrbuch der Physiologie des Menschen Bd. 2. (Braunschweig 1844. 2. Aufl. 1848, 犊) S. 272.

Vanlair, C.: De la régénération des nerfs périphériques par le procédé de la suture tubulaire. (Arch. de Biologie Bd. 3, 1852, p. 379-496, Taf. 16-19.) S. $186,212$.

- - Nouvelles recherches expérimentales sur la régénération des nerfs. (Arch. de Biologie Bd. 6, 1885, p. 232.) S. 186, 212.

- - Sur la persistance de l'aptitude régénératrice des nerfs. (Bulletins de l'Acad. royale des Scienc. de Belgique Série III. T. 16. 18s8, p. 93-110.) S. 186,212 .

Veratti, E.: Richerce sul sistema nervoso dei Limax. (Memor. del r. Istit. lombardo di scienze e lettere Vol. 1s, 1900 , p. 163-17S, 4 Taf. Sep.) S. 25, 26,31 .

- - Su alcune particolarita di struttura dei centri acustici nei mammiferi. (Pavia 1900.) S. 63.

Verworn, M.: Tonische Reflexe. (Pflïgers Arch. Bd.65, 1597, p. 63-s0.) s. 364 .

- Zur Physiologie der nervösen Hemmungserscheinungen. (Arch. f. Physiologie, Supplementband 1900, S. 105.) S. $327,380,383$. 
Verworn, M.: Ermidung, Erschöpfung und Erholung der nervösen Centra des Rückenmarks. Ein Beitrag zur Kenntnis der Lebensvorgïnge in den Feuronen. (Arch. f. Physiologie, Supplementhand 1900, p). 152.) S. 327.

- Das Neuron in Anatomie und Physiologie. Jena 1900. S. 52, 331, 332.

Vignal, W.: Recherches sur l'appareil ganglionnaire du cœur des vertébrés.

(Travaux du laboratoire d'histologie de Ranvier, Paris 1881, p. 1S6-254, f)l. 7 u. 8.) S. 91.

Villa, J. la: Alcunos detalles concernientes a la oliva superior y focos acusticos. (Revista trimestral micrográfica '1. 3, 1595, n. 75.) S. 63.

Vöchting, H.: Über Transplantation am Pflanzenkörper. (Tïbingen 1592.) S. 220.

Vogt, H.: Über Neurofibrillen in Nervenzellen und Nervenfasern der Retina. Monatsschr. f. Psychiatrie u. Neurol. Bd. 11, 1902, p. 167-1s1 u. Taf. V bis VII.) Si. ati.

Vulpian, A.: Leçons sur la physiologie générale et comparée du système nerveux. Paris 1866. S. 184.

- Note sur de nouvelles expériences relatives à la réunion bout à bout du nerf lingual et du nerf hypoglosse. (Archives de Physiologie norm. et pathol. Bd. 5, 1873, p. 597-602.) S. 228 .

- - Note sur la régénération dite autogénique des nerfs. (Arch. de Physiol. norm. et pathol. Série 2, Bd. 1, 1874.) S. 185.

Wagner, R.: Sympathischer Nerv, Ganglienstruktur und Nervenendigungen. (Wagners Handwörterbuch der Physiologie Bd. III, Abt. 1, p. 360, 1646.) S.6, 154.

- - Neue Untersuchungen über den Bau und die Endigung der Nerven und die Struktur der Ganglien. Leipzig 1847. S. 6.

- - Neurologische Untersuchungen. (Nachricht. d. Georg-Augusts-Universität u. d. kgl. Gesellsch. d. Wiss. zu Göttingen 1550, p. 41.)

- - Neue Versuche über das Verhältnis der Innervation zur IIuskelirritabilitit, mit besonderer Rücksicht auf Herzbewegung. (Nachricht. v. d. Georg-AugustsUniversität $\mathrm{u.} \mathrm{d.} \mathrm{kgl.} \mathrm{Gesellsch.} \mathrm{d.} \mathrm{Wiss.} \mathrm{zu} \mathrm{Göttingen} \mathrm{1550,} \mathrm{p.} \mathrm{209.)} \mathrm{s.} 434$. W aldeyer, W.: Über einige neuere Forschungen im Gebiete der Anatomie des Centralnervensystems. (Deutsche med. Wochenschr. 1591. Sep.) S. 9.

Waller, A.: Sur la reproduction des nerfs et sur la structure et les fonctions des ganglions spinaux. (Müllers Archiv 1552, p. 392-401.) S. 153, 15t, 184 . - Nonvelles observations sur la régénération des nerf (s. Compt. rend. Bd. 34, 1852, p. 393.) S. 184.

- - Recherches expérimentales sur la structure et les fonctions des ganglions. (Compt. rend. Bd. 34, 1852, p. 524-52T.) S. 154.

- - Observations sur les effets de la section des racines spinales et du nerf jneumo-gastrique au-dessus de son ganglion inférieur ches les Mammifüres. (Compt. rend. Bd. 34, 1552, 1) 552-558.) S. 154, 184.

- - Nonvelles recherches sur la régénération des fibres nerveuses. (Compt. rend. Bd. 34,1852, p. $675-679$.

- Examen des altérations qui ont lieu daus les filets d'origine du nerf pneumogastrique et des nerfs rachidiens etc. (Compt. rend. Bd. 34, 155\%, p. S42- 447. ) S. 154,184 .

- Sixième mémoire sur le système nerveux. (Compt. rend. Bd. 3.1, 1852, p. 979.) S. 184.

Walier, A. D.: The effect of $\mathrm{CO}_{2}$ upon nerve and the production of $\mathrm{CO}_{2}$ by nerve. (Journal of Phisiol. Vol. 19, 1595-1S96, 1). I-VI.) S. 27.1.

- - Effects of $\mathrm{CO}_{2}$ and Et. $\mathrm{O}$ upon the polarisation increment, upon electrotonic Bethe, Nervensystem. 
variations, and upon electrotonic currents. (Journal of Physiol. Tol. 19, 1595 bis 1896, p. VII-IX.) S. $274,319$.

Waller, A. D.: Influence of temperature on electrotonic currents. (Journal of pliysiol. Yol. 21, 1896, p. XI-XII.) S. 291.

- - Influence of Acids and Alkalis upon the electronic currents of medullated nerve. (Proceed. of the Royal Society Vol. 62, 1597, p. S0.) S. 274, 319.

- A. F. and Reid, E. W.*: On the action of the excised mammalian heart. (Phil. Transact. of Royal Soc. Bd. 178, 1583, p. 215.) S. 44.

W arburg, E., Über elektrische Leitung und Conaction in schwach leitenden verdiinnten Lösungen. (Annalen d. Physik u. Chemie. Nene Folge. Bd. jł, 1895. p. 396 -433.) S. 292.

Ward: Cher die Anslïsung ron Reflexbetegungen durch eine summe schwacher Reize. (Arch. f. Physiol. 1880, p. 72.) S. 351.

Weber, Ed. u. Ernst: Experimenta, quibus probatus nervos vagos rotatione machinae galvano-magneticae irritatos, motum cordis retardare et adeo intercipere. (Annali universali di medicina. Serie III. Vol. 20, Milano 1545, p. 227.) S. 373.

Wedenskii, N.: Wie rasch ermiidet der Ners? (Centralbl. f. medizin. Wiss. 1584, p. $64-68$.$) S. 319$.

_ _ Über die Beziehungen zwischen Reizung und Erregung im Tétanus. (St. Petersburg 1886.) S. 387.

- Die fundamentalen Eigenschaften des Nerven unter Einwirkung einiger Gifte. (Pflügers Arch. Bd. 82, 1900, p. 134-191.) S. 310, 315, 318.

Weil, R. and Frank, R.: On the evidence of the Golgi Methods for the Theory of Neuron Retraction. (Arch. of Neurology and Psychopathology Vol. II. Nos. 3-4, 1599. Sep.)

W erigo, Br.: Die sekundäre Erregbarkeitsïnderung an der Kathode eines andauernd polarisierten Froschnerven. (Pflügers Arch. Bd. 31, 18s3, p. 417-479.) $\therefore .73$.

- - Zur Frage iiber die Beziehung zwischen Erregbarkeit und Leitungsfïhigkeit des Nerven. (Pfliigers Arch. Bd. 76, 1899, p. 552-607.) S. 270.

Wieting: Zur Frage der Regeneration der peripherischen Nerren. (Zieglers Beiträge Bd. 23, 1898.) S. 187.

Will, Fr.: Vorläufige Mitteilung iiber die Struktur der Ganglien und den Ursprung der Nerven bei wirbellosen Tieren. (Miillers Arch. 1544, p. 76.) S. 6.

Me William, J. A.: On the rhythm of the mammalian heart. (Journal of Physiology Bd. 9, 1889, p. 167-198.) S. 446.

Winkler, H.: Ein Beitrag zur Physiologie der glatten Muskeln. (Pflügers Arch. Bd. 71,1898 , p. $357-398$.)

Winterstein, H.: Über die Wirkung der Kohlensäure auf das Zentralnervensystem. (Arch. für Physiol. Supplement-Bd. S. 177, 1900.) S. 394.

Wittich, 0.: Über die Abhängigkeit der rhythmischen Bewegung des Herzens von den Herzganglien. (Königsberger mediz. Jahrbiicher Bd. 1, 1559, p. 15.) S. 447 .

Wundt, W.: Untersuchungen zur Mechanik der Nerven und Nervenzentren. (I. Erlangen 1871, II. Stuttgart 1876.) S. 273, 343, 346, 34S, 351, 375.

- - Grundziige der physiologischen Psychologie. (4. Aufl. Leipzig 1893.) S. 327.

Ziegler*: Archiv f. klinische Chirurgie Bd. 51, 1896. S. 160, 215.

$\mathrm{Z}_{\text {w a a }} \mathrm{rem}$ aker, H. und La us, L. S.: Über ein Stadium relativer Unerregbarkeit als Ursache des intermittierenden Charakters des Lidschlagreflexes. (Centralbl. f. P'hysiol. Bd. 13, 1899, p. 325-329.) S. 407. 


\section{Sachregister.}

Dic Ziffern hedenten die Seitenzahlen.

Achsenfortsatz, Terjiingung an Ursprungskegel 60 .

Achsevizylinder (Begriff) 5 .

- embryonale 244.

- intrazentrale 64.

- Unterschiede zwischen denen der peripheren Nerven und den zentralverlanfenden 145 .

- Verhalten bei Kompression 260.

- Wirbelloser 2s.

Achsenzylinderhosen 62 .

Achsenzylinderplasma 48 .

Achsenzylinderursprungskegel 131.

Achsialstrangfasern 202, 205, 206.

Aquiralentbild der Ganglienzelle 129 ,

Äther 254, 257, 297.

$[151$.

A thermethode 146 .

Affinitit zwischen Fibrille und Fibrillensäure $303,310,312,320$.

Aktinien, Nervensystem 21.

Aktionsstrom $310,313,315$.

Alkohol (Erregbarkeitssteigerung) 359.

Alles oder Nichts-Gesetz 110, 411.

Ammoniak zur Leitungsunterbrechung 172.

Anastomosen (Nerven-), physiolog. Nachweis 190.

- zwischen Neuriten 65.

Anastomosieren der Kollateralen 9.

- der Protoplasmafortsäitze 9, 10.

Anelektrotonus 274.

Anfangszuckung 295, 317, 315.

Anfangsstörung bei Nervenreizung 316.

Anneliden, Nervensystem 22.

Anode 272, 278.

Antagonistenhemmung 377 .

Antikinese (Definition) 2, 322.

Antiklise 322.

Aplysia $113,368,385,407$.

Apnoe 393.

Arion, physiologisches 119.

Arthropoden, Nervensystem 24.

Assimilation 253, 293.

Atropin 391.

Atemrhythmik 393.

Atemstillstand 377 .

- durch Cocaïn 401.

Atemzentrum 393.

Außengitter 39.

Ausstrichpriparate 136.
Auswachsen von Nerven 213.

Auswachsungstheorie 234.

Autogene Regeneration, siehe Rereneration.

Automatische Bewegungen 325.

Axostromafirbung 137.

Balinen, lange, Genese derselben 100. - schnellere Leitumg ders. gegeniber den Nervennetzen 119.

- ungefirbte der Ganglienzellen, ilure Beziehungen zum Fibrillenyerlauf 59.

Bahnung 350, 353.

Bandfasern 156, 200.

Basische Farbstoffe 125, 133.

Bauchmark 23.

Bauchganglion 23.

Belegkörper (Belegungsformationen) 4 .

Biddersche Ganglien 95.

Block 447 .

Blockfasern 446 .

Blutgefäße 111.

Careinus Maenas 328.

Centrosomen 149.

Chemische Reizung von Her\% und Meduse $419-422$.

Chloralose 314.

Chromatolyse $150,178$.

Chromatophoren der Cephalopoden 392.

Cocainversuch (Atmung 401.

Coelenteraten, Nervensystem der 20.

Cotylorhiza, anatomisches 56 .

Central- 11. S. w. unter 7.

Darmperistaltik 374 .

Dämpfende Substanz 360,362 .

Danererregung dureh den konstanten Strom 275, 306.

Degeneration der Nerven 153.

- - Beschleminigung durch lieizung

- clironische 176. [16.4.

- plysiologische und morphologische 155.

- Schnelligkeit derselben 15s, 130.

- trammatische (entziundliche), paralytische (sekundire) 167.

- nicht errecrbarer Nerven 195.

Dekrement, 252.

lemarkationsstrom 311.

Dendriten (legriff) 6 . 
Dendriten (Entwicklung) 245.

Dichroismus 340.

Dissimilation 253, 293.

Driisen der Schmecken 120.

Dynamogene Reize 352, 356.

Dyspnoe 393.

Echinodermen, Nervensystem 21. effektorisch 1.

Eimpflanzen von Nervenstiicken 216.

Elastische Fasern des Herzens 94.

Elektrotonus (Du Boisscher) 251, 273.

- (physikalischer) 274.

- (Pfligerscher) 272, 273, 302.

Elementargitter Apathys 18, 42.

Ellipsoide 157.

Entwicklung der Nervenelemente 233.

Ermiidung der Nerven 316, 318.

Erregbarkeitsherabsetzung 267, 269, 272.

Erregbarkeitssteigerung 258, 269, 272.

- durch Gifte 355.

Erregung, Ausbreitung ders. proportional der Reizstiorke 116.

Erstickung des Nervengewebes 148.

Erstickungskrämpfe 362.

Extrasystole 423, 425, 427, 429.

Fasermasse, zentrale 41.

Faradische Reizung von Herz und Meduse 413.

Färbbare Substanz der Ganglienzellen $127,132$.

- - der Neurofibrillen, siehe: primïre Färbbarkeit.

Fibrillen, nervöse, siehe: Neurofibrillen.

Fibrillensäure, Eigenschaften derselben $143,14 \pi$.

- Verhalten derselben 265, 268, 282, 285, 287, 293, 303, 362 .

- kein Dissimilationsprodukt 293, 296.

Fische, Atmung 394.

Füllungshypothese (Herz, Neduse) 432, 437.

Ganglientheorie des Herzens 450.

Ganglienzellen, Begriff 4 , 5 .

- Formverhältnisse bei Wirbellosen 25.

- der Herzspitze 91, 93.

- Masse im Verhältnis zu der der faserigen Elemente 103.

- Menge im Verhïltnis zur Masse der Zwischensubstanz in der Hirnrinde 76 .

- Neurofibrillen derselben bei Wirbeltieren 55.

- - bei Wirbellosen 38.

- prinüre Färbbarkeit 127.
Ganglienzellen, retrograde Veränderumgen 176 .

- trophische Funktion siehe unter Zentrum, trophisches.

- zentrale Natur 326.

Ganglienzellgifte 356.

Ganglienzellhypothese $327,32 \mathrm{~S}$.

Gehirn der Wirbellosen 23.

Gehirnlipoïde 358.

Geschlechtsakt 354.

Giftwirkung 325, 355.

- auf Ganglienzellen 150.

Gitter, Definition derselben 38.

- pericelluläre $61,65,69$.

Gliascheide 28, 33.

$[67$.

Golgische Methode, zur Kritik derselben

Golginetze $61,65,69$; Beziehungen zu

Nervenfasern 72 ; Beziehungen zu Fibrillen 74 .

Grau, das 75 .

Gruenhagensches Phänomen 269, 271,

Hemmung 373.

- Theorie 380.

Hemmungsfasern $380,385$.

Hemmungszentren 378.

Herz der Hiihnerembryonen 434.

- Nervennetze 90 u.f.

- physiologisches 109, 405 u. f.

- Reizleitung 432.

- Ursachen der rhythmischen Bewegungen 452 .

Herzganglien 423.

Herzmuskulatur, Trennung zwischen Vorhof und Kammer 92.

Hinterstränge, Autoregeneration derselben 210 .

Hintere Wurzeln 364.

Hiihnerembryonen 237.

Hypoglossus 227, 231.

Individualität der Neurofibrillen 17.

Indifferenzpunkt 272, 281, 309 .

Inkrement 252.

Imnendruck bei Aplysia 369.

Innengitter 39.

Interferenz $38 \%$.

Intrazentrale Hemmung 386.

Inversion der Kontraktionswelle beim Herzmuskel 415.

Ionen 290, 312, 391, 419.

Irreziprozitiat der Leitung von Nerv auf Muskel (neuer Beweis bei Medusen) 108.

- der Zentralteile 325, 342. 
Kanälchen der Ganglienzellen 141.

Katelektrotonus 274.

Kathode 275, 295.

- sekundïre Undurchgingigkeit 305.

Kernleitermodell 251.

Kernleitertheorie 251, 290, 321.

Kochsalzhemmung 376.

Kohlensiure, Wirkung auf Nerven 259,

- Wirkung auf Medusen 421. [319.

Kollateralen 9, 30 .

Kommissuren 23.

Kommissurelemente 28.

Kompensatorische Ruhe 424, 425.

Kompression der Nerven 52, 165, 256,

konduktil 1.

[358.

Konkurrenzsubstanz 145, 352, 361, 362 .

Konnektive 23.

Konstanter Strom 272.

$[417$.

- - Wirkung auf Herz und Meduse

Kontinuität der Neurofibrillen 18, 45.

Kontinuitätsfrage 9.

Kontraktionswelle, Geschwindigkeit derselben im Hundeherzen 435, in der Meduse 440.

Kontraktionswelle und Leitungsgesehwindigkeit 437.

Konvektion 292.

Koordination der Herzteile 447, 448 .

Korbzellen 64.

Krampfgifte 360 .

Kratzreflex 375.

Krebsschere $341,385$.

Laryngaeus superior 377 .

Labyrinth 364 .

Leitung, doppelsimnige 344 .

Leitungsfähigkeit autoregenerierter Nerven 193.

Leitungsgeschwindigkeit im Herzen 436.

- der Nerven $311,321,345,438$.

Leitungsverzögerung in den Zentralteilen 345 .

Lidschlufreflex 346,407 .

Lingualis $22 \%$.

Limax, physiologisches 119.

Lungenkollaps 398.

Malonnitril 152.

Markhaltige Nervenfasern 46.

Marklose Nervenfasern 49.

Markscheide 156, 201.

Mechanische Reizung von Herz und Meduse 415,416 .

Medusen (Alkoholwirkung) 359.

- Beweise für die nervöse Leitung 107 u. f.
Medusen, Hemmung :356.

- Nervennet\% 55.

- Physiologisches 106, 339.

- rhythmische Bewegungen $405 \mathrm{nd}$.

Melken der Fibrillensïure 257.

Methylenblau 34, 127, 131, 133.

Milieu der Organe 361.

Mollusken, Nervensystem 25.

- physiologisehe 113.

Motorische Elemente („Neurone") bei Wirbellosen 31.

Motorischer Impuls 350 .

Motorische Zonen $37 \mathrm{~S}$.

Muschelschließmuskel 385 .

Muskeln, rhythmische Eigenschaften 390.

Muskelfelder und muskelfreie Felder von Rhizostoma 89.

Muskuläre Leitung im Herzen. Kritik der Beweise fiir dieselbe 433 u. f.

Muskarin $435,443$.

Nachschwankung, positive $253,314,316$.

Nareotica 268, 289, 297, 356, 357.

Narkose $309,35 \mathrm{~S}$.

Negative Schwankung 269, 313.

Nerr als anatomisch-physiologischer Begriff 2.

Nervendegeneration siehe Degeneration der Nerven.

Nervenfaser (Begriff) 5. - (Ursprung) 7 .

Nervenkompression 52, 165, 256, 355.

Nervenkörper 4.

Nervenleitung 248.

Nervenuetze 9, 11.

- bei Arthropoden 24, 81.

- an Blutgefäßen 79.

[so.

- Beziehungen zu markhaltigen Fasem

- im Froschherz 90.

- der Medusen s.j.

- bei Mollusken 25, 81 .

- im Darm von Pontobdella. Neurofibrillen desselben 24, S4.

- physiologische $107,109,110,111,120$. $121,324,372,433,454$.

Nervenregeneration siehe liegeneration der Nerven.

Nervenringe $199,223$.

Nervenscheiden als schutzormane 355.

Nervenstrom 311.

Nervensystem wirbelloser Tiere 20.

Nervenzelle (Kö̈llikers) \&.

Nervenzellen (im Gegrensat\% zu Ganshienzellen) $238,243,245$.

Nervenzelleniaquivalent 129.

Nervös, Benriff desselben 2, 3. 
Nervöse Fasern 4.

Neuralrohr 234.

Neuroblasten 234, 246.

Neurome 213.

Seuronentheorie 9, 12, 160, 187, 246, $326,343$.

Neurofibrillen 13, 33, 35, 255, 282.

- autoregenerierter Nerven 195.

- Degeneration 156.

- in den Ganglienzellen Wirbelloser $38-40$. - von Wirbeltieren 55.

- leitende Funktion 19, 51, 261.

- Methoden sie primär zu färben 135,

- motorische 18, 37.

- nackte 34.

- primäre Färbbarkeit derselben, siehe unter Primäre Fiirbbarkeit.

- rezeptorische (sensorische) 18, 37.

Neurofibrillengitter im Neuropil 42.

- Lagebeziehungen. 97.

Neurokeratinhülle der Ganglienzellen 65 .

Neuropil 8, 17, 41, 328, 329.

Neurosomen 66.

Neurotisation 212.

Neurotrope Farbstoffe 133.

Neurotropismus 232.

Neutralrot 131.

Netze, Definition derselben 38.

Nisslsäure, Eigenschaften derselben 144.

Oberschlundganglion 23.

Öffnungstetanus 275,308 .

Öffnungszuckung 307 .

Opticus 229.

Ösophagus, physiologisches 121.

Otolithen der Mledusen 455.

Pedicellarien 21, 354.

Pelletierinsulphat 113, 369.

Perifibrillärsubstanz 15, 33, 48, 134, 261.

- Unterbrechung an den Ranvierschen

Einschnïrungen 49.

Peristaltische Bewegungen (Mollusken)

Pigment der Ganglienzellen 150. [115.

Planarien, physiologisches 112.

Polarisationsbilder $278,290$.

Polaritait der Nerven 218.

Primäre Färbbarkeit autoregenerierter Nerven 195, 197.

- - Begriff 125. - Wesen 138.

- - der Neurofibrillen 133, 244, 255, 265, 267. - Schwinden derselben bei Degeneration 161. - Verïnderung derselben durch Reizung 298.

Primärfärbbare Substanz, Lösungsverhiiltnisse derselben 139, 141.
Primäre Reizung, Methode der 17s.

Primitivfibrillen siehe Neurofibrillen.

Protoplasmafortsätze, Anastomosieren derselben 9.

- (Begriff) 5.

- bei Wirbellosen (?) 30.

- Endigungen 11.

- reizleitende Natur 61.

- Unterscheidung zwischen diesen und Achsenzylindern 68.

- Verzweigungsmodus 67.

Protozoen, kernlose Teile 332.

Pulsierende Luftblase 359.

Purkinjesche Zellen 64.

Pyramidenzellen 55.

Quakreflex 374, 350, 407.

Querdurchströmung 306.

Radialnerven der Echinodermen 21.

Randkörper der Medusen 20.

_ _ _ als Stelle der geringsten Reizschwelle 455.

_ - _ Verbindung mit dem Nervennetz 88

Ranviersche Einschnürungen 49 .

Reaktionszeit 349 .

Reflex, Definition desselben 2.

$-322$.

- diffuser 100.

- ohne Ganglienzellen 226, 329.

- Hemmung 374.

Reflexbogen 335 .

Reflexlähmung 376 .

Reflextonus 364, 366 .

Reflexrepublik 338 .

Reflexumkehr 335.

Reflexverkettung 335, 373 .

Reflexzeit 346.

Refraktäre Phase (Periode, Stadium) $390,403,407,423,451,456$.

Regeneration der Nerven 182.

— - - autogene 185, 189.

- - bei Erwachsenen 205.

Regenerationskraft 203.

Reizleitung im Herzen 432.

Reizsummation siehe Summation.

Respiration 393.

Restitutorische Phase im Nerven 317.

Retrograde Ganglienzellveränderungen

Reusssches Phänomen 253.

Rezeptionsorgane 323,324 .

Rezeptionszellen $31,40,105$.

Reziprozitait der Herzkoordination $44 \mathrm{~s}$.

Rhizostoma, anatomisches 56 .

Rhythmische Bewegungen 358. 
Sa uerstoffbediirfinis der Zentralteile 362.

Schließungstetanus 275.

Schliefungszuckung 307 .

Schlunttiommissur 23.

Schnecken, physiologische 118.

Schollen, Nissische 127.

Schwamsche Kerne 244.

- - Vermehrung derselben 200.

Seeigel (Hemmung) 355.

- Nervensystem 21.

- (Tonus) 372.

Selachier, Atmung 394.

Selbststeuerung der Atmung 395, 404.

Sensible Wurzeln, Autoregeneration (lers. 209.

Sensorische Biindel 35.

Sensorishhe Schläuche 35 .

Shok 377.

Siebplatten an den Ranvierschen Einschniirungen 50.

Sinneshaare 31 .

Simnesnervenzellen 31 .

Sinus venosus als Stelle von geringster Reizschwelle 455.

Sphinkter 365 .

Spinalganglien 330 .

- Exstirpation ders. 208.

Spinalganglienzellen 5 .

Spindelzellen 200.

Spitzenbesatz der Protoplasmafortsaitze $7 \%$.

Splanchnicusreizung 374 .

Statolithen der Medusen 455.

Strangdegeneration 163.

Strychnin 152, 360 .

Subumbrella der Medusen 85.

Summation der Reize 325, 350, 406, 456.

Sympathicus 231.

Synchronität; Störung ders. bei Herz und Meduse 427 .

Tabelle der Hunde mit Autoregeneration (ler Nerven 191.

'Tastscheiben im Entenschnabel 55.

Temperatureinfluß auf die Ermüdbarkeit der Nerven 316.

- auf das Polarisationsbild 291.

Tetanusgift 152 .

Theorie der Nervenleitung 301.

'Tigroid 127.

Toluidinblau 134.

'Ionus 325, 329, 363, 352.

Tonusfall (Aplysia) 369.

T'onuslabyrinth 365 .
'Tonusleitung $36 \%$.

Tonusmuskulatur $336,340,366$.

Tonusselialter 339.

Tonussteigerung nach Fortuahue des Zentralnervensystems 113,370 .

'Torpedo, Nervenfisern 50 .

- Zellen des Lobus electricus 59.

'Trigeminus 229.

'Trophisehe Funktion der Ganglienzellen u. s. w. siehe unter Zentrum, trophisches.

'Tunikaten 25.

Ureter 111.

Vagus 231, 373, 377.

- der lische 399.

Verïstelte Fortsätze 5.

Voltasche Alternative 308.

Vorderhornzellen 5\%.

Wachstumskeulen 235.

Wallersches Gesetz-15£, 177, 330 .

Wärmestarre Nerven 266, 257.

Wasser, destilliertes, Wirkung auf Yerven 265 .

Wasserstarre Muskeln 443.

WVirbellose 'Tiere, Nervensystem derselben 20.

Wurzeln des Rückenmarks 342.

- vordere, Veriinderung ihrer Erregbarkeit 351 .

Wiirmer, Nervensystem 22.

- physiologisches 111, 123.

Zellfunktion, Lehre der spezifischen 151.

Zellkettentheorie 236 .

Zentralnervensystem, im anatomischen und physiologischen Sinne 23.

- als einziger Reflexort bei höheren Thieren 123.

- physiolog. Unterschiede zwischen diesem und den peripheren Nerven

Zentralteil 335.

$[325$.

Zentrum (nutritorisches, troplisches) 154 $160,163,177,151,197,212,330$.

Zickzackversuch 433.

Zuckungsgeset\% "274.

Zusammenheilung zentraler Nervenstiimpte 220 .

-- durchschnittener Nerven 211, 215. Iethoden dieselhe zu verhindern 1s9.

- motorischer und sensibler Nerventaserul 227.

- peripherer Nervenstimple 224. 


\section{Tafelerklärung.}

Figuren I-III stellen Vorderhornzellen rom Ochsen dar, welche Ausstrichpriiparaten entnommen sind. Alle drei Prïparate wurden gleichzeitig und in sleicher Weise mit Alkohol fixiert. in Xylol geloracht und nach einiger Zeit wieder in Alkohol iibertragen. Von hier an wurden sie verschieden behandelt:

I. wurde direkt mit Toluidinblau gefïrbt, mit Wasser gewaschen und mit Ammoniummolybdat fixiert. Es wurde eine Zelle zum Zeichnen ausgewiihlt, welche wenig Nisslschollen enthät. Man sieht zwischen diesen die "ungefirhten Bahnen" in einem rötlichen Ton gefärbt. An vielen Stellen ist eine deutliche fibrilläre Streifung vorhanden.

II. Das Präparat wurde aus reinem Alkohol für 24 Stunden in eine Mischung von fün Teilen Alkohol und einen Teil verdimnter Salzsïure gebracht und dann wie I gefärbt und fixiert. Die primäre Färbung der Fibrillen fehlt; es sind nur noch die Nisslschollen und die Kerne gefïbt. Genau der gleiche Endeffekt d. h. dasselbe Bild wäre erzielt worden, wem man ein wie I hehandeltes Prïparat olme zu fixieren in Alkohol iibertragen hätte.)

III. Das Priiparat wurde aus dem Alkohol für 24 Stunden in eine Mischung von fiunf Teilen destillierten Wassers und einem Teil Salzsïure gebracht und damn wie I und II gefärbt und fixiert. Die Färbung der Nisslschollen fehlt, der Kern zeigt fäberische Veränderungen, aber die primire Fürbung der Neurofibrillen ist iiberall erhalten.

(Die drei Figuren sind bei Ölimmersion aus freier Hand gezeichnet. Sie geben keinen optischen Durchschnitt wieder, sondern das, was man bei verschiedenen Einstellungen sehen konnte. Infolgedessen habe ich auch die ïber die Zellen fortlanfenden Nervenfasern nicht an der Zellperipherie abbrechen lassen.)

IV und V stellen je einen Teil des Rïckenmarksquerschnitts eines Kaninchens dar. Das Tier wurde zu Tode ätherisiert. Das Rïckenmarksstiick, von dem der Schnitt IV stammt, wurde mit Äther entwässert, eingebettet und geschnitten. Das Stiick, von dem der Schnitt V stammt, wurde mit Alkohol fixiert $u$. s. w. schnitte beider stiicke wurden auf denselben Objekttrïger grebracht und zusammen mit Toluidinblau gefärbt, gewaschen und fixiert. Der Unterschied in der Behandlung besteht also nur darin, daß IV nicht in Alkohol gewesen ist. - (Lüßst man einen Schnitt von dem Ätherblock vor dem Färben in Alkohol, so erhält man ein Bild wie $V$. Bringt man einen Objektträgrer mit Schnitten von IV und V nach dem Fïrben ohne zu fixieren in Alkohol, so bekommt man in beiden Schnittsorten ein reines Nisslbild.)

Vergleiche im Text S. 141 und $14 \pi$. 


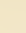




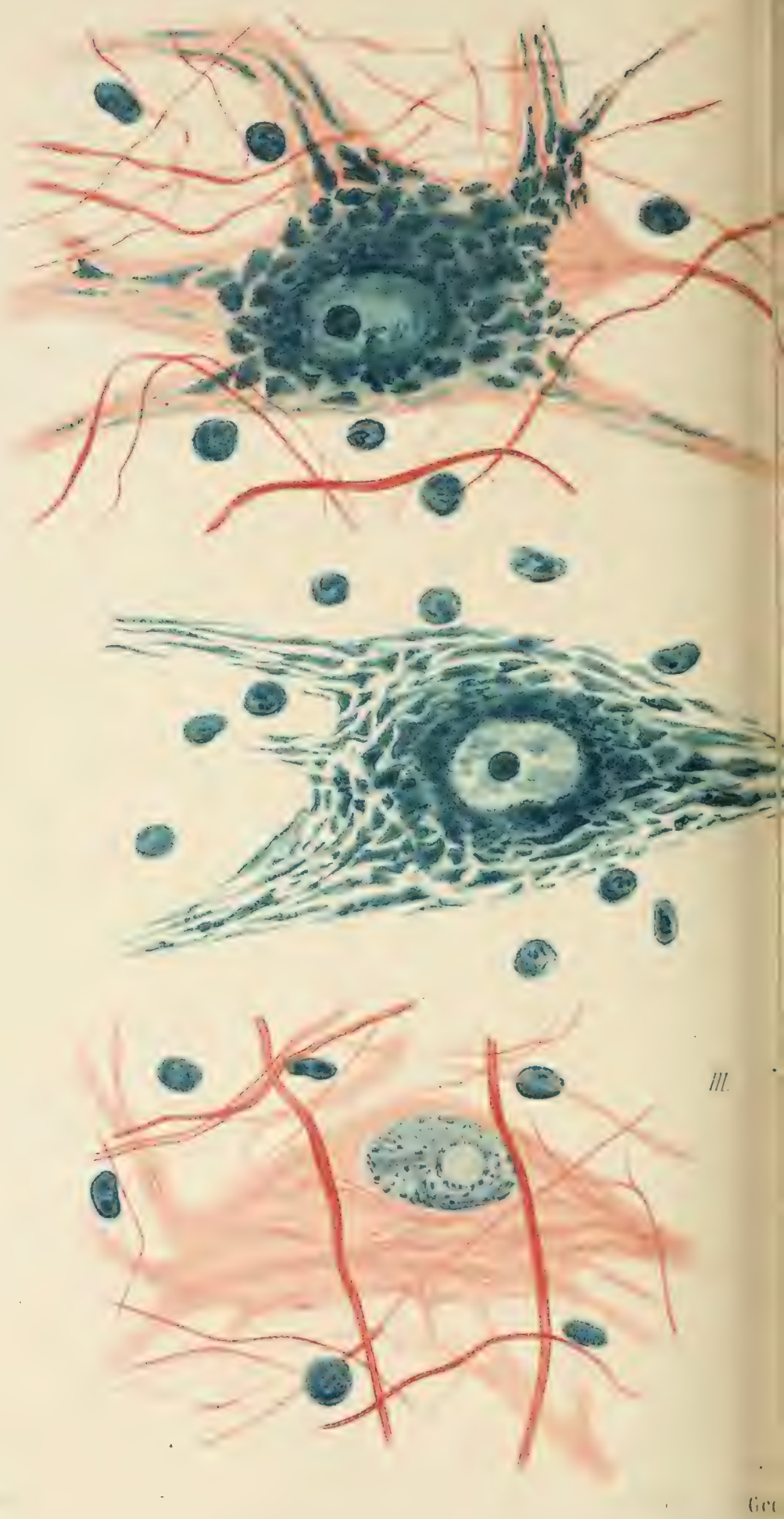



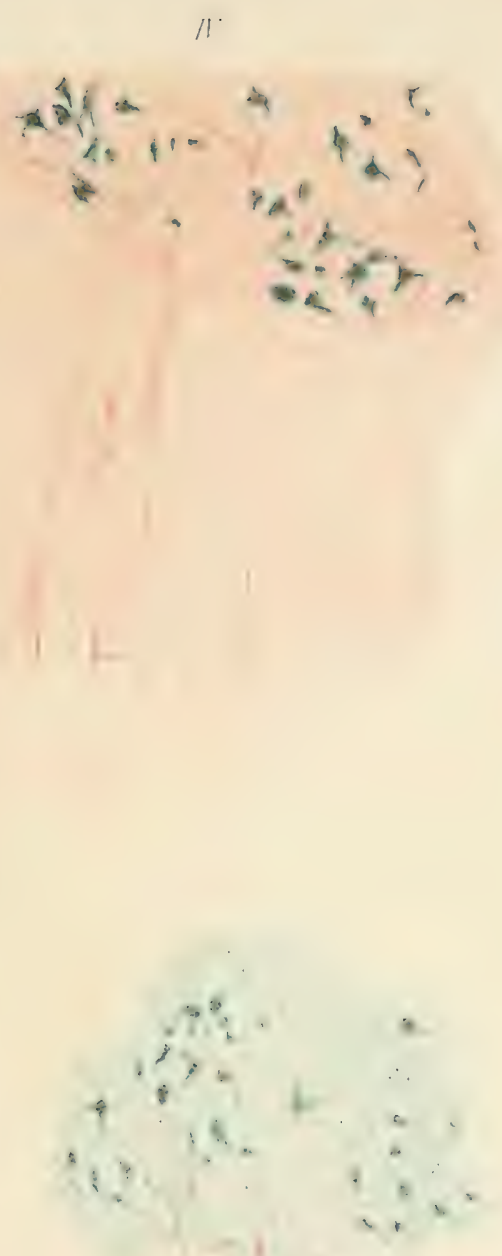



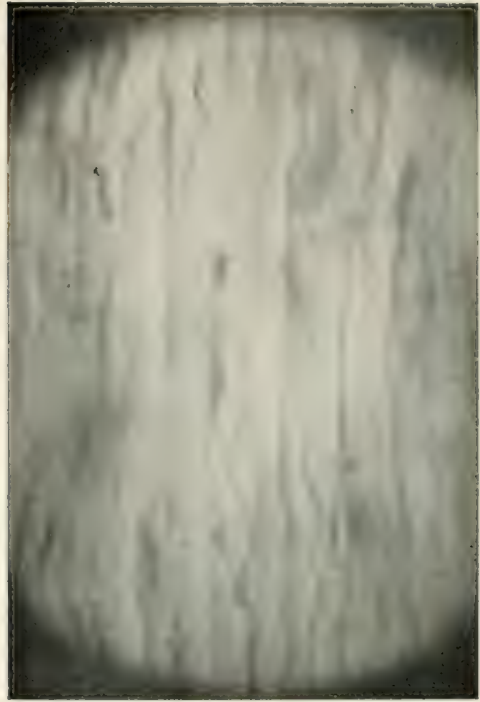

A.

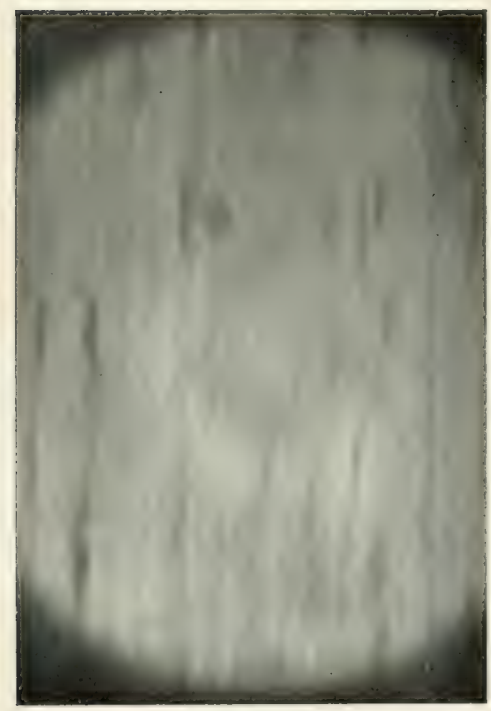

(

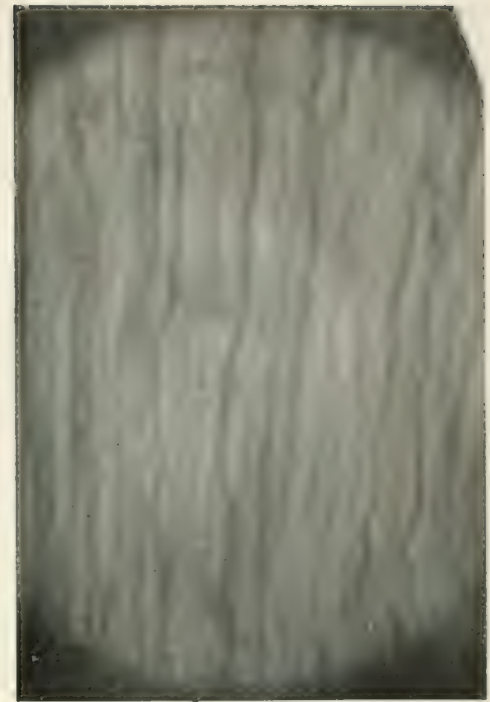

B.

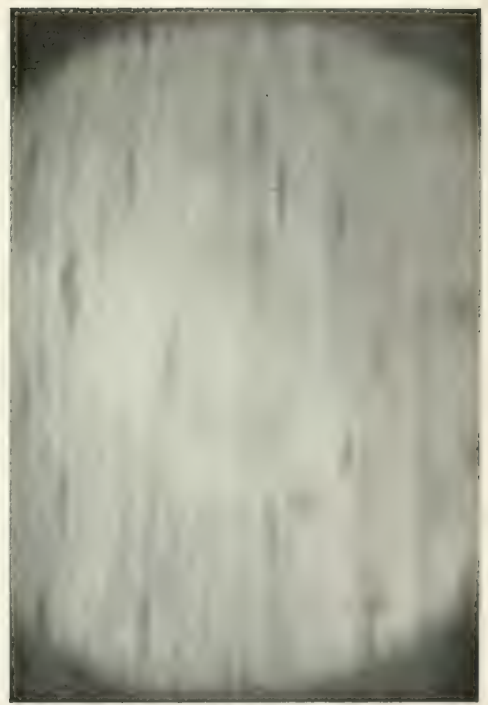

n.

Fig. 71. Photogramme von vier Stellen im Verlauf des Schnittes Fis, 70 I. Vergrïßerumg 300 mal. Bei allen vier Aufnahmen wurde gleichlange bei gleicher Lichtinelle (Anerbrenner) expmiert (1 Min. 45 Sek.). Die Platten sind genau gleichlange (3 Min. 50 sek.) mit jedesmal der fleiclen Menge frisch bereiteten Entwieklers entwickelt. - I normale extrapolare Jervenstelle. Achsenzylinder von mittlerer Dunkelheit. Die dïnnen, helleren Streifen zwisehen demellen sim tlic schwach gefärbten Hïllen der Markscheiden; stellenweise erkennt man auch das Neurokeratingeriist. Die dunkleren Flecke sind die Kerne. $B$ Stelle aus ter Kathode. Achsenzylinder dickor und viel dunkler als in .1. Der Untergrund infolge der darunter und dariber liegenden Fasern dumklor als in . 1. - C Stelle aus der intrapolaren strecke, zwischen Indifferenzpunkt und Anode. Dic meisten Achsenzylinder gan\% ungefiirbt, rechts ein жienlich normalgefirbter, in aler Mitte einige zanz blasse. $D$ Stelle aus der Anodengegend, etwas naeh innen voll der Auflacestelle auf der Elektrode. Alle Achsenzylinder ungefïrbt mon nur noch die Kerne und die Hiillen zu sulven. 





QI Bethe, Albrecht Th

925 Julius

B47

Allgeine Anatomie und Physiologie des nervensystems

Biological

\& Medical

PLEASE DO NOT REMOVE CARDS OR SLIPS FROM THIS POCKET

UNIVERSITY OF TORONTO LIBRARY 
